


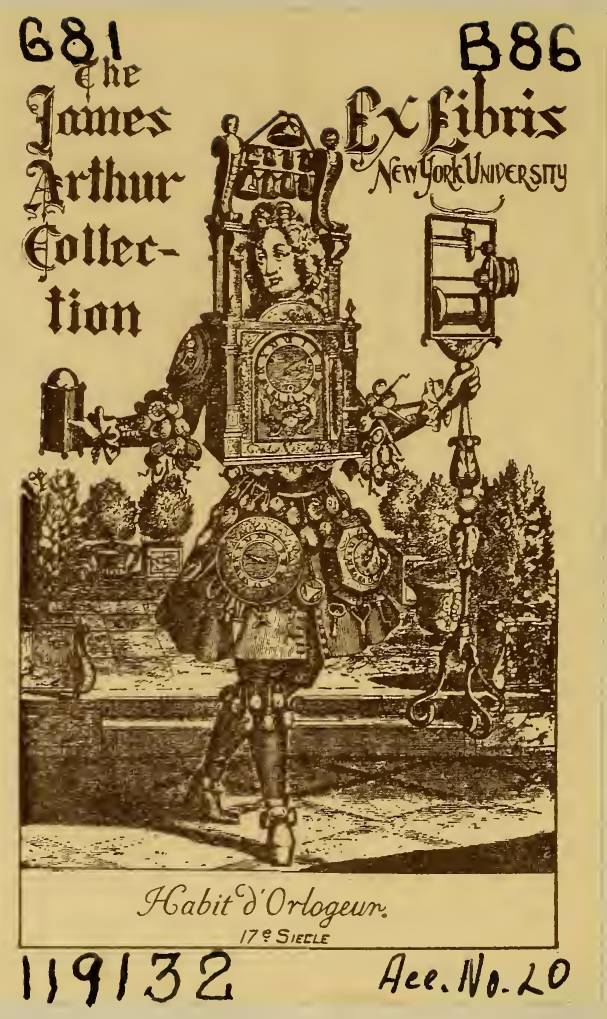






OLD CLOCKS AND WATCHES AND THEIR MAKERS. 



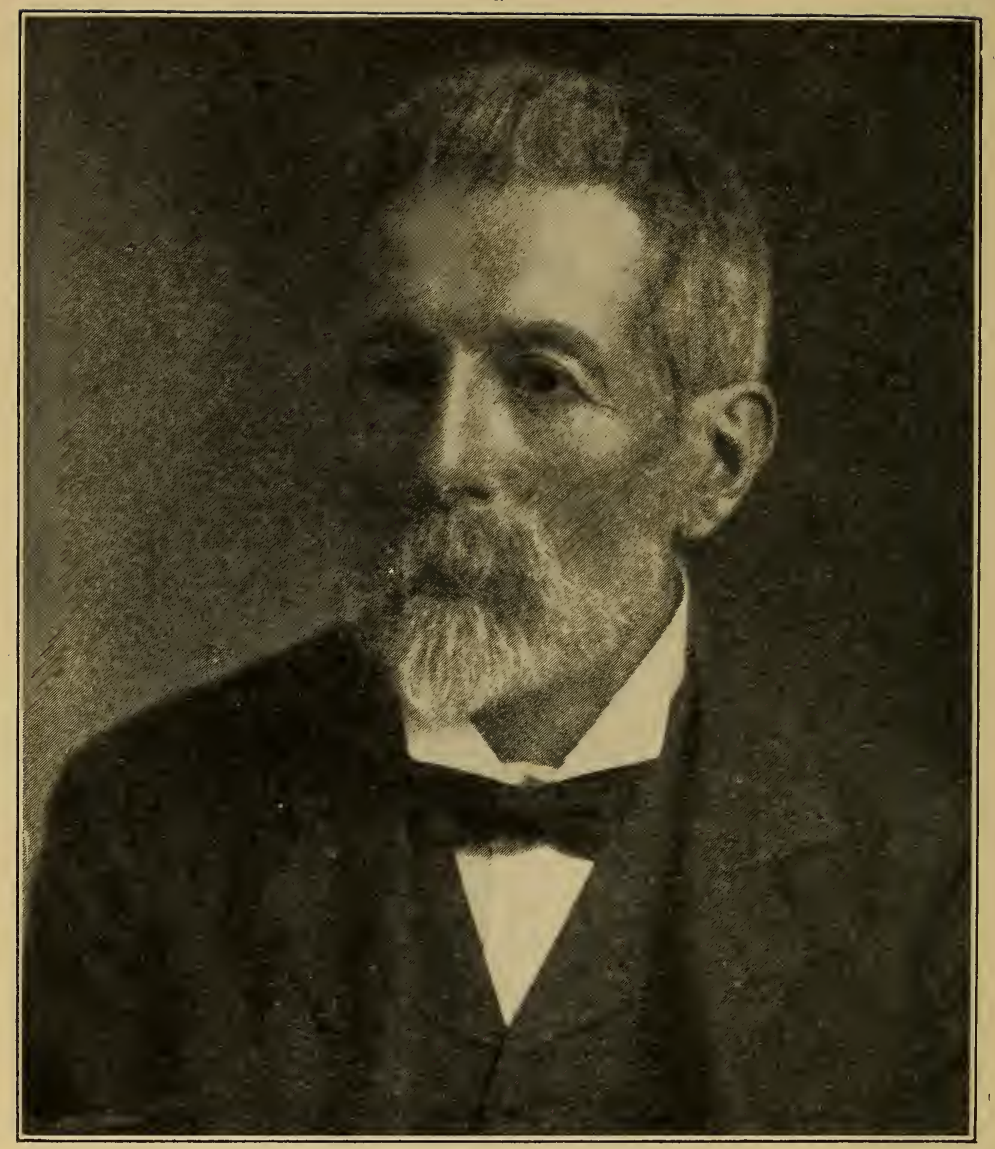

FREDERICK JAMES BRITTEN, 1843-1913. 


\section{OLD CLOCKS AND WATCHES \& THEIR MAKERS}

Being an Historical and Descriptive Account of the Different Styles of Clocks and Watches of the past, in England and Abroad

TO WHICH IS ADDED

A LIST OF NEARLY TWELVE THOUSAND MAKERS

$\mathrm{BY}$

\section{F. J. BRITTEN}

ALTHOR OF "THE WATCH AND CLOCKMAKERS' HANDBOOK, DICTIONARY, AND GUIDE"

FIFTH EDITION, MUCH ENLARGED WITH 859 ILLLSTRATIONS, MOSTLY FRON PHOTOGRAPHS

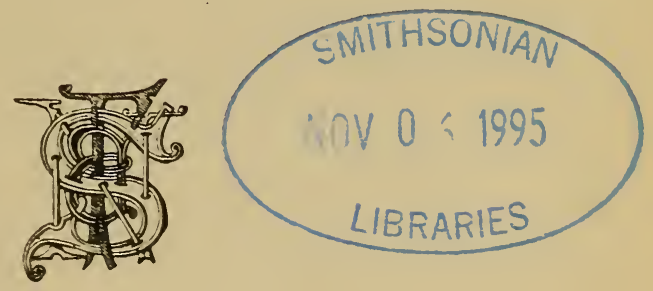

LONDON :

E. \& F, N. SPON, LIMITED, 57 , HAYMIARKET, S.W.I 
Printed in Great Britain by

Mackays Ltd., Chatham

$$
\begin{aligned}
& b=1 \\
& 13 \times 6
\end{aligned}
$$




\section{WORK BY THE SAME AUTHOR}

\section{The Watch and Clock Makers' Handbook, Dictionary and}

Guide. By F. J. Britten. Demy 8vo., 500 pp., 400 illus. Twelfth edition. (1920). 12s. 6d. net.

Preface-Hints on Mechanical Drawing-Acceleration-Adjusting for Temperature-Assaying-Astronomical Clock-Balance-Balance Spring-Timing BoxIsochronism-Adjustment-Balance Staff-Barometric Error-Barrel-BenchBlind Man's Watch-Bow-Calendar Clock and Watch-Callipers-Cannon Pinion-Capillarity-Case Springs-Case Stake-Cement-Centre SecondsCentre Wheel-Centrifugal Tendency-Chain-Chimes-Chronograph-Chronometer-Clepsydra-Clocks, Westminster, etc.-Compensation Balance-Conical Pendulum-Conversion-Decimal Fractions-Depthing Tool-De Vick's ClockDial-Dipleidoscope-Douzieme Gauge-Drilling-Eccentric Arbour-Electric Clocks-Equatorial Clock-Escapements-Ferguson's Clock-Ferrule-FileFriction-Frosting-Fusee-Gilding - Glass - Graver - Gravity-Hall-MarksHands-Hardening-Hand Wheel-Huygens' Clock-Ice Box-Inclined Plane Clock-Jacot Tool-Jewelled-Kew Trials - Keyless-Lacquering-LathesMagnetism-Mainspring-Mandril-Marble Clock Cases-Meridian Dial-Micrometer-Middle Temperature Error-Millimeter-Moment of Elasticity-Movement-Musical Box-Non-Magnetisable Watch-Oil-Oven-Pendulum, Zinc Tubes, Mercurial, etc.-Pinion-Pneumatic Clocks-Polishing-Potential Energy -Precious Stones-Ratchet-Regulator-Repeating-Rounding-up ToolScrews-Sector-Self-Winding-Shaping, Sinking-Silver-Slide Gauge-Slide Rule-Snailing-Soldering-Spotting-Stop Work-Striking Work-SundialsTell-Tale Clock-Tempering-Tidal Clock-Time-Tourbillon-Train-Transit -Turret Clocks-Up and Down Indicator-Watch-Wheel Cutting EngineWheels and Pinions-Table of Chronometer Trains-Circumference and AreasClock Trains-Conversion-Date Marks-Wheels and Pinions-Equation of Time-Properties of Metals, etc.-Fusees-Lever Trains-Local Time-Motion Work-Pendulums-Sines, Tangents, etc.-Square Roots-Index.

\section{E. \& F. N. SPON, Ltd.}





\section{PREFACE TO THE FIFTH EDITION}

I response to repeated requests for a complete edition of "Old Clocks and Watches and their Makers" this has been prepared. It comprises the whole of the last edition compiled by my father, revised and enlarged.

Over 400 names have been added to the list of makers, and some fifty fresh illustrations of interesting specimens included.

I have to acknowledge the kindness of many owners of old timekeepers for valuable assistance. In particular I should mention Mr. D.A. F. Wetherfield and Mr. Hansard Watt, whose courtesy and willing help have considerably facilitated the revision of the work, and my thanks are due to them for providing fresh illustrative material from their fine collections of old English clocks. In addition I wish to take this opportunity of specially recording my thanks to $\mathrm{Mr}$. Hansard Watt for his valuable aid in correcting the proofs and seeing the publication through the press.

Through the courteous assistance of Mr. F. T. Haschka I have been granted the privilege of reproducing several of the beautiful watches from the collection of Mr. H. J. Heinz, which is regarded as one of the most important in the United States and has been deposited in the Carnegie Museum.

I am indebted to Mr. D. J. Parkes for giving me the benefit of his expert knowledge, and to Mr. Arthur Westwood (Assay Master of Birmingham) for enabling me to bring the hall-marks up to date.

Acknowledgment must be made to Herbert Cescinsky and Malcolm R. Webster's book on "English Domestic Clocks" for several new makers' names which have been added to the list.

Since the publication of the last edition Mr. Evan Roberts has passed away. A number of his watches were sold to the Morgan collection in New York several years ago, others have been distributed to various museums throughout this country.

ANNIE BRITTEN.

I922. 


\section{PREFACE TO THE FIRST EDITION}

SINCE the publication, in I894, of "Former Clock and Watch$\checkmark$ makers and their Work," so many suggestions have reached me. from lovers of old clocks and watches that I have been induced to recast the volume. Much additional information of a general character has been embodied in the present book, and details relating to modern construction which appeared before are now omitted.

Technical terms are, I am told, particularly exasperating to people unacquainted with horological phrases, and I have therefore avoided them as much as possible. "The Watch and Clockmakers' Handbook, Dictionary, and Guide" may be consulted by those especially interested in the mechanism of clocks and watches, and who desire more explicit details than I have given here.

Few places can boast of a finer display of eighteenth-century clocks than Windsor Castle. The principal representative specimens I have been enabled to illustrate and describe by special permission of the Queen.

Additions have been made to the list of old makers and some inaccuracies corrected. Several items of information in connection with this list I have obtained from the collection of tradesmen's cards owned by the Hon. Gerald Ponsonby, who allowed me free access to this most interesting record. A perusal of the Banks collection of tradesmen's cards at the British Museum has also elicited particulars not to be met with in ordinary channels. Mr. J. E. Hodgkin, F.S.A., furnished me with a list of the clock and watchmakers in his collection, which proved a useful check in several instances. Mr. C. H. Read, of the British Museum, has given me every possible help in going over the unsurpassed display of timekeepers in his charge, for the purpose of revising the references thereto. A similar favour in respect of the collection at South Kensington Museum has been accorded by Mr. A. B. Skinner.

I have to acknowledge the kindness of many owners of old timekeepers who permitted me to inspect their treasures. In particular I. should mention Mr. Albert Schloss, who has choice examples of every period; he placed the whole of them in my hands for examination, and of these between sixty and seventy have been selected for illustration.

April, I899. 


\title{
CONTENTS.
}

\author{
CHAPTER I \\ TIME, AND EARLY TIME RECORDERS
}

Solar Time-Cycle of the Sun-Sidereal Time-Duration of a Year-Golden Number-Epact-Number of Direction-Roman Indiction-Julian Period-Meridian Dials-Horizontal Sun-Dial-Portable DialClepsydræ-Wick and Lamp Timekeepers-King Alfred-Sand Glass .

\section{CHAPTER II}

IVEIGHT CLOCKS

Early Clocks-Jacks-St. Paul's-Westminster-Rouen-GlastonburyVimborne-De Vick-Palais de Justice-Foliot or Verge-Exeter-Oxford-Strassburg-I iibeck-Heavenly Calendar Dial-Hans of Jena -Fifteenth Century Clocks-Anne Boleyn-Hampton Court-FineHabrecht-Lyons-Venice . . . . . . . .

\section{CHAPTER III}

\section{PORTABLE TIMEKEEPERS}

Robert Bruce-Henlein-Early Examples-Zech-Mainspring and FuseeOctagonal - Nef - Dresden - Pendulum - Balance-Spring - Alarm -Automata-Bacchus-Crucifix-Elizabeth-Mary of Scots-Death'shead-Tambourine Case-Spherical Watch-Astronomical WatchBook-Padlock-Lion-Cruciform-Fancy Shapes-Tulip-PoppyFloral-Olive-Ring extremely Diminutive-Horn-Butterfly-Octagonal-Reputed Whiting-Square Steel-Oval-Holbein-Salt-cellar

\section{CHAPTER IV}

POCKET WATCHES, ETC.

Cromwell-Watch Glasses-Chatelaines-Cases-Enamel-Pair CasesChasing - Repoussé - Steel - Carnelian - Tortoise-shell - Bull's-eye -Watch Papers-Engine-turning-Parti-coloured Gold-Dials-Early Minute Indicators-Hands-Changing Hour-Figures-Fencing Soldiers -Pendulum Watches-Musical Watches-Moving Figures-Pearl Decoration-Souvenir Watch-Travelling Watches-Watch Keys 


\section{CHAPTER V}

RECORDS OF EARLY MAKERS, ETC.

Cratzer-Newsam - Bull - Nouwen - Garret - Grinkin - Henche -

PAGE

Flood - North - Crayle - Alcock - Ramsay - Partridge - The Clockmakers' Company - East - Jones - Barlow - Betts - Tompion - Graham - Quare - Fromanteel - Hooke - Huygens - Barrow Knibb - Harrys - Bradley - Ellicott - Sully - Harrison - Pinchbeck - Mudge - Arnold - Earnshaw - Ascertaining the Longitude at Sea by means of the Chronometer-Vulliamy-Clay-Ferguson-Jenkins - Margetts - Breguet - Equation Clocks - Enderlin - Lichfield Clock-Bridges-Lovelace-Cox-Horstmann-Fan Clocks

\section{CHAPTER VI}

FRENCH CLOCKS AND CASES IN THE FRENCH STYLE-OTHER CURIOUS TIMEKEEPERS

Early Records-Paris Guild-Boulle or Buhl Work-Clocks at Windsor Castle-Marot-Martinot-Le Roy-Lepaute-Mantel Clocks-Hanging or Cartel Clocks-Thuret-Courtois-Courvoisier-Gudin-Ie Noir - Robin - Leguesse - Dauthiau - Passement - Solians - Berthoud -Lepine-Bailly l'Aîné-Porcelain Cases-Orrery Clock-Glass Plate Calendar Clock-Symbolical Clock Hands-Italian Cartel TimepiecesMystery Clocks-Falling Ball-Grollier de Servière-Rolling BallAtlas-Globes-Urns-Vases - Marie Antoinette-Falconet-Three Graces-Negress Head-Rolling Clock-Schmidt's Mystery ClockFan-shaped Clock-Bird Cage-Magnetic Timekeepers-Congreve Clock-Japanese Clocks .

\section{CHAPTER VII}

THE PROGRESSION OF ENGLISH DOMESTIC CLOCKS

Lantern Clocks-Bob Pendulum-Bowyer - Knifton-Dyde-Frets Sheep's Head Clocks-Hood Clocks-Long-Case Clocks-SmithClement-Dials-Prime-Tompion-Clay-Cornerpieces of Various Periods-Further Examples of Dials and Hands-Cases-Examples-Iarquetry-Oriental Lacquer-Chippendale-Sheraton-Bracket or Pedestal Clocks-Basket Top-Bell Top-Engraved Back PlatesMusical Clocks-Broken Arch-Balloon-Lancet-Taxes on ClocksWinged Mercury-Act of Parliament Clocks-Hogarth . . .

\section{CHAPTER VIII}

\section{MECHANISM OF CLOCKS AND WATCHES}

Pendulum-Striking Work-Watch Movements-Pendulum WatchesBalance-Springs - Hog's Bristle - Hooke - Huygens - Tompion Barrow-Le Count-Enamelled Balance Covers-Watch Cocks-Pillars -Escapements-Watch Jewelling-Compensation-Winding Mechanism - Self-Winding - Pedometer-Winding - Repeating Watches Musical Watches-Hall Marks

\section{CHAPTER IX}




\section{OLD CLOCKS AND WATCHES AND THEIR MAKERS.}

\section{CHAPTER I}

\section{TIME AND EARLY TIME RECORDERS}

$A$ S defined by the title, our subject may be said to begin with the timekeeping should not, perhaps, be passed over without notice, it will be unnecessary to make more than a brief reference to them. It may be convenient and useful to begin with some explanation of the various time standards.

Solar Time.-A solar day is the period which elapses between two successive returns of the sun to the meridian. The instant the sun is seen at its greatest height above the horizon it is true midday, which sometimes takes place $16 \mathrm{~min} .18 \mathrm{sec}$. sooner, and at others $14 \mathrm{~min} .28 \mathrm{sec}$. later, than twelve o'clock mean time. The diurnal rotation of the earth on its axis might naturally be supposed to bring each place to the meridian at regular intervals; this would be nearly the case if the earth had no other movement; but it advances at the same time in its orbit, and as the meridians are not perpendicular to the ecliptic, the days are not of equal duration. This may be easily perceived by placing a mark at every $15^{\circ}$ of the equator and ecliptic on a terrestrial globe, as, by turning it to the westward, the marks on the ecliptic, from Aries to Cancer, will come to the brazen meridian sooner than the corresponding ones on the equator, those from Cancer to Libra later, from Libra to Capricornus sooner, and from Capricornus to Aries later; the marks on the ecliptic and equator only coming to the meridian together at Aries, Cancer, Libra, and Capricornus. True and mean time do not agree, though, on the days in which the sun enters these signs, in March, June, September, and December, for the earth moves with greater rapidity in December, when it is nearer the sun, than it does in July, when it is farther from it. The regularity of the earth's motion is also further disturbed by the attraction of the moon, Venus, and Jupiter. True and mean agree about the 25th December, 15th April, 14th June, and 31st August; these coincidences vary 
slightly in different years, because the earth takes about a quarter of a day more than a year to complete a revolution in its orbit, and this error accumulates from leap year till the fourth year, when the extra day is taken in.

Sun-dials mark apparent time, while clocks measure equal or mean time ; if, therefore, a timekeeper, perfectly regular in its motion, were set to apparent solar time, it would be found to agree with it only on four days in the year.

Cycle of the Sun.-A cycle of the sun is a period of twenty-eight years, after which the days of the week again fall on the same days of the month as during the first year of the former cycle. The cycle of the sun has no relation to the sun's course, but was invented for the purpose of finding the Dominical Letter which points out the days of the month on which the Sundays fall during each year of the cycle.

Sidereal Time.-Sidereal time, the standard used by astronomers, is measured by the diurnal rotation of the earth, which turns on its axis in 23 hours $56 \mathrm{~min} .4 \cdot 1 \mathrm{sec}$. The sidereal day is therefore $3 \mathrm{~min}$. $56 \mathrm{sec}$. less than the mean solar day, and a clock to show sidereal time must have its pendulum a trifle shorter than a mean-time clock with the same train.

Mean-time clocks can be regulated by the stars with greater facility than by the sun, for the motion of the earth with regard to the fixed stars is uniform, and a star will always appear at the meridian $3 \mathrm{~min}$. $56 \mathrm{sec}$. sooner than it did on the preceding day. In the absence of a transit instrument and a table giving the right ascension of particular stars, choose a window having a southern aspect, from which the steeple of a church, a chimney, or any other fixed point may be seen. To the side of the window attach a thin plate of brass having a small hole in it, in such a manner that by looking through the hole towards the edge of the elevated object, some of the fixed stars may be seen; the progress of one of these being watched, the instant it vanishes behind the fixed point a signal is made to a person observing the clock, who then notes the exact time at which the star disappeared, and on the following night the same star will vanish behind the same object $3 \mathrm{~min}$. $56 \mathrm{sec}$. sooner. If a clock mark ten hours when the observation is made, when the star vanishes the following night is should indicate $3 \mathrm{~min} .56 \mathrm{sec}$. less than ten hours. If cloudy nights intervene and render it impossible to compare the clock with the star, it will be necessary to multiply $3 \mathrm{~min} .56 \mathrm{sec}$. by the number of days that have elapsed since the previous observation. The same star can only be observed during a few weeks. Care must be taken that a planet is not observed instead of a star. The planets may, however, be 
distinguished, for being comparatively near the earth, they appear larger than the stars ; their light also is steady because reflected, while the fixed stars scintillate and have a twinkling light.

Duration of a Year.-The sidereal year starts with the spring equinox, when the sun enters the sign Aries, that is, when the sun crosses from the south to the north of the equator. The earth in its revolution round the sun makes rather over 366 rotations or 366 sidereal days, which are equal to 365 solar days. The sidereal year is equal to 365 days 6 hours 9 min. 11 sec., nearly, of mean solar time. The earth, on the completion of its revolution, returns to the same place among the stars, but not exactly at the spring equinox, owing to the precession of the equinoxes, so in order that the year may accord with the seasons the sidereal year is disregarded in favour of the equinoctial, tropical or solar year, taken as 365 days 5 hours $48 \mathrm{~min} .48 \mathrm{sec}$. Among the Romans no regular account was taken of the difference between the year and 365 days till B.c. 45 . Then the surplus was reckoned as six hours, making one day in four years and one day was accordingly added to every fourth year. There still remained the apparently trifling difference of $11 \mathrm{~min}$. $11 \mathrm{sec}$. between the civil and the tropical year; this, however, produced an error of about seven days in 900 years. In 1582, Pope Gregory XII. struck out ten days, which represented the accumulated error, from the calendar, and it was decided that three leap years should be omitted every 400 years; thus, as 1600 was leap year, the years 1700,1800 , and 1900 were not, but 2000 will be leap year. This rectification. was not adopted in England till 1752, when eleven days were omitted from the calendar. As our year still exceeds the true year, although by an extremely small fraction, another leap year in addition to those should be omitted once in 4,000 years.

There is a distinction to be noticed between the sign Aries and the constellation of that name. The first point of the sign Aries or the equinoctial point $\mathrm{Y}$ is the zero from which the right ascension, or longitude, of celestial bodies is measured, just as Greenwich is an initial meridian for measuring the longitude of terrestrial places. Ancient astronomers called it the first point of Aries because in their time the phrase correctly described its position, but the vernal equinox retrogrades $50 \frac{1}{4}$ seconds of a degree each year, and so the first point of Aries is now really in the constellation Pisces. The moment the point $Y$ passes the meridian it is sidereal noon, and sidereal time would then be 0 hour $0 \mathrm{~min} .0 \mathrm{sec}$.

The civil year began on 25th March before 1752, when the present reckoning for the year to commence on 1st January was adopted. 
The Golden Number.--Meton, an Athenian astronomer, B.C. 432 , discovered that after a period of nineteen years the new and full moons returned on the same days of the month as they had done before; this period is called the cycle of the moon. The Greeks thought so highly of this calculation, that they had it written in letters of gold, hence the name Golden Number; and at the Council of Nice, A.D. 325, it was determined that Meton's cycle should be used to regulate the movable feasts of the Church.

The Epact.-The Epact serves to find the moon's age by showing the number of days which must be added to each lunar year, in order to complete a solar year. A lunar month is composed of 29 days 12 hours $44 \mathrm{~min} .3 \mathrm{sec}$, or rather more than 29.5 days; 12 lunar months are, therefore, nearly 11 days short of the solar year-thus, the new moons in one year will fall 11 days earlier than they did in the preceding year, so that were it new moon on 1st January, it would be nearly 11 days old on the 1st of January of the ensuing year, and 22 days on the third year; on the fourth year it would be 33 ; but 30 days are taken off as an intercalary month (the moon having made a revolution in that time), and the remaining would be the Epact; the Epact thus continues to vary, until, at the expiration of 19 years, the new moons again return in the same order as before:

The Number of Direction.--The Council of Nice decided that Easter Day is always the first Sunday after the full moon which happens upon or next after the 21st of March. In 463 it was decreed that instead of the actual full moon the fourteenth day of the moon should be considered the paschal moon. Easter Day cannot take place earlier than the 22nd of March or later than the 25th of April. The Number of Direction is that day of the thirty-five on which Easter Sunday falls.

The Roman Indiction.-The Roman Indiction was a period of fifteen years, appointed A.D. 312 by the Emperor Constantine for the payment of certain taxes.

The Julian Period.-The Julian Period of 7,980 years is the product obtained by multiplying together 29,19 , and 15 , which numbers represent the cycles of the sun, the moon, and the Roman Indiction. The beginning of the Julian Period is reckoned from 709 before the creation of the world, so that its completion will occur A.D. 3267 , until which time there cannot be two years having the same numbers for three cycles.

Timekeepers are more immediately concerned with the subdivisions of a day. The Persians divided the day into twenty-four 
hours, starting from sunrise ; the Athenians began the day at sunset; the present civil day begins at midnight, and is divided into two equal periods of twelve hours each, but astronomers reckon from noon and count the hours continuously from 1 to 24 .

Sun-Dials.-The simplest form of sun-dial, and a useful one for setting a timekeeper when no standard is available for comparison, is one for showing when the sun is on the meridian. With a timekeeper showing mean time and an equation table, a meridian line may, of course, be at once traced for future reference. In the absence of these, the following, which are practically Ferguson's instructions, may be followed: "Make four or five concentric circles, a quarter of an inch from one another, on a flat stone, and let the outmost circle be but little less than the stone will contain. Fix a pin perpendicularly in the centre, and of such a length that its whole shadow may fall within the innermost circle for at least four hours in the middle of the day. The stone being set exactly level, in a place where the sun shines, suppose from eight in the morning till four in the afternoon, about which hours the end of the shadow should fall without all the circles; watch the times in the forenoon when the extremity of the

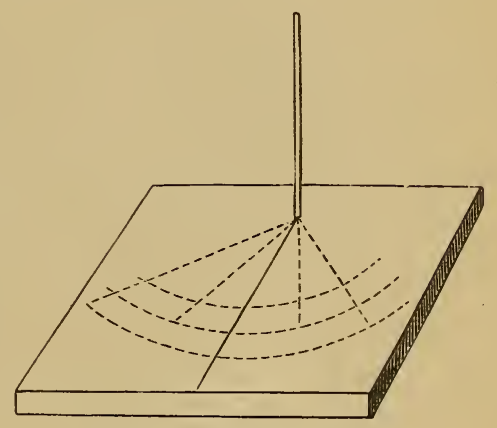

FIG. I.-Meridian Dial. shortening shadow just touches the several circles, and there make marks. Then, in the afternoon of the same day, watch the lengthening shadow, and where its end touches the several circles, in going over them, make marks also. With a pair of compasses, find exactly the middle points between the two marks on any circle, and draw a straight line from the centre to that point, which line will be covered at noon by the shadow of the pin."

By observation the hours of the morning and afternoon may also be marked on the meridian dial, and it will be noticed that, although the position of the hour immediately preceding corresponds with the one immediately after noon, these divisions will not aswer for any of the remaining hours.

Curious Meridian Dial.-The very ingeniously contrived meridian dial shown on the next page and reproduced from " $L$ 'Horlogerie" by Joseph Rambal, formed part of St. Peter's Cathedral, Geneva, from 1760 till the renovation of the building in 1894, and has since been restored on the initiative of the Society of Arts. The white spot in 
the centre of the disc's shadow not only indicates accurately solar noon when it is bisected by the central vertical line, but also approximately mean solar noon when it is centrally over a line of the figure-of-8 loop which allows for the equation of time on each particular day. The full line of the loop serves from June to December, and the dotted line during the complement of the year. As the year is not made up of a complete number of days, and a

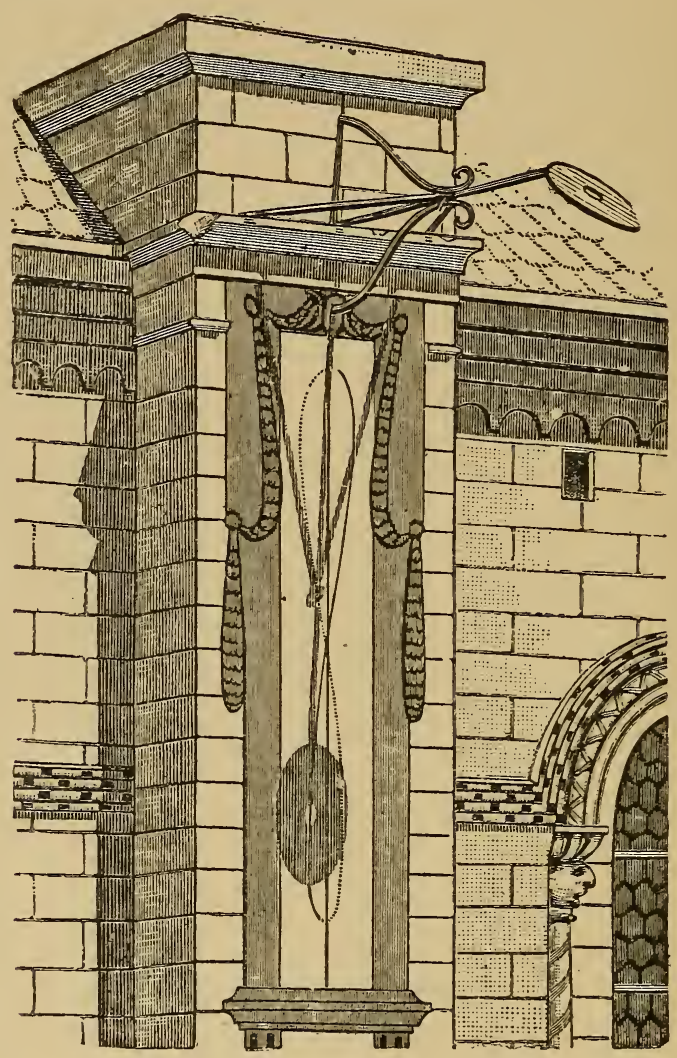

FIG. 2.-Curious Meridian Dial.

day is interpolated every fourth year, the exact equation in each year of the four is different; still the approximate equation would be practically sufficient for all but scientific purposes.

The art of dialling is somewhat complex. A glance at the figure on the next page will show why, except for places on the equator, the hour spaces are not all equal. A sun-dial may be regarded as a circle round the earth, or as the edge of a disc which passes through the 
centre of the earth from the spot where the dial is fixed. $a, b, c, d, e$, $f, g$, \&c., are longitudinal circles, representing the hours, в the spot where the dial is situated, $\mathrm{D}$ the corresponding latitude, $\mathrm{P}$ P the poles, and $\mathrm{E}$ the centre of the earth.

A dial prepared for any particular place is useless for another place in a different latitude, with the exception that a horizontal dial for a certain latitude will be a vertical dial for a latitude which is the complement of the first, or what it wants of $90^{\circ}$. That is, a horizontal dial for our latitude of $51 \frac{1}{2}^{\circ}$ would have to be placed in a vertical position facing the south in latitude $38 \frac{1}{2}^{\circ}$.

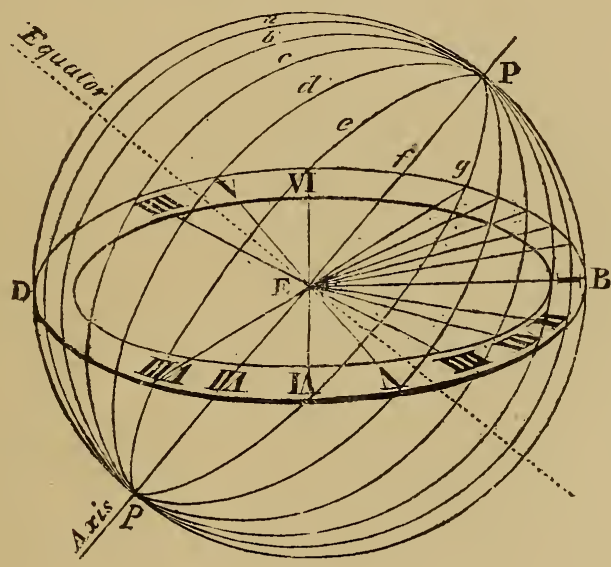

FIG. 3 .

Horizontal Sun-Dial.-To set out a horizontal dial, first draw two lines parallel to each other, at a distance equal to the thickness of the gnomon which is to cast the shadow. Next, draw a line at right angles to these, the extremities of which will indicate respectively the hours of six in the morning and six in the evening. Then, with $A$ and B as centres (see Fig. 4), draw quadrants of circles, and divide each into $90^{\circ}$. Now assuming the dial to be for the latitude of London, lay a rule over $\mathrm{B}$, and draw the first line through $113^{\circ}$, the second through $24_{4}^{1}$, third $38_{12}^{1}{ }^{\circ}$, fourth $53 \frac{1}{2}^{\circ}$, and fifth $71_{1^{1}}^{1}{ }^{\circ}$. Proceed the same with the other side. Extend the afternoon hour lines of four and five across the dial, and these will form the morning hours, while eight and seven of the morning hours prolonged will give the same evening hours. To form the style or gnomon, draw a radial line through that degree of the quadrant which corresponds to the latitude $=511_{2}^{\circ}$. This will show the elevation of the style, which is here represented as if lying on the surface of the dial. The thickness of the style must be 
equal to the distance between A and B. Place the style truly upright on the dial, and it is finished.

A dial, or rather a series of dials of every conceivable description, forming a structure, as shown in Fig. 5, was erected at Whitehall in 1669 , by order of Charles II. It was the invention of Francis Hall, alias Line, a Jesuit and professor of mathematics at Liège. Vertical dials, inclining dials, and dials for showing time as computed by various nations at different periods were all included.

Of these, the bowls or brackets appear to be the most attractive. One, on the first platform, to show the hour by fire, consisted of a little glass bowl filled with clear water. This bowl was about 3 ins.

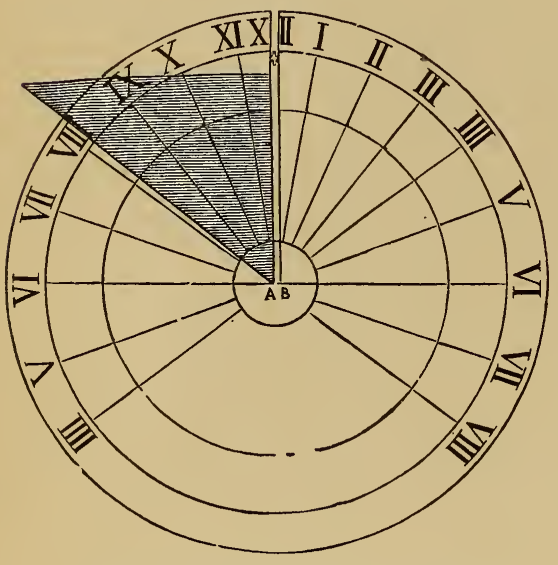

FIG. 4.-Horizontal Sun-Dial.

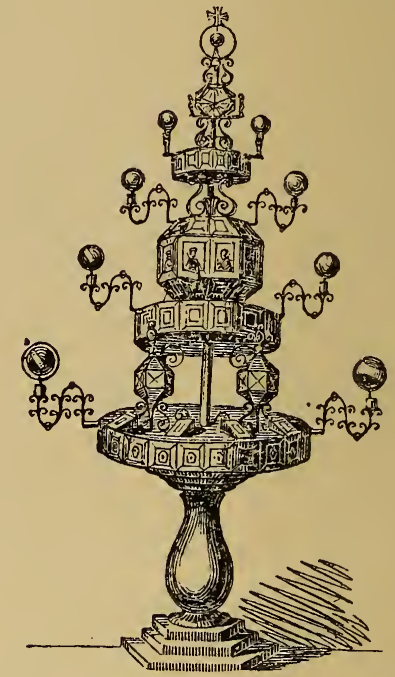

FIG 5.-Dials at Whitehall, I669.

diameter, placed in the middle of another sphere, about 6 ins. diameter, consisting of several iron rings or circles, representing the hour circles in the heavens. The hour was known by applying the hand to these circles when the sun shone, and that circle where you felt the hand burnt by the sunbeams passing through the bowl filled with water showed the true hour.

This curious erection had no covering; exposure to the elements and other destroying influences led to its speedy decay and subsequent demolition. The engraving is taken from the Mirror, vol. xiv.

Portable Dials.-The commonest form of portable dial is shown in Fig. 6. When held to the sun, by means of the small ring at top, a ray of light passed through a tiny hole and impinged on the inner surface of the opposite side of the rim, which was engraved with numerals 
corresponding to the hours of daylight. The hole was formed in a slide which covered a slit in the rim. The slide could be moved higher or lower, and signs of the zodiac were engraved on the rim as a guide to its position in different months of the year. Dials of this sort were in general use during the sixteenth and seventeenth centuries. A small horizontal dial like Fig. 4, but with a hinged style and a compass attached, formed a more costly pocket "horologium."

Fig. 7 is a Bronze Octagonal Portable Sun-dial and Compass. Made by Butterfield, an Englishman, who settled in Paris in the year 1720. It is from the collection of Mr. H. J. Heinz.

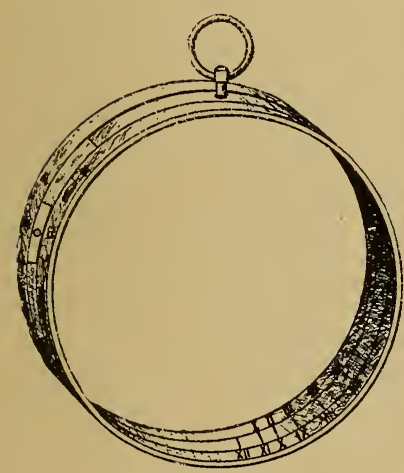

FIG. 6.-Pocket Sun-dial.

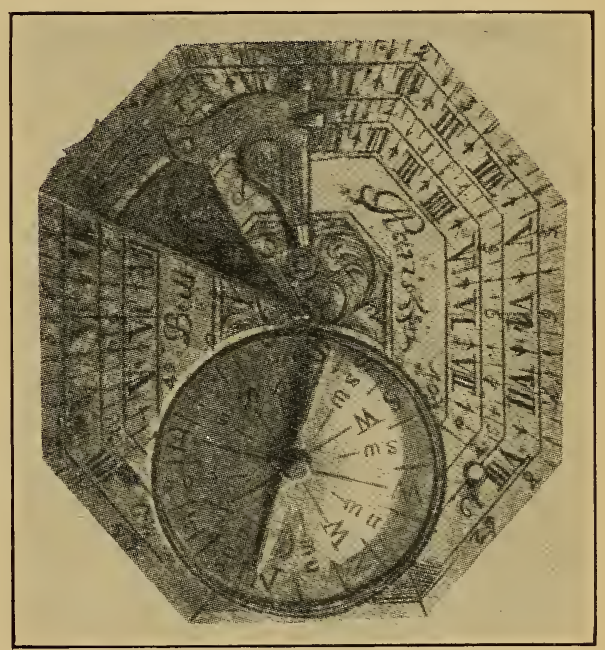

FIG. 7.-Portable Sun-dial and Compass.

Clepsydræ, or Water Clocks. - These indicate intervals of time by the passage of water, and may be divided into two classes: the ancient recorders for hours of varying length, and the more simple instruments used during and after the seventeenth century, when equal hours were measured.

Clepsydræ are of remote antiquity. They were known by the Egyptians, in Judea, Babylon, Chaldea, and Phœnicia, but these contrivances for measuring time were of the simplest description. They appear to have consisted each of a basin filled with water and exposed in some niche or corner of a public place. At the extreme end of the vessel was a spout or tap, from which trickled the liquid, drop by drop, into a receiver having on its inside marks for indicating the hours of the day and night. 
In parts of Southern India was used a thin copper bowl about 5 ins. in diameter, and rather deeper than a half sphere, having a very small hole in the bottom. The bowl, placed in a vessel containing water and floating thereon, gradually filled. At the expiration of an arranged interval it sank, and a boy or other watcher then struck a gong, and thus announced the time. The Brahmins divided the day into 60 hours of 24 minutes each, and, I am told, used a timekeeper of this sort which sank in twenty-four minutes. One of the bowls which is among the collection of the Horological Institute sinks after the lapse of forty-five minutes with tolerable accuracy, but the time is varied somewhat with the temperature of the water.

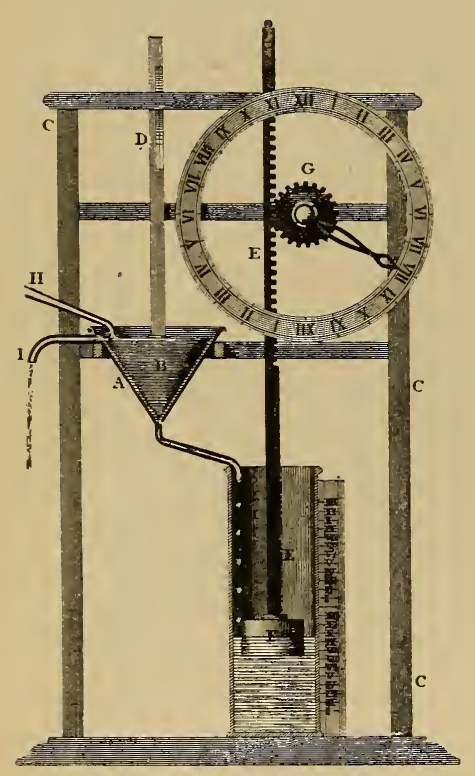

FIG. 8.-

A form of Clepsydra, about 300 B.C.

A form of clepsydra, said to have been in use in Egypt about 300 B.C., is shown in Fig. 8, for which I am indebted to Dr. Pearson's article in Rees' "Cyclopædia." A supply of water ran through the pipe $\mathrm{H}$ into the cone $\mathrm{A}$, and from there dropped into the cylinder $\mathrm{E}$. A conical stopper $B$ regulated the flow, and the superfluous water escaped by the waste-pipe I. The Egyptians divided the period between sunrise and sunset in to twelve equal hours, so that the conical stopper had to be adjusted each day, and marks for every day in the year, and for the particular latitude of the place, were cut on the stalk $\mathrm{D}$ as a guide to the position of the stopper. A floating piston terminating in a rack served to actuate a pinion, to the arbor of which an hour hand was fixed.

In Fig. 9 is shown an improved clepsydra, constructed so that its aperture is adjusted as the year advances by the putting of an index to the sun's place in an ecliptic circle. It consists, first, of a reservoir $A$, to the top of which is attached a waste-pipe to carry off the superfluous water, and thus keep it at the same level. A pipe B projects from this vessel into the rim of a drum $\mathrm{x} N$, on the front of which is a circle with the signs of the ecliptic engraved thereon. A smaller drum O F I passes within the large one, having attached to it an index. This drum has a groove or slot $a b$ cut through it, tapering in breadth both 
ways to a point. When in its place, this tapering groove comes just under the orifice of the pipe leading from the reservoir. This inner drum turns on a pipe or tube $\mathrm{F}$, which is continued within and has a funnel at the end (not seen) for receiving the water as it drops through the groove in the drum. The index is double, $\mathrm{L}$ for day and o for night, and it will be evident that, as it is turned, the capacity of the orifice is altered, and the water passes more or less rapidly through the pipe. The ecliptic being properly divided, the hand was set to the proper sign in which the sun then was, and was altered as he shifted round the ecliptic. The water, thus regulated, dropped into a cylindrical vessel $\mathrm{H}$, within which was a float $\mathrm{I}$, connected by a chain passing over a pulley on an arbor $\mathrm{P}$,

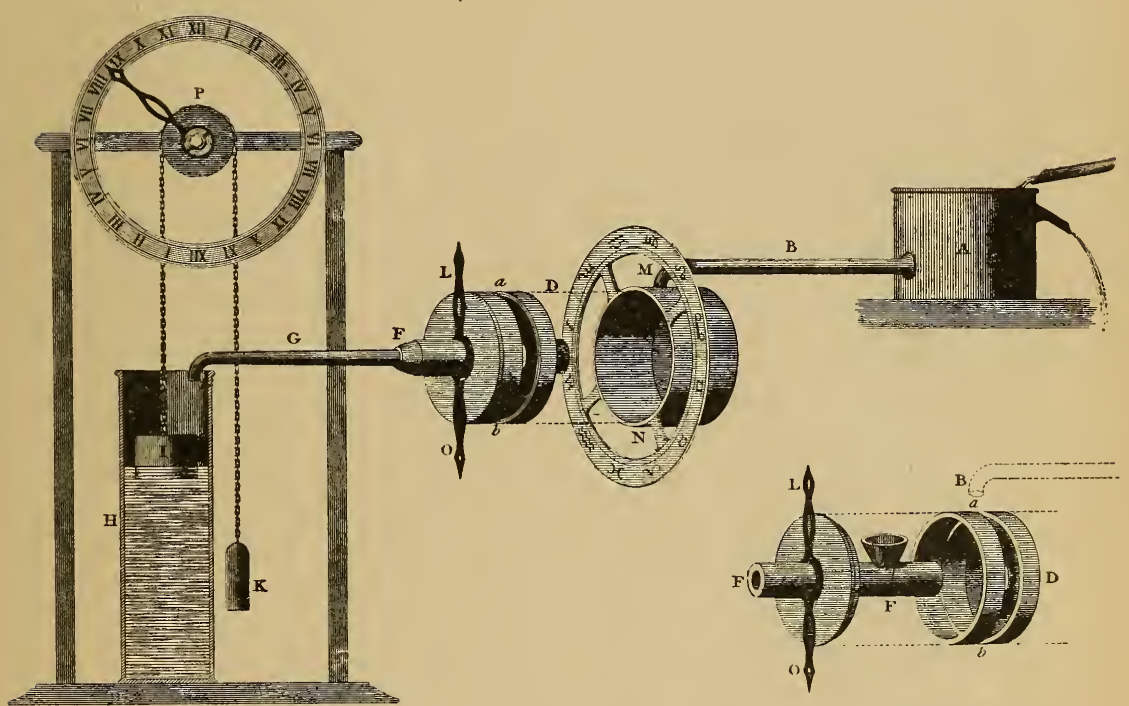

Fig. 9.-An Improved Clepsydra.

and having a counterpoise $\mathrm{K}$ at its other end. This pulley carried an index which pointed out the hours on a circle.

The next is ascribed to Ctesibius, about 200 B.C. It was a selfadjusting machine, and is shown in Fig. 10. The water dropped into a funnel A, from the eyes of a figure placed over it, and connected with a full reservoir, thus ensuring a constant pressure. The tube conveyed the water into an open cylinder with a float and a light pillar c attached. On the top of this pillar a human figure is placed, which points to the divisions on a large column. As the water rises 
in the cylinder, it also rises in the small tube or short leg of a syphon F B E, till it reaches the top, when it flows over the bent part, and quickly empties the cylinder, bringing down the float, and with it the index to the starting point. So far it would have measured hours of equal length; but the Egyptian method required some further contrivance to accommodate it to hours of varying length. This was done by drawing the divisions around the large column out of a horizontal line, so as to vary in their distance on different sides. The

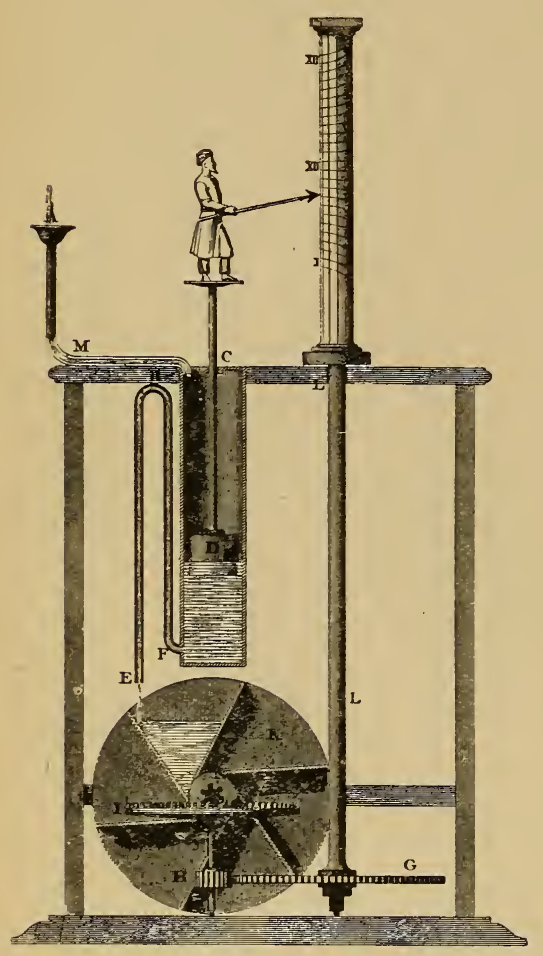

Fig. Io.-

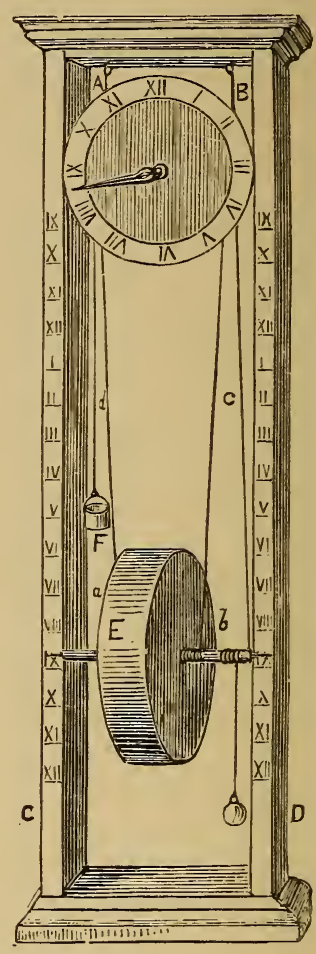

FIG. II.-

Self-adjusting Clepsydra, about 200 B.C. Clepsydra of the Seventeenth Century. water as it came from the syphon fell into a chambered drum $\mathrm{K}$, which turned with the weight as each compartment became filled. On the axis of this drum was placed a pinion-gearing with a contrate wheel I, which, by another pinion $\mathrm{H}$, turned a wheel $\mathrm{G}$, to the axis $\mathrm{L}$ of which the column was fixed. The lines were drawn slanting round the column to suit the hours of varying length throughout the year. The clepsydra was introduced in to Greece by Plato. The introduction of the clepsydra into Rome took place about 157 B.c., by Scipio Nascia. 
Pliny tells us that Pompey brought a valuable one among the spoils from the Eastern nations, which he made use of for limiting the speeches of the Roman orators. Julius Cæsar met with an instrument of the kind in England, by the help of which he observed that the summer nights of this country are shorter than they are in Italy.

With the decadence of Rome, when orators had certain periods of time allotted to them in the law courts for accusation or defence, the clepsydra was often, it is said, tampered with in the interest of particular suitors by adding to or subtracting from the wax used in the lawful regulation of the flow of water, or by using the fluid in an impure condition.

In 807 a water clock of bronze inlaid with gold was presented by the King of Persia to Charlemagne. Gifford in his history of France

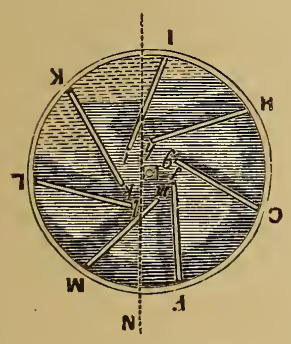

FIG. I2.-Section of Drum.

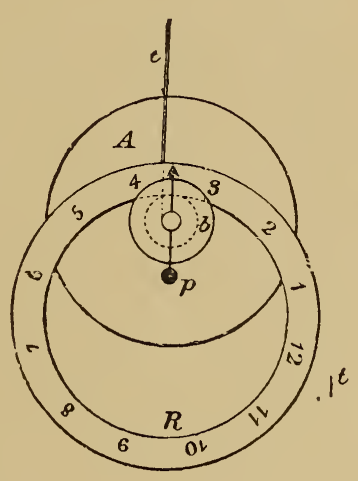

FIg. I3.-Front View. FIG. I4.-Side View.

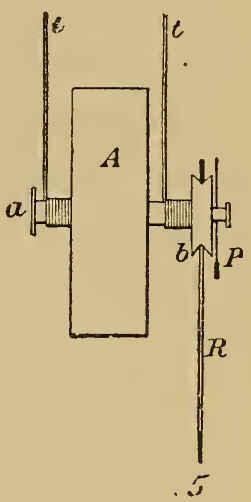

says: "The dial was composed of twelve small doors, which represented the hours; each door opened at the hour it was intended to represent, and out of it came the same number of little balls, which fell one by one, at equal intervals of time, on a brass drum. It might be told by the eye what hour it was by the number of doors that were open, and by the ear by the number of balls that fell. When it was twelve o'clock twelve horsemen in miniature issued forth at the same time and shut all the doors."

Hamburger, in Beckmann's "History of Inventions," dates the revival of clepsydræ to some time between 1643 and 1646 ; and Dr. Hutton asserts that in 1693 the first water clock was brought to Paris from Burgundy.

Fig. 11 represents a clepsydra of the seventeenth century, consisting 


\section{I4 Old Clocks and Watches and their Makers}

of an oblong frame of wood, A B C D, to the upper part of which two cords are fixed, their lower ends being wound round the axis of the drum $\mathrm{E}$. The drum is shown in section at Fig. 12. It has seven water-tight metallic portions, $\mathrm{F} f, \mathrm{G} g, \mathrm{H} h, \mathrm{I} i, \mathrm{~K} k, \mathrm{~L} l$, and $\mathrm{s} m$. If the cord be wound around the axis until the drum rises to the top of the frame, and the drum be left to obey the force of gravity, it will tend to fall, and the cord resisting this tendency will cause it to rotate rapidly as it descends. But if water is introduced into the vessel, it will be retained in certain parts by these partitions, and, one side being heavier than the other, the tendency to rotate will be counteracted,and the drum will remain stationary. If now a small hole is pierced near the bottom of each cell, the water will slowly ooze from one cell into another, thus reducing the opposing weight of water, and causing the drum slowly to rotate. The rate of motion being properly regulated by altering the size of the apertures, the axis will point out the hours on the side of the frame ; or a cord $c d$, with a weight $\mathrm{F}$, may be made to pass over a pulley attached to an arbor bearing an index or hand to point out the hours on an engraved or painted ring. A night clock, with transparent dial, on this principle, by Arnold Finchett of Cheapside, is in the British Museum, the date assigned to it being 1735.

The sealed water drum with partitions was utilised in another way which was described in "Engineering" some years ago, and will be understood on reference to the front and side views (Figs. 13 and 14). The drum $\mathrm{A}$ is suspended from two cords $e e$. An index placed loosely on the end of the arbor $a$ is weighted at its lower end $p$. A grooved pulley $b$ is fixed to the arbor, and on it hangs the hour ring $\mathrm{R}$ which is carried round by its adhesion to the pulley $b$.

The construction of clepsydræ, sand glasses, and weight clocks went on contemporaneously for a long period. With the introduction of the pendulum, clocks were made in which water acted as the motor and a pendulum as the controller. Such a clock was invented by Perrault in 1699. At the Royal Observatory, Greenwich, I remember seeing, a few years ago, a water-driven clock with a revolving pendulum, which was used for driving the equatorial telescope. Water at a pressure escaping from holes in a pair of horizontal arms caused the arms to revolve. One of the earliest steam engines was made on this principle; a similar contrivance, under the name of a sparger, has long been used by brewers to sprinkle water on their malt, and more recently a sprinkler of the same kind has been adopted for watering gardens.

Wick and Lamp Timekeepers.-Among the primitive time- 
keepers adopted by Chinese and Japanese was a kind of wick about two feet in length, made of material resembling flax or hemp, which underwent some process, so that when ignited it would smoulder without breaking into a flame. Knots were tied at particular distances, and the effluxion of time estimated as the sections between the knots smouldered away. Mons. Planchon, of Paris, has one of these curiosities, which I am assured is a genuine relic.

Asser narrates how King Alfred, who reigned from 871 to 901 , contrived a timekeeper consisting of wax candles twelve inches long with marks an inch apart. Each candle burnt for four hours. The king, finding the time varied owing to the guttering of the candle, then devised a lantern of white horn scraped thin so as to be transparent. This is an unsatisfactory story. Having to provide and light a fresh candle every four hours was a clumsy device, costly to maintain and not so accurate in action as the clepsydra, which was certainly known in England at the time.

In "Le Passe-Temps" of Jehan L'Hermite, who was born at Antwerp in 1560, and died at Madrid in 1622, having served as Gentleman of the Chamber to Philippe II. of Spain, mention is made of a lamp timekceper to show the hours at night as among the contents of his royal master's room. Fig. 15 is a drawing of what appears to be a similar instrument in the Schloss collection. On a stand of pewter is a glass reservoir, fastened with longitudinal slips of pewter, on one of which are cast

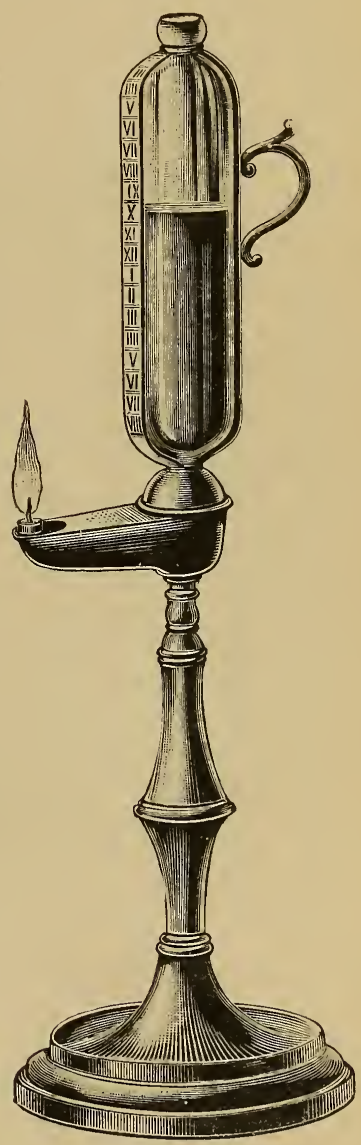

FIG. I 5.Lamp Timekeeper. the hour numerals from III at the top downwards to XII and then from I to VIII, thus covering the period of darkness during winter. From the base of the reservoir extends a nose to receive the wick, which, when alight, illuminates the hour hand and the reservoir.

Lamp timekeepers of this kind were, I am told, to be met with 
occasionally in German and Dutch outlying country dwelling still a comparatively recent date.

Sand Glasses.-These, consisting of two glass bulbs joined by an intervening neck, measure a prearranged period by the falling of fine sand from the upper into the lower bulb. The invention of clepsammia, as they are called by several writers, is ascribed to Luitprand, a monk of Chartres, who at the end of the eighth century

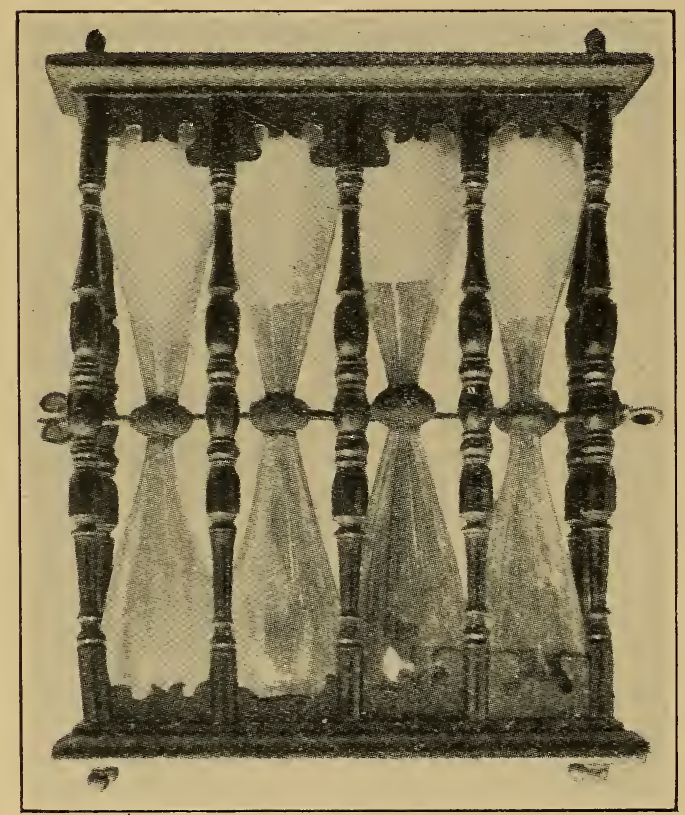

Fig. 16.-Set of Sand Glasses. resuscitated the art of blowing glass. As already related, Charlemagne in 807 received from Persia a magnificent clepsydra. $\mathrm{He}$ then ordered to be made an immense sablier, or sand glass, with the horal divisions marked on the outside and which required to be turned once only in twelve hours. Sand glasses perform with a remarkable approach to accuracy and from this time became popular, especially in France. In Fig. 16 is shown a handsome set of sand glasses of the seventeenth century, for the photograph of which I am indebted to Mr. Hansard Watt. Great care seems to have been taken in the preparation of the sand. According to a prescription in "Le Menagier de Paris," " pour faire sablon à mettre ès orloges," ground black marble dust was to be boiled in wine, and, after being thoroughly dried, to be ground again, the process to be repeated about nine times.

To this day a sand glass is used in the House of Commons to measure certain intervals, and in comparatively recent times it was not uncommon to see a preacher, as he began his discourse, turn a sand glass attached to the pulpit. 


\section{CHAPTER II}

\section{WEIGHT C L OCKS}

SO many vague and contradictory records exist as to the inven$\int$ tion of clocks composed of an assemblage of wheels actuated by a weight, that any attempt to fix the exact date of their introduction would be mere guesswork.

According to the "Anthologia" quoted by E. M. Antoniadi, the Byzantine Emperor, Justin II., and his wife Sophia, in the sixth century offered to the building called the Basilica of Constantinople a horologium in which " the ingeniously devised brass was beating the hours from one to twelve." In the tenth century the Byzantine Emperor, Constantine VII., mentions " a small silver horologium which must stand in the chamber, and another one of brass which must stand where the chamberlains are residing."

It is claimed that Pacificus, Archdeacon of Verona, who died in the middle of the ninth century, devised a clock which Bailly, in his " History of Modern Astronomy," considers was furnished with an escapement; but this is not substantiated, and other authorities decide that it was a water clock. Charlemagne's clepsydra which sounded the hours is also sometimes erroneously referred to as a weight clock.

In Stow's "Chronicles," under date 606, it is stated: "This year dyed St. Gregory; he commanded clocks and dials to be set up in churches to distinguish the houres of the day." These were probably sun-dials, and Stow's introduction of the word clocks is therefore unwarranted. The Latin " horologium" or the Italian " orologio" was used indiscriminately for sun-dials, clepsydræ, and other timekeepers. Clocks other than sun-dials were also designated nocturnal dials to distinguish them from those which showed the hour by the solar shadow only.

Havard says there is hardly a word in the French language that underwent so many transformations as the word horloge. It assumed in turn reloge, oroloige, orloge, oreloge, ologe, and even auloge, before arriving at horloge. In an inventory of Charles V. made in 1380, a reference is found of " ung grand orloge de mer," consisting of 
" deux grans fiolles (flasks) plains de sablon." In other words, an hour glass.

The French equivalent for dial has been for several centuries cadran. But at one time, heurier, from heure, the hour, appears to have served. Richard, Archbishop of Reims, at the Château de Porte Mars, in 1389, refers to " ung petit orloge à ung heurier de cuivre peint en vert, prix IIII. livres p.," that is, a small clock with a dial of copper painted in green colour, price 4 livres parisis.

Gerbert, a monk, afterwards Pope Sylvester II., placed a clock in Magdeburg Cathedral at the end of the tenth. century; but Dithmar declares it was only a kind of sun-dial; other writers consider Gebert to be the originator of the escapement. Whatever may be inferred, there is no absolute proof that an escapement was constructed for more than two centuries after Gerbert's time, though it is pretty certain that clocks of some sort existed in cathedrals and monastries during the twelfth and thirteenth centuries.

The word " clock," whether derived from the Saxon clugga, the Teutonic glocke, the Latin glocio, or the French cloche, signified " a bell," and there is reason to suppose that many of the early efforts consisted merely of a bell sounded at regular intervals by hand, the instant of ringing being determined by a sun-dial or sand-glass.

In monasteries prayers were recited at certain fixed hours of the night as well as of the day, and as the monks were not always unfettered by sleep at the needful moment, this horloge or alarm was probably invented to rouse the drowsy religieux to a due sense of his duties. In the "Rule" of the monks of Citeaux, drawn up about 1120, and quoted by Calmet, the duty is prescribed to the sacristan of so adjusting the abbey clock that it may strike and awake the monks for matins. Durandus, in the thirteenth century, alludes to the clock as one of the essential features of a church. Dante, who was born in 1265 and died in 1321, mentions an " orologia" which struck the hours; and Chaucer, who was born in 1328 and died in 1400 , speaks of the cock crowing as regularly as clock or abbey horologe.

Berthoud considered it likely that a revolving fly was used as a controller prior to the invention of an escapement.

Captain Smyth, R.N. (Archxologia, vol. xxxiii.), suggests that John Megestein of Cologne, who is spoken of as having improved clocks in the fourteenth century, was possibly the inventor of the escapement. Still it is only surmise. 
An early clock often referred to is the one which was presented by Saladin of Egypt to the Emperor Frederick II. of Germany, in the year 1232. It is described as resembling internally a celestial globe, in which figures of the sun, moon, and other planets, formed with the greatest skill, moved, being impelled by weights and wheels. There were also the twelve signs of the zodaic, with appropriate characters, which moved with the firmament.

In 1359 John II. of France, then a prisoner in London, desirous of measuring the time, addressed himself to " the King of the Minstrels," to whom was delegated the task of entertaining this royal personage, and in the "Journal de la depense du roy Jean" the following occurred: " Dymenche XII. jour de Janvier le roy des menestereulx, sur la façon de l'auloge qu'il fait pour le roy, VII. nobles valent CXIII. sols $\mathrm{X}$. deniers et a promis que parmi cette somme et $\mathrm{XX}$ sols, qui paravant li ont ésté baillier le VI. de Janvier, il rendra l'auloge parfait,"' the translation of which is that on the 12th January, Sunday, the king of the minstrels was paid for making a clock for the King seven " nobles" worth 113 sous and 10 derniers, and promised, having already been lent on the 6 th January the sum of 20 sous, to deliver the clock in perfect condition.

Jacks.-Mechanical figures for striking the hour on bells seem to have been in use before the introduction of dials, and they proved to be a lasting attraction. There was, prior to 1298 , a clock at St. Paul's Cathedral with such figures ; and Decker, in his " Gull's Hornbook," calls them " Paul's Jacks." In the accounts of the cathedral for the year 1286, allowances to Bartholomo Orologiario the clockkeeper are entered, namely, of bread at the rate of a loaf daily. In 1344 the dean and chapter entered into a contract with Walter the Orgoner of Southwark to supply and fix a dial, from which it may be inferred that the clock previously had no dial. In Dugdale's history of the old cathedral the dial is referred to as follows: "Somewhat above the stonework of the steeple was a fine dial, for which there was order taken in the 18th of Edward III., that it should be made all splendour imaginable, which was accordingly done; having the image of an angel pointing to the hours both of the day and night." The dial was placed below the " Jacks," which were not ousted from office, but continued to strike the hour with their accustomed regularity. Decker says "the time of St. Paul's goes truer by five notes than St. Sepulchre's chimes."

Other writers confirm the supposition that ciials were absent from most of the early clocks. M. Viollet-le-Duc (" Dictionnaire Raisonné 
de l'Architecture Française ") observes that from the twelfth to the fourteenth century no space was arranged in the towers of churches for dials which could be seen at a distance. The earliest dials, he says

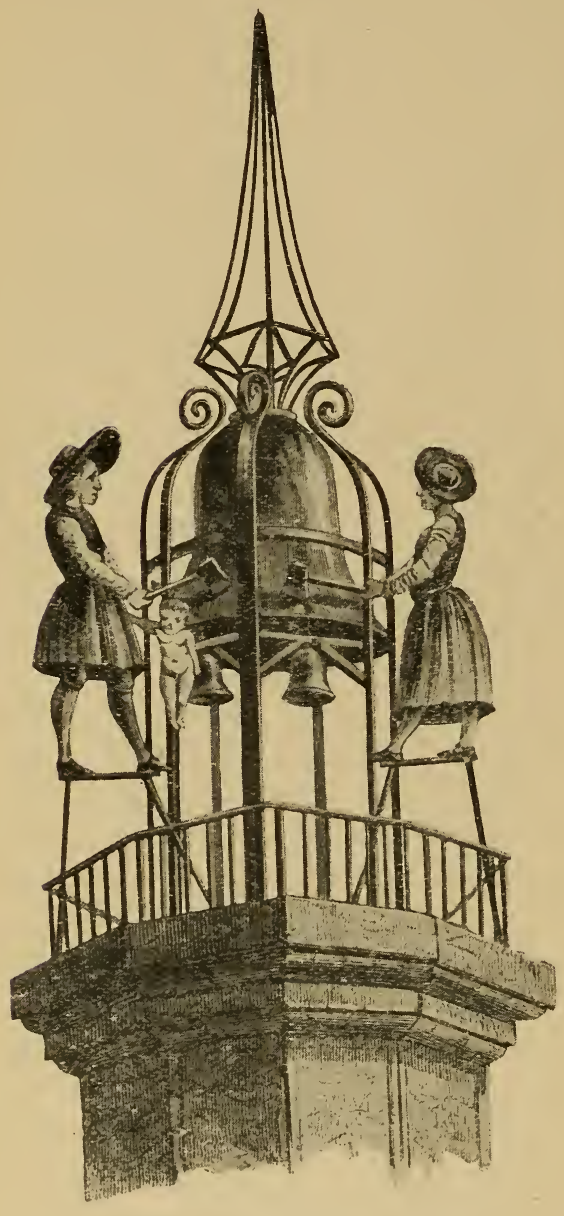

FIG. I7.- Jacquemarts at Dijon.

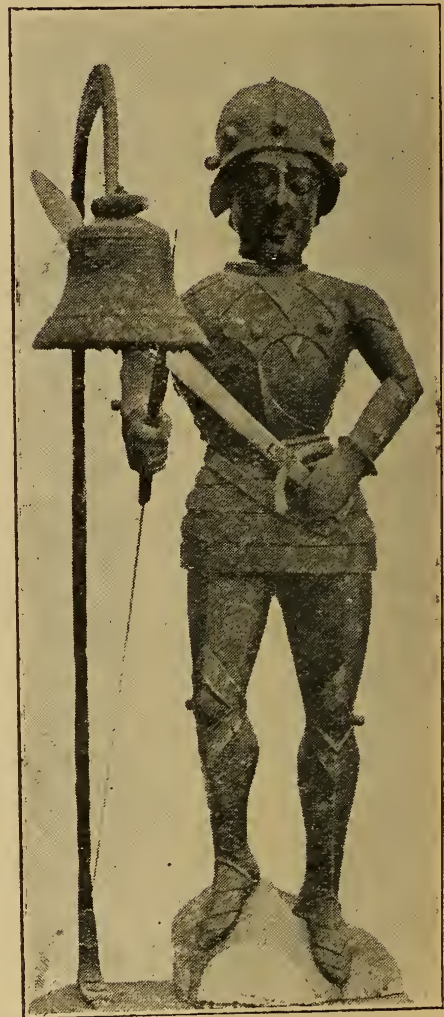

FIG. I8.- "Jack the Smiter," Southwold Church.

were covered by small projecting roofs and made either of wood or lead and decorated in colours.

Froissart, who had an affection for clocks, speaks of one which existed at Courtray prior to 1370 as the largest which had then been made. It was brought from thence with other spoils of war in 1382, by Philip, Duke of Burgundy, who presented it to the people of Dijon. 
The clock was surmounted with his crest, and set up at Dijon in a tower of the Church of Notre Dame. In a turret over it were a bell and the figures of a man and woman, one on each side, which struck the hours, as shown in Fig. 17. To the present day these automata arc locally jacquemarts, and G. Peignot, author of a dissertation on them, contended that they received their name from Jacquemart, a clock and lock maker of Lille, who was employed by the Duke of Burgundy in the year 1442. The appellation, however, seems to be merely a corruption of Jaccomarchiadus, i.e., a man in a suit of armour.

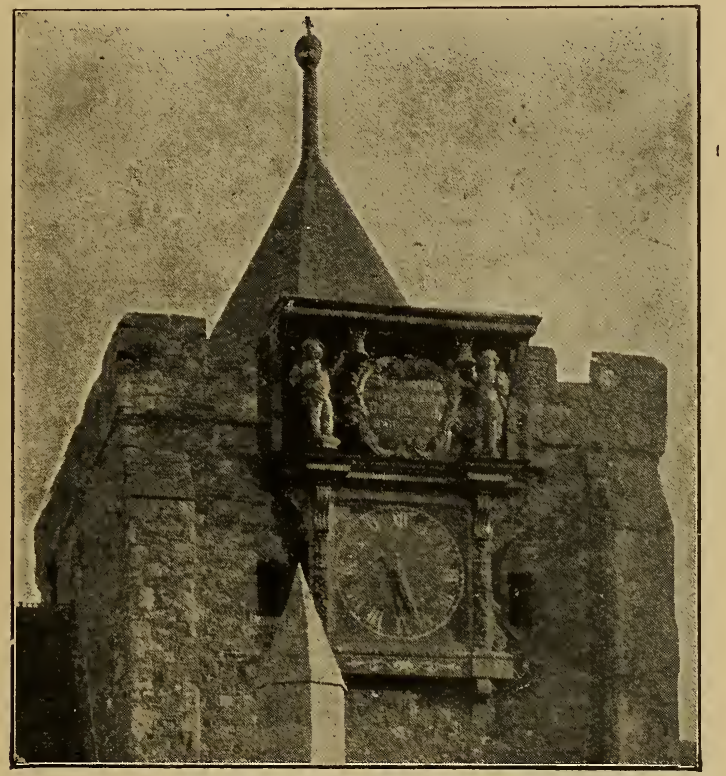

FIG. I9.-Jacks at Rye.

During the Middle Ages it was the custom tc place as sentries on the belfries on tops of towers mailed men to watch over the safety of castles and towers, and their office was to give alarm at the approach of an enemy, a fire, or other disturbing event. And at many castles in Europe till quite late in the seventeenth century a trumpeter was posted on a tower to announce by a blast on his instrument the time of day for meals to be served.

In Fig. 18 is shown a "Jack" which, though not on active service, is still in Southwold Church. It is an oak figure, $3 \mathrm{ft}$. 6 ins. in height, of a man clad in armour, and is said to date from early in 
the fifteenth century. Locally it is known as " Jack the Smiter." The engraving is from a photograph by Mr. J. Martyn, Southwold. At the Parish Church, Rye, Sussex, is a clock said to have been the gift of Queen Elizabeth. This may be so, but the hands are certainly of

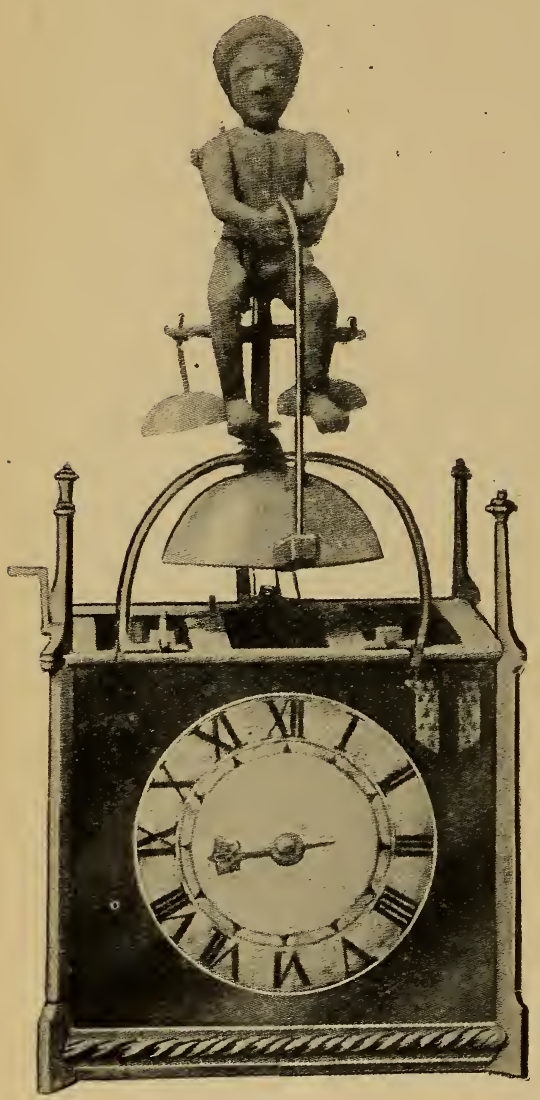

FIG. 20.-Portable Clock, with Striking Jack. much later date, and the movement has undergone reconstruction, for it is now fitted with a pendulum which beats but once in two seconds and a half, and projects below the clock into the church. Fig. 19, from a photograph by Mr. W. L. F. Wastell, shows the dial surmounted by a canopy, under which stand two Jacks, which strike the quarters on small bells. Between these two figures, within an ornamental border, is a label thus inscribed: "For our time is a very shadow that passeth away. Wisdom i. 5." An excellent representative of Striking Jacks exists at the Church of St. Mary Steps, Exeter ; there is a pair at York Cathedral, and a pair, from Glastonbury, at Wells ; a pair, formerly on the eastern wall of St. Martin's Church, Oxford, has lately been restored and placed upon the tower of the church ; the quarters are struck by Jacks at All Saints' Church, Leicester, where the clock, which is said to date from the time of James I., was restored in 1899 ; in the tower of Holy Trinity Church, Bristol, which was demolished in 1787, was a pair; and in a recess of the south aisle of Norwich Cathedral were two small Jacks which, actuated by wires from the clock, struck the quarters on adjacent bells. Of the Exeter Jacks, and two at the Church of St. Dunstan's, Fleet Street, which were dear to Londoners of the last century, I shall be able to give engravings. 
The peculiar clock shown in Fig. 20 appears to be a sixteenthcentury production. There are three trains of wheels, all arranged to face the sides of the clock. The clock is 12 ins. wide, 11 ins. high, 9 ins. from front to back, and $2 \mathrm{ft}$. $2 \frac{1}{2} \mathrm{ins}$. from the bottom of the clock to the top of the figure. By means of wires at the back, which extend to levers actuated by the striking and quarter trains, the figure on top of the clock strikes the hours on the large bell with the large hammer in his hands, and at the quarters kicks the two small bells with his heels.

In the early part of the fourteenth century, a large stone tower was built in Palace Yard, opposite to Westminster Hall, and a clock placed therein which struck every hour upon a great bell. There is a tradition that in the sixteenth year of the reign of Edward I. (1298) the Lord Chief Justice Randulphus de Hengham, having made an alteration in a record, was fined 800 marks by the king's order, and the money was applied to defray the cost of erecting a public clock opposite the entrance to Westminster Hall. The first official mention of Hengham's punishment extant appears to be in a Year Book of the time of Richard III., where it is stated that on an occasion when the king closeted the judges in the Inner Star Chamber to consider various points submitted to them, one of the judges cited the case of Hengham, and said the offence consisted of altering a record so that a poor defendant might have to pay but 6 s. $8 \mathrm{~d}$. instead of $13 \mathrm{~s} .4 \mathrm{~d}$., but nothing is said respecting the building of a clock. Stow, who was born in 1525 and died in 1605, in his "Account of Westminster" (vol. ii., p. 55) states that the clock was provided from Hengham's fine; and the Hon. Daines Barrington, in an interesting letter to $\mathrm{Mr}$. Justice Blackstone in 1778 (Archaologia, vol. v.), accepts the tradition, which is very possibly well founded, although it must be confessed that the evidence on the point is not conclusive. In an Issue Roll of the forty-fourth year of the reign of Edward III. is recorded the payment of two pounds to John Nicole, keeper of the great clock of the king within the Palace of Westminster, being his wages for eighty days at the rate of sixpence a day. In subsequent reigns further references are made to the keeper of this clock. In the first year of Henry V. was granted a patent to "Henricus Berton Valectus camerae Regis custos horologii Regis infra Palatium Westm. pro vita. cum feod. VI. dem per diem." Henry VI. entrusted its custody to William Warby, Dean of St. Stephen's, together with sixpence a day remuneration. The tower was standing in the time of Elizabeth, for Judge Southcote mentions 
the tradition, stating that the clock still remained which had been made out of the Chief Justice's fine. The engraving which I am enabled to give of this interesting erection is from the Mirror, vol. xi., which was published in 1825. The sketch is copied from an engraving by Hollar, who was born in 1607 and died in 1677 . It doubtless represents the locality as it existed about the middle of the seventeenth century, shortly after which time the tower was pulled down, but the exact date of its destruction is unknown.

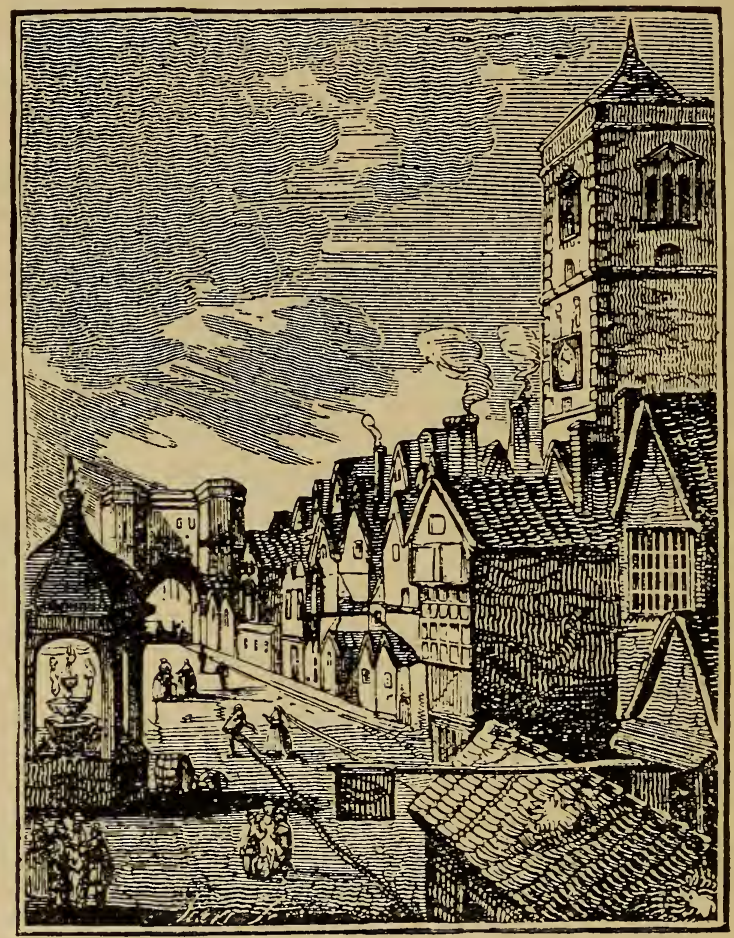

FIG. 21.-Clock Tower in Palace Yard, Westminster.

On the old Houses of Parliament, which were destroyed by fire in 1834, a dial on the second pediment of the buildings in Palace Yard marked the site, the remarkable motto on which, "Discite Justitiam Moniti," may be taken to relate to its origin. The clock tower of the present home of our Legislature is, it is conjectured, but a few paces from the situation of the original clock. The great bell, "Tom of Westminster," was broken up and recast for the 
St. Paul's Cathedral clock, of which more particulars will be given later on.

There was a large clock in Canterbury Cathedral at the end of the thirteenth century, which, according to Dart's history of the sacred edifice, was put up at a cost of $£ 30$ in 1292 , and one at Exeter at the beginning of the fourteenth century.

An " orologium " of some kind was under construction at Norwich Cathedral in 1323. From that date numerous entries relating to it occur in the Sacrist's Rolls. There were twenty-four small images, which it may be conjectured represented the hours of the day and night; thirty images, probably corresponding to the days of the month, and also painted and gilded plates portraying the sun and moon.

About 1326 Richard Wallingford, Abbot of Saint Albans, placed a " horloge" in his monastry, and the account which he gave of his machine is still preserved in the Bodleian Library at Oxford. From this, Wallingford's conception really appears to have been more of a planetarium for showing the course of the heavenly bodies than a timekeeper, for his description contains no mention of any escapement of regulator for ensuring equable motion.

The earliest clock worthy of our modern definition, of which we have any authentic details, is the one which is said to have been made about the year 1335, by Peter Lightfoot, an ingenious monk of Glastonbury Abbey, for and at the expense of his superior, Adam de. Lodbury, who was promoted to the Abbacy of Glastonbury in 1322 and died in 1335. The fourteenth century was distinguished by the introduction of the peculiar class of clocks which, besides indicating the flight of time, were furnished with mechanism for other purposes. One of the earliest of this kind was described by Viollet-le-Duc as having been given about the year 1340 to the monastry of Cluny by the Abbot Pierre de Chastelux. In addition to its indication of the phases of the moon, the movements of the sun, \&c., this clock had a quantity of little figures which acted various scenes, as "The Mystery of the Resurrection," "Death," \&c. The hours were announced by a cock, which fluttered its wings and crowed twice. At the same time an angel opened a door and saluted the Virgin Mary, the Holy Ghost descended on her head in the form of a dove, God the Father gave her His benediction, a musical carillon chimed, animals shook their wings and moved their eyes; at last the clock struck, and all retreated within it.

From a horological point of view such marionette exhibitions may 
be puerile and contemptible; still they caught and held the popular fancy, their producers being as a rule more honoured than those who merely strove after exactness of timekeeping.

Horological construction of this kind was not confined to the western part of Europe. Anent the wonders in the Palace of Abu Hammou, Sultan of Tlemcén, the Abbé Barges, a French scholar and Orientalist, speaks of a clock in the king's palace, ornamented by figures wrought in solid silver. Above the case containing the works was a scene representing a thicket in which was a bird spreading its wings over its young. A serpent stealthily crawled out of its hiding place towards the birds, endeavouring to surprise and devou $r$ them. Ten doors introduced in the forepart of the clock represented the ten hours of the night. At the end of each hour one of these doors creaked and shook. Two wider and higher doors occupied the lateral extremity of the case. Above these doors and near the cornice, a sphere of the moon moved in the directon of the equatorial line and indicated the course of this heavenly body. At the commencement of each hour, when one of the smaller doors rattled, an eagle swooped out of each of the two bigger doors and settled on a copper vase or basin dropping into it a piece of metal-also copper-which he had carried in his beak. These weights, which glided into a cavity introduced at the bottom of the vase, dropped into the interior of the clock, subsequently rising again when required. Then the serpent, which by that time had wound itself up to the top of the thicket, emitted a sharp hiss, pounced upon and bit one of the young birds, its mother meanwhile squeaking and endeavouring to defend it. At this moment the door which marked the time opened by itself, a young female slave appeared, and in her right hand presented an open book whereon the name of the hour could be read in verses. She held her left hand up to her lips as if to salute a khalifa. This clock was named in Arabic "Menganah," and was first seen in 1358 .

The first of the celebrated Strassburg Cathedral clocks was begun about 1350, under the direction of John, Bishop of Lichtenberg. Henry Wieck, of Wurtemberg, constructed a clock for Charles V. of France, surnamed the Wise, and it was erected at Paris in the Royal Palace (now the Palais de Justice). Henry Wieck, or, as he was afterwards known, Henry De Vick, began his task in 1370 and completed it eight years after. He was lodged in the tower and received six sous parisis per day during the time he was employed.' Somewhat similar clocks were, probably about the same time, erected at Caen and Montargis, though some French writers assert that the 
Caen clock was made by one Beaumont in 1314. In Rymer's " Foedera" there is printed a protection given by King Edward III. of England to three Dutchmen named John Lietuyt, John Uneman, and William Uneman, who were " orologiers," invited from Delft to England in 1368. The title of this protection is "De Horlogiorum Artificio exercendo." There were probably also English artificers practising their craft at the same time as that of the issue of the decree which gave the Dutch men protection, for that document enacted that the English artificers should not be molested. The "horologium " of John Dondi, constructed at Padua in 1344 by order of Hubert, Prince of Carrara, seems also to have been a true clock. It is described as being placed on the top of a turret on the steeple, and designating the twenty-four hours of the day and night. De Maizières, a contemporary writer, says it was visited by all the scientific men of the day, and from thenceforward the family of Dondi took the name of "Dondi d'Orologia." He also speaks of Joseph Dondi, apparently a son of John, as one who excelled in clockmaking, and after sixteen years' labour constructed a sphere or ${ }^{{ }^{*}}$ clock governed by a single balance, and which correctly showed the

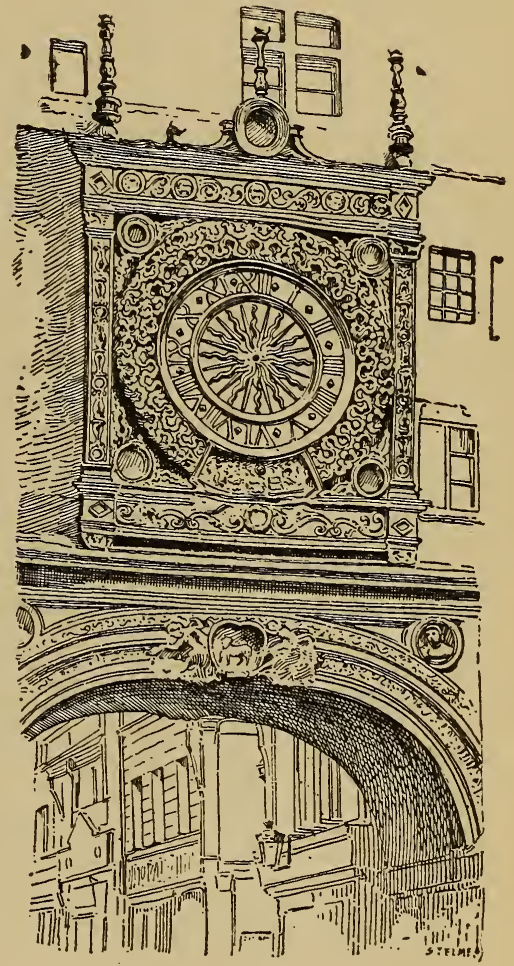

FIG. 22.-Clnck at Rouen. "Dictionnaire de l'Ameublement." motion of the celestial bodies. John Visconti, Archbishop of Milan, set up a clock at Genoa in 1353; in 1356 one was fixed at Bologna.

Froissart has left a descriptive eulogium of a clock, written in 1370 in the form of a fragmentary poem, entitled " l'Horloge Amoureuse." In this the controlling medium is referred to as a "foliot," which was doubtless the straight-armed balance with weights such as appears in the drawing of De Vicks' clock presently to be described. In 1389 a 
splendid clock, made by Jehan de Féalins, was erected at Rouen, which with some modern alterations to the movements is still a reliable timekeeper, showing the hours and also the days of the week and the phases of the moon. The handsome dial shown in Fig. 22 is about $6 \mathrm{ft}$. square. At Spires, in Bavaria, there was a clock in the year 1395. Dr. Helein describes a complicated clock which at the end of the fourteenth century was erected at Lund, in Sweden. When the hours were struck, two knights came forward, and gave each other as many blows as the number of the hour; a door then opened and showed the Virgin Mary, seated on a throne with the infant Jesus in her arms. The Magi then presented their offerings, during which trumpets sounded, and the figures disappeared. From the beginning of the fifteenth century mathematicians, astronomers, and mechanicians throughout Europe vied with each other in contriving timekeepers with various supplementary actions. In 1401 a large clock with bells was placed in the Cathedral of Seville, and in 1404 a similar one for Moscow was constructed by Lazare, a Servian. The clock of Lubeck was made in 1405 and one at Pavia by G. Visconti a little later. In 1442 Nuremberg had a clock with figures to represent soldiers which went through evolutions periodically. The Auxerre clock was finished in 1483, and shortly after an astronomical clock was erected at Prague; the clock at Munich dates from the same period. The first monumental timekeeper in the Square of St. Mark's, Venice, was put up in 1495. Among clocks of the sixteenth century may be cited one at Brussels, one at Berne, the latter constructed in 1557 by Gaspard Brunner, having performing soldiers something in the style of the Nuremberg one; "Hans of Jena," in which a pilgrim offered an apple to an immense open-mouthed grotesque head as the hours struck; the clock at Coblentz, where, in the belfry of the Kaufhaus, was fixed a large helmeted head, the mouth of which opened and shut as the hours were sounded; an astronomical clock at Beauvais Cathedral, of $36 \mathrm{ft}$. in height and having fifty dials; the second great Strassburg clock, which was begun in 1570 ; a clock with numerous mechanical figures set up at Niort, in Poitou, the same year; a clock at Calais, with two figures which attacked each other as in the Lund clock; and the celebrated Lyons clock which dates from 1598. These are but some of the more notable clocks erected up to the close of the sixteenth century, by which time nearly every town in Europe had at least one public timekeeper of some pretensions. Of several typical ones among those enumerated I am able to give fuller particulars. 
The Glastonbury ancient and complicated piece of machinery was, according to William of Worcester, originally in the south transept of the abbey church; but it was removed with all its appendages from thence to Wells Cathedral at the time of the dissolution of the monastry in the reign of Henry VIII., where, in an old chapel in the north transept, it still remains. The face of the clock as it now appears is shown in Fig. 23. The dial is $6 \mathrm{ft}: \mathbf{6}$ ins. in diameter, and contained in a square frame, the spandrels of which are filled with

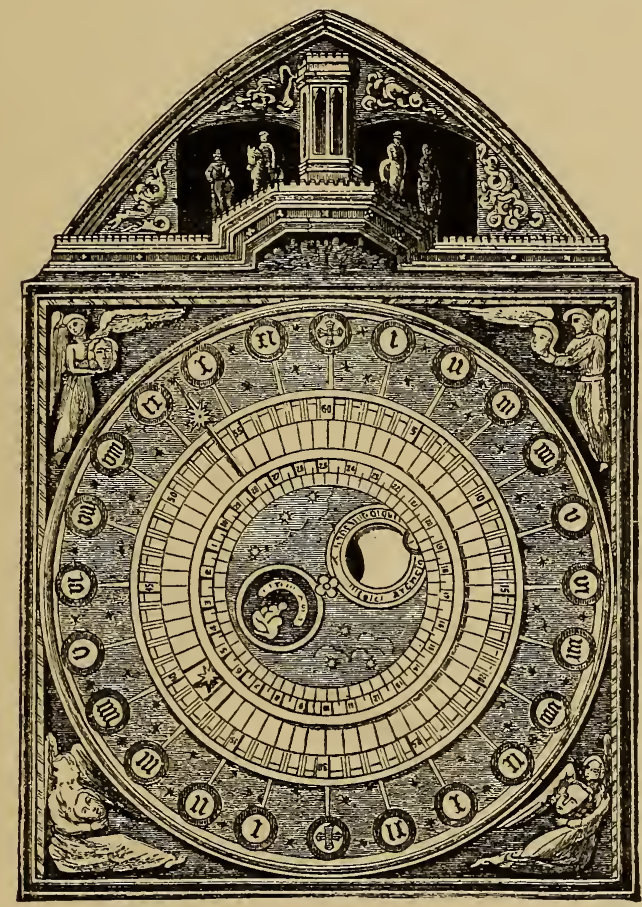

FIG. 23.-Dial of Glastonbury Clock.

angels, holding in their hands each the head of a man. The outer band is painted blue, with gilt stars scattered over it, and is divided into twenty-four parts, corresponding with the twenty-four hours of the day and night, in two divisions of twelve hours each. The horary numbers are painted in old English characters, on circular tablets, and mark the hours from twelve at noon to midnight, and from thence to twelve at midday again. The hour-index, a large gilt star, is attached to the machinery behind a second circle, which conceals all except the index. On this second circle are marked the minutes, indicated 
by a smaller star. A third and lesser circle contains numbers for indicating the age of the moon, which is marked by a point attached to a small circular opening in the plate, through which the phases of the moon are shown. Around this aperture is an inscription, not very intelligible, which one author reads as " $\mathrm{Ab}$ hinc monstrat micro ... ericus archery pung," meaning, probably, that in this microcosm were displayed all the wonders of the vast sidereal hemisphere.- Corresponding to the moon aperture on the opposite side of the centre is a circle, in which is a female figure, with the motto "Semper peragrat Phœbe." An arched pediment surmounts the whole, with an octangular projection from its base line, forming a cornice to the face of the clock. A panelled turret is fixed in the centre, around which four equestrian knights, equipped for a tournament and mounted on two pieces of carved wood, used to revolve in opposite directions, two on each side, as if running at the ring in a tilt, when set in motion by a connection with the clock. A "Jack" seated at one angle of the transept, within the church, is connected by rods with the clock, and he is made to strike the quarters with his feet on two little bells, and the hours on another bell before him with a battle-axe in his hands. If the date of the construction of the clock be correct, the figures at present moved by its machinery cannot, according to J. R. Planché, be the original ones, or they have undergone strange alteration. Those that circulated in a sort of tilting match are very clumsily carved, and have suffered some injury from time ; but two of them appear to be intended for jousters ; one wears a hood with ears to it ; the third is a nondescript ; the fourth is painted in the civil costume of the reign of James or Charles I., with faliing collar, striped doublet, and the peaked beard and moustache of that period. Outside the transept is another dial surmounted by two figures of knights clad in armour of the fifteenth century. They strike the quarters on bells with their battle-axes.

The old interior works of this clock were of iron, not differing materially in principle from the mechanism of much later date clocks except that the appliances for the variety of the movements of the dial-plate were necessarily complicated. They exhibited a rare and interesting specimen of the art of clockmaking at.so early a period, in which the monks particularly excelled. After going for nearly five centuries, the works were found to be so completely worn out that, about the year 1835, they were replaced by a new train. The old movement, now controlled by a pendulum, may be seen in action at South Kensington Museum. Except for the quarter striking part and 
the lunation work, the movement is identical with that of De Vick's clock, presently to be described.

Another clock attributed to Lightfoot was erected at Wimborne in Dorsetshire. The dial as it at present appears is represented in Fig. 24, and an examination will show many features in common with these two fourteenth-century clocks.

Figs. 25, 26 and 27 represent De Vick's clock in front and in

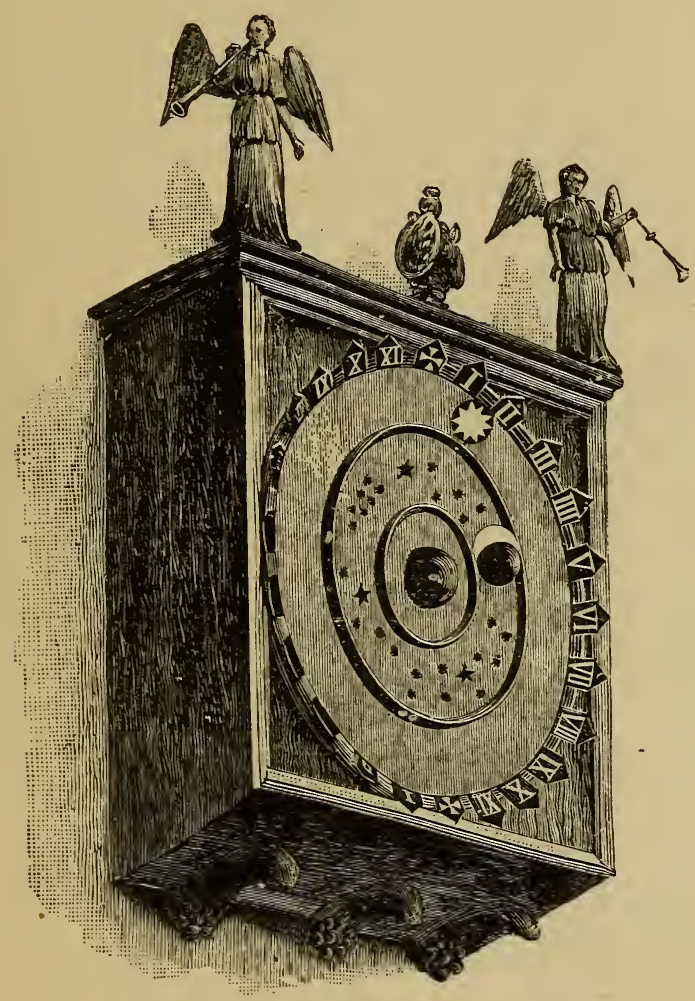

FIG. 24.-Dial of Wimborne Clock.

profile. There was but one hand, and that in its revolution round a dial-plate indicated the hours. A heavy weight tied to a rope, which was wound round a cylinder or barrel, served as the power to cause the hand to revolve; but the hand, instead of being fixed to the axis of the barrel, had its motion communicated through a wheel and pinion, so that the weight did not need to be wound up so frequently as would c.therwise be the case. If the weight were freely subjected to the 
influence of gravity, its motion would have been accelerated, and so an escapement and controller had to be devised in order that all the spaces traversed by the hand should be passed through in the same time as
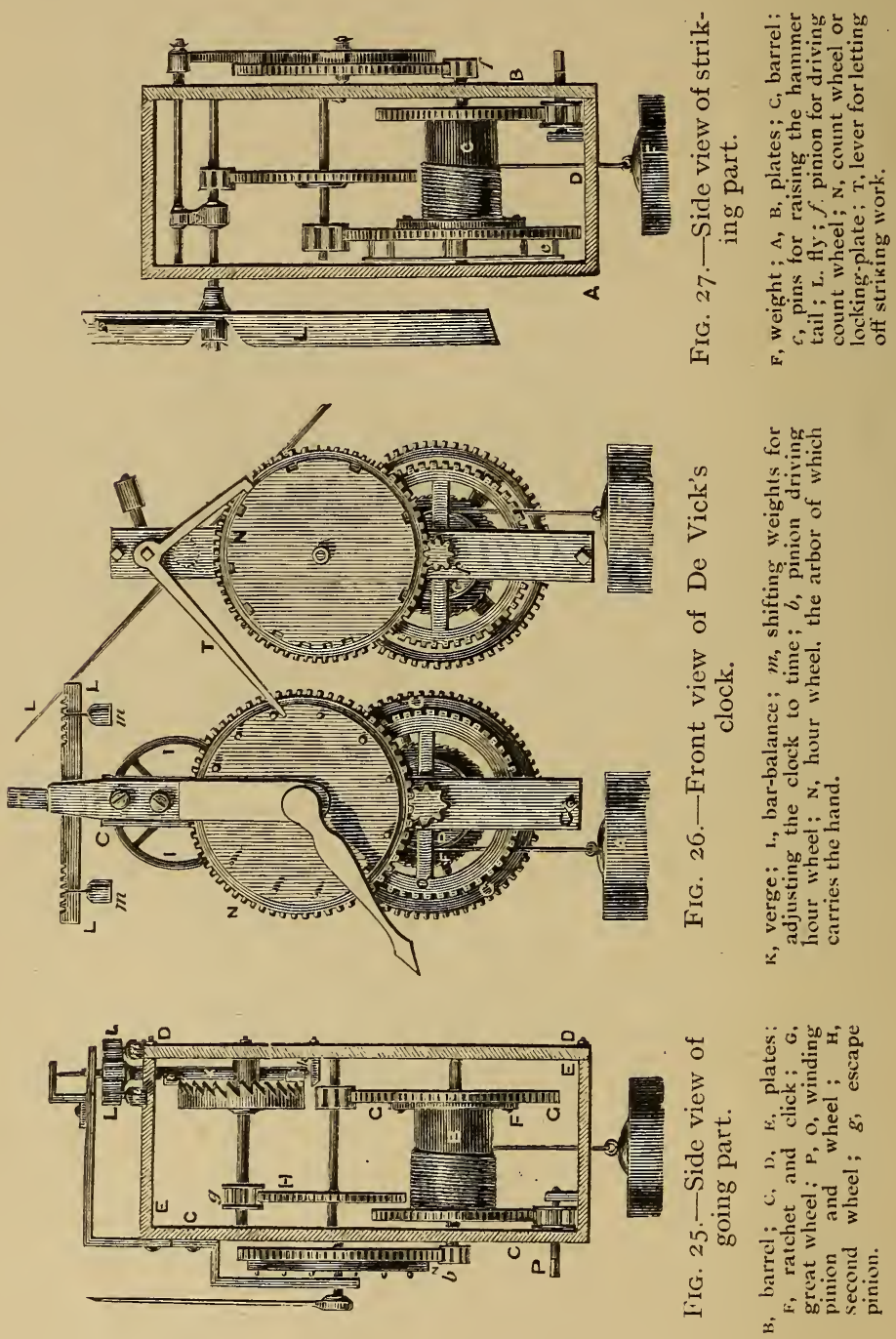

each other. The device adopted to check the progress of the weight was as follows: Connected with the arbor carrying the hand is a spindle carrying a wheel with ratchet-shaped teeth, as will be seen 
from Fig. 25. This wheel, called the "escape wheel," has an odd number of teeth, and on a vertical rod or "verge" are two beds or " pallets," of a distance from each other equal to the diameter of the wheel. The acting faces of these pallets form nearly a right angle, and the verge is planted close to the teeth of the wheel, so that one of the projecting pallets is always intercepting the path of the wheel teeth. In this way an alternating rotary motion is imparted to the verge, the escape wheel slipping by a space equal to half the distance between two teeth at every alternation. The action of the teeth of the wheel on the pallets will perhaps be better understod by a reference to

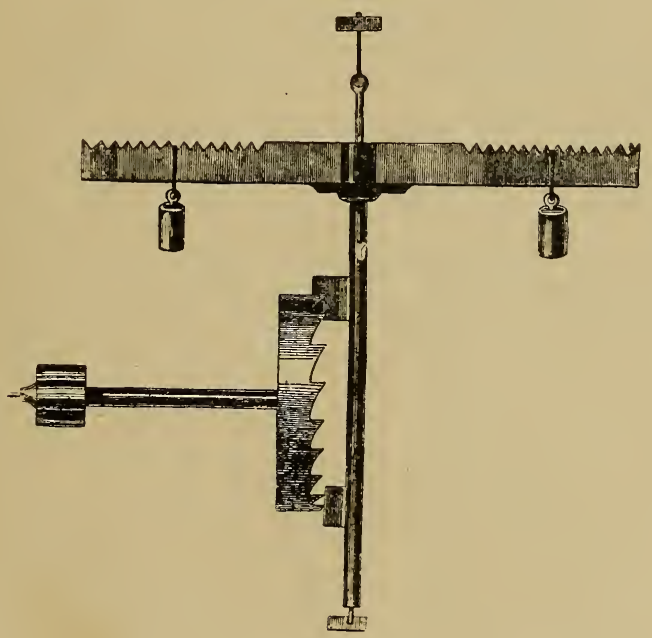

FIG. 28.-Verge Escapement with Cross-bar or "Foliot" Balance.

Fig. 28, which is drawn to an enlarged scale. A tooth of the escape wheel is pressing on the upper pallet; as it drops off the under tooth will reach the root of the lower pallet, but the motion of the verge will not be at once reversed. The escape wheel will recoil until the impetus of the cross-bar and weights mounted on the verge is exhausted. The teeth of the wheel are undercut to free the face of the pallet during the recoil. The inertia of the cross-bar and weights, by opposing the rotary motion, forms the regulator, and as the centre of gyration may be altered by shifting the weights along the bar, the time occupied by each vibration can be increased or lessened, as may be required. The verge was usually suspended by a cord to lessen the friction and wear at the pivot $0_{1}$ " toe" on which it rested. This controller, the foliot 


\section{Old Clocks and Watches and their Makers}

of Froissart, admirable as it was, did not give anything like the exact result now attained by means of a superior escapement and pendulum, for its constancy was seriously affected through variations in the motive force, such as would be caused by deterioration and thickening of the lubricant used to the pivots and bearing surfaces. It is, however, curious to note that the balance of a modern chronometer or watch, which vibrates with such marvellous accuracy, is analogous in its action to that of the early cross-bar regulator.

To understand the way the weight was raised after the rope was uncoiled from the barrel, it may be necessary to explain that, though the great wheel is tight on its arbor, the barrel on the same arbor is loosely fitted, the connection between the two being established by means of a ratchet-wheel and click. To lessen the labour of winding, a wheel is attached to the barrel, into which a pinion gears, and on the squared extremity of the pinion arbor the winding handle is placed. The different parts are shown and lettered in Fig. 25.

The manner of striking the hours in regular order will be apparent from Figs. 26 and 27, with a little explanation. The striking part of the clock is distinct from the going part, and is actuated by a separate weight. It occupies the right in Fig. 26. The wheel to which the hand is attached turns once in twelve hours, and it will be observed that, projecting from its face, are twelve pins, equidistant from each other. Although continually solicited by the weight, the striking train of wheels cannot turn except once at each hour, because it is locked by a tooth at one extremity of a "bell-crank" lever T, engaging with one of a series of notches in the locking-plate $N$. At the completion of each hour this tooth is lifted out by one of the twelve pins depressing the other end of the lever, and the striking train then rotates till the tooth of the lever falls into the next notch of the locking-plate. The tail of the hammer which strikes the bell intersects the path of the lifting pins $c$, which are arranged around the great wheel of the striking train. The notches around the edge of the locking-plate are placed at such distances that at one o'clock the tooth enters a notch directly one blow has been struck on the bell. At the next hour there is a longer space before a notch is reached, and so two blows are struck before the train is again locked; at the succeeding hour the space permits of three blows, and so on, till at twelve o'clock the plate has made a complete rotation, and the action of the preceding twelve hours recurs. The striking train would run down with increasing velocity but for the fan $L$, which keeps the periods between the strokes of the bell practically uniform. This is 
the principle of the striking work still used in most turret clocks, and till recently in nearly all small clocks of French make. The chief

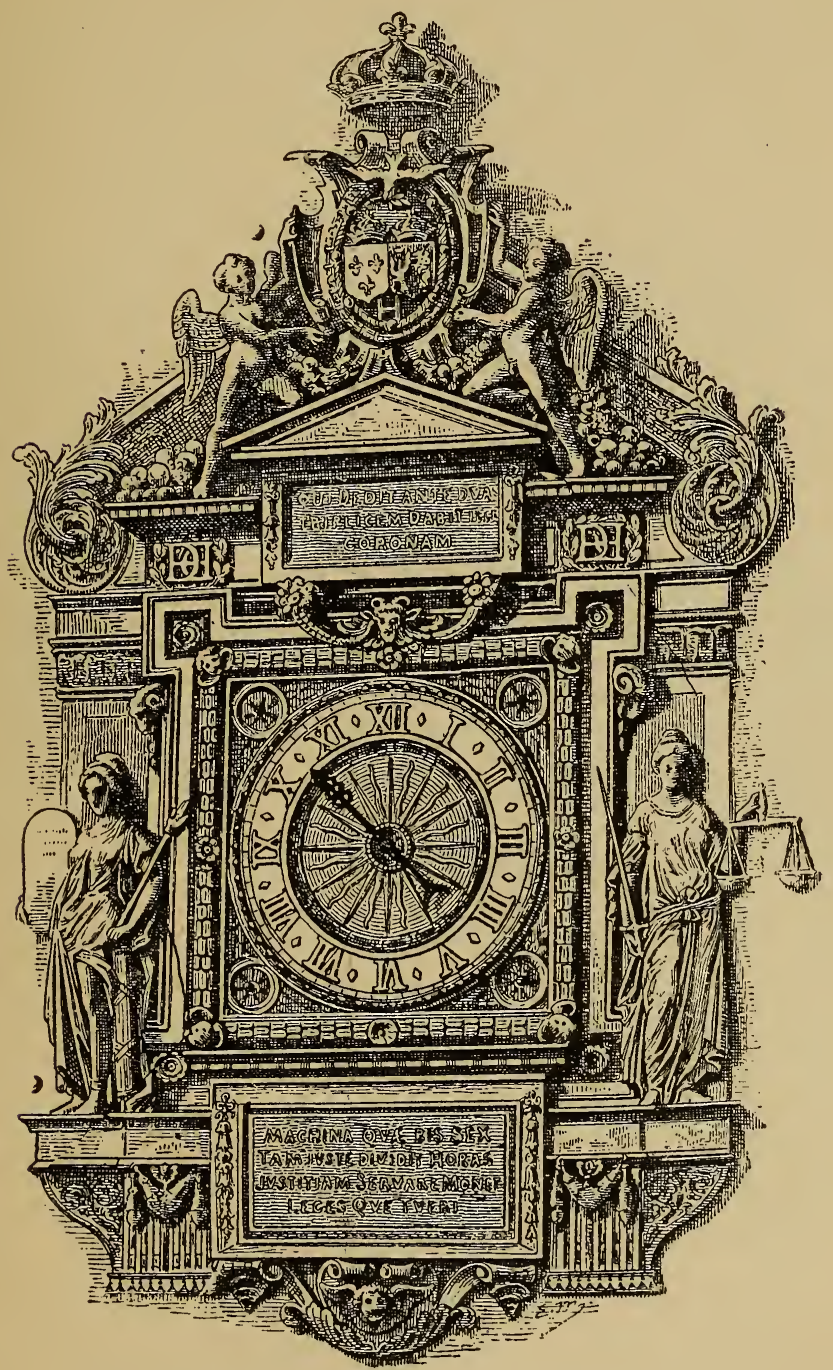

FIG. 29.-Clock of the Palais de Justice, Paris.

objection to it is that the hours are struck in regular progression without reference to the position of the hands; so that if the striking part happens to run down before the going part, the striking will be all 
wrong when it is started again, unless the precaution has been taken to set it going at the same hour as that at which it stopped.

Fig. 29 shows the dial of De Vick's clock and its splendid surroundings, adjoining the side of the Palais de Justice, which faces the Quai aux Fleurs. Though the clock appears to have been erected in the round tower of the palace in 1370 , the present architectural environment was not completed till 1585. The engraving is from "Les Merveilles de 1'Horlogerie." The figures of Piety and Justice flanking the dial, and the angels supporting the coat-of-arms which crowns the pediment, are by Germaine Pilon. On the upper tablet is the inscription, "Qui dedit ante duas triplicem dabit ille coronam." The panel below the dial perpetuates the quotation from Passerat :-

"Machina quae bis sex tam juste dividit horas, Justitiam servare monet legesque tueri."

This celebrated clock has experienced several long intervals of neglect, and been many times repaired. In 1852, after thorough examination, its defects were made good, and it was in some measure reconstructed. The bell on which the hours are struck was cast by John Jouvance, and it is said that upon this bell was repeated the signal from St. Germain l'Auxerrois for the massacre of St. Bartholomew in 1572. The bell for the Montargis clock was also made by Jouvance.

A turret clock which was erected at Dover Castle in the fourteenth century is still in action at South Kensington Museum. In construction it is somewhat similar to those of Lightfoot and De Vick. On the wrought-iron frame are the letters R.L. arranged as a monogram. The train, however, consists of only one wheel, which drives the escape-pinion so fast that there must have been either a very long driving-cord, or the clock must have been wound at frequent intervals. The winding is accomplished by means of handles or spokes projecting radially from one end of the barrel, which runs freely on the arbor of the wheel. On the face of the barrel which is nearest the wheel is a spring click, catching into the arms of the wheel, the arms thus serving the purpose of a ratchet. This click and ratchet arrangement was long favoured by some makers, and is often found in lantern clocks of the seventeenth century. The wheels of these early clocks were of wrought iron, the arms being riveted into the rim. A clock very 
similar to the Dover one was erected at Peterborough about the same date.

Exeter Clocks.-Few places probably can show more interesting relics of primitive horology than Exeter. "From the Patent Rolls of Edward II.," the late Mr. Britton observes, in his description of Exeter Cathedral, "it is evident there was a clock in this church in 1317. Other entries relating to the clock appear in the Rolls. In 1376-77, the sum of 1193 . $9 \mathrm{~d}$. is set down for expenses 'circa cameram in boreali turre pro Horlogio quod vocatur de novo construendam.' 'The whole charge in the roll 'nova camera pro horlogio' is $f_{\mathrm{s}} 10$ 6s. $5 \frac{1}{2} \mathrm{~d}$. In $1424-25$, two men were sent off on horseback to fetch Roger, clockmaker, from Barnstaple."

Whatever its construction, no trace of the original horologe can be found, but Bishop Courtenay is credited with having presented a clock in 1480 . It is said that this clock was made by Peter Lightfoot, but if the date of its construction (1480) is correct, this cannot be true, for Lightfoot had then been dead some years. The dial which still does duty bears a resemblance to the

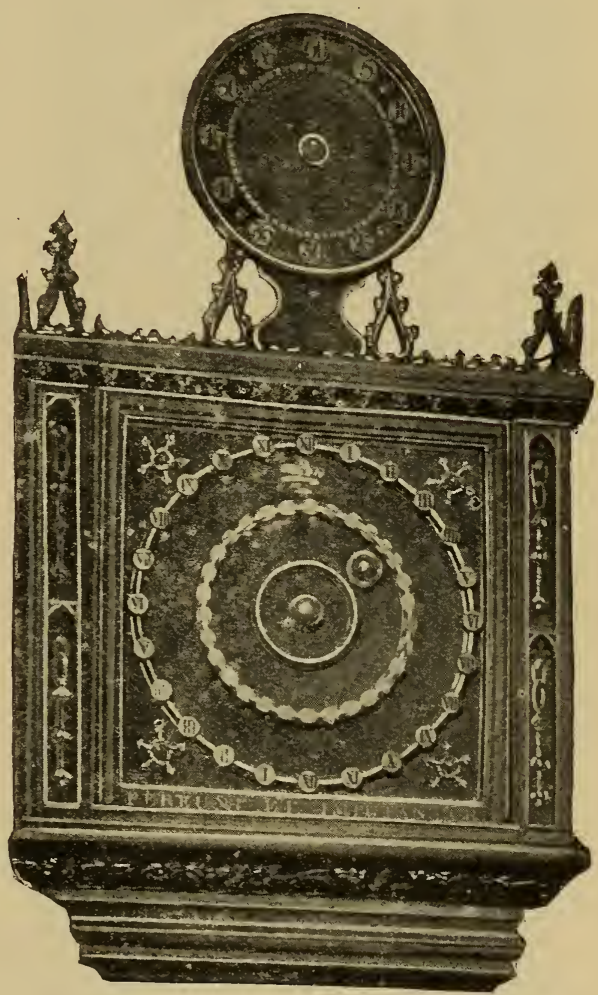

FIG. 30.-Exeter Cathedral Clock. one of Lightfoot's at Glastonbury, from which it was possibly copied, though Mr. J. J. Hall suggests that it formed part of the clock mentioned as existing in 1317. It shows the hour of the day, and the age of the moon; upon the face or dial, which is about $7 \mathrm{ft}$. in diameter, are two circles, one marked from one to thirty for the moon's age, the other figured from I. to XII. twice over, for the hours. In the centre is a semi-globe, representing the earth, round which a smaller ball, 
the moon, painted half white and half black, revolves every month, and in turning upon its axis shows the varying phases of the luminary which it represents ; between the two circles is a third ball, representing the sun, with a fleur-de-lis, which points to the hours as the sun, according to the ancient theory, daily revolved round the earth. Underneath it is the inscription, "Pereunt et imputantur" (they [the hours] pass and are

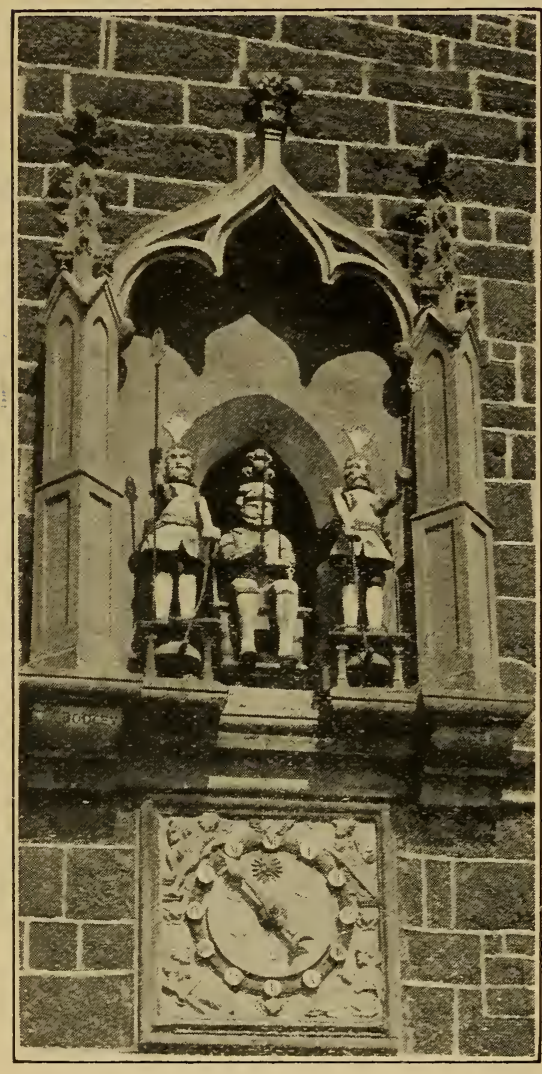

FIG. 31.-St. Mary Steps, Exeter. placed to our account). In 1760 the clock was thoroughly repaired by William Howard, when an additional dial to show the minutes was provided and placed on the top of the case as shown in Fig. 30. (I am indebted to Messrs. Worth \& Co., of Cathedral Yard, Exeter. for this illustration). The movement was replaced by a modern one in $\mathbf{1 8 8 5}$.

The hours are still struck on "Great Peter," a finetoned bell in the north tower. This bell was the gift of Bishop Courtenay and was brought from Llandaff (147886). According to Worth's excellent Guide to Exeter Cathedral it was recast in 1676 by Thomas Perdue. Its weight, ' as computed by the Rev. H. T. Ellacombe, is 14,000 lbs., its diameter at the mouth 76 in., and its height 56 in.

In the tower of the Church of St. Mary Steps, near by where once stood the old West Gate, is a most curious clock, which is probably a production of the sixteenth century. The corners of the dial are embellished with basso-relievos representing the four seasons, and in an alcove over the dial are the ee automatic figures, as shown in Fig. 31, (for this illustration I am indebted to Messrs. F. Frith and Co., Ltd.). 
The centre one is a statue of Henry VIII in a sitting posture, which. on the clock striking the hour, inclines the head at every stroke. On each side is a soldier in military attire, holding a javelin in one hand and a hammer with a long handle in the other. These soldiers strike the quarters by alternate blows on two bells beneath their feet.

The three figures are termed by many Exonians " Matthew the Miller and his two sons," from the fact that "Matthew the Miller," who resided in a place known as Cricklepit Lane, was remarkable for his integrity and regular course of life. His punctuality of going at one hour for and returning with his grist led his neighbours to judge with tolerable exactness the time of day from his passing. By this the statue received its vulgar name. The following distich used to be current in Exeter :-

\footnotetext{
Matthew the Miller's alive, Matthew the Miller is dead, For every hour in Westyate Tower, Matthew nods his head.
}

A clock placed in the tower of the Church of St. Mary Ottery about 1340, by John de Grandison, Bishop of Exeter, has been recently restored by Mr. J. J. Hall. In the tower of St. Petrock's Church, in the High Street, was till recently a clock believed to date from 1470 . In the tower also is a peal of six bells, the oldest of which bears the arms of Henry V. or VI., not later than 1425.

St. Mary's Church, Oxford.--There was a clock at St. Mary's Church, Oxford, in the fifteenth century, and one of the ancient Latin statutes of the University is devoted to the duties of its custodian. Other references are made to it in the proctor's accounts. Under date 1469 is "Pro custodia horilogij vjs. viijd.," and a somewhat similar entry occurs in 1473 . In 1523 a new clock was erected from fines imposed on negligent students. In the vice-chancellor's accounts from 1550 to 1554 is an item, "Paid to Thos. Masey for mendinge St. Maryes clocke, 25 Junii, travellinge (travailing) by the space of two weekes thereon, and was moreover paid the sum of tenpence for a clock for the said machine." On some parchment rolls in the tower of the schools, among the proctor's accounts, appears, "1469, Pro custodia horilogii, iijs.," and "1472, Pro reparatione horilogij, vjs. viijd."

Although details are in most instances wanting, there are sufficient references among the ecclesiastical records of the country to show that church clocks were pretty general throughout England in the fifteenth 
century. According to the churchwardens' accounts for Walberswick, in Suffolk, 11d. was paid to the clockmaker in 1451, and 12s. $8 \mathrm{~d}$. in the following year. In 1495, John Payn, the smith, of Southwold, received 6s. 8d. for a new clock, and in 1499, Nicholas Schrebbys was paid four sums- $\_1$ 13s. 4 d., 6s. 8d., $£ 12$ s., and 13s. 4 d.--for the clock.

John Baret, of Bury St. Edmunds, by his will dated 1463, bequeathed 8 s. yearly to the sexton of St. Mary's Church, "To keep the clokke, take hede to the chymes, wynde vp the peys and the plummeys as ofte as nede is."

The records of Dunstable mention a clock over the pulpit in 1483, and the churchwardens' accounts of Wigtoft, Lincolnshire, refer to several sums paid to Richard Angel for keeping the clock from 1484 onward.

An old clock at York Cathedral, which was fixed to the wall near the south door and covered with a large Gothic case, was removed in 1752, when the present clock, made by John Hindley, was erected.

Strassburg Clocks.-The first clock set up in the interior of the cathedral at Strassburg was begun in 1352, and completed two years after, under John, Bishop of Lichtenberg. It consisted of a calendar, representing in a painting some indications relative to the principal movable feasts. In the middle part there was an astrolabe, whose pointers showed the movements of the sun and moon, the hours, and their subdivisions. There was placed at the same elevation the prime mover, and the other wheel-work which caused the clock to go. The upper compartment was adorned with a statuette of the Virgin, before which, at noon, the three Magi (wise men of the East) bowed themselves. An automaton cock, placed upon the crown of the case, crowed at the same moment, moving its beak and flapping its wings. A small set of chimes, composed of several cymbals, formed a part of this work.

The Second Clock, of which an exterior view is shown in Fig. 32 was certainly a triumph of ingenuity. It was projected in 1547 ; but though the designs appear to have been then ready, the execution went no further than the building of the chamber and the preparation of some of the heavier ironwork, till 1570, when Conrad Dasypodius, a mathematician of Strassburg, and David Wolkstein, of Augsburg, undertook to supervise the completion of the horologium. The mechanical works were confided to Isaac and Josiah Habrecht, mechanicians of Schaffhausen, in Switzerland, while Tobias Stimmer (or Sturmer), of the same place, was employed to do the paintings and the sculpture which were to serve as decorations of the achievement. 
Josiah Habrecht being summoned to Cologne for other work, the construction of the clock was left in the hands of Isaac alone.

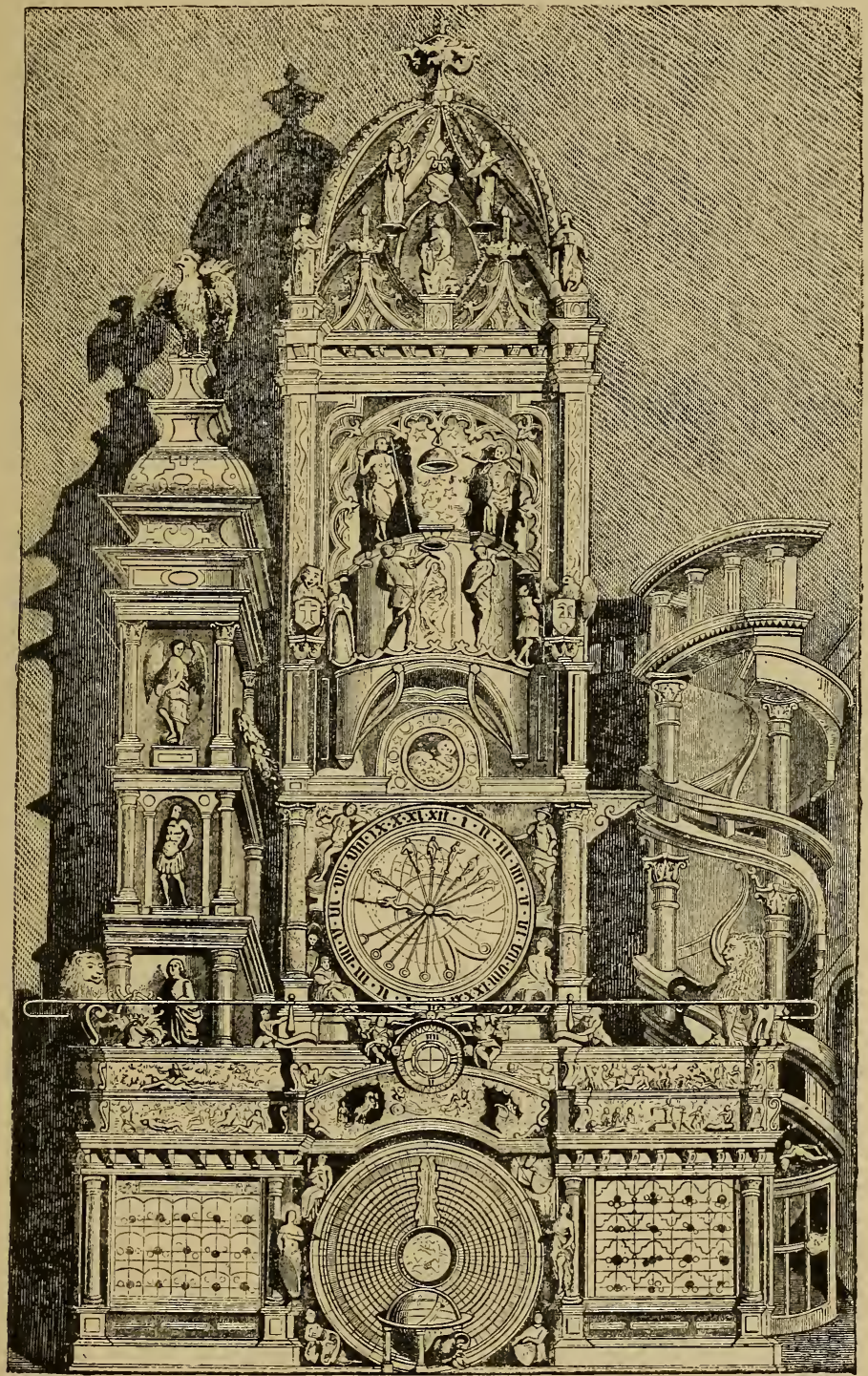

FIG. 32.-The Se:ond Strassburg Clock.

Before, and at the foot of the clock, there was a celestial globe supported on four columns of wood richly carved. It performed a 
revolution on its axis, showing the stars known in the time of Ptolemy, about A.D. 140. These stars, to the number of 1,020 were grouped in forty-eight constellations, represented by as many figures. Two circles, one carrying the sun and the other the moon, turned round the globe, the first in twenty-four hours, the second in the space of about twentyfive hours.

Immediately behind the celestial globe there was a large wooden disc in which was painted a calendar for the space of a century, the months, the days, the Dominical letter, the names of the saints, and the dates of the principal movable feasts. The calendar made an entire revolution every year. The statues of Apollo and Diana, placed on two sides of the disc, pointed out, with their sceptres, the one the day of the year, the other the corresponding day at the end of six months. The central part of the calendar was immovable; on it were represented the countries of Germany situated along the Rhine, and the topographical plan of the city of Strassburg.

The compartments on each side of the calendar were occupied by large panels upon which were painted the principal eclipses of the sun and moon visible in the northern hemishpere, and answering to the interval of thirty-two years from 1573 to 1605 .

Above the calendar there were seen in the clouds the seven pagan divinities that have given their names to planets, and afterwards to the days of the week. These allegorical figures, seated in cars, each one drawn by the animals, which mythology assigns to that particular divinity, showed themselves successively on the days which were sacred to them. On Sunday, Apollo was seen, this day being dedicated to the sun. The ancients named it Dies solis (the day of the sun), and the Christians the Lord's Day (Dies Dominica), whence is derived the French word, Dimanche, for Sunday. A representation of Diana was shown on the second day, which was called Dies lunae (day of the moon)-Lundi-Monday. Mars, the god of war, appeared on (Mardi) Tuesday, the English word being derived from Tuesco, the Saxon name of the god of war. The fourth day was represented by Mercury, the messenger of Olympus; French, Mercredi: English Wednesday (the latter being derived from Wodin, the Saxon name of the same deity). The following day Dies Jovis, Jupiter's day; French, Jeudi; English, Thursday (derived from Thor, the Saxon name for Jupiter). Venus succeeded on Friday (which in English is derived from Friga, the Saxon name of the goddess Venus). Saturn, the god of Time, came on Saturday, to close the Olympian procession.

Immediately above the divinities of the week was erected a gallery, 
in the middle of which a small dial plate indicated the quarter-hours and the minutes, the hours being represented upon the astrolabe ; at the sides of the dial plate were seated two genii, of which the one placed on the right raised a sceptre each time the hour was to strike, and of which the other at the same moment turned upside down an hour glass which he held in one hand, turning it always in the same direction. An astrolabe, constructed according to Ptolemy's system, occupied the greater part of the middle story, in the interior of which was contained the wheel-work of the clock. Six pointers, bearing the same number of planets, indicated, upon twenty-four divisions of the astronomical day, the movements of these heavenly bodies; one pointer, larger than the others and terminated by a sun, finished in twenty-four hours an entire revolution round a small map of the world placed in the central part of a large dial plate, which was ornamented at the same time by the circles of a horoscope and by the twelve signs of the zodiac. The upper part of the astrolabe was crowned with the phases of the moon. There was visible a small dial plate cut in its lower part by two semicircles, behind which the moon, represented by a golden disc, disappeared at the time of the new moon, and came out from day to day to show successively a quarter part of its orb, till it presented to view its entire disc, at the time of full moon.

At the third story of the clock there was a platform, upon which were fixed four small statues representing the four periods of lifeinfancy, youth, manhood, and old age; these figures struck the quarter-hours upon cymbals.

Above this platform was suspended the bell intended for sounding the hours. Two figures stood beside this bell; the one was Death under the form of a skeleton, the other represented Christ, having in one hand the cross and the palm branch. At the instant the hour ought to strike, the Saviour came forward, and the skeleton drew back; but hardly had this movement taken place when Christ retreated precipitately, and Death advanced in the same way, to strike on the bell the number of strokes required. This movement was repeated as many times as there were strokes in the hour.

The turret, placed on the left of the principal edifice, contained the weights of the clock, as well as the machinery intended for the cock which was perched on the summit of this turret. This cock (the only piece which was preserved from the first clock, called the clock of the three kings) crowed at first daily, at noon, flapping its wings and opening its beak; but having been struck with lightning in 1640, it was made to crow only on Sundays and feast days. It ceased 


\section{Old Clocks and Watches and their Makers}

crowing entirely in 1789 , at the time when overwhelming attention bestowed upon the great events that were taking place caused it to be completely forgotten.

Third Strassburg Clock.-At length it was evident that some reconstruction was necessary. After considerable debate, the necessary work was entrusted to Jean Baptiste Schwilgue, who entered on his task in 1838, and completed it about the middle of 1842 . On the 2nd of October of that year the life of the resuscitated marvel was solemnly inaugurated. Some of the former actions were altered or omitted, and fresh ones added, the greater part of the movement being entirely new, for only in some few cases was a restoration of the former mechanism practicable.

The structure of the second clock was retained to encase the mechanism with but slight alteration. It is over $20 \mathrm{ft}$. in height, and is surmounted by a remarkably handsome dome, as shown in Fig. 32. On the right is a spiral staircase, by means of which the various galleries are reached.

The motions now are briefly as follows:-On the floor level is a celestial globe, indicating sidereal time. In its motion round its axis the globe carries with it the circles that surround it-namely, the equator, the ecliptic, the solstitial and equinoctial colures, while the meridian and horizon circles remain motionless, so that there are shown the rising and setting, as well as the passage over the meridian of Strassburg, of all stars which are visible to the naked eye, and whïch appear above the horizon. Behind the celestial globe is the calendar ; on a metallic band, $9 \mathrm{in}$. wide and $30 \mathrm{ft}$. in circumference, are the months, the days of the month, Dominical letters, fixed and movable feast days. The band is shifted at midnight, and a statue of Apollo points out the day of the month and the name of the saint corresponding to that day. The internal part of the annular band indicates true solar time; the rising and setting of the sun; the diurnal motion of the moon round the earth, and its passage over the meridian; the phases of the moon, and the eclipses of the sun and moon. Adjacent compartments are devoted to a perpetual calendar, solar and lunar cycles, and other periodic recurrences, solar and lunar equations, \&c. Above the calendar appear allegorical figures, seated in chariots, and representing the days of the week. These chariots, drawn by such animals as are assigned as attributes of the divinities, run on a. circular iron railway and appear each in order.

The dial for showing mean solar time is in the gallery above, called the Gallery of Lions. A genius stands on each side of the 
dial. The one on the left strikes the first note of each quarter-hour with a sceptre he holds in his hand, the second note being struck by one of the four ages in a still higher gallery, as will be described presently. At the completion of each sixty minutes the genius on the right of the dial reverses an hour-glass filled with red sand.

The story above is occupied by a planetarium, in which the revolutions of the planets are represented upon a large dial plate.

Above the planetarium, and upon a star-decked sky, is a globe devoted to showing the phases of the moon.

Next come movable figures representing the four ages, one of which in turn appears and gives upon a bell the second stroke of each quarter of an hour. At the first quarter a child strikes the bell with a rattle; a youth in the form of a hunter strikes it with an arrow at the half-hour; at the third quarter the blows are given by a warrior with his sword; at the fourth quarter an old man produces the notes with his crutch. When he has retired a figure of Death appears and strikes the hour with a bone.

In the upper apartment is a figure of Christ; and when Death strikes the hour of noon the twelve Apostles pass before the feet of their Master, bowing as they do so. Then Christ makes the sign of the cross. During the procession of the Apostles, the cock perched at the top of the weight-turret flaps his wings, ruffles his neck, and crows three times.

In addition to the mean time dial in the gallery, there is one, $17 \mathrm{ft}$. in diameter, above the principal entrance to the cathedral.

A clock with performing automata and calendar register was in 1405 erected in the church of St. Mary at Lübeck. Doubtless it has been much altered since that time; but in I 820 , from the description of Downes, it was in going order, as it is still, I am told. Downes also describes another extraordinary clock of much later date which is in the Dome Church at Lübeck. The full account just given of the Strassburg clocks will suffice as an example of ingenuity displayed in this direction.

Ancient Oriental Calendar Clock.-Some time ago in the Jewelcrs' Circular-Weekly there appeared a masterly analysis of ancient Oriental methods of recording the progression of days and seasons, by Mr. Daniel Arthur, of New York. Under the title of " The Calendar Concept and its Evolution " this has been issued in book form, and by permission of Mr. Arthur I reproduce in Fig. 33 an engraving of a remarkably interesting example showing the early Oriental conception of using the heavenly motions as day counters, and how the sidereal 
month was formed. The moon's path is divided into twenty-eight mansions, or " halting places." The sun is regarded as a great clock hand making a daily sweep around the sky, its progress being marked off by " Kih" or double-hour discs, twelve in number, each having an animal name. The "Yin " discs or night hours are dark, the sunrise and sunset hours grey, while the sunlit hours of day are white. These "Yang Kih," or bright hours, average longer than the "Yin Kih, or black hours of night. The central dark hour is "rat" (midnight),

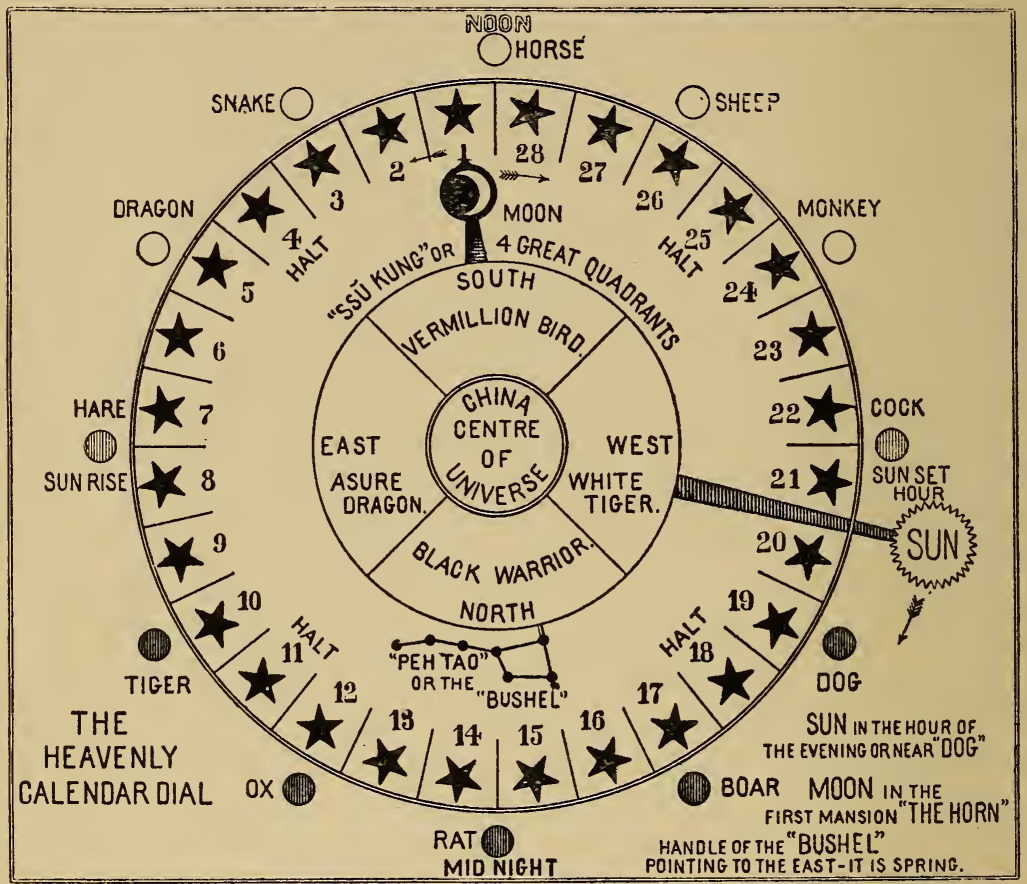

Jig. 33.-Ancient Oriental Calendar Timepiece, or Heavenly Calendar Dial.

while the central bright hour is "horse" (noon). "Dragon" and "snake" constitute the forenoon known as "before-horse," while "sheep" and "monkey" are afternoon hours (" after-horse"). Particulars relating to the arrangement of these hour marks will be given in Chapter VI. under the head of Japanese clocks. The moon hand is shown as going in the opposite direction to its apparent motion. The lower of the two arrows shows normal moon direction, the upper one how it moves in the mansions with a left-hand motion. Each 
time the sun-hand gets to the evening hours, or near "dog," the moon-hand will be in a new mansion of heaven. Mr. Richard S. Geoghagen, formerly Chinese scholar of Oxford, has pointed out that the 4 th, IIth, 18th, and 25th mansions invariably correspond to what are now our western Sundays. At first in these calendar timepieces the days were distinguished by titles instead of numbers, their English equivalents being "the horn" which was the first mansion, representing the frontier gate of heaven; then in order came the Neck, Bottom, the Room, Heart, the Tail, the Sieve, the Bushel, the Ox, Woman, the Void, Danger, the House, the Wall, Astride, Wound, Stomach, Pleiades, the End, Bristling Up, Mixture, the Well, the Ghost, the Willow, the Star, Drawn Bow, the Wing, Crossbar. Of the "Ssu Kung," or four great quadrants, the first is named Azure Dragon, the second Black Warrior, the third White Tiger, and the last Vermillion Bird. The third hand, or season indicator, is the group of stars which we call Ursa Major (Chinese name "Peh Tao"). In Dr. Carus' "Chinese Thought" we are told that when the handle of this "big dipper" points to the east at nightfall it is spring throughout the land; when to south it is summer, to the west it is autumn, and when north it is winter.

In the Metropolitan Museum of Art, New York, is an Oriental calendar clock on the dial of which are depicted the twenty-eight groups of stars, "Erhshih-pa Su" is the Chinese name for them (the twenty-eight mansions of heaven). These constellations vary a great deal in degrees of width, and were selected in piehistoric times to guide the eye to single stars of about the proper distances apart.

While the third edition of this book was in the hands of the printers I learnt of the accidental death of Mr. Daniel Arthur, an event which may be regarded as a world-wide loss. He advocated uniform months of twenty eight days, thirteen months, and one dies-non in the year. The days would then recur on the same date of each month.

The Hans of Jena clock, already referred to, is showin in Fig. 34. which is reproduced from Dubois' work. The legend is that Hans of Jena, represented by a monstrous head of bronze, is to be tantalised for three centuries by the pilgrim who presents to the open mouth a golden apple as the clock strikes, but quickly withdraws it before the mouth can be closed. The figure of an angel on the right raises its eyes and shakes the bell as each blow of the hour is struck.

Whatever variations were made in the form or :ize of clocks during the fifteenth century, the principle of the mechanism remained 
unaltered, and such as were constructed appear to have been mostly for public buildings or persons of exalted position.

The fact that small clocks and portable clocks are mentioned as existing in the fourteenth century, seems to have led to the supposition that the mainspring as a motor was then in use, but such a conclusion is unwarranted. Most of these descriptions, or rather references, though interesting, are of the vaguest character, for instance, among the ancient inventories

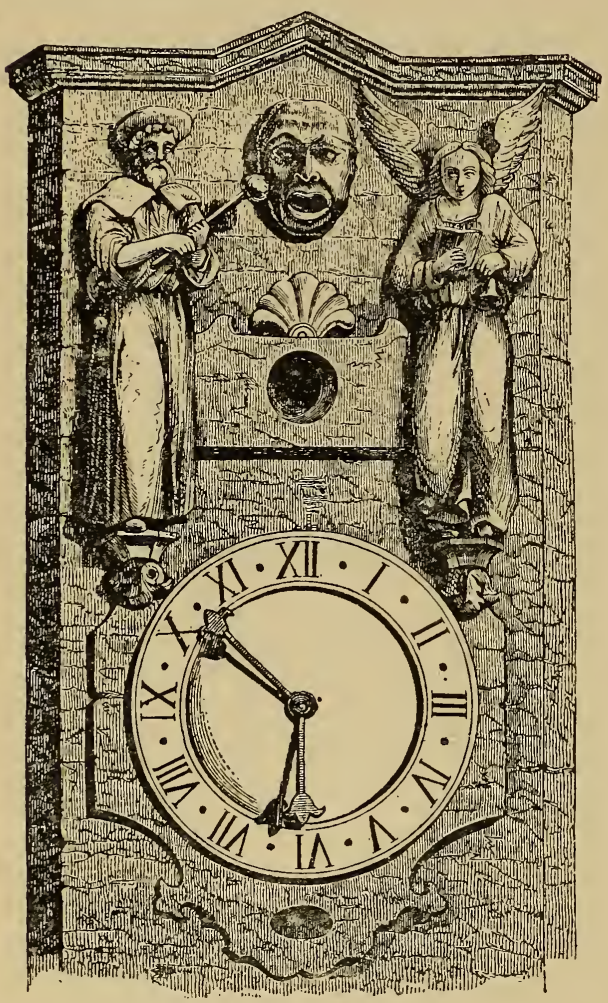

FIG. 34--Hans of Jena. quoted by $\mathrm{M}$. de Laborde are "A.D. 1380, a clock of silver, entirely without iron ;" and " a clock oî white silver for placing on a column." In 1381, "l'oreloge" of Charles VI. being out of order, a smith from Senlis, named Robert d'Origny, who repaired it, received sixteen sols parisis. The accounts of the Duke of Burgundy recite that in 1407 a smith (fevre) named "Jehan d'Alemaigne," supplied a movement for a small clock (petite orloge) to be placed in the chamber of "Madame."

Sir John Paston, in the course of a letter written in the spring of 1469, says: "I praye you speke wt Harcourt off the Abbeye ffor a

lytell clokke whyche I sent him by James Gressham to amend and yt ye woll get it off him an it be redy, and send it me, and as ffor mony for his labour, he hath another clok of myn whiche St. Thoms Lyndes, God have hys sowle, gave me. He maye kepe that tyll I paye him. This klok is my Lordys Archebysshopis but late him not wote off it." 
The appended Fig. 35, from the Bibliothèque Nationale at Paris, purports to represent the remains of a fifteenth century chamber clock. It is pretty evident there was originally a bell at the top of the case, and perhaps a hand to indicate the hour. It is not, however, certain there was a hand, for some of the early clocks had revolving dials. In the South Kensington Museum there is on a "tarsia," or inlaid wood panel of Italian late fifteenth-century production, a representation of a clock with a revolving ring, on which the twenty-four hours are

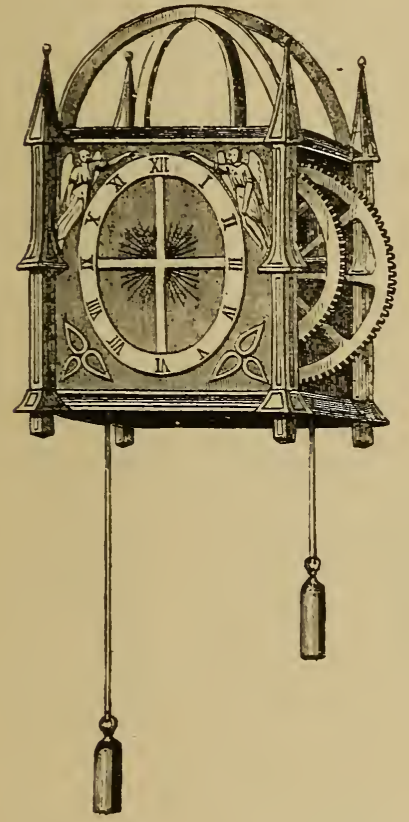

FIG. 35.-Cham ber Clock, Fiftectith Century. Bib. Nat. Paris.

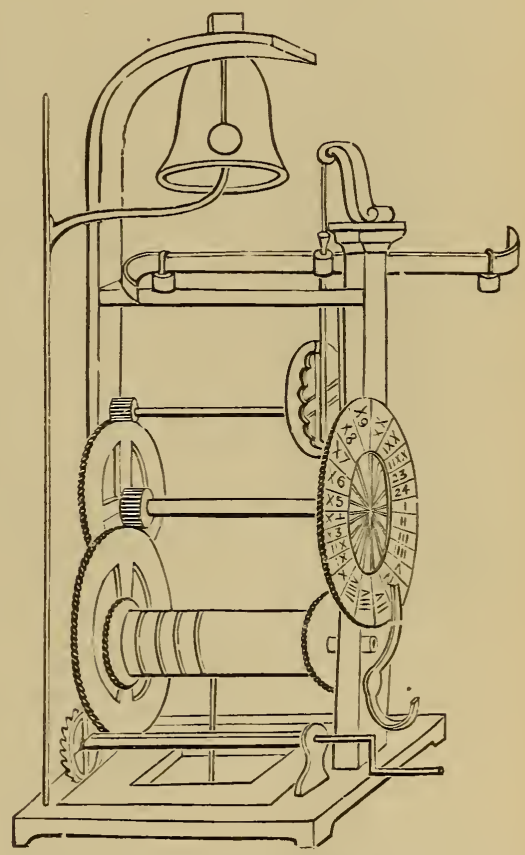

FIG. 36.-Fifteen th Century Clock from Italian tarsia-work.

marked, the current hour being indicated by a fixed pointer, as seen in Fig. 36. The whole panel represents an open cupboard, in which there are, besides the clock, a flagon, a chalice, a cross, etc. ; so one may infer that the clock was of comparatively small size, and of course of older date than the panel, which careful comparison by the experts of the Museum fixes at certainly not later than 1500. The action of the winding work is obscure, but with that exception the construction of the clock is tolerably clear.

In the Bibliothèque de l'Arsenal at Paris is a MS. prayer book 
50 Old Clocks and Watches and their Makers

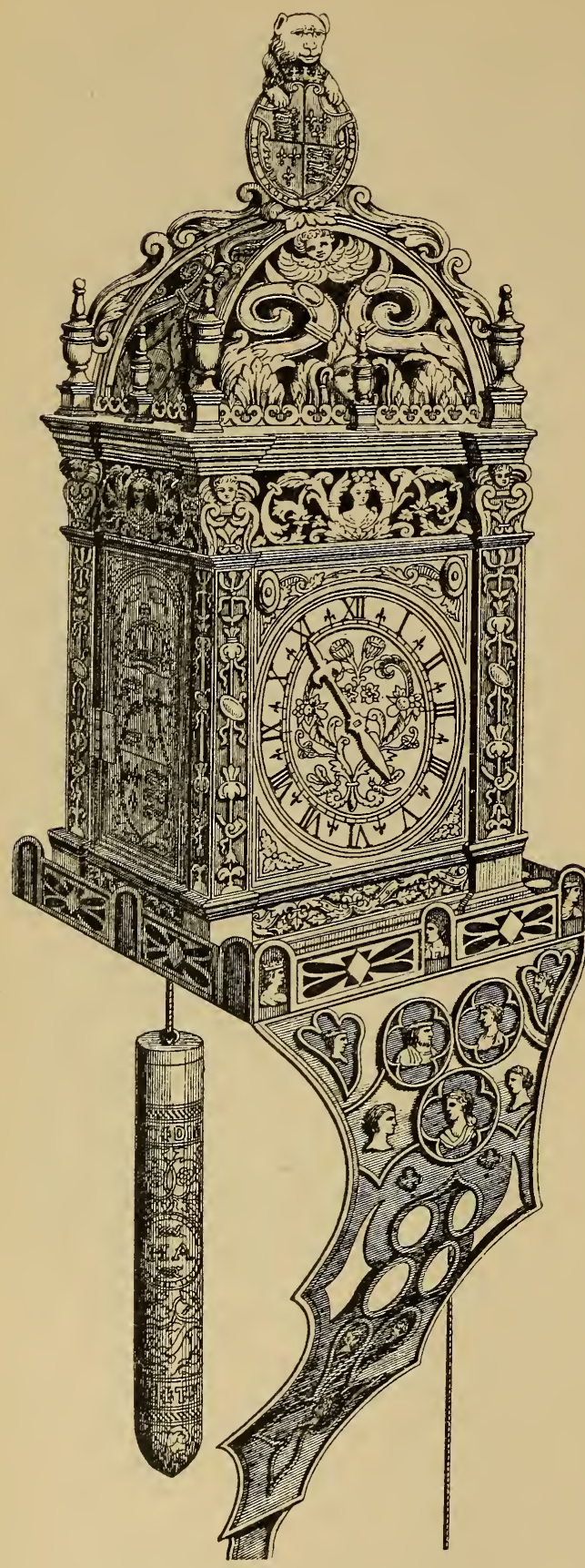

FIG. 37.-Anne Boleyn's Clock. containing two small pictures of chamber clocks called, from the family name of the person for whom the book was executed, the "Heures de Bossu." It dates from about $1490-1500$.

Anne Boleyn's Clock.--In the corridor at Windsor Castle is a clock which is said to have been presented to Anne Boleyn on her wedding morning by Henry VIII. It is rather over $4 \mathrm{in}$. square and $10 \mathrm{in.} \mathrm{high,}$ exclusive of the bracket on which it is mounted, as shown in Fig. 37. It was purchased on behalf of Queen Victoria for $£ 110$ 5s. when Horace Walpole's collection at Strawberry Hill was sold, and was then described as "a clock of silver, gilt, richly chased, engraved and ornamented with fleursde-lys, little heads, etc. On the top sits a lion holding the arms of England, which are also on the sides." This description is not quite correct, for the case is of copper gilt; the weights are of lead 
cased in copper, gilt and engraved; on the one visible in the engraving are the initial letters of Henry and Anne with true lovers' knots above and below; on the other H.A. alone; at the top of each is "Dieu et mon droit ;" at the bottom " the most happye !" The movement at present in the case has brass wheels, a crown wheel escapement and a short pendulum ; though not modern it is certainly later than the middle of the sixteenth century. A sight of the clock evoked from Harrison Ainsworth a reflection to which but few will take exception. "This love token of enduring affection remains the same after three centuries, but four years after it was given the object of Henry's eternal love was sacrificed on the scaffold. The clock still goes! It should have stopped for ever when Anne Boleyn died." And whether by accident or design, though the weights are suspended below the supporting bracket, the mechanism, which appears to be in fairly good condition, is now silent, and the hand remains stationary. There is no record as to the maker of this interesting relic, but at this time most of the "orologes" were the production of foreign artists, judging from the names quoted in State Papers of the period.

In the "Privy Purse Expenses of Henry VIII., from 1529 to 1532," edited by Sir Harris Nicolas, it is recorded that in July 1530 fl5 was paid to the Frenchman who sold the king "ij clocks at Oking." In the following month was paid to " a Frenchman called Drulardy, for iij dyalls and a clokk for the King's Grace the sum of f15." In December of the same year $£ 19$ 6d. 8s. was "paid to Vincent Keney clok maker for xj clokks and dialls." So many payments within a brief period warrant the assumption that clocks werc a form of present favoured by his Majesty.

In the "Sixth Report of the Historical Manuscripts Commission" mention is made of an agreement dated 1599, between one Michael Neuwers, a clockmaker, and Gilbert, Earl of Shrewsbury, for the construction of a clock. "It is agreed that Michael should make a striking clock about the bigness of that which he made for the Earl six years past ; it is to be made by the last of December next. The cover or case of it to be of brass, very well gilt, with open breaking through all over, with a small fine hand like an arrow, clenly and strongly made, the ... or white dial plate to be made of French crown gold, and the figures to show the hour and the rest to be enamelled the fynelyest and daintyest that can be, but no other colour than blew, white, and carnalian; the letters to be somewhat larger than ordinary; the price of the clock must be $f 15$, which 
makes with the earnest already given $£ 16$, but the circle I must pay for, besides the gold which shall make it ; the sides of the brass case must not be sharp, but round, and the case very curiously made."

The Michael Neuwers here referred to was probably Michael Nouwen, a sixteenth century horologist, several specimens of whose work survive. That the Earl of Shrewsbury was somewhat of a connoisseur of timekeepers, as well as an authority on horological matters, is borne out by the following letter, dated 1611, from him to Sir Michael Hickes, which is preserved in the Lansdowne MSS. at the British Museum :-

"I perceived by you to-day that you understand My Lord Treasurer's design was to have a watch, but I conceaved he wysshed a stryknge clock, made lyke a Watch, to stande oppon a Cubbart, \& suche a one (though no new one, \& yet under a dozen years ould) I havt found oute, \& send you by this bearer, which I pray you deliver to his Lordship from me, \& tell him that I am very well perswaded of the truth of it, or else I should be ashamed to send him so gross \& rude a piece as this is, \& if I hadd thought his Lordship could have well forborne it but for four or five days longer, I would have bestowed a new case for it, for this is a very bad one. If his Lordship would not have it stryke, either in the dayes or nyghts, the striker may be forborne to be wounde up, and so the Watch being wounde up it will go alone. It will goe twenty-six houres, but I wysh it may be wounde up every mornyng or nyght about eight or nine o'clock, which will be sufficient until the next day or nyght at the same tyme."

Among the State Papers of the time of James I. there is an original letter, dated 4th August, 1603, addressed by Sir Julius Cæsar to the clerks of the signet, requesting them to prepare a warrant to pay $£ 300$ to Hans Niloe, a Dutchman, for a clock with music and motions. And on the 17 th of the same month Sir Julius wrote from the Strand to Salisbury, stating that he was pressed by Hans Niloe for the $f 300$ for his clock.

In " A true certificat of the names of the Straungers residing and dwellinge within the City of London," \&c., taken by direction of the Privy Council, by letters dated 7 th September 1618, it is stated that in the ward of Farringdon Within was then living " Barnaby Martinot, clockmaker : $b$. in Paris ; a Roman Catolicque." In Portsoken ward was living " John Goddard, clockmaker; lodger and servant with Isack Sunes in Houndsditch; $b$. at Paris, in Fraunce; heer three years ; a papist; yet hee hath the oath of allegiance to the king's supremacy, \& doth acknowledg the king for his soveraigne dureing his abode in England ; \& is of the Romish church." 
Clock at Hampton Court Palace.-Derham gives the numbers of the wheels and pinions of a large clock which appears to have been erected at Hampton Court Palace about 1540. This date is assumed from the marks N.O. or N.C. and the figures 1540 which were engraved on a bar of the original wrought-iron framework. If the letters were N.C., they may have referred to Nicholas Cratzer.

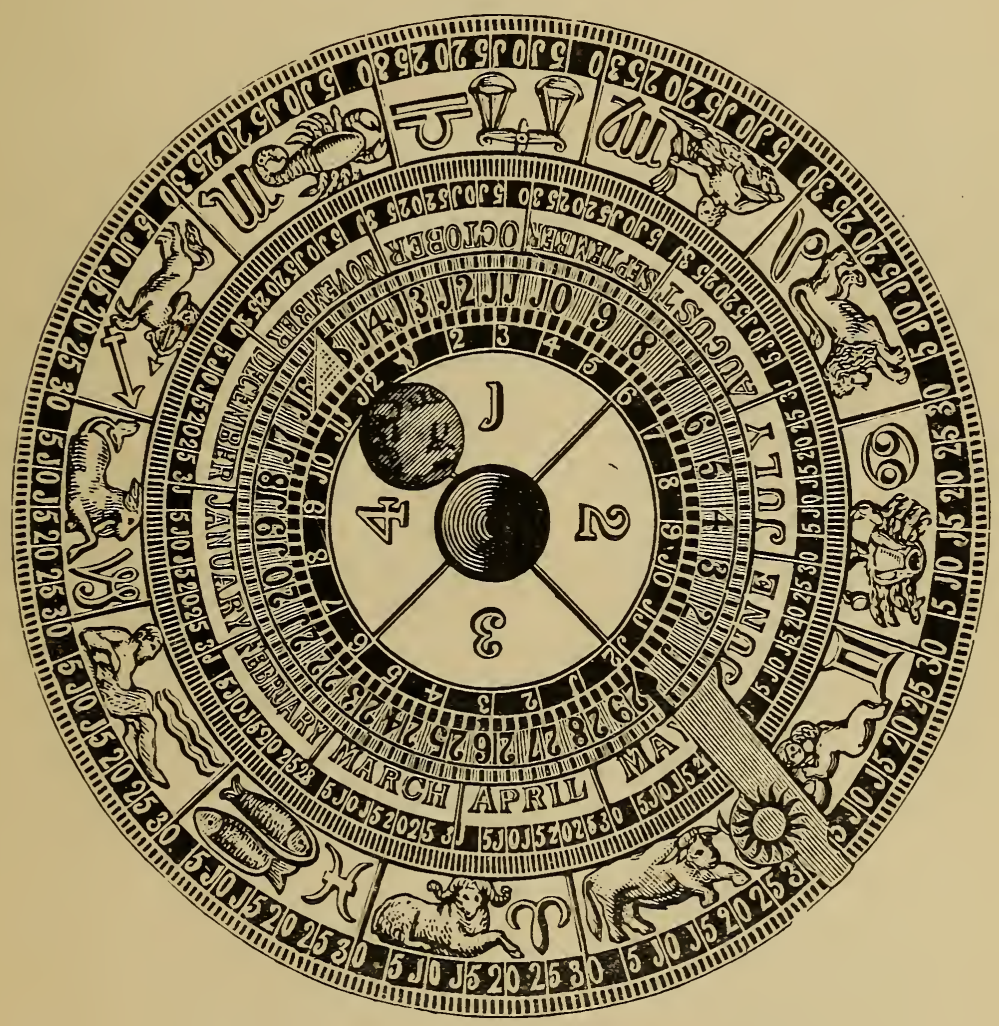

Fig. 38.-Dial of Hampton Court Palace Clock.

In 1711 the clock was repaired by Langley Bradley. The original and curious dial of the clock is on the eastern side of the gate-tower in the second quadrangle. It is composed of three separate copper discs of different sizes, with a common centre, but revolving at varying rates. The smallest of these is $3 \mathrm{ft} .3 \frac{1}{2} \mathrm{in}$. in diameter, and in the middle of this is a slightly projected globe, painted to represent the earth. The quarters marked on the centre disc by thick lines are 
numbered with large figures, and round the edge this disc is divided into twenty-four parts, a red arrow painted on the second disc pointing to these figures and showing at once the quarter in which the moon is, and the time of southing. Next to the figure of the earth in this centre disc, a circular hole, $10 \mathrm{in}$. in diameter, allows a smaller disc travelling behind to show the phases of the moon. On the second disc, $4 \mathrm{ft} .1 \frac{1}{2}$ in. in diameter, but of which only the outer rim is seen, are twenty-nine divisions, and a triangular pointer, projecting from behind the central disc, shows the moon's age in days. The largest of the three discs is $7 \mathrm{ft} .10 \mathrm{in}$. in diameter. There are many circles painted on so much of the rim of this as is seen, the inner, or, following the order above observed and proceeding from the centre, the first circle, giving the names of the months, the second the days of the months (only twenty-eight for February), the third the signs of the zodiac, and on the rim, with $30^{\circ}$ for each space filled by a sign, a circle divided into 360 parts. A long pointer with a gilded figure of the sun attached projecting from behind the second disc, shows on this third or outmost disc of the dial the day of the month and the position of the sun in the ecliptic. This pointer performs another duty, acting like the hour hand of an ordinary clock, and showing the time of day or night as it passes the twenty-four figures-two sets of twelvepainted on the stonework within which the dial revolves. The diameter of this outer immovable circle on the stone is $9 \mathrm{ft} .8 \mathrm{in}$., and the characters for the hours are Roman numerals, 9 in. in length.

In 1575 a payment appears to have been made to George Gaver, serjeant painter, for painting the great dial at Hampton Court Palace, containing hours of the day and night, the course of the sun and moon, and doubtless since that time the same necessary restoration has been often undertaken. In 1835 an extraordinary transposition was made, for the works of the old clock were removed, and have since disappeared. In their place was fixed a movement with the following inscription: "This clock, originally made for the Queen's Palace in St. James's Palace, and for many years in use there, was, A.D. 1835, by command of his Majesty King William IV., altered and adapted to suit Hampton Court Palace by B. L. Vulliamy, clockmaker to the king ; " and on another plate on the clock-"Vulliamy, London, No. 352, A.D. 1699." Worse than all, the precious dial was taken down and stowed away in a workshop at the palace, the gap left being filled by a painted board. In 1879, however, a new and sufficient clock movement was provided, the dial found, restored by Mr. James Thwaites, and replaced. It now shows the hours, the motions of the sun and moon, \&c., 
with certainly as much regularity as formerly, and as well as N.O. or N.C. could have desired. For the illustration of the dial I am indebted to Mr. Thwaites.

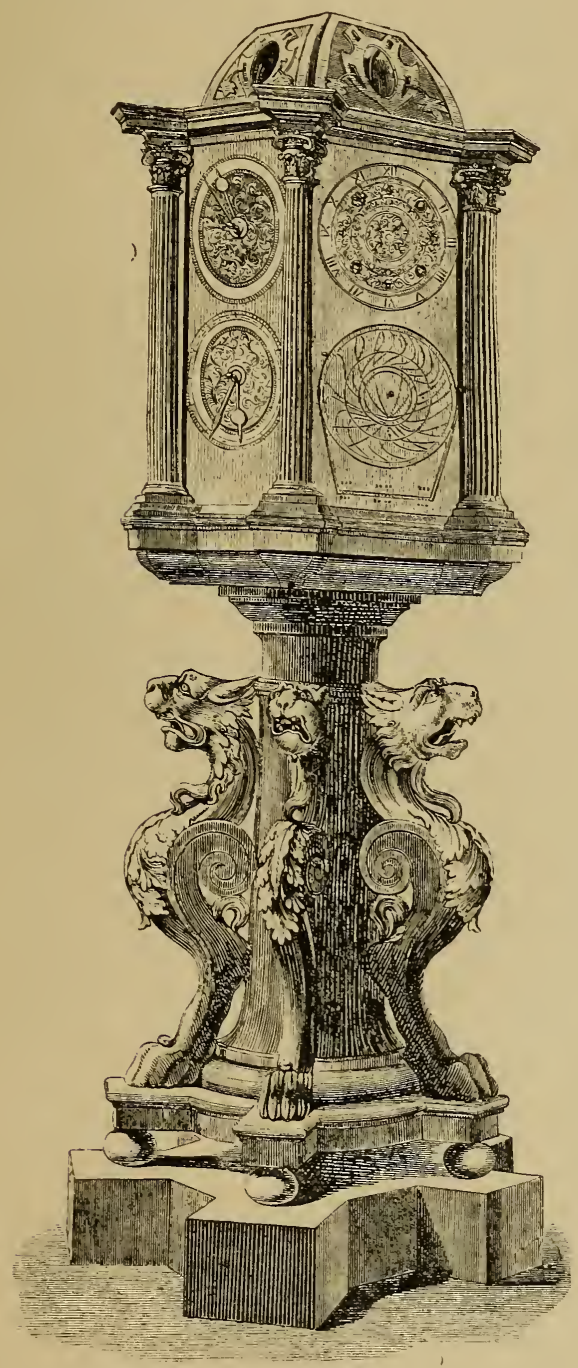

FIG. 39.-Planetary Clock of Oronce Fine.

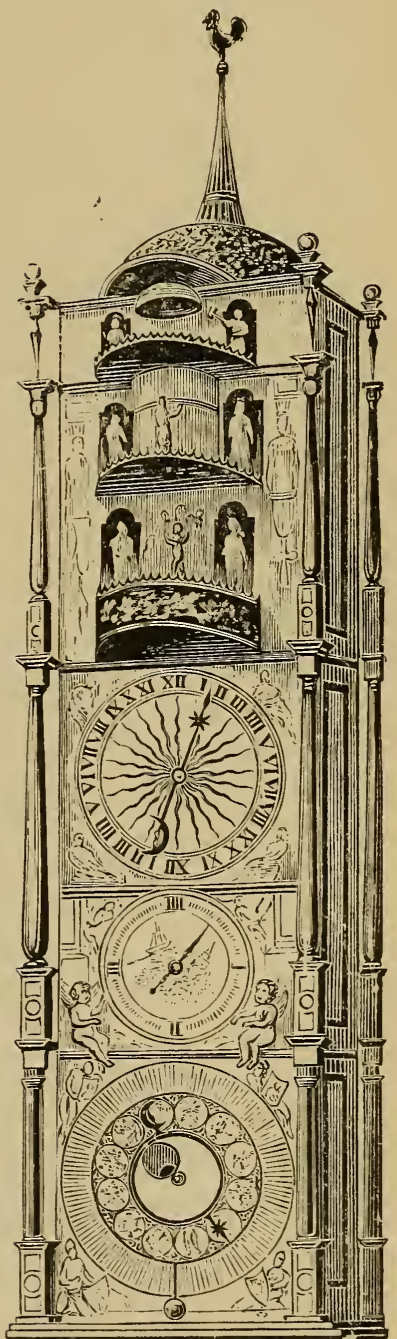

FIG, 40.--Clock by Isaac Habrecht.

Oronce Fine, mathematician to Francis I. and Henry II. of France, devised what is often spoken of as a planetary clock, which is shown 
in Fig. 39. The construction of this machine was begun in 1553, and after seven years, when it was completed, it was presented to the Cardinal de Lorraine. Afterwards it was placed in the library of St. Geneviève at Paris. It is in the form of a pentagonal column $17 \mathrm{in}$. in diameter and $6 \mathrm{ft}$. high. The movement concealed in the pillar is composed of over one hundred wheels, and actuated by a weight which falls $1 \mathrm{ft}$. per day, and was calculated to keep the apparatus going for forty-eight hours.

Clock by Isaac Habrecht.-At the top of the main staircase of the British Museum is a most curious clock, which was bequeathed to the nation by Mr. Octavius Morgan. It was constructed in 1589 by Isaac Habrecht, who made the second famous clock mechanism at Strassburg. It is about $4 \mathrm{ft}$. in height, and the general design is the same as that of the left tower of the Strassburg clock, and on the sides of both are figures of the three Fates, Clotho, Lachesis, and Atropos, and each is surmounted by a figure of the cock of St. Peter, which at the stroke of the hour flaps its wings and crows. It had originally a balance as a controller, for which a pendulum was subsequently substituted. The quarters are struck by four figures, representing the ages of man, and the hour by a figure of Death. On a lower balcony is a seated figure of the Virgin and Child, before whom passes a circle of angels, who, as they are set in movement by the striking of the clock, are caused to make an obeisance in front of the Virgin. Below this, the gods of the days of the week perform their circuit, each driving in a chariot, while the dials on the lower stages fulfil the more useful functions of indicating the hour, the phases of the moon, the feasis of the Church, \&c. The case is of gilt copper, with wellengraved figures and ornamental designs, perhaps by Tobias Stimmer, who was employed to decorate the original clock at Strassburg. The history of this clever piece of mechanism is somewhat curious, though it rests upon slender foundations. It is stated that Pope Sixtus V. was so pleased with the Strassburg clock that he ordered Habrecht to make one of the same kind. The timekeeper of which a view is given on p. 55 was the result, and it remained at the Vatican for two hundred years. Its next appearance was in Holland, where it was in the possession of the king; from Holland it was brought to London and exhibited about 1850.

In the royal palace of Rosenborg, Copenhagen, is a similar clock by Isaac Habrecht, and at the Historical Museinm, Dresden, is one, also very similar, which was made for the Elector Augustus between 1563 and $\mathbf{1 5 6 8}$ by the astronomer-horologist Baldwein, of Marburg, and 
H. Bucher, under the direct superintendence of the learned Landgrai William IV. of Hesse-Cassel.

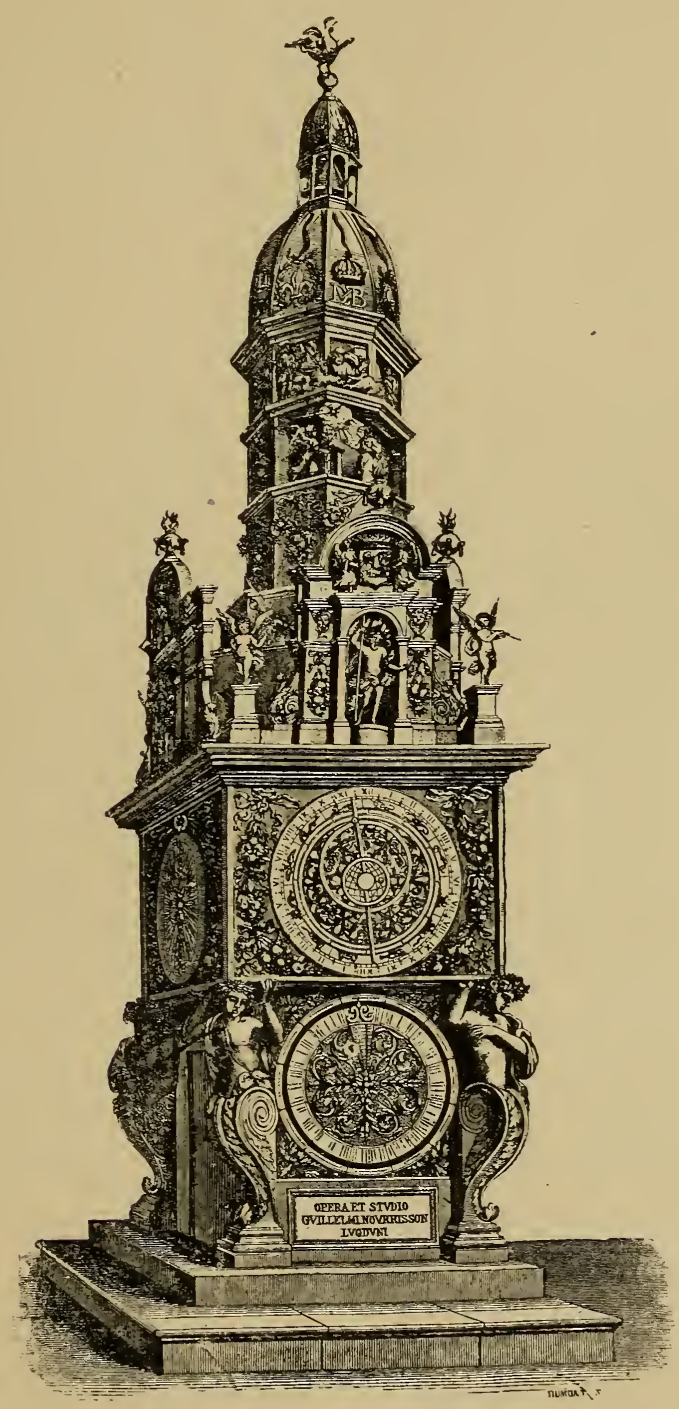

FIG. 41.-Lyons Clock.

Lyons Clock.-The cathedral of Lyons contains a remarkable specimen of complicated horological work, which is in the form of 
a tower $40 \mathrm{ft}$. high. The original clock was constructed by a mechanician named Nicholas Lippius, of Basle, who completed it in 1598. Guillaume Nourisson in 1660 repaired the structure, and among other alterations introduced a large oval dial. Not only was the outline of the dial oval, but also the graduated and figured band, which was divided into sixty to represent the minutes, and with

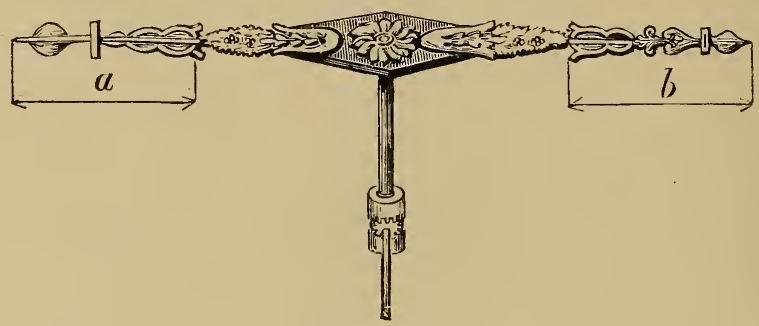

FIG. 42.

distinct marks for the quarter-hours. From a description of this curious clock published in 1677 are taken the accompanying engravings, which show how the hand dilated and contracted as it travelled around the dial in order that one tip might always indicate the minute and the other the quarter-hour.

Fig. 42 is the exterior of the hand stretched to its maximum length. As the hand approaches the narrower part of the oval, the

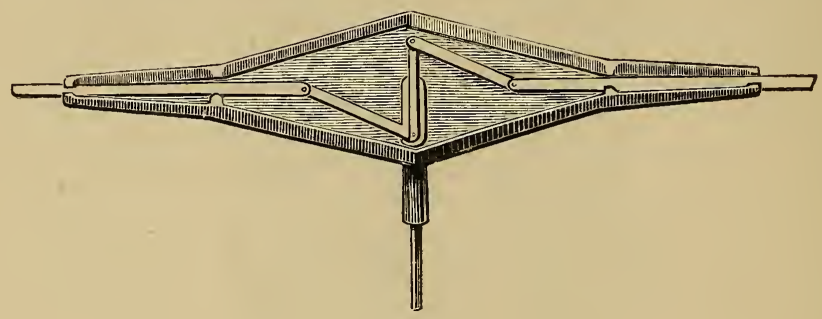

Fig. 43.

inner socket-like ends of $a$ and $b$ pass over the extremities of the fixed central portion.

Fig. 43 is a view of the central part with the ornamental covering removed.

Fixed to the centre part is a cannon pinion driven by a bevelled pinion which also drives another pinion, the stalk of which passes through the cannon to the upper part of the hand, and there engages with a double crank attached by means of connecting rods with the solid core of the parts $a$ and $b$. 
This dial is on one side of the tower. On the front are two dial plates as shown in the engraving on p. 57. The lower one is a calendar, and the other an astrolabe. The calendar is divided into 365 divisions, on which are fixed crowns. Each crown represents

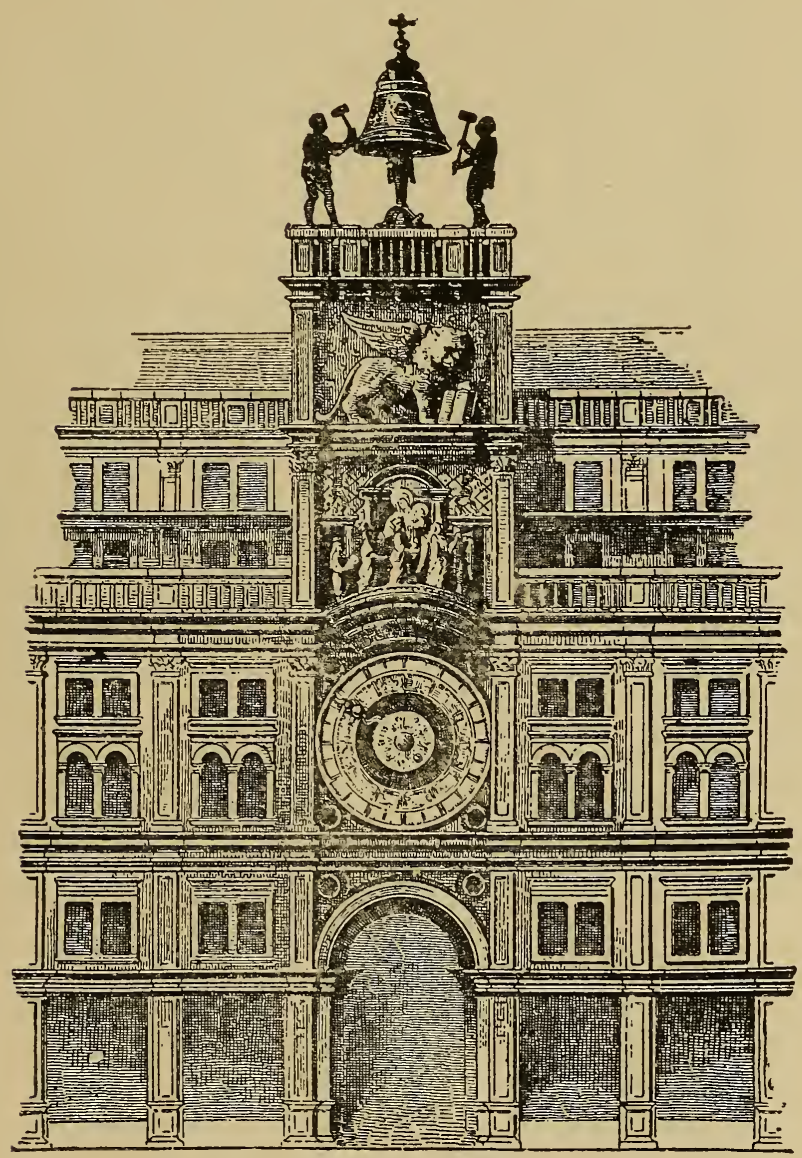

FIG. 44.-The original Venice Clock.

the day of the month in the calendar, and the name of the saint, when the anniversary of the latter is due. The names of the months are on the circumference. The circle forming the centre is divided into sixty-six years, and moves one division forward on the 31st of every December. The inscriptions about the religious festivals, \&c., are in handwriting on parchment. The astrolabe is exceedingly 
60 Old Clocks and Watches and their Makers

ingenious. Thereon all the zodiacal and other astronomical signs are displayed, the solar and lunar movements, \&c. In the upper part of the tower are various automatic pieces. There is a gilt niche

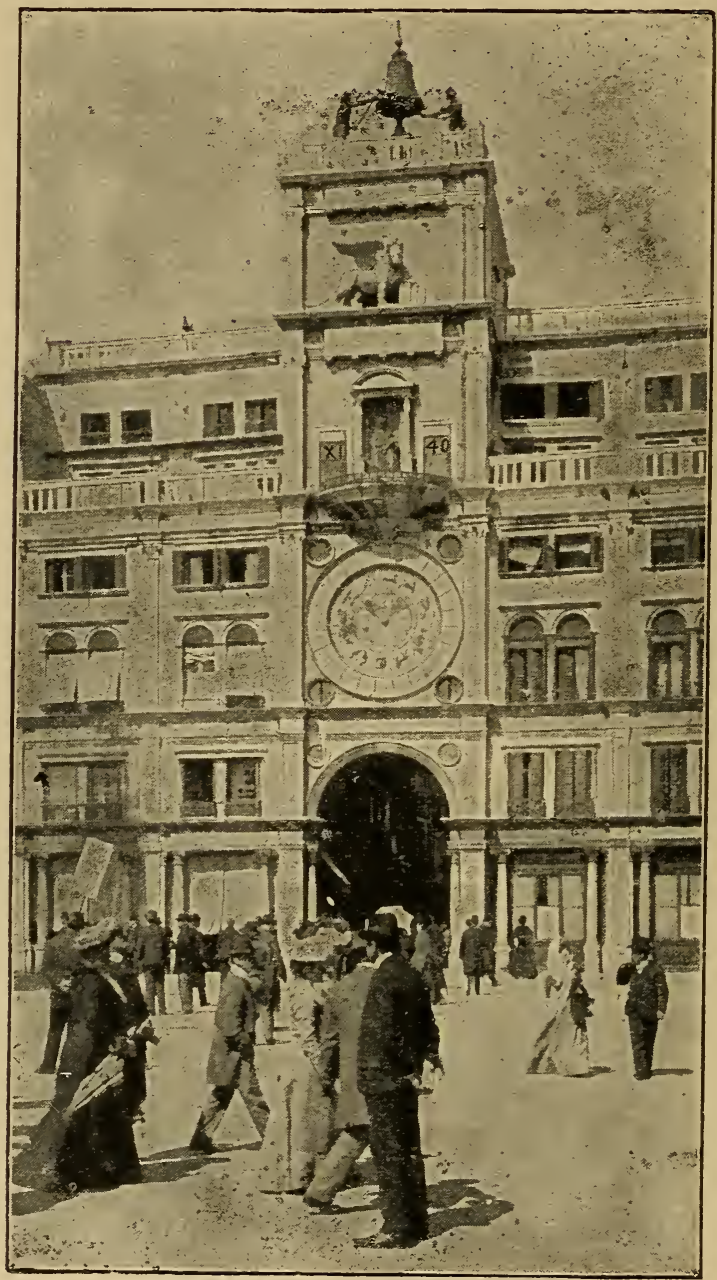

FIG. 45.-Venice Clock as now.

in which appear representations of the days of the week. For Sunday the symbol is the Resurrection; Monday, Death; Tuesday and Wednesday, Saints Stephen and John; Thursday, the Sacrament; Friday, the Passion; Saturday, the Virgin. At midnight, the statue 
that has finished duty cedes the place to that for the coming day. On the left is an angel which turns a sand glass every hour; on the right, another angel beats the measure with head, hand, and foot, as the clock strikes each hour. Above all is a large space, where the Almighty in the scene of the Annunciation bestows His benediction. The cupola terminates the monument and covers the bells, which play several religious chants and the Ave Maria. There is the figure of a beadle who appears, and marches round the gallery, to inspect, as it were, the bells.

In 1895, Chateau, of Paris, thoroughly repaired the clock, by direction of the French Government.

Venice Clock.-The first clock in the Square of St. Mark, at Venice, the work of Giovanni P. Rainaldi, of Reggio, and his son Carlo, was completed in 1495. Of its construction but little is known. Its successor, the monumental timekeeper shown on p. 59, was erected at the Grand Piazza early in the seventeenth century. There is a large dial showing the hours, and above is a balcony of gilt lattice surrounding an image of the Blessed Virgin, seated between two doors overlaid with gold. Evelyn, in his "Memoirs," under date 1645, speaks of this " admirable clock, celebrated next to that of Strasburgh for its many movements; amongst which about twelve and sixwhich are their houres of Ave Maria when all the towne are on their knees-come forth the 3 kings led by a starr. and passing by ye image of Christ in his Mother's armes do their reverence, and enter into ye clock by another doore." Another writer in 1841 remarked that at a certain period of every year, on the Feast of the Ascension, and fourteen days afterwards, as the hour struck, the door on the right hand opened and an angel with a trumpet issued forth, followed by three Eastern kings, each of whom, as he passed the Virgin, raised his crown, bowed, and then disappeared through the other door. The hours are struck by two bronze giants on a large bell which surmounts the structure.

Alterations to the movements appear to have been made from time to time, the most recent in 1859. The clock as it now exists is shown in Fig. 45, reproduced from a photograph taken by Mr. Julien Tripplin. Above the balcony is seated a figure of the Virgin Mary, and the doors on each side are utilised to exhibit by means of jumping figures the hour and minute. On the left facing the structure appear Roman numerals representing the last completed hour, and on the right the number of minutes past, these figures changing automatically every five minutes. 


\section{CHAPTER III}

\section{PORTABLE TIMEKEEPERS}

I T was not until driving weights depending from cords or chains were superseded by a more compact motor, which allowed small timekeepers to be readily transported from place to place, that they became objects of particular interest, the acquisition of which was sought in fashionable circles.

The Hon. Daines Barrington, in vol. v. of the Archceologia, speaks

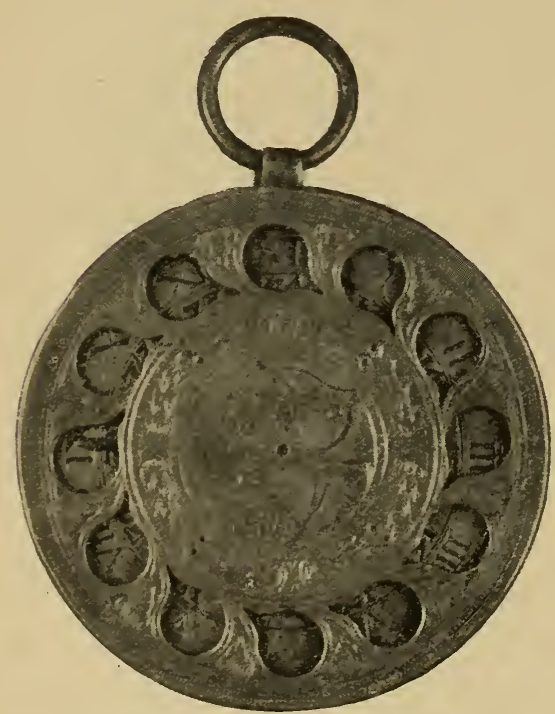

FIG. 46.

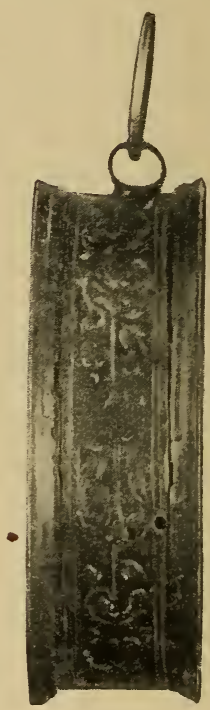

FIG. 47 .

Canister case; covers pressed on, back and front (no hinged joints).

of a watch as belonging to Robert Bruce, who died in 1328. This watch was of small size, with an enamelled case, a piece of transparent horn over the dial, and had engraved on the plate " Robertus Bruce," in Roman characters. Though it passed current for some time at the end of the eighteenth century, and eventually became the property of 
George III., careful examination revealed the fact that the inscription was undoubtedly a recent addition, and the watch a production of three centuries later than Bruce. Except that the quotation of Barrington's statement is perennial, it would be hardly worth while to refer to so clumsy an imposition. A watch in the Schloss collection was, I believe, the one referred to. It will be illustrated in Chapter IV.

It is now generally con'ceded that the production of a portable

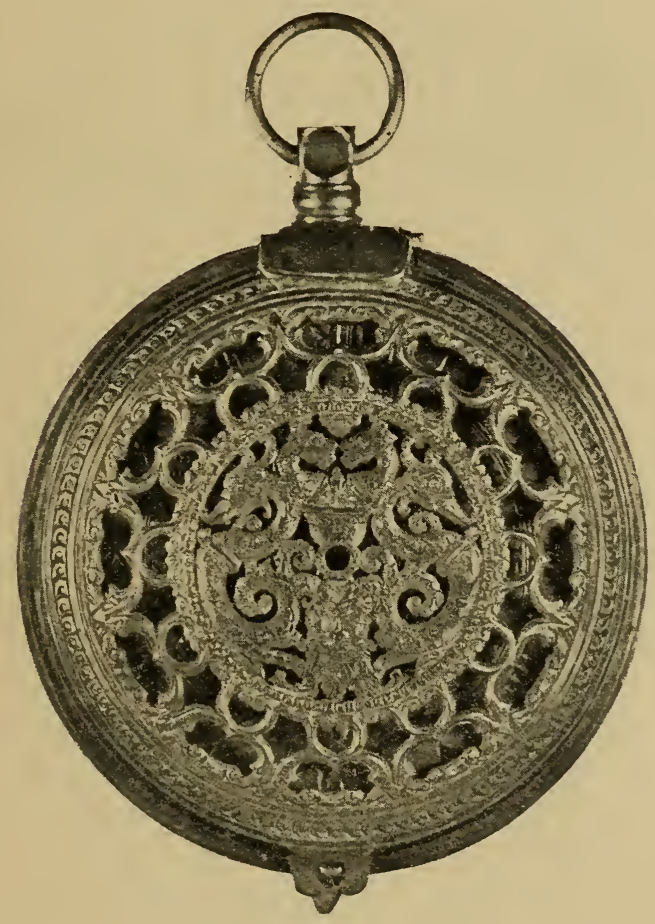

FIG. 48.--Cover closed.

timekeeper was accomplished by Peter Henlein or Hele, a clockmaker of Nuremberg, who was born in 1480 and died in 1542 . He, shortly after 1500 , used a long ribbon of steel tightly coiled round a central spindle to maintain the motion of the mechanism. The invention has been ascribed to Habrecht and others, at a much later date, but Johannes Coccleus, who was born in 1470 , in his commentary dated 1511, accurately describes a striking watch and distinctly credits its introduction to Henlein. Although portable timekeepers were not in 


\section{Old Clocks and Watches and their Makers}

general use for a long period afterwards, a taste for table clocks and watches was at once apparent among wealthy people, who delighted in the possession of curious novelties.

The earliest watches are scarcely to be distinguished from small table clocks. The case was a cylindrical box, generally of metal, chased and gilt, usually with a hinged lid on one side to enclose the dial, the lid being engraved, and, as a rule, pierced with an aperture

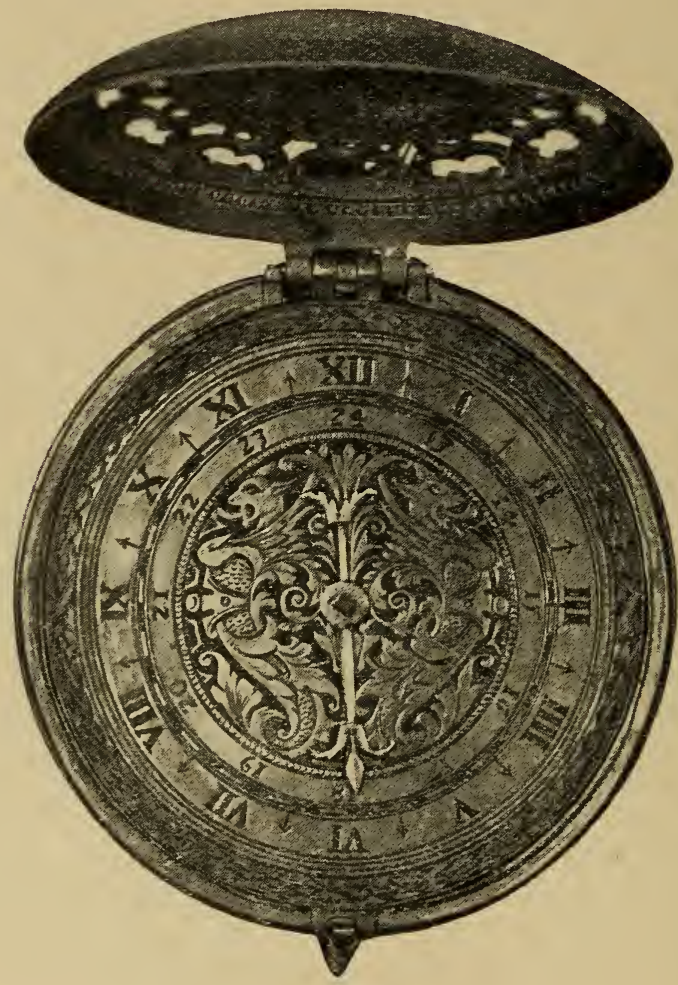

FIG. 49.-Cover open

over each hour, through which the position of the hand might be seen. Most of the watches were provided with a bell, on which in some cases the hours were sounded in regular progression ; in other instances the bell was merely utilised for an alarum. When furnished with a bell the case was, as a rule, worked $\grave{a}$ jour to emit the sound. Cases in which the covers over the dial and back are quite flat, and the edges of which project over the middle of the body, are often 
spoken of as tambourine or drum cases. A canister case is understood to be one in which the covers are not hinged to the body of the case, but simply pressed on in the same way as is the cover of a canister.

Illustrations of dissimilar examples are given on p. 66. All are

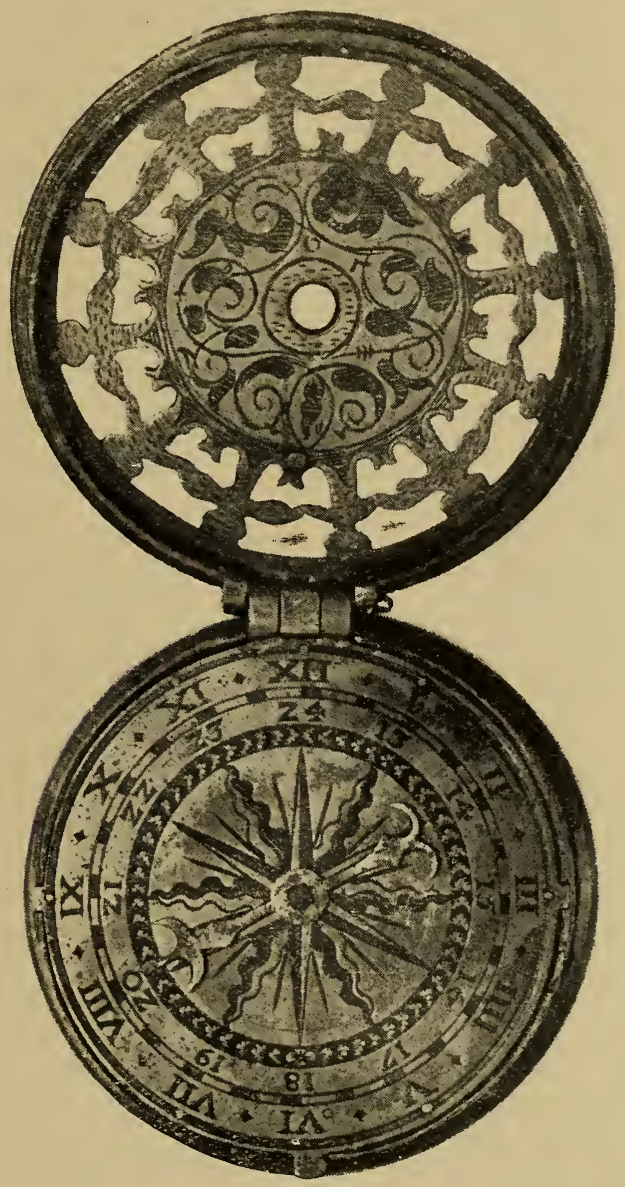

FIG. 50.-Tambourine Case, Jointed Cover.

worth examination. In Fig. 51, to form twelve apertures through which the position of the hand might be seen, and to connect the outer part of the cover with the centre, are six pairs of male and female figures joining hands, well carved with very pretty effect. A happier combination of ornament and utility would be difficult to conceive. At the South Kensington Museum is a circular table clock, about 
66 Old Clocks and Watches and their Makers

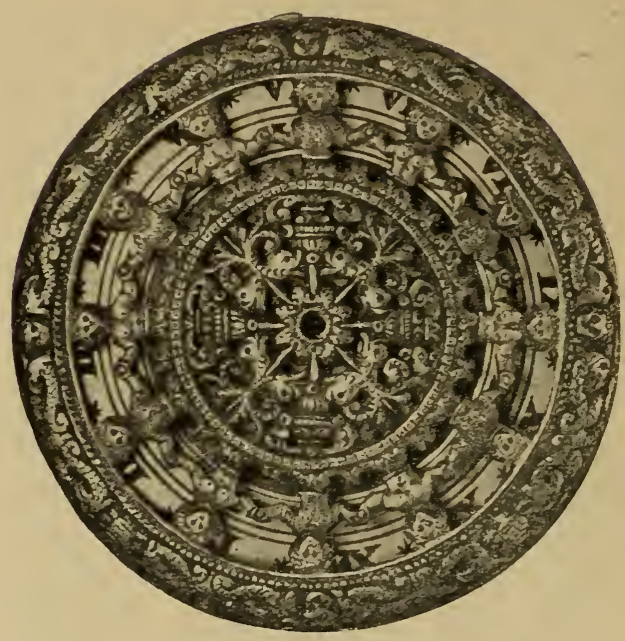

FIG. 51.

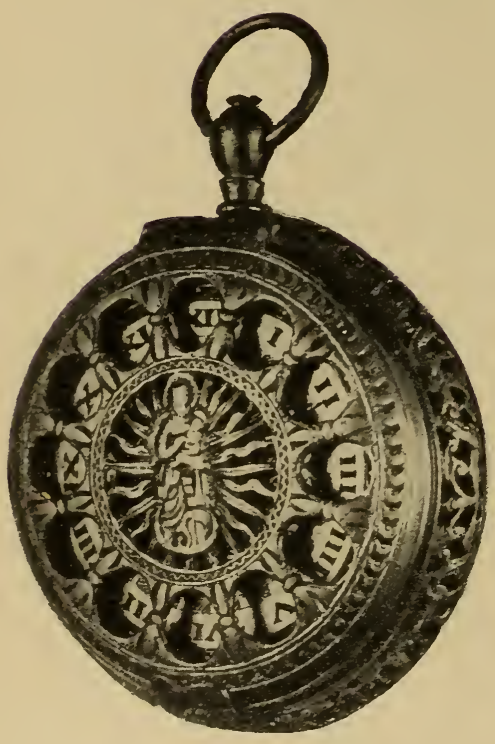

FIG. 52.

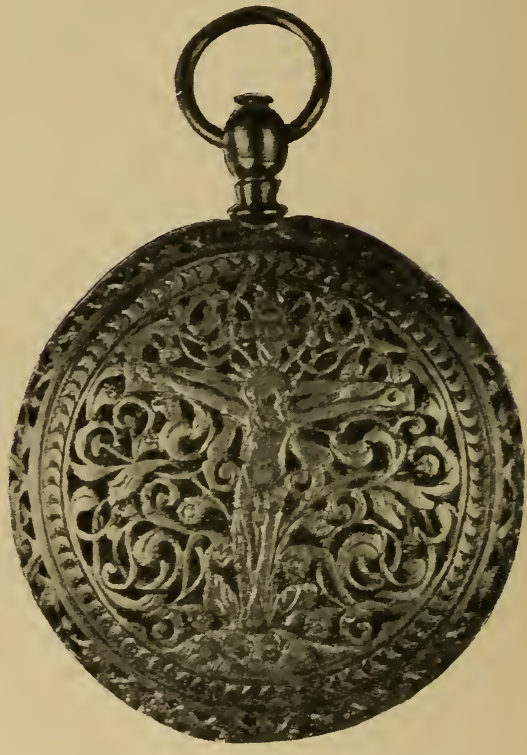

FIG. 53.

3 in. in diameter, in an engraved brass case having a perforated dome surmounted by a small horizontal dial. On the inside of the bottom cover is inscribed, "P. H. Nor . 1505." This led to the supposition 
that "Nor " stood for Norimbergæ, " at Nuremburg," and that the clock was the handiwork of Hele. The plates of the movement are of steel, and the piece appears to be evidently a production of the sixteenth century, but the balance and its accessories are compara-

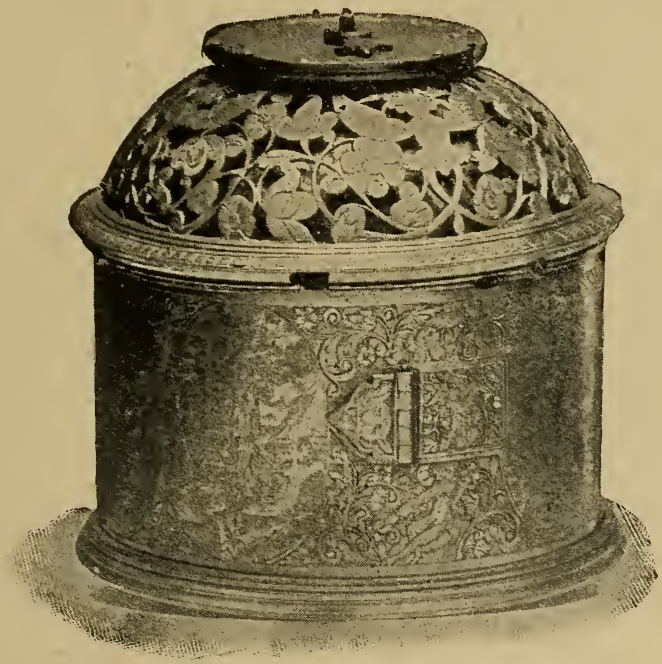

FIG. 54.-Circular Table Clock.

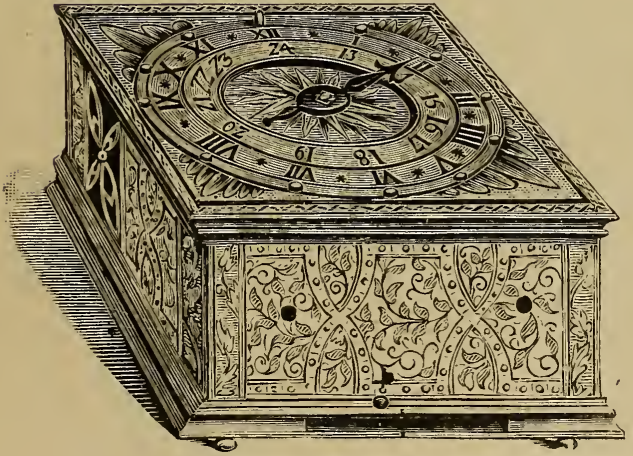

FIG. 55.

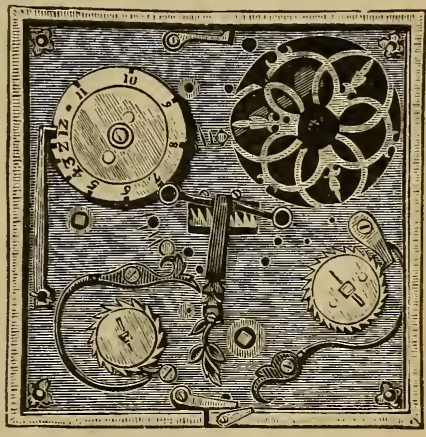

FIG. 56 .

Two views of square Table Clock.

tively modern, and it would be unsafe to rely on the inscription as conclusive evidence of authenticity.

A somewhat similar piece, of rather later date, is shown in Fig. 54, which is about two-thirds of the actual size of the clock. 
The square table clock of which two views, Figs. 55 and 56 , are given, is, judging from the engraving and general construction, a sixteenth-century production. It is furnished with the primitive cross-bar balance. There is no indication of the maker or his place of abode.

On very early productions the maker's name is exceptional;

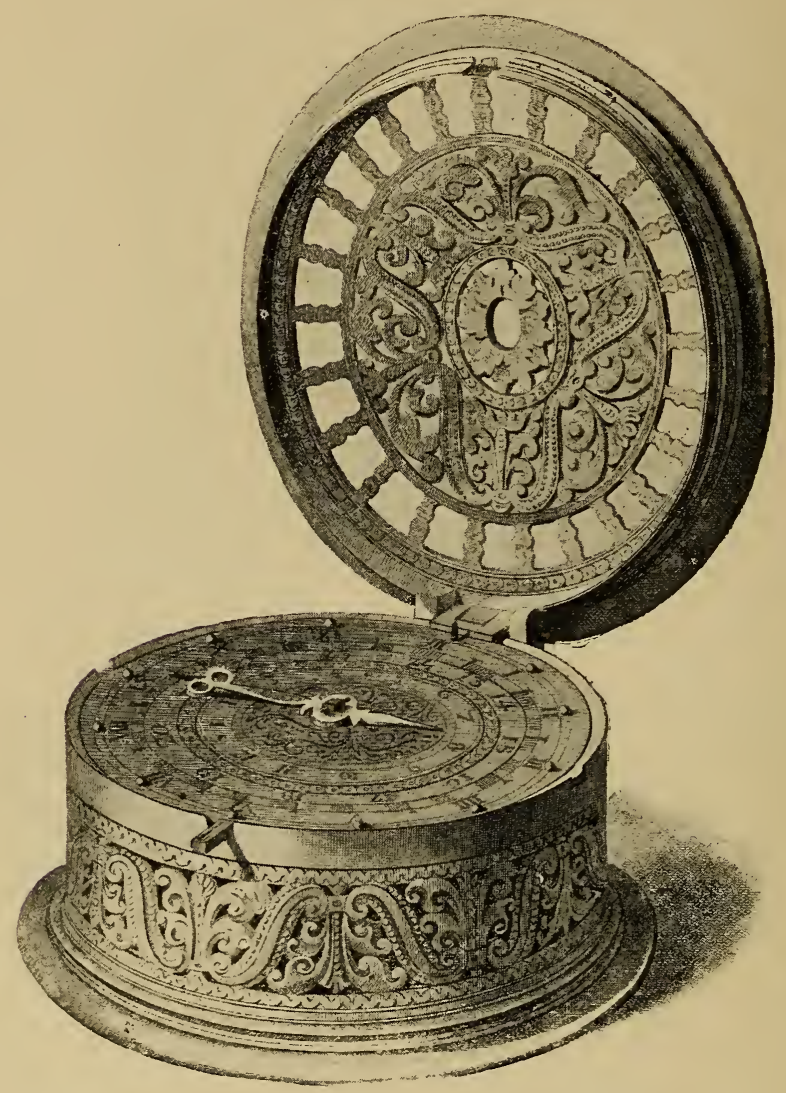

FIG. 57.-Sixteenth-Century production.

initials were a more usual signature, and occasionally a work stamp is to be found, from which it may be possible to ascertain the locality of manufacture. Some towns had a distinctive trade or work mark, that for Nuremberg being the letter $\mathrm{N}$ in a circle, for Augsburg a pineapple, for Berne a bear, and for Mayence a wheel. Sebastian Lehr, clockmaker to the city of Nuremberg, who died in 
1556, may be taken to have been an eminent craftsman. Among others of the period of whom mention is made is Hans Gruber,

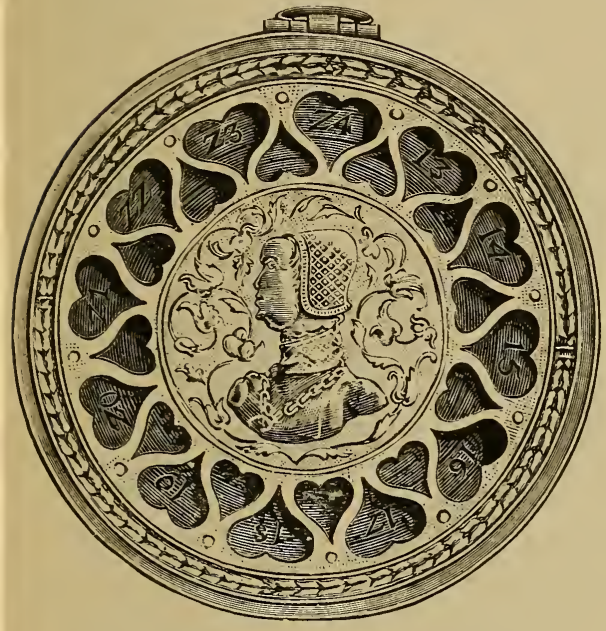

FIG. 58. Front with Cover closed.

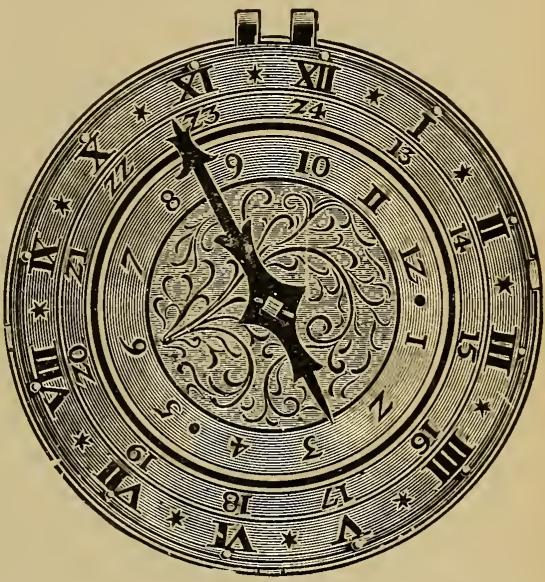

FIG. 59.-Front with Cover removed.

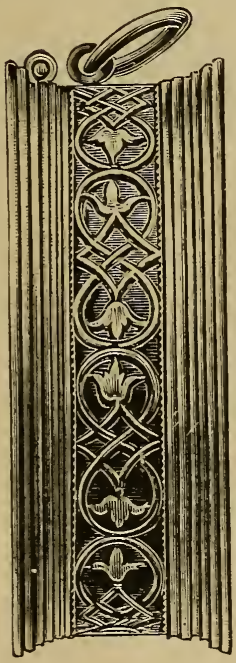

Fig. 60.-Edge.

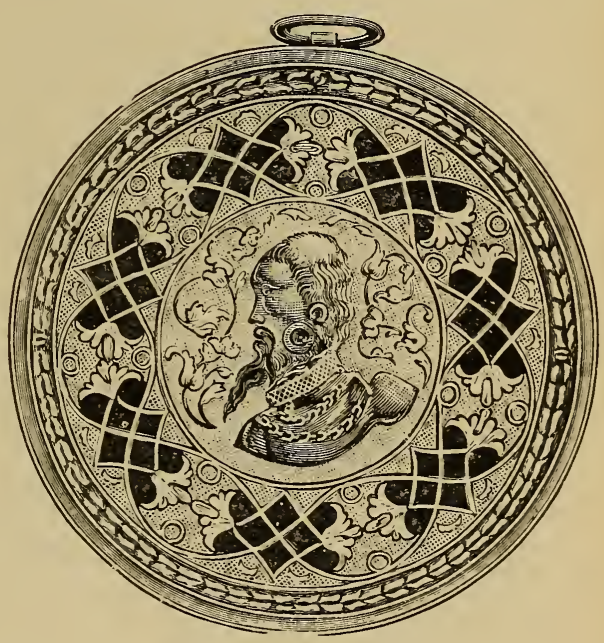

FIG. 61.-Back.

Four views of a fine mid-sixteenth-century Alarm Watch.

clockmaker and master of the Locksmiths' Guild about the middle of the sixteenth century.

There are several specimens in the British Museum of a date 
between 1535 and 1570. Of two by Jeremia Metzger (or Metzker), Augsburg, one is furnished with a bow, and one is without any provision for suspending the watch. The South Kensington collection includes a circular striking and alarum clock, supported by a figure of Atlas on a pedestal of gilt brass, inscribed thus: "Jeremias . Metzger . Vrmacher . 15.60 . in Avgspvrg." A clock with complicated movements by this maker in the Vienna Treasury is dated

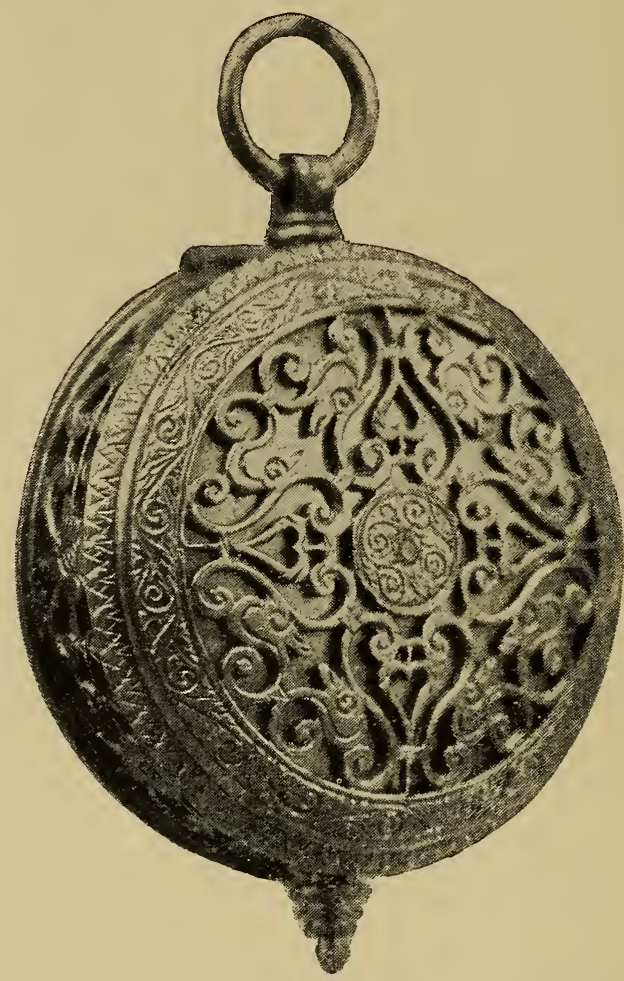

FIG. 62.-An early example from the Schloss collection.

1564. In the same repository are two watches in cylindrical brass cases which match each other. The movements bear the letters A.S. arranged as a monogram, but there is no other indication of the maker.

Fig. 57, from the Soltykoff collection, is one of the earliest of the kind. It is unnamed, but doubtless of German make, in a brass gilt case with covers top and bottom. In the open top cover may be seen the twenty-four perforations, through which the position of 
the hand could be discerned. For this engraving and other lllustrations of sixteenth century horology, formerly in the magnificent collection of Prince Pierre Soltykoff, I am indebted to the sumptuous descriptive quarto prepared by Pierre Dubois.

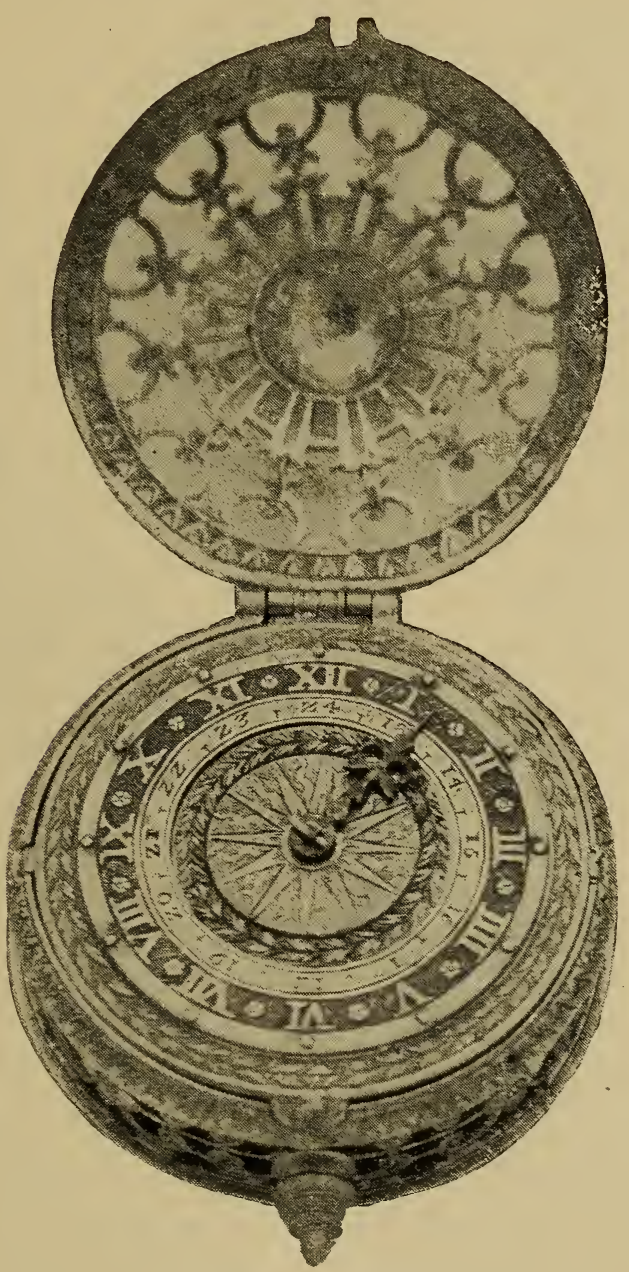

FIG. 63.-Dial of Fig. 60.

Figs. 58, 59, 60, 61, are four views of a fine mid-sixteenthcentury alarum watch, in a case of gilt metal, the front, back, and edge of which is perforated. On each of the covers is a bust as shown. 
72 Old Clocks and Watches and their Makers

Of an early example from the Schloss collection three views are given (Figs. 62, 63, 64). The movement is especially interesting. It is of the most primitive character, the balance for controlling the

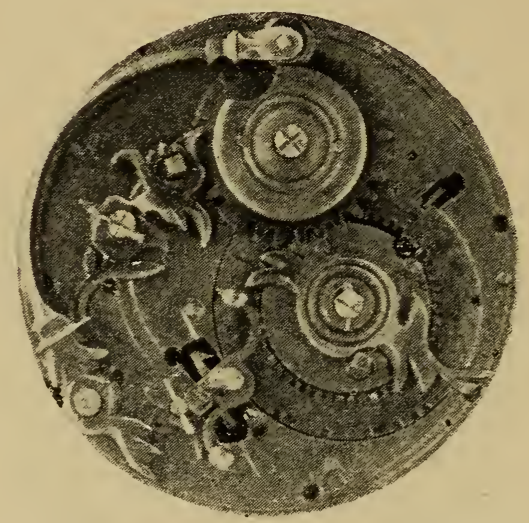

FIG. 64.-Movements of Figs. 62 and 63.

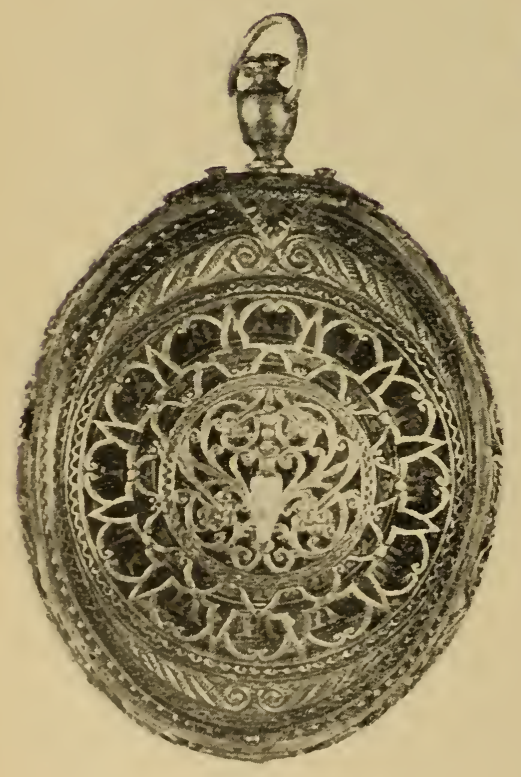

FIG. 65.-Early oval Watch.

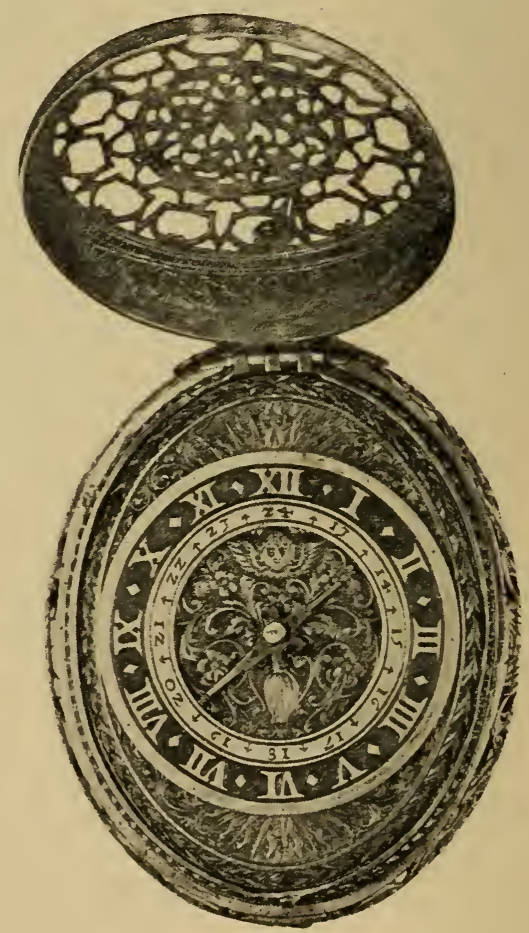

FIG. 66.-Early oval Watch. 


\section{Portable Timekeepers}

motion of the wheels being of the cross-bar type, designated by Froissard "le foliot" and by German writers "waag." Another feature, the "stackfreed," for equalising the power, will be referred to a little further on.

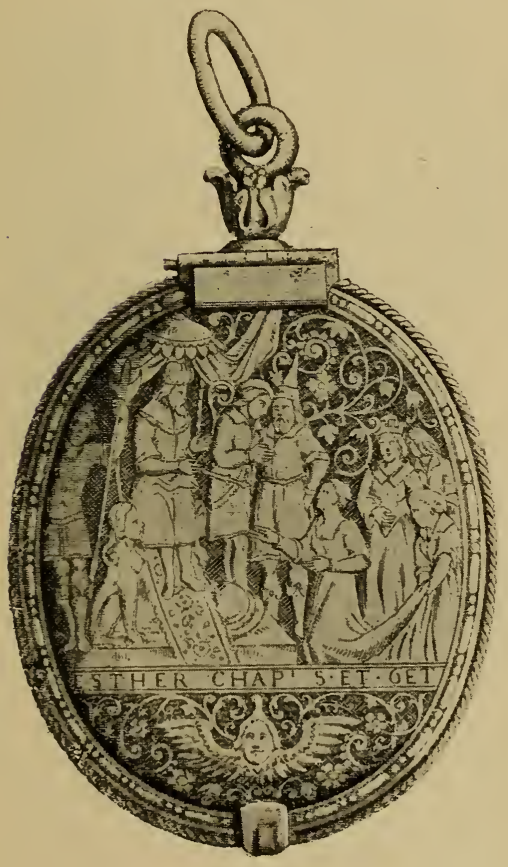

FIG. 67

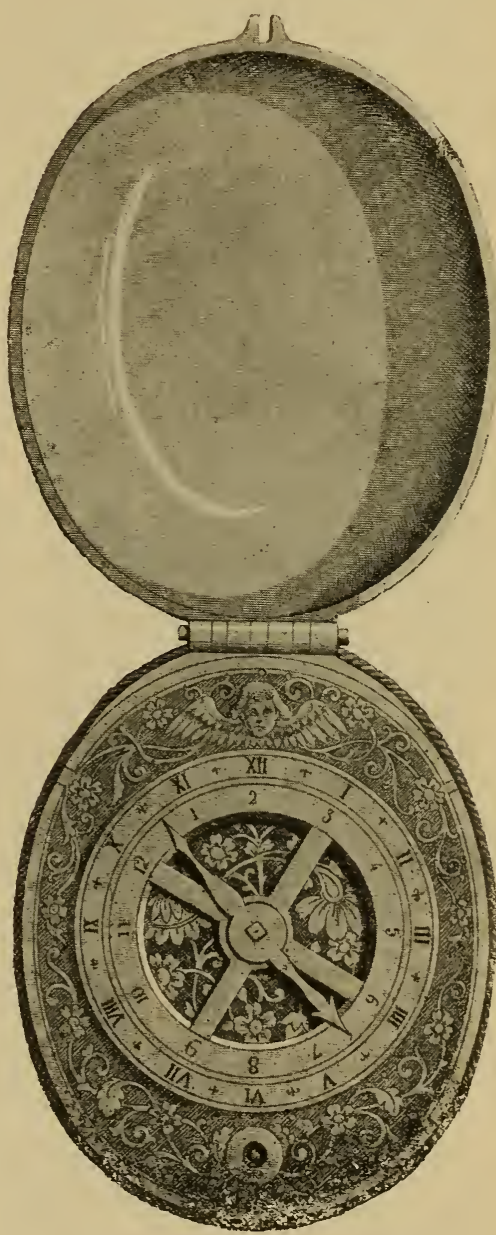

FIG. 68 .

Oval Striking and Alarm Watch (two views).

A large oval case, with geometrical perforations in the lid, was almost contemporaneous with the circular box form, and an oval shape, either small and plain or larger with more or less of decoration, remained in favour for over a century. An early specimen is shown in Figs. 63 and 64 . The oval striking and alarum watch 


\section{Old Clocks and Watches and their Makers}

reproduced in Figs. 67 and 68 is sixteenth-century work by Jacques Duduict, " maitre orologier en la bonne ville de Blois," and is from the Soltykoff collection. It has covers back and front, on each of which is a tableau reproducing a scene in the life of Esther.

The luxury and extravagance in dress which characterised the Elizabethan period required more variety of form and colour than could be found in a plain regular form of gold or silver, so rock

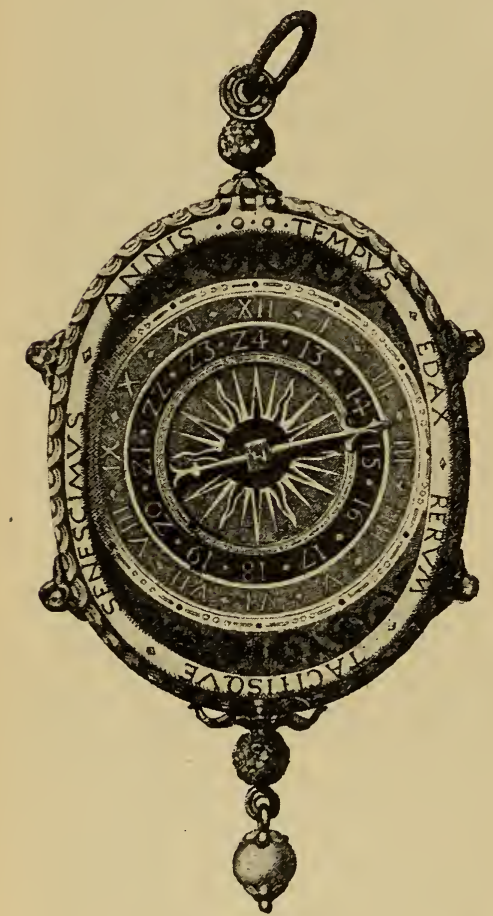

Fig. 69.

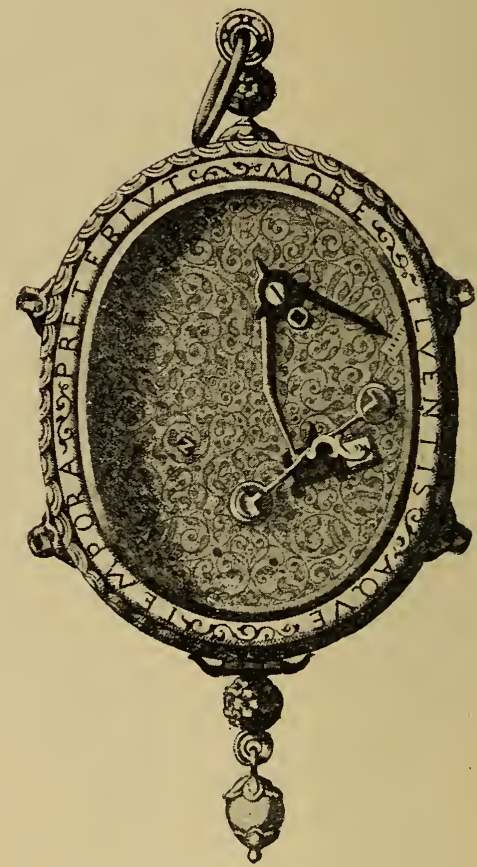

FIG. 70.

Two views of one of the richest productions of the kind which has survived.

crystal and other stones were often converted into cases which were cut in the form of crosses, stars, shells, and other extraordinary fancies, while the dials and mounts were occasionally enriched with coloured enamels. The most elegant of these costly toys emanated from France, Blois being distinguished as an early seat of manufacture.

Figs. 69 and 70 represent what Dubois declared to be one of the richest productions of the kind which has survived. It is from the Soltykoff collection, oval in form, with square edges, in a case of crystal, with mountings engraved, splendidly enamelled, and further 
embellished with diamonds and rubies. The ball depending from the bottom of the case is a fine pearl. The dial is of gold, the borders above and below being enriched with enamel of various colours. The back plate is engraved all over with arabesques, giving

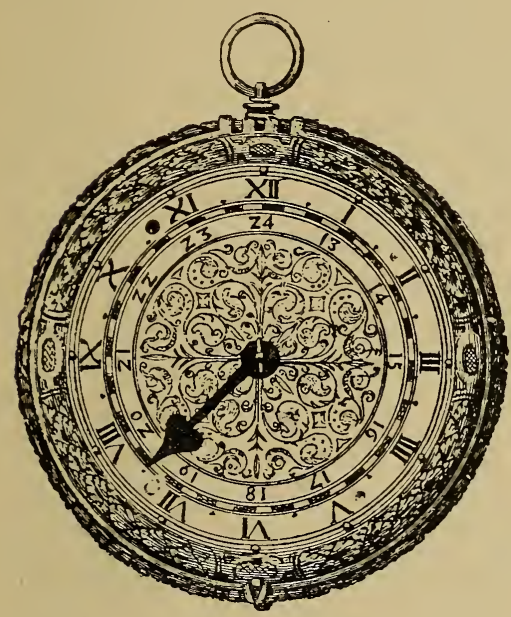

Fig. 71.-Front with Cover removed.

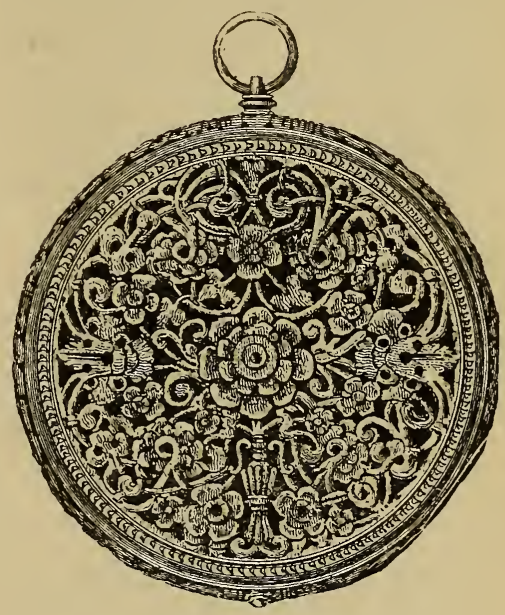

FIG. 72.-View of Back.

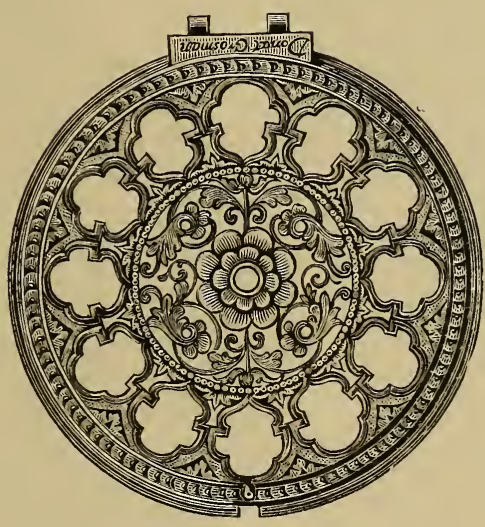

FIG. 73.-Front Cover.

a delightful effect. In the midst of the engraving may be discerned the letter $\mathrm{N}$, the Nuremberg work mark. It bears no indication of the maker's name, but from the primitive foliot balance and other features it may safely be classed as not later than mid-sixteenthcentury work. 
There is at the Horological Institute a print of a very old striking or clock-watch, the case of which is enriched with remarkably fine

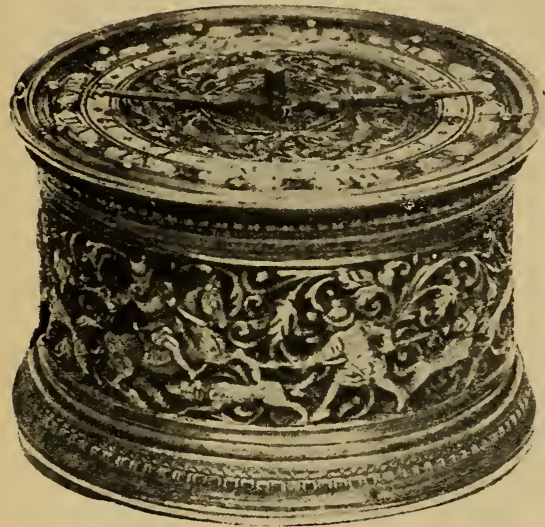

FIG. 74.-Table Watch dating from about 1550 .

arabesque work, pierced to emit the sound. Three views of it are appended: Figs. 71, 72, 73. The dial has two hour circles, the divisions of the outer circle being marked with Roman, and those of the inner with Egyptian characters, while between the two is a circle of minute marks. I have had an opportunity of examining the watch, which is from the Schloss collection. It is $1 \frac{3}{4}$ in. in thickness, and $3 \mathrm{in}$. in diameter; the wheels are of iron, but it has neither barrel nor fusee. There are two springs, one the motive power for timekeeping, and the other for striking which is effected upon a broad bell occupying the whole bottom of the watch. The outer end of the mainspring appears to be attached to a pillar between the plates -an arrangement reintroduced in quite modern times for cheap clocks.

There is at the British Museum a table watch in a drum-shaped case, dating from about 1550 . It is from the Zschille collection, and is shown in Fig. 74 . The mechanism is very crude, without screws, and includes a foliot balance and

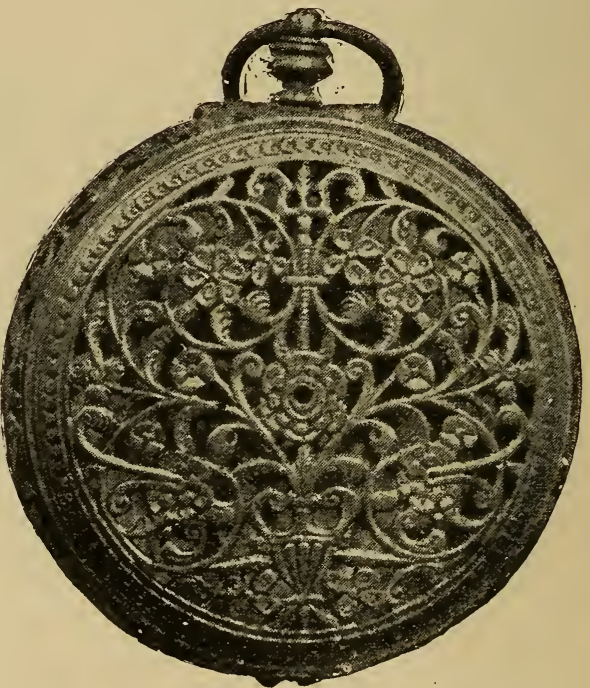

FIG. 75.--Interesting specimen of pierced chasing. "stackfreed." The movement bears, in a shield, the work mark M and a fleur-de-lis. 
The watch case shown in Fig. 75 is interesting as a specimen of pierced chasing, probably German, dating from about 1560 .

A fine striking watch in a circular table case, from the Soltykoff collection, is shown in Fig. 76. It dates from about 1575, and is by Charles Cusin, " maitre horloger de la ville d'Autun." The hour band is of silver and the hand of blue steel. It has covers top and bottom, the upper one pierced as shown ; the solid centre is the reverse of a mounted cavalier, of which the obverse is visible when the cover is closed; this, it is averred, represents Henry IV., King of France and of Navarre. The under-cover, similarly pierced, contains in the centre a mounted figure, said to be a counterfeit of the son of Marie de Medici, afterwards King of France.

The origin of the term "watch" is not very clear. It may have been taken from the Swedish vacht, or from the Saxon weeca, " to wake;" but whatever its derivation, it had not, when introduced, the signification we now attach to it, because timekeepers were not then worn in the pocket. But "watch," or " clock," or " orologe," seems to have been used indifferently as a title for timekeepers, and so it is often difficult to decide whether a

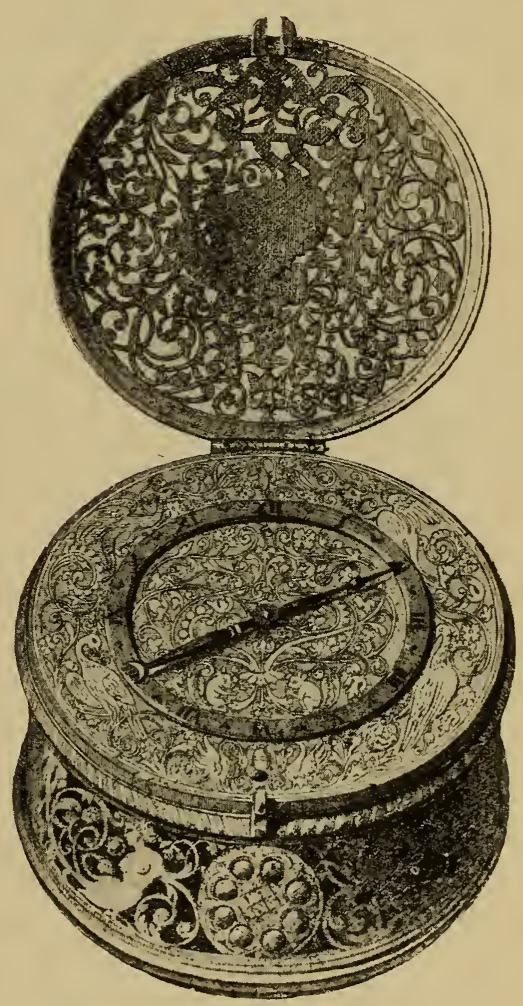

FIG. 76.-Striking Watch about 1575 . weight clock of large size or a very minute spring timepiece is meant. Derham, in all the editions of his book, speaks of timekeepers driven by weights as watches, reserving the word clock for parts connected with the striking.

The action of the mainspring, which still retains its place as a motor for portable timekeepers, will be understood with the aid of Fig. 77. Here, as is usually the case, the spring is contained in a circular box or barrel $c$, its inner edge being hooked on to the enlarged 
part of the arbor $a$, and its outer end attached to the inside of the rim of the barrel. The arbor passes through and fits easily a hole in the bottom of the barrel, and a hole in the barrel cover $e$. The spring is wound by turning the arbor, and then, if the spring barrel is attached to the largest wheel of the clock, in place of the cylinder or drum from which the weight was suspended, the spring in its effort to unwind turns the barrel, and with it the wheels composing the clock train. Of course, some provision must be made to prevent the spring from at once uncoiling when the arbor is released after winding, and the simplest plan is to have a ratchet wheel fixed on one end of the arbor, with which a click pivoted to the framing of the timekeeper engages. When the barrel is used in conjunction with a fusee, as will be

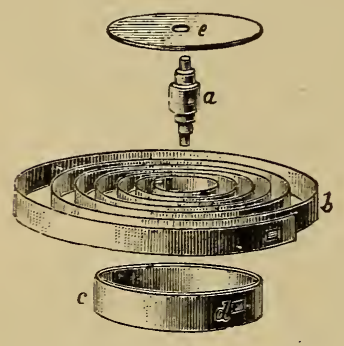

FIG. 77.-Mainspring and Barrel.

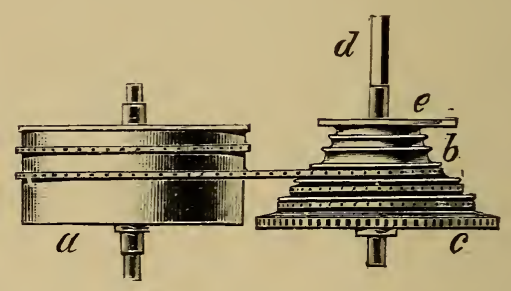

FIG. 78.-Mainspring Barrel and Fusee.

$a$, mainspring barrel; $b$, fusee ; $c$, great wheel ; $d$, winding square; $e$, snail-shaped flange

described presently, the spring is wound by turning the barrel instead of the arbor.

But it is evident that, just as the spring offered increased resistance to every successive turn of the arbor in winding, so the force transmitted by it when fully wound would be very much greater than the force exerted after the barrel had made a few turns and the spring had partially run down, and this variation of force was the cause of considerable perplexity for some time after the invention of the mainspring, for with the verge escapement variation of force means variation of timekeeping. The first contrivance applied with a view of overcoming or abating the drawback was that known as the "stackfreed." I have tried in vain to trace the derivation of this curious word, but am told it is of Persian origin. The device did not prove to be an enduring one; but it was applied to most portable timekeepers up to about 1540 , and occasionally afterwards to the end of the century. It is shown in Fig. 79, which is a watch in a canister case with the back cover removed. The front and edge of the case have already been illustrated. The action of the " stack- 
freed " may be gathered from an examination of the engraving with the following explanation.

Fixed to the mainspring arbor above the top plate is a pinion having eight leaves. This gears with a wheel having twenty-four teeth, which do not quite fill out the circumference of the wheel, but leave a block of two spaces in width which acts as a stop to the pinion when the mainspring is wound, and after it has run down three whole turns. Fastened to the wheel is a cam, nearly concentric for about seven-eighths of its circumference and indented for the

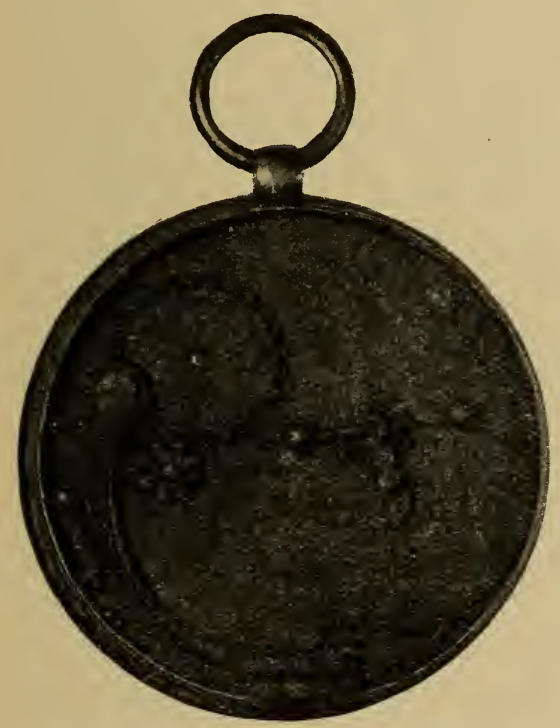

FIG. 79.

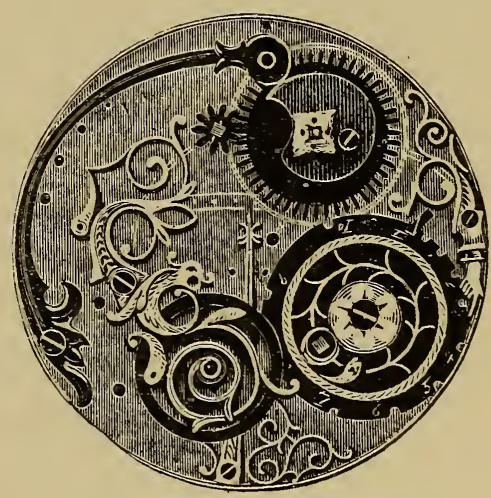

FIG. 80 .

Watch movements with "Stackfreed."

remainder. There is a groove in the concentric portion of the edge, into which is pressed a roller which is pivoted at the free end of a strong curved spring. When the mainspring is fully wound the roller rests in the curved depression of the cam, and the effort required to lift the roller up the incline till it is placed upon the concentric contour absorbs so much of the force of the mainspring as to prevent banking. When the mainspring has nearly run down, the roller, in entering the depression by pressing the cam in the direction that it is moving, really aids the mainspring in its effort. Besides the stackfreed and its appurtenances may be noticed in Fig. 79 the cross-bar balance, the very small balance cock, and two hinged bolts which shut into 
holes in the edge of the case, and so secure the movement in position. The plates, the train wheels, stackfreed, balance-cock, and balance are all of iron or steel, and the various fastenings are made by means of pins or rivets, there being no screws used throughout. This movement is, in fact, an excellent example of the very earliest kind of portable timekeepers.

In Fig. 80, which shows a later stackfreed movement, is a point worthy of note. As a form of regulator are two banking pins of stiff bristle, which the straight arm of the balance knocks against. These are mounted on a lever which is pivoted at one end by means of a screw near the edge of the plate. The pins may be caused to approach or recede from the centre of the balance by moving the free end of the lever, and in this way the vibrations of the balance would be retarded or quickened. An engraved scale on the platc registers the movement of the free end of the lever.

It is not a matter for surprise that a frictional brake like the stackfreed, which must have absorbed an appreciable proportion of the force, failed to give satisfaction for equalising the pull of the mainspring. The fusee invented for the same purpose by, it is said, Jacob Zech, of Prague, about 1525, is of a far different nature, and still survives. It consists of a spirally grooved pulley, which is interposed between the mainspring barrel and the great or driving wheel of a clock or watch, the connection between the barrel and the fusee being made by a cord or chain, one end of which is attached to the barrel and the other to the fusee. When the spring is relaxed there must be at least as many coils of the cord around the outside of the barrel as the barrel is to make turns in winding the spring. To wind the spring, the fusee is rotated by means of a key fitting a square formed at one end of its arbor, whereby the cord is drawn from the barrel on to the fusee, the first coil being on the larger end of the fusee, as shown in Fig. 78 .

Then, as the mainspring runs down, the barrel rotates and coils the cord on to its periphery again. But while the mainspring when fully wound turns the fusee by uncoiling the cord from the smallest part of the fusee, it gets the advantage of a larger radius as its energy becomes lessened, and by proportioning the diameter of the fusee to the varying pull of each successive turn of the mainspring an excellent adjustment is obtained, so that the pressure exerted by the great wheel on the centre pinion is constant. The fusee is fixed to its arbor, on which, in the simplest arrangement, the great wheel rides easily, the connection between the fusee and great wheel being made by 
means of a ratchet wheel and click; this allows of the fusee being rotated to wind the mainspring. To prevent undue strain on the cord when the winding is completed, the cord, as it is being coiled on to the smallest turn of the fusee, pushes an arm which is pivoted to the framing of the timekeeper in the path of a snail-shaped flange of the fusee, and this forms a stop. The barrel arbor is always stationary. In the early fusees the cord was of catgut, and this material is still sometimes "used for clocks. Chains were introduced in the place of catgut for watches in 1664 , by one Gruet, a Swiss, and they are still used for marine chronometers, for some clocks, and for the few fusee watches that are made.

Table clocks or watches of the sixteenth century are exceedingly rare. Many specimens put forward as such are found on examination to be of a later date. There is no doubt that the manufacture of portable timepieces extended to Holland and France before the end of the century, but very few examples of that period survive. A genuine specimen would have no covering glass over the dial, and, if a fusee were present, the connection between it and the barrel would be by a piece of catgut, and not a chain. There would be, of course, no controlling spring to the balance at that period, while the balancecock, instead of being spread over the whole extent of the balance, would be narrow. The workmanship of the movement would be comparatively rough, however lavishly the case might be ornamented.

During the first quarter of the century the frames and wheels were of iron or steel ; productions of the second quarter having brass plates and pillars are occasionally to be met with. But brass wheels before the middle of the century were quite exceptional. Screws seem to have been introduced to join pieces of metal in German timekeepers about I550, so that in the early sixteenth-century timekeepers these convenient fasteners would be absent, and the various junctions made by riveting or the use of either pins or cotters. Screws are not met with in English work till quite late in the century, and are absent in some early seventeenth-century watches. There were rarely any winding holes in the cases of sixteenth-century watches; to attach the key to the winding squares the case had to be opened and usually the movement to be turned out of the case, a cover at the back being the alternative.

The Society of Antiquaries possess an undoubted example of the handiwork of Jacob Zech, the inventor of the fusee. It is a table timepiece with a circular brass gilt case $9 \frac{3}{4}$ in. in diameter, and 5 in. in height, which was bequeathed to the Society by Mr. Henry Peckitt, 
an apothecary, of Compton Street, Soho, and handed over by his executrix in 1808. It was given to James Ferguson, the astronomer and mechanician, by Mudge, and at the sale of Ferguson's effects it was bought by Mr. Peckitt in 1777. Captain W. H. Smyth gives a minute description of this relic in Archeologia, vol. xxxiii., from which the engraving of the dial (Fig. 81) is taken.

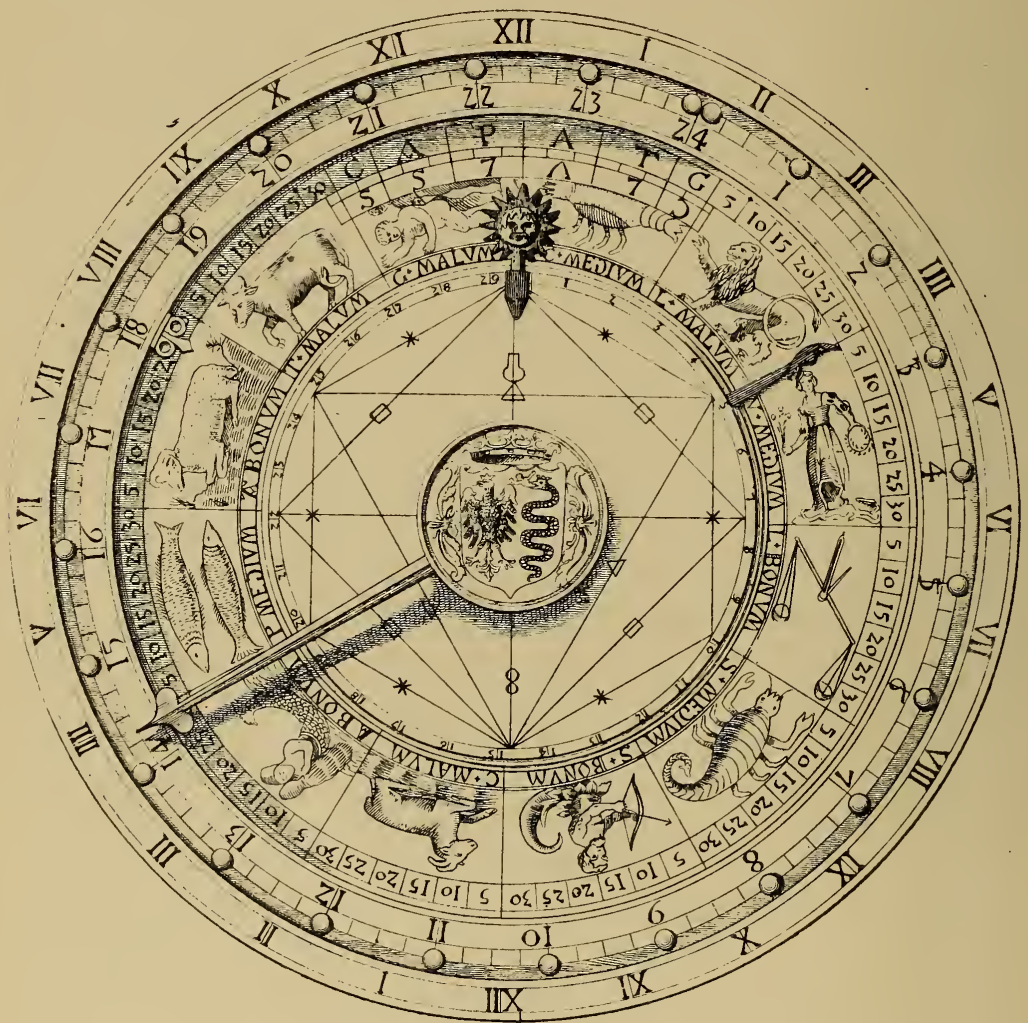

FIG. 81.-Dial of Table Clock by Jacob Zech.

From the decoration of the case and dial, it is inferred that the clock was made for Sigismund I., King of Poland, and that he presented it to Bona Sforza, to whom he was married in 1518. There are three shields equidistant round the case, which is altogether nicely decorated. On one shield is an eagle displayed and crowned, representing Poland; the second contains a serpent entwined and wavy pale crowned, a child issuant from its mouth and surmounted by a 
ducal crown - the coat of the house of Visconti ; the third shield bears the arms of Lithuania, a knight armed $c a p-\grave{a}-p i e$, and mounted on a horse proper, holding in his dexter hand a drawn sword, and having pendent from his neck a shield charged with the Hungarian cross. The frame is fastened by buttons on dogs. The verge pivots act on iron dovetails. The regulator is a cross-bar balance of the kind used in De Vick's clock, except that instead of loose weights of iron there

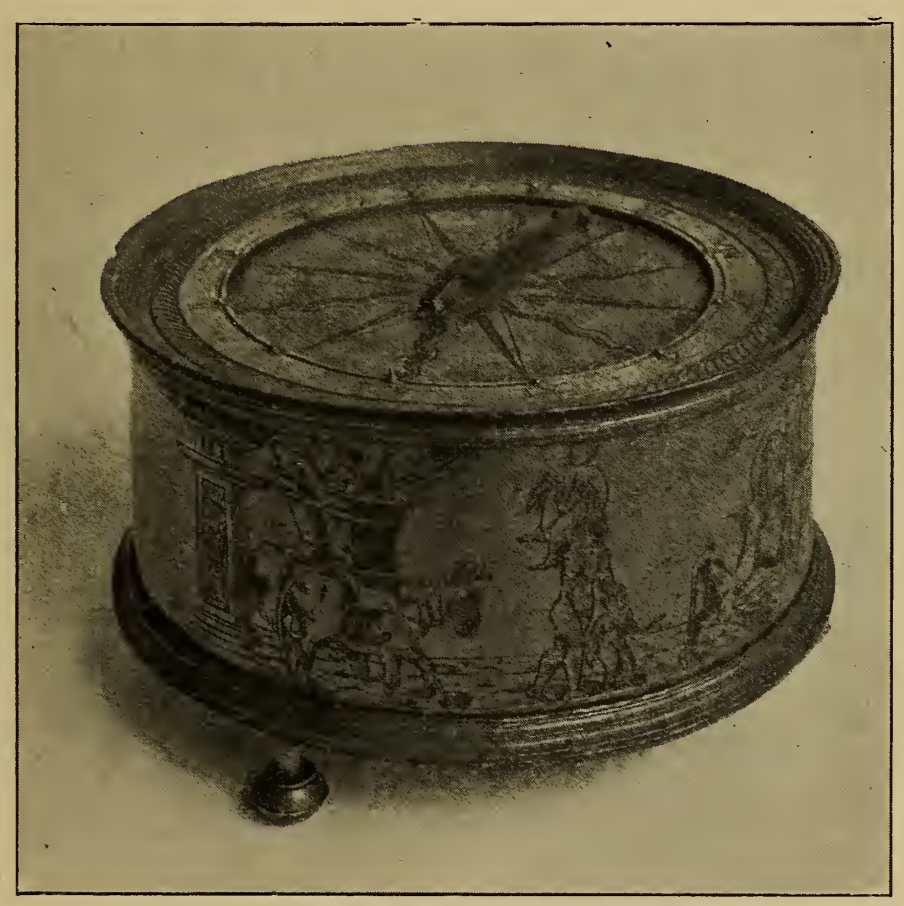

Frg. 82.-Primitive Table Timepiece.

are leaden weights screwed one on each end of the cross-bar, and the adjustment is made by screwing to or from the centre of motion. Originally these were doubtless fixed weights riveted on and without any provision for adjustment. There are two yielding brass arms to act as a banking and check excessive vibration of the cross-bar. There are eight turns to the fusee, which is of soft metal, and in a circle on the face of the barrel is engraved in Bohemian an inscription which Smyth translates thus: "When we counted 1525 years, then made 


\section{Old Clocks and Watches and their Makers}

me Jacob Zech" (or rather Jacob the Bohemian) " at Prague ; it is true."

There was originally some additional wheelwork to show the motion of the sun and moon on an engraved ecliptic, and also a contrivance to strike one at every hour. The wheels are of iron and show punch marks of division, proving that they had been cut with a file by hand. A catgut had been used to connect the barrel with the fusee, but the metallic chain was subsequently applied, which

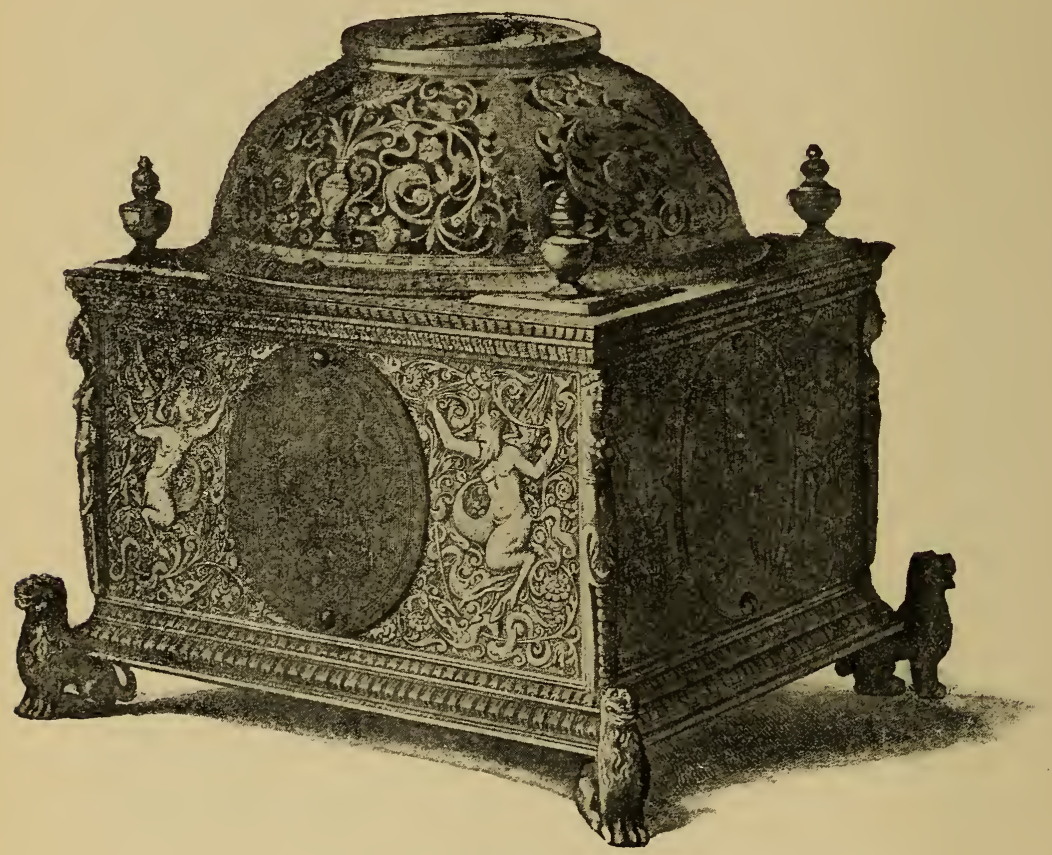

Fig. 83.--Square Table Clock.

destroyed several of the threads. Before this was done it went for forty-eight hours with one winding, and gave about 3,600 beats in the hour.

Fig. 82 shows a primitive table timepiece which formerly belonged to Baron Pichon and was after in the Schloss collection. The drumshaped case of brass gilt is engraved in the Renaissance style, and measures $5 \frac{1}{2}$ in. across. On the bottom is stamped in a scroll " $\mathrm{N}$. Plantart." A very similar piece is in the South Kensington Museum.

In the British Museum is an excellent specimen of a German 


\section{Portable Timekeepers}

early table clock of a square oblong shape. The works are of iron. It has no fusee. It fits into an engraved metal box, having a hinged cover. The date of production is stated to be 1530 .

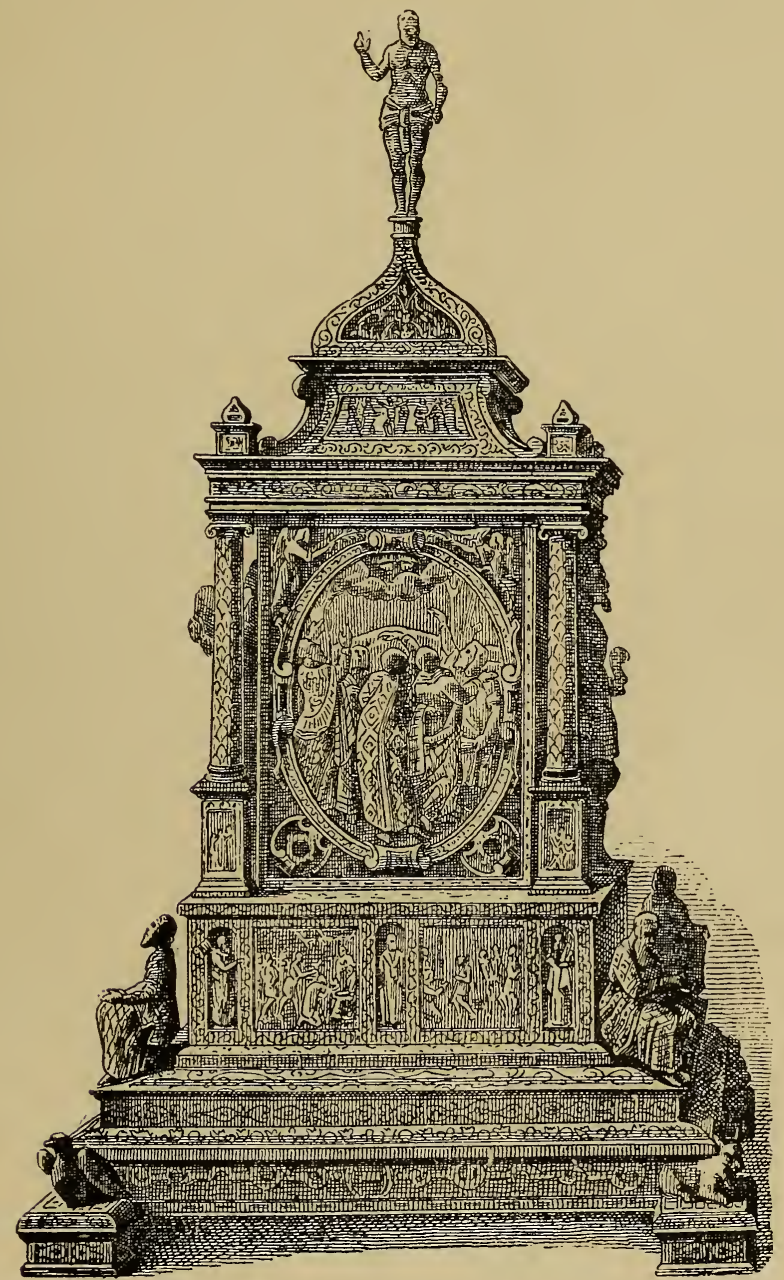

FIG. 84.-A very choice example of Iron, damascened with Precious Metals.

Among the collection of Prince Soltykoff was the square table clock shown in Fig. 83. The sides are of bronze gilt, very finely engraved with allegorical subjects. Representations of St. Paul, Matthew, Mark, and Luke are engraved on silver medallions which 
86 Old Clocks and Watches and their Makers

occupy the centres. Inside the perforated dome. is a bell, and surmounting it a horizontal dial enriched with coloured enamels.

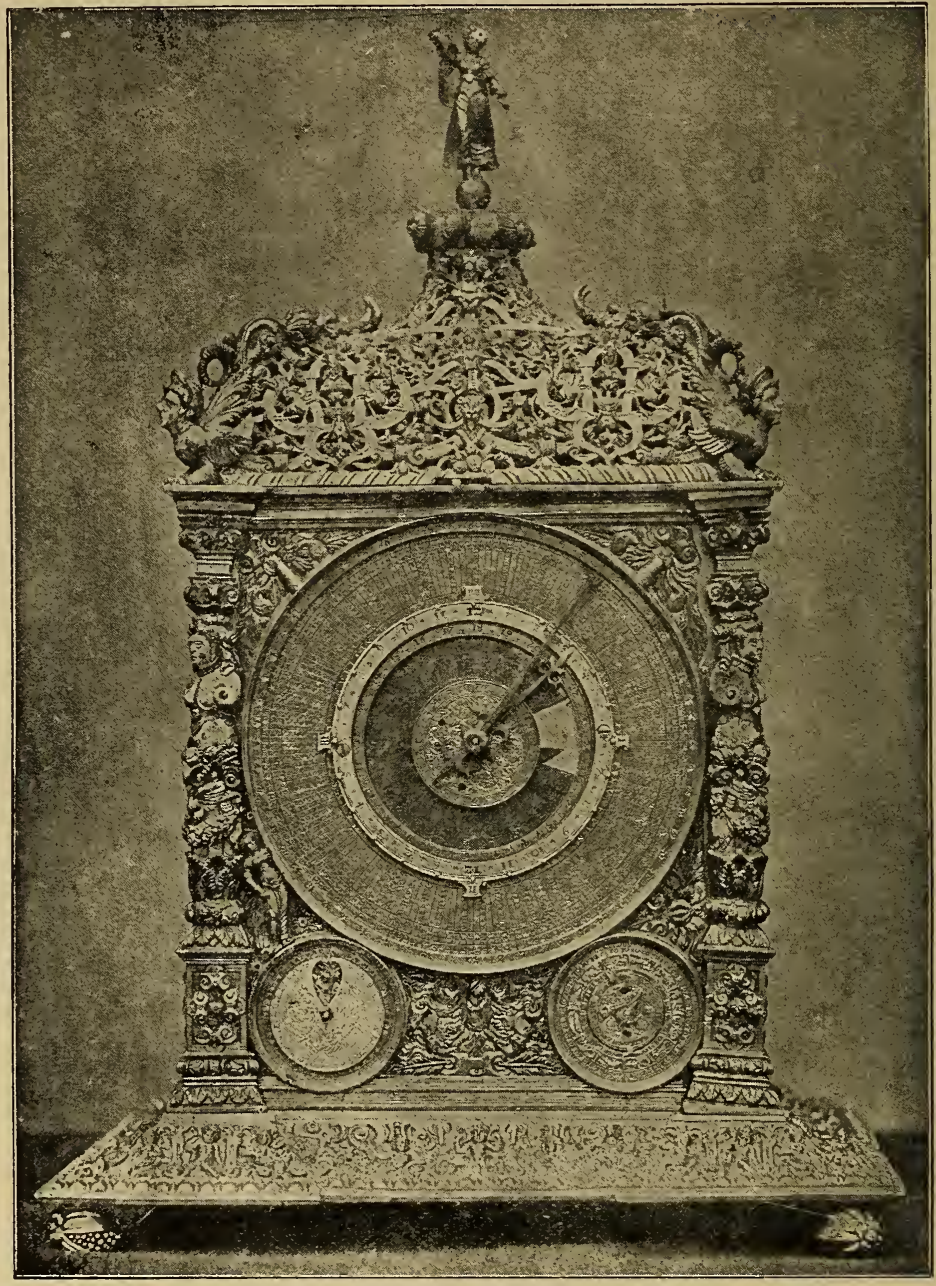

Fig. 85.- "Venetian" Astronomical Clock.

It was the work of Louis David, and dates from the middle of the sixteenth century.

Nuremberg and Augsburg pursued the manufacture of portable timekeepers with considerable spirit. The plain square brass towers, round and octagonal boxes, gave place to cases of a much more 
ornate design when expense was no object. A very choice example from Dubois' historical work is shown in Fig. 84; it is of iron, damascened with precious metals, a style of work for which Augsburg was particularly famous.

Several good representative specimens belonging to the King

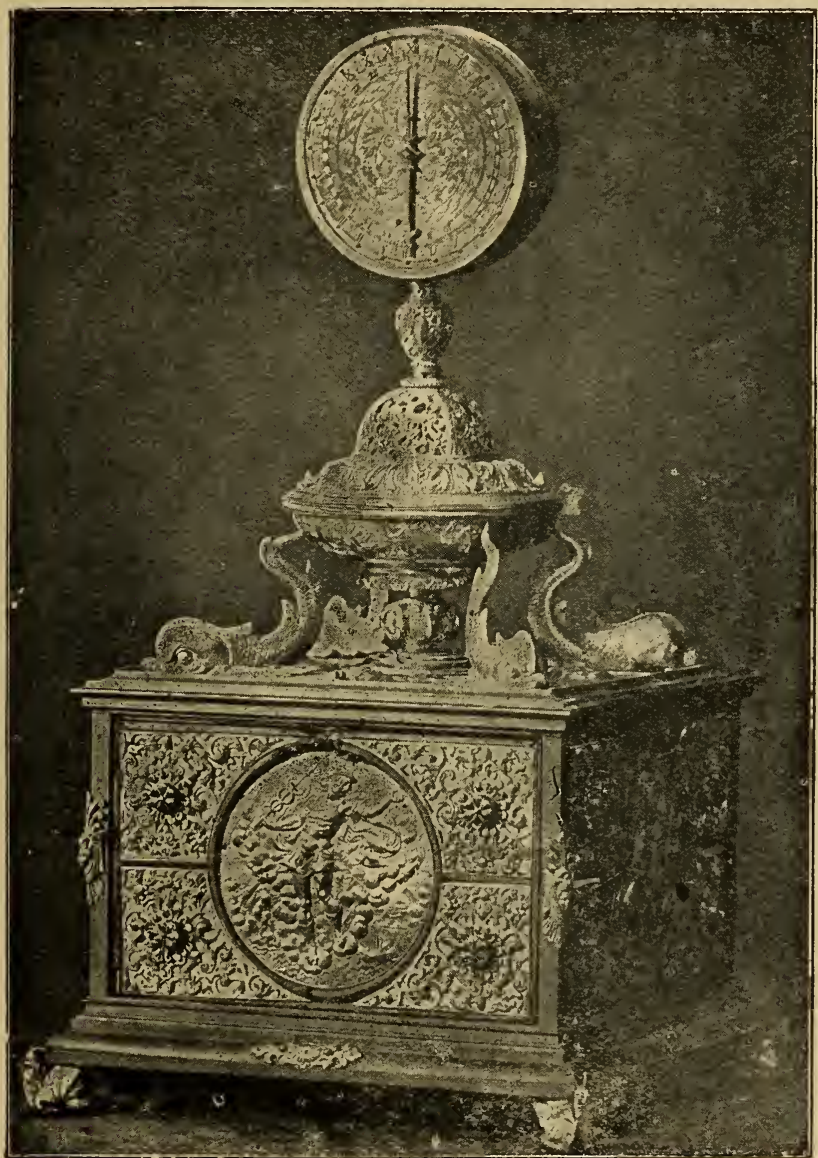

Fig. 86 - Clock in the Historical Museum at Dresden.

of Saxony are to be seen in Dresden, part of them in the treasury of the palace and part in the Historical Museum. In the green vaulted chambers or treasury of the palace is the so-called Venetian astronomical clock, which is, though, really of German workmanship. A front view of it is given in Fig. 85, but a photograph naturally 
fails adequately to convey the splendour of the case, which is of gold and silver covered with gorgeous work in enamel, or the extraordinary complexity of the mechanism. The movement bears no maker's name, but of two somewhat similar clocks of the same collection

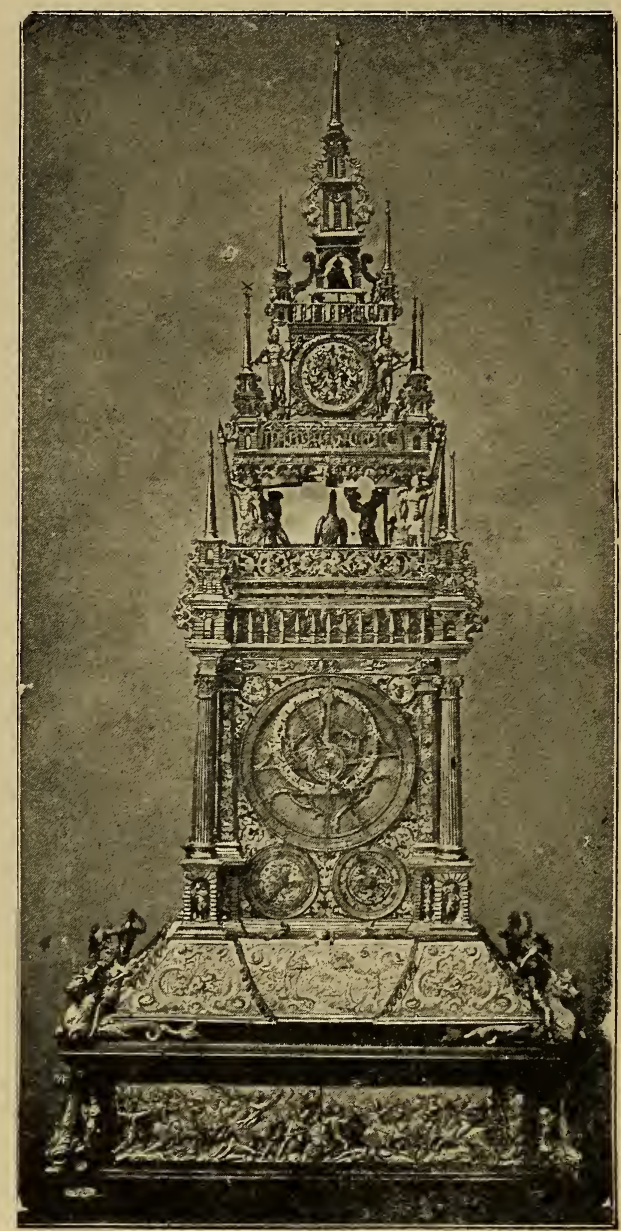

FIG. 87.-Clock with Eleven Dials.

one is signed by Andreas Schelhorn, of Schneeburg, in Saxony, 1570, and the other by Christoph Ullmey, of Augsburg.

Of other specimens in the same repository may be mentioned a table clock of very rich appearance, which belonged to the queen of Augustus the Strong and was made, presumably about 1700 , by 
Jakob Streller, of Nuremberg. Another very wonderful clock, the so-called Hunting clock, the movement of which was made about 1700 by J. G. Graupner, is set in a magnificent case with figures of liuntsmen at the corners and a group representing the legend of

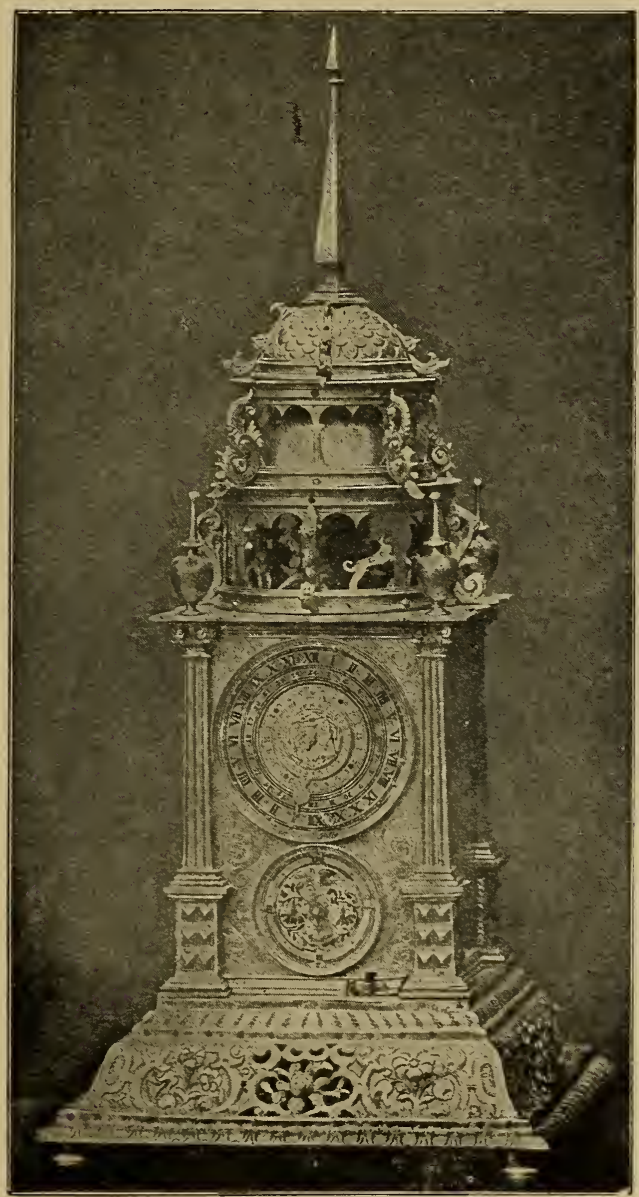

FIG. 88.-Clock Curious with Moving Figures.

St. Hubert on the top, all enamelled in brilliant colours and blazing with diamonds and emeralds, the work of Johann Christoph Köhler. Then there is the famous "Tower of Babel Kugeluhr" (Ball clock), made in 1602 by Hans Schlotheim, of Augsburg. It is in the form of a tower of gilded metal about $4 \mathrm{ft}$. high, with a gallery in the 
90 Old Clocks and Watches and their Makers

manner of an inclined plane running round it spiralwise from top to bottom; every minute a little crystal ball comes out of a door

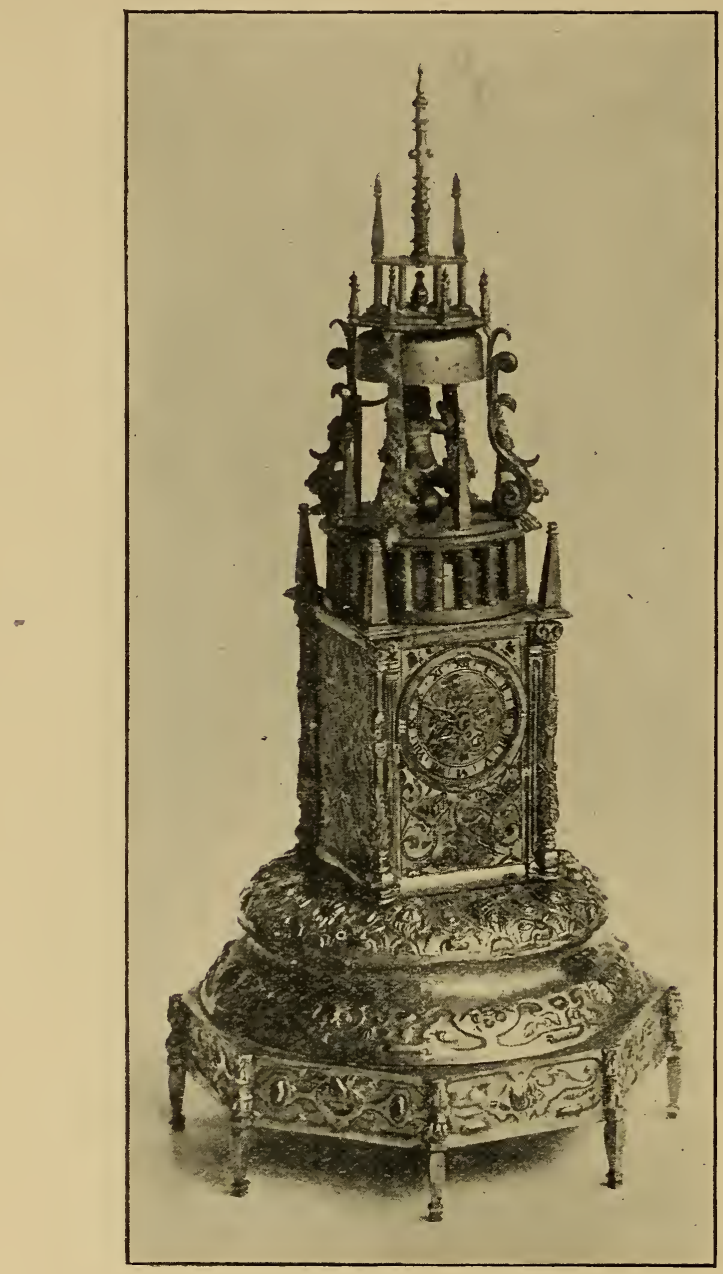

FIG. 89.-Early instance of a Sixteenth-Century Table Clock having provision for striking the quarter-hours.

at the top of the tower and, running all the way down the spiral galley, enters a door at the bottom, when a bell rings.

Of the horological treasures in the Historical Museum at Dresden I can give three illustrations, and will begin with the remarkable clock of which a view appears in Fig. 86. It was bought in 1587 
for 500 gulden of Sebald Schwerzer, who was alchemist to the Elector Augustus of Saxony (1526-1586) and afterwards ennobled by the Emperor Rudolph II., and he is supposed by some to have

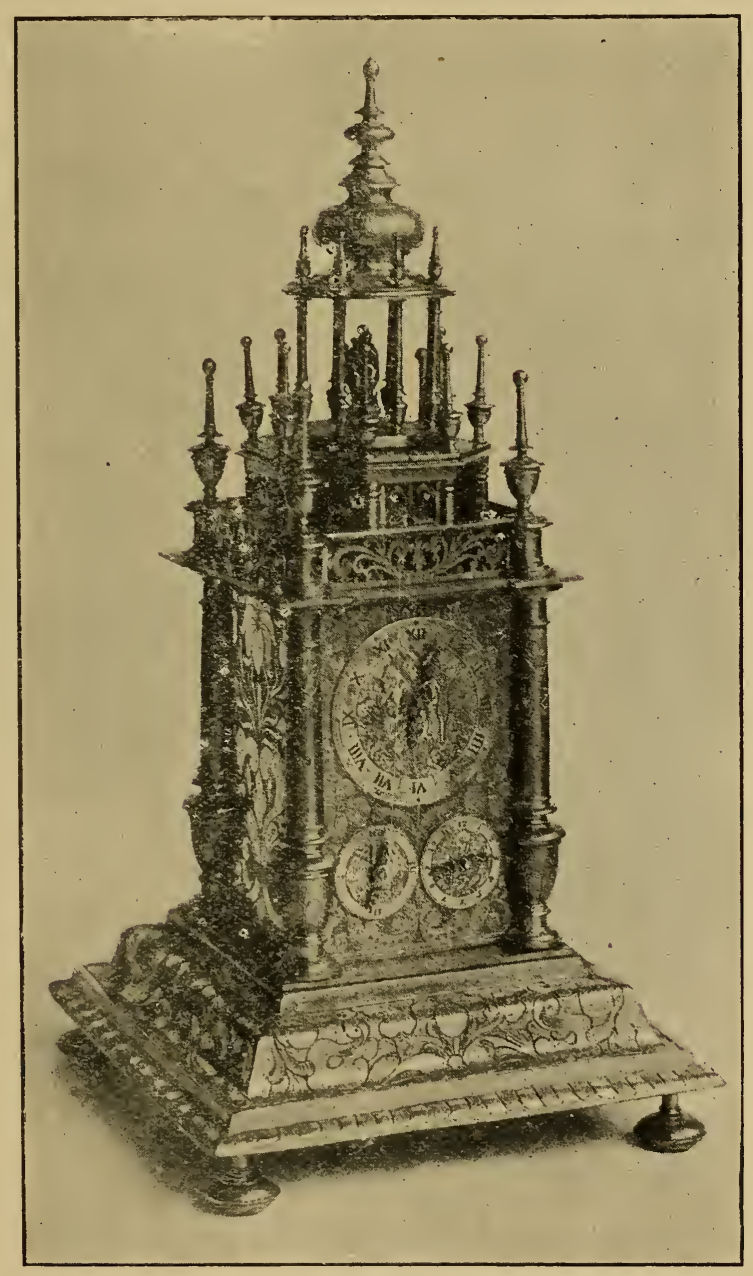

FIG. 90.-The Movement is controlled by a Pendulum which swings outside of the case at the back.

been the maker of the clock, though the claim has been disputed. The silver work of the case bears the mark of Elias Lenker, of Nuremberg, who died in 1591.

Fig. 87 is a very elaborate clock with eleven dials and automata. 


\section{Old Clocks and Watches and their Makers}

The case is decorated with many beautiful plaques of bassetaille enamel upon silver. It is considered to be the masterpiece of its maker, Paul Schuster, of Nuremberg ; it was bought in 1591, and so was presumably completed in that year.

In Fig. 88 is another curious clock of the same type, with moving

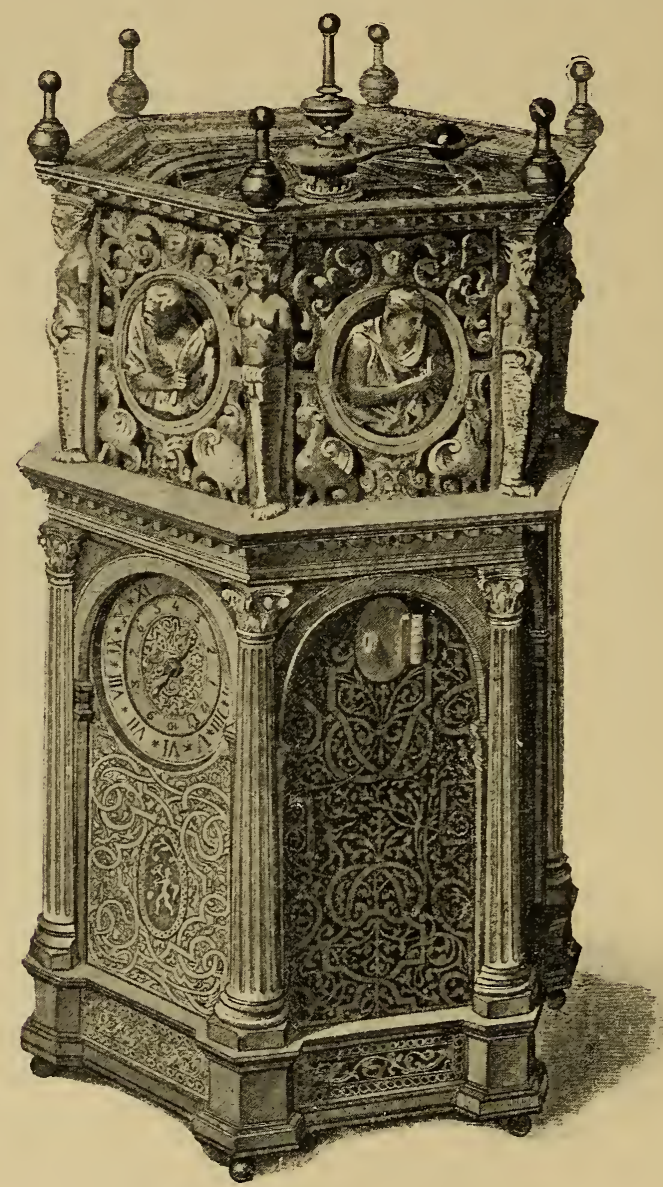

FIG. 91.-Sixteenth-Century Hexagonal Clock.

figures representing an Indian king hunting with elephants. The maker's name is unknown, but the clock was already in the collection of the Elector of Saxony in 1587.

There is as well a curious clock which has upon it the figure of a man leading a dancing bear; when the hours strike, the bear beats 
a drum, and the man blows a horn. This piece also bears no maker's name, but it has Augsburg marks, and probably dates from the end of the sixteenth century.

The Comte de Lambilly has a clock somewhat resembling Fig. 88, in which, at the striking of the hour, figures of the twelve Apostles move round in the upper gallery. The main front dial shows the hours and the lower one quarters and half-quarters.

The examples on pp. 90 and 91 are from the Schloss collection. Fig. 89, a sixteenth-century production, is notable as being an early instance of a table clock having provision for striking the quarter-hours. There are three bells : a large one, concealed by the base; a smaller one, enclosed by the gallery above the tower ; and a third, still smaller, which serves as a canopy over the figure seated above the gallery on a ball. The quarter-hours are struck on the smallest bell, and the last hour then repeated on the bell behind the gallery. On completion of the hour it is sounded on the largest bell. There are two dials, one on the front and one on the back. On the main dial in front are shown the hours, and outside the hour numerals are marked, the quarter-hours, which are indicated by a hand, travelling round in one hour, but moving independently of the hour hand. The movement bears the signature V.M. in a shield. It has a cross-bar balance with shifting weights, and there are no fusees. The chasing of the case is exceedingly good, and the sides of the square part bear evidence of having been beautifully enamelled with birds and flowers.

Fig. 90 is of later date. There are three dials on the front and one on the opposite face. The movement is controlled by a pendulum which swings outside of the case at the back.

In the South Kensington Museum is an Augsburg astronomical striking table clock, in an engraved brass and damascened iron case. On the bottom is a sun dial and the inscription :-

Jacob . Marqvart . von . Avgspvrg . bin . ih . genant . mein . Nam . ist. in . VVelslandt . gar . vvol . bekant . der. hat . das . VVerck . gemacht. firvarv .

im . 1567 . Jar.

ain . svnenvr . ist das genant .

avf. Wels . vnd. Deisch . Landt. erkant.

(I am called Jacob Marquart, of Augsburg;

My name is right well known in Foreign Lands,

Who has indeed done the work

In the year 1567 ;

This is called a sundial,

Available in Foreign Lands and Germany.) 


\section{Old Clocks and Watches and their Makers}

The hexagonal clock in the form of a temple from the collection of Prince Soltykoff and shown in Fig. 91 is also a sixteenth-century production. The movement is arranged in stories, the watch part being at the bottom and the striking work above. The six doors or panels between the fluted columns are of steel damascened with arabesques of elegant design. In the arched centre of one of the panels is the dial with a band of blue steel for indicating the hours of the day; various planetary and astronomical motions were shown on the horizontal dial at the top of the structure. The upper part of the case in the style of Henri II. is very handsome ; the entablature

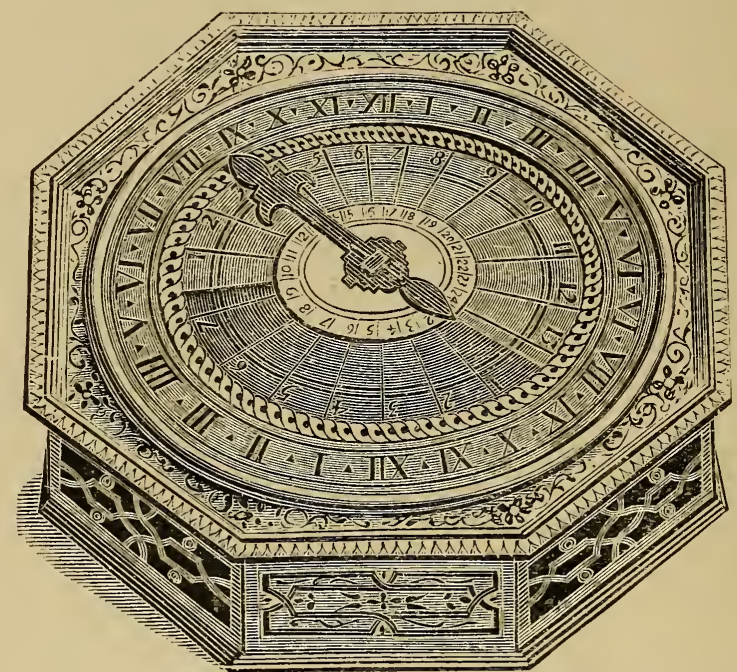

Fig. 92.-Curious Table Clock, Early Sixteenth-Century.

is supported at the angles by six caryatides, and in the centre of each panel is a medallion with the head of a Roman emperor or warrior sculptured in high relief and surrounded by a gilt border. A clock similar to the engraving, but surmounted by a statuette, is in the British Museum.

Curious Octagonal Table Clock.-Some time ago, by favour of Mr. Charles Shapland, I had through my hands a curious sixteenthcentury striking clock of octagonal form, of which a view is subjoined (Fig. 92). This clock, which is now in the British Museum, is probably of Nuremberg or Augsburg manufacture, and has a peculiar method of indicating the rising and setting of the sun daily throughout the year, by means of two thin metal dials within the hour circle. One of 
these dials is of silver and the other of steel for contrast ; each of them forms a segment nineteen twenty-fourths of a circle, divided by radial lines into nineteen parts, which are numbered at the circumference from one onward in Arabic figures, so that each division is one twenty-fourth of the whole circle. A brass disc, divided into twentyfour, is fixed to the steel dial by rivets at Nos. 1 and 3 ; No. 24 , or zero point of the circle, coinciding with what may be called the initial edge of the steel dial. The steel and silver dials are interlaced-that is to say, the concealed portion of the steel dial is underneath the silver one, while the initial edge is above it. At the shortest day in the year the least portion of the silver dial would be visible, and the figure on the silver dial next to the initial edge of the steel dial would represent the number of hours the sun was above the horizon, while the figure on the central brass circle, which happened to be coincident with the initial edge of the silver dial, would represent the number of hours he was below the horizon, and the subdivisions of the hour could be well estimated to within a tenth. The dials are continually rotating in opposite directions, so that as the days lengthened more of the silver and less of the steel dial would be seen. At the close of the longest day the motion of the dials would be reversed, and the visible surface of the silver dial would be diminished each day in the same ratio that it was formerly increased, till the shortest day recurred. It is probable that these dials were arranged to show the beginning of the Hebrew day at sunset, as well as its duration and close at the succeeding sunset.

On removing the dial plate, the way in which the dials are actuated is apparent. Fitting loosely on the centre wheel which carries the hour hand is a pinion of twenty-four leaves. The pipe of this has a cruciform top fitting into the centre of the silver dial. On the pipe of this pinion is another, larger in diameter, but also of twenty-four leaves, and with a similar top to carry the steel dial. A double rack or segment of a wheel, having internal and external teeth, is pivoted close to the edge of the movement, and engages with both of the dial plate pinions, the internal teeth being farthest from the centre of motion, and of such a distance that they reach beyond the centre arbor and engage with the teeth of the larger pinion on the other side of it ; the external teeth are so placed that they engage with the teeth of the smaller pinion, but on the side of the centre arbor nearest to the centre of motion of the rack. There is on the plate of the movement, midway between its centre and its edge and driven from the fusee, a wheel which turns once a year. This carries a crank, from which is a connecting rod catching hold of the double rack; 


\section{Old Clocks and Watches and their Makers}

so that, as the crank revolves, it gives a to-and-fro motion to the rack. To meet the varying length of the years from leap year to leap year,

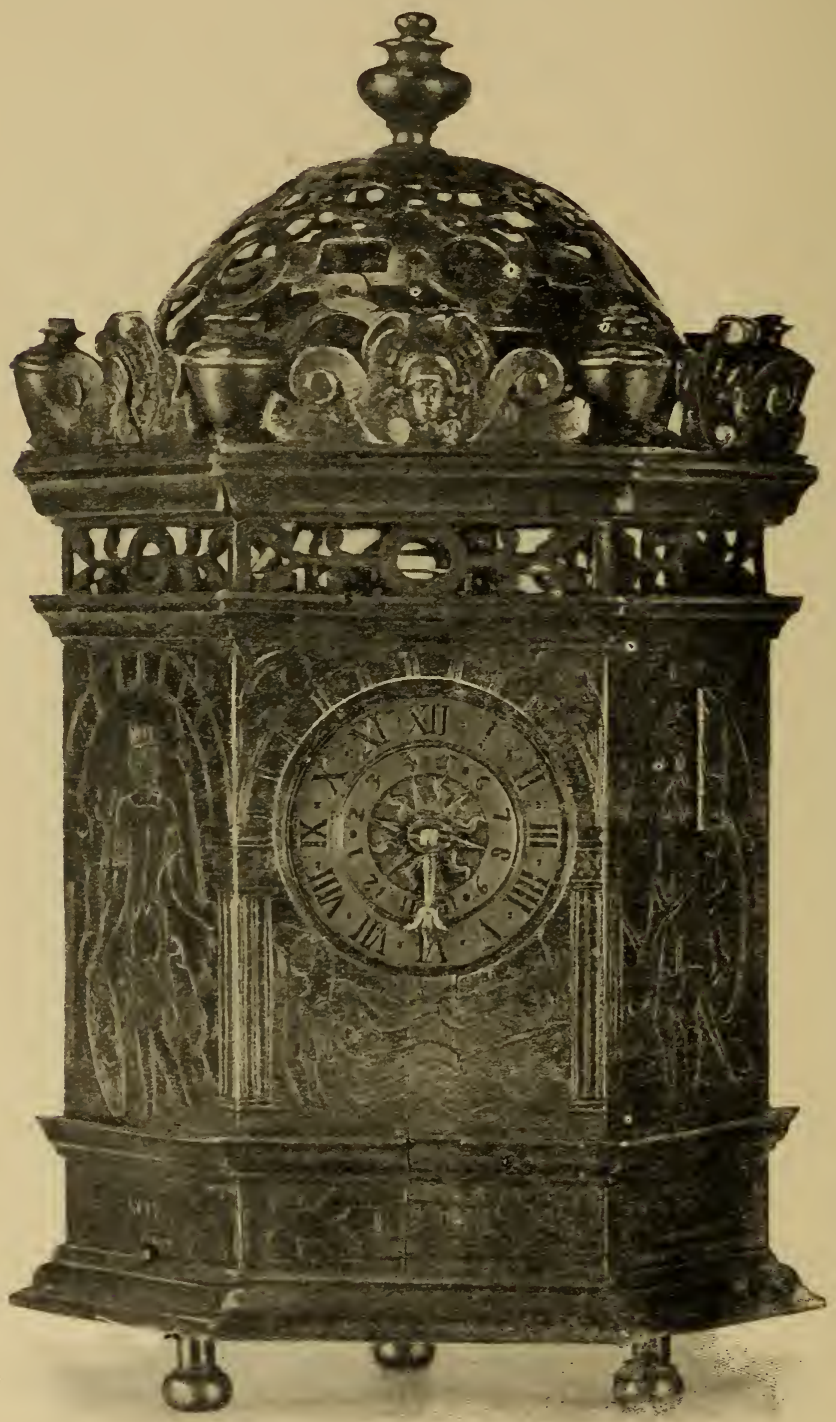

FIG. 93.-Quaint Hexagonal Striking and Alarm Table Clock.

there are four pins by which the position of the crank could be altered, but, so far as one could see, there is no provision for automatic 
regulation, so that, if the reading of the scale is to be exact, the dial would have to be removed and the position of the crank altered once a year.

Recessed into the under-side of the clock case is an annual dial engraved with the signs of the zodiac, the titles of the months, and

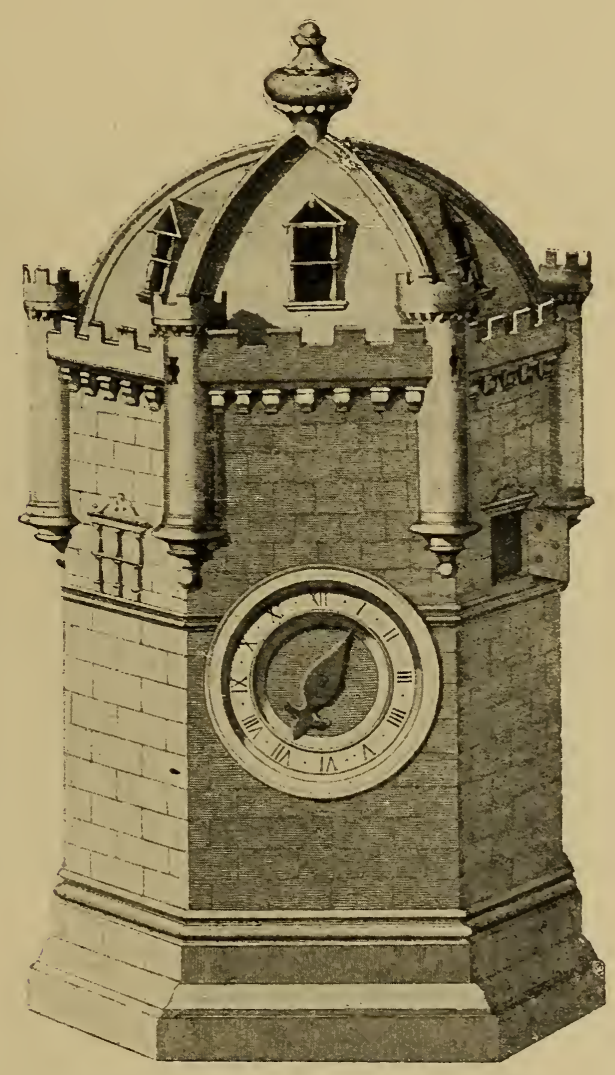

FIG. 94.-Striking Clock about 1560.

the days. The index for this is fixed to the arbor of the annual wheel already mentioned, and the annual dial is therefore less than half the diameter of the movement.

The case is of brass, engraved and gilt. The hour band is of silver, divided into two periods of twelve hours each, and marked with Roman numerals. Within the hour ring, and separating it 
from the sun rising and setting discs, is a brass gilt ring engraved with a cable pattern.

All the dial work, the striking train and the going train wheels,

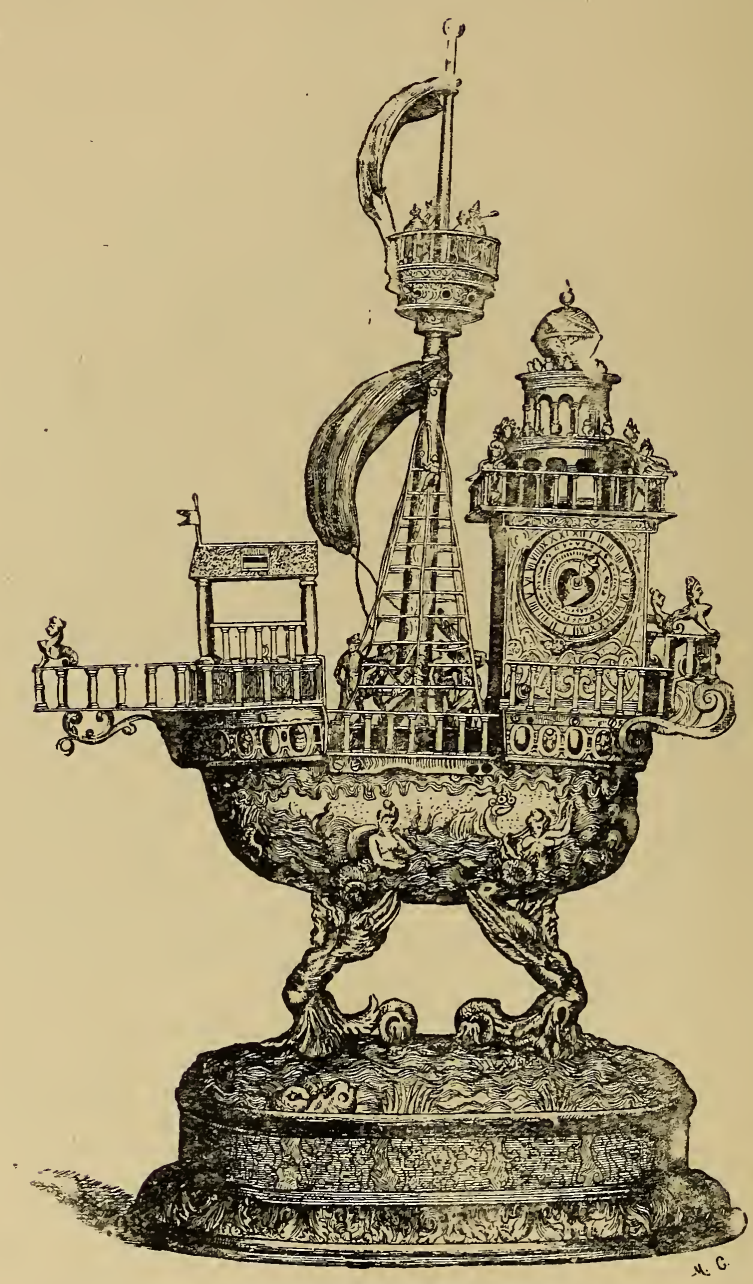

FIG. 95.- “Nef," or Ship Clock, Sixteenth-Century.

(Havard, "Dictionnaire de 1'Ameublement.")

up to the fusee, are of iron or steel; the connection between the fusee and barrel is by a catgut, and the balance is very light, of the old cross-bar pattern, but with weights riveted on with no provision for 
after-adjustment. There is, of course, no balance-spring. The hours are struck on a cap-shaped or cylindrical bell.

In the construction of this timekeeper there is not a single screw used. All fastenings are either pins or wedge-shaped keys or rivets.

The quaint hexagonal striking and alarm table clock shown in Fig. 93 is a mid-sixteenth-century production from the Schloss collection. On the six faces of the case are engraved allegorical figures representing the sun, the moon, Mars, Mercury, Jupiter, and Venus, corresponding to the days of the week from Sunday to Friday,

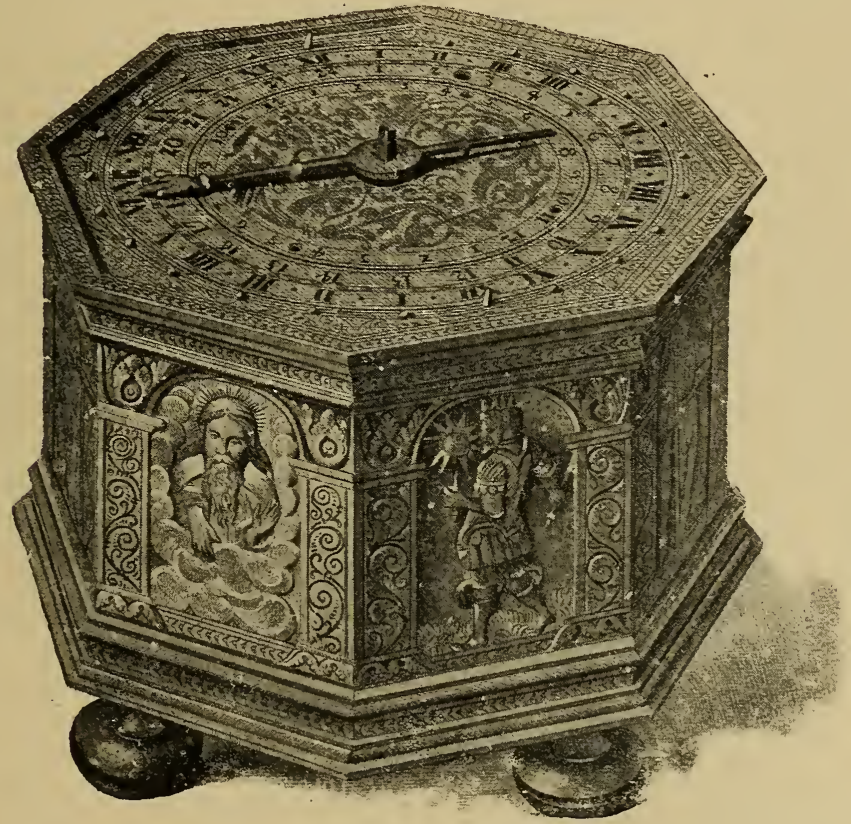

FIG. 96.-Octagonal Clock.

and, on the bottom of the case, Saturn for Saturday. A little door seen on the face immediately to the right of the dial permits the inspection of the fusee in order to estimate the period for winding. The movement is arranged in stories, the striking mechanism below and the going part above, the hemispherical bell being supported from the upper plate and covered by a perforated dome. On the upper surface of the plinth is the maker's punch mark, a square shield with "M.H.B." arranged as a monogram.

The example engraved in Fig. 94 is from the Soltykoff collection. The case appears to be a reproduction in miniature of a mediæval 
hexagonal fortress. It is a striking clock, probably German, dating from about 1560. In the Webb collection at the South Kensington Museum is a somewhat similar clock; the bottom of the case is stamped "AIX * A * P" (perhaps for Aix in Provence).

"Nef," or Ship clocks, were a peculiar fancy of the sixteenth century. There is one in the British Museum, by Hans Schlott, dating from about 1580 , which is supposed to have belonged to

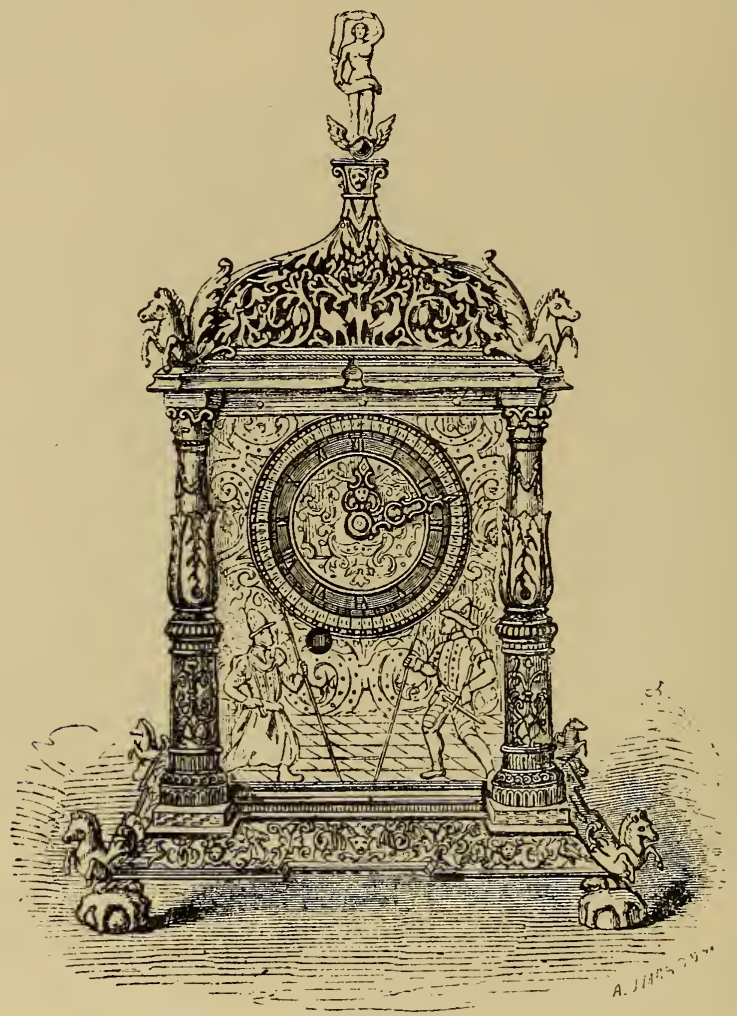

FIG. 97.-Early Clock with Minute Hand, dated 1587.

Rudolf II., and another in the Vienna Treasury. The clock mechanism included provision for showing various astronomical movements, and was quite subsidiary to the ship and its appurtenances, as will be gathered from the excellent example given in Fig. 95.

In Fig. 96 is shown a German octagonal clock from the Soltykoff collection.

Early Clock with Minute Hand.-At the South Kensington 
Museum is a clock, in an elegant case of metal gilt, in the form of a temple, as shown in Fig. 97 . Its height is $13 \frac{1}{2} \mathrm{in}$. and its width $8 \mathrm{in}$. It is most elaborately chased and engraved with figures and arabesques

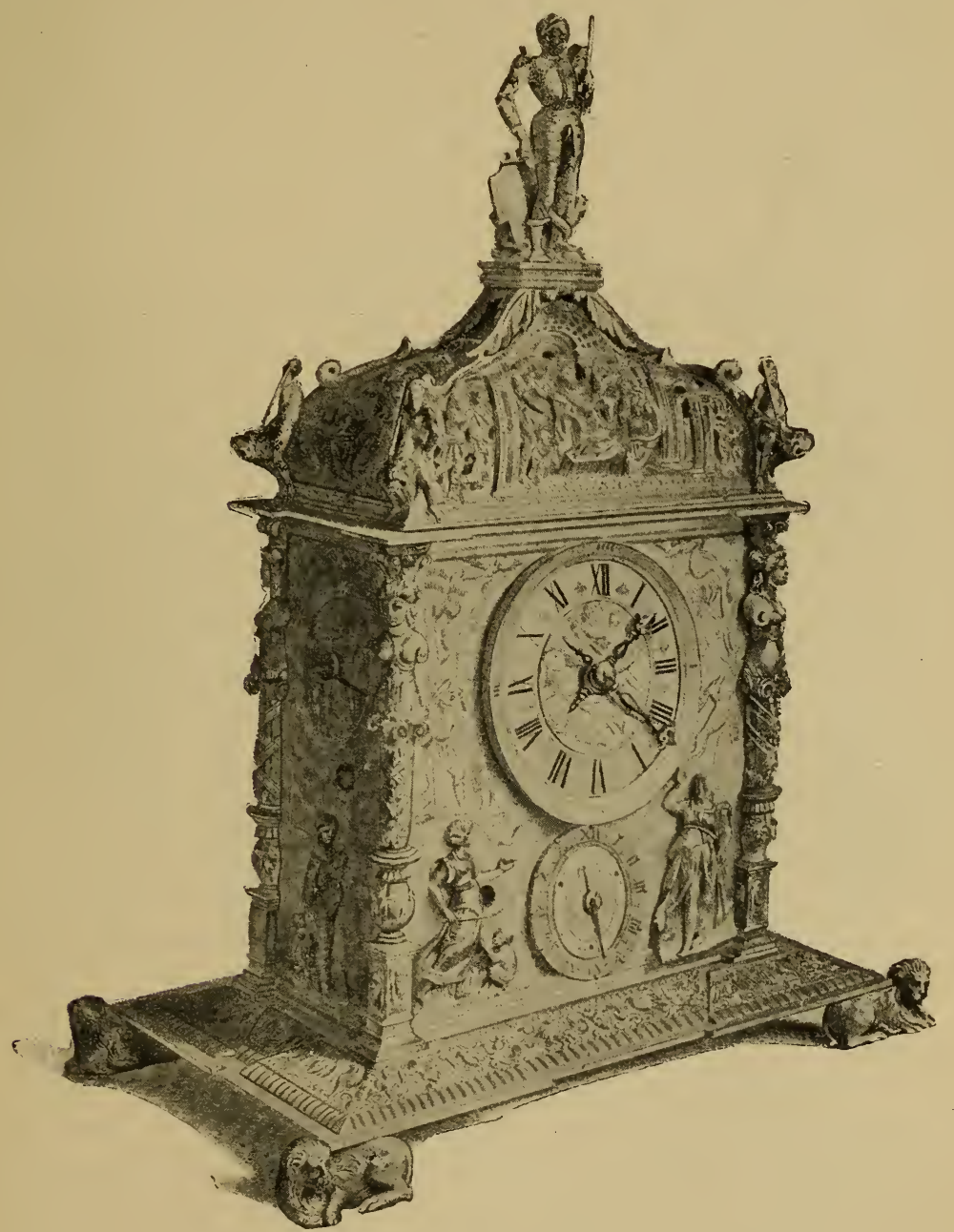

FIG. 98.--Portable Clock with Five Dials.

The pierced dome covers two bells, and is surmounted by a figure standing on a globe. The base is chased with masks and cartouche ornaments, with winged horses at the angles, and a dial on each of the four sides showing, besides the hours and minutes, motions of various 


\section{I02 Old Clocks and Watches and their Makers}

heavenly bodies. This choice and interesting timekeeper, which formed part of the Bernal collection, was produced at Munich, and is dated 1587. Every minute is figured from 1 to 60 , as was the custom on early timekeepers with minute hands. Though the presence of the concentric minute hand on sixteenth-century work is exceptional, there is nothing to lead one to suppose that it is in this case an addition to the original construction ; and providing the minute hand would certainly present no difficulty to the mind capable of devising such intricate mechanism as is con-

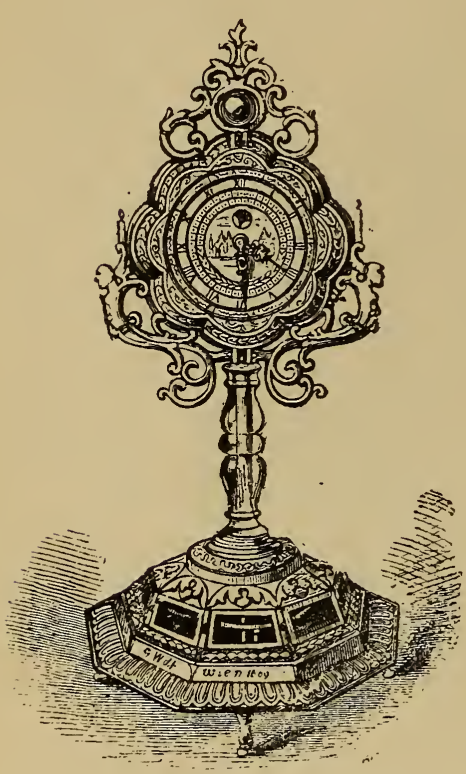

FIG. 99.-Medallion Clock, in Rock-crystal Case. tained in the astronomical motions of this clock.

I recently saw another clock of very similar character, which was inscribed, " ASMUS BIRLN B RYNLR IN AVGVSTA VINDLLICORUM 1577," and the letters "A.B." formed into a monogram.

A somewhat similar portable clock (Fig. 98) from the Soltykoff collection is about $15 \mathrm{in}$. high and $10 \mathrm{in}$. across the base, which is supported by four heraldic lions. There are five dials, two on the front face and one on each of the others; they mark the hours of the day, the day of the month, the phases of the moon, the signs of the zodiac, and the course of certain planets.

This clock bears no maker's name, but a very similar one, also in the Soltykoff collection, was inscribed, "Andreas Muller, Tristen." It is probably mid-sixteenth-century work.

The next example, from the South Kensington Museum, is an elegant form of medallion clock in a rock-crystal case, on a stem as shown in Fig. 99. The plinth is of metal gilt, with crystal plaques, and contains the striking train. The remainder of the movement is in the upper case. The longer of the two hands, which at the first glance seems to be a minute hand, really points to the day of the month marked on a ring outside the hour ring. The age of the moon is shown by a revolving gilt plate behind the dial, which is cut away to make the 
moon plate visible. The total height is $7 \frac{3}{4}$ in. It is signed " $\mathrm{J}$. Wolf, Wien," and dated 1609 , but the name " J. Wolf " appears on examination to be a recent addition. It was formerly in the Bernal collection.

The table clock represented in Fig. 100 resembles one at South Kensington Museum, which, as already mentioned, was probably made by Peter Hele, except that in the present example the body of the case is square. It is of brass gilt, with bold mouldings as shown, and very nicely engraved. Rising from this is a hemispherical

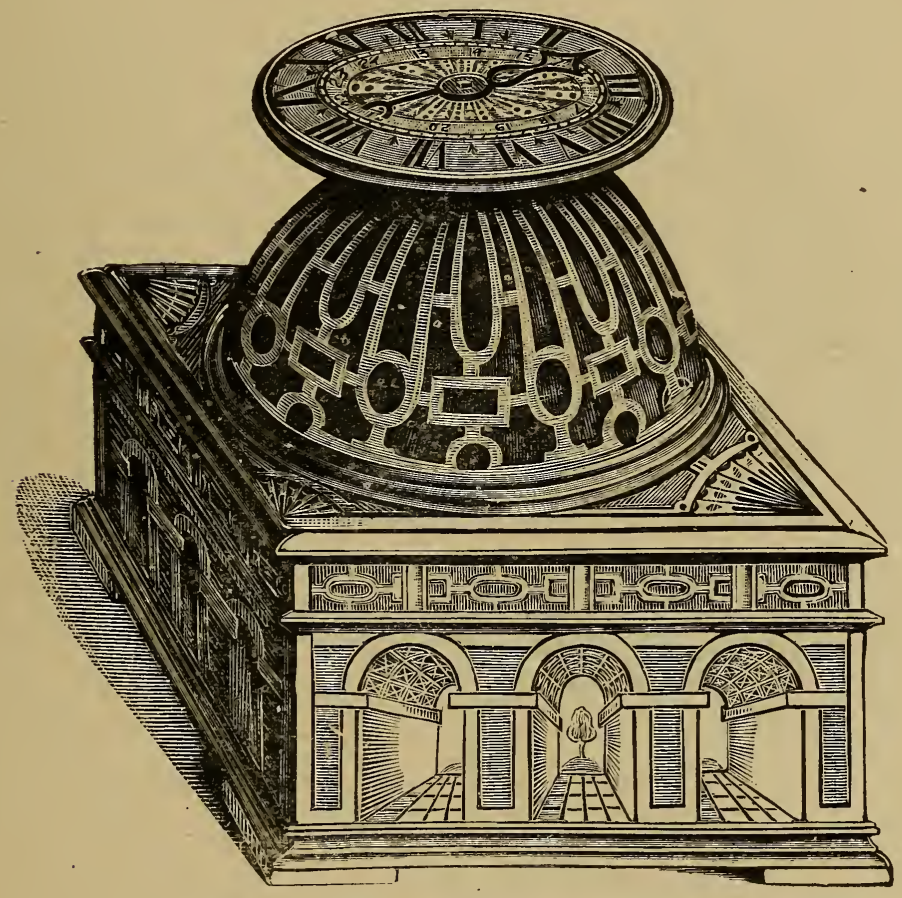

FIG. 100.-Table Clock, probably made by Peter Hele.

dome pierced to emit the sound of the bell which it covers, and supporting above it a horizontal dial. The arrangement of placing the bell between the movement and the dial allows a handsome and appropriate design with which no fault can be found, except, perhaps, that in order to keep the dial from overshadowing the dome it is necessarily rather small. On the exterior of the bottom of the case is engraved the word VALLIN. The Roman numerals I. to XII, are engraved on a silver band, and within are smaller Arabic figures, 13 to 24 . 


\section{I04 Old Clocks and Watches and their Makers}

The chief plate of the movement is square and pinned to the upper part of the square box. Running vertically inside the box are two feathers; these pass through notches in the lower plate of the movement; two turn-buckles on the lower plate butt against the ends of the feathers, and so secure the box after it is placed over the movement. The hand is driven from a pinion on the great wheel by means of an arbor, which passes through the post to which the bell is secured. It is

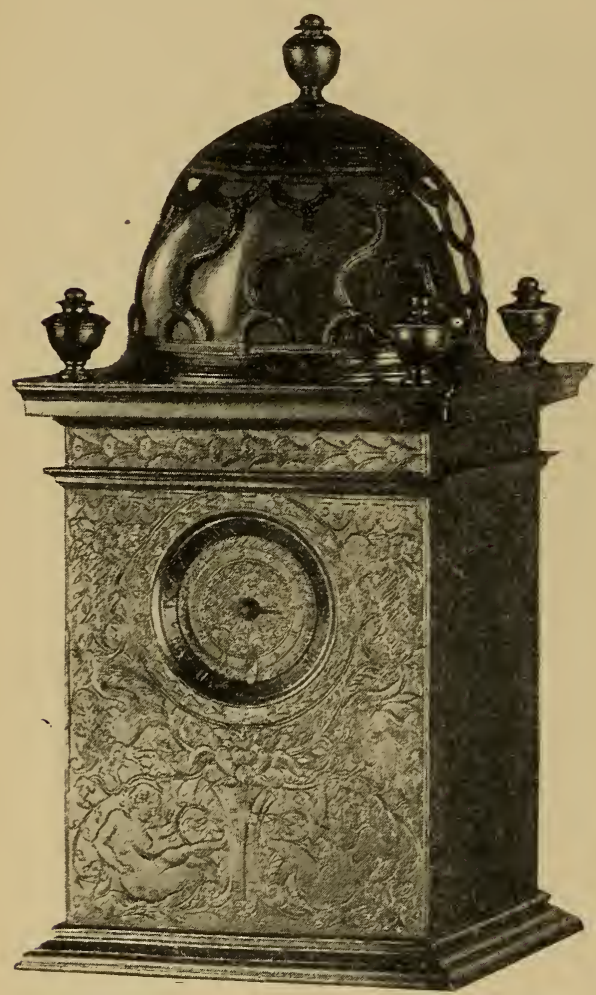

FIG. 101.-Table Clock about 1580. probably a late sixteenthcentury French production. An almost identical specimen is in the library at Welbeck Abbey.

In Fig. 101 is shown a table clock, apparently English, dating from about 1580 , in a square brass case, gilded and beautifully engraved. It belongs to Mr. J. Hall, and very closely resembles one by Bartholomew Newsam, which is at the British Museum and illustrated in Chapter V.

A good example cf early seventeenth century table clocks is shown in Fig. 102. It is in a brass case, with silver hour ring, divided into twelve, and a fleurde-lis midway between each hour. The charactęristic features which note the departure from the earliest specimens are the glass panels in the sides of the case and the bronze feet, which give a better effect than is obtaincd with the primitive flat hexagonal and octagonal clocks, besides allowing space for the bell to project below the bottom surface of the case.

The cocks and hammer are very nicely engraved and pierced, and on the plate is the name Johan Scheirer. A balance-spring has been 
applied subsequently to the manufacture of the piece, and as the original balance-cock is retained, the spring is much cramped. The balance appears to be the original one, and is weighted with pieces of metal to keep the vibration sufficiently slow after the addition of the spring. A notable peculiarity is that the fly pinion has but four leaves.

The handsome striking and alarm clock shown in Fig. 103 is from the Soltykoff collection. It bears no indication of its origin, but the monogram "G.O." engraved on it leads to the conjecture that it belonged to Gaston of Orleans, son of Henry IV.

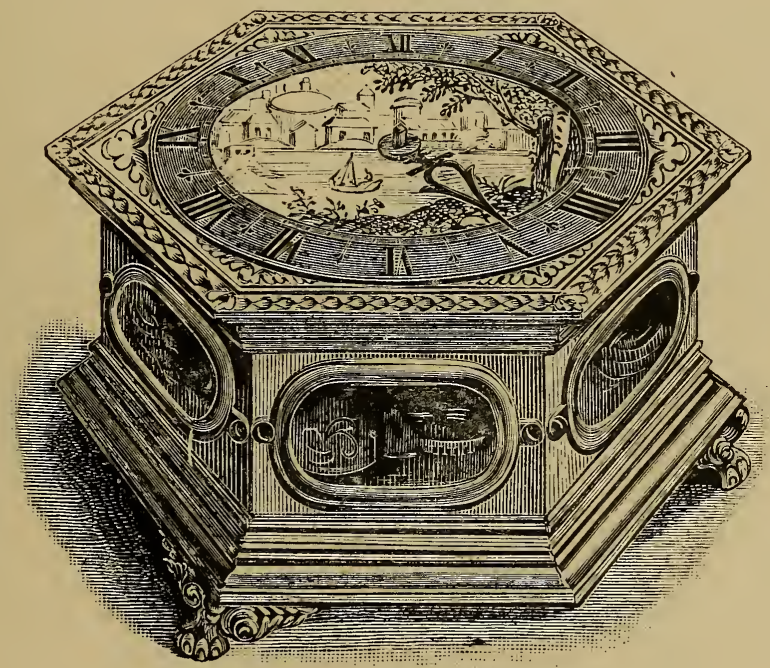

Fig. 102.--Seventeenth-Century Table Clock.

Early Clock with Balance-Spring.--The interesting clock shown in Fig. $104 \mathrm{I}$ saw at Messrs. Thwaites \& Reed's. In the centre of the dial is a plate with the moon's age marked on it and carrying the hour hand ; concentric with this a disc with a round hole showing the phases of the moon and age. In front, and also concentric with these, is an alarm dial with hands. This turns once in twentyfour hours. The wheel carrying the hour hand and moon's age has sixty teeth, the one carrying the disc showing the phases and age of the moun sixty-one teeth, and the wheel carrying the alarm dial sixty teeth. The two wheels showing the moon's age and hours are driven by a pinion of twenty, and the alarm wheel by a pinion of ten, both fixed on the same arbor, which makes one revolution in four hours. 


\section{Io6 Old Clocks and Watches and their Makers}

The clock strikes one blow at the first quarter, two at the second, three at the third, and four at the hour, besides the ordinary hours from one to twrelve; and then repeats the hours at any interval the

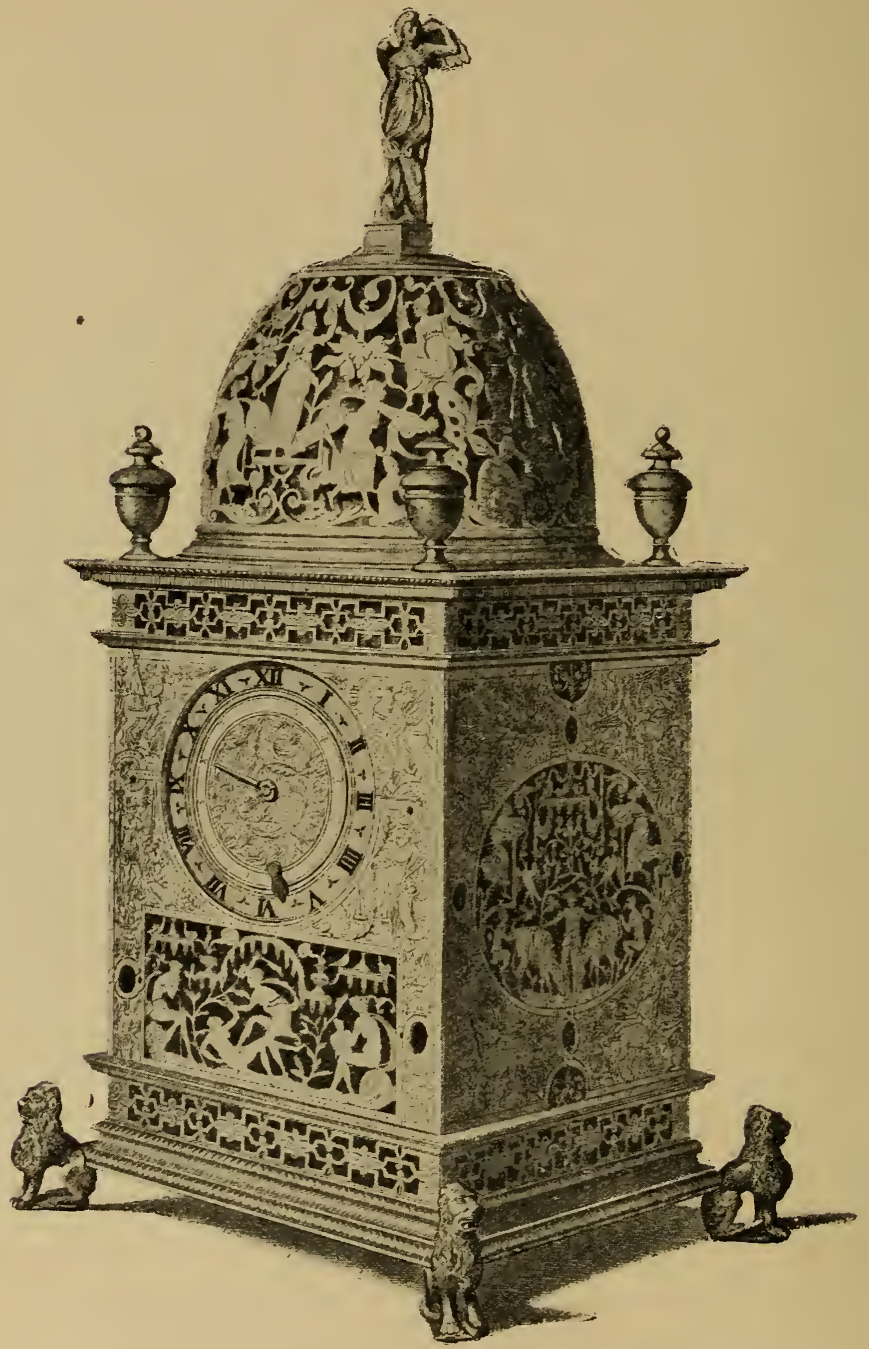

FIG. 103.-Striking and Alarm Clock.

clock is set for: that is, one, two, three, or more minutes after the ordinary hours are struck. This part strikes the hours up to twentyfour, and, while striking, the figure on the top of the clock revolves. 


\section{Portable Timekeepers}

There is a separate train for each part, and the chain on the fusee of the going part has the appearance of having been made at the same time as the clock. The other springs are in brass barrels screwed to the frame.

The small dial indicates quarter-hours only, and the hand makes a revolution in one hour. There are two hands on this; the under

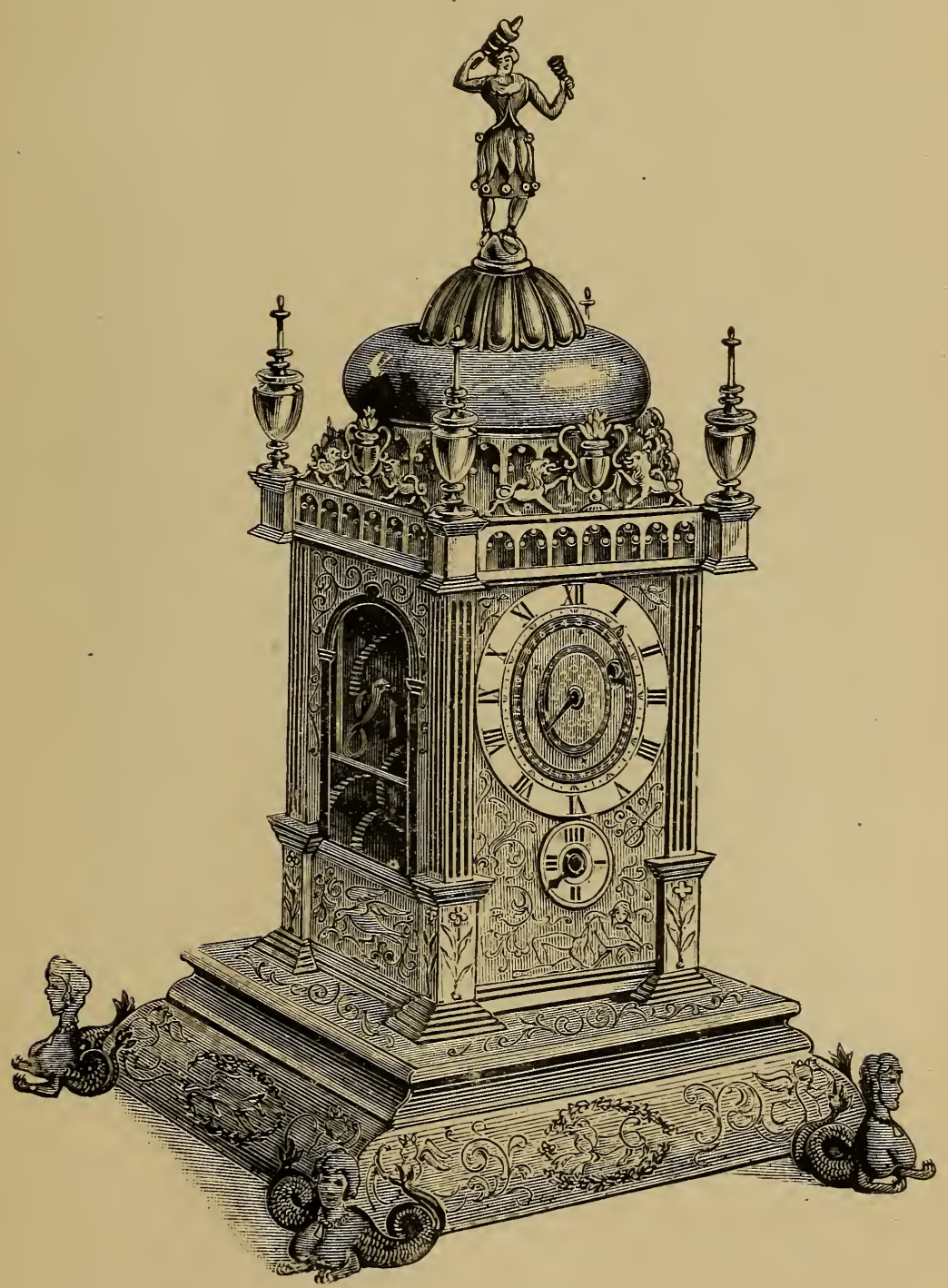

FIG. 104.-Clock with early Balance-Spring. 
I08 Old Clocks and Watches and their Makers

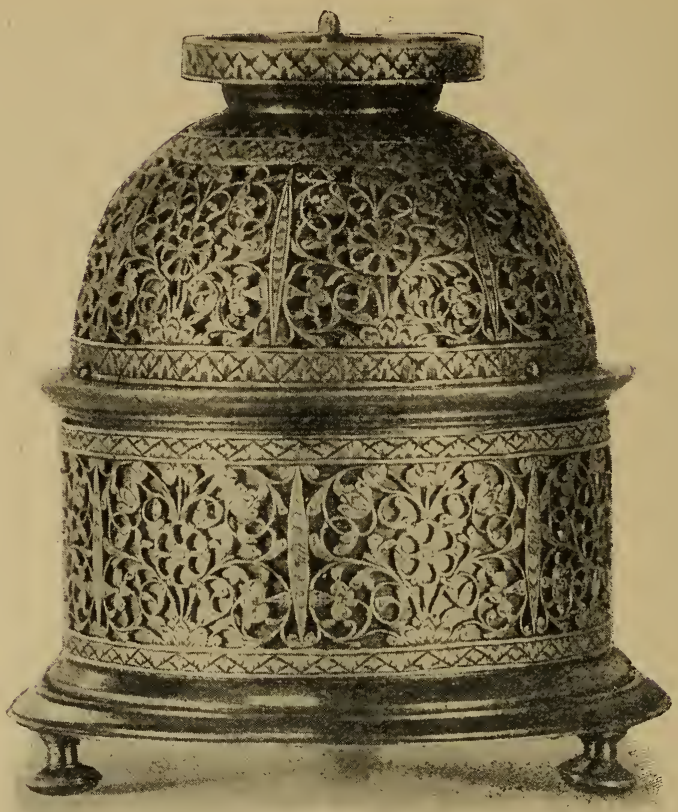

FIG. 105.

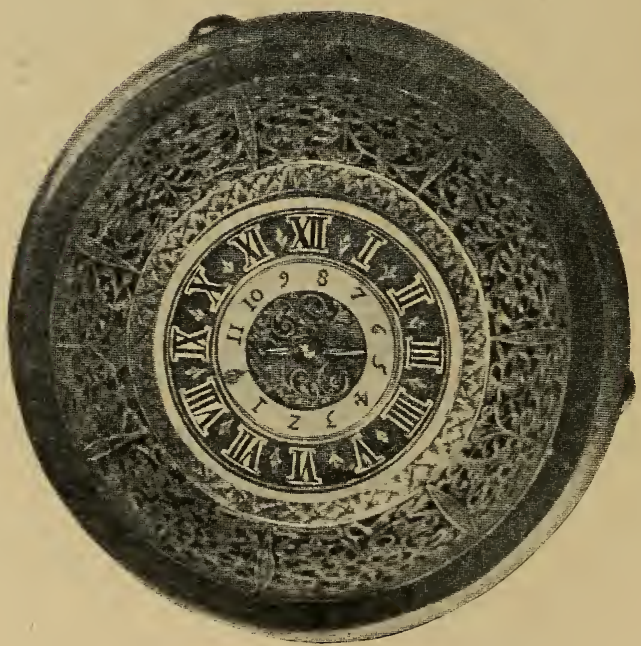

FIG. 106.-Plan, showing Dial.

Two views of an early Seventeenth-Century Alarm Table Clock. 
one is to set the interval between the ordinary striking and the twenty-four-hour striking.

The escapement is, of course, a verge. It has a plain circular

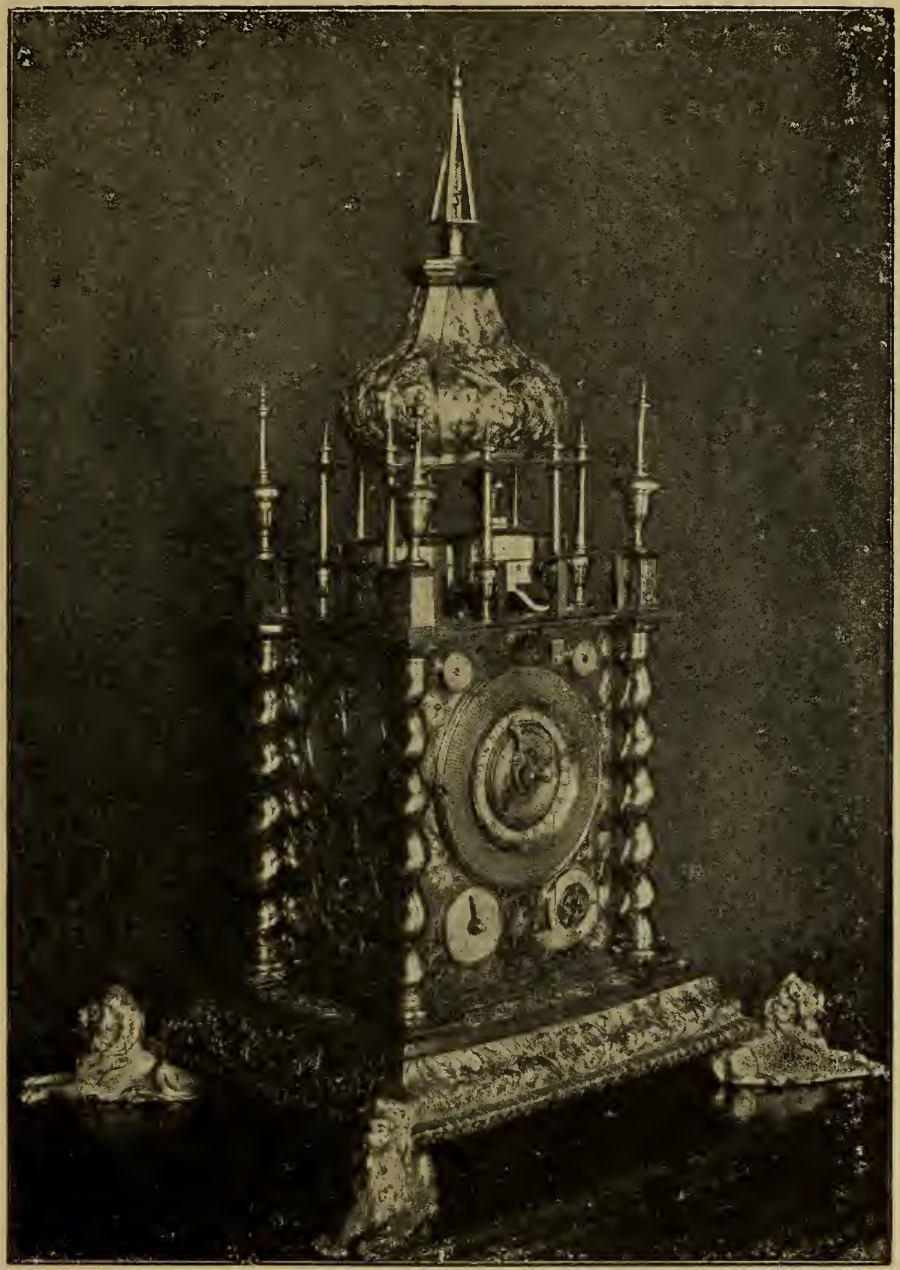

FIG: 107.-Astronomical Clock:

balance rather large in diameter. Over the balance is a straight spring, one end of which is fixed to the plate, the free end being embraced by two pins standing up from the rim of the balance, and so acting as a controller. 
I IO Old Clocks and Watches and their Makers

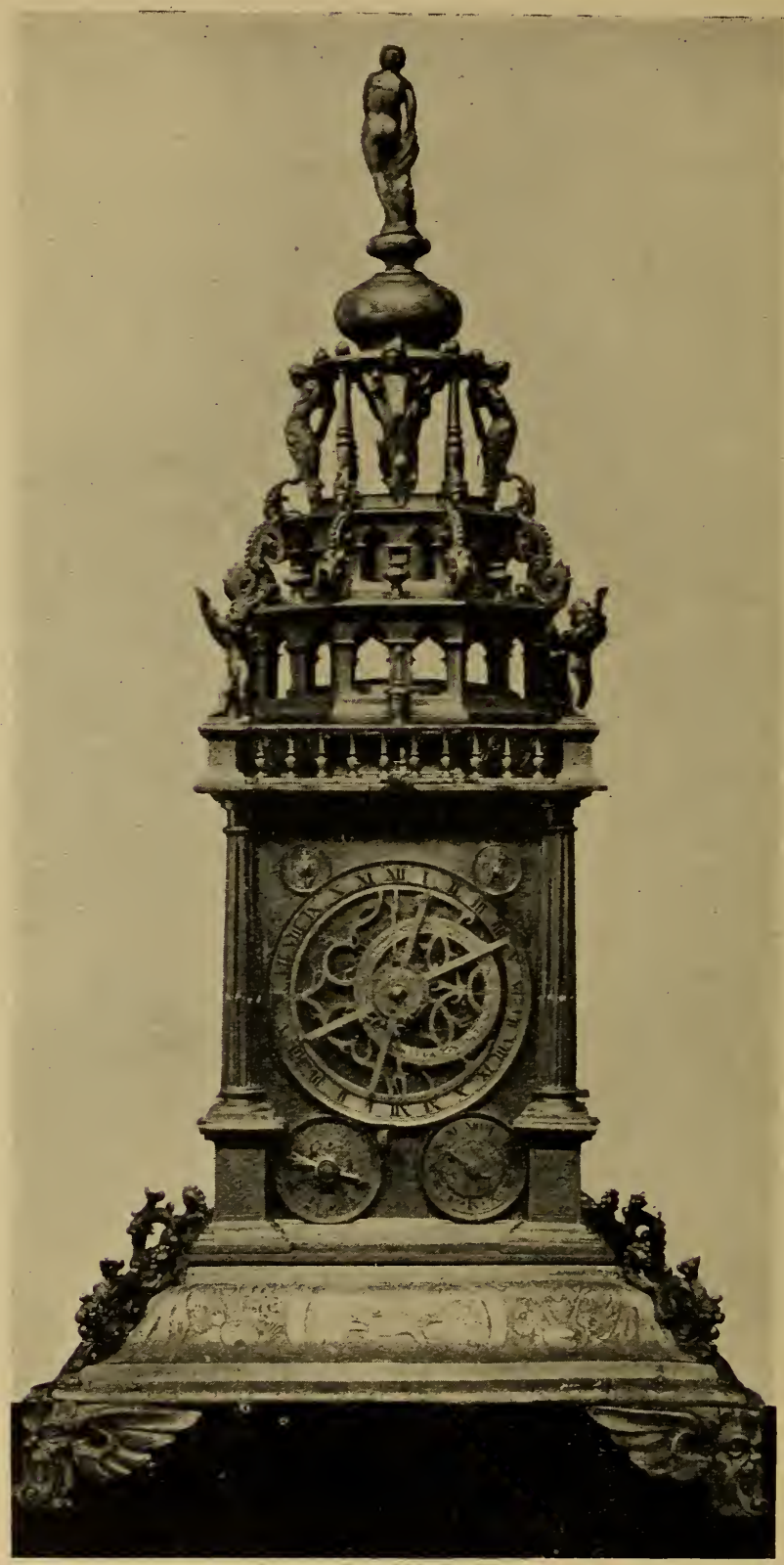

FIG. 108.-Gilt Metal Astronomical Clock. 
On the bottom of the clock is engraved :-

\section{A.D. 1634. Adam Klyzovicz Kiakovie Fecit Polonvs.}

Two views of an exceedingly pretty early seventeenth-century alarm table clock of small size from the Schloss collection are given in Figs. 105 and 106 . The case is of brass gilt, the exterior of the bottom and the under-side of the movement plate are covered with beautiful engraving, and over the body of the case is a silver ring or jacket with piercing so fine as to appear almost like filigree work.

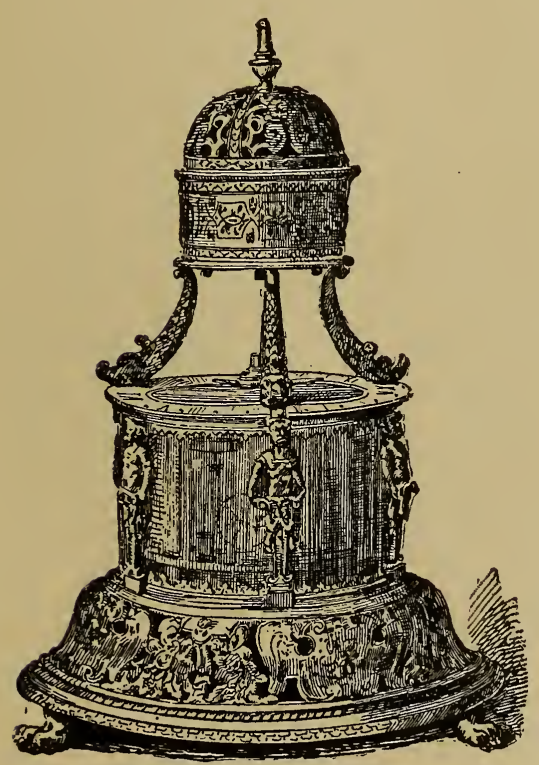

FIG. 109.

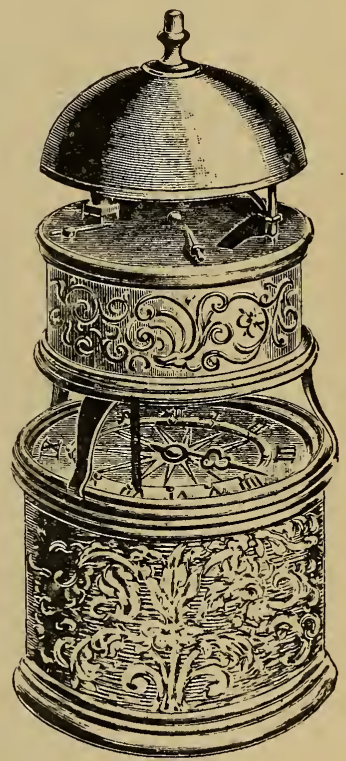

FIG. 110 .

Horizontal Dial Timepiece, latter part of the Sixteenth Century. (Havard, "Dictionnaire de l'Ameublement.")

The dome, of silver, similarly pierced, covers a hemispherical bell, and supports the horizontal dial, on which are engraved the horary numerals in Roman characters, the time being indicated by a projecting ornament at the edge of the centre, which rotates and is figured as a guide for setting the alarm hand.

Seventeenth-Century Pendulum Clocks.-Fig. 107 represents the front of an astronomical clock by Marcus Bohm, Augsburg. It is $21 \mathrm{in.} \mathrm{high} \mathrm{and} 10 \mathrm{in}$. wide, engraved, chased, and gilded. Under the dome, which is hammered out of one piece of metal, are two bells, the smaller being struck at the quarters, and the larger at 


\section{2 Old Clocks and Watches and their Makers}

the hours and as an alarm. By adjustment at pleasure the clock can be made to sound the hours from one to twelve or from one to twenty-four. The large dial shows the time, the length of days, and a calendar of saints. In front hangs the pendulum, the bob being in the form of a cherub. The back is very similar to the front ; the main dial there indicates the annual course of the astral

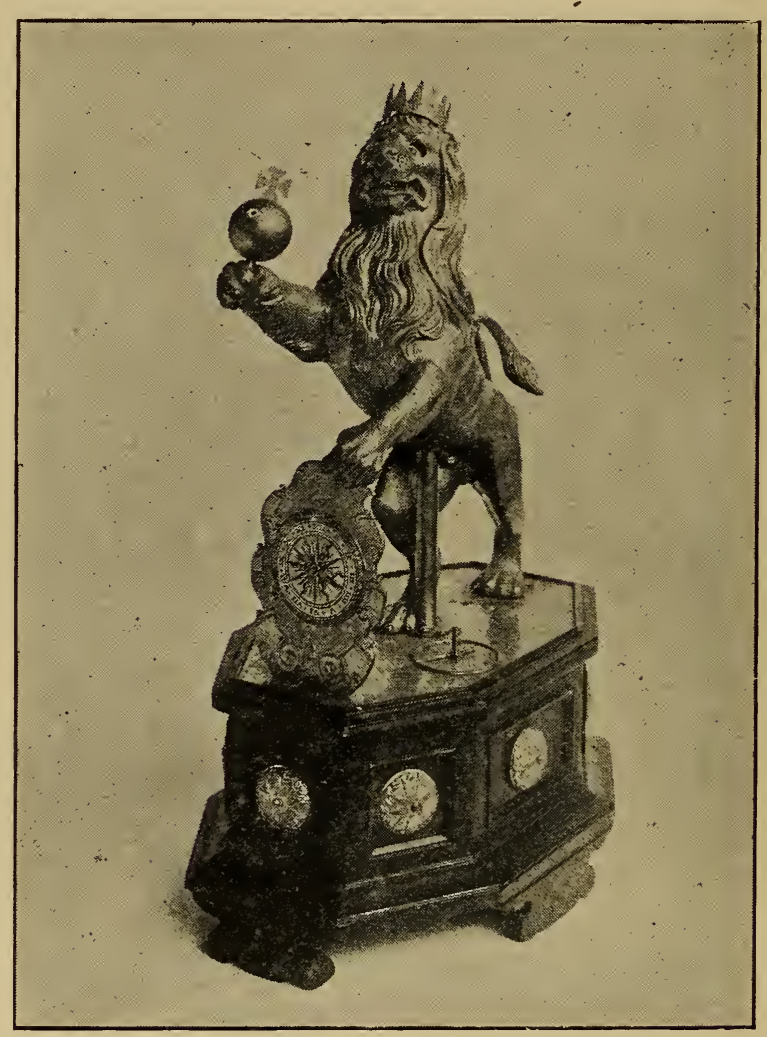

Fig. 111.-Crowned Lion Clock of Gilt Copper.

world. Some of the subsidiary dials on the front, back, and sides exhibit other motions, and the remainder are for adjustment and regulation of the mechanism.

At the Ashmolean Museum is a fine German astronomical clock, $22 \frac{1}{2}$ in. high, belonging to Mr. Henry J. Pfungst. The case is of gilt metal with dials on each of the four sides, of which the chief one is seen in Fig. 108. On the opposite side to that shown in the 
engraving a pendulum is suspended. The dials are of silver, decorated with basse taille enamel red, white, blue, and green.

During the latter part of the sixteenth, and the first half of the seventeenth century, timepieces with horizontal dials over which a dome containing an alarm could be placed at pleasure were in favour. There are several in the British Museum. An early example is show1 in Fig. 109. Fig. 110, from the Schloss collection, is of a

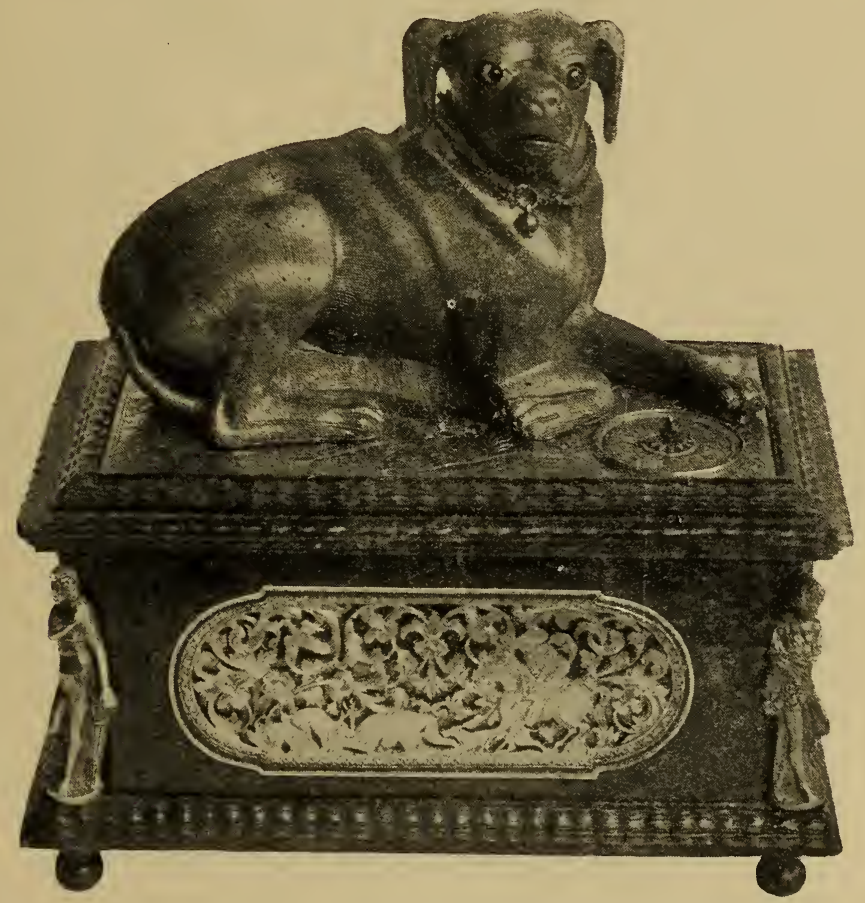

FIG. 112.-Dog guarding Dial.

rather later date. Three springy legs fixed to the alarm were made to clasp the outside of the dial of the timepiece in such a position that a wire depending from the alarm case was moved by the hand at the hour it was desired the alarm should be discharged.

These timepieces must have been exceedingly useful before the advent of lucifer matches, when recourse had to be made to the tinder box in order to obtain a light; but, apart from these and machines with"complicated movements such as were designed by astronomers, 
II4 Old Clocks and Watches and their Makers

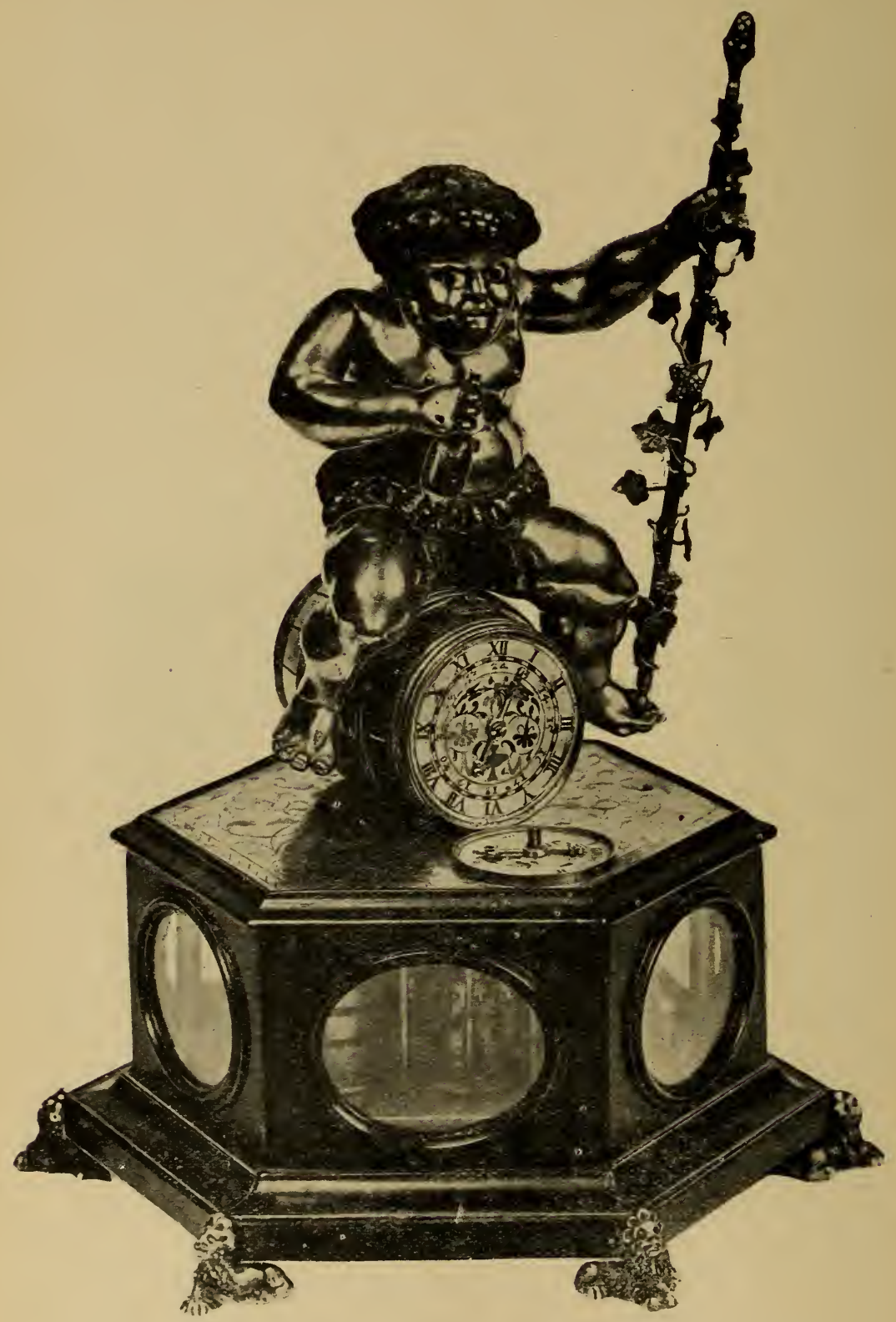

FIG. 113.-Splendid example of its kind, probably made by Conrad Freizer, early Seventeenth-Century. 
regard seems to have been more generally paid to the effectiveness of the exterior as a whole rather than to its fitness and convenience

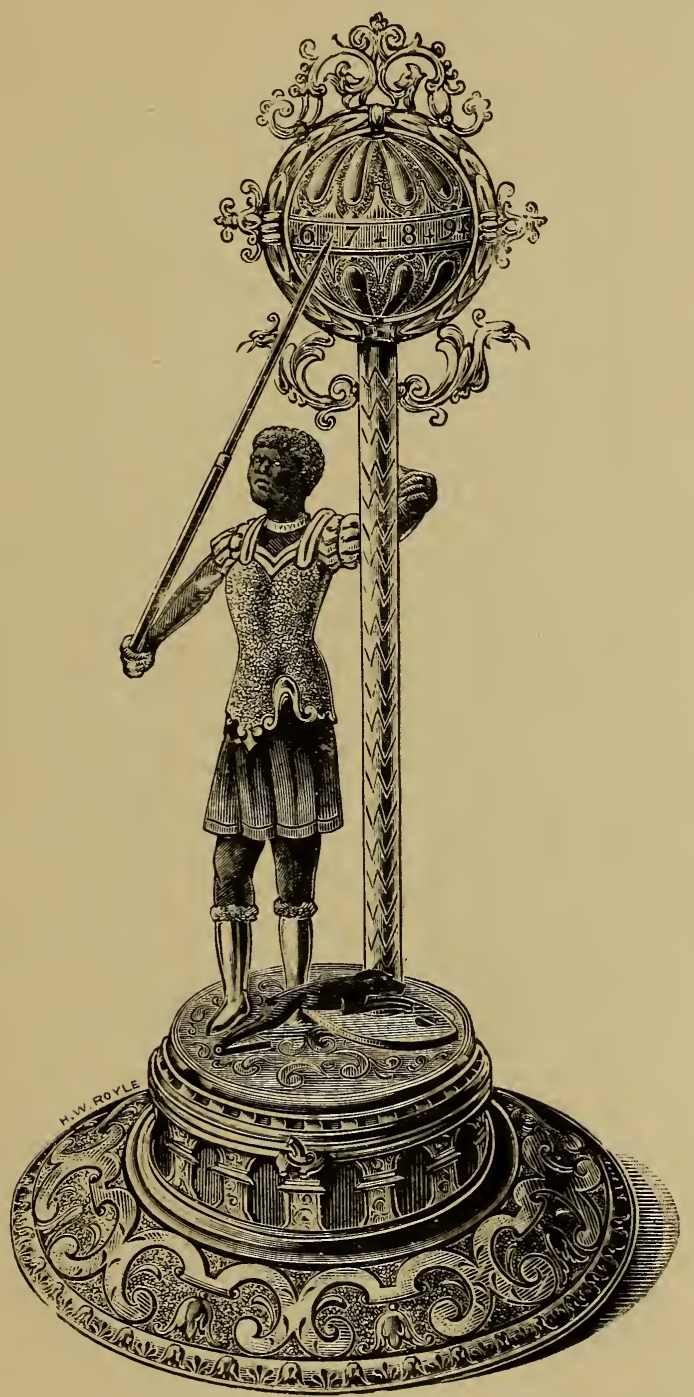

FIG. 114.-Peculiar Early-Seventeenth-Century Striking Clock, similar one at the British Museum.

for showing the hour. Some instances of the more or less grotesque conceptions then in favour are appended, most of them being from the Schloss collection. 


\section{II6 Old Clocks and Watches and their Makers}

Fig. 111 shows a crowned lion of gilt copper holding an orb in its right paw and supporting the dial with its left. By means of two wires standing up from the balance the eyes, which have bright red pupils, move to and fro when the clock is going. As the hours are

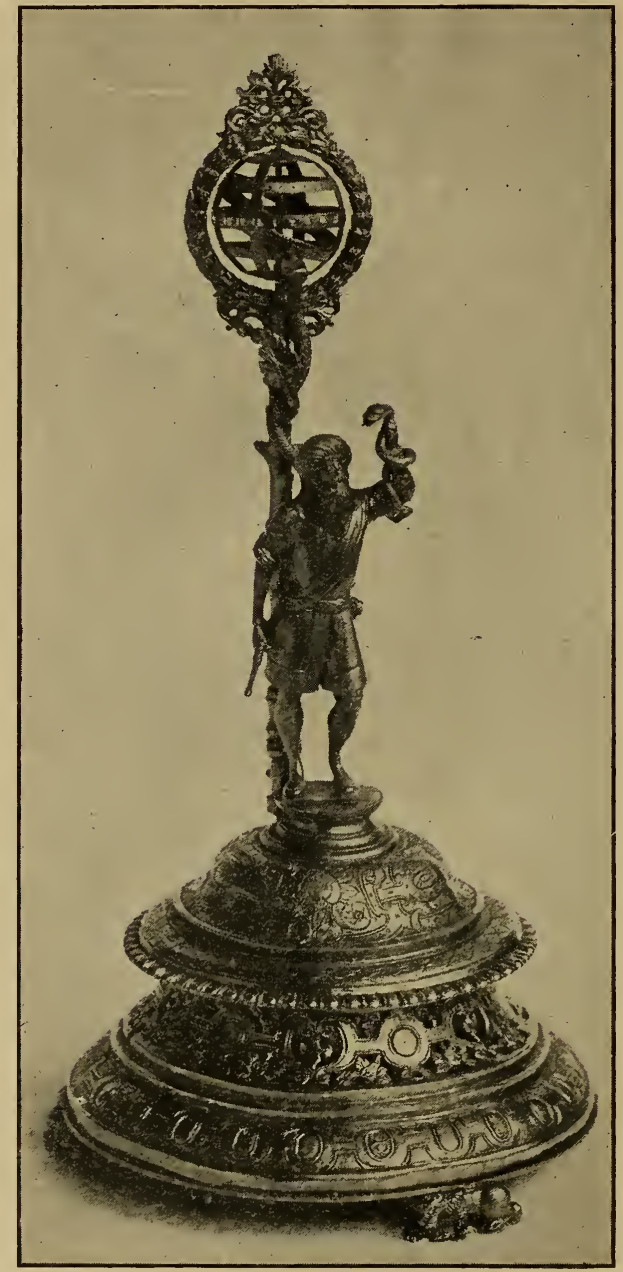

FIG. 115.-Revolving Hollow Globe, dating from about 1650 .

struck the animal's lower jaw moves up and down. The movement is contained in an ebony box, which forms the plinth.

A dog guarding the dial with its paw, as shown in Fig. 112 is of much the same character. 
Fig. 113 shows a splendid example of its kind, in which a boldly modelled figure of Bacchus sitting astride a cask is utilised as an automaton. As the hours are struck it opens its mouth and raises to its lips the bottle held in the right hand. In its left hand is a

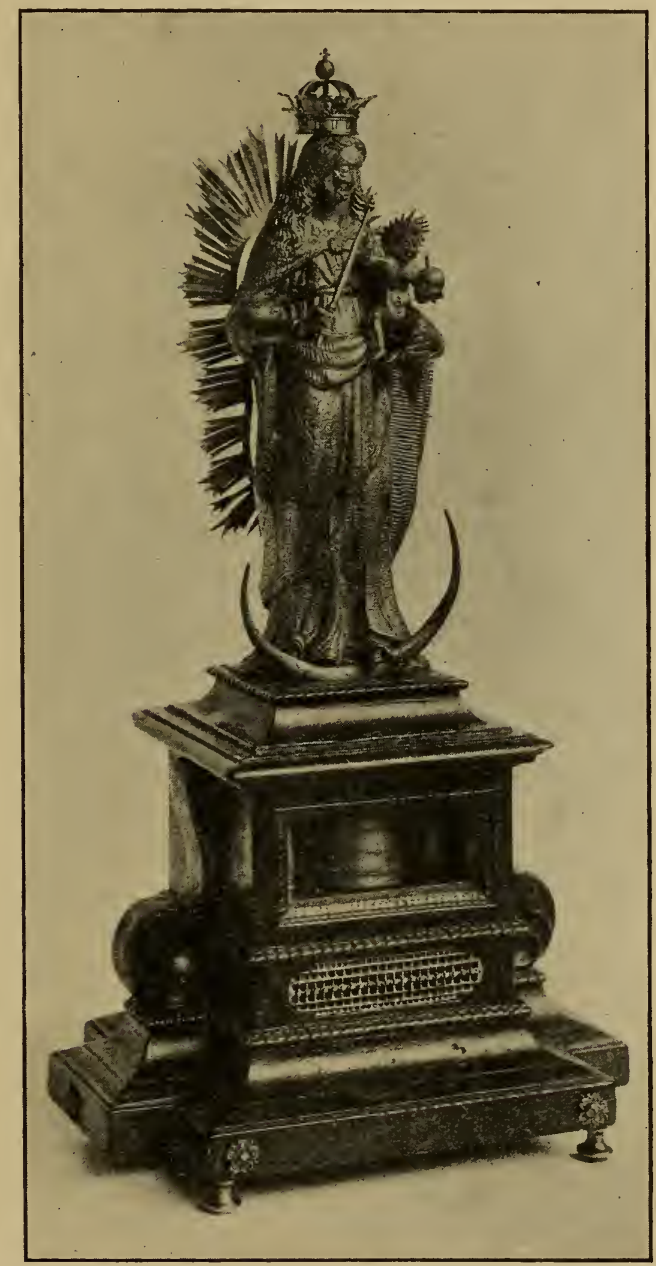

FIG. 116.-Clock with horary numerals on a revolving crown.

staff entwined with grape leaves and fruit and surmounted by a pineapple, the Augsburg mark. On a silver dial attached to the front of the cask the hours are indicated, and at the back, between a pineapple in a shield, are the letters "C.K.", which very possibly stand 
II 8 Old Clocks and Watches and their Makers

for Conrad Kreizer, a well-known early seventeenth-century maker. Just in front of the cask is a horizontal dial divided into quarter-hours

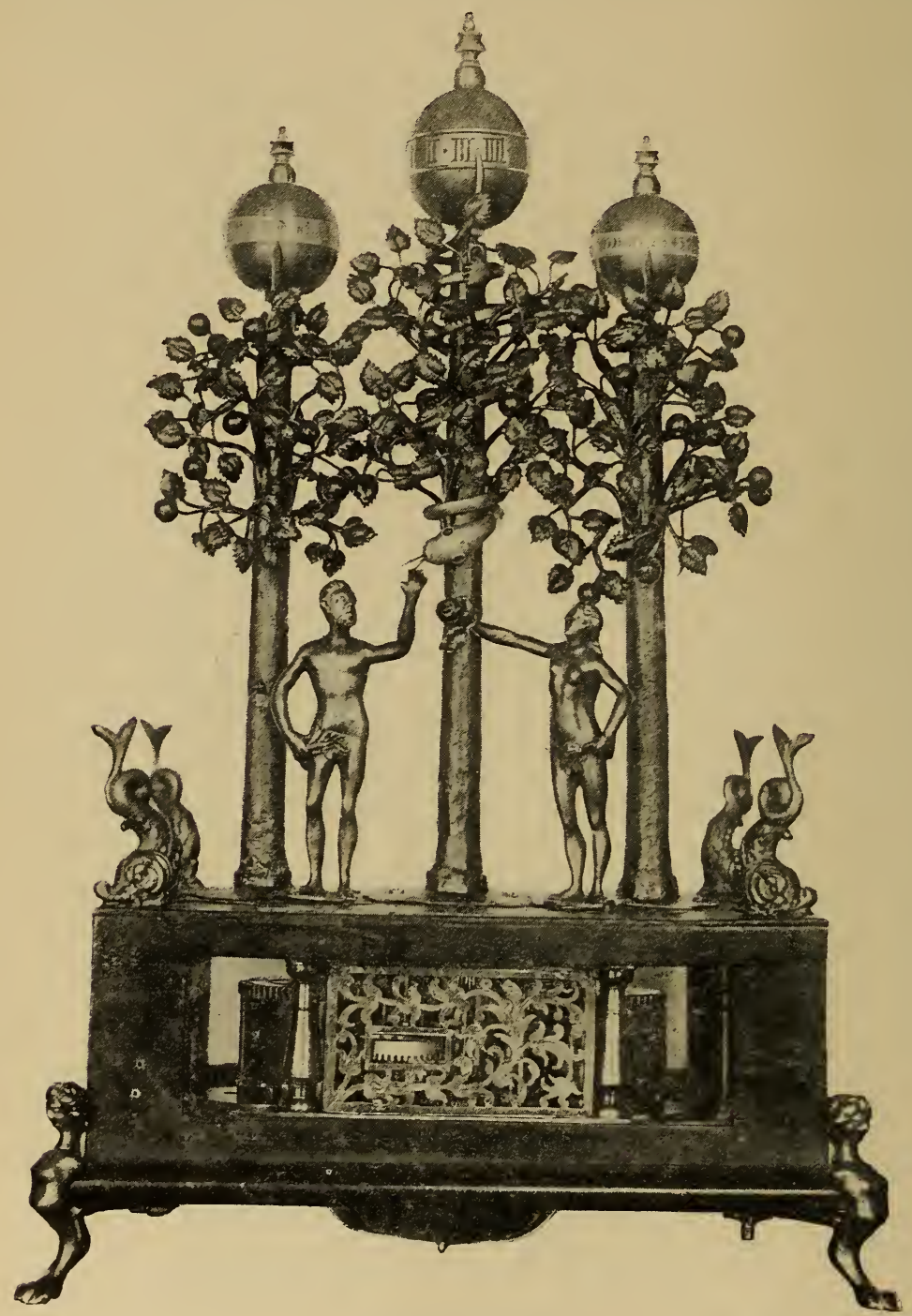

FIG. 117.-Clock with three horizontal band dials showing the hour, the day of the week, and the day of the month.

for setting the striking. The eyes of the figure move to and fro continuously while the clock is going ; but instead of being connected directly to the balance, as in the preceding examples, they are worked 
by a separate escapement and ingenious mechanism actuated by the fusee wheel which drives the train. In this way the motion of the eyes is slower, and the timekeeping of the clock is not affected. The

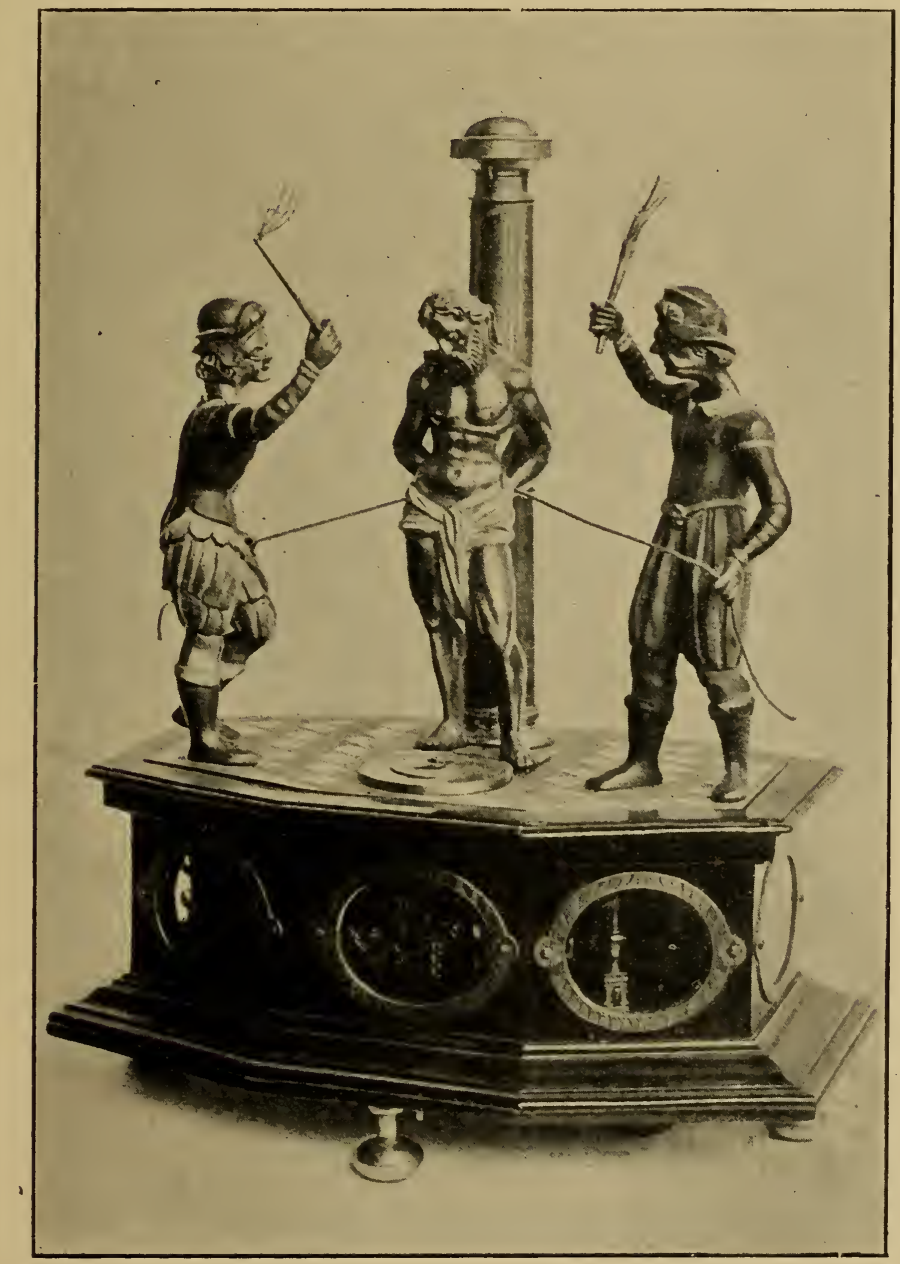

FIG. 118.-The flagellation of Jesus Christ forms the subject of this clock.

plates of the movement are gilded, and the train wheels are of steel. The case is of ebony.

A peculiar early-seventeenth-century striking clock is shown in Fig. 114. As the hours are sounded the negro's head moves, and the 


\section{I20 Old Clocks and Watches and their Makers}

dog at his feet jumps. He indicates the time on a revolving band which bears the hour numerals. Another of these quaint conceptions is in the British Muesum.

On similar lines are Figs. 115 and 116. The one with a revolving

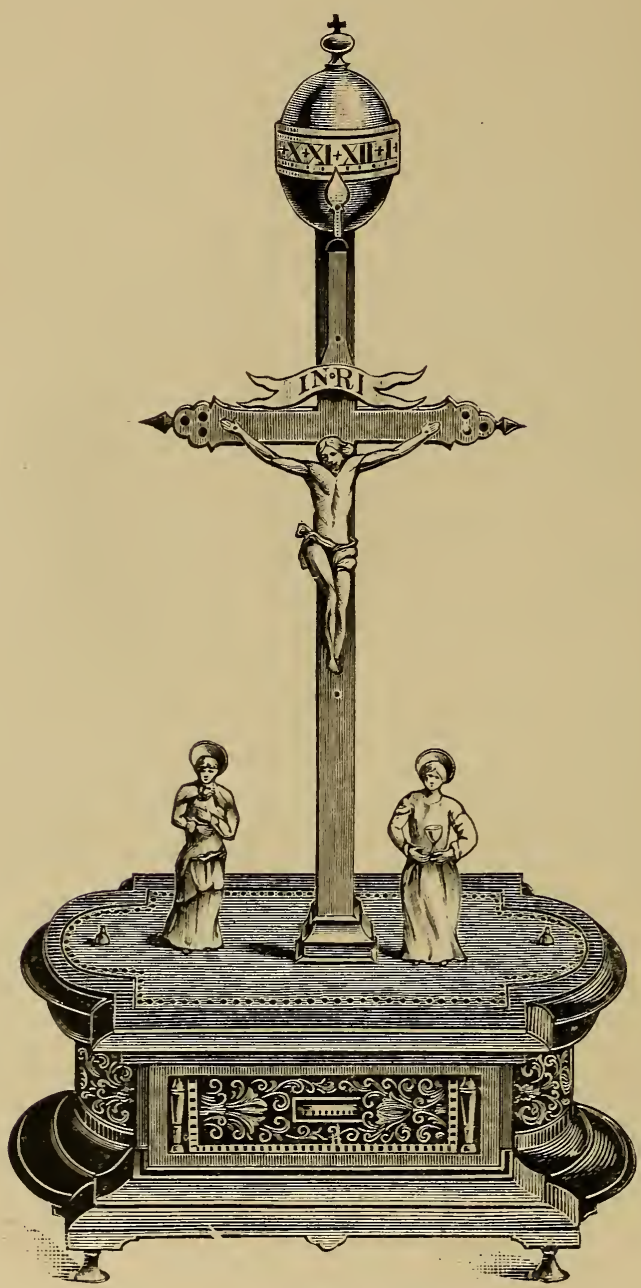

FIG. 119.-Crucifix Clock.

hollow globe, on which the hours are marked, dates from about 1650 ; the figure of the Virgin bearing the horary numerals on a revolving crown and holding a sceptre and the infant Christ with an orb is a little later. The movement of this is inscribed " Jereme Pfaff, -Augsburg." 
Fig. 117 shows a clock which belongs to Mr. Robert W. de Forest. It has three horizontal band dials showing respectively the hour, the day of the week, and the day of the month. Below are portrayed Adam and Eve in the Garden of Eden. As the hours are struck Eve turns and presents an apple to Adam, who appears to hesitate, and then retires, refusing the gift. Abundance of foliage and fruit is spread over the three trees or columns supporting the dials, while a huge serpent gazing menacingly at Adam is twined around the central trunk, and indicates the hour with its tail. For the photograph from which the engraving is produced I an indebted to M. Eugène Wehrle, of Brussels.

The flagellation of Jesus Christ forms the subject of the clock

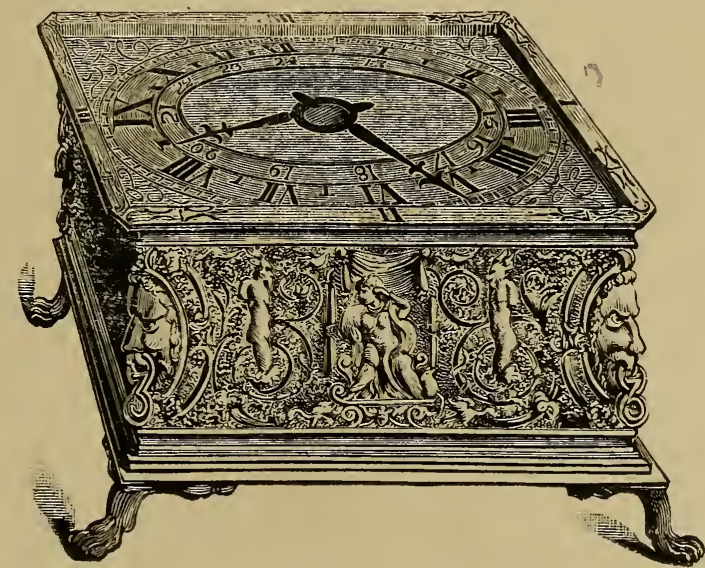

FIG 120.--Style and decoration of the Late-SeventeenthCentury Clock.

with moving figures which is shown in Fig. 118. An hour dial is at the feet of the Captive, whose bound hands are tied to a post, surmounted by a rotating band, on which the quarter-hours are engraved. As the hour strikes the passive Prisoner is belaboured by the soldiers, their weapons rising and falling with each sound of the bell. The movement contained in the ebony case is signed, "Nicolaus Schmidt der Junger."

The crucifix clock represented in Fig. 119 is from the Schloss collection. The drawing is one-third of the actual size of the clock, which measures $12 \mathrm{in}$. in height and $6 \mathrm{in}$. across the widest part. The base is made of wood and gilt metal, the top being covered with cloth or velvet, now very much worn. The cross is of gilt metal, the figures and mounts of silver. The figure on the cross is most 


\section{I22 Old Clocks and Watches and their Makers}

beautifully modelled. St. John, standing at the left of the cross, holds in his hands a chalice, which he raises when the clock strikes the hours. The ball surmounting the structure revolves once in twelve hours, and on it is a band containing the Roman hour numerals, the time being indicated by the pointer fixed to the cross. No minutes are shown, and subdivisions of an hour would have to

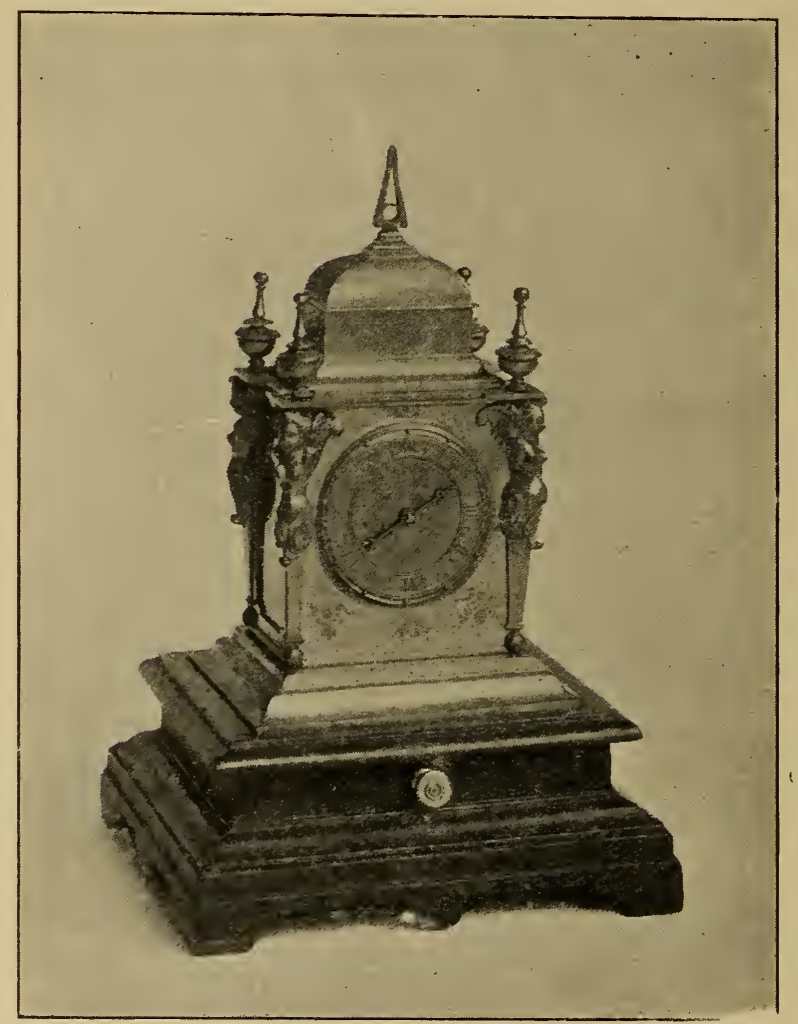

FIG. 121.-Diminutive Table Clock dating from about 1690.

be estimated. The escapement is, of course, a verge. The clock goes thirty hours between windings, and strikes on a bell below the plinth. Portions of the movement can be seen through apertures in chased metal gratings fixed in the front and back panels of the plinth. There is no maker's name, but it is probably a French seventeenthcentury production.

The style and decoration of the late seventeenth-century clock, 
shown in Fig. 120, may be studied with advantage by those who wish to be able to distinguish pieces of different periods. The ornament at the sides of the case is in bold relief; the feet are of bronze, as was the usual practice, and form a contrast to the yellower metal of which the case is composed. The movement of this clock is regulated by a very short balance-spring, and bears the signature "Andreas Fehmel."

Fig. 121 shows a diminutive table clock by Hans Buschman dating from about 1690 . There are dials front and back, and a pendulum which swings at the rear outside of the case.

Janvier speaks of the watches made between 1560 and 1590 as being beautifully ornamented and of all sizes, and there is no doubt that by the last-named date watchmaking had become in France a flourishing art of considerable magnitude, Blois and Rouen being two of the most important seats of manufacture. But I am unable to trace any reliable evidence of English watches having been made before quite the end of the sixteenth century, although German and French productions were doubtless imported earlier.

Among the collection of Mr. T. Whitcombe Greene is an early box-shaped, metal gilt case and dial, probably of German make. Around the projecting bead at the bottom of the case is engraved the following: " Sr. Wm Cooper to Eleanor, daughter of Sr. Michael Stanhope, wife to Thomas Cooper, his son, of Thurgarton, Co. Nots, 1539." A coat of arms is engraved on the cover. The dial is engraved with the figure of the Saviour and emblems of Death, with the mottoes, "Vigilate et orate quia nescitis horam," and "Quælibet hora ad mortem vestigium" ("Watch and pray, for ye know not the hour," and "Every hour is a step towards death"). If the dedicatory inscription is an authentic record, this relic certainly represents one of the first table watches seen in England. The case has no bow. Derham, in his second and subsequent editions, mentions an eight-day watch which, he was told, belonged to Henry VIII., but the context clearly shows a weight timepiece is referred to. Among the possessions of Edward VI., as quoted by Wood from a Royal Household Book, is " oone larum or watch of iron, the case being likewise of iron gilt, with two plummettes of lead." The first words of this description may seem to indicate a watch with a mainspring, but such an assumption is at once dispelled by the mention of the " plummettes of lead."

Queen Elizabeth.-That Elizabeth owned a large number of watches is certain, and the following relating to her horological 


\section{I24 Old Clocks and Watches and their Makers}

possessions will be of interest. In 1571 the Earl of Leicester gave to his royal mistress " one armlet or shakell of golde, all over fairely garnished with rubyes and dyamondes, haveing in the closing thearof a clocke." In the same year two other gifts are mentioned, a " juell, being a chrysolite garnished with rubyes and dyamondes, haveing in the closing thearof a clocke:" and "a juell, being a chrysolite garnished with golde, flagon facyon, th'one side sett with two emeraldes, . . . th'other side having in it a clocke." In 1573 Elizabeth received from Margaret, Countess of Derby, "a white beare of gold and mother of perle, holding a ragged staffe, standing upon a toune of golde, whearin is a clocke, the same toune staffe garnished with dyamondes and rubyes." The "clock and all" weighed three ounces. In $1575 \mathrm{Mr}$. Hatton, captain of the guard, gave the queen " a riche juell, being a clocke of golde, garnished with dyamondes, rubyes in the bottome, and a fayre emeralde pendante sett in golde and two mene perles pendaunte, all ix oz. iii qa." In 1578 the Earl of Leicester presented Elizabeth with " a tablet of golde, being a clocke fully furnished with small diamondes and rubyes; abowte the same are six bigger diamondes pointed, and a pendaunte of golde, diamondes, and rubyes very smale. And upon eche side losengye diamonde, and an apple of golde enamuled green and russet." In the same year the Earl of Russell gave to the queen " a ring of golde, called a parmadas, sett with vj small diamonds and garnished round about with small rubies and two sparcks of ophalls, and in the same backeside a dyall." In 1580 the Earl of Leicester gave her a " cheyne of golde made like a payre of beades contayning viii long peeces fully garnished with small diamondes, and fower score and one smaller peeces fullie garnished with like diamondes; and hanging thereat a rounde clocke fullie garnished with dyamonds, and an appendante of diamondes hanging thearat." In the same year was presented to the queen by Lord Russell, "item, a watche sett in mother of pearle with three pendaunts of goulde garnished with sparckes of rubyes, and an ophall in everie of them, and three small pearles pendaunte." In the same year Mr. Edward Stafford gave her "a little clocke of goulde with a cristall, garnished with sparckes of emeraldes, and furnished on the back syde with other dyamondes, rubies, and other stones of small value." There were also many humbler contributors to her store. In 1556 her clockmaker, Nicholas Urseau, presented " a faire clocke in a case cover with blake vellat ;" and her " clocke keeper, John Demolyn, a clocke with a lambe on it of copper guilt." 
The following is from an inventory of the possessions of Queen Elizabeth :- " A watche of golde sett with small rubies, small diamondes, and small emerodes, with a pearle in the toppe called a buckett, watinge two rubies; a clocke of golde conteyning in the border four table diamonds and two very small rocke rubies, havinge on th'one side foure table rubies and sixe small diamondes; and on th'other side eleven table diamondes, whereof the one is more bigger than the residue. On the one side a man sitting aslepe with a childe before him ; a clocke or tablett of golde garnished on th'one side with five faire diamondes and one faire rubie ; and on th'other side five faire rubies and one faire emerod garnished with lij litle diamonds, and liij litle rubies, with a pearle pendent at it ; one clocke of golde curiously wrought and fullie furnished with diamonds, rubies, emerodes, and opalls, havinge in middes thereof a beare and a ragged staffe of sparkes of diamondes and rubies; one clocke of gold curiously wrought with flowers and beastes, with a queene on the toppe on th'one side ; and on the other side a beare and a ragged staff of sparkes of diamonds, fullie furnished with diamonds and rubies of sundry sortes and bignes; one emerode under it, a faire table diamond with a ragged staff in the foyle thereof and a faire rubie under it squared, and a pearle pendaunt of either side of the clocke; one clocke of golde wrought like deyses and paunseyes, garnished with little sparks of diamonds, rubies, and emerodes, and eight small pearles on the border, and a pendant acorn ; one clocke of gold curiously wrought with small sparkes of stones, having on th'one side a horse bearing a globe with a crowne over it; one clocke of golde with a George on both sides garnished with sparkes of diamondes and a pendant of opalls ; a litle watch of christall slightly garnished with golde; one litle clocke of golde th'one side being agate with a mouse on the toppe and heddes round about it ; one litle watch of golde garnished on the border with very small sparkes of rubies and emerodes with christall on both sides, and a pearle pendand garnished with golde like a flesh flye; one rounde clocke of golde enameled with a man on horseback, and divers colors aboute it; a watch of golde garnished with three small diamondes and eight sparks of rubies, with a very little pearle; one litle clocke of golde enameled of the History of Time; a litle watche of golde, th'one side with a frogge on the topp, th'other side garnished with small garnets like a pomegranite; one litle clocke sett in eliotropie and garnished with golde; a. litle watche of golde enameled with sundry colors on both sides alike; a litle watche of christall slightlie garnished with golde, with her Ma'ties picture in it; one faire flower of golde fully garnished with 


\section{I26 Old Clocks and Watches and their Makers}

rubies and diamonds enameled on the backside with a man and a scripture about him having a watch in it and a pearl pendant; one flower of gold fully garnished with emerodes of sondrie bignes and sparkes of emerodes and rubies, with thre antique women and five litle perles with a watch or clocke therein; a watch of agatte made like an egg garnished with golde; one clocke garnished with golde, being round and sett with 6 table diamondes and 6 rubies
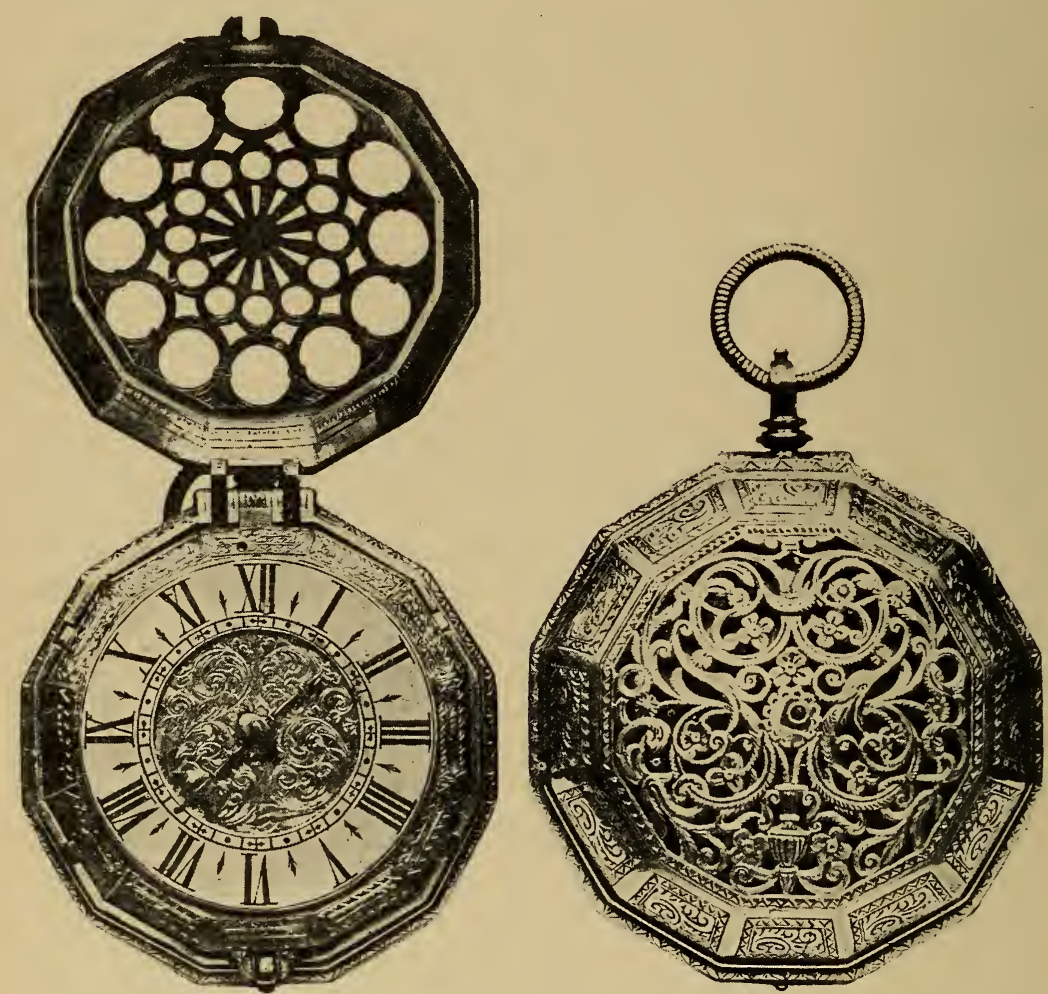

FIG. 122.-Clock-Watch about 1580 .

in the same border, and garnished with xvij diamondes on th'one side, and 8 diamonds and one rubie on th'other side, lacking two pearles."

In Fig. 122 is shown a clock-watch from the Pierpont Morgan collection. It is in a polygonal case, which measures nearly $4 \mathrm{in}$. across. On the top plate of the movement is the mark $\mathrm{B} \times \mathrm{N}$, and the piece, which dates from about 1580 , is very possibly the production of Bartholomew Newsam.

The late Mr. Edward Parr had a watch or table clock dating from 
1581, and probably of English make. It is in a circular case, about . $4 \frac{1}{2}$ in. in diameter, as shown in Fig. 123. A large hemispherical bell rises from the space inside the dial ring, and the hand is curved down over the bell to read the hour numerals. The head of Queen

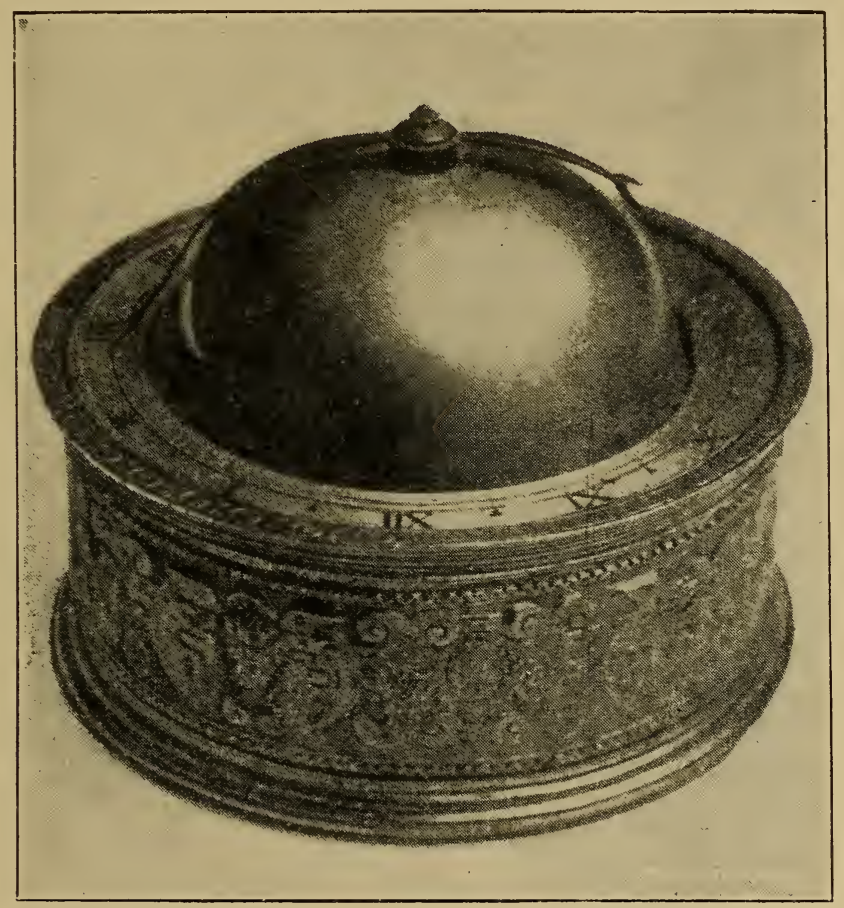

FIG. 123.-Table Clock, about 1581.

Elizabeth in high relief, and other chasing, ornament the side of the case. In a ring on the bottom of the case is the inscription :-

POSVI DEVM ADIVTOREM MEUM.

(I have placed God as my Helper.)

Against one of the winding holes is the letter $\mathrm{W}$, and against the other the letter $\mathrm{S}$; these stand doubtless for Watch and Striking, and strengthen the conclusion that the clock is an early-English production.

Skull Watches-Mary, Queen of Scots.-The skull watch (Fig. 124) is an excellent example of the fantastic forms in which some of the early makers delighted to encase their work. It is from the Soltykoff collection, and is said to have belonged to Henri III. The case is 


\section{I28 Old Clocks and Watches and their Makers}

- of crystal, the dial of silver bordered with chased brass gilt, the centre being adorned with what is called champ-levé engraving to a floral design. The movement is inscribed "Jacques Joly."

Fig. 125 represents one of the ghastly productions of a larger size. The skull is of silver gilt, and on the forehead is the figure of Death with his scythe and sand glass; he stands between a palace on the one hand and a cottage on the other, with his toes applied equally to the door of each ; around this is the legend, from Horace :-

" Pallida mors æquo pulsat pede pauperum tabernas regumque turres." (Pale Death visits with impartial foot the cottages of the poor and the palaces of the' rich.)

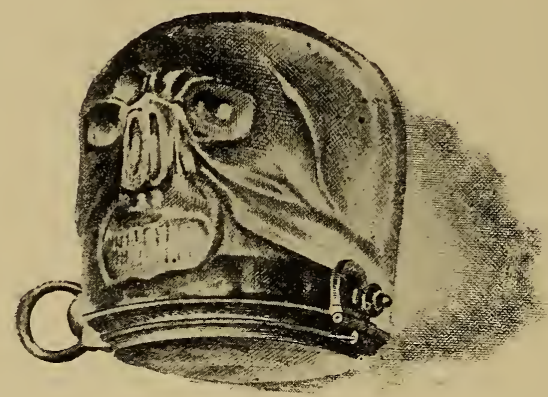

FIG. 124.-Excellent example of a Skull Watch.

On the opposite or posterior part of the skull is a representation of Time, with another inscription from Horace :-

"Tempus edax rerum tuque invidiosa vetustas."

(Time, and thou too, envious Old Age, devour all things.)

He has a scythe ; and near him is a serpent with his tail in his mouth, being an emblem of Eternity.

The upper part of the skull is divided into two compartments. On one are represented our First Parents in the Garden of Eden, attended by some of the animals, with the motto :-

"Peccando perditionem, miseriam æternam posteris meruere."

(By sin they brought eternal misery and destruction on their posterity.)

The opposite compartment is filled with the subject of the salvation of lost man by the crucifixion of our Saviour, who is represented as suffering between two thieves, whilst the Marys are in adoration below ; the motto to this is :-

"Sic justitiæ satisfecit, mortem superavit, salutem comparavit."

(Thus was Justice satisfied, Death overcome, and salvation obtained.) 
Running below these compartments on both sides there is an open work, of about an inch in width, to permit the sound to come out freely when the watch strikes. This is formed of emblems belonging to the Crucifixion-scourges of various kinds, swords, the flagon and cup of the Eucharist, the cross, pincers, lantern used in the garden, spears of different kinds, one with the sponge on its points, thongs, ladder, the coat without seam, and the dice that were thrown for it,

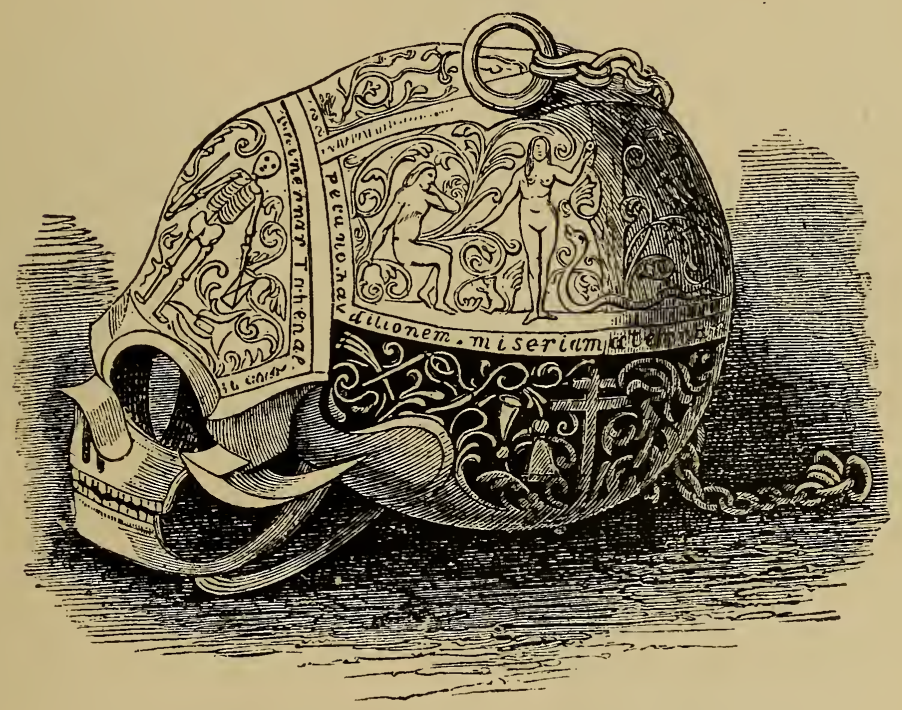

FIG. 125.-Silver-Gilt Skull Watch of a large size.

the hammer and nails, and the crown of thorns. Under all these is the motto :-

"Scala cœli ad gloriam via."

(The way to glory is the "ladder" to heaven.)

The watch is opened by reversing the skull and placing the upper part of it in the hollow of the hand, and then lifting the under-jaw, which rises on a hinge. Inside, on the palate, is an excellent engraving of apparently a later date than the rest of the work. It shows the Holy Family in the stable, with the infant Jesus laid in the manger, and angels ministering to Him; in the upper part an angel is seen descending with a scroll, on which is written :-

"Gloria [in] excelsis Deo, et in terra pax hominibus bona voluntatis."

(Glory to God in the highest; on earth peace to men of goodwill.) 


\section{I30 Old Clocks and Watches and their Makers}

In the distance are the shepherds with their flocks. A representation of this cover is given separately.

The works of the watch occupy the position of the brain in the skull itself, the dial plate being on a flat where the roof of the mouth and parts behind it under the base of the brain are to be found in the human subject. The dial is of silver, and fixed with a golden circle richly carved in a scroll pattern; the hours are marked in large Roman letters, and within them is the figure of Saturn devouring his children, with this legend :-

"Sicut meis sic et omnibus idem."

There is no date, but the maker's name and the place of manu-

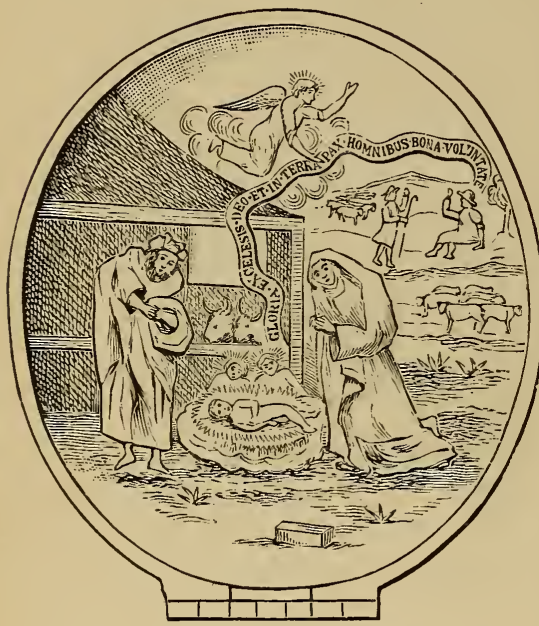

FIG. 126.-Interior of Skull Watch above the Dial. facture, "Moyse, Blois," are distinctly engraven on the plate. A silver bell fills the entire hollow of the skull, and receives the works within it when shut; a small hammer, set in motion by a separate train, strikes the hours on it.

The workmanship of the case is admirable, and the engraving really superb. The date of this relic may be taken to be between 1550 and 1600 .

It is stated that it belonged to Mary, Queen of Scots, by whom it was given to Mary Seaton, one of her maids of honour, and much circumstantial evidence has been adduced in support thereof. I have recently had an opportunity of examining an almost similar Death's-head watch, which is also said to have been the property of the same royal lady and now belongs to Miss Mary Laura Browne, of Anerley. Except that beside the ring on the top of the skull is a screw for the reception of a cross, the case is an exact facsimile of the Mary Seaton one, with the additional inscription around the eyebrows, "Ex Dono $F_{R}$ s. R. Fr. AD. Marias de Scotorum Fr. Regina." The original movement has, however, unfortunately been replaced by a comparativeiy modern one.

These two skull watches were doubtless intended to occupy stationary positions: the cross on one of them suggests a prie-dieu 
or small altar in a private oratory. At all events, they are too large and heavy to be worn on the person. The engravings represent the

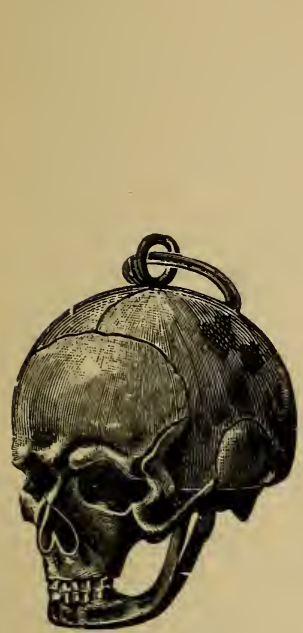

FIG. 127.

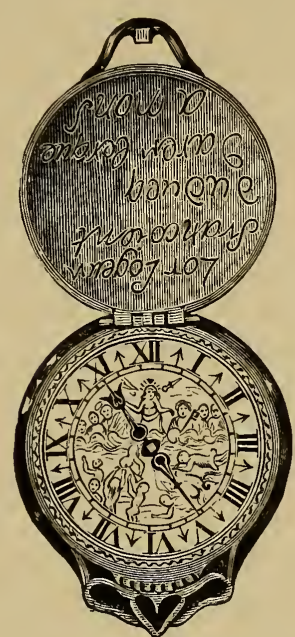

FIG. 128.

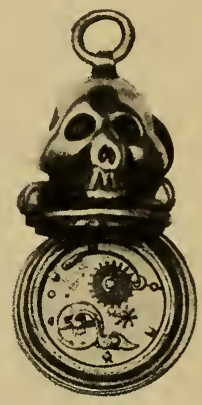

FIG. 129.

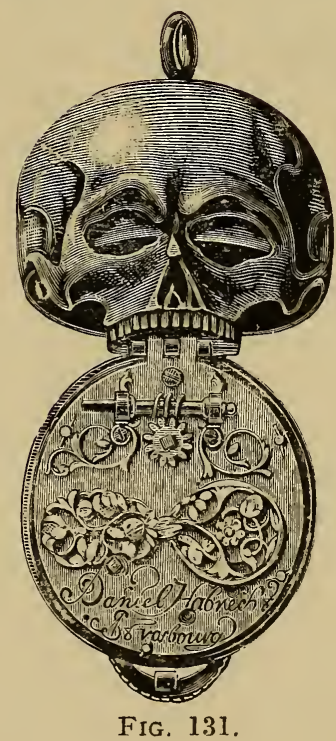

FIG. 130.

FIG. 131 .

Skull or Death's-head Watches.

natural size of the relics, each of which. weighs over three-quarters of a pound.

In the British Museum are two Death's-head watches, much 


\section{I32 Old Watches and Clocks and their Makers}

smaller and with plain cases. One of these was made by Johann Maurer, and the other by J. C. Vuolf. A similar watch, dating from about 1630, which was in the Dunn Gardner collection, and is now in the Pierpont Morgan collection, bears the signature of Isaac Penard. Another of these extraordinary conceptions, which belonged to Mr. Robert Roskell, of Liverpool, and formed part of the Schloss collection, is shown in Figs. 127 and 128. The skull or case of silver, much darkened by age, is a startingly excellent counterfeit and a fine example of silver work. The plate bears the name of the maker thus, " Johann Leudl." On the dial of silver is an engraving evidently intended to portray the day of judgment. Inside the lower jaw, which closes on to the dial, is roughly cut the following inscription: "Lor logeur francoient duducq d'aremberque a mons." This specimen dates from about 1625 ; but the inscription is later, as the first Duke of Aremberg obtained his title in 1644 .

A very diminutive Death's-head watch in the form of a seal is shown open in Fig. 129. The movement is furnished with the stackfreed, and dates apparently from the first half of the seventeenth century.

Of about the same period is the example by David Habrecht, shown in Figs. 130 and 131.

In the Vienna Treasury is a small skull watch of the time of the Emperor Rudolph II. in which the movable lower jaw strikes the number of hours against the upper one.

The late Rev. H. L. Nelthropp, who presented his splendid collection of watches to the Clockmakers' Company for exhibition in the Guildhall, considered the statements as to the ownership of skull watches by Mary, Queen of Scots, to be apocryphal, and said that a careful investigation of the catalogues of the jewels, dresses, furniture, belonging to Queen Mary proved beyond doubt that watches were not among her valuables. I cannot say that Mr. Nelthropp's criticism is quite destructive of the original account, for if both of the watches vere given away by the queen, they could hardly be expected to figure in any subsequent inventory of her property. It is certain that watches were made during her lifetime; also that Blois was one of the earliest manufactories of watches, and that the family of Moyse flourished there during the sixteenth century. In the face of the fact that Elizabeth had such a large number of watches, it seems almost incredible that the Scottish queen should never have possessed any of the fashionable novelties.

While the probability is that Mary, Queen of Scots, had watches of some kind, it must be confessed that the statements made respecting 
her ownership of specimens which have survived will not always bear examination. Among others which tradition has assigned to the Scottish Queen, Octavius Morgan examined two which he considered to be of the period claimed for them. One was a ghastly Memento Mori watch in a case of crystal formed like a coffin, and the other an octagonal watch. The latter, which is now in the British Museum, is said to have been given by Mary to John Knox the reformer. The case of crystal had covers front and back, and the movement was inscribed "N. Forfaict à Paris." A large oval watch made by F. Le Grand, and said to have been found, immediately after the queen's escape from her imprisonment, in Lochleven Castle, was exhibited to the Philosophical Society of Edinburgh in 1850. A small circular watch by Estinne Hubert, of Rouen, presented, it is averred, by the queen the night before her execution to a French attendant named Massey, was a few years ago in the possession of Rev. Mr. Torrance, of Glencross. In the Massey-Mainwaring collection was a round rather thin watch by Moysant, of Blois, in a case whereon is splendidly painted, in enamel, a representation of the Adoration of the Magi. This watch was some time ago exhibited at the Bethnal Green Museum with a label stating that it was given by Mary Queen of Scots, to the Earl of Mar, from whom it passed into the possession of the family of Lord Forbes. But the style of the watch and the enamel painting did not seem to me to be entirely in accord with other productions of the sixteenth century.

In 1575, Parker, Archbishop of Canterbury, bequeathed to his brother Richard, Bishop of Ely, his walking-stick of Indian cane having a "horologium" in the top. This is generally quoted as a watch, but is quite likely to have been a portable sun-dial.

The possession of many watches is ascribed to James I., but such as he did possess do not appear to have been utilised as timekeepers on every occasion, for in Savile's record of a state journey to Theobalds in 1603 , it is stated that the king stopped at the Bell at Edmonton, and, wishing to count the number of vehicles passing in a certain time, he " called for an houreglass."

An early striking watch in a nearly spherical case of brass, chased and gilded, having the dial at the bottom of the sphere and a ring for carrying at the top, is shown on p. 134. The form and arrangement of the mechanism are exceedingly rare. The movement is in stories, and the dial, which is seen in Fig. 133, is attached to the lowest plate of the movement and not to the case. Between the dial and the plate, besides the wheels for actuating the hand direct from the mainspring 
I34 Old Clocks and Watches and their Makers
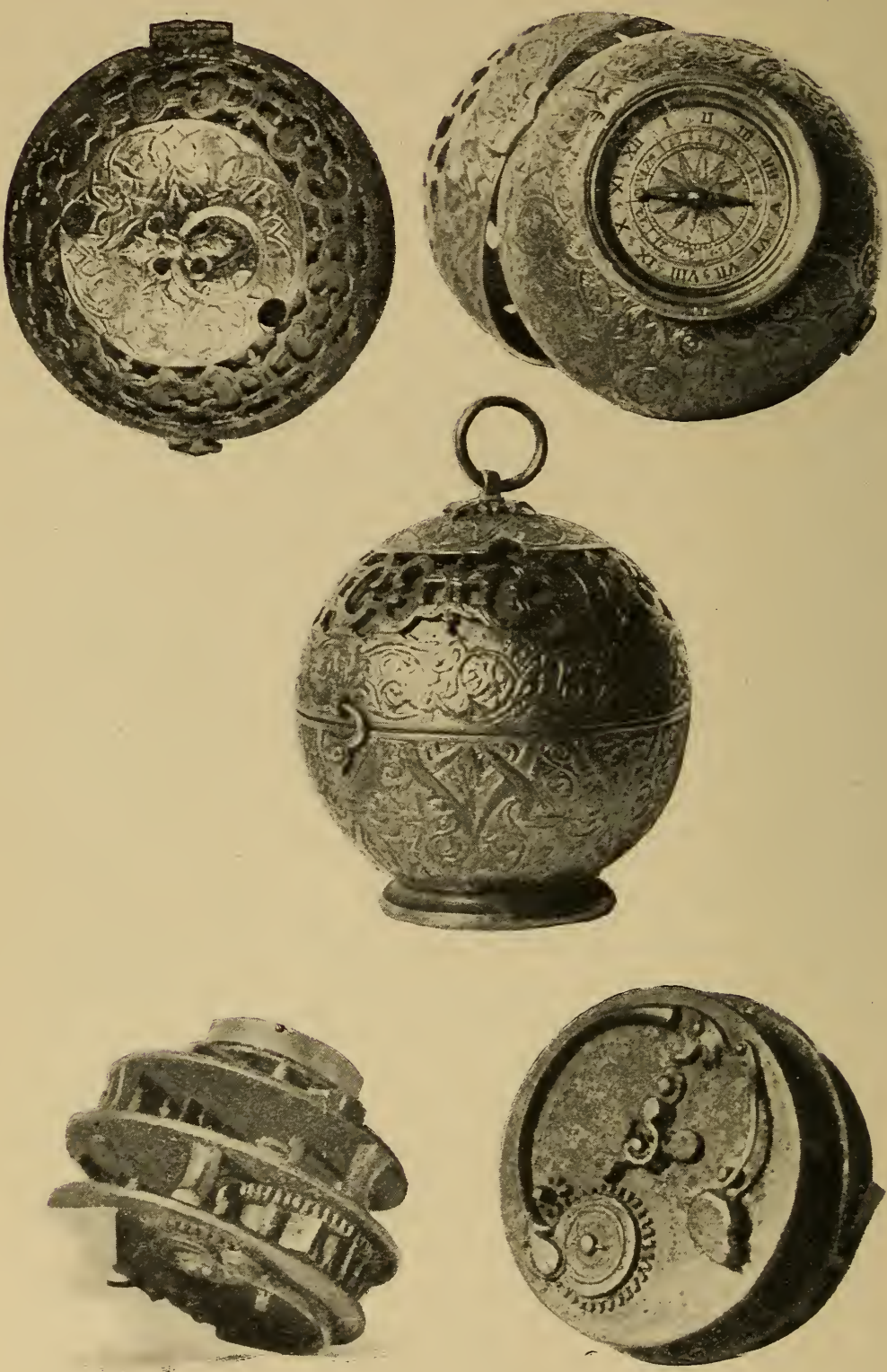

FIGS. 132-136.-Spherical Watch, about 1535.

1, plan of top ; 2 , dial and case partly opened; 3 , elevation ; 4, movement and dial removed from case; 5 , movement showing top plate. 
and not through the intervention of the train, is the count wheel or locking-plate. Above this plate is the striking train; then another plate, between which and the top plate are the going train and escapement. All wheels save the escape wheel are of iron or steel ; the pillars are of iron shaped as shown, the plates and balance-cock are also of iron: there are no screws nor barrels to contain the mainsprings ; one of the mainsprings broken into many pieces is visible in the engraving (Fig. 135). The case is divided in the centre hori-

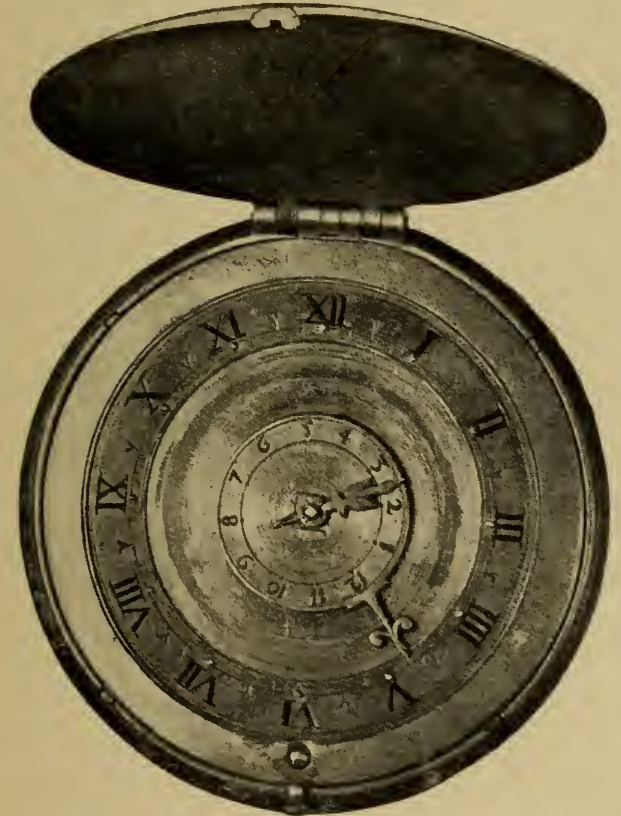

FIG. 137.

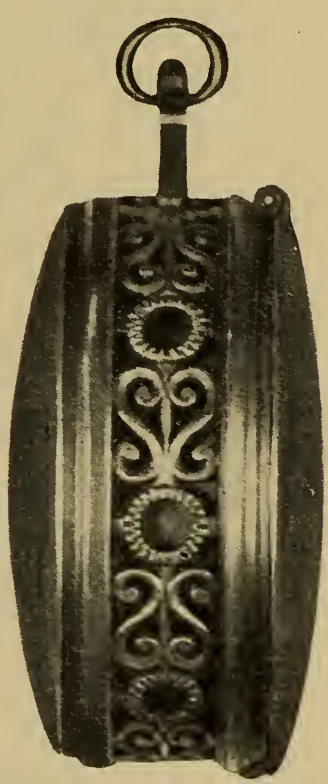

FIG. 138.

Plain exterior Alarm Watch, end of the Sixteenth Century.

zontally and fastened with a hooked catch; it opens on a hinged joint exposing the movement, which occupies the whole of the lower half of the case and extends into the upper part of the sphere. Over the top plate, of which a view is given in Fig. 136, are the primitive stackfreed, the cross-bar balance or foliot and the hammer for sounding the hours on a silver bell fixed to the crown of the sphere; which is perforated as shown in Fig. 132. Through the case and the bell are holes for obtaining access to the winding squares, and near the bottom of the case is another aperture covered by a shutter ; this, apparently, was for the purpose of adjusting the striking of the hours in case it had 


\section{I36 Old Clocks and Watches and their Makers}

been allowed to become incorrect. The movement is fitted to the case in a peculiar way. Inside the lower half of the case are projections, and the movement together with the dial having been pressed into position, is twisted round till corresponding slits catch the projections and make it fast. The fixing is, in fact, what is known as a bayonet joint. This watch, I should judge, dates from about 1535 . M. Paul Garnier has a somewhat similar one, which was stolen from him some years ago, and which he recovered by journeying to America and repurchasing it. It is signed Jacques De la Garde, Bloys, 1551.

Towards the end of the sixteenth century watches designed for use rather than to excite wonder or admiration were constructed with plain exteriors, as in Fig. 137 and 138, which show an alarm watch formerly in the Dunn Gardner collection at South Kensington. The little hand in the centre of the dial is for setting the alarm, and the hour indicator consists of an ornament attached to a disc around the edge of which are figures from 1 to 12 marked backwards, reversely to the usual direction, as a guide for setting the alarm. The hour numerals are

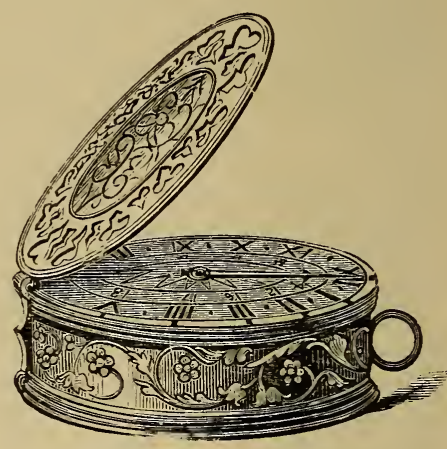

FIG. 139.- Tambourine- or Drumshaped Watch.

on a silvered band with an unusually prominent pin at each hour so that the time could be more readily estimated by feeling. The case is of brass with plain cover and back: the only attempt at enrichment being the fine perforated work around the edge.

Fig. 139 shows a tambourine- or drum-shaped watch from the collection of M. Paul Garnier. The case, brass gilt, is furnished with a bow, and has hinged covers back and front. The front cover is finely engraved and is pierced over each of the hour numerals on the dial. Inside the back cover is a representation of Christ rising from the tomb, well engraved after the design by Albert Dürer. The dial is of silver, finely engraved with rays and flames in the centre, beyond which are the hour marks, with Roman numerals from I. to XII. on the outside of the circle, and smaller figures from 13 to 24 within.

A striking watch in a curious octagonal case of gilded brass fixed to a stand is shown in Fig. 140. The plates of the movement are of iron; it is fitted with the stackfreed, and its construction altogether shows it to be a mid-sixteenth-century production. An interesting 


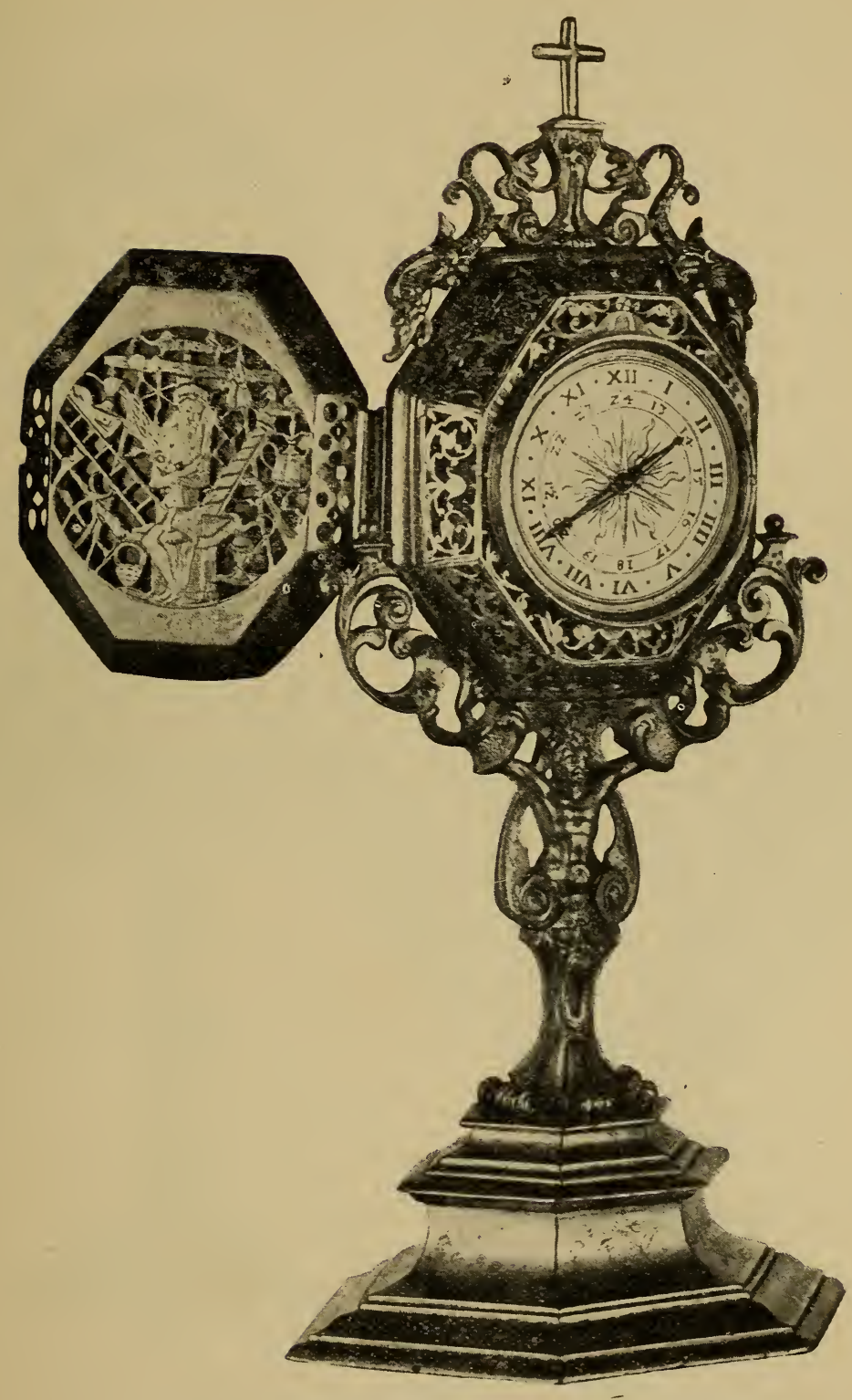

FIG. 140.-Watch in a curious Octagonal Case fixed to a Stand, 


\section{I38 Old Clocks and Watches and their Makers}

feature of this watch is the pierced door at the back, which is shown open in the illustration. Amid the piercing are represented the Man

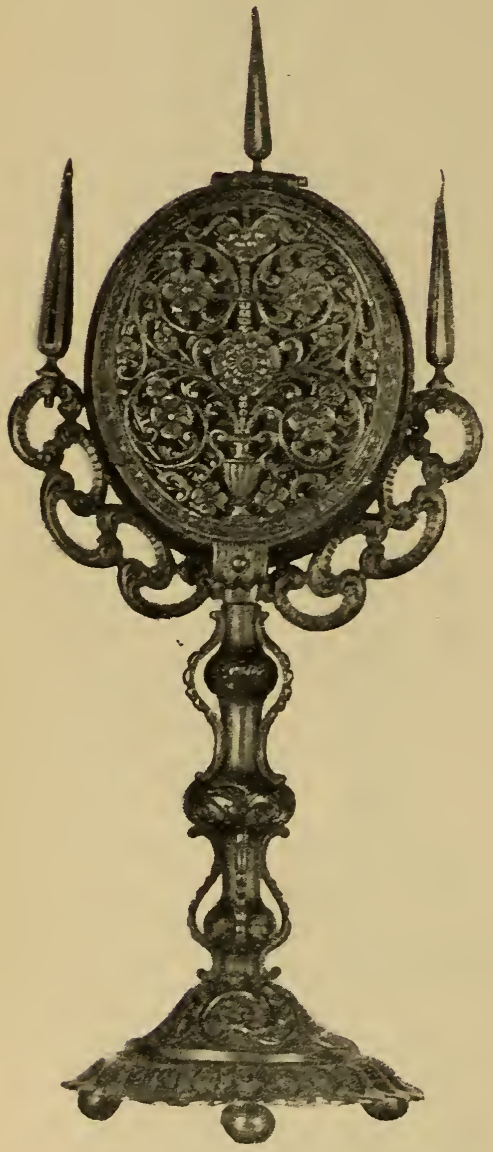

FIG. 141 .

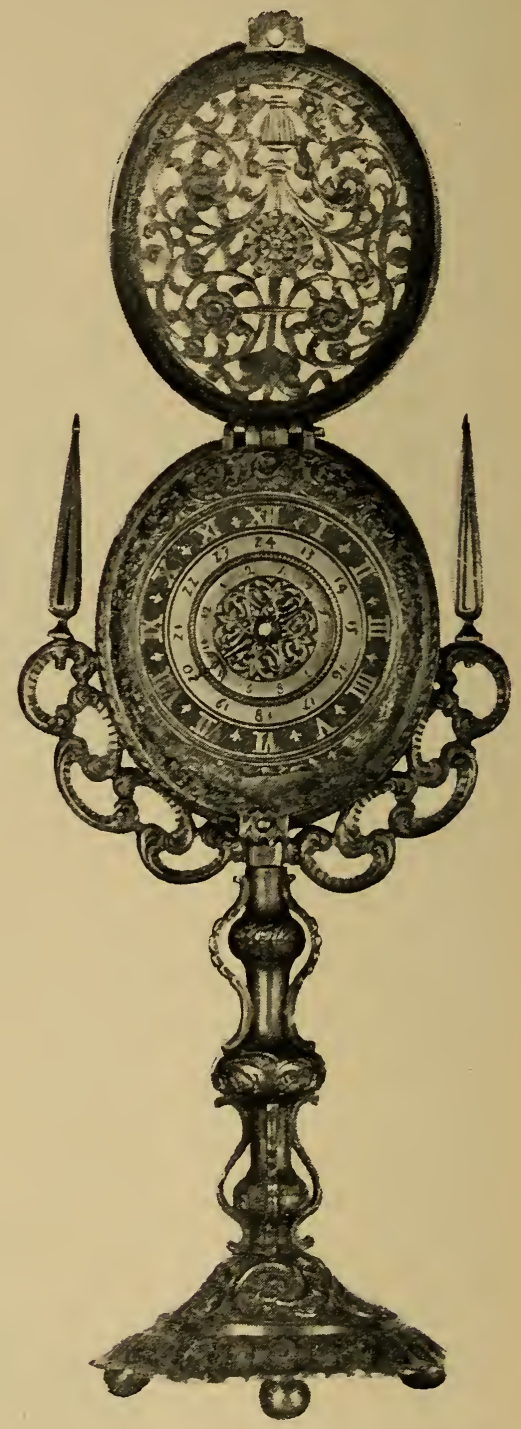

FIG. 142.

Two views of a pretty Pedestal Watch.

of Sorrows preparatory to the Crucifixion and around Him various items appertaining to His torture-a hammer, pincers, sponge, lamp, 
ladder, sword, spear or javelin, staves, lanterns, torches, cup, bunch of hyssop, \&c. Two views of a pretty pedestal watch furnished with an alarm of about forty years later date are given on p. 138. Mr. J. C. Joicey has a somewhat similar piece.

In the British Museum is a splendid watch made by Nicklaus Rugendas, of Augsburg. The case of metal, gilt, with open work very nicely pierced, is of an oval shape measuring $2 \frac{3}{4} \mathrm{in}$. by $2 \frac{1}{4} \mathrm{in}$. and $1 \frac{3}{4}$ in. thick. It is mounted on a plain brass pillar 4 in. high. The hours are shown on a silver dial, and the minutes on a gilt bevelled outer rim which really forms part of the case. This arrangement and the fact that each five minutes space is figured, as is the modern custom, may lead to the assumption that the concentric minute indicator was a later addition; but Octavius Morgan, in whose collection the watch was, expressed his conviction (Archaologia, vol. xxxiii.) that it formed part of the original construction, and an examination of the hand-work which I have been allowed to make, quite removed a doubt I previously felt

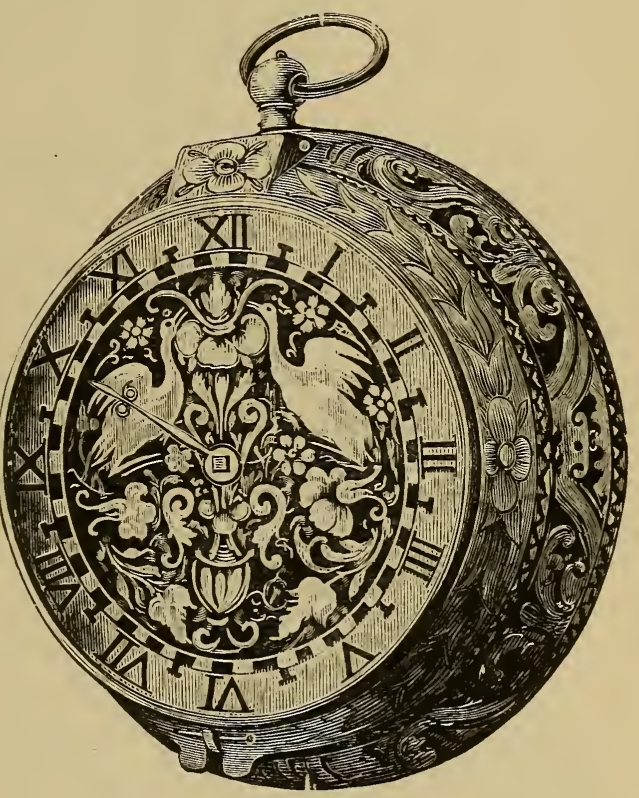
as to the correctness of his judgment. The internal arrangement shows considerable ingenuity, every atom of the space being utilised to the best advantage. There are four mainsprings, but no fusee. Between the dial and the movement is a small bell on which the quarterhours are sounded. The hours are struck from one to six and then over again in conformity with what was formerly an Italian method of computation, the hour bell being oval to suit the shape of the case; at the back is a large bell on which an alarm may be rung. The train wheels are of brass, and the quarter part of steel. 


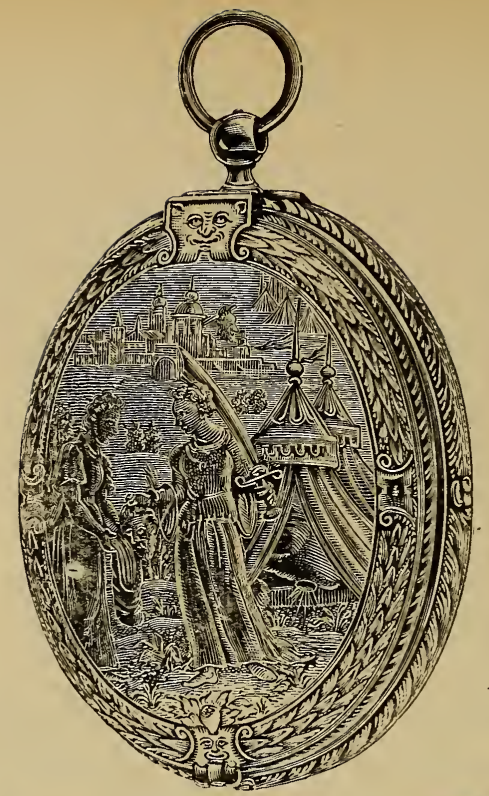

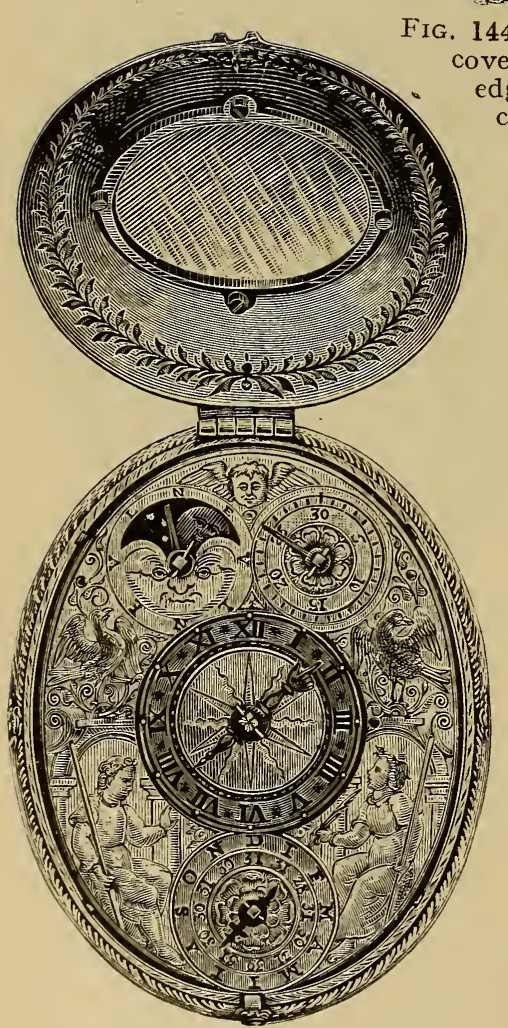

FIG. 145.-Dial with front cover raised.

\section{ack} over and edge of case.
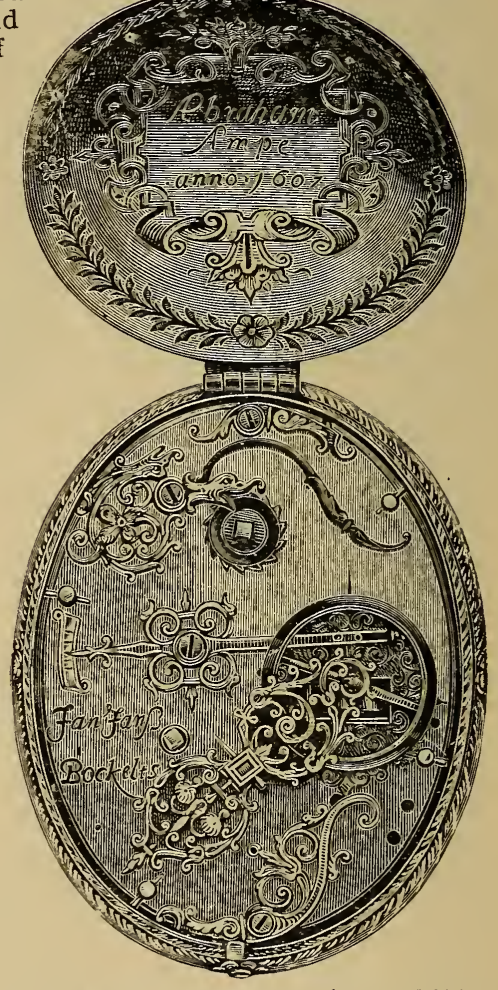

FIG. 146.-Back cover raised exhibit. ing movcment. 
Mr. Morgan considered this watch to be a production of the second quarter of the sixteenth century, but the general style of the work and the construction of the movement negative such an assumption ; 1610 or a little later would be nearer the correct date. Messrs. Patek Phillipe \& Co. have an octagonal calendar watch by the same maker, which, judging from a photograph of the movement, I should say was produced about 1630 .

In the Vienna Treasury is a clock marked "Nicklaus Rugendas junger," dating from the middle of the seventeenth century.

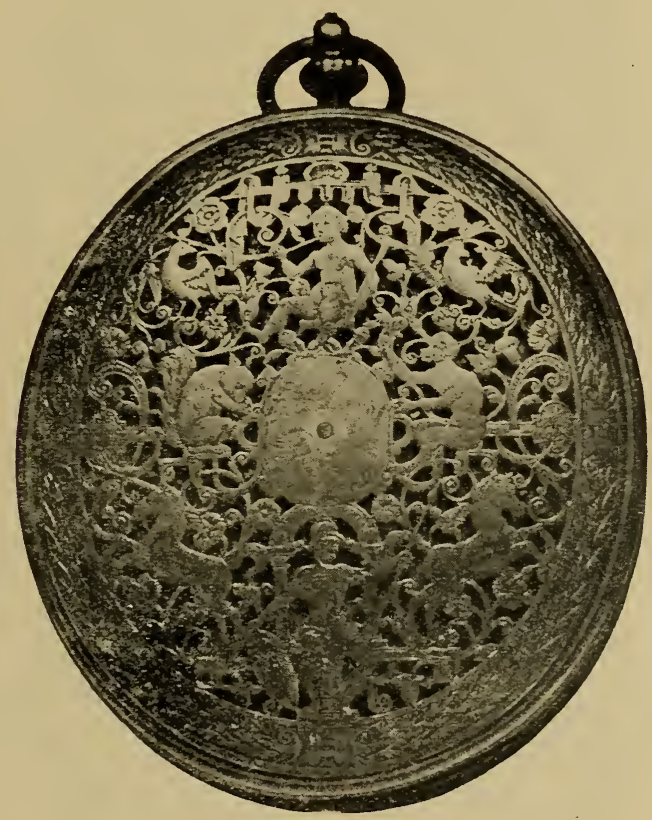

FIG. 147.-View of back.

Fig. 143 is an exterior view of a large circular clock-watch from the collection of the late Mr. Evan Robeits. It is unnamed, and is most probably of German or Dutch origin ; the silver dial and brass openwork case are very fine, as may be judged from the drawing. The stackfreed and the wheels are of steel, and the plates of brass. This watch has been pronounced to be a production of the second quarter of the sixteenth century, and the construction in many respects agrees with that period.

Three views of a splendid oval watch from the Schloss collection 


\section{I42 Old Clocks and Watches and their Makers}

are on p. 140. Fig. 144 shows the back cover and edge of the case ; Fig. 145 shows the dial with the front cover raised, and Fig. 146 the

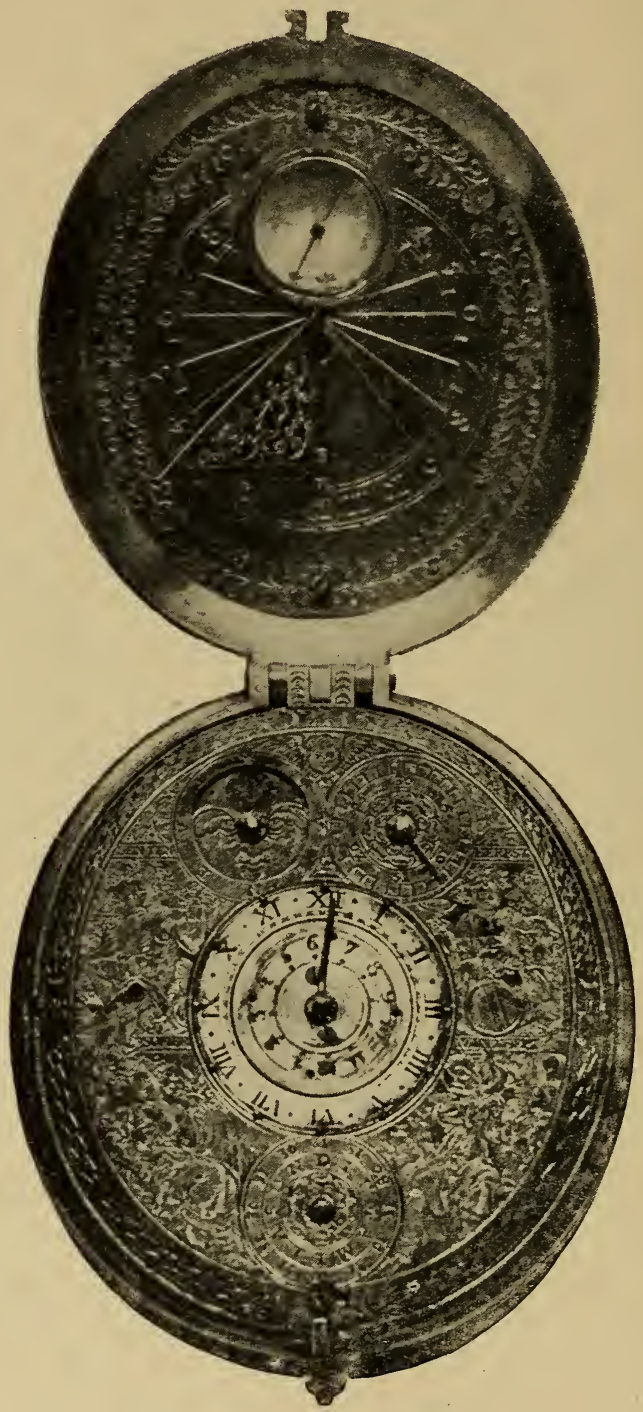

FIG. 148.-Dial with Cover open.

back cover raised, exhibiting the movement. The case is of brass, gilt and very finely chased. The front cover is pierced to receive a small 
glass, allowing the centre of the dial to be viewed without opening the cover. This style of glass, and the method of fixing it by means of a loose ring, is perhaps the most primitive; and taking the date on the inside of the back cover (1607) to represent the period the watch was made, it may be assumed to be an early instance of the application. The dial, also of brass gilt, is very handsome. On looking at the movement (Fig. 146) a lever carrying two pins at one end and pointed at the other may be observed. These two pins are of stiff bristle, and

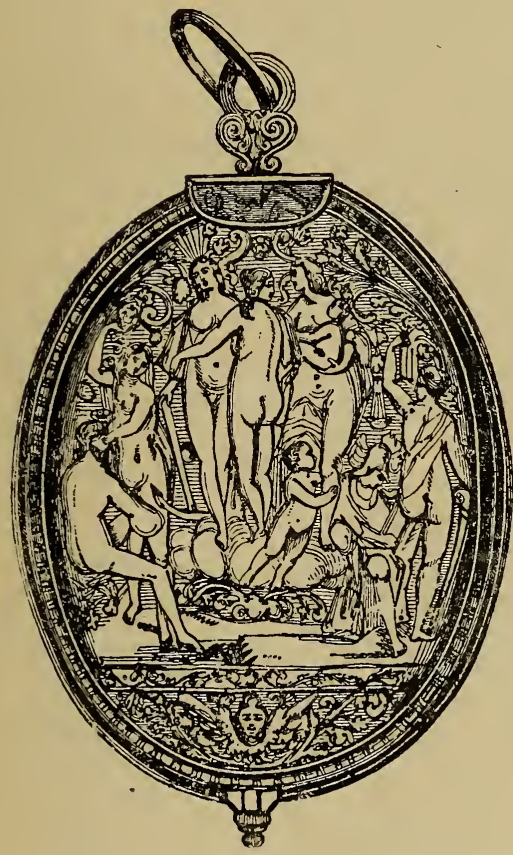

FIG. 149.-French Astronomical Watch. (Two views).

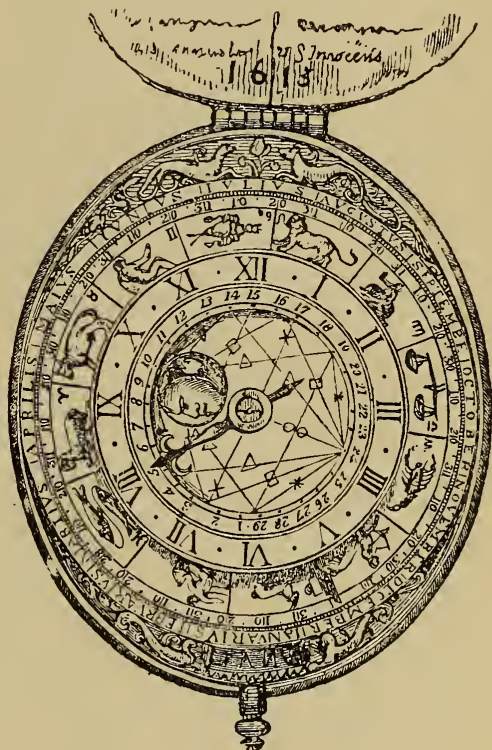

FIG. 150.

by shifting the lever they may be caused to approach or recede from the arm of the balance, whose path they intercept. In this way the vibration of the balance and the timekeeping of the watch were controlled. The pointed end of the lever traverses a divided arc, and serves to indicate the movement given to the lever. At the top and bottom of the plate are pivoted bolts, which pass into holes in the edge of the case to secure the movement in position.

In the Pierpont Morgan collection is an oval brass watch of extreme beauty signed " Jan Jansen Bockelts van Aacken." dating from about 
1640. It is shown in Figs. 147 and 148. Round the sides of the pierced case are a greyhound chasing a hare and a hound chasing a stag amidst floral designs. The back is finely engraved, representing figures of a naked shepherd with his crook and horn, a squirrel, and a monkey. In the centre a river scene, beneath the figure of a warrior in armour with a prancing horse on each side, intermixed with scrolls and flowers. The outside of the lid is engraved with allegorical subjects, one represents Abraham offering up Isaac; upon the righthand top corner is a scroll on which is engraved, IAN. IANSEN-BOCKELTZ INV. ET SCVLP. The inside of the lid, which together with the dial plate is brass gilt, contains a compass and a sun-dial with a movable gnomon. The dial plate is very fine. There is a small silver dial with alarm dial in the centre, and also a dial for the moon, one for the minutes, one for months-the seasons are engraved with LENTEN HERBST. WINTER.

Adam Thomson mentions an interesting astronomical watch of French make which is shown in Figs. 149 and 150. It has a silver case highly ornamented, with mythological subjects elaborately chased, bearing the following inscription on the inside of the back cover: "From Alethea Covntess of Arvndel, for her deare sone, Sir William Howard, K.B. 1629." It is of an oval form, the extreme size $2 \frac{1}{2}$ in., and $1 \frac{1}{2}$ in. in thickness. It struck the hours and has an alarm; showed the days of the week, the age and phases of the moon, with the days and months of the year, and the signs of the zodiac. On the inside of the front cover there is a Roman Catholic calendar with the date 1613. The watch movement is inscribed " $\mathrm{P}$. Combret, à Lyons." A watch by Combret with a shell-shaped silver case is in the South Kensington Museum.

Toy Watches.--These were occasionally shaped to imitate books, animals, fruit, flowers, and insects.

Of cases formed to resemble books several examples are known to exist. A very early watch of this kind dating from the first half of the sixteenth century is shown, rather smaller than the actual size, in Figs. 151, 152, and 153. On the back plate of the movement is the maker's punch mark, F.C., and another impression partly obliterated, which appears to be a pineapple. There is a stackfreed for regulating the force of the mainspring, and sticking up from the longer end of a bell-crank lever is a short stiff bristle, against which the cross-bar balance banks. By means of its shorter arm this lever may be moved and its position noted by an index on the plate. 
In the British Museum is a book-shaped watch dated 1550. The specimen shown in Fig. 154 was in the Bernal collection which was dispersed by auction in 1855, and belonged to Bogislaus XIV., Duke of Pomerania, in the time of Gustavus Adolphus. On the dial side there is an engraved inscription of the duke and his titles, with the
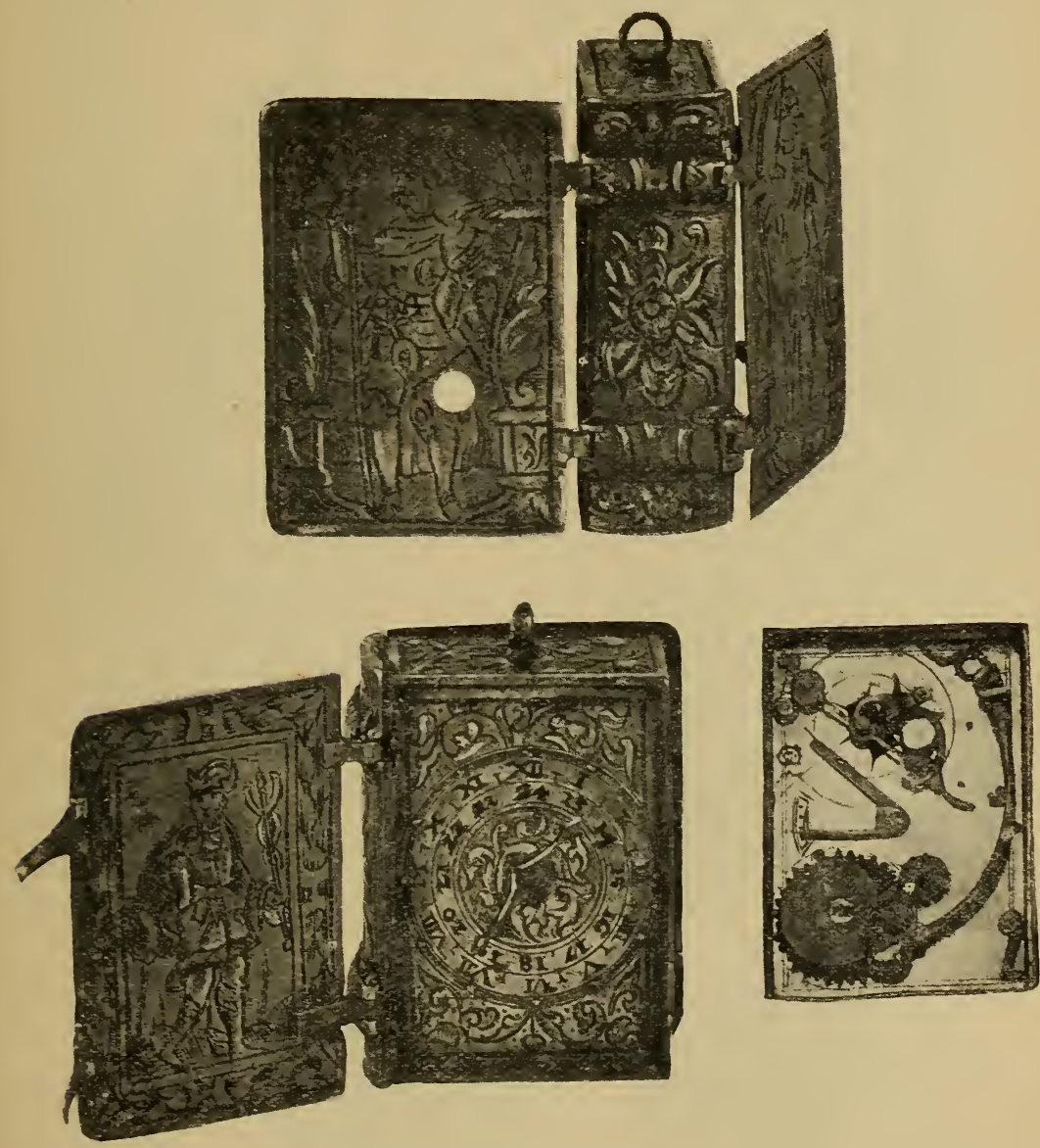

Figs. 151-153.- - Sixteenth-Century Book-Watch. Outside with Covers open, inside of front Cover and Dial. View of mechanism inside back Cover.

date 1627, together with his armorial bearings: on the back there are engraved two male portraits, buildings, \&c. The covers are of brass gilt; the clasps and other ornaments are of silver; the dial is of silver, chased in relief; the insides of the covers are chased with 


\section{I46 Old Clocks and Watches and their Makers}

birds and foliage. There are apparently two separate movements, and a large bell at the back; over the bell, the metal is ornamentally

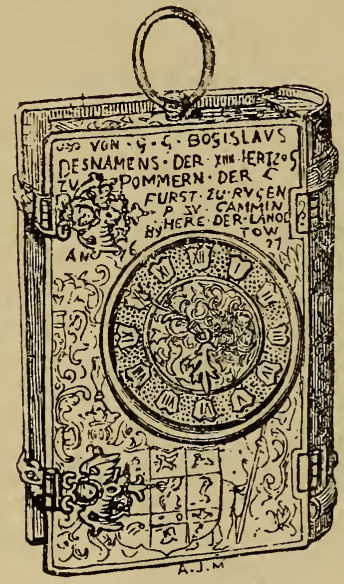

FIG. 154.--Interesting Book-Watch.

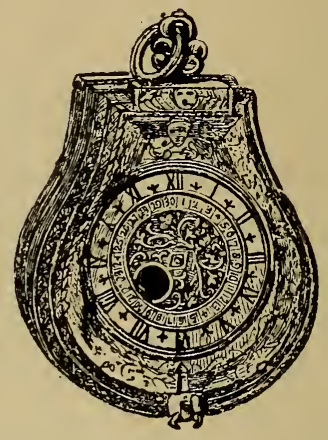

FIG. 155.-Watch in the form of a Padlock.
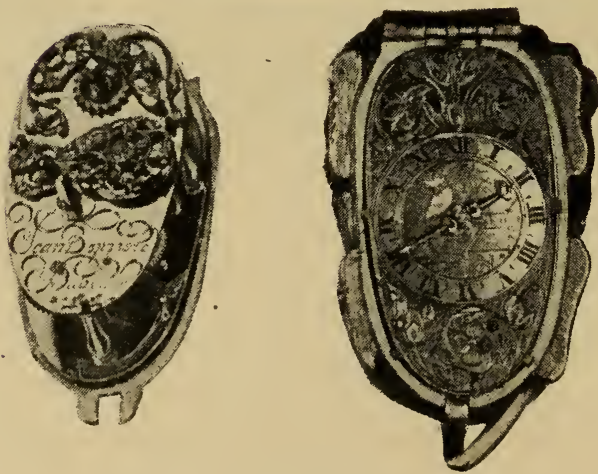

FIG. 156.-Lion-shaped Watch. 


\section{Portable Timekeepers}

pierced in a circle with a dragon, \&c.; the sides are pierced and engraved in scrolls. The maker's name is "Dionistus Hessichti."

Fig. 155, also from the Bernal Collection, is in the form of a padlock. It has a crystal front and ribbed crystal back, gilt metal engraved mounting, dial of gilt metal; the days of the month are noted on a silver circle, with a steel plate, apparently for the moon's

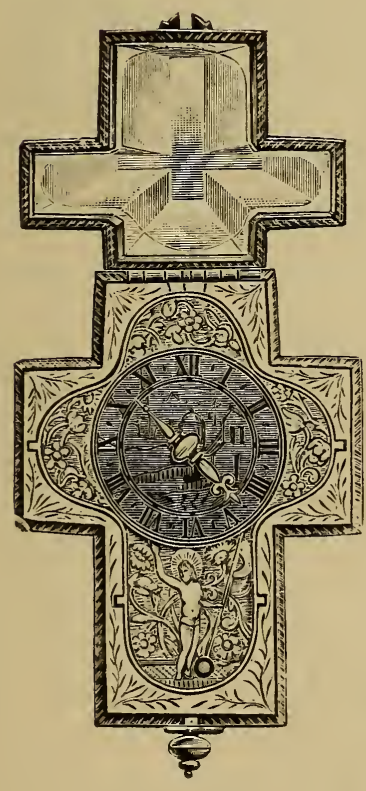

FIG. 157.

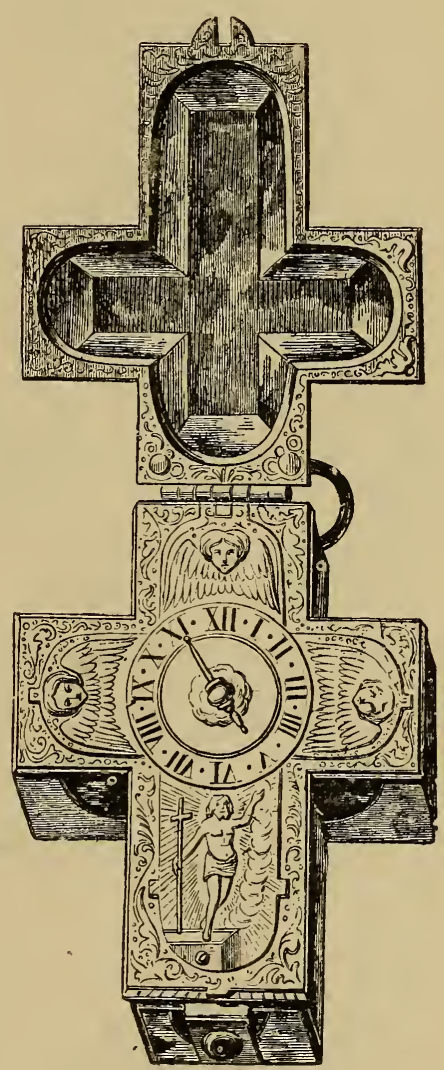

FIG. 158.

age. The maker's name is Gio. Batt. Mascarone, and it is probably sixteenth-century work.

Three views of a peculiar watch, dating probably from about 1600, are given on p. 146. The case, of silver, is in the form of a lion, the tail being looped, evidently for the attachment of a guard or other suspender, The movement is inscribed, "Jean Bap- 


\section{I48 Old Clocks and Watches and their Makers}

tiste Duboule." A watch by the same maker in a nut-shaped case forms part of the Wallace collection at Hertford House.

Of the other more quaint and grotesque designs for watch cases favoured by the early makers may be mentioned one in the form of an eagle, which was in the collection of Lady O. Fitzgerald. It illustrated the story of Jupiter and Ganymede, and could either be suspended from a ring in the back of the bird or rested by its claws on $a$ flat surface. In the British Museum is a watch shaped like an

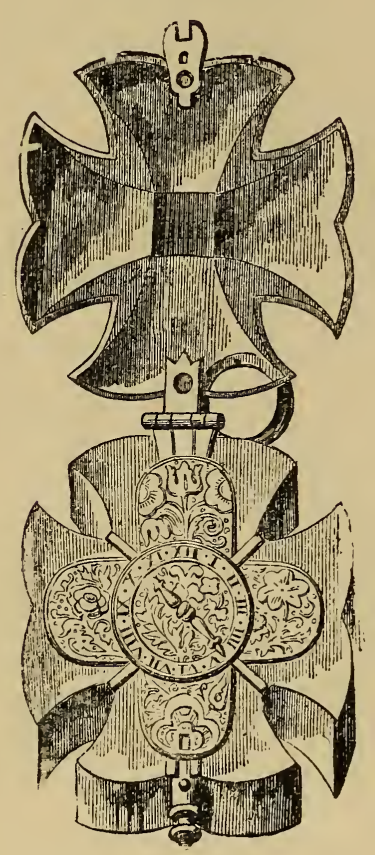

FIG. 159.

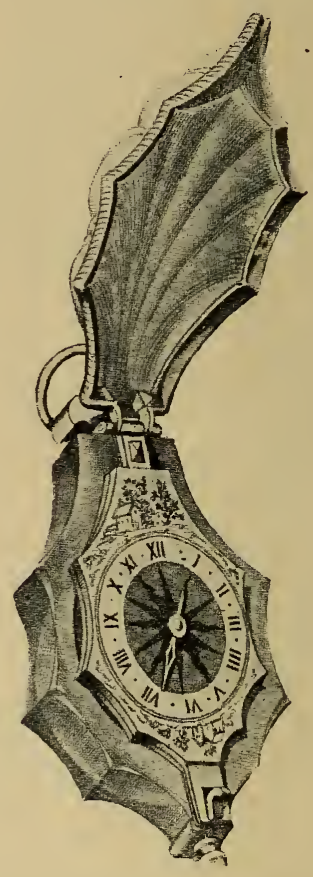

FIG. 160.

Pectoral Cross IVatches.

acorn, another resembling a dog, and one with silver cases made in imitation of cockle-shells. In the South Kensington Museum is a French watch resembling a pelican, and a diminutive timekeeper concealed in one of two enamelled cherries with stalks connected was in the Mainwaring collection

"Memento Mori" watches in the form of a Latin cross, and usually with scenes from the life of the Saviour engraved on the dials, were for a long period a favourite pattern, especially with French artists, among whom they were known as montres d'abbesse. Dubois says 
cruciform watches were probably devised by Myrmécides, a watch. maker of Paris, who flourished between 1530 and 1550, and whose name appears on several early specimens. They appear to have been

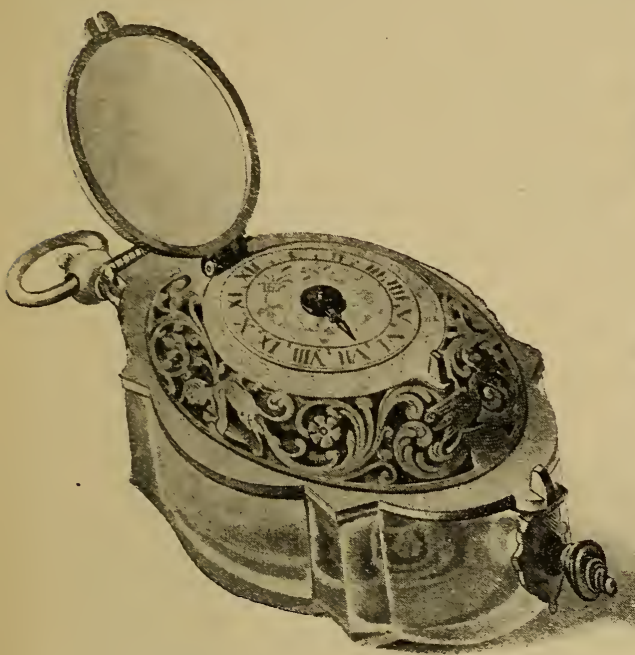

FIG. 161.-Clock-Watch in Crystal case.

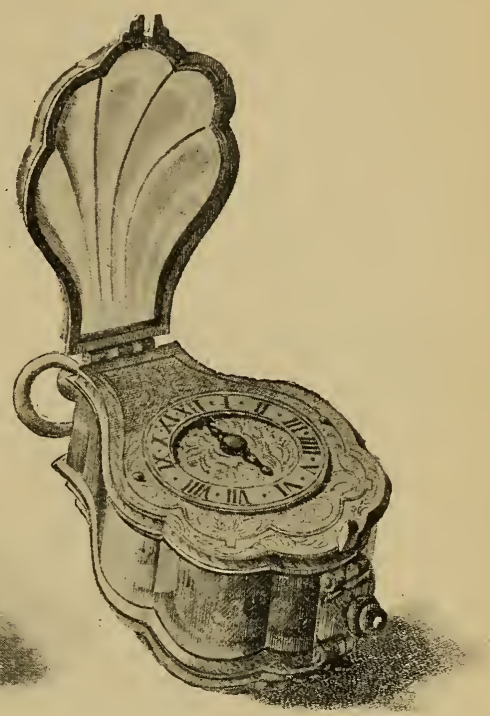

FIG. 162.-Watch in the form of a Cockle-shell.

worn, generally, on the breast, and are often spoken of as pectoral cross watches. Of three in the British Museum, one, in a case of rock crystal, very similar to Fig. 157, was made by Jean Rousseau the elder about 1580; another, also a sixteenth-century production, is by Tinnelly, Aix; the third dates from the latter part of the seventeenth century, and is cased in emerald glass.

The watch, Fig. 158, which is unnamed, seems to be late sixteenth-century work.

In the Archaological Journal is mentioned a Latin cross watch by the celebrated Johannes van Ceulen, which has a cover of crystal and is enamelled in opaque colours; on the front the Man of Sorrows and emblems of the Passion, and on the back the Crucifixion.

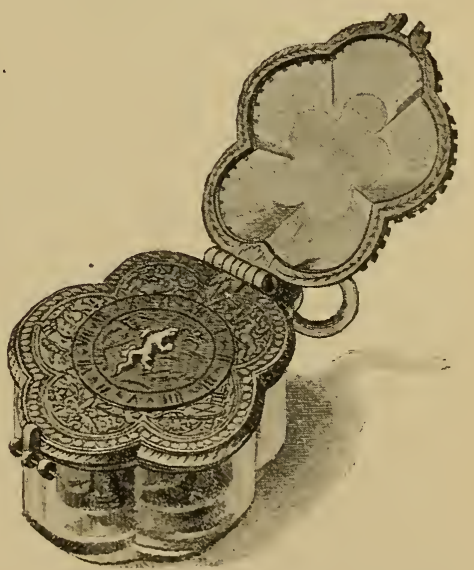

FIG. 163.-Watch with very primitive mechanism. 
Of three cruciform watches in South Kensington Museum, one, dating from about 1590 , is signed "Senebier" ; another, of slightly later date, bears the initials "N.R." ; and the third, which forms part of the Salting collection, has a silver and crystal case, and is by Charles Bobinet, a French seventeenth-century maker of repute.

The Maltese cross watch, Fig. 159, from Dubois' historical work is a sixteenth-century production of French origin, and a much rarer form than the Latin cross.

A very early crystal case watch by Thomas Franck, from the Soltykoff collection, is shown in Fig. 160.

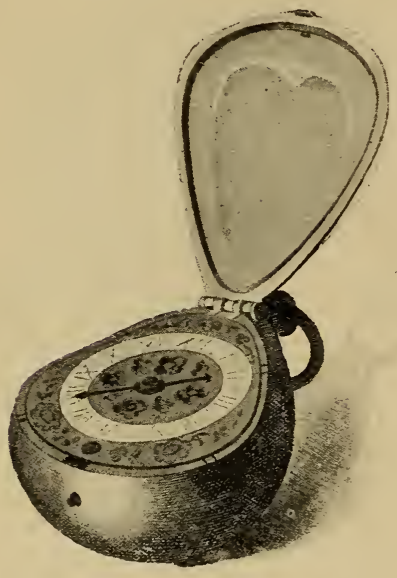

FIG. 164.-Pear-shaped Watch.

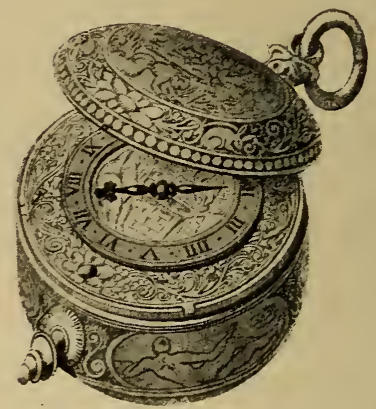

Fig. 165.-Circular Watch, dating from about 1605 .

In Fig. 161 is shown a clock-watch by Conrad Kreizer, from the Soltykoff collection. The case is of crystal, the dial of silver and the cover of brass gilt. A peculiar feature is the oval, raised, pierced work of brass, introduced evidently to allow the sound of the bell to be heard more distinctly. The movement is of a primitive character, and the maker is said to have been contemporary with the brothers Habrecht. An octagonal watch in the South Kensington Museum, signed "Conradt Kreizer," is certainly early-seventeenth-century work.

The crystal case watch in the form of a cockle-shell, shown in Fig. 162, also from the Soltykoff collection, is a late-sixteenth-century production. It has covers back and front; the dial is gilt, with silver hour band and steel hand. 
Another specimen trom the Soltykoff collection is a crystal escallop case, shown in Fig. 163, has very primitive mechanism, by Phélisot, horloger de la ville de Dijon. The dial, finely engraved, is of silver, with gilt hour-band; the hand is in the form of a lizard.

The pear-shaped watch shown in Fig. 164 was made by Conrad Kreizer, of Strassburg, and is also gathered from the Soltykoff treasures. A similar watch is in the British Museum.

The circular specimen shown in Fig. 165, selected from the same repository as the preceding, has covers back and front; around the band are figures typ:cal of spring, summer, autumn, and winter. The

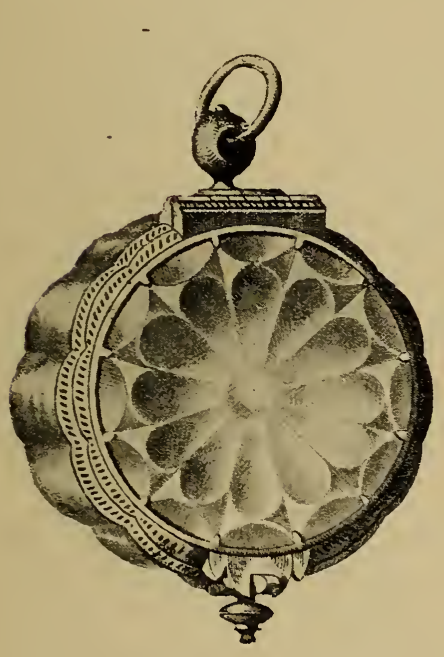

FIG. 166.-Crystal Case Watch, about 1640.

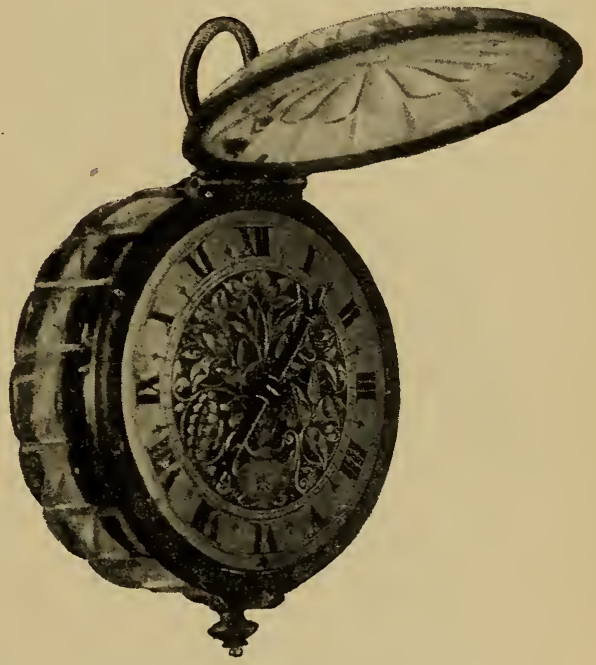

FIG. 167.-Watch by Benjamin Hill.

dial is of silver gilt, with a white band on which the hour numerals are engraved. In the centre of the dial is engraved a representation of Christ and the woman of Samaria; on the upper cover is portrayed the spectacle of Mary Magdalene washing the feet of Jesus, and on the lower cover another Biblical scene. The movement is inscribed " James Vanbroff," and it dates from about 1605.

Fig. 166, with crystal case in the form of a bonbonnière, is from the Soltykoff collection. From the movement, which is inscribed "Denis Bordier," one may judge that it was made about 1640.

Of a little later date is the beautiful specimen by Benjamin Hill, a well-known London maker, which is shown in Fig. 167.

Of all the quaint fancies exhibited in the formation of early watch 


\section{I52 Old Clocks and Watches and their Makers}

cases, none are, I think, more charming than the various floral designs popular during the sixteenth and seventeenth centuries.

The Fleur-de-lis, the national flower of France was favoured by early French makers. The opening bud, from the Soltykoff collection, which is shown in Fig. 168 must be admitted to be a very pretty artistic conceit. The dial and the covers or leaves are of silver, and so is the twisted stalk that forms a ring for the attachment of a chain or cord. The movement bears the name of Rugend of Auch, and dates from the beginning of the seventeenth century. A very similar specimen by Bayr, who was, I think, a Dutch maker, is to be seen

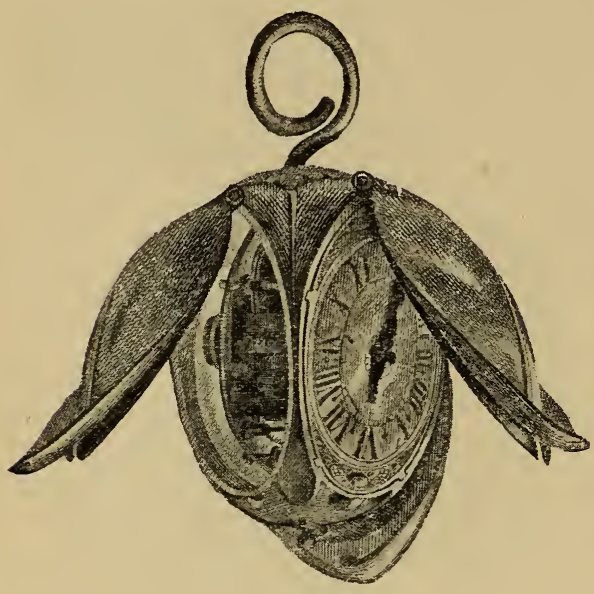

FIG. 168.

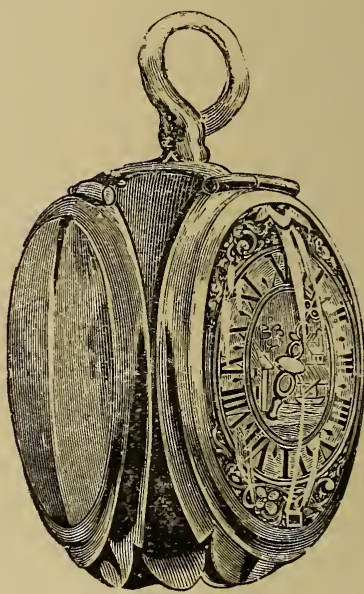

FIG. 169.

Fleur-de-lis Watches.

In the British Museum. Another by J. Dracque of Nerac is in the Garnier collection.

A larger floral counterfeit appears in Fig. 169. The body of the case is of gold, and there are three bezels or covers of silver, each comprising a piece of rock crystal formed in the shape of a tulip petal. The hand is of gold, the dial of silver, with a landscape engraved thereon. Through one cover the dial is seen, and through the other two the movement is visible. It has a three-armed steel balance and a balancespring. Jean Rousseau the younger, who is said to have died in 1684, was the maker of this watch. The presence of a balance-spring would therefore stamp it as one of his later productions.

There is a splendid fleur-de-lis watch among the Nelthropp collection at the Guildhall Museum, without a balance-spring, by F. Sermand, 
dating from about 1650 ; another at the South Kensington Museum, and one at the British Museum by Henry Ester.

A very pretty floral watch of an early date, from the Soltykoff

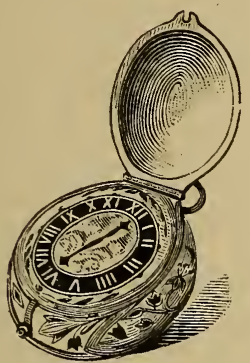

FIG. 170.

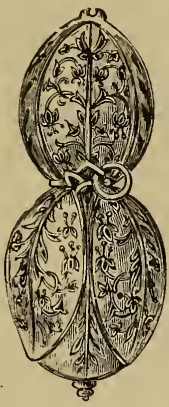

FIG. 171.

Two views of a pretty Floral Watch, about 1600 .

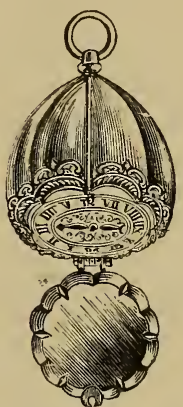

FIG. 172.

Watch in the shape of a Poppy-bud.

collection, is shown in Figs. 170 and 171. The case is gold, adorned with fine floral ornaments in green and Cassius purple enamel on a white ground. The dial is of gold, decorated also in green and purple enamel on a white ground. The plates and train wheels of

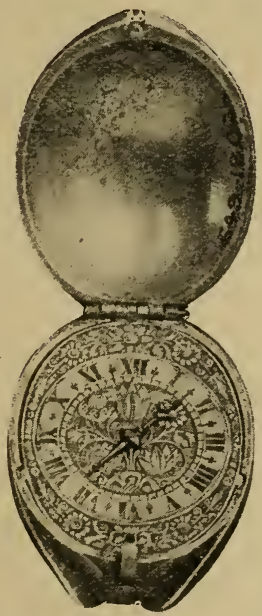

FIG. 173.

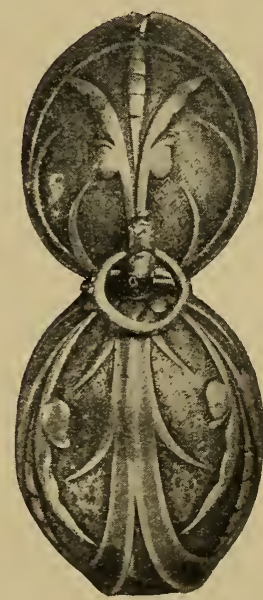

FIG. 174.

Front and back views of a pretty English Watch, about 1610 .

the movement are of brass. It is provided with a fusee with catgut and a circular balance. The movement is signed " J. Jolly," and dates from about 1600. Fig. 170 shows the dial and edge fairly well, but does not give a good idea of the elegant form of the case, which 


\section{I54 Old Clocks and Watches and their Makers}

will be better gathered from Fig. 169, which is a back view with the

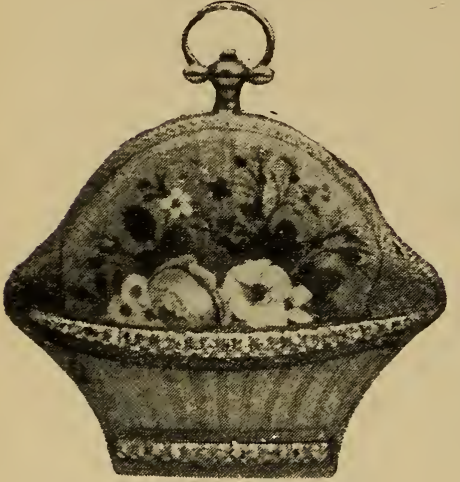

FIG. 175.- Wratch Case in the form of a basket of flowers.

\section{cover open.}

Fig. 172, another diminutive watch of a later date from the same collection, is in the shape of a poppy bud. The case is of amber, with mountings of gold, finely engraved and maintained on the amber by means of close gold wire running down the angles to the knob which holds the ring on which the chain is to be fastened. The dial is of silver, with enamelled ornaments; it is covered with a piece of rock crystal fitted in a bezel.

Front and back views of a very pretty English watch in the form

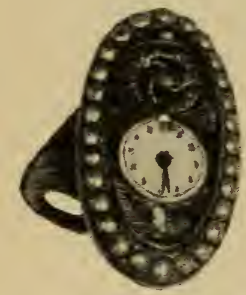

FIG. 176.-Watch set in a finger-ring.

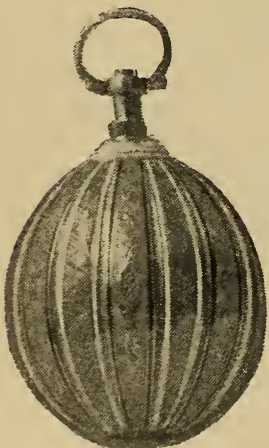

FIG. 177.

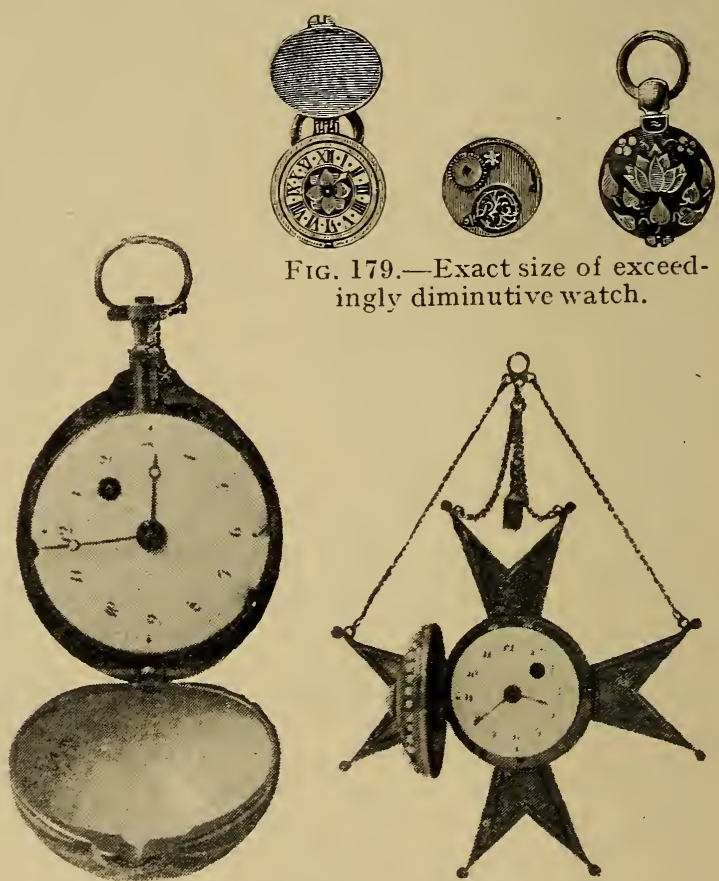

FIG. 178.

Olive-shaped Watch.

FIG. 180.

Star-shaped Watch.

of a flower bud, which formed part of the Dunn Gardner collection, and was purchased for the South Kensington Museum, where it may 
be seen, are given in Figs. 173 and 174. It dates from about 1610, and is inscribed " Henry Grendon at ye Exchange Fecit."

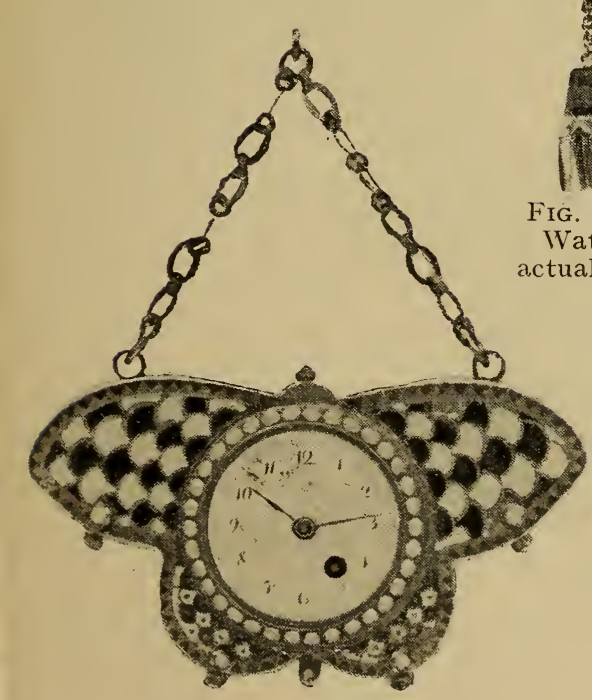

FIG. 182.

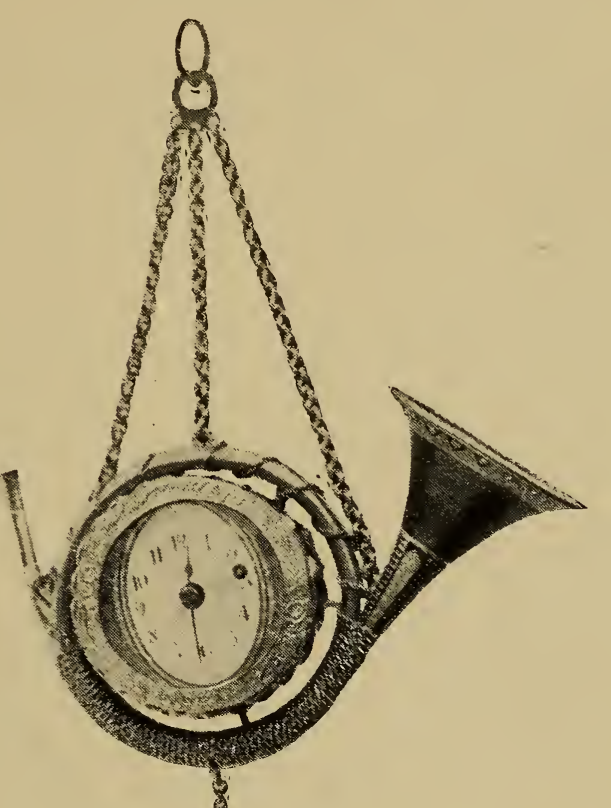




\section{I56 Old Clocks and Watches and their Makers}

In the British Museum are three watches in the form of insects or fritillary flowers. One labelled as English work, by Edward Bysse, is in a nielloed silver case. Another, also English, in a silver case, is by Thos. Sande.

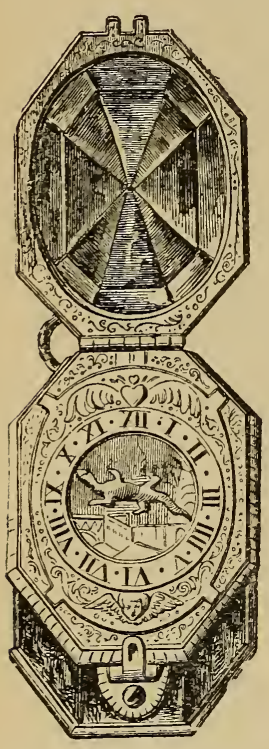

The watch-case in the form of a basket of flowers (Fig. 175) is of gold, enamelled and studded with diamonds.

A watch set in a finger ring is shown in Fig. 176.

Figs. 177 and 178 represent an olive-shaped watch in the Schloss collection. The case of gold is beautifully enamelled in green and dark blue.

Three views portray the exact size of an exceedingly diminutive watch. Its dial and tiny case of gold are beautifully decorated with champ levé

FIG. 184.-Crystalcase Watch.

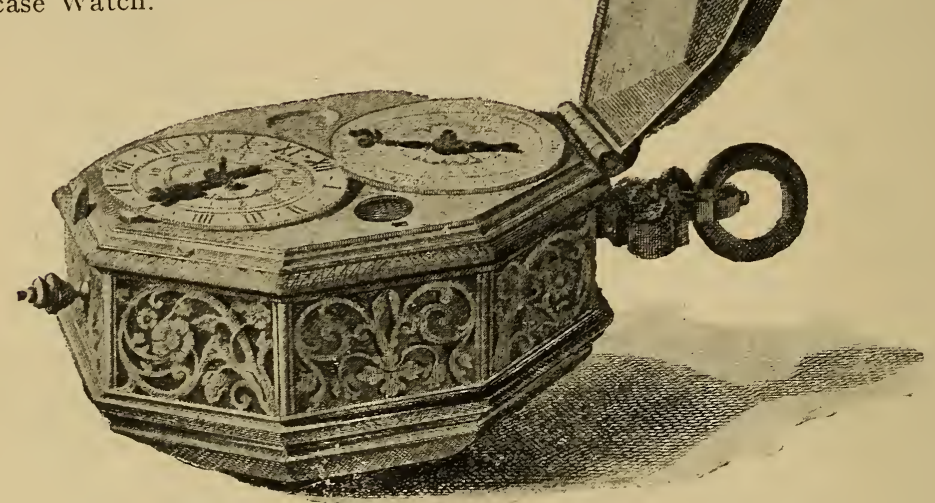

FIG. 185.-Late-Sixteenth-Century work.

enamel, and the movement is fitted with the primitive stackfreed for regulating the force of the main-spring (Fig. 179). One might with tolerable confidence say that this is the smallest enamelled watch of the stackfreed period. 
A pretty star-shaped watch, decorated with enamel and pearls, is shown to two-thirds the actual size in Fig. 180.

The miniature watch surrounded by a horn or trumpet (Fig. 181) is engraved to the actual size.

Front and back views of a superb specimen in the form of a buttertly are given in Figs. 182 and 183 . It is impossible to give more than an idea of the choicely enamelled back by reproduction in black and white.

Most of these "toy" watches are of French or Swiss origin. It

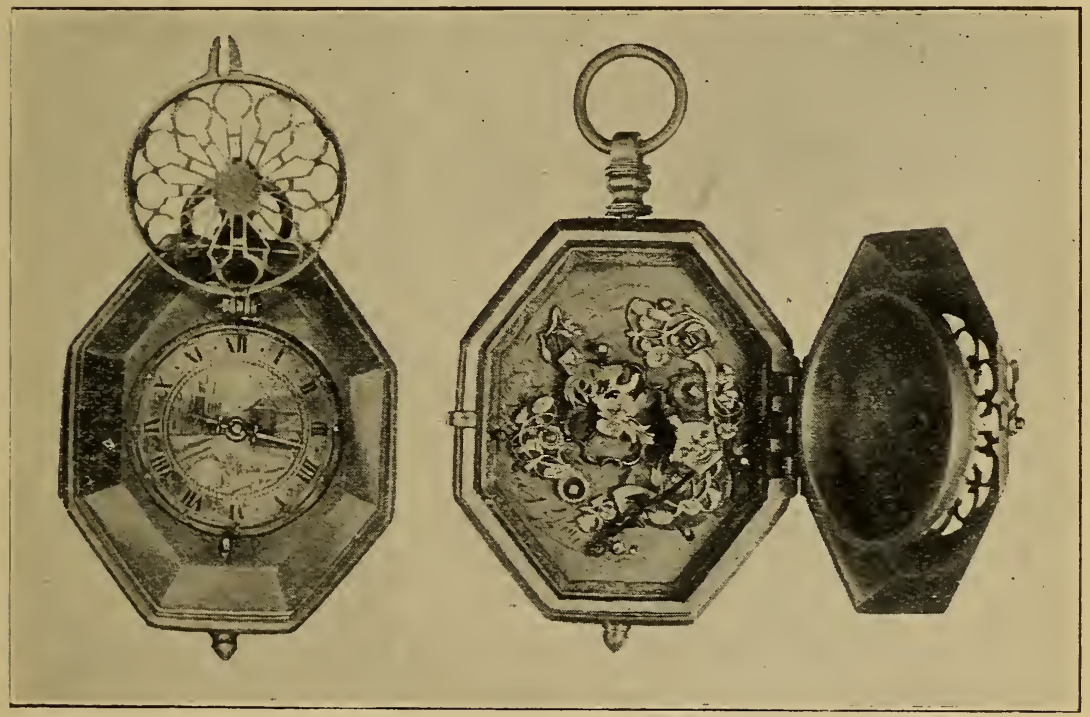

FIG. 186.-Striking or Clock-Watch.

is curious to note in eighteenth-century advertisements the references to the sellers of them as "toymen."

Irregular-shaped octagonal watches are met with among the productions of the latter part of the sixteenth till quite the close of the seventeenth century. Many variations in the size and material of the cases were made by French and afterwards English artists to suit their own tastes or the desires of their patrons; the cover was often of crystal, lapis lazuli, agate, or other semi-precious stone. The crystal case specimen (Fig. 184) is an early one, apparently of French origin. . Another, from the Soltykoff collection, is shown in Fig. 185. The covers are of silver, and by means of a second dial 


\section{I58 Old Clocks and Watches and their Makers}

and two small apertures in the dial plate it indicated the sign of the zodiac corresponding to the month, the day of the month, the day of the week, and planetary motions. It also struck the hour and provided an alarm. It is unnamed, but probably late-sixteenthcentury work. Back and front views of a striking or clock-watch of nearly the same period are given in Fig. 186. There is a cagelike covering over the dial, and the back is similarly perforated. Very nice engraving is to be seen on the head of the hammer as well as on the balance-cock and other fittings connected with the plate of the movement, which is signed "J. Boudon, à S. Flour"

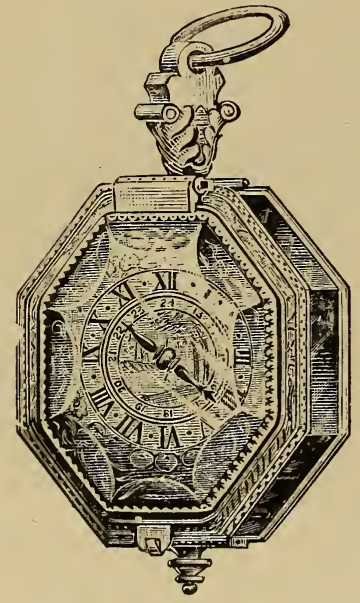

FIG. 187.--Early-SeventeenthCentury work.

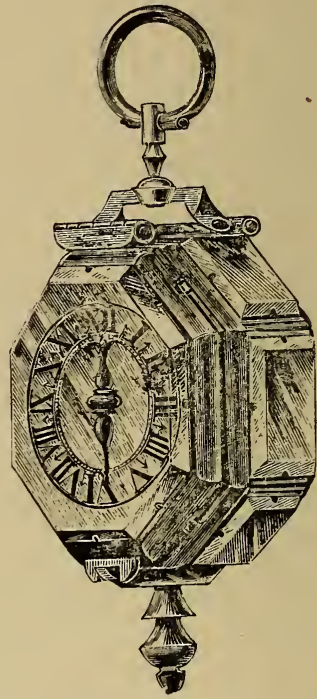

FIG. 188.-Watch by Jeremie East, about 1600 .

Fig. 187 is probably French early-seventeenth-century work. It has covers of crystal and side panels of brown topaz. The movement is signed " J. Dubie à Parıs."

Fig. 188 represents a watch in a case of crystal, which is in the possession of Messrs. Lambert, who allowed me to examine it. On the plate of the movement is inscribed " Jeremie East, fecit," and it is, I should say, a very early example of English work, dating from not later than 1600 .

In Fig. 189 is shown a superb watch of large size in an octagonal case of crystal, with a crystal cover and gilt brass mountings. The movement is oval, and bears the signature of "P. Cuper," who was 


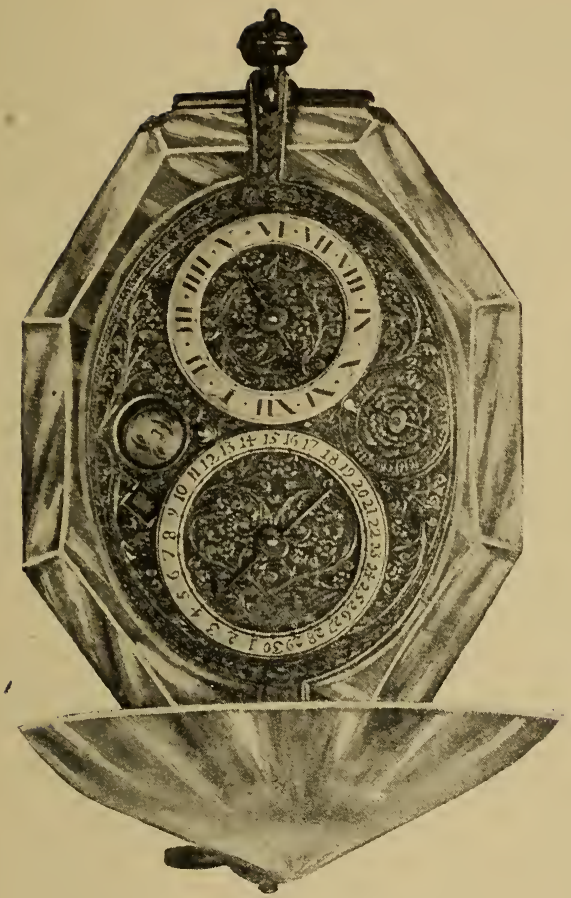

FIG. 189.-Large-size Watch, Crystal case, dated 1634 .

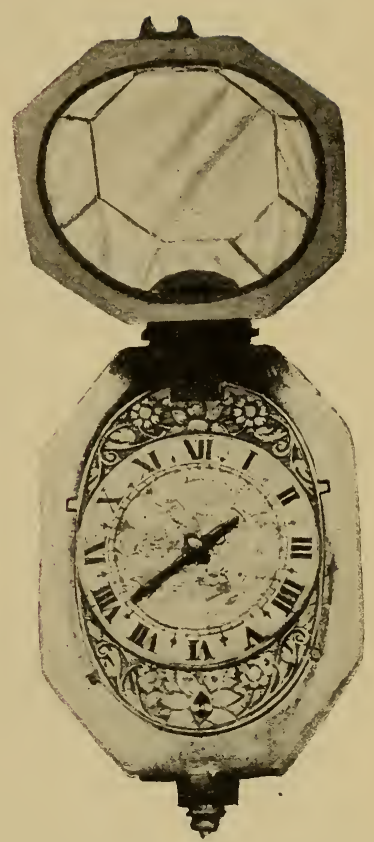

FIG. 190.-Watch by Henry Grendon, about 1660 .

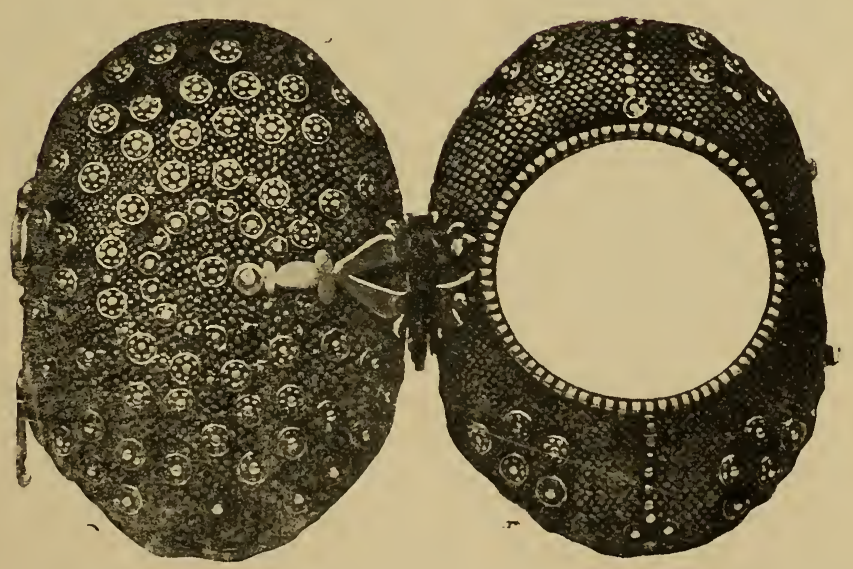

FIG.-191.-Outer case of grey fish skin studded with silver pins. 


\section{I6o Old Clocks and Watches and their Makers}

a well-known maker of Blois. The dial plate is beautifully engraved, and near the joint is the date 1634. It indicates the phases of the moon and her age, the days of the week, and days of the month.

An octagonal crystal case watch by Henry Grendon, "of ye Exchange," which dates from about 1660, is shown in Fig. 190.

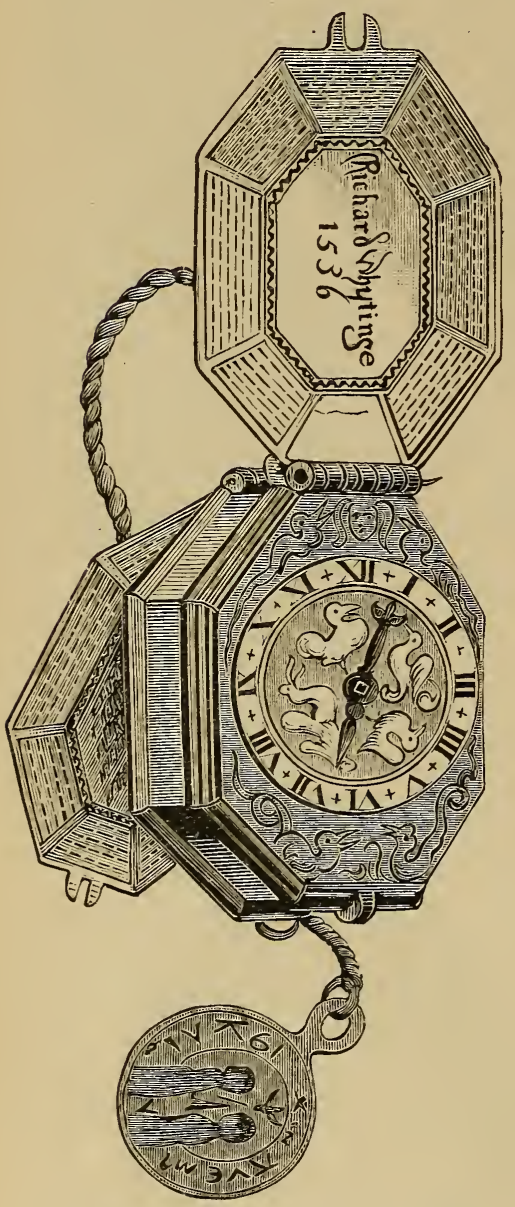

FIG. 192.-Watch said to have belonged to Abbot Whiting.

It was formerly an attractive item in the Dunn Gardner collection and subsequently belonged to the late Mr. J. Pierpont Morgan. On the gilt dial plate are engravings of tulips; the ring is of silver. There is an outer case of grey fish skin studded with silver pins, rosettes, hinges and clasps, which is shown open in Fig. 191.

Some time ago I saw a small octangular watch movement inscribed "Nicasius, London," dating from about 1605 .

In the British Museum is a choice octangular watch, dated 1620 , by the celebrated Edward East. The body, as well as the cover of the case, is of crystal, faceted, and the exterior altogether closely resembles Fig. 188. Another, somewhat similar, but dated 1609 , is inscribed, " Michael Nouwen, London." A watch of this shape, said to have belonged to Abbot Whiting, is shown in Fig. 192, which is copied from Warner's " History of Glaston Abbey." On the inside of the cover will be noticed the inscription, "Richard

Whytinge, 1536." Warner seems to have accepted the inscription, but beyond it there is really no evidence except a seal attached to the watch by a string; this is certainly not conclusive, and I confess I do not believe such a watch was made so early as 1536 . 
Fig. 193 is from the collection of M. Paul Garnier. The square case has a ground of bluish steel, overlaid with chased gold ornament, the combination producing a very striking effect. The edges are decorated in the same way. The dial is square, enamelled blue in the centre and white all round, the corners being adorned with motifs in red enamel. The movement is signed "Balthazar Martinot," who was horologer to Louis XIII. in 1637. Steel cases with gold filigree work attached were rather popular at the middle of the seventeenth century. Among others in the British Museum is a choice specimen by Benjamin Hill.

Two views of a clock-watch in a remarkably well pierced circular case are given in Figs. 194, 195. The dial of brass gilt is finely engraved, and altogether it is a good example

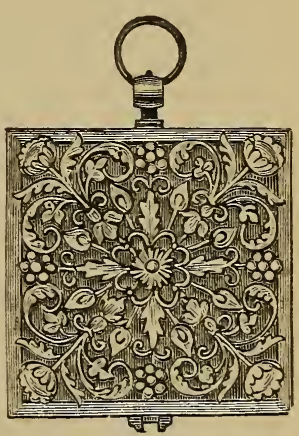

FIG. 193.-Square case watch. of the style in vogue about 1640. The movement is signed " Martinot Au gros Orloge, Rouen."

Oval Watches.-From the designation " Nuremberg eggs," which

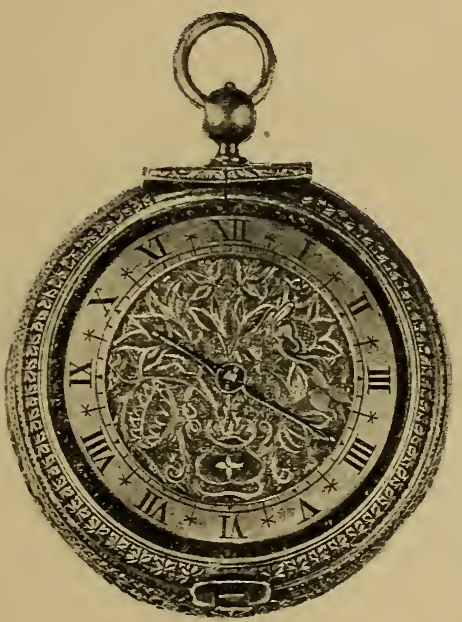

FIG. 194.

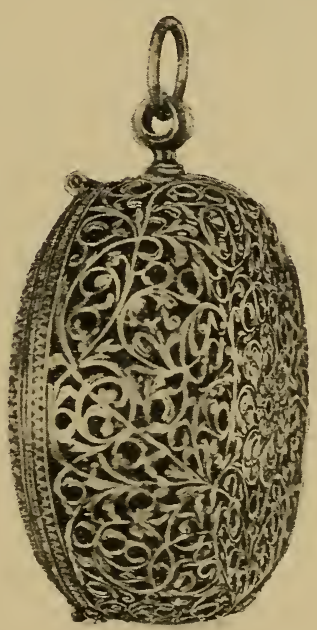

FIG. 195.

Two views of a Clock-IVatch in pierced circular case.

is often applied to watches of a flattened oval form, it may be supposed that they originated in Nuremberg. They appear to have • been manufactured here as early as 1600 . On p.162 are two specimens 


\section{r62 Old Clocks and Watches and their Makers}

from the Schloss collection. That reproduced in Fig 196 is a striking watch of a very early date. The movement, furnished with the primitive stackfreed, is fitted into a case of brass nicely pierced at the

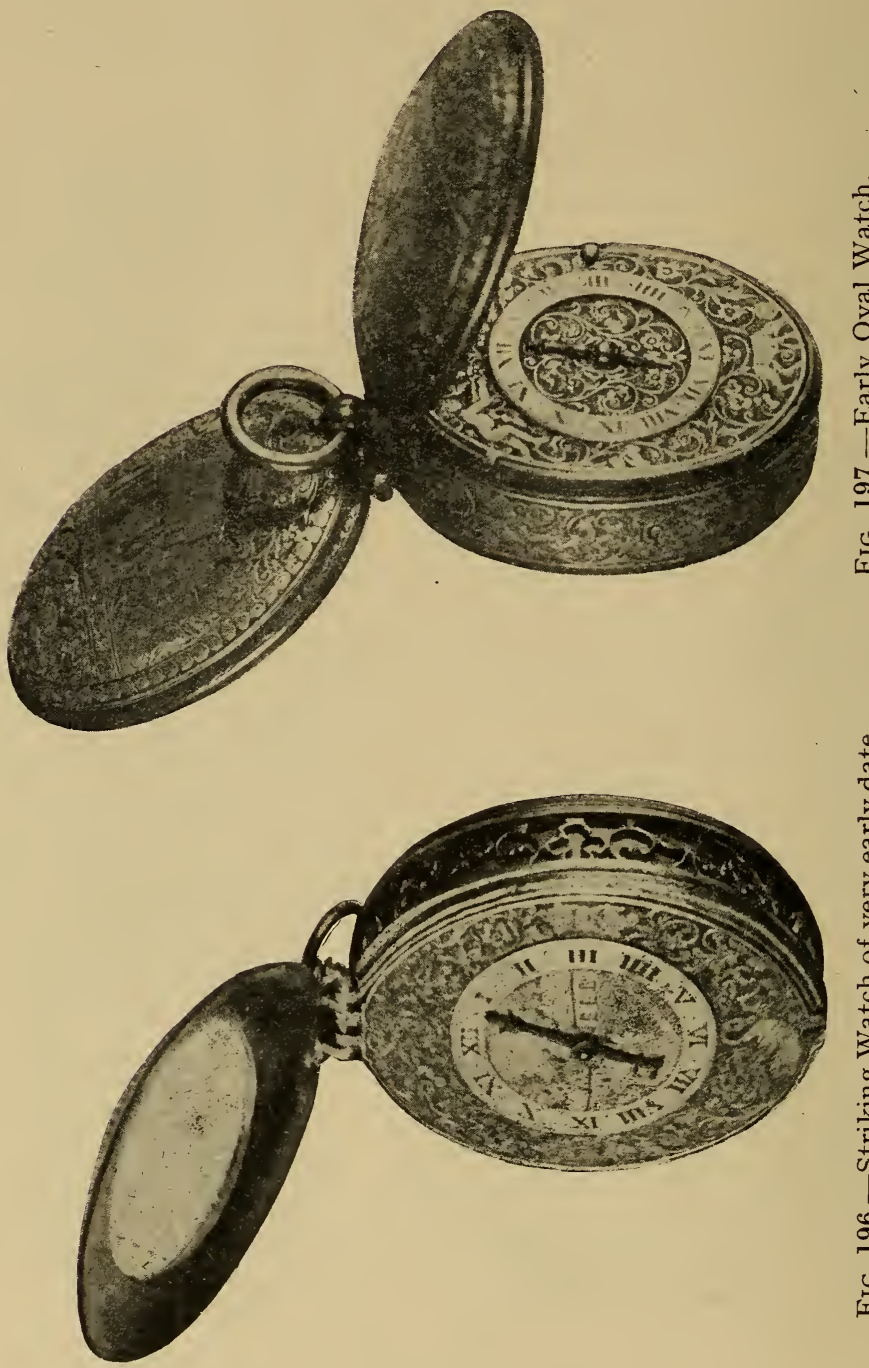

sides as shown. On the joint of the case is the signature " J. Burgis." The outer part of the dial is of brass, the centre, including the hour ring, of silver, and on the cover over it is fixed a circular crystal, an addition doubtless made subsequent to the manufacture of the watch. 
Some of these early oval watches had covers back and front-the movement not being hinged to the case but simply pressed into it and supported by tenons which projected from the dial. Fig. 197, an example of this kind, represents a watch the movement of which is signed " $\mathrm{R}$. Delander fecit." It is in a silver case having brass mouldings at the edges; the outsides of the covers are finely engraved with groups typical of the beneficial use of fire and water respectively ; and on the inside of the back cover is a sundial with a stud for the reception of a movable gnomon. The dial is wholly of silver.

In Fig. 198 is shown an oval watch from the Evan Roberts collection. The dial is of silver, and has mounted thereon a brass hour ring. At each hour, near the exterior edge of the ring, is a slight knob to allow of the time being ascertained by feeling the hand and estimating its position with relation to the knobs. Over the hour ring is the engraved inscription, "Our time doth passe a way." The case is of silver.

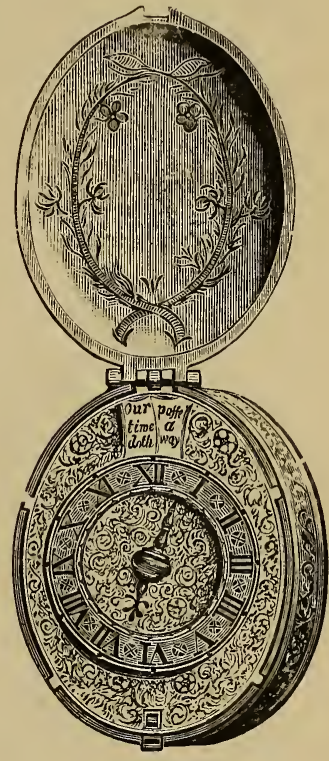

Fig. 198.-Watch with brass hour ring.

On the movement plate is engraved, "Thomas Aspinwall fecit."

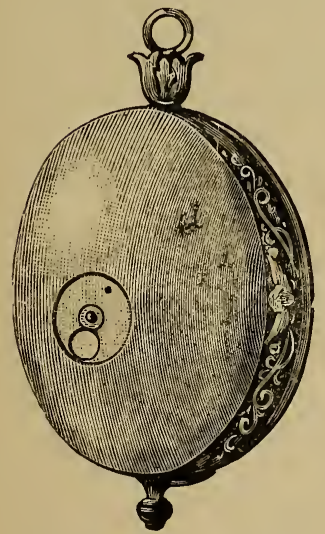

FIG. 199.-Oval Watch by Simon Bartram. The name of Aspinwall is not unknown among the celebrated early-English watchmakers; it is recorded that in 1675 Josiah Aspinwall was admitted as a brother of the Clockmakers' Company. His admission as a "brother" probably signifies that he was free of one of the other City Guilds. In 1863 Lord Torphichen exhibited, at the Archæological Institute, a clock-watch made by Samuel Aspinwall, of a date presumably about 1650 or 1660 . But I should be inclined to place this watch as among the productions of a much earlier date. A few years ago I saw a watch very similar to the one here depicted, on which was engraved, "Samuel Aspinall fecit." Bearing in mind the vagaries of seventeenth-century orthography we may assume that this referred to a member of the same family. 


\section{I64 Old Clocks and Watches and their Makers}

Oval or egg-shaped watches were usually worn on chatelaines. They were apparently more popular than any other form from 1610 to 1625 , and continued in fashion with the fair sex for a long time. In Hollar's plates of the four seasons, dated 1641, summer is represented by a lady having an egg-shaped watch on her left side depending from her girdle. The British Museum contains several similar specimens, most of which are assigned to the first quarter of the seventeenth century. One, by Nicholas Waller, is dated 1610 . Another, almost a counterpart of the one illustrated in Fig. 199, is

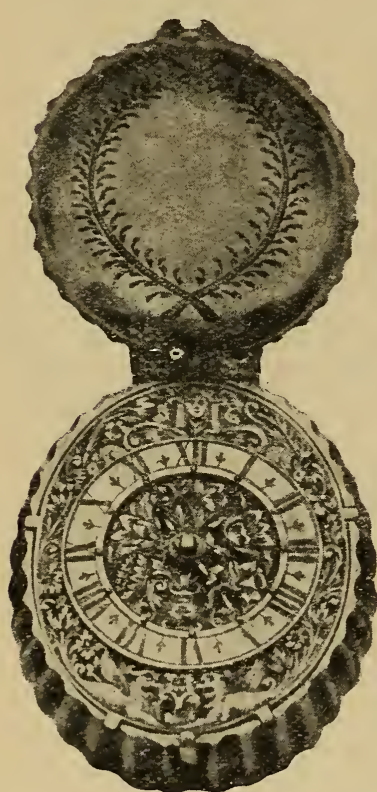

FIG. 200.-Watch by Denis Bordier, Paris. by John Limpard, and was made about 1610. It is calculated for going sixteen hours between windings. The case is of silver, partially gilt and very elegantly chased; on one side is a figure representing Hope, and on the other a corresponding figure of Faith.

An exterior view of an oval watch by Simon Bartram is given in Fig. 199. The circular patch on the left is a " hit or miss" shutter, which covers the winding hole to prevent the ingress of dirt. This shutter is found on many really seventeenth-century watches. It had to be moved round when the watch was wound, and on completion of the operation was replaced. The dial is very similar to that shown in Fig. 198. A drawing of the movement, which is of particular interest, will be given later on.

In the Pierpont Morgan collection is a watch of the same kind by the same maker, another oval one by Edward East, which has an outer capsule case, one by Samuel Linaker, and that shown in Fig. 200, which is by Denis Bordier, Paris. It has a brass gilt dial prettily engraved and a fluted silver case.

The small oval watch in a case of crystal which belongs to Mr. Max Rosenheim and is shown in Fig. 201 bears the signature, "Jean Nuer, A Saintes."

Fig. 202 represents an oval watch, apparently English, in a silver case and with a silver dial. There are no screws used in the movement, which is signed "William Yate" The late Mr. Edward Parr 
had a somewhat similar watch in a brass case, the movement of which is signed "Wm. Nash, London."

There is a very small oval watch in the British Museum. It measures but half an inch across by three-quarters of an inch long, and has plain silver capsule-shaped outer cases. The South Kensington Museum contains a still smaller one.

Early in the seventeenth century plain circular watch cases came into favour, but not to the entire exclusion of more fanciful shapes.

On p. 166 are examples of some diminutive round watches of the period. Fig. 203, in a case of silver gilt, dates from about

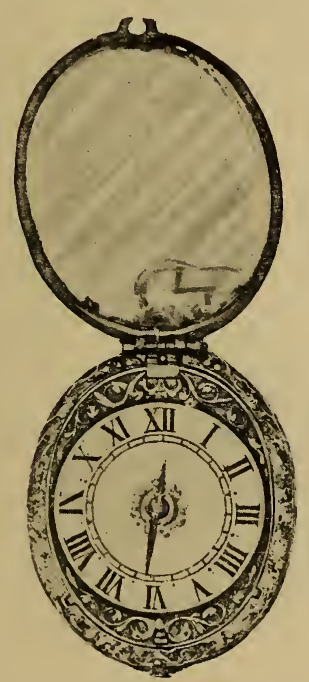

FIG. 201.-Small Oval Watch.

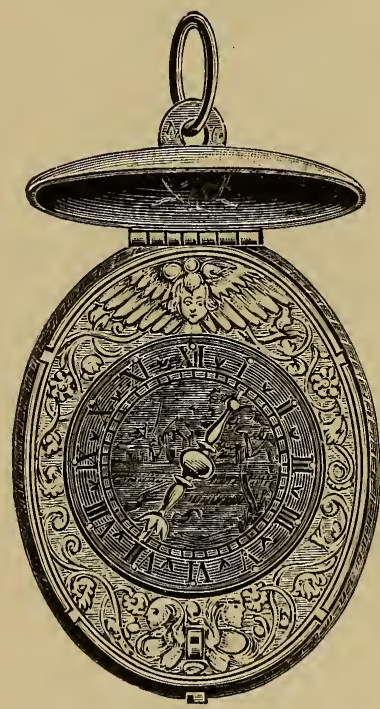

FIG. 202.-Watch without screws in movement.

1630 , and the movement is signed " Jacob Wibrandt, Leuwarden." A plainer specimen of a slightly later date bearing the name "Chaunes le jeune" is shown in Fig. 204.

Front and back views of a watch bearing the signature, "Arnolts, Hamburg," are given in Figs. 205, 206. The case is of silver handsomely chased in repoussé, with a remarkably well executed portrait on the back. It is a production of about 1635 .

Figs. 207 and 208 represent a watch by Jeremie Gregory, a wellknown English maker. The outside of the case is covered with champ levé engraving, a style of decoration rather uncommon and very effective if well done, as it is in this instance. 
I66 Old Clocks and Watches and their Makers

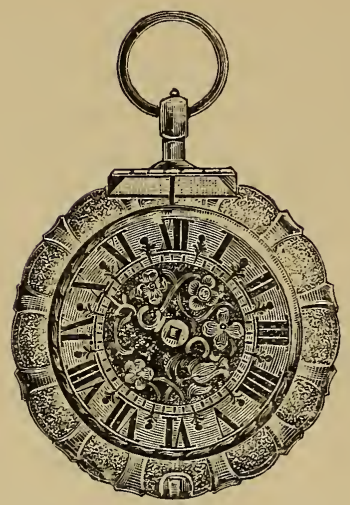

FIG. 203.-Watch dating from about 1630 .

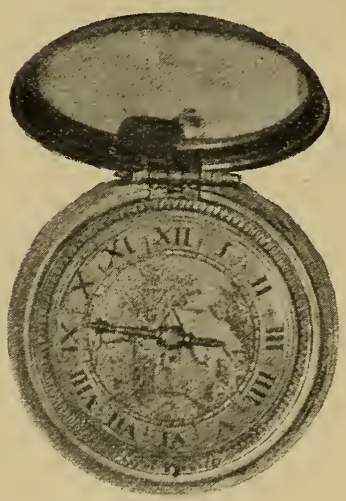

FIG. 205.

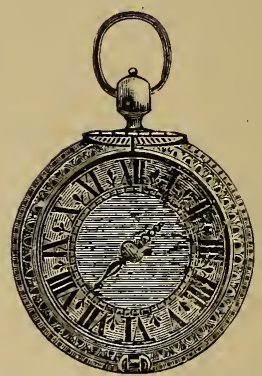

FIG. 204.-Watch bearing the name "Chaunes le jeune."

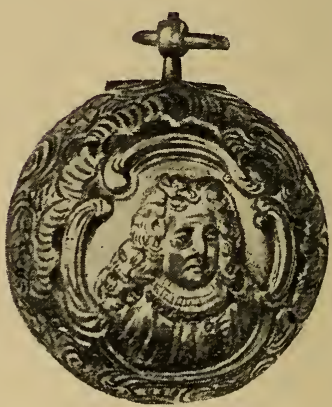

FIG. 206.

Front and back view of Watch, about 1635 .

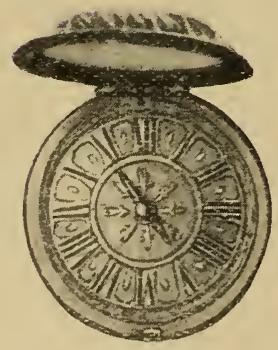

FIG. 207.

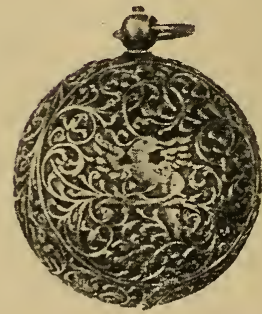

FIG. 208.

Front and back view of Watch by Jeremie Gregory. 
Holbein.-Holbein the painter seems to have taken a remarkable interest in horology. In his famous picture of "The Family of Sir Thomas More," painted 1526-30, is to be seen hanging on the wall a clock much resembling the one of Anne Boleyn which is illustrated on p. 50. The bracket on which Anne Boleyn's clock now stands was probably added by Horace Walpole.

Holbein was on very intimate terms with Nicholas Cratzer (or Kratzer), horologer to Henry VIII., and painted a superb portrait of him, which is dated 1528, and is at the Louvre, Paris. Cratzer is there represented at work on a sun-dial, with other instruments of the kind near him. Holbein's last dated drawing (1543), now at the British Museum, is a design for the casing of a combination of clock and sun-dial, intended for presentation to Henry VIII. by Sir Anthony Denny. But Holbein's interest in the craft was quite exceptional in England at that period, and it must be confessed that up to nearly the end of the sixteenth century English horologists had but a very small share in the production of portable timekeepers.

Salt Cellar Clocks. - In the early part of the seventeenth century it was apparently the custom to have clocks combined with salt cellars on the table at state banquets, to judge by the following curious items from an inventory of the plate in the lower and upper jewel rooms of the Tower, 1649 :- " A salt of state with a clocke in it, valued att $£ 1200$; a clocke salt with a christall case, supported with 4 pillars, silver-gilt, valued at $£ 4100$; an agatt salt and cover garnisht with gold, enamelled, supported by 3 men, and a ship on the top of the cover, p. oz. $10 \frac{1}{2}$ oz., valued att $£ 3300$; two clocke salts standing upon 4 christall balls and 4 christall pillars, each with aggatt salts on the topp, and gold covers, p. oz. $3 \mathrm{lb} .2 \frac{1}{2} \mathrm{oz}$. valued att $£ 368$ per oz. $=£ 7700$; a christall watch salt garnisht with gold, and supported with 3 faces with several fruiteages hanging about them, p. oz. $30 \mathrm{oz}$., valued att $£ 3000$." 


\section{CHAPTER IV}

\section{POCKET WATCHES, ETC.}

DOCKETS were used for the reception of timekeepers in Shakespeare's time, for Jaques, in " As You Like It," remarks, " And then he drew a dial from his poke." Portable sun-dials, sometimes with a compass attached, were then made, and the reference was probably to one of these.

Watches were not usually carried in the pocket for more than a century after the mainspring was invented. The larger ones would be kept on a table or cabinet, and the smaller kinds, when worn on the person, were originally held by a chain around the neck, or attached to the dress in other ways, unless incorporated with bracelets and such-like ornaments, as many of Queen Elizabeth's seem to have been.

The grotesque and uneven cases applied to most of the early watches clearly rendered them unsuitable for the pocket. Decker in 1609 (Gull's Hornbook) apostrophising the fashionable young bloods idling in the cathedral says, "Here you may have fit occasion to discover your watch by taking it forth and setting it to the time of St. Paul's." This suggests a pocket, but long after this date oval and round watches were made with a pointed projection depending from the bottom of the case, and these were clearly never intended for the pocket nor fit for it. The fob, from the German fuppe, "a small pocket," was very possibly introduced by the Puritans, whose dislike of display may have induced them to conceal their timekeepers from the public gaze. This conjecture is strengthened by the fact that a short "fob" chain attached to a watch of Oliver Cromwell's, in the British Museum, is, in point of date, the first appendance of the kind to be found. The watch is a small oval one, in a silver case, and was made about 1625, by John Midnall, of Fleet Street, who was one of the first members of the court of the Clockmakers' Company, and warden in 1638. On one side of a silver plate at the seal end of the chain are the Cromwell arms, and on the other the crest of the Protector with the letters O.C. as shown 
in the appended engraving, Fig. 209. The Cromwell crest was a demi-lion holding a ring in its paw, but the Protector substituted for the ring the handle of a tilting spear as here represented.

This watch and chain formed part of the Fellows collection. By the will of Dame Harriet Fellows (relict of Sir Charles Fellows), late of West Cowes, Isle of Wight, who died in 1874, the testatrix bequeathed to the trustees of the British Museum her collection of watches, to be placed and held with Milton's watch, bequeathed to them by her late husband.

Fig. 210 is an illustration from the Illustrated London Neres, February 1850 , of a clock watch which is said to have belonged to Oliver Cromwell. It is, I believe, the property of Mr. J. H. Fawkes, of Farnley Hall, and bears the name of Jaques Cartier. The outer case of leather is perforated and studded with silver.

In the Gentleman's Magazins for December 1808 is shown a small oval watch, similar to the one by East, Fig. 410, which, it is stated, Cromwell at the siege of Clonmel took out of his fob and presented to Colonel Bagwell.

In the South Kensington Museum is a circular clockwatch, by John Bayes, which probably belonged to Cromwell's

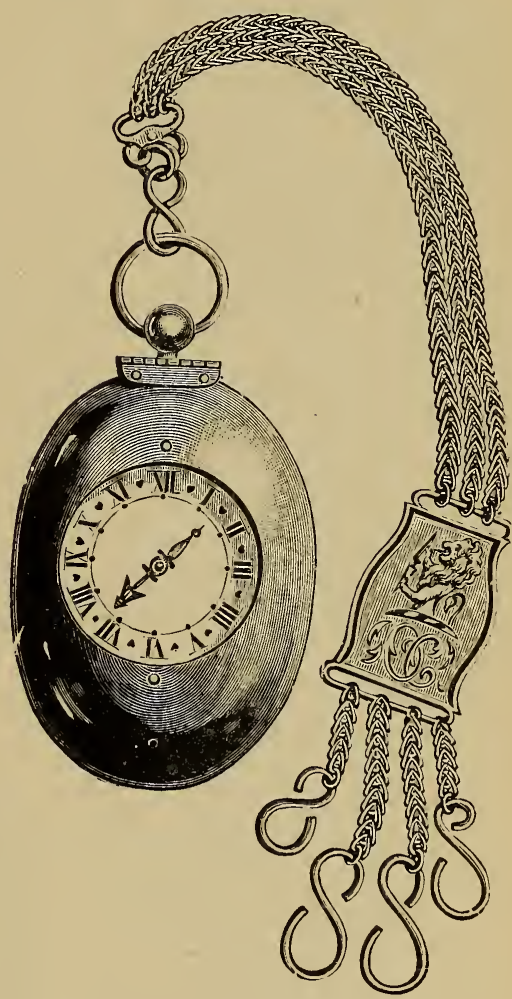

FIg. 209.-Oliver Cromwell's Watch and Fob Chain. secretary. The outer case of tortoise-shell bears the inscription, "Johne Pyme hes watch, A.D. 1628."

A very handsome watch by Henry Harpur is shown in Fig 211. It has a silver dial with day of the month ring and beautifully pierced centre; the inner case is of silver having on the back the arms of Cromwell, to whose daughter Bridget the ownership of the watch is assigned; the outer case of fish skin is pique with silver pins. 


\section{I70 Old Clocks and Watches and their Makers}

Watch Glasses.-Watch glasses seem to have been introduced about 1610. At first they were flat, rather thick, and fitted into split

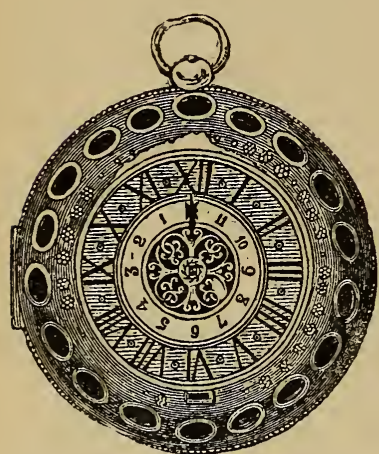

FIG. 210.-Clock-Watch of Oliver Cromwell. bezels, as the containing rings are called, the opening in the bezel being at the middle of the joint, so that the corresponding knuckles of the case would keep the slit tightly closed on to the glass. Glasses of this kind are found on oval watches, and also on circular ones with dials much smaller than the cases, which were a fashion at the beginning of the seventeenth century. Then followed the high, rounded glasses, which were cut from spheres. Afterwards came the bull's eyes, with a circular flat centre ; these, which were of German origin, gave place to the flatter "lunettes" from France, such as to-day divide popular favour with the thick " crystal" glasses.

Glasses were apparently used for table clocks some years before they were applied to watches. German and French table clocks, dating from the latter part of the sixteenth century, are occasionally to be met with, having glasses over the dials, and some octagonal ones with glass panels in the sides. But the innovation did not at once prevail, as table clocks, either without any covering over the dial, or with metal covers, were made long after the first examples with glasses, and watches with metal covers continued in fashion till the middle of the seventeenth century.

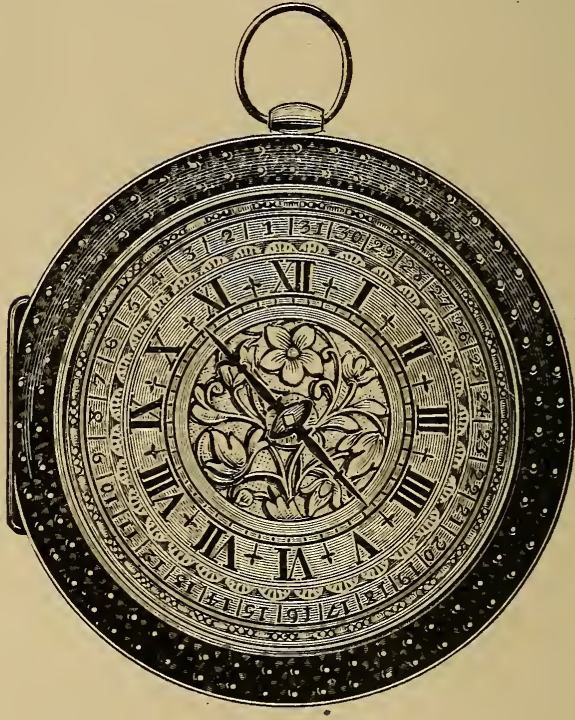

FIG. 211-Handsome Watch having on the back the arms of Cromwell.

In the British Museum is an oval watch by Guy Mellin, Blackfriars, the dial of which is covered with a glass in a split bezel ; also 
a circular watch by John Duke, Fleet Street, with a dial one-half the size of the case, and a glass of a corresponding size fitted into a split bezel. Mellin's watch is considered by the authorities to have been made about 1600 , but I should be inclined to put the date of its production a few years later. Several other watches, whose manufacture is ascribed to the beginning of the seventeenth century, may be noticed with glasses; but these adjuncts in some instances have been subsequent applications. - The split bezel is perhaps a tolerable criterion of originality, but it does not absolutely follow that such a bezel was originally fitted with a glass, for the frames of early watches and clocks were occasionally furnished with crystal.

Another method of fixing the glass prior to the introduction of the present practice of springing or snapping it into the bezel consisted of forming three or four thin metal ears on the bezel and bending them over the glass when it had been placed into a suitable rebate. I saw this in a watch by Benjamin Hill. It was, however, but a survival of the mode in which crystal was held in octagonal and other fancy cases, and must be regarded as an inferior arrangement which does not seem to have been at all general, whereas the split bezel was used preferentially by some makers long after the custom of snapping

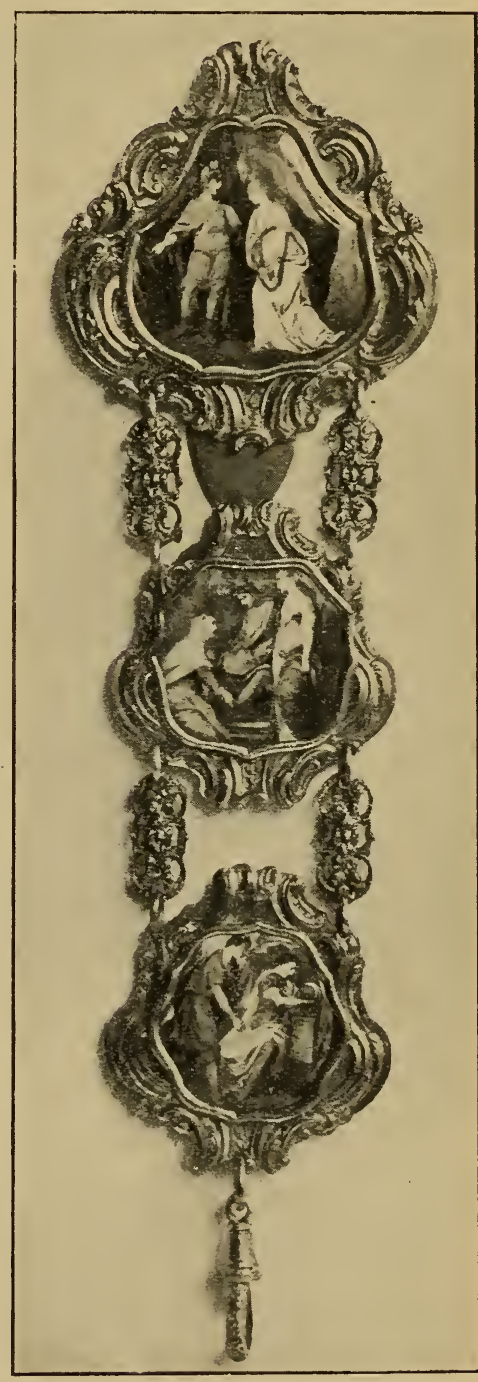

FIG. 212.-Handsome Chatelaine. the glass in was introduced. The watch shown in Fig. 478, and made about 1700 by the celebrated Langley Bradley, had a split bezel. 
Chatelaines.-The convenience of the "fob" to those who carried watches for use rather than for ornament was soon apparent, and its adoption speedily became general with men, though ladies continued to wear their watches suspended from chatelaines till the latter part of the eighteenth century. Some of the chatelaines were exceedingly handsome, as may be judged by an example from the Schloss collection which is shown in Fig. 212. The plaques are painted in enamel in the style of Huaud ; the mounting and painting are French. In 1749 Benjamin Cartwright patented a secret spring to secure a watch hanging by a lady's side. In the Winter Palace, St. Petersburg, is a splendid array of chatelaines. They are attached to English watches, and probably of English make. Many of them are set with gems of the most costly description.

Like many other fancies, the one wearing two watches is but a revival pace the Universal Magazine for 1777 , where the description of a " modern fop" includes-

\footnotetext{
"A lofty cane, a sword with silver hilt,

A ring, two watches and a snuff-box gilt."
}

Watch Cases.-It will be observed from the preceding examples that a great number of dissimilar materials were used to enclose portable timekeepers: wood of various kinds, precious and semi-precious stones, amber, metal and leather were all utilised for this purpose. With few exceptions the earliest watches had but a single case. Metal was the predominating material, the plainest cases being usually of brass, or of polished steel; silver also was favoured both for smooth and engraved cases; for the more costly coverings gold was, of course, selected, either by itself or in combination with precious stones, and occasionally the two precious metals would be used together with pleasing effect.

Sometimes the watch movement, instead of being fastened to the case, was simply placed in four tenons which projected from the edge of the dial fitting into corresponding mortises in the middle band of the case. The case then had two hinged covers, one over the dial and one over the back, the movement being rendered secure by the closing of the front cover; the back cover had to be opened to wind the watch. The oval watch by $R$. Delander, which is illustrated on p. 162 ; the one by David Bouquet formerly in the Mainwaring collection, and another by David Ramsay in the South Kensington Museum, are examples of this method. But more often the movement was joined to the case by means of a linge near the 
pendant and a spring bolt at the opposite point of the dial, four projecting tenons on the dial resting in notches cut from the middle of the case. This mode of construction is clearly shown in the engraving of the oval watch by Thomas Aspinwall on p. 163. Till about 1720 the spring bolt generally projected through the dial; after that the nib for unbolting was more often arranged outside the circle of the dial and below the surface of it.

Enamel.-Dccoration in enamei is sometimes to be found on watch dials and cases produced during the early part of the seven-

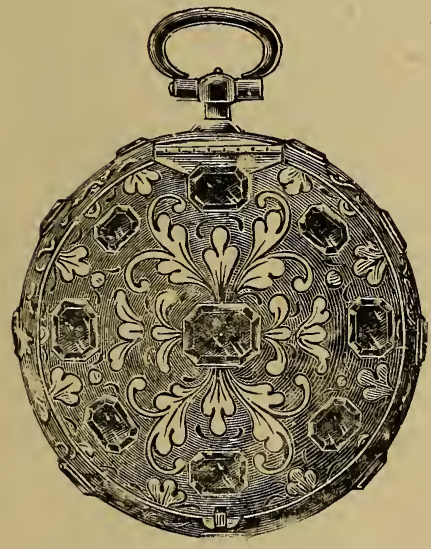

FIg. 213.-Front, with Cover closed.

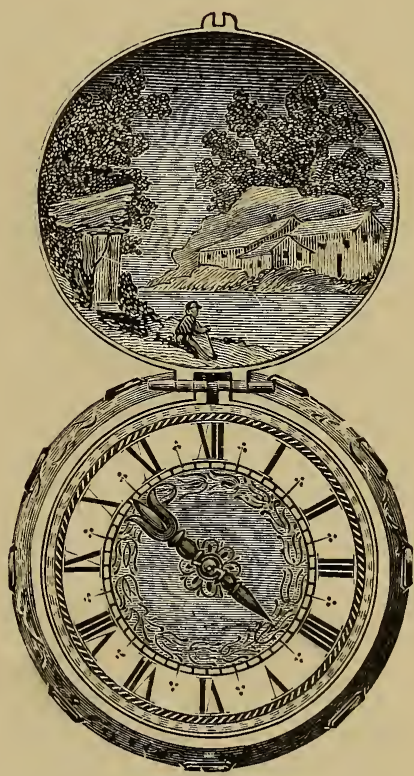

FIG. 214.-Dial and inside of Cover.

teenth century. An exceptionally good specimen is shown in Figs. 213 and 214 . The outside of the cover and the back are embellished with enamel, the ground being of turquoise blue with white arabesques moulded thereon in relief and studded with fine garnets of large size. Though " jewelled watches" are referred to as belonging to Queen Elizabeth, and in other records of the period, it is very rarely that so early a combination of enamel and gems is now to be met with. The inside of the case and of the cover are also painted in enamel, and so is the dial. There is no glass over the dial. The hand is well shaped. The plate of the watch is inscribed " Pierre Soret." 
Front and back views of a watch covered with the same kind of enamel, but of later date, are given in Figs. 215 and 216 . The centre of the dial is blue, and a portrait on an enamelled plaque occupies the centre of the back. A very thin name-plate is engraved " James Coupé, London," and underneath the name-plate appears the signature "Marc Grangier."

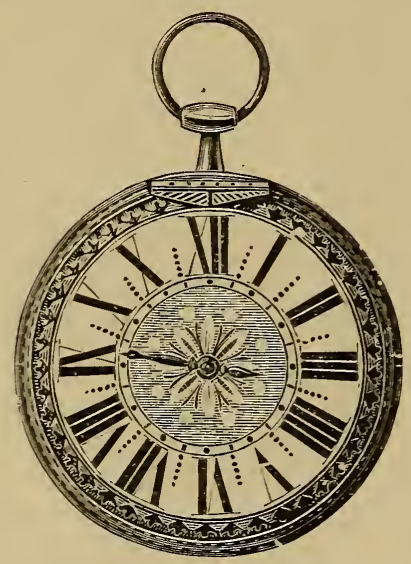

FIG. 215.

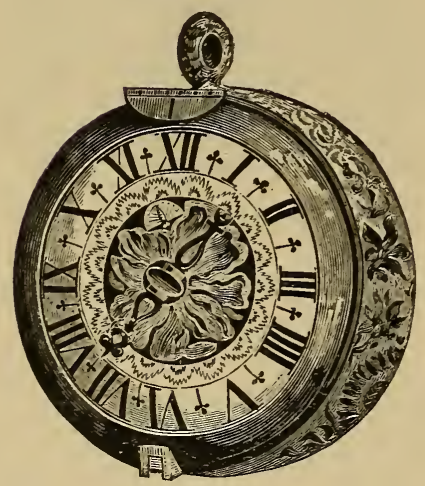

FIG. 217.

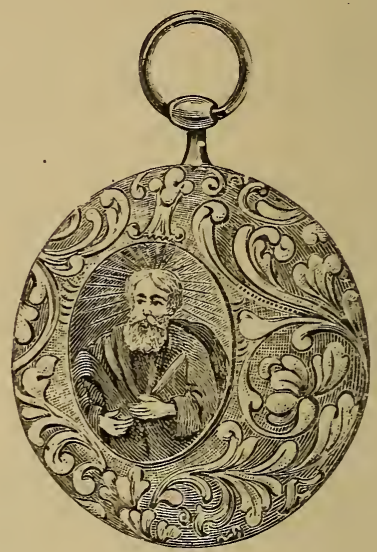

FIG. 216.

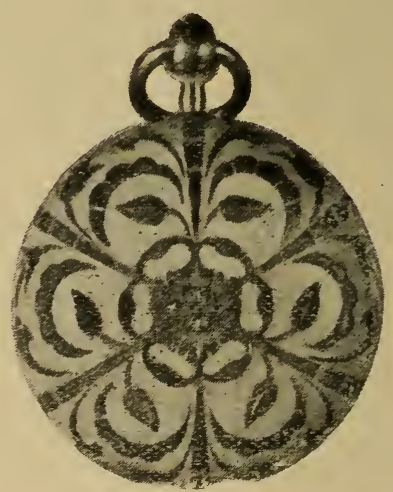

FIG. 218.

Enamelled Watches of different styles.

In Fig. 217, by permission of Mr. Charles Shapland, I am enabled to give a representation of a specimen in a different style, dating from about 1630. On the top plate of the movement is the inscription "Georgius Merkell, Dantzig." The case is of gold, and is wholly incrusted with enamel both inside and outside; flowers of various colours and kinds, as well as winged in:ects, are charmingly represented. 
Of other kinds of enamelling to be met with but rarely on early seventeenth-century watches may be mentioned champ levé. This somewhat resembles the well-known cloisonne, but, instead of the various sections being divided by the insertion of metal strips, the partitions are solid with the base, and the intervening spaces cut out to receive the enamel. A watch, signed " Du Hamel à Paris," dating from about 1635 , in a gold case very effectively decorated in this way with cream-coloured enamel, which is at South Kensington Museum, is shown in Fig. 218. Another example is given in Fig. 219, which is the back of a watch with a peculiar notoriety, referred to in Chapter III. : the dial bears the inscription " Robertus Bruce Rex Scottorum," as shown in Fig. 220, while the watch is a production of about 1645, the movement of it being signed "Johann Kreitt Mayr."

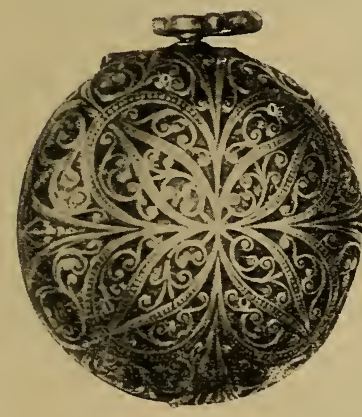

FIG. 219.

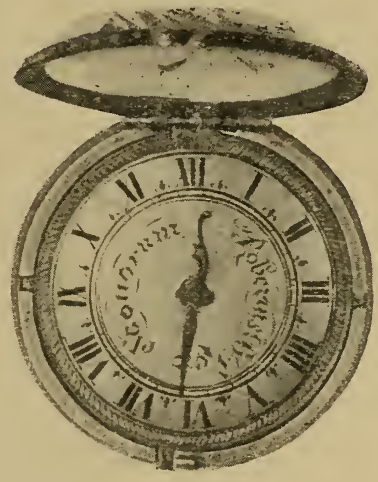

FIG. 220.

Gold and Enamel decoration, about 1645.

The diminutive watch on p. 154 is also decorated with champ levé enamel.

Occasionally translucent enamel was employed, and effects of light and shade obtained by varying the depth of a cavity which was cut to the required design in a metal base.

Watches with enamel painting before about 1640 are exceedingly rare, and there is a marked difference in the character of such decorative work executed at the beginning, compared with that done during the later years of the seventeenth century. As examples of the earlier style, which presented a comparatively lustreless surface and subdued tints, may be taken the watches shown on pp. 176-179. During the first quarter of the century the Holy Family appears to have afforded the theme for decoration in nearly every instance. Afterwards, though 
I76 Old Clocks and Watches and their Makers

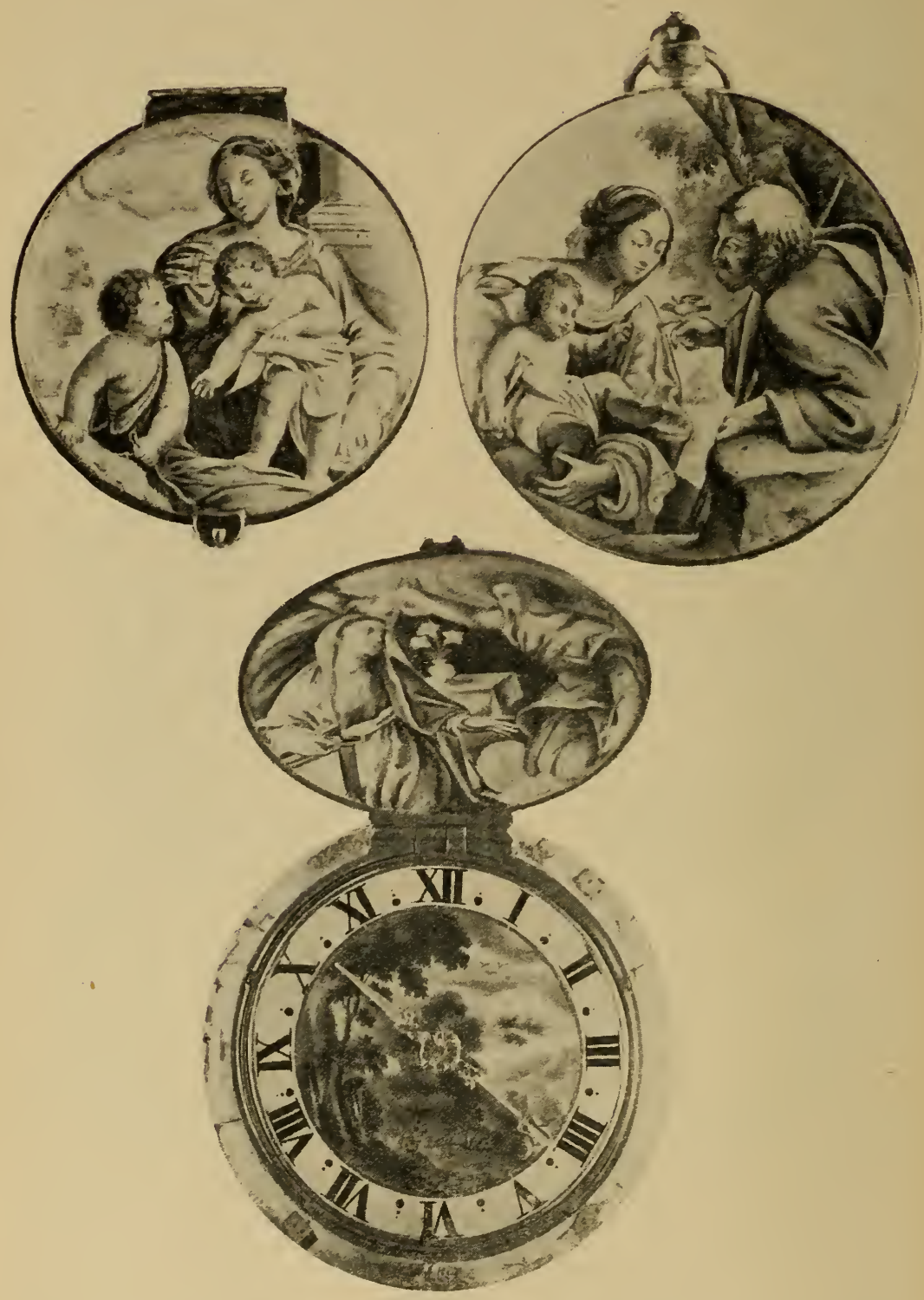

FIgs, 221-223. - Watch by Salomon Plairas, Blois, with Enamel Painting, about 1625 .

I, outside of cover ; 2, back or case ; 3 inside of cover and dial. 


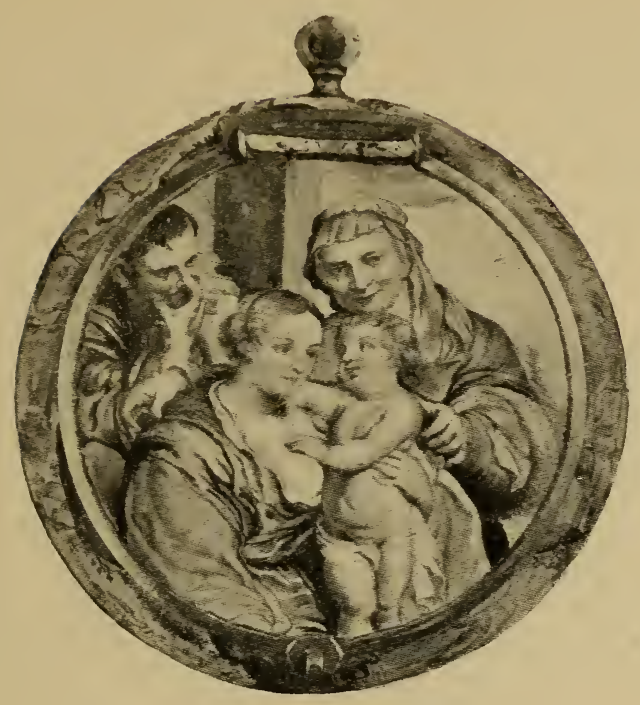

FIG. 224.-Watch from the South Kensington Museum.

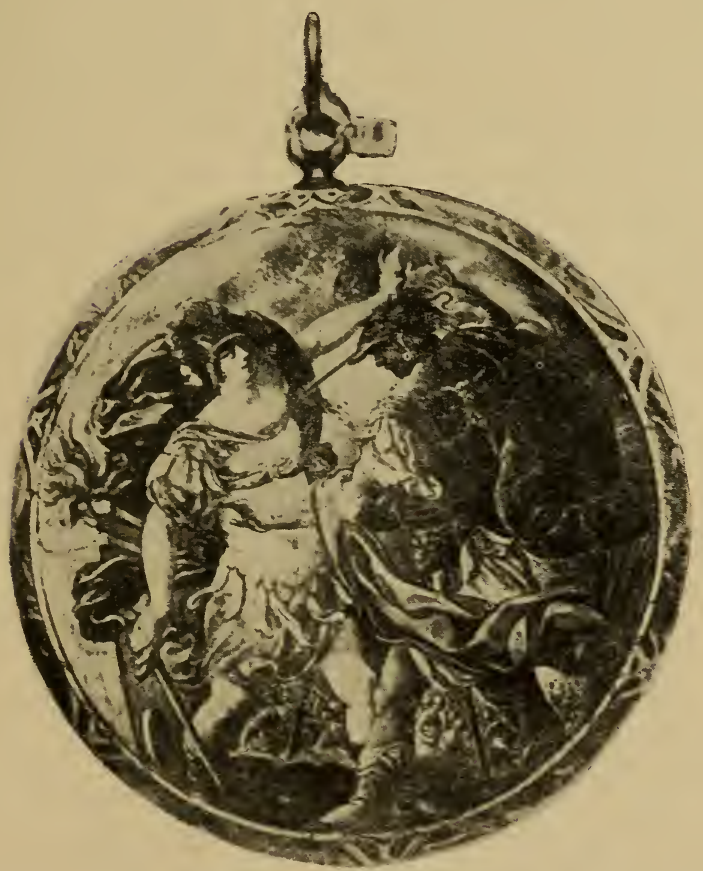

FIG. 225.-The movement of Watch signed "B. Foucher, Blois." 
I78 Old Clocks and Watches and their Makers

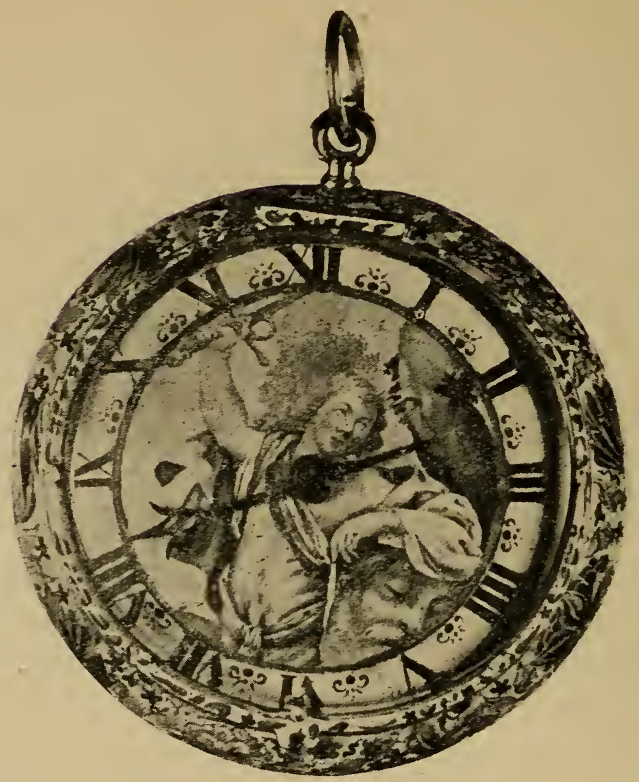

FIG. 226.

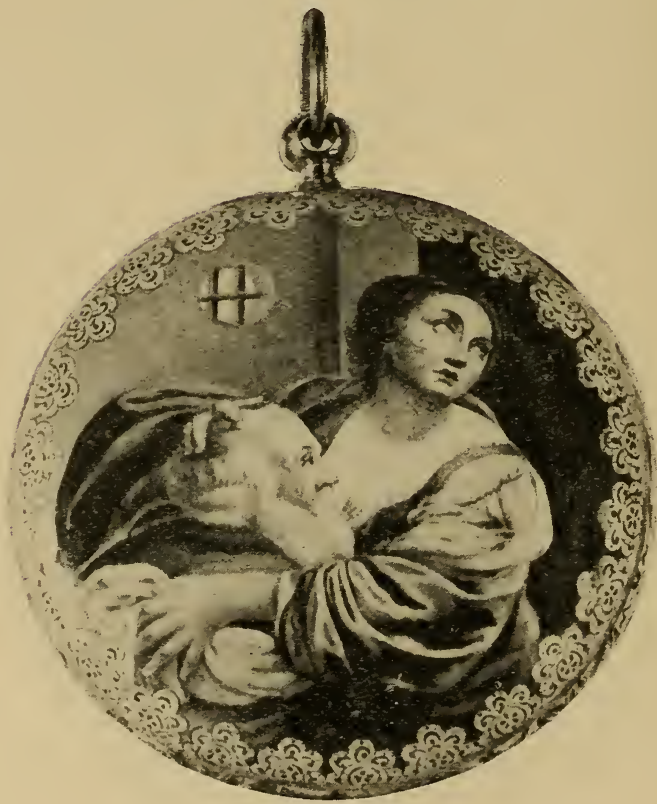

FIG. 227

Front and back views of Watch. The movement signed "Barthelmy Mace à Blois." 
sacred subjects were not ignored, mythological incidents were sometimes selected by artists for reproduction, and occasionally original conceptions and portraits of contemporary personages were applied to watches intended most probably for presentation.

On p. 176 are three views of an early and very fine seventeenth century enamelled watch from the Schloss collection. The movement is signed "Salomon Plairas, horlogeur, A Blois."

Fig. 224, from the collection at the South Kensington Museum, shows the front of a watch dating from about 1630 , on which is a pairiting of the Holy Family, after Rubens.

Fig. 225 represents the back of a watch of the same period at the British Museum, for which the artist has apparently taken the romance of Theseus and Hippolyta as the subject of his painting. The moveinent is signed "B. Foucher, Blois."

Front and back views of a watch, the movement of which is signed " Barthelmy Mace a Blois," are given on page 178. Nearly all artists who painted watch cases up to the end of the eighteenth century seem to have included the "Roman Piety" in their selections; the representation on the back of this watch could, I think, hardly be excelled.

Fig. 228, from the British Museum, shows the back of a watch by Jean Hebrat, of Brussels, of a slightly later date than Fig. 227 ; the painting is bordered with turquoises.

Back and front views of a very beautiful watch, the enamel painting of which is probably English as well as the movement, are given in Figs. 229-230. On the back of the case, within a charming floral border, is a well-painted portrait, said to be that of Henrietta Maria, daughter of Henry IV. of France and wife of Charles I. of England. The dial is finely painted to a floral design and covered by a glass kept into a recess in a primitive way by six pins bent over from the bezel. The hand is of brass, pierced and chased. On the plate of the movement is engraved "Simon Hackett, Londini." He was elected a member of the Clockmakers' Company on its formation in 1632, and served as master in 1646.

An improved method of painting in opaque enamel, which appears to have been discovered abovt 1635 , is generally credited to Jean Petitot, who was born in Geneva in 1607, and attained much success as a miniature painter in France and in England. The new process consisted of applying to thin gold plates thick colours of different tints which would, after being subjected to fire, retain their brilliance and lustre. Petitot exercised his art on snuff-boxes, but I have never met with enamel decoration on a watch which bore his 
signature. The invention of this particular kind of enamel painting is also claimed for Jean Toutin, a goldsmith of Château Surr,

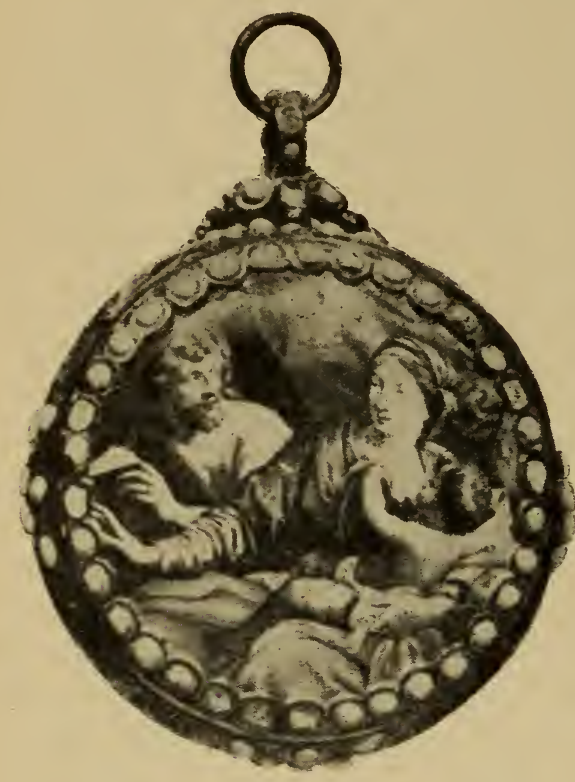

FIG. 228. - Watch by Jean Hebrat of Brussels.

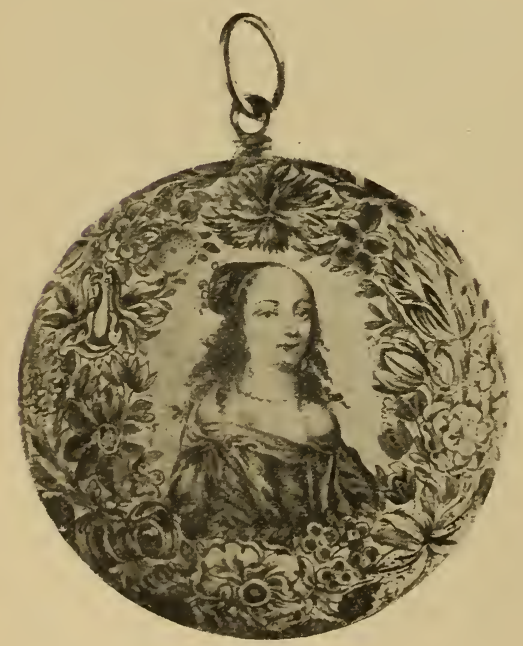

FIG. 229. who was previously distinguished for painting in enamels, and who certainly seems to have been one of the first to apply it to watches. Other French and Swiss artists quickly devoted themselves to the new kind of enamel painting. Among those who excelled in it may be mentioned Henry Toutin, brother of Jean, a gold smith and enameller at Blois ; Dubie, a court goldsmith who worked at the Louvre; Paul Viet, of Blois; Morlière, a native of Orleans, who worked at Blois; Robert Vauquer, of Blois, a pupil of Morlière,

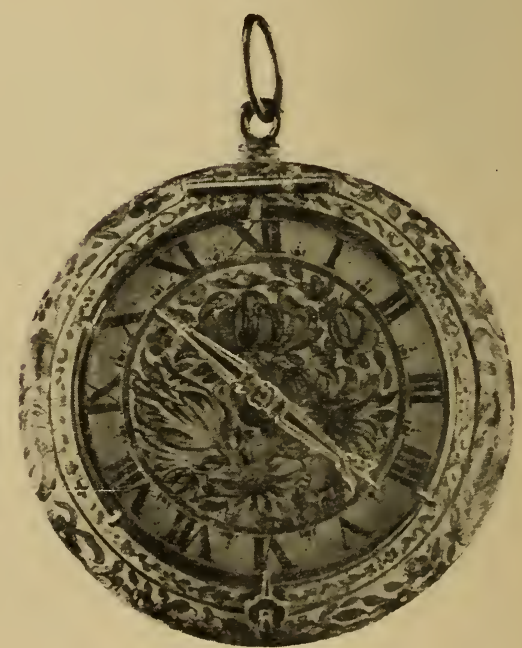

FIG. 230.

Watch signed "Simon Hackett, Londini," about 1635. 


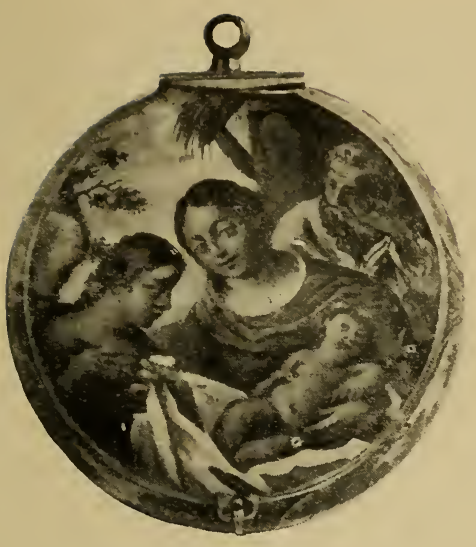

FIG. 231.-Front of Case.

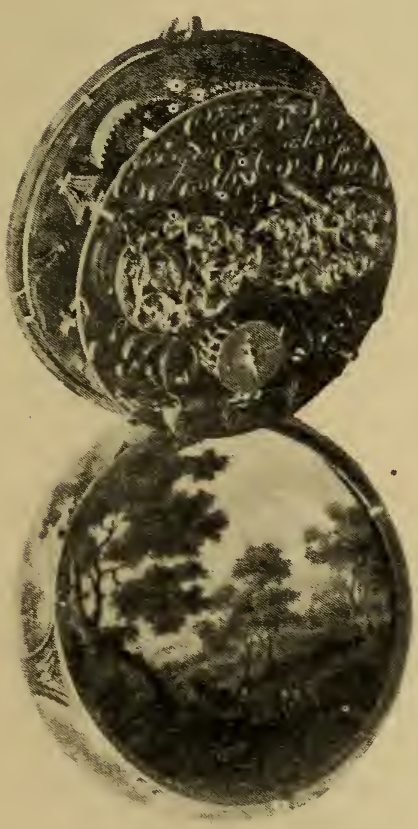

FIG. 233.-Movement and inside of Case.

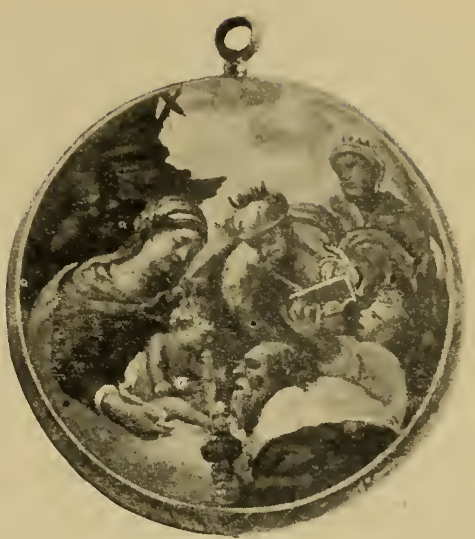

FIG. 232.-Back of Case.

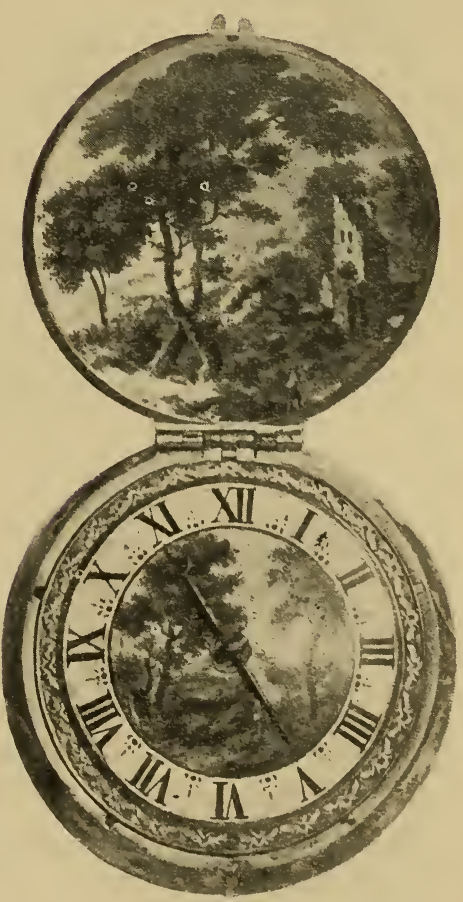

FIG. 234.-Dial and inside of Cover.

Watch about 1640. Movement signed "Barbaret à Paris." 


\section{I82 Old Clocks and Watches and their Makers}

of pre-eminent ability, whose enamel painting has never been excelled either for colour or design, though specimens of his art are rarely to be met with on watch cases ; Pierre Chartière, of Blois, who was noted for his painting of flowers; and the brothers Jean Pierre and Ami Huaud (or Huaut, also spelt Hualt), of whom " Huaud le puisne," as he usually signed himself, was particularly celebrated for figure-painting. Several examples are to be found in the British, South Kensington, and Guildhall Museums.

Four views of a splendid watch from the Schloss collection, dating from about 1640, appear in Figs. 231, 232, 233 and 234. The movement is signed " Jacque Barbaret à Paris."

Front and back of a smaller watch from the same collection, signed " Romieu, Rouen, Fecit," are given in Figs. 235 and 236.

The representation of the toilet of Venus on the back of a watch by Robert Lochard, which is shown in Fig. 237, is an extremely beautiful example.

The admirable painting of figures and a landscape shown in Fig. 238 is signed by "Huaud le puisne," and is on the back of a watch by Stever Tracy, Rotterdam, which is at the British Museum. Among other examples there may be cited a representation of some nymphs bathing, excellently executed in enamel by Jean Toutin ; an enamelled case, very finely painted by Henry Toutin, illustrating the story of Tancred and Clorinda in "Orlando Furioso;" another by the same artist which treats of the " Rape of the Sabines;" a watch by David Bouquet, a well-known London maker, the case being ornamented with flowers, in relief, and enriched with diamonds; a very finely enamelled watch case, illustrating the early life of Christ ; a very thick rounded watch by Tompion, with case splendidly painted in enamel by Camille André.

Fig. 239 shows the case of a watch by Jean de Choudens, dating from about 1680 , which is painted in a really charming manner and bears the inscription "Les deux frères Huaut pintre de son A. E. Berlin." It is at the South Kensington Museum.

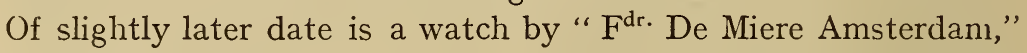
with a painting on the back of the Roman Piety, as shown in Fig. 240. This is signed "Huaud le puisne fecit," and is also to be seen. at South Kensington. A similar painting covering a watch by "Pieter Paulus Amsterdam," which is from the Schloss collection, bears the signature " P. Huaud, P. Genius, F. Geneva."

There were two examples in the Dunn Gardner collection which was dispersed by auction in 1902: a choice piece of figure painting 

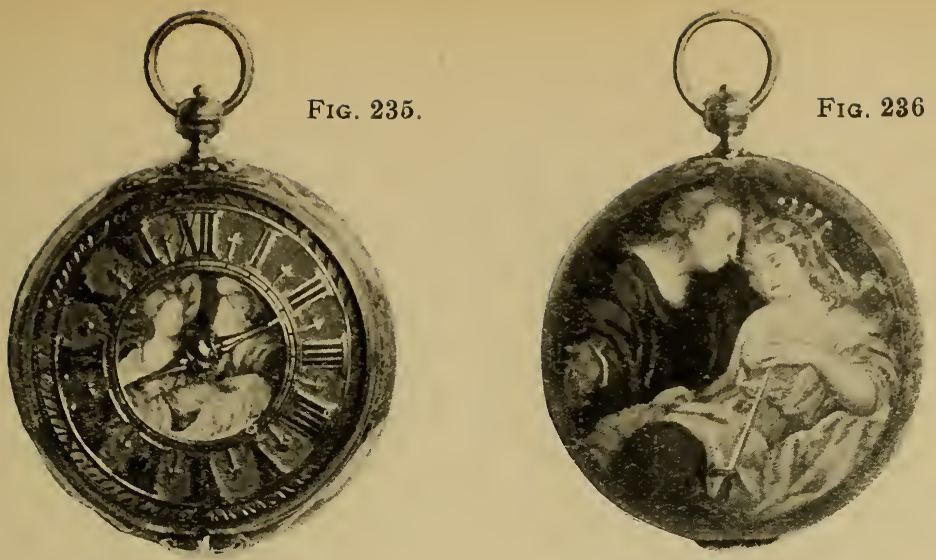

Front and back of Watch signed "Romieu, Rouen, Fecit."
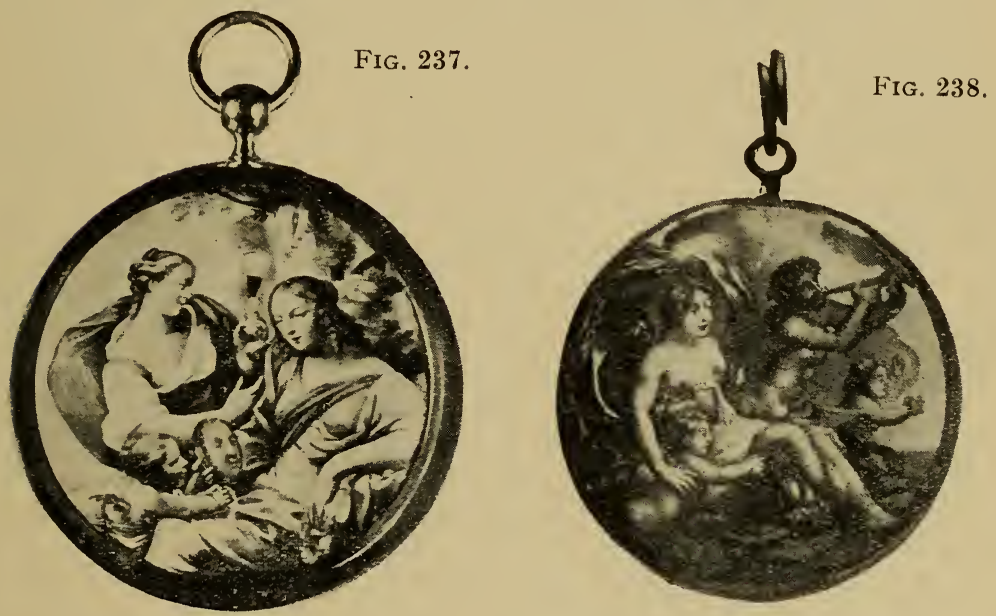

Watch by Robert Lochard.

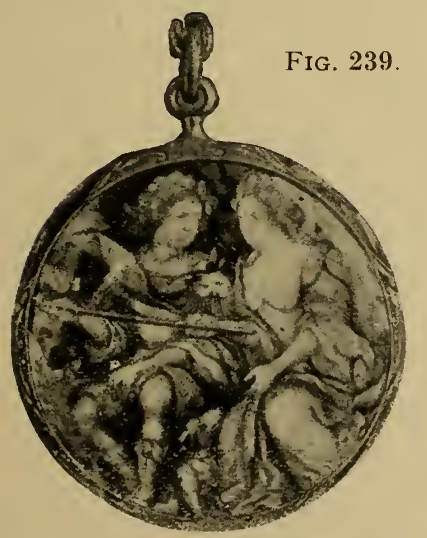

Watch at the British Museum.

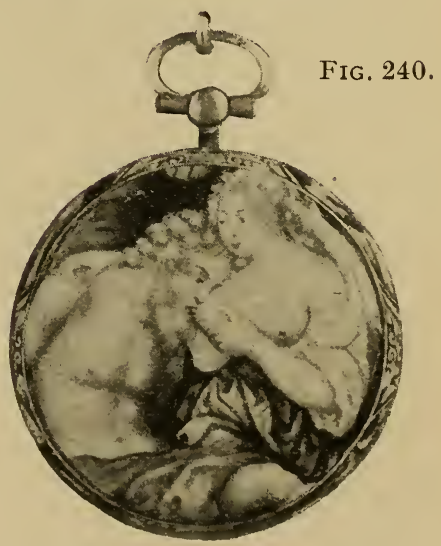

Two Watches at the South Kensington Museum. 183 

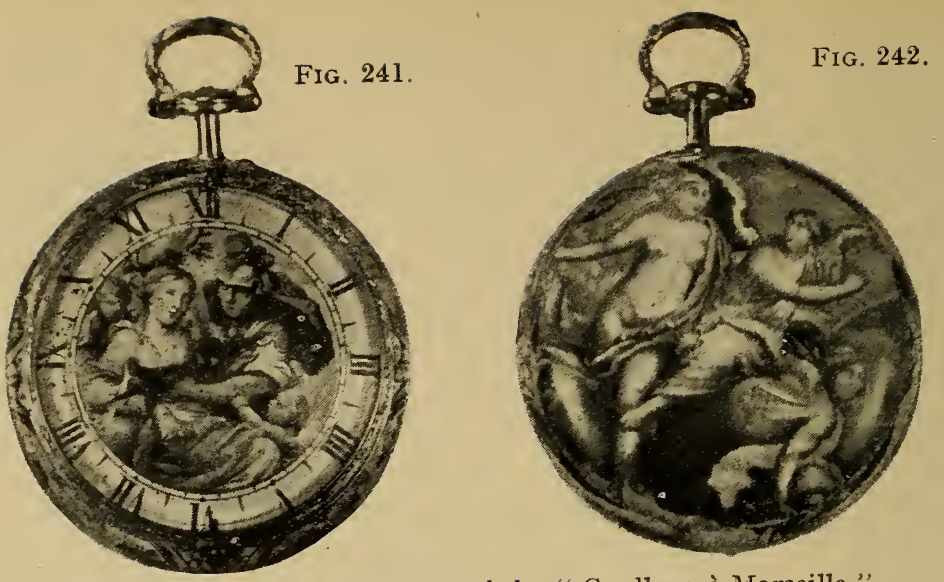

Front and back views of a Watch by " Goullons à Marseille."

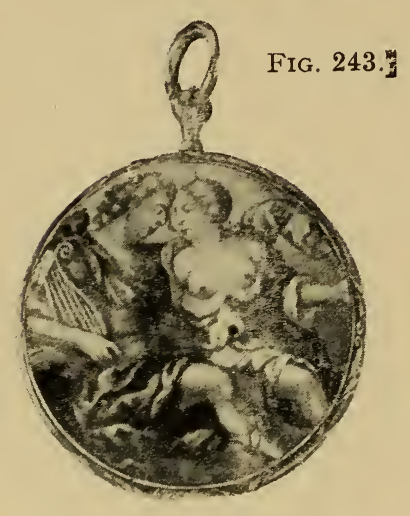

Watch by " Ofard a Gex."

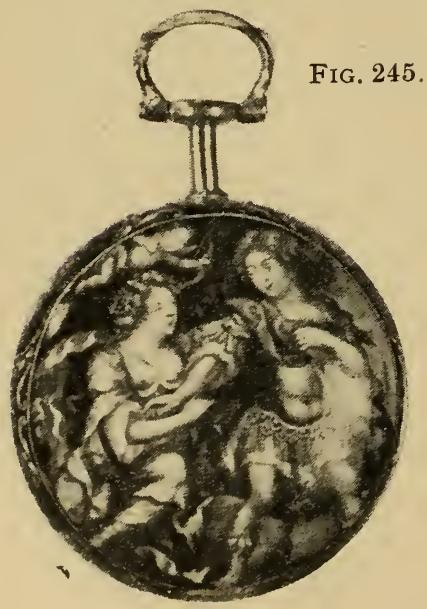

Watch by "Vanenhove, Amsterdam."

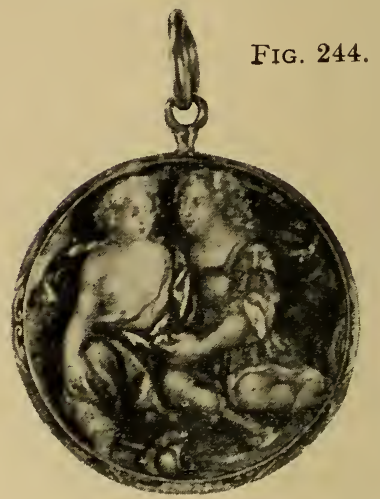

Watch by " Johannes van Ceulin, Hague."

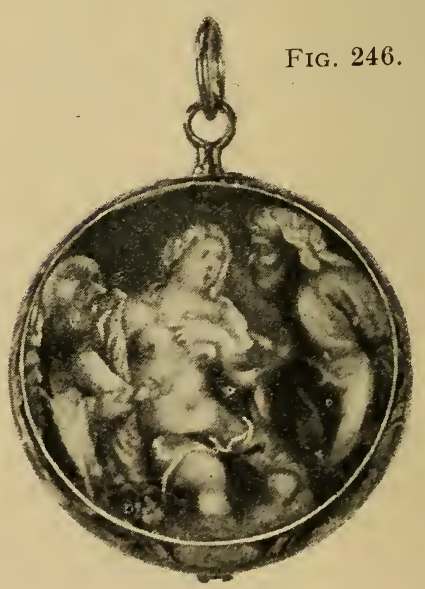
Watch by "Jan Bern Vrythoff, 
covering a watch by Lucas, Amsterdam, the enamelled case being signed "Huaud l'aisné pinxit à Geneue," and a watch by Julien Le Roy, with enamelled case, bearing the signature of G. Bouvier.

All on p. 184 are signed specimens of the Huauds' work. 'The first consists of front and back views of a watch by "Goullons à Marseille," dating from about 1670, which is signed "Huaud le puisne." On the front are Mars and Venus with Cupid, and on the back "The Hours."

The next two bear the same signature, and are a little later. A pair of lovers is painted on each; the first Apollo and Diana, the second possibly Mars and Venus. The former covers a watch by " Ofard à Gex," and the latter one by " Johannes Van Ceulin, Hague."

"Venus and Adonis" is signed "Le deux frere Huaut, p. d. V. A. Fct, à Berlin," and is on the back of a watch by "Vanenhove, Amsterdam."

The group "Susanna and the Elders," most beautifully painted, is signed "Les deux freres Huaud les jeunes," and is on a watch named " Jan Berns Vrythoff, Hague."

Pigments of different composition yielding colours not so superlatively warm and rich as characterises the work of what I will venture to call the Huaud school seem to have been introduced towards the middle of the eighteenth century. Prevost (or Prevaux) who is described as "Peintre du cabinet de S. M." (Louis XV.), may be taken as one of the best exponents of the new method. He painted a portrait of Madame Pompadour, by conmmand of the king, for which he was paid 1,000 livres. A really beautiful piece of his enamel painting, signed "I. Prevaux, pin. 1749," on the back of a watch by Pascal Hubert le Jeune, Rouen, from the Schloss collection, is shown at the top left-hand corner of p. 186, with others decorated in a somewhat similar style. The watch on the same level, with a pair of lovers and a landscape on the back, is by Julien Le Roy. Vulcan, Venus, and Cupid are on a repeating watch by the same maker. The sylvan scene with a flute player and a lady holding the music adorns a watch signed "Raphard, London," and the remaining two are watches by Julien Le Roy. Naomi and Ruth are represented in the bottom left-hand corner, and the tableau in the last example is founded, I believe, on a tragic incident in the romance of Orestes and Hermione.

Painted groups, bordered with translucent enamel over a wavy or engraved metal ground, were favoured during the last half of the eighteerith century, and in many instances the surface of the painting 


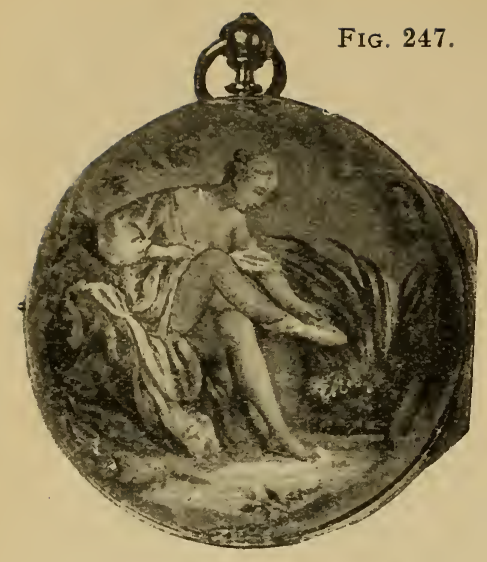

Watch by Pascal Hubert le Jeune, Rouen.

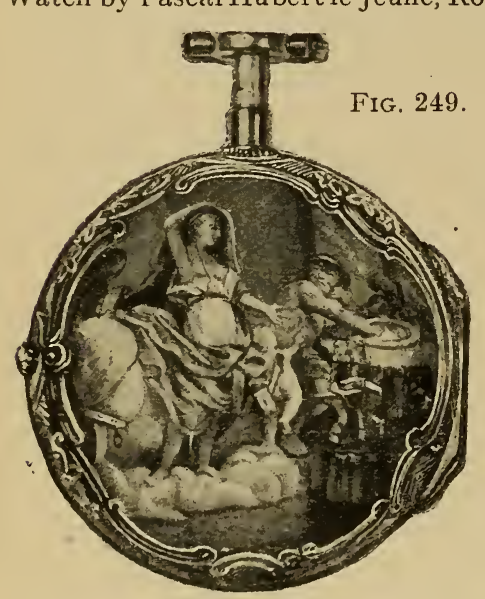

Repeating Watch by Julien le Roy.

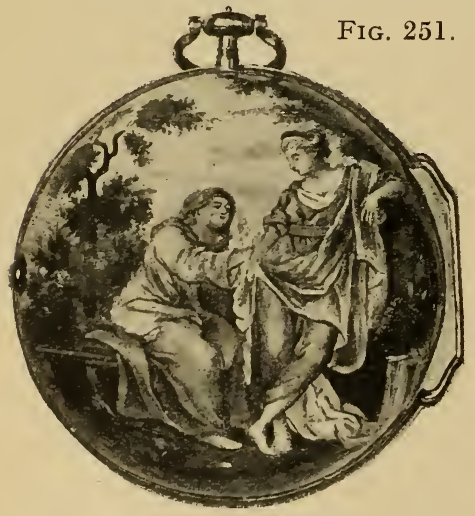

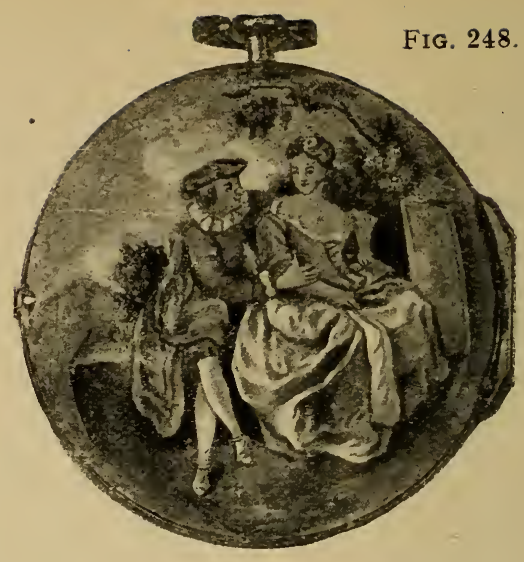

Watch by Julien le Roy.

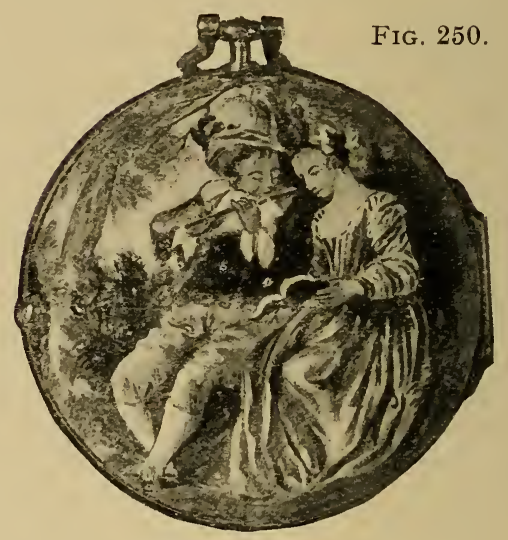

Watch by Raphard, London.

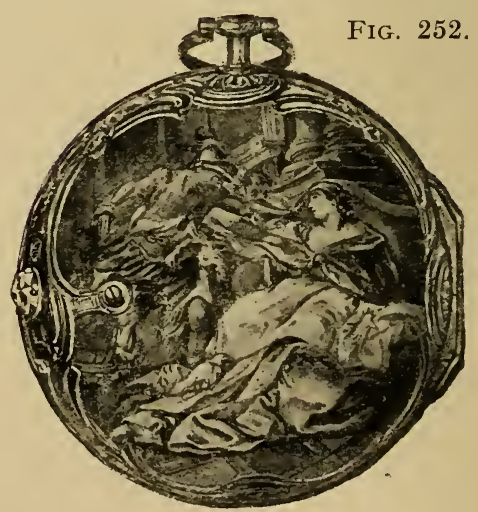

Two Watches by Julien le Roy. 
was covered with a transparent flux, which gave it a glassy appearance.

During the first half of the nineteenth century portraits and views in small panels attached to the backs of watch cases were popular and of very uneven merit. Most of them were, I think, of Swiss origin.

In the Vienna Treasury is a watch case finely enamelled inside and out by the brothers Huaud.

Other representative examples of French, Swiss, and English enamel are appended.

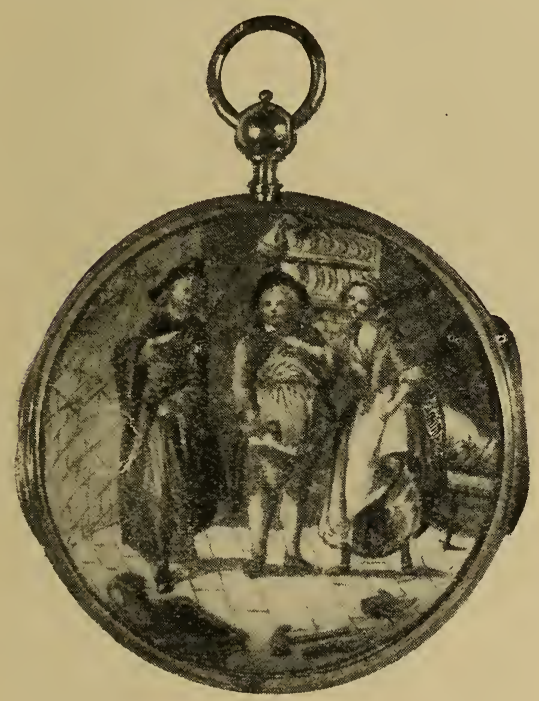

FIG. 253.-Watch by Henry Harper, London.

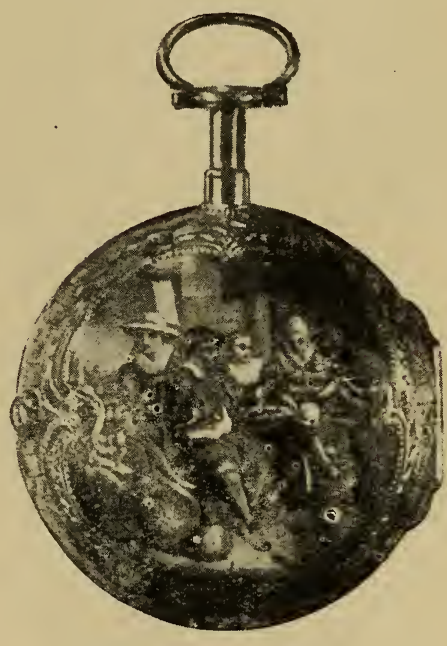

FIG. 254.-Watch signed by "Honoré Lieutand, Marseille."

Fig. 253 shows the back of a watch by Henry Harper, London, of a style corresponding to 1670 . The painting is probably Dutch, and of a later date.

The beautiful painting set in an engraved gold border shown in Fig. 254 encloses a watch signed " Honoré Lieutand, Marseille."

Two views of a half-quarter repeater by Rd. Gregg, London, from the Pierpont Morgan collection, are given in Figs. 255-256. The centre of the outer case is enamelled with figures of cupids in a landscape, and small vignettes are painted around the edge; the dial bears the arms of Herbert, second Viscount Windsor ; this title became extinct in 1758. The painting is signed with the initials " A.C."

An excellent specimen of floral decoration in enamel bordered by 
I88 Old Clocks and Watches and their Makers

engraving appears in Fig. 257, which represents the gold back of a watch signed " Jn. L $\mathrm{L}^{\mathrm{s}}$ Argand, Paris," and dating from about 1770

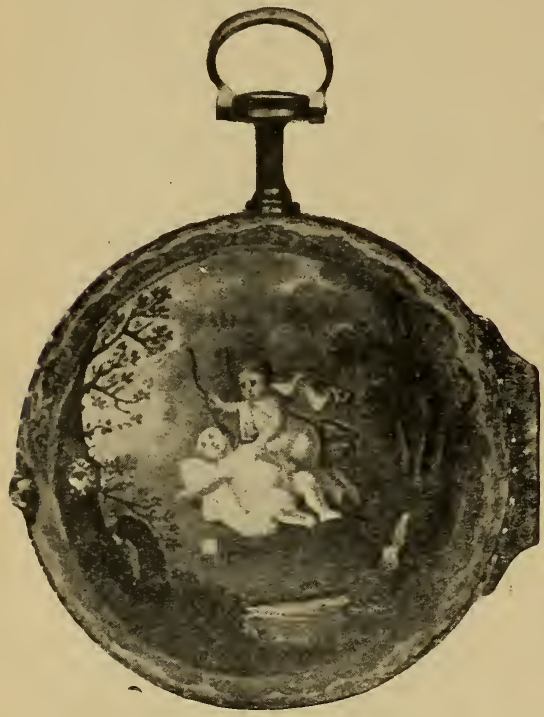

FIG. 255.

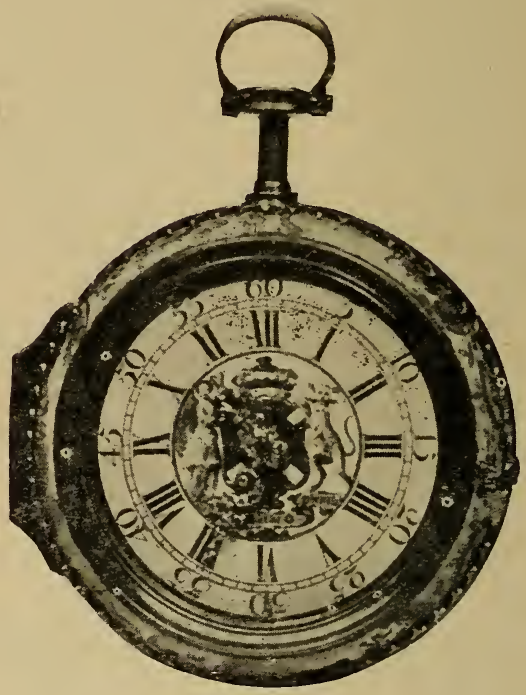

FIG. 256.

Two views of a half-quarter Repeater by Rd. Gregg, London.

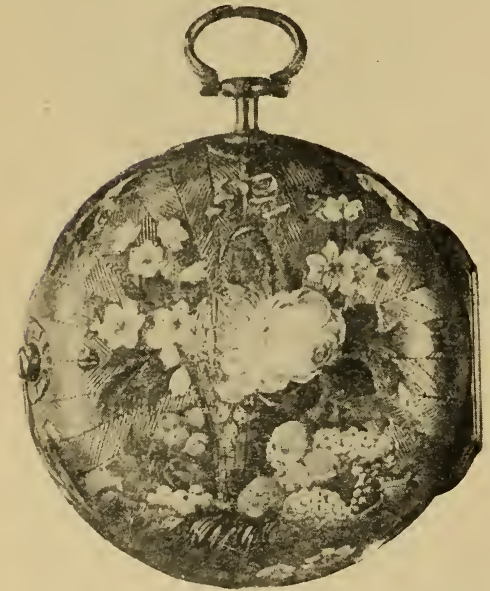

FIG. 257.-Watch by J. L. Argand, Paris, about 1770.

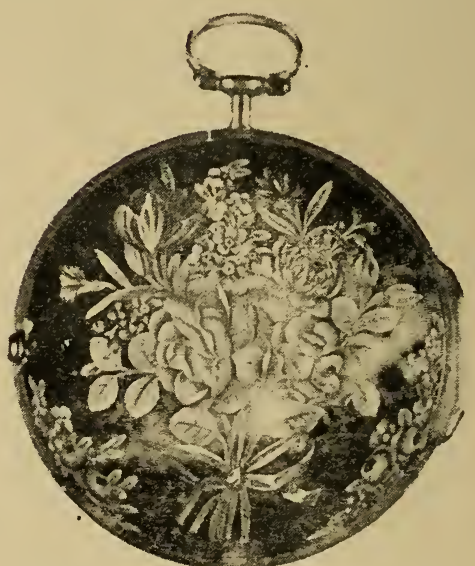

FIG. 258.-Watch by Romilly, Paris.

A back view of a contemporary watch by Romilly, Paris, with pretty flower painting on a brown enamelled ground, is given in Fig. 258. 
A choicer piece of flower painting on enamel than is shown in Fig. 259 it has never been my good fortune to see. This watch belongs to the Hon. Gerald Ponsonby, by whose permission it is illustrated. It is a sourdine repeater by Julien Le Roy ; the hands, bow, push piece at pendant, thumb piece and sourdine toucher are all set with diamonds.

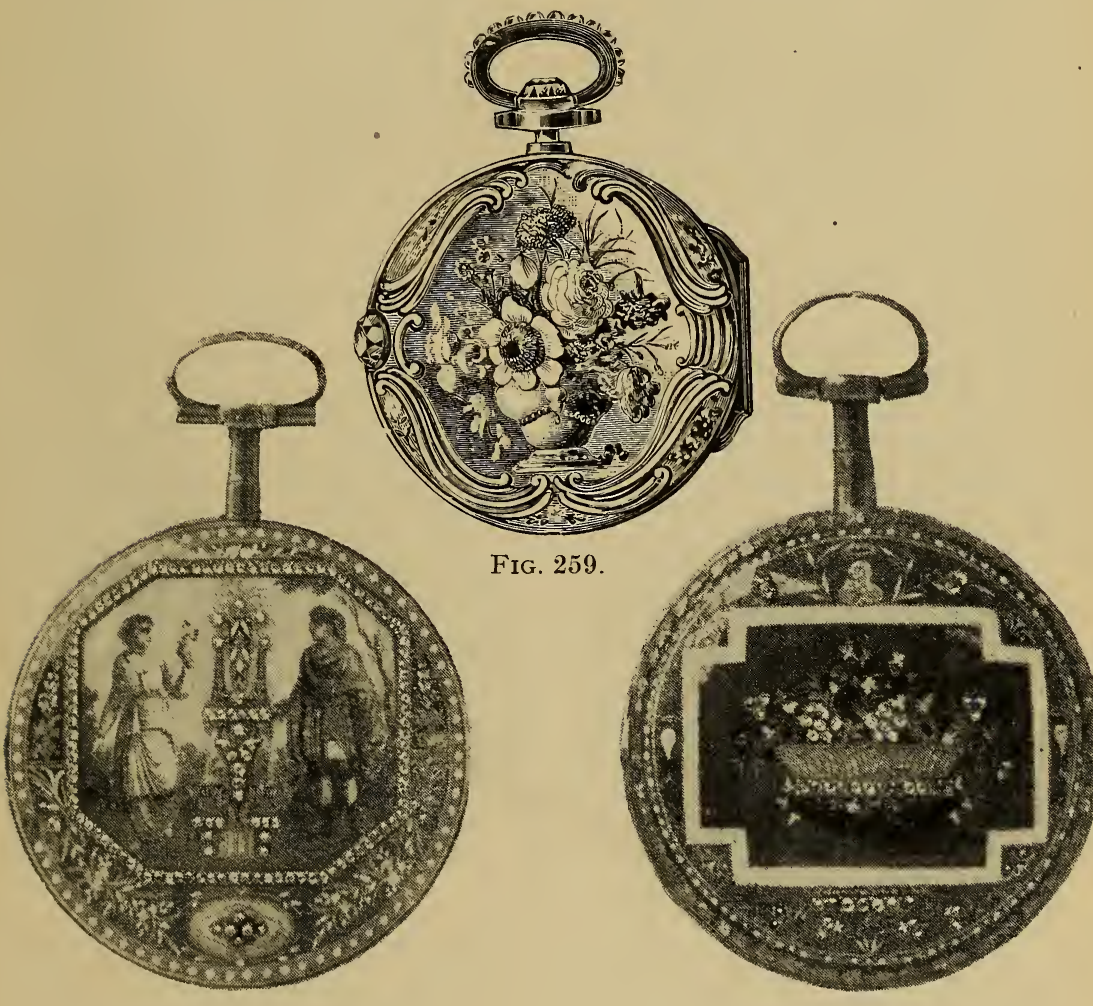

FIG. 260.-Back of Watch by G. Archard et Fils, Geneva. Fnamel painting studded with diamonds.

FIG. 261.-Back of French Watch. Enamel painting studded with diamonds; surmounted by a bust of Louis XVI.

As an example of English enamelling dating from about the middle of the eighteenth century, is shown, in Fig. 262, the exterior of a watch by Arl. Dobson, London, which is in the British Museum. I wish I could say the painting is better than contemporary specimens of foreign artists.

Notwithstanding the taste tor Chinese art which was so apparent in France during the eighteenth century, it is very seldom a watch 


\section{I90 Old Clocks and Watches and their Makers}

is met with having a back of porcelain enamel with a Chinese subject moulded thereon. An example covering a watch by Julien Le Roy may, therefore, be of especial interest, though it makes but a poor picture. The figures are in bright colours, and the ground a dark brown.

On p. 191 are some fine examples of varying periods. "The Nativity" is a beautiful piece of painting in the incomparable Huaud style on the back of a watch by Gribelin, Paris, dating from about 1680. On the same horizontal line is a watch the movement of which is signed " Abraham Le Schegs, Amsterdam." The painting is doubtless also by one of the Huauds. The first of the middle pair is the

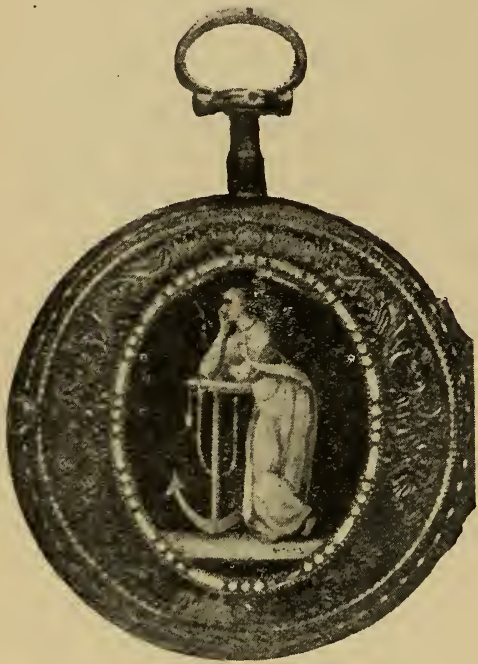

FIG. 262.-Watch in British Museum.

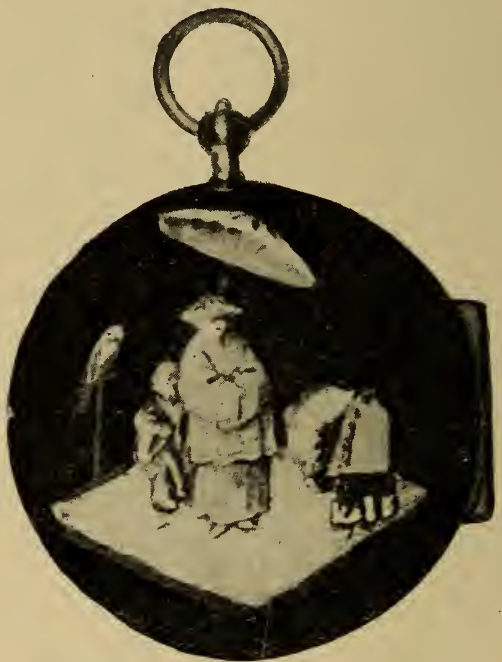

FIG. 263.-Watch by Julien le Roy.

back of a watch by the younger Caron. Any appearance of vulgarity in the subject of the painting is quite atoned for by the adjoining view of the inside of the case, where are represented the young mother and her babe. The representation of the mother of Achilles dipping him in the Styx is on the back of a watch by Julien Le Roy. Diana and her attendant nymph, which adorns the last watch on the page, dates from about 1780 .

Fig. 270 shows a watch by J. Leroux, Charing Cross, which is said to have belonged to Viscount Windsor, whose title became extinct in 1758. The case is enamelled blue and white on a gold ground. 

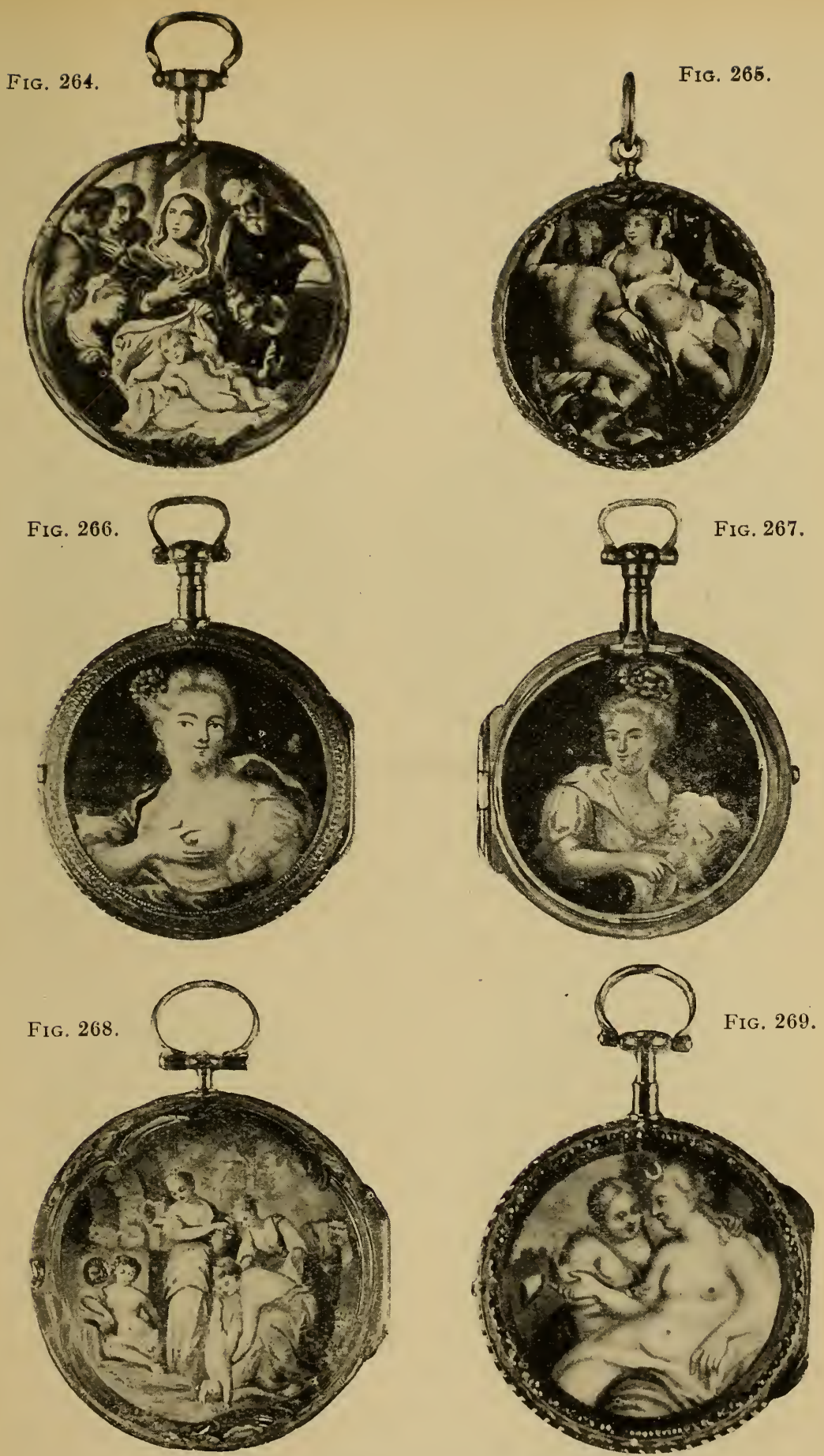

Fine examples of varying periods. 


\section{I92 Old Clocks and Watches and their Makers}

In Fig. 271 is shown a repeating watch by Lepine; on the gold case in an oval medallion are finely carved figures of gold and silver

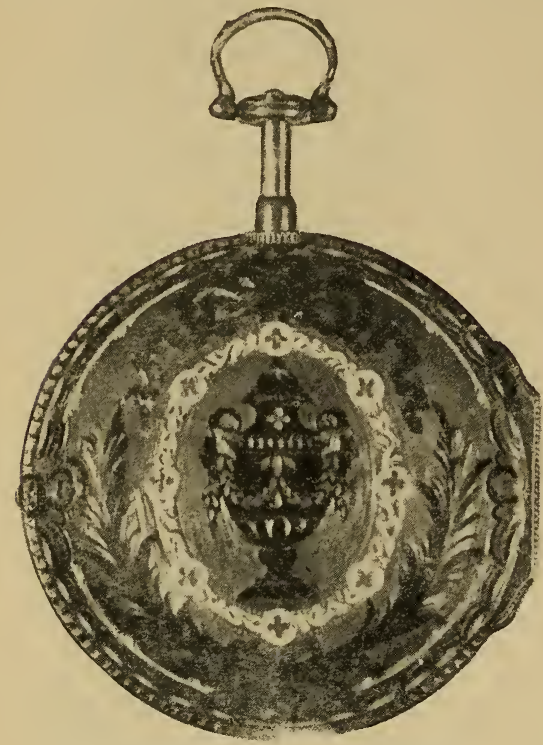

FIG: 270.-Watch by J. Leroux, Charing Cross.

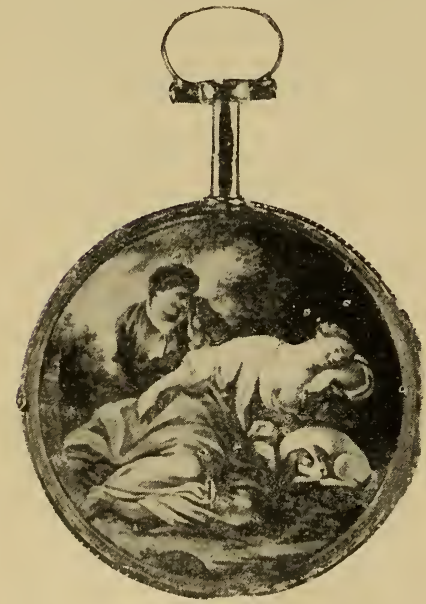

FIG. 272.-Late Eighteenth-Century. French painting.

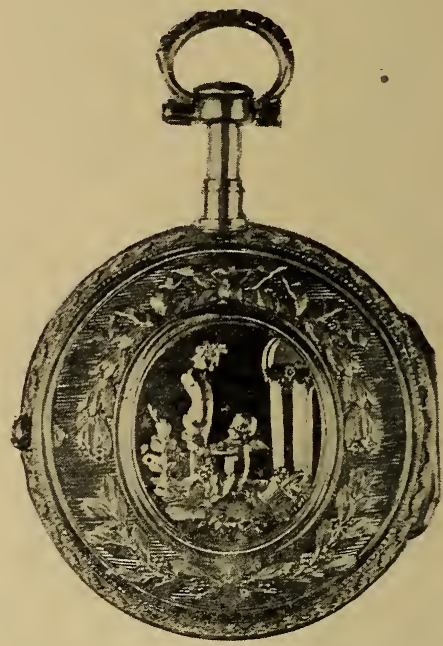

FIG. 271.-Repeating Watch by Lepine.

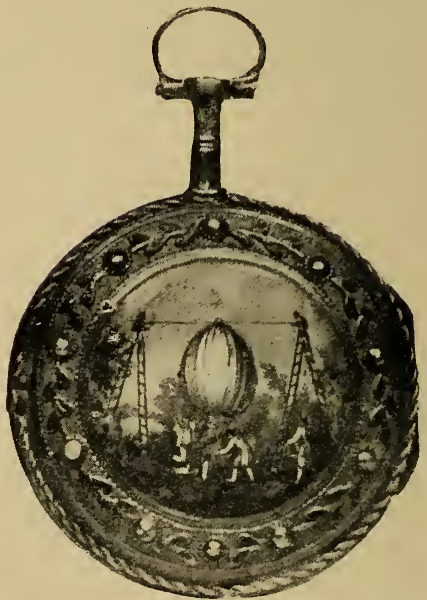

FIG. 273.-The back of what is callcd a "Mongolfier" Watch.

on a ground of green enamel, outside of which is a wreath carved in silver. This decoration is exceedingly effective. The push piece, thumb piece, and bow are studded with diamonds. 
Fig. 272 is a late-eighteenth-century French painting representing Cymon and Iphigenia.

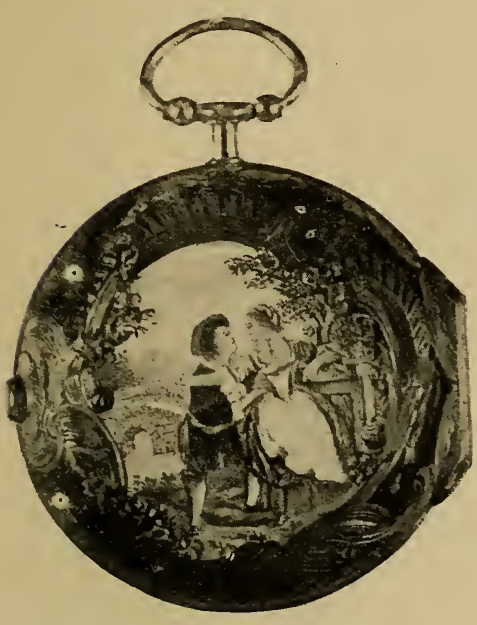

FIG. 274-Watch by J. B. Baillon à Paris, about 1765.

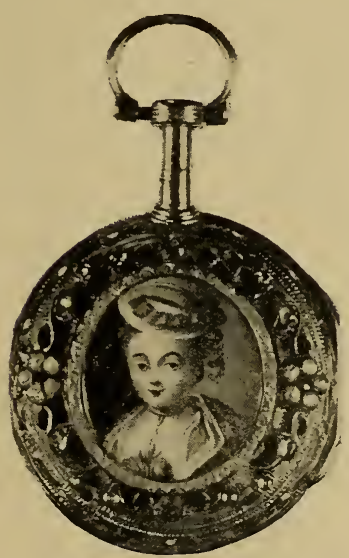

FIG. 276.-Watch by Alexander Patry à Geneva, about 1790 , miniature bordered with pearls and coloured stones.

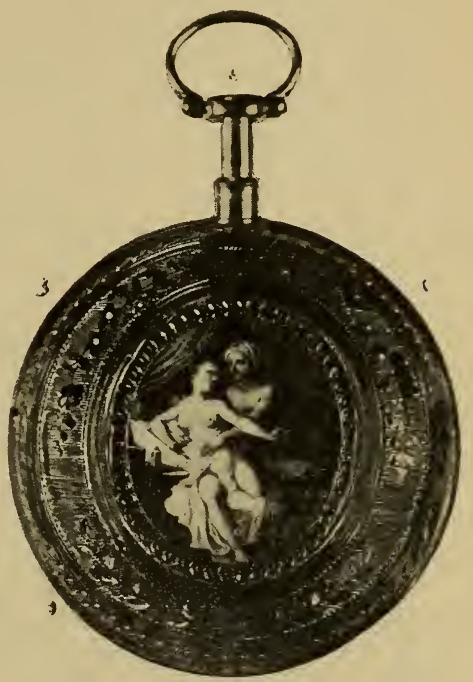

FIG. 275.-Watch by Gregson, Horloger du Roy, Paris, about 1785:

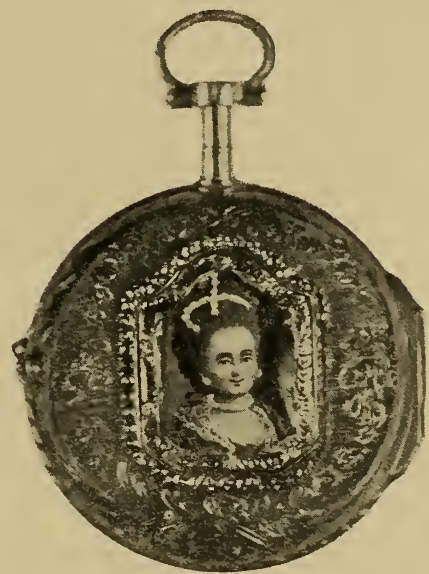

FIG. 277.-Watch by Lepaute, Paris, about 1790, enamelled portrait bordered with diamonds.

In Fig. 273 is shown the back of what is called a "Mongolfier" watch, from the Pierpont Morgan collection, on which is painted a representation of a balloon undergoing inflation, intended, I suppose, 


\section{I94 Old Clocks and Watches and their Makers}

to commemorate the success of Montgolfier's aerostatic machine in 1782. The movement is signed "Vauchez, Paris."

Fig. 278 shows the back of a thin watch by "Pierre Gregson, Paris, Horloger du Roy." The case is enamelled on gold, the outer part rayed and covered with royal blue translucent enamel ; on a medallion of opaque enamel in the centre is a well-painted group with Cupid and a dog, denoting love and faith. It is characteristic of the Louis XVI. period, when this style of enamelling was in fashion. Fig. 279 is another watch by Gregson from the collection of Mr. H. J. Heinz. It
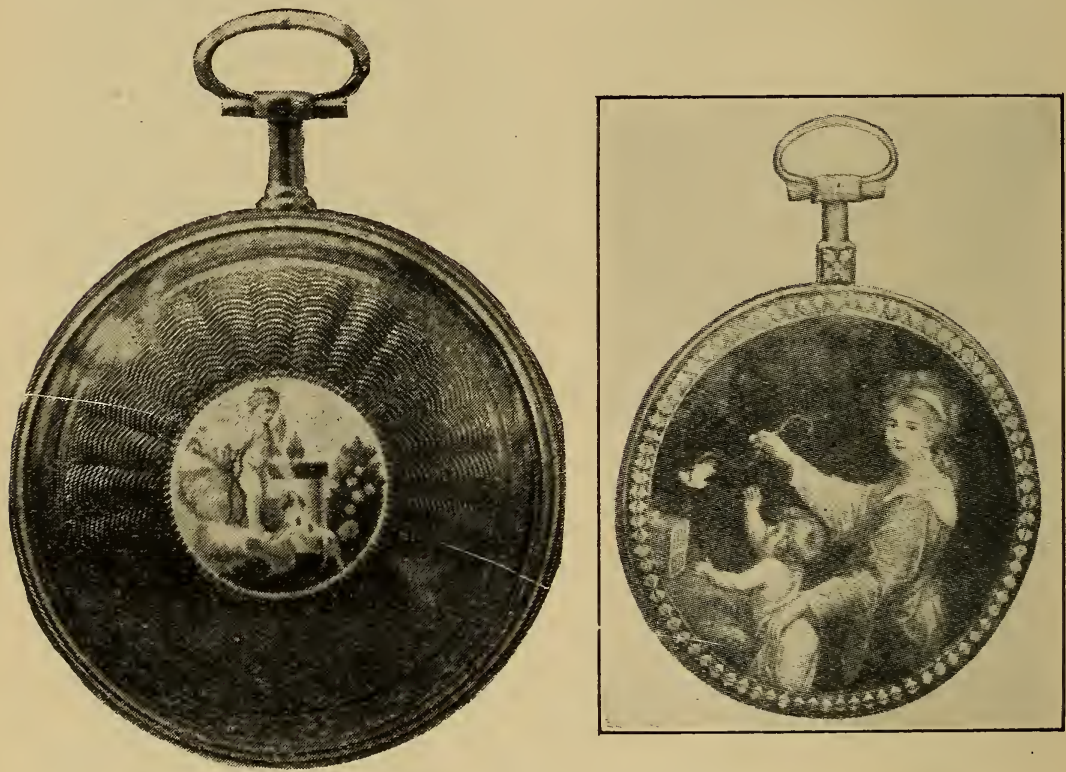

Figs. 278-279.-Two Enamelled Watches by Gregson.

is gold with the back of the case ornamented with an enamel picture of a woman and child with pet bird ; surrounded with a border of blue and white enamel. Fig. 280 shows an English watch, with the London hall-mark corresponding to 1787 . The margin is of translucent royal blue as in the preceding example.

Two French watches of slightly later date, finely painted in enamel, are shown in Figs. 281 and 282.

Battersea enamel dates from about 1750 , when Sir Theodore Janssen, who was Lord Mayor of London in 1754, established a manufactory at York. House, Battersea. Horace Walpole described his collection as "stamped with copper plates." Transfer printing may have been employed for flat surfaces, but certainly not for watch 
cases, the painting on some of which was by artists of note. A very good example is shown in Fig. 285. Back and front views

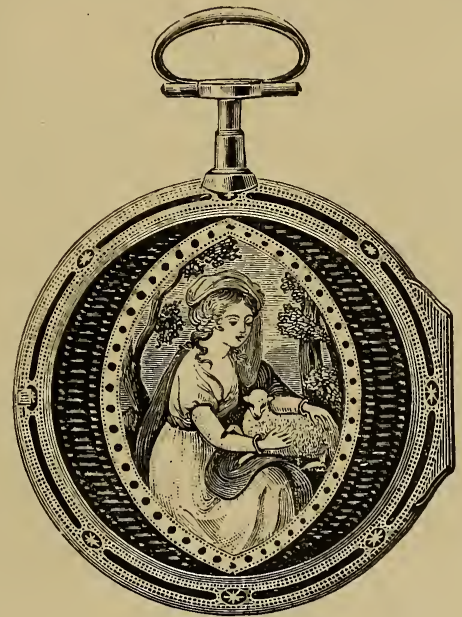

FIG. 280.-English Enamelled Watch.

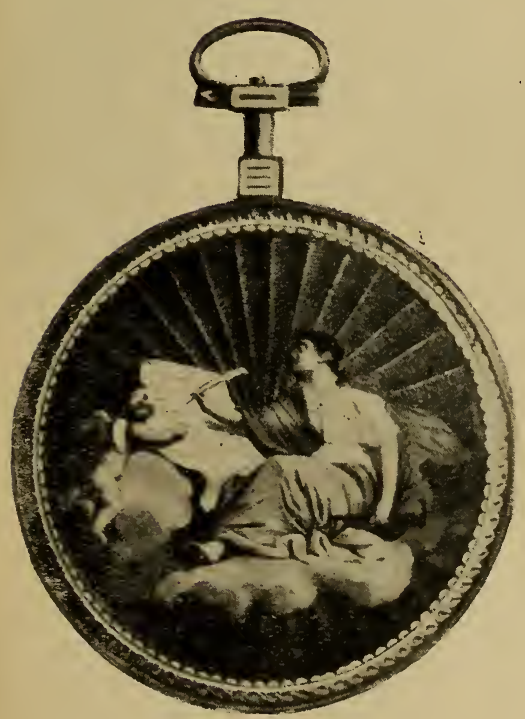

FIG. 281.

Two French Watches finely painted in Enamel.

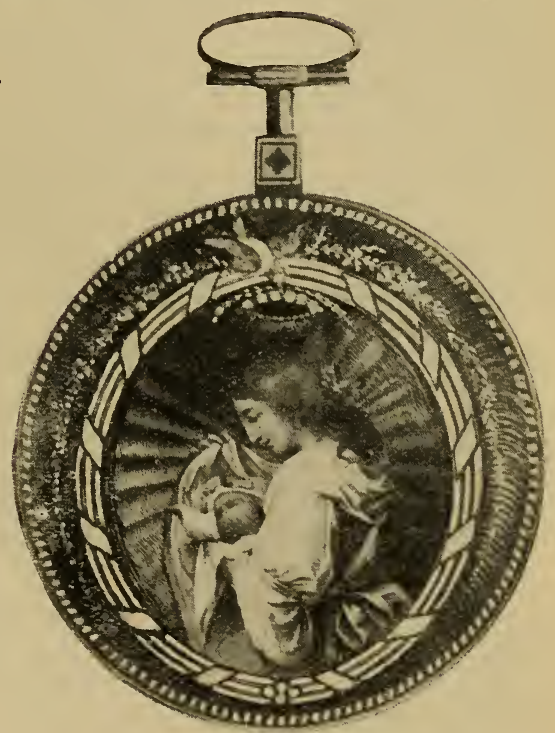

FIG. 282.

of a very choice little watch by Hughes, London, of a slightly later period, are given in Figs. 286 and 287.

Watch dials of enamel, with pictures painted in bright colours 
I96 Old Clocks and Watches and their Makers

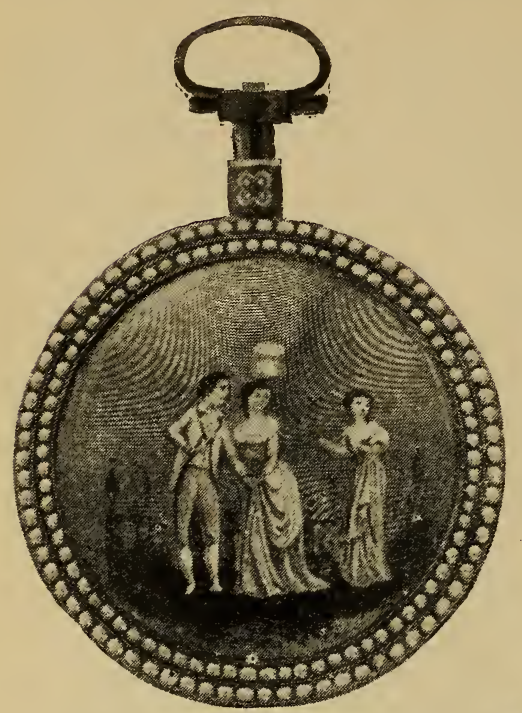

FIG. 283.-Enamel bordered with Pearls.

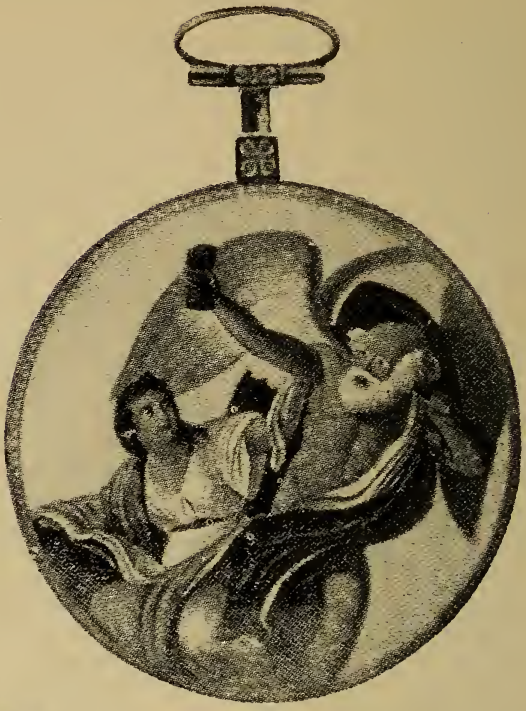

Fig. 284.-Enamel Painting on back of Watch by Breguet.

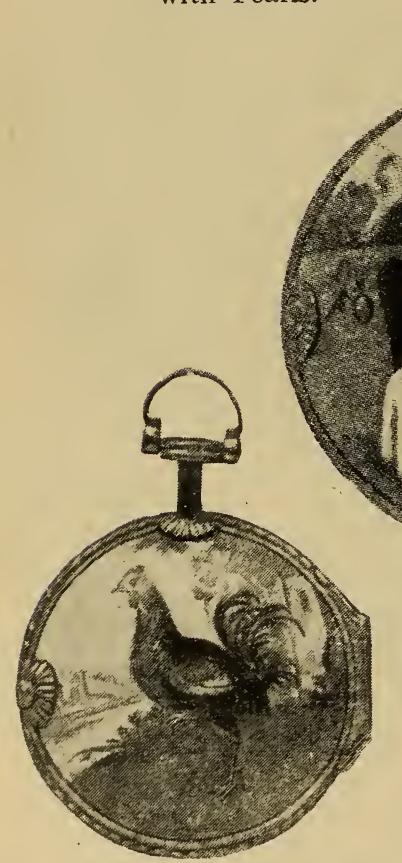

FIG. 286.

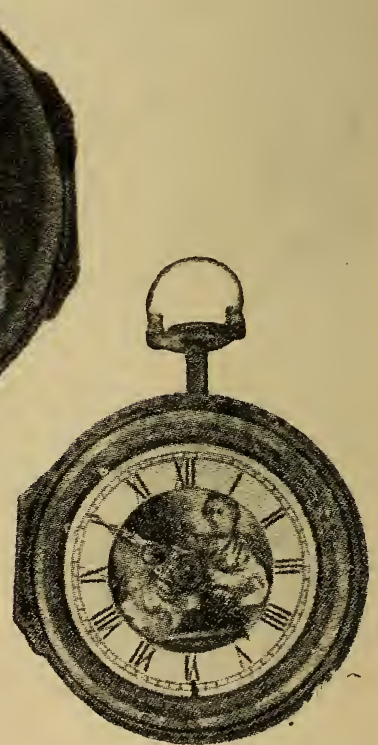

FIG. 287.

Back and front views of Watch by Hughes, London. 


\section{I98 Old Clocks and Watches and their Makers}

signature induced, doubtless, by the regulations applied to watches imported into Turkey, for the dial is marked with Turkish numerals. It may be assumed that Borrell was the manufacturer. The movement is of admirable finish, has a verge escapement and fancy pillars,

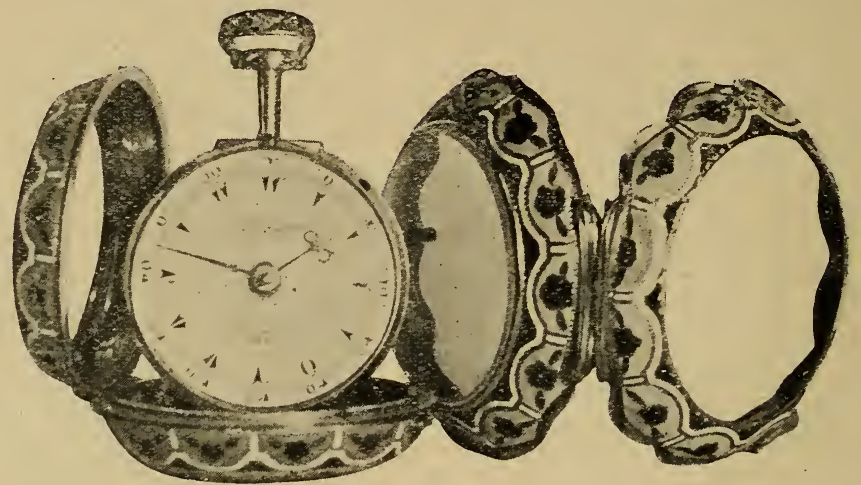

FIG. 290.-A credit to English mechanical and artistic work of the period.

but the particular attraction is the beautiful gold cases, of which there are three. The outer one, instead of having a flat surface where the halves meet, is scalloped all round, but still forming a well-fitting junction by no means easy to attain. This case is enamelled, with a

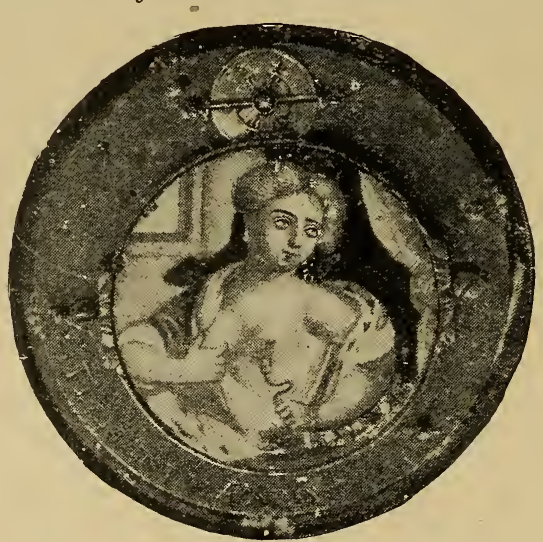

Fig. 291.-A Gold Enamelled Plaque, finely painted over the balance.

glass in the back, through which a very choice bit of floral enamel painting is to be seen. The back of the two cases are so well fitted together that it requires minute scrutiny to detect that the enamelled centre is not part of the outer case. The innermost case is a plain one, but exceedingly well made. 
During the eighteenth century the cock or bridge covering the balance of the watch, and concealed until the movement was turned out of the case, was occasionally decorated with painting in enamel. Fig. 291, given as an illustration, is a watch signed "Flamant à Paris." It has a gilt metal case, and dates from about 1710 ; over the balance is a gold enamelled plaque with a finely painted representation of Cleopatra.

Fig. 292 is a gold repeating watch from the collection of Mr. H. J. Heinz, contained in an outer case of brown and white opaque enamel attiched to a chatelaine of the same material. The movement was made by Peter Mackdonald in London in the years 1790-1794. This watch was formerly the property of Admiral, Lord Nelson, the hero of Trafalgar. On the back of the watch an " $\mathrm{N}$ " is engraved, surmounted by a coronet, and also the letter " $\mathrm{B}$." The " $\mathrm{N}$ " is for Nelson and the "B" for Bronte. The Neapolitan title of Duke of Bronte was granted to Nelson in 1799. This watch was made some years before being presented to Nelson, the date of manufacture antedating the conferment of the title "Duke of Bronte."

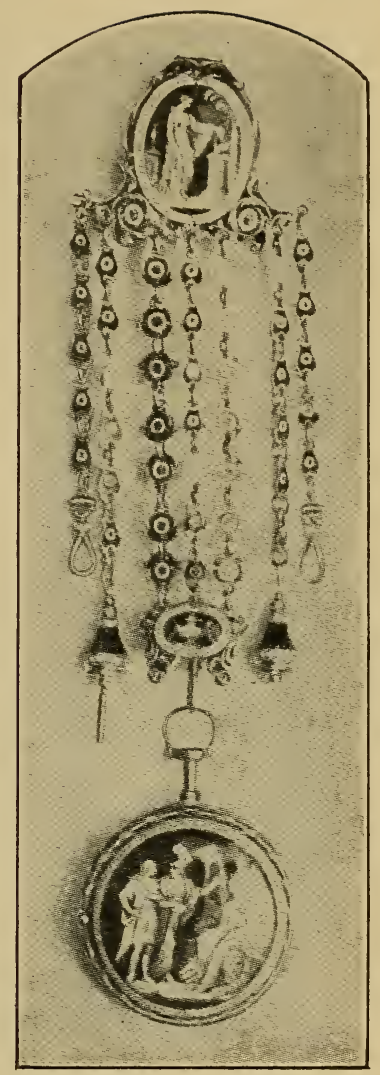

FIG. 292.—Gold Repeating IVatch.

Pair Cases.-To protect the surface of the decoration, watches with exterior ornament of enamel were generally provided with an additional cover, and from about 1640 the practice of adding a loose outer case to watches, forming what are called "pair cases," continued to the early part of the nineteenth century.

Loose cases of gold and silver, with designs chased in repoussé, were at this period an important art in connection with watchmaking. Chasing as distinguished from engraving and carving is the formation of ornament in relief by punching or pressing, rather than by cutting away the material. It is a very ancient art, and chased ornament is to be found on some of the earliest of watch cases. Much of the work on old clocks, which at first sight appears to be 


\section{Old Clocks and Watches and their Makers}

engraving, proves on examination to be chasing. All the small numerals on Habrecht's clock at the British Museum are stamped.

The silver chased work applies to the edges of English oval cases at the beginning of the seventeenth century is said to have been imported in strips from France.

An excellent piece of flat chasing, including the head of Charles II., with the Royal Crown and supporters, on the case of a watch by Daniel Le Count, dating from about 1680, is shown in Fig. 293. The case is a single one, and on the right is a little catch, by pressing which a disc on the left springs on one side, exposes a round hole in

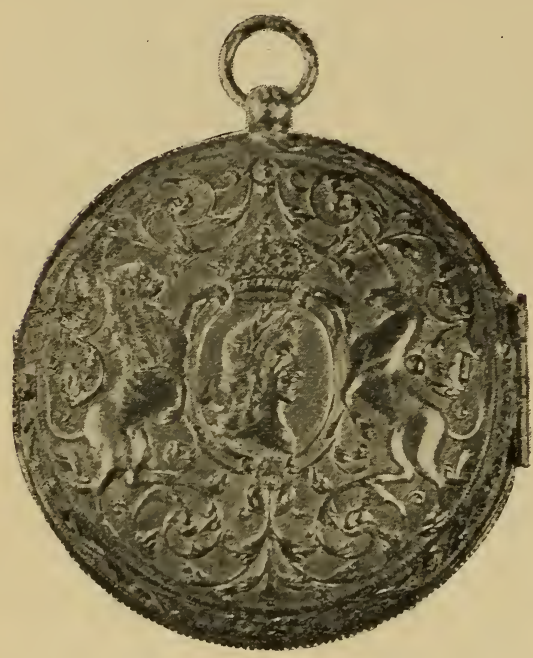

FIG. 293.-Flat Chasing on Single Case Watch by Daniel Le Count, about 1680.

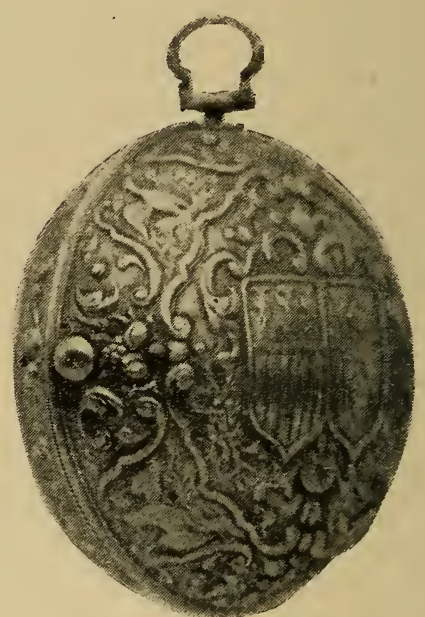

FIG. 294.-Flat Chasing on Outer Case of Watch by William Scafe.

the case, and thus allows access to the winding square. The dial of this watch is shown on p 217 and the movement in Chapter VIII.

The same style of decoration of a later date on the outer case of a watch, by William Scafe, may be seen in Fig. 294.

In repoussé chasing the material is punched or pressed up from the back, whereby the design is obtained in higher relief than is the case with the ordinary method of punching from the face. Some very choice specimens of repoussé work, marked "H. Manley" in very small characters, are in the British Museum. An outer case at the South Kensington Museum is signed " H. Manley fec.," and a watch by Ellicott, bearing the hall mark for $\mathbf{1 7 6 7}$, in a fine repoussé case, which 
appears to be signed "Manby," is in the Guildhall Museum. Among the signatures on other good examples may be mentioned Parbury, Cochin; and Moser, but as a rule decorative work of this kind bears no indication of the producer.

Occasionally cases decorated in repoussé à jour are to be met with, some of the best of them being the work of Dutch artists, but this iorm of crnament is hardly suitable for watch cases, as it affords

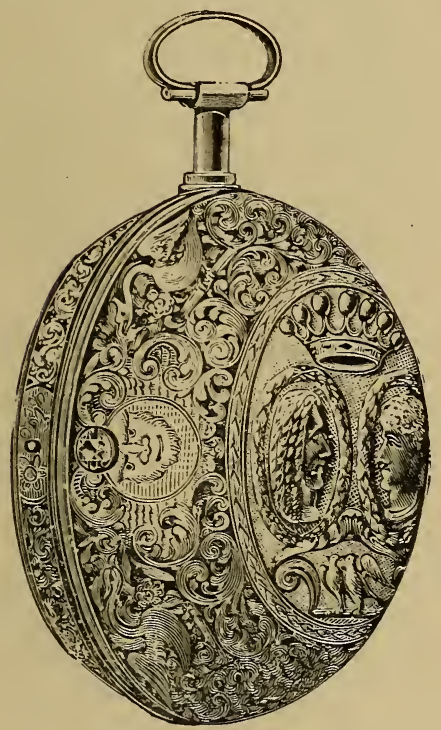

FIG. 295.-Pair Case Repeating Watch by Paul Dupin, about 1700 , showing repoussé outer cover. The chasing is of exceptional fineness.

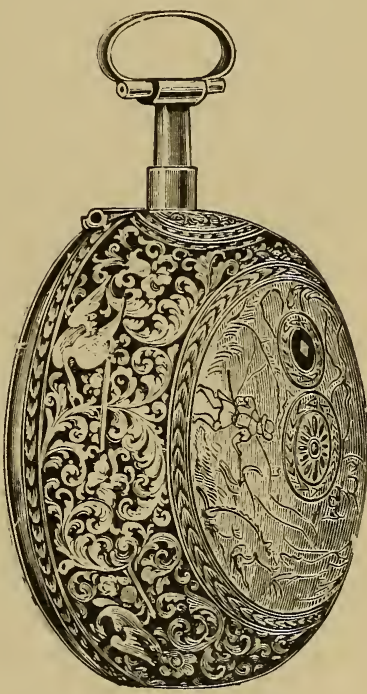

FIG. 296.-Repeating Watch by Paul Dupin, showing pierced work of inner case.

no protection against the ingress of dirt, unless a separate lining is employed. For striking watches, apertures of course serve a useful purpose.

Sometimes, and particularly with à jour cases, the ornament is in high relief, and to obtain the best possible effect the metal constituting the case is not only worked in repoussé, but the figures, or parts of some of the figures standing up farthest from the ground, are soldered on, considerable skill and judgment being displayed. Illustrations of repoussé chasing are given on pp. 202-204, but bright gold cases embelished in this way do not, it must be confessed, lend themselves kindly to reproduction by photography. Incidents from English 


\section{Old Clocks and Watches and their Makers}

history were occasionally portrayed, but mythological and Biblical subjects appear to have been more favoured. Among the examples may be recognised " King John signing Magna Charta," “ Alexander

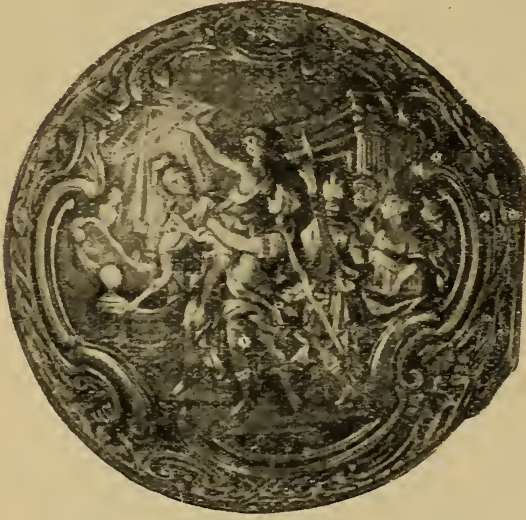

Fig. 297.-Silver repoussé, signed "D. Cochin."

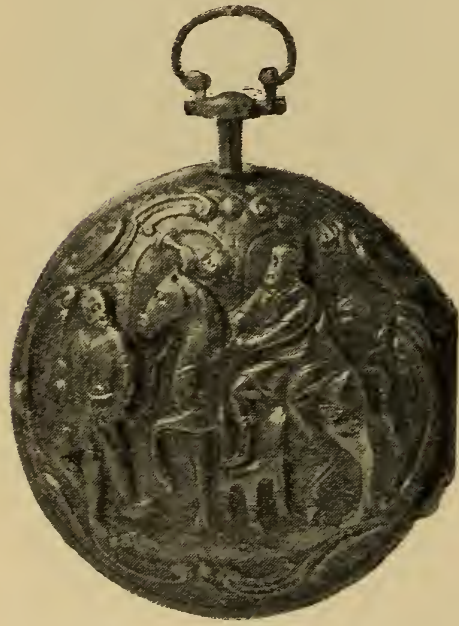

FiG. 299.-Gold repoussé Chasing.

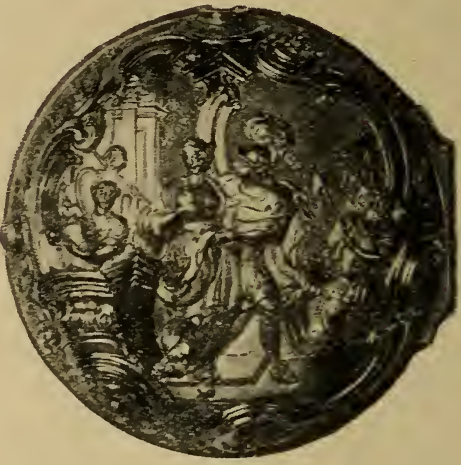

FIG. 298.-Repoussé Chasing on Gold Out-case.

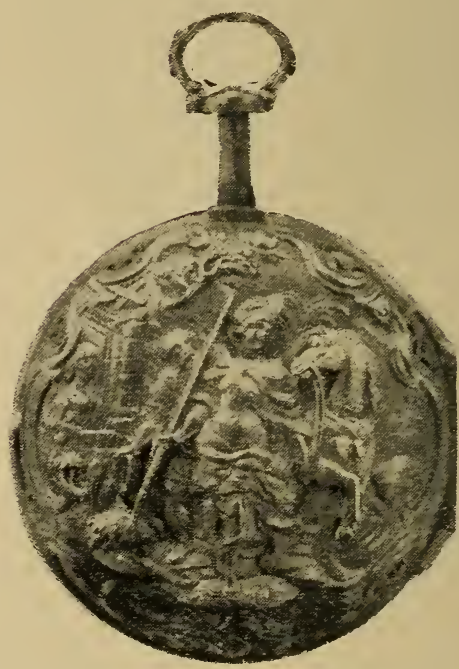

FIG. 300.-Gold repoussé Chasing.

and Roxana," "The Conversion of Saul," "The Judgment of Paris," " Rebecca at the Well," "Æneas and Dido," \&c.

Fig. 308 is an exceptionally late and fine specimen, covering a watch by James Murray, London. It has an oval pendant, and the 
Pocket Watches, Etc.

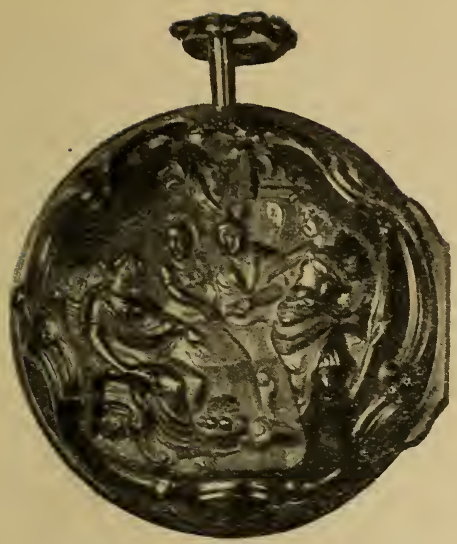

FIG. 301.

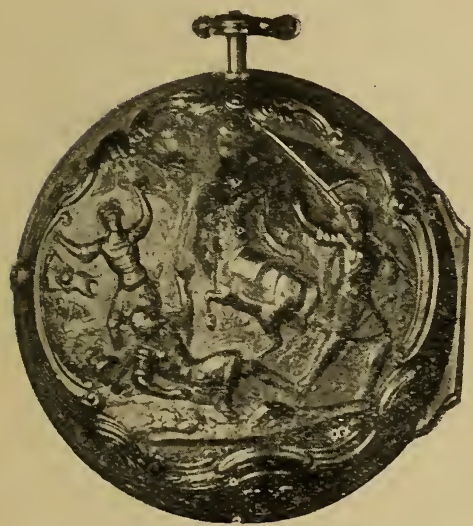

FIG. 303.

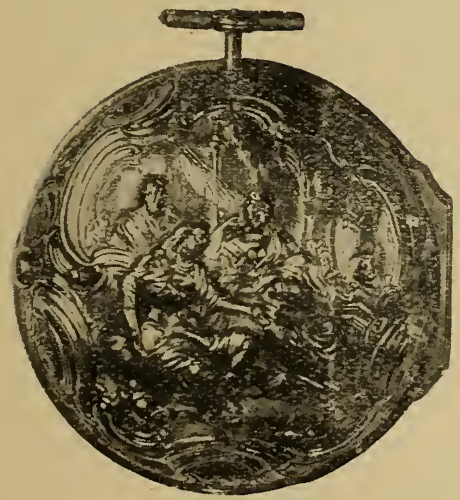

FIG. 305.
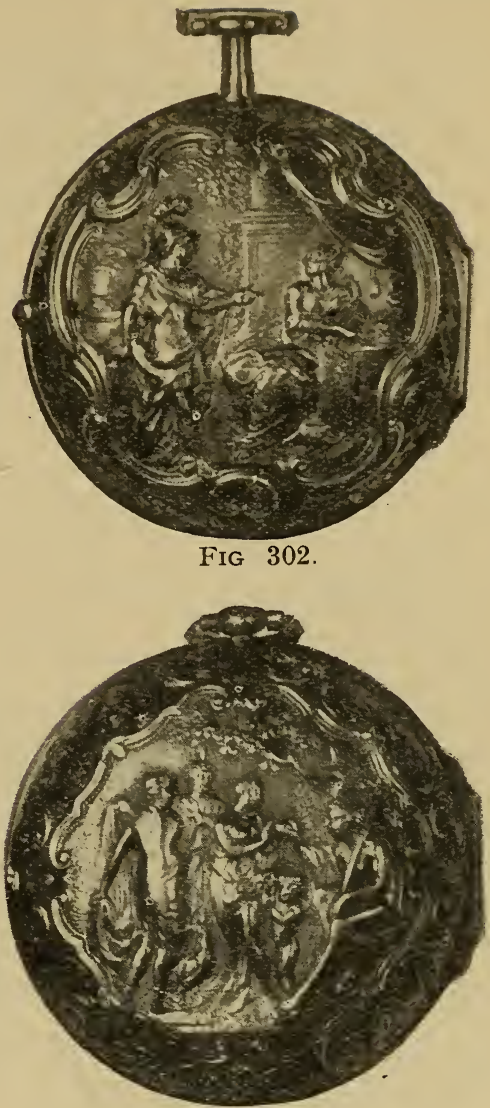

FIG. 304.

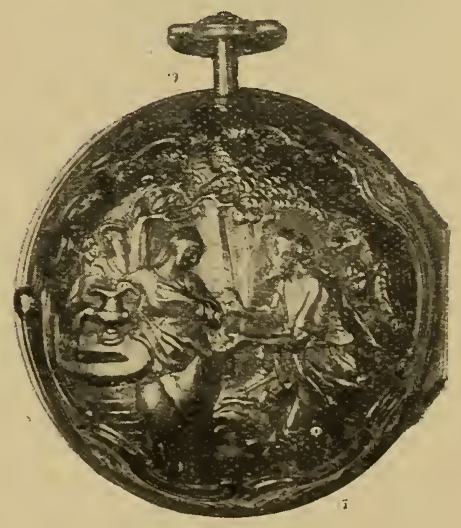

FIG. 306.

Illustrations of repoussé Chasing. 


\section{Old Clocks and Watches and their Makers}

date mark corresponding to 1810 . On the outside of the inner case is engraved "Francisco Joseph, 1811."

A combination of chasing and engraving was also effectively employed in the embellishment of gold cases; some of the choicest specimens of early eighteenth century work which survive being the work of George Michael Moser, R.A.

What is called champleve engraving, in which the ground is cut away, leaving the design in relief, was often adopted for decorating

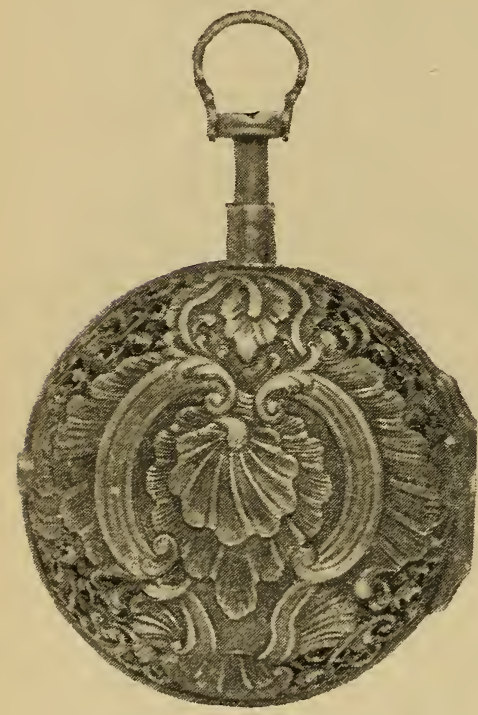

IG. 307.-Half-quarter English Repeater with Silver Out-case.

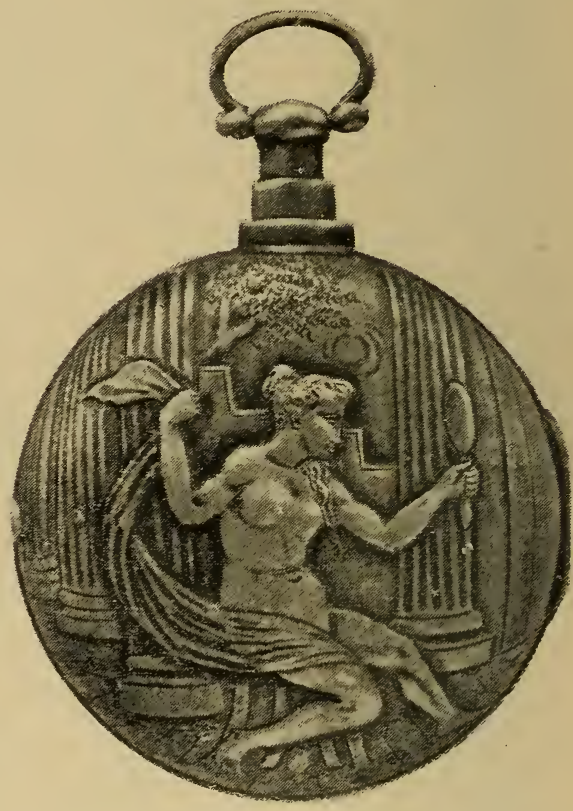

FIG. 308.- Silver Out-case of Watch by J. Murray, hall mark 1810.

English dials and inner cases from about 1640 to 1680 . The watch by Jeremie Gregory (Fig. 208) is an instance of this work. Many French watches and clocks of an earlier date were so treated.

In the Nelthropp collection is a watch by Thomas Windmills, the cases of which are engraved in an exceptional style, corresponding to the Italian niello work, where the effect of light and shade is produced by rubbing in a preparation of lead and sulphur. On the outer case is a view representing the yard of an inn with the sign of a pitcher. In the yard is being played the game of Paille Maille, 
popular in the time of Charles II., and from which the thoroughfare of Pall Mall takes its name. Under the title of Croquet a pastime bearing some resemblance to it was introduced in recent years.

The watch shown in Fig. 354 has an outer case of steel, damascened, and Fig. 309 represents a steel out-case of a watch by "Flower, London," decorated with engraving ; such cases are, however, quite exceptional. The dial of this watch is also of steel, blued and having gilt figures. A watch by Vulliamy, having a steel pendant and steel out-case pierced, is shown in Fig. 310. The monogram (C. A. R.,

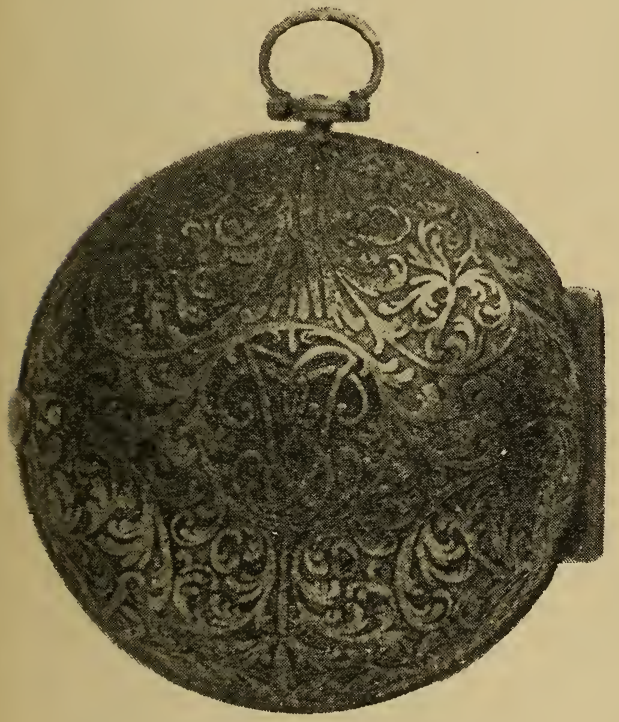

Fig. 309.-Watch by " Flower, London," with Out-case of Steel.

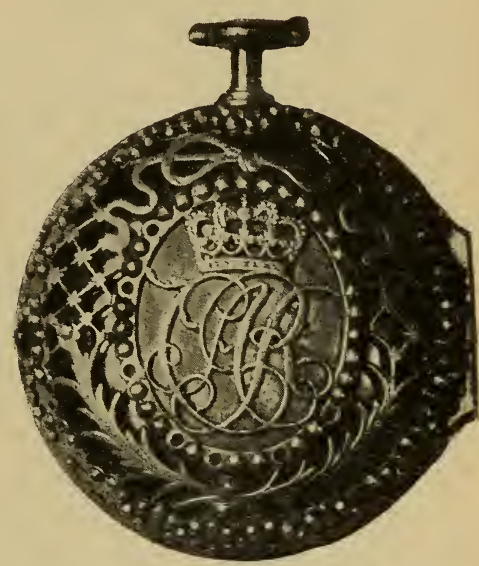

Fig. 310.-Watch by Vulliamy, with Steel Pendant and Steel Out-case pierced.

Charles Albert Rex) refers to the King of Sardinia, for whom the watch is said to have been made. He was father of Victor Emmanuel, first King of United Italy.

Occasionally, during the latter part of the seventeenth century and early in the eighteenth century, outer cases were made of gold filigree work. An example is shown in Fig. 312.

As a curiosity may be mentioned an outer case of carnelian which is to be seen in the British Museum. It belongs to a watch made by Stringer for James II., and by him given to his daughter, Catherine, Countess of Anglesey and Duchess of Buckingham, about 1687. In the Hawkins collection was a magnificently clothed 
repeater by John Ferron, London, dating from about 1710. The watch now belongs to Mr. James W. Usher, of Lincoln. It has a

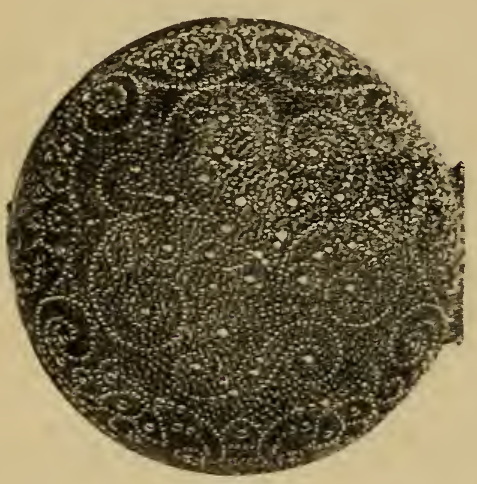

FIG. 311.-Out-case of Fish Skin piqué with Gold Pins, about 1690.

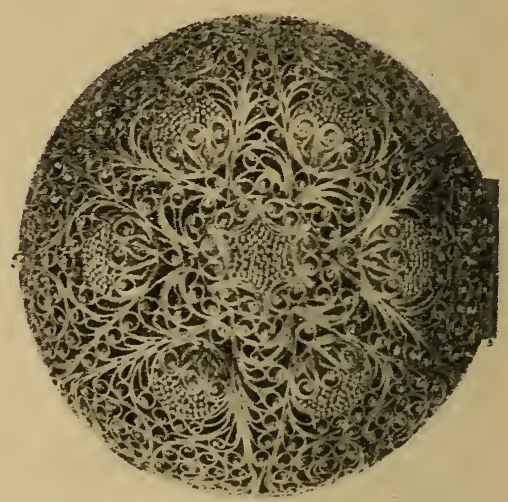

FIG. 312.-Gold Filigree Out-case.

pierced and engraved inner case of gold; the second case, also of gold, is chased with flowers and arabesques, inlaid with plaques of moss agate, and set with numerous brilliants and coloured stones. A view of this is given in Fig. 313 . There is also a shark-skin outer case. Fig. 314 shows a watch by Cabrier which is furnished with an outer case of gold, carnelian, and mother-of pearl, and Fig. 315 another, by the same maker, with an out-case of gold, studded with large garnets. Mr. George Carr Glyn, at the Guelph Exhibition, showed a watch by Jas. Hubert, which had an agate case studded with diamonds.

In Fig. 320 appears a water scene and landscape very finely carved in ivory and applied under a glass to the back of a watch case, which is coated with royal

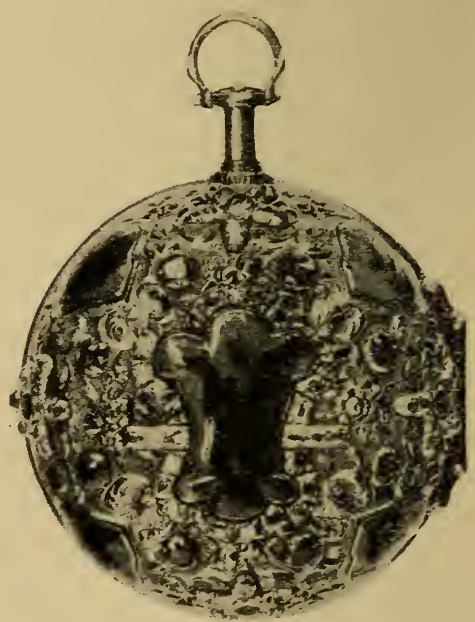

FIG. 313.-Magnificently clothed Repeater by John Ferron, London, about 1710 . blue enamel. The carving is enclosed in an oval frame of pearls outside of which is a floral design also executed in pearls. Around the edge of the case at both back and front is a leaf border 
enamelled green, and within it a ring composed of pearls and garnets alternately. This watch dates from about 1790, and though the case is Swiss, the movement bears the signature "Jaquet Droz, London." The mechanism is marked by one or two interesting features. The mainspring is wound by pushing in and withdrawing a shaft passing through the pendant, a device known as "pumping keyless," of which this is an early example. Jaquet Droz was a well-known Swiss mechanician, and he may possibly have at one time resided in London. The cap, balance-cock, and other pieces are quite in the English style. The dial is furnished with a centre

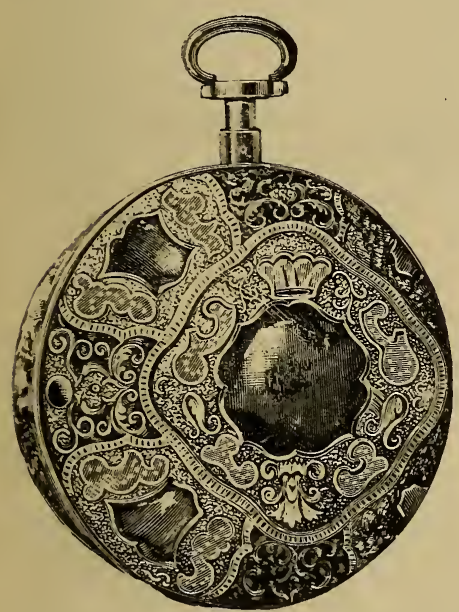

Fig. 314.- Watch by Cabrier, with Outer Case of Carnelian and Mother-of-Pearl set in Gold.

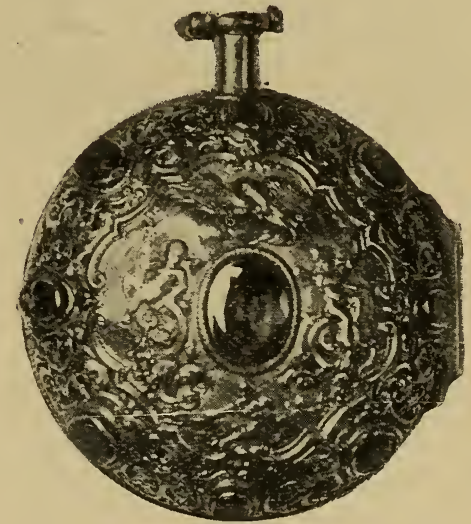

FIG. 315.-Watch by Cabrier about 1750. Out-case repoussé and studded with large Garnets.

seconds hand, which is placed between the hour and minute indicators. At this period such an adjunct was not at all common.

Outer cases of horn and of tortoise-shell, either plain or piqué, were not uncommon, and the semi-transparency of these materials was sometimes utilised for a superior kind of decoration. A thin disc of tortoise-shell having been moulded to the metal foundation, a landscape or other design was either etched or painted on the under side and a row of pins inserted around the edge of the tortoise-shell to secure it to the metal. The picture could be clearly seen through the tortoise-shell and appeared to be covered with a kind of glaze. Strong and inexpensive outer cases of metal, covered with some kind of skin, were also made. Among these coverings 


\section{Old Clocks and Watches and their Makers}

shagreen was perhaps the most popular. The true shagreen is a remarkably tough kind of leather, made chiefly at Astrachan from

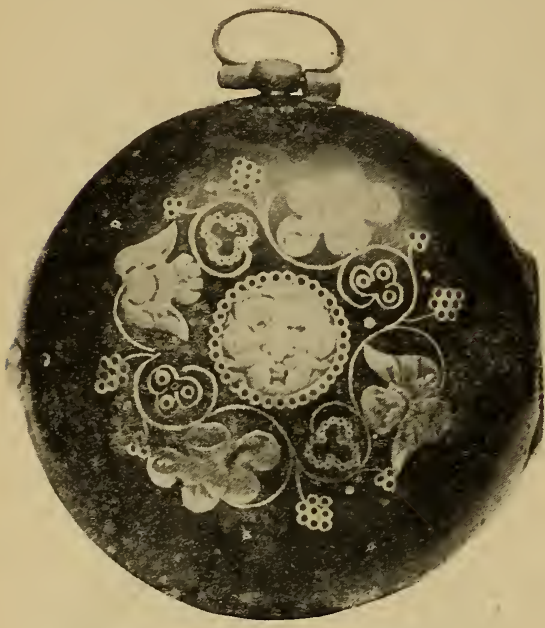

Fig. 316.-Out-case of Watch by Tompion, about 1695 . Tortoiseshell with Silver inlaid as shown.

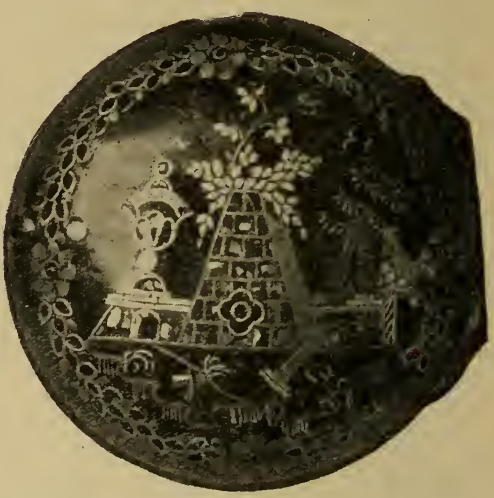

FIG. 317.-Tortoise-shell Out-case, decorated with Silver in the Chinese style; about 1730 .

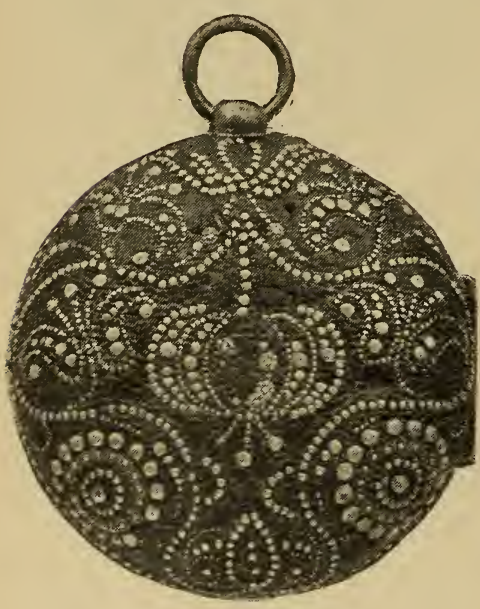

Fig. 318.-Leather-covered Outcase studded with Silver Pins.

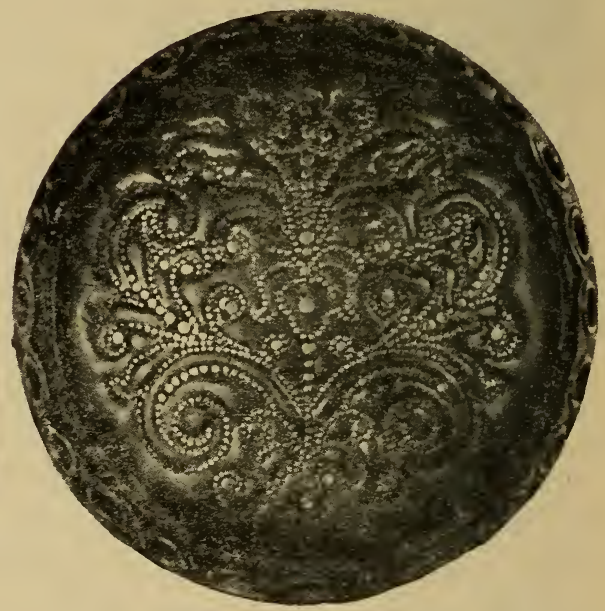

FIG. 319.-Leather, piqué with Gold Pins, back of Watch by I. Mornand, Paris.

the strong skin that covers the crupper of the ass or horse. In its preparation a peculiar roughness is produced by treading into theskin hard round seeds, which are shaken out when the skin has been 
dried; it is then stained green with copper filings and sal-ammoniac, and the grains or warts are then rubbed down to a level with the rest of the surface, which thus presents the appearance of white dots on a green ground.

The skin of the shark and of various other fishes, when properly prepared, formed an excellent covering, being thin and durable. This, if dyed green, was also known as shagreen. It was left with a slightly matted face, whereas the true shagreen bore a high polish.

The piqué surface on outer cases of leather or shagreen obtained

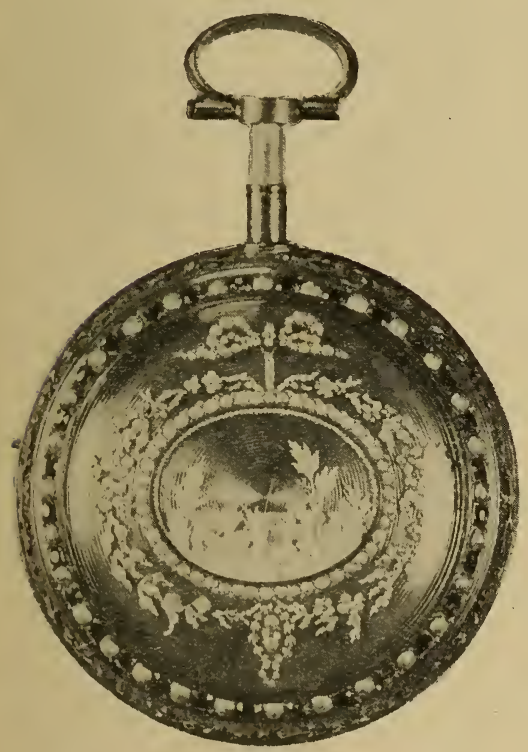

FIG. 320.-Watch by Jaquet Droz. by pins, usually of silver, passing through the covering and the inner metal case, had a good effect and afforded considerable scope for the skill of the producer, see Figs. 311, 318, 319. Besides an ornamental border there was usually a central design which in some instances embodied the crest or initials of the owner. These onter cases had of course to be removed. when the watches were wound, and many of them left in coaches and other places, were advertised for in the London Gazette during the latter part of the seventeenth and beginning of the eighteenth centuries. Where considerable cost had been lavished on the decoration of the removable case, covering the box or watch case proper, a third case would be provided to protect the second one.

In some instances two second cases would be fitted to the "box," or inner case. A leather or tortoise-shell one for everyday use, and a more elaborate and costly one to be worn on gala days or other special orcasions, when the watch, hanging from a chatelaine, could be displayed on the person.

As both the box and the loose case of striking watches and repeaters were pierced to emit the sound, something further was required to prevent the ingress of dirt or other obstructive matter, and a thin metal cap to cover the movement was invented almost 


\section{I0 Old Clocks and Watches and their Makers}

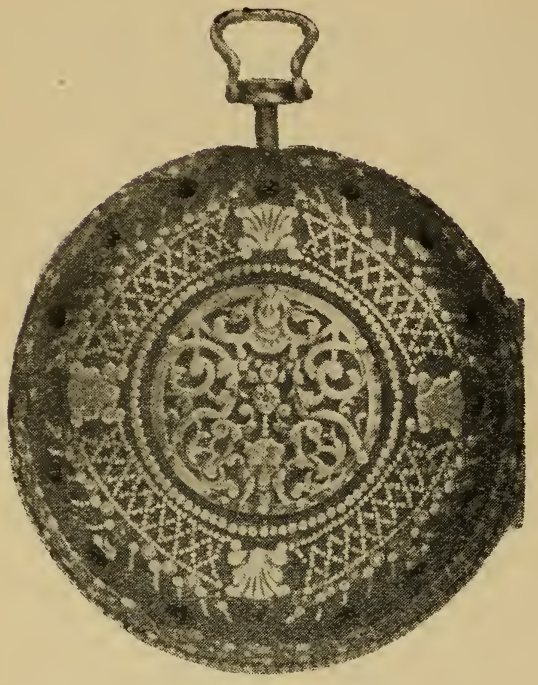

FIG. 321.-Tortoise-shell with Silver Overlay.

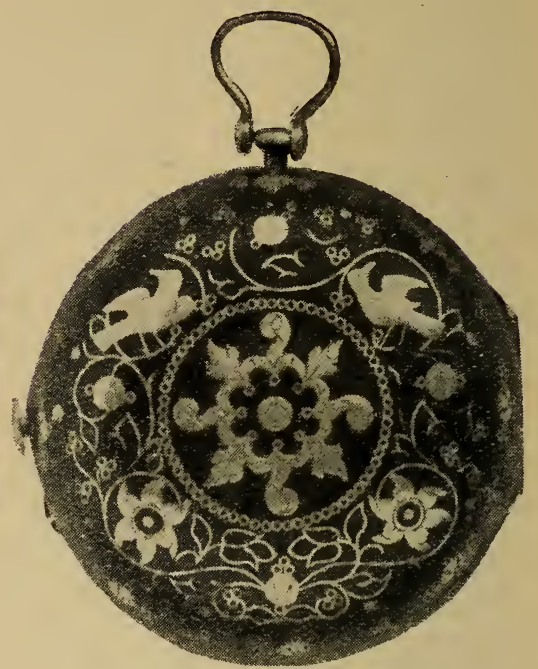

FIG. 322.-Tortoise-shell with Silver Overlay.

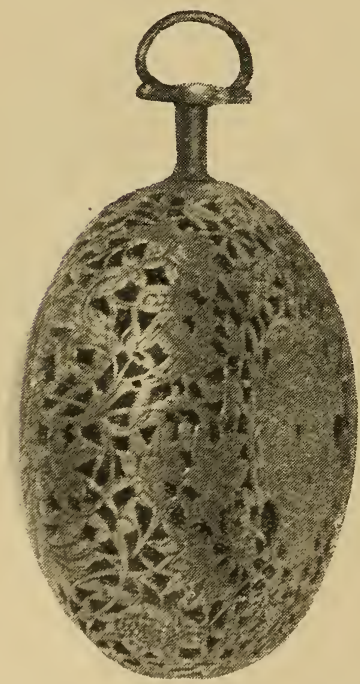

FIG. 323.-Clock-Watch by Abraham Beckner, Pope's Head Alley, with finely pierced Inner Case, about $\mathbf{1 6 7 0 .}$

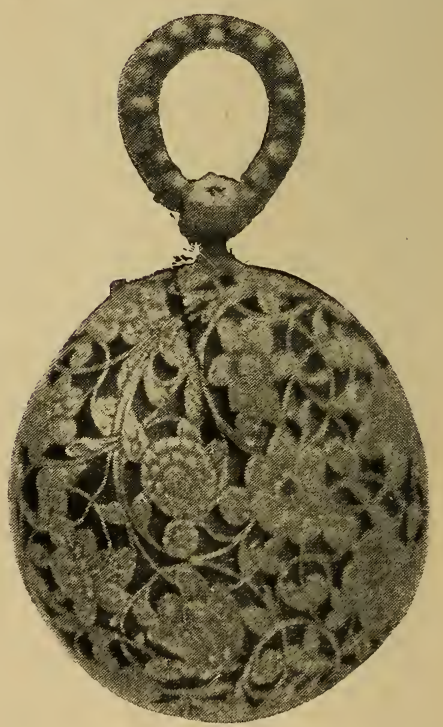

FIG. 324.-Pierced Case of ClockWatch. "Louis Arthaud à Lyon." 
contemporaneously with repeating watches. These caps were sometimes of silver, but more generally of brass; they performed their office of keeping dust and dirt from the movement very efficiently, and have remained a feature of the English full plate watch to this day.

“ Bull's eye," also known as " Ram's eye," cases, introduced about 1780 , were the last variety of pair cased watches; they derived their titles from the form of the bezel of the outer metal case, which from the groove to the outer edge followed the curve of the glass.

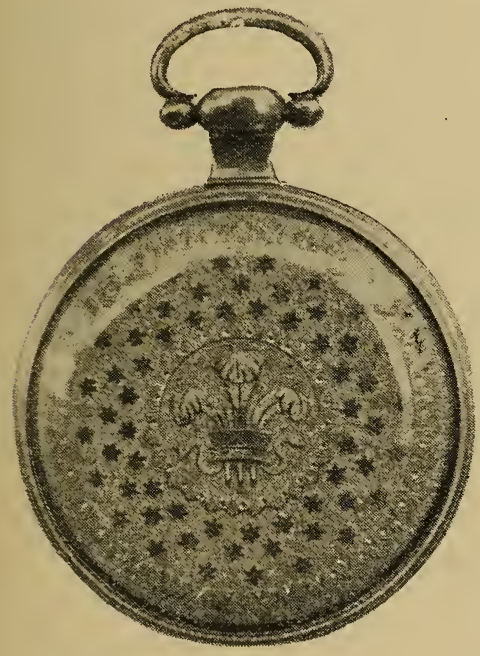

FIG. 325.-Back of Watch by Jas. M'Cabe, decorated with Gold of various tints. In many of the later "Bull's eyes" the usual round form of pendant was abandoned in favour of a broad flattened-oval shape which was much stronger. A good example on a case decorated with Prince of Wales' plumes, etc., in gold of various colours, is given in Fig 325, which represents a watch made by James M'Cabe and bearing the hall mark of 1811 .

After the introduction of pair cases it gradually became the custom to insert in the outer case a thin pad consisting of a circular piece of velvet, muslin, or other material, adorned with fancy needlework, a favourite form being a pieçe of white cambric having the initials of the owner as well as a fancy border worked in gold thread, or hair ; in the latter case hair from the head of the fair artist would presumably be used for the purpose. The following lines were very neatly executed in needlework on a silk pad in a watch dating from 1780 :-

\footnotetext{
"Take this token which I give thee,

It is one from friendship's shrine,

Place it where thou'lt think upon me,

When it meets those eyes of thine-
}

FORGET ME NOT."

"Watch papers" formed an alternative pad. Some of these were cut to geometrical designs, more or less intricate, and covering the whole surface or leaving the central space either circular or oval on 


\section{I2 Old Clocks and Watches and their Makers}

which a miniature or sketch could be painted. Papers of this kind had a backing of bright coloured silk or satin to give the best effect to the perforations. Some time ago I saw in a watch by Isaac Alexander, Nottingham, a paper, in the centre of which was an excellent coloured portrait of Charles Stuart and the following rhyme arranged in a circle around it:-

\section{" O'er this loved form \\ Let every British breast, \\ With conscious joy \\ Its gratitude attest, \\ And hail ye Prince}

In whom ye nation's blest."

In very tiny characters was the signature " J. June," and the date 1745 . The paper had probably been transferred, for the watch dated from about 1760. Papers having printed thereon a likeness of the Duke of Cumberland were issued in 1746, and in 1821 a superior pad of white and pink satin, bearing a portrait of Queen Caroline, was produced and speedily became popular among admirers of the Royal Lady. Two examples from the Ponsonby collection giving really fair portraits of Queen Charlotte and Queen Victoria., the latter when she ascended the throne, are illustrated in Figs. 326 and 328.

Papers printed on the

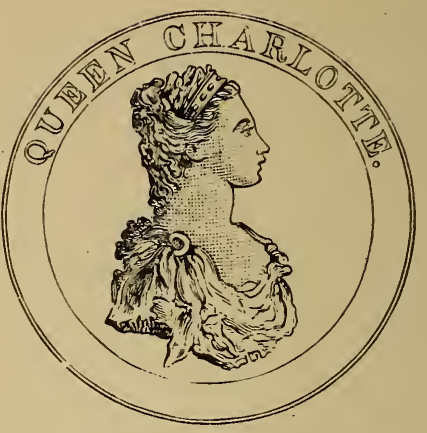

Fig. 326.-Watch Paper.

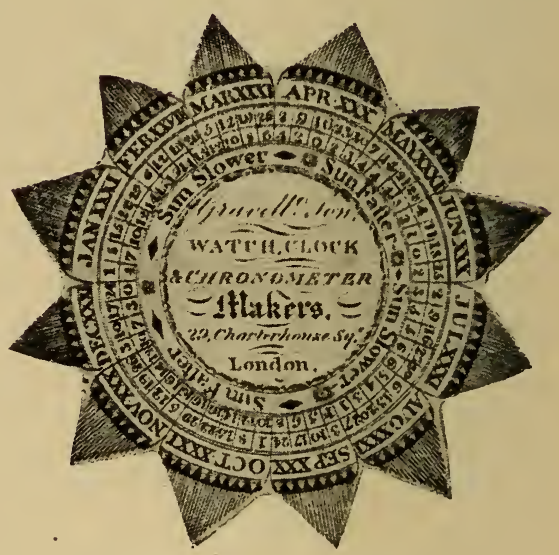

FIG. 327.-Watch Paper,

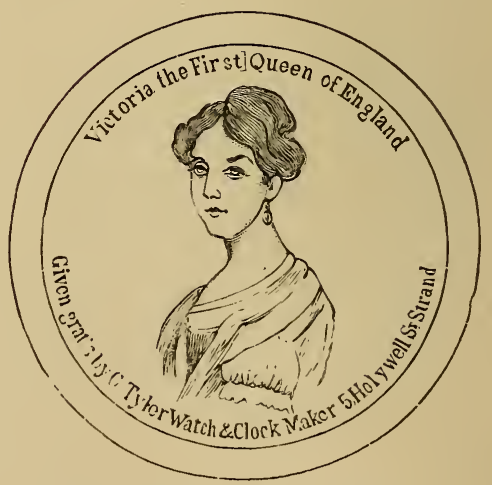

Fig. 328.-Watch Paper. 
frozen Thames during the prolonged frost of 1814 were a cheap novelty which commanded a ready sale. Most commonly watch papers contained an advertisement of the watchmaker, and sometimes an equation of time table for comparing the watch with the sun-dial, as in Fig. 327; and occasionally admonitory or sentimental verses in addition.

"Memento Mori" formed the text of many rhymes ; the following, often met with, may be taken as examples :-

" Onward perpetually moving,

These faithful hands are ever proving

How quick the hours fly by;

This monitory, pulse-like beating,

Is oftentimes, methinks, repeating,

'Swift ! swift ! the moments fly.'

Reader, be ready, for perhaps before

These hands have made one revolution more

Life's spring is snapped-you die!"

The next example was printed around the edge of a paper by John Herron, Cowpen Quay, Blyth :-

"Behold, O mortal man,

How swift thy moments fly,

Thy Life is but a Span,

Prepare, Prepare to die."

Another from the Ponsonby collection is as follows :-

" Time is, thou hast, employ the portion small.

Time past is gone, thou can'st not it recall.

Time future is not, and may never be.

Time present is the only time for thee."

Another admonitory verse, equally popular, runs :-

"Time is-the present moment well employ ;

Time was-is past-thou canst not it enjoy;

Time future-is not and may never be ;

Time present-is the only time for thee."

The next I take from a watch paper by T. Humphreys, Barnard Castle :-

" Could but our tempers move like this machine,

Not urged by passion nor delayed by spleen.

And true to Nature's regulating power,

By virtuous acts distinguish every hour.

Then health and joy would follow as they ought

The laws of motion and the laws of thought.

Sweet health to pass the present moments o'er,

And everlasting joy when time shall be no more."

These lines appear on papers of many other makers. They are from the pen of "Dr." J. Byrom, and appeared in the Scots Magazine for October, 1747. 


\section{I4 Old Clocks and Watches and their Makers}

An apposite but more uncommon inscription for timekeepers is Tempus metitur omnia sed metior ipsum; " Time measures all things, but I measure it."

Loose outer cases are troublesome, and, after being endured for two centuries or so, they gave place gradually to the more compact modern styles, with ornament of a different character.

A series of wavy curves cut into the material and known as " Engine turning," which is said to have been introduced as a decoration for watch cases about 1770 by Francis Guerint of Geneva, was long in fashion. It has a good effect, does not readily show scratches, and will doubtless again return to favour. The earliest specimens
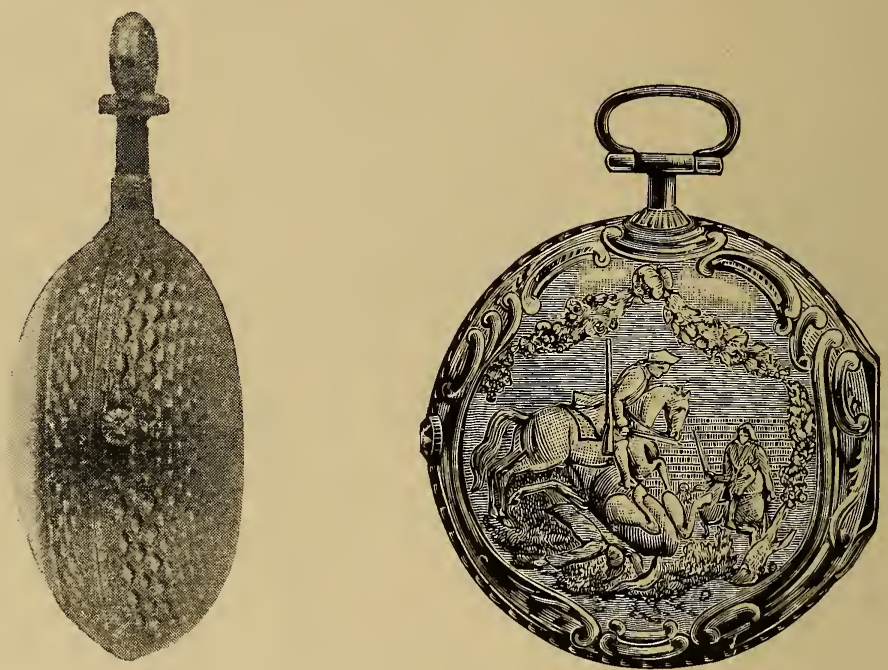

FIG. 329.-Farly Engine-turned Case. FIG. 330.-Chased decoration, about 1760.

were cut very deep into the metal, leaving coarse " barleys," as the projections are called, and could only be applied to a considerable thickness of metal. Finer divisions with shallower cutting, applicable to lighter cases, speedily became the rule, and an early specimen of coarse-cut engine turning is now rarely to be met with. The example shown in Fig. 329 is on a repeating watch by Terroux l'Ainé, Geneva, and is very little later than $\mathbf{1 7 7 0}$.

Shortly after the middle of the eighteenth century a very beautiful art was utilised to enhance the effect of chasing and engraving as applied to watch cases and dials. A subject having been selected and drawn upon the gold or other metal ground, pieces of gold of various colours were formed to represent the parts in relief and soldered to the 
ground. A good artist was then able to produce a fine effect with the chasing tool and graver. As a specimen is shown in Fig. 330 a watch signed Gudin à Paris, dating from about 1760. Here the chased decoration with gold of green, yellow, copper, and silvery tints is very effective, but its whole charm cannot, of course, be justly conveyed in a black and white engraving. Lepine seems to have been fond of this coloured gold decoration, for it appears on the cases of many of his watches. Whatever the number of tints employed, this style of decoration is generally spoken of as à qualre couleurs.

Dials.--With few exceptions the earliest clocks and watches had

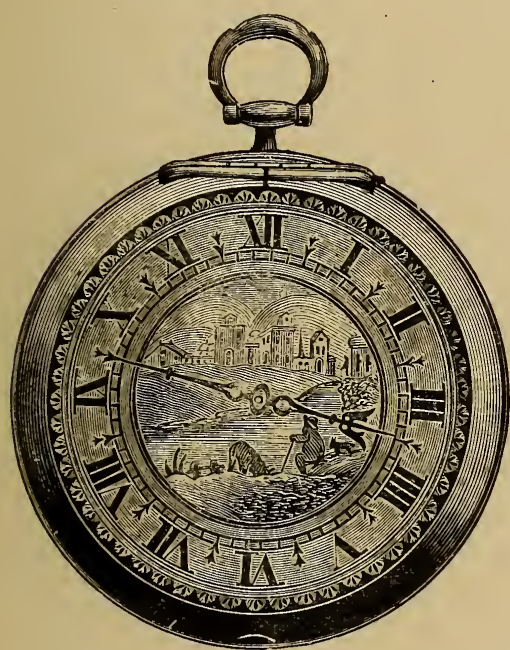

FIG. 331.-Watch by Nathaniel Barrow.

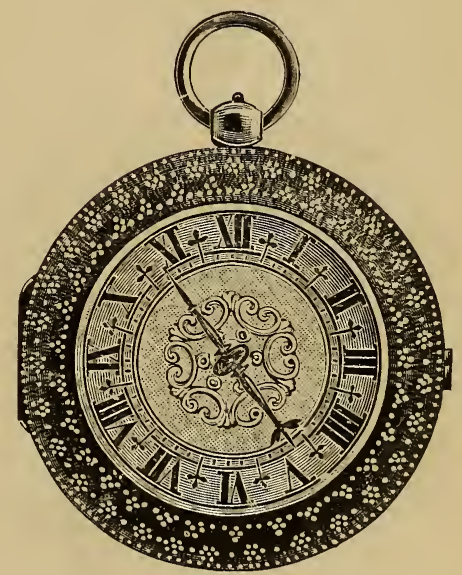

FIG. 332.-Watch by V. Costontin.

the hours marked with Roman numerals placed radially with the bottom of each numeral towards the centre of the dial, so that the V., VI., and VII. appear to be upside down. Another peculiarity is that the fourth hour was denoted in a very primitive way, thus: IIII., instead of by IV., which was then the more orthodox manner. And it is somewhat remarkable that these features have been continued to the present day almost unnoticed, as may be proved by asking anyone to sketch the figuring of his watch without looking at the timekeeper, for in most instances such a sketch would be incorrect. But the fact is, we do not read the figures when looking at a watch or clock, but judge the time from the position of the hands. Lord Grimthorpe was 


\section{2i6 Old Clocks and Watches and their Makers}

instrumental in having the hours of the turret clock at the dining-hall of Lincoln's Inn marked each by a short thick radial stroke instead of figures, and it is rarely that passers-by notice anything unusual, except that the dial seems particularly clear.

Some of the very earliest portable timekeepers had incised figures cut in the dial plate, but more often the numerals were engraved on a separate belt, which was generally of silver, the inner ground of the dial being" of brass gilt (or gold) and matted or engraved. In addition to the numerals, many early watches were furnished with a knob at each hour, for the convenience of estimating the position of the hand

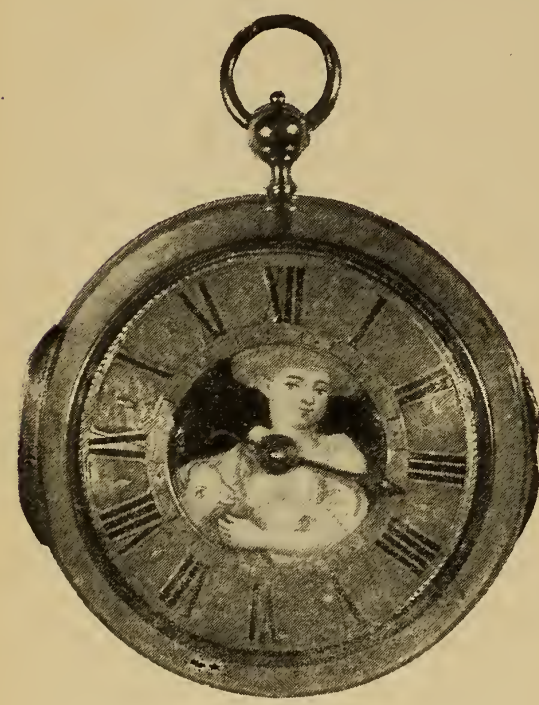

FIG. 333.-Watch by Henry Harper.

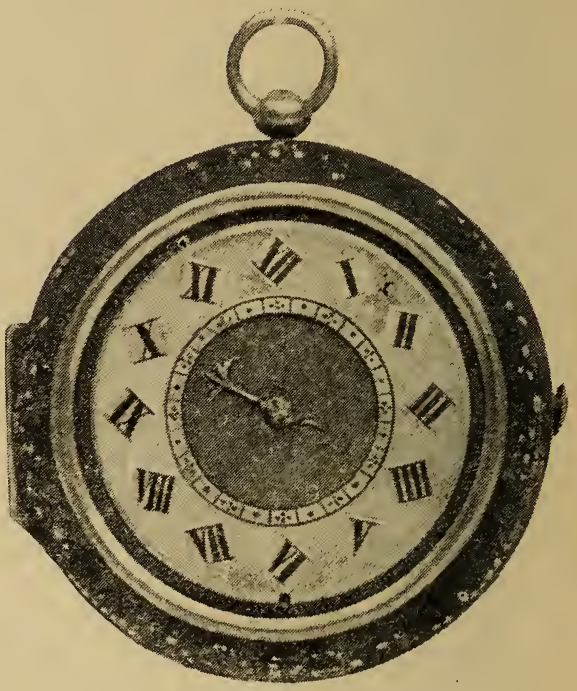

FIG. 334.-Watch by Richard Jarrett about 1665 .

by feeling. The first noticeable departure from this construction took place about 1600 , when watch dials wholly of one metal were introduced with landscapes and other views engraved on the centre. These dials were usually of silver and recessed into what is now called a " brass edge," that is, a ring independent of the plate of the movement, and to which the dial was attached. The dial was rather smaller than the movement, and a narrow margin of the brass edge, which appeared outsicle the dial, was engraved, the contrast of the silver and brass having a good effect. A fine example by Nathaniel Barrow, owned by Mr. Franklin Dennison is shown in Fig. 331. The watch by Edward East, said to have been given by Charles I. to Mr. Herbert, and engraved on p. 265 , had a very similar dial. Instead of a landscape 
a floral design sometimes occupied the centre, while occasionally it was engraved to a geometrical pattern and filled in with coloured enamel or wax, as in a watch by Vincent Costontin, Dieppe, which is shown in Fig. 332.

Illustrations have already been given of the painted dials on the costly, enamelled watches in vogue during the seventeenth century The single hand of the earliest of these was usually of brass, and, except for watches with cases and dials painted in enamel, gold and silver dials with long figures in relief came into general use in England shortly after the middle of the seventeenth century. On a watch by

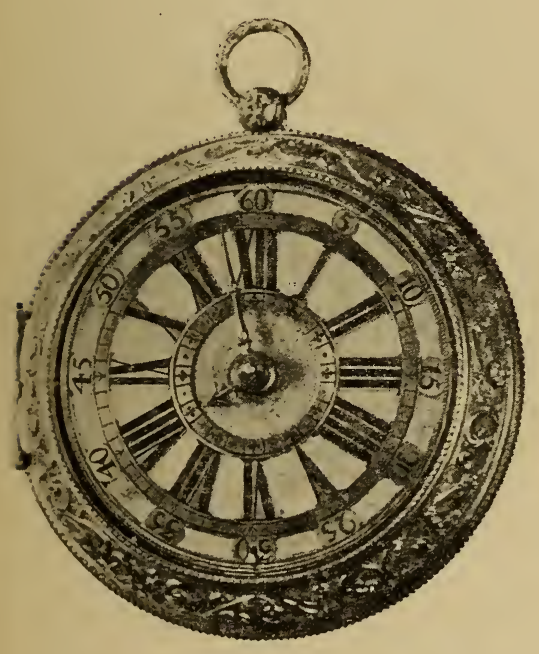

Fig. 335.-Daniel Le Count, about 1680.

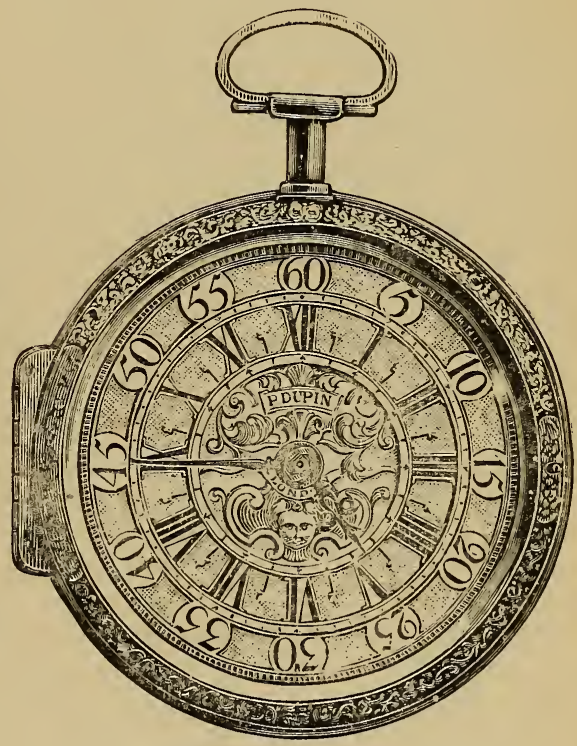

FIG. 336.-P. Dupin, about 1700 .

Henry Harper, shown in Fig. 333, the outer part of the dial is of metal, the centre being filled by an enamelled painting, which is, however, of a later date than the movement. A still more exceptional and somewhat grotesque treatment of the dial is shown in Fig. 334, representing a watch made about 1665 , by Richard Jarrett, who was master of the Clockmakers' Company in 1685. The centre of the dial is of brass matted, and the ring, on the inner edge of which are engraved quarter-hour spaces, of silver, finely matted, with polished plaques for the hour numerals.

With the introduction of the minute hand, the minute circle and 


\section{I 8 Old Clocks and Watches and their Makers}

figures to indicate each five minutes appeared outside the hour numerals. These additions, with the long hour numerals, allowed of but a very short hour indicator; and this occupied a slightly recessed centre, as shown in Fig. 335, which represents a watch by Daniel Le Count, dating from about 1680. Shortly afterwards the hour numerals were shortened and the hour hand lifted out of the recess and lengthened, as.in the watch by P. Dupin, represented in Fig. 336. In this the outlines of the hour numerals are polished, and the bodies filled in with black wax, the small ornament between the numerals being polished and the minute figures engraved on polished plaques. Except that the inner circle, marked with subdivisions of an hour, was discontinued, dials of this kind, with slight: variations, remained in favour for many years. The central disc was a separate piece recessed into the brass edge, and was as a rule nicely chased and engraved. It usually bore two tablets for the name of the maker and the place of origin of the watch. An excellent example is the watch by Langley Bradley, shown in Fig. 478. Sometimes the lower label was

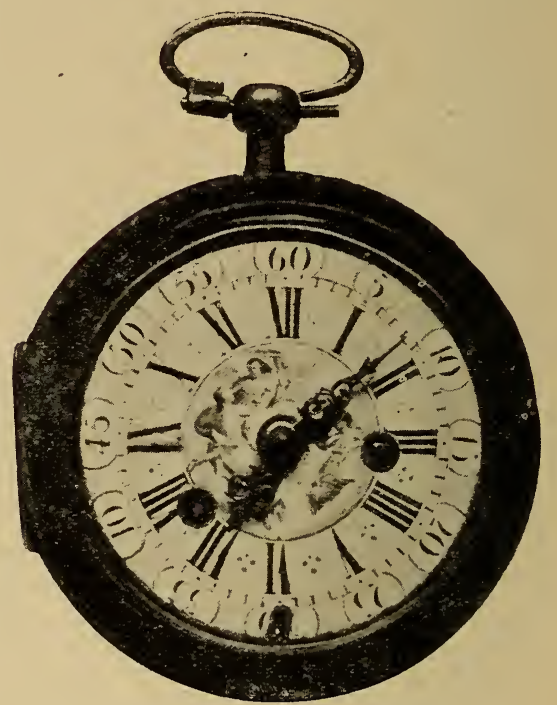

FIG. 337.-Pink and White Enamel Dial on Tompion Watch.

omitted and a day-of-the-month aperture substituted therefor. Dials of this description had a very handsome appearance, and must have been costly, for cutting out the groundwork to leave the plaques for the minute figures, the outline for the hour numerals, and the ornament between the numerals in relief involved considerable labour. In 1729, engravers petitioned the Clockmakers' Company to debar one Griliat from proceeding with a project he had for producing dial plates by stamping. Nevertheless, many later ones were embossed in this way.

Painted enamel dials of the Huaud period had often an outer ring of white enamel for the reception of the numerals, and towards the end of the seventeenth century dials with a gold centre and 
outer ring of enamel were favoured by some French makers. Plain white enamel dials seem to have been introduced in France and Switzerland about 1690, but were not used in England for at least ten years afterwards.

A pink and white enamel dial, with angels in the centre, on a watch by Tompion, from the Pierpont Morgan collection, and dating from about 1700 , is shown in Fig. 337.

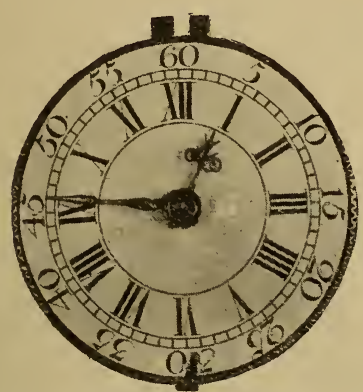

FIG. 338.-Hands of the " beetle " pattern.

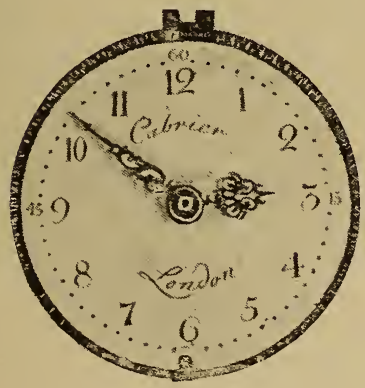

FIG. 340.-Beautifully pierced gold hands.

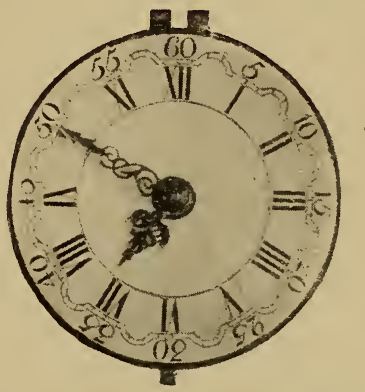

FIG 339.-Pierced hands.

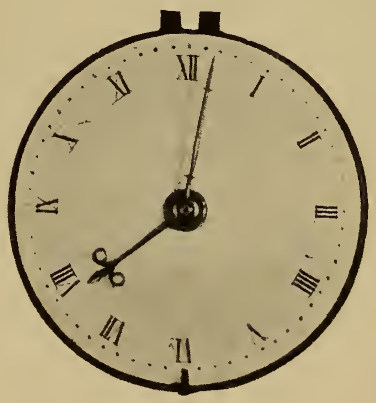

FIG. 341.-Dial with small and stumpy hour numerals, about 1750 .

Though English watches of the seventeenth century are occasionally to be met with having dials of white enamel, it will generally be found that they are subsequent applications, the original dials having probably been discarded owing to the superior legibility of the white enamelled discs.

So far as my observation goes, the earliest plain enamelled dials on English watches are those of a bluish tinge, the enamel of which is generally spoken of as Venetian. They date from about 1705, and have the nib for unlocking the movement projecting through a 
slit at the VI. numeral, as in some of the older and contemporary metal dials. The visible margin of the brass edge was usually either engraved or knurled, and the hands were of steel. An example, given in Fig. 338, has hands of the "beetle" pattern, a kind very popular then and onwards to the middle of the century. Dials with the minute band formed in a series of wavy curves were made here during the eighteenth century chiefly for the Dutch market. They usually had hands of gold or of brass, nicely pierced, as in Fig. 339.

The bold minute figures which occupied so much room outside

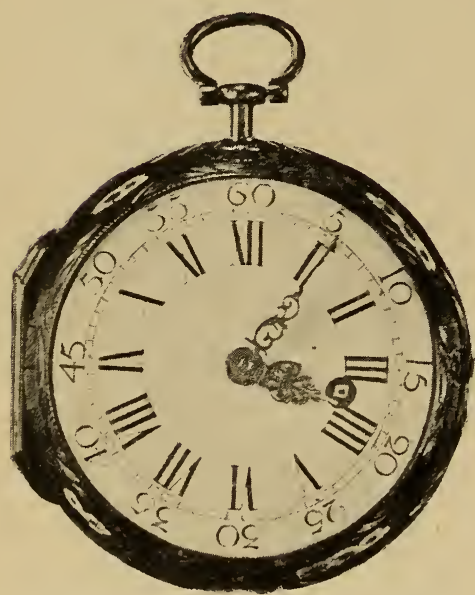

FIG. 342.-French Watch, about 1770 .

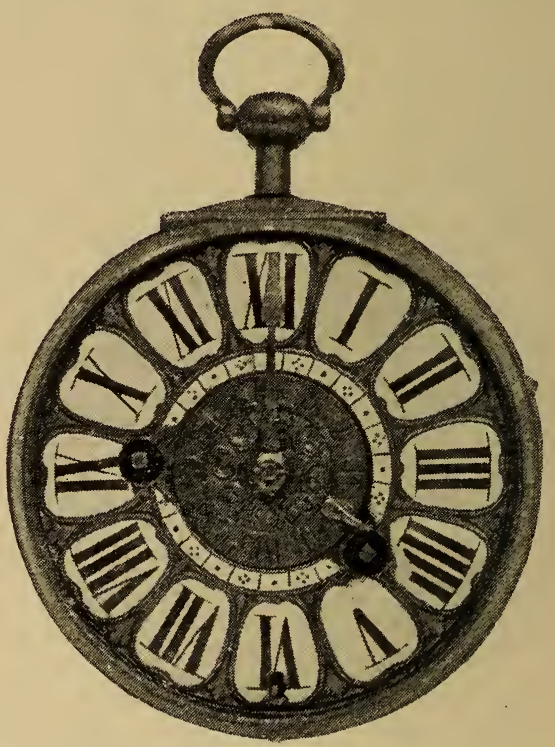

FIG. 343.-Hour numerals on Enamelled Plaque, about 1680.

the hour circle were gradually discarded. On a watch by Cabrier, dating from about 1740 , and shown in Fig. 340, there are small minute figures at the quarter-hours only, and a little later came into favour dials with small and stumpy hour numerals, as in Fig. 341, the minute figures being entirely omitted. The hands of the Cabrier watch are of gold. Owing to the character and arrangement of the figures, the hour indicator, which is beautifully pierced, appears to be rather short. If it were a solitary example one might suppose the hands or the dial to be not original, but I incline to the belief that a certain proportionate length of hand was as a matter of course selected for a certain size of dial. The French and, I think, the 
Swiss, adhered longer to the large minute figures than did English manufacturers.

Fig. 342 shows a French watch dating from about 1770, which is a good example of the period, with a hole for winding cut through the dial, a plan much favoured in France for fifty years or so from that date, but not so popular in England. Lepine, who reconstructed the movements of watches, was, I believe, responsible for the systematic adoption of this feature, though winding at the dial was occasionally resorted to for watches having painted enamel cases

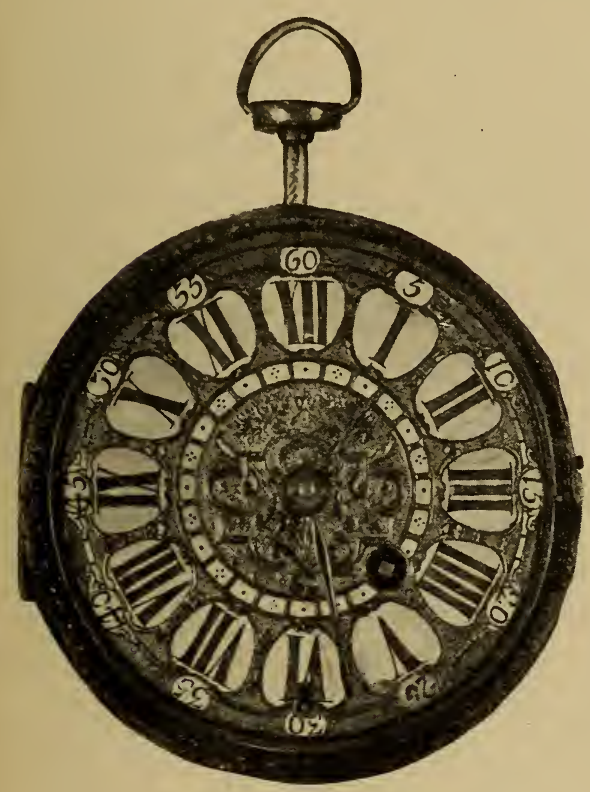

FIG. 344.-Watch by I. Mornand, Paris, about 1690 .

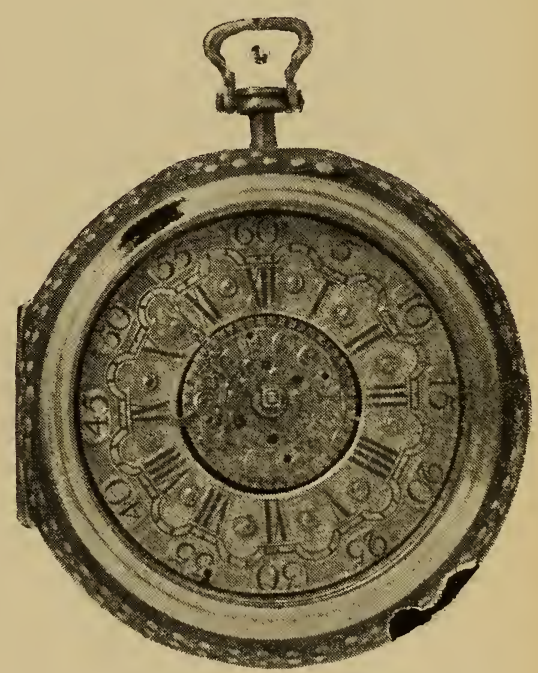

FIG. 345.-Watch with Silver Dial, about 1700 .

a century before this time, and for the thick French watches with porcelain enamel hour figures, in some of which the unsightly holes in the dial were avoided by planting the winding square at the centre.

Many French and Swiss watches made towards the end of the seventeenth and at the beginning of the eighteenth centuries had the hour numerals on enamelled plaques, though they do not seem to have been favoured here. A dial of this sort is on the alarm watch shown in Fig. 343, made about 1680 by Dumont Frères, Besançon. The body of the dial is of brass gilt. Another specimen of about ten years later, by I. Mornand, Paris, is shown in Fig. 344. 
Watches of this class were very thick, and had cases of brass gilt and engraved to a fine pattern.

Watches made for the Dutch market were often fitted with silver dials having raised numerals filled with wax, and ornamental centres of various designs engraved and pierced. Occasionally a figure of Time was introduced, the Destroyer being represented with a flag in his hand, on which the name of the maker was engraved. A watch with a silver dial by John Van Ceulin, of the Hague, having the wavy minute circle already mentioned, and dating from about 1700 , is shown in Fig. 345 .

Dials of metal, with polished hour numerals of a different tint soldered on, introduced during the latter part of the eighteenth century, were for some time popular; a specimen of this style, on a watch by James $\mathrm{M}^{\prime} \mathrm{C}$ Cabe, is shown in Fig. 346. But though considerable skill has been expended in the enrichment of metal dials by chasing and engraving as well as by variations of colour, enamel has practically ousted all other materials, except for scientific purposes, where extreme accuracy of division is desired.

In modern dials the hour numerals are too long, the position of the hands being more easily discerned with the stumpy figures used in the earliest timekeepers. The fact is, the dialmaker has been allowed to regard his work without reference to the hands, and he has adopted a rule to make the " chapters" in length equal to two and a half minutes of the circle, because they are more obtrusive than the shorter ones previously used. The most effective hands were those seen in clocks and watches of the eighteenth century. The chief fault of most varieties now used is that the spade or heart or other enlargement of the hour hand is too close to and overlaps the numerals. It should be of good size and nearer the root of the hand, the tip of which, though closely approaching, should in its sweep just clear the numerals.

People who are used to reading a dial with but one indicator can estimate the time with astonishing closeness, and it is pretty certain the two hands did not meet with general favour for a long period. Although we are, from long practice, able instantly to note the minute and hour from the position of the two indicators, it is an acquirement. Children and other tyros seem to go through a slower process by separating the functions of the two and deciding upon the position of each singly. In fact, there can be no doubt that it is at first difficult to decipher the double indication together. Many devices were tried during the latter part of the seventeenth century 
to give the accuracy of the separate minute circle without the confusion of two similar hands. Of these may be mentioned dials with revolving centres, having a finger to point to the hours. In another plan representations of the sun and moon were utilised for the purpose. Sometimes figures corresponding to the current hour were shown through an aperture in the dial, and warriors with swords as pointers are among the most familiar of other varieties.

Fig. 347 represents a watch by Tompion, from the Schloss collection. It is in an enamelled case, and dates from about 1705. Though

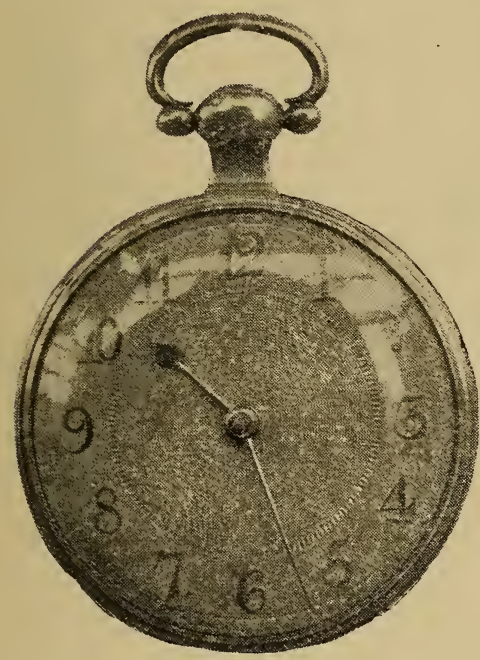

FIG. 346.-Watch by Jas. M'Cabe.

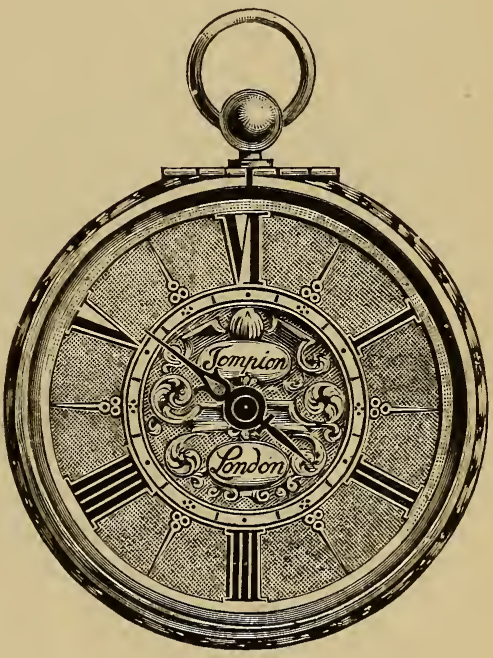

FIG. 347.-Curious Tompion Watch.

the concentric minute hand was introduced certainly thirty years before this date, the specimen here shown has only one hand; but the chief peculiarity in connection with the dial is its division into six hours. This may have been for use in Italy, where in some parts the day was divided into four periods of six hours each. Or the idea may have been to give with one hand a longer space than usual for more nearly estimating small fractions of an hour. Quare adopted the same method, as will be seen from the following advertisement, quoted from the London Gazette for March 25-29, 1686 : " Lost, on 2nd inst., a Silver Pendulum Watch, the name Daniel Quare, London; it had but six hours upon the dial-plate, with six small 


\section{Old Clocks and Watches and their Makers}

cipher figures within every hour, the hand going round every six hours, which shows also the minutes between every hour. Whoever gives notice of it to Daniel Quare, at the King's Arms, in Exchange Alley, London, shall have a guinea reward."

Early Minute-hand Watches.-Fig. 348 shows the front and Fig. 349 the movement of a watch dating from about 1665 , which is a particularly interesting specimen, and affords evidence that the maker of it was far in advance of his time. It shows hours, minutes, and seconds and has a long train containing the same number of wheels and pinions as modern watches, the minute hand being attached to the centre pinion. The dial is of silver,

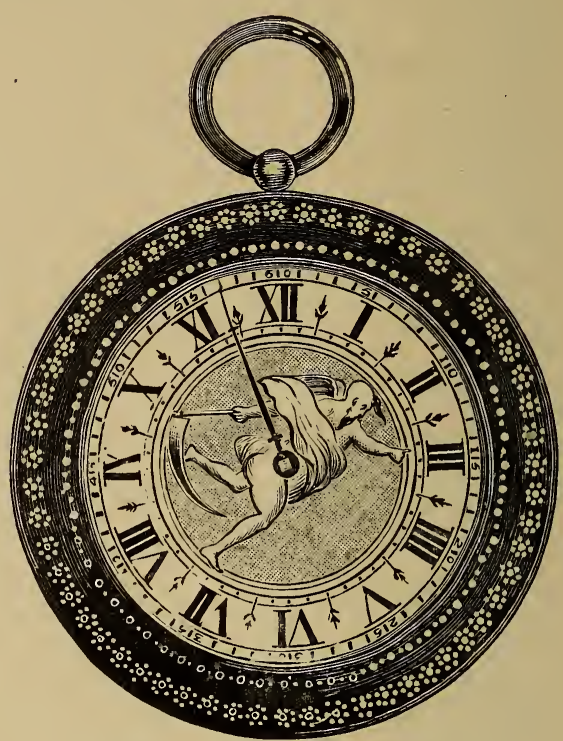

FIG. 348.-Watch by John Fitter, Battersea, about 1665.

and the middle portion of it, driven by a pinion on the great wheel arbor, revolves once in twelve hours, a figure of Time engraved thereon pointing to the hour; the seconds dial is a silver plate on the back

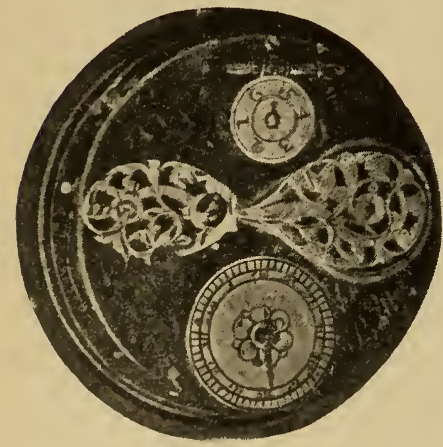

FIG. 349.-Watch with no balance spring. of the movement, the seconds hand being carried by the contrate wheel, which rotates once in a minute. On the plate is engraved "John Fitter, Battersea." There is " no balancespring. It has a nicely-pierced and engraved silver balance-cock and arched top harp pillars. The potence is peculiar, being carried by a pivot into the top plate; the side view of it is very wide, nicely pierced, and engraved to a floral design. On the back of the inner case is engraved a kind of calendar remembrance,

shown overleaf. It appears to be a key for finding at a glance the days of the month upon which any particular day of the week will 


\begin{tabular}{|c|c|c|c|c|c|c|}
\hline \multicolumn{2}{|c|}{ Mar | Nov } & 1 & 8 & 15 & 22 & 29 \\
\hline \multicolumn{2}{|c|}{ Augus } & 2 & 9 & 16 & 23 & 30 \\
\hline \multicolumn{2}{|c|}{ May | Jan } & 3 & 10 & 17 & 24 & 31 \\
\hline \multicolumn{2}{|c|}{ Octob } & 4 & 11 & 18 & 25 & + \\
\hline$A p r$ & $J u l$ & 5 & 12 & 19 & 26 & + \\
\hline Sep & Dec & 6 & 13 & 20 & 27 & + \\
\hline Jun & $F e b$ & 7 & 14 & 21 & 28 & + \\
\hline
\end{tabular}

fall. The outer case, covered with leather piqué with silver pins, is snapped together without a bolt-a most unusual construction. This watch was formerly in the Roskell collection.

Mr. Charles Shapland has an early minute-hand watch by Robert Whitwell, which is shown in Fig. 350. It indicates also the day of the month by a rotating ring.

On a watch by David Lestourgeon, shown in Fig. 351, there are two narrow rotating rings between the centre of the dial and the hour numerals; one of these carries a very short and the other a longer pointer, the former for indicating the hour and the latter for the minutes.

The handsome key for this watch is shown in Fig. 352. For winding

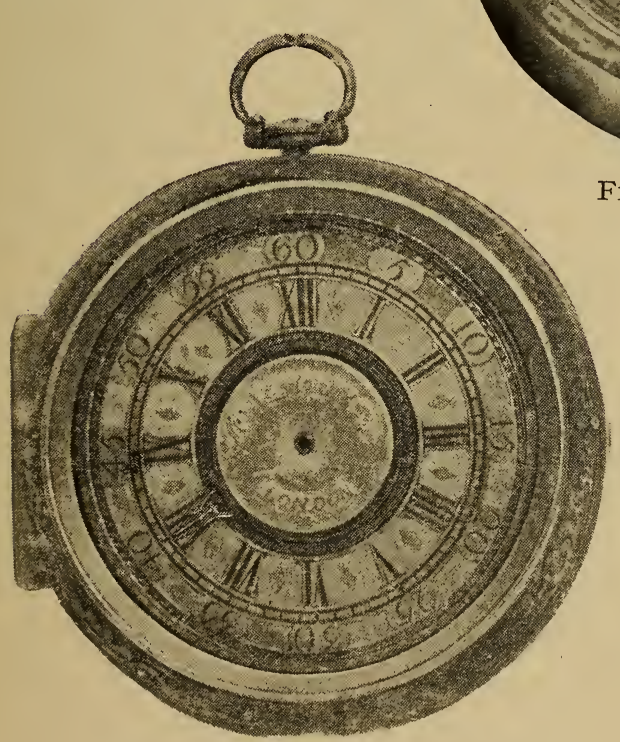

FIG. 351.-Watch by David Lestourgeon.

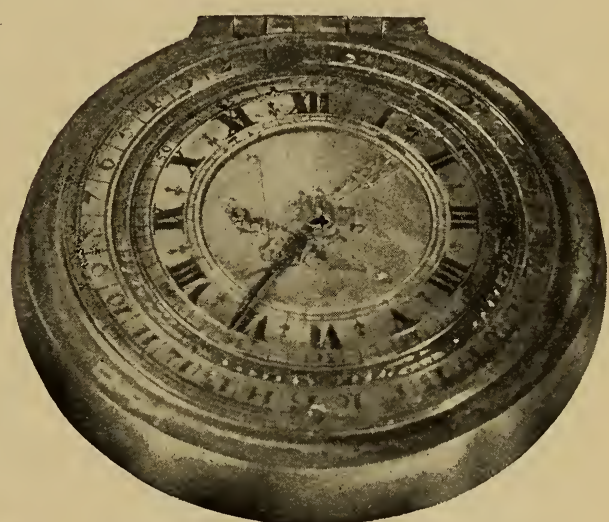

FIG. 350.-Early Minute-hand Watch.

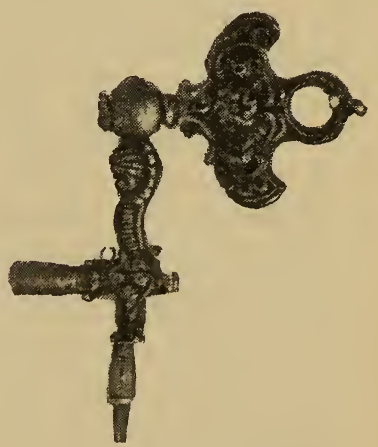

FIG. 352.-Handsome Watch-key. 
or setting the hands it is used as a crank; the squared extremity at the bottom is for altering the regulator, which may be done without opening the inner case, an aperture being made in the back of the case for the purpose.

Perhaps the very best method of indicating the hour and minutes with one hand only is that shown in Fig. 353, which represents a watch by Peter Garon, illustrated by favour of the late Mr. Henry Levy to whom it belonged. The central disc on which the hour numerals are engraved rotates, but its speed of progression is one-twelfth less

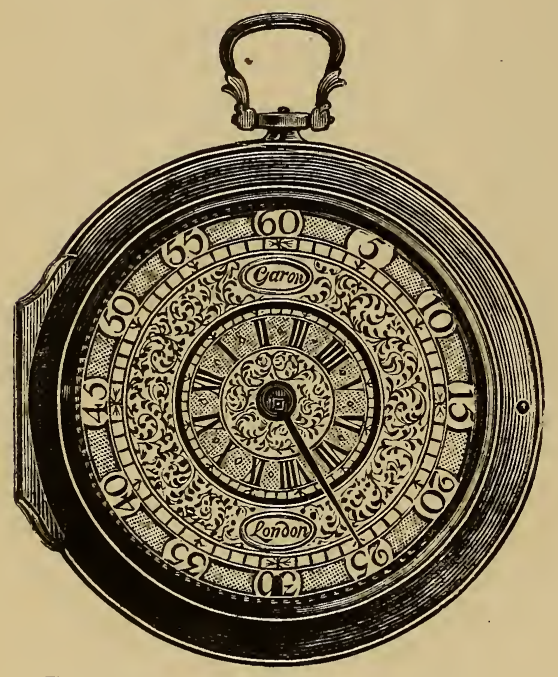

FIG. 353.-Watch by Peter Garon. han that of the minute hand. Starting together on the completion of any particular hour, the minute hand would stand exactly over the numeral corresponding to that hour: by the time half an hour had elapsed the minute hand would stand midway between the aforesaid numeral and the next succeeding one, and at any other point the relation of the hand to the hour numerals would correspond to the fraction of the hour, while the tip of the hand would indicate the minutes. In the sketch the indication is twenty-five minutes past seven. Both parts of the dial are of silver, the annular space between the hours and minutes being engraved as shown. Though but little is known of Peter Garon, he was elected to the freedom of the Clockmakers' Company in 1694, and appears to have been a maker of repute at the end of the seventeenth century and until 1706, when his bankruptcy was noted in the London Gazette.

Watches with Seconds Hands.-The watch by Fitter, dating from about 1665, which, as shown in Fig. 249, has a seconds dial on the back of the movement, seems to have been quite an exceptional application of a seconds indicator for watches. Sir John Floyer, a physician, in 1707 speaks of the "Physicians' Pulse Watch," which he had invented to take the place of the " common sea minute glass" with which and "common watches" he had been in the habit of trying 
pulses. The pulse watch which he caused to be made ran, he said, for sixty seconds. Harrison's timekeeper with a centre seconds hand was tested in 1760 , and seconds hands were not usually applied to watches till after that date.

Sun and Moon Indicators.-Two examples of a peculiar method of indicating the hour which obtained some popularity at the end of the seventeenth century are shown in Figs. 354 and 355. A semicircular piece is removed from the upper part of the dial, and through it is seen one half of a disc which rotates underneath once in twentyfour hours. On one half of the disc is engraved the sun, which points

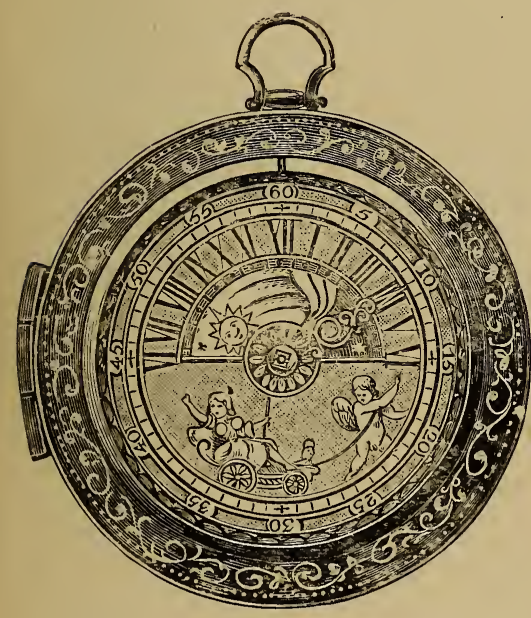

FIG. 354.

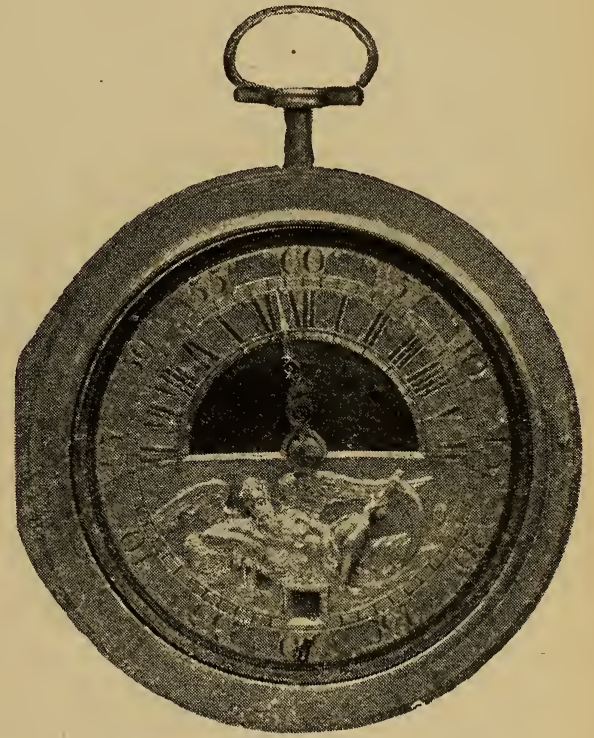

FIG. 355.

Two examples of a peculiar method of indicating the hour.

to the hour from 6 A.M. to 6 P.M., and on the other the moon, which performs the same office from 6 P.M. to 6 A.M. The minutes are indicated in the usual way by a hand travelling round the dial in an hour.

Fig. 354 is an early specimen. On the lower portion of the dial is an engraving, possibly representing Venus in a car drawn by Cupid. The movement is furnished with tulip pillars, and on the plate is engraved " Jo Holoway, Newbery." The balance-cock is of floral design with a narrow waist and foot of irregular outline following the curve of the plate. The outer case is of steel damascened with silver.

Fig. 355, of a slightly later date, is inscribed "Harns Smit, Amsterdam." 
Changing Hour Figures.-In this ingenious arrangement, which was probably designed by Cratzer, and applied by Fromanteel, $\mathrm{Knibb}$, and others to clocks, hands are dispensed with altogether and numerals corresponding to the last completed hour caused to appear through a hole in the dial, a principle favoured in recent years by several inventors, who have devised various means of accomplishing this end. As an example of the contrivance is shown a watch by M. Lögg, of Vienna, which was in the Marfels collection. It has an upper silver dial on which is chased a group, representing Saturn dragging the car of Helios. As may be seen by the illustration, Fig. 356, there is above the group on the silver dial a semicircular slit, through which is visible a second dial lying under

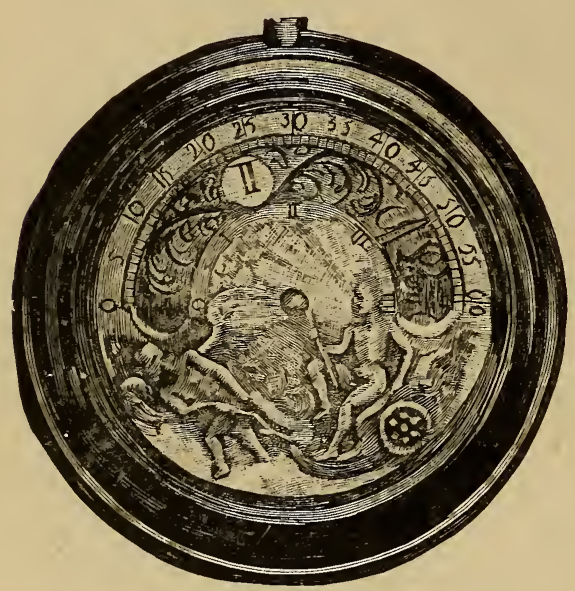

FIG. 356.-Watch with changing hour figures.

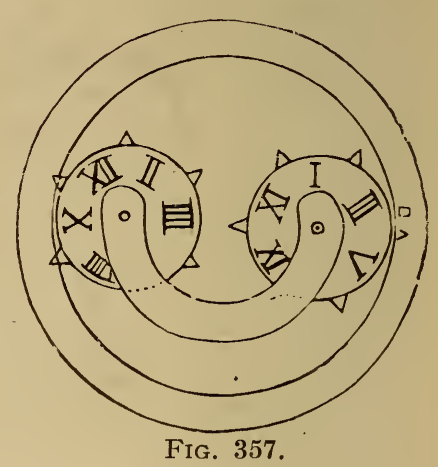

FIG. 357.

it. This second dial is gilt, for contrast. Above the opening of the silver dial are engraved the minutes from 1 to 60 , and underneath it the quarter-hours I. to IV. The lower dial is movable, revolving once in two hours, and has two circular openings exactly opposite each other, through which the hour chapters appear upon a silver disc. A pin is fixed upon and near the edge of the front plate, over which the dial revolves. The dial passes freely by it, while the projecting teeth of the two numeral wheels in turn meet the pin, and are each time advanced one hour (see Fig. 357). Suppose, in the opening under which is located the disc with the even figures, we see the number II., as in Fig. 356. This number has entered from the left into the semicircular slit of the silver dial, through which it slowly passes in one 
hour, while the other numeral wheel (which is during the same time

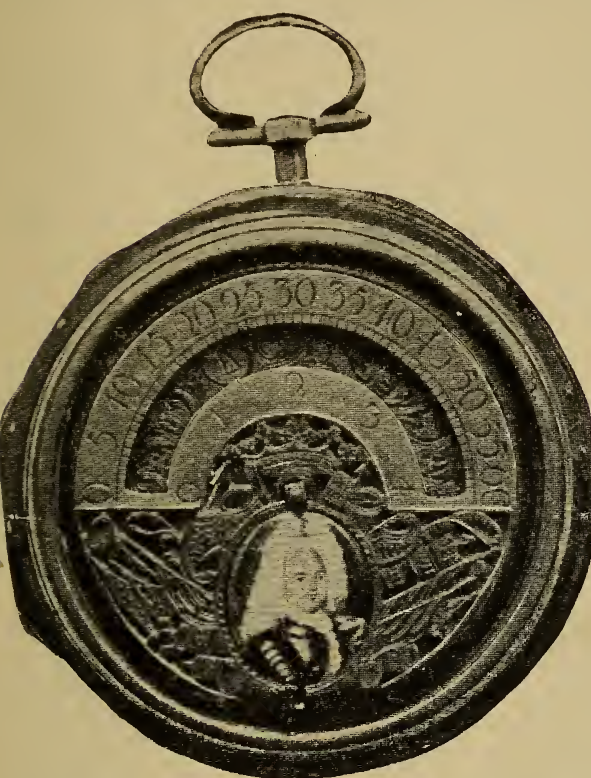

FIG. 358,-Watch with changing hour figures.

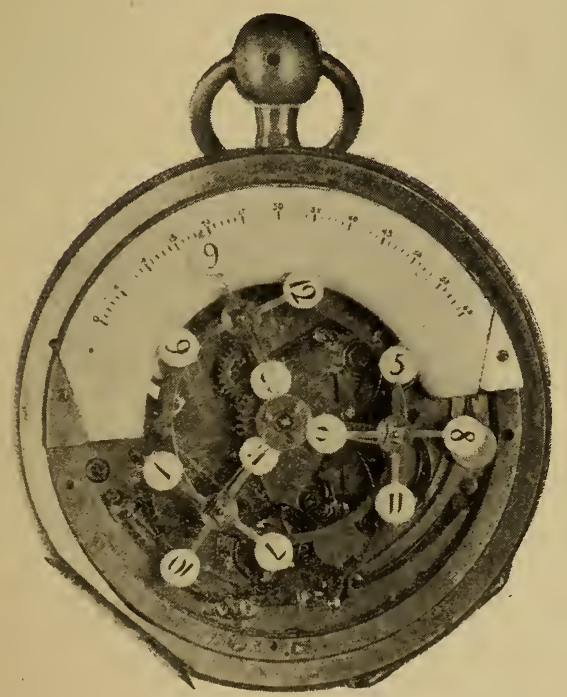

FIG. 359.-Watch with changing hour figures. under the Saturn group and therefore invisible), with the odd figures, passes by the stationary pin, and is by it turned one tooth, or from I. to III. When the number II. has passed its course through the semicircle it disappears to the right under the Saturn group, and the number III. enters from the left into the semicircle, in order to pass through its course in the same manner. The disc with the hour II. meanwhile keeps on its way invisibly, passes the stationary pin, and is also turned one tooth further on, so that at the next hour it enters again with the number IV. from the left into the semicircle of the silver dial. This procedure is repeated with all the succeeding numerals. The number of minutes which have elapsed since the last completed hour is indicated by the position of the revolving hour chapter with relation to the figures which are engraved on the fixed dial plate.

Fig. 358 shows another watch of this character, taken from the catalogue of the Geneva Exhibition,

1896. It is by Paul Lullin, and most probably French. In the lower 
portion of the fixed dial is an enamelled medallion, with portrait, said to be that of Louis XIV. when a youth.

The late Mr. Henry Levy had one of these curiosities by Fromanteel, which may be either English or Dutch. On the lower part of the fixed dial is a late-seventeenth-century design, with birds, \&c. A peculiarity of this watch is that the fusee may be turned either way to wind it, a device advertised by Thomas Moore, of Ipswich, in 1729, and illustrated by Thiout in 1741 .

In Fig. 359 the arrangement is varied, and the whole of the

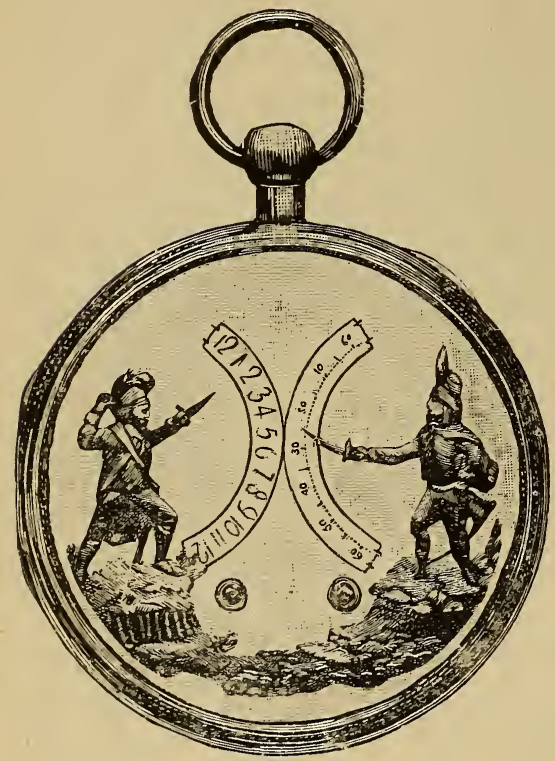

FIG. 360.

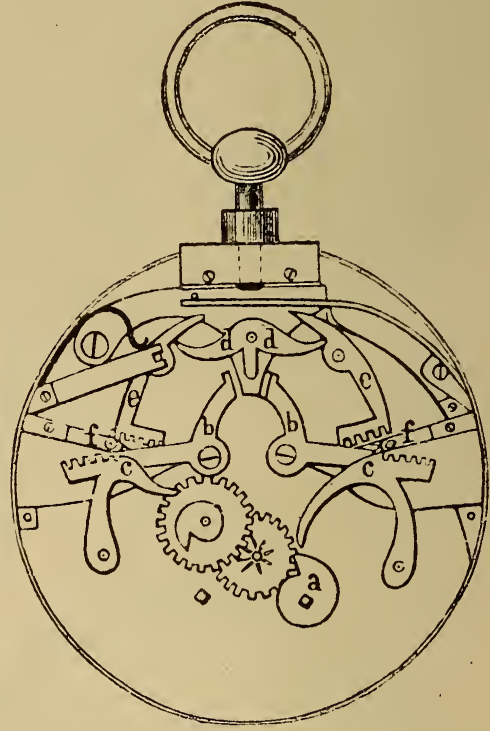

FIG. 361 .

Watch of peculiar construction, about 1760 .

actuating mechanism is visible. On a carriage which revolves once in three hours are three crosses, each carrying four hour numerals on enamelled discs. These in turn pass over an enamelled arc on which every minute is marked.

"Fencing Soldiers" Watch.-Figs. 360 and 361 show a watch of very peculiar construction, formerly in the Marfels collection, dating probably from about $\mathbf{1 7 6 0}$. The metal dial plate has a blue enamelled ground, with thin white lines, and upon it are fastened two quadrants. The hours from I. to XII are marked upon one, and upon the other the minutes from 1 to 60 . It also bears two 
chased figures of soldiers in a fencing attitude, one on each side of the quadrants. By pressing upon the pendant, the soldiers draw their swords, the one to the left pointing with his sword to the hour, while the one to the right points to the minute upon their respective quadrants. The construction is shown in Fig. 361, which is the movement without the dial. Upon the arbor of the wheel, which is usually in the centre, is the cannon $a$, upon which is fixed the snail used for determining the minutes. The cannon drives in the ordinary manner a minute wheel, the pinion of which depths in a wheel located to one side, which it rotates once in twelve hours. Upon the latter wheel is fastened a snail for determining the hour. When the pendant is pressed down, the two levers $b \quad b$ are first unlocked, which unlocking actuates the four racks $c c$ and $e e$, each two of which depth together into pinions $f f$. Upon the arbors of the two pinions $f f$ are placed the arms of the soldiers. By the unlocking of the levers $b b$, the racks $e e$ (situated above the centre of the plate), freed from the arm $d d$, are then moved upward by springs operating on them. The pinions $f f$, into which the racks depth, turn an appropriate distance, and with them the arms of the soldiers, which are located on the pinions, and thereby carry with them downward at the same time the lower stationary racks $c c$. These racks $c c$ are provided with projections, which in their downward motion finally strike upon the snails, the one to the left lying upon the hour rack, and that to the right'upon the minute rack. When the pressure upon the pendant is removed, all the parts of the motion work, and with them also the arms of the soldiers are by a spring brought back into a position of rest. The cannon pinion $a$, fitting with gentle friction upon the centre wheel arbor, is provided with a setting square passing through the dial, for the purpose of setting the motion work mechanism.

Pendulum Watches.-A curious fancy which obtained some popularity at the end of the seventeenth and beginning of the eighteenth centuries is shown in Fig. 362. The balance was placed under the dial and its arms weighted. A semicircular slit in the dial allowed one weight of the balance to be seen, and this, as it vibrated somewhat, resembled a pendulum in motion. It was, however, an inconvenient arrangement, by reason of the difficulty of getting at the balance for regulation, and it appears to have been abandoned in favour of a pendulum balance at the back of the watch. The watch here illustrated is by "Mitzell, London," and dates from about 1700 . 


\section{Old Clocks and Watches and their Makers}

Musical Watches of large size, with moving figures, were a favourite conceit among French and Swiss makers during the latter part of the eighteenth century. The appended example (Fig. 363) is from the collection of Mr. James W. Usher. It is mounted on both sides with fine pearls and chased gold. The back is enamelled with a landscape in colours; in the foreground is a pavilion (supposed to represent a place at Versailles) and

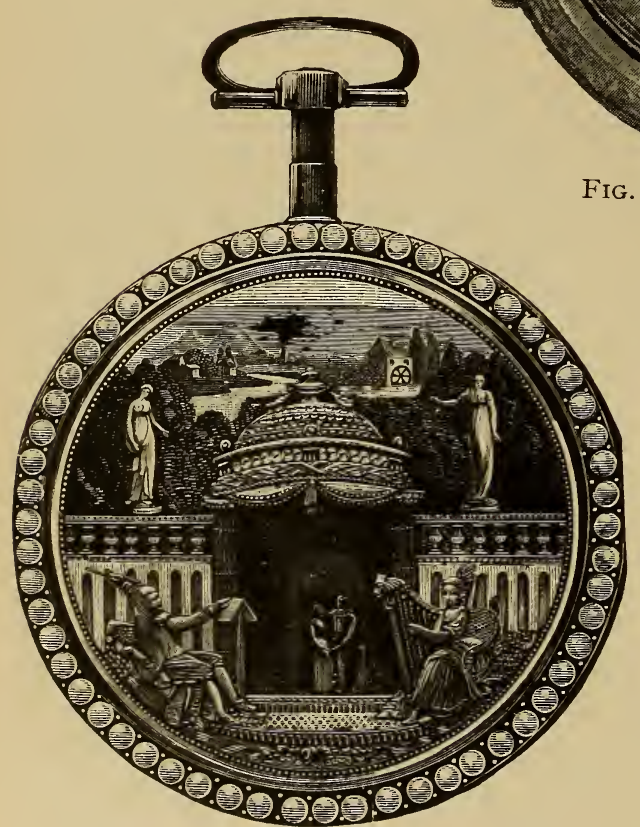

FIG. 363.-MIusical Watch with Moving Figures.

figures, in gold of different colours; inside are small figures (couples of lady and gentleman) in the dress of the Louis Seize period, which dance when the movement is wound. The lady seated outside the pavilion plays the harp, and the gentlem a n seated opposite beats time with his bâton. Inside the pavilion are walls of burnished steel, which reflect and multiply the dancing figures in a remarkable manner. The escapement is a cylinder one with brass scape wheel. The going part is driven direct from the barrel. The musical box and figures are driven by 
one mainspring, the train passing beneath the pavilion and revolving the centre of the floor upon which the dancers stand; smaller wheels

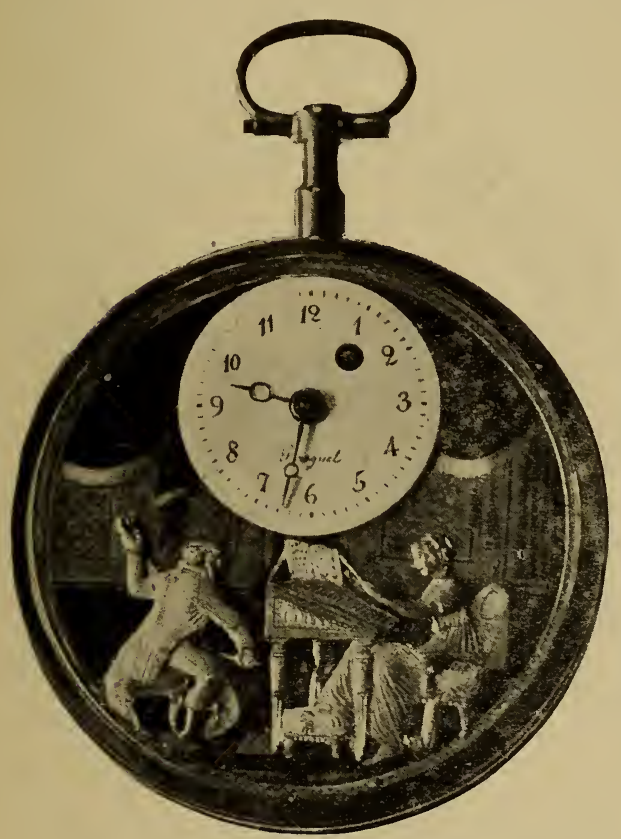
being employed to revolve each pair of dancers three times for every one dance round the room; the conductor and harpist being worked by pins and levers between the plate and the dial.

A musical watch with moving figures of a man playing a violoncello and $\eta$ lady a dulcimer is shown in Fig. 364.

Fig. 365 is a repeating watch of French make.

FIG. 364.-Musical Watch with Moving Figures.

The hours and quarters are really struck on gongs curled around the inside of the case in the usual way, but, when the pendant is pushed in to repeat, the hammermen in the recess at the upper part of the dial appear to strike on the bells shown there, and the woman below works a spinning wheel.

Figs. 366 and 367 , from the collection of Mr. H. J. Heinz, illustrate a large silver-gilt double case watch, both cases pierced and engraved. In the outer case a large enamel "Mother 


\section{Old Clocks and Watches and their Makers}

watching a sleeping child " is set. The watch is provided with hour, minute, second, and split-second-hand. Two tunes may be played upon a concealed musical attachment. The watch was made by Timothy Williamson, of Fleet Street, in 1769, and was looted from the Chinese Imperial Palace in Pekin during the "Boxer Rebellion."

In Fig. 368 the arrangement is a little differen't. Here the

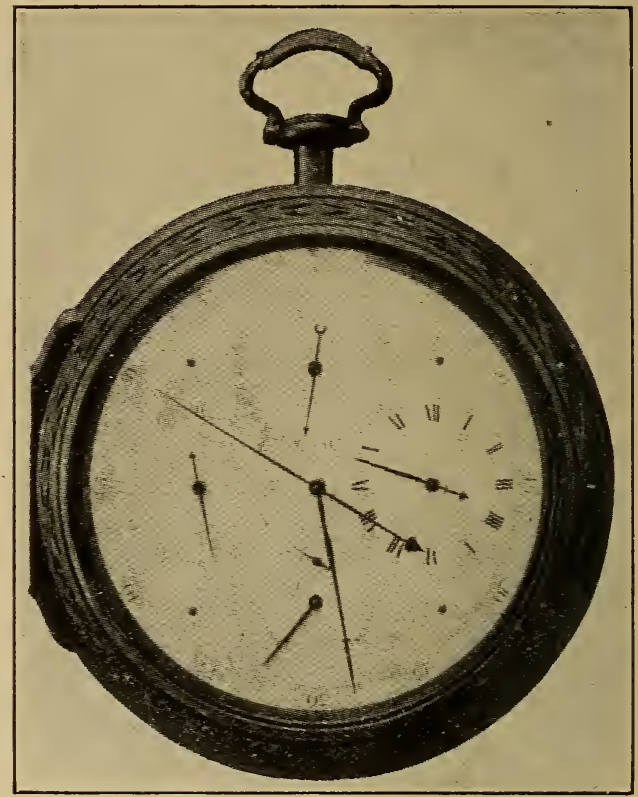

FIG. 366 .

Large Watch with Musical Attachment, by Timothy Williamson.

upper rectangular space is vacant till the pendant is pushed in for repeating. Then the figure on the right bearing a huge gong advances, and the one on the left comes forward and appears to strike the hour on the gong. The quarters are repeated by the figures below, and during that operation the figures above slowly retire out of sight.

FIG. 367.-Back of Watch, by Timothy Williamson. 
The projected invasion of England by Napoleon Buonaparte is treated as an accomplished fact on the dial of a watch from the Schloss collection which is shown in Fig. 369. A large moving ship in full sail just appearing above the horizon occupies the centre, in the foreground many vessels are portrayed, and armed men are marching up the shore undeterred by the firing of some apparently very primitive cannon. Above is the inscription, "Descente en Angleterre."

Another arrangement of moving figures is shown

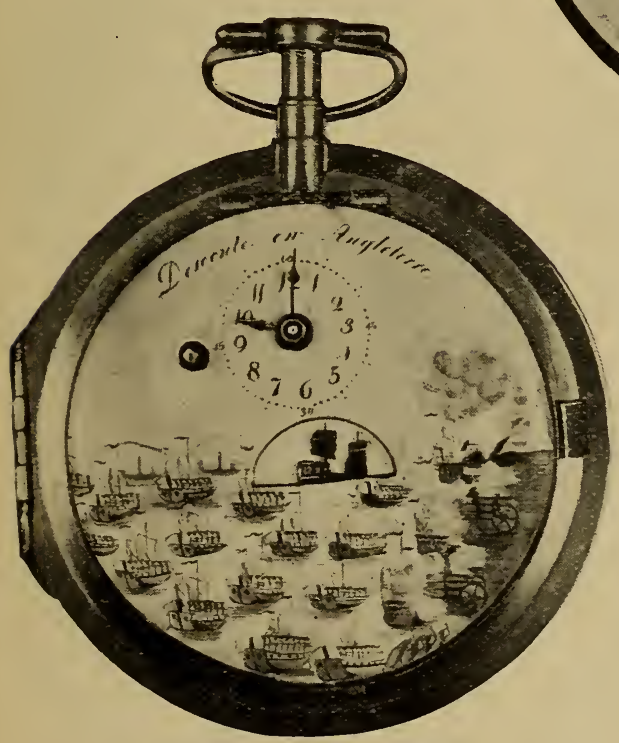

FIG. 369.-Watch inscribed " Descente en Angleterre."

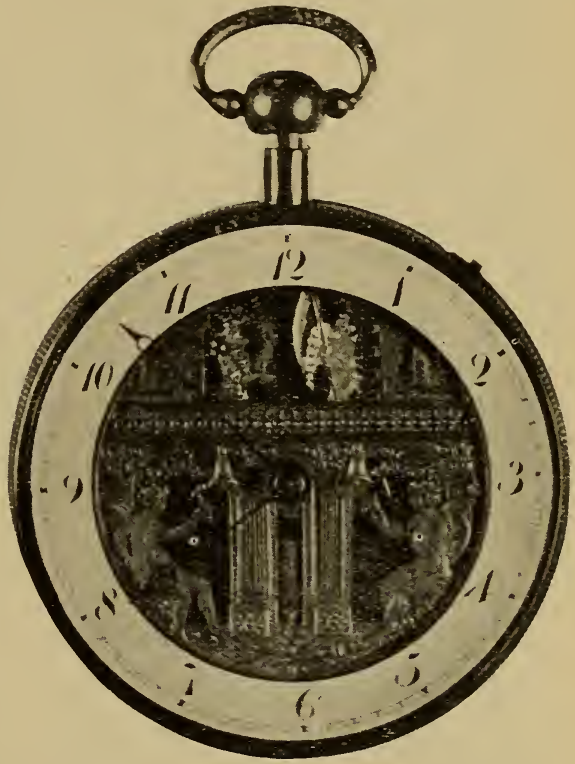

FIG. 368.- Repeating Watch with Moving Figures.

in Fig. 370. Here the sails of the windmill are constantly moving while the watch is going, and seen through the round aperture is part of a rotating disc with figures of horses and men painted thereon.

Many of the metal watch dials of the seventeenth century which were devoted to other purposes than the indication of the hour or other subdivisions of a day well repay examination. Here are some representa-
tive specimens from the Schloss collection. Fig. 371 represents 


\section{Old Clocks and Watches and their Makers}

a silver single-cased watch which doubtless dates from about 1640. On the back of the case is the characteristic circular shutter over the winding hole and the owner's name engraved thus, "Richard Baille, at the Abbay." The maker's name is Henry Arlaud. There is a spring to control the balance, but there are unmistakable indications that this was an addition made subsequent to the manufacture of the watch. The dial is p=ettily arranged gives a calendar, the age and phases of the moon, the signs of the zodiac, etc. A similar watch by "Jean Rousseau" is to be scen at the South Kensington Museum.

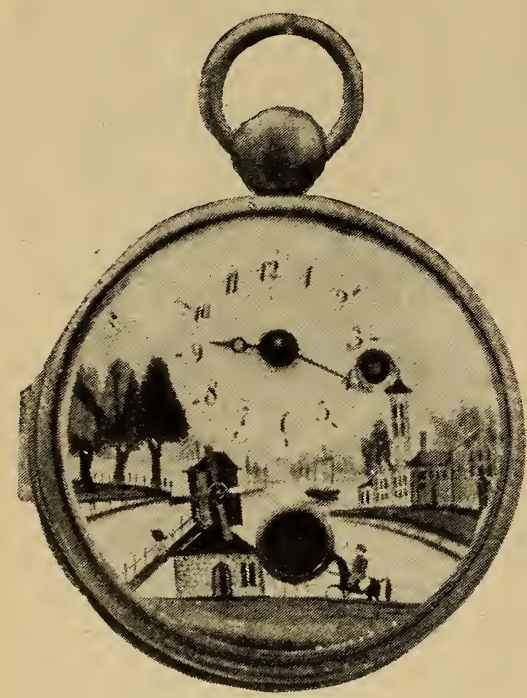

FIG. 370.-Watch with Moving Figures.

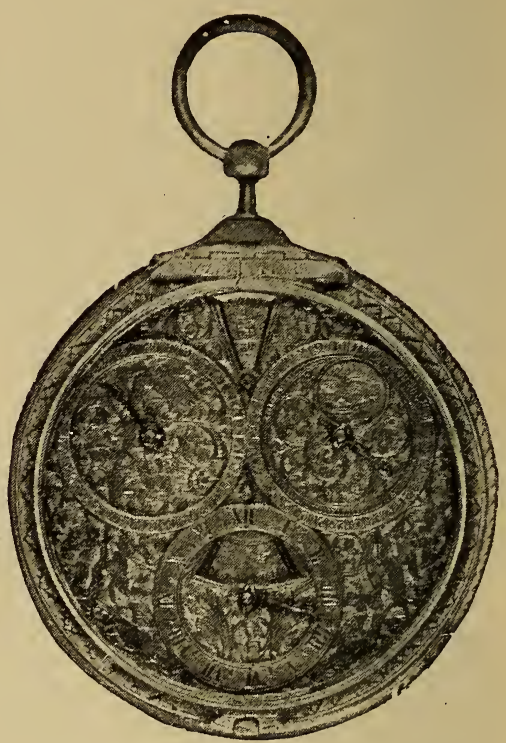

FIG. 371.-Watch by Henry Arlaud, about 1640 .

A double-cased watch by $\mathrm{N}$. Bouquet, of which a front view is given in Fig. 372, is of about half a century later date; though attractive and of broadly the same character as the preceding example, the execution is comparatively coarse.

In pendulum watches, such as the one shown in Fig. 373, where the balance was planted immediately under the dial, there was often at the back of the watch, in place of the balance, an enamelled plaque, occasionally exhibiting painting of artistic merit. This fashion seems to have been introduced by some of the Dutclr makers, but it was decidedly an inconvenient arrangement, which necessitated an 


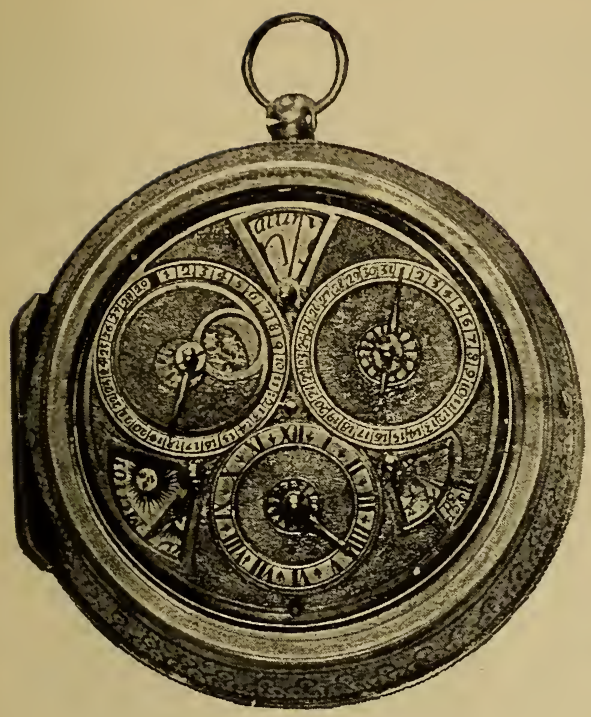

FIG. 372.-Double-cased Watch by $N$. Bouquet.

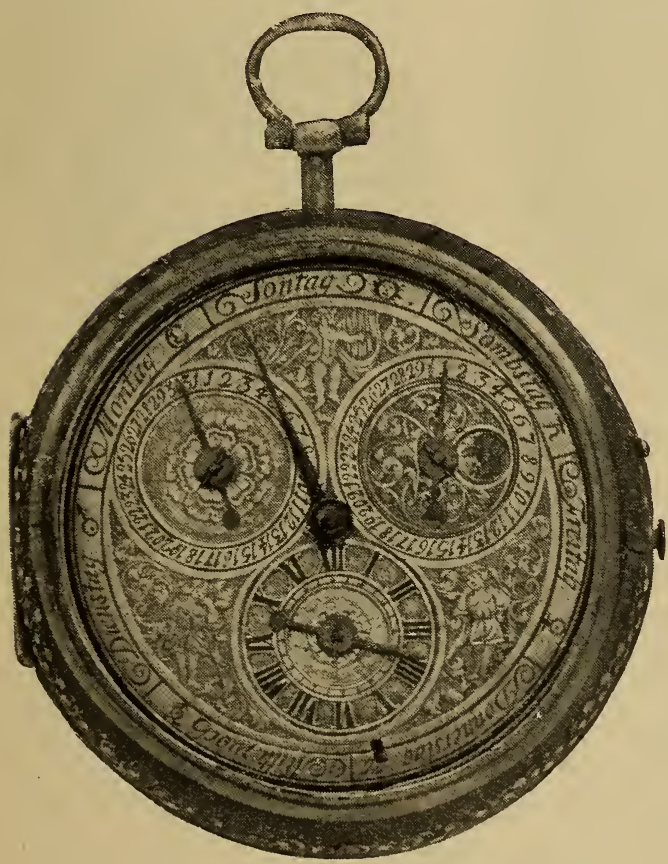

FIG. 374.-Large Astronomical Watch, about 1690 .

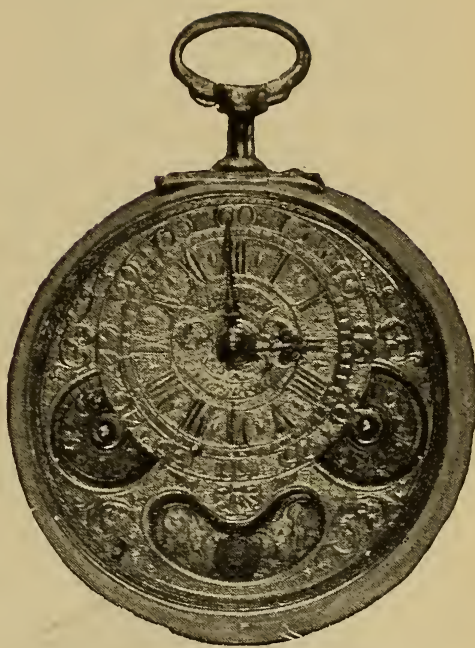

FIG. 373.-Pendulum Watch.

inferior method of regulation from the front, besides crowding the hour division into a smaller circle. The name on this watch is Hilderr.

At first sight the large astronomical watch, dating from about 1690, which is represented in Fig. 374, appears to be of English make, for it bears the name-plate of " Willing, London;" but on removing the name-plate the signature "Ferdinandus Zehng, Hamburg," is revealed. The dial is really excellent; the engraving shows it 


\section{Old Clocks and Watches and their Makers}

was prepared for use in Germany. Such a watch at that period would doubtless be made to order for presentation to some person of distinction.

One of the finest calendar watches of late-eighteenth-century production it has been my privilege to examine is shown in Figs. 375, 376, and 377. It is by Samuel Ruel, Rotterdam, and stamps him as a horologist of the first rank. Besides the age and phases of the moon and the title of the month, it shows through apertures over the $\mathrm{XI}$. and I. the day of the month according to the old style and the new style. The cases bear the English hall-mark of 1788 with the

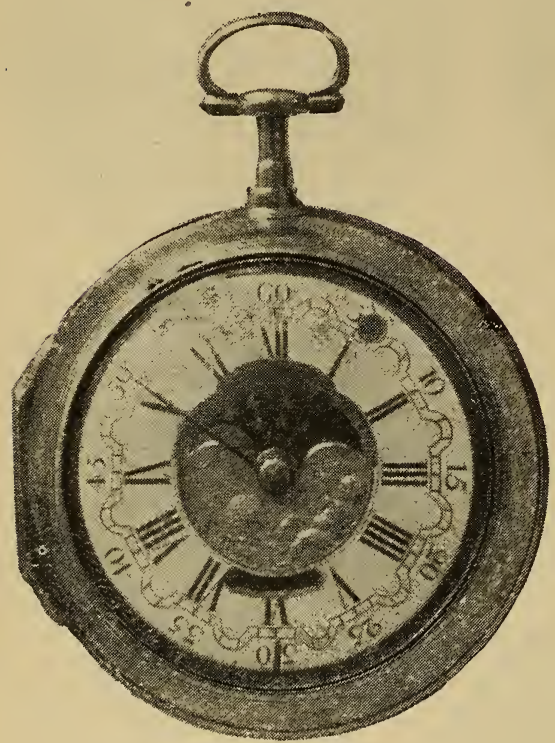

FIG. 375.

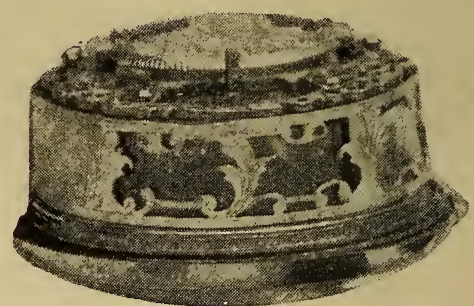

FIG. 376.

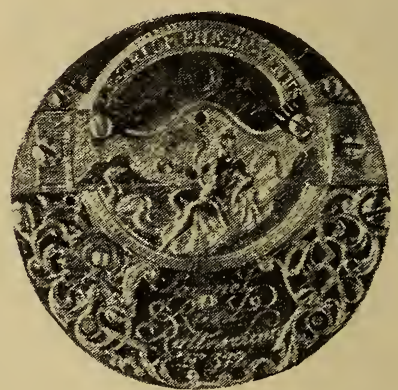

FIG. 377.

Fine Calendar Watch of late-eighteenth-century production.

duty head; on the back of the inner case is "A.S." arranged as a monogram. The outer case has a diamond thumb piece. There is a rim cap (as seen in Fig. 376) of silver, having perforations covered with horn. The cock, as seen in Fig. 377, is a fine piece of chased work.

Pearl Ornament.--There appears to have been quite a rage for pearl ornament at the beginning of the nincteenth century, particularly among French and Swiss watchmakers. Mr. Willard $\mathrm{H}$. Wheeler has a heart-shaped repeating and musical watch, ascribed to Froissard, of Geneva, with covers over the front and 
back. The latter, shown in Fig. 378, conceals a landscape with moving figures of a windmill, and a boy and girl playing on musical instruments. Altogether there are 1,700 pearls used in the decoration. The Napoleon watch on p. 197 and the musical watch on p. 232 afford other examples of pearl enrichment. In the Marfels collection was a watch by Albery, London, with a very pretty design in pearls over the back.

A souvenir watch, such as is shown in Fig. 379, was deserving

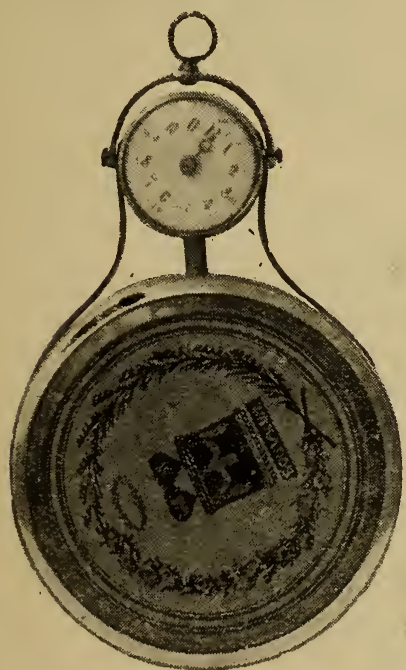

FIG. 379.-Souvenir Watch, about 1780 .

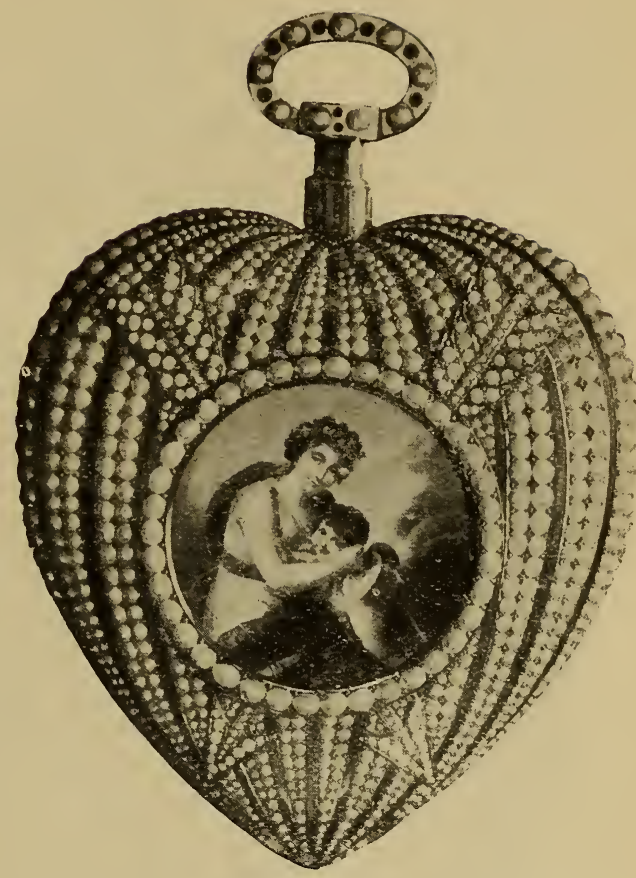

FIG. 378.-Musical Watch with Pearl Decoration.

of more popularity than it seemed to have attained. The surface enclosed by the large circle was reserved for inscriptions, monograms, or other personal references. Underneath is the mechanism of the watch, whose motion is conveyed to the hands by means of a small rod concealed in the connecting neck. On the movement is engraved, "Inventio Jôhannis Holtmann in Wienns No. 25." It dates from aboit 1780 .

Large Travelling Watches introduced at the end of the seventeenth century continued in favour till the advent of railways. They were thick and heavy, with dials ranging from $3 \mathrm{in.}$ to nearly $7 \mathrm{in}$. in diameter, and seem to have been manufactured more in France 

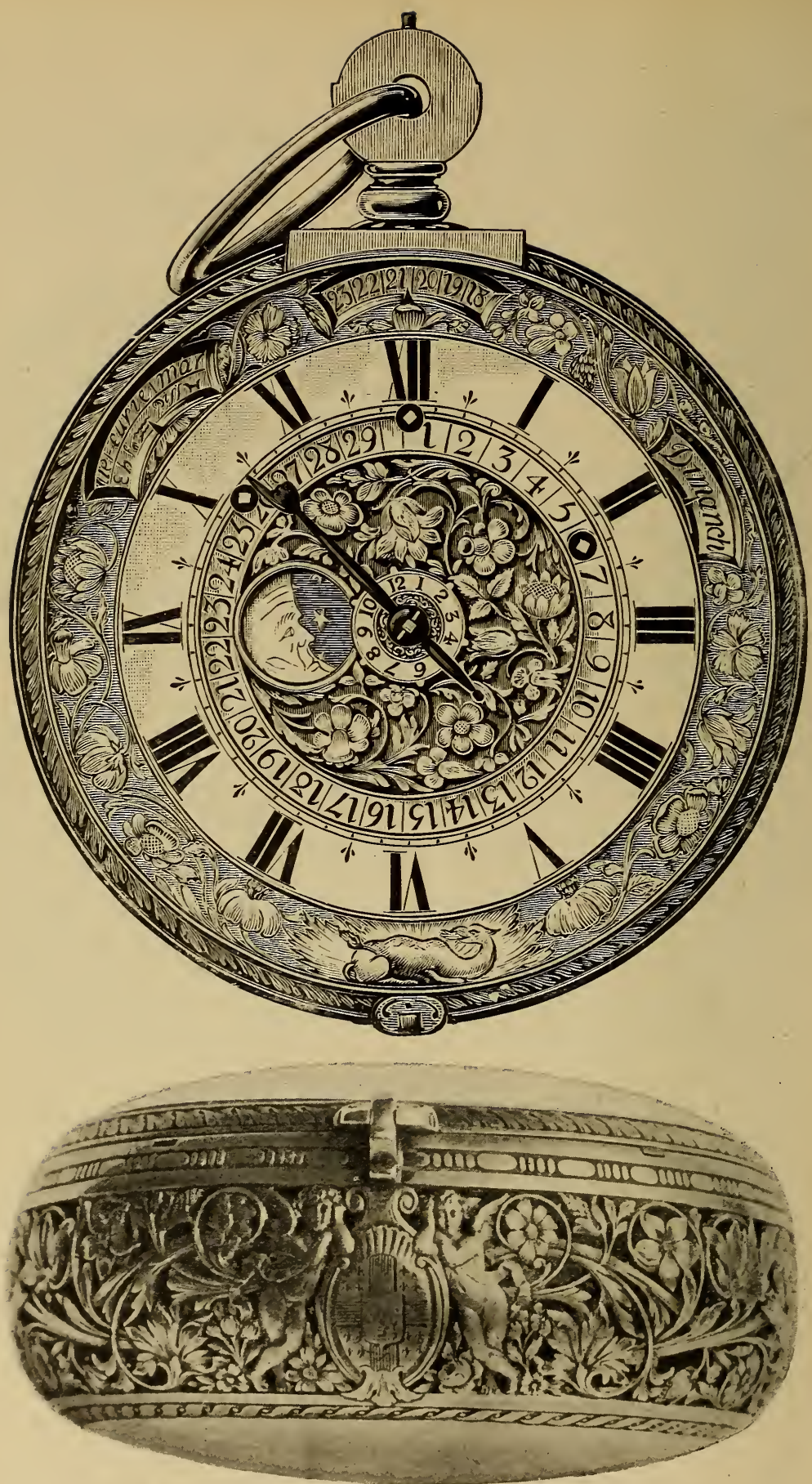

FIGS. 380 and 381.-Large Travelling Watch, about 1680. 


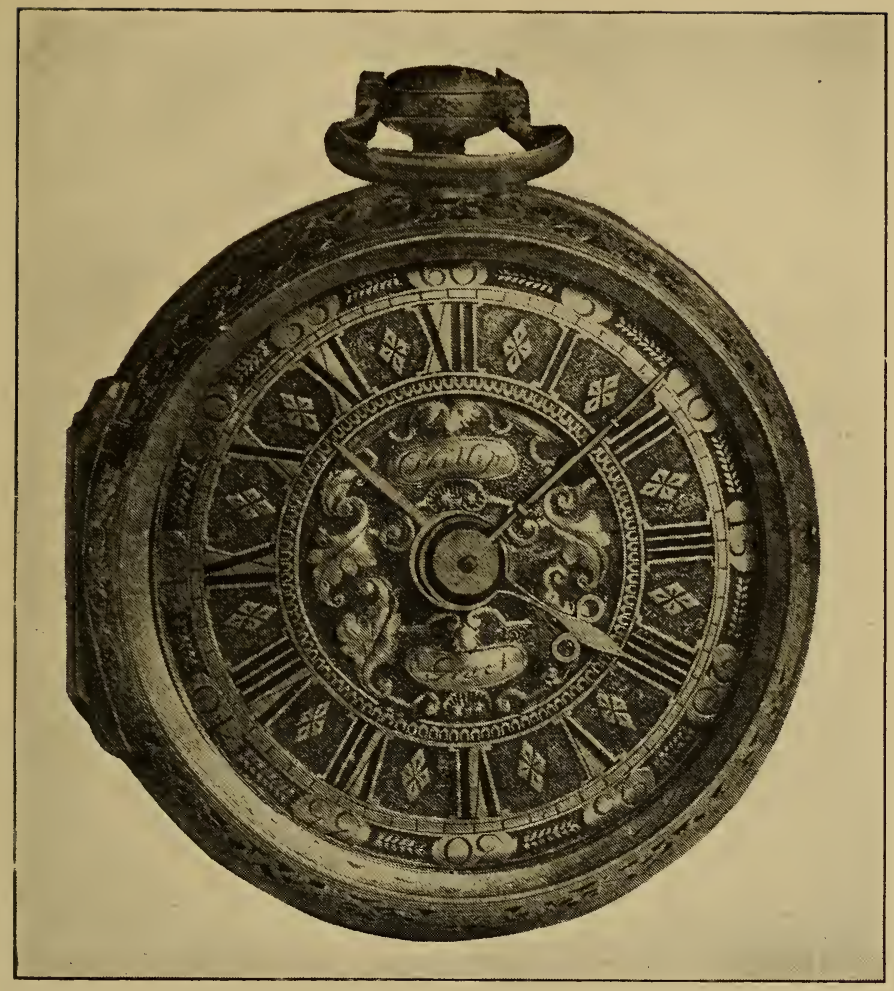

Fig. 382.-Smaller example.

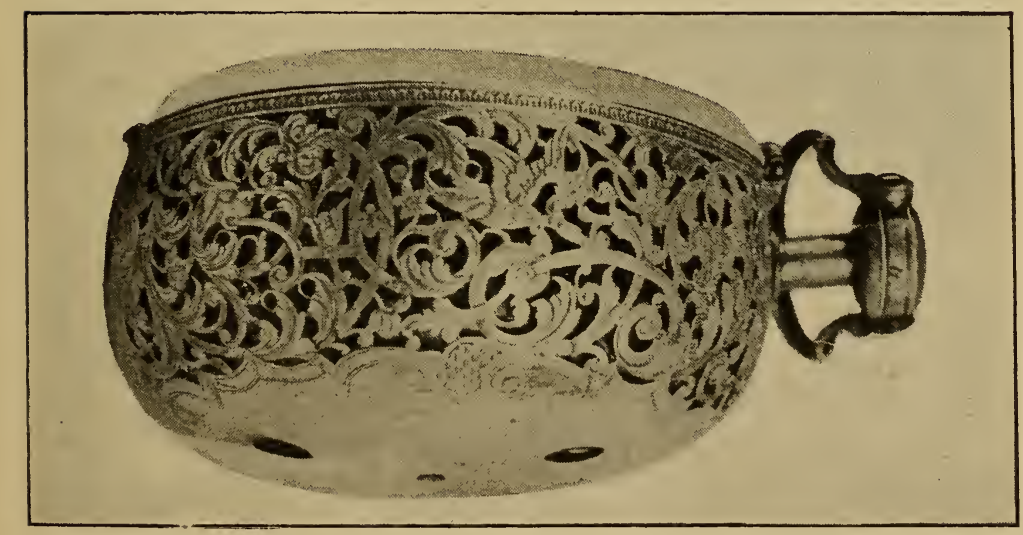

FIg. 383.--Side view of Inner Case. 


\section{Old Clocks and Watches and their Makers}

and Germany than in England. As a rule they struck the hour on a bell inside the case, many of the earlier ones being in addition furnished with an alarm. Afterwards, a repeating motion took the place of an alarm, so that by pulling a string which passed through a pipe at the edge of the cover the number of blows last struck would be again sounded on the bell. They had generally two cases, an outer one covered with leather or fish skin and an inner one of silver, which latter material was also used for the dial. The pendant was sometimes

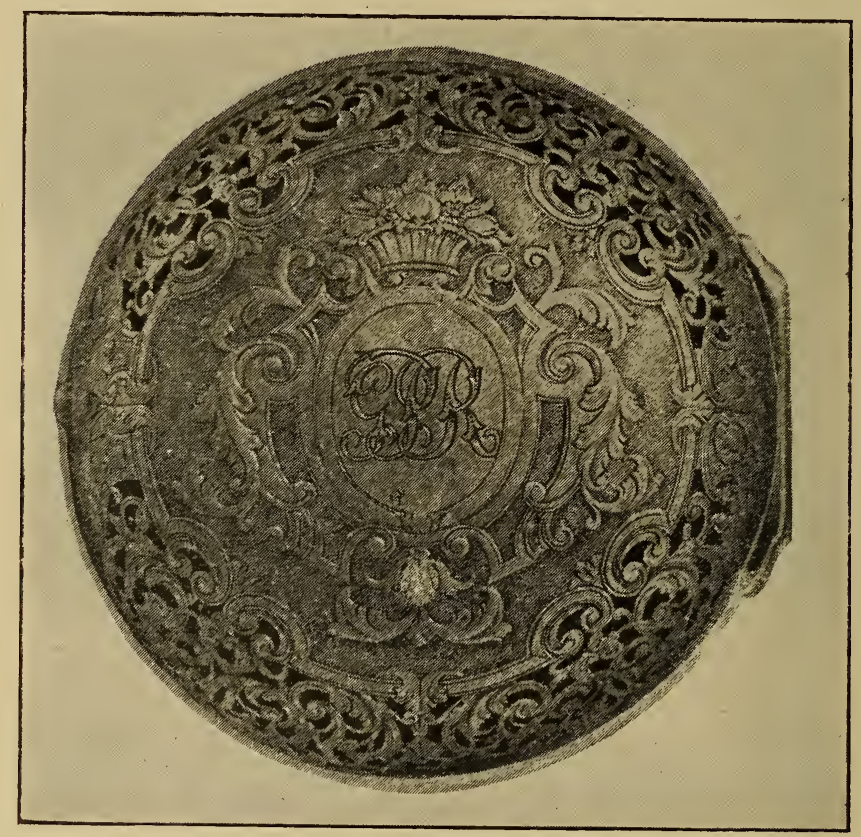

FIG. 384.-Back of Outer Cover.

n two pieces connected by a loose thimble, an arrangement which allowed of sufficient movement to enable the watch to adjust itself to an adjacent surface when it was hung from the bow. Front and edge views of an excellent example in a remarkably well pierced and carved silver case dating from about 1680 are given on p. 241. The central portion of the dial rotates, indicating the age of the moon and exhibiting her phases. Through slits near the outer edge are shown the day of the week, the day of the month, and the title of the month in 
French. The movement is signed "Samuel Michelin à Langres." and is now in the Franklin Dennison collection. This or a very similar instrument was illustrated in Dubois' historical work.

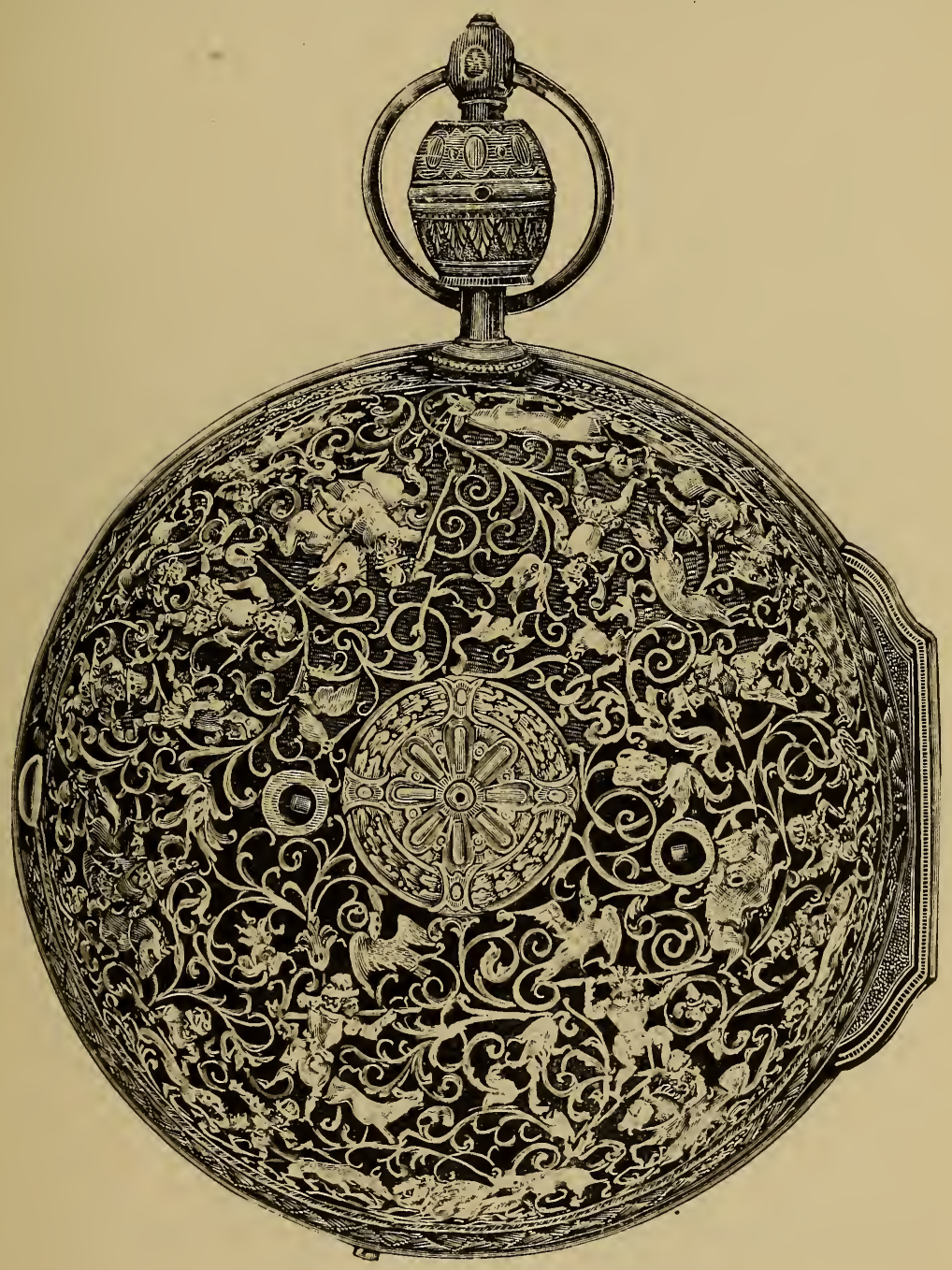

FIG. 385.-Fine specimen, about 1710 .

In Figs. 382, 383, and 384 are shown a rather smaller clock and alarm watch, which strikes the hours and half-hours. The inner and outer cases as well as the dial are of silver. On the movement is the inscrip- 


\section{Old Clocks and Watches and their Makers}

tion, "Philip Graet, Lintz." It is of slightly later date than the preceding one.

Fig. 385 is a back view of another fine specimen by "Anthony Bradl, Augsburg" which dates from about 1710: the inner case is of

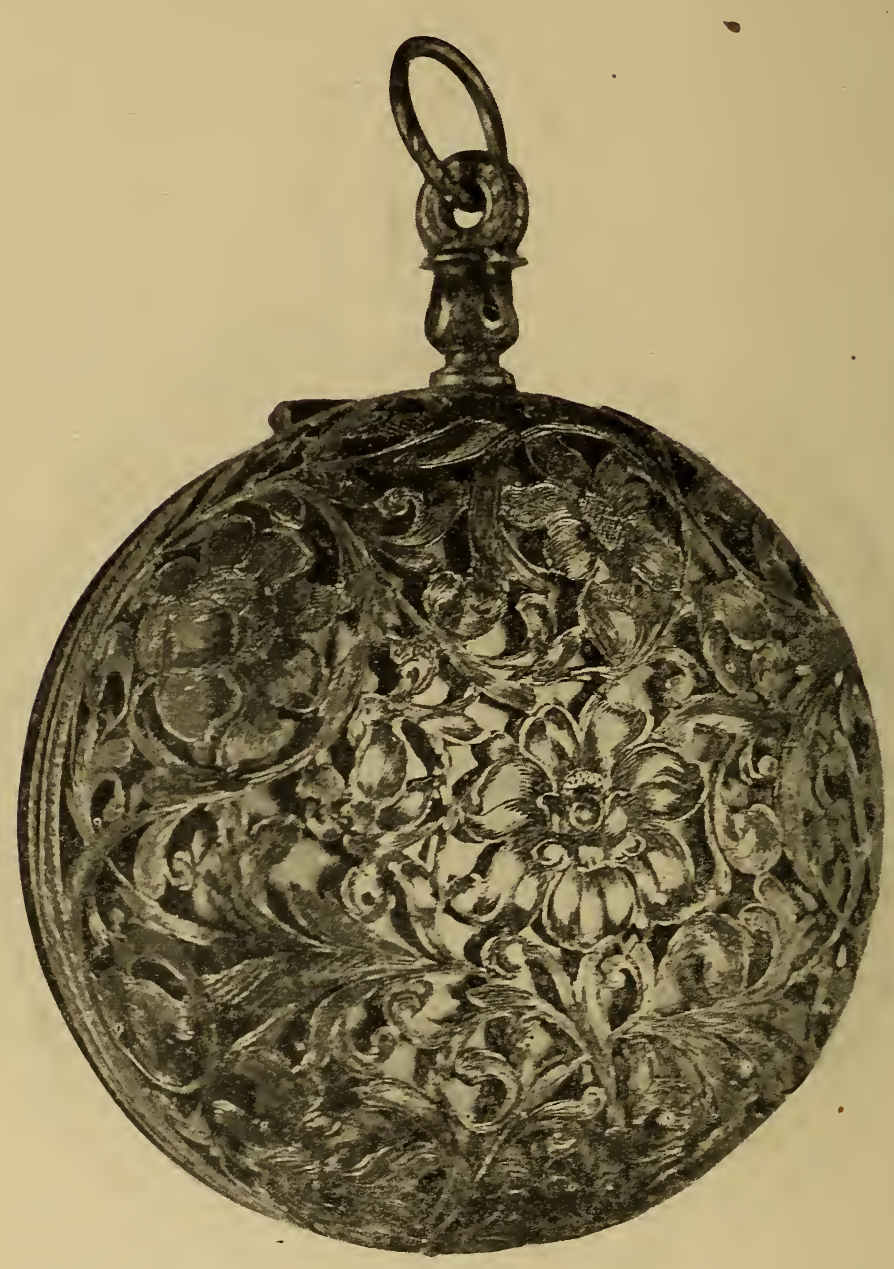

FIG. 386.-Beautifully pierced and engraved specimen, about 1680 .

silver splendidly pierced and chased, with representations of hunting scenes, flowers, and birds, as shown; there is an outer case of fish skin. The number of blows last struck may be repeated at pleasure by pulling a string depending from the case as already described. 
Back and edge of a beautifully pierced and engraved specimen signed, "David Buschmann, Augusta," and dating from about 1680, are given in Fig. 386 .

The splendid travelling clock-watch, of which two views are given

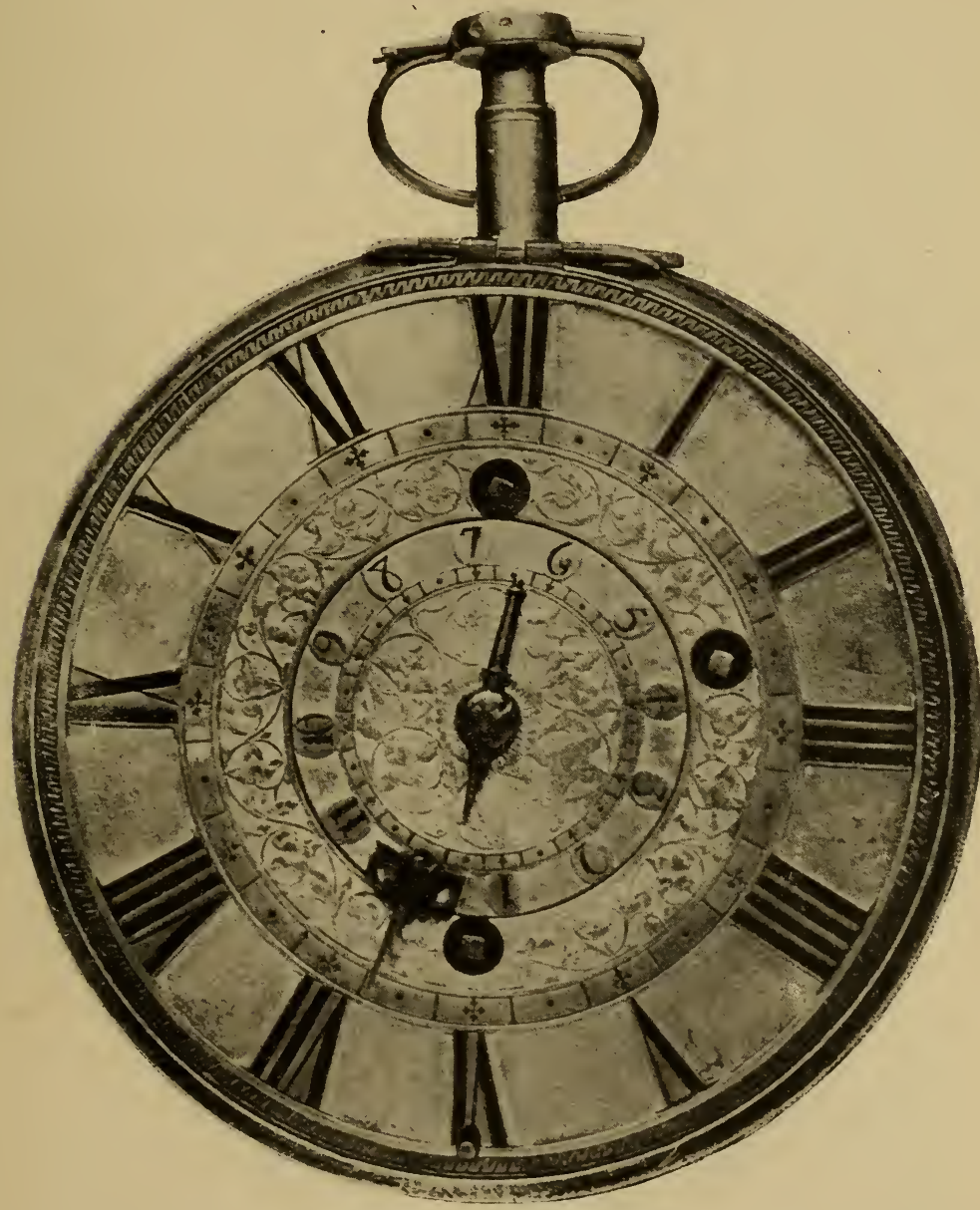

FIG. 387.-Travelling striking and alarum watch by Tompion, actual size.

in Figs. 387 and 388 is in the Pierpont Morgan collection, and dates from about 1695 . The case and dial are of silve1.

Sedan Chair Watches.-During the eighteenth century watch movements having plain silver dials from $3 \mathrm{in}$. to $4 \mathrm{in}$. in diameter were 
246 Old Clocks and Watches and their Makers

fixed in circular frames of wood, polished and with a moulded edge. They were called "Sedan Chair Watches," though I cannot aver that they were as a rule carried in those useful but obsolete conveyances.

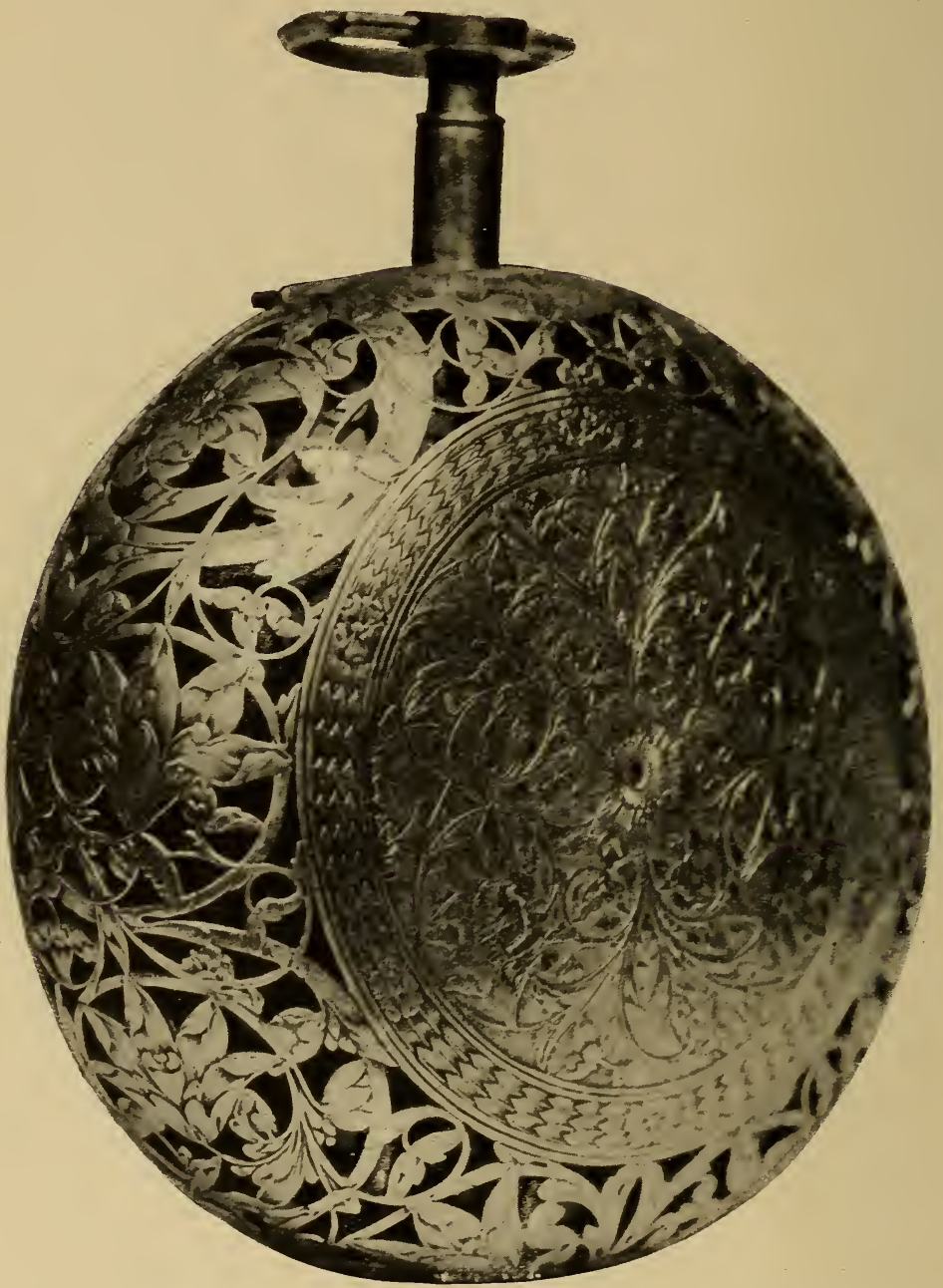

FIG. 388.-Travelling striking and alarum watch by Tompion, actual size.

Occasionally one may yet be seen hung on the wall beside a chimney piece or at the head of a bedstead. I have heard timekeepers of this sort spoken of as "Post Chaise Watches." 
Watch Keys.-Before the advent of the most common variety of watch key which had a circular ring to afford the necessary purchase in winding, and a smaller swivelled bow for attachment to the guard or chain, there must have been a considerable number of keys used by our grandmothers and grandfathers and by their progenitors, on the design and construction of which much consideration and labour had been bestowed. M. Paul Garnier, M. Planchon, and Mr. Arthur F. Hill are among the few collectors of such interesting adjuncts, of which a few examples are given on this page. Several of them, it will be noticed, are formed to give a crank action for winding the watch, and a separate straight pipe, at right angles to the first, for the purpose of
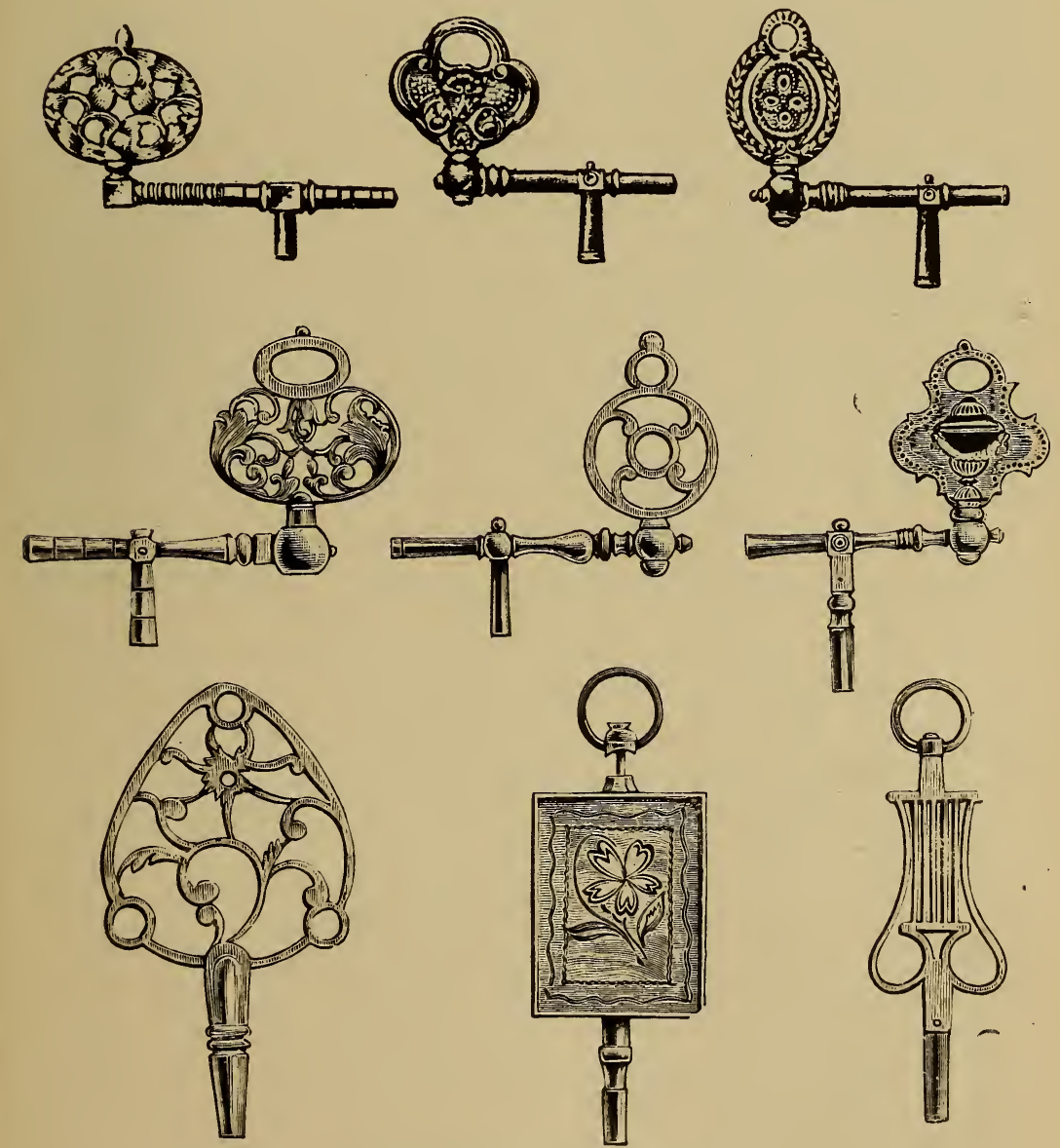

FIGS. 389-397.-Watch Keys. 


\section{Old Clocks and Watches and their Makers}

setting the hands. Keys of this kind appear to have been very generally used from the middle of the seventeenth to the end of the eighteenth century. The first of the lowest row seems to have been intended as a winder for a table clock, while the remaining two, with swivelled bows, recall the days of chatelaines and fob chains. Indications are not wanting that hanging chains, as guards or accessories of timekeepers worn on the person, have in part returned to popular favour, even though watch keys may not be numbered among their appendages. Sir James M. Moody has a cranked watch key ornamented with military emblems, and bearing the name "Jno. Cook, London." A watchmaker of this name carried on business at 22 Cheapside in 1760, and afterwards in Wood Street. This is an early instance of impressing a name on the key, a practice adopted in later years by many watchmakers in a large way of business.

In 1761 George Sanderson, of Exeter, patented a lunar and calendar watch key, which, when daily pressed on to the winding square of a watch, caused the mechanism in the key to advance one day. Etienne Tavernier, a Paris watchmaker who devoted particular attention to keys at the end of the eighteenth century, made some on this plan. Eardley Norton, a well-known London maker of musical clocks, obtained in 1771, a patent for a striking arrangement, which he said could be conveniently contained in a key, seal or trinket. 


\section{CHAPTER V}

\section{RECORDS OF EARLY MAKERS, ETc.}

N ICHOLAS CRATZER (or Kratzer), " deviser of the King's horologies and astronomer" to Henry VIII., was a Bavarian, born in 1487, who, it is said, resided for thirty years in this country without being able to speak English. In the second part of the facsimiles of the National Manuscripts, photographed by Colonel Sir Henry James, there is a letter from Cuthbert Tunstal, Master of the Rolls (who was then in Germany) to Cardinal Wolsey. It is dated 12th October 1520, and contains the following : "Please it your Grace to understand that here, in these parts, I met with a servant of the King's, called Nicholas Craczer, a German, deviser of the King's horologes (who showed me how the King had licensed him to be absent for a season, and that he was ready to return into England), whom I desired to tarry until I might write to the King's Highness, to know his pleasure whether he would suffer him to be in company with me for a season, until the assembling of the electors were past." In a Book of Payments by the Treasurer of the Household from Candlemas-day, 29 Henry VIII., to Midsummer 33 Henry VIII., in the Arundel Manuscripts (No. 97), among the discharges of the former year (1538) is the entry, "Nicholas Cratzer, Astronomer, received five pounds as his quarter's wages."

Cratzer's connection with Holbein was mentioned on p. 167, and there is no doubt that Holbein assisted Cratzer by designing cases and decoration for clocks and sun-dials. Horace Walpole purchased at Mons. Mariette's sale a complicated piece of horology which embodied the conceptions of the two masters. On the summit was a clock driven by wheel work, below were fore and afternoon dials showing the time by shadows, and beneath these a clepsydra indicating the quarters of an hour on an exceedingly ingenious plan, the invention of which has been claimed for many subsequent horologists. It is mentioned by Bettinus, and in Plot's " Oxfordshire" 1676, Christopher Wren is credited with having made for Sir Anthony Cope at Hanwell a Clepsydra on the same principle which is thus 
described: " moves by water and shows the hours by a new gilded sun for every hour, moving in a small hemisphere of wood, each carrying in their centres the number of some hour depicted black ; as suppose of one a clock, which ascending half way to the zenith of the arch, shows it a quarter past one, at the zenith half hour; whence descending half way towards the horizon, three quarters past one; and at the last absconding under it, then presently arises

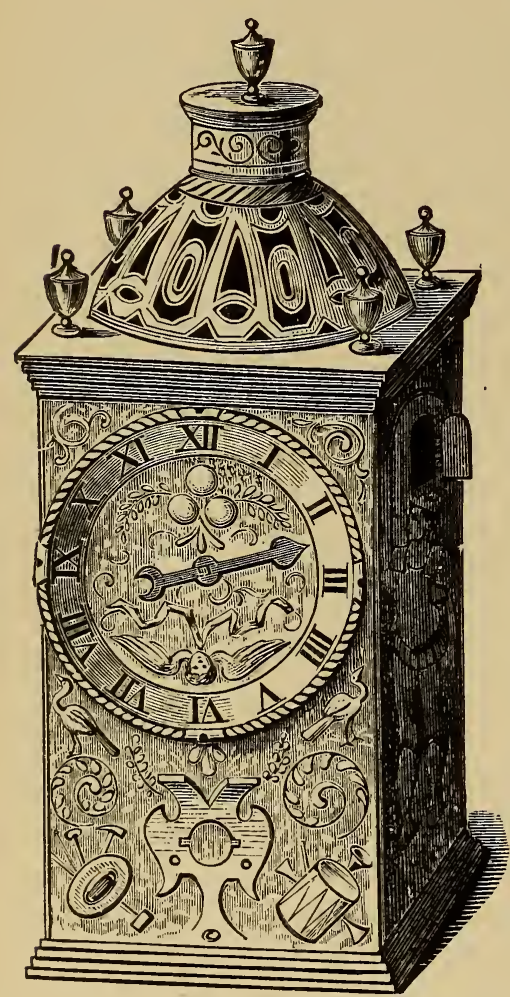

FIG. 398.-Clock by Bartholomew Newsam. another gilded sun above the horizon at the other side of the arch, carrying in its centre the figure two; and so of the rest." Fuller particulars of the action will be found in Chapter IV. The clepsydra for driving appears to have been in the form of a drum with divisions as shown on pp. 12 and 13.

\section{Bartholomew News am.-} BARTHOLOMEW NEWSAM was one of the earliest English makers of portable clocks whose work survives. It is conjectured he was a Yorkshireman, but he must have attained some position in London before 1568 , for in that year he secured a thirty years' crown lease of premises in the Strand, near Somerset House, where he resided till his death. In the British Museum is a very fine example of his skill, which proves Newsam to have been a master of the craft. This is a striking clock, in a case of brass, gilded and engraved, about $2 \frac{1}{2} \mathrm{in}$. square and $4 \mathrm{in}$. high, exclusive of an ornamental domed and perforated top, which brings the total height to $6 \frac{1}{2}$ in. The centre of the dial as far as the hour ring is below the surface of the case, so that on removing the base the movement, together with the centre of the dial and hand, may be drawn out. The hours are engraved on a broad bevelled ring, which extends from the sunk part of the dial to beyond the front of the case. An exterior view of Newsam's clock is appended (Fig. 398). The 
movement is arranged in stories, there being three plates held in position by four corner posts. Above the top plate is a semicircular bell; between the upper and middle plates is the going train, and between the middle and lower plates the striking train, the locking-plate occupying a position below the lowest plate. The arbors are placed vertically, and the winding holes are at the bottom of the case. The wheels are of steel or iron, the fusees very long, and with but little curve in their contour; they are connected with the barrels by means of catgut. The plates, posts, and barrels are of brass, the barrel covers of iron held in by a number of tenons around the edge. The hand is driven from the great wheel of the going part by a contrate wheel. The escapement is, of course, the verge. The workmanship, unusually fine for the period, is remarkably free from subsequent interference. There is a very small hinged door on each side of the case, giving, when open, a view of the fusees to estimate the period for winding. No screws are used in the construction of the movement, which is inscribed "Bartilmewe Newsum." An equally well-made table clock by Newsam in a case similar to Fig. 100 forms part of the Pierpont Morgan collection. It is in a leather case for travelling with a small hinged cover which may be opened to disclose the dial. The bottom plate bears the signature "Bartholomew Newsam."

A large clock-watch very possibly by him is illustrated in Chapter III. In vol. lv. of Archeologia is illustrated a fine casket by Bartholomew Newsam.

In the "Calendar of State Papers" of the time of Queen Elizabeth is a record of a grant in 1572 to B. N. (who no doubt was Bartholomew Newsam) of the office of clockmaker to the Queen in reversion after the death or surrender of $\mathrm{N}$. U. (probably Nicholas Urseau). In the same Calendar is a letter dated 5th August 1583, from Bartilmew Newsham to Sir Francis Walsyngham. This letter probably refers to a renewal of Newsam's lease, and it desires Sir Francis to favour the writer's petition to Her Majesty for the augmenting a certain term of years, wherein he had moved Sir Philip Sidney to speak for him. He was clock-keeper to the Queen prior to 1582, and on 4th June 1583, under Privy Seal was paid 32s. 8d. for " mending of clocks during the past year." Under date 1590 is a grant to Bartholomew Newsham of the office of clockmaker to the Queen, in place of Nicholas Urseau, deceased. Newsam appears then to have combined the offices of clock-keeper and clockmaker, which had previously been kept distinct. 
His tenure of the double appointment was a brief one, for he died in 1593. By his will, dated in 1586, he bequeathed to his apprentice his "seconde clock;" to John Newsam, clockmaker of York, his " best vice save one, a beckhorne to stand upon borde, a great fore hammer, and to (two) hand hammers, a grete longe beckhorne in my backe shoppe; and all the rest of my tools I give unto Edward Newsom, my sonne, with condicion that he become a clockmaker as I am, yf not I will the foresaid tooles to be sold by my executors." He gave to a friend " a sonne dyall of copper gylte;" to another, " one cristall jewell with a watche in it, garnished with goulde ;" to another " one watch clocke, in a silken purse, and a sonne dyall to stande upon a post in his garden;" and to another, " a chamber clocke of fyve markes price."

John Newsam continued at York for some years. In 1593 he repaired the clock on Ousebridge in that city.

Buli.-Rainulph or Randulph Bull appears to have been an English horologist of some note. In the British Museum is a rather large oval watch by him, dated 1590. It has on a shield the arms of the owner and his name, "W. Rowley." Bull was also keeper of the Westminster great clock. In Devon's Issues of the Exchequer there is an entry under date 1617, 1st April: "By order, dated 29th March 1617. To Ranulph Bull, keeper of his Majesty's great clock, in his Majesty's palace at Westminster, the sum of $£ 5613 \mathrm{~s} .4 \mathrm{~d}$., in full satisfaction and discharge of and for divers sums by him disbursed for mending the said clock, in taking the same and other quarter clocks all in pieces, and repairing the same in the wheels, pulleys, hammers, weights, and in all other parts, and in new hanging, wiring, and cordings of the same clock, and other necesssary reparations thereunto belonging, the charge whereof, with his own workmanship and travail therein, doth amount to the sum aforesaid, appearing by a note of the particular demands, delivered upon his oath, taken before one of the Barons of his Majesty's Exchequer, without account or imprest to be made thereof. By writ dated 27th March 1617, $£ 56$ 13s. 4d."

In an account of the household expenses of Prince Henry, in 1610, "Emanuel" Bull, the " clocke-keeper," is mentioned.

At the South Kensington Museum are two watches inscribed " Edmund Bull in Fleet Street fecit ;" one is in an oval case of brass and silver, and the other in an octagonal case; both are earlyseventeenth-century productions; a watch, similarly inscribed, in a small oval pair of cases of silver, is in the Guildhall Museum, and 
another watch by the same maker is in the Fitzwilliam Museum, Cambridge.

Nouwen.-The watch shown in Fig. 399 is by Michael Nouwen, who was referred to on p. 51. It is from the Schloss collection, and dates from about 1590. The very handsome dial is of brass, as is also the case, finely pierced as shown. The movement is furnished with the stackfreed and a straight bar balance. There are no screws used in the construction of the watch. Inside of the case is a bell on which the hours are sounded.

Of perhaps slightly later date is a watch by him in the British Museum, which has an irregular octagonal-shaped case of crystal; the plates of the movement are enamelled. In the Ashmolean Museum at Oxford is an oval watch with a gilt metal case. The dial is engraved with a figure subject, and at each of the hour numerals a pin projects. The movement is signed "Michael Nouwen fecit, 1613."

Garret. - Among watches which Octavius Morgan exhibited to the Archæological Society in 1840 was an early-English one in the form of a Tudor rose. The dial he described as elegantly engraved and gilt, with an

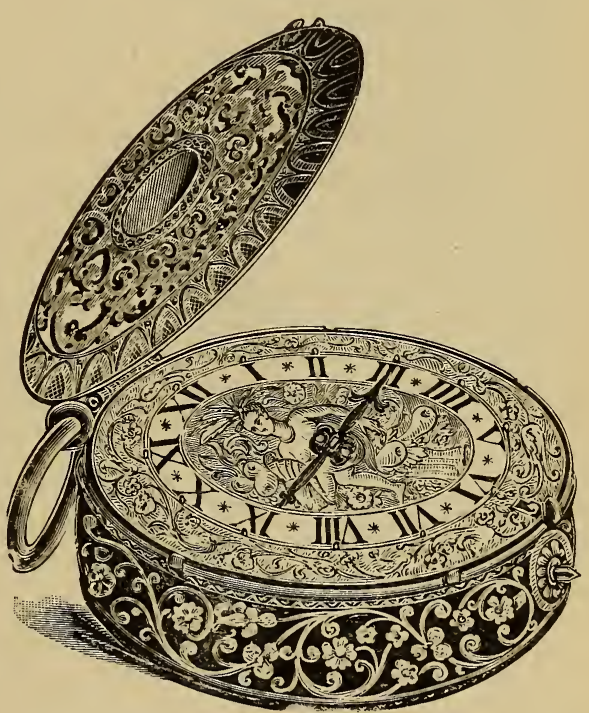

FIG. 399.-Watch by Michael Nouwen, about 1590 .

hour circle of silver. There was no ornament on the balance-cock and the movement was imperfect. The watch was made about 1600 by Ferdinando Garret. In the British Museum is an oval watch by the same maker in a case of metal gilt, of the same period. Another watch by him is mentioned in the London Gazette for March 29April 1, 1680, as follows: "A small eight square Watch, the edges Brass, and the Cover and Bottom silver, made by Ferdinando Garet."

Grinkin.-Fig. 400 is a view of an oval watch by Robert Grinkin, London, which dates from about 1605. The case is of silver. In the British Museum is a still smaller oval watch of the same period by him, with outer case of leather piqué. In the Pierpont 


\section{Old Clocks and Watches and their Makers}

Morgan collection is an oval watch of his make dating from about 1640. Grinkin was admitted to the freedom of the Clockmaker's Company in 1632 and served as master in 1648. He died in 1660.

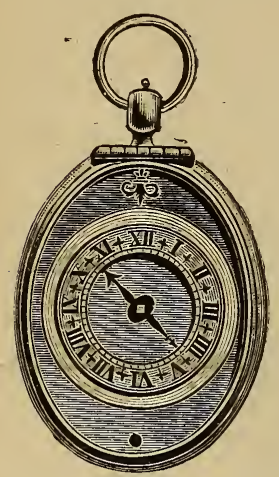

FIG. 400. - Watch by Robert Grinkin, to his Majesty's use, at the price of $£_{220}$, whereof London, about 1605 .

North.-As an example of oval astronomical watches of English make, such as were popular in the early part of the seventeenth century, may be taken one in the British Museum, inscribed "William North, Londini," and of which an exterior view is given in the subjoined engraving. It shows the hours on the lower and day of the month on the upper circular band. There are, in addition, four apertures in the dial. Through the largest of these, on the left, are shown the days of the week, with the corresponding allegorical figures: Apollo for Sunday, Diana for Monday, Mars for Tuesday, Mercury for Wednesday, Jupiter for Thursday, Venus for Friday, and Saturn for Saturday. Through the three openings on the right are seen the phases of the moon, the quarters of the moon, and its age in days. These three subjects are all engraved on one circular plate below. Symbols re-

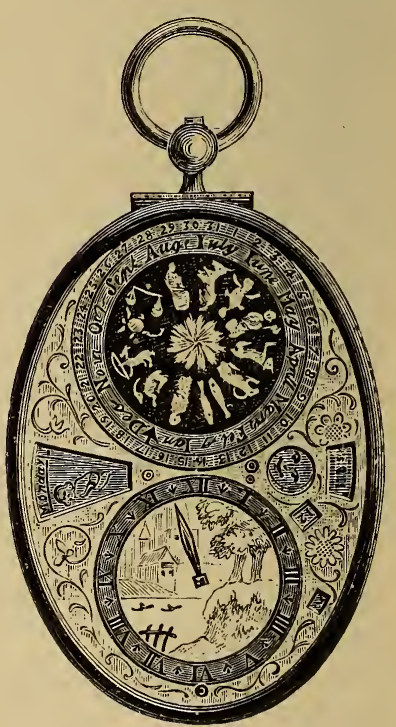

FIg. 401.-Watch by William North, London, about 1615. presenting six planets appear in rotation below the small square on the right, just outside and lower than the centre of the hour ring. 
It may with tolerable certainty be affirmed that the movement of this watch was made about 1615 , although the case is probably of a later date. William North was admitted as a brother of the Clockmakers' Company in 1639, and the fact of his being noted as a brother would indicate that he had then been established for some time, and was free of another Company.

Crayle.-In the South Kensington Museum is a particularly diminutive watch in a plain oval case, which measures outside but $\frac{1}{2}$ in. in length and $\frac{3}{8}$ in. across, by Richard Crayle, London, and said

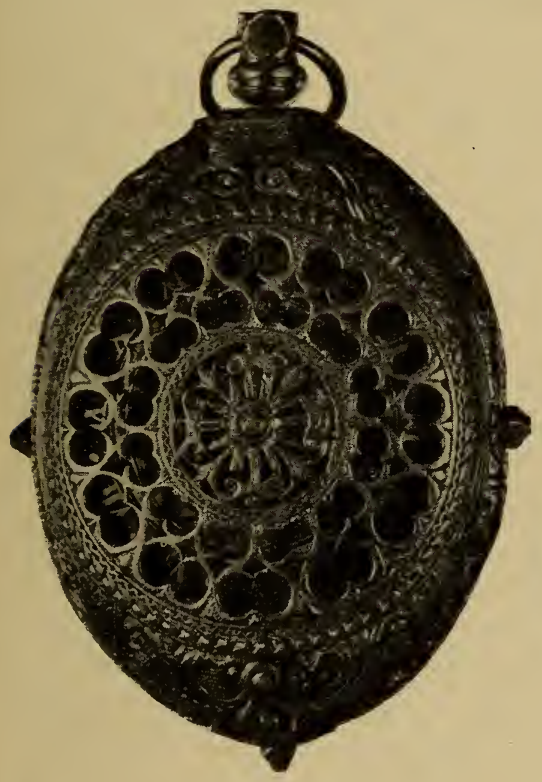

FIG. 402.

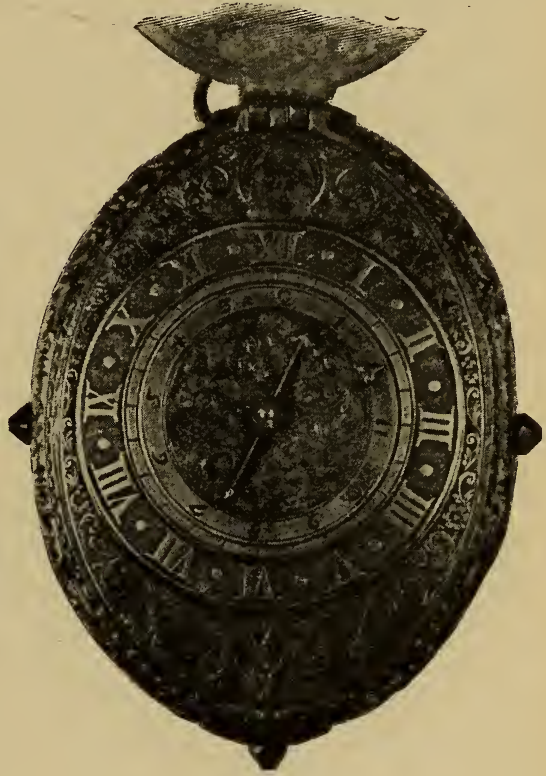

FIG. 403.

Two views of large Oval Alarum Watch signed " Richard Crayle, Londini, fecit."

to have belonged to Lord Hussey, who was beheaded in 1537 . I am not aware what evidence exists to warrant this statement, but 1537 is rather an early date for a watch of this character to be in existence, and I should be inclined to think it was the production of the Richard Crayle who was a member of the Blacksmiths' Company before the existence of the Clockmakers' Company, and who signed the petition for its incorporation.

Two views of a large oval alarm watch signed "Richard Crayle, Londini, fecit," and not later than 1610, are given in Figs. 402 and 403. The first shows the front cover closed, and the second exposes 


\section{Old Clocks and Watches and their Makers}

the whole of the dial. On the back plate are two small rotating dials of silver, one engraved with the days of the week, with a mythological figure corresponding to each, while the other, divided into months contains also the signs of the zodiac.

In the British Museum is a round watch movement inscribed "William Crayle, in Fleete Street, London," a production of about 1620. William Crayle, who in 1676 carried on business in Fleet Street, and afterwards at the Black Boy in the Strand, near the Savoy, was probably a descendant of Richard.

Alcock.- In the Pierpont Morgan collection is a very fine circular

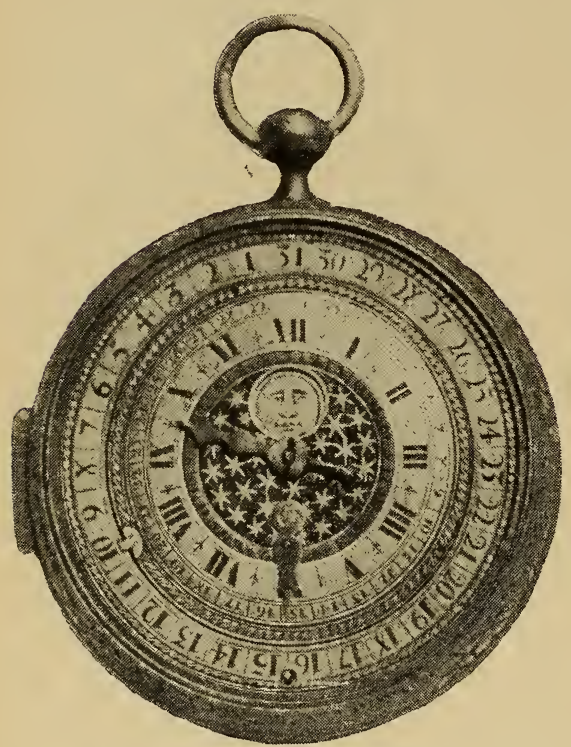

Fig. 404.-Fine Circular Calendar Watch by Thomas Alcock, about 1635. calendar watch by Thomas Alcock, as shown in Fig. 404. The dial is really superb; it indicates the age and phases of the moon by means of the central rotating disc, and the day of the month by a rotating ring outside the hour circle. The movement is very well made and in good order ; it dates from about 1635 . The case is of brass, curiously engraved, and though old, of later date than the movement. Thomas Alcock was one of the petitioners for the incorporation of the Clockmakers' Company in 1630. In Kingdom's Intelligencer, 4th February 1661, was advertised as lost " a round high watch of a reasonable size showing the day of the month, age of the moon, and tides; upon the upper plate 'Thomas Alcock fecit'."

David Ramsay.-One of the earliest British watchmakers of particular renown was David Ramsay.

Among the Salting collection at South Kensington Museum is a very early watch by him in a small irregular octagonal case of gold and silver. It has hinged covers over the front and the back, and is decorated with engravings of the Annunciation and the Nativity.

In the British Museum is an oval watch of his make, with a gold 
case in the French style. The period assigned to this watch is 1600 to 1610. It is inscribed "David Ramsay, Scotus, me fecit."

There is an entry in the account of money expended by Sir David Murray, Kt., keeper of the privy purse to Henry, Prince of-Wales, who died in 1612. "Watches three bought of Mr. Ramsay the Clockmaker lxj li " ( $£ 61)$. In the same account, among the list of " Guyftes and Rewards," is the item, "Mr. Ramsay the clockmaker xjs " (11s.).

An oval calendar watch, showing the age of the moon, which is supposed to have belonged to James I., is described in the Archceological Journal, vol. vi., p. 415. It had a plain outer case of silver, the inner one being beautifully engraved; on one side was represented Christ healing a cripple, also the motto used by James, "Beati pacifici," and on the other side the Good Samaritan with the inscription, "S. Lucas c. 10." Inside the cover was a wellexecuted engraving of James, with his style and titles. Under a small shield which concealed the hole for winding was the name of the engraver, "Gerhart de Heck." Around the edge of the case were the Rose, Harp, and Thistle, and the initials " J. R." On the plate or the watch was engraved, as before, "David Ramsay, Scotus, me fecit," and these inscriptions, together with the fact that he had a grant of denisation in 1619, prove that he was a native of Scotland.

Mr. J. Sancroft Holmes had another watch by Ramsay, which was found seventy or eighty years ago behind the tapestry which then covered the wall of the dining-room of Gawdy Hall. With the watch were two apostle spoons and papers relating to the troublous times of Cromwell. The case of the watch is of silver and shaped like a star or heraldic mullet of six points.

The engravings on page $\mathbf{2 5 8}$ show a splendid clock-watch with alarm by him, from the Evan Roberts collection, dating from about 1615. It has the three-wheel train usual in early watches, and Mr. Crewe, in describing the movement, remarks that the fusee is cut for twelve turns, and the end of the great wheel arbor, which goes through the pillar plate, is fashioned into six pegs or leaves, identical with a lantern pinion in its action. These leaves work in a wheel pivoted into the centre of the pillar plate, having sixty teeth, and carrying the single hand of the watch. Thus ten turns of the fusee are equivalent to an entire circuit of the hand on the dial and so the watch would require to be wound twice a day. The ratchet wheel, which sets up the mainspring, is on the top plate, and the stop work is identical in principle with that in modern fusee watches. The stop for the alarm part is effected by a wheel and 


\section{$25^{8}$ Old Clocks and Watches and their Makers}

pinion, the wheel having a portion the size of two teeth left uncut, and which serves as a block to the pinion after it has been wound three turns. The wheels and pinions have a wonderfully smooth action, though they appear to be cut by hand rather roughly. The count or locking wheel of the striking portion is made of silver, and the notches have been certainly made with a file. The alarm part has a verge escapement with counter and crown wheels. Attached to its verge is a V-shaped piece of brass with an arm, and this pressed by a spring drops into a notch made in the edge of a brass disc on the hand or hour wheel, and so liberates the verge and lets off the alarm. Between this disc and the hour wheel, and working con-

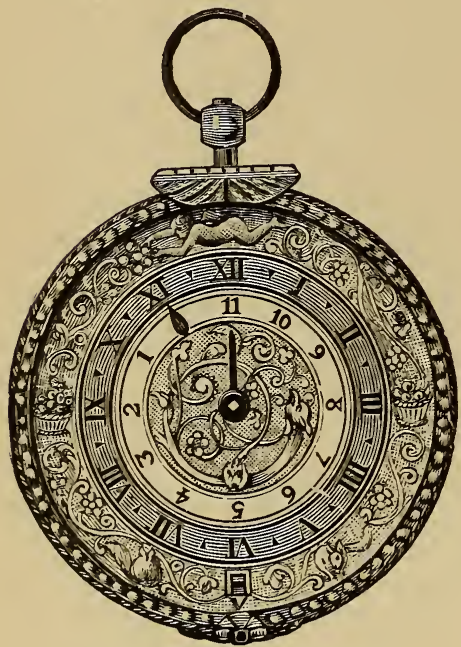

FIg. 405.-Front View.

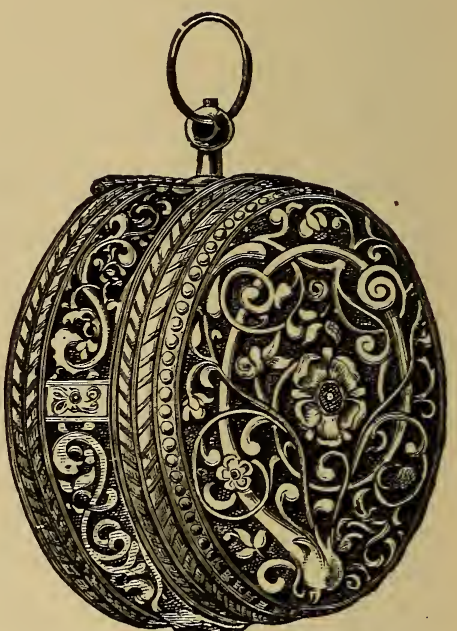

FIG. 406.-View of Edge and Back.

Clock-Watch and Alarm by David Ramsay.

centrically with them, is a star wheel having twelve teeth, which, by lifting up a brass arm connected with the count wheel, causes it to strike. The potence is a rather slender piece of square brass, and is riveted to the top plate, and the banking is made by steps cut in it. These riveted potences are found in nearly all watches made before 1700. The balance-cock is a slender piece of work, and is pierced throughout, and the neck very narrow, so different from specimens of Tompion and other later masters. The case is very elegant in design, is pierced in the back and band, the bezel being engraved, and in every respect it will compare favourably with any work of the kind. Curiously enough, the band is silver, and bezel and 
back of bronze, and the whole case gilt. On the margin of the top plate, in tiny characters; as if almost to escape observation, is engraved "David Ramsay inv ${ }^{\mathrm{t}}$ Fecit," the et having been obliterated.

In the Pierpont Morgan collection is an oval calendar watch by Ramsay in a Limoges enamel case. It dates from about 1610 . Besides the hour of the day are given the days of the week in order thus-Sondai, Mondai, Tvesdai, Wensdai, Thordai, Fridai, Saturdai, with a symbol for each day. Days of the month and phases of the moon are also shown. The cock over the balance is of silver and pinned on. A balance-spring and the letters A. and R., for regulation, were doubtless added at a later date in France.

R. B. P., in the "Dictionary of National Biography," says David Ramsay belonged to the Ramsays of Dalhousie, and quotes Ramsay's son William to the effect that "when James I. succeeded to the crown of England he sent into France for my father, who was there, and made him page of the bedchamber and keeper of his Majesty's clocks and watches." In 1613, James gave David Ramsay a pension of $£^{200}$ per annum, and in the same year a further pension of $f_{5} 50$ per annum. In the grant he is styled " Clockmaker Extraordinary." In 1616 a warrant was signed to pay him $£ 23410$ s. for the purchase and repair of clocks and watches for the king. On 26th November 1618 he was appointed to the office of "Chief Clockmaker" to his Majesty, with fees and allowances for workmanship. On 30th September 1622 he received $£ 23215$ s. for repairing clocks at Theobalds, Oatlands, and Westminster, and for making a chime of bells adjoining the clock at Theobalds.

In 1625 James I., his patron, died, but Ramsay appears to have retained his appointments, for on 25th January 1626 a warrant to pay to David Ramsay $£ 150$ for coins to be given by the king, Charles I., on the day of his coronation, was signed. Again, " 17th March 1627, is a warrant to David Ramsay, Page of the Bedchamber and Clockmaker, $£ 441$. 3s. 4 d. for work done for his late Majesty, and $£ 358$. 16. 8d. in lieu of diet and bouche of Court." In 1628, 13th July, a warrant was signed to pay him $£ 415$ for clocks and other necessaries delivered for the king's service.

Among the State Papers, Dom., 1653, are two receipts taken from the Jewel House at Whitehall soon after the death of Charles I. The first is as follows: " 18 die Feb. 1649. Recd. one clocke with divers mocons, two globes, one case for a clocke, and a glassee, one Bullet Clocke, one clocke with five bells, and one other clocke, all which were lying at Whitehall late in the charge of David Ramsay." 
The second is merely a subsidiary receipt of the same date for "one other clocke in a Bow received from Ramsay."

Sir Walter Scott introduces Ramsay in "The Fortunes of Nigel," as the keeper of a shop a few yards to the eastward of Temple Bar, and in a note to that novel he is described as "Constructor of Horologes to His most Sacred Majesty James I."

That Ramsay was the most celebrated watchmaker of the day may be inferred from the fact that, when the clockmakers obtained their charter of incorporation, he was therein appointed to the office of master. He does not appear to have taken a very active part in the management of the company. During his absence in the country, Mr. Henry Archer was appointed deputy master. William Ramsay dedicated "Vox Stellarum " to his father in 1652, and in a postscript dated 1653 remarks, " from my study in my father's house in Holborn, within two doors of the ' Wounded Hart,' near the King's Gate," and there David Ramsay probably died. The exact date of his death is uncertain, but it occurred about 1654 , and though his age is not stated, he was then certainly very much past the meridian.

$\mathrm{He}$ is known to have becn an inventor or schemer from the beginning of the century, and between 1618 and 1638 he took out no less than eight patents, none of which, however, seemed to be connected with horology; they related to raising water, draining mines, making saltpetre, separating gold and silver from the base metals, smelting iron, constructing furnaces of various kinds, dyeing fabrics, \&c. He was a friend of James Lilley the astrologer, who, in his autobiography, relates that he accompanied Ramsay to Westminster at night to make some experiments with a view to discover treasure by means of the divining rod.

William Partridge.-In the "Calendar of State Papers" (Domestic Series), under date May 1660, there appears the following petition to the king from Captain William Partridge, setting out " that hee was sworne servant to $\mathrm{yo}^{\mathrm{r}}$ Royall father of blessed memory, and to $\mathrm{yo}^{\mathrm{r}} \mathrm{Ma}^{\text {tie }}$ in the yeare 1645 , to attend ye in the qualitie of a Clockmaker, and did officiate in that place, all the time of his $\mathrm{Ma}^{\text {tie }}$ being at Oxford, And did likewise serve his $\mathrm{Ma}^{\text {tie }}$ a yeare and a halfe in his life Guard of foote ; And afterwards did raise a Company att his owne charge; And hath bene a great sufferer by Plundering, Imprisonm ${ }^{\text {ts }}$, and expulcõns. Hee most humbly prayeth that $\mathrm{yo}^{\mathrm{r}} \mathrm{Ma}^{\text {tie }}$ will vouchsafe unto him the like grace and favo $^{r}$ as to others of yo $^{r}$ servants is extended, That hee may bee restored unto his said place of Clockmaker to yor $\mathrm{Ma}^{\text {tie }} \mathrm{w}^{\text {ith }}$ 
all such priviledges and Impunities as belong unto it according to his warrant."

On the same page there is also a petition from Sarah, his wife, begging that her husband's place may not be filled up until he has been heard for himself ; that he was bred under Mr. Este (? East), spent much time in improving himself in his trade in France and Flanders, and only discontinued it when in arms or in prison for His Majesty. At the foot of the petition is the note, "To succeede Da. Ramsay." But nothing further is known of Partridge, and he may be passed over. The king's clockmaker, after Ramsay, really seems to have been Edward East, of whom more will be said hereafter.

The Clockmakers' Company.--_-In 1627 a proposal to grant letters patent authorising French clockmakers to carry on their trade within the city appears to have occasioned an agitation among the London craftsmen in favour of incorporation as a trade guild. Prior to that date, individual freemen had been associated with one or other of the existing companies, that of the Blacksmiths having been most favoured. In 1630 a committee of clockmakers was formed, funds were raised to defray expenses, and petitions were addressed to the king, with the result that a charter was obtained from Charles I. on the 22nd of August 1631.

In this document, "The Master, Wardens, and Fellowship of the Arts or Mystery of Clockmaking of the City of London" had very comprehensive powers for ruling and protecting the rights of the craft. They were entitled to make by-laws for the government of all persons using the trade in London, or within ten miles thereof, and for the regulation of the manner in which the trade should be carried on throughout the realm. And in order to prevent the public from being injured by persons " making, buying, selling, transporting, and importing any bad, deceitful, or insufficient clocks, watches, larums, sun-dials, boxes, or cases for the said trade," powers were given to the company " to enter with a constable or other officer any ships, vessels, warehouses, shops, or other places where they should suspect such bad and deceitful works to be made or kept, for the purpose of searching for them;" and, if entrance should be denied, they might effect it by force. Any such works as were faulty or deceitfully wrought they had power to seize and destroy, or cause them to be amended. Every member of the fellowship paid fourpence a quarter to meet the necessary expense of these searches. In 1708 this quarterage produced over $£ 28$.

By the charter, David Ramsay was appointed to be the first I8 
master ; Henry Archer, John Willowe, and Sampson Shelton were the first wardens ; and James Vantrollier (or Vautrollier), John Smith, Francis Foreman, John Harris, Richard Morgan, Samuel Linnaker, John Charlton, John Midnall, Simon Bartram, and Edward East, assistants of the said fellowship of the said art or mystery.

The charter also declared that future masters and wardens must be, or have been, professed clockmakers, an important regulation, which certainly appears to have been contravened in late years. The right of search was exercised regularly till 1735, when it was abandoned.

On the incorporation of the company, stringent by-laws were made regarding apprentices. No person was to take an apprentice without leave of the master, and then to have sut one, until he shall be called to bear the office of master, warden, or assistant, and after that, not to exceed the number of two apprentices at any time whatsoever. But when his first apprentice had served five years, any member of the fellowship might take another, but not sooner, under a penalty of $£ 10$. And in the early history of the company several of its members were brought to an account and fined for disobeying this regulation. Among them were several eminent members of the craft, including Thomas Loomes and Ahasuerus Fromanteel.

Then it was ordained that after an apprentice had served his time he should serve his master or some other member of the fellowship for two years as journeyman, and produce his " masterpiece " of work before he was allowed to be a workmaster. This period of probation might, if the company saw fit, be commuted to one year on payment of a fine.

Those craftsmen who had joined the Blacksmiths' and other Companies prior to the incorporation of the Clockmakers' were from time to time admitted as " brothers " of the Clockmakers' Company.

As provided by the charter, the " court" or directorate consists of the master, three wardens, and ten or more assistants. The assistants are chosen for life from among the freemen, and the usual, but not invariable, course is that the assistants fill the higher offices in succession according to seniority; each one being elected first as junior warden, the next year as renter, the next year as senior warden, and the following year as master. After his retirement as master, he resumes his seat as an ordinary member of the court.

Occasionally members were transferred from and to other companies. In $1636 \mathrm{Mr}$. Richard Masters was transferred from the Clothiers' at a cost to the Clockmakers' Company of $£ 10$. 9s. $6 \mathrm{~d}$. A lesser sum sufficed for the transference, in the same year, of Mr. Dawson and Mr. Durant 
from the Imbroderers'. In $1724 \mathrm{Mr}$. John Shirley gave a bond to pay the Clockmakers' Company $£ 20$ for being transferred to the Vintners'. On Mr. James Masters applying in 1811 to be transferred to the Goldsmiths', a little haggling appears to have ensued. The Clockmakers' Company at first demanded $£ 50$ for consenting ; Masters offered $£ 30$ in 1812, and this amount was accepted. George Russell, in 1844, had to pay the Clockmakers' Company $£ 30$ for permission to be transferred to the Salters', and an additional $£ 5$ for a special meeting of the court to attend the Court of Aldermen with the Salters' Company.

In 1656 Ahasuerus Fromanteel and thirty-one other members complained to the court that, is spite of members having to pay $\mathrm{xii}^{\mathrm{d}}$ a quarter, the meetings were held in taverns. They also objected to the presence of Frenchmen among the ruling body, and recounted other grievances. A counter-petition traversed the allegations, and asserted the confidence of the signatories in the management of the company.

In 1671 the company obtained the right to bear arms, and in that year letters patent were granted for this distinction. They recounted " that whereof at present Nicholas Coxeter is Master, Samuel Horne and Jeffery Bailey areWardens, as also Edward East, the only persons now living of those mentioned in the said Letters Patents of Incorporation, John Nicasius, John Pennock, Edmond Gilpin, Jeremie Gregory, Thomas Taylor, Thomas Clayton, John

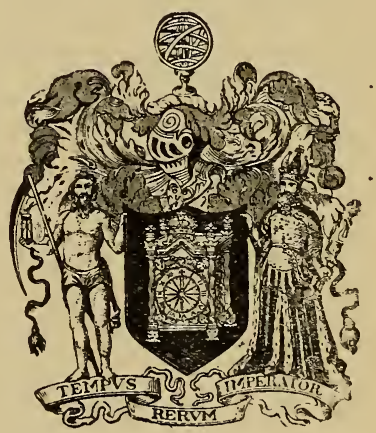

FIG. 407.-Arms of the Clockmakers' Company. Freeman, Evan Jones, Isaac Daniell, John Browne, Nicholas Payne, Richard Ames, and Benjamin Bell, are Assistants, and to the rest of the Fellowship and Company thereof, and to their successors for ever: the Armes, Crest, Supporters and Motto hereafter mentioned, viz $^{\mathrm{t}}$ Sable, A Clock $\mathrm{y}^{\mathrm{e}} 4$ Pillars therefore erected on four lyons, and on each capitall a globe with a Crosse, and in the middest an Imperial Crowne all Or, and for Their Crest upon an helmet Proper Mantled Gules Doubled Argent and Wreath of their Colours a Spheare Or, The Armes Supported by the Figures of a Naked Old man holding a Scithe and an Hour Glasse representing Time, and an Emporour in Roabes Crowned holding a Scepter, Their Motto--

TEMPVS RERVM IMPERATOR.

As in the margent they are all more lively Depicted." 


\section{Old Clock and Watches and their Makers}

In $1677 \mathrm{Mr}$. George Deane, engraver, a member of the company, " having by the hands of Henry Jones presented to this court the company's coat of arms engraved on a copper-plate fit to be used for tickets and divers other occasions of the company which was very well liked, this court did kindly accept it, and returned him thanks."

During the latter part of the seventeenth century the suitability of watchmaking as a profession for women was recognised, and in $\mathbf{1 7 1 5}$ the company sanctioned the taking of female apprentices. The names of several will be found in the list at the end of this book, where also is recorded the admission of a few female members of the company. The employment of female labour in watch work does not, however, seem to have made much progress in England till watch factories were established in quite recent years.

In 1781 it was decided to elect leading members of the trade as honorary freemen. This course, politic as it probably was, seems to indicate that at this period the prestige of the company in the horological world was insufficient to induce distinguished craftsmen to take up the freedom in the ordinary way.

The company has never risen to the importance and comfort of possessing a hall of its own for meetings and other business. For brief periods during its history it had the use of a hall belonging to a more favoured guild, but most of its meetings were held in taverns, more than forty of these establishments having been so favoured. Its last meeting before the Great Fire of I.ondon was held on 20th August, at the Castle Tavern in Fleet Street; and the first meeting after, on 8th October 1666, at the Crown Tavern, in Smithfield. Later still, the Devil Tavern, near Temple Bar, was patronișed.

Only a certain number of freemen from certain of the companies is permitted to take up the livery or freedom of the City, the whole matter being in the discretion of the Court of Aldermen. The claims of the Clockmakers' Company were not recognised in this respect till 1766, when it was allowed to select sixty of its members for the privilege ; this number was upon petition increased to 120 in 1786, a still further increase to 200 was sanctioned in 1810 , and in 1826 the present limit of 250 was reached.

No. 2 of the bye-laws provided " that every person of the said Fellowship chosen in the said Livery shall accept and take upon him to be of the said Livery, and shall within fourteen days after notice of such election take such oaths as by these ordinances shall be appointed for him."

The honour of election to the livery does not seem to have been 
always appreciated, for in 1813 "William Mansell, of Rosoman St., Clerkenwell, Watch casemaker, who was summoned to take the Livery on the 19th August 1812, again on 7th September 1812, and repeated on the 11th October last, was peremptorily summoned to be at this court, and being now in attendance for the first time; refused to take the Clothing, and the penalty of Fifteen Pounds being awarded against him for such refusal, he paid the sum in Court, and his Election to the Livery was thereupon discharged."

"William Welborne, of Leather Lane, Holborn, has been summoned to take the Livery in November 1811, and also in January, February, and July 1812, but having failed so to do, was again summoned for that purpose to the last Quarter Court, when he attended and requested until this day, promising either to take the clothing or pay the penalty for refusal. He being now present and declining to take the same, the penalty of $£ 15$ was ordered to be enforced, which being paid in Court, his election to the Livery was likewise thereupon discharged."

The fine on taking up the livery was then fixed at $£ 21$.

In 1820 it was resolved to allow the quarterly payments or quarterage from members in support of the company to be commuted by an immediate payment ; the amount to be paid being dependent on the age of the member availing himself of the arrangement. The fee to be paid on taking up the freedom of the company by purchase was in 1876 increased to $£ 20$.

As already stated, the company does not possess a hall of its own. Its business is transacted at the Guildhall, where, by permission of the Corporation, its library is kept and its remarkably fine museum of timekeepers displayed for public inspection.

Edward East.--Edward East, watchmaker to Charles I., was a true horologist and a worthy successor to David Ramsay. $\mathrm{He}$ at one time resicled in Pall Mall, near the tennis court, and attended the king when tennis and other games were being played in the Mall, his Majesty often providing one of East's watches as a prize. Edward East seems to have removed to Fleet

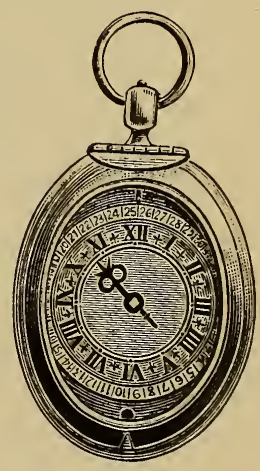

FIG. 408.--Watch by Edward East, about 1620 . Street, for it is related that at a later period the king's attendant, Mr. Herbert, failing in the punctual discharge of his duties in the morning, his Majesty provided him with a gold alarm watch, which 
266 Old Clocks and Watches and their Makers

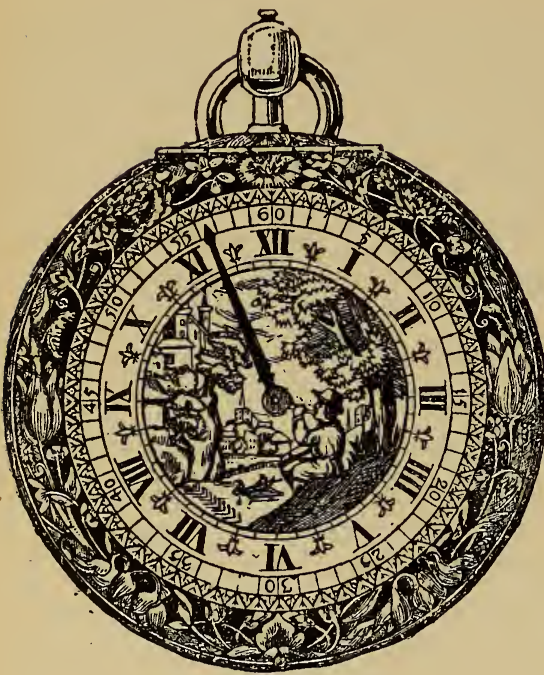

FIG. 409.

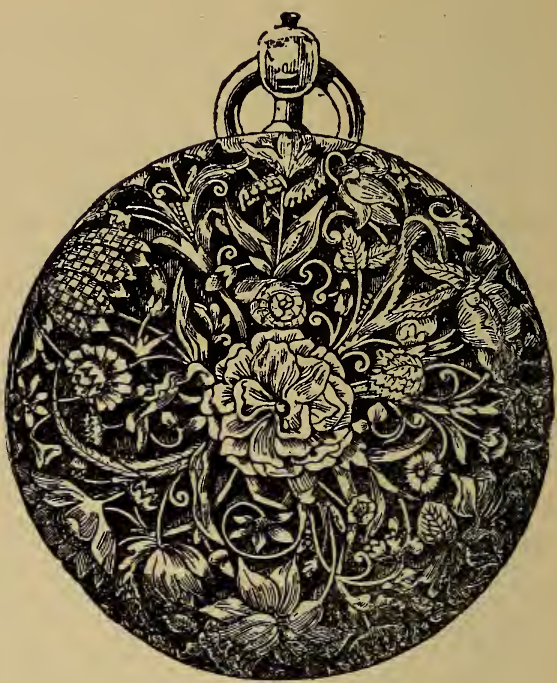

FIG. 410.

Two views of a very large Silver Alarm Watch, by Edward East.

was fetched from the king's watchmaker, Mr. East, in Fleet Street. He was in Fleet Street in 1635, for a correspondent of Notes and Queries had in 1900 a MS. Return of Strangers within the ward of Farringdon Without wherein East is referred to as of Fleet Street, in the parish of St. Dunstan's in the West, and as the employer of one Elias Dupree, a Dutchm a n. L a d y Fanshawe, in her "Memoirs," stated that when she came from France in the autumn of 1646 she lodged in
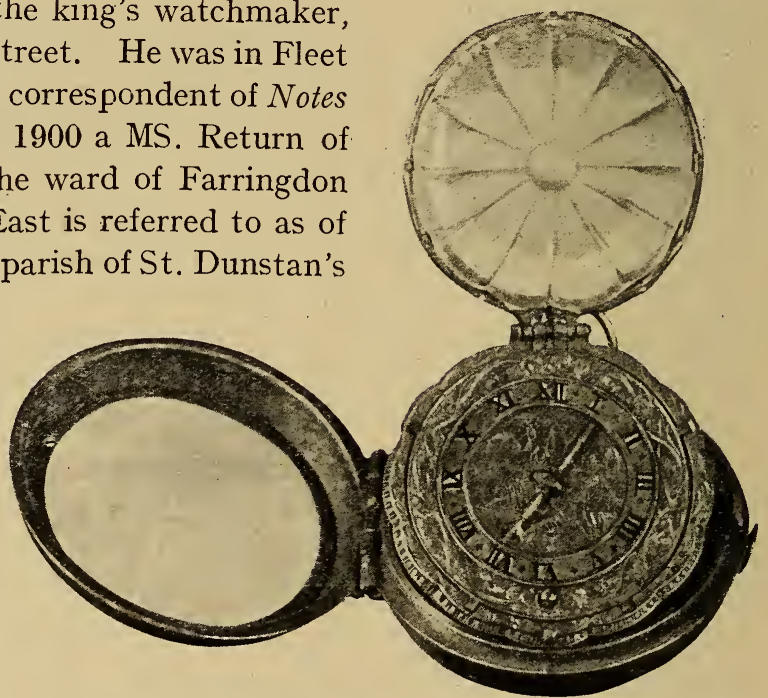

FIG. 411.-Watch with Outer case, by Fdward East.

Fleet Street at Mr. East's the watchmaker. The locality of a presumably still later residence is indicated by a reference to " Mr. East at the Sun, outside Temple Bar," in the London Gazette, January 22-26, 1690. 
A very large silver alarm clock-watch by Edward East, which was kept at the bedside of Charles I., was presented by the king on his way to execution at Whitehall, on 30th January 1649 , to his faithful and attached servant, Mr., afterwards Sir, Thomas Herbert. It was illustrated in "Sussex Archæological Collections," 1850, and in the Archeological Journal, vol. vii., from which Figs. 409 and 410, twothirds the size of the watch, are reproduced. I presume its history is well authenticated. The owner of it, Mr. William Townley Mitford, was quoted as saying, "It came into possession of my family by intermarriage with the Herberts about a century ago, and since that time has remained with us," and the Society of Antiquaries seemed

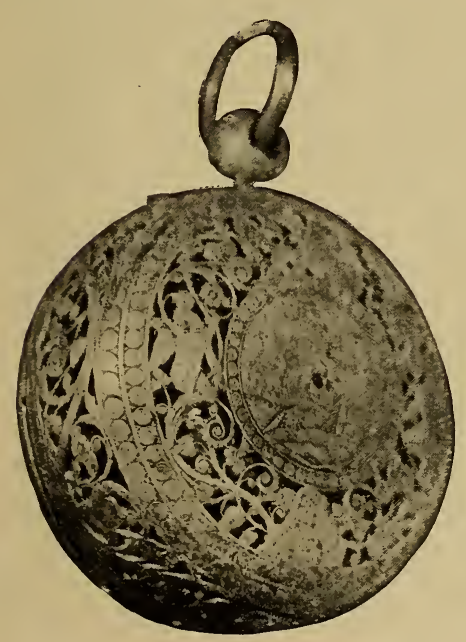

FIG. 413.-Finely pierced and engraved Case.

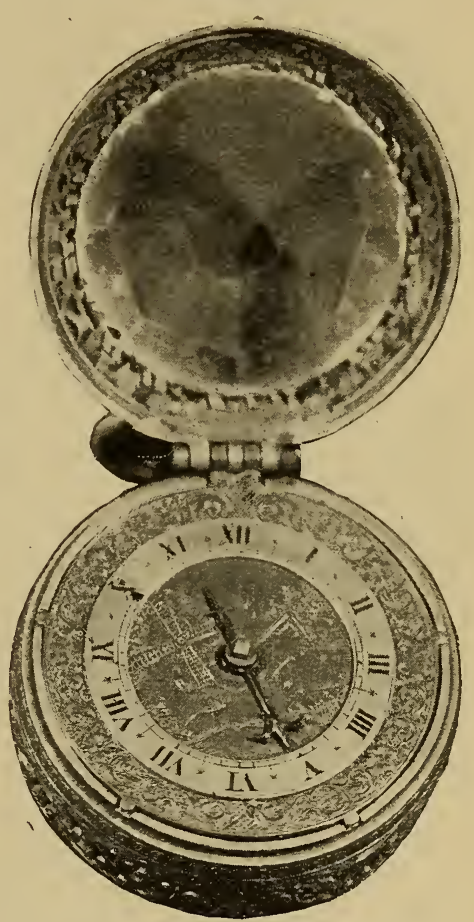

FIG. 412.-Clock-watch, by Edward East.

to be quite satisfied with their examination. Still, from the engravings, it is rather a perplexing watch. The dial and pierced back are of Charles I. period and, though a minute hand at that date would be very unusual, it would not be an impossible adjunct; presumably there was also an hour hand, but I can see no alarm disc or indicator ; the centre of the dial may, of course, have been turned to set the alarm, but there is no sign of its having been so utilised. Amongst the collection of autographs and manuscripts in the possession of Mr. Alfred Morrison, of Fonthill 
House, Wilts., is a warrant, dated 23rd June 1649, from the Committee of Public Revenue to Thomas Fauconbridge, Esq., Receiver-General

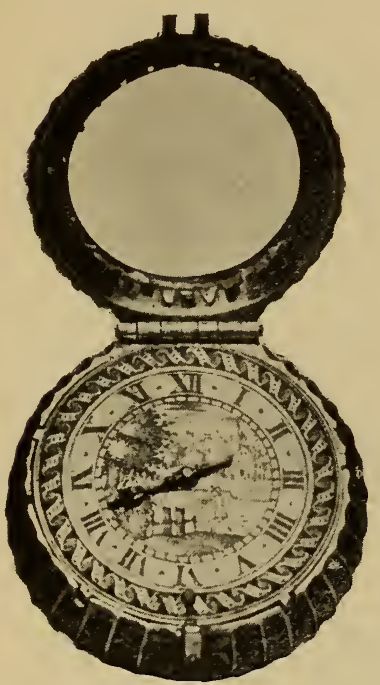

FIG. 414.-Watch by Edward East.

about the same period $i$; the small oval watch by him shown in Fig. 408. Another example of his work is the pretty little watch of slightly later date having an outer case and with a faceted crystal over the dial which is represented in Fig. 411. Two views of a clockwatch by East in a finely pierced and engraved case and also with a crystal covering for the dial are given in Figs. 412 and 413. These three watches are from the Schloss collection.

In the Pierpont Morgan collection is the little watch by East which is represented in Fig. 414. The dial of silver has a view authorising him to pay " vnto Mr. Edward East, Watchmaker, the so'me of fortie pounds for a Watch and a Larum of gould by him made for the late King Charles by directions of the Earle of Pembrooke, by order of the Committee, and deliuered for the late King's use the xviith of January last." In the Fellows collection at the British Museum is a splendid octangular crystal-cased watch, a recumbent female figure holding an hour-glass being engraved on the dial; 1620 is mentioned as the probable date of this specimen of East's work. Of

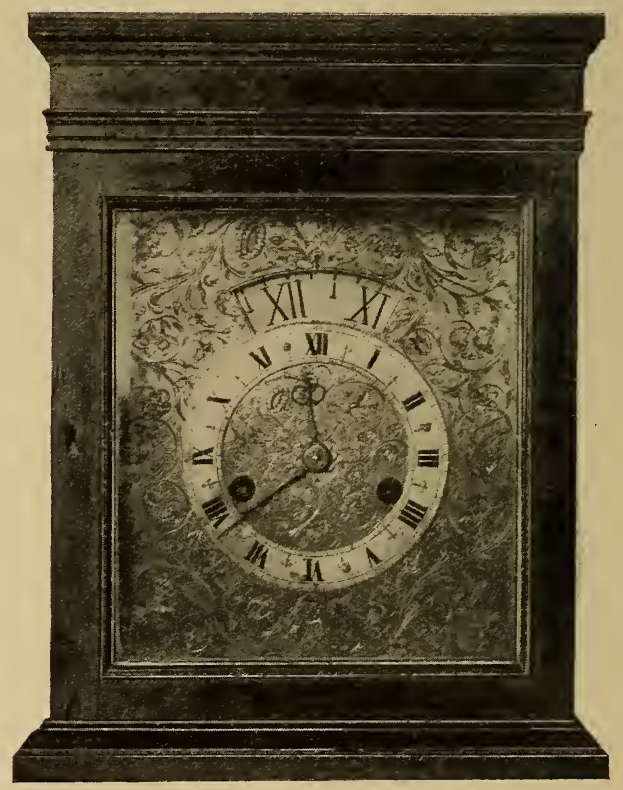

FIG. 415.-Night Clock. 
engraved on it, and the case, of the same metal, is fluted ; the channels which broaden radially from the centre of the back extend over the edge and are finely engraveci.

Wood refers to another watch by him with a silver case in the form of a cross, the dial being engraved with the Crucifixion and angels. In the Ashmolean Museum at Oxford is a watch by East with gold case in the form of a melon, studded all over with turquoises, the pendant being enamelled blue to match. Two other undoubted

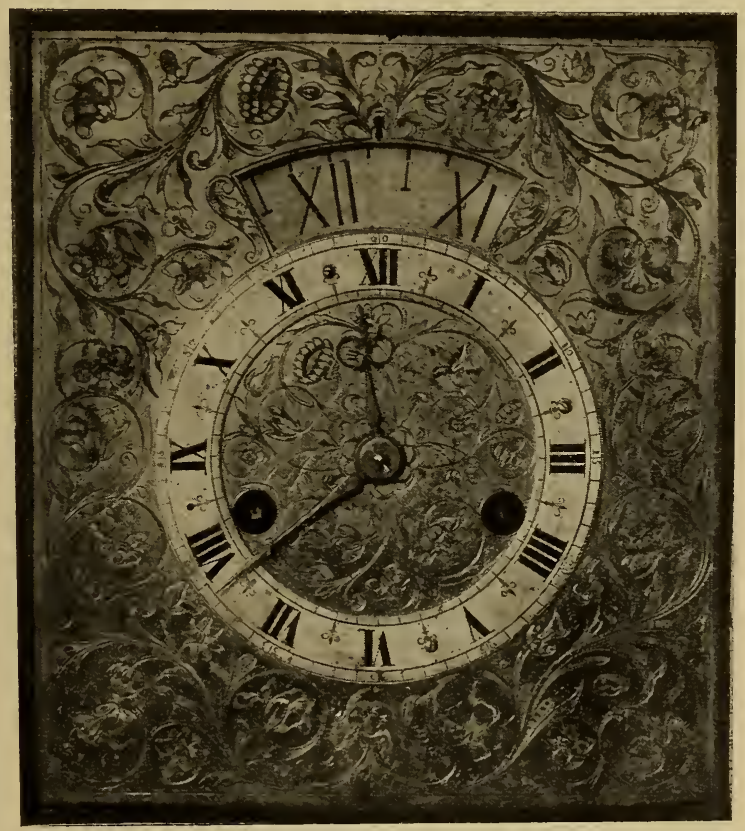

FIG. 416.-Dial of Night Clock.

specimens of this master's work are in the Guildhall Museum. One, a watch movement, inscribed, "Eduardus East, Londini," was thus described by E. J. Thompson: "The fusee of ten turns is cut for gut. There are great second and contrate wheels and a left-handed cut balance-wheel, the verge being of course left-handed. The end of the verge is driven into the balance which has one straight bar or arm. The cock is secured on a stud by a pin. There is no provision for a balance-spring, and the regulating must have depended upon the setting up or down of the mainspring by the endless screw. It had 
one hand only. The fusee is hollow, having the cap and winding square solid; it is fitted on to an arbor riveted on the great wheel. The great wheel has fifty-five, the second forty-five, the contrate forty, and the balance-wheel fifteen teeth ; the second, contrate, and balance pinions being all of five leaves."

The second example is a watch in a silver oval case with hunting cover, having a crystal centre, which E. J. Thompson described as finely worked in to suit its shape. The dial is of silver, and is traversed by an hour hand only. The movement is inscribed, as in the first instance, "Eduardus East, Londini." There is a twelve-turn fusee cut for catgut. The mainspring is white and no doubt original.

In the British Museum is a watch by East with a tortoise-shell case, dating from about 1640. At the South Kensington Museum are two or three watches by him; one, a clock-watch in a pierced and engraved case of silver, has on the back dates of Church Festivals and Law Terms.

In Fig. 415 is shown a night clock 17 in. high by East, belonging to Mr. T. W. Bourne. The case is of ebony on oak, and the top lifts off to allow the insertion of a lamp. Showing through a curved slit in the upper part of the dial is a disc with perforated hour numerals, so that the time can be seen at night. The light would also shine through a keyhole-shaped aperture above which serves as a pointer. Fig. 416 shows the dial to an enlarged scale. This clock answers to the description of one belonging to Catherine of Braganza, Queen of Charles II., which Pepys refers to under date 24th June 1664 as follows: "After dinner to White Hall; and there met with Mr. Pierce, and he showed me the Queen's bed-chamber and her closett, where she had nothing but some pretty pious pictures, and books of devotion ; and her holy water at her head as she sleeps, with her clock by her bedside, wherein a lamp burns that tells her the time of the night at any time."

Fig. 417 in the collection of Mr. Hansard Watt is a large-sized lantern or birdcage clock, with two hands, the minute hand being original. The centre of the dial and subsidiary alarm dial are finely engraved with tulips. The frets are similarly engraved, and the one above the dial bears the maker's name "Eduardus East Londini fecit." The anchor pendulum bob in the centre of the movement oscillates between curious wings, glazed in front, and ornamented with engraved frets. The height to the top of the spire is $15 \frac{1}{2} \mathrm{in}$. ; the width from wing to wing, $12 \frac{1}{2}$ in.

Among the Wetherfield collection are several long-case and 
bracket clocks by East. Illustrations of some of these will be given in Chapter VII.

The beautiful clock shown in Fig. 418, from the collection of Mr. Hansard Watt is, I believe, unique. Although East is known to have made night clocks of the bracket variety, this is, so far as I have been able to discover, the only one in a long case.

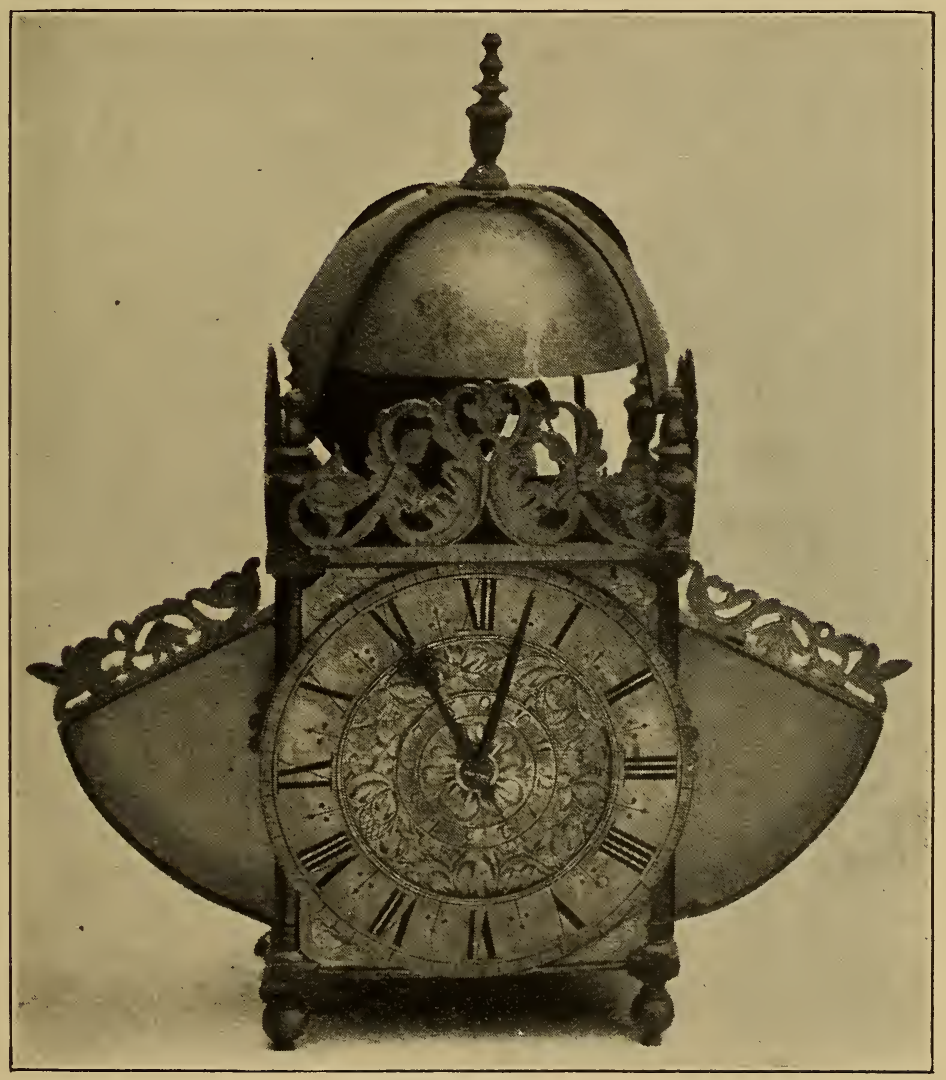

FIG. 417.-Large-sized Lantern Clock, by Edward East.

Its motion work is most ingenious and interesting and on a different principle to that of the bracket clocks.

The case is of oak veneered with walnut oysterpieces and inlaid with coloured marquetry in panels of ebony. The dial (Fig. 419) which measures $10 \frac{1}{2}$ in. by $11 \frac{1}{2}$ in. is most beautifully engraved and is signed "Eduardus East, Londini." The movement is an eight- 


\section{Old Clocks and Watches and their Makers}

day-the escapement a recoil. Height, $6 \mathrm{ft} .10 \mathrm{in}$. ; width, $10 \frac{1}{2}$ in. : depth, 7 in.

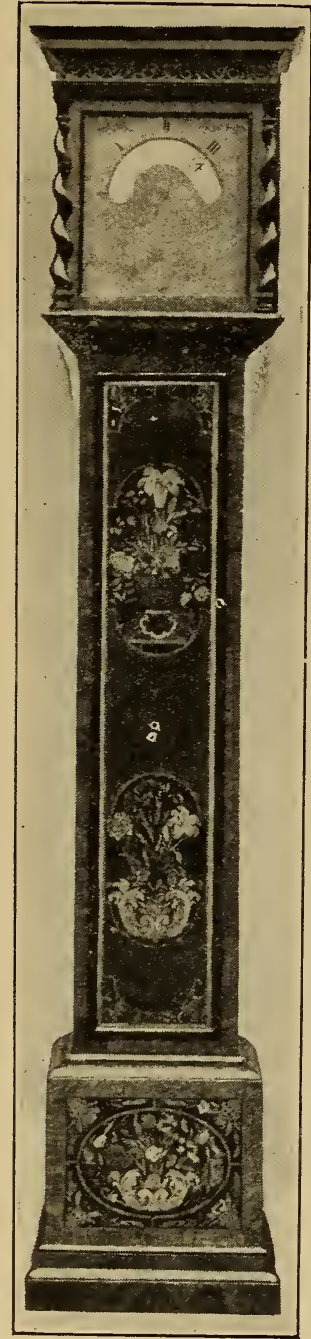

FIG. 418.-Night Clock, by Edward East.

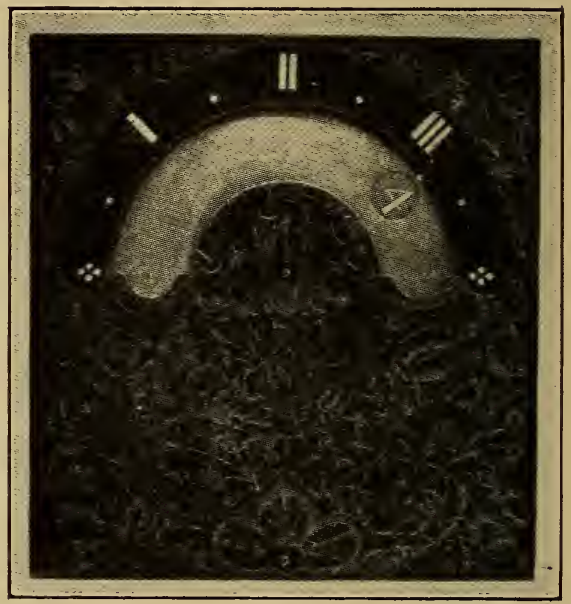

FIG. 419.-Dial of Night Clock, by Fdward East.

Edward East was one of the ten original assistants named in the charter of incorporation of 'the Clockmakers' Company, and at cnce took a leading part in its proceedings, and after serving in the subordinate capacities was elected master in 1645 , a post he again occupied in 1652. He was the only treasurer ever appointed, and the creation of the office came about in a curious way. In 1647 the renter warden, Mr. Helden, retused to give the usual security for the stock of the company, and in this dilemma the office of treasurer was created, Mr. East and Mr. Hacket being nominated thereto, and the former chosen. On the death of Mr. East the office was allowed to lapse.

Edward East lived to a good age. There is no record of his death, but it probably occurred not long after 1693 . In 1692 his quondam apprentice and friend, Henry Jones, who was then Master of the Clockmakers' Company, acquainted the court that Mr. East 
desired during his lifetime to make a gift of $£ 100$ to the company for the benefit of the poor. Mr. Jones added that he would also contribute a like sum for a similar purpose. In the following year Mr. East gave the $£ 100$, and it was ordered "that the master and wardens do go to Mr. East and give him hearty thanks for his charity."

Taking into account that Edward East at the time of the incorporation of the Clockmakers' Company in 1631 must have been a man of considerable standing in the trade, it seems probable that during the seventeenth century there were two of the name, one succeeding the other. In the "Calendar of State Papers (Domestic)" is an entry of a grant in 1662 to Edward East of the office of " chief-clockmaker and keeper of the Privy clocks, fee 12d. per day and $£ 3$. 6s. 8d. livery."

Under date 4th April 1662 is an entry of a warrant for an order to swear in James East, the king's servant, as clockmaker to the queen.

John Ebsworth.-A good clockmaker of some repute judging from what remains of his work. $\mathrm{He}$ was apprenticed in 1657 to Richard Ames and was made free of the Clockmakers' Company in

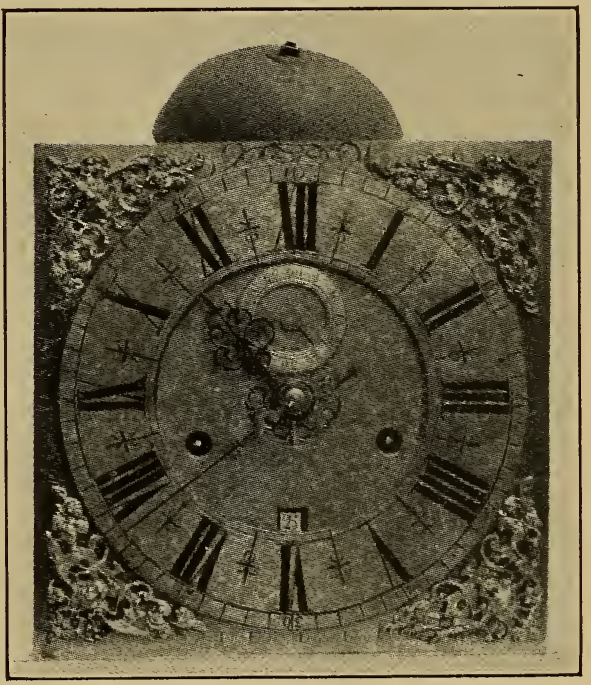

Enlarged Dial of Fig. 420. 1665 , served as master in 1697. On many full-sized lantern clocks with dolphin frets (originally with balances) is inscribed the address " at ye Cross Keys in Lothbury." He probably succeeded Thomas Knifton at the Cross Keys and afterwards removed, for on another clock is the address, "New Cheap Side." Lantern clock by him dated 1665, Agence de Commerce Etranger Ltd.

Fig. 420 is a beautiful example of John Ebsworth's work. It is a square-topped long-case clock from the collection of Mr. Hansard Watt. The long door is inlaid with small panels of early marquetry of ivory 


\section{Old Clocks and Watches and their Makers}

and coloured woods on black ground, and the square base inlaid in the same manner. The brass dial with matted centre is $10 \frac{1}{2} \mathrm{in}$. square and the Tudor rose is engraved round the centre

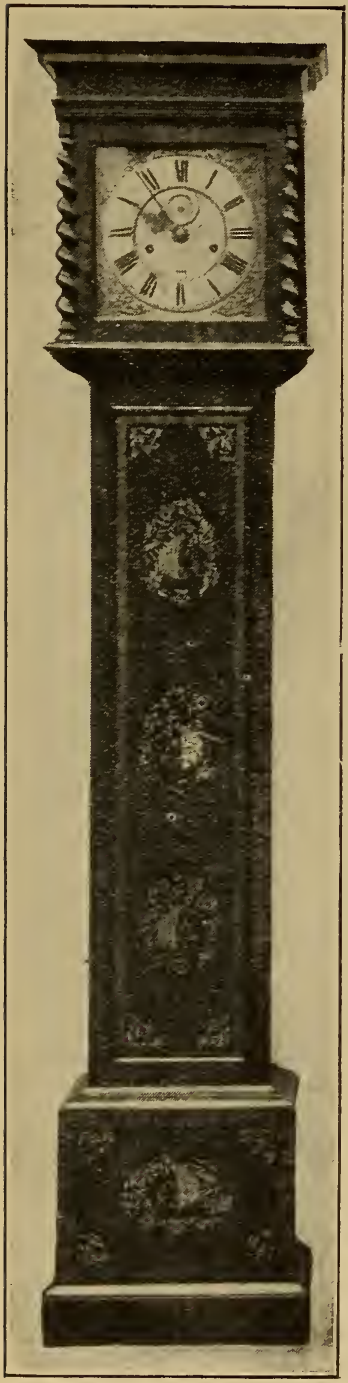
years, but being by His Majesty given unto a lady it came into the hands of Robert Seignor, clockmaker, of Exchange Alley, to be

of the finely pierced hands. Month striking movement with locking plate on main wheel and recoil escapement. The maker's name "John Ebsworth Londini Fecit" is engraved on the bottom of dial. Height, 84 in., width, 12 in., depth, $6 \frac{1}{2}$ in. The following appeared in the "Post Boy," May 2nd, 1699 :- " Lost a small silver watch made by $\mathrm{J}$. Ebsworth in a tortoise-shell flowered case and notice being given so as it may be recovered to Mr. John Ebsworth watchmaker at the sign of the Cross Keys in Lothbury, two guineas reward."

Henry Jones.-Henry Jones, already referred to, was apprenticed to Edward East on 22nd August 1654. He was made free of the Clockmakers' Company in 1663, and served as master in 1691-92. He resided near the Inner Temple Gate, and attained a considerable reputation, which was quite justified judging from what remains of his work. Charles II., according to tradition, gave to Mrs. Jane Lane a clock, in memory of her services after the battle of Worcester. On the clock was engraved, "Henricus Jones, Londini." In Overall's " History of the Clockmakers' Company" is a record which just possibly refers to this clock. It states that, on 19th January 1673, " Mr. Henry Jones, clockmaker, acquainted the Court of the Company that he had made for the King (Charles II.) a clock of the value of $£ 150$, whereon was engraven 'Henricus Jones, Londini,' and which stood
FIG. 420.-Long-case Clock by John Ebsworth. 
repaired, and he caused Edward Staunton, clockmaker, or some other person, to take out the maker's name and insert his own."

In North's "Life" it is stated that barometers were first made and sold by one Jones, a noted clockmaker in the Inner Temple Gate, at the instance of Lord Keeper Guildford; and very probably Jones was the first Englishman who constructed a Torricellian tube, as the barometer was originally called, after its inventor, Evangelista Torricelli, who propounded its theory about 1650 .

In the London Gazette for October 21$24, \quad 1689$, was the following advertise ment : "Lost on the 21st Instant, between the Hay Market near Charing Cross and the Rummer in Queen St. near Cheapside, a round Gold Pendulum Watch of an indifferent small size, showing the hours and minutes, the Pendulum went with a strait spring, it was made by Henry Jones, Watchmaker in the Temple, the Out-case had a Cypher pin'd on it, and the Shagreen much worn. If it comes to your hands, you are desired to bring it to

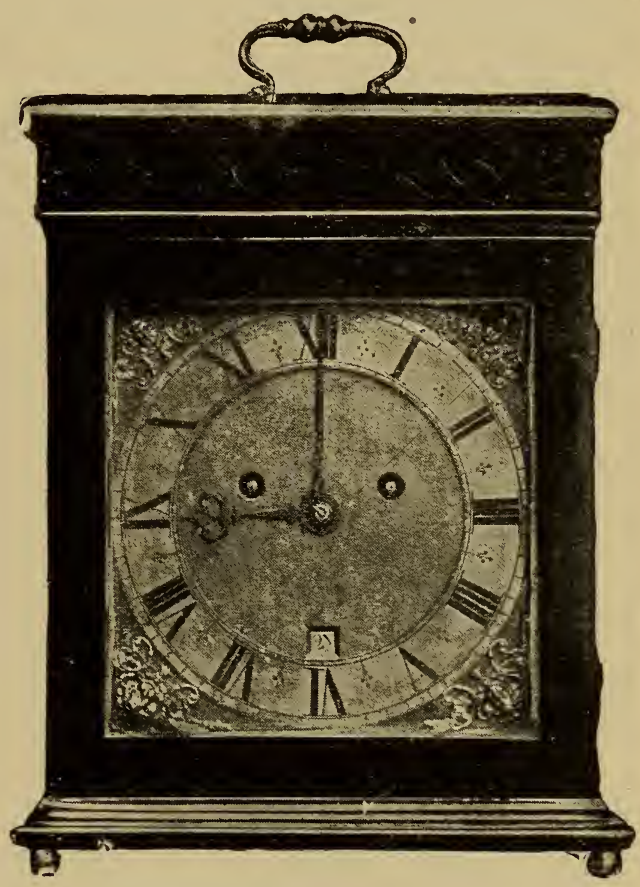

FIG. 421.-Early Bracket Clock by Henry Jones. the said Mr. Jones or Mr. Snag, a goldsmith in Lumbard Street, and you shall have two Guineas Reward."

In the Guildhall Museum is one of Henry Jones's watches, which Mr. E. J. Thompson speaks of as having very fine pillass. Another watch by the same maker was in the Evan Roberts collection.

Fig. 421 shows an early bracket clock by Jones, which belongs to Mr. A. Riley. The case of oak, veneered with fine pollard oak, is about $15 \mathrm{in}$. high and $11 \mathrm{in.} \mathrm{broad,} \mathrm{has} \mathrm{the} \mathrm{usual} \mathrm{glass} \mathrm{door} \mathrm{in}$ front and back, and glass panels at the sides. At the top is a narrow 


\section{Old Clocks and Watches and their Makers}

band or frieze of rosewood fretwork. The signature, " Henry Jones in the Temple," is engraved on the bottom of the dial just under the circle, but concealed when the door is closed.

Mr. Holden, of Yeadon, has an eight-day long inlaid-case-clock with a brass dial, inscribed " Henry Jones in ye Temple," which is a later production than any of those already quoted.

Mr. Hansard Watt has in his collection a clock by this maker in a superb walnut case,

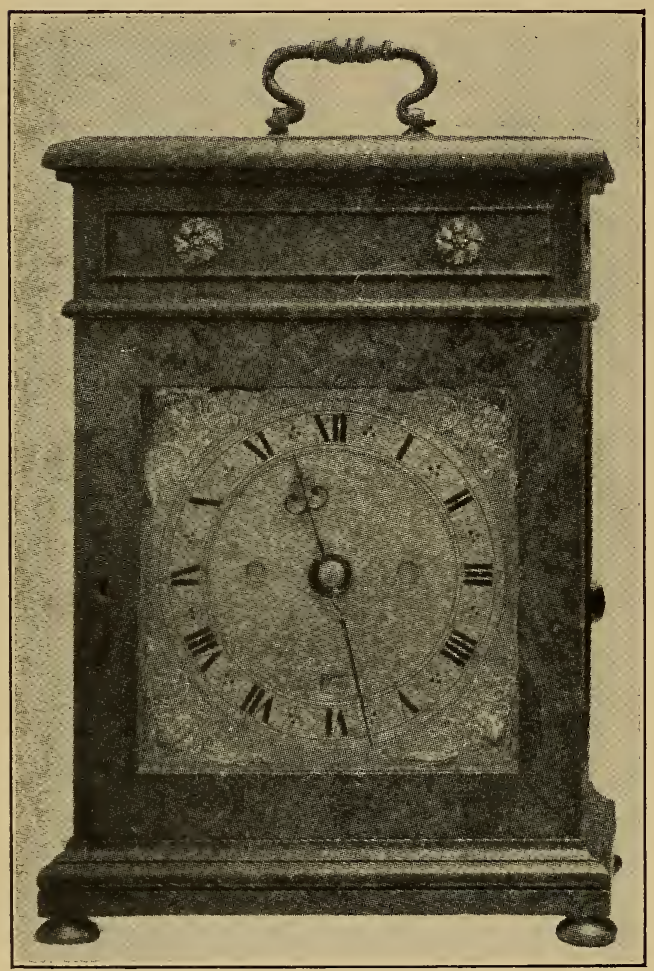

Fig. 422.-Bracket Clock by Henry Jones. shown in Fig. 422. The back plate is signed "Henricus Jones Londini."

Henry Jones, who was the son of William Jones, vicar of Boulder, Southampton, died in November 1695 , aged sixty-three years, and was buried within the precincts of the old church of St. Dunstan's in the West, Fleet Street, where a monument was erected to his memory by his widow.

Edward Barlow (Booth).-This talented man was born near Warrington in 1636 . He was ordained in the English church at Lisbon, and took the name of Barlow from his godfather, Ambrose Barlow, a Benedictine, who suffered at Lancaster for his religion. Edward Booth devoted considerable attention to horological instruments. He was undoubtedly the inventor of the rack repeating striking work for clocks, which was applied by Tompion about 1676 . He also devised a repeating watch on the same principle, and made application to patent it in $\mathbf{1 6 8 6}$. His claim was successfully opposed by Daniel Quare, who was backed by the Clockmakers' Company. The king, James II., tried both watches, and gave his preference to Quare's, which repeated the hours 
and quarters with one push from a pin near the pendant, whereas Barlow's watch was furnished with a pin on each side of the pendant and required two distinct operations to attain the same end.

Booth invented the cylinder escapement, and patented it in conjunction with William Houghton and Thomas Tompion in 1695 (No. 344). The invention is described as a " ballance wheele either flatt or hollow, to worke within and crosse the centre of the verge or axis of the balance with a new sort of teeth made like tinterhooks to move the balance and the pallets of the axis or verge, one to be circular, concave, and convex." He died in 1716.

Betts.-Fig. 423 shows a watch by Samuel Betts remarkable for its particularly handsome dial of silver and brass. The central leaf ornament of silver polished is partly filled in with crimson enamel or hard wax, the pretty effect of which is enhanced by a dull matted surface between it and the hour hand, which is also of silver. On a nicely chased revolving ring outside the hours is a fleurde-lys to indicate the day of the month on a fixed silver band, divided into thirty-one and figured as shown. An outer chased margin of brass completes the arrangement. At the end of the short months the day of the month ring has to be moved by hand. The boss of the hour indicator is

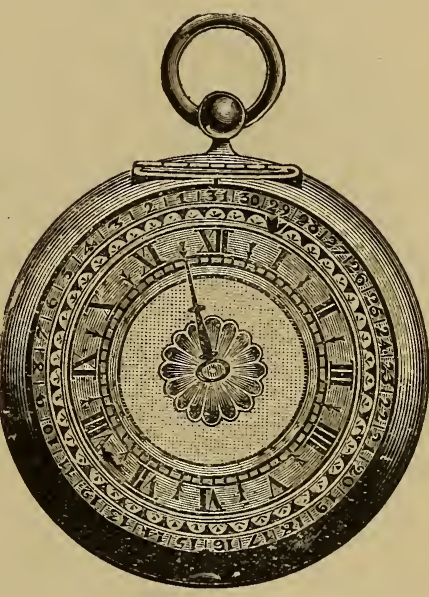

Fig. 423.-Watch by Samuel Betts, about 1640 . oval, and although but one limb now exists, there was probably a trident tail, as may be seen on other specimens of the period. The case is of silver with a hit-and-miss shutter over the winding hole ; the glass is nearly one-third of a sphere and exceedingly thick. Betts carried on business at the back of the Royal Exchange, and appears to have died prior to 1673, when "Mr. Marquet" (Markwick ?) advertises himself in the London Gazette as the successor of "Mr. Samuel Betts, deceased." In 1656 Betts attested the genuineness of Jas. Lello's masterpiece to the Clockmakers' Company. The watch here shown dates from about 1645 .

Tompion and Graham.-Thomas Tompion, "the father of English watchmaking," was born at Northill, Bedfordshire, in 1638. It is said that his father was a farrier, and that he was brought up 


\section{Old Clocks and Watches and their Makers}

to the same trade; but the first reliable record shows him to have been in business as a clockmaker at Water Lane, Blackfriars, when quite a young man.

Water Lane was a long, tortuous thoroughfare, the western portion of which is now Whitefriars Street, and Tompion's shop, known by the sign of the Dial and Three Crowns, was at the Fleet Street corner

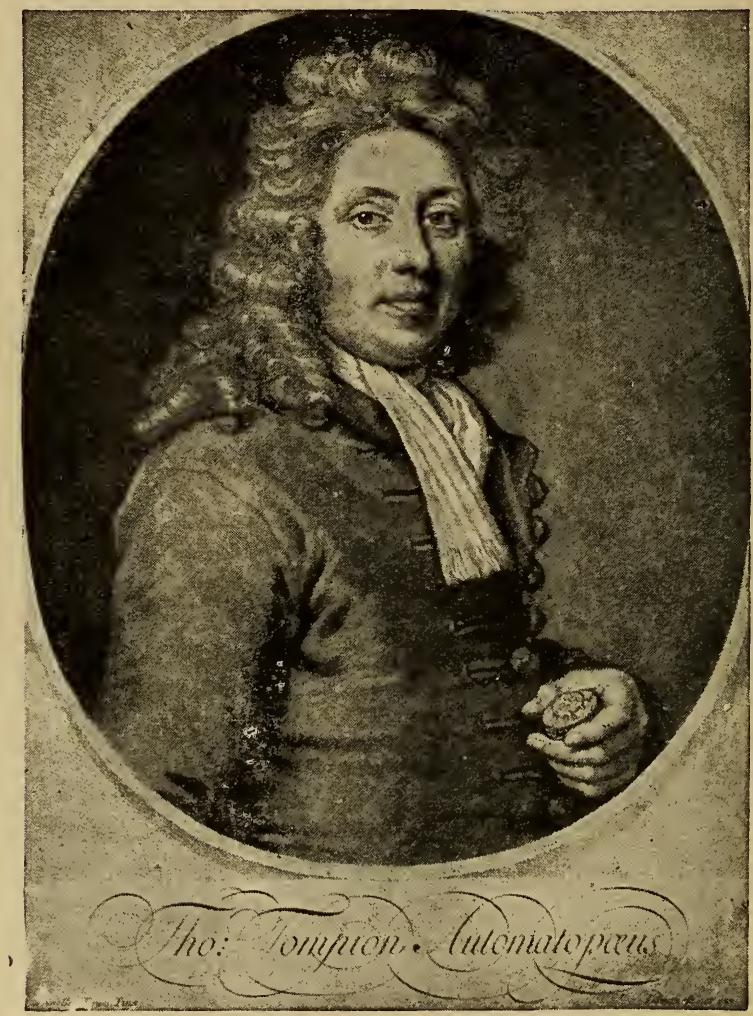

Fig. 424.-Thomas Tompion, 1638-1713.

where the offices of the Daily Nere's are. His advent marks a distinct epoch in the history of the horological art. Throughout his career he was closely associated with some of the leading mathematicians and philosophers of his time. The theories of Dr. Hooke and the Rev. Edward Barlow would probably have remained in abeyance but for Tompion's skilful materialisation of them. He soon became the leading watchmaker at the court of Charles II., and was everywhere welcomed 
as an artist of commanding ability. When he entered the arena the performance of timekeepers was very indifferent. The principles on which they were constructed were defective, and the mechanism was not well proportioned. The movements were as a rule regarded as quite subsidiary to the exterior cases, and English specimens of the art had no distinctive individuality. By adopting the inventions of Hooke and Barlow, and by skilful proportion of parts, he left English watches and clocks the finest in the world and the admiration of his brother artists. Of course he did not reach finality; improvements continued under his immediate successors. Indeed some of the most remarkable and progressive horological conceptions emanated from the mind of his favourite pupil, Graham, whom he inspired, and who continued the work which Tompion began. Of the few horologists of Tompion's time who can be admitted as his peers, Daniel Quare was perhaps the most notable example. As a clockmaker Joseph Knibb may perhaps be admitted to rank with these.

Among others above mediocrity who made watches before and after the introduction of the balance-spring, Nathaniel Barrow is worthy of mention.

Tompion was primarily a clockmaker ; in the records of

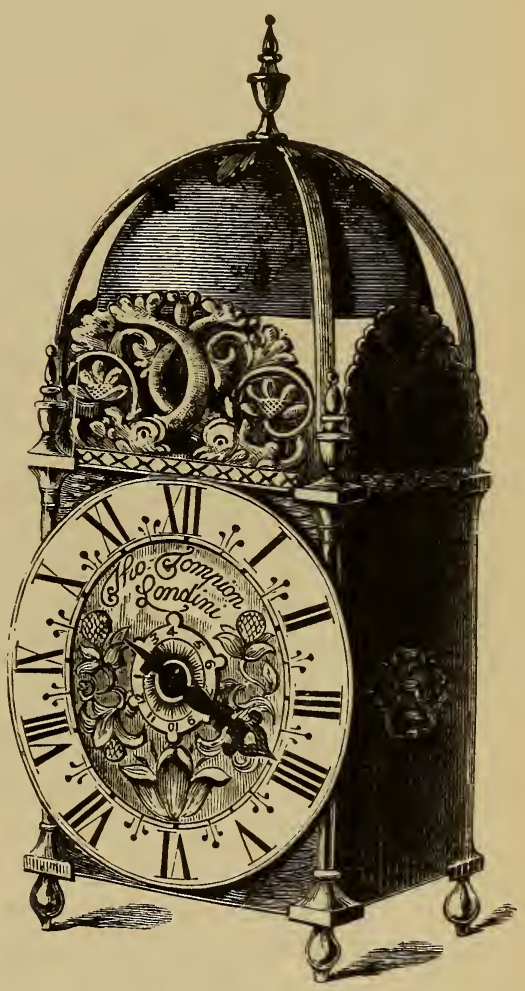

FIG. 425.-One of Tompion's earlier Clocks. the Clockmakers' Company he is referred to as a " great clockmaket" when he was associated as a brother in 1671; and it is doubtful if he made watches in the early part of his career. I have never met with a specimen not furnished with a balance-spring, and those with but an hour hand are exceedingly rare.

The portrait on p. 278 is from a mezzotint produced in 1697 after a painting by Sir Godfrey Kneller. 
One of Tompion's earlier clocks, which belonged to the late $\mathrm{Mr}$. Norman Shaw, is shown in Fig. 425. It has a light pendulum 6 in. in length fixed to the verge ; the escapement for the alarrm is behind the going train, and when the alarm is let off the hammer strikes the bell which forms the domical top of the clock. In the British Museum is another chamber clock by Tompion, as well as a very thick watch by the master, in a case superbly painted in enamel by Camille André. In the same repository is a curious universal pocket sun-dial with compass, all of gold, also by Tompion.

In 1675, he made for Charles II. a watch with two balances and balance-springs as devised by Hooke. Derham says, "This watch

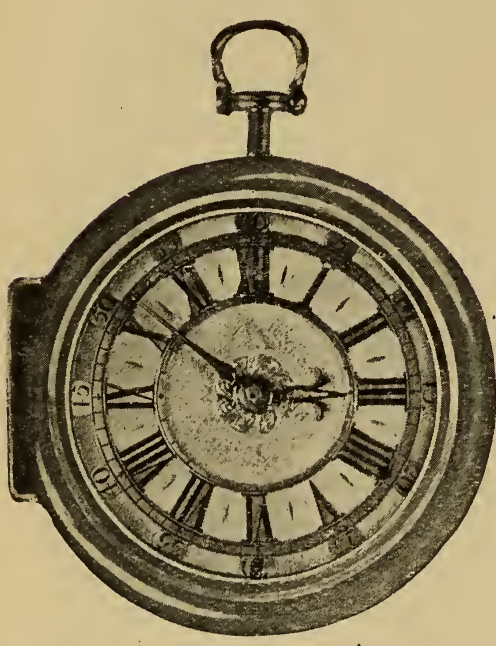

FIG. 426.-Watch by Tompion in Gold Case.

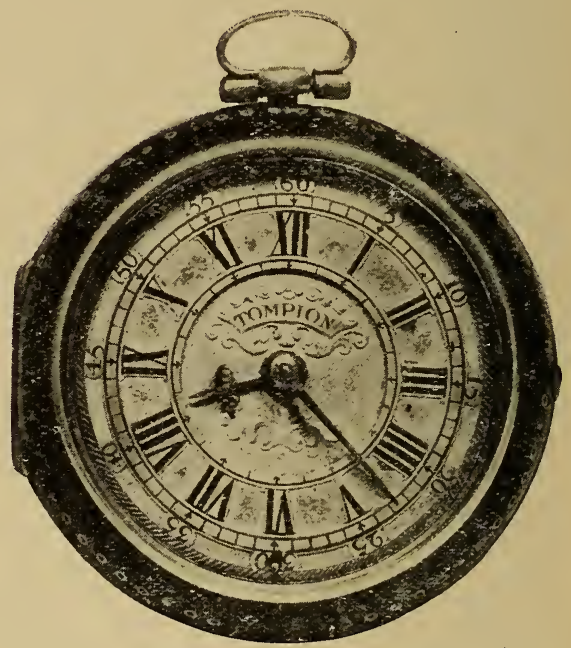

FIG. 427.-Tompion Watch in Silver Inner Case ; Out-case, Tortoise-shell.

was wonderfully approved of by the King; and so the invention grew into reputation and was much talked of at home and abroad. Particularly its fame flew into France, from whence the Dauphin sent for two, which that eminent artist Mr. Tompion made for him."

The introduction of the balance-spring involved a reconstruction of the watch movement. The disc or dial for indicating the adjustment of the mainspring was discarded as no longer necessary, and a somewhat similar one introduced for showing the movement of the curb pins round the balance-spring. This disc was placed upon a pinion with a squared extremity for the reception of a watch key to actuate the curb pins, which were carried by a toothed segment or circular rack 
gearing with the pinion. The tangent wheel and screw for mainspring adjustment were placed beneath the plates. The balance was considerably enlarged and covered with a circular cock. In Tompion's early watches there is a kind of bevelled fringe around the edge of the cock for the more effectual protection of the balance, as in Fig. 429, but after 1688 or 1690 he adopted the now well-known form with a broad base curved to suit the edge of the plate, a circular table the same size as the balance, and just where the table narrows to join the base a cherub's head or a grotesque mask engraved between projecting ears or streamers.

His watch movements were deep, top plates exceedingly thin, and near the edge was usually engraved, "Tho. Tompion, London."

He was, I believe, the first manufacturer to number his watch movements consecutively in plain figures for the purpose of identification. His early ones were not so marked, and I should judge he commenced the practice about 1685 .

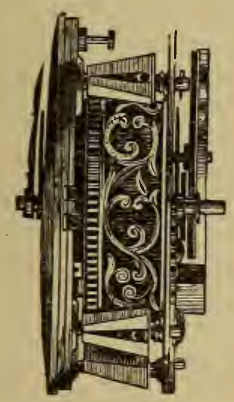

FIG. 428.

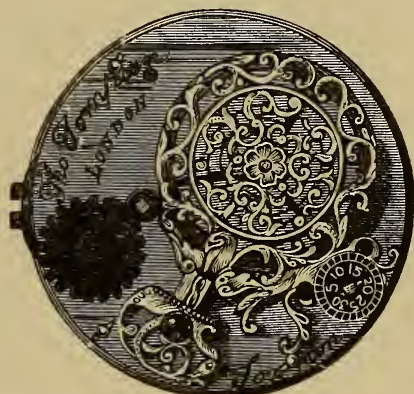

FIG. 429.

An example of Tompion's versatility of genius.

Fig. 426 shows a watch by him in plain gold cases, bearing the hallmark corresponding to 1685 ; the dial is of gold with raised numerals. The hands are very fine, the hour indicator being of the tulip pattern. A watch with silver dial, about ten years later, from the Pierpont Morgan collection is shown in Fig. 427.

As an example of the versatility of Tompion's genius two views of a watch from the collection of Mr. Willard $\mathrm{H}$. Wheeler are given in Figs. 428 and 429 . The distinctive feature of this watch is that, although a verge escapement is used, the fusee has been discarded; the mainspring being surrounded by a handsomely pierced guard which is fixed to the plate; and to this the outer end of the mainspring is attached. In order that the watch might have a coil of mainspring of the largest possible dimensions, what is usually the centre wheel 


\section{Old Clocks and Watches and their Makers}

is planted out of the centre; the cannon pinion rides ioose on a stud planted in the centre of the frame; and to get the proper motion for the minute-hand without the introduction of an intermediate wheel in the motion work, the train rotates reversely to the usual direction. The movement is not numbered; this fact, together with the style of the engraving and the form of the balance-cock, enables one to fix the date of its production at about 1680 .

Before September 1695, Tompion produced a watch in which the teeth of the horizontal

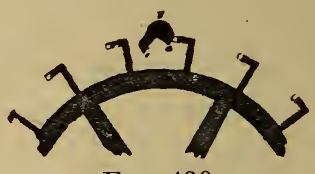

FIG. 430. escape wheel dropped on to the cylindrical body of the verge, as shown in the appended drawing (Fig. 430), thus avoiding the recoil incidental to the usual verge construction; and in September 1695 he, in conjunction with Booth and Houghton, patented the cylinder escapement. In the account of Barlow the wording of the description is given.

One of the boldest of Tompion's conceptions was a small clock to strike the hours and quarters, driven by mainsprings and yet requiring to be wound but once a year. The successful embcdiment of this is shown in Fig. 431. The clock was made for William III. at a cost of $£ 1,500$, and was in his bedroom at Kensington Palace when he died. It was left by him to the Earl of Leicester, and now belongs to Lord Mostyn, in whose family it has been for over 150 years. It is still in going order, and Lord Mostyn has the name of nearly every one who has wound it during the last 100 years.

The total height to the top of the spear is $30 \mathrm{in.}$; the body or plinth below the dial is $10 \mathrm{in}$. in width, $7 \mathrm{in}$. in height, and 6 in. from front to back.

The case, of ebony with silver mounts, is a fine piece of work in one piece, forming really a hood or cover, for it slides down over the movement and rests on the metal feet. 
The movement is in three portions; the lower part below the dial is attached to the heavy scroll feet, and contains the two mainspring barrels, the two fusees, and the larger driving wheels. The middle portion behind the dial contains the smaller wheels and pinions; while the verge escapement above is held separately, so that it may

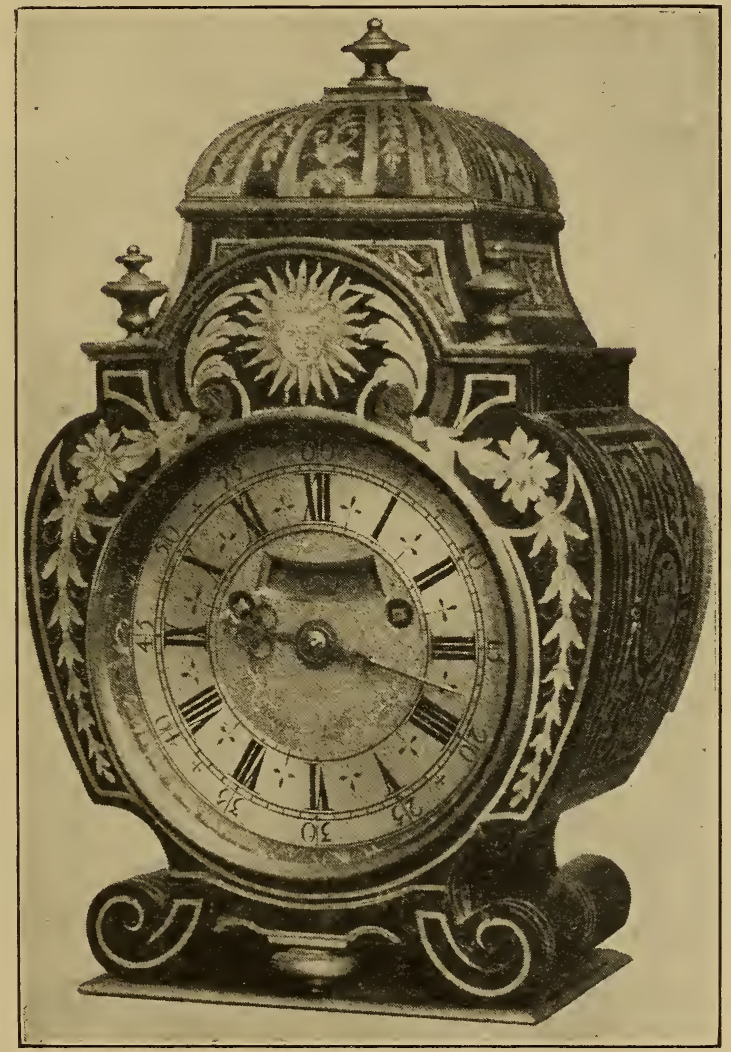

FIG. 432.-Unique Eight-day Clock by Tompion, in elaborate Buhl Case.

be easily detached. The pendulum, 6 in. long, is in front of the movement just behind the dial, and its action may be seen through the glazed door below the dial, which is removed when winding or regulation is needed. Regulation is effected by raising or lowering the chops which embrace the pendulum spring, very much in the way adopted for modern clocks ; the sliding chops are actuated by a tangent wheel and 


\section{Old Clocks and Watches and their Makers}

screw, and there is on the front plate a micrometer index for noting the amount of adjustment made.

The hours are struck on a bell attached to the front plate, the ting-tang quarters being sounded on this and on a smaller bell,

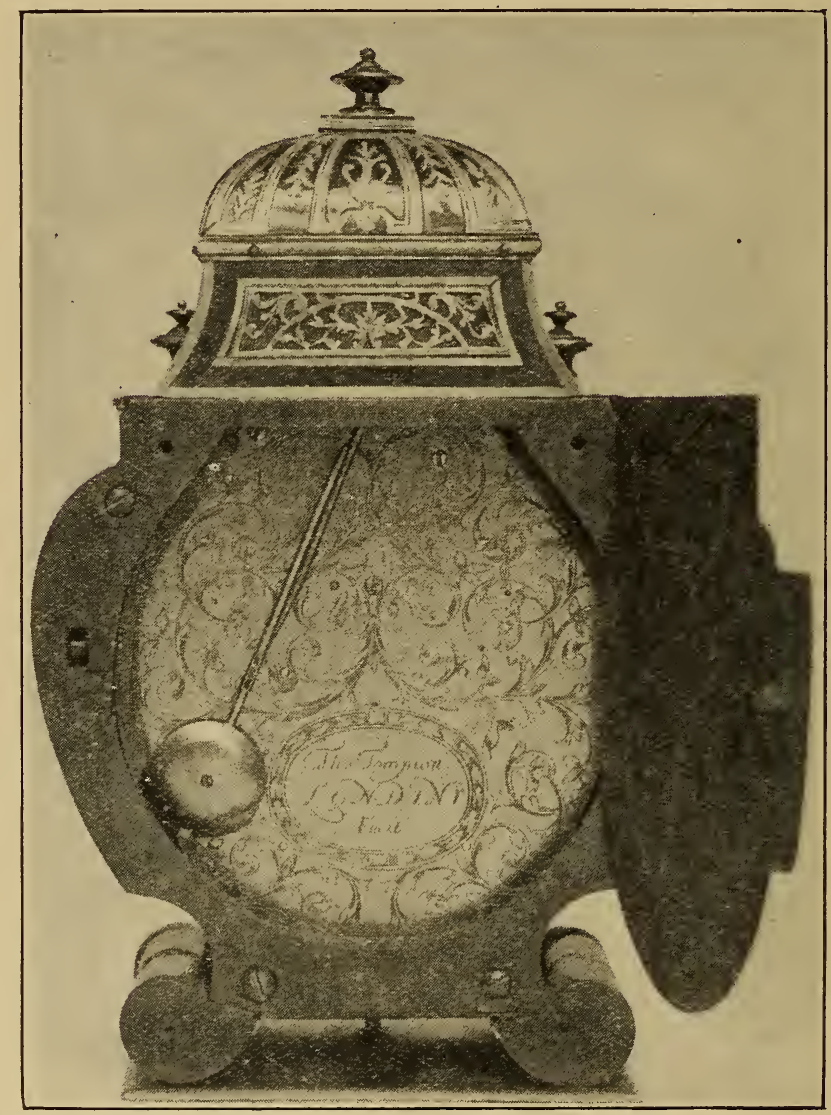

FIG. 433.-Back view of Fig. 432. Showing engraved movement plate and brass back door engraved both sides.

which surmounts the movement. On each side of the case is a pull-repeating arrangement.

By the courtesy of Mr. D. A. F. Wetherfield it is possible to include photographs of a unique eight-day clock by Tompion (Figs. 432 and 433). The clock is enclosed in"an ornate Buhl case of red tortoise-shell with white metal inlay. This is probably of French workmanship, 
although it was obviously made expressly for the clock. The height of this elegant timepiece is $10 \mathrm{in}$., and it dates from the latter part of the seventeenth century.

A particularly interesting bracket clock by Tompion, in the collection of Mr. Hansard Watt is illustrated in Figs. 434 and 435. The clock itself is very similar to one in the Wetherfield collection shown in Fig. 784, but is has the additional attraction of its original travelling case of oak with iron decorative hinges and handles. The illustrations

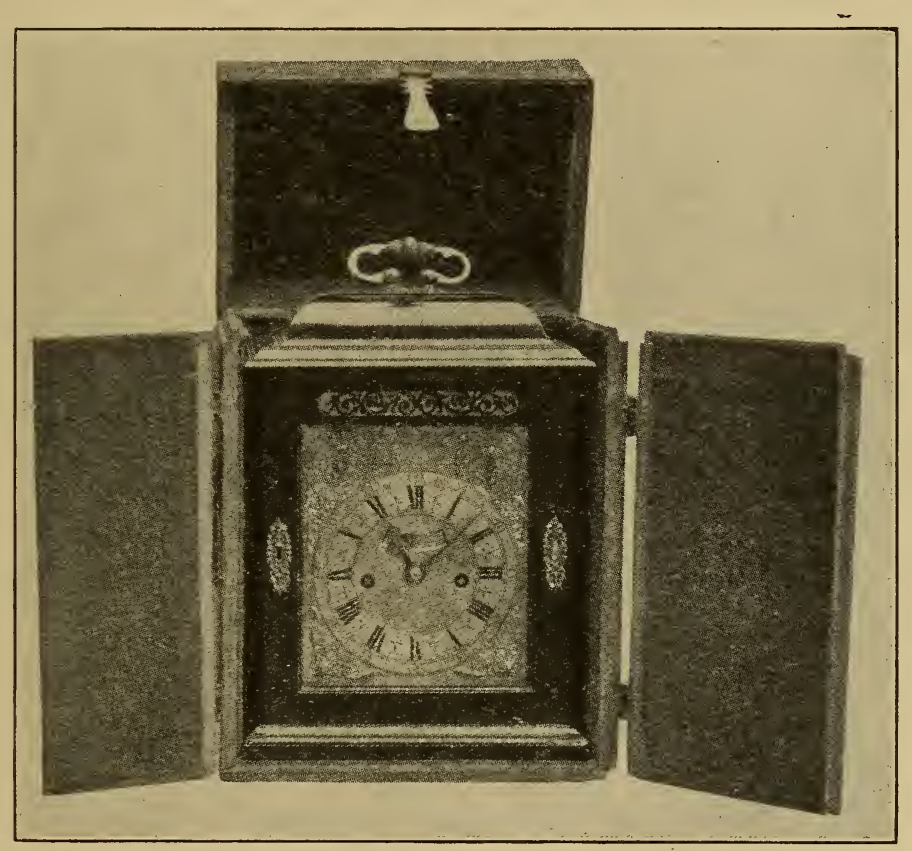

FIG. 434.-Brackęt-clock by Tompion.

show the clock in its case and the case closed. This is a rare if not unique specimen.

During the building of St. Paul's, it was frequently reported that Tompion was to construct a wonderful clock for the cathedral; and in " The Affairs of the World," published in October 1700, the following announcement appeared: "Mr. Tompion, the famous watchmaker in Fleet Street, is -making a clock for St. Paul's Cathedral, which it is said will go one hundred years without winding up ; will cost $£ 3,000$ or $£ 4,000$, and be far finer than the clock at Strasburg." 


\section{Old Clocks and Watches and their Makers}

Though this statement seems to have been unwarranted, it is quite possible he would have been entrusted with the construction of a timekeeper of some kind, but, after unremitting application to his profession for more than thirty years, he was at this time, it may be assumed, just beginning to indulge in well-earned leisure; during the last years of his life he allowed himself considerable relaxation, and was absent from London for extended periods. In the course of his migrations he visited Bath, possibly to derive benefit from the healing properties of the hot mineral water which wells up in the Queen of the West, as the chief

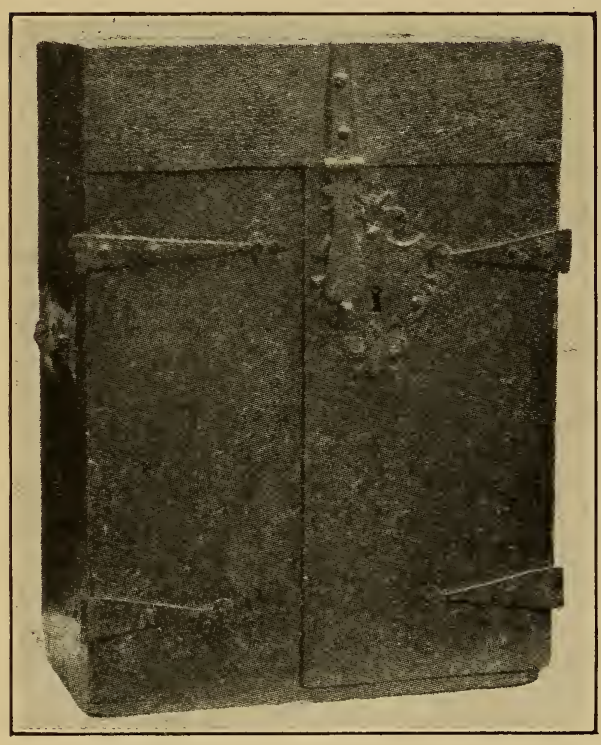

FIG. 435.--Original Travelling Case of Clock by Tompion. Somersetshire city is called. In the Grand Pump-room there is a splendid example of Tompion's later work, which he presented to the city, as is thus recorded on a tablet adjacent to the timekeeper: "The Watch and Sun-dial was given by Mr. Thos. Tompion, of London, Clockmaker. Anno Dom. 1709." In Fig. 436, I am enabled to give an illustration of this stately timekeeper. Mr. Olds has kindly furnished some description of the movement. The dial is of brass, with ornamental corner pieces and silvered rings, the minute circle being 15 in. in diameter; the day of the month is shown through an aperture. On a high arch above is an equation index and scale, 0 being in the centre, and the variation to a maximum of fifteen minutes shown on each side ; on the right, "Sun faster," and to the left, "Sun slower." The months and days are engraved on a silvered 10-in. circle, of which an arc is shown through an opening. The number of minutes shown by the index gives the difference between sun time and mean time; this 10 -in. circle has over 2,000 finely cut teeth, and makes its annual circuit by means of an endless screw and pinion, worked from the dial wheel, which 
makes one revolution per hour. The index is kept in position by a small counterpoise with a pulley fitted to its arbor; the pulley is attached by a fine chain to a cranked arm, which rises and falls with the indentations and protuberances of a properly shaped plate or cam attached securely to the 10 -in. circle.

The train and frame of the timepiece are in remarkably good order, considering its age. The driving power is a lead weight of $32 \mathrm{lbs}$. hung on a 3-in. pulley, having a fall of $6 \mathrm{ft}$. It is wound monthly on to a $2 \frac{1}{2}$-in. barrel ; the great wheel of 94 teeth, and $4 \frac{3}{4}$ in. in diameter, drives a pinion of sixteen leaves; thereon is a 3 -in. wheel of 80 teeth, and this drives the centre pinion of 10 teeth; the centre wheel is $2 \frac{7}{8} \mathrm{in}$. of 72 teeth, driving the third pinion of 9 teeth; on this is a $2 \frac{5}{8}$-in. wheel of 60 teeth, driving the escape pinion of 8 teeth; on this is a 2 -in. escape wheel of 30 teeth, shaped as in a recoiling escapement. The pallet staff is $2 \frac{3}{4} \mathrm{in}$. above the escape arbor, and carries pallets of the anchor pattern, having inclined planes to allow recoil. The one-second pendulum rod is of steel, of a flattened oval section, with 6-in. bob of lenticular form. The amount of oscillation; being only $2 \frac{3}{4}^{\circ}$, causes the recoil of the escapement to be barely apparent.

The day of the month circle is moved by an extra wheel from the hour wheel. Maintaining power while winding is given by a spring-propelled click through a steel arm on an arbor between the plates, acting on the teeth of the centre wheel, which is put

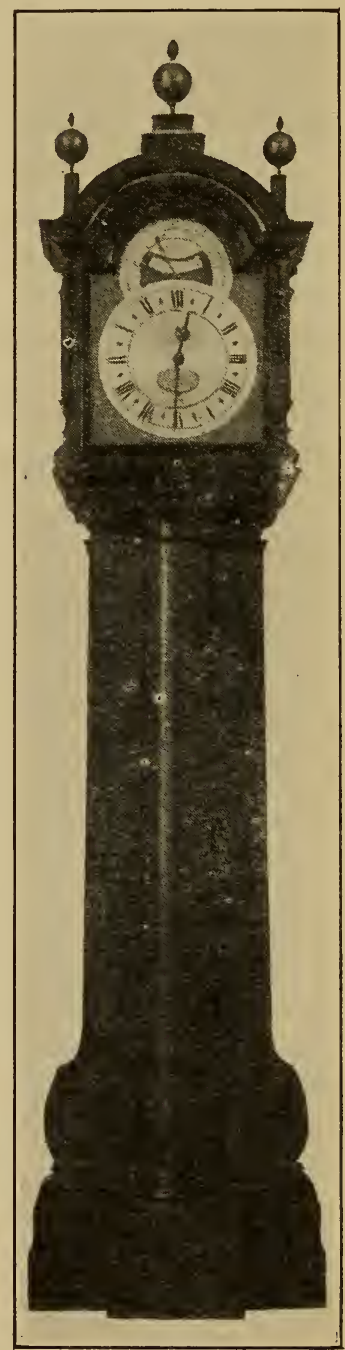

FIG. 436.

Clock by Tompion, at the Pump-room, Bath. into action by lifting the sliding cover of the winder hole in the dial.

The case is of solid unpolished oak, $9 \mathrm{ft}$. high to the top of the arched head which is surmounted by brass ball ornaments. The 


\section{Old Clocks and Watches and their Makers}

body of the case is 17 in. wide and about 6 in. narrower than the head and base, with a semicircular door $8 \mathrm{in}$. across and $5 \mathrm{ft}$. in length. As will be seen from the drawing, the case has much the appearance of a pillar rising from a substantial base.

The clock is in a recess at the eastern end of the room, and it occupied a similar position in the old Pump-room, the erection of which was finished in 1706. As the spot is particularly suited for the reception of a clock, it may be conjectured that Tompion was in Bath when the old Pump-room was being built, and that the ever-vigilant "Beau " Nash obtained from him a promise to present a timepiece when the building was completed.

At first sight the phrase "watch and sun-dial " on the tablet recording the gift seems to include a gnomon of some sort for regulating the timekeeper from observations of the sun. There would be nothing far-fetched in this surmise, because sun-dials to check the going of public timekeepers were not at all an unusual adjunct. But I am inclined to think that in this instance sun-dial meant the equation dial over the ordinary one.

Fig. 438 shows another example of Tompion's work, which is almost a facsimile of the Bath clock. It belongs to Mr. Philip T. Godsal, of Iscoyd Park, Whitchurch, Shropshire.

The clock shown in Fig. 437 belongs to Mr. D. A. F. Wetherfield, and is one of the finest specimens of Tompion's work in existence. The movement is of great excellence, even for this master, and, as the clock has suffered little from injudicious repair, it is still in perfect going order. The dial-plate is thickly mercurial gilt and the four corner dials are all engraved exactly the same. The top dials indicate -on the left-hand side, the " rise and fall " of pendulum for regulating and on the right, the "strike silent." The two bottom dials have hands that are moved to secure the pendulum in case the clock is moved. The hands and dials are beautifully pierced and engravedall are in their original condition, never having been damaged or repaired. The metal mounts of the cases are of unusual design, elaborately chased, and thickly mercurial gilt, while the plaque at the back of the case is even finer than the rest of the mountings. The basket top of this clock, unlike the majority of those of the period, is solid, cast and chased. The complicated mechanism is very typical of Tompion, and the clock strikes the "Grand Sonnerie" (hours and quarters at each quarter).

A long-case chiming clock by Tompion to go a month between windings which is at Windsor Castle is shown in Chapter VII., and at 
Buckingham Palace is a very similar one. At the Guildhall Museum is a Tompion clock with a square dial, one hand, and in a long black case, which may be accepted as an indubitable example of his early work. In the same collection is a more modern specimen which goes

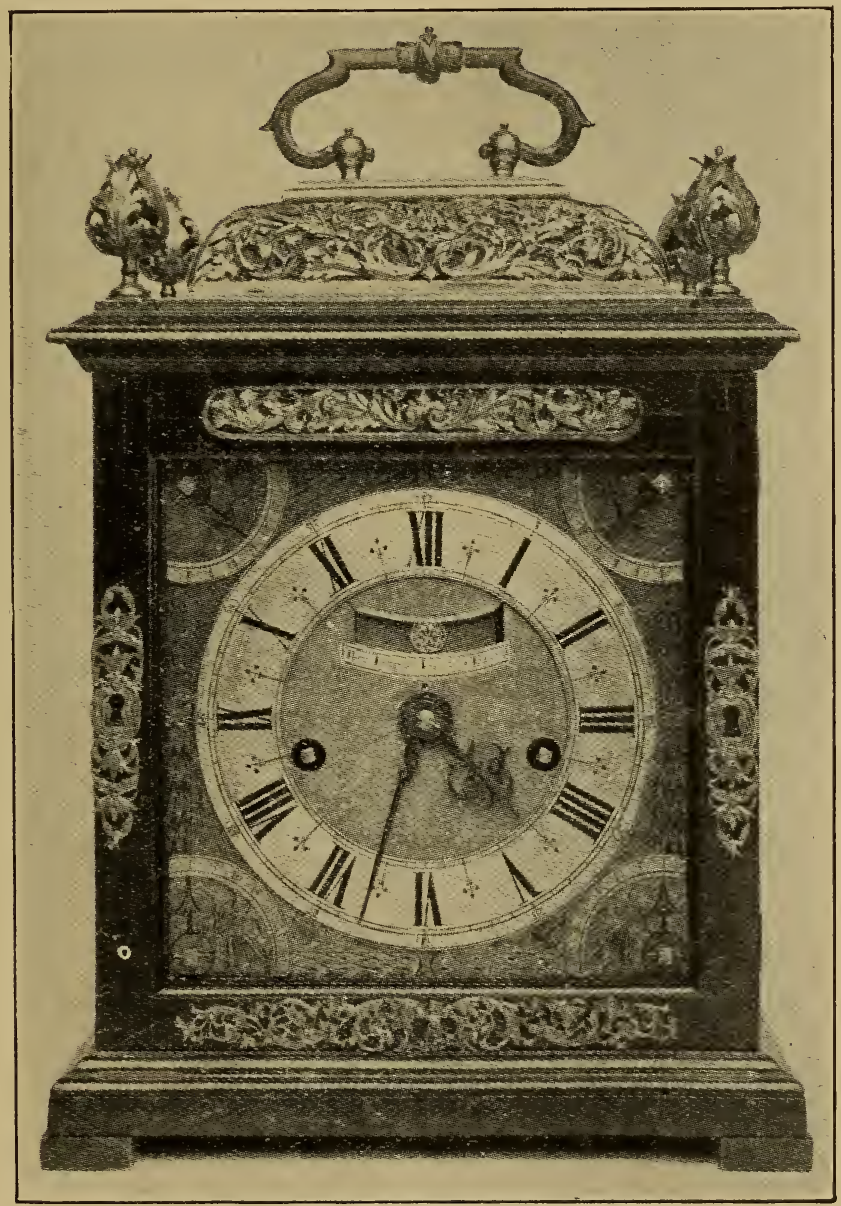

FIG. 437.-A very fine Bracket Clcck by Thomas Tompion.

four months between windings, has an arch dial, and maintaining work similar to that in the Bath Pump-room clock. It is inscribed "Thomas Tompion, London," a form of signature rather unusual. In the Wetherfield collection are no fewer than eighteen Tompion clocks. Some of these and others I propose to illustrate in. 


\section{Old Clocks and Watches and their Makers}

Chapter VII. Mr. T. W. Bourne owns a good example dating from about 1670. It has a $10 \frac{1}{2}$-in. dial, shown on p. 507, and is in a long case of burr walnut on oak. According

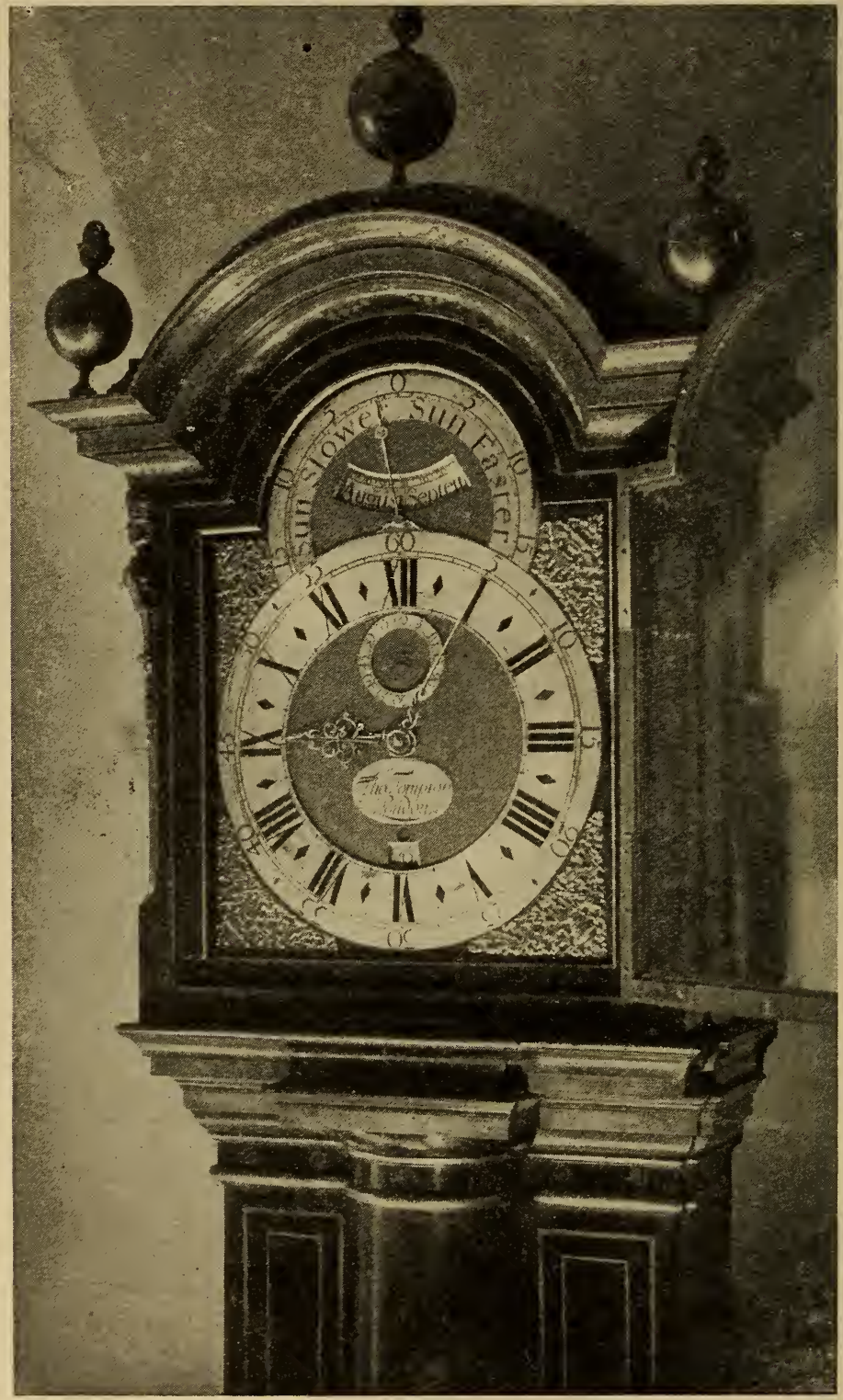

FIG. 438.-Another example of Tompion's work. 
to Reid, the Earl of Moray has a clock by Tompion at the house of Donibristle in which the hours are struck on two bells in accordance with the plan explained on p. 328.

Figs. 439 and 440 show the famous Threemonth Tompion clock now in the possession of Mr. D. A. F. We therfield (formerly in the collection of the late Duke of Cambridge, and sold at Christie's in 1904, and later in the collection of $\mathrm{Mr}$. George Dunn, of Woolley Hall, $\mathrm{M}$ a id e $\mathrm{n}$ he ad, sold in 1914).

The clock, which is $10 \mathrm{ft}$. high, is made to go for three months between windings, and has a perpetual calendar with a provision for leap year.

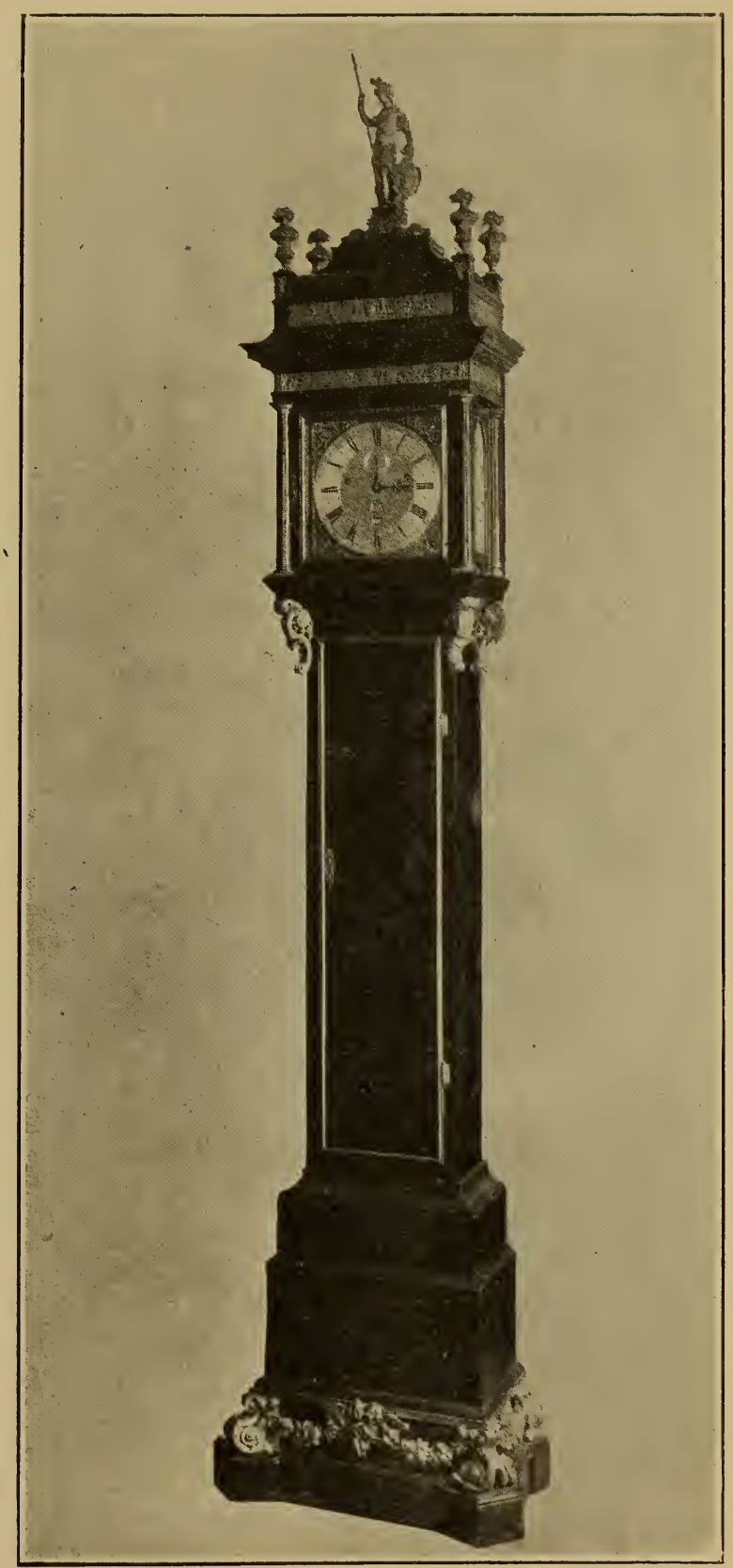

FIG 439.-The "Record" Tompion Clock, from the Wetherfield Collection. 


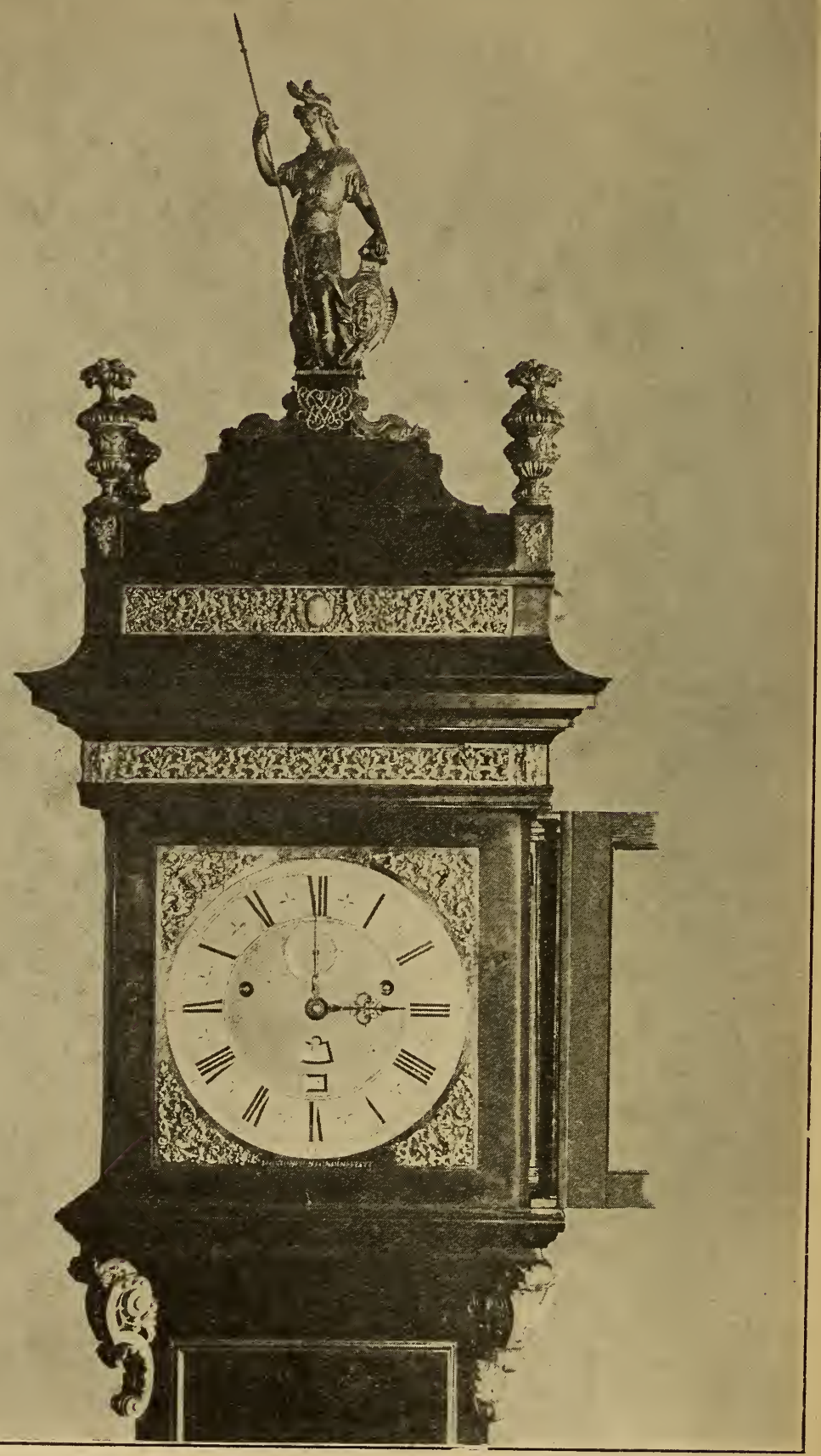

FIG. 440,-Enlarged Dial of Fig. 439. 
The following further particulars are taken from the description of the clock given in the catalogue of the George Dunn sale, viz.:"The dial is brass chased with masks and scrolls showing month, day of month, and with seconds hand: the case is of walnut wood, mounted with brackets of metal-gilt pierced and chased with Amorini among scroll foliage, surmounted by four vases of fruit, and in the centre a statuette of Minerva, which is supported by a square walnut pedestal, to which is applied the monogram of William III., of chased metal gilt: on plinth of metal-gilt chased with cherubs and festoons of flowers with scroll feet at the corners '."

The Royal Society possesses a paper in Hooke's handwriting, imperfect and undated, showing that Tompion and Hooke were in communication on the subject of the barometer, which is of interest as evidence of the estimation in which Tompion was held by Hooke. It occurs about the middle of a parchment-bound volume lettered " 20 Hooke's Papers," and is headed "Aerostatick Instruments." In it Hooke states that a form of his barometer, in which the height of the mercury was indicated by a column of water, "was tryed at Mr. Thomas Tompion's, a person deservedly famous for his excellent skill in making watches and clocks, and not less curious and dexterous in constructing and handworking of other nice mechanical instruments." A barometer by Tompion is at Hampton Court Palace.

The extent of Tompion's business may be judged from the fact that in the advertisements for the recovery of lost watches during the period he was in business, timekeepers of his make largely preponderate. Trivial though some of them may be, I venture to submit a selection from these announcements, as the quaint descriptions in the words of the owners are interesting, and convey a very good idea of the various styles in favour at the time:--

" Lost on Wednesday 20th of this Instant September at night in or about St. James's, a Gold Pel:dulum watch of Mr. Tompion's making, having three motions, a shagreen case, a cipher on the Back Side, and marked within the Box 277, with a Gold Chain and three seals, viz. one Figure and two Heads. Whoever give notice thereof to Mr. Nott, a Bookseller in Pall Mall, or to Mr. Loman at the Lord Cavendish's House in St. James's Square, shall have 15 Guineas Reward " (London Gazette, September 22, 1682).

" Lost on Monday the 25th Instant in the Fields betwixt Islington Church and Newington Green, a gold watch with a Shagreen Case, with a cipher studded in gold on the Bottom. Made by Thos. Tompion, London. Whoever brings the said watch to Mr. Robert Halstead, Goldsmith at the Crown in Fleet St. shall have three Guineas Reward " (London Gazette, January 25, 1685-6).

"Lost out of a gentleman's Pocket, the 19th past, betwixt Lyme St. end in Fenchurch St. and the end of the Minories, an indifferent small size gold pendulum watch, going without string or chain, showing the hours of the day, and day of 
the month, the name Tompion, in a shagreen case, pinned with a Cypher in the bottom of the case, wound up on the dial plate, at the hour of 12, a straight key with a Steel Nose. Whoever brings it to Mr. Tompion, Clockmaker, at Water Lane, and in Fleet St., shall have one guinea reward, or, if bought, their money again with reasonable profit" (London Gazette, November 10-13, 1690).

"Lost, the 3rd inst., between the Sun-Dial, in St. James Park, and Man's Coffee House, a silver Minute Pendulum watch, made by Tho. Tompion, in a Shagreen studded case, on the bottom of the inner case the number 458 ; with a gold Ring hanging upon the silver chain, with the Effigies of their Present. Majesties" (London Gazette, March 3-7, 1691).

" Lost on the 24th instant, about Kingston-on-Thames, a Gold Minute and Second Chain Pendulum watch, with a Stop, the hours seen through a hole in the Dial plate, and in a plain Shagreen Out-Case, the name Tho. Tompion, London, a number in the bottom of the Box, 0201 . Whoever gives notice of it to Mr. Tho. Tompion, Clockmaker, at the corner of Water Lane, in Fleet St., shall have 3 guineas reward ; or if bought already, your money again with reasonable profit " (London Gazette, June 25-29. 1691).

" Lost on the 23rd instant a Gold Pendulum Watch made by Thos. Tompion, Fleet Street, in a Shagreen Studded Case with a Steel Seal set in gold tied to it, bearing a Coat quartered with the arms of the Crown battoned; the Box numbered 422 and the maker's mark [II]" (London Gazette, July 23-27, 1691).

" Lost on the 21st instant from the Duke of Richmond's in St. James's Square, a gold striking watch with a Shagreen case studded round, with little holes between, having 3 links of plain gcld chain, made by Thos. Tompion, in Fleet St. Whoever brings it to Mr. Compton, Goldsmith, in Duke St., near Lincoln's Inn Fields, shall have 6 Guineas" (London Gazette, February 21-23, 1694).

" Lost, some time in November last, at Oxon, a Gold Minute Pendulum watch $\mathrm{n}$ a plain gold case ; the names on the upper peak, Tho. Tompion, Edwd. Banger, London; and on the Dial Plate, Tompion, Banger, London, with this number, 3428 , on the bottom of the Box within side, and likewise upon the upper plate. Whoever give notice of it (so as it may be had again) to the Reverend Dr. King, of Christ Church College, at Oxon, or to Tho. Tompion, Clockmaker, at the Dial and Three Crowns, at the Corner of Water Lane, Fleet St., London, shall have three guineas reward; or if bought or pawned, your money again with reasonable profit" (London Gazette, December 4-7, 1704).

Tompion was associated as a brother of the Clockmakers' Company in 1671 ; admitted as a freeman by redemption in 1674 ; chosen as assistan: in 1691, as warden in 1700, and master in 1704. He died on the 20th November 1713, and was buried in Westminster Abbey. In the same grave were interred the remains of Graham, and particulars of their tomb had therefore better be left till after the brief notice of Graham which follows.

Little is known of Tompion's domestic life, but he appears to have been unmarried. His will, executed on the 21st October 1713, was proved on the 27 th November, in the same year, by George Graham, who was one of the executors. By this document he bequeathed to his nephew, Thomas Tompion, son of his brother James, his land and property at Northhill, Bedfordshire, and the interest on $£ 100$. To his 
niece, Margaret Banger, wife of Edward Banger, clockmaker, and daughter of his late sister, Margaret Kent, he gave a life interest in $f 500$, which at her death was to revert to Elizabeth Graham, wife of George Graham, daughter of his said brother James. Another daughter of his sister, Elizabeth Kent, is mentioned, and a cousin, Thomas Finch. George Graham and his wife were residuary legatees. Tho. Tompion, junr., was apprenticed to Charles Kemp in 1694 and admitted as a member to the Clockmakers' Company in 1702, presumably when he had completed his apprenticeship. A "Mr. Tompion, watchmaker," attended the funeral of Daniel Quare, in 1724. Watches by Tho. Tompion, junr., are to be met with occasionally, and I have examined two or three inscribed "Tho. Tompion, Edw. Banger, London." Edward Banger was apprenticed to the Tompion in 1695, and it may therefore be fairly assumed that he was in partnership with Tompion junr. At Buckingham Palace is a one-year clock inscribed " T. Tompion, Edwd. Banger, London." In the Wetherfield collection is a long-case clock, with an oval label just below the centre of the dial, on which is engraved "Tho. Tompion and Edw. Banger, London." I saw a watch for sale but a few months ago inscribed "Tompion, London," the hall-mark in the case of which corresponded to the year 1745. But Tompion bequeathed his business to Graham who, it is pretty certain, secured the best of the trade on the demise of his patron and friend.

George Graham.--George Graham, "Honest George Graham," who was born at Kirklinton, or Rigg, Cumberland, in 1673, trampecl to London at an early age, and in 1688 became apprenticed for seven years to Henry Aske. He was admitted a freeman of the Clockmakers' Company on completing his indentures in 1695 , and immediately entered the service of Thomas Tompion, thus beginning a life-long friendship, severed only by the death of Tompion in 1713. The following announcement appeared in the London Gazette for 28th November to 1st December 1713: "George Graham, Nephew of the late Mr. Thomas Tompion, who lived with him upwards of seventeen years, and managed his trade for several years past, whose name was joined with Mr. Tompion's for some time before his death, and to whom he left all his stock and work, finished and unfinished, continues to carry on the said trade at the late Dwelling House of the said Mr. Tompion, at the sign of the Dial and Three Crowns, at the corner of Water Lane, in Fleet Street, London, where all persons may be accommodated as formerly." In Uphill Castle is a long-case clock with the signature "Tompion Graham." 


\section{Old Clocks and Watches and their Makers}

In 1720 Graham relinquished Tompion's old premises, as will be seen by the appended official notification from the London Guzette of March 22-26, 1720: "George Graham, watchmakel, is removed from the corner of Water Lane, in Fleet Street, to the Dial and One Crown on the other side of the way, a little nearer Fleet Bridge, a new house next door to the Globe and Duke of Marlborough's Head Tavern." Here in the rooms over the shop Graham resided till his decease. The quaint little shop had two plain bow windows, with the doorway between them, and, with but little alteration in appearance, remained as a watchmaker's for many years, being occupied first by Mudge, who succeeded Graham, then by Mudge \& Dutton, and afterwards by the younger Duttons. It is No. 148, and now the offices of the Sporting Life. Graham was elected as a member of the Royal Society in 1720 , and chosen as a member of the council of that body in 1722. He contributed twenty-one papers on various subjects to the " Philosophical Transactions."

After the expiration of Booth, Houghton, and Tompion's patent, Graham devoted some thought to the cylinder escapement, which in 1725 he modified to practically its present form, and introduced into some of his watches. Securing to himself the monopoly of any of his discoveries was,foreign to his disposition. The reputation which English horology acquired on the Continent during the eighteenth century was due in no small measure to Graham's candid treatment of his brethren in the art in other countries. In answer to inquiries, Julien Le Roy received from Graham one of his cylinder escapement watches in 1728, and the French horologist's generous avowal of its superiority is worthy of his acknowledged greatness. But it must be admitted, after examination of surviving specimens, that Graham's cylinder escapements were wanting in the necessary closeness of construction afterwards attained by Ellicott and others ; and as Graham continued to use the verge escapement till his death, it may be assumed that he was not oblivious of the constructional difficulties presented by the cylinder. In his younger days he would undoubtedly have pursued the matter with his usual acumen and patience, till nothing was left for later artists to improve; but now his mind was taken up with astronomy and astronomical instruments, and the production of a perfect clock as an aid to the astronomer absorbed him, as I venture to suggest, almost to the exclusion of horological instruments for the pocket.

In all Graham's work his first consideration was to make every part most suitable for its purpose. Judicious embellishment in its 
proper place was not wanting, but it was quite subsidiary to usefulness. This trait is apparent in many little details of a splendid

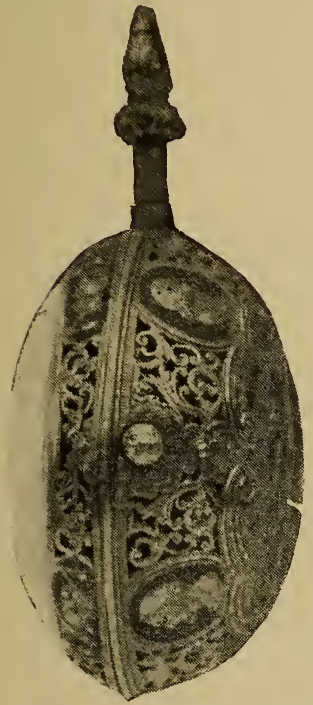

FIG. 441.--Repeating Watch by Graham. repeating watch shown in Figs. 441 and 442 made by him in 1714, when he was in the zenith of his power as a watchmaker, which belongs to Mr. Paul E. Schweder. Thus the pillars are of a plain cylindrical form, with turned bases and caps, whereas other horologists were lavish in shaping, decorating, and piercing these passive items, whose characteristic of strength and holding power was certainly not less apparent by Graham's more simple treatment. A little addition I have noticed in the watches of any other maker is a light spring jumper or click on the under side of the cap, for securely locking the cap spring. It has a fine enamelled dial and jewelled balance-cock. The piercing of both the gold cases and the repousse chasing of the outer one are perfect. On the movement and on both cases is the number 445 . On the back of the inner case are the letters M.P. arranged as a monogram. The lock spring is beyond the edge of the dial.

Attached to this repeater is also a useful little adjunct which apppears to have been invented by Graham, and, though not much seen in English work, became very popular with French makers. Projecting from the case is a small nib, or "pulse piece," called by the French sourdine, or " deaf piece," which upon being pressed keeps the hammer olf the bell and receives each blow. It not only enables those who have defective hearing or sight to ascertain the time by touch, but persons whose organs are perfect, who

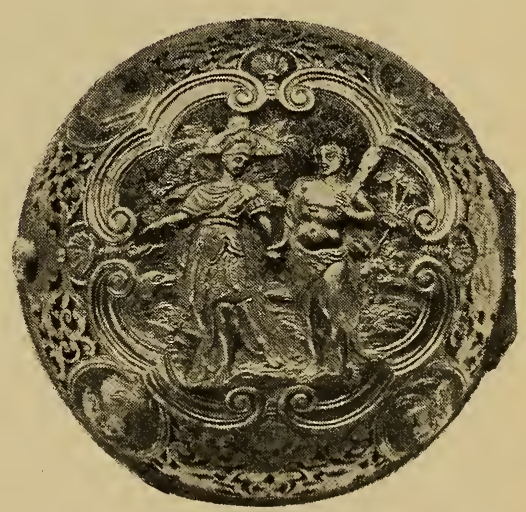

FIG. 442.-Back of Outer Cover. may desire to know the hour at night without disturbing an adjacent sleeper, can do so by pressing the pulse piece and counting the beats. 


\section{Old Clocks and Watches and their Makers}

Graham used stout proportionate-looking bows for his watch cases in place of the thin wiry rings previously in vogue, but by a curious obliquity Ellicott seems to have reverted to the former style. The difference in the two "handles" is very marked in specimens of the two makers I have before me. Another watch by Graham is in the possession of Mr. A. Ruskin Severn.

With the introduction of the pendulum, and more exact workman-

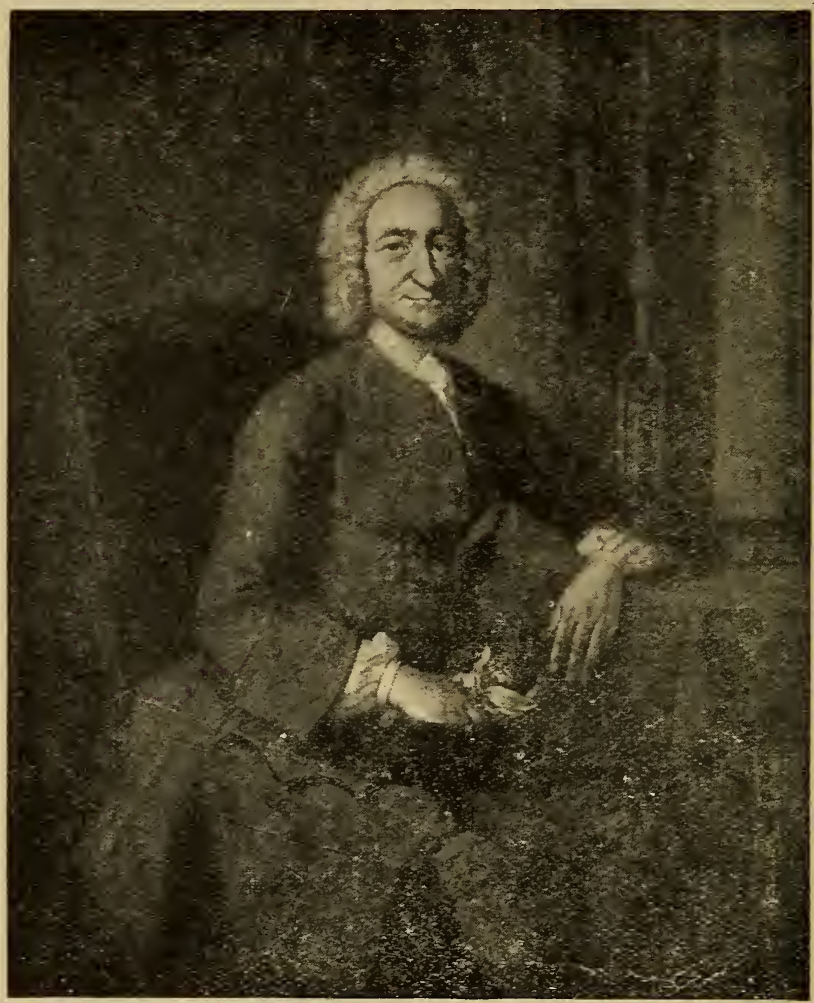

Fig. 443.-George Graham, 1673-1751.

ship and consequent improvement in the performance of timekeepers, the errors arising from expansion and contraction of metals in varying temperatures became manifest. Graham therefore turned his attention to the best means of preventing irregularity in the going of clocks when exposed to thermal changes, and invented the mercurial pendulum. His paper, communicated to the Royal Society in 1726, on "A Contrivance to avoid Irregularities in a Clock's Motion by the Action of Heat and Cold upon the Pendulum," demonstrated the suitability 
of mercury as a compensating medium after observations extending over a lengthened period.

The form of Graham's mercurial pendulum is shown in the sketch, Fig. 444; $a$ is the rod, $b$ the stirrup containing the glass jar of mercury $o$. For regulating the time, Graham employed a a sliding weight, $d$ upon the rod.

Another of Graham's inventions applicable to clocks of precision, and which is still unsurpassed in the opinion of many leading horologists, is the dead-beat escapement.

In the Wetherfield collection are two of his bracket clocks dating from about 1715, and also a month regulator timepiece which has a dead-beat escapement with jewelled pallets, a gridiron pendulum, bolt and shutter maintaining power; this is in a mahogany case and shows solar as well as mean solar time.

An elegant bracket clock by him, dating from about 1740 , is in the possession of Mr. J. Rutherford, Jardington, Dumfries, to whom I am indebted for the representation of it which is given in Fig. 448. The case of oak measures $15 \frac{1}{2}$ in. in height, and the dial $8 \frac{1}{4}$ in. by $4 \frac{7}{8}$ in. On the back plate is engraved a Cupid surrounded by scroll work. The regulator hand on the right of the dial raises or lowers the pendulum through the intervention of a snail-shaped cam.

Fig. $44 \tilde{5}$ is from a photograph of a small travelling alarm clock by George Graham. It is 5 in. high and $3 \frac{1}{2} \mathrm{in}$. broad, and is in the collection of Mr. Hansard Watt.

A very handsome long-case clock by Graham, which is also in the collection of Mr. Hansard Watt is shown in Fig. 446, and an enlargement of the dial in Fig. 447. This is a particularly fine example of the master's work.

Graham's mode of living was distinguished by its sim-

FIG 444 . Grahams Mercurial
Pendulum. plicity. As already stated, his later years were chiefly occupied with astronomical work, which he carried on as the valued coadjutor of Halley and Bradley till his death, which occurred in November 1751. By his will, executed in 1747, he left to his wife one-half of his personal estate. He also bequeathed $£ 20$ to the Clockmakers' Company, of which he was elected an assistant in 1717, and after filling the subordinate offices served as master in 1722-3. The grave of Tompion, in Westminster Abbey, was opened to receive his pupil, and the exceptional honour of their interment in that place is 


\section{Old Clocks and Watches and their Makers}

the best testimony that can be adduced as to the estimation in which these eminent horologists were held. Fig. 449 is a reduced facsimile

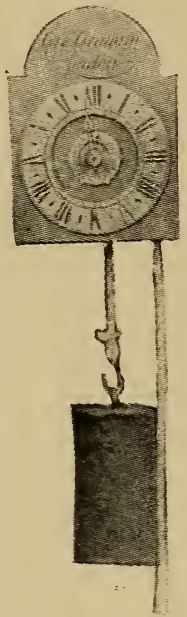

FIG. 445.-Small Travelling Alarm Clock by Gecrge Graham.

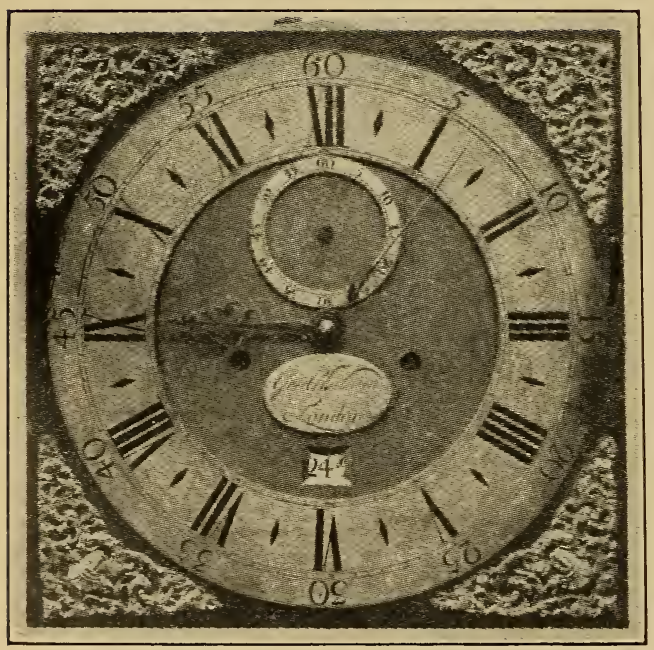

FIG. 447.-Enlarged Dial of Fig. 446.

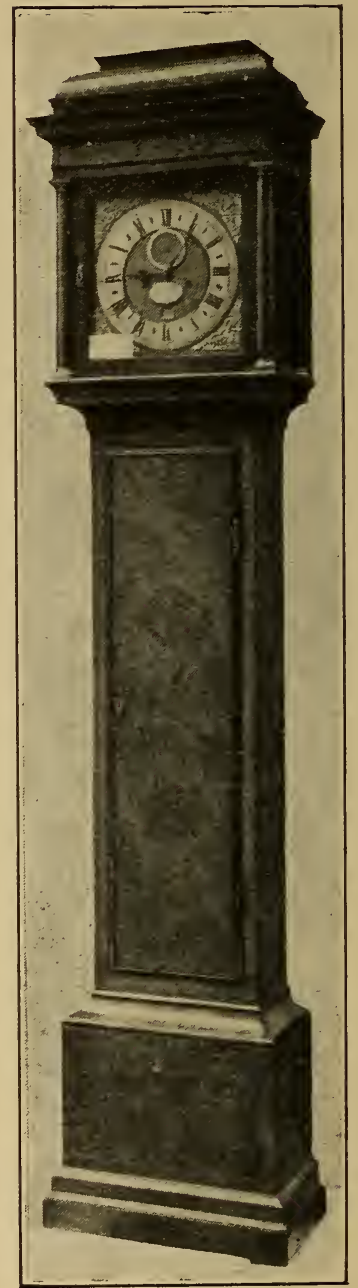

FIG. 446.-Long-case Clock by George Graham.

of the stone placed to mark their resting-place by an appreciative nation. 
In 1838 this slab was removed, and small lozenge-shaped stones, with the name and date, as in the sketch on p. 303, were substituted. In a little work, " Time and Timekeepers," published in 1842, Adam

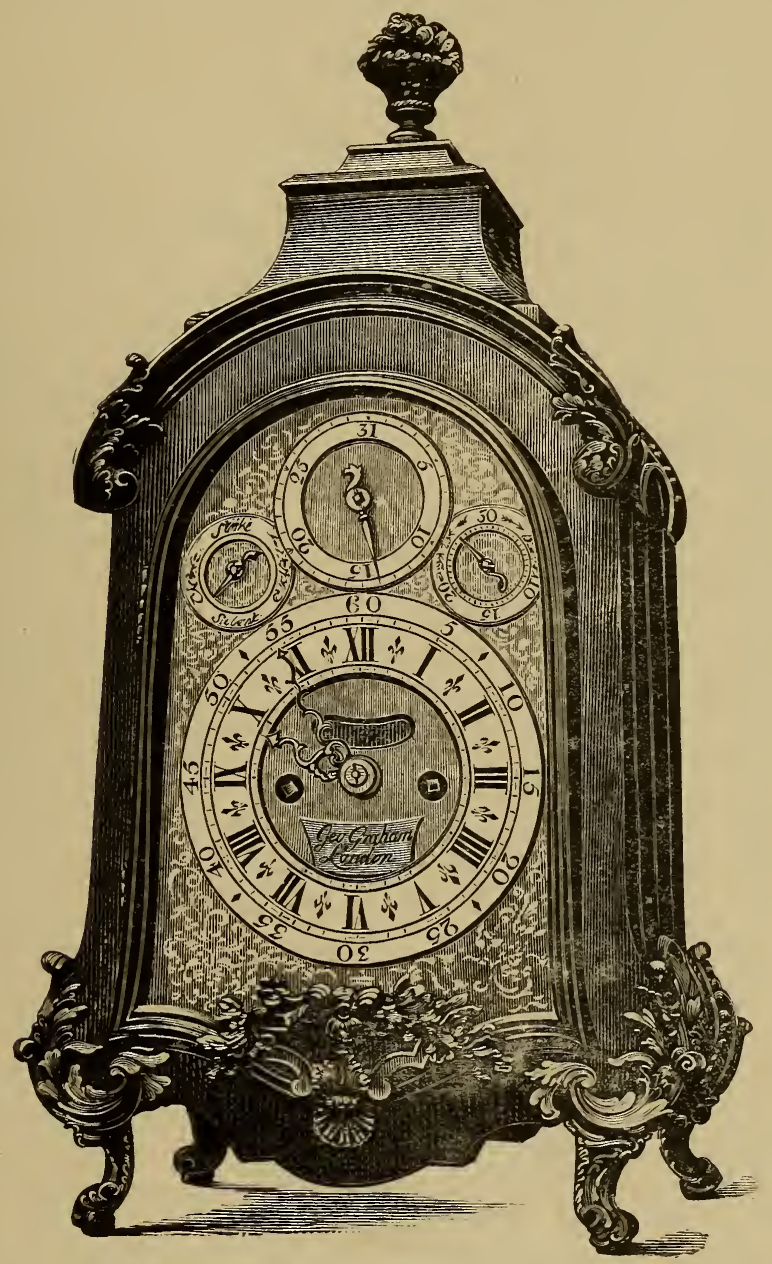

FIG. 448.-Elegant Bracket Clock by Graham, about 1740 .

Thomson, a Bond Street watchmaker, wrote: "Who would suppose that a small lozenge-shaped bit of marble is all that is left to indicate where lie the bodies of the ' Father of Clockmakers,' Thomas Tompion, and honest George Graham, greater benefactors to mankind than thousands whose sculptured urns impudently emblazon merits that 
never existed?" To this outspoken, indignant protest, and the good feeling of the late Dean Stanley, is due the reinstatement of the original memorial, for which English horologists will be ever grateful. "The passage was pointed out to me by a friend," said

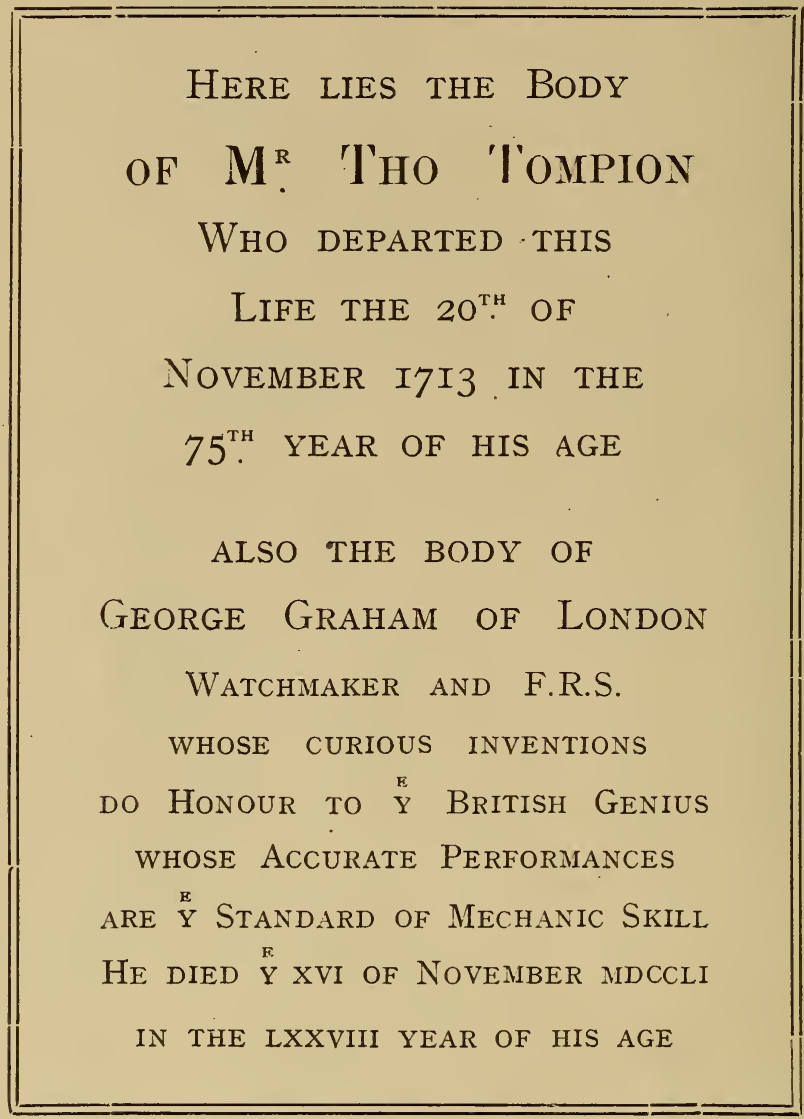

FIG. 449.-A reduced facsimile of the stone in Westminster Abbey placed to mark their resting place by an appreciative nation.

the Dean, "in consequence of the strong irritation expressed on the subject by an obscure watchmaker in a provincial town. The gravestone had not been destroyed, and was restored in 1866." Let us hope future generations of clock and watchmakers will jealously guard this tribute to the work of their fellow-craftsmen against any further attempt at desecration. 
The position of the tomb is marked by the two parallel lines on the accompanying plan of the Abbey Church (Fig. 451). E is the altar floor; $w$ the nave and western entrance; $N$, north transept; $s$, south transept and Poet's Corner.

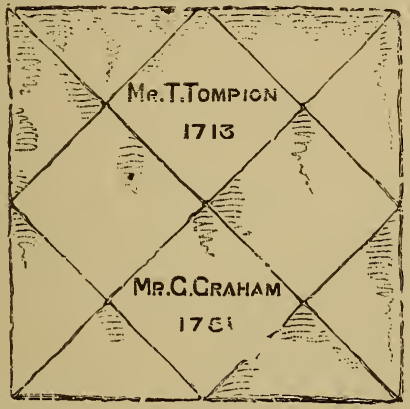

FIG. 450 .

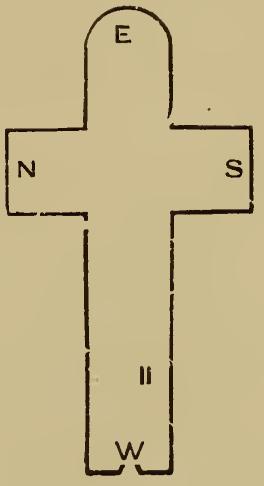

FIG. 451 .

Two of Graham's clocks were sold by auction in 1765 at the dispersal of the library of the Earl of Macclesfield, " a month clock, that shows equal and sidereal time, with the day of the month perpetual, with a compound pendulum," realised $£ 42$. 10s., and was bought by Lord C. Cavendish; " a month clock that shows equal and apparent time, with a quicksilver pendulum," fell to I.ord Morton for $£^{34}$ 2s. 6d. ; " a wheel barometer by Graham " was not sold.

Daniel Quare.-.-This worthy contemporary of Tompion was born in 1648. Mr. Robert Meldrum has a lantern clock, dating from about 1670, inscribed " Daniel Quare Londini fecit." I had a clockwatch by him, inscribed "Daniel Quare, St. Martin's le Grand, London." From its construction, one could with tolerable certainty decide that it was made about 1676 , and $I$ am therefore inclined to think St. Martin's le Grand was his first business address. It is said he afterwards caried on business at the "Plow and Harrow," in Cornhill, but all the authentic records I have been able to consult refer to him from 1680 to the time of his death as of the "King's Arms," Exchange Alley.

About 1680 he produced repeating watches of his own design, and when the Rev. Edward Barlow, in 1686, sought to patent a repeating device, Quare, backed by the Clockmakers' Company, opposed the monopoly. The case was considered by the Privy Council on 2nd 


\section{Old Clocks and Watches and their Makers}

March 1687, and Barlow's application for a patent refused. In Quare's arrangement a single push on a pin projecting from the case near the pendant sufficed to sound the hour and the quarters, while Barlow's required a distinct action for each. The king, after a trial of both repeating watches, gave the preference to that of Quare, which fact was notified in the Gazette. This watch was, in 1823, in the possession of Mr. John Stanton, of Benwell, near Newcastle-upon-Tyne

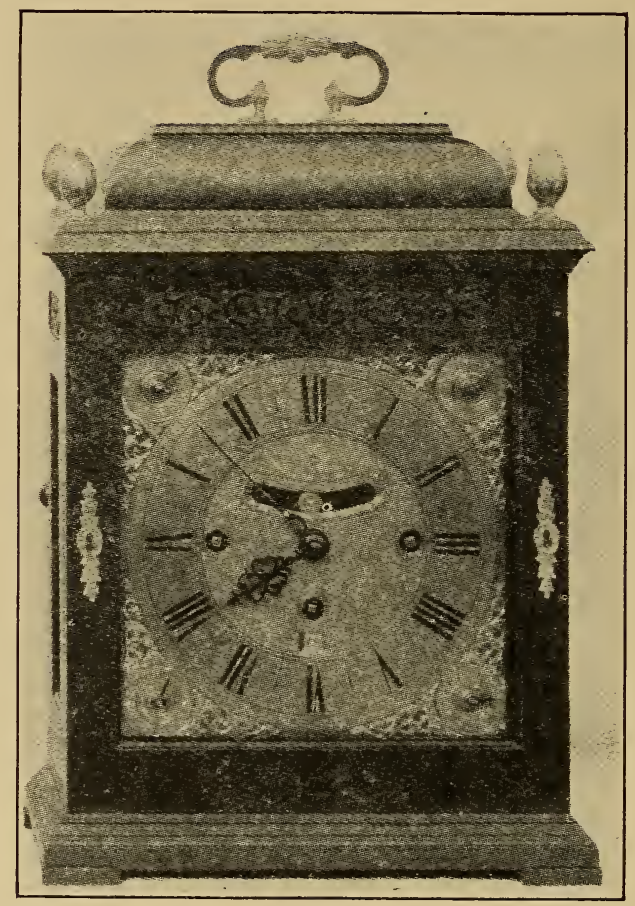

FIG. 452.-Fine Pracket Clock by Daniel Quare, chiming quarters on six bells.

from whose description of it in the Morning Chronicle the following is taken: "The outer case, of 22-carat gold, is embossed with the king's head in a medallion. The dial is of gold, with black Roman numerals for the hours and figures for the minutes. In the centre is a piece of pierced work in gold upon blue steel, representing the letters J.R. R.J. combined so as to appear like an ornamental scroll, 
above which is the royal crown. The box is pierced with scroll-work intermixed with birds and flowers. About the joint is engraved a landscape. The watch is considerably thicker than, but otherwise not much above, the common size."

Quare afterwards made another and more highly finished repeating watch for William III. ; it appears probable that in this, as in all subsequent repeaters by Quare, the pendant was thrust in to set the mechanism in action, instead of having a separate pin in the edge of the case for the purpose. Repeating watches seem to have taken the public fancy at once. Some of the early records refer to them as "squeezing watches."

Figs. 452 and 453 show front and back views of an ebony eight-day quarter clock, chiming on six bells, by Daniel Quare. This is a fine and rare example, about 15 in. high, and dating from about 1700 . The engraving on the back plate is of the usual "tulip" design, but is both elaborate and finely executed. (From the Wetherfield collection).

There is in the British Museum a small lantern alarm clock of Quare's make, which has, above

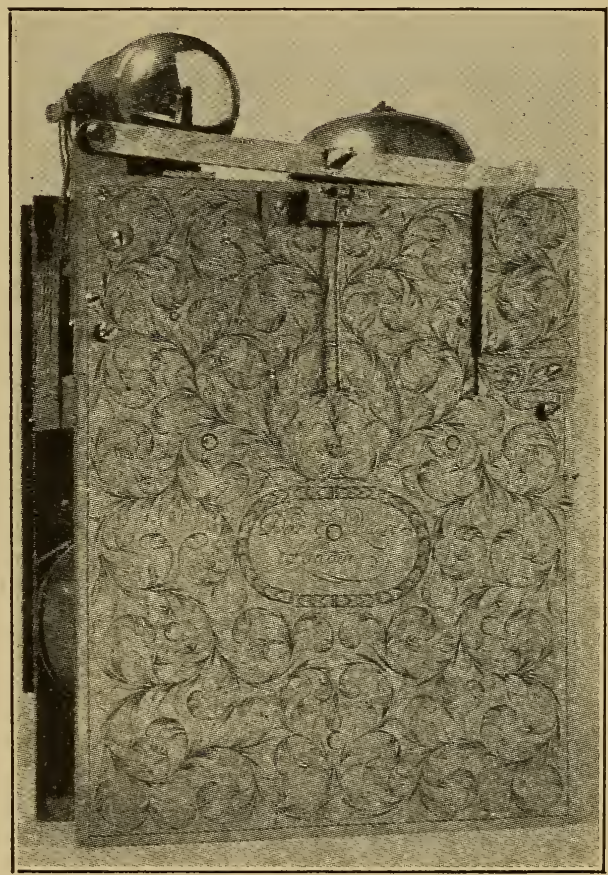

FIG. 453.-Engraved Back Plate of Fig. 452. the bell, a perforated dome surmounted by a handle for carrying. In the wardens' room at Drapers' Hall stands a long-case clock by Quare. A fine bracket clock by him in Windsor Castle is shown in Fig. 454 ; and a little clock, 6 in. in height, illustrated in Fig. 455, is said to have been the favourite timekeeper of Willıam III., and was brought to England by him. This also is at Windsor Castle. A bracket clock similar to 454 is in the possession of the Rev. Walter Scott. There are seven of Quare's clocks in the Wetherfield collection. 


\section{Old Clocks and Watches and their Makers}

Fig. 457 is a beautiful specimen of a long-case clock in burr walnut by Daniel Quare. The hands are very fine as will be seen by the enlarged dial on p. 308. The clock is in the collection of Mr. Hansard Watt, to whom I am indebted for the fine photographs illustrating it.

As splendid specimens of horological work of this period may be mentioned one-year clocks, of which at least three or four bear Quare's name. One of the most celebrated of these is at Hampton Court Palace. The case is of oak veneered with burr walnut or some similar wood, and, including a stand of gilt brass work, is $10 \mathrm{ft}$. high, the plinth being 22 in., the waist 48 in., the

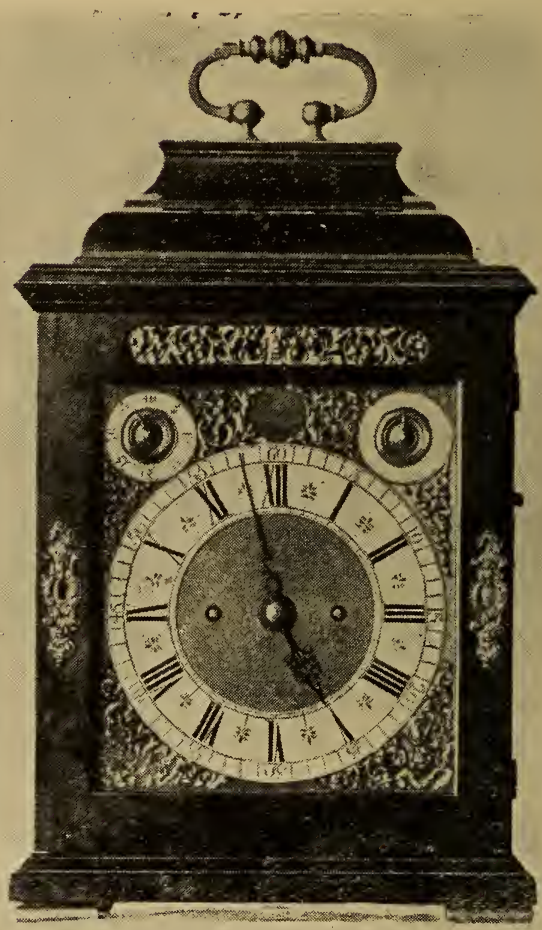

FIG. 454.-Bracket Clock, by Quare, at Windsor Castle.

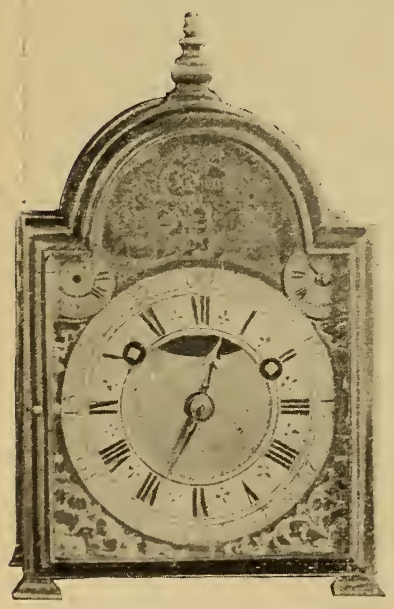

FIG. 455.-Favourite Timekeeper of William III.

hood $24 \mathrm{in.}$; the dome, $10 \frac{1}{2} \mathrm{in}$. high, is surmounted by a gilt brass figure, 12 in. high. Four other well-modelled gilt figures occupy the corners of the hood, as shown in Fig. 456, which is from a photograph lent to me by Messrs. Gaydon, of Kingston. The dial plate is 16 by $14 \mathrm{in}$., and along the bottom of it are three subsidiary dials; one shows the rising and setting of the sun, the middle one has an index and a scale for latitude; the index for the third is removed, but it was evidently for the purpose of disconnecting certain equation work, the circle being engraved on one side "Tempus apparens" and on the 
opposite " Tempus cquale." In 1836 Vulliamy substituted a dead

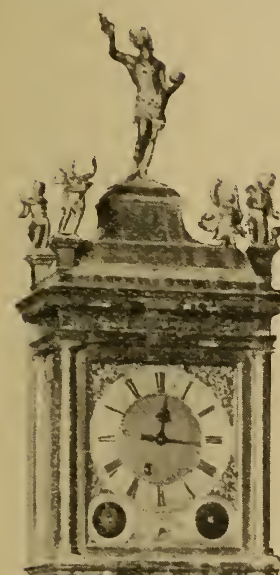

beat escapement and

a new pendulum for the original ones, but until 1898 the clock had not been going for some years. In the Philosophical Transactions for November and December, 1719 , is a paper by Joseph Williamson, claiming the invention of equation mechanism for clocks, and in it he mentions having made for Mr. Quare, among other twelvemonth clocks, the one at Hampton Court, which, by means of a cam moving in a slit in a piece of brass at the top of the pendulum spring, raised or lowered the pendulum as required in order to show apparent time. As this claim appears to have remained unchallenged, it may be accepted. Doubtless the reputation of many manufacturers then, as in later years, was acquired in great measure through the ingenuity and excel-

lent workmanship

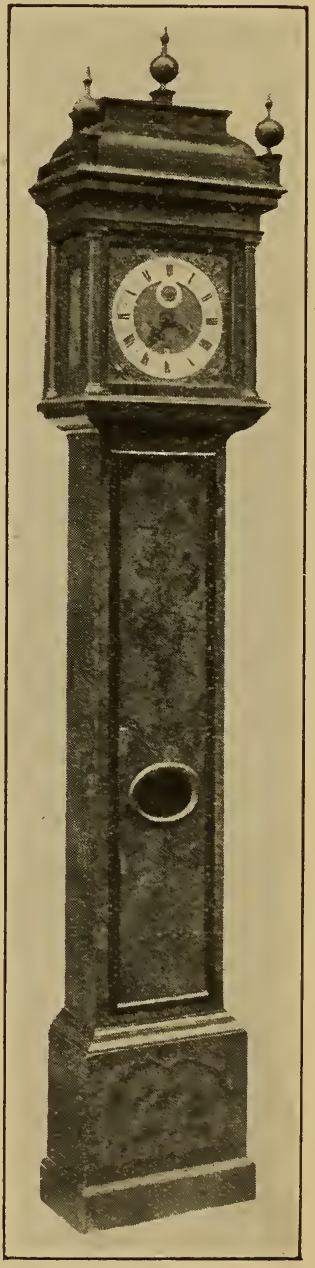

FIG. 457.-Long-case Clock, by Daniel Quare.
FIG. 456.-Quare's twelvemonth Clock at Hampton Court.

displayed by the chamber masters and other assistants whom they employed. Still it would be idle to attempt, now, to apportion the 


\section{Old Clocks and Watches and their Makers}

merit; the world-wide reputation of Quare remains as evidence of his individuality. He is mentioned in a comedy by Carlo Goldoni as the foremost of English horologists, then considered the first in the world.

Some years ago one of Quare's twelve-month clocks was in the possession of Mr. J. H. Arkwright, of Hampton Court, near Leominster, where it probably is still. Many stories have been told of the structure of this remarkable production, and in $1873 \mathrm{I}$ obtained the following very precise details concerning it from Mr. Palmer, a clockmaker of Leominster. The hour hand, beautifully pierced, fits tight on to the hour socket with a square ; the minute hand is pinned

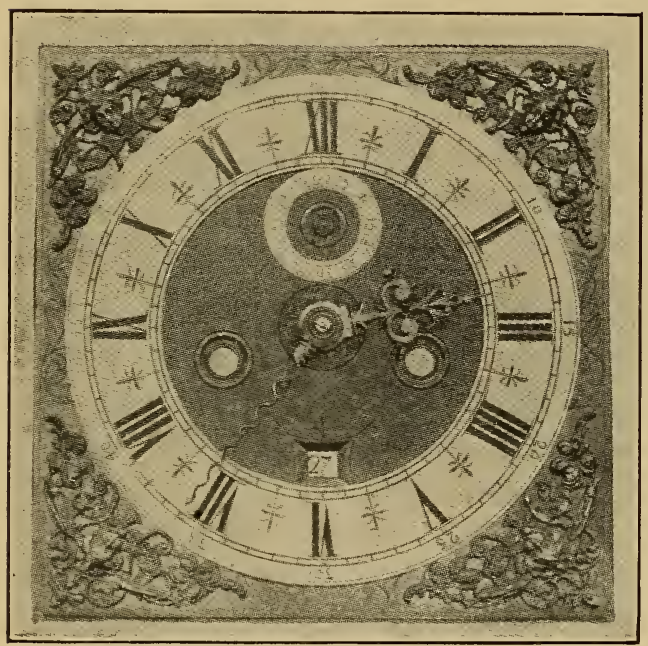

FIG. 458.-Dial of Clock, by Daniel Quare (see p. 306). on to a square with a collet as usual ; it has a counterpoise, and is not so elaborately pierced as the hour hand. The dial is 14 in. square, the centre being matted and gilt; the spandrels are also gilt, but left plain to show up the silver fretwork corner pieces. The hour circle is of brass, silvered; it is divided into minutes on the outside, and into quarters of hours on the inside. The name "Dan Quare " is engraved between the hour figures

7 and 6 , and "London" is engraved between the 6 and the 5 . On the dial plate just below the figure 6 the name is again inscribed in full, "Daniel Quare, London." The numbers of the teeth of the wheels in the train are as follows:-

\begin{tabular}{|c|c|c|c|c|}
\hline \multirow{2}{*}{\multicolumn{2}{|c|}{ Great wheel }} & \multicolumn{2}{|c|}{ Teeth. } & Leav \\
\hline & & 96 & & \\
\hline Fir: & & 96 & pinicn & \\
\hline Second & d ,", & 90 & ," & \\
\hline Centre & e ,", & 60 & ,, & 10 \\
\hline hird & & 56 & ., & \\
\hline wing & ,", & 30 & ,, & \\
\hline
\end{tabular}

The minute wheels have each thirty-six teeth, well shaped and very regular; the minute pinion has six leaves ; the hour wheel has 
seventy-two teeth, and it is keyed on to the hour socket. The centre, third, and swing wheels are very small and light, the diameter of the last-named is $\frac{7}{8}$ in. ; the pivots also are very small. These three pinion arbors are an inch shorter than the other arbors of the train, and are pivoted into a small false plate which is pinned by four small pillars on to the inside of the large pillar plate. The collets on which these three wheels are mounted are either brazed or driven on the pinion arbors. The third and swing wheel pinions are thickest at the collet, and taper off with a gentle curve to the head of the pinion. The frame plates are $7 \mathrm{in}$. by 5 in. There are six pillars; they are riveted into the back plate, and the front plate is kept on by pins. The pallets are of the original anchor form. The seconds pendulum has a lenticular bob, and altogether weighs $2 \mathrm{lbs}$. $1 \frac{1}{2} \mathrm{ozs}$. It is suspended from the same cock that carries the back pivot of the verge. The suspension spring is $2 \frac{1}{2} \mathrm{in}$. long, narrow, and very thin. There is no degree plate, but a brass finger projecting from the base of the case is filed to an edge just below the pendulum, and serves to estimate the vibration (which is about $1^{\circ}$ on each side of zero), and also to set the clock in beat when fixing it. The case is of oak, handsomely veneered with walnut.

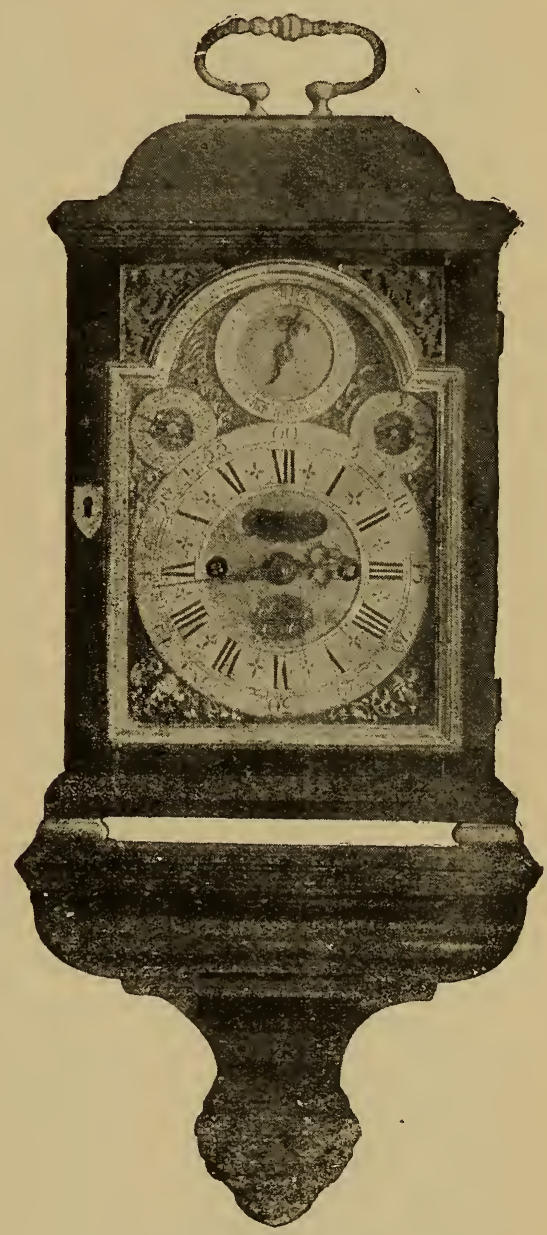

FIG. 459.--Bracket Clock, by
Quare.

The barrel has fourteen grooves. The clock weight and pulley weigh $81 \mathrm{lbs}$.; the fall is $4 \mathrm{ft}$. 6 in. ; the length of the weight and pulley is $1 \mathrm{ft}$. 6 in., which, added to the fall, makes $6 \mathrm{ft}$., which is 
the distance from the bottom of the clock case up to the seat board; the weight is hung by a double line. The

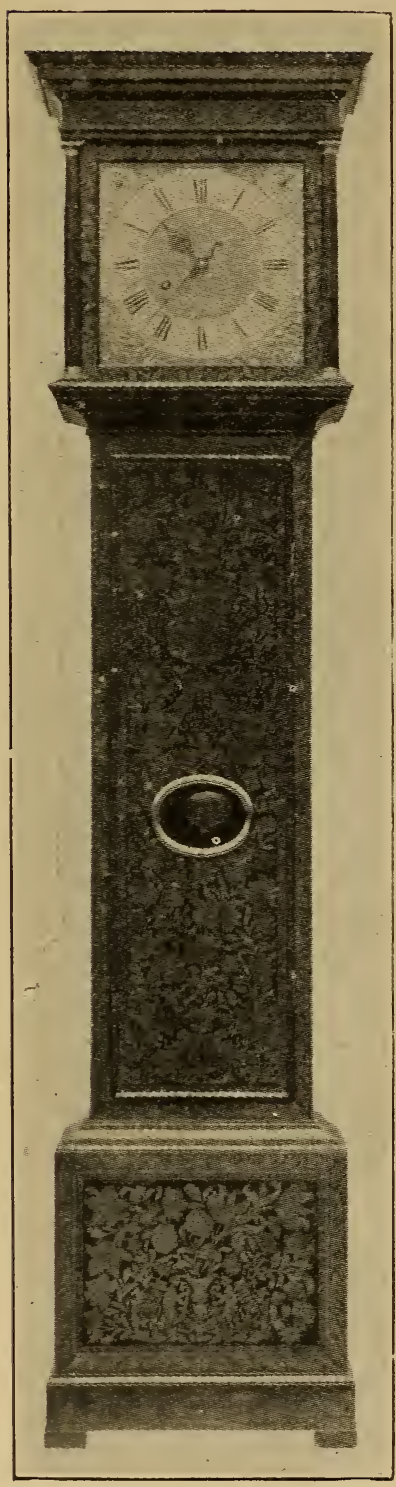

FIG. 460.-One-year Timepiece, by Dan el Quare.

Fig. 459 shows a little bracket clock by Quare, which belongs clock is still an excellent timekeeper. On casting up the numbers of the train it will be found to go 403 days, 4 hours, and 24 minutes.

Now, I cannot help thinking this is a very extraordinary achievement, for $81 \mathrm{lbs} . \times 4 \mathrm{ft} .6 \mathrm{in}$. to drive the clock for more than thirteen months seems almost incredible; still, I believe the facts are as I have stated them. There is no doubt that everything was done that was possible to economise the force. The very small and light swing wheel, the balanced minute hand, and the small shortened arbors with extra fine pivots, all conduce to the end in view.

The twelve-month timepiece by Daniel Quare shown in Fig. 460 forms one of the gems of the Wetherfield collection and is remarkable for the somewhat peculiar outline of the case and for its extremely beautiful marquetry surface. Of the subsidiary discs in the upper corners of the dial-plate the right hand one is a twelve-month calendar and that on the left is engraved "Tempus cequale" and "Tempus apparens," and the main dial can be caused to show at pleasure either mean time or solar time according as the pointer is set.

At Marston House is a month-clock by Quare belonging to the Earl of Cork. Mr. C. F. Bell has another, and in the Wetherfield collection are several calculated for the same period. Quare's dials were particularly good, as may be judged from the specimen shown in Fig. 458, for which I am indebted to Mr. Hansard Watt. 


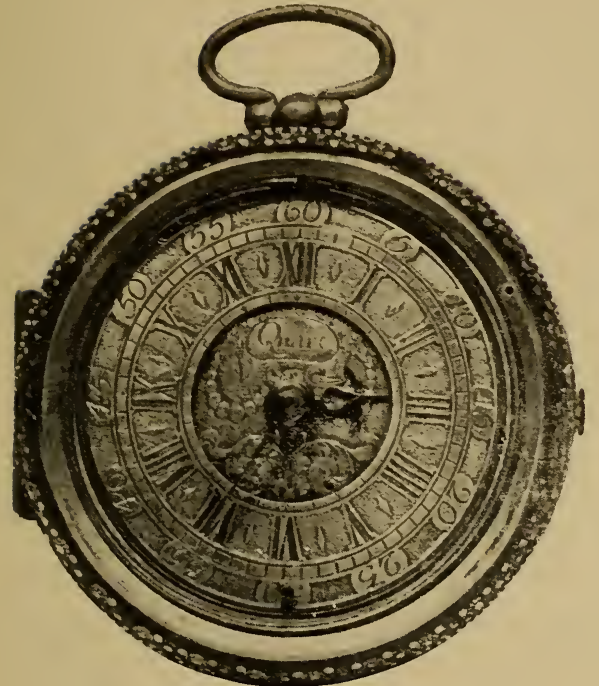

FIG. 461.-Watch with Silver Dial, by Quare.

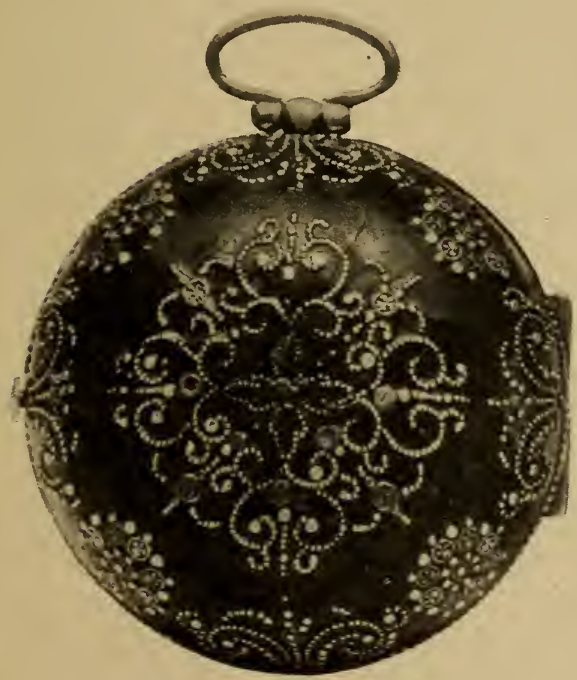

FIG. 462.-Outer Case of Red Tortoise-shell piqué.

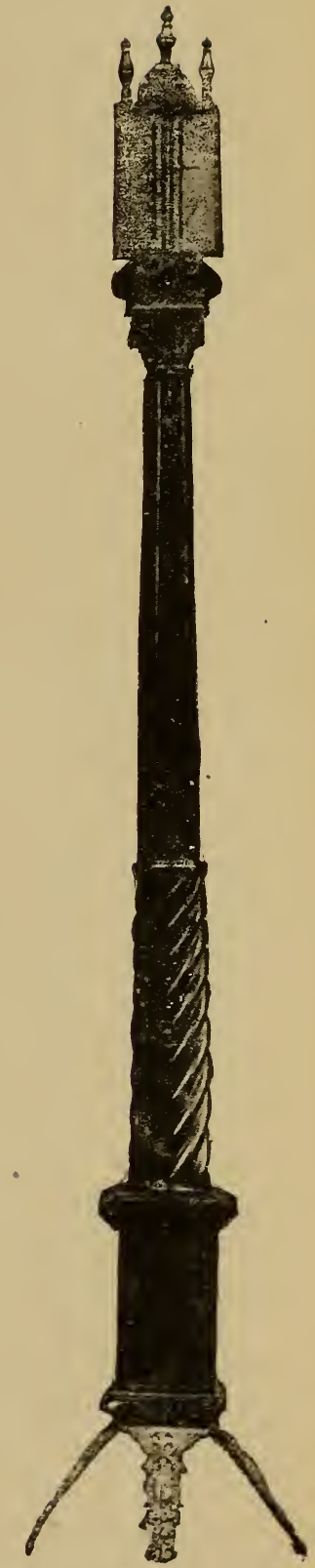

FIG. 463.-Barometer. by Quare. 


\section{I2 Old Clocks and Watches and their Makers}

to Mr. J. W. Abbot. The extreme height of the clock is $12 \mathrm{in.}$, and the depth of the bracket $5 \frac{1}{2}$ in. The clock case is covered with tortorse-shell, and is $6 \frac{1}{2} \mathrm{in}$. wide. The handle, the feet, and the bezel of the door are of silver.

By several writers Quare is credited with the invention of the concentric minute hand, but such indicators were in use long before his time, the hour hand being driven from the great wheel, and the minute hand from the centre arbor. Quare's improvement consisted in devising mechanism so that the hour and minute hands should be actuated together. The earliest form of this device is applied to the clock-watch, which has been already referred to. At first sight there appears to be motion work of the kind now in general use, but an important variation is apparent on examination. Both of the hands are driven direct from the great wheel. A wheel and pinion corresponding to the minute wheel and nut fit on to a squared arbor projecting from the great wheel. The canon pinion runs loose on a stud in the centre of the watch, and on it is placed the hour wheel in the usual way. The wheel and pinion attached to the great wheel are of brass, and to allow the hands to be set they fit friction tight on to a steel boss which has a square hole to correspond with the end of the great wheel arbor. Attached to the bottom face of the canon pinion is a snail for releasing the striking work every hour. Under the arrangement in vogue before Quare's time, by which each hand was driven independently of the other, if the minute hand was set forward or backward, the hour hand would cease to correspond with it. As the canon pinion was mounted on a stud, there was no necessity of having the second wheel of the train in the centre of the movement, and so the going train was continued to one side of the centre, leaving the other side for the striking work. The one advantage of the present arrangement of motion work over Quare's is that the minute hand now follows the motion of the centre pinion without shake, but in Quare's plan the position of the minute hand was not so absolute on account of the backlash of the motion wheels.

A watch by him with silver dial and outer case of red tortoise-shell piqué, dating from about 1690 , which is in the Pierpont Morgan collection, is shown in Figs. 461 and 462 . A quarte1-repeating watch of later date, with pierced and engraved silver cases, is in the South Kensington Museum.

In 1695 Quare obtained a patent for a portable weather glass, and six or seven instruments made by him according to his specification are known to exist. One of them is in the United Service 
Institution; another, belonging to Mr. C. F. Bell, is by his favour shown in Fig. 463. The case is of walnut; three urns surmount the head, and two of them when rotated move the pointers on the scale, which is of gilt metal richly engraved. But the contrivance for which the patent was granted consists of a pad to cover the bottom of the tube. The cistern is of ivory, and attached to the bottom of it is a brass nut, through which a threaded rod passes; on the lower extremity of the rod is a knob, and the upper carries the pad. If the barometer is turned upside down until the tube is full of quicksilver and the screwed rod turned for the pad to block the tube, the instrument may be carried about in any position.

Quare was admitted as a brother of the Clockmakers' Company in 1671 , and served as master in 1708. During the latter part of his career he took into partnership Edward Horseman, who had been apprenticed to him, and the business was carried on at the same address under the title of Quare and Horseman.

Reproduction of a selection from the inquiries respecting Quare's timekeepers may not be out of place. On p. 223 is one which refers to an attempt to indicate minutes with the hour hand by dividing the circle into but six hours in order to obtain room for the minute marks :--.-

"Lost, between Firle and Shoram Ferry, in Sussex, a gold watch, made by D. Quare, in a black Shagreen Case with a Cypher J.C. Whoever brings it to Mr. Shelley, Goldsmith, in Panton Street, near the Haymarket, shall have 2 guineas reward" (London Gazette, 16th May 1691).

"Lost, April 25, a Gold Minute Pendulum Clock, the name on upper plate D. Quare, London, 726 engraven on it, and a Shagrine case. Whoever gives notice of it to Daniel Quare, Clockmaker, at the King's Arms in Exchange Alley, shall have 3 guineas reward; or if already bought, their money returned again with content" (London Gazette, 26th May 1692).

" Lost, on the road between Hungerford and Marlborough, a Gold Repeating Watch, made by Quare and Horseman, with an old Gold Chain, and several seals hanging to it. Whosoever will bring them to Mr. Horseman, at Mr. Quare's, in Exchange Alley, shall have 20 guineas reward and no questions asked " (London Gazette, 9th August 1718).

"Lost, on the road between Newark and Tuxford, about 22 of June last, a Gold Watch, made by Quare in London, No. 4448, double cased and winds up on the dyal Plate. Whoever shall secure the watch if offered for sale, or send it or notice ( $\mathrm{f}$ it to Mr. Andrew Drummond, Goldsmith, by Charing Cross, shall receive 5 guineas reward" (London Gazette, 8th July 1732).

The books of the Society of Friends show that Daniel Quare was a trusted man among the Quakers, and that he at first refused the office of Clockmaker to George I. because he objected to take the wath of allegiance; the difficulty respecting the taking of an oath was, however, overcome, and freedom to enter the palace by the back stairs accorded to him. "The Yeoman of the Guard," he said, "lets me frequently go up without calling anybody for leave, as 


\section{I4 Old Clocks and Watches and their Makers}

otherwise he would tho' persons of quality." He had one son, Jeremiah, who does not seem to have followed the craft, and three daughters. At the marriage of his daughter Elizabeth with Silvanus Bevan in 1715 , among witnesses who signed the deed of settlement was the Duchess of Marlborough. Daniel Quare died at Croydon in 1724, and was buried in the Quakers' ground at Bunhill Fields, Finsbury.

Fromanteel.-Fromanteel, also spelt " Fromantel," " Fromantil," and "Fromenteele." Ahasuerus Fromanteel primus, of Dutch extraction, was a maker of steeple clocks at East Smithfield. In 1630 he was warned by the Blacksmiths' Company to bring in his certificate of seven years' service as apprentice. With this he complied, and was forthwith elected free of the company. On the incorporation of the clockmakers, he joined them. In 1656 he became restive under the somewhat inquisitorial proceedings of the court relating to his apprentices and the antecedents of his workmen, and for a long period in the history of the guild his name appears in petitions and other documents, expressing disapproval of the management of the company, or as being called to account for infraction of its rules, some of which, it must be confessed, could not fail to be exasperating to a man with an extensive business, as Fromanteel appears to have had.

A second Ahasuerus Fromanteel appears on the list as free of the Clockmakers' Company in $\mathbf{1 6 5 5 .}$

A third Ahasuerus Fromanteel was, in 1663, on completion of his apprenticeship with Simon Bartram, admitted as a member of the Clockmakers' Company.

In 1663 also, John Fromanteel, who had been apprenticed to Thomas Loomes, was admitted to the freedom.

Then Abraham, son of Ahasuerus Fromanteel, was elected in 1680.

In 1658 proceedings were taken against Ahasuerus Fromanteel and his son Louis for keeping more apprentices than the regulations of the company allowed, so that there was a fairly large family of the Fromanteels in the clock trade at that period, and most of them seem to have been connected in business.

Beyond their squabbles with the Clockmakers' Company, there is a celebrity attaching to them as being the first to introduce the pendulum into England, the assumption being that one of the family had seen or heard of Huygens' clock in Holland, and brought particulars of it over to his relatives. Their claim has been challenged on behalf of Richard Harris ; and it has also been asserted that Dr. Hooke investigated the properties of the pendulum as a controller for timekeepers before Huygens applied it. However, there is evidence 
that the claims of the Fromanteels to its introduction from Holland, if not unanimously allowed, was accepted pretty generally at the time.

Under date lst November 1660, Evelyn, in his Diary, writes:

"I went with some of my relations to Court to show them his Maj ${ }^{\text {ties }}$ cabinet and closet of rarities... Here I saw . . . amongst the clocks one that showed the rising and setting of the sun in $\mathrm{Y}^{\mathrm{e}}$ Zodig, the sunn represented by a face and raies of gold upon an azure skie, observing $\mathrm{Y}^{\mathrm{e}}$ diurnal and annual motion rising and setting behind, and landscape of hills, the work of our famous Fromantel."

Again, under date 1st April 1661, Evelyn records that he "dined with that great mathematician and virtuoso, Mr. Zulichem (Huygens), inventor of the pendule clock;" and on 8th May, "I returned by Fromantel's, the famous clockmaker, to see some pendules, Mr. Zulichem being with us."

The clock by John Fromanteel which is shown in Fig. 464 belongs to $\mathrm{Mr}$. H. A. Bleichert and has a curious history. In the

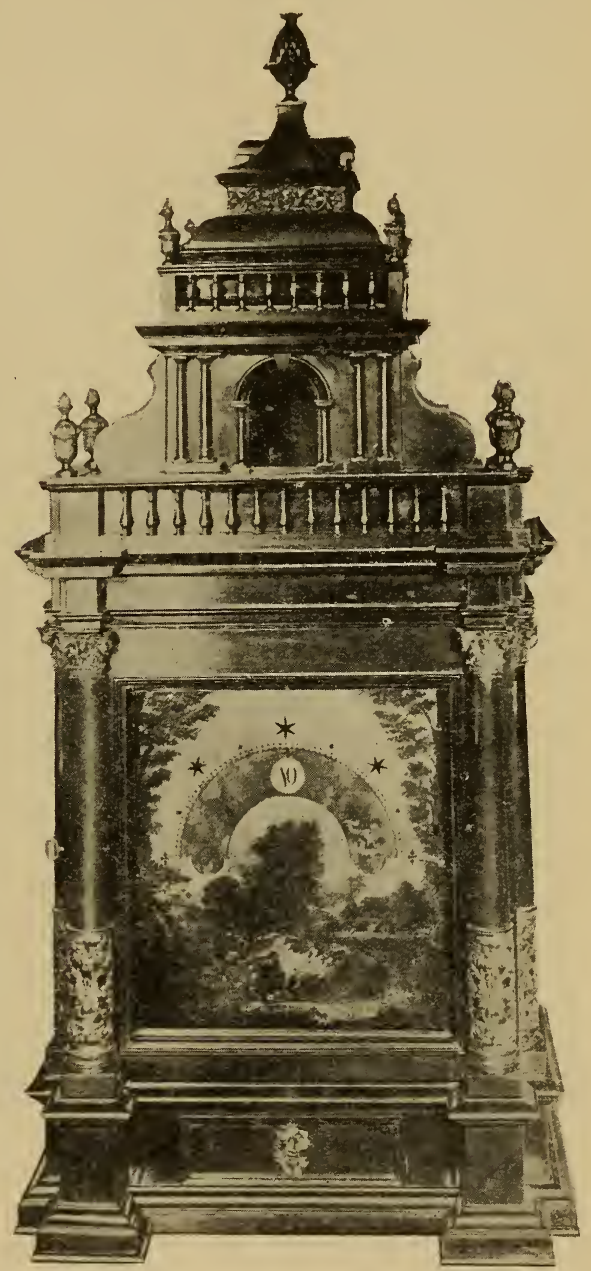

FIG. 464.-Clock, by John Fromanteel. last edition of this book it appeared with a small dial and the signs of the zodiac showing in the curved recess above, but Messrs. A. \& H. Rowley found the movement had been turned hinder part before, probably for the convenience of winding in front, and that originally the hour was 


\section{3i6 Old Clocks and Watches and their Makers}

indicated by revolving discs on the plan described in detail on pp. 228,245 and 327 . They restored it as nearly as possible to its pristine state, and to them I am indebted for a photograph of it. The hour numerals and divisions are perforated and so the clock answers the purpose of a night clock of the kind referred to on p. 270 .

Fig. 465 shows a hanging clock in an ebonised case, by " A. Fromanteel, London," of

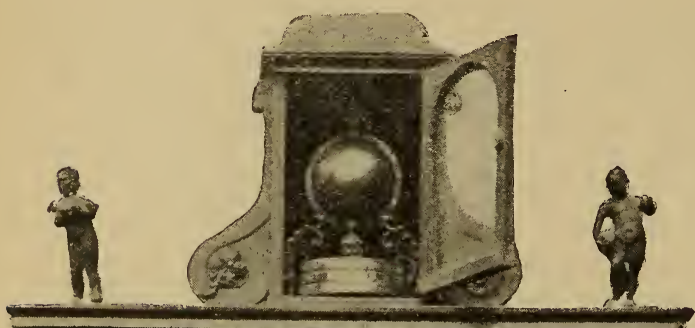
about the same date, and for which I am indebted to $\mathrm{Mr}$. Thomas Wyat The dial is of brass with a silvered band to contain the hour numerals, which are very small and formed each within a ring. The original hand is missing. There are three bells and five hammers, the hours and first, second, and third, quarters being sounded. The movement is well made, with three trains, the back plate in one piece, the front arbors carried in three separate strips so that any of the trains may be removed separately. The pillars are square, and on one is engraved the name of the maker as quoted :

FIG. 465.-Hanging Clock in Ebonised Case.

the plates are fastened by hooks which fit into slots cut in the pillars. Below the moon are silvered rotating discs with figures on the edges to indicate the ages of the lunar and the calendar months. This was a long-case clock when I saw it, but examination showed that the lower part was a later addition. All that was original of the case is given in the engraving. 
At the Guildhall Museum is a very well made clock by Ahasuerus Fromanteel dating from about 1675 . It has a bob pendulum; dial $8 \mathrm{in}$. square, with matted centre and cherub head corners. It is furnished with what is called the "bolt and shutter maintaining power." In this device a shutter which obstructs the winding hole has to be lifted before the key can be inserted, and this action causes

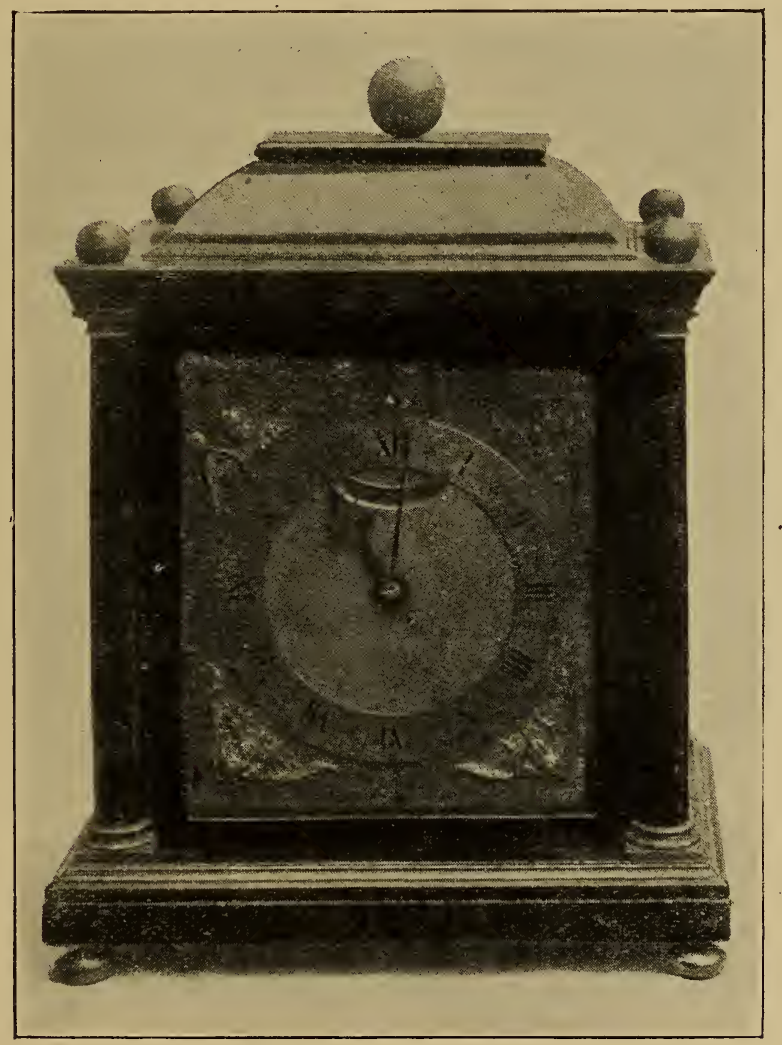

FIG. 466.-Choice and Interesting Clock, by A. Fromanteel.

a spring or a weighted lever to impel the wheels during the operation of winding, when the driving weight is inoperative.

The clock shown in Fig. 466 is a magnificent and very choice specimen The case is ebony veneered on oak The door in front is opened by releasing a concealed spring and the case lifts off in the manner of an early long-case clock. The construction of the whole 


\section{I 8 Old Clocks and Watches and their Makers}

movement is rare and extremely curious. It will be noted in Figs. 467 and 468 that the winding squares are not within the hour circle and in order to place thenı where they are the maker has employed a most ingenious system of double cranks at the back of the movement to connect the winding squares with the barrels. The escapement is crown wheel with a direct bob pendulum, regulating from the dial.

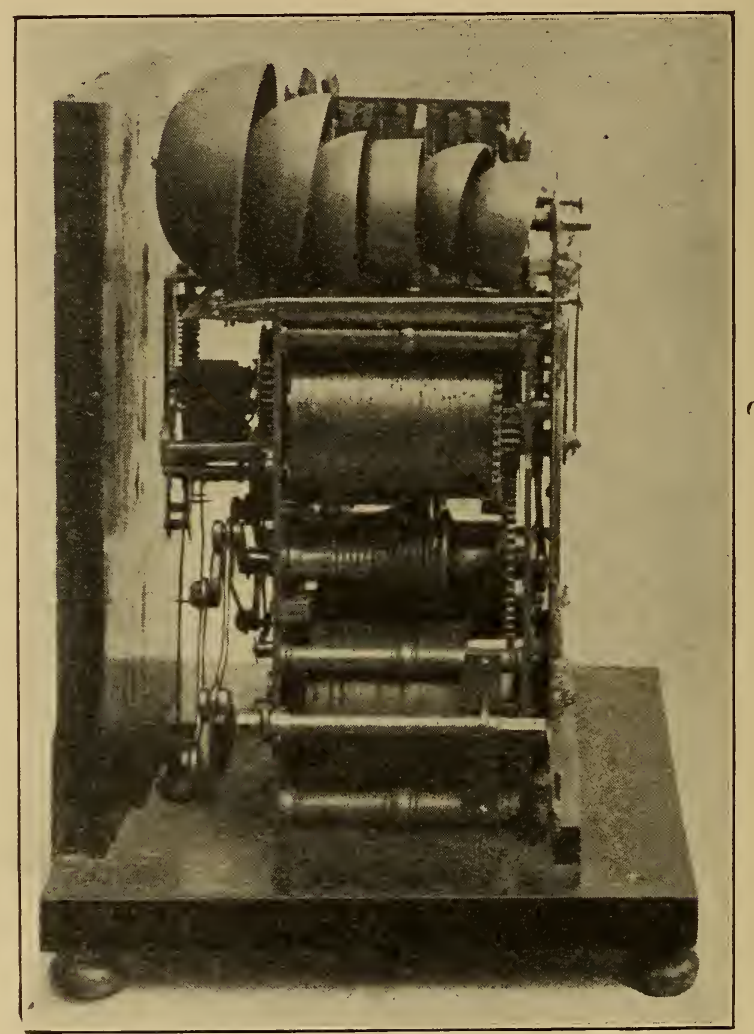

FIG. 467.-Showing curious construction of Fig. 466.

The clock strikes ting-tang quarters and the hours on separate bells, and at 5, 9, and 12 o'clock plays one of two tunes on eleven bells. The maker's name is engraved along the bottom of the dial, " A. Fromanteel Londini fecit." Height, 14 in. ; width 12 in. ; depth, $9 \frac{1}{2}$ in. ; dial, $7 \frac{3}{4} \mathrm{in}$. by $8 \frac{1}{4} \mathrm{in}$. This clock is in the collection of Mr. Hansard Watt to whom I am indebted for the very fine photographs illustrating it. 
Mercurius Politicus for 27 th October 1658 contained the following advertisement which also appears in the Commonwealth Mercury of Thursday, 25th November 1658 :-

" There is lately a way found out for making clocks that go exact and keep equaller time than any now made without this regulator, examined and proved before His Highness the Lord Proctor (Protector?), by such doctors whose knowledge and learning is without exception, and are not subject to alter by change of weather, as others are, and may be made to go a week, a month, or

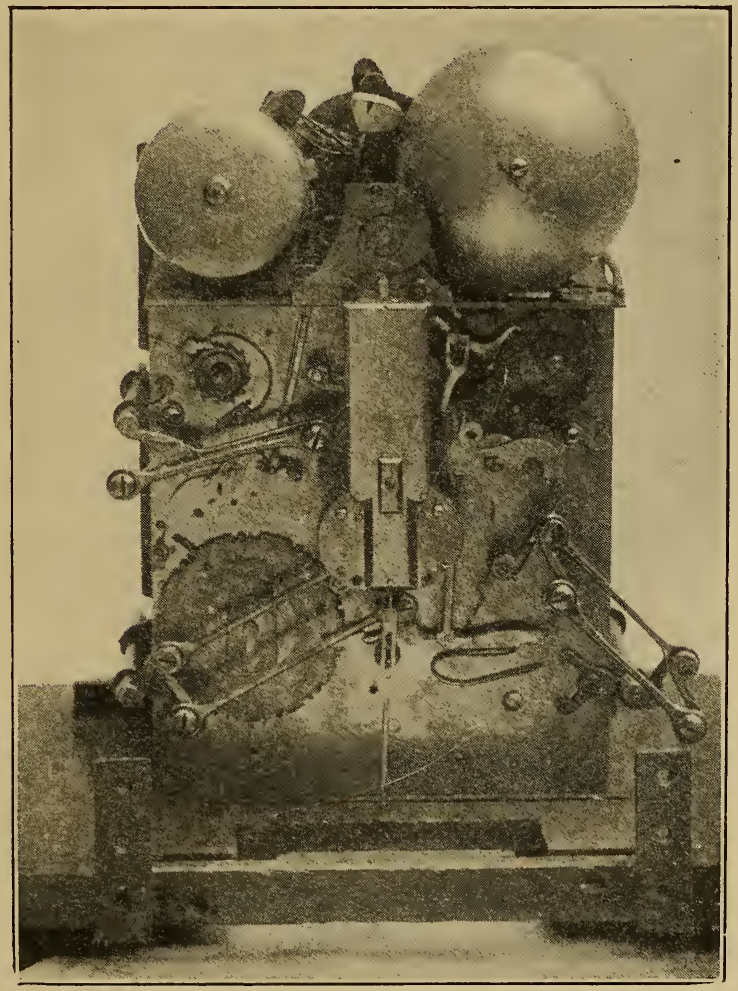

FIG. 468.--Showing curious construction of Fig. 466.

a year, with once winding up, as well as those that are wound up every day, and keep time as well, and is very excellent for all house clocks that go either with springs or weights; and also steeple clocks that are most subject to change of weather. Made by Ahasuerus Fromanteel, who made the first that were in England. You may have them at his house on the Bankside, in Mosses Alley, Southwark, and at the sign of the Mere Maid, in Lothbury, near Bartholomew Lane end, London."

Mosses Alley, or Moses Alley, was a passage leading from the northern end of Bankside, Southwark, to Maid Lane. 


\section{Old Clocks and Watches and their Makers}

The Mermaid in Lothbury was for over a century a noted shop for clocks. In 1650 Thomas Loomes, who was associated with the eldest Fromanteel in his attacks on the government of the Clockmakers' Company, and to whom John Fromanteel was apprenticed, resided there, and, after the time of Loomes, it was occupied by John Fromanteel. Mr. D. A. F. Wetherfield has a remarkably wellmade long case clock by him dating from 1676-80. It is shown in Fig. 469. The dial is $10 \mathrm{in}$. square with cherub corners, and in one line along the bottom is the inscription, "Johannes Fromanteel, Londini fecit." Around the hour circle every minute from 1 to 60 is numbered The case is of walnut with small raised panels. The frame is large, having three trains, viz., going, striking, and ting-tang. The pendulum makes but forty-eight beats a minute and is therefore unusually long; regulation is effected by means of a large milled nut fixed above the pendulum cock, the spring rising and falling between chops as in many modern clocks. It has the bolt and shutter maintaining power referred to on p. 317. The striking at the hour is peculiar, there being four bells of different notes, the shape of Chinese gongs, and four hammers which are on one arbor and strike a chord at each blow. The quarters are sounded on two bells.

There are two long-case clocks by John Fromanteel at the Dutch Church, Austin Friars, and one at the Philadelphia Library. Daniel O'Connell had a long-case clock by A. Fromanteel which was very similar to Fig. 469. Mrs. Benwell has a long-case clock by " Fromanteel " dating from about 1720 .

Dr. Hooke.- Robert Hooke was born in 1635 at Freshwater, Isle of Wight. After his father's death in $\mathbf{1 6 4 8}$ he resided with Dr. Busby, headmaster of Westminster School. He entered Christ Church College, Oxford, in 1653, and there his genius soon attracted the notice of Dr. Wallis, whom he frequently assisted in his chemical operations. Dr. Wallis introduced Hooke to the Hon. Robert Boyle, who engaged him as an assistant in his mechanical and philosophical works.

Hooke took part in and wrote upon all the scientific questions of his time. Sir Isaac Newton styled him "The Considerer." On the institution of the Royal Society he became one of its fellows, was afterwards entrusted with the care of its Repository, and made Professor of Meclianics to that body. About the same period he was elected Professor of Geometry in Gresham College.

I have been unable to obtain any portrait of Hooke, but will quote the following description of him from Aubrey's " Lives of Eminent Men : " "He is of middling stature, somewhat crooked,_pale faced, 
and his face but little belowe, but his head is lardge; his eie is full and popping, and not quick; a grey eie. He has a delicate head of haire, browne, and of an excellent moiste curle. He is and ever was very temperate and moderate in dyet, \&c. As he is of prodigious inventive head, so he is a person of great vertue and goodness."

He discovered that the resilience of a spring is proportional to the angle through which it has been wound, and propounded the whole theory in the sentence, "Ut tensio sic vis," meaning that the force is proportionate to the tension. He proposed to patent his discovery in 1660, and, to quote his words, "Sir Rubert Moray drew me up the form of a patent, the principal part whereof, viz., the description of the watch, is his own handwriting, which I have yet by me; the discouragement I met with in the progress of this affair made me desist for that time."

Derham describes the earliest of Hooke's essays in this direction as a " tender straight spring, one end whereof played backward and forward with the ballance." It is stated that several watches were made under Hooke's supervision at this period, and one of the first to which the balance-spring was applied he is said to have presented to Dr. Wilkins, afterwards Bishop of Chester, about 1661 .

It appears that Hooke then conceived it to be an advantage to have two balances coupled together, and had two double balance watches constructed. In the first, which had no balance-spring, the escape wheel was placed in the centre of the movement with its teeth in a horizontal plane. There were two verges standing vertically on opposite sides of the wheel and connected with each other by means of toothed wheels of equal size; each verge had one pallet and carried a balance at its upper end, one balance overlapping the other.

In the second watch the verge escapement was arranged in the ordinary way, the balance being mounted on a verge with two pallets ; on the verge was also a toothed wheel which engaged with another of the same size mounted on a stud, and the pipe of this wheel carried the second balance; the toothed wheels being of small size, one balance was placed a little higher than the other and overlapped it. Each balance was controlled by a balance-spring.

However, Hooke turned his attention to other matters, and in January 1673 Huygens addressed a letter to Henry Oldenburg, secretary of the Royal Society, in which he described as his invention the application of a spring to control the balance in watches. This aroused the wrath of Hooke, who accused Oldenburg of having 


\section{Old Clocks and Watches and their Makers}

divulged the discovery in his correspondence with Huygens. Hooke

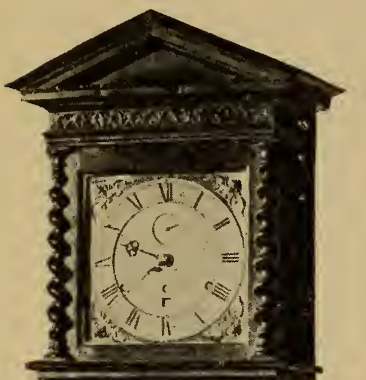
enlisted the interest of Charles II., and in a lecture, entitled "Potentia Restitutiva," \&c., said, "His Majesty was pleased to see the experiment that made out this theory tried at Whitehall, as also my spring watch."

In 1660 , Hooke devised a pendulum timekeeper for ascertaining the longitude at sea. This was tried in 1662, and he subsequently proposed a compensation pendulum in the form of a rhomboid, the outline being of steel and the long horizontal diagonal of brass. This form, being wider than it was long, was considered to be impracticable. Troughton afterwards constructed a pendulum in which the rod was a series of small rhomboids arranged to compensate on Hooke's plan.

Hooke devised the first wheel-cutting engine about 1670 . Prior to that time the operation of forming the teeth was tedious and imperfect. Blanks for watch and clock wheels were placed in the centre of a circular brass platform, having thereon concentric circles and radial lines corresponding to the various numbers of teeth in general use. An arm pivoted at the centre of the platform carried a hard point at its other extremity, by which the positions of the teeth were marked on the blanks. The spaces were then filed out. Hooke contrived a circular file and made the platform movable so that each part of the circumference of the wheel could be brought within the action of the file or cutter.

Hooke also invented the anchor escape-

FIG. 469.-Long-case Clock, by Fromanteel.

ment for clocks about 1675. Among his conceptions for a marine timekeeper was one with two balances geared together, the idea being to avoid 
the effect of external motion. It is stated that this timekeeper had an escapement resembling the duplex.

His investigations covered a very wide field of science, but his restless disposition rarely allowed him to pursue steadily any subject to a conclusion. No sooner was he satisfied of the feasibility of any project, than he left it, thus allowing others to perfect his inventions. On the death of Oldenburg, in 1677, he was appointed secretary to the Royal Society, and, by an order of the Society, he was requested to give a full description of all the instruments which he had contrived, but ill-health prevented him from performing it. During the last year of his life he was almost helpless. He died at Gresham College, 3rd March 1703, and was buried at St. Helen's, Bishopsgate.

Christian Huygens.-This distinguished mathematician was born at The Hague in 1629. Early in life he devoted his attention to the principles on which timekeepers were constructed, and in 1657 presented to the States of Holland a clock controlled by a pendulum. He seems to have acquired the additional cognomen of Zulichem from the place of his birth, and is so referred to by Evelyn during a short visit he paid to England in 1661, as quoted in the account of Fromanteel. In 1665 his reputation induced Louis XIV. to invite him to Paris, in order to found a Royal Academy of Sciences there, and in 1673 was published his folio work, "Horologium Oscillatorium," \&c., from which the appended drawings of his clock are taken.

The upper part of the pendulum is a double cord hanging between two cycloidal cheeks, to give a cycloidal path to the bob. Fig. 471 gives a better idea of this device, which was no doubt of advantage with the long arcs required by the verge escapement. Another feature of Huygen's clock is the maintaining power. $P$ (Fig. 472) is the driving weight, supported by an endless cord passing over the pulley $\mathrm{D}$ attached to the great wheel, and also over the pulley $\mathrm{H}$, which is provided with ratchet teeth and pivoted to the inside of the clock case. The cord $m$ is pulled down to wind the clock, and the ratchet wheel $\mathrm{H}$ then runs under its click. So that while winding, as in going, one-half of $\mathrm{P}$ minus one-half of $p$ is driving the clock. The pulleys $\mathrm{D}$ and $\mathrm{H}$ are spiked to prevent slipping of the cord.

This ingenious maintaining power is to be found in many eighteenthcentury clocks. When applied to a clock with a striking train, the pulley with the ratchet is attached to the great wheel of the striking part, one weight thus serving to drive both trains. A chain is 


\section{Old Clocks and Watches and their Makers}

preferable to a cord, owing to the dust which accumulates in the clock through the wearing of the latter. The drawback to the arrangement is that it is not suitable for clocks going for more than thirty hours between windings. It is, however, worth knowing that a thirty-hour striking clock on this plan can be readily converted to an eight-day non-striker by simply disconnecting the striking work.

Huygens devoted much attention to the production of a timekeeper for ascertaining the longitude ; and finding the pendulum too unstable at sea, he in 1674 constructed a marine timekeeper controlled by a balance and balance-spring. The balance, instead of being on the

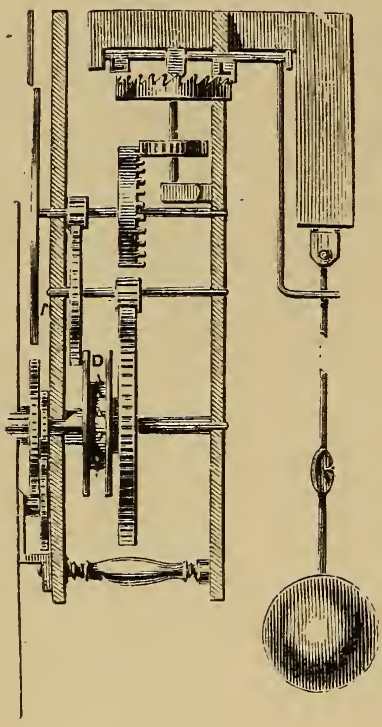

FIG. 470.

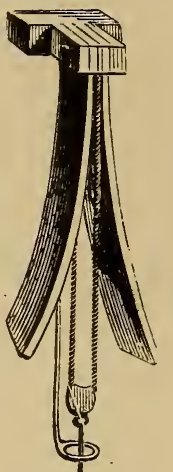

FIG. 471.

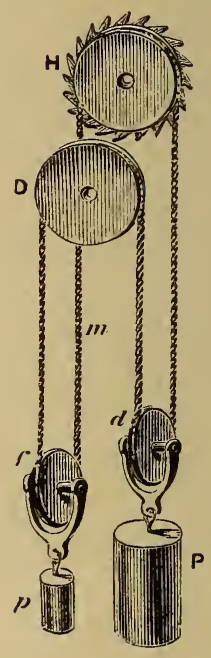

FIG. 472.

Christian Huygens' Clock.

verge, was on a separate staff, and driven by a wheel and pinion, so as to vibrate through very long arcs; and this necessitated the use of a very long balance-spring. Huygens endeavoured to obtain a patent for the application of the balance-spring, but in this he was successfully opposed by the Abbé Hauteville, who alleged a prior use of springs for the purpose. The marine timekeeper was not a complete success, for Huygens found himself baffled by the error in changes of temperature. He returned to Holland in 1681 , and died there in 1695.

An exceedingly well-made clock, exactly corresponding to Huygens' drawing, which I saw some years ago, bore the inscription, " Johanne 
Van Ceulin fecit, Hagæ," and had a very handsome gilt skeleton dial upheld by a figure of Time. This and many other watches and clocks of that period by Van Ceulin suggest the possibility of Huygens and Van Ceulin having been associated in Holland as were Barlow and Tompion in England.

Nathaniel Barrow.-A watch by this maker, with a short train and without a balance-spring, is shown on p. 215. Fig. 473 represents the exterior of a clock-watch with doubled pierced cases. A view of the movement will be given further on.

Probably to get room for the striking work a most peculiar arrangement of the going train is adopted; the winding square of the fusee arbor projects within the rim of the balance, which has three arms clustered together in the form of a fleur-de-lis or trident head, so that a vibration of over half a turn is possible before the balance arms bank against the fusee arbor.

Knibb.--Three or four members of this family are known among the seventeenth-century clockmakers.

Samuel Knibb was admitted to the freedom of the Clockmakers' Company in 1663; Joseph Knibb

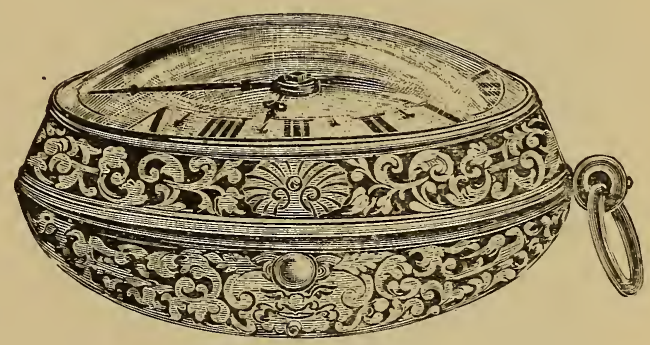

FIG. 473.-Clock-watch, by Nathaniel Barrow. in 1670 ; Peter Knibb in

1677. In the Guildhall Museum is a verge watch with curiously wrought pillars, made about 1690, by " John Knibb at Oxon.," and among the Wetherfield collection are two long-case clocks, inscribed "John Knibb, London," one dating from about 1690, and the other a little later. Mr. J. Drummond Robertson has a small-sized lantern timepiece with verge escapement by this maker.

Of these the most eminent maker was Joseph Knibb, mentioned as of Oxon., in the records of the Clockmakers' Company. He made a turret clock which was fixed over the state entrance in the quadrangle of Windsor Castle, which Captain Smyth (Archœologia, vol. xxxiii.) speaks of as one of the earliest movements constructed with brass wheels. This statement may be correct if it refers to turret clocks only, but it would not apply to smaller timekeepers. This clock was inscribed "Joseph Knibb, Londini, 1677," and did duty till 1829, when. a new one by B. L. Vulliamy replaced it. He issued a token, having on the obverse: "Joseph 


\section{Old Clocks and Watches and their Makers}

Knibb, Clockmaker in Oxon.," and on the reverse, "I.K.," with a clock face and hand. In the Camden Society's "Secret Services of Charles II. and James II." are various records of payments on behalf of King Charles. In the account up to 3rd July 1682 is an item, paid "To Mr. Knibb by his said Ma'tie's comand upon a bill for Clockwork, £141." Judging by the Windsor Castle clock, he was in London in 1677, and till nearly the end of the century he carried on business there. His work was of the highest class,

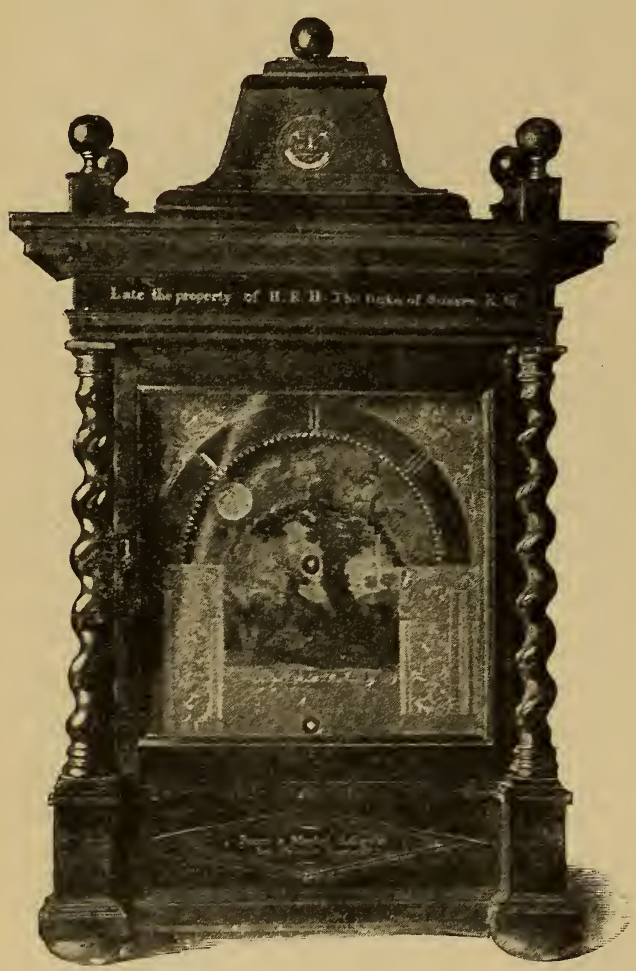

FIg. 474.-Remarkable Clock, by Joseph Knibb. judging from the specimens I have had the opportunity of examining. An alarm watch with pierced and engraved case of silver, dating from about 1690 , in the South Kensington Museum, is signed "Jose Knibb, London." A short time ago Mr. Thomas Peake had a $\mathrm{squ}$ are black case bracket clock by him, fitted with a surious striking part, of the locking plate kind, but striking both hours and quarters from one pinwheel, which had pins on both sides. The back plate was engraved to an ornamental design, and on it was the inscrip tion, "Joseph Knibb, Londini, fecit."

A remarkable clock, formerly the property of the Duke of Sussex, but which now belongs to Mr. Ernest Swanwick, is shown in Fig. 474. The case is of ebony, and measures $22 \mathrm{in}$. in height to the top of the knob. The particular feature which commands attention is the way in which the time is indicated. The upper portion of the dial is fixed and divided into four quarter-hours, the divisions being marked by Roman numerals. Each minute is indicated by a tooth at the edge, 
and five-ininute intervals by round holes. The central part of the dial rotates, and carries at opposite points near its periphery two blue discs on which are gilded figures representing the hours. In the illustration the time shown is thirteen past two, and the two will move on till it disappears at the right hand behind a screen, when the figure three will appear at the left. The mechanism in connection with this device is illustrated on p. 228. In front of the centre part of the rotating dial is a fixed screen, on which stags and a landscape are painted. Below is the signature, "Joseph Knibb, Londini." The exposed annular space of the rotating dial is covered with a painting of cupids and clouds. On the plinth is a label inscribed in gold lettering, "From a model designed by Prince Rupert." Above the entablature of the case is a double-headed bird with outstretched wings and the motto. " DEUS MEUM Que Jus." This clock is probably referred to in White's " Natural History of Selborne," in a letter to T. Pennant, speaking of the Royal Forest of Wolmer and Ayles Holt, which says: "The grantees that the author remembers are BrigadierGeneral Emanuel Scroope Howe and his lady Ruperta (who was a natural daughter of Prince Rupert by Margaret. Hughes)." . . . " The lady of

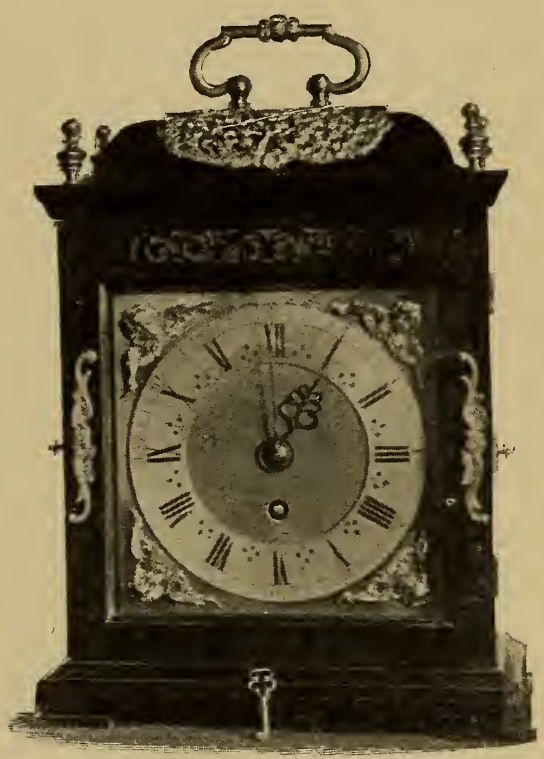

FIG. 475.-Miniature Timepiece, by Joseph Knibb.

General Howe lived to an advanced age, long surviving her husband : and, at her death, left behind her many curious pieces of mechanism of her father's constructing, who was a distinguished mechanic and artist as well as warrior, and among the rest a very complicated clock, lately in possession of Mr. Elmer, the celebrated game painter, at Farnham, in the county of Surrey."

The miniature timepiece by Joseph Knibb shown in Fig. 475 belongs to Mr. J. D. Robertson. It repeats the hour and quarters on two bells. The case is of black wood, and on the brass ornament at the left is represented the head of William III. This ornament is 


\section{Old Clocks and Watches and their Makers}

pivoted near the top, and is drawn aside to expose the keyhole. In the Wetherfield collection is a striking clock very similarly cased.

Messrs. Desbois recently had a long-case clock made by Joseph Knibb when he was in London. It was formerly in the collection of the Duke of Sussex, and therein described as having been the property of Charles II., when it was called a "drinking clock." * The dial was square, of brass well gilt, with a skeleton silvered ring to receive the Roman hour numerals and a subsidiary silvered ring for the seconds. The centre of the dial was coarsely matted, and every minute noted with Arabic figures. The corner pieces, boldly chased, were of the cherub-head pattern, and the hands finely carved. A herring-bone border was engraved at the edge of the square, and altogether the dial presented a handsome appearance.

But the distinctive feature of the clock was the peculiar striking work, which was on the locking-plate principle. There were two bells, a large and a small one, and two corresponding hammers ; also two sets of lifting pins, one on each side of the pin wheel, one set actuating the large and the other the small hammer. And the pins were arranged so that at I. o'clock one stroke was given on the small bell, at II. two strokes, at III. three strokes, at IV. one on the small followed by one on the large, at V. one on the large, at VI. one on the large followed by one on the small, at VII. one on the large followed by two on the small bell, and so on. It will be noticed that so far each stroke on the small bell stands for the Roman unit, and each stroke on the large bell for the Roman V. Perhaps the procedure through the twelve hours will be best shown by differentsized dots to represent the bells as follows :-

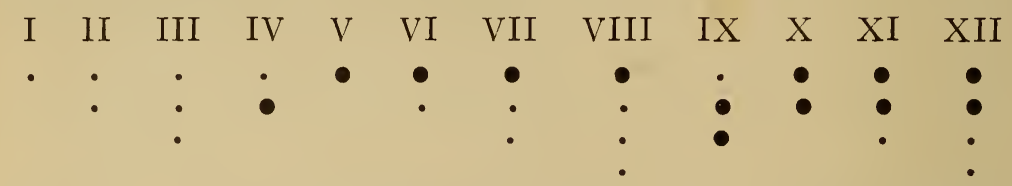

Among varieties of striking, this plan seems to have a distinct value, inasmuch as it materially economises the energy required for telling the round of hours, only thirty blows being required in place of the usual seventy-eight. This particular clock was arranged for a run of a month between successive windings.

* I confess I cannot understand this application of " Drinking Clock." August Demmin speaks of Drinking Clocks constructed at Nurembərg in the seventeenth century, which had extra outside wheels. At a banquet such a clock being put on the table commenced to move slowly along it, and the guest before whom the clock stopped was compelied to empty his flagon; but, though interesting, this does not help us in connection with Knibb's timekeeper.

$$
(N, N, 13) ; 152 \text {; }
$$


When a few years ago it was proposed to alter the subdivision of the civil day by counting the hours continuously instead of duplicating them, whereby any possible confusion as to whether a particular hour meant a.m. or p.m. might be avoided, one of the difficulties presented to the minds of those who attached particular importance to a sound signal was the impracticability of counting so many strokes as would correspond to the hour as the day neared its close. But by adopting what perhaps may be called the Roman notation, as here shown to be practicable, even that reform may yet be approved of by the majority.

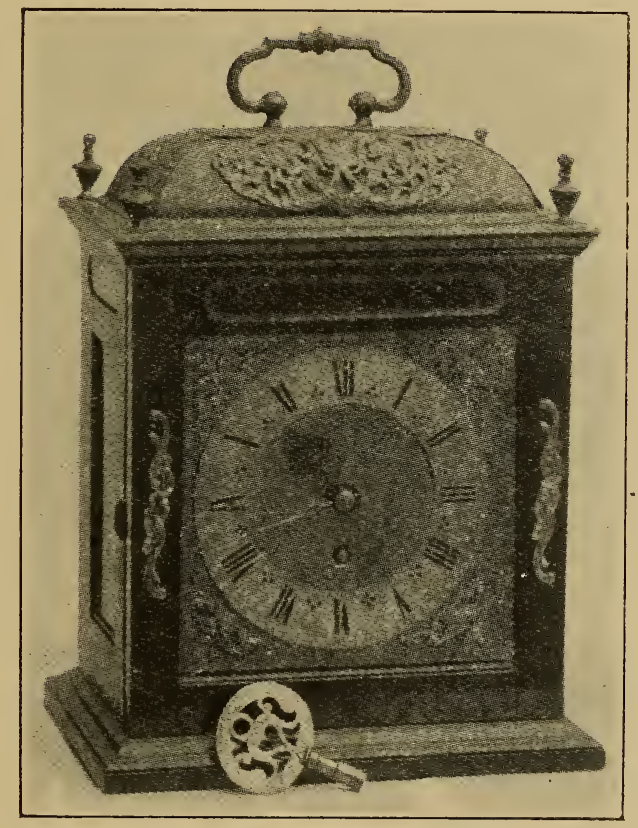

FIG. 476.-Miniature Timepiece, by Joseph Knibb.

Viscount Ridley has a three-months long-case clock by Joseph Knibb, which is inscribed " Joseph Knibb, Londini, fecit," along the bottom of the dial, and has the striking arranged in the same way. The case is of ebony. The Wetherfield collection includes two almost similar specimens. Mr T. W. Bourne owns a bracket clock, 12 in. in height, by Knibb.

Mr. Hansard Watt has a miniature timepiece by Joseph Knibb as shown in Fig. 476. It has unusual floral corner pieces.

In the London Gazette, July 9-12, 1688, " a striking watch, two 


\section{Old Clocks and Watches and their Makers}

gold cases engraven, a brass case over them, Joseph Knibb, maker, day of the month, pins to feel the hours," was advertised for, " information to be given to Mr. Jos. Knibb, at the Dial, in Fleet Street." There are other references to hini, of which the following may be of interest:-

" Lcst on the 26th inst., near the Ferry Place, Putney, a gold Pendulum Chain Minute-watch, made by Joseph Knibb, of London, in a Shagreen case, studded, with a Gold Knob, and marked with 48 on the inside of the case. Whoever will give notice of it to Mr. Joseph Knibb, watchmaker, in Fleet Street, shall have 2 guineas and charges; or, if pawned or sold, their money again and a good gratuity" (London Gazette, April 30, May 4, 1691).

"Left in a coach or drop'd, the 12th inst., a Gold Out-Case of a striking watch, engraven. Whoever shall bring it to Joseph Knibb, clockmaker, at the Dyal, near Serjeants-Inn, in Fleet Street, shall receive 40s. reward " (London Gazette, January 11-14, 1691).

"At the Clock Dyal, in Suffolk Street, near Charing Cross, on Friday, the 23rd inst., will begin the sale of a great Parcel of very good Pendulum Clocks, some do go a year, some a quarter of a year, some a month, some a week, and some 30 hours; some are Table Clocks, some repeat themselves, and some, by pulling, repeat the hours and quarters; made and sold by Joseph Knibb, at his House at the Dyal, in Suffolk Street, aforementioned. There are also some watches to be then and there sold " (London Gazette, April 15-19, 1697).

I may mention that some time ago I saw a long-case clock dial, dating from about 1705, which was inscribed, "Joseph Knibb, of Hanslope." Hanslope, is, I believe, a village near Stony Stratford, Bucks. In the Wetherfield collection is a long black case month clock signed "Joseph Knibb att Hanslop" which strikes the hours on two bells in accordance with the Roman numerals as described on p. 328 .

After an examination of many clocks by Joseph Knibb, I should be inclined to class him as a clockmaker with Tompion and Quare. Further on I will give some illustrations of his long-case clocks.

Thomas Harrys.-ST. Dunstan's C.Lock.-Above the main entrance at the western end of the old church of St. Dunstan's-in-the-West, in Fleet Street, were erected in 1671 two gilt clock dials, placed back to back, and mounted in a handsome square case, with circular pediment, which projected well out over the footway, the tube containing the rod for actuating the hands being supported by a well-carved figure of Time. An alcove was built on the roof of the gateway, and within were large gaudily painted and gilt figures of Gog and Magog, which struck " ting-tang " quarters with clubs on two bells suspended above them. The clock and figures were designed and erected by Thomas Harrys, a clockmaker, then living at Water Lane, Blackfriars. Harrys submitted a statement of what he proposed to do, and after describing the "two figures of men with pole-axes to strike the quarters," continues, "I will do one thing more, which London shall not show the like; I will make two hands show the 
hours and minutes without the church, upon a double dial, which will be worth your observation, and to my credit." The figures of Gog and Magog proved to be a great attraction ; they speedily became one of the sights of London, and their removal, in 1830, when the church was rebuilt, elicited many expressions of regret. Fig. 477, taken from an old print of the church in my possession, represents the clock as it was in $\mathbf{1 7 3 7}$.

In 1830 , when the old church was in course of demolition, the Marquis of Hertford bought for two hundred guineas the clock, the quarter figures, and three statues representing King Lud and his

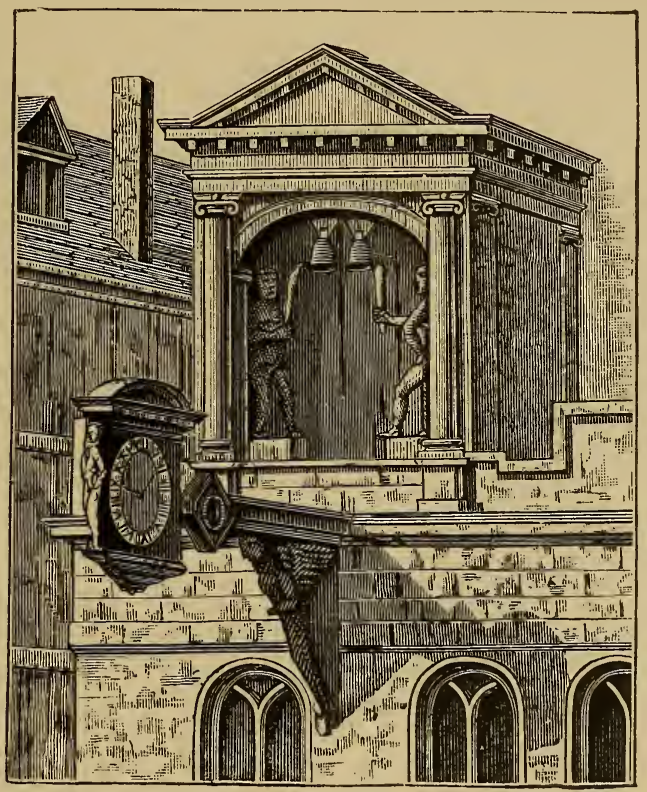

FIG. 477.-St. Dunstan's Clock as it was in I737.

sons taken from the old Ludgate. The Marquis of Hertford was at that time building a residence at the north-west corner of Regent's Park. This he called St. Dunstan's Lodge, and in the grounds thereof the clock and accessories are still to be seen from Regent's Park. The dials are now in a circular case ; but the movement, though it has, of course, undergone repair from time to time, is still, I believe, substantially the one Harrys supplied over two centuries ago.

Bradley.-ST PAUL's ClOCK.-Langley Bradley was apprenticed to Joseph Wise in 1687, and admitted to the freedom of the Clockmakers' Company in 1694. Dr. Derham, in acknowledging technical 


\section{Old Clocks and Watches and their Makers}

information obtained from Bradley, for the first edition of the " Artificial Clockmaker," published in 1696, speaks of him as an ingenious workman of Whitechapel; but during the greater part of his career he resided at the "Minute Dyall" in Fenchurch Street. Watches by him with deep movements, very similar to Tompion's, will bear comparison with the works of that master. An exterior view of one is given in Fig. 478. In the Soane Museum is a calendar watch by him, which belonged to Sir Christopher Wren. It is a fine piece of work, and was probably made to the order of William III..for presentation to the architect of St. Paul's. The dial resembles Fig. 404, and the pillars are pierced to form the royal monogram W. M., surmounted

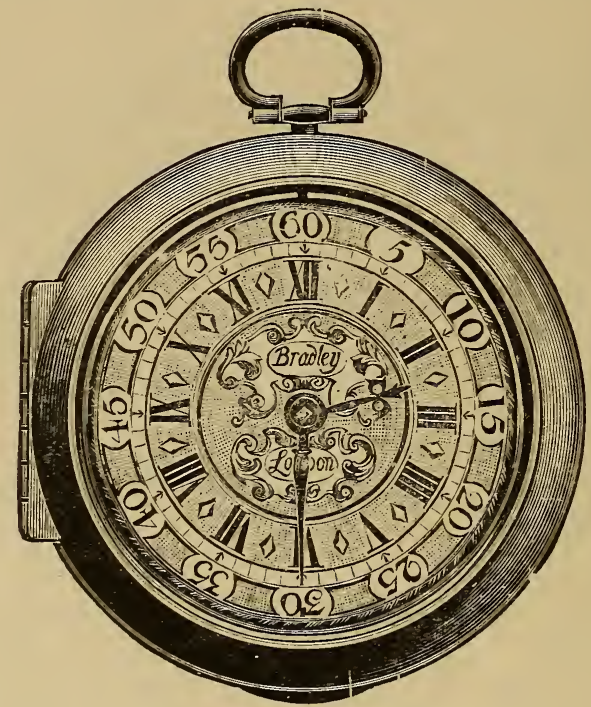

FIG. 478.-Watch, by Langley Bradley, 1700.

by a crown. Among other watches by him may be mentioned one in the British Museum and one in the Guildhall Museum. In the Wetherfield collection are a long marquetry-case three-train chiming clock and a long walnut case clock. But Bradley seems to have devoted most attention to larger work, and is perhaps best known as the maker of the noted clock for St. Paul's Cathedral, which did good service from 1708 till 1892, and was generally regarded as the standard timekeeper of the metropolis till the giant dials and Big Ben at Westminster took the popular favour. He made a clock for the Church of St. Clements Dane, Strand, in 1721, and one for Cripplegate Church in 1722.

The following particulars of the St. Paul's clock, from notes I 
made shortly before it was taken down, will probably be of interest. The frame consisted of a cast-iron rectangular base plate, from which rose cast-iron columns supporting an entablature of the same metal. The going train occupied the centre of the space between the base and entablature, the wheels being arranged vertically; while the gun-metal bushes for the pivots were carried in wrought-iron straps bolted to the base plate and entablature. On one side of the going train was the quarter part, and on the other side the hour-striking part, similarly arranged. All the wheels were of gun-metal, the great wheels being $2 \mathrm{ft} .8 \mathrm{in}$. in diameter, 1 in. pitch, and $1 \frac{3}{4}$ in. wide. For the original recoil escapement was substituted a half-dead one in 1805 , but with this exception it may be said that the whole of Bradley's mechanism remained in good working order till the clock was taken down. The two-second pendulum had a wooden rod and a cast-iron bob weighing nearly $180 \mathrm{lbs}$. The striking work was on the rack principle. The mitre wheels for driving the dial works were commendably large, being $20 \mathrm{in}$. in diameter, and for supporting the dial end of the minute-hand arbor there were three friction wheels placed at equal distances apart round the outside of, and carried by, the hour-hand tube. Slits were cut in the tube to allow a portion of the circumference of the friction wheels to enter, and the wheels were of such a size that they projected into the tube just sufficient to meet the minute-hand arbor. This ingenious contrivance is also applied to the Westminster clock, and is generally supposed to have been invented for it. Two sides of the St. Paul's clock tower, one facing down Ludgate Hill, and the other looking towards the south side of the churchyard, were utilised for the dials of Bradley's timekeeper, black rings being painted on the stonework, on which the hour circles and the numerals were engraved and gilt. Each dial is a trifle over $17 \mathrm{ft}$. in diameter, and the central opening measures about $10 \mathrm{ft}$. 6 in., the hour numerals being about $2 \mathrm{ft}$. deep. Though but two sets of dial-work were used, the stonework of the four faces of the tower is alike, and on the eastern side, just visible from Cannon Street, although the dial was not painted, the hour numerals were cut in the stone: this suggests the inference that it was at one time intended to show the time there; it was probably found that the pediment over the southern entrance to the cathedral so obscured the view as to render the third dial comparatively useless. On the roof, just outside of this dial aperture, was a horizontal sun-dial, with a plate, over $2 \mathrm{ft}$. in diameter, for the purpose of regulating the clock by the sun. 


\section{Old Clocks and Watches and their Makers}

Bradley's bill appears in the Cathedral Accounts, December 1708, as follows :-

To Langley Bradley, Clockmaker, vizt. :-

For a large Quarter clock, going 8 days, as by agreement

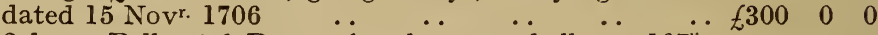

For 2 large Bellmetal Braces for the great bell, wt. 107ii.,

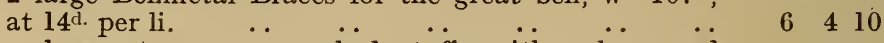

For a large strong canvas bed stuffe with oakam and sewed $w^{\text {th. }}$ strong thread line to receive the clock

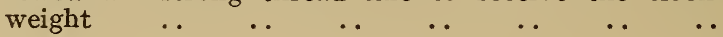

\begin{tabular}{rrr}
$2 \quad 5 \quad 0$ \\
$\$ 308 \quad 9 \quad 10$ \\
\hline
\end{tabular}

A curious feature is the description of the clock as an eight-day one, whereas, for many years at least, it was but a thirty-hour one. Indeed, it seems doubtful if it ever went eight days between windings, for, by the arrangement of the train and barrel, the weight fell about $40 \mathrm{ft}$. for twenty-four hours' going.

From the clock room the upper part of the belfry is approached by a stone staircase formed in the wall of the tower itself, which is $5 \mathrm{ft}$. thick, composed of two stone shells, with a space of $15 \mathrm{in}$. between them. Here, $40 \mathrm{ft}$. from the clock floor, was hung the celebrated hour bell which, in addition to its piimal duty of recording the hours, was tolled when the Sovereign, the Bishop of London, the Dean of St. Paul's, or the Lord Mayor of London passed away.

The commissioners appear to have had just as much trouble with their hour bell as was afterwards experienced over the casting of Big Ben for the Houses of Parliament. In the year 1700, when the cathedral was approaching completion, they purchased, for $10 \mathrm{~d}$. a lb., from the churchwardens of St. Margaret's, Westminster, the celebrated Great Tom, which formerly hung in a clock tower facing Westminster Hall, as related on p. 24, and which appears to have been given to the churchwardens by William III. They then entered into a contract with William Whiteman to recast the bell, and when the work was done the bell was temporarily hoisted into the north-west tower of St. Paul's and exhibited to the public, Whiteman being paid f509. 19s. for his labour. But lo! after sustaining many blows for the delectation of the ears of the citizens, Great Tom the Second exhibited a crack which rapidly developed, so that the bell was pronounced to be useless. The commissioners suggested that of course Whiteman would make good his work by recasting the bell. "Not so," rejoined Whiteman. "I delivered to you a sound bell for which I was paid, and since it has been in your possession it has been cracked." So, to make the best of a bad job, a very stringent agreement was entered into with another founder--Richard Phelps, to wit. 
The accident with the first hour bell accounts for the difference between the date of the finishing of the clock and the time when the Phelps hour bell was cast, around the waist of which is the inscription, "Richard Phelps made me, 1716." It is $6 \mathrm{ft}$. $9 \frac{1}{2} \mathrm{in}$. in diameter at the mouth, and according to Phelps' account, dated 31st December 1716, weighs 99 cwt. 3 qrs. 7 lbs., of which 7 cwt. 2 qrs. 21 lbs. were new metal. For tolling it has a clapper weighing $180 \mathrm{lbs}$., and the total weight of the bell and fittings is, 1 believe, 5 tons $4 \mathrm{cwt}$. The hammer-head which struck the hours on the outside of the sound bow weighed $145 \mathrm{lbs}$. Just below the hour bell were two bells on which the "ting-tang" quarters were struck; the larger of these weighed 1 ton 4 cwt., and the smaller 12 cwt. 2 qrs. 9 lbs.

Ellicott.-The first John Ellicott, watchmaker, whose parents came to London from Bodmin, in Cornwall, was apprenticed to John Waters in 1687, admitted to the freedom of the Clockmakers' Company in 1696, elected on the Court of Assistants in 1726, and served as warden from 1731 till his death in 1733 . He resided in the parish of Allhallows, London Wall. But the most eminent watch and clockmaker of the family was his son John Ellicott, born in 1706, who established himself in business about 1728 at Sweeting's Alley, which was situated just where the statue of Rowland Hill now stands, near the Royal Exchange. After the fire which destroyed the old Royal Exchange in 1838, Sweeting's Alley was not rebuilt. He was elected a fellow of the Royal Society in 1738, being recommended for that honour by Sir Hans Sloane, Bart., Martin Ffolkes, John Senex, the celebrated globe maker, and John Hadley, the astronomer. At the meetings of the Royal Society, he became acquainted with James Ferguson, who afterwards frequently visited Ellicott's private house at St. John's, Hackney, where an observatory was fitted up, and various scientific experiments were made.

Ellicott was the inventer of a compensation pendulum in which the bob rests on the longer ends of two levers, of which the shorter ends are depressed by the superior expansion of a brass bar attached to the pendulum rod. In Fig. 479, $a$ is the suspension spring; $s s s$ screws for uniting the steel rod to the brass bar, slotted holes in the latter allowing it to move freely in answer to changes of temperature ; $f f$ the two levers pivoted to the steel rod; on the shorter ends rests the brass bar; the screws $g g$ pass through the pendulum bob C C, and rest on the longer ends of the levers. By turning the screws their bearing on the levers may be adjusted. This device has not proved to be of much practical value, although there is a clock to 


\section{Old Clocks and Watches and their Makers}

which it is attached still going at the London Institution, Finsbury Circus.

A well-proportioned long-mahogany-case clock by him, with deadbeat escapement, and a bracket repeating clock in a green lacquer case, are among the Wetherfield collection. In the same collection also is the bracket repeating clock shown in Chapter VII., which is charming

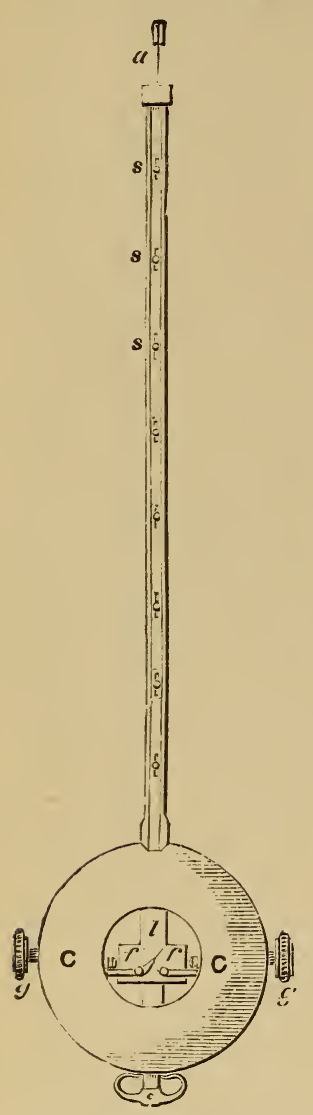

FIG. 479.--Ellicott's Compensation Pendulum. in its simplicity. The case is of mahogany.

Ellicott's productions were distinguished by excellent workmanship. He paid great atten tion to the cylinder escapement, and did much to bring it into use. In some of his later examples the cylinders were of ruby. His more costly watches were lavishly decorated, the cases in repoussé, and the dials enamelled on gold, some of these being really works of art. They are now rarely to be met with, for the iconoclastic dealer as a rule ruthlessly changes the dial for one of cheaper material. In reference to the prices Ellicott obtained, it may be mentioned that Horace Walpole, writing to Sir. H. Mann at Florence, on 8th June 1759 , with regard to a commission to purchase a watch, states that for one of Ellicott's the price was 150 guineas. In the British Museum is a silver repeater by him which belonged to Jeremy Bentham. Mr. Talfourd Ely, M.A., in the Archoological Journal for June 1895, gives an interesting description of a watch by John Ellicott. It is in gold cases, the outer one decorated in repoussé, and appears to have been made in 1751. A small gold watch by him with gold dial is in the Pierpont Morgan collection. The collection of the Czar of Russia in the Winter Palace at St. Petersburg containerl a good example of his manufacture. It is a large repeater in gold cases; the inner one bears the hall mark for 1760-61 and the outer one a repoussé decoration.

Ellicott was on the council of the Royal Society for three years, and read several papers before the Society. They included one on the "Influence which two Pendulum Clocks were observed to have on each other." The ball of each pendulum weighed above $23 \mathrm{lbs}$. ; the cases 
were placed sideways to each other, so near that the pendulums when at rest were little more than $2 \mathrm{ft}$. asunder. In less than two hours after they were set going, one of them, called No. 1, always stopped. As it had always kept going with great freedom before, the other regulator, No. 2, was placed near it, Ellicott conceived its stopping must be owing to some influence the motion of one of the pendulums had upon the other ; and upon watching them narrowly the motion of No. 2 was found to increase as No. 1 diminished. At the time No. 1 stopped, No. 2 described an arc of $5^{\circ}$, being nearly $2^{\circ}$ more than it would have done if the other had not been near it, and more than it moved in a short time after the other pendulum came to rest. On this he stopped the pendulum of No. 2, and set No. 1 going, the pendulum describing as large an arc as the case would admit, viz., about $5^{\circ}$; he presently found the pendulum of No. 2 begin to move, and the motion to increase gradually, till in 17 minutes 40 seconds it described an arc of $2^{\circ} 10^{\prime}$, at which, the wheel discharging itself off the pallets, the regulator went, the arcs

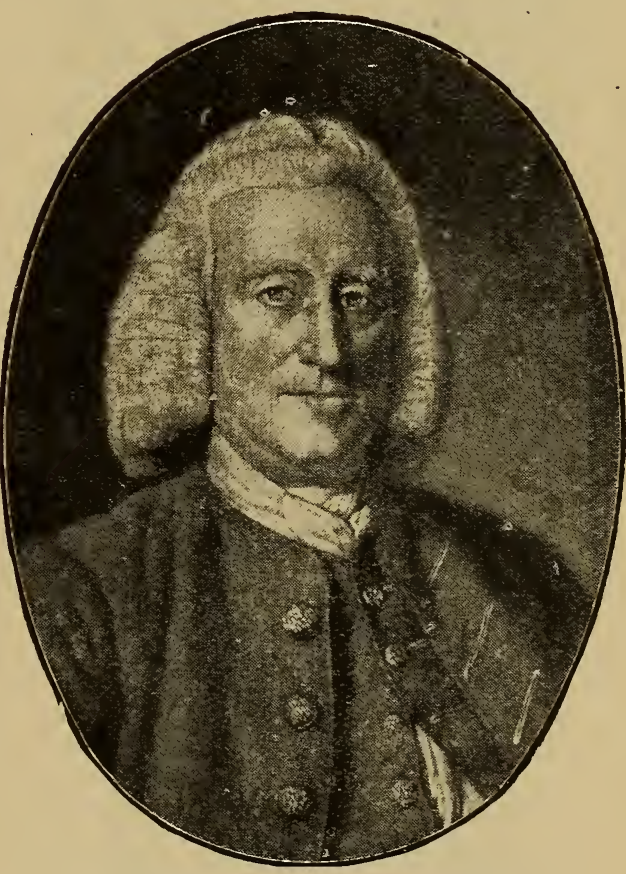

FIG. 480.-John EliICotT, 1706-1772. of the vibrations continued to increase till, as in the former experiment, the pendulum moved $5^{\circ}$, the motion of the pendulum of No. 1 gradually decreasing as the other increased, and in 45 minutes it stopped. He then left the pendulum of No. 1 at rest, and set No. 2 going, making it also describe an $\operatorname{arc}$ of $5^{\circ}$; it continued to vibrate less and less till it described but about $3^{\circ}$, in which arc it continued to move ; the pendulum of No. 1 seemed but little affected by the motion of No. 2. Ellicott's explanation was that, as the pendulums were very heavy, either of them set 


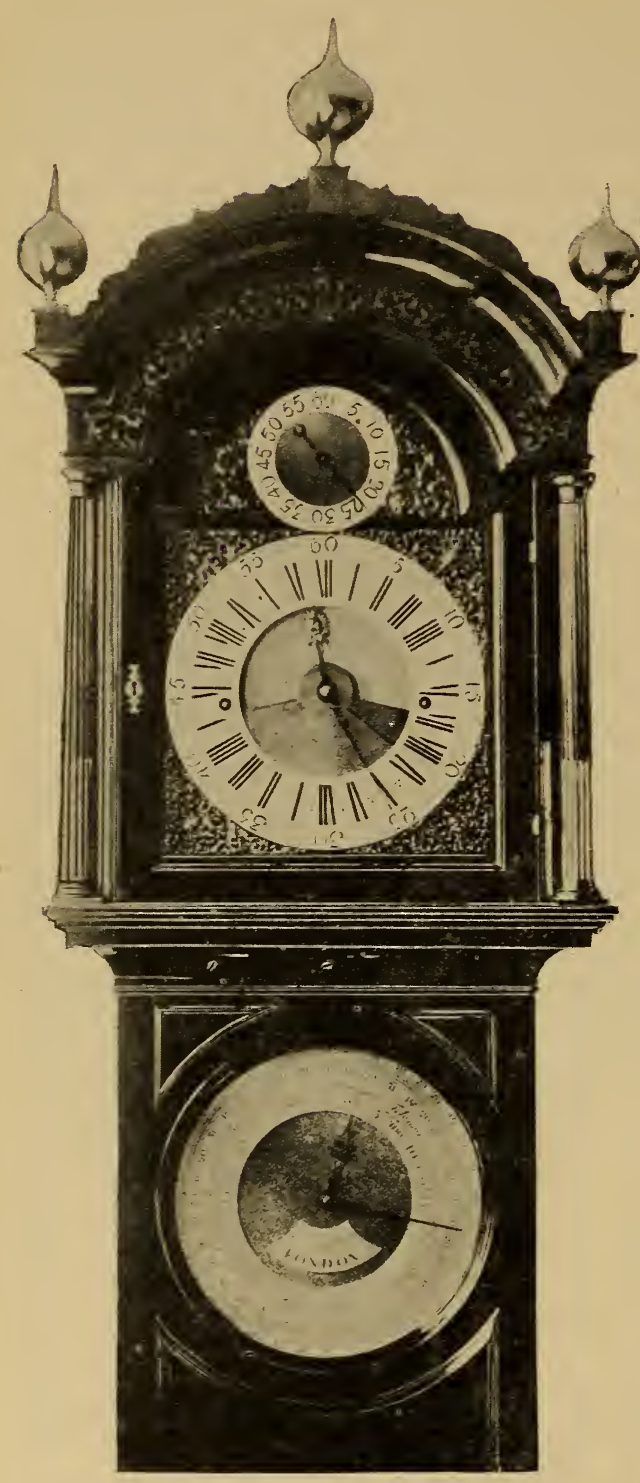

FIG. 481.-Long-Case Clock, by John Ellicott with Equation of Time Dial below the Hood. going communicated a slight motion to the case and in a lesser degree to whatever the case touched. Ellicott's experiment was useful as showing the necessity of fixing clocks with heavy pendulums to the wall of a building or other ponderous and unyielding structure.

In Fig. 481 is shown by favour of Mr. E. Beaven the upper part of an exceedingly choice long-case clock by Ellicott. By means of two darkened annular segments, arranged to pass one over the other, the hours of day and night are indicated in the centre of the dial. Below the hood a secondary dial gives the equation of time. I remember seeing a sketch of a twelve - month timekeeper by Quare similarly equipped.

E11icot t designed several of our public clocks, amongst them that of the London Hospital, and was appointed clockmaker to the king. $\mathrm{He}$ died suddenly in 1772 , having dropped from his chair and instantly expired. The accompanying likeness (Fig. 480) is from a fine portrait of him shortly before his 
decease, by Dance, afterwards Sir Nathaniel Dance Holland. John Ellicott was succeeded by his eldest son, Edward, who had been in partnership with him since 1769. Edward Ellicott died at his residence in Great Queen Street, in 1791. The business was then carried on by his son Edward, who, after serving in the subordinate offices, was elected as master of the Clockmakers' Company in 1834. Though brought up as a watchmaker, he had but little liking for the business, and left the conduct of it in a great measure to others. From Edward Ellicott \& Sons the title of the firm was altered to Ellicott \& Taylor in 1811, and to Ellicott \& Smith in 1830. After the destruction of Sweeting's Alley, Ellicott \& Smith removed to 27, Lombard Street, and remained there till 1842 .

There was a third John Ellicott admitted to the freedom of the Clockmakers' Company by patrimony in 1792. He was the second son of the first Edward, but appears to have taken no part in the watch or clock making business. His grandson, Dr. Ellicott, was the late Bishop of Gloucester and Bristol.

Henry Sulley. - This talented but unfortunate horologist was born in 1680, and apprenticed to Charles Gretton, of Fleet Street, in 1697. On the completion of his apprenticeship he travelled over the Continent, visiting Holland and Austria. From Vienna he went to Paris with the Duke d'Aremberg, where he made the acquaintance of Julien Le Roy, Law, the noted Scottish speculator, and others. Le Roy at once recognised the genius of the young enthusiast who was imbued with ideas for perfecting timekeepers, and encouraged him to continue his researches. In 1717 Sully published " Règle Artificielle du Temps." The following year, commissioned by Law, he journeyed to London and engaged sixty watch and clockmakers, who, with their families, were located at Versailles, where a factory was started. After two years of unremitting toil Sully was displaced from the directorate, but a little later, under the protection of the Duke de Noailles, another factory was established at St. Germain. This lasted but a year, when Sully returned to England, bringing his staff of workpeople with him. The same ill fortune dogged his steps here, and in his extremity he returned to Paris, where for a time he sustained existence by repairing watches. In 1721, when a little more prosperous, he turned his attention to the production of a marine timekeeper, and in 1724 presented it to the Academy of Sciences. This instrument has a modification of Debaufre's escapement, which Sully devised for the purpose, and a vertical balance which was really a pendulum. It carried cycloidal metal pieces, around which the upper end of a slender 
wire was wound, the lower end being attached to a lever with an adjustable weight, with the idea of keeping the vibrations of the balance isochronous. The pivots of the balance, instead of being in holes, were supported on the edges of large rollers, to diminish the friction, a device adopted afterwards by Mudge. In 1726 Sully published " Abrégée d'une Horologe d'une Nouvelle Invention pour la Juste Mesure du Temps sur Mer." When subjected to the tossing of the ocean, his timekeeper failed to yield the results anticipated from its performance on land. Though mortified by his failure, he again set himself to the solution of the problem. He had already made a marine watch with two balances geared together, as designed by Dr. Hooke, and now proceeded with a new timekeeper of different construction ; but while engaged thereon he was seized with a serious illness, induced by over-application and worry, and succumbed to inflammation of the lungs in 17.28 .

At the church of St. Sulpice, Paris, he had traced a meridian line on the pavement of the transept, and secured its permanence by inlaying a thin brass edge. He blocked up the south transept window except for a small hole in a metal plate at the upper part through which the rays of the sun cast a luminous disc about $10 \frac{1}{2}$ in. in diameter on the floor. The disc moves across the line which at noon bisects it. In this church he was buried, and a fine obelisk of white marble erected to his memory in the north transept, in a position that allowed the meridian line to be carried up the face of the monument. A laudatory inscription recounted his services to horo$\log y$, but the greater part of it was cut out by the revolutionists of 1793, who possibly resented the suggestion that French watchmakers could be indebted to a foreigner.

In the Guildhall Museum is a timekeeper with Sully's curious vertical balance. It is in the form of a bracket clock with a walnut bell-top case, has a seconds hand above the centre of the dial, and shows the days of the month through a slit below the centre. It is inscribed "Henricus Sully, invenit et fecit (1724), Horloger to the Duke of Orleans."

John Harrison.--John Harrison was born at Foulby or Wragby near Pontefract, Yorkshire, in'1693. He was the son of a carpenter, which business he followed for several years. In 1700 the family removed to Barrow, in Lincolnshire. At a very early age John Harrison showed a great predilection for mechanical pursuits, and particularly directed his attention to the improvement of clocks.

The offer, by Act of Parliament, of large sums for the production 
of a timekeeper sufficiently accurate to ascertain the longitude at sea, induced him to turn his attention to the subject. He devised a peculiar form of recoil escapement, and a pendulum in which the effects of heat and cold in lengthening and shortening the pendulum were neutralised by the use of two metals having different ratios of expansion. His escapement, generally called the " grasshopper," is shown in Fig. 482. The

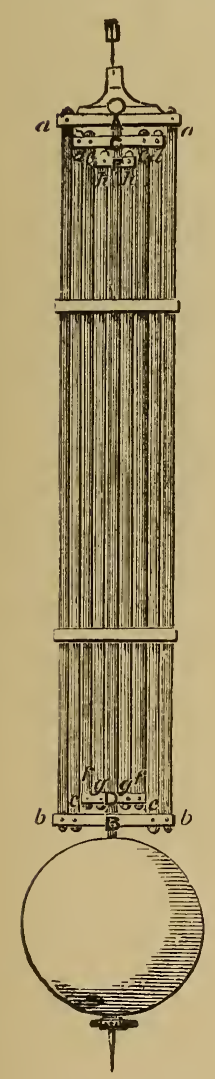

FIG. 483.

Harrison's

Pendulum. pallets of ebony, or other hard wood, are jointed to a bell-crank lever carried by the crutch; though free to move at the joints they are kept sufficiently near to position by springs which are not shown in the draw-

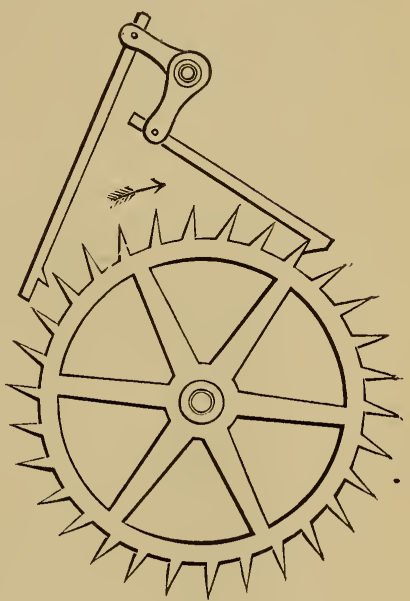

FIG. 482.-Harrison's Escapement.

ing. The teeth of the escape wheel alternately push the left-hand and pull the right-hand pallet, this action giving the necessary impulse to the pendulum. The chief merit appears to be that, as there is no rubbing between the pallets and the wheel teeth, there would be no lubrication required at these contacts. However, the invention was never adopted by others, and need not be further described. His pendulum, known as the gridiron form of compensation, shown in Fig. 483 , is still the form of compensation adopted in many foreign regulators. It is composed of nine parallel rods, five of steel and four of brass, the total length of each kind being nearly as 100 to 60 , that being the ratio of expansion of the two metals. Depending from the cross frame $A$ are two rods of steel $a a$. The frame $B$, to which they are fixed at their lower extremities $b b$, carries also two brass rods $c c$, which at their upper ends $d d$ are carried in the frame $\mathrm{c}$, together with two other steel rods $e e$. Those at the lower extremities $f f$ are fastened in the frame $\mathrm{D}$, which also carries the brass rods $g g$. The frame $F$ carries the upper ends of this last pair of 


\section{Old Clocks and Watches and their Makers}

brass rods at $h h$, and also the central steel rod to which the bob is attached.

One of his early efforts, with wheels and pinions of wood, which was in the possession of the late Mr. Evan Roberts, has John Harrison's signature with the date 1713 on the face of the day of the month wheel. Another long-case clock by him is at the South Kensington Museum, and one made about 1730, fitted with the grasshopper

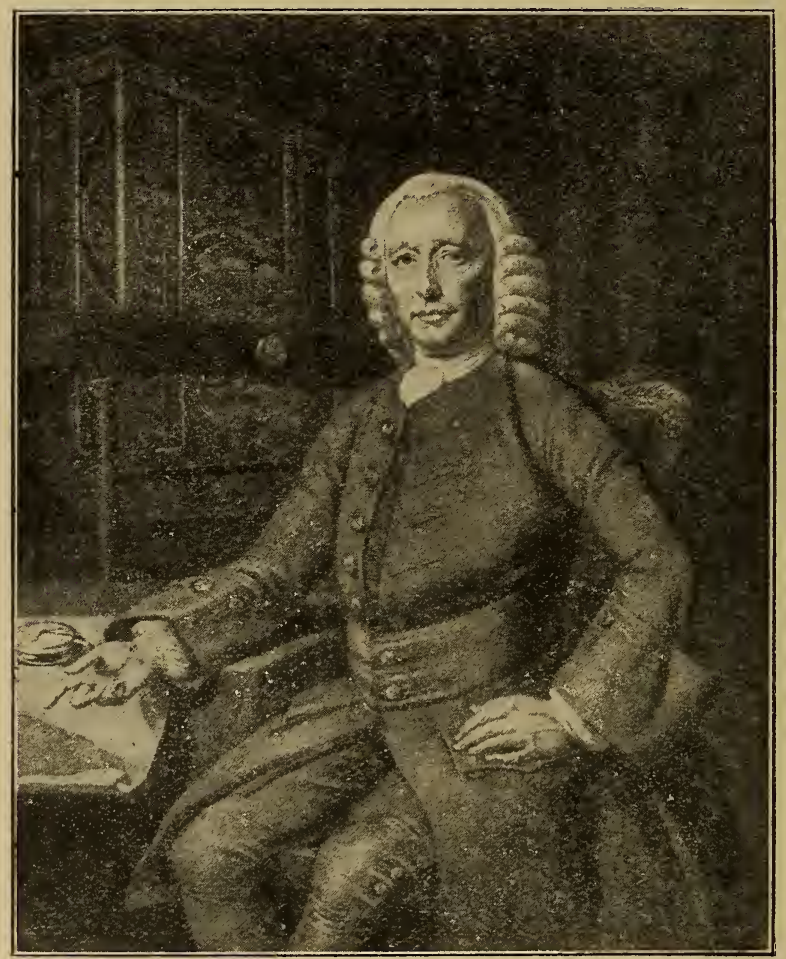

Fịg. 484.-JOHN HARRISON, 1693-1776.

escapement, which was for some years in the possession of Mr. Thos. Nicholson, Barton-on-Humber, now belongs to his grandson, Mr. W. W. Nicholson. In the Guildhall Museum may be seen a very similar relic.

In 1728 Harrison journeyed to London, taking with him his pendulum, his escapement, and drawings of his proposed timekeeper, hoping to obtain the approbation and aid of the Board of Longitude. Before being submitted to the notice of that body they were inspected by Graham, whose maturer judgment prompted him to advise 
Harrison to first make the timekeeper, and then ascertain, from its actual going, what claims it might have to further notice.

Harrison continued plodding on in the country, repairing watches and clocks and making a variety of experiments till 1735 ; then, in his forty-second year, he came to London and took up his residence in Orange Street, Red Lion Square. He brought with him a timepiece he had invented and constructed. It was a cumbersome affair in a wooden frame, and had two balances. He obtained certificates of the excellence of this timekeeper from Halley, Graham, and others. On their recommendation he was allowed, in 1736, to proceed with it to Lisbon in a king's ship, and was enabled to correct the ship's reckoning by $1^{\circ} 30^{\prime}$, actually $1^{\circ} 27^{\prime}$, the difference of longitude between the start and the Lizard. In consequence, the error of the machine must have been almost negligible-say 5 miles at most.

It is of interest and importance to note that this machine-Harrison's No. 1-had a gridiron compensation for heat and cold, the first recorded instance of such a device being applied to a marine timekeeper-or, indeed, to any time-keeper fitted with a balance (or balances).

In consideration of this result, the Board of Longitude gave him $£ 500$ "to proceed with his improvements." In 1739 he finished another timekeeper, and afterwards a third, which was smaller and appeared to the members of the Royal Society to be more simple and less likely to be deranged than either of the preceding ones. In 1749 he received the gold medal which was annually awarded by the Royal Society to the most useful discovery, but he was still not satisfied with his productions. The experience gained by prolonged trial led him to abandon the heavy framing and wheels which characterised his earlier essays and to devise and construct his celebrated "watch" which eventually won for him the coveted reward.

He spent some time in improving and correcting his fourth nautical timekeeper, and then applied to the Commissioners of the Board of Longitude for a trial according to the Act of Parliament. This, after much delay, was granted, and his son William was in his stead allowed to take a voyage to Jamaica. William Harrison embarked in the " Deptford," at Portsmouth, on 18th November 1761. After eighteen days' navigation the vessel was supposed to be $13^{\circ} 50^{\prime}$ west of Portsmouth by ordinary calculations, but by the watch was $15^{\circ} 19^{\prime}$, and the timekeeper was at once condemned as useless. William Harrison, however, maintained that if Maderia were correctly 


\section{Old Clocks and Watches and their Makers}

marked on the chart, it would be seen on the following day; and in this he persisted so strongly that the Captain was induced to alter his course accordingly, and the island was discovered the next day. A contemporary points out that had the ship continued on her course she would not have sighted Madeira at all, and that her doing so "was a matter of relief to the ship's company, who were then in great scarcity of beer." In like manner William Harrison was enabled by the watch to announce all the islands in the order in which they would fall in with them. When he arrived at Port Royal, after a voyage of sixty-one days, the chronometer, as we may now call it,*

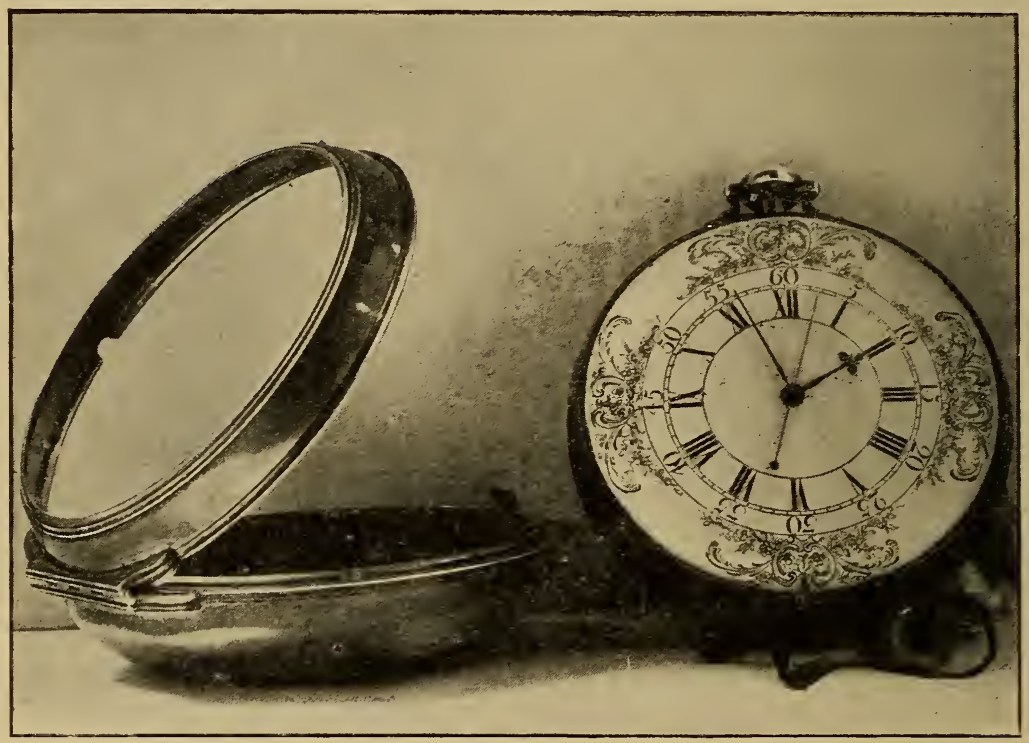

FIG. 485.-Harrison's celebrated Marne Timepiece.

was found to be about nine seconds slow. On 28th January 1762 he set sail from Jamaica on board the "Merlin," after an absence of five months the error on returning to Portsmouth was $1 \mathrm{~m}$. $53 \frac{1}{2}$ secs., or $28 \frac{1}{2}^{\prime}$ of longitude at the Equator, equal to $18^{\prime}$ in the latitude of Portsmouth. This was much within the limit of the 30 miles prescribed by the Act of 1713 ; yet, several objections being raised, William Harrison was obliged to undertake a second voyage, the

* The late Mr. R. B. Prosser said the term chronometer appears to have been introduced by Loulie of Amsterdam in 1698 as descriptive of the instrument now known as a metronome. John Arnold was the first to apply it to a precision timekeeper. 
proof from the first not being considered sufficiently decisive by the Board, although they advanced $£ 5,000$ on account of the reward.

Accompanied by Dr. Maskelyne, as the representative of the Board, William Harrison embarked in the man-of-war " Tartar," on 28th March 1764, and arrived in Barbados on the 13th May, when it was found the chronometer had gained forty-three seconds; he set out for the return journey on board the "New Elizabeth" on the 4 th of June, and arrived at the Surrey Stairs on 18th July, when it was ascertained that, after allowing for the estimated rate of one second a day gaining, there was an excess of fifty-four seconds for the whole period of 156 days. The result of this second voyage was so satisfactory, that the Board unanimously declared Harrison had really exceeded all expectations and demands of the Act of Parliament, and he was paid a further advance of $£ 5,000$, with the condition that he explained the construction of his timekeeper. A sub-committee, consisting of Maskelyne, John Mitchell, Ludlam, Bird, Mudge, Mathews, and Kendall, were appointed, and instructed to make themselves acquainted with the mechanism of the instrument. They reported themselves satisfied in 1765 , but even then considerable delay occurred. Kendall was commissioned to make a duplicate of the chronometer, which appears to have taken three years to execute, for the date of Kendall's instrument is 1769. The final payment of $£ 8,750$ was made to Harrison in 1773 , after the personal intervention of H.M. King George III., who afforded a private trial at the Kew Observatory to Harrison's No. 5, now in the Guildhall Museum. Its total error in 10 weeks was $4 \frac{1}{2}$ secs. only.

Harrison's timekeeper is in the form of a large silver pair-case watch, with a centre seconds hand. The representation in Fig. 485 is from a photograph for which I am indebted to the Astronomer Royal. It has been stated that the piece hung in gymbals. This was not the case ; it reposed on a soft cushion, and on its trial voyages was carefully tended by William Harrison, who avoided position errors as far as possible by shifting the timekeeper to suit the lie of the ship.

The plates are $3.8 \mathrm{in}$. and the balance $2.2 \mathrm{in}$. in diameter; the fusee makes six and a quarter turns. The escapement beats five times in a second. The pivot holes are jewelled with rubies.

One of the chief features is a bimetallic arm fixed at one end, and carrying at its free end two pins, to embrace the balance-spring near its outer point of attachment. "The thermometer kirb is composed of two thin plates of brass and steel riveted together in several places, which, by the greater expansion of brass than steel by heat, and 


\section{$346^{\circ}$ Old Clocks and Watches and their Makers}

contraction by cold, becomes convex on the brass side in hot weather, and convex on the steel side in cold weather; whence, one end being fixed, the other end obtains a motion corresponding with the changes of heat and cold, and the two pins at this end, between which the balance-spring passes, and which it touches alternately as the spring bends and unbends itself, will shorten or lengthen the sping."

Lieut. Rupert T. Gould states that "Harrison provided a curved rack which carried the fixed end of his compensation curb, and which could be moved bodily by a pinion with a squared arbor and indicator dial-almost exactly like Tompion's regulator. It is figured in his "Description of Mr. Harrison's timekeeper and plates of the same," and can be seen in No. 4 now at Greenwich. It is not fitted in Kendall's duplicate of No. 4. He found that it did not answer, however, and abandoned it."

It is, of course, easy to be wise after the event ; but, on examining the remontoir and escapement of Harrison's chronometer in the presence of the simple detent escapement introduced shortly after, it seems marvellous that he should have spent so many years over such complicated and by comparison inefficient contrivances. Harrison's drawings are most difficult to understand, and were left, it is believed intentionally, obscure, but I venture to reproduce some contributed to the Horological Journal by Mr. H. M. Frodsham, which were made from Kendall's duplicate of Harrison's timekeeper at the Greenwich Observatory.

Fig. 1 is a section through the fourth wheel, Fig. 2 a plan of the remontoir and contrate wheel, Fig. 3 a plan of the remontoir and escapement. The pin:on at the top of Fig. 1 is driven by internal teeth on the third wheel of the train. The wheel immediately below the pinion in Fig. 1 is the fourth wheel, which drives a pinion $x$ (Fig. 3). The dished wheel below the fourth wheel in Fig. 1 is the contrate wheel (c, Figs. 2 and 3). In the recess of the contrate wheel is contained the remontoir spring which is wound eight times in a minute. The wheel at the bottom of Fig. I is the seconds wheel. This and the contrate wheel move continuously, while the fourth wheel and the other part of the train are locked by the lever $\mathrm{D}$ catching the stop $\mathrm{P}$ on the wheel $\mathrm{P} \mathrm{x}$, except during the winding of the remontoir. On the collet of the contrate wheel are eight pins, shown in Fig. 1, and at $\mathrm{Q}$ in Fig. 3. The eight pins in the contrate wheel in succession push the arm $\mathrm{H}$ (Fig. 3), and so unlock the train. The locking wheel $\mathrm{P} X$ drives a fly pinion and fly $\mathrm{v}$ to moderate the velocity with which the remontoir was wound. The seconds arbor is in the centre of the 
watch, and is driven by the seconds wheel below the contrate wheel. The projections $\mathrm{P}^{\mathrm{P}^{\prime}}$ on the barrel of the remontoir are to prevent the remontoir running down.

Fig. 4 shows the pallets, which, instead of forming an angle of $95^{\circ}$ or so, as is usual, are set parallel to each other, and in this way there is very little recoil, but increased tendency, to set. These acting surfaces of the pallets are diamonds set in brass collets.
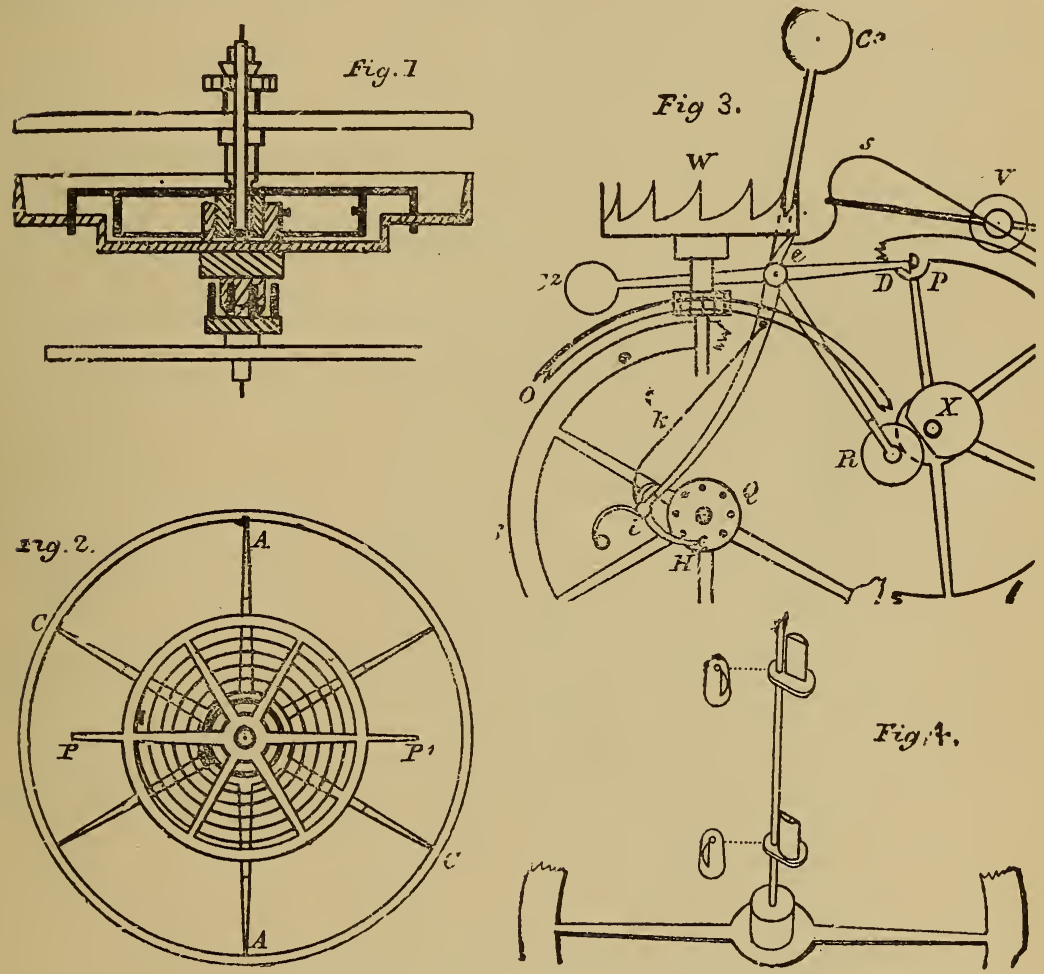

FIG. 486.-Harrison's Remontoir Escapement.

During William Harrison's voyages, the rate of the watch could not, of course, be checked daily for want of some means of comparison, and so in May 1766 the Board of Longitude placed the instrument at the Greenwich Observatory in the hands of Dr. Maskelyne, who had then been appointed Astronomer Royal, for the purpose of testing its daily rate. Dr. Maskelyne was supposed to favour lunar observations as a solution of the longitude problem and William Harrison considered he was prejudiced against the watch; it was, therefore, put in a box having a glazed lid and two locks, the keys whereof were kept, one 


\section{Old Clocks and Watches and their Makers}

by Dr. Maskelyne and the other by Captain Baillie, Governor of Greenwich Hospital. The trial lasted 298 days, during which the watch gained 1 hour 10 minutes 27.5 seconds. Its greatest gain in one day was 30 seconds, the temperature being $60^{\circ}$ and the pendant vertical ; its greatest loss in one day was 6.5 seconds, the thermometer being at freezing point, the piece lying dial up.

Harrison's watch and the three bulky timepieces which preceded it are all preserved in the Greenwich Observatory.

Besides the early clocks mentioned on p. 342, one of very superior workmanship and much later date, in the possession of the Royal Astronomical Society, has been described in the R. A. S. Notices by Mr. E. T. Cottingham. A view of the dial and movement appears in Fig. 487. The whole affair is a mass of ingenious complications departing, wherever possible, from the beaten track. Several of the contrivances embodied may be briefly summarised. The escapement is a variation of the " grasshopper." Cycloidal guides are provided for the pendulum, which vibrates through no less than $12^{\circ}$ of arc. There is a double minute hand which goes round in two hours, being jumped forward at half-minute intervals by a remontoir which the escape wheel releases. The escape wheel has 120 teeth, and as it makes but one turn in four minutes a four-finger seconds indicator is provided. The seconds dial is sunk, and each of the fingers in succession comes into sight and points to the seconds figures. The bearings of the great wheel run on rollers pivoted into rings and the other bearings are supported on the edges of large friction rollers. Altogether the cost of this timekeeper must have been enormous.

On Harrison's tomb in the south-west corner of Hampstead Churchyard is the following inscription :-

" In memory of Mr. John Harrison, late of Red Lion Square, London, inventor of the timekeeper for ascertaining the longitude at sea. He was born at Foulby, in the county of York, and was the son of a builder at that place, who brought him up to the same profession. Before he attained the age of twenty-one, he, without any instruction, employed himself in cleaning and repairing clocks and watches, and made a few of the former, chiefly of wood. At the age of twentyfive he employed his whole time in chronometrical improvements.

" He was the inventor of the gridiron pendulum and the method of preventing the effects of heat and cold upon timekeepers by two bars fixed together; he introduced the secondary spring to keep them going while winding up; and was the inventor of most (or all) the improvements in clocks and watches during his time. In the year 1735 his first timekeeper was sent to Lisbon, and in 1764 his then much-improved fourth timekeeper having been sent to Barbadoes the Commissioners of Longitude certified that it had determined the longitude within one-third of half a degree of a great circle, having not erred more than forty seconds in time. After sixty years' close application to the above pursuits, he departed this life on the 24th day of March 1776, aged eighty-three. This tombstone was put up many years after his death."

In 1878 the tomb had become very dilapidated, the inscription 
being barely decipherable, and I then suggested to Mr. W. H. Prosser that he should obtain subscriptions, and have it restored. This he proceeded to do ; but on applying to the Clockmakers' Company, some inembers of the Court expressed $A$ wish that the matter should be placed in the hands of the Company, and the restoration was accordingly made under the direction of the Court forthwith. The engraving

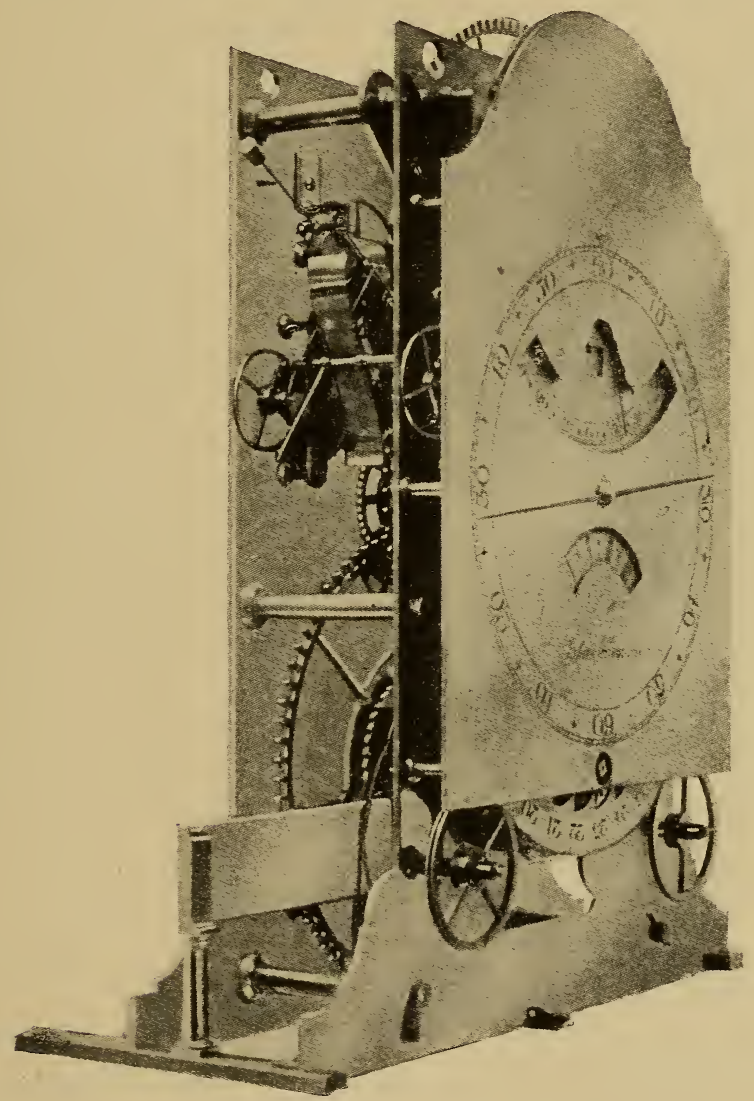

FIG. 487.-Late Clock by John Harrison, in possession of the Royal Astronomical Society.

(Fig. 484) is from one by P. L. Tassaert, after a portrait by T. King, taken in 1768. The "earlier effort" behind Harrison is his No. 3 timekeeper, now at Greenwich, but the artist has drawn it about three times as large as it really is.

Pinchbeck.-Among the celebrated clock and watch makers of the eighteenth century must be reckoned Christopher Pinchbeck, 


\section{Old Clocks and Watches and their Makers}

known principally as the discoverer of an alloy of metals, called after him "Pinchbeck," and as an inventor of "Astronomico-Musical Clocks." In the "Dictionary of National Biography," R.B.P. suggests that he probably sprang from the small town of Pinchbeck in Lincolnshire. $\mathrm{He}$ resided at Clerkenwell in a turning out of St. John's Lane called Albion Place, which, prior to 1822, when it was rebuilt, was known as St. George's Court. From there he removed to Fleet Street, as is shown by the follow-

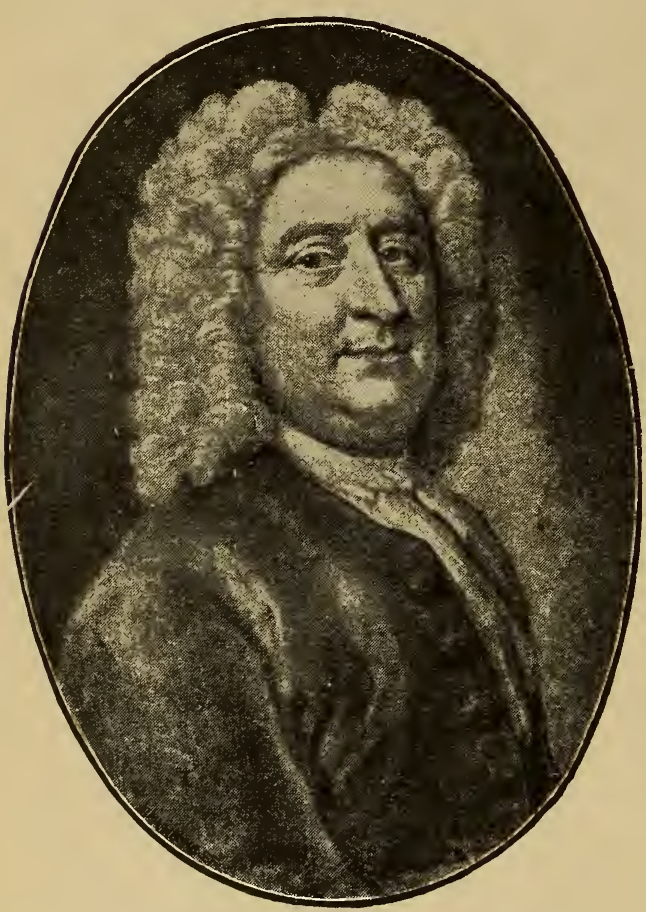
ing advertisement which appeared in Applebee's Weekly Journal of 8th July 1721:

" Notice is hereby given to Noblemen, Gentlemen, and Others, that Chr. Pinchbeck, Inventor and Maker of the famous Astronomico-Musica] Clocks, is removed from St. George's Court, St. Jones's Lane, to the sign of the Astronomico-Musical Clock in Fleet Street near the Leg Tavern. He maketh and selleth Watches of all sorts and Clocks, as well for the exact Indication of Time only, as Astronomical, for showing the various Motions and Phenomena of planets and fixed stars, solving at sight several astronomical problems, besides all this a variety of Musical performances, and that to the greatest Nicety of Time and Tune with the usual graces; together with a wonderful imitation of several songs and Voices Fig. 488.-Christopher Pinchbeck. I670-I732, of an Aviary of Birds so natural that any who saw not the Instrument would be persuaded that it were in Reality what it only represents. He makes Musical Automata or Instruments of themselves to play exceeding well on the Flute, Flaggelet or Organ, Setts of Country dances, Minuets, Jiggs, and the Opera Tunes, or the most perfect imitation of the Aviary of Birds above mentioned, fit for the Diversion of those in places where a Musician is not at Hand. He makes also Organs performing of themselves Psalm Tunes with two, three, or more Voluntaries, very Convenient for Churches in remote Country Places where Organists cannot be had, or have sufficient Encouragement. And finally he mends Watches and Clocks in such sort that they will perform to an Exactness which possibly thro' a defect in finishing or other Accidents they formerly could not."

His reputation was world-wide, to judge from the appended extract from a letter of the period, quoted by W. J. Pinks :- 
"Mr. P. has finished a fine musical clock, said to be a most exquisite piece of workmanship, and worth about $£ 1,500$, wch is to be sent over to ye King of France (Louis XIV.) and a fine organ to ye great Mogul, worth $£^{300}$."

Pinchbeck exhibited his " astronomico-musical clocks," together with a variety of curious automata, at Bartholomew Fair, and the Daily Journal of 27th August 1729 announces that the Prince and Princess of Wales went to Bartholomew Fair to see his exhibition. Pinchbeck also attended Southwark Fair, and with Fawkes, a celebrated juggler and conjurer of that day, had a united "show." This may shock many who avail themselves of the fine arts of advertising in vogue to-day; but, however undignified it may have been, it cannot detract from his ability as a horologist.

Mr. J. E. Hodgkin has a trade card, "Pinchbeck, senr., at Pinchbeck's Head in Fleet Street," a change of sign possibly induced by the popularity of Pinchbeck's name. Mr. William Norman has a metal token ; on the obverse, a bust of George II. ; reverse, a bust in a frame, surrounded by representations of a walking-stick, snuffbox, signet ring, watch (or medal) attached to a double chain, and other articles, with the inscription, "Pinchbeck, senr., at Pinchbeck's Head in Fleet Street."

Specimens of Christopher Pinchbeck's work are rarely met with. The clock illustrated in Fig. 489 is a very rare and unusual one, constructed in the manner of the German early 18th-century clocks. It strikes the hours and repeats the quarters by pulling a string. The case is in the Louis XV.taste. The dial is enamel, shcwing hours and minutes and there is a subsidiary alarm dial. At the top of the case are two chased cherubs supporting an enamelled cartouche bearing the name $\mathrm{C}$. Pinchbeck.

This clock belonged to the Prince of Wales, afterwards George IV., who had a house in Hammersmith Mall. It afterwards passed into the possession of Louis Welfe, maître de cuisine at Carlton House, who lived subsequently at the Hammersmith establishment. It is now in the possession of Mr. Hansard Watt to whom I am indebted for the excellent photograph.

Pinchbeck gold was much used for watch cases and the like. It is an alloy of three parts of zinc to four of copper ; but its composition was jealously guarded by the inventor, as may be gathered from the following extract from a letter quoted by W. J. Pinks :-

"Mr. Xtopher Pinchbeck had a curious secret of new-invented metal wch so naturally resembles gold (as not to be distinguished by the most experienced eye), in colour, smell, and ductibility. Ye secret is communicated to his son," 


\section{Old Clocks and Watches and their Makers}

He died in 1732, at the age of sixty-two years, and was buried in St. Dunstan's Church, Fleet Street. The portrait (Fig. 488) is from an engraving by Faber after a painting by Isaac Whood.

Edward Pinchbeck, second son of Christopher, who was born in 1713, succeeded his father in the business, as is evident from a "Caution to the Public" which he inserted in the Daily Post of 9th July 1733.

"To prevent for the future the gross imposition

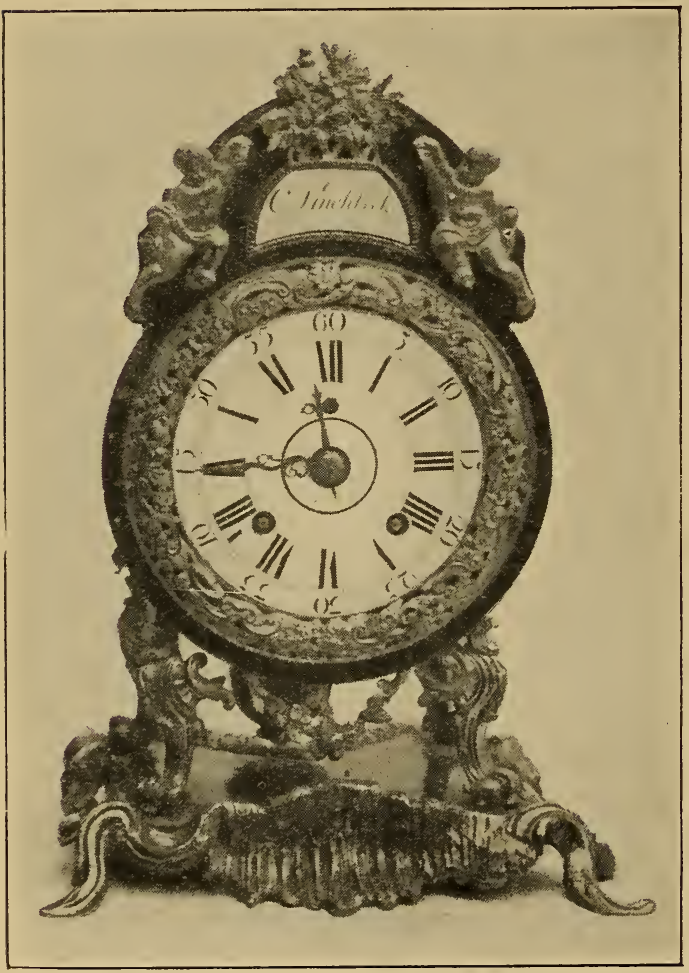

FIG. 489.--Rare and Unusual Clock, by Christopher Pinchbeck. that is daily put upon the publick by a great number of shopkeepers, hawkers, and pedlars, in and about this town, Notice is hereby given, that the ingenious Mr. Edward Pinchbeck, at the Musical Cock, in Fleet Street, does not dispose of one grain of his curious metal, which so nearly resembles gold in colour, smell, and ductility, to any person whatsoever; nor are the toys made of the said metal sold by any one person in England except himself." After recounting the various articles he makes from the alloy, the notice continues: "And in particular watches, plain and chased in so curious a manner as not to be distinguished by the nicest eye from real gold, and which are highly necessary for gentlemen and ladies when they travel, with several other fine pieces of workmanship of any sort made by the best hands. The said Mr. Pinchbeck likewise makes astronomical and musical clocks; which new invented machines are so artfully contrived as to perform on several instruments great variety of musick composed by the

most celebrated masters, with that exactitude, and in so beautiful a manner that scarce any hand can equal them. They likewise imitate the sweet harmony of birds to so great a perfection as not to be distinguished from nature itself. He also makes repeating and all other sorts of clocks and watches ; particularly watches of a new invention, the mechanism of which is so simple, and the proportion so just, that come nearer truth than any others yet made."

Christopher Pinchbeck, eldest son of the first named Christopher, 
carried on a successful business as a clock and watch maker in Cockspur Street, being described as clockmaker to the king. In 1766 he is said to have bought from Ferdinand Berthoud, for George III., the first pocket watch made with a compensation curb. In 1781 he was elected as an honorary freeman of the Clockmakers

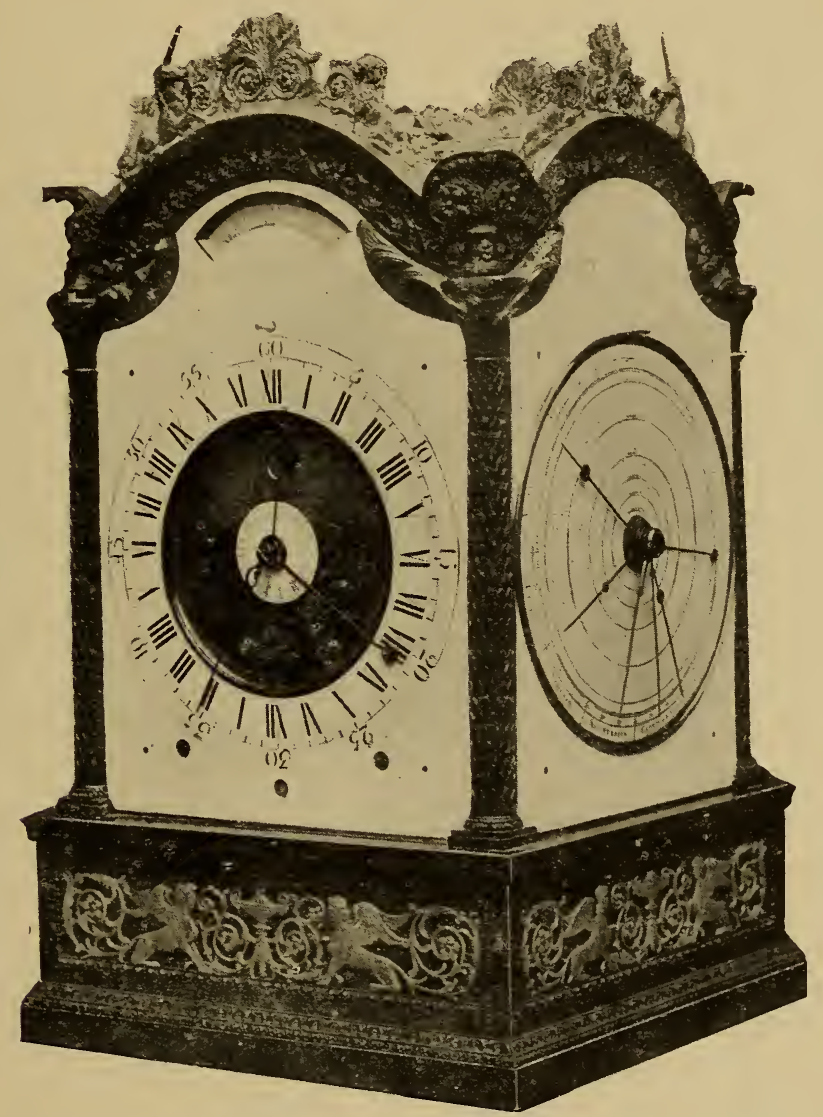

Fig. 490.-Square Four-Faced Clock, by Eardley Norton, at Buckingham Palace.

Company. He died at Cockspur Street in 1783 , aged seventy-three, and was buried at St. Martin's-in-the-Fields.

A Richard Pinchbeck, "toyman," who seems to have carried on business $1760-70$, was probably a member of the same family.

Pinchbeck-Norton.-In the Gentleman's Magazine of June 1765 it is stated that Pinchbeck and Norton had " just set up at 


\section{Old Clocks and Watches and their Makers}

the Queen's House a new complicated clock, having four dials, and amongst them it denoted clock and sun time, sunrise and setting for every day in the year in various places of the world, the Copernican motion of the planets, the ages and phases of the moon, highwater at thirty-two different seaports, and the days of the week and the months of the year." Notwithstanding this announcement, it is very doubtful if Pinchbeck and Norton were ever in partnership. The probability is that each of them provided a clock, for there are still two astronomical clocks at Buckingham Palace, one by Christopher Pinchbeck, the younger, and one by. Eardley Norton. Each of these clocks chimes the quarters and has four enamel dials, one on each face of the square case. Pinchbeck's clock is the larger of the two, and has a handsome tortoise-shell case with silver spandrels at the corners of the dial. Norton's clock is shown in Fig. 490, for which I am indebted to Mr. A. E. Rutherford. The dial on the left, besides Greenwich mean time and solar time, shows sunrise and sunset. A disc rotates once a day behind a rising and falling shutter. During the shortest days the shutter is at its greatest height and hides the sun from 3.53 P.M. till 8.5 A.M. After remaining stationary three days it falls gradually as required by the lengthening of the days. The right-hand dial is an orrery, having hands to represent the movement of Mercury, Venus, the Earth, Mars, Jupiter, and Saturn. The third dial is a calendar, and the fourth shows the age and phases of the moon, as well as the time of high and low, tide at thirty-two places.

Thomas Mudge.-Thomas Mudge, born at Exeter in 1715, was the son of a clergyman, who kept a school at Bideford. Young Mudge showed so great a taste for mechanics, with a particular inclination for horology, that his father placed him as an apprentice with Graham. Here he made rapid progress in his art, and on the completion of his indentures took a leading position in the establishment. He was admitted to the freedom of the Clockmakers' Company in 1738, and called to the livery in 1766. At Graham's death, in 1751, Mudge succeeded to the business, as shown by the following from the Daily Advertiser of 18th November 1751 :- “ Thomas Mudge, watchmaker, apprentice to the late Mr. Graham, carries on the business in the same manner Mr. Graham did, at the sign of the 'Dial and One Crown' opposite the 'Bolt and Tun ' in Fleet Street." Shortly after Mudge was established, Ferdinand the Sixth, of Spain, ordered an equation watch from John Ellicott, who, in consequence of the difficulties presented by this unusual construction, had recourse to Mudge. 
Ferdinand was a lover of mechanical work, and hearing of this circumstance, sent an order direct to Mudge to construct for him any piece of horology which he thought the most curious, and to charge for it whatever he chose. In response Mudge constructed a watch which showed true and apparent time, struck the hours, and repeated not only the hours and quarters, but the minutes also; the watch was set in the top of a walking cane, with sliding shutters over the dials. The king set great store by this piece of workmanship, for which Mudge charged him 480 guineas. About 1755 he entered into partnership with William Dutton, another apprentice of Graham.

Mudge invented the

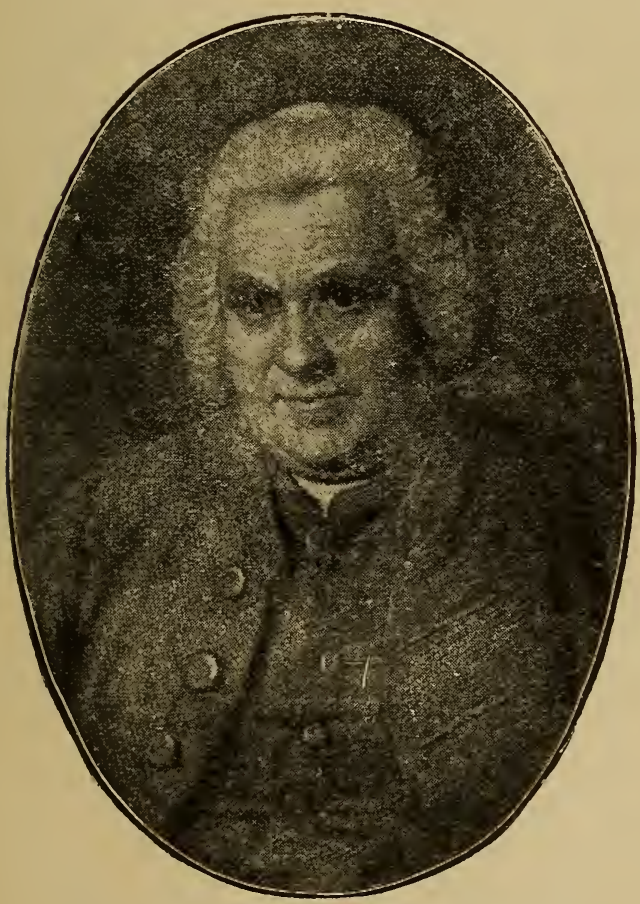

Fig. 491.-Thomas Mudge, 1715-1794. lever escapement about 1765 , but it appears only constructed two watches on this principle: one for Queen Charlotte, which performed admirably, the other for his patron and friend Count Bruhl which, after several journeys, subjected to all the inconveniences of changes of position and quick travelling, kept time within a few seconds during several weeks. Mudge showed this escapement to Berthoud, when he was in London in 1766, but he did not think so favourably of it as Margetts, Emery, and other English horologists did.

In 1765 he published "Thoughts on the Means of Improving Watches, particularly those for Use at Sea." From this time his attention was mainly directed to marine timekeepers, and in 1771, leaving the conduct of the Fleet Street business to Dutton, he quitted London, and went to reside at Plymouth, where he devoted himself to the construction of chronometers. The first one was 
sent to Greenwich Observatory in 1774, and afterwards to Baron Zach (who was astronomer to the Duke of Gotha), and lastly to Admiral Campbell, who took it a voyage to Newfoundland, when its performance was pronounced to be satisfactory. The Board of Longitude sent him $£ 500$, requesting him to continue his reseårches. Two other chronometers were sent to the Greenwich Observatory for trial in 1779 .

Dr. Maskelyne and Mudge could not agree. Maskelyne, who was Astronomer Royal, carried the Board of Longitude with him. It was asserted that chronometers by Arnold performed better than those of Mudge. Arnold had not submitted his chronometers for the Government reward, and therefore Mudge objected to the comparison. On the petition of Mudge, the House of Commons, in 1791, appointed as a committee to investigate the performance of his chronometers the Bishop of St. David's, Mr. Atwood, Mr. De Luc, Mr. Ramsden, Mr. Edward Troughton, Mr. Holmes, Mr. Haley, and Mr. Howells, the last three being watchmakers of repute. After much bickering, Mudge, in 1793 , was paid $f_{5} 2,500$, in addition to $f_{500}$ he had already received as encouragement, although the Board of Longitude dissented from this course.

Mudge was often employed by George III. on delicate pieces of work, and on the death of George Lindesey, in 1776, was appointed watchmaker to the king. He was made free of the Clockmakers' Company in 1738 , and admitted to the livery in $\mathbf{1 7 6 6}$. The engraving on p. 355 is from a painting by Dance, executed for Count Bruhl in $\mathbf{1 7 7 2 .}$ He died at his son's house in Walworth, on 14th November 1794.

That an accomplished horologist and sound mechanic as Mudge seems to have been should, after his invention of the lever escapement, have persisted in the complication of a remontoir and vertical escapement for his marine timekeepers, must be ascribed to the perversity of genius.

The salient features of his chronometer are shown in the accompanying drawings. To obviate the difficulty of the compensating curb action interfering with the action of the regulating curb pins there are two balance-springs. The upper one for regulating has its stud $\mathrm{C}$ screwed to the balance-cock, the stud D of the lower spring, with which the pins of the compensation curb engage, being fixed to the upper plate of the chronometer. There are two remontoir springs, $\mathrm{H}$ and $\mathrm{I}$, which are wound by the escape wheel $G$, and which alternately impel the balance through the pins $a, b$, connected with the upper, and $e, f$ with the lower one. The wheel 
and pallet actions will be understood from an examination of the lower figure, which is a plan. - After the wheel tooth has given impulse to the pallet, and thereby wound the remontoir, it is locked on the projecting nib of the pallet till the balance in its excursion unlocks it, and allows the tooth on the opposite side of the wheel to impel the other pallet. The balance staff is cranked, and the pallets with the remontoirs are pivoted partly in the balance staff and partly in separate cocks, so that there are six pivots moving from the balance staff centre.

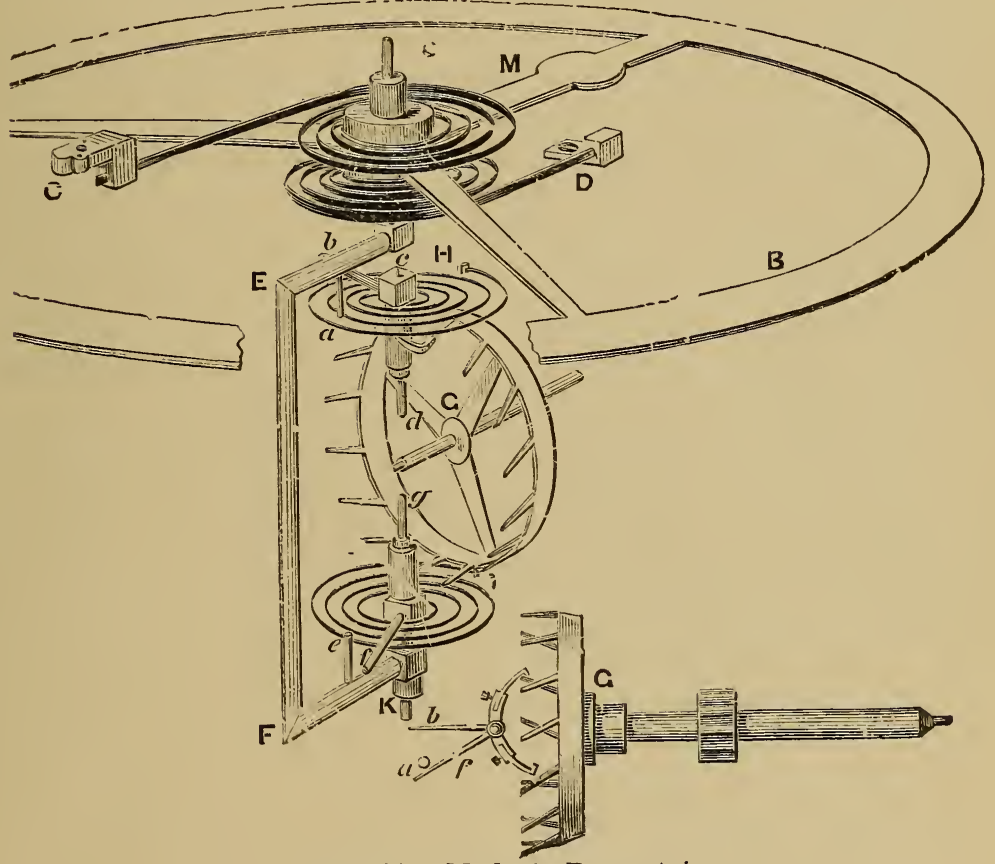

Frg. 492.-Mudge's Remontoir.

After Mudge's migration to Plymouth, the Fleet Street business seems to have reverted entirely to William Dutton, although the title of Mudge \& Dutton was retained till 1794.

Thomas Mudge, junr., who was an attorney at 3 Old Square, Lincoln's Inn, engaged Messrs. Howells, Pennington, Pendleton, and Coleman to produce chronometers on his father's plan; but they were too costly, and not successful. By 1799 the younger Mudge sold eleven at 150 guineas each, which did not pay him. Of others in course of manufacture some were finished by his coadjutors, 


\section{Old Clocks and Watches and their Makers}

and some by Messrs. Barraud \& Jamison. One of these instruments is in the Soane Museum, one at South Kensington, lent by Mr. A. Mallock, another at the Horological Institute, and another at the Guildhall Museum.

John Arnold.-This famous horologist was born in 1736, at Bodmin, in Cornwall, where he was apprenticed to his father, a watchmaker. While a youth he left home, and after a stay of some time in Holland he determined to try his fortune in London. Arnold, by his own account, was for some time a gunsmith. He afterwards worked as a journeyman, but soon found an opportunity of establishing himself at Devereux Court, Fleet Street. One of his earliest acts here was to make an exceedingly small half-quarter repeating watch, which he had set in a ring, and presented to George III. in June 1764. When it is stated that the whole movement measured but little more than $\frac{1}{3}$ in. across, his ability as a fine workman and his marvellous sense of touch will be appreciated. The escapement selected was a cylinder one, the cylinder, made of ruby and measuring $\frac{7}{54}$ in. in diameter, being the first made of that material. The king accepted the repeater, and presented its maker with 500 guineas as an acknowledgment of his surpassing skill.

According to the AnnualRegister for 1764, the whole of this repeater, composed of 120 parts, weighed but 5 dwts. $7 \frac{3}{4}$ gr., the following being the weight of the principal items: The movement, complete, is 2 dwts. $2 \frac{1}{8}$ gr. ; great wheel and fusee, $2 \frac{3}{4}$ gr. ; second wheel and pinion, $\frac{3}{4}$ gr. ; barrel and mainspring, $3 \frac{1}{2}$ gr. ; third wheel and pinion, $\frac{1}{9}$ gr. ; fourth wheel and pinion, $\frac{1}{10}$ gr. ; cylinder, wheel, and pinion, $\frac{1}{16}$ gr. ; balance-spring, cylinder and collet, $\frac{2}{3}$ gr. ; the balance-spring $\frac{1}{30} 0$ gr. ; the chain, $\frac{1}{2}$ gr. ; barrel and mainspring, $1 \frac{3}{4}$ gr. ; great wheel and ratchet, 1 gr. ; second wheel and pinion, $\frac{1}{7}$ gr. ; third wheel and pinion, $\frac{1}{8}$ gr. ; fourth wheel and pinion, $\frac{1}{9}$ gr. ; fly wheel and pinion, $\frac{1}{17}$ gr. ; fly pinion, $\frac{1}{20}$ gr. ; hour hammer, $\frac{1}{2}$ gr. ; quarter hammer, $\frac{1}{2}$ gr.; rack, chain and pulley, $1 \frac{1}{3}$ gr.; quarter and half-quarter rack, $\frac{2}{3}$ gr. ; the quarter and half-quarter snail and cannon pinion, $\frac{2}{3}$ gr. ; the all-or-nothing piece, $\frac{1}{2}$ gr. ; two motion wheels, 1 gr. ; steel dial-patae with gold figures, $3 \frac{1}{2}$ gr. ; the hour snail and star, $\frac{1}{2}$ and $\frac{1}{16} \mathrm{gr}$.

Arnold's achievement at once brought him into notice, and from that time his future success was assured.

It is said that the Empress of Russia offered Arnold 1,000 guineas for a duplicate of the repeater made for George III., but the offer was declined, not that Arnold doubted his ability to produce 
it, but because he desired the miniature timekeeper to remain unique.

Arnold now turned his attention seriously to the problem which was engaging the thoughts of leading horologists here and in France. John Harrison had already fulfilled the conditions laid down by the Board of Longitude, and thus practically secured the $£ 20,000$ offered by Parliament in $\mathbf{1 7 1 4}$ for a timekeeper sufficiently exact to ascertain the longitude within certain limits. A subsequent Act of Parliament, however, devoted a further $£ 10,000$ as a stimulus to continued research and improvement. Mudge was already in the field, and seemed bent on adhering to the remontoir principle somewhat on Harrison's plan. But it was clear to other minds that a nearer approach to perfection might be obtained by a chronometer of altogether a different character to the one invented by Harrison.

The chronometer which Captain Cook took with him in the "Resolution" on his second voyage, in 1772, was Arnold's No. 3. Two other timekeepers of Arnold's were on board the "Adventure." The two in the "Adventure " were earlier, and presumably Arnold's No. 1 and 2.

Lieut. Rupert T. Gould, who has examined No. 3, and either 1 or 2 recently, which are the property of the Royal Society, states that they are pivoted-detent escapements of peculiar design, the unlocking taking place in a direction parallel with the escape-wheel arbor, and the impulse being given on the line of centres. Neither beats half seconds. No. 3 by actual and repeated count, beats 112 to the minute, and, the other 94 only. There is probably $\frac{1}{3}$ beat error in these figures, since the trains as far as could be observed, were identical, the only difference being that one escape wheel has 10 teeth, and the other 12. Hence-

$$
\frac{112 \times 10}{12}=93 \frac{1}{3}
$$

Lieut. Gould also states that the timekeeper by Kendal, aboard the "Resolution," was his copy of Harrison's No. 4, and Cook expressed the very highest opinion of its performance.

Arnold was not to be daunted. He profited by experience, and devised the helical form of balance-spring, and a form of compensation balance. Lieut. R. T. Gould states " Arnold first applied the helical spring in torsion, but Harrison had used it in tension forty years earlier, in his No. 1 and 2 machines, and curiously enough their springs have incurved ends just like Arnold's, although merely for the purpose of centralising the pull on the spring. Hence, 
the actual form of Harrison's and Arnold's helical springs is identical, although the application is different." The spring, as shown in the sketch, is very similar to the one now in most general use for marine chronometers, but the balance was rather a complicated affair. These components he patented in 1775 (Patent No. 1,113), and his specification describes compensation to be effected by a brass and steel volute fixed at its inner end to the collet of the balance, and actuating weighted rods by means of a lever attached to its outer end. Some years later Fig. 493. he adopted the simple circular bi-metallic-rim balance
practically as now used, except that he soldered the brass
and steel together and formed the circular rim with pliers, whereas FIG. 493. he adopted the simple circular bi-metallic-rim balance
practically as now used, except that he soldered the brass
and steel together and formed the circular rim with pliers, whereas Earnshaw first turned a steel disc and then melted the brass on to its periphery, a plan which, according to Rees, was introduced by Brockbank.

In May 1782 Arnold patented his improved detent escapement (Patent No. 1,328). This is practically the chronometer escapement of to-day, which was almost simultaneously invented by Thomas Earnshaw, except that in Arnold's escapement the escape whee! teeth, instead of being flat where they gave impulse, were epicycloidal curves, as shown in Fig. 494 ; but they required oiling, and were consequently abandoned. While Earnshaw's wheel is locked on the points of the teeth and the detent moves away from the centre of the wheel to unlock, Arnold's locked on the heel of the tooth and the detent moved towards the centre of the wheel to unlock, the sunk part of the body of the wheel allowing the locking stone to pass.

Arnold was now admitted to be a very

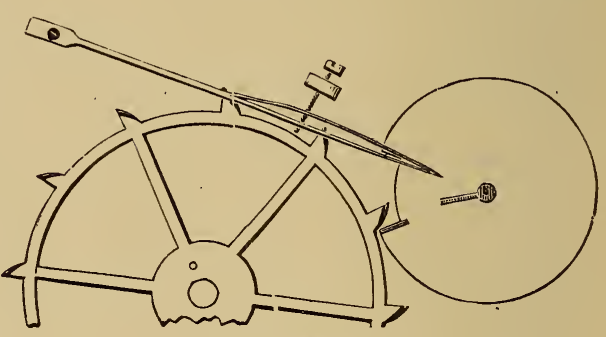

FIG. 494. successful chronometer maker, but he still continued his investigations, and made countless experiments with a view to improvements.

Some time after 1764 Arnold quitted Devereux Court for Adelphi Buildings, which is the address given in his patent specifications, and in an account of the going of a pocket chronometer, in 1781, it is stated to have been compared with the regulator at his house in the 
Adelphi. About 1785 he removed to 112 Cornhill, where he carried on business until his death, his son being admitted into partnership during the latter part of the time. Arnold \& Son also had a chronometer manufactory at Chigwell in Essex.

In a book of " Certificates and Rates of Going," which he published in 1791, he gives the price of his large marine chronometers as from 60 to 80 guineas; pocket chronometers, in gold cases, 120 guineas, and in silver, 100 guineas ; repeaters from 150 guineas for the best kind in gold, down to $\mathbf{2 5}$ guineas for the commonest, in silver cases.

The rival claims of Mudge, Arnold, and Earnshaw to the rewards offered for the best chronometer were submitted to a Select Committee of the House of Commons, assisted by a committee of experts, and eventually each was awarded $£ 3,000$; but a moiety of Arnold's portion was not paid till after his death, when it was received by his son. Arnold had not laid claim to the reward when depositing his chronometers at the Greenwich Observatory; but their good performance was made use of by Maskelyne as a reason why Mudge's claim should not be recognised.

Arnold told the committee he had then made upwards of 900 timekeepers, but never two alike, so long as he saw room for any possible improvements; adding, "I have twenty number ones."

According to Beillard, Arnold's son John Roger was apprenticed in Paris to Breguet. Some time ago, by favour of Mr. Hurcomb, I examined a Tourbillon chronometer in an engine-turned silver case, with square edges, which appears to have been the original model for the celebrated Tourbillon of Breguet on a chronometer by Arnold. The foot of the balance-cock was especially wide, and bore the following inscription:- " Premier régulateur à tourbillon de Breguet réuni à un des premiers ouvrages d'Arnold. Hommages de Breguet à la mémoire révérée d'Arnold offerts à son fils. An 1808.' The workmanship throughout was splendid, and the graceful tribute to Arnold's genius of course enhanced the value of the piece.

John Arnold was admitted as a member of the Clockmakers' Company in 1783, and chosen on the livery 1796. He died at Well Hall, near Eltham, Kent, in 1799. The portrait (Fig. 495) is from an engraving by Susan Ester Reid, after a painting by R. Davy.

At South Kensington is a painting showing John Arnold, his wife and son, together with a label stating that Arnold was assisted in his profession by his wife. A reproduction of this group is given in Fig. 496. 
362 Old Clocks and Watches and their Makers

John Roger Arnold seemed to have inherited neither the horological ability nor the commercial aptitude of his father whom he succeeded. He was admitted to the Clockmakers' Company in 1796 , and became master in 1817. In 1820 he removed from Cornhill to 27 Cecil Street, and from thence, in 1830, to 84 Strand, where he entered into a partnership agreement for ten years with E. J. Dent and during this period the business flourished; but, immediately the term expired, Dent set up for himself at $82 \mathrm{~S}$ trand,

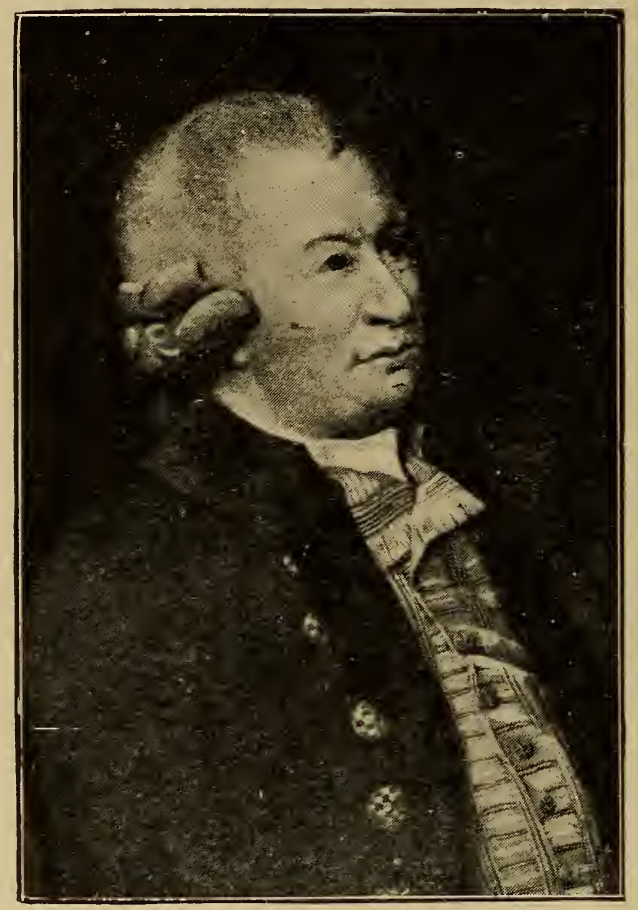

FIG. 495.-JOHN ARNOLD, 1736-1799.

carrying with him the confidence of most of the customers of the late firm. John R. Arnold continued at 84 Strand till 1843, when he died.

Thomas Earnshaw.--To Thomas Earnshaw, who was born at Ashton-under-Lyne in 1749, must be ascribed the merit of having devised the chronometer escapement and compensation balance precisely as they are now used.

The comparison of Arnold's and Earnshaw's escapement and balance just given in the sketch of the former's career may be referred to and need not be repeated. 
That Earnshaw was a true horologist by intuition is evident. $\mathrm{He}$ is said to have been honest and straightforward, but somewhat rugged in his manner. There are, however, but few details of his life to be obtained. He was apprenticed to a watchmaker when fourteen years of age, and seems to have come to London inmediately on completion of his indentures. After working for some time as a finisher of verge and cylinder watches, he taught himself watch jewelling and then cylinder-escapement making, using ruby cylinders and steel wheels.

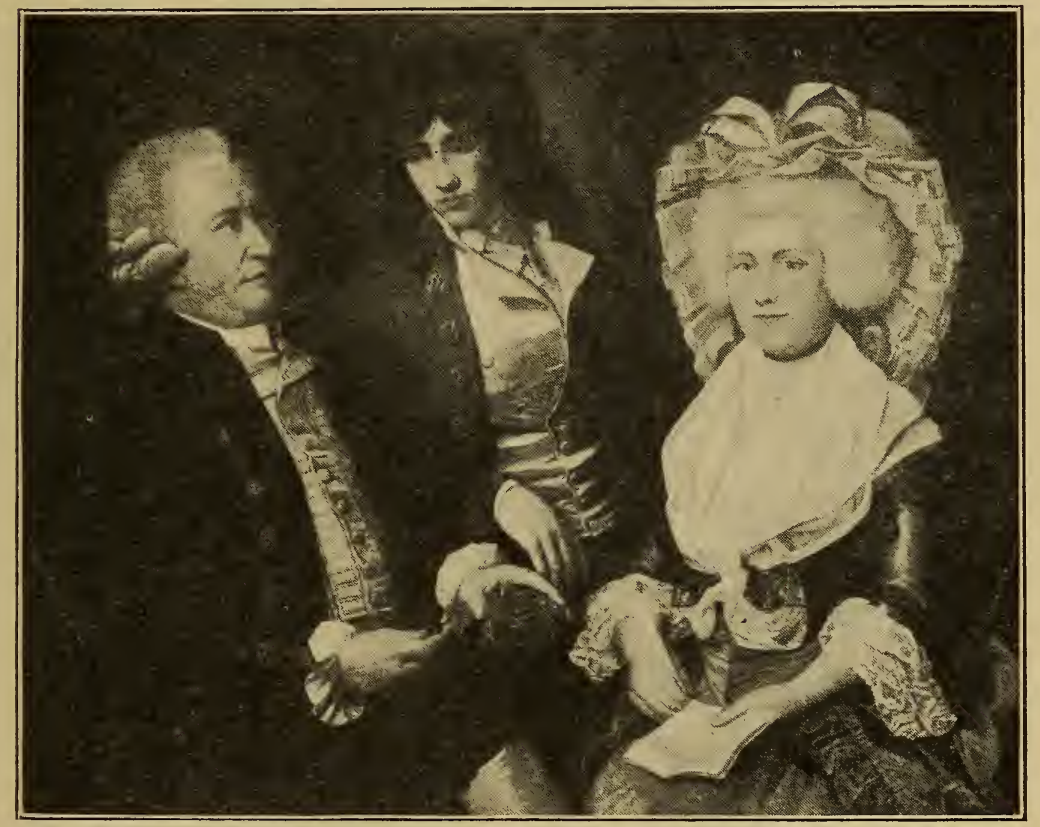

Fig. 496.-John ARnold, his Wife And Son.

He married early in life, and the necessity of providing for a family out of his earnings seems to have hampered him considerably in carrying out his projects.

To improve the chronometer escapement he, in 1781, conceived the idea of substituting a spring detent for the pivoted form as applied by Le Roy and other French artists. After showing the new method to John Brockbank, for whom he worked, he took it to Thomas Wright of the Poultry, another of his customers, and agreed that when a watch with the device was finished, Wright should patent it. But the latter 


\section{Old Clocks and Watches and their Makers}

kept the watch for a year to observe its going, and did not obtain the patent till 1783. In the meantime John Arnold had lodged a patent specification, claiming the same thing as his invention. To the end of his life Earnshaw lost no opportunity of declaring in emphatic language his belief that John Brockbank had divulged his plan to Arnold. According to Earnshaw's account his own actions were always marked by trusting simplicity, though his confidence was continually betrayed.

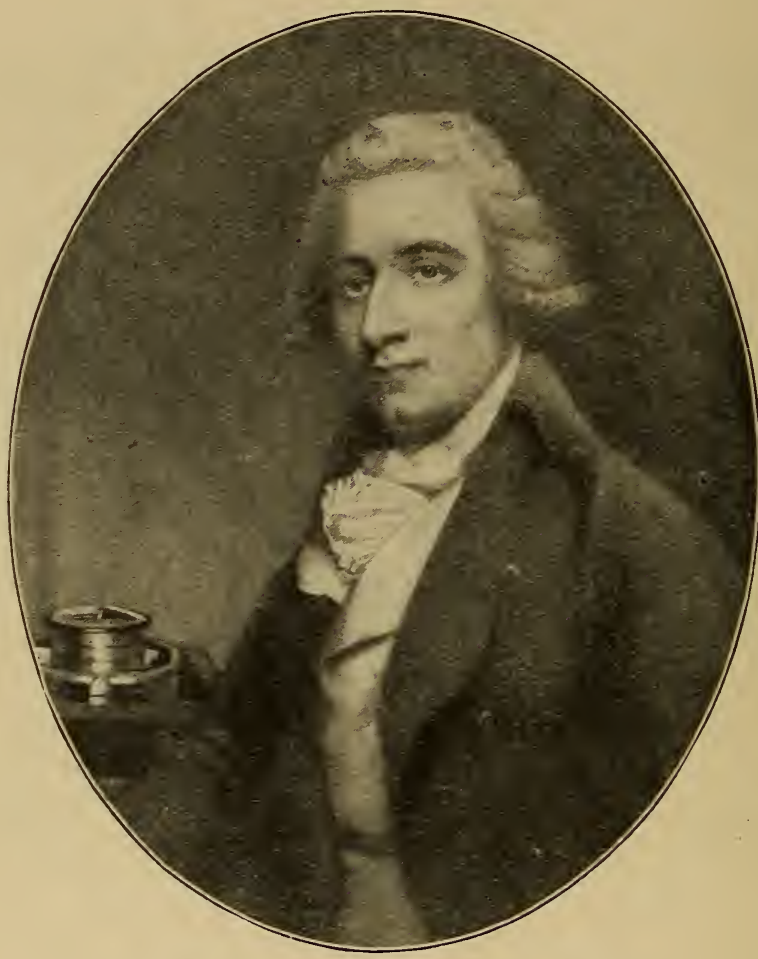

Fig. 497.-Thomas EARnshaw, 1749-1829.

The patent cost Wright $£ 100$, and as all negotiations with Brockbank, Haley, Wm. Hughes, Best, and other leading watchmakers to purchase a share of it failed, watches with the new escapement were manufactured for various people on payment to Wright of a royalty of $£ 1$ each. The first dozen were not a success; the impulse roller being too small with relation to the escape wheel, they were liable to stop. Earnshaw discovered the fault and with better proportions brought the new 
escapement into favour for pocket watches. The earlier ones were

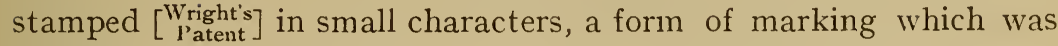
dropped after a few years.

Dr. Maskelyne, the Astronomer Royal, having tried one of his watches in 1789, advised Earnshaw to apply to the Board of Longitude for permission to submit timekeepers for official trial at Greenwich Observatory. Five of his watches were tested there in 1791, and then he obtained an order for two chronometers, and these were deposited at the Observatory on 1st January 1798.

In 1794 or 1795 Earnshaw succeeded to the business which had been carried on for some years by Wm. Hughes at 119 High Holborn, one door east of the turning then known as King Street but now called Southampton Row. The shop referred to was pulled down when the thoroughfare was widened in 1901 .

The committee of investigation appointed to consider the claims of chronometer improvers awarded Earnshaw $£ 500$ in 1801 on account of his inventions, and in 1803 a further $£ 2,500$, making his total reward $£ 3,000$. Rightly or wrongly, he was of opinion that he was not well treated, and in 1808 issued "An Appeal to the Public," declaring he was entitled to more pre-eminent recognition. The engraving on p. 364 is copied from one by S. Bellin after a portrait by Sir M. A. Shee.

Earnshaw also made a number of clocks. For the first one, which was ordered by the Archbishop of Armagh, he was paid $f 150$ and an additional $£ 100$ for going to Armagh to fix it.

$\mathrm{He}$ died at Chenies Street in 1829, but the business was carried on for some years by his son, first at the Holborn premises and afterwards at Fenchurch Street.

Ascertaining the Longitude at Sea. Development and use of the Marine Chronometer.-The discovery of America, in 1492 caused considerable attention to be paid to the question of finding the longitude at sea, for it was evident that, if ocean navigation was to be carried on with anything like safety, some more certain means of ascertaining the position of a ship than was possible by dead reckoning would have to be provided.

Columbus had not an azimuth compass, nor a sextant, nor a chronometer, nor a patent log, and he, and his immediate successors, were several months making the voyage across the Atlantic, while the early voyagers took about three years to circumnavigate the globe. Even in the middle of the eigtheenth century Commodore Anson, in his celebrated voyage round the world, had no safe guide. When he 
rounded Cape Horn he unexpectedly made the land on the eastern side, and found himself in consequence three hundred miles more to the east than he expected, and so his voyage was delayed. Then, again, he wanted to make the island of Juan Fernandez to recruit the crew. He got into the latitude of the island and thought he was to the west of it, but he was really to the east; he ran eastward and made the mainland of America, and turned round and had to sail westward again before he got to the island.

With a sextant the latitude may be readily ascertained by measuring the altitude above the horizon of certain of the heavenly bodies and reducing the observations by references to tables.

Finding the longitude is not so simple a matter, owing to the rotation of the earth on its axis, and the apparent change of places of the stars. As early as 1530 Gemma Frisius suggested solar observations and a timekeeper as a possible solution of the problem But the most important adjunct, an accurate timekeeper, was wanting.

In 1598 the matter had risen to such importance that the King of Spain offered a reward of one hundred thousand crowns for any invention which should gain that object. The rulers of one or two other maritime States followed his example, but all without effect.

Early in the seventeenth century John Baptist Morin proposed the preparation of tables with a view of making lunar observations available. Although Morin's suggestion was ridiculed at the time, it has become a perfectly practicable method. The moon is nearer the earth than the stars, and consequently appears to occupy a different position with regard to them when viewed from different points on the surface of the globe. And as the moon moves so swiftly from night to night through the sky, she shifts her position with respect to the stars very rapidly. If the sailor be provided with a book giving the distances of the moon from certain fixed stars for certain hours of, say, Greenwich time on every day of the year, he can, in any position in which he may be, by observing the position of the moon, secure a datum from which the longitude may be deduced. But even after the position of the moon with relation to these fixed stars has been ascertained, and the voluminous tables provided, somewhat tedious calculations are necessary to reduce the elements afforded by the observations obtained; besides which, if the lunar method alone is relied on, there is the disadvantage that the moon is not always visible. However, Morin's suggestion led to nothing at the time, and the greater simplicity of solar observations induced most investigators to consider the 
possibility of providing a correct timekeeper The first attempts to supply the want seem to have been made by Huygens and Hooke.

Huygen's marine clock, constructed about 1660, suspended in gymbals and actuated by a spring, was controlled by a pendulum. A marine pendulum clock constructed by Huygens was taken to sea by a Scottish captain, named Holmes, and tried by Lord Kincardine. in 1662 with but moderate success, only to demonstrate the futility of relying on the pendulum as a regulator when tossed about in a ship on the ocean.

In the course of a paper he read before the Royal Society in 1662, Dr. Hooke said: "The Lord Kincardine did resolve to make some trial what might be done by carrying a pendulum clock to sea, for which end he contrived to make the watch to be moved by a spring instead of a weight, and then, making the case of the clock very heavy with lead, he suspended it underneath the deck of the ship by a ball and socket of brass, making the pendulum but short, namely, to vibrate half seconds; and that he might be the better enabled to judge of the effect of it, he caused tivo of the same kind of pendulum clocks to be made, and suspended them both pretty near the middle of the vessel underneath the decks. This done, having first adjusted them to go equal to one another, and pretty near to the true time, he caused them first to move parallel to one another, that is, in the plane of the length of the ship, and afterwards he turned one to move in a plane at right angles with the former; and in both these cases it was found by trials made at sea (at which I was present) that they would vary from one another, though not very much." Dr. Hooke concludes by saying that " they might be of very good use to the sea if some further contrivances about them were thought upon and put ints practice."

In 1714 the British Parliament, on the recommendation of a commission, of which Sir Isaac Newton was a member, passed " an Act for providing public reward for such person or persons as shall discover the longitude at sea." This Act ordained "that any offered method or invention on this subject shall, in the first instance, be investigated by a specially selected body of practical men, who may then recommend it to the Royal Commissioners constituting the Board of Longitude." The award was fixed at $f 10,000$ for a method or invention to define on a voyage from England to any of the West India Islands and back the longitude within one degree, $£ 15,000$ to define the longitude within twothirds of a degree, and $£ 20,000$ to within half a degree. 
The Paris Academy of Sciences in 1729 offered a prize for the best description of a suitable timekeeper. This was won by Massey, a Dutch clockmaker. In 1721 Sully produced a clock which he laid before the Academy in $\mathbf{1 7 2 4}$. It had a vertical balance, which, from the description, seems to have been a pendulum with cycloidal guides. This timekeeper promised success till tested in the open sea, when its performance, like that of the preceding instruments, was found to be unsatisfactory. Sully, however, seemed to be on the high road to success, and he was engaged on another timekeeper just before his untimely decease.

In 1675 Greenwich Observatory was founded. Flamstead was instructed to rectify the tables of the motions of the heavens and the places of the fixed stars. He made a large star catalogue, and many observations on the moon and other bodies, and the results of his lunar observations were taken in hand by the philosophers of the time, Newton and others. The construction of lunar tables, and to predict the place of the moon with sufficient accuracy for the adoption of the lunar method of longitude, was a very serious task.

It was not until 1767 that Maskelyne, a succeeding AstronomerRoyal, founded the "Nautical Almanac," and gave therein, for the first time in any country, distances of the moon from certain fixed stars, that the lunar method came into use. In the early part of the nineteenth century the reliability of the chronometer was established, and since then the chronometer method has gradually superseded the "lunar."

Stimulated by the prospect of obtaining the reward offered by the British Parliament, John Harrison, after thirty years of unremitting labours and vicissitudes, recounted in the sketch of his life (see pp. 340-349), fulfilled, in 1761, the conditions laid down by the Board of Longitude. Thoroughly as Harrison deserved the reward he so laboriously earned, it is curious to note that of all his inventions embodied in his timekeeper, the maintaining spring in the fusee is the only one that has survived.

Other Acts of Parliament relating to the subject were passed in 1741,1753 , and 1774 . The last, repealing all former Acts, offered $£ 5,000$ for a timekeeper determining the longitude to or within one degree ; $£ 7,500$ for determining the same to within 48 geographical miles; and $£ 10,000$ for a determination at or within half a degree. Further, to obtain the smallest portion of the reward, the error of the timekeeper was not to exceed more than four minutes in six months. Mudge, the inventor of the lever escapement and an experienced 
horologist, with almost incredible infatuation, proceeded on the lines adopted by Harrison. Though he produced a superior instrument to Harrison's (see p. 350), he allowed Arnold (p. 358) and Earnshaw (p. 362) to develop the marine chronometer of to-day.

The investigations of Berthoud and Pierre Le Roy considerably antedate those of Mudge, Arnold, and Earnshaw. Each of the French masters designed a detached escapement, and while Berthoud used a gridiron arrangement of brass and steel to compensate for temperature errors, and fitted his timekeeper with two balances geared together, Le Roy experimented with a balance composed of two mercurial thermometers, the bulbs being furthest from the centre of motion and the ends turned inwards. No one could question the ability of Berthoud and P. Le Roy, but in executing their respective conceptions the Englishmen showed superior judgment. The French marine timekeepers were by comparison very unwieldy, which may perhaps be traced to theinfluence of M.DanielBernoulli, an eminent mathematician, who, says P. Le Roy, "wishes marine watches to be as large as good clocks are commonly made, that the pieces may be worked with greater exactness, and that their defects, if there are any, may be more easily perceived. This is nearly what I have practised in the new marine watch." However, the simplicity of construction and the compactness of Arnold and Earnshaw's chronometers have ensured the general adoption of their models.

Lieut. Rupert T. Gould states : "Berthoud, in his earlier machines, used a cylinder escapement, occasionally with pirouette, but he tried an extraordinary variety of escapements, compensations and driving mechanisms, and it is very hard to select any one machine as really typical of his earlier work. I have a chronometer of his, No. 37, made circa 1782, which is smaller than most modern chronometers, and has a pivoted detent escapement, compensation curb, and compensation balance.

Le Roy's chronometer, made in 1766 , is the true parent of the modern machine. It is not unwieldy, being very little, if at all, larger than a present day one. It has a detached escapement, going barrel, and compensation balance. If one recollects that Le Roy was the first to enunciate the true theory of the isochronous spring and to invent the detached escapement and both a metallic and mercurial form of compensation balance, it must be conceded that he was the true pioneer of the chronometer of to-day. For its period, and indeed even to-day, his design is a masterpiece of simplicity combined with efficiency." 


\section{Old Clocks and Watches and their Makers}

Vulliamy.-This noted family of clockmakers was of Swiss origin. Justin Vulliamy emigrated from Switzerland and settled in London early in the eighteenth century. He became connected with Benjamin Gray, of Pall Mall, whose daughter he married, and with whom he subsequently entered partnership. Watches of very fine quality, inscribed "Benj. Gray, Just. Vulliamy," are occasionally to be met with. A choice example fetched $f_{12} 15 \mathrm{~s}$. when the Hawsins

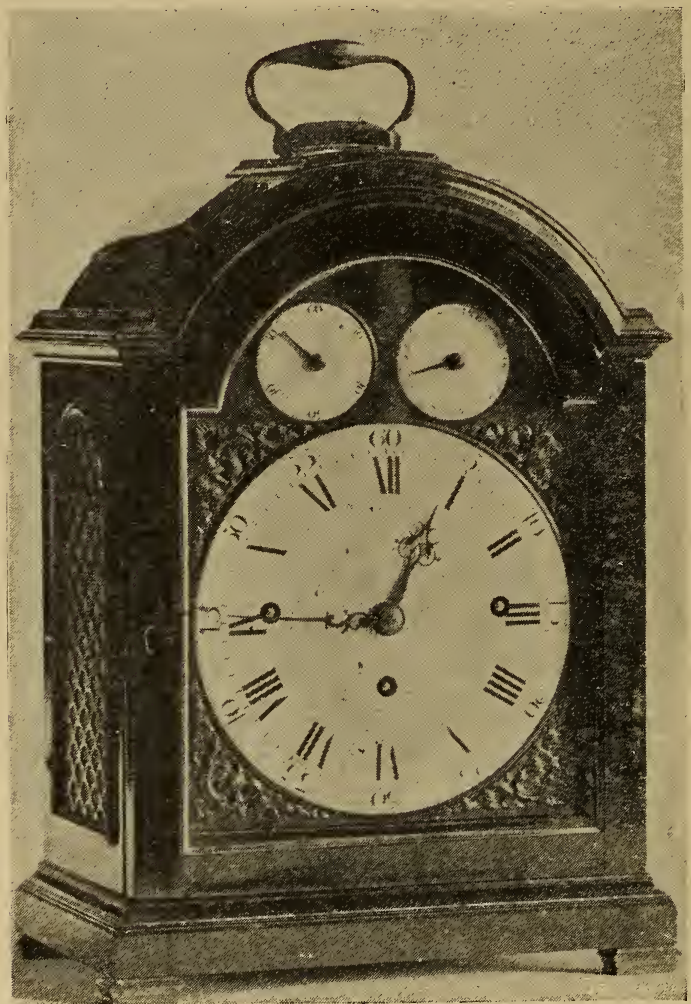

Fig. 498.-Clock, by Justin Vulliamy, Windsor Castle.

collection was dispersed by auction in 1895. The case of gold was enamelled in colours with figures in a garden, birds and flowers; the outer case was of gold and crystal, and had a diamond thumbpiece to press back the locking spring. A fine watch by them, with the hall-mark for 1757, formerly the property of Lieut. James Stockham, who commanded the "Thunderer" at the battle of 
Trafalgar, is in the Guildhall Museum. In the Wetherfield collection are two long-case clocks of their make, and two by Justin Vulliamy who carried on the business at Gray's death. Benjamin Gray was appointed as clockmaker to George II., and the family of Vulliamy held the office of clockmaker to the reigning sovereign till the death of Benjamin Lewis Vulliamy in $18 \check{5} 4$.

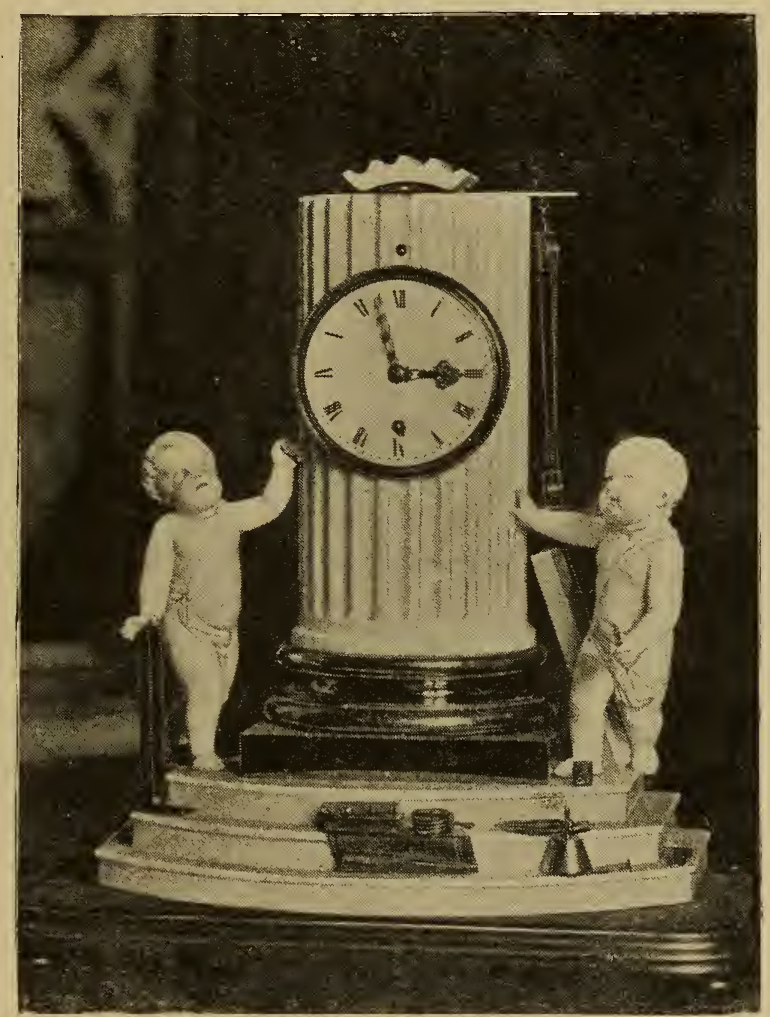

FIG. 499.-Clock, by Vulliamy, in an uncommon and wellexecuted case of White Marble.

Benjamin Vulliamy, the son of Justin, was much favoured and consulted by George III. on mechanical subjects, especially in connection with Kew Observatory, which was a hobby of the king.

Benjamin Lewis Vulliamy, born in 1780, was noted for the exactness and excellent finish of his work, in both clocks and watches. The large clock at the old Post Office, St. Martin's-le-Grand, and one at Christ Church, Oxford, are among the public timekeepers by him. 


\section{Old Clocks and Watches and their Makers}

He took an active interest in the Clockmakers' Company, of which he was five times master between 1821 and 1848. In 1849 the Court presented him with a piece of plate in recognition of his services to the Company. He wrote several pamphlets on trade subjects. One of them, on the construction of the dead-beat escapement for clocks, advocated the turning of the pallets for ensuring greater exactness.

Specimens of Vulliamy's handiwork abound at the royal palaces, and in many instances clocks originally by other makers now contain Vulliamy movements either wholly or in part. All those I have illustrated are at Windsor Castle.

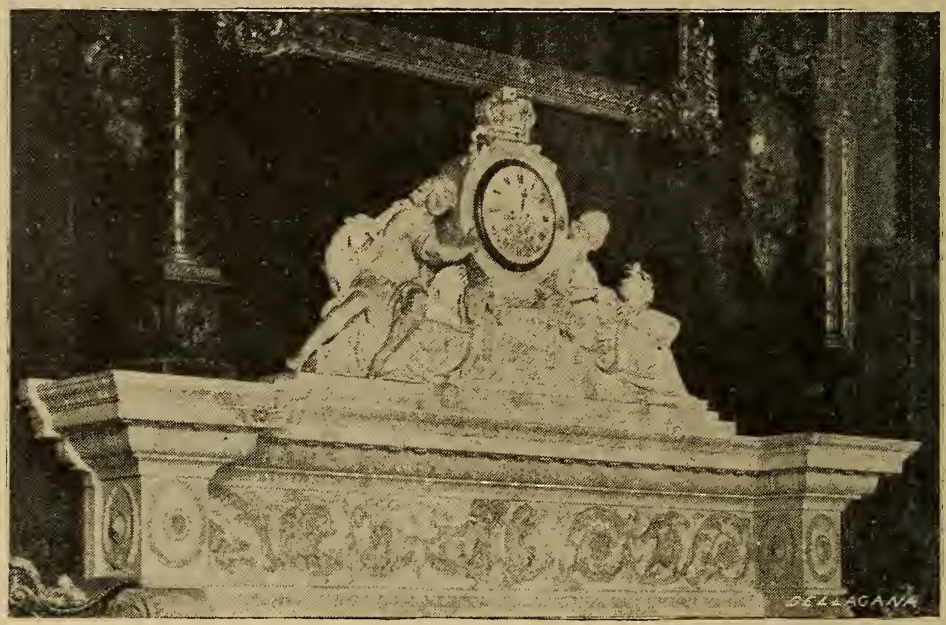

FIG. 500.-Clock in the Presence Chamber at Windsor Castle.

On the mantelpiece of Queen Victoria's dining-room was a chiming clock by Justin Vulliamy, in a plain blackwood broken arch case as shown in Fig. 498. It has a white enamel dial, and was chosen by Her Majesty for the situation by reason of its particular legibility. The subsidiary dials in the upper corners are for guidance in actuating the rise and fall of the pendulum and strike-silent hands.

A clock by Vulliamy in an uncommon and well-executed case of white marble, with two boys of biscuit china and particularly realistic building materials, is shown in Fig. 499.

The Presence Chamber contains a sumptrous mantelpiece of white marble, a magnificent piece of sculpture by J. Bacon, R.A., 
executed in 1790, and incorporating the clock case as seen in Fig. 500.

The clock is by Vulliamy, the fine enamelled dial, slightly convex

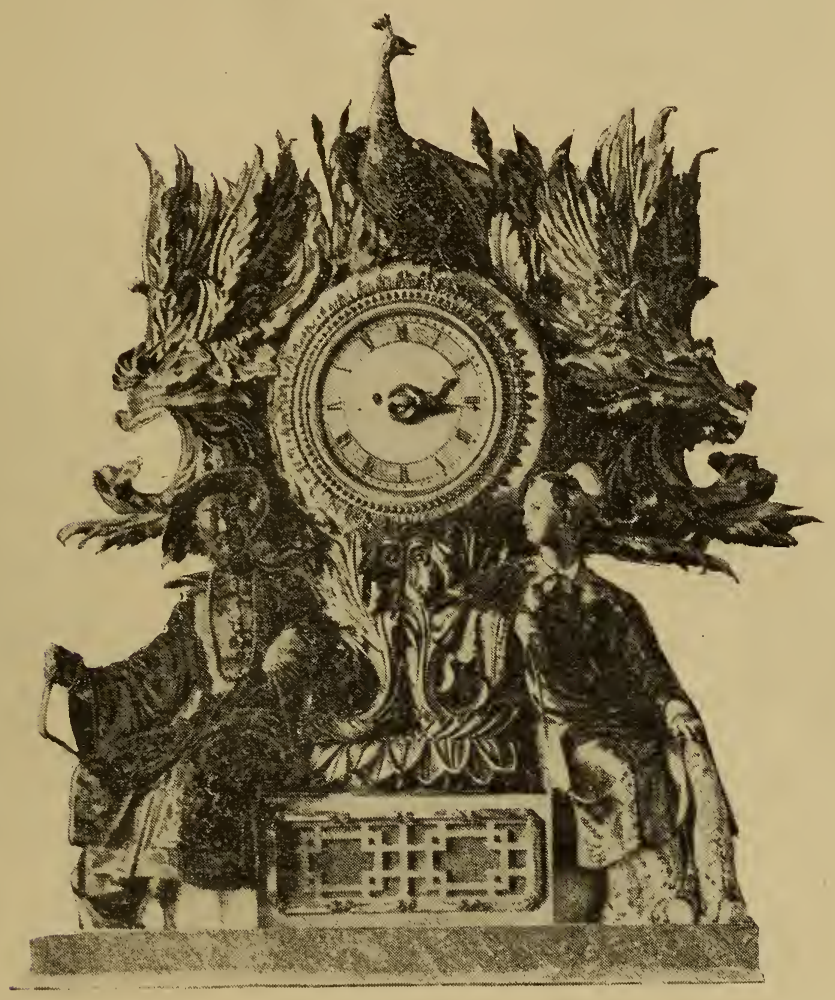

FIG. 501.-Clock in the Grand Reception-room at Windsor Castle.

in form, measures about $10 \mathrm{in.}$ across. Under the clock is the insrription by Cowper :-

\section{QUE LENTA ACCEDIT QUAM VELOX PRETERIT HORA \\ UT CAPIAS PATIENS ESTO SED ESTO VIGII,}

which Hayley happily rendered :-

"Slcw comes the hour, its passing speed how great!

Waiting to seize it-Vigilantly wait."

In the Grand Reception-room is a clock with a movement by Vulliamy and the peculiar case in the Chinese style shown in 
374 Old Clocks and Watches and their Makers

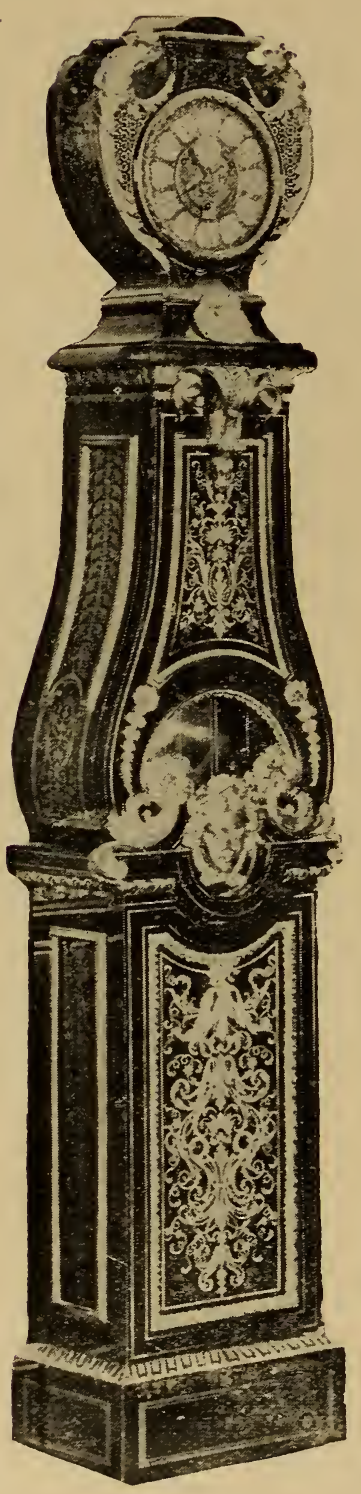

FIG. 502.

Chiming Clock, by Vulliamy.

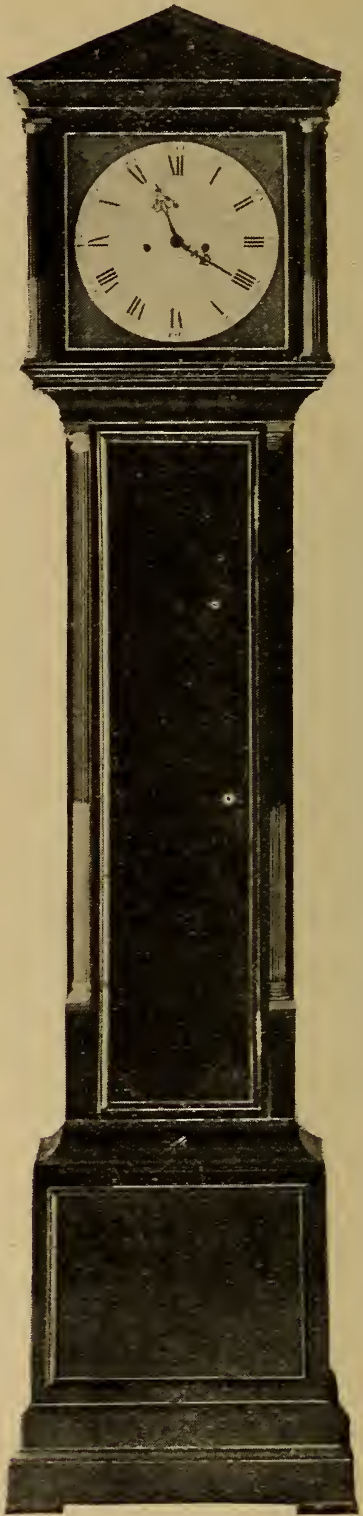

FIG. 503.

Standard Clock at Windsor Castle. 
Fig. 501. This and the companion case, which contains an aneroid. barometer, were made to the order of George IV. for the Pavilion at Brighton, and removed to Windsor on the accession of Queen Victoria.

A fine chiming clock by Vulliamy, with case in the Louis XIV. style, and dating from about 1820 , which is in the Zuccarelli room at Windsor Castle, is shown in Fig. 502. The outline of the case is excellent, the surface of black shell is inlaid with brass and decorated with bold but rather coarsely chased ormolu mounts.

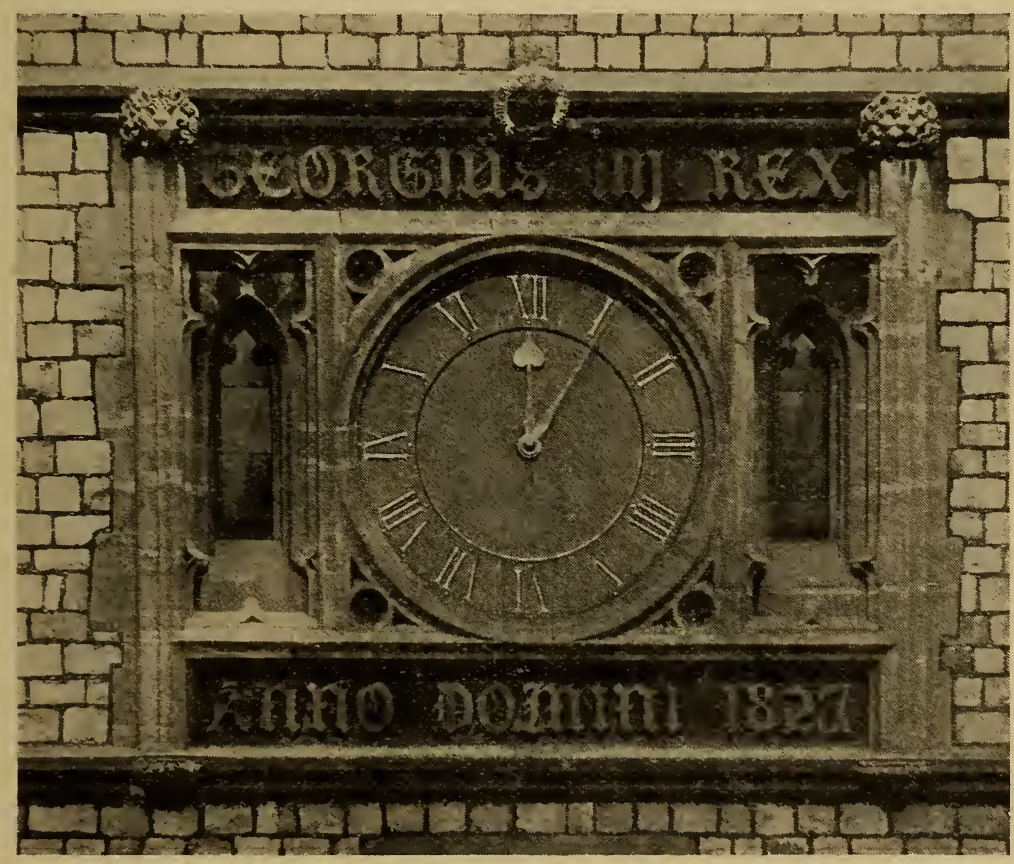

FIG. 504.-Clock over the state entrance in the Quadrangle or Windsor Castle, by Vulliamy.

On the landing by the Administration Offices of the Castle is the long-case clock by Vulliamy shown in Fig. 503. It is well made, with jewelled pallets, and is now used as a standard timekeeper. The dial is of enamel with gilt spandrels. The case though plain is of choice mahogany and has an effective appearance. A long-case clock by him with square silvered dial and case very similar to that in Fig. 503 is among the Wetherfield collection.

Over the state entrance in the Quadrangle of Windsor Castle was 
376 Old Clocks and Watches and their Makers

formerly a clock by Joseph Knibb, which B. L. Vulliamy replaced in 1829 by one, the dial and sur-

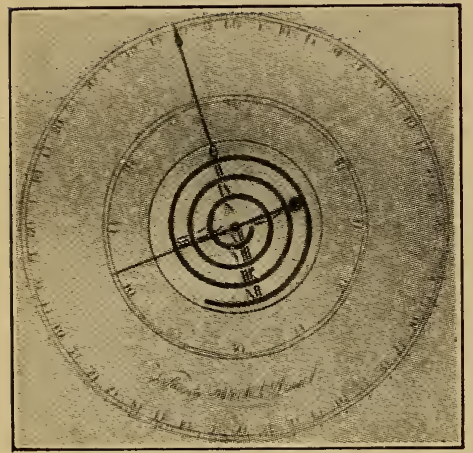

FIG. 505.-Dial of Regulator, by Tulliamy. roundings of which are shown in Fig. 504. Though plain, the dial and hands are certainly an example of the best style of that period.

Mr. Hansard Watt has a regulator in a mahogany case by Vulliamy constructed on the SmeatonFranklin plan. By the ingenious employment of a bullet running in a spiral groove the exact hour is indicated, and by favour of Mr. Watt I am able to reproduce the dial in Fig. 505. When the bullet

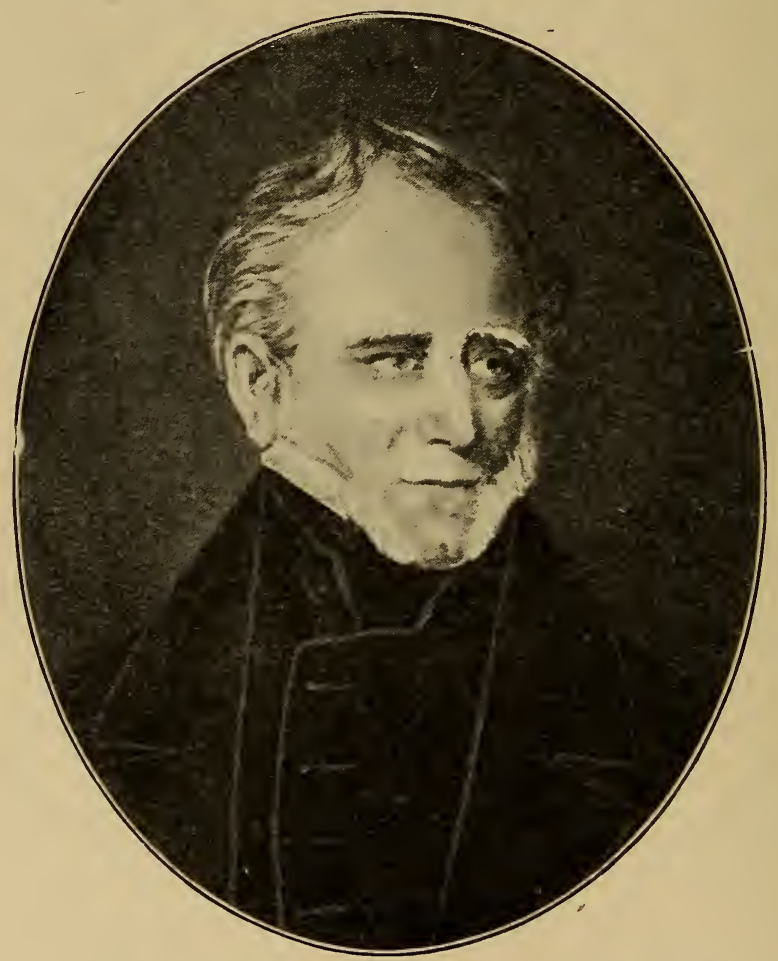

Fig. 506 Benjamin Lewis Vulitamy, 1780-1854.

reaches the upper XII. it falls through a hole and emerges 
underneath the lower XII. to begin its ascent again. This is an uncommon and interesting clock.

When the new Houses of Parliament were being brilt, the architect, Mr. Barry, applied to Mr. B. L. Vulliamy for information respecting the construction of the clock tower, and this circurnstance, together with Vulliamy's influential position in the horological world, led people to think he would make the clock, as indeed it was intended by Barry and others that he should. But Vulliamy objected to the conditions laid down by Mr. Denison, who was commissioned by the Government to draw up a specification in conjunction with the Astronomer Royal, and, backed by the Clockmakers' Company, declared the stipulations to be too onerous and unnecessary. Vulliamy submitted drawings of what he considered the clock should be like, and this design Denison ridiculed as being merely suited for a village clock of the old style, and quite unworthy of the national timekeeper. Denison's masterful attitude prevailed, and Vulliamy had to succumb, feeling, there is no doubt, the keenest mortification at being ousted from the proud position of leading clockmaker. It must be admitted that his talent lay rather in the perfection of details than in comprehensive departures from the beaten track. He died in January 1854. The portrait (Fig. 506) is from a miniature at the Horological Institute.

Justin Theodore Vulliamy, who was warden of the Clockmakers' Company from 1820 to 1822 , appears to have had no other connection with the horological trades. He was, I believe, a brother of B. L. Vulliamy.

Charles Clay.-A remarkably handsome musical clock by Charles Clay, which stood for many years in a manor house in Suffolk, is shown in Fig. 507 . It is $8 \mathrm{ft}$. $6 \mathrm{in}$. in height, the case being divided into two portions, the upper part of which is of Amboyna wood, relieved with heavy brass mounts, well finished. In the arch of the dial are shown the age of the moon, the day of the month, and the following list of tunes played by the clock:-

“(1) Mr. Arcangelo Corelli's Twelfth Concerto, 1st Adagio, 2nd Allegro, 3rd Saraband, 4th Jigg.

(2) The fugue in the overture of Ariadne."

On the hour circle is engraved the maker's name, "Charles Clay, London." The pedestal, which is of Spanish mahogany and Amboyna wood, contains Clay's chiming machine with twenty-one bells. It is a fine piece of mechanism, driven by an ordinary chiming weight, though the barrel is fully 12 in. in diameter. Dampers 


\section{Old Clocks and Watches and their Makers}

are used to avoid vibration of the bells one with another, and

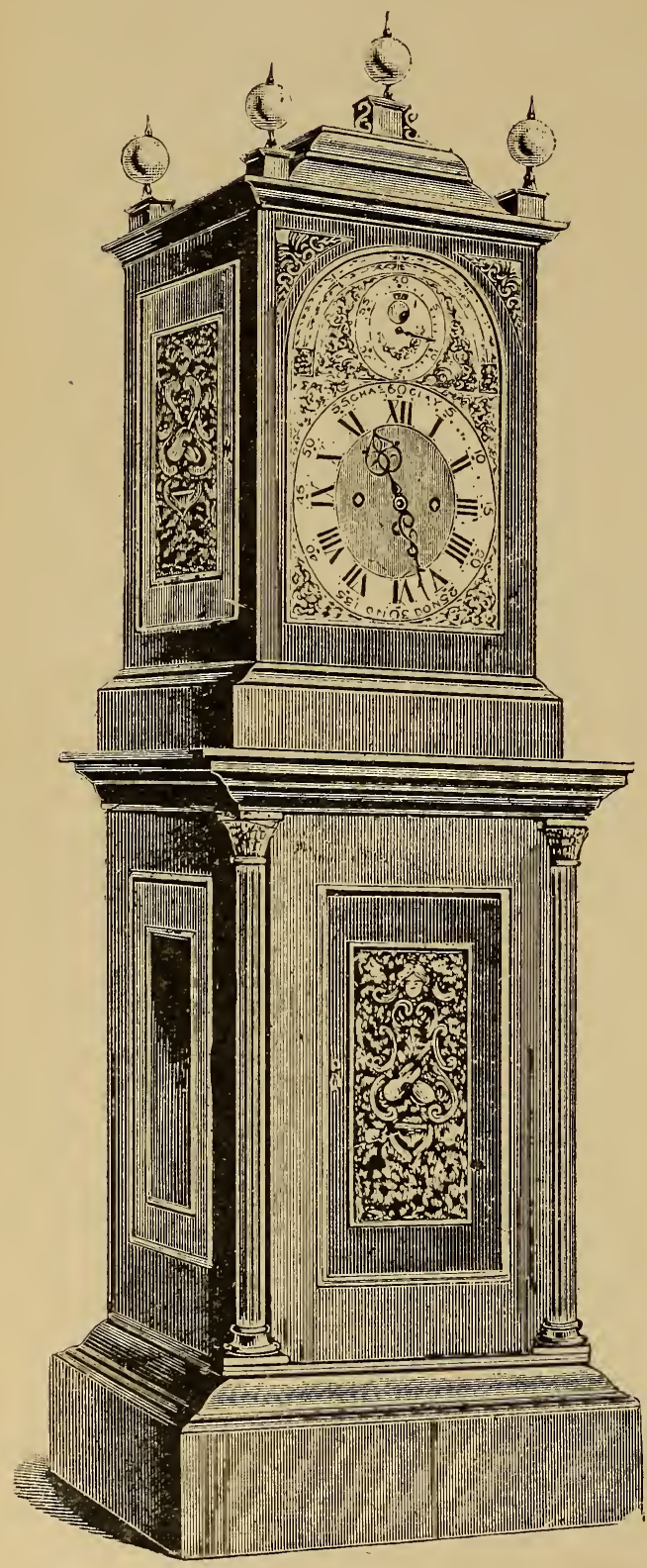

FIG. 507.-Musical Clock, by Charles Clay. by an ingenious contrivance the music starts immediately the clock finishes striking. The fly is attached to an endless screw, which ensures smooth running. This clock is apparently referred to in the following extract from the Weekly Journal, 8th May 1736:- " On Monday Mr. Clay, the inventor of the machine watches in the Strand, had the honour of exhibiting to her Majesty at Kensington his surprising musical clock, which gave uncommon satisfaction to all the Royal Family present, at which time her Majesty, to encourage so great an artist, was pleased to order fifty guineas to be expended for numbers in the intended raffle, by which we hear Mr. Clay intends to dispose of this said beautiful and most complete piece of machinery."

James Ferguson.James Ferguson was born at Keith, Banffshire, in 1710. He lived for some years at No. 4 Bolt Court, Fleet Street, where he died in 1776, and was buried in 
Marylebone churchyard. Among other conceptions of this celebrated astronomer and mechanician is a clock contrived with only three wheels and two pinions. It is shown in Fig. 508. The hours are engraved on a plate fitting friction-tight on the great wheel arbor; the minute hand is attached to the centre wheel arbor, and a thin plate divided into 240 equal parts is fitted on the escape wheel arbor, and shows the seconds through a slit in the dial. The clock has a seconds pendulum. The number of teeth in the escape wheel is higher than is desirable, and the weight of the thin plate or ring in the escape wheel arbor is objectionable, though it might now be made of aluminium, vulcanite, or other very light material.

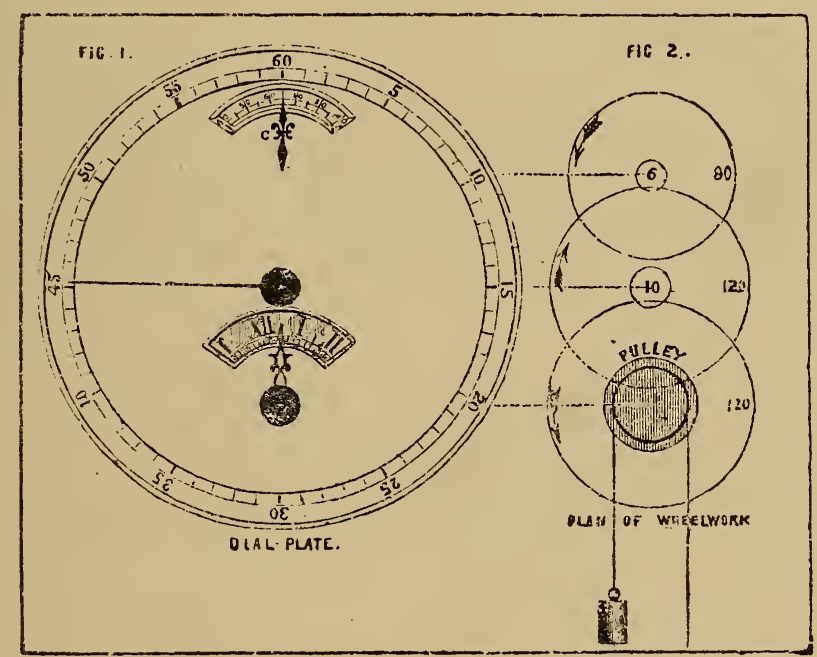

FIG. 508.-Clock, with only three wheels and two pinions, by James Ferguson.

Ferguson also designed a curious and useful clock for showing the time of high and low water, the state of the tides at any time of the day, and the phases of the moon. The outer circle of the dial in the left-hand corner of Fig. 509 is divided into twice twelve hours, with halves and quarters, and the inner circle into 29.5 equal parts for showing the age of the moon, each day standing under the time of the moon coming to the meridian on that day. There are two hands on the end of t?:e arbor coming through this dial, which go round in 29 days 12 hours 45 minutes, and these hands are set as far apart as the time of high water at the place the clock is to serve differs from the time the moon comes to the meridian; so that, by 
looking at this dial, one may see at what time the moon will be on the meridian and at what time it will be high water. On the dial in the right-hand corner all the different states of the tide are marked. The highest points on the shaded ellipse represent high, and the lowest, low water. The index travels round this dial in the timc that the moon revolves from the meridian to the meridian again. In the arch above the dials a blue plate, to represent the sea, rises and falls as the tides do, and over this a ball, half black and half white, shows the phases of the moon.

The mechanism as it would appear at the back of the dial is. shown in Fig. 510. A wheel of 30 fixed to the hour wheel on the

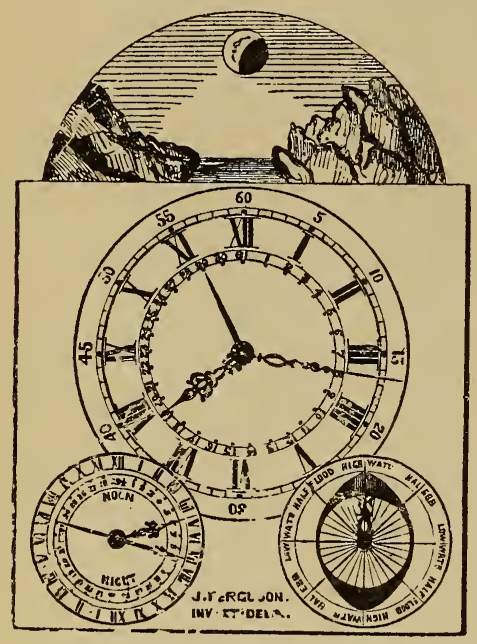

FIG. 509.-Ferguson's Clock for showing the time of high and low water.

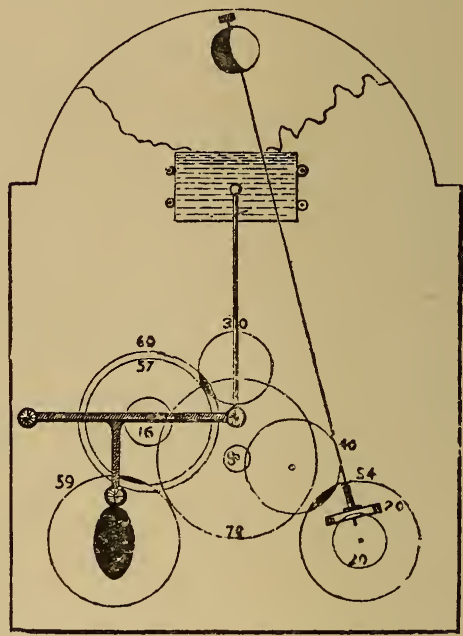

FIG. 510.-Mechanism at back of. dial.

centre arbor goes round once in twelve hours, and gears with a wheel of 60 , on whose arbor a wheel of 57 drives a wheel of 59 , the arbor of which carries the hand for the right-hand dial. On this arbor is an elliptical cam which carries and lets down the tide plate twice in 24 hours 50.5 minutes. On the arbor of the wheel of 57 is a pinion of 16 driving a wheel of 70 , on whose arbor is a pinion of 8 driving an idle wheel of 40 . This idle wheel is merely to reverse the direction of the wheel of 54 with which it gears, and which carries the hands for the left-hand dial. The moon is driven from this last arbor by means of a pair of mitre wheels.

Smeaton-Franklin.-Two clocks by John Smeaton, the eminent engineer, are preserved at Trinity House, and he is said to have 
devised a clock having but three wheels and two pinions, the dial of which is shown in Fig. 511, though Rees attributed the design to Dr. Franklin. Possibly Ferguson, Franklin, and Smeaton were all
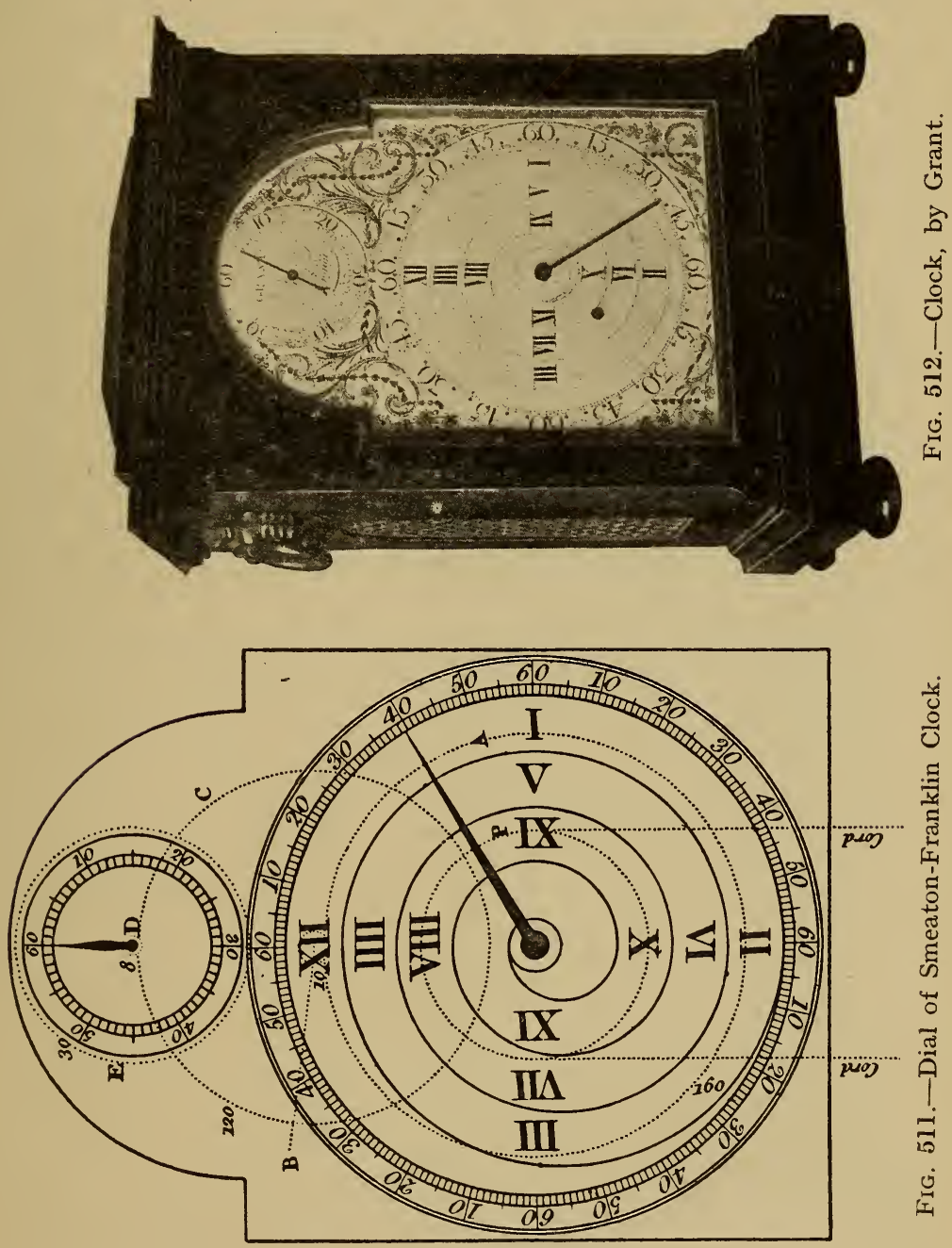

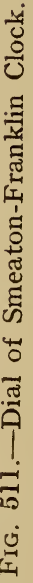

taken with the idea of a three-wheel movement, and each embodied it. The late R. J. Lecky had a clock on this plan made about 1820 by Austen, of Dublin. It had a case of slate, the back, to which the pendulum was hung, being a single slab, $1 \frac{1}{4} \mathrm{in}$. thick. It was 
a thoroughly good clock and Mr. Lecky converted it from a thirty-

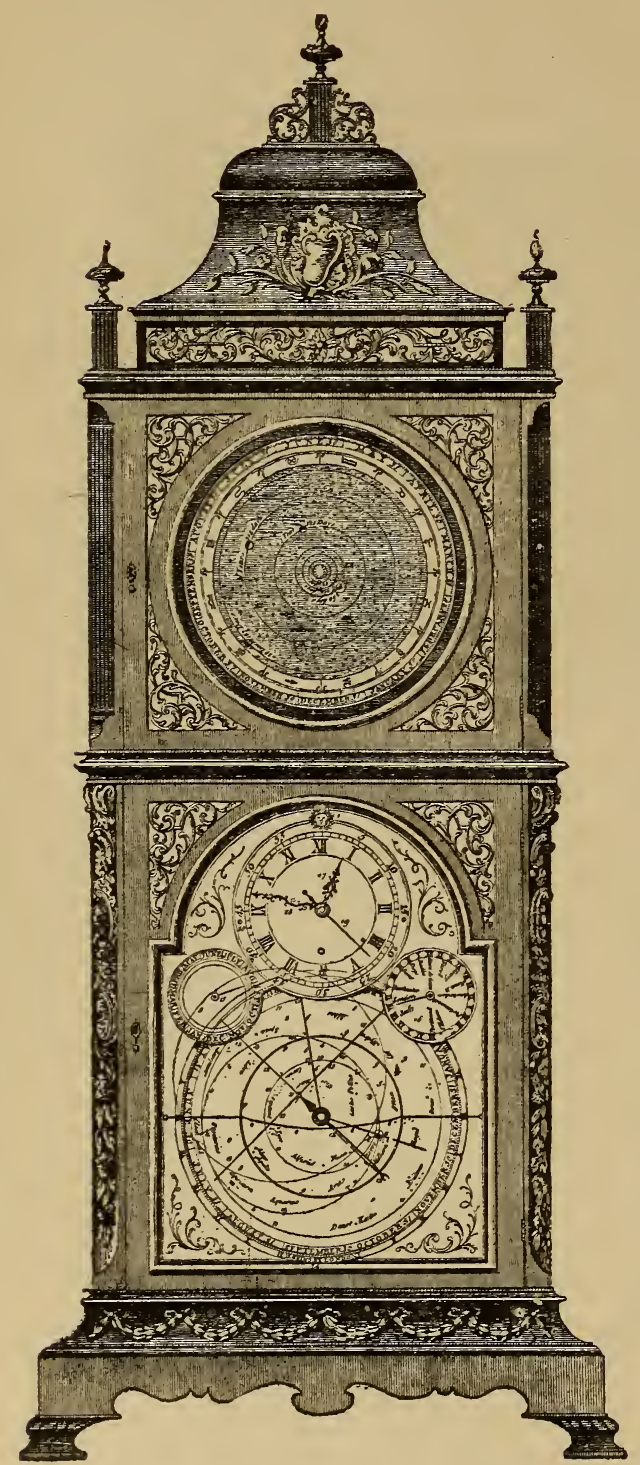

FIG. 513.-Astronomical Clock, by Henry Jenkins. hour to an eight-day by providing a weight and counterpoise fitted as double-sheaved blocks, the sheaves being contained in the body of the weights, and making the cord endless, on Huygens' principle, illustrated on p. 324. Mr. R. J. Lecky's son, Mr. John Lecky, who now owns the clock, tells me it is still an excellent timekeeper.

Dr. Herbert N. Evans has a bracket or table clock by Grant, with a similar dial. It is shown in Fig. 512. Vulliamy made a bracket clock on the Smeaton-Franklin plan in which the pendulum, in order to beat seconds, was weighted above its point of suspension on the principle of the metronome.

\section{Jenkin's Astronomical} Clock. - Henry Jenkins, who flourished from 1760 to 1780 , first at 46 Cheapside, and afterwards at 68 Aldersgate St., must be reckoned among the celebrated clock-makers of his time. Fig. 513 shows one of several astronomical clocks he contrived and produced. There are concentric second and minute hands, and among other motions are shown: equation of time, days of the month, age and phases of 
the moon, time of high water at many seaports, the apparent motion of the fixed stars, motions of the planets, \&c.

The lunar and other motions, except the revolution of the planets, are nearly as in Enderlin's clock, and need not be recapitulated. From the earth's diurnal motion wheel, rotating once in twentyfour hours, is driven a worm which carries forward an annual wheel, and the representation of the fixed stars one tooth each day. From thence is a communication to the planetary system dial above, and the motions of the planets are obtained by six wheels fixed together on one stud and driving six other wheels whose sockets are circles, and represent their respective orbits. On the stud are wheels of 108 , $78,84,40,8,5$, driving on sockets $26,48,84,75,95,147$.

George Margetts.-By the originality of his conceptions embodied in exact and well-finished mechanism this chronometer and watch maker must be ranked with the masters. He was admitted as a member of the Clockmakers' Company in 1779 and carriêd on business at 21, King Street, Cheapside, till the end of the century, when he removed to No. 3, Cheapside. In Fig. 514 is shown a watch by him with a series of intricate superimposed dials and indicators. A small centre dial indicates mean time, and on this dial at the XII is the word Ports ${ }^{\mathrm{h}}$; London at 7 minutes; Hull at 15 minutes Yarmouth at 22 minutes; Dover at 29 minutes; Downs at 35 minutes; $\mathrm{P} \mathrm{ym}^{\mathrm{h}}$ at 45 minutes, and Dublin at 55 minutes. An enamel ring outside this dial gives tidal hours. Through a hole in this ring is shown the age of the moon, and a hand attached to the ring indicates the part of the heavens the moon is in. A gold band below this carries a pointer indicating the position of the sun. The signs of the zodiac are painted on the lower large dial. Beyond the tropic of Cancer is figured the Sun's declination in correspondence with the days of the year; beyond that the degrees, $30^{\circ}$, of each sign of the zodiac, and nearer still to the edge of the dial the months and days of the year, so that, except that no provision is made for leap year, it is a correct calendar. The large dial niakes one turn in a sidereal day; the sun hand, making one turn in a solar day, becomes the pointer indicating the date because it gets $\frac{1}{36}$ th of the circle after the dial each day. A finger attached to a large gold band on the dial shows the declination of the sun throughout the year. The different pointers can be set independently of each other. Fitted round the smallest dial and extending to the large gold band is a curved frame of gold with arcs within it. It carries a pointer and may be moved round, but its purpose is not evident. An eccentric circle on the large 


\section{Old Clocks and Watches and their Makers}

dial represents the orbit of the earth, farthest from the sun in June, nearest in December. The watch is in pair cases, the inner one of brass, and the outer one of twenty-two carat gold bearing the London hall mark of 1783 . I recently saw a watch of earlier date with a similar dial. Watches by him with complicated dial work are also in the British and Guildhall Museums.

As the cost of these watches must have been very great, one is inclined to think they were probably ordered for presentation by some wealthy corporation such as the East India Company. A ship's

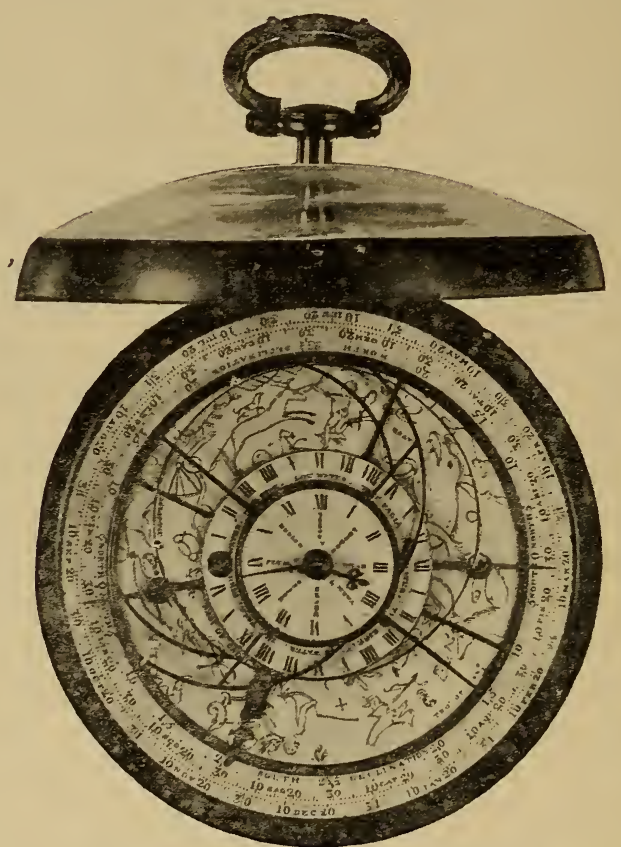

FIG. 514.-Complicated Watch, by George Margetts.

captain for instance would particularly appreciate a piece of complicated horology. Some time ago I was shown a chronometer by him on the dial of which was inscribed "Margetts' eight-days timepiece, 202," and on the plate, " Geo. Margetts, London, Invt. et fecit, eight-day nautical chronometer." It was the size of a small two-day marine chronometer, the great wheel being planted near the top plate ; it had a spring detent; an escape wheel of sixteen teeth, measuring 47 of an inch in diameter, and an impulse roller one quarter the size of wheel. He made a regulator for the Archbishop of Armagh in 1790 , and can be traced at 3 , Cheapside till about 1806 . 
Fig. 515 is a large watch by George Marget ts, dating from about 1779, in a pierced and engraved pinchbeck case; a border of imitation pearls and rubies at both sides of the case; with musical attachment. From the collection of $\mathrm{Mr}$. H. J. Heinz.

\section{Abraham Louis B reguet. - T h e intense and abiding interest taken in the works of this, the predominant Con- tinental horologist of his period, may} be traced to the great variety of his conceptions and the

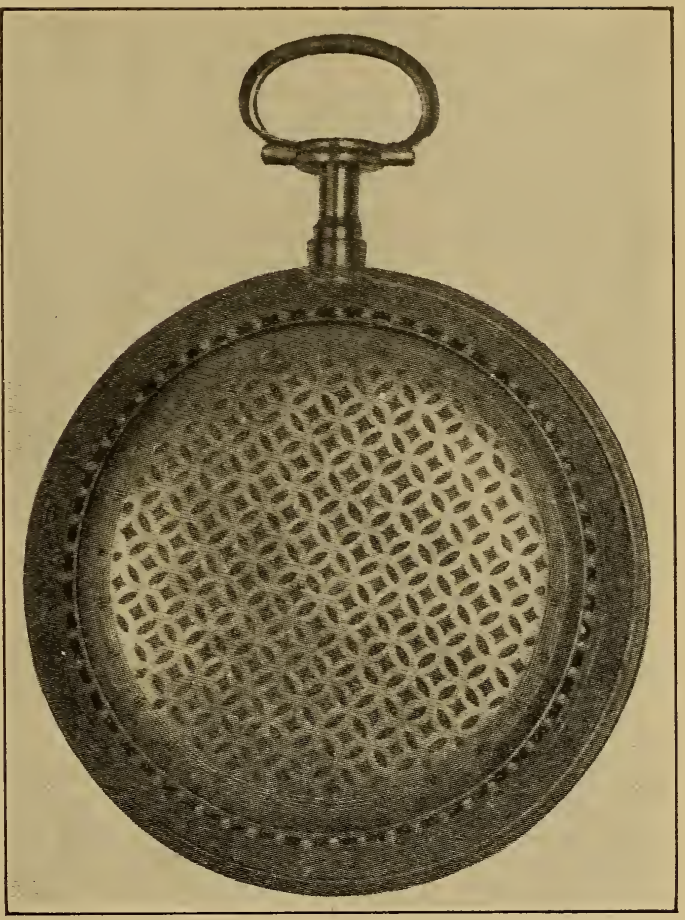

FIG. 515.-Large Watch, by George Margetts. exactness with which they were carried out. He seems to have had the faculty of surrounding himself with assistants who were good mechanicians and able to embody his ideas to the best advantage. Clocks, chronometers, and watches of his make all bore the stamp of originality in some particular. A defect in construction had only to be pointed out or the whim of a customer revealed, when Breguet was ready with the requirement. Of his more daring contrivances may be mentioned a "synchronizer" or clock for setting a watch right, a tourbillon or revolving carriage in which the escapement of a watch was placed so as to nullify the effect of change of position, which was one of the most perplexing problems of the adjuster, and a device for allowing the bearing surfaces to the balance-staff pivots of a watch to yield, which he termed a "parachute," the object being to prevent damage to the pivots through shocks.

Beillard quotes a letter from Breguet to the "Citoyen" Minister 
386 Old Clocks and Watches and their Makers

of the Interior, asking for a patent for his escapement à Tourbillon, dated Paris le 18 Brumaire An IX.

Of Breguet's writing no extracts can be given for he published

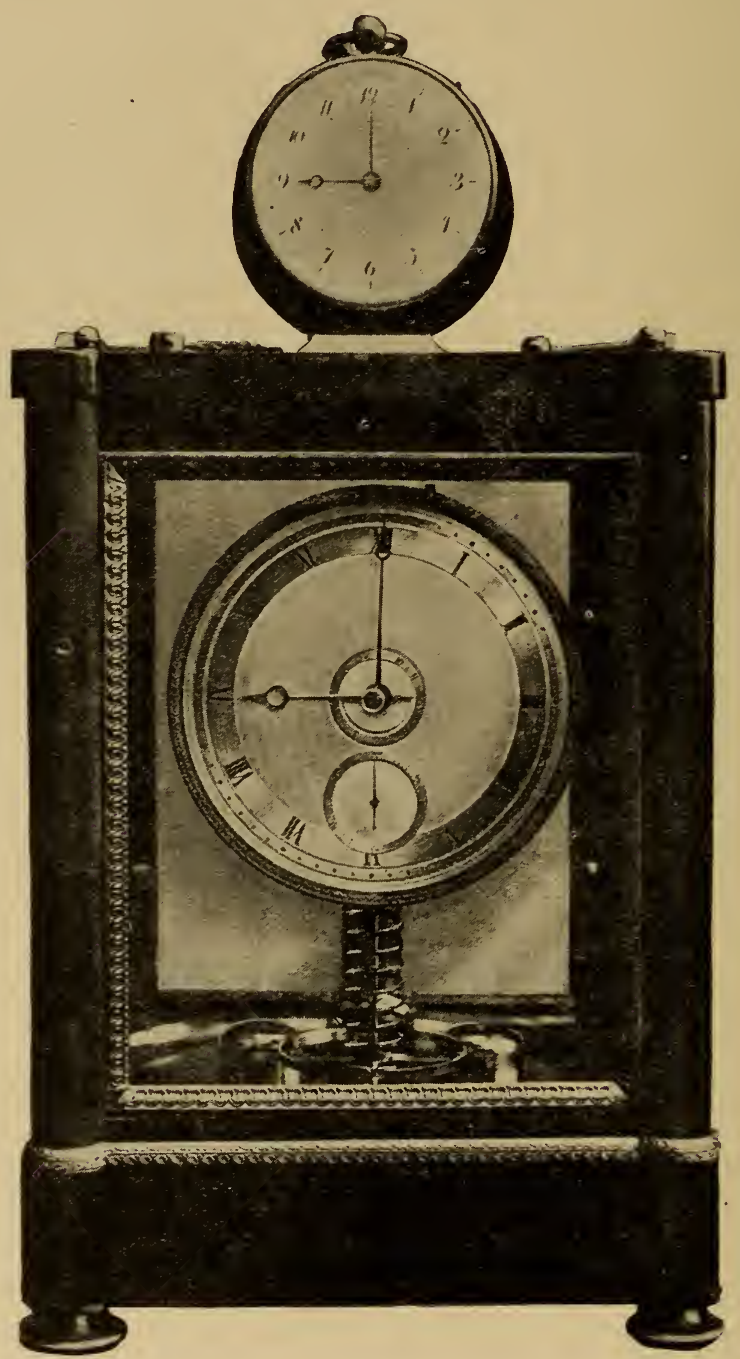

FIG. 516.-Breguet's Synchronizer. The mainspring barrels are in the base of the case, the winding being accomplished by means of a rack and lever underneath. Above the base may be seen the compensation balance, and rising from it part of a tall balance-spring, which is of gold. 
nothing; his works form the best tribute to his memory. Of these a few are selected for illustration.

Fig. 516 is a view of a clock and watch forming the "Synchronizer" which is the property of His Majesty the King: and I am indebted for the illustration to Mr. A. E. Rutherford. As already stated, the object of the invention is to set the watch right. Projecting above the case of the clock are two crescent-shaped slips to hold the watch. The clock may be regarded as a standard, and when the watch is placed in position, as shown, it is not only set to time at any desired hour, but, if necessary, the regulator of the watch is also shifted. Projecting from the top of the clock is a pin which enters a small hole in the case of the watch and so establishes connection between the special pieces added to the two. There is an extra train of wheels in the watch to set the minute hand to zero and this train is discharged by a snail-shaped cam in the clock. With this general statement I must be content; the details are most complicated, and to attempt anything like a clear description within a reasonable space would be hopeless. In the Napier collection was a Synchronizer by Breguet similar in principle, but in which the clock was controlled by a pendulum instead of a balance.

In Fig. 517 are front and back views of a gold watch, No. 92, which was sold to the Duc de Praslin for 4,800 francs on the 11 Thermidor, An 13 (13th July 1805). It repeats the preceding hour, each period of ten minutes which has elapsed, and then the number of minutes beyond. On an enamelled dial in front are a perpetual calendar and an equation of time register. It has an independent seconds hand. At the back of the watch is a gold engine-turned dial, showing the age of the moon, the amount the mainspring is wound, a regulator for time and one also for the repeating train.

Front and back views of what is often spoken of as Breguet's chef-d'ceuvre are given in Fig. 518. It is a watch measuring $2 \frac{5}{8} \mathrm{in}$. across, which, as stated in Breguet's certificate, was orderer in 1783 by an officer of the Marie Antoinette Gardes with the condition that it should contain all complications and improvements then known or possible, and that in its construction gold instead of brass should be used. No price was fixed, and its manufacture was begun in 1789 , stopped during the Revolution of 1789 , again started in 1795 , and completed in 1802, costing altogether 30,000 francs. It is furnished with a lever escapement, compensation balance, gold balance spring, and two parachutes. All the pivots, without exception, run 


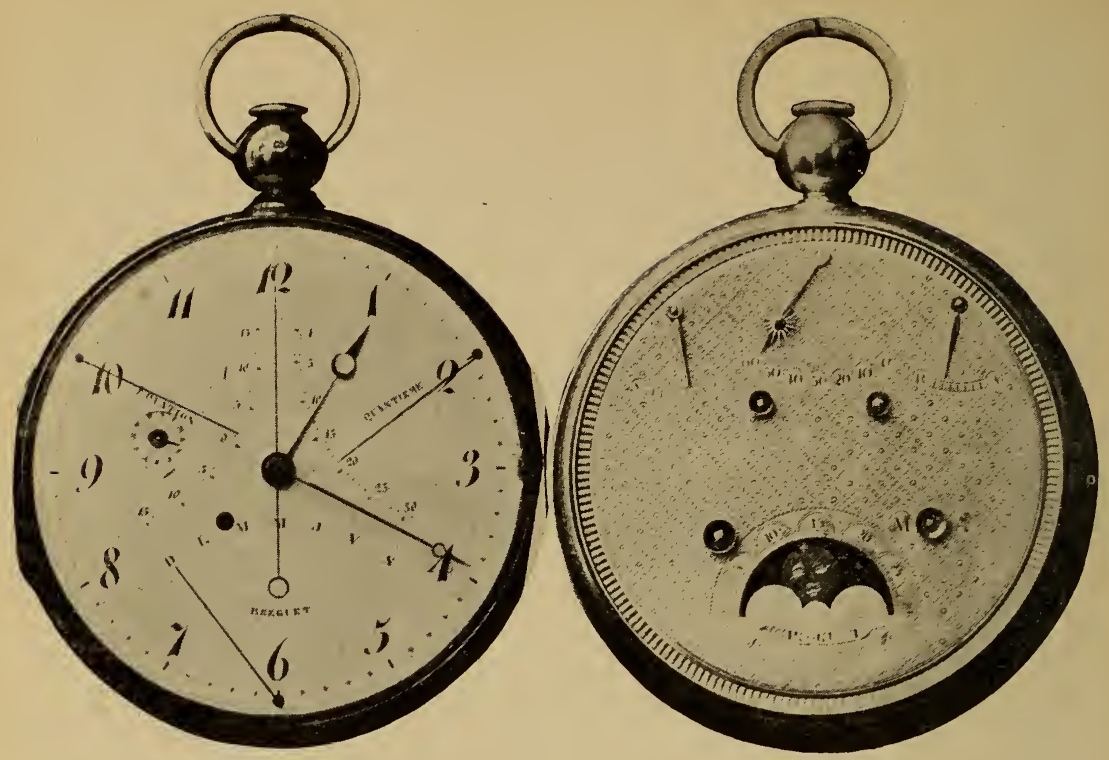

FIG. 517.-Watch with Perpetual Calendar and Equation of Time Register.

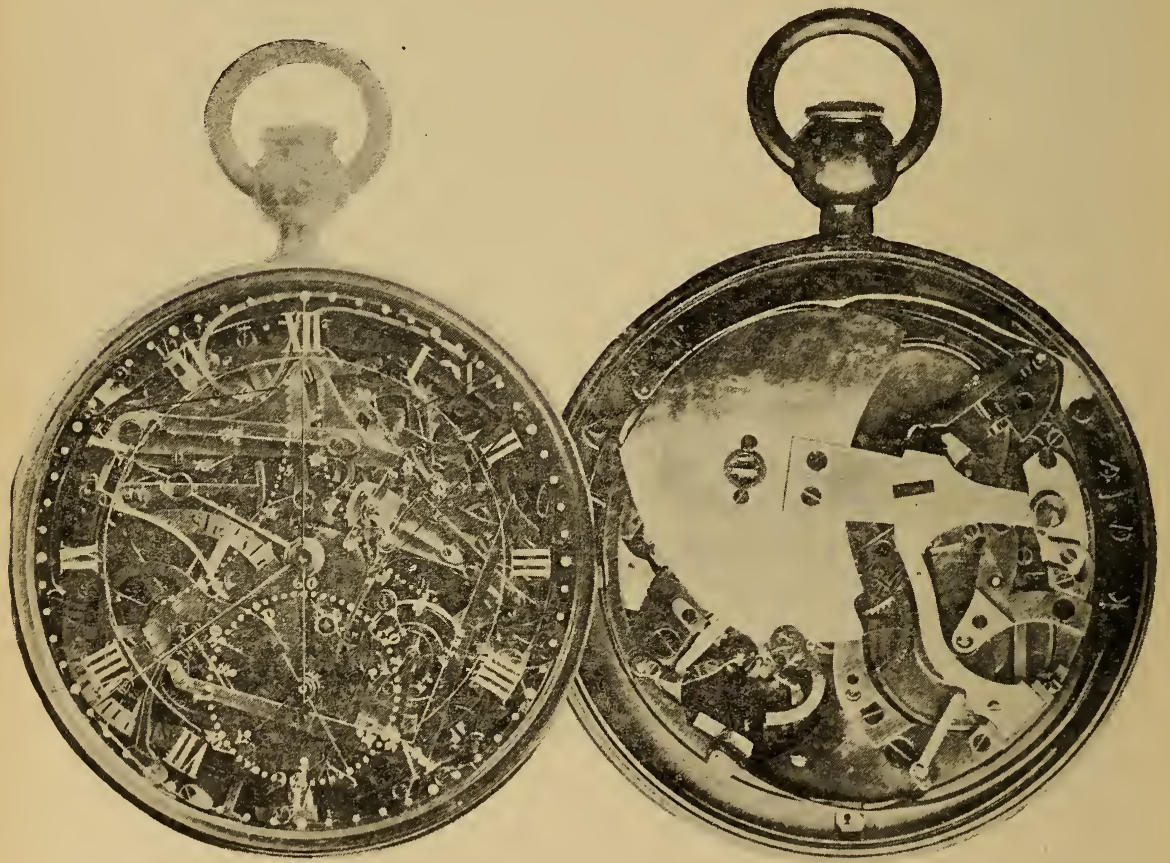

FIG. 518.-Breguet's "Chef-d'cuvre," Perpetual or Self-Winding Watch with Gold Movement. 


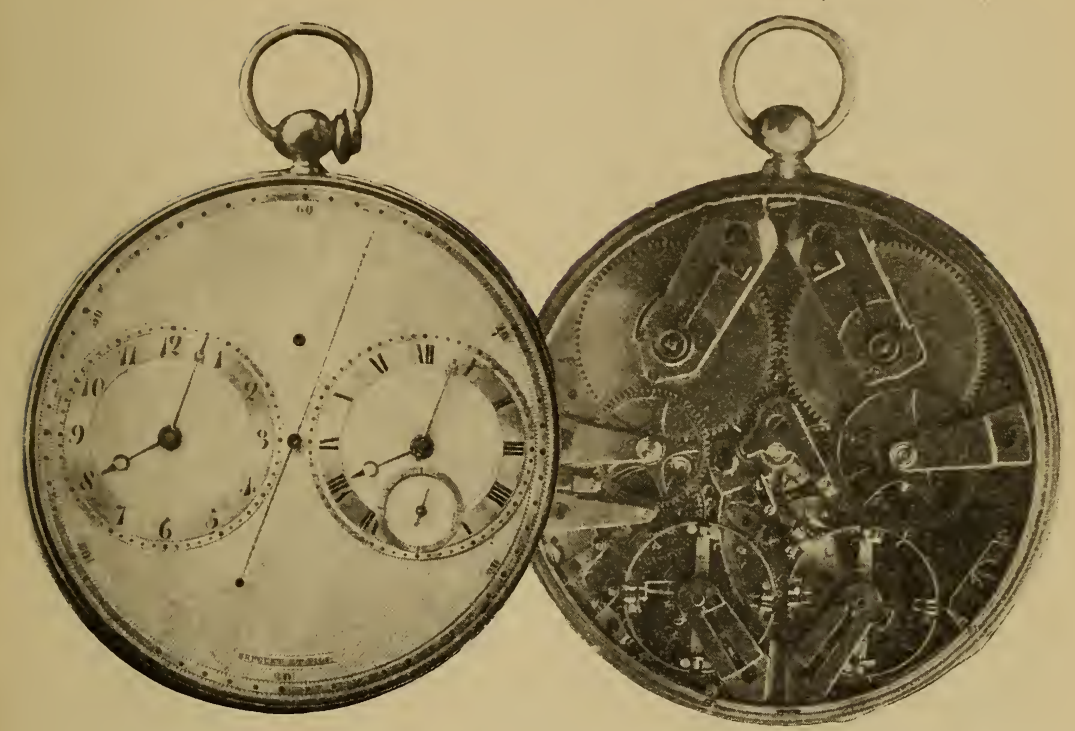

FIG. 519.-Watch with Synchronous Balances; two Movements in one Case.

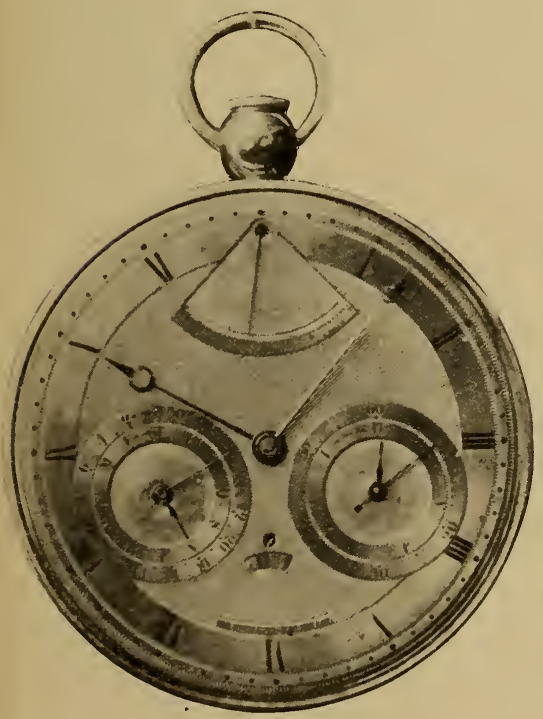

FIG. 520.

Prince Murat's Repeating Watch. 26

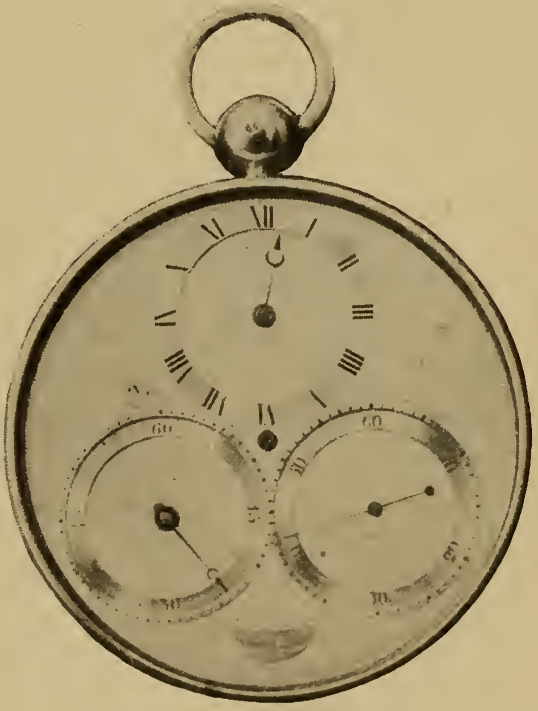

FIG. 521.

Watch with Chronometer Escapement mounted in Tourbillon Carriage. 


\section{Old Clocks and Watches and their Makers}

in ruby or sapphire holes. All parts usually of brass are of gold. It repeats the hours, quarters, and minutes, has an independent seconds hand, perpetual calendar, equation of time register, and a thermometer. But perhaps the most ingenious feature of the mechanism is that there is no provision for a watch key, nor is any periodical operation needed to keep the watch going. So long as it is worn, recharging of the energy is automatically accomplished by a heavily-weighted but lightly-balanced arm or lever, to which ordinary movements of the wearer give sufficient up and down motion to wind the mainspring with which it is connected. Breguet is generally credited with the invention of this device, but of this I am not sure,

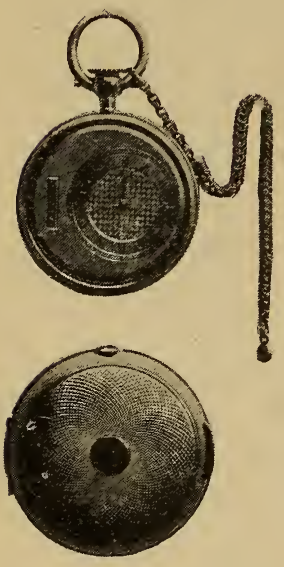

FIG. 522. - Queen Victoria's Watch. Exact size.

for a patent granted in 1780 to Recordon may have been a prior disclosure of it. Back and front the movement is covered with rock-crystal, and the dial also is of crystal, though another dial of white enamel with gold figures is provided. This extraordinary watch is the property of Mr. Louis Desoutter, to whom I am indebted for the photographs of this and of the other Breguet watches here shown.

Fig. 488 gives front and back views of a watch by "Breguet et fils, No. 2,794," which was sold to Louis XVIII. in September 1821 for 7,000 francs. Here are really two movements side by side in one case, with separate numerals and hands for each. The object of its production was to demonstrate the effect on the timekeeping of a balance when another similar balance was set in motion near it. It was thought the errors of one would neutralise the errors of the other, and that they would vibrate in unison. There is a provision for lessening or increasing the distance the balances are apart. A counterpart of this watch was made for George III.

The watch of which a front view is given in Fig. 520 has a gold case and dial, repeats the hours and quarters, and is furnished with a calendar and a thermometer. It is numbered 1,806 , and was sold to Prince Murat in 1807 for 4,000 francs.

In Fig. 521 is represented a silver watch having a chronometer escapement mounted in a tourbillon carriage. It is signed "Breguet et fils," and numbered 2,520 . Its original cost was $£ 96$.

An exceedingly diminutive and thin double-cased watch is shown 
to its exact size, with the outer case detached, in Fig. 522. The cases and dial are of gold ; it needs no key, but is wound from the pendant, has a lever escapement, and is numbered 5,102. It carries an especially interesting association, for it was sold to Queen Victoria on 17 th July 1838 . The price was 4,250 francs.

A clock by Breguet, held aloft by a kneeling figure of bronze gilt, is shown in Fig. 523. The clock has a chronometer escapement and silver dials front and back. On the back is a calendar, the indicators for which turn to the left, so that, if viewed through a mirror, the actions appear to be right-handed. It is $19 \mathrm{in}$. in height.

The majority of Breguet's watches had very plain exteriors, the dials as a rule being either of silver or white enamel, while the cases were generally embellished with a delightful kind of fine engine turning which it was a pleasure to see and handle; his less

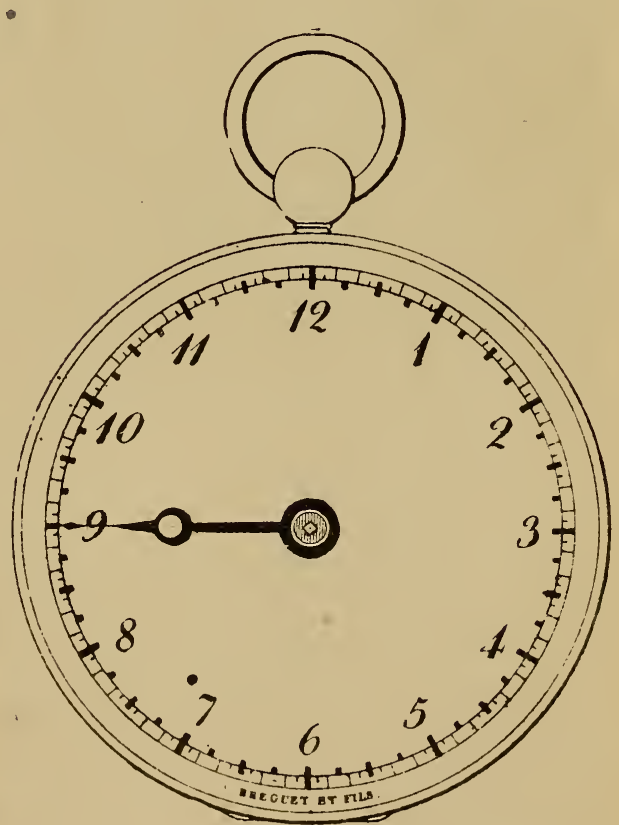

Fig. 523.-Clock, by Breguet.

FIG. 524.-Breguet's " Subscription Watch." 


\section{Old Clocks and Watches and their Makers}

costly productions seemed to be purposely devoid of all enrichment. As an example, one of his "souscription" watches is here shown. It was made in 1821, bears the inscription "Breguet et Fils," and cost $£ 26$. The bezels and bow are of gold, and the body and back of the case are silver. It winds at the centre of the dial and has an hour hand only, though this is of peculiar construction, for beyond the part which indicates the hour is a fine prolongation to reach the subdivisions, which are each a twelfth of an hour, equal to five minutes. With practice one could doubtless estimate the time very closely in this way. It is said that

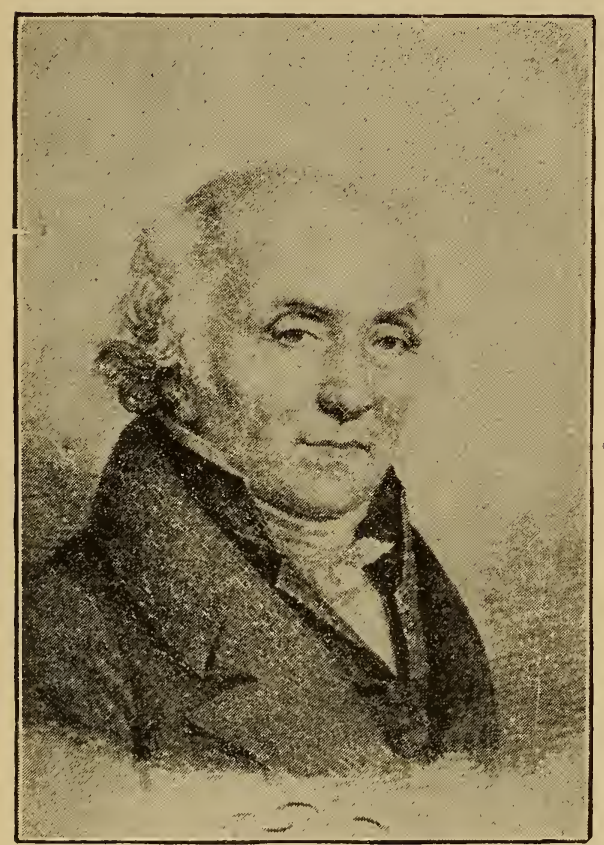

Fig. 525.-Abraham Louis Breguet, 1747-1823. the subscription watches obtained their title from the combination of Breguet and certain of his workpeople to produce a reliable watch at a moderate price. Many of his watches had the signature Breguet scratched on the dial in script, the characters being so very tiny as to be indistinguishable without a magnifier. His early watches, it may be supposed, were not so marked. I cannot ascertain when the practice began, but it doubtless continued during the " Reign of Terror." In some instances the number of the watch was on the pendant, but this again did not occur on all his watches.

Mr. Lionel Faudel Phillips has a watch by Breguet in which the balance pivots are carried between friction rollers, a plan tried by Mudge in his marine chronometers.

Breguet was born at Neuchâtel, Switzerland, in 1747, his parents being of French origin. He settled in Paris in early manhood and quickly achieved success in business. Beillard relates that Marat, who also came from Switzerland, and Breguet were intimately acquainted, and one night when they met at a friend's house in the 
rue Greneta, the populace under the windows shouted, " Down with Marat." The situation becoming serious, Breguet dressed Marat up as an old woman and they left the house arm in arm. Some time after, when the guillotine was set up "en permanence," Marat, finding Breguet was in danger, gave him a pass to Switzerland. Breguet took a post-chaise forthwith and reached Locle in safety. He afterwards returned to Paris and died there in 1823, being succeeded in business by his son, Louis Antoine, who retired in 1833, and was followed by his son Louis, a worthy grandson of Abraham L. Although as an horologist Louis was overshadowed by the greatness of his grandsire, he established a reputation among electricians, as well as among horologists, and timekeepers issued from the house of Breguet during his administration were of the highest possible quality.

Equation Clocks.-To meet the perplexity caused by the fact that sun-dials recorded true solar time and clocks mean solar time, as explained on p. 2, equation dials to indicate the difference each day were added in the latter part of the seventeenth century. Foremost among the inventors of equation work must be mentioned Joseph Williamson, whose paper in the Philosophical Transactions is referred to on p. 307. As well as clocks to indicate the variation between solar and mean time, he appears to have arranged mechanism to raise or lower the pendulum of a clock as required, in order that the hands might indicate true solar time, as in the twelve-month timepiece at Hampton Court which bears Quare's name. Figs. 526 and 527 are drawings of an equation clock by Enderlin, which gives, in addition to true and mean solar time, a perpetual day of the month, the sun's place in the zodiac, his rising and setting, and the moon's age and phases.

Fig. 526 is the dial work, and Fig. 527 the dial itself. In Fig. 526 the wheel $\mathrm{Q}$, of 24 teeth, takes its motion from the striking part. It impels the wheel $\mathrm{R}$, of 32 teeth, with a vertical arbor, which has a bend and compound joint $\mathrm{T}$. This arbor has an endless screw $\mathrm{s}$, in the middle of the inclined half, turning wheel $\mathrm{A}$, of 487 teeth, and also a pinion $a$, of 24 leaves, actuating a wheel $\mathrm{v}$, of 32 teeth. This last wheel revolves in 24 hours, $a$ in 18 hours, and with it the arbor R T S $a$. $Q$ revolves in 13 hours 30 minutes, and $\mathrm{A}$ in 8,760 hours, or 365 days 6 hours, whence it is called the annual wheel. The wheel $\mathrm{x}$, with 62 inclined teeth, and the wheel $\mathrm{z}$, with 90 teeth, revolve separately round one common centre $5, \mathrm{z}$ being in front. $\mathrm{x}$ is impelled by a tooth or pallet on the 24-hours arbor of the 
wheel $\mathrm{v}$, and $\mathrm{z}$ by an endless screw $\mathrm{y}$. This screw has a pinion 6 , of $2 \mathrm{I}$ leaves, upon its upper end, and, impelled by the pinion $a$, turns $z$ in 59 days 1 hour 30 minutes, being the sum of two lunations. The wheel $\mathrm{x}$ is impelled one tooth every 24 hours, therefore an entire revolution would be performed in 62 days; but it does not in fact make more than one-half of a revolution when it jumps back.

The Equation Movement.--On the point D, in Fig. 526, the rack E

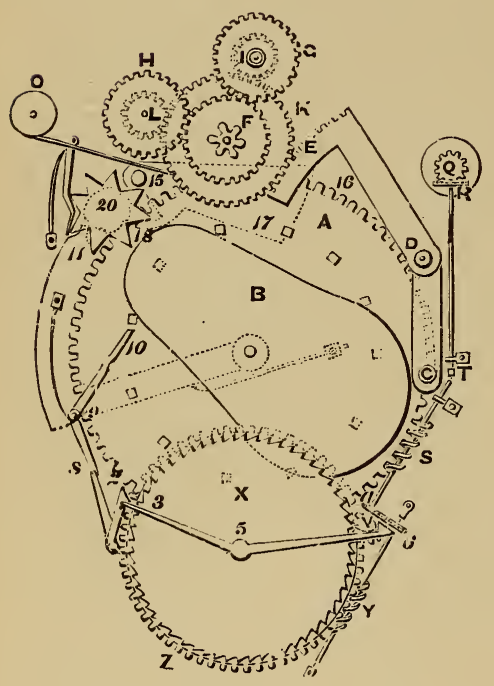

FIG. 526.

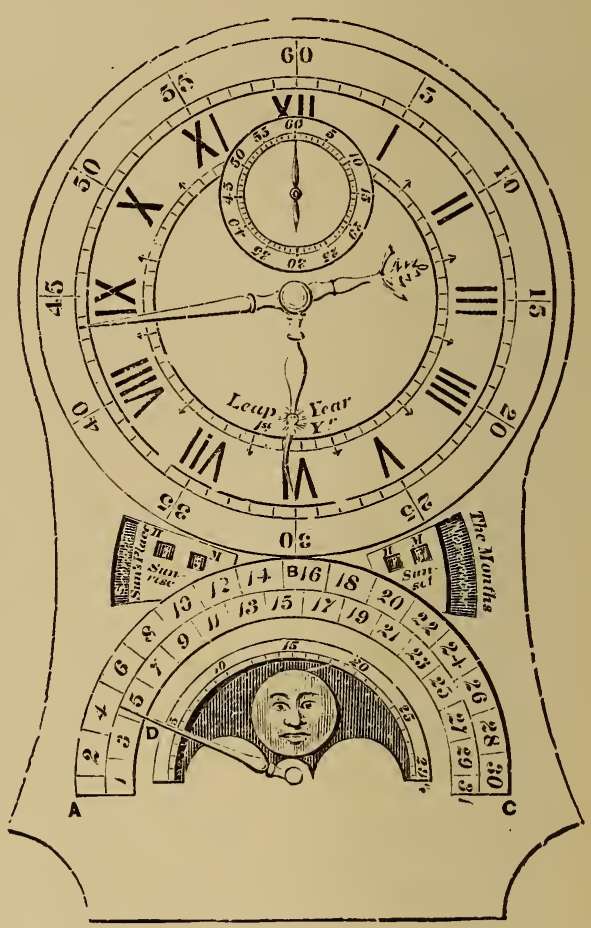

FIG. 527.

The Dial work and Dial itself of an Equation Clcck, by Enderlin.

moves, its tail $c$ resting on the circumference of the equaticn curve. At $o$ is a box with a spring, which keeps the cord 15 always stretched. This cord surrounds a pulley on the place of a concealed wheel $\mathrm{N}$, under $\mathrm{K}$ but not attached to it. This wheel acts into the rack which is always resting on the equation curve. The pinion $\mathrm{I}$, of 30 teeth, revolving in 60 minutes and carrying the minute hand, turns the wheel $\mathrm{K}$, of 60 , which drives a pinion $\mathrm{L}$, of 30 , also in 60 minutes. To $\mathrm{L}$ is attached a wheel $\mathrm{H}$, of 48 teeth, which turns a similar wheel $\mathrm{F}$, and this again a third similar wheel $\mathrm{G}$, the tube of 
which surrounds the arbor of I, and carries the equation hand with a little sun on it pointing to 30 , in Fig. 527. The wheel $\mathrm{N}$, below $\mathrm{K}$, is pinned to a bar, which is not seen, but which carries the wheel II and pinion $L$; and as the tecth of the rack are acting in the wheel $\kappa$, the concealed bar moves alternately towards $I$ and 15 as the radius of the equation cam varies. This motion makes the pinion $\mathrm{L}$ sometimes advance and sometimes retrograde a few teeth, independently of the motion it receives from the rotation of $\mathrm{k}$; and this additional motion is also communicated to the wheel in in consequence of its

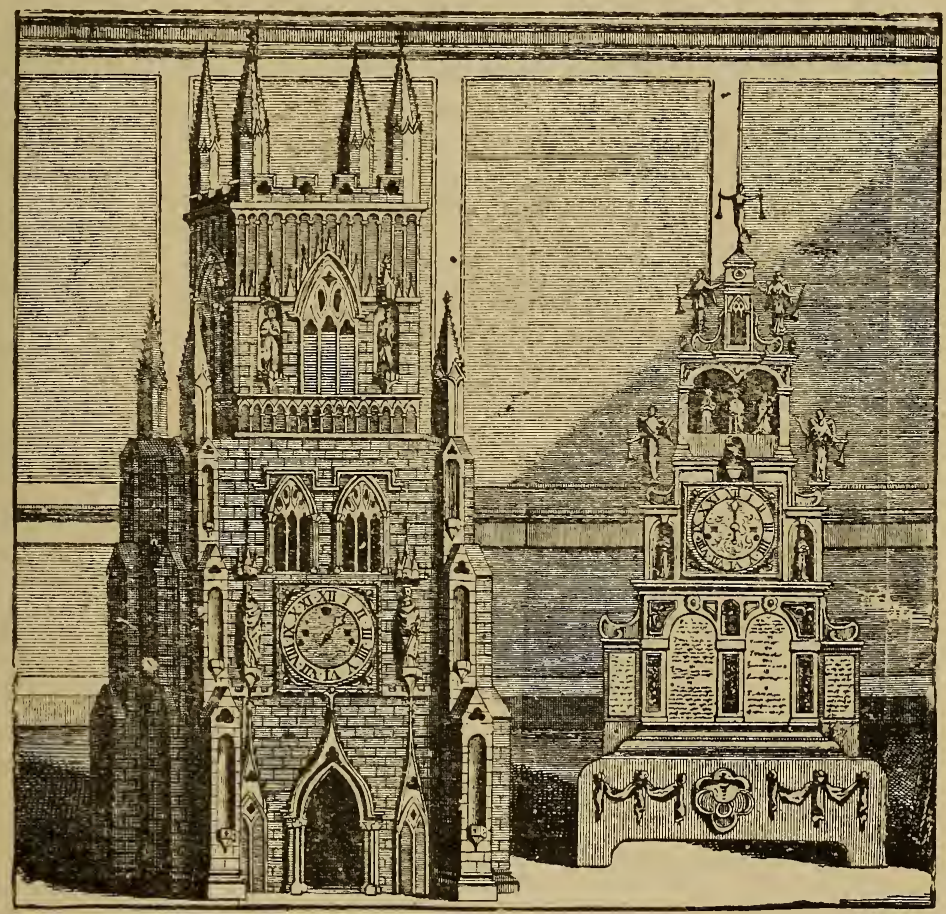

FIG. 528.-Lichfield Clock.

connection with $\mathrm{L}$, and hence to both $\mathrm{F}$ and $\mathrm{G}$, the latter bearing the equation hand.

Altogether this is an interesting example of the mechanism of early complicated clocks. The perpetual calendar work is now done with more simplicity, in cases where such devices are demanded, and the equation indicator of Tompion's Bath clock, of which a description is also given, is actuated in a more direct way, as may be seen from comparison. 


\section{Old Clocks and Watches and their Makers}

Green's Lichfield Clock.-In the Universal Magazine for 1748 is illustrated a singular clock with a peculiar outer case, about $4 \mathrm{ft}$. high, built in three tiers, and shown in Fig. 528. The early history of the clock does not appear to be known, but at the date quoted it belonged to Mr. Richard Green, of Lichfield.

The upper part represents a pavilion, whereon stands a brazen statue of Fame. Within the pavilion, in the centre appears Pontius Pilate, having a basin of water before him, as washing his hands; and round him move continually three images, representing our Saviour as going to His crucifixion, the Virgin Mary, and Simon the Cyrenian bearing the cross. These three last-mentioned figures make one entire revolution every minute. The musical part of this clock executed eight different tunes, any one of which it played several times over every three hours, with also provision to play it occasionally.

The outward case of this horological machine occupies the left of the engraving. It represents a highly decorated church tower of Gothic architecture, with pinnacles, battlements, windows, mouldings, images, buttresses, \&c., admirably painted and well carved. This perspective view of the outward case is so contrived that no part of the inner structure but the dial appears to view, except when the front of this case (which consists of an upper and lower door) is thrown open. The clock may be then taken out, appearing then as is shown on the right of the engraving, and placed on the table or elsewhere. The height of the outside case is $5 \mathrm{ft} .2 \mathrm{in}$.

Henry Bridges.-Henry Bridges, who lived at Waltham Abbey, and was brought up as an architect, seems to have obtained a greater reputation abroad than at home as the producer of clocks with motions representing the heavenly bodies. The specimen of his work delineated in the accompanying figure was publicly exhibited in 1741 at the Mitre, near Charing Cross, according to an advertisement in the Daily Advertiser for $23 \mathrm{rd}$ December of that year. It is a monumental clock $10 \mathrm{ft}$. high and $6 \mathrm{ft}$. broad at the base. Within the pediment at the top of the structure is a scene representing the Muses on Parnassus; this changes periodically to a forest with Orpheus and wild beasts, which in its turn gives place to a sylvan grove with birds.

On the upper large dial and the four small ones are indicated the seconds, minutes, and hours; the rising and setting of the sun; equation of time, the age phases of the moon, and signs of the zodiac. On the lower of the large dials is exhibited the Copernican system of time, consisting of seventeen bodies, the sun being in the centre and the planets moving round it. On a panel below are a landscape 
and the sea with representations of moving persons and vessels, and on a second panel men at work in a carpenter's yard. These automata were very popular, and quite suited to the taste of the

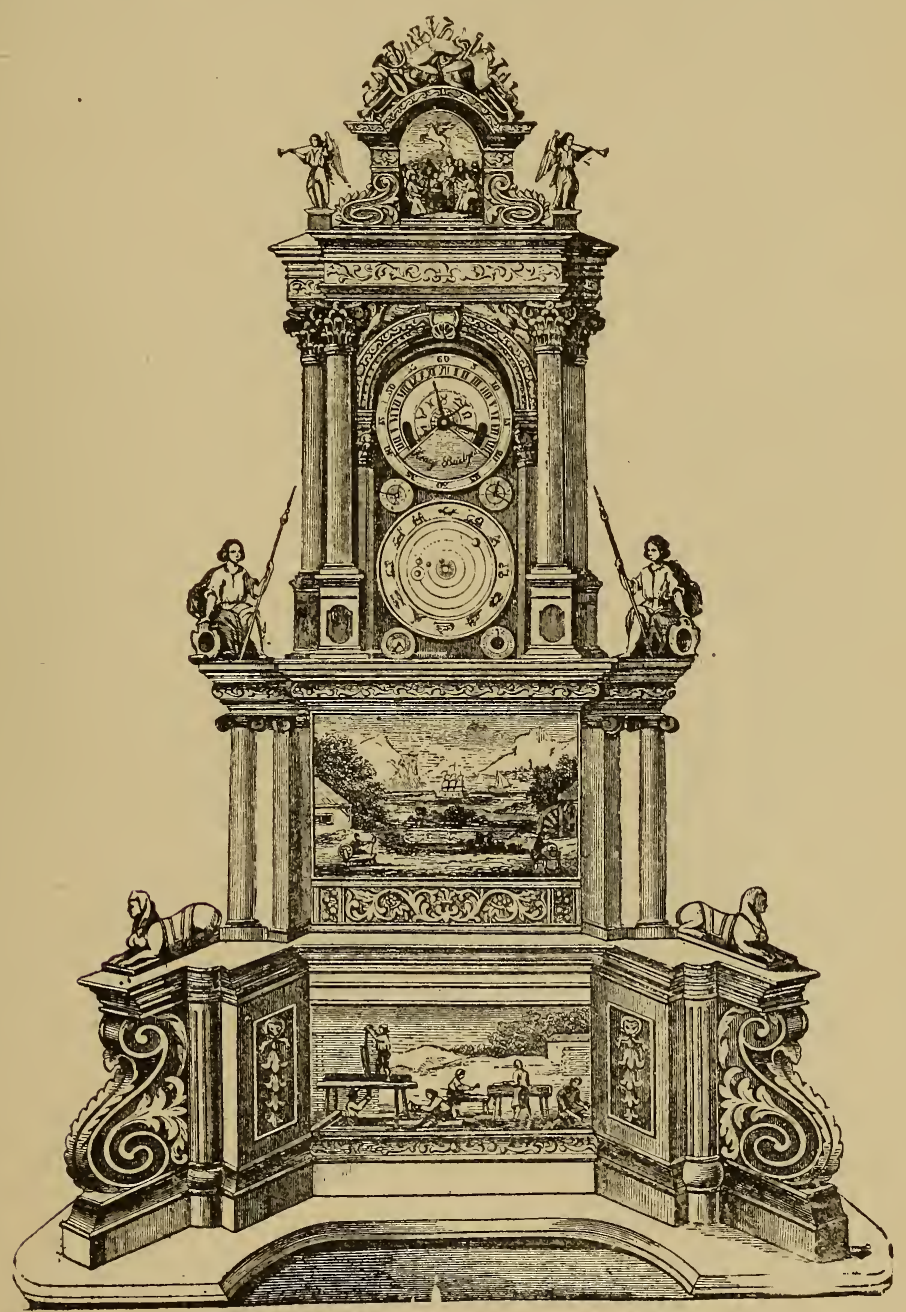

Fig. 529.-Bridges' Clock.

period. Besides these, the edifice contained an organ, which was played at intervals. Altogether there were, it is stated, over a thousand wheels and pinions in the composition of the mechanism.

It is remarkable how little is to be gathered respecting Henry 
Bridges among English horological records. Dubois says he was clockmaker in the court of Charles I., and that the identical clock illustrated on p. 397 was made for the Duke of Buckingham. But this account cannot be accepted, for seconds and minute hands were not usual in the time of Charles I. In the Ashmolean Museum is a copy of the print from which Fig. 529 is taken, and it is dated 1734 . A portrait of Bridges appears on it, and the wig and dress are of the style in viogue at the beginning of the eighteenth century. In the Daily Advertiser announcement, already referred to, is the following note: "Mr. Bridges being engaged in much Business at home would be willing to dispose of this Machine, either wholly, or in Partnership." In 1770, the clock was again exhibited, this time by one Edward Davis, who wrote a descriptive pamphlet concerning it.

Lovelace's Exeter Clock. - It is stated that Jacob Lovelace, a native of Exeter, spent thirty-four years constructing the monumental clock shown in the accompanying engraving. A printed description of it says: "The mechanism is enclosed in an elegant cabinet, $10 \mathrm{ft}$. high, $5 \mathrm{ft}$. wide, and weighing half a ton, ornamented with Oriental figures and finely executed paintings bordered by richly carved fretwork. The movements are: 1. A moving panorama descriptive of Day and Night. Day is represented by Apollo in his car drawn by four spirited coursers, accompanied by the twelve Hours; and Diana in her car drawn by stags, attended by the twelve Hours, represents Night. 2. Two gilt figures in Roman costume, who turn their heads and salute with their swords as the panorama revolves, and also move in the same manner while the bells are ringing. 3. A perpetual almanack, showing the day of the month on a semi-circular plate, the index returning to the first day of every month on the close of each month, without alteration even in leap years, regulated only once in 130 years. 4. A circle, the index of which shows the day of the week, with its appropriate planet. 5. A perpetual almanack showing the days of the month and the equation of time. 6. A circle showing the leap year, the index revolving only once in four years. 7. A timepiece that strikes the hours and chimes the quarters, on the face of which the whole of the twenty-four hours (twelve day and twelve night) are shown and regulated; within this circle the sun is seen in his course, with the time of rising and setting, by an horizon receding or advancing as the days lengthen or shorten, and under is seen the moon, showing her different quarters, phases, age, \&c. 8. Two female figures on either side of the dial-pate, representing Fame and Terpsichore, who move in time when the organ plays. 9. A move- 
ment regulating the clock as a repeater, to strike or to be silent. 10. Saturn, the god of Time, who beats in movement when the organ plays. 11. A circle on the face shows the names of eight celebrated tunes played by the organ in the interior every four hours. 12. A belfry with six ringers, who ring a merry peal. The interior of this part of the cabinet is ornamented with beautiful paintings, repre-

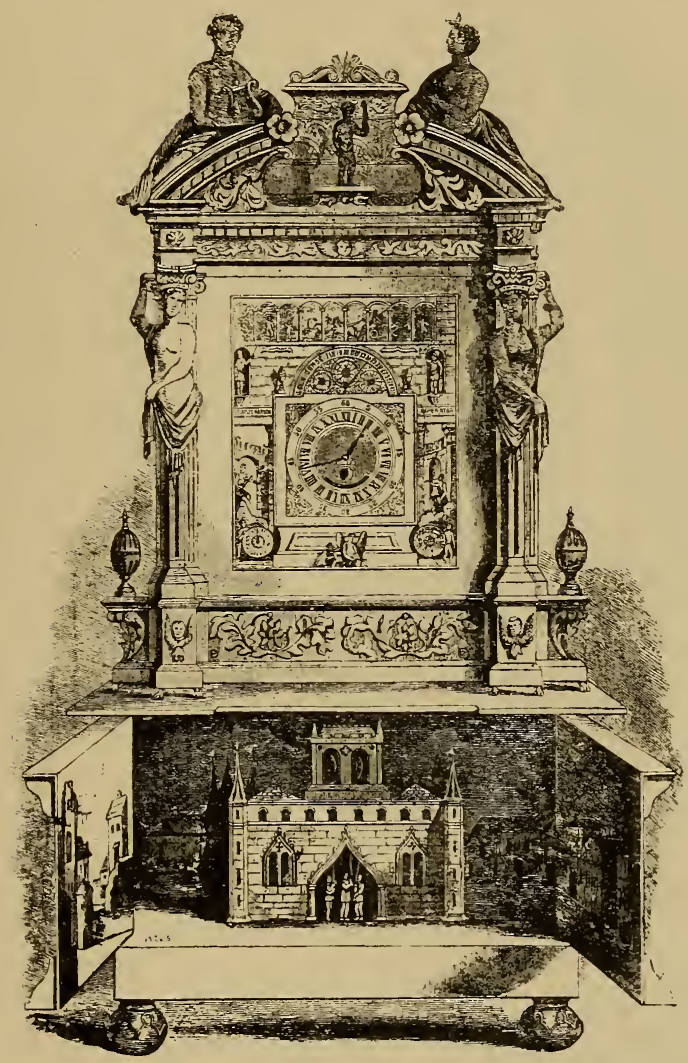

FIG. 530.--Lovelace's Clock.

senting some of the principal ancient buildings in the city of Exeter. 13. Connected with the organ is a bird organ, which plays when required. Beside the dial is the inscription, Tempus rerum Imperator.

According to an advertisement in the Exeter Flying Post, 5th July 1821, this clock was about to be publicly exhibited; and in the same publication for 8 th September 1834, it was announced that " Lovelace's 
celebrated clock," which for several years was in the collection of

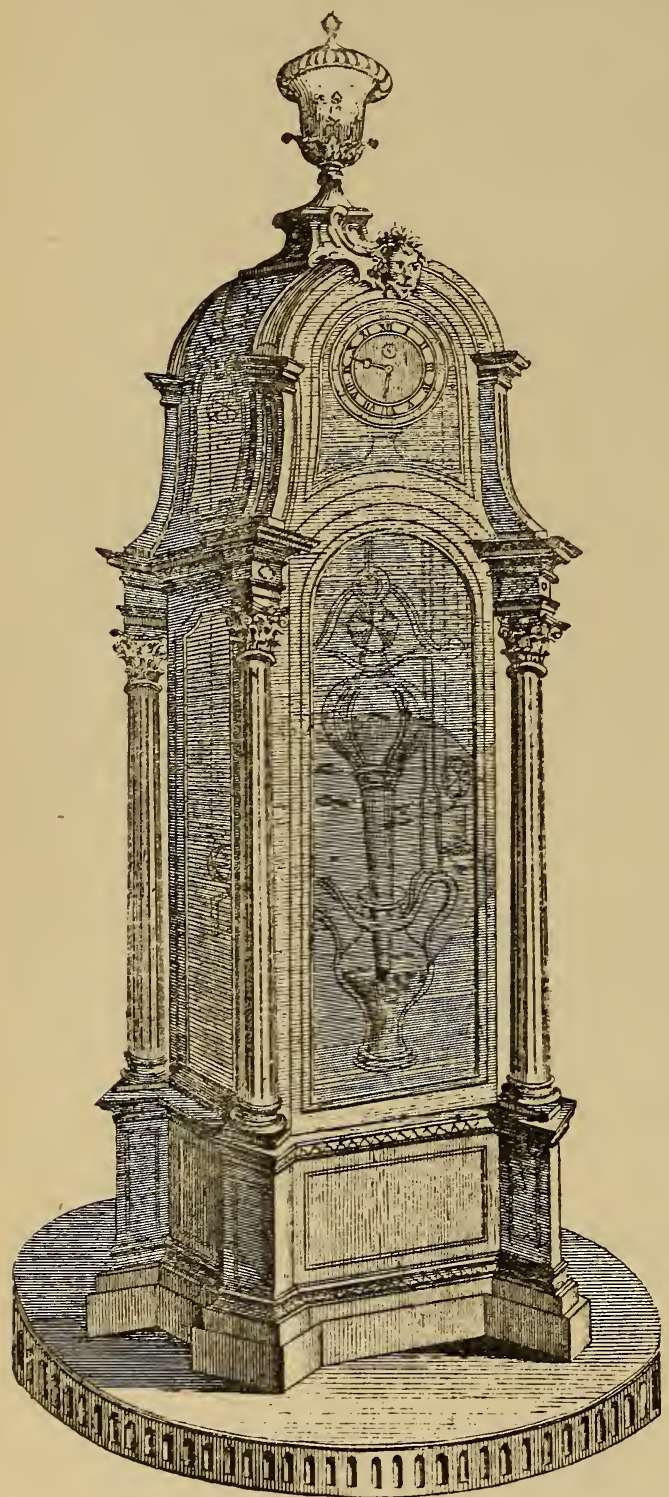

FIG. 531.-Cox's Perpetual Motion.

Mr. James Burt, had the previous week been sold by auction for 680 guineas by the noted George Robins.

At the International Exhibition, 1851 , it was a prominent feature in the Western Gallery. It then belonged to $\mathrm{Mr}$. Brutton, who had it put in order by Mr. Frost, of Exeter, after it had been deranged for some years. In 1888 a suggestion in the Exeter Press that the clock should be purchased for the Imperial Institute, resulted in nothing, and it was afterwards acquired for the Liverpool Museum, where it remains.

There seems to be no reasonable doubt that Lovelace died at the age of sixty, in 1766. It has been suggested that his death occurred half a century earlier. There is nothing in the clock here shown to warrant such a conclusion, and he is known to have made long-case clocks of a style quite inconsistent with a period anterior to 1716 . 
James Cox and his Perpetual Motion Clock.--By favour of Mr. George Ellis I am enabled to reproduce an engraving of a selfwinding or, as the inventor termed it, " a perpetual motion " clock, which belonged to the late W. F. B. Massey-Mainwaring. The energy for keeping the mechanism in motion was obtained by changes in the pressure of the atmosphere. What at first sight seems to be a huge pendulum is an ornamental glass jar of mercury, suspended from chains. Into this is dipped a tube of mercury, also hung from chains, open at its lower end, and with a large bulb at its upper extremity. With increased atmospheric pressure a little of the mercury in the jar would be forced into the tube. The jar and tubes were balanced by weights, so that the tube, being a little heavier by the addition of mercury, would fall a little, and in so doing would raise the weight ; and with a fall in the pressure of the atmosphere, the mercury in the jar would be increased and the weight would be raised a little. There is no pendulum, but the escapement, which is at the back of the dial, is controlled by a straight bar balance. Wherever possible, the rubbing surfaces were jewelled with diamonds to reduce the friction. The clock which is over $7 \mathrm{ft}$. in height, was constructed by James Cox, who resided for some time in Shoe Lane, and really devoted his life to the production of mechanical curiosities, very much in the style of those devised by Grollier de Servière. Cox obtained an Act of Parliament in 1772 , authorising him to dispose of his museum by means of a lottery, and for some months his conceptions formed an exhibition at Spring Gardens, where half a guinea admission for each person was charged. It was stated in an advertisement that the perpetual motion would occupy the centre of the room. The following certificate was appended to the advertisement:--

"Sir,-I have seen and examined the above described clock, which is kept constantly going by the rising and falling of the quicksilver, in a most extraordinary barometer; and there is no danger of its ever failing to go, for there is always such a quantity of moving power accumulated as would keep the clock going for a year, even if the barometer should be quite away from it. And, indeed, on examining the whole contrivance and construction, I must with truth say, that it is the most ingenious piece of mechanism I ever saw in my life.

"Bolt Court, Fleet Street,

"James Ferguson:"

"Jan. 28th, 1774."

The awarding of the various prizes to subscribers of the lottery took place in June 1775. Mason, a rhymester of the time thus refers to one of his exhibits :-

"Great Cox, at his mechanicall,

Bids orient pearls from golden dragons fall;

Each little dragonet, with brazen grin, 
Gapes for the precious prize, and gulps it in.

Yet, when we peep behind the scene,

One master wheel directs the whole machine;

The selfsame pearls, in nice gradation, all

Around one common centre, rise and fall.."

Another of his " perpetual motion " clocks, which was really to be kept going by the opening and shutting of the door of the room in which it was contained, was

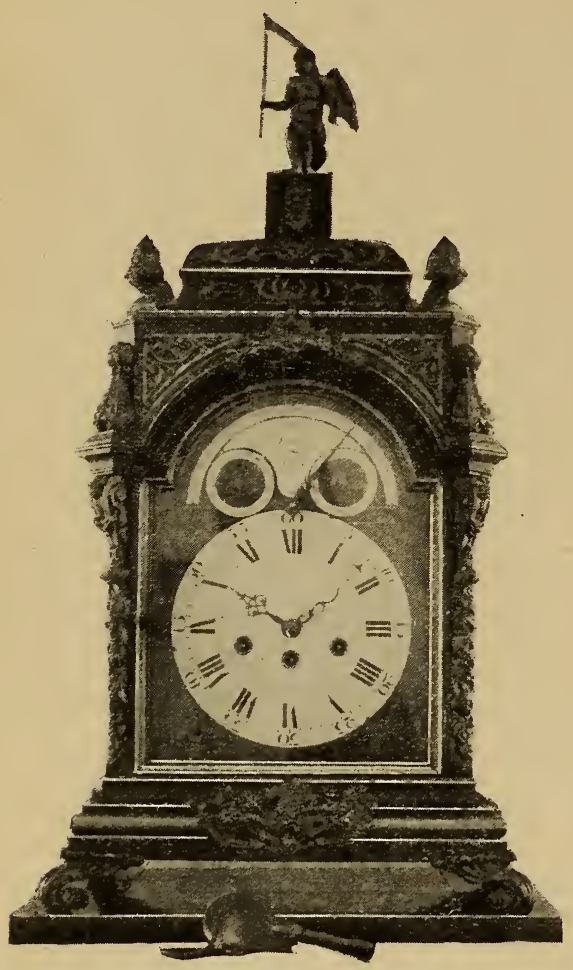

FIG. 532.-Bracket Chiming Clock, by, James Cox, 1769 . for some years on view at the Polytechnic in Regent Street.

Apart from his mysterious mechanism, Cox was an accomplished horologist. I saw a large travelling watch by him, belonging to Mr. William Johnson, in which everything was well proportioned and of the best execution. A chime clock of his make, in an ormolu case with allegorical figures surmounted by a lion holding the arms of England and a miniature of dancing bacchanals by Degault below the dial fetched $f 861$ at the Hamilton sale in $\mathbf{1 8 8 2}$. The handsomely cased bracket chiming clock shown in Fig. 532 belongs to Colonel R. W. Peckitt. In the upper part of the dial is a semicircular band containing the list of tunes played, and below it the signature " James Cox, 1769."

Horstmann's Self-winding Clock.-In a self-winding clock invented by the late Gustave Horstmann, of Bath, the expansion and contraction of a liquid are used to wind the clock. A strong metal vessel, $\mathrm{A}$ in the figure, is filled with an easily expanding fluid, such as benzoline, mineral naphtha, \&c. Connected to this vessel by a strong tube with a very small bore are a cylinder and piston $\mathrm{B}$ and $\mathrm{C}$. Owing to the fact that most expanding fuids are incapable of driving a piston, being too volatile and thin, the cylinder and tube are charged 
with a thicker and more lubricating fluid, such as glycerine. The vessel containing the expanding fluid is on a higher elevation than the piston and cylinder. This is done to prevent them mixing, as benzoline is lighter than glycerine, and, therefore rises to the top. It is easy to see now how that when the temperature rises; the expanding liquid will force the piston upward, and, by means of a slight counterforce, the piśton will fall on the temperature lowering.

The piston terminates in a cross-bar, to each end of which is attached a steel ribbon like a wide watch main-spring. These two bands are brought down over pulleys at $\mathrm{D}$, fixed on each side of the cylinder, and then carried direct to the winding mechanism $\mathrm{E}$ of the clock, which is all fixed on the back of the case and independent of the movement. The two bands join into one a little before they reach the winding. A large pulley $\mathrm{E}$ is fitted on a stud at the back of the case, and is driven by means of a ratchet and click. The pulley $\mathrm{E}$ has a flat groove, and is studded with short pins at equal distances apart, over which works a long steel ribbon perforated with oblong holes. This chain passes down through the weight pulley $\mathrm{F}$, which also has a flat groove, but no pins, and is carried over the main wheel pulley G which is supplied with pins, the same as the winding pulley. It then passes under the pulley of the counterweight $\mathrm{H}$, and is then joined to

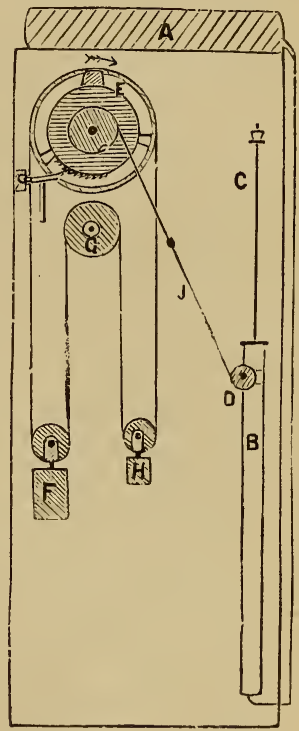

FIG. 533.- Self-winding Clock. its other end, thus forming an endless chain. As the piston falls, a coiled spring causes the smaller pulley at the top of the case to turn independently of $\mathrm{E}$, and to coil the band $\mathrm{I}$ on to itself, ready for the next rise of temperature.

Fan or Windmill Clocks.-Fans actuated by currents of air have been from time to time used as motors for actuating timekeepers. One, by Lepaute, is in the Louvre, Paris. Benjamin Hanks, of Litchfield County, Connecticut, patented one in 1783. In Dardenne's more recent patent the weight is wound up by the current of air in a chimney acting upon the blades of a fan, which is stopped by a selfacting brake as soon as the weight nears the top of its course. 


\section{CHAPTER ·VI}

\section{FRENCH CLOCKS AND CASES IN THE FRENCH STYLE. OTHER CURIOUS TIMEKEEPERS}

$\mathrm{B}^{\mathrm{EYOND}}$ the examples which have already been given little need B be said respecting French horology of the sixteenth and first half of the seventeenth century. Of the early French clockmakers, Julian Couldray (or Couldroy) is mentioned as having, in 1529, received from Francis I. xlix. livres iv. sols for two "monstres d'orloge" without weights. The same king, in 1531, caused to be paid to his " orlogeur" a sum of 50 écus (ducats) for taking in hand a " monstre d'orloge." The term " monstre d'orloge "seems to have been generally used to designate a chamber clock up to about the middle of the seventeenth century. Henry III. of France ordered Gilbert Martinot to make two " monstres," viz., a large round one to place in the apartment of the said "Seigneur" (the king), and another vertical clock with columns, which latter "hys majestie" had promised to the Bastard of Orleans, of both of which " hys majestie " had agreed the price.

After the introduction of the pendulum, the term horologe appears to have been dropped so far as clocks for domestic use were concerned, and the title of " pendule" substituted.

Paris Guild.-According to Savary, a corporate body of clockmakers was established about 1453, but the first statute of incorporation appears to have been granted by Francis I. in 1544, on the petition of Fleurant Valleran, Jean de Presles, Jean Pantin, Michel Potier, Anthoine Beauvais, Nicholas Moret, and Nicolas le Contandois. The enactment decreed that no one, of whatever station, if he has not been admitted as a master, should make, or cause to be made, clocks, alarms, watches, large or small, or any other machine for measuring time, within the said town, city, and precinct of Paris, on pain of forfeiture of the said works. There were provisions for the regulation of apprentices, and for the appointment of officers to enforce the powers conferred on the Corporation, very similar to the privileges accorded to the London Clockmakers in 1630. Upon the entry into Paris of Henri II., ten "orlogeurs" 
formed part of the procession composing the crafts: The Paris Clockmakers had their statute varied in $\mathbf{1 5 5 4}$ under Henri II., in 1572 under Charles IX., and in 1600 under Henri IV. In 1646, under Louis XIV., their laws were thoroughly revised, and it was ordained that apprenticeship should be for eight years, after which the apprentice could leave the employed, but subject only to the approval of his master, and that of the master of the Company. In 1691 was issued a regulation declaring that an apprentice was not qualified for membership, i.e., for submitting a master work, until he had attained the age of at least 29 years. The number of members was limited to 72 , of which only six could be admitted without qualifying. Special privileges were accorded to sons of members, a fact which perhaps accounts for so many successive generations of a particular family following the craft. Widows could continue the business of their husbands, and enjoyed the same privileges. Artisans who practised their trade in districts administered by the king, the lord of the manor, the Church, or the princes of the blood, claimed exemption from control of the Guild. The districts where this immunity existed were: the Cloistre Parvis of Notre Dame, the Court of the Church of Saint Benoit, the enclosures of Saint Denis de Chartres, Saint Jean de Latran, Saint Martin des Champs, Saint Germain de Prés; also the Rue de Lourcine (because subject to Saint Jacques de Latran), the Courts of the Temple and of the Trinity, and the Faubourg Saint-Antoine. The work produced in these quarters was generally considered to be of an inferior order unless executed by a craftsman who had voluntarily joined the Corporation. To the privileged places enumerated have to be added those where work was carried out for the king or the State, such as the Galeries du Louvre. The Associated Clockmakers appear to have governed the trade till the Revolution of 1789, when all the guilds were abolished.

Alfred Franklin, in "La Vie Privée D'Autrefois," says the Martinots and Bidaults for a century and a half occupied lodgings in the Louvre, reserved by the king for distinguished artists. In 1712 Louis XIV. had for clockmakers Louis Henri Martinot, Augustus Francis Bidault, and Jérôme Martinot. They were engaged by the quarter, received 395 livres for salary, dined in the Castle, at the table of the Gentlemen of the Chamber, and had the right of entry to the king's presence along with the distinguished members of his household. Every morning, during the dressing of the king, the horologist on durty wound up and properly adjusted the watches which his Sovereign was about to wear. 


\section{Old Clocks and Watches and their Makers}

Towards the end of the seventeenth century decorative art in France underwent a remarkable change, and cases of "Pendules d'appartement," or chamber clocks, were produced in harmony with the extravagant demand for more sumptuous furniture of all kinds. Eminent artists and designers vied with each other in ministering to the pronounced taste for novelty of form and style. J. Berain, Jacques Caffieri, Boulle, and Marot were among the most noted of those engaged in horological coverings. As will be seen, some of the earlier designs were rather heavy and formal. The ornamentation consisted of masks, escutcheons, shields, and other attributes of the style hitherto in vogue, the structure in many instances being surmounted by a representation of Father Time with his scythe, or Minerva helmeted and holding a lance, or warriors, ancient or mediæval, and occasionally a cupid or nude female figure. Flatterers of Louis XIV. likened him to the sun, and it will be noticed that pendulums and other parts of many clocks produced during the latter part of his reign were decorated with the face of Phœbus. But in the closing days of Louis XIV. the comparatively stiff and sedate outlines gave place to freer and more coquettish forms, and the traditional masks, \&c., to Rocaille of " Rococo" decoration.

Rocaille is, strictly speaking, a style of ornamentation which obtains its effects from the kingdom of shells, but the products of luxurious vegetation, such as palms and other leaves were also put under contribution, blended and twisted to produce a fanciful confusion of curves and spirals. To make the eccentricity more marked, designers, borrowing an idea from the Chinese, perversely strove to obtain originality in their conceptions by the avoidance of symmetry, though it must be confessed that in some instances the judicious incorporation of well-posed figures and groups from the piciures of Watteau and other celebrated artists produced effects sufficiently beautiful quite to atone for the outré character of the surroundings.

Like many other fashions, the Rocaille style degenerated. It lost favour, and was done to death by the grotesque forms and unmeaning contemptible decoration which characterises so many works executed during the latter part of the reign of Louis XV. Such mad travesty caused a reversion during the reign of Louis XVI. to simpler and more symmetrical designs.

Boulle or Buhl Work.-Charles André Boulle, who was born at Paris in 1642 , became celebrated there as a chaser and inlayer. In 1672, Louis XIV. allotted to him rooms at the Louvre, and his effective inlay work of metal, usually brass and tortoise-shell or turtle- 
French Clocks and Cases in the French Style

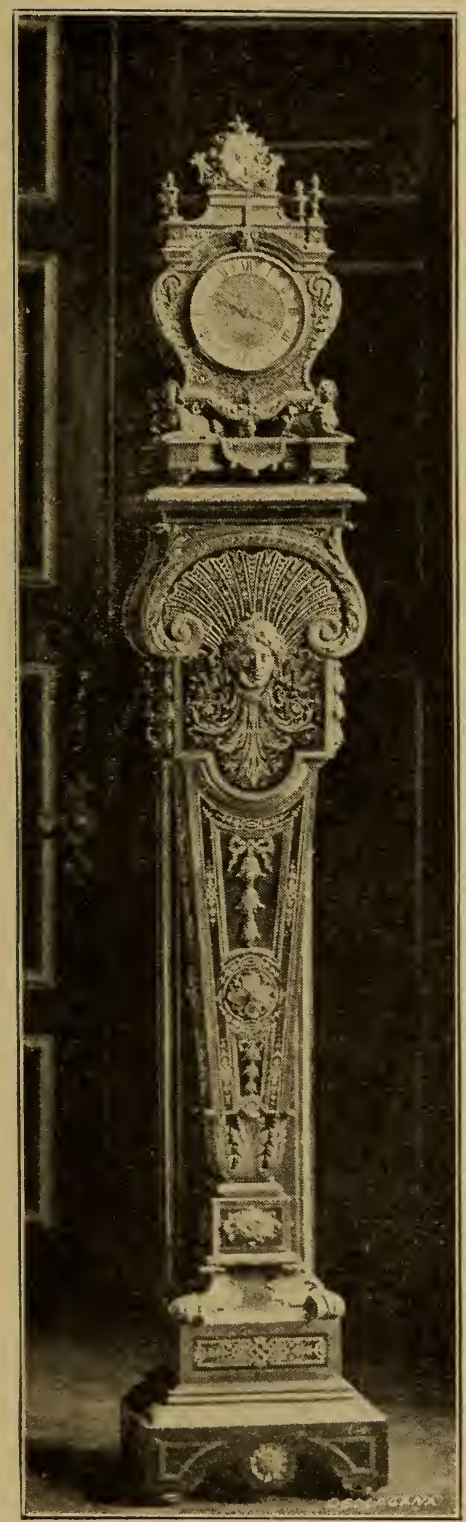

FIG. 534.-Handsome Louis XIV. Clock and Slender Pedestal.

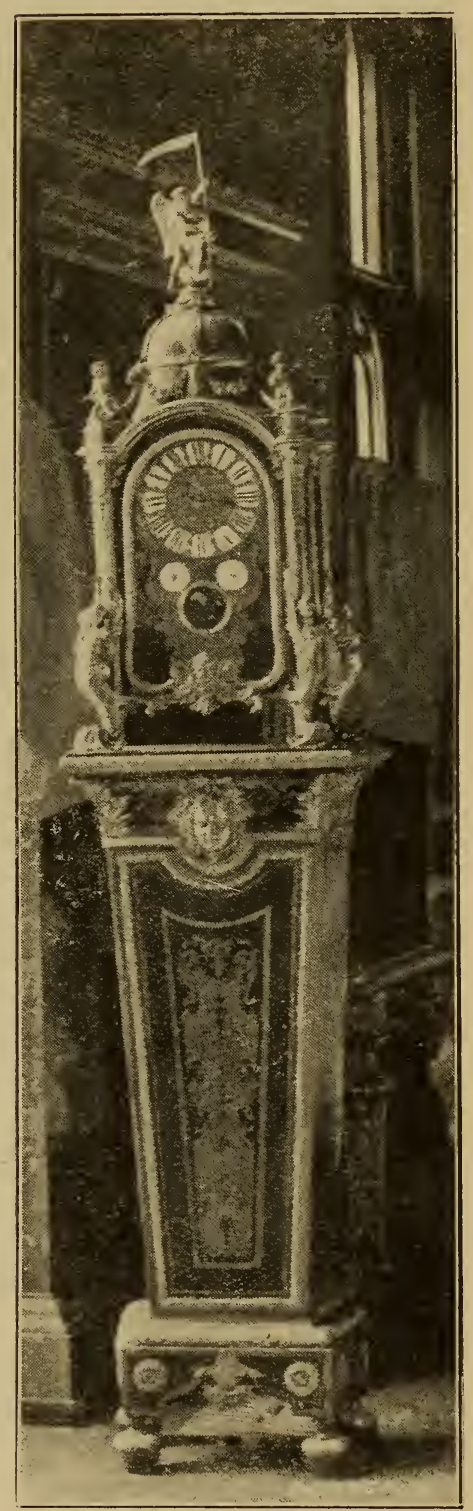

FIG. 535.-Calendar Clock, supported by a very effective Pedestal. 
408 Old Clocks and Watches and their Maker's

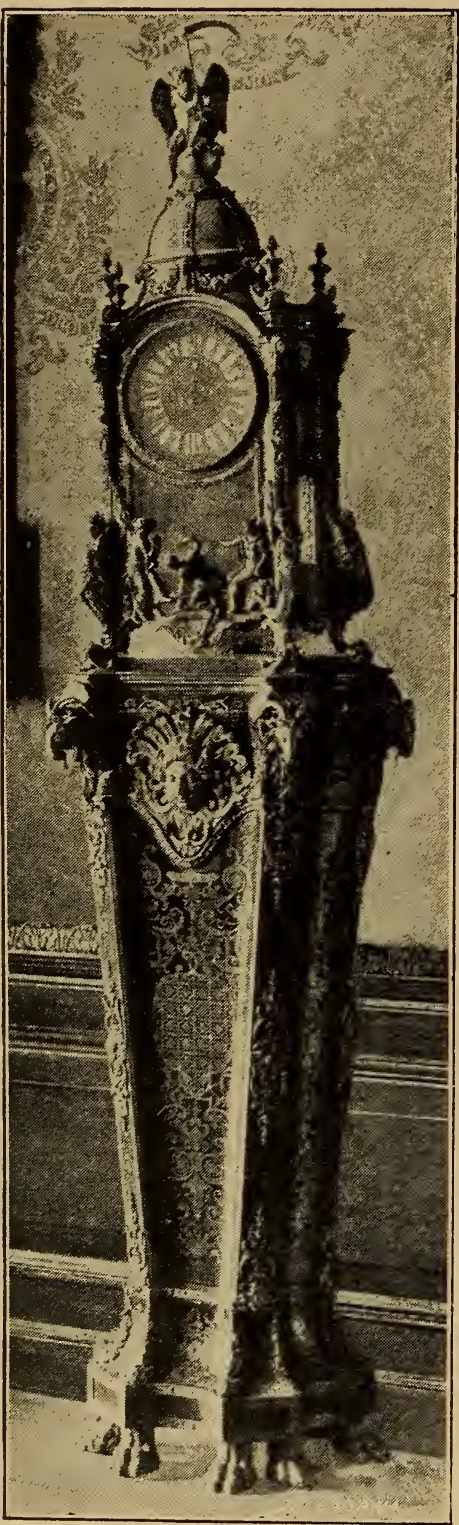

FIG. 536.-Clock in the Rubens Room at Windsor Castle.

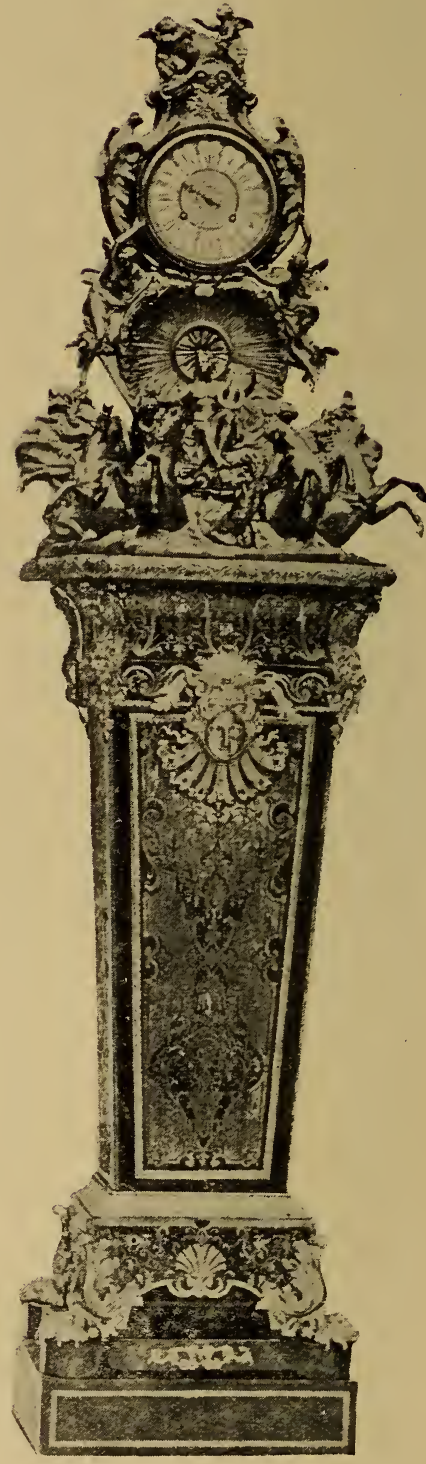

FIg. 537.-Splendid Pedestal Clock, was at the Palais du Louvre, Paris. 
shell, speedily became the favoured decoration for furniture of all kinds. He died in 1732. Boulle work for clock cases and pedestals continued popular in France throughout the eighteenth century, and in a lesser degree here, where the title became corrupted into "Buhl." In some instances the natural tint of the shell would appear. In

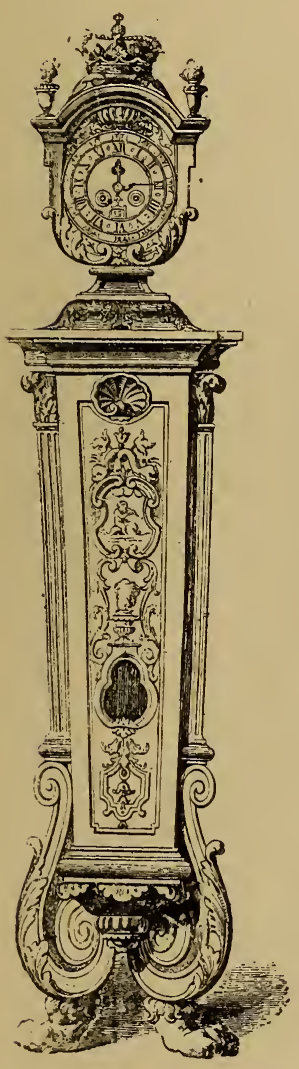

FIG. 538.

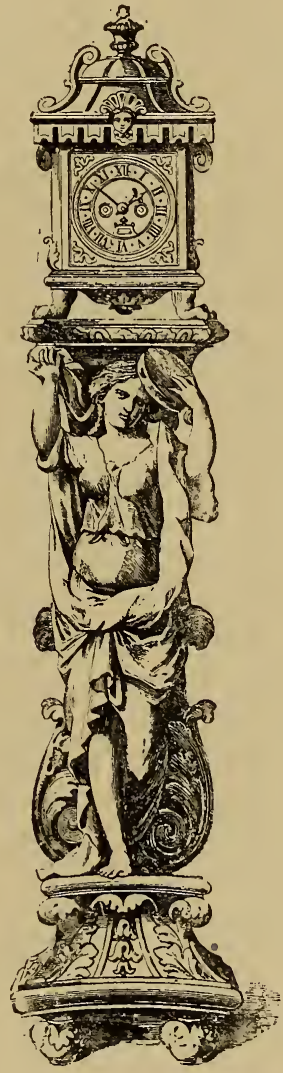

FIG. 539.

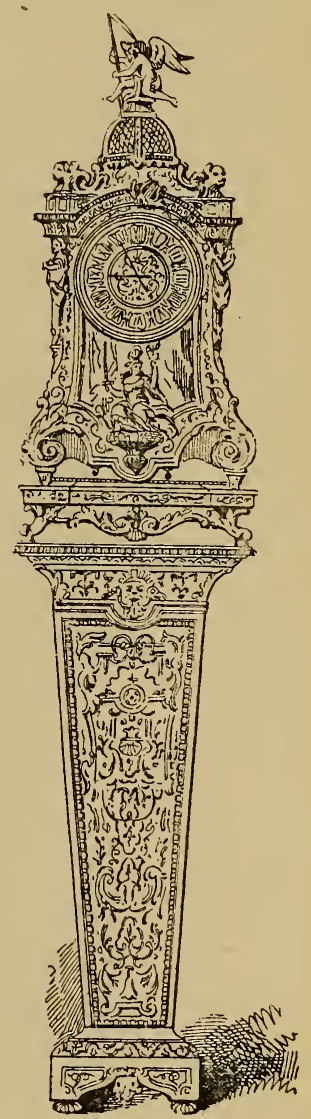

FIG. 540 .

Clocks, by Daniel Marot.

others the shell would be painted on the back, red or black, according to the effect desired by the designer. Then, by way of contrast, the arrangement of the materials used was varied in different parts of the same object ; for instance, if on the front the outline was of shell, with a design inlaid with metal, the sides or perhaps panels elsewhere would be decorated with the counterpart or "counter," that is, the 


\section{Io Old Clocks and Watches and their Makers}

outline would be metal and the inlay shell. "Counter"' or metal outline, though often effective, is considered to be an inferior production.

The particularly handsome Louis XIV. clock and slender pedestal shown in Fig. 534 are in the Council Chamber at Windsor Castle. Together they stand over $7 \mathrm{ft}$. in height, and are decorated with red shell and white metal Boulle work, relieved with ormolu mounts

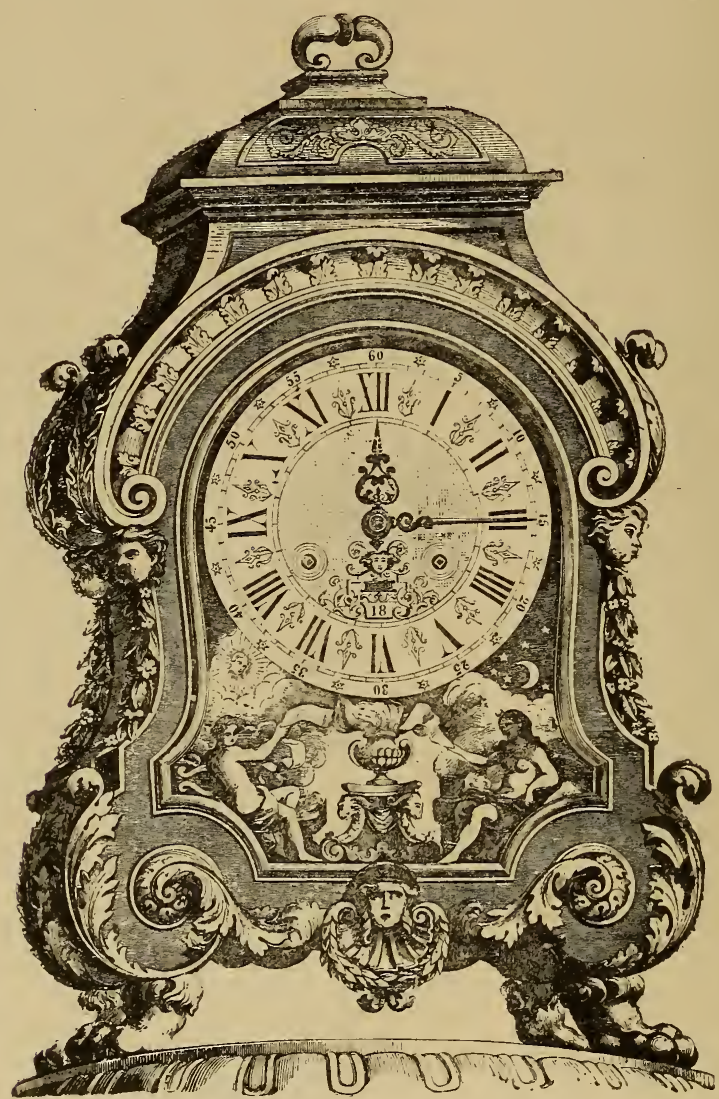

FIG. 541.-Clock; by Daniel Marot.

sharply chased. The pendulum of the clock is $17 \mathrm{in}$. long, descending below the clock case into the pedestal. The upper panel of the latter is hinged to afford access for regulation. This and several other engravings of the clocks at Windsor Castle are reproduced from photographs taken for me by Mr. J. H. Agar-Baugh.

A plainer but very effective pedestal, supporting a calendar clock as 
represented in Fig. 535, is in the corridor at Windsor Castle. The surface is Boulle work of black shell and brass.

Another choice example, in the Rubens room, appears as in Fig. 536.

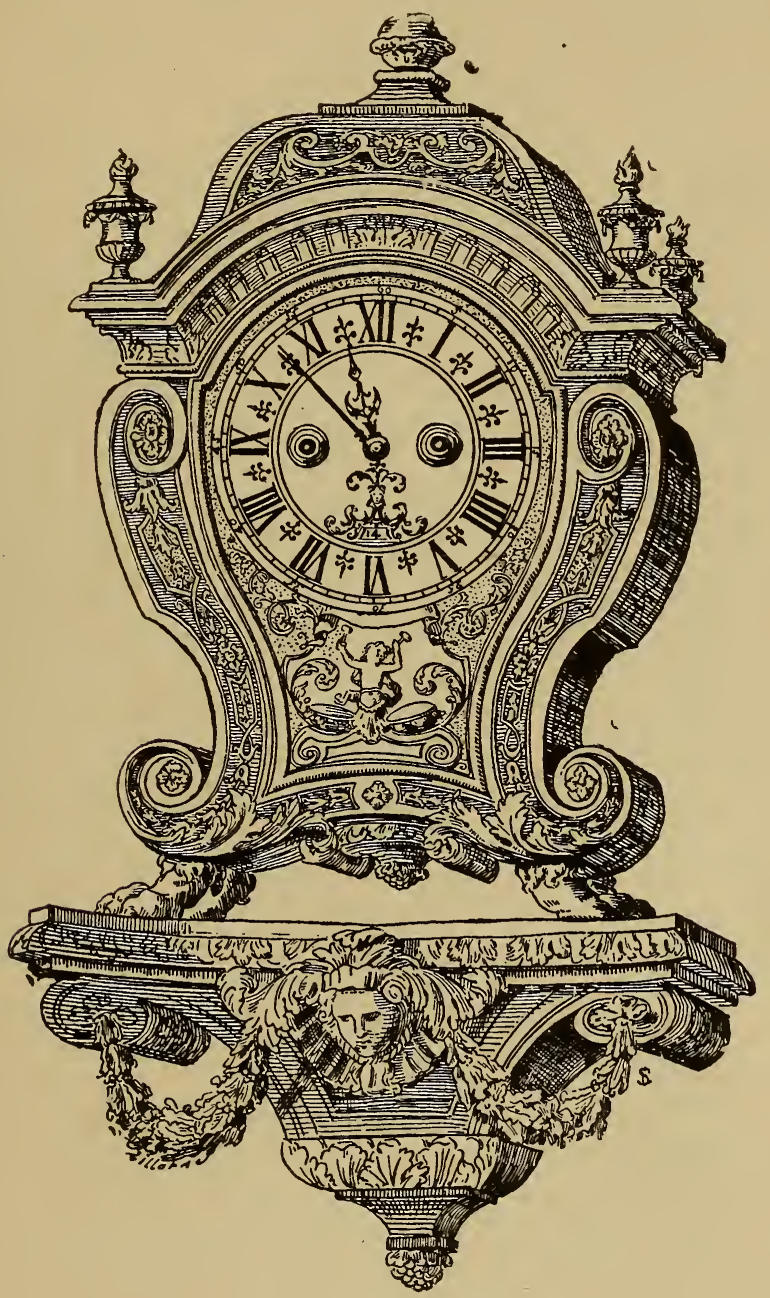

Fig. 542.-Clock, by Daniel Marot.

Havard, "Dictionnaire de l'Ameublement."

The front surface is brown shell inlaid with brass, the covering of the sides being in counterpart. The clock case has sphinx corner supports of ormolu and a domed top surmounted by a figure of Time. At the 


\section{I2 Old Clocks and Watches and their Makers}

base of the case the three Fates are represented. The hour numerals are on plaques of enamel. Through the glazed part of the front below the dial may be seen the pendulum and the inside of the back of the case, which is covered with inlay in counterpart. The style of

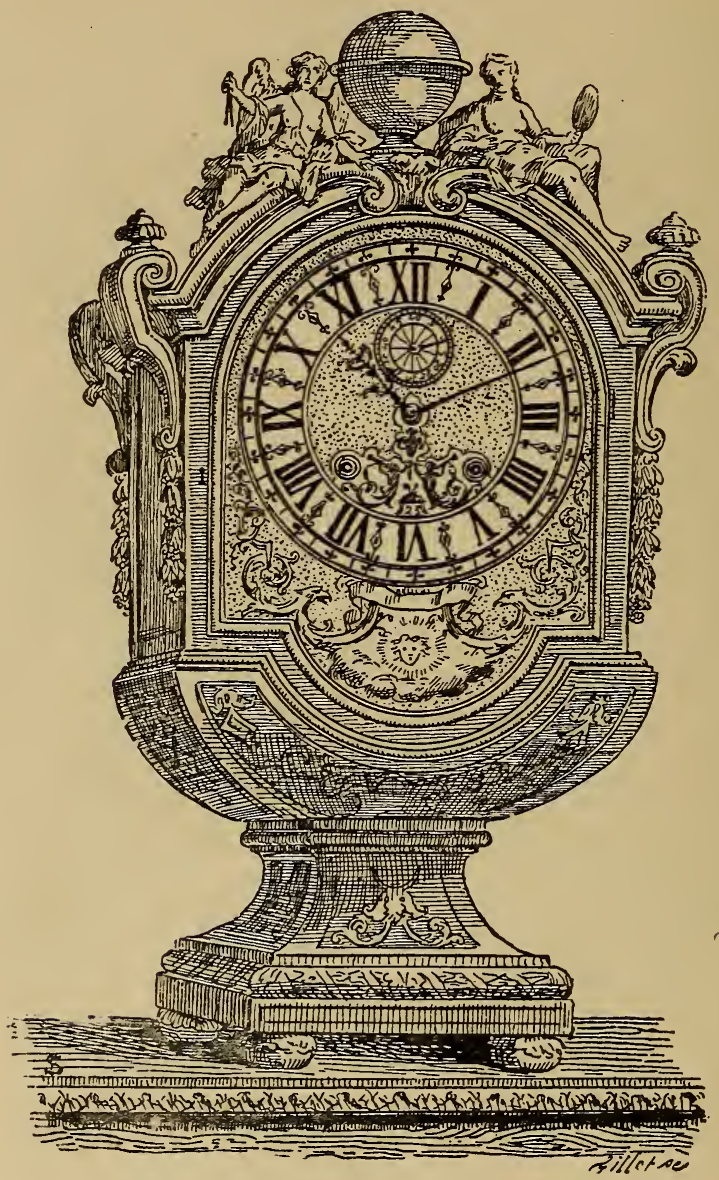

Fig. 543.-Clock, by Daniel Marot.

Havard, "Dictionnaire de l'Ameublement."

this clock, apart from the pedestal, was long in favour with French manufacturers.

In the Wallace collection is a clock by Mynuel, with case and pedestal by Boulle of nearly the same period, and bearing a general resemblance to Fig. 536. They were purchased in 1863 for $f_{8,000}$ 

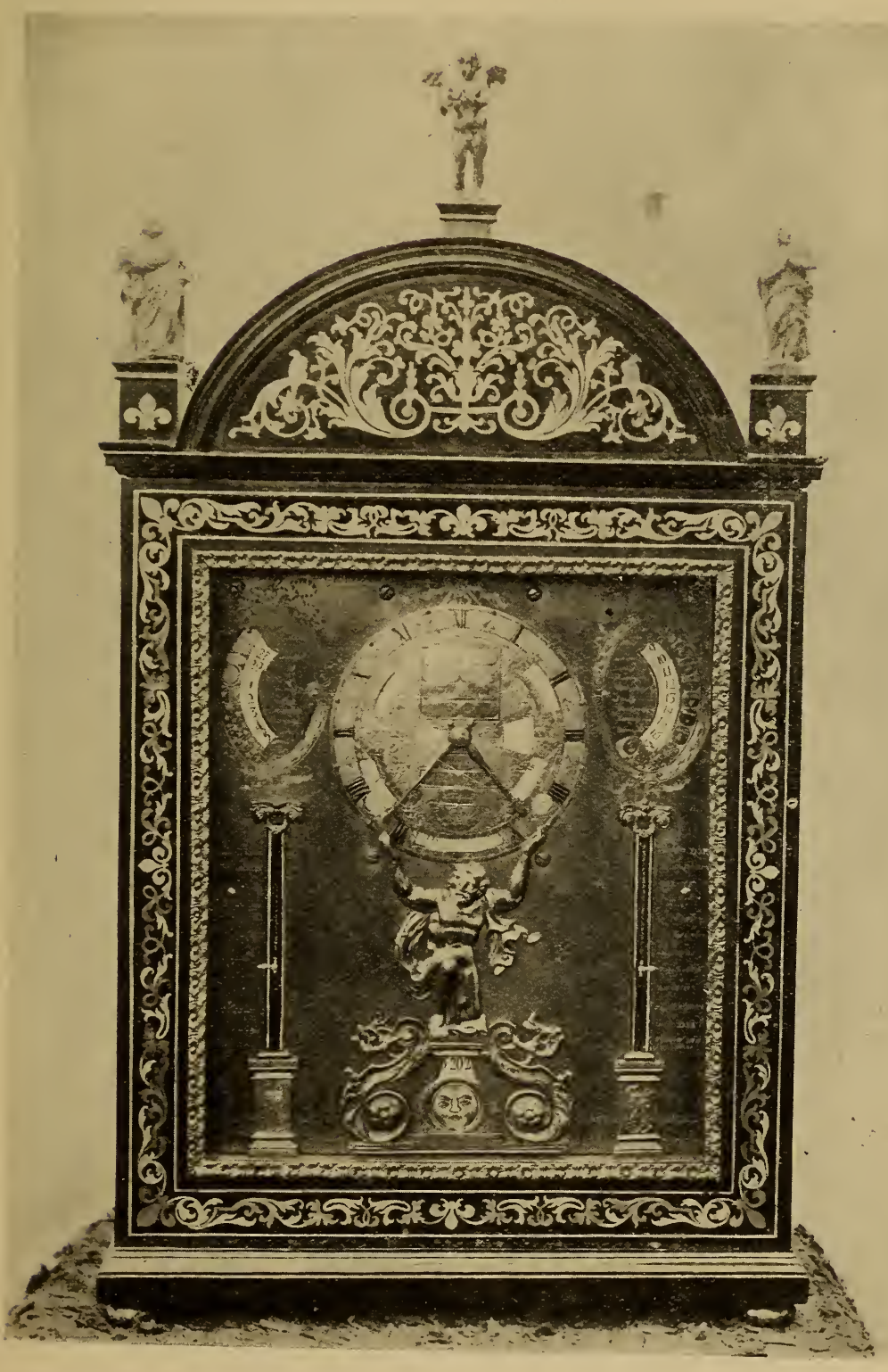

i.

FIG. 544.-Interesting Bracket Clock with Complicated Movement. Schloss Collection, 
4I4 Old Clocks and Watches and their Makers

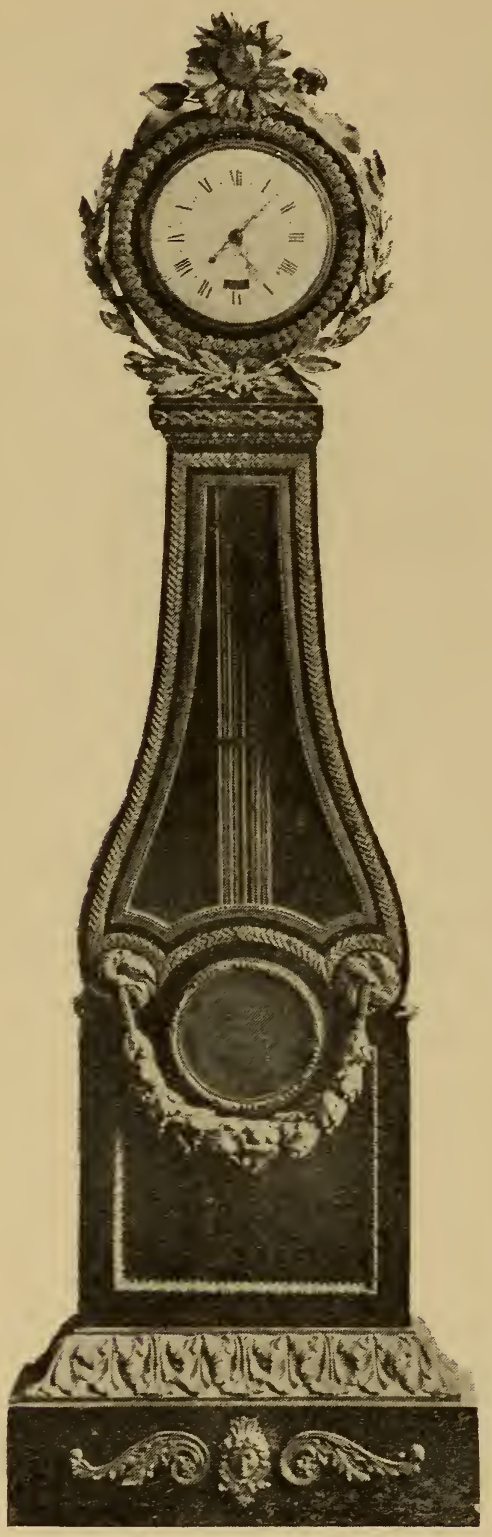

FIG. 545.

Timepiece, by Lepaute,

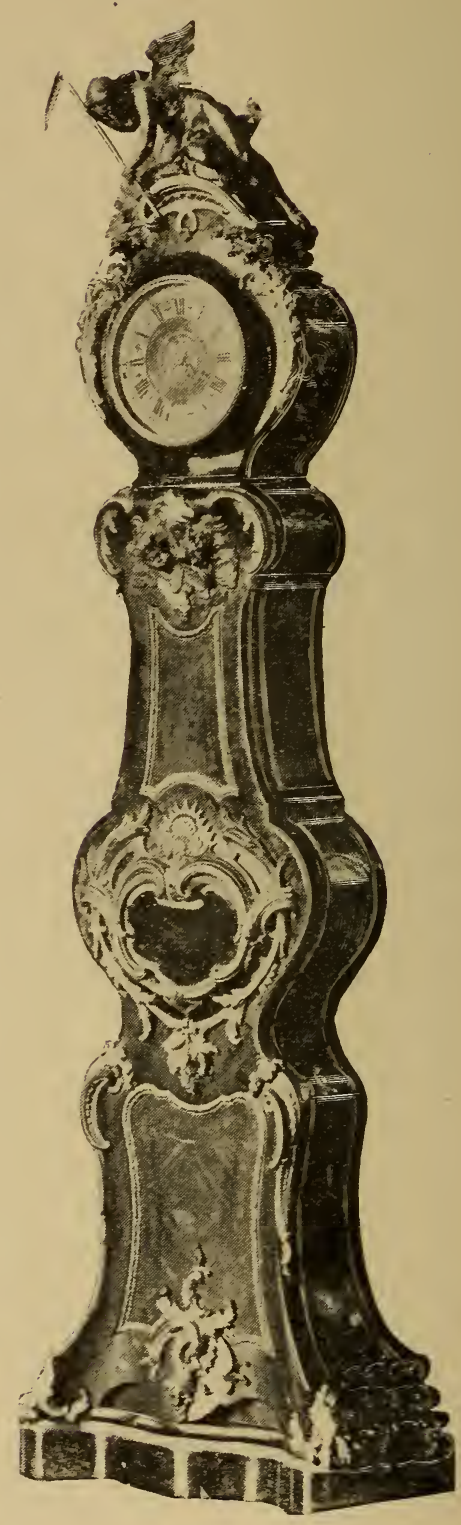

FIG. 546.

Clock, by Julien Le Roy. 
The clock is supported on figures of fantastically costumed warriors with their accoutrements, and on its summit is a statuette of Cupid

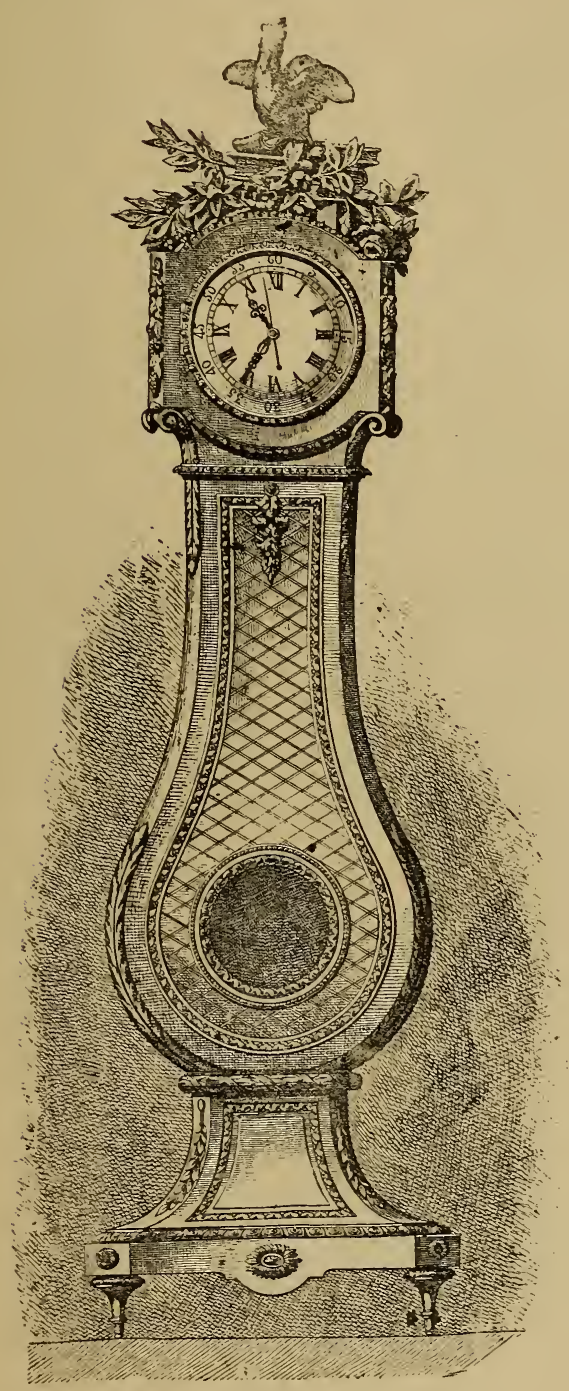

FIG. 547.-Elegant Regulator at the Conservatoire des Arts et Métiers, Paris.

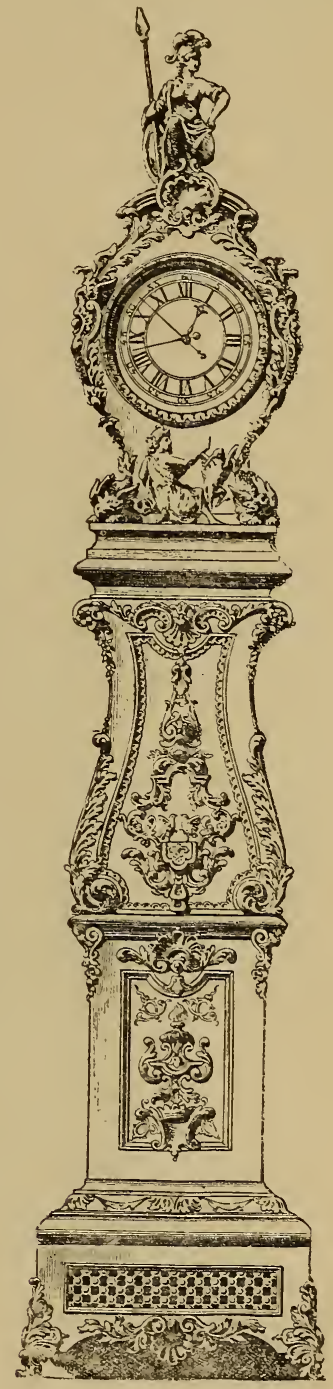

FIG. 548.-Good French Style.

shooting. On the upper part of the pedestal is a medallion representing Hercules relieving Atlas of the burden of the Globe. 
4I6 Old Clocks and Watches and their Makers

A clock and pedestal of the same dimensions, and nearly identical in design, is in the Bibliothèque de l'Arsenal at Paris. Another of the

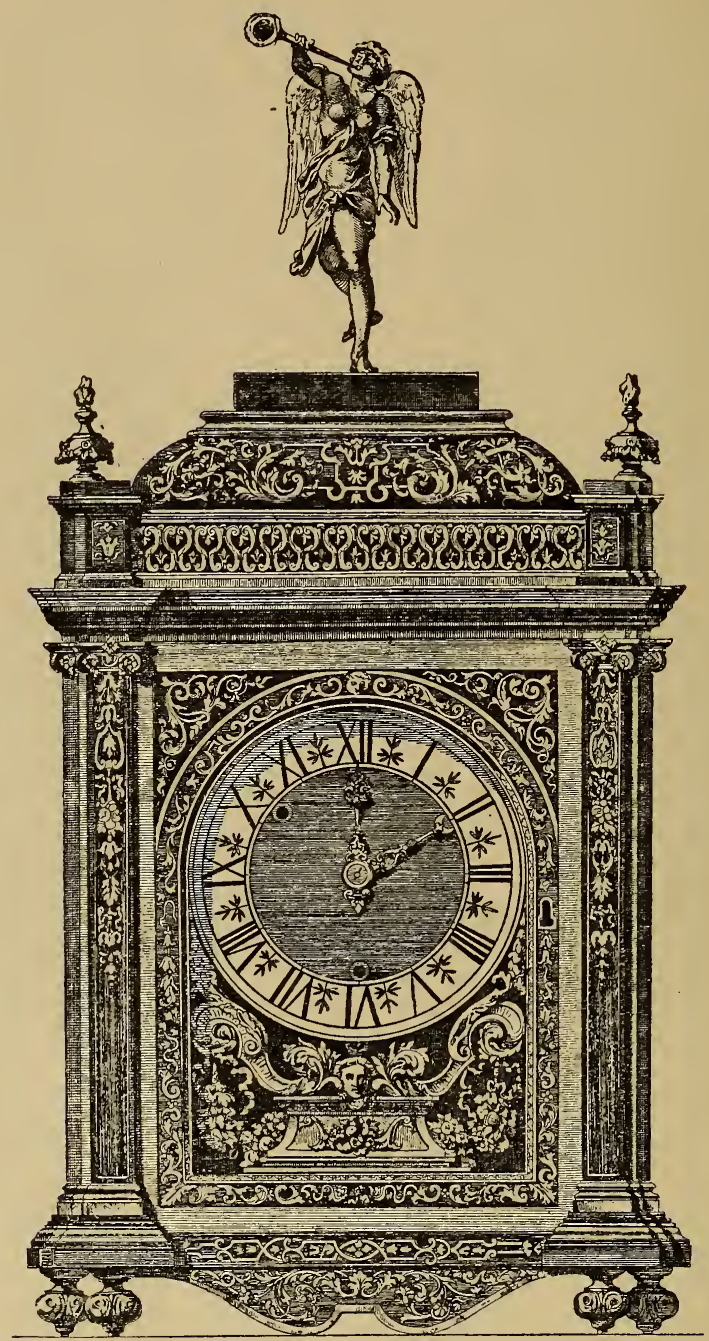

FIG. 549.

(FIGS. 549 to 558 arranged nearly in the order of date contain some feature of excellence.)

same type is in the collection at Waddesdon Manor. The splendid pedestal clock shown in Fig. 537 was at the Palais du Louvre, Paris. Many of the best designs of the Louis XIV period were by Daniel 
Marot, who was born in Paris in 1660 . By the revocation of the Edict of Nantes he was driven to England, but in 1702 took up his abode in the Netherlands. Appended are some examples from a collection of his works published at Amsterdam in 1712. In this book he

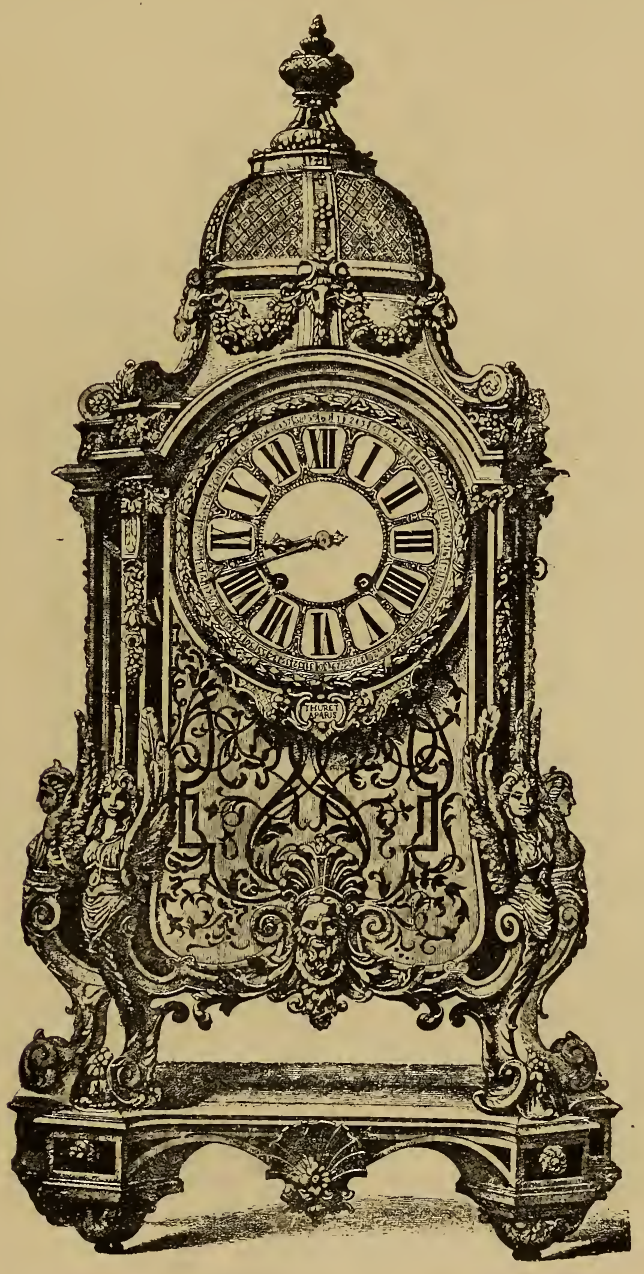

FIG. 550.

was described as "Architecte de Guillaume III., Roy de la Grande Bretagne." Fig. 538, by him, does not show the minutes; it has an hour hand and a hand for pointing to the day of the month on a circle 
outside of the hours. Fig. 539 , also by Marot, has a minute indicator, and may be of a slightly later period. Fig. 540, though very much in the style of the Windsor Castle brass inlay clocks, is of more recent date.

Figs. 541, 542 and 543 are bracket or table clocks, by Marot. The superbly designed specimen shown in Fig. 541 is really perfect.

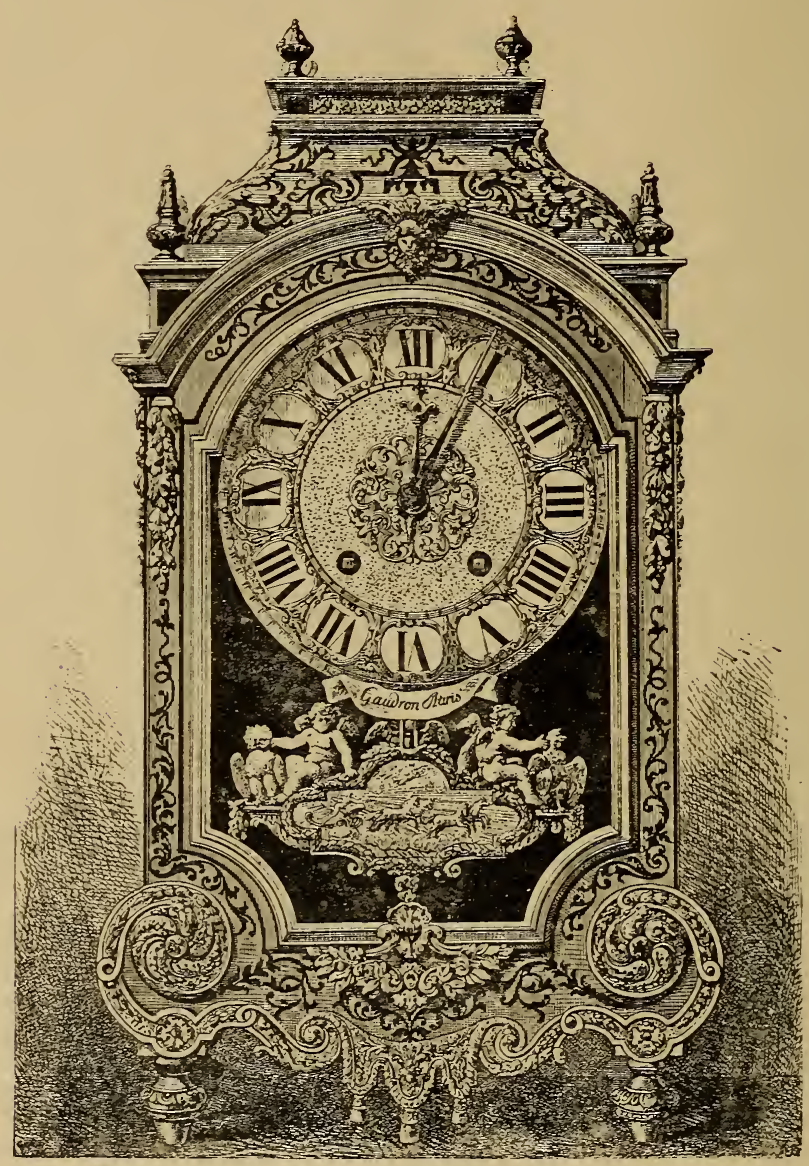

FIG. 551.

An interesting bracket clock, with complicated movements, in a case inlaid with white metal and brass Boulle work, dating from about 1690-1710, is shown in Fig. 544. At the top of the dial plate is engraved the motto, "Nec pluribus im par," the first two words pre- 
French Clocks and Cases in the French Style 419

ceding and the second two following a representation of the sun. At the foot of the dial plate is the inscription, "Henricus Martinot, motum arljunxit. Pouilly Inventor Fecit Parisis." Henry Martinot was Chief

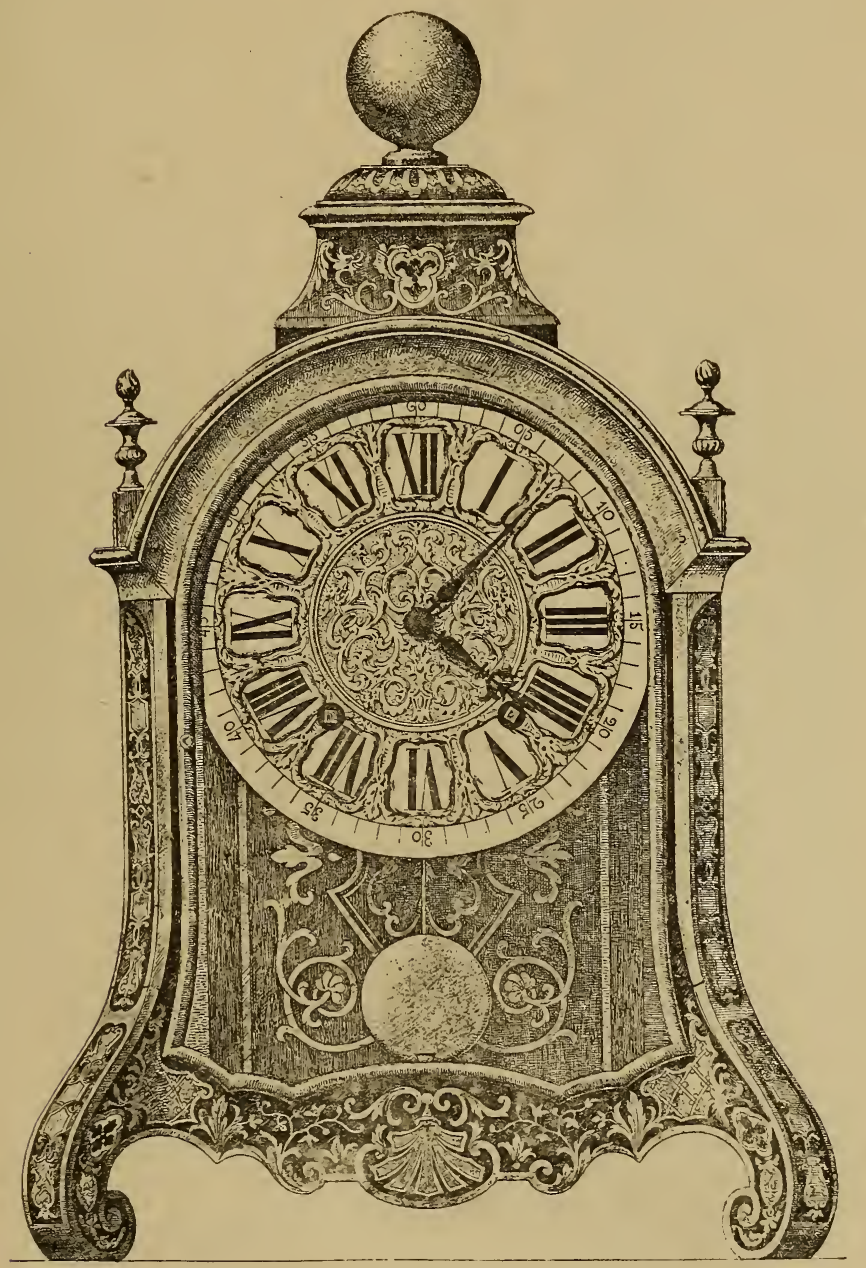

FIG. 552

Clockmaker to Louis XIV., having lodgings in the Louvre, and on the pedestals of the two columns, which are prominent features of the dial plate, is the doubled initial of the King, L.L., interlaced and reversed, surmounted by a crown. This treatment, coupled with the 
fleur-de-lys ornament formed by the Boulle work of the case, led to the conclusion that the clock was made for Louis XIV., possibly for

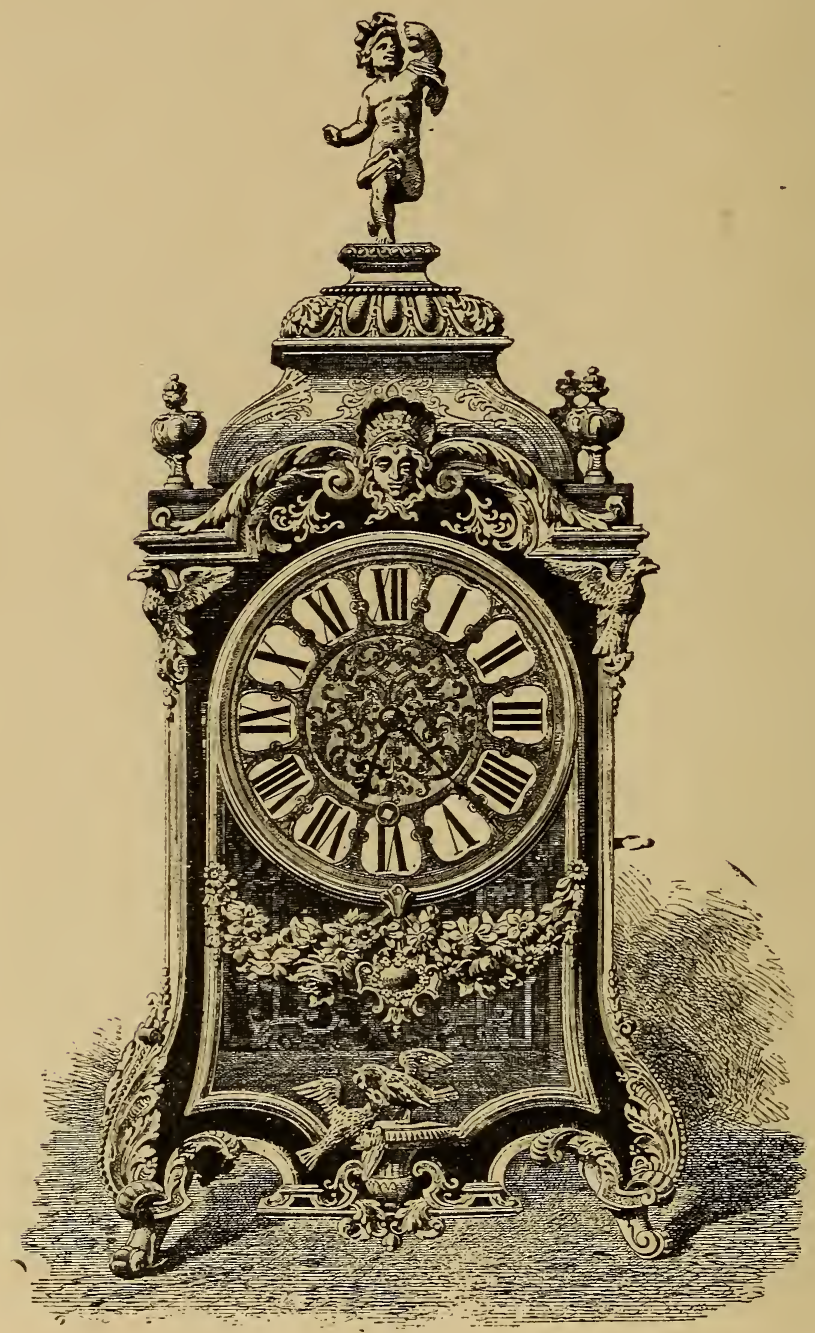

FIG. 553.

presentation to some distinguished person. The dial circle, supported by a figure of Saturn, shows hours and minutes, besides which appear, through seren openings within the circle, sunrise, sunset, the length 
of the day, the length of the night, the month of the year, and certain events of the year as they occur.

Above the centre of the dial are eight tablets, and below the centre four more. These contain each the title of a month, with a number arranged in a peculiar way, thus : April 2; July 5 ; September 7 ; December 10; June 4; February 12; March 1; November 9. These are the eight upper ones, the four below, arranged in a cruciform frame, are August 6 ; May 3 ; January 11 ; and October 8. Underneath a fleur-de-lys, engraved over the words "Premiers jours du mois," points direct to the figure 8 of the month of October. On each side of the dial centre is engraved an oval border within which, showing through curved slits, are, on the left the age of the moon, and on the right the days of the month; the title of each day is engraved on the plate in each case, and on the right are also allegorical figures to represent the days.

The shafts of the columns already referred to are slit, and each.has a pointer which travels from top to bottom during the

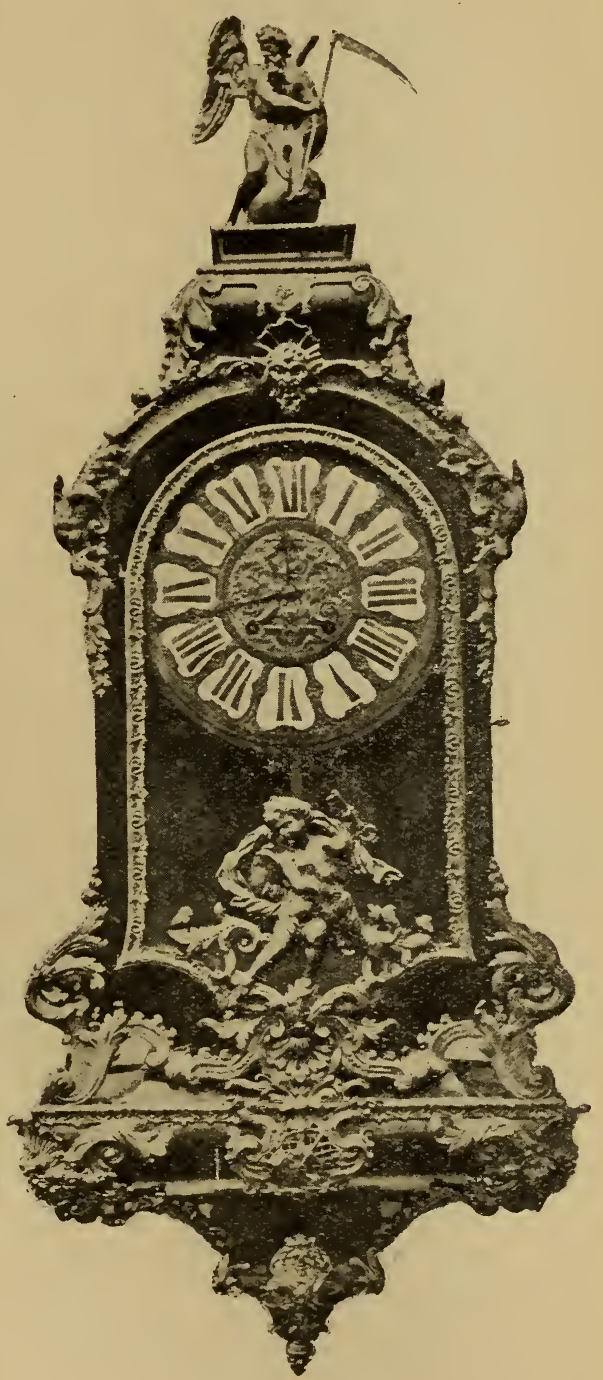

FIG. 554. space of one year. On the plate, beside the left-hand column, at equal distances, are enumerated the months of the year, and on the corre- 
sponding space at the other side are the following twelve annual notes : "Nombre d'or, Cicle solaire, Epacte, Indication romaine, Lettre dominical, Jours de cen-

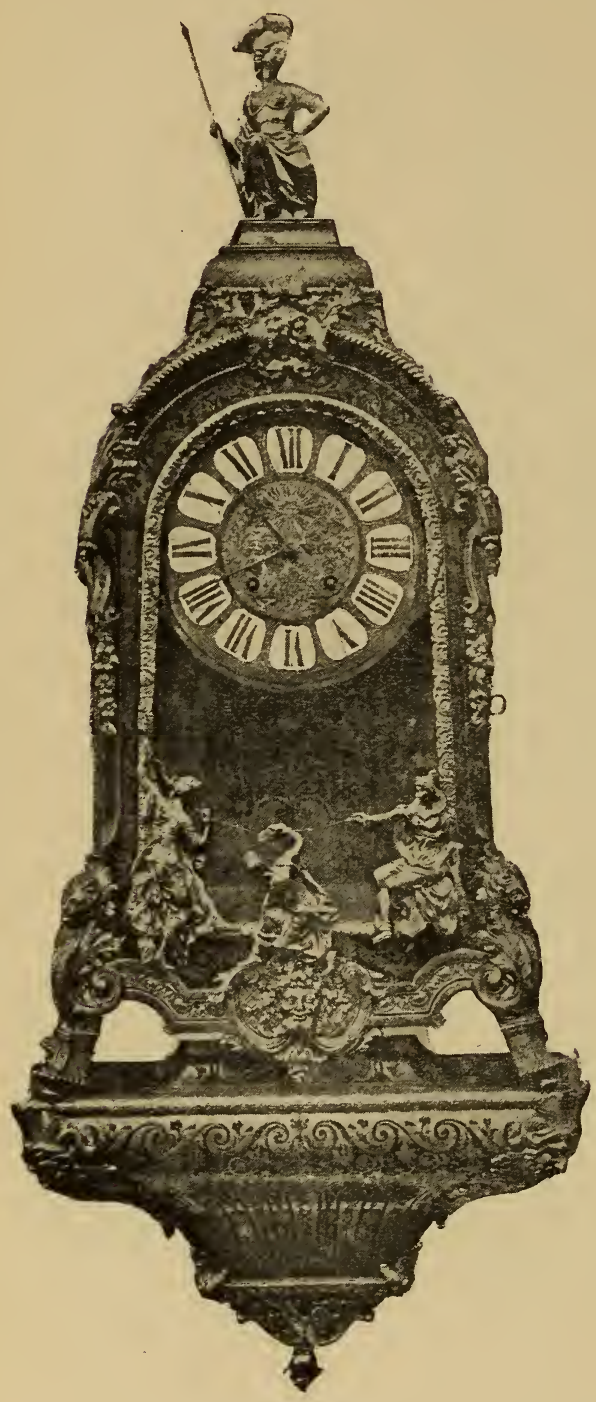

FIG. 555. dres, Pasques, Rogations, Ascencion, Pentecoste, Festes Dieu, Premier Dimanche des Adüents." Below the figure of Saturn are two apertures, and an inscription underneath denotes the purpose to be to indicate the eclipse of the sun and moon.

Pouilly seems to have been a man especially ingenious in devising calendars and the like. $\mathrm{He}$ is referred to in the Paris Directory for 1691 as " Le Sieur Pouilly, of Rue Dauphine, mathematical instrument maker and seller of a peeuliar calendar." In 1692 is mentioned in connection with him an invention relating to the compass and an extraordinary microscope.

Another scientific instrument maker (" ingénieur "), the Sieur Haye, collaborated with Martinot in the production of a movable sphere, which was presented to the king in 1701. Henry Martinot died at Fontainebleau in 1725 at the age of seventynine.

In the corridor at Windsor Castle is the fine long-case clock by. Julien Le Roy illustrated on p. 414. The dial has a brass centre 


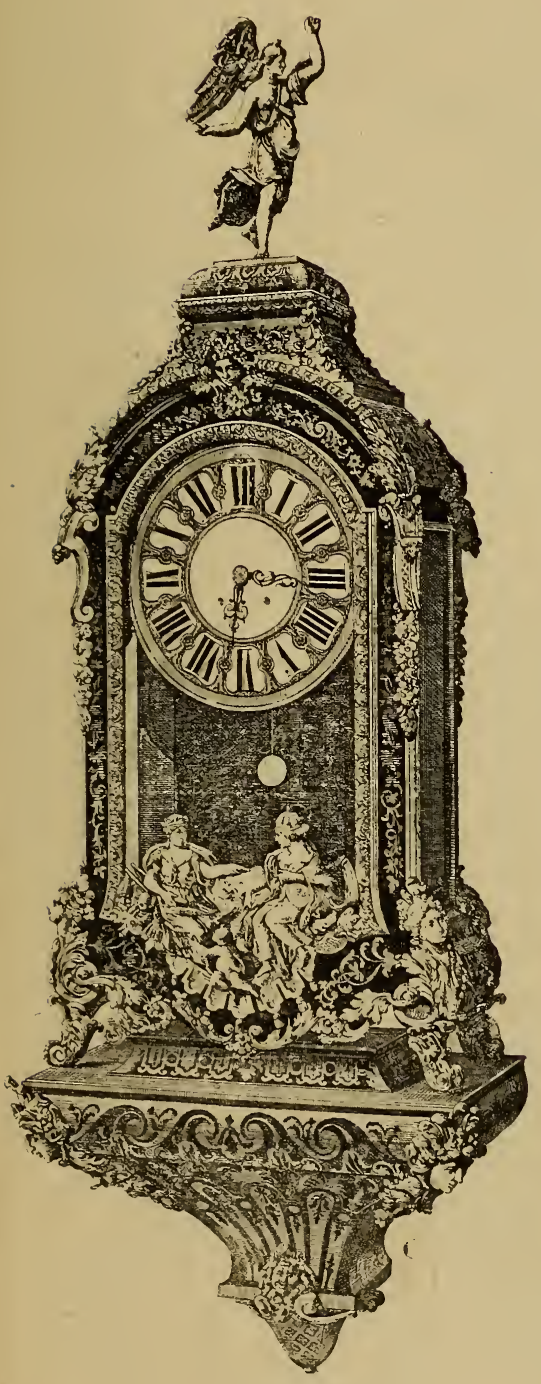

FIG. 556.

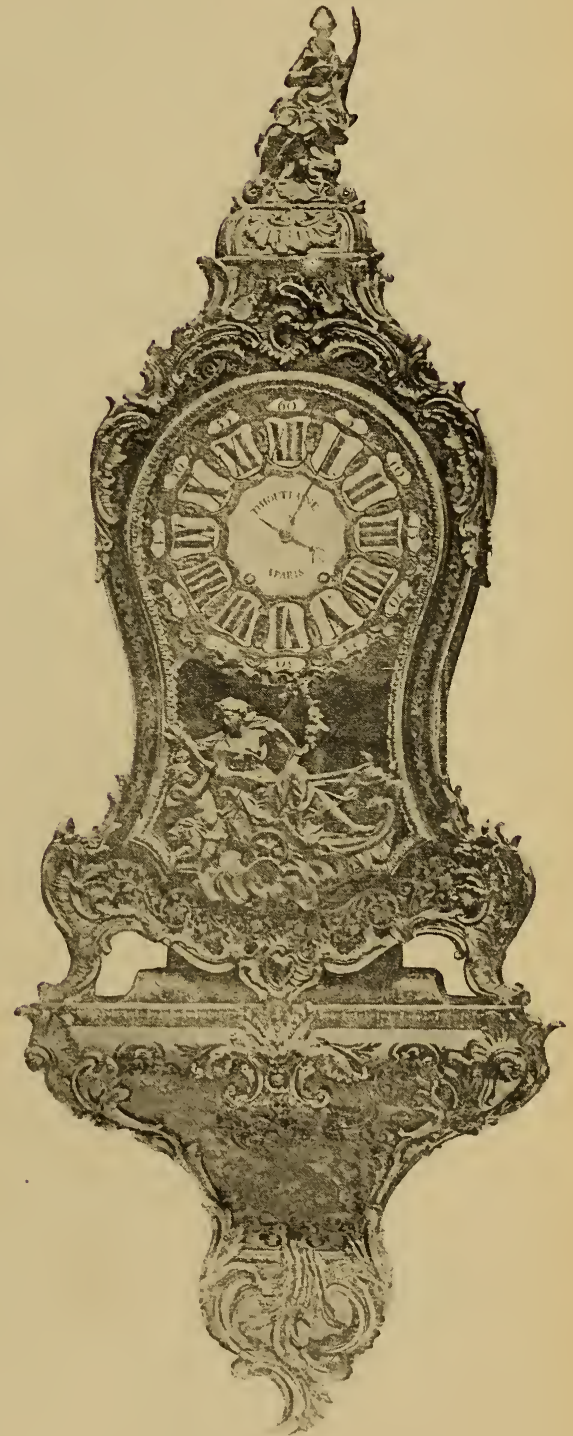

FIG. 557 
424 Old Clocks and Watches and their Makers

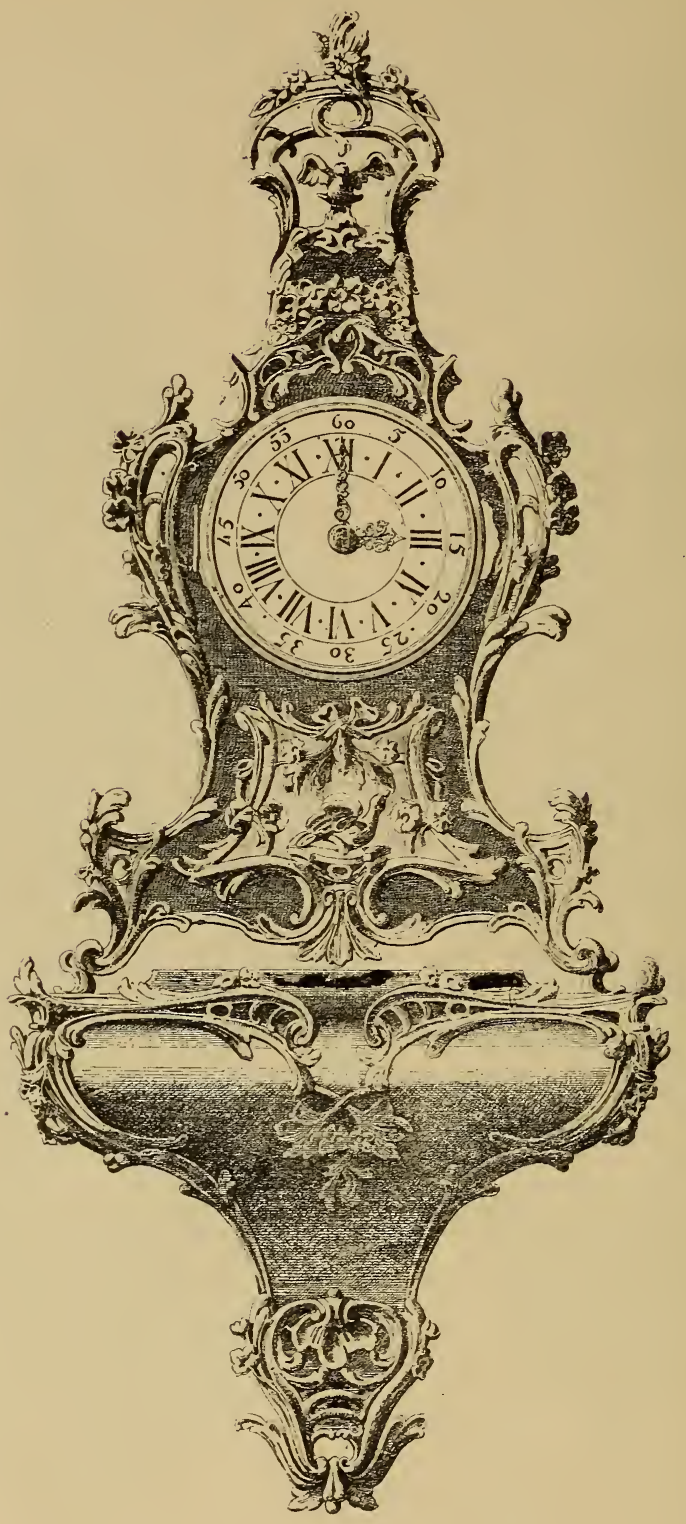

FIG. 558.

with silvered border, and shows solar and mean time and the day of the month. The escapement is a modification of the Graham, 

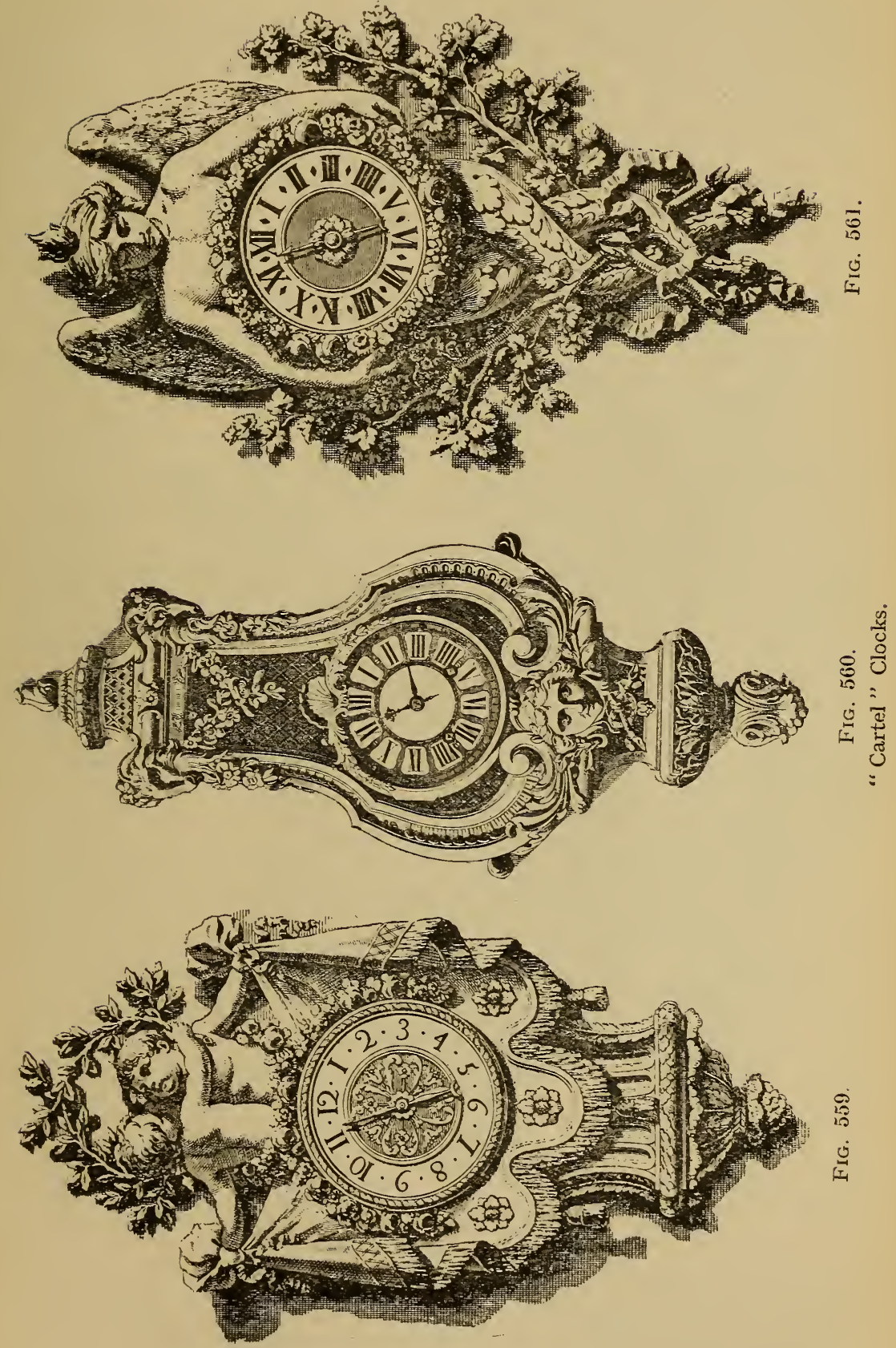
426. Old Clocks and Watches and their Makers

each pallet being pivoted separately. On the dial is inscribed, "Inventé en 1736 par Julien Le Roy, de la Société des Arts."

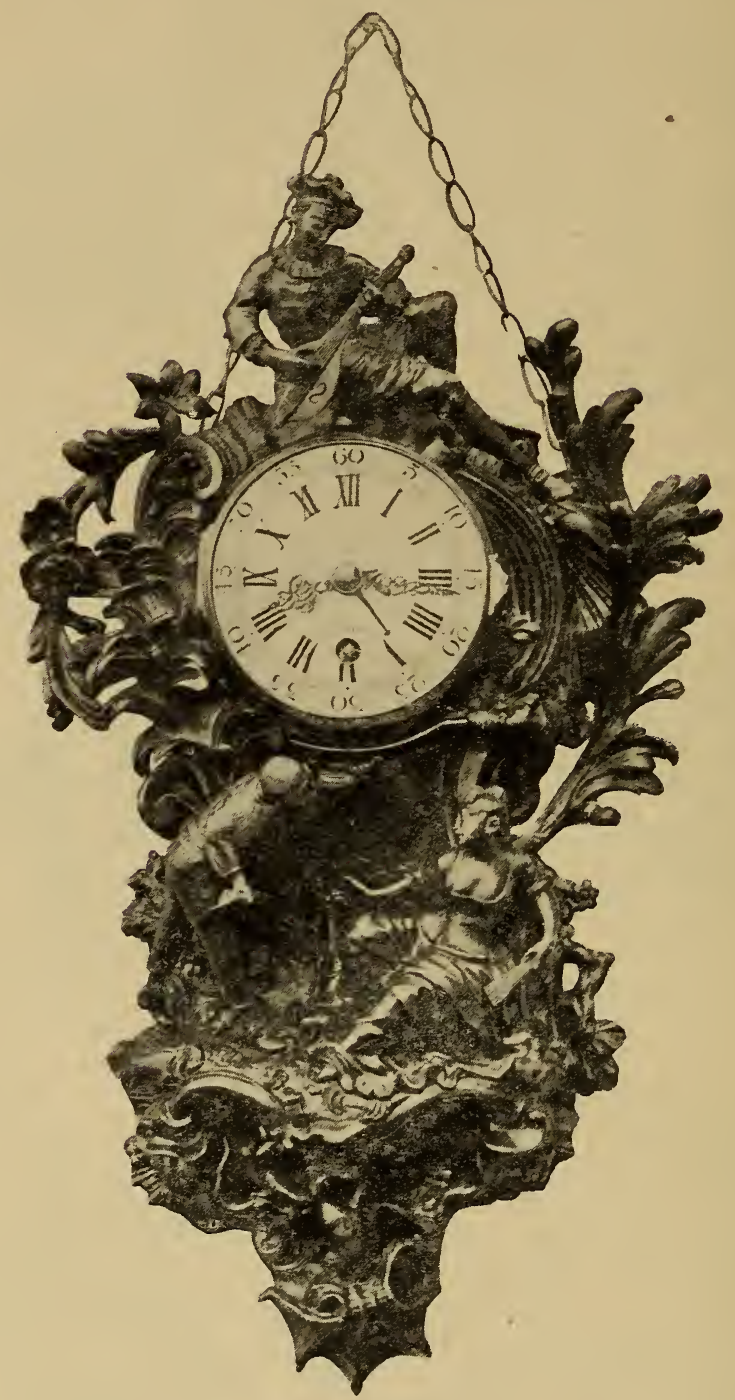

FIG. 562.-A Rccaille Cartel Clock in the Caffieri stıle, about 1760 .

The cașe is of kingwood inlaid with some lighter veneer to an angulated design and carries heavy ormolu well-chased mountings. 
A companion case in the corridor contained a clock by Ferdinand Berthoud, but the movement has been reconstructed by Vulliamy and the dial altered.

On p. 414 is shown a superb twelve-month timepiece by Lepaute, which adorns the Zuccarelli room at Windsor Castle.

The movement is exceedingly well made, and has a very light pin-wheel escapement furnished with pins on one side only. The pendulum beats seconds, and is compensated on Harrison's "gridiron" principle. The dial, of enamel, is very fine, and the lower edge of it bears in tiny characters the signature "G. Merler." Besides the hour and minute indicators, which still exist, there was originally a centre seconds hand and one for showing the equation of time. The month and day of the month appear through a slit in the lower part of the dial. There are no winding holes, the weight being raised on Huygens' flan, by pulling down the rope. The case is of ebony, relieved with exceptionally fine crmolu mountings. The Baroness Burdett Coutts had a similar timepiece, also by Lepaute. Among French artists with wealthy patrons the formal square long-case, so

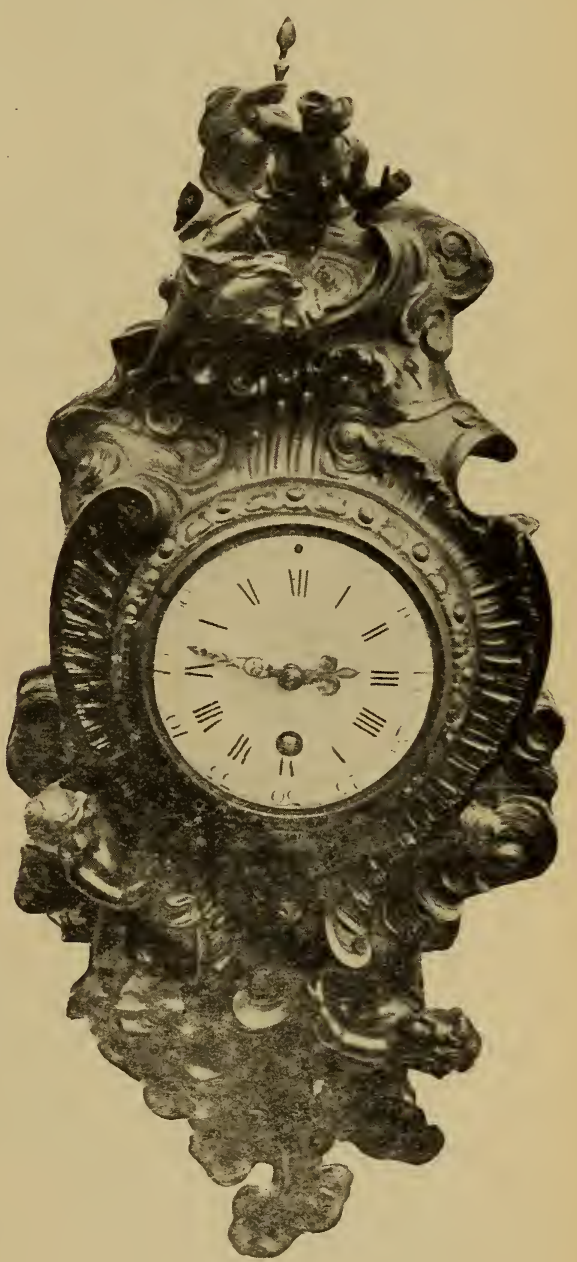

Fig. 563.-Clock of Bronze, Chased and Gilt. characteristic of English clocks, was never liked. As examples of their best style may be quoted the elegant regulator shown in Fig. 547, which is at the Conservatoire des Arts et Métiers, Paris, and the 


\section{Old Clocks and Watches and their Makers}

equally meritorious design on the same page, Fig. 548. Lepaute's clock shown on p. 414, and the more florid design which encloses Julien Le Roy's work, as shown beside it, are also worthy of reference. In the series of bracket clocks, Fig. 549 to Fig. 558, arranged nearly in the order of date, every specimen contains, I think, some feature of excellence.

Hanging or "Cartel" Clocks.-The word Cartel, probably

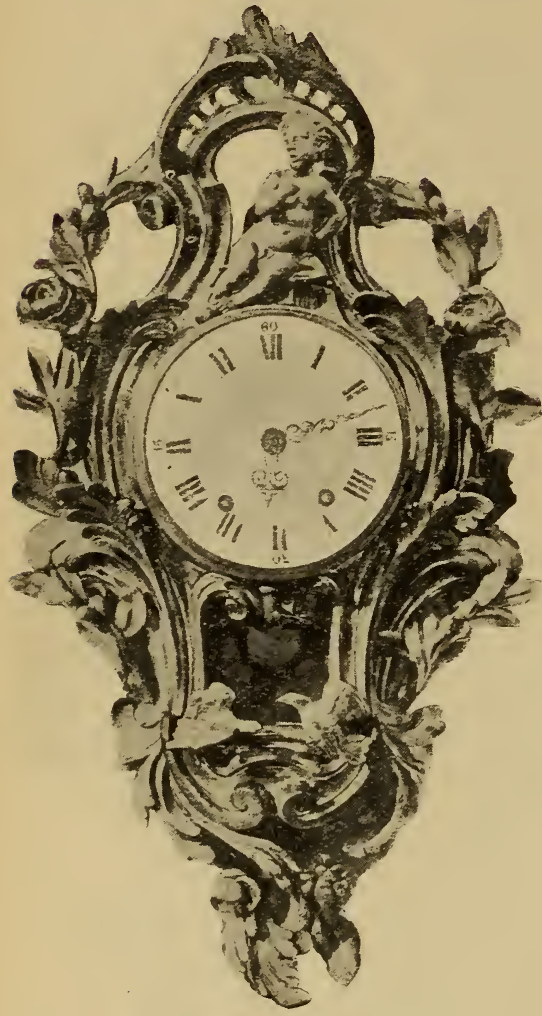

FIG. 564.-Striking Clock.

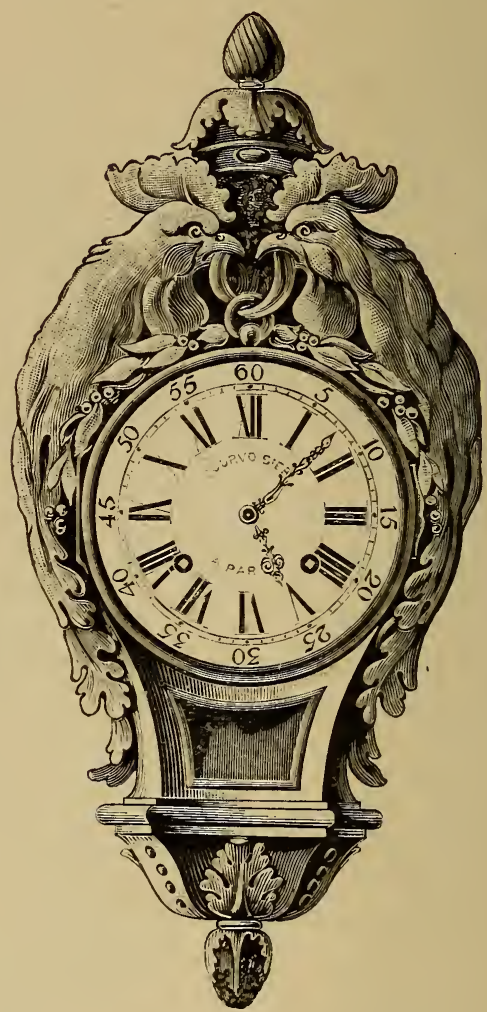

FIg. 565.-Cartel Clock of the Louis XVI. period.

from the Italian Cartela, a bracket, seems, during the seventeenth century, to have been applied to any ornament, frame, or other object fixed against a wall or ceiling and having a shape more or less rotund or oval with elongated or pointed ends. The intense desire for fresh forms in articles of furniture which permeated French society during the latter part of the reign of Louis XIV. led to the production of the "Pendule à Cartel" or " en cartel," a title 

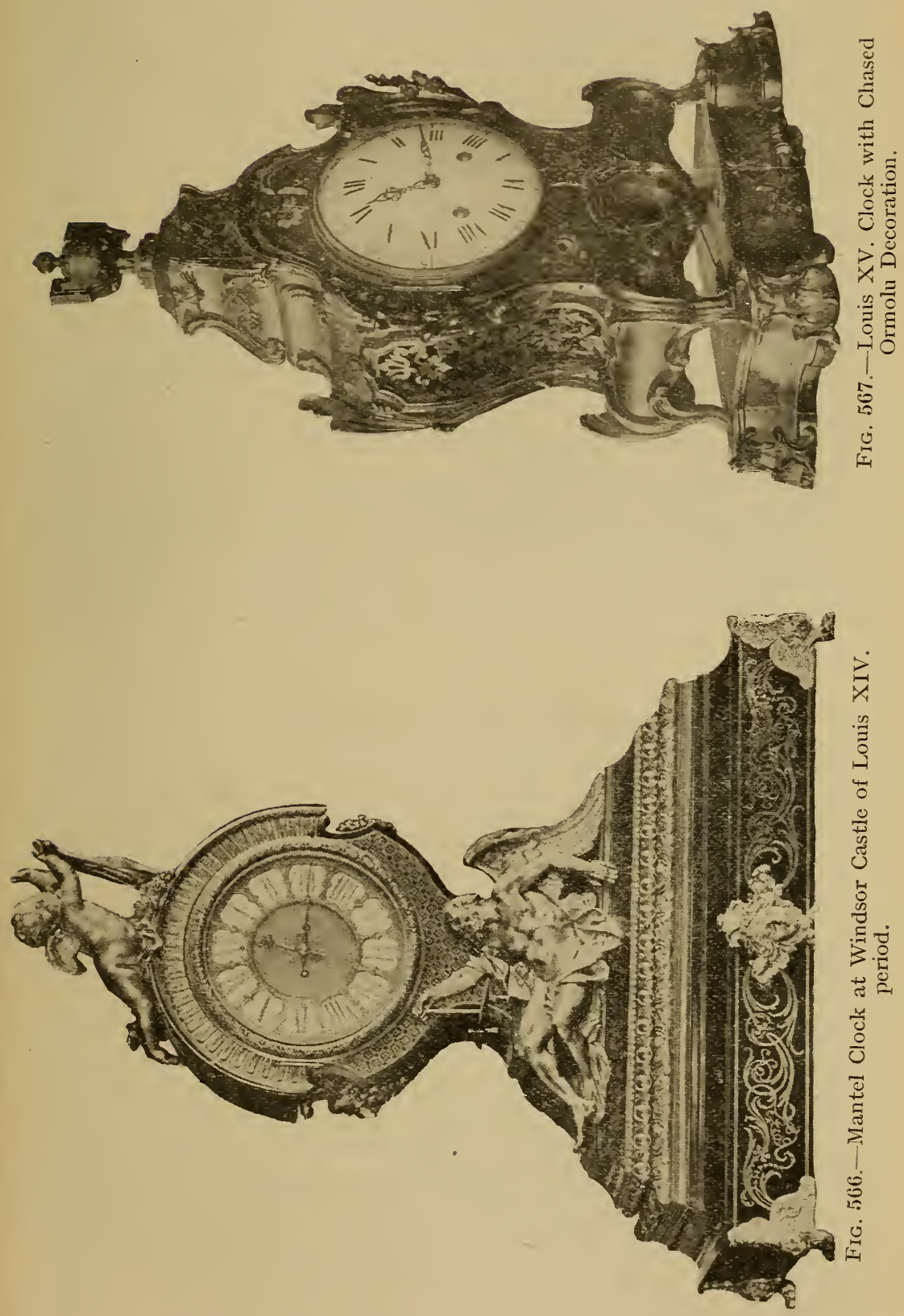
$43^{\circ}$ Old Clocks and Watches and their Makers
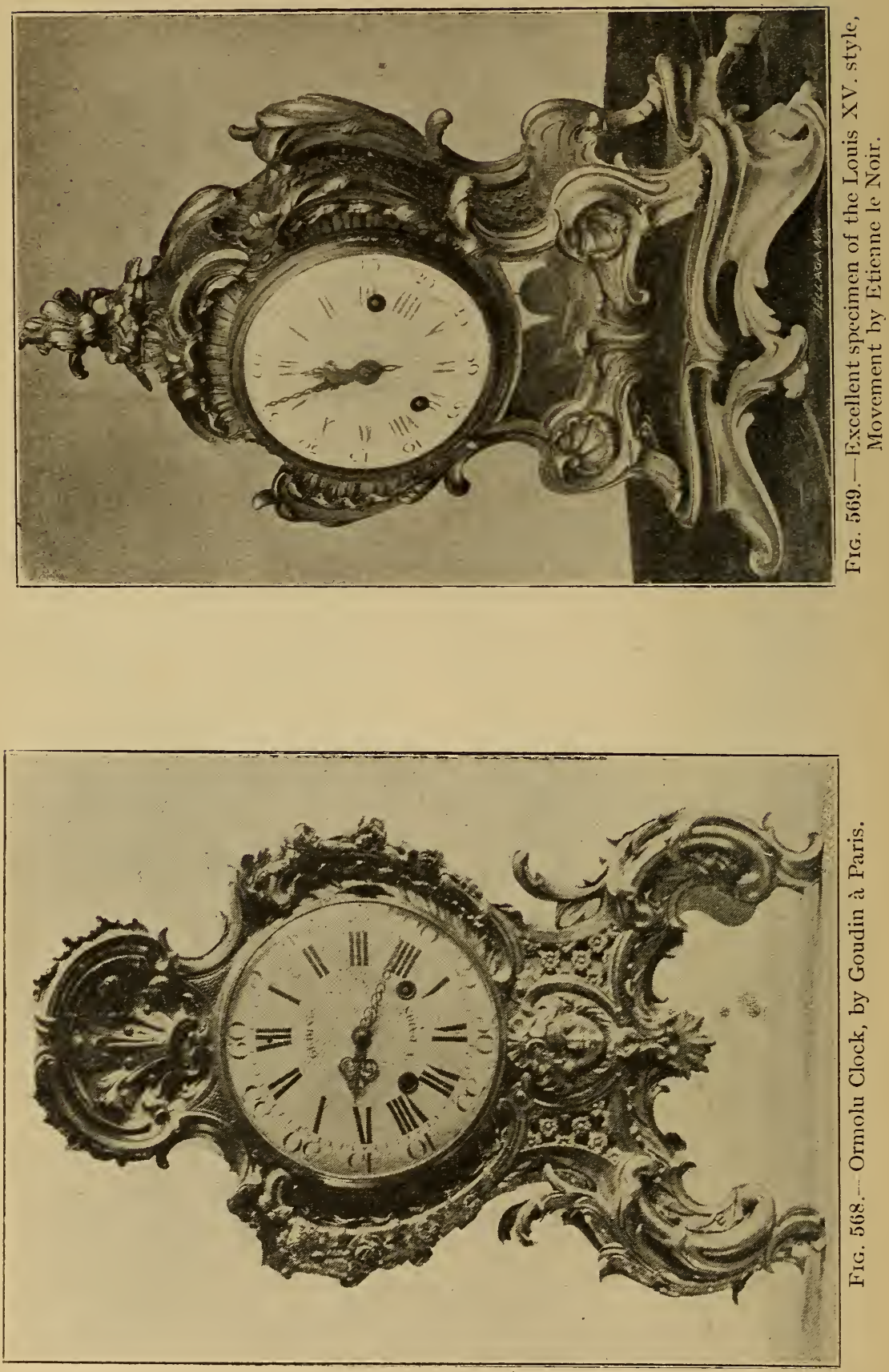
French Clocks and Cases in the French Style 43I
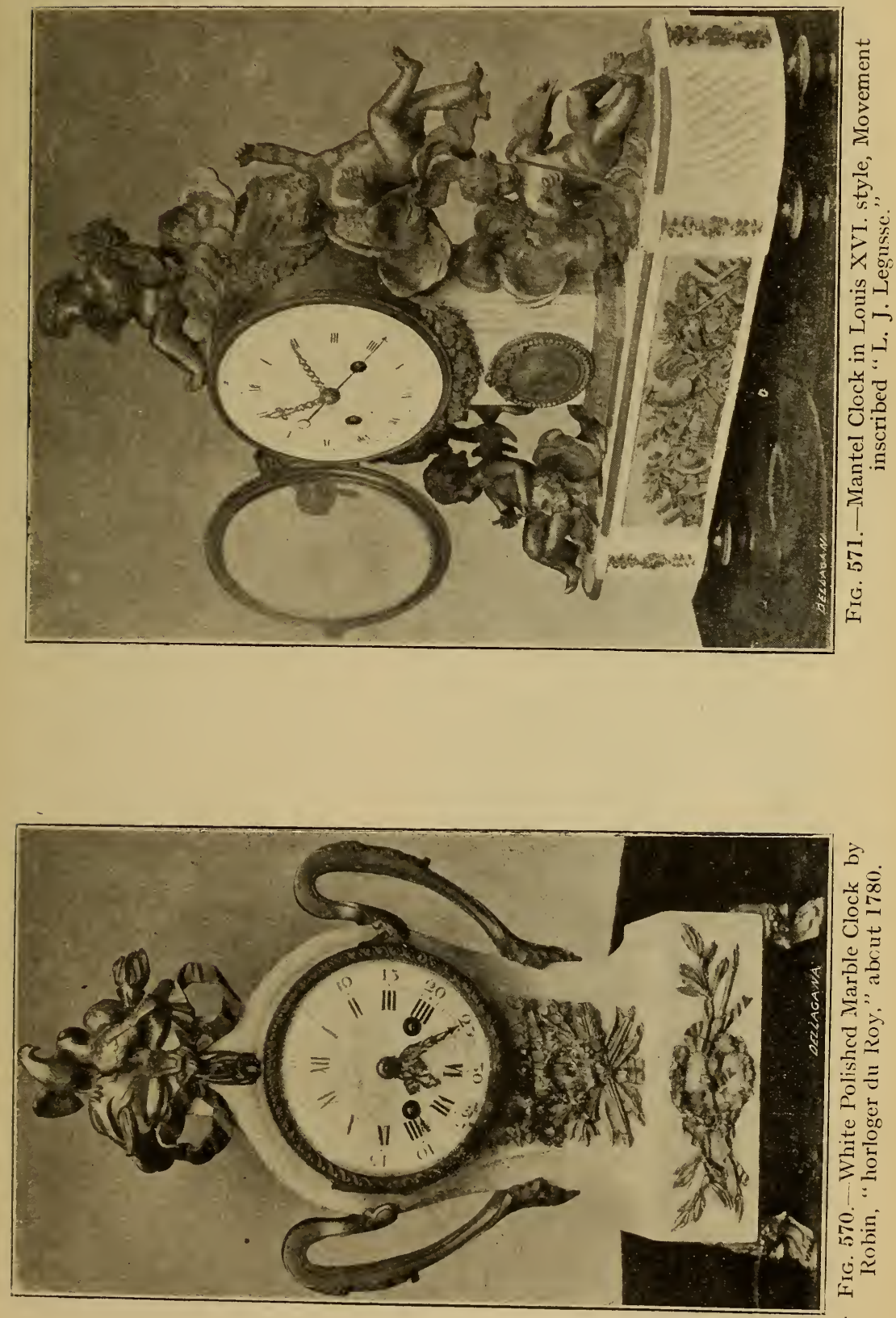


\section{Old Clocks and Watches and their Makers}

subsequently contracted to simply "cartel." The cartel cases were made occasionally of wood,

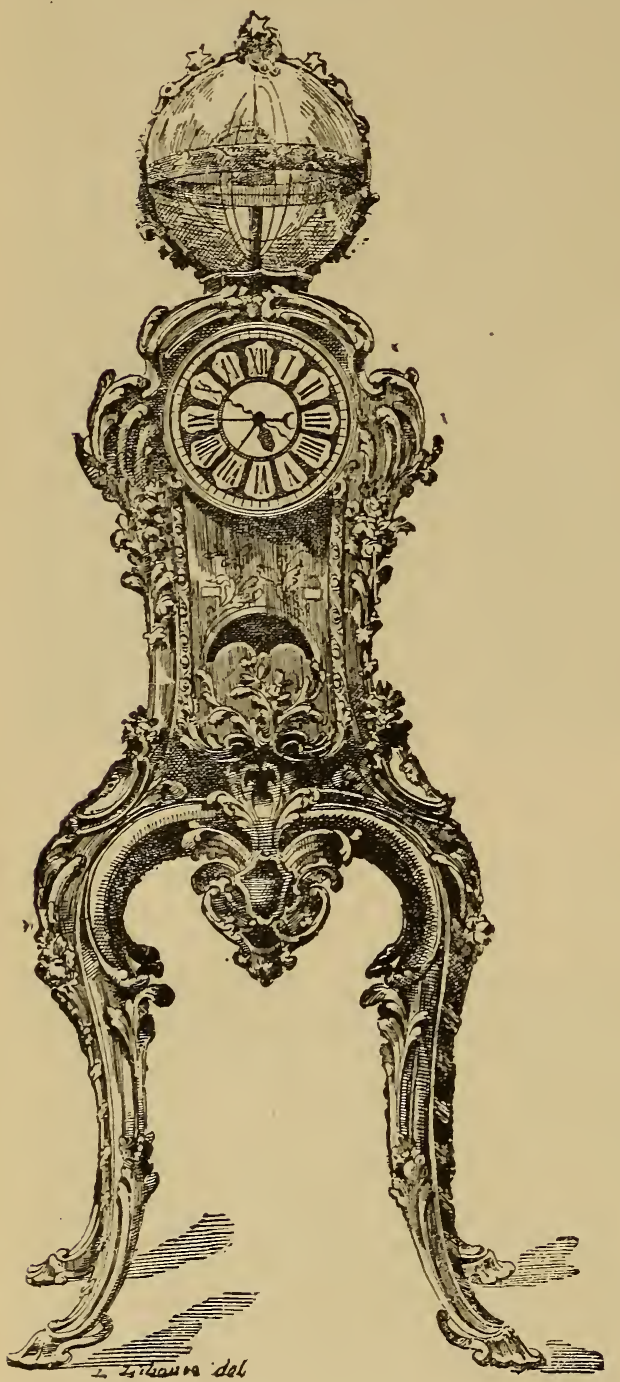

FIG. 572.-Astronomical Clock, by Passement at Versailles.

Havard, "Dictionnaire de l'Ameublement." lead, or zinc, but more often of bronze, thickly gilt. As may be gathered from the examples I am able to illustrate, they were, as a rule, graceful in torm and, when oxidation had toned down the somewhat obtrusive garishness of the gilding, of very pleasing appearance.

Small clocks of the same shape and of a size to be easily fastened on the inside of the bed curtain, were designated Cartels de Chevet. They were generally furnished with watch movements, the cases being of brass or of wood with Vernis Martin or other decoration, though large cartel clocks with pull strings for repeating were occasionally placed inside the bed against the hangings or wall, for the convenience of those French ladies who, in accordance with accepted custom during the earlier half of the eighteenth century, held receptions while reclining on their beds.

In Fig. 560 is shown a mural clock of Louis XIV. period by J. Thuret, Paris, which belonged to the Marquis of Hertford. The panels are filled with Boulle work which sets off 
and subdues the ormolu mountings. Side by side with it are two nearly contemporary designs.

Cartel time pieces were in especial favour throughout the time of Louis XV. A representation is given in Fig. 562 of a Rocailie cartel clock in the Caffieri style dating from about 1760. It is of mediun size, measuring $2 \mathrm{ft}$. in length and $14 \mathrm{in}$. across the widest part. The movement is by Courtois, clockmaker to Louis XV., who had premises in the Rue Saint Jacques, facing the Collège du Plessis, and acquired a reputation for the excellence of his movements, both silent and musical. There is a pull string for repeating on two bells; it strikes the hours and-half hours, also an alarm. The case of bronze gilded is boldly chased, and the modelling of the figures is exceedingly good. Pierrot and Pierette appear to enjoy life among fantastical vegetation and scrolls, so popular during the epoch of Louis $\mathrm{XV}$. The mandoline player at the top is

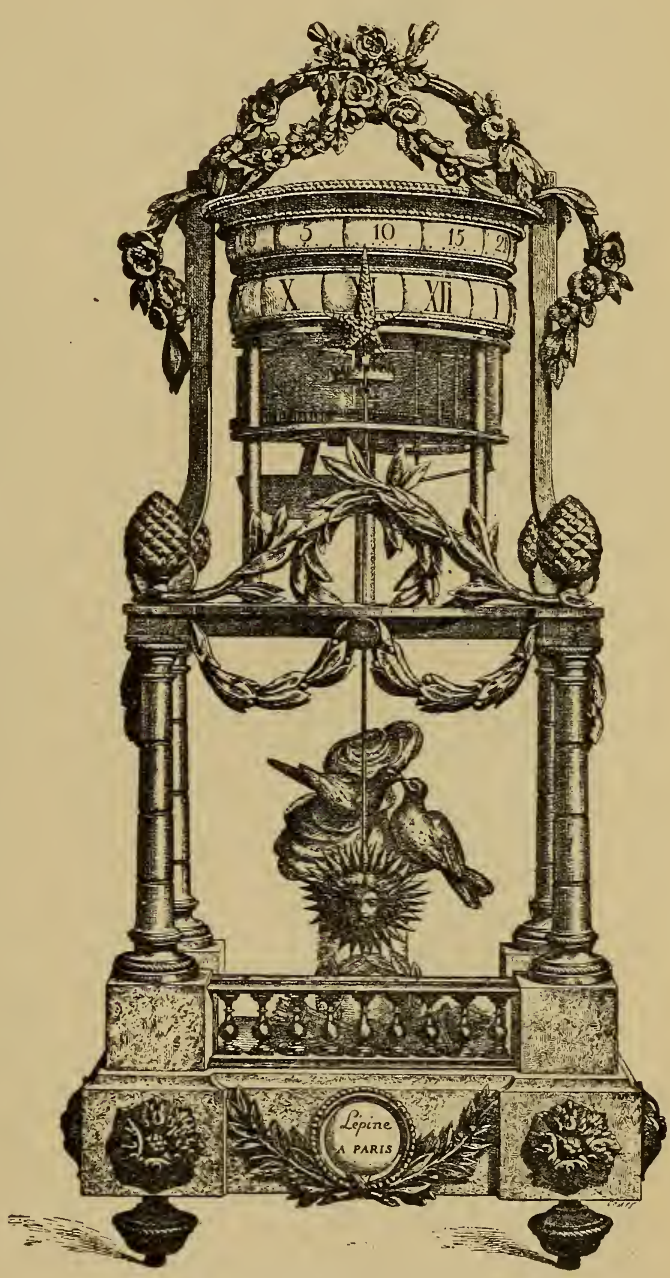

FIG. 573.-Curious timekeeper by Lépine. well posed and of pleasing expression. Hardly so large and of perhaps ten years later date is another specimen, also of bronze, chased, and gilt, which is shown in Fig. 563. Below the dial is an aperture through which 
434 Old Clocks and Watches and their Makers

the vibrations of the pendulum may be seen, and the design includes a female figure and cupids, subjects brought into favour by Boucher

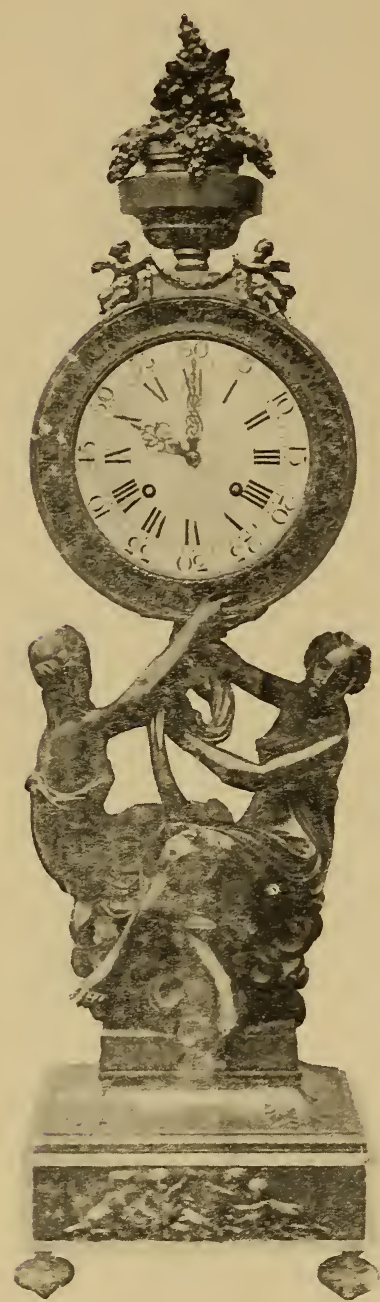

FIG. 574.

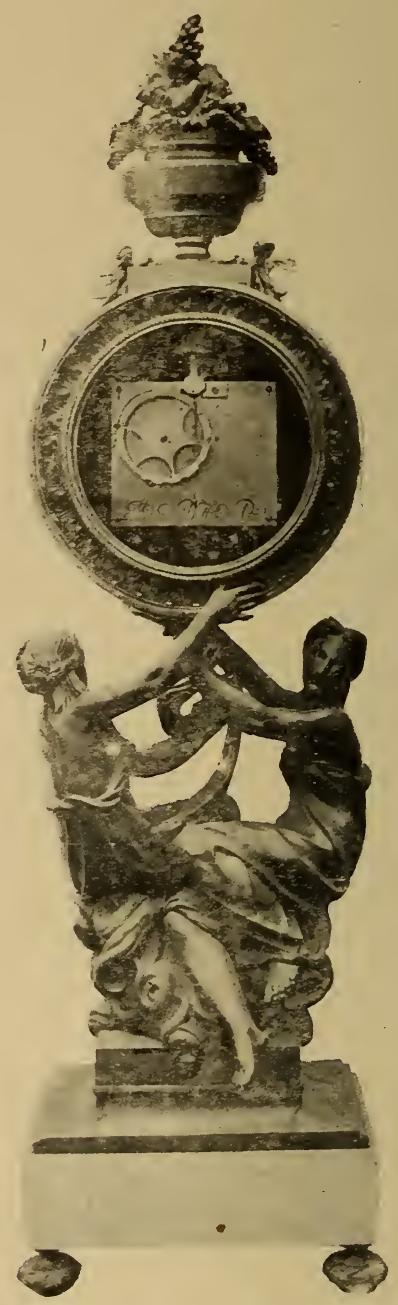

FIG. 575 .

Front and back view of Mantel Clock, by Ferdinand Berthoud.

and his school. The detail of the chasing is finer than was usual with an object to be exhibited on a wall at some distance from the eye. Dial and movement bear the signature of "Thiout l'aîné, Paris." 
There are two bells and a pull string for repeating on them the hours and quarters at pleasure.

Fig. 564, a smaller striking clock of later date, indicates the decline of the more extravagant features observed in some of the Rocaille designs.

An excellent cartel clock of the Louis XVI. period, which belongs to the Hon. Gerald Ponsonby, is shown in Fig. 565.

I may mention that the movements of old cartel clocks are inserted into the case from the front. Ignorance of this has, I know, sometimes led to damage by attempts to force the movements out at the back.

Mantel Clocks before the time of Louis XV. are exceptional. When not supported by a long case or a pedestal or a bracket, chamber clocks were hung to a nail on the wall. An early mantel clock, which is in the Octagon room at Windsor Castle, is shown in Fig. 566. The case is decorated with Boulle work and very fine ormolu mountings. A well-modelled Cupid surmounts the structure and below the dial is an equally effective reclining figure of Time holding a balance. Except the base, which is of later date, this splendid clock is of Louis XIV. period. Base and clock together are $3 \mathrm{ft}$. high.

The choice Louis XV. clock on a stand with Vernis-Martin and chased ormolu decoration as shown in Fig. 567 belongs to the Comte de Lambilly. A characteristic example of design in the Louis XV. style is the ormolu clock by "Gudin à Paris " at Windsor Castle, and shown in Fig. 568. The chasing is bold, though somewhat coarse. The pierced diaper work below the dial is backed with crimson silk with good effect.

Another excellent specimen of the Louis XV. style is the drawingroom clock represented in Fig. 569. The movement is by Etienne le Noir, a noted clockmaker of the time, while the chasing has been executed by Saint Germain, who also probably did the casting of the model. Saint Germain was one of the small number of founders and chasers of the period whose productions were characterised by remarkable excellence of finish and lightness. He was frequently employed by, or on behalf of, the king and the court. His productions bear his full name, punched in the metal. The crafts of founder and chaser were nearly always combined, forming an exception to the rule then prevailing as to regulation of trades by corporations or companies.

No better example of the Louis XVI. period could be selected than the chaste and elegant boudoir or ante-room clock shown in 
436 Old Clocks and Watches and their Makers

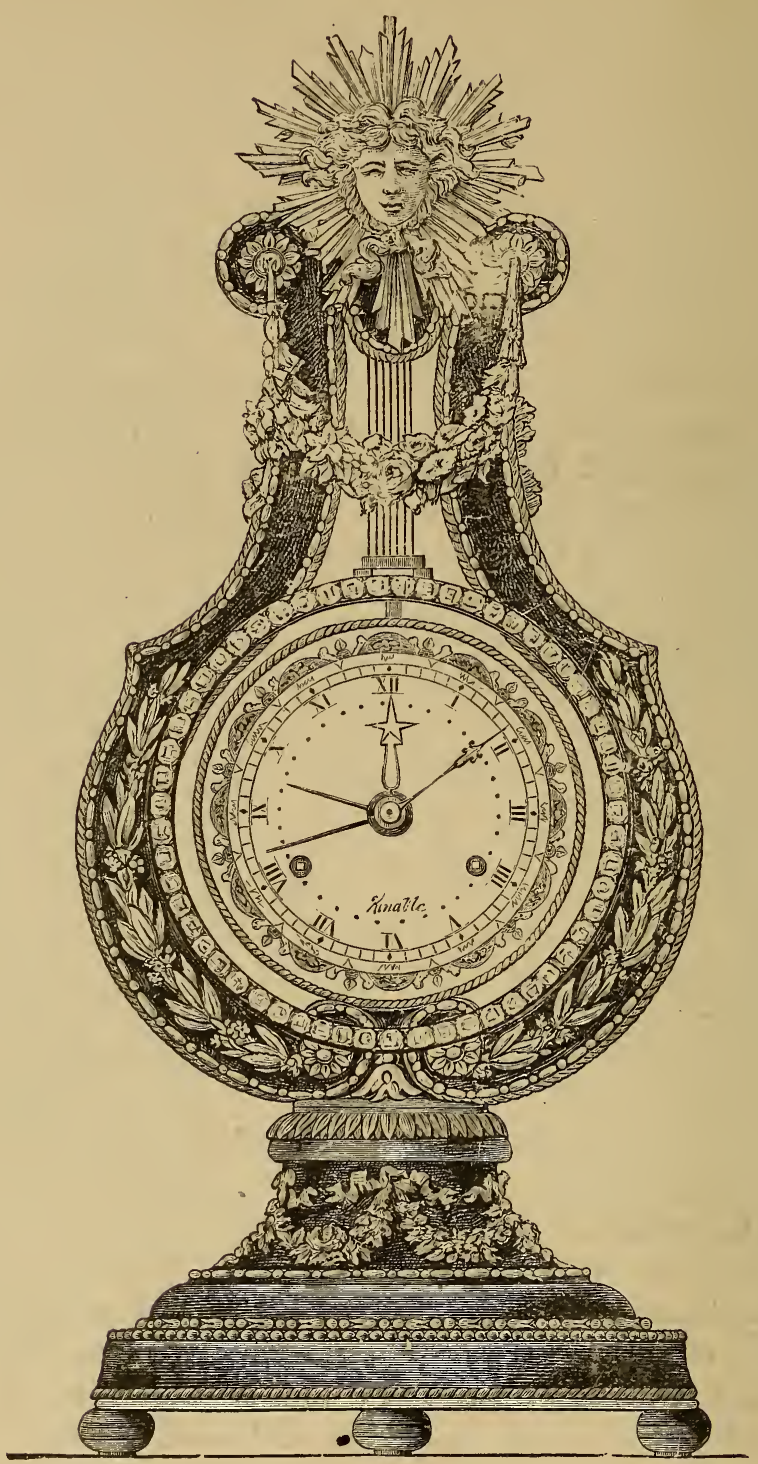

FIG. 576.-Lyre Clock, Sèvres.

Fig. 570. It is of white polished marble, which age has tinted to a dark cream, with gilt mountings, the contrast harmonising perfectly. It dates from about 1780 and is by Robin, " horloger du Roy." 
French Clocks and Cases in the French Style
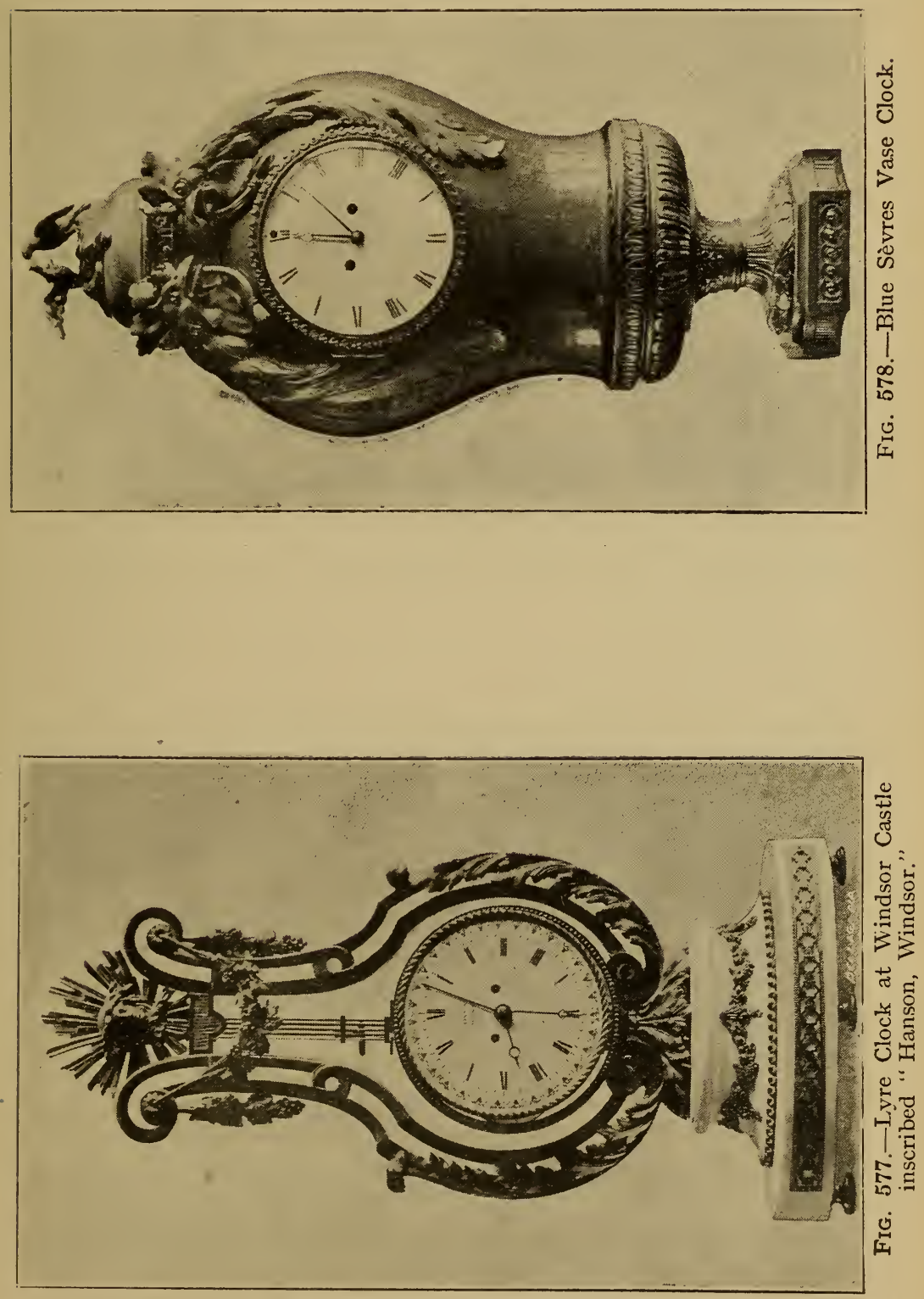
438 Old Clocks and Watches and their Maker's

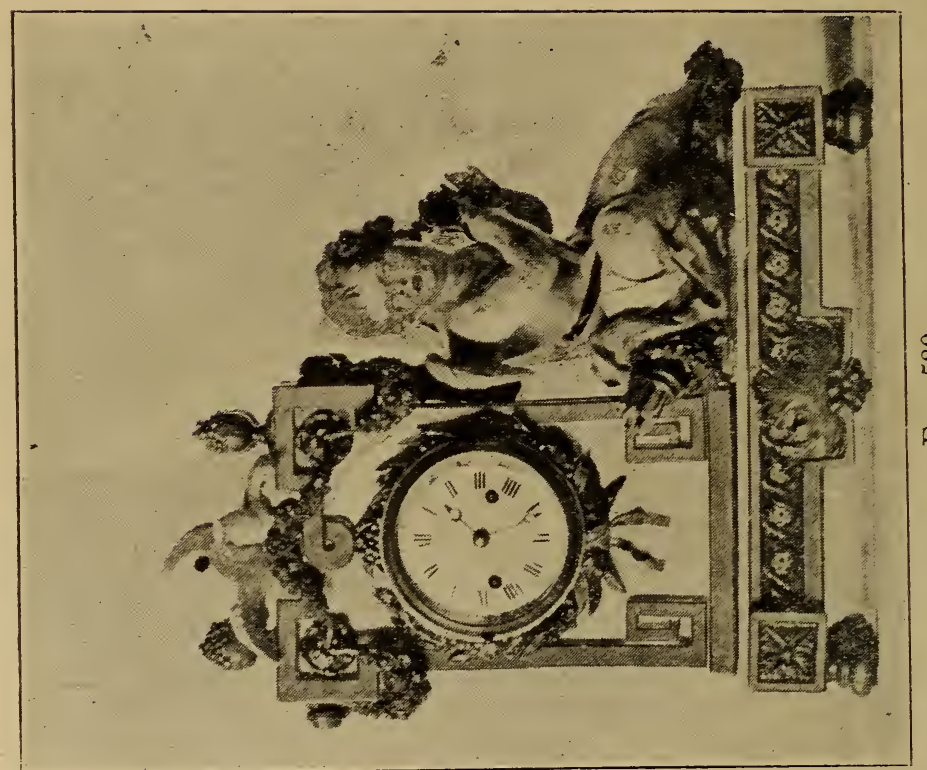

$\dot{8}$
$\infty$
20
0
0

|

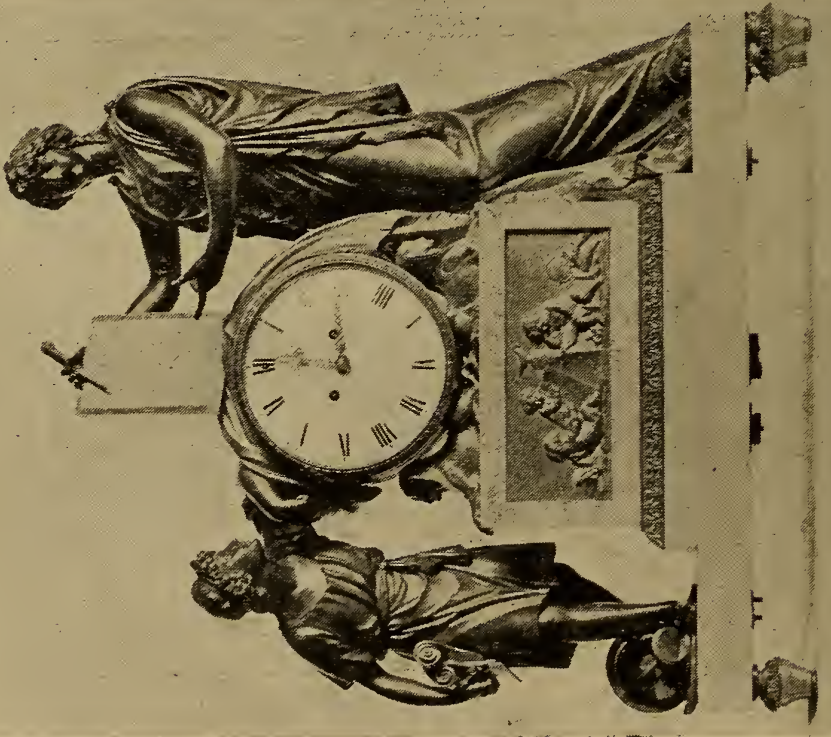

$\stackrel{0}{5}$
$\stackrel{5}{0}$
0
0 
French Clocks and Cases in the French Style 439
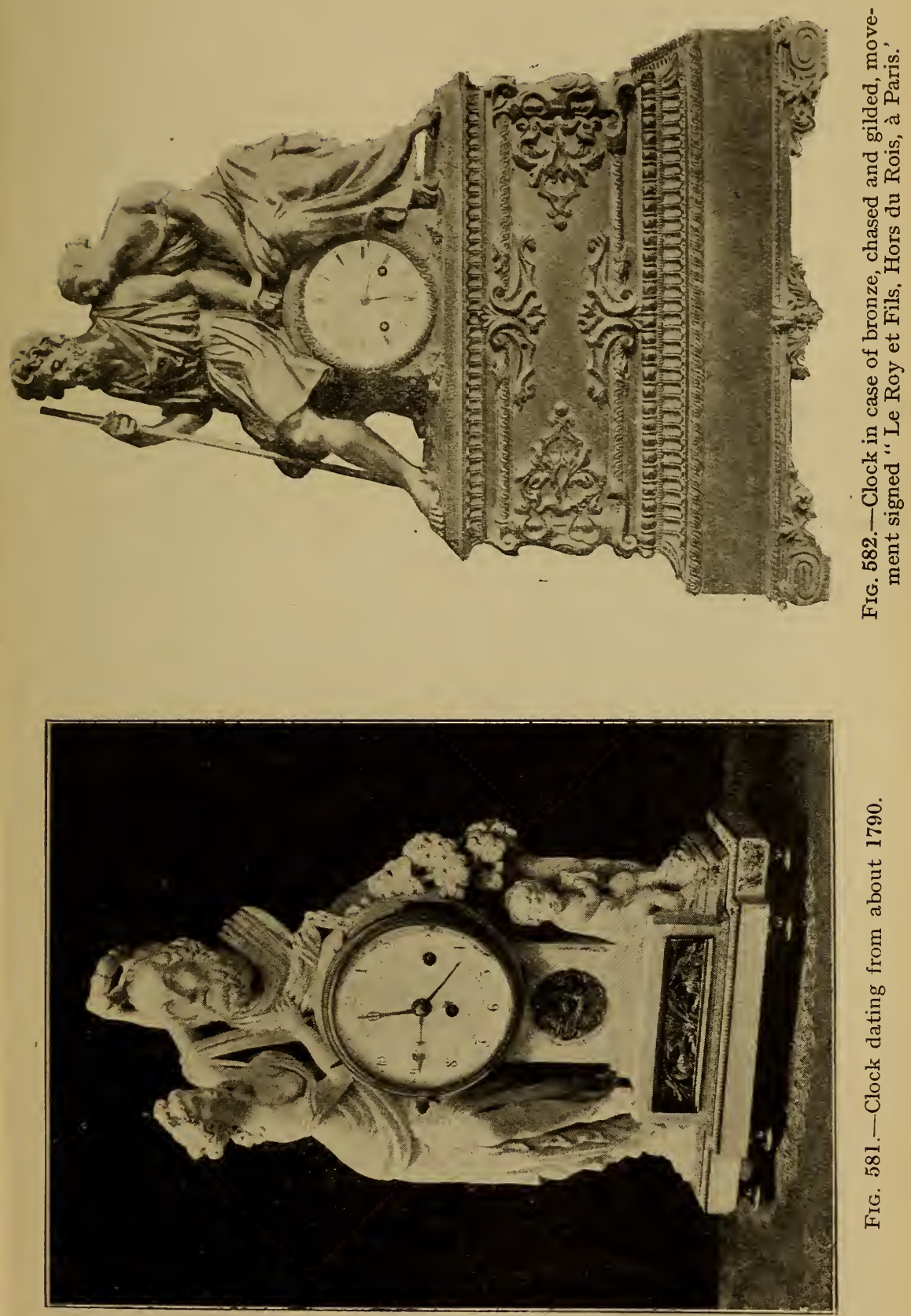


\section{Old Clocks and Watches and their Makers}

The splendid mantel clock shown in Fig. 571 in the Louis XVI. style is perhaps of a little later date, and well represents decorative art during the last few years of the reign of that monarch. The beautifully modelled cupids representing sculpture (adjacent to a completed bust of Henri IV. of Navarre), music, dancing (or singing), and painting appear to be nestling in clouds around a celestial sphere

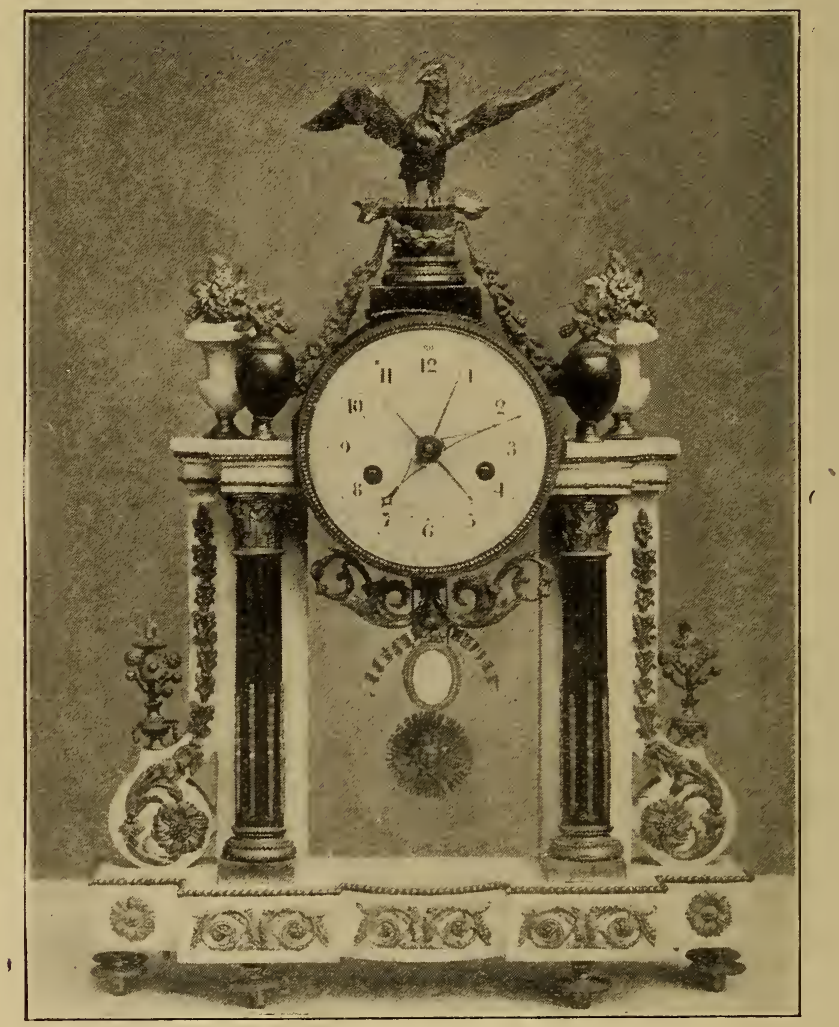

Fig. 583.-Clock, by Engaz, of Paris.

in which the dial is placed. The base of white marble with rounded ends contains a gilt frieze of trophies. It is $17 \frac{1}{2}$ in. in length and 18 in. high. The movement is inscribed " L. J. Leguesse." The gilding and chasing are excellent, the minutest details of the bronze work being brought out in the style of a master artist. Here, as in the last example, the association of white marble and bronze produces a most pleasing effect. These two clocks are from the Schloss collection. 


\section{French Clocks and Cases in the French Style 44I}

Fig. 572 shows a celebrated clock invented by Passement and constructed under his direction by Dauthiau, clockmaker to Louis XV. Passement is said to have been engaged for twenty years in calculating the various movements, and the construction of the machine occupied Dauthiau for twelve years. It was completed in 1749, and in 1750 presented to the king, who ordered a new case for it, after

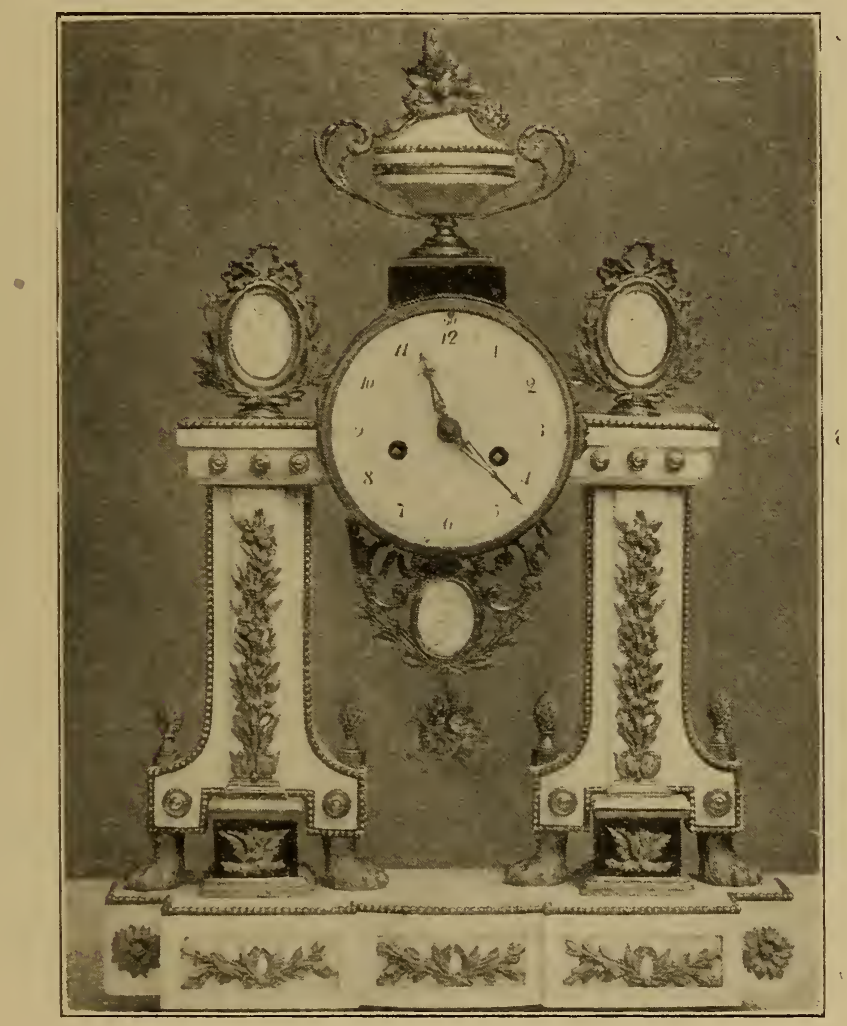

FIG. 584.-Clock, by La Crcix, Paris.

his own choice. This was made by Messrs. Caffieri (father and son), and when finished in 1753, the clock was deposited at Versailles. It lias a dead-beat escapement and a seconds compensation pendulum ; indicates solar and mean time, has a seconds hand, strikes the hours and quarters, and has provision for repeating at pleasure the blows last sounded. The striking part is driven by a spring, and the remainder by a weight of 22 lbs., doubly suspended, which falls 8 in. 


\section{Old Clocks and Watches and their Makers}

in six weeks. Within a glass sphere over the clock are marked the age and phases of the moon, days of the week, month, and year correctly for a period of 10,000 years. Antide Janvier repaired the clock for the First Consul.

As a curiosity in design, the timekeeper by Lepine, shown in Fig. 573, is worthy of record. Hours and minutes are indicated on two bands rotating horizontally, and there is a long pendulum which terminates very effertively in a representation of the face of Phœbus.

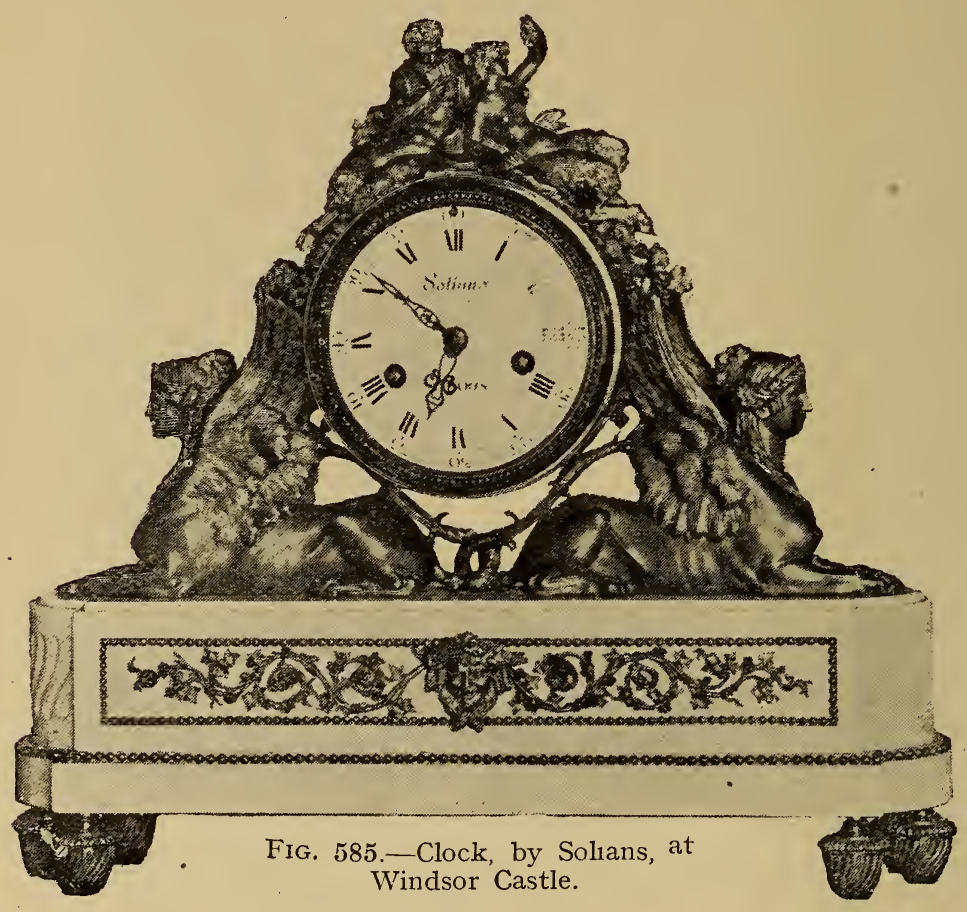

Front and back views of a most effective mantel clock by Ferdinand Berthoud are given in Figs. 574 and 575. The design as a whole is. excellent ; the primary object of a clock is to indicate the time, and this point, which seems to have been too often ignored, has here been properly kept in view, and the elegant supporters in no way detract from the due prominence of the dial which measures $9 \mathrm{in}$. across, the whole structure being $3 \mathrm{ft} .8 \mathrm{in}$, in height. The plinth is of white marble, with bas-reliefs of cupids struggling for vines; the Bacchantes are of dark-coloured bronze; the vase with overhanging 
French Clocks and Cases in the French Style 443

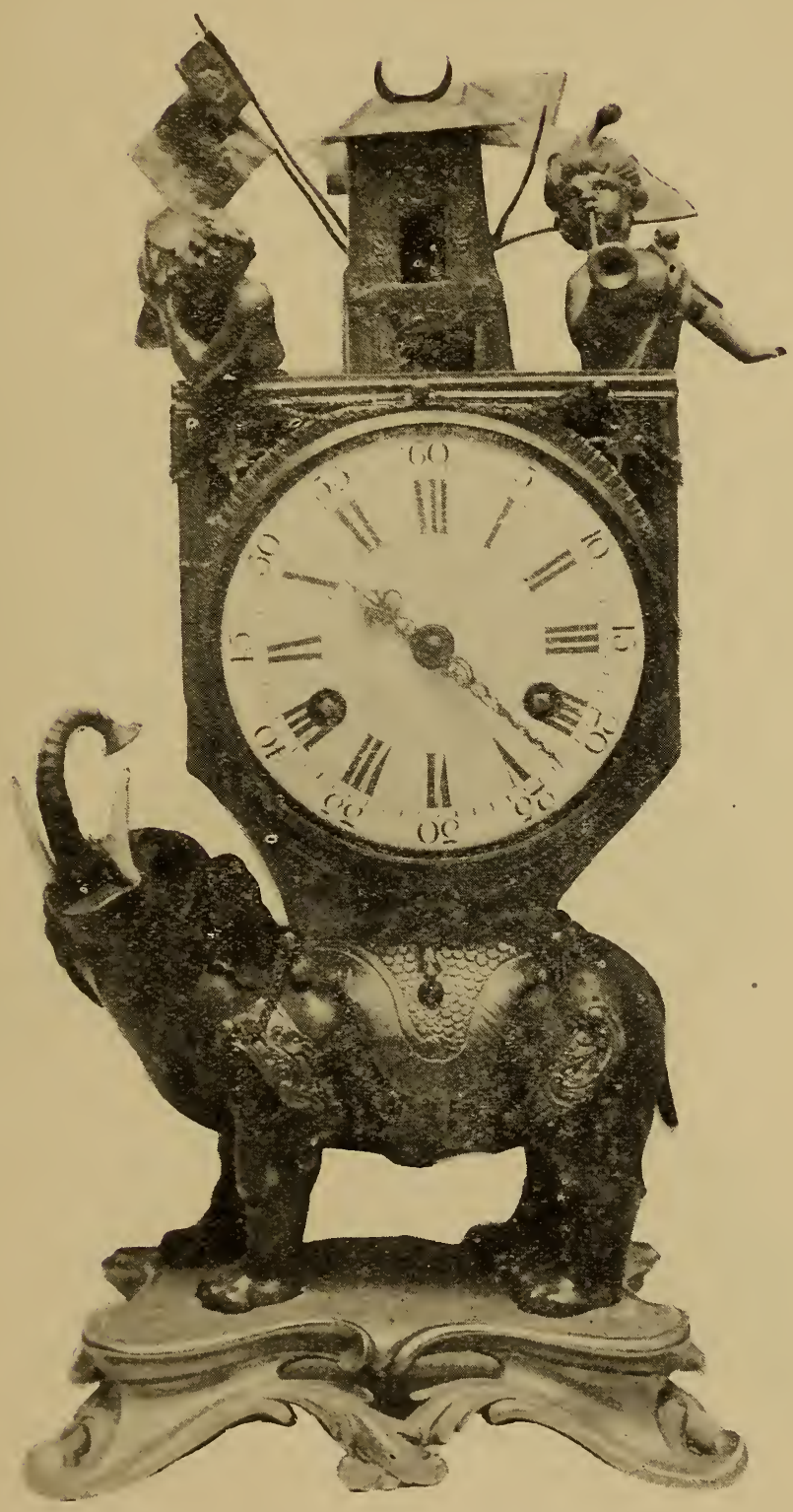

Fig. 586.-Clock, by Bailly l'aîné, Paris, about 1769 . 


\section{Old Clocks and Watches and their Makers}

leaves and grapes which surmounts the dial is gilded. Thus a charming combination of colour is obtained quite worthy of the

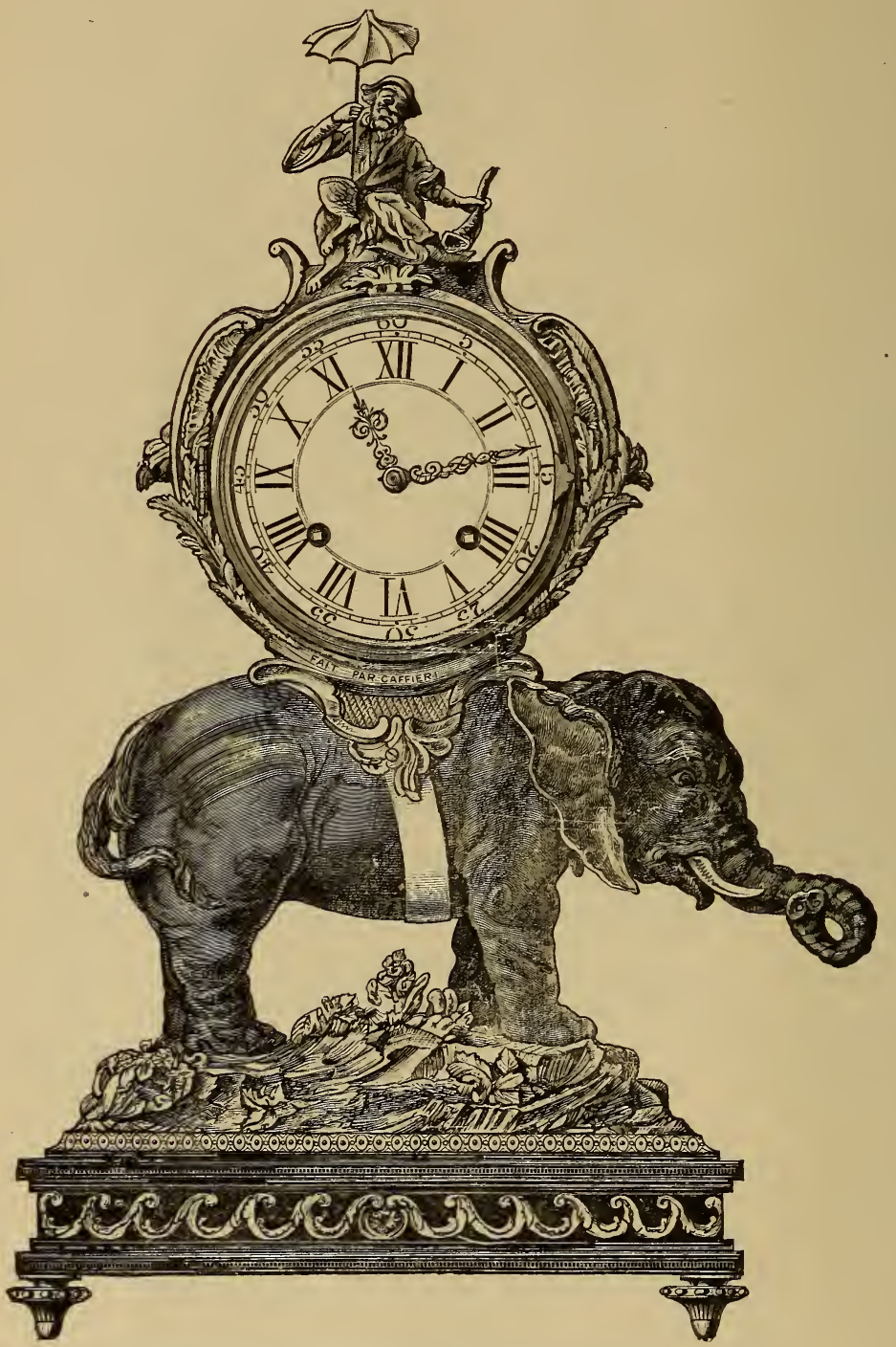

FIG. 587.-Clock at South Kensington Museum

modelling and chasing, which are admirable. The design altogether is a good example of the return to simpler and more reposeful forms 


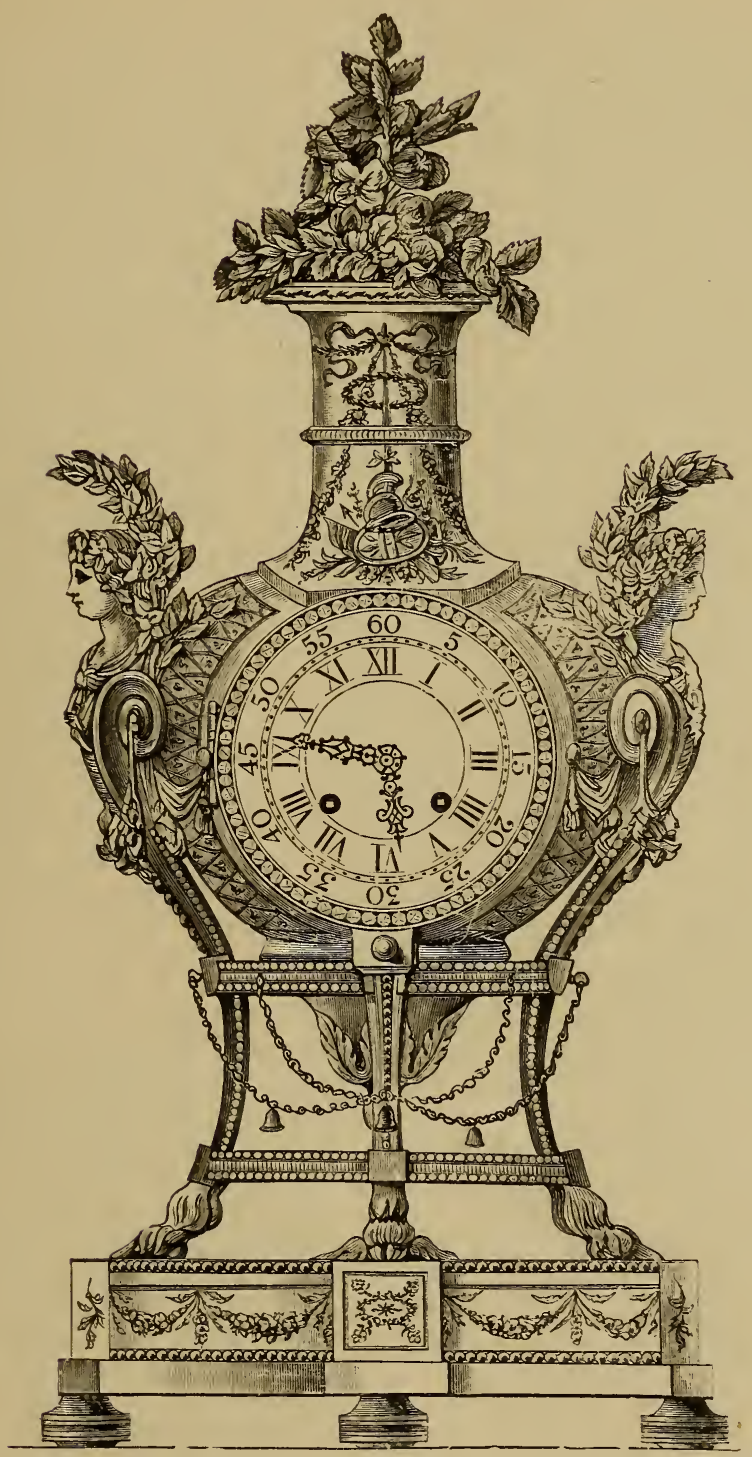

FIG. 588.-Porcelain Case with Mounts, by Gouthière.

suggested by Clodion and his school, in place of the overdone and discredited Rocaille. On the chased work is a punch mark corresponding to $\mathrm{P}$. C., which may possibly be that of Pierre 


\section{Old Clocks and Watches and their Makers}

Cauvet, a celebrated modeller under Louis XVI., several of whose productions are in the collection of Garde Meuble at the Louvre.

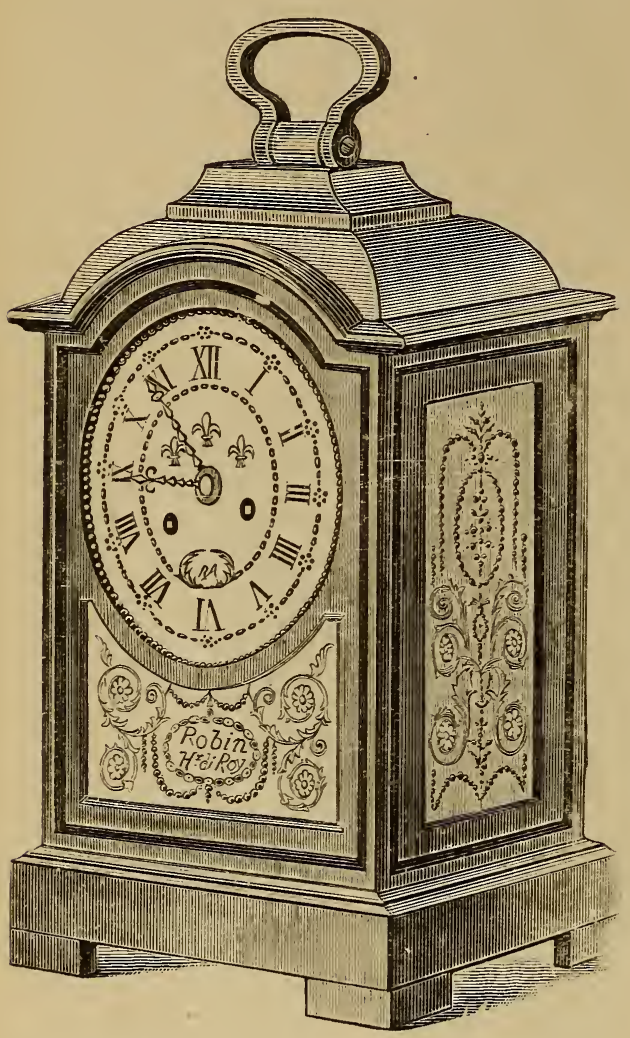

Lyre-shaped exteriors were, it must be confessed, among the most elegant conceptions of the Louis XVI. period. From the example illustrated in Fig. 576, it will be seen that the upper part of the pendulum is formed to represent the strings of the instrument; the lower end, shaped as a ring, passes and repasses behind the dial with very pleasing effect. This clock, which in among the Jones collection at South Kensington Museum, is said to have belonged to Marie Antoinette. The case of Sèvres blue porcelain is $2 \mathrm{ft}$. in

FIG. 589.-Carriage Clock of Marie Antoinette.

height, has ormolv mountings, and the ring of the pendulum being studded with large pastes enhances its very handsome appearance. It bears the signature " Kinable." A somewhat similar clock realised $£ 462$ at the Hamilton sale in 1882.

The lyre clock shown in Fig. 577 is at Windsor Castle. The

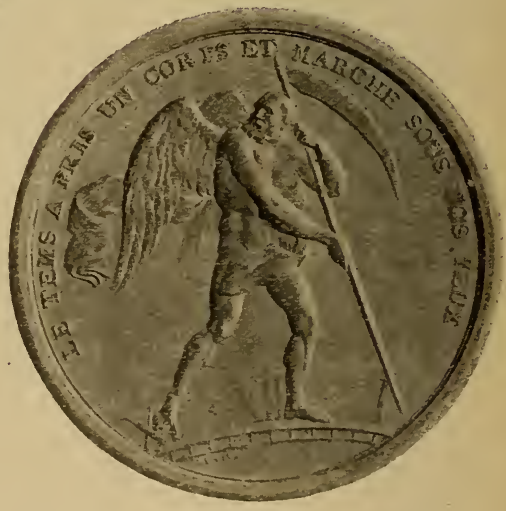

FIG. 590.-Medal issued by the French Government in 1789.

dial is quite modern and bears the inscription "Hanson, Windsor," 
French Clocks and Cases in the French Style

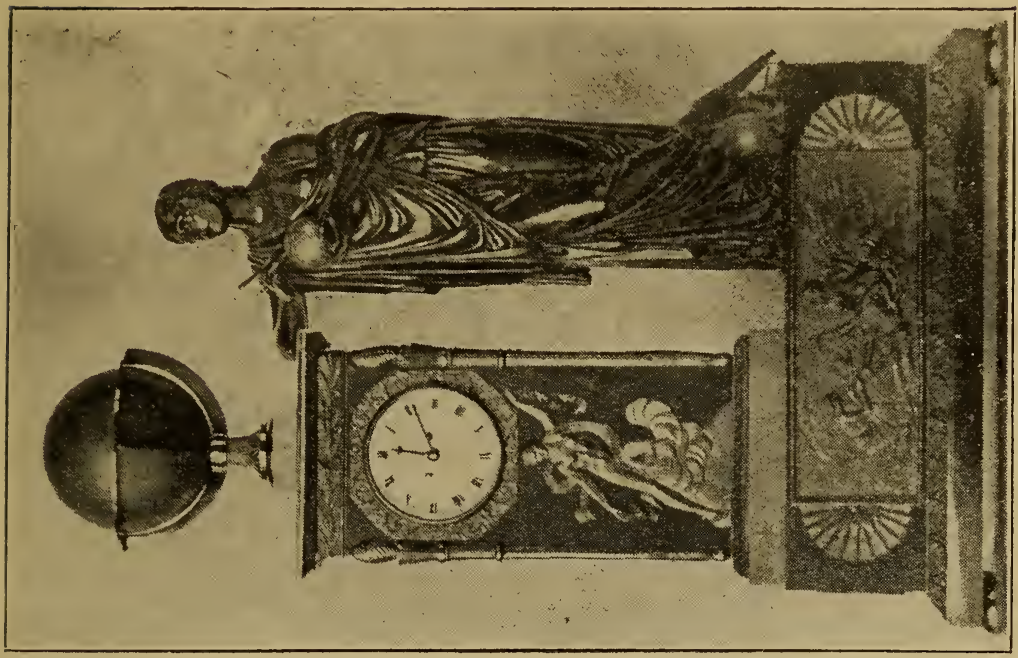

of

0
0
0
0
0
0
0
0
0
0
0
0
0
0
0

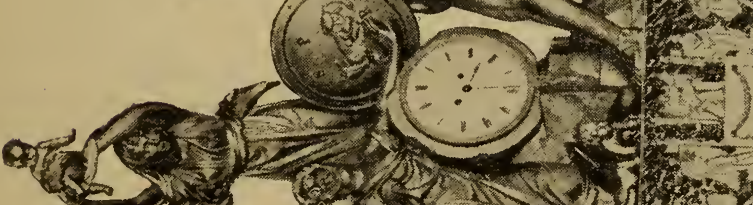

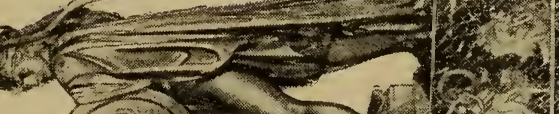

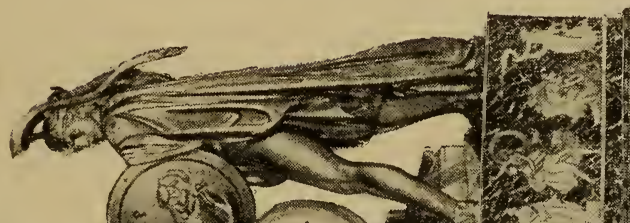

$(\infty)+4$ 
The blue Sèvres vase clock shown in Fig. 578, in the Louis XVI. style, affords another example of the fancies characterising the latter part of the eighteenth century.

The very pretty example of Louis XVI. style which is shown in Fig. 579 is by Vulliamy, and graces one of the drawing rooms at Windsor Castle. On the ormolı slab

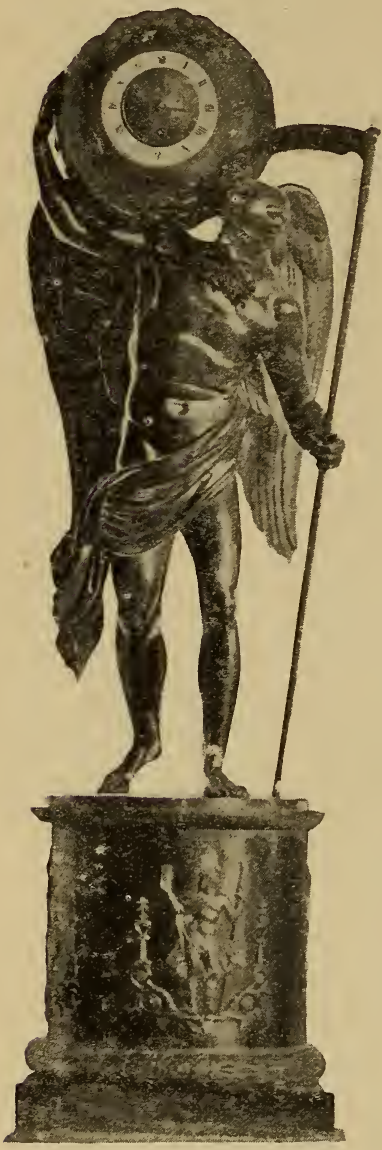

FIG. 593.-Clock in Windsor Castle. above the dial is a drawing of the fusee and demonstration of its action.

Fig. 580 is another specimen by the same maker, and is also at Windsor Castle.

For the example shown in Fig. 581, dating from about 1790 , I was indebted to the late Mr. Robert Rolfe.

From about 1760 till well on in the nineteenth century, elegant mantel clocks of marble and bronze, in which the dial depended from a handsome entablature, were much favoured in France.

The two examples on pp. 440,441, for which I am indebted to Messrs. Jump \& Sons, give a good idea of the best of them.

Fig. 583 is a clock by Engaz, of Paris, which shows the day of the week and the day of the month, on a dial bearing the signature of Dubisson.

Fig. 584 represents a somewhat similar design covering a clock by La Croix, Rue Denis, Paris.

Berthoud was apparently partial to this form, judging from the number to be seen with his name thereon.

The clock with white marble base and sphinx supporters for the dial, and shown in Fig. 585, by Solians, Paris, is at Windsor Castle.

In Chapter III. were given illustrations of early German timekeepers, in which figures of animals formed a most important part of the structure. A revival of this extraordinary conception seems to have found favour in France during the eighteenth century, when huge beasts were introduced as carriers for timekeepers. 


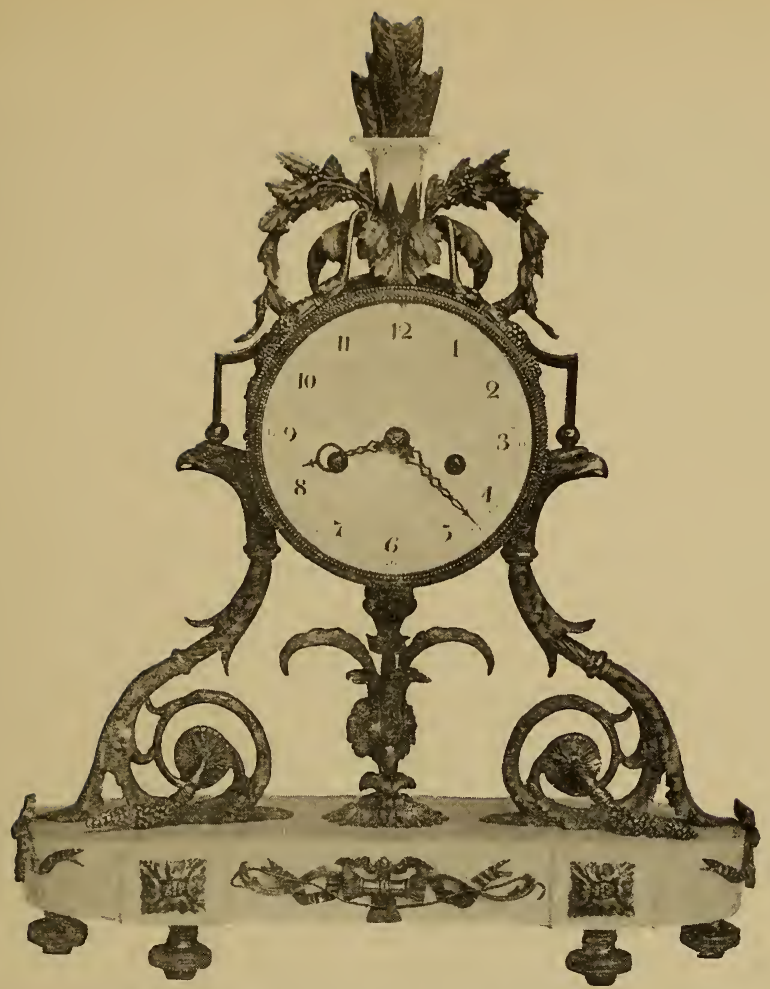

FIG. 594.-Clock with White Marble Case.

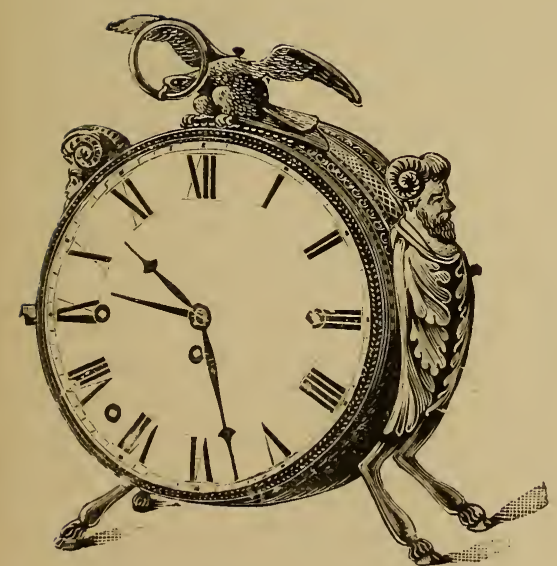

Fig. 595.-Portable Table Clock.

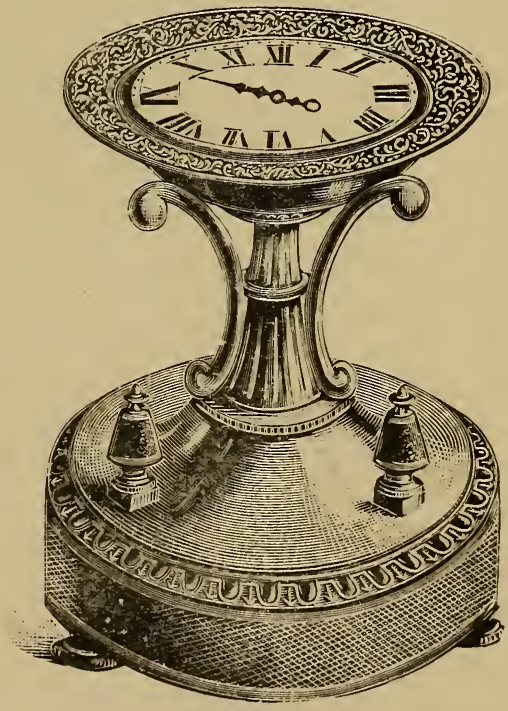

FIG. 596.-Table Clock with Horizontal Dial. 


\section{$45^{\circ}$ Old Clocks and Watches and their Makers}

The example illustrated in Fig. 586 is a clock by a noted Paris maker, Bailly l'aîné, dating from about 1769. It strikes the hour and half-hour in passing, and its dial, as in most French clocks of that period, stands out conspicuously. The occupants of the ponderous castle are evidently engaged in warfare. The elephant is of dark-coloured bronze, the remainder being chased and richly gilt, while the rajah, a coloured terra-cotta figure, seated inside the castle, complacently directs operations against the enemy. A small hole between his lips suggests the possibility of his having

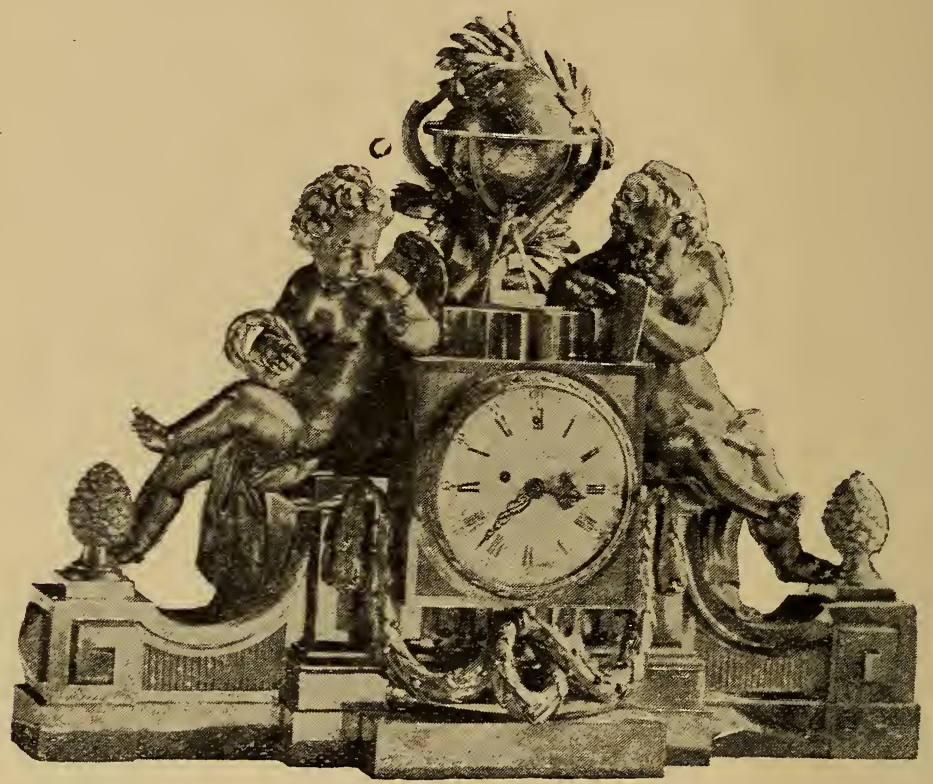

FIG. 597.-Clock with gilt metal ornaments popular at the latter part of the eighteenth century.

at one time a pipe in his mouth. In the Jones collection at South Kensington is an elephant with a clock on its back. It is signed by Caffieri, and illustrated in Fig. 587.

Clock cases of porcelain were made during the eighteenth century, chiefly at Dresden and Sèvres, though Berlin, Worcester, Derby, and Chelsea contributed to the demand. Some of them were very beautiful, especially French productions of Louis XV. period, which were decorated with figure subjects and scenery taken from pictures by Watteau, Lancret, and other artists. But comparatively few survive, for, apart from such accidents as lead to the destruction of china 
generally, the fixing of a clock movement to so brittle a material sufficiently tight to withstand the strain of winding is responsible for the fracture of a large proportion.

Among the Jones collection at South Kensington is a splendid clock in a case of Sèvres porcelain, formed like a vase, with mounts by Gouthière, which is believed to have been made for Marie Antoinette, and is shown in Fig. 588.* Charming it certainly is, and beyond criticism ; still, if one might be permitted to complain, I would say it is too small, too condensed; it measures but about 12 in. in height.

The travelling or carriage clock belonging to the same royal lady, also in the Jones collection, of which a sketch appears in Fig. 589, has the dial, front, side, and back panels all of Sèvres porcelain, jewelled ; it is between 10 and $11 \mathrm{in}$. high. The front panel bears the signature, "Robin $\mathrm{H}^{\mathrm{r}}$ du Roy." Though undoubtedly of French make, the outline bears a singular resemblance to English productions of the period.

The elegant lyre-shaped clock of Sèvres, illustrated on p. 436, is another excellent example. A clock by "Godon, Paris," in a vase-shaped case of Sèvres porcelain of Louis XVI. period, which was in Lord Strathallan's collection, realised two thousand guineas at Christie's in 1902. A quaint clock case of Chelsea china is to be seen at the British Museum.

From the middle to the end of the eighteenth century, the shops of leading horologists in Paris were, it is said, a grea: attraction to visitors. The earlier ones included Thiout l'âné, at the sign of " La Pendule d'Equation," Quai Pelletier; Julien Le Roy, at Rue de Harley, where also was Berthoud; Pierre Regnault, père, Rue Vielle-du-Temple; Le Paute, aux galeries du Louvre, opposite the Rue Saint-Thomas; Lepine, and also Romilly, Place Dauphine; Leroux, Rue Guenegaud ; Gosselin, Rue St. Honoré. Later on were Carcel, at Pont Saint-Michel ; Breguet, at Quai d'Horloge, 65 ; Caron, RueSaint-Denis, 224 ; Lepaute jeune, Place du Palais-Royal ; Lepine, Place des Victoires ; Pierre Le Roy, Palais-Royal ; and Wagner, at the sign of the Carillon, Bout-du-Monde, 2.

Louis XVI. had from a youth a liking for the mechanical parts of timekeepers, and Marie Antoinette possessed a large number of choice specimens, notably those illustrated on pp. 445,446 , but there

* The four illustrations of clocks in the Jones collection are from the official Handbook, and are inserted by permission of the Controller of His Majesty's Stationery Office. 


\section{Old Clocks and Watches and their Makers}

are in existence clocks and watches purporting to have belonged to her, and having thereon M. A. interlaced, which were really made between about 1818 and 1830 , when enthusiasm at the restoration of the French monarchy induced people to pay high prices for anything connected with the Court of Louis XVI. Watches apparently of Swiss manufacture, the cases decorated with gold of different tints (à quatre couleurs), as illustrated in Chapter IV., or with small oval plaques containing enamelled portraits of ladies, bordered with paste, diamonds or pearls, and surrounded by engravings of bows and knots are often seen, with a pedigree of former ownership, which will not bear expert examination.

Undeterred by the failure of Sully's enterprise at Versailles in 1718, and the collapse of Voltaire's venture at Ferney sixty years afterwards, the French Government in 1786, on the strong recommendation of Berthoud, Gregson, Romilly, and Lepaute, established a clock manufactory at Paris, which, however, had but an ephemeral existence for it succumbed to the stormy events of 1789 . The episode is little known, and might escape record but for the splendid medal issued as a reward for meritorious pupils, the obverse of which is reproduced on p. 446. It was designed by Duvivier, engraver to the Paris Mint, and contains a representation of Father Time journeying round the periphery of a clock. The aphorism, "Le temps a pris un corps et marche sous nos yeux," is a quotation from Delille. In 1838 yet another attempt was made in the same direction, and a factory initiated at Versailles under the special protection of the king. This also proved to be an ill-starred venture, for it languished almost from its inception and collapsed in the course of three or four years.

With the return of Napoleon from Italy came a marked change. in the French style of design. The soft harmonious conceits of Louis XVI. artists gave place to more severe and statuesque productions with heavy draperies, founded on ancient Roman models. Representative specimens at Windsor Castle are illustrated in Figs.591 and 592. A good example having a characteristically long and deep base, is shown in Fig. 582. The case, 27 in. high, is of bronze, with finely executed chased work, gilded. It belongs to Mr. A. House The movement is signed "Le Roy \& Fils, Hors du Rois, à Paris."

Fig. 593 shows a fine clock in the First Empire style, which is at Windsor Castle. It is by Jefferson, London, and dates from about 1810.

For a photograph of the little clock shown in Fig. 594, I am indebted to Messrs. Jump \& Sons.

Portable table or bedroom clocks, cased in the form of a drum, and 


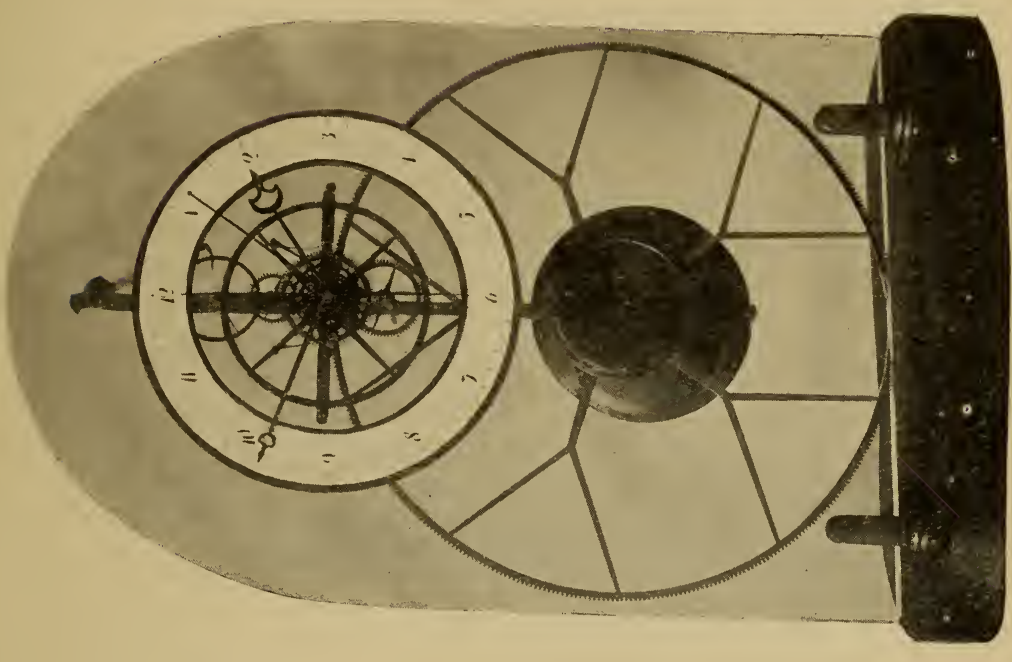

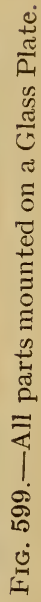

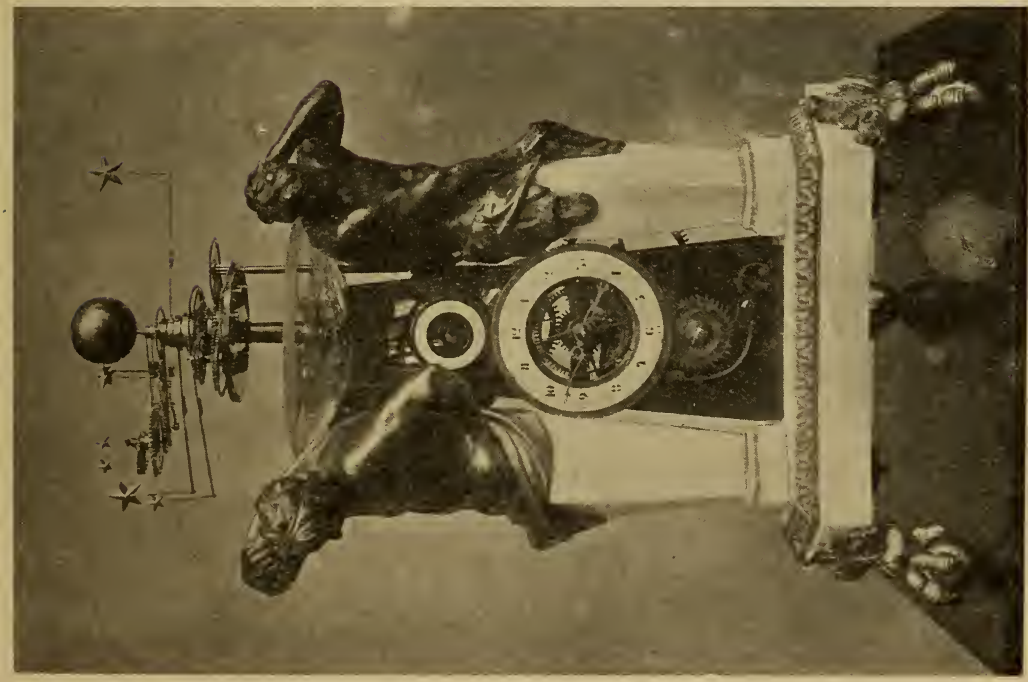

0
0
0
0
0
0
0
0
0
0
0
0
0
0 
especially convenient to travellers, were in favour from the latter part of the eighteenth century till, debased and shorn of all enrichment, they degenerated both as ornaments and timekeepers. An example in the best style, with well-chased gilt fauns as supporters, and surmounted by an eagle holding a ring by which the clock could be lifted, is shown in Fig. 595. It strikes the hours and quarters, and the striking may be repeated at pleasure by pulling out the knob on the back of the eagle; it is also provided with an alarm.

Table clocks with horizontal dials were revived during the first Empire. A pretty specimen of gilt metal, in which the movement

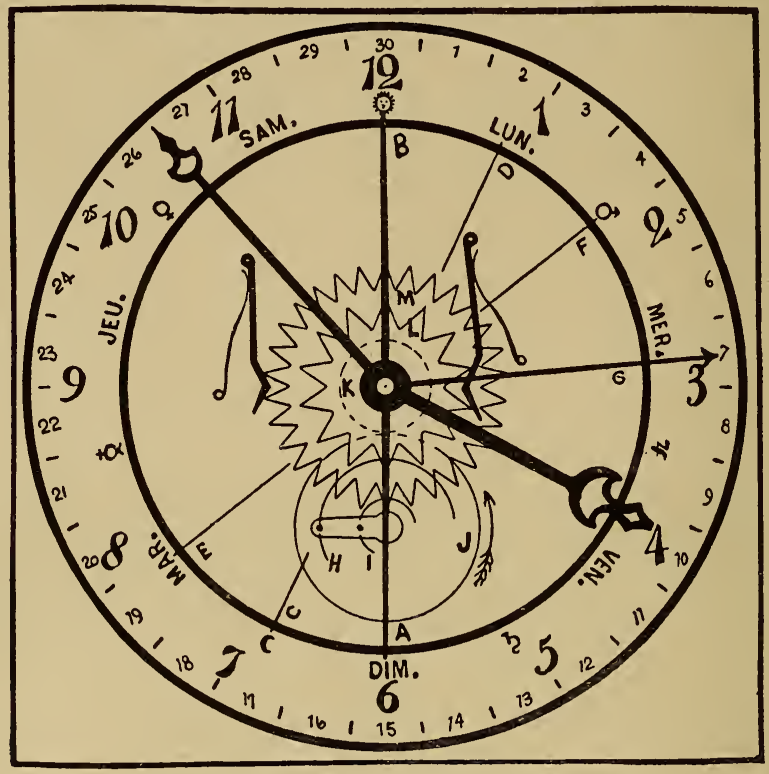

FIG. 600.-Dial of Glass Plate Clock.

is enclosed by the base, is shown in Fig. 596. It dates from 1806-10 and has but one hand, which may be set by turning one of the little ornaments standing up from the lower part of the case. The band around the dial is pierced to a pretty design. It strikes the hours and quarters.

The handsome clock carrying an orrery actuated by the mechanism of the timekeeper which is shown in Fig. 598, belongs to Mr. S. H. Hole. For the photograph of it I am indebted to Mr. J. Bolton Smith. An orrery clock by Raingo, of a later date; in a plain case is at Windsor Castle, and in the Soane Museum is a similar piece by the same maker. 
A fine example of French horological ingenuity, from the collection of Mr. James Arthur, is depicted in Fig. 599. All the parts are attached to a sheet of plate glass, giving the structure the appearance of a clock floating in the air. The mainspring barrel is seen in front of and just a little higher than the pendulum bob, and on its arbor runs the truly great wheel. It goes for a month between windings, and shows the day of the week and day of the month.

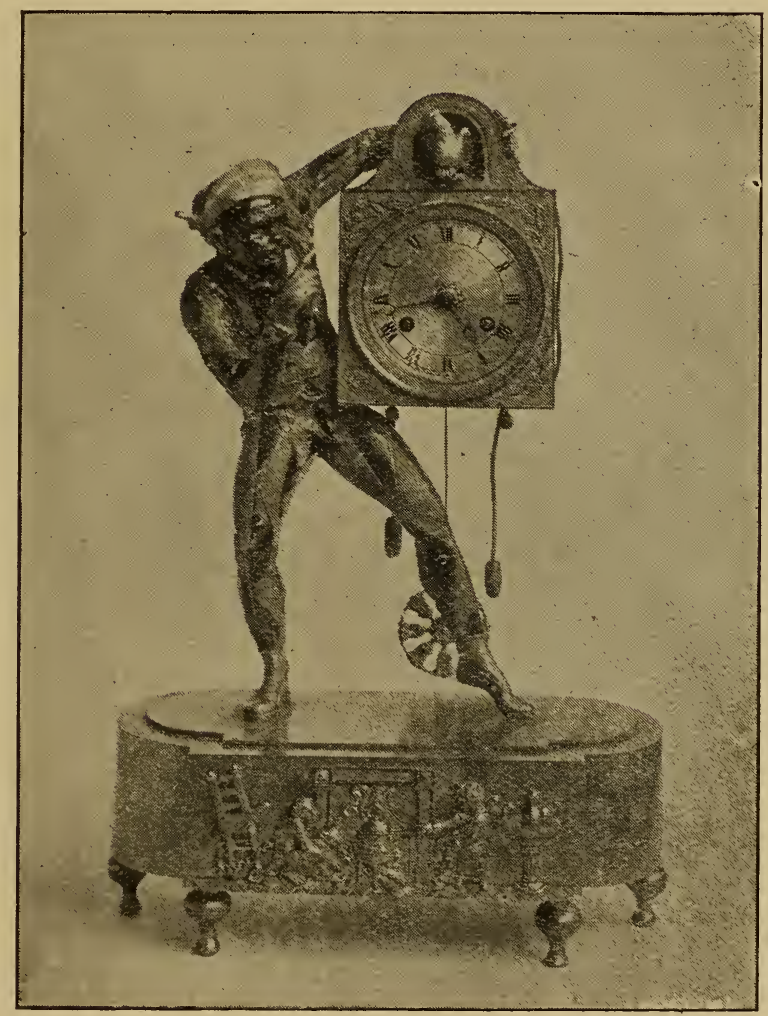

FIG. 601.-Harlequin and Bird Clock.

An enlarged view of the ring dial, together with mechanism for operating the calendar which is given in Fig. 600, will repay examination. The hour and minute hands are easily distinguishable, and of excellent form. There is a double-ended pointer marked A B which goes round in fourteen days. Each extremity of it alternately indicates the day of the week and the sign corresponding to that day. At present it is in the position for Sunday (Dimanche) and the Sun. 
Next day the points will have shifted to C D, Monday (Lundi) and the Moon, the following day to E F, Tuesday (Mardi) and Mars, and so on throughout the two weeks, when the pointers will have returned to the position shown. The minute circle is utilised for the day-of-the-month hand G, every alternate minute mark being numbered for this purpose.

The pointer A B is connected with the star wheel $L$ of fourteen teeth, the day-of-the-month hand $\mathrm{G}$ with the star wheel $\mathrm{M}$ of thirty
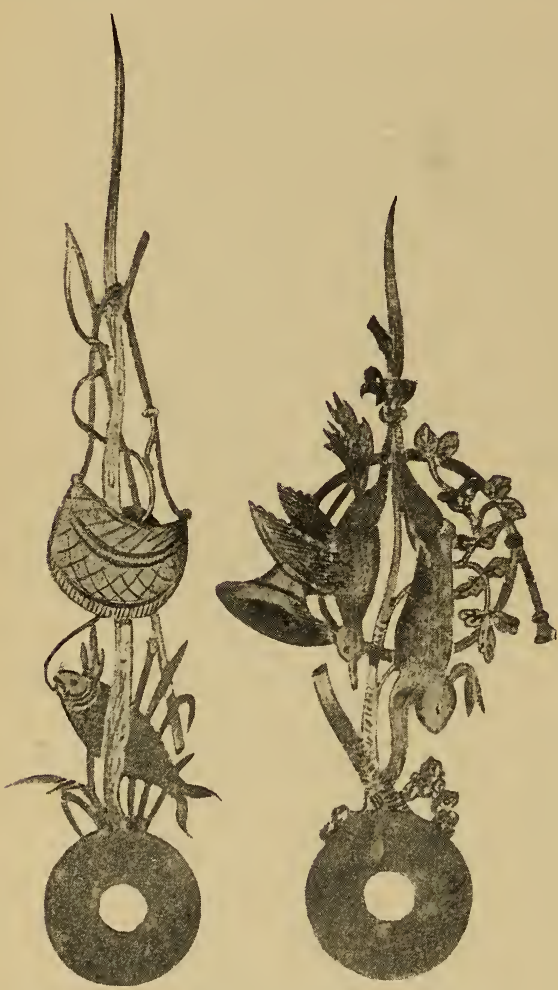

FIG. 602.-Clock Hands representing Sport. teeth. The usual twelve-hour wheel $\mathrm{K}$ drives the twentyfour-hour wheel J, carrying the crank $\mathrm{H} I$ and its two projecting pins, which in their course turn the star wheels one tooth per day.

A more ingenious plan for day-and-month calendar work with so few extra parts it would be difficult to devise. It is clever by its simplicity. For months other than those of thirty days the hand G would, of course, have to be adjusted at the end of the month. A timepiece, doubtless by the same maker, but without the calendar, is in the Conservatoire National des Arts et Métiers, Paris.

Clocks with cases of a nondescript character, but abounding in ormolu or gilt metal ornament so popular at the latter part of the eighteenth and beginning of the nineteenth centuries, seem to have entirely died out of favour. At Windsor Castle is an early example with a winged boy on each side of the dial, and a celestial globe and mathematical instruments above it, as shown in Fig. 597.

Fig. 601 shows a remarkably well modelled figure of a harlequin, who is represented as drawing attention to the notes of the bird peeping from an alcove above the dial. 
Clock hands do not as a rule lend themselves to decoration symbolical of a particular subject, but three pairs typical respectively of Sport, Agriculture, and Music, which appear to be worth reproduction, are shown in Figs. 602-3-4. They are French, and were, I believe, designed for presentation timekeepers.

It may be noted that up to the end of the eighteenth century movements of the French chamber clocks were rectangular even though the cases were circular, as in the example by Berthoud shown on p. 434 ; the bell always surmounted the movement instead of being at the back of it, as the modern custom is, and the pendulum was suspended by means of a silken cord.

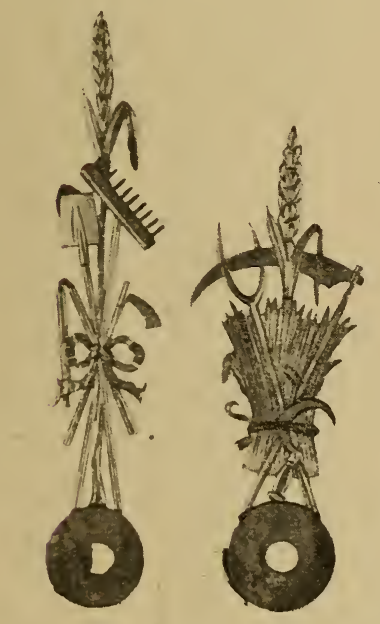

FIG. 603.-Clock Hands representing Agriculture.

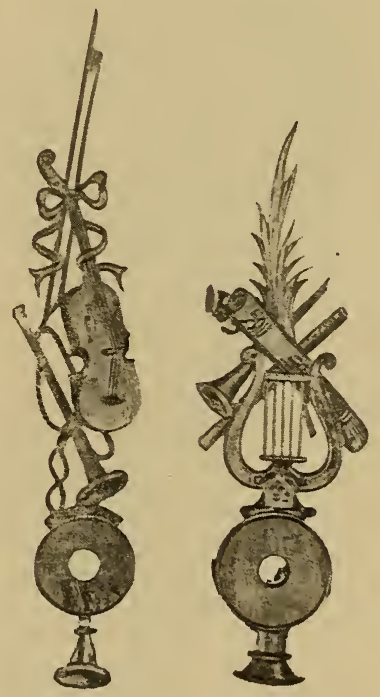

FIG. 604.-Clock Hands representing Music.

Adjuncts to a clock in the way of candelabra, tazzas or figures en suite, were not in use till nearly the end of the reign of Louis XVI.

Italian Cartel Timepieces.-By way of contrast to the French treatment the two cartel timepieces shown in Figs. 605 and 606 will be of interest. They are reproduced from designs by Giovanni Battista Piranesi, which were published in 1761. Fig. 606 is modelled upon the form of an ancient Roman rudder, a conceit particularly to the taste of that age. It will be noticed that each of the dials is divided into six hours, in conformity with the counting of the hours in many parts of Italy at that time. 
Falling Ball Timekeepers.-This remarkably clever and elegant piece of seventeenth-century mysterious horology consists of a sphere of brass, to be suspended from a bracket, or the ceiling of a room. The upper and lower portions of the ball are gilt, while around a silvered band in the middle are marked two serials of Roman numerals from I. to XII., and subdivisions for the quarter-hours. The extremity

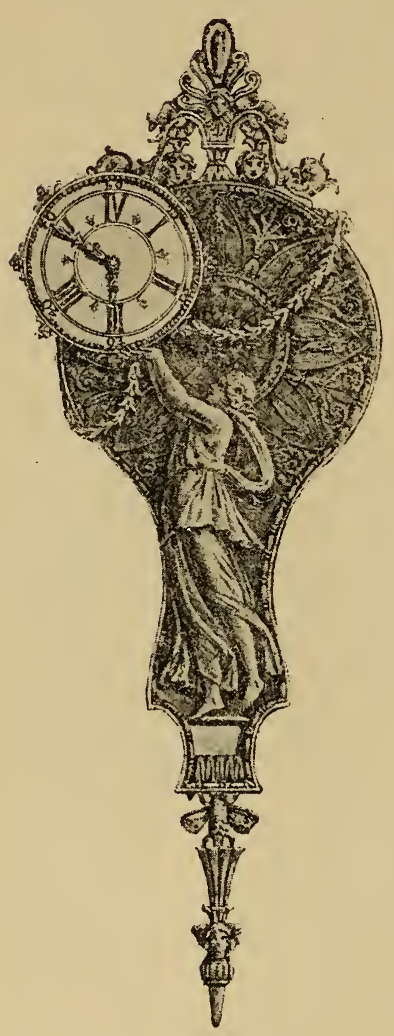

FIG. 605 .

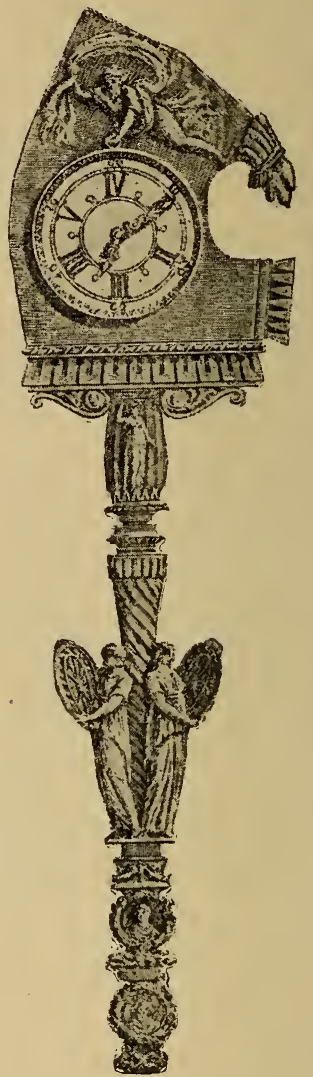

FIG. 606.

Italian Cartel Timepiece.

of one of the wings of a cupid on the lower part of the ball points to the hour of the day or night. The construction may be gathered from the vertical and horizontal sections which are given in Fig. 607, borrowed from "Les Merveilles de l'Horlogerie." The suspending cord is coiled round a barrel, with which is connected a train of wheels terminating in an escapement and balance. While the top 
and bottom of the ball are rigidly connected, the middle is free to move, and is furnished with a ring of teeth projecting inside, through which the middle is rotated once in twenty-four hours, the weight of the ball acting as a driving force. The mechanism is wound by simply raising the ball with the hand, there being a weak spring in the barrel, which causes it to turn and coil the suspending cord on to itself.

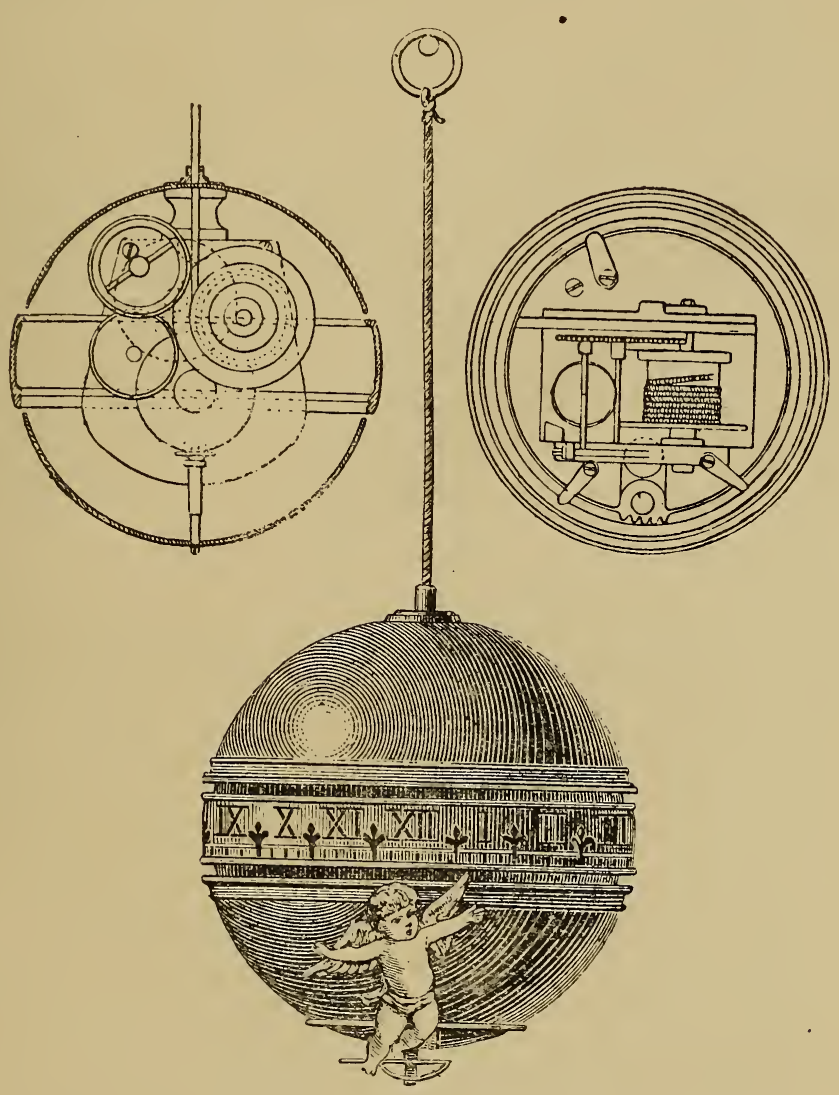

FIG. 607.-Vertical and horizontal sections of Falling Ball Timekeeper.

At the British Museum are two of these falling ball timekeepers of 4 in. in diameter. One of them is inscribed "Jacob Behan, Vienna." In the National Museum, Cracow, is one signed "Davidt-Schröter-in Elbing." Schröter flourished about 1680-90. The Society of Antiquaries possesses a very fine example, measuring $10 \mathrm{in}$. across, but 


\section{Old Clocks and Watches and their Makers}

of, I fancy, much later date. It was given to the Society by B. L. Vulliamy.

Figs. 608 and 609 represent two of many timekeepers designed and made by a truly remarkable mechanical genius, Nicolas Grollier,

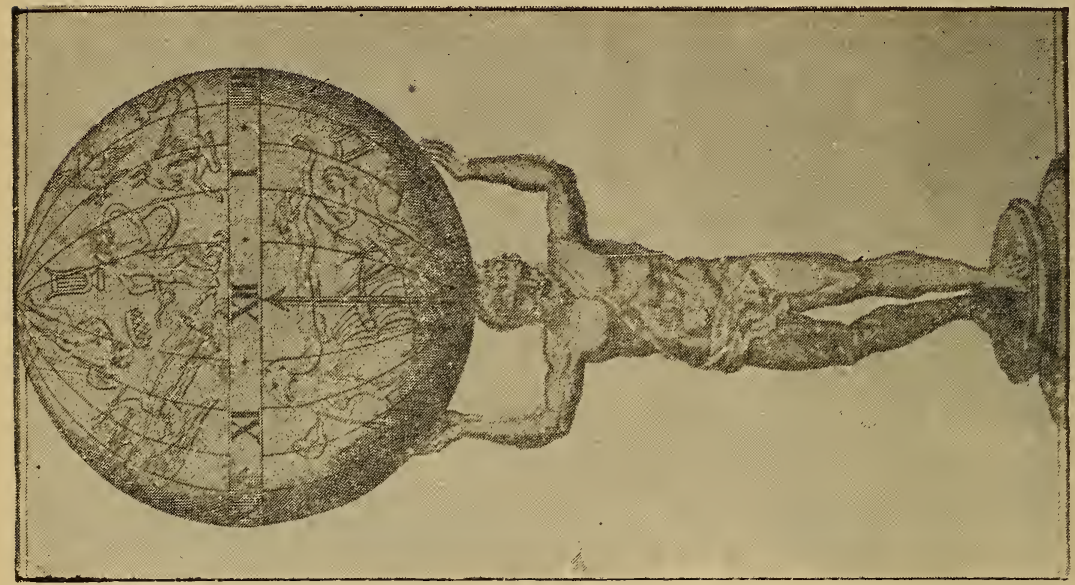

$\stackrel{0}{0}$
0
0
1

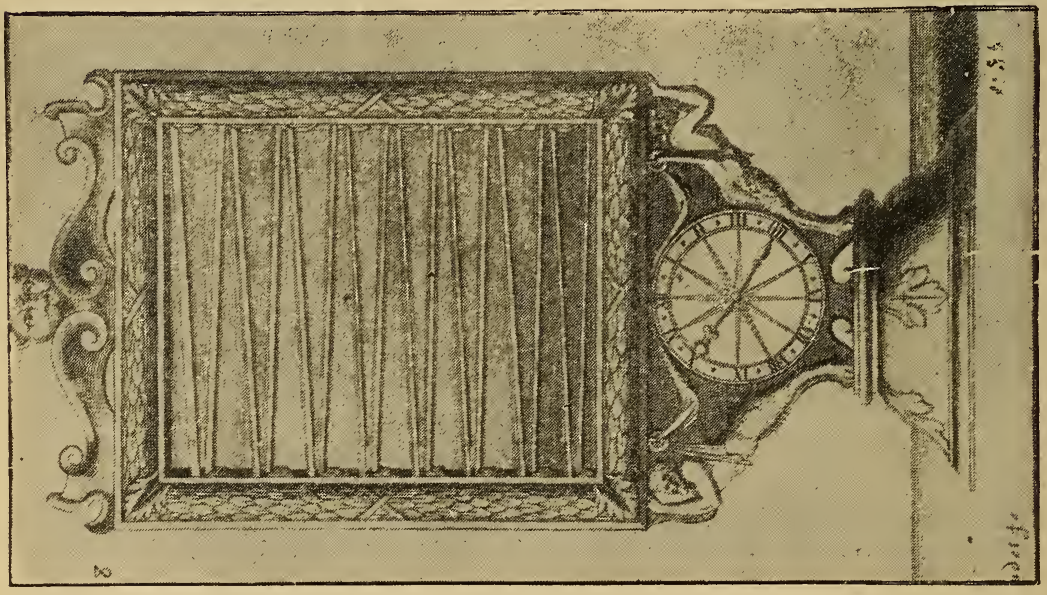

5
0
0
0
0
0
$\frac{5}{0}$
0
0
7
5
0
0
0
5
0
0
0
$\frac{0}{0}$
0
0
0
3
5

$\stackrel{\infty}{0}$

afterwards M. Grollier de Servière, who was born at Lyons in 1593, and passed his early manhood in the service of the French army. His later years he devoted to designing all sorts of mechanism, and, thus providing himself with ample occupation, he managed to reach the good old age of ninety-three years. 
These two drawings are from a thick quarto book written by his grandson, and dedicated to Louis XIV. In the first example a small ball runs down inclined shoots, and by its momentum unlocks the train as it reaches the bottom. There are two balls, and as the first disappears from view the second one begins its descent. The balls are, in turn, carried up at the back by a kind of tape ladder with pockets, which passes over a pulley at the top, and another at the lower part of the case.

Globes, Urns, and Vases.-One of the most remarkable timepieces embodying the form of the earth is in the Bibliothèque des Jagellons, Cracow. For illustration and particulars of this I am indebted to Dr. Tad Estreicher, professor of the University, Fribourg, Switzerland. The result of his research places the date of its construction at about 1510, the French a s $\mathrm{r}$ o n o m e r, Louis Boulengier, being probably the inventor of it. The photograph is rather dim, but the action will be understood with the following explanation. The

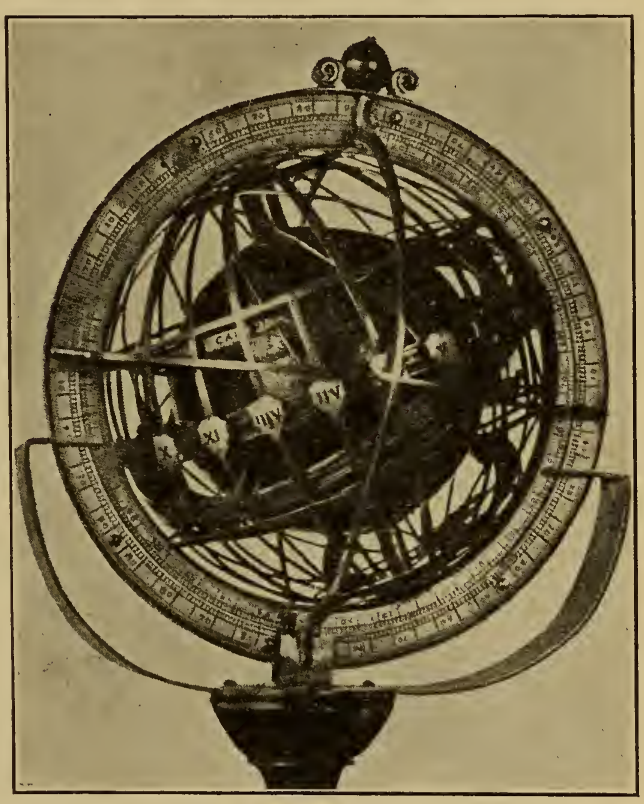

FIG. 610.-The Jagellons Timepiece. outer part of the initial meridian is mounted on a stand and the inner is free for adjustment of the inclination of the earth. Fixed to it is a light cage giving the hours I. to XII. twice over on hourly meridians. Within is another frame of meridians with the ecliptic which, actuated by mechanism within the globe, makes one turn in twenty-four hours. A figure of the sun travels with the ecliptic, and denotes the time. The sun is carried by a curved wire emanating from a wheel near the south pole and, as it passes a fixed pin in the axis of the globe, it is, by the intervention of a pinion, each day put back on the ecliptic one 365 th 


\section{Old Clocks and Watches and their Makers}

part of the circle. So that not only is mean solar time shown, but the sidereal day, the height of the sun, and, as the months are named around the ecliptic, it forms a calendar as well. An interesting feature of this timekeeper is the globular representation of the earth, which has been pronounced by leading cartologists to be the earliest postcolumbian globe, and the earliest to give any part of the new world.

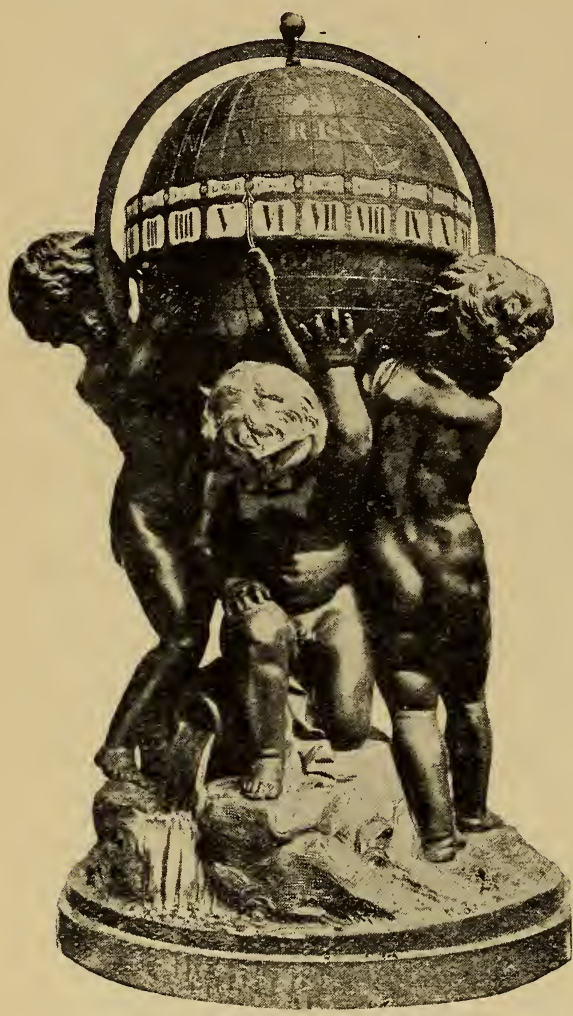

FIg. 611.-Revolving Band Timekeejer, about 1780 . America, though, is put in quite a wrong place. A continent marked "AMERICA Noviter REPERTA" corresponds fairly well with Australia, and is believed to be the first cartographical recognition of that place. In the "Atlas " timekeeper by Grollier de Servière (Fig. 609), the movement within the globe causes the central band, on which the hours are marked, to revolve, the arrow, of course indicating the time. The upper and lower portions of the globe are stationary.

A taste for revolving band timekeepers, formed as globes, urns, and vases, revived in France during the eighteenth century. The exteriors of some of these were of very elegant design, as may be judged from the examples submitted.

Fig. 611 shows a particularly attractive one dating from about 1780 , which is at the South Kensington Museum. The boys supporting the globe are of bronze. The moving band contains two sets of numerals painted blue on enamelled plaques; the lower set represents the hours counted twice from I. to XII., and the upper set each fifteen minutes. The tongue of a snake forms a bar across each successive hour numeral, as an indicator, and reaching beyond it, points to the minutes also. By counting the hours I. to XII. twice over, the band as it travels in 
French Clocks and Cases in the French Style 463

its course round the earth becomes a universal time-teller. At Nether Swell Manor is a somewhat similar structure standing on an ornamental base and surmounted by a pair of love-birds.

Mr. George H. Gabb owns a terrestial globe, dated 1620, constructed to serve as a timepiece; supported by a gilt bronze figure of Atlas. This globe was made by the famous cartographer, Joannes Janssonius, successor to Mercator's house in Amsterdam, and is one of the earliest globes extant, and probably unique. The globe is formed of

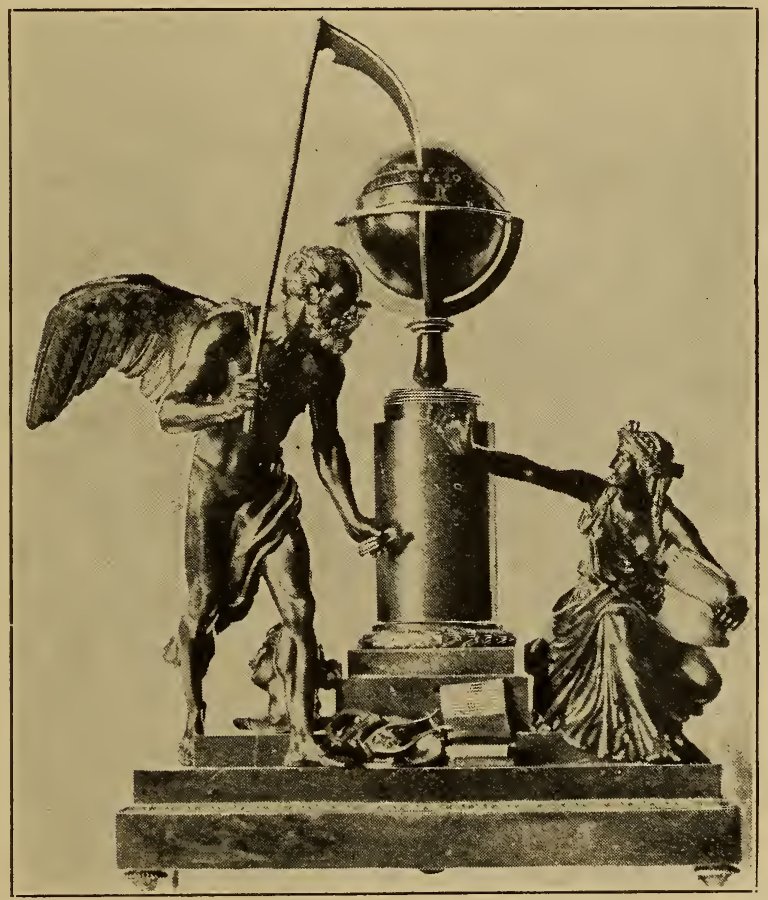

FIG. 612.-At Windsor Castle.

two hemispheres of copper, on which is an engraved map of the world on paper, arranged in gores. The engraving is doubtless by the hand of Peter Kerius, perhaps the finest map engraver of the period. Inside the globe is a movement of the verge type, made by Johann Tomas Seyler, a contemporary clockmaker, so geared to the axial spindle that the globe revolves once in 24 hours, the time of which is regulated by the primitive method of altering the tension of the main spring by means of an endless screw and tangent wheel geared to it. 
Attached to a point on the Equator is a small star, which indicates the hour on a dial band, as the globe revolves.

In the Throne room at Windsor Castle is a globe clock which has double revolving bands, Roman hour numerals being marked on one band, and on the other Arabic figures to represent the minutes. It is by Manière, of Paris, and adorned with a well-executed group, as in Fig. 612. The ball, enamelled in royal blue, forms a properly conspicuous centre, on each side of which the statuettes are arranged. The hour is shown by the coincidence of a numeral with the brass vertical bar supporting the globe, while the Destroyer is posed to

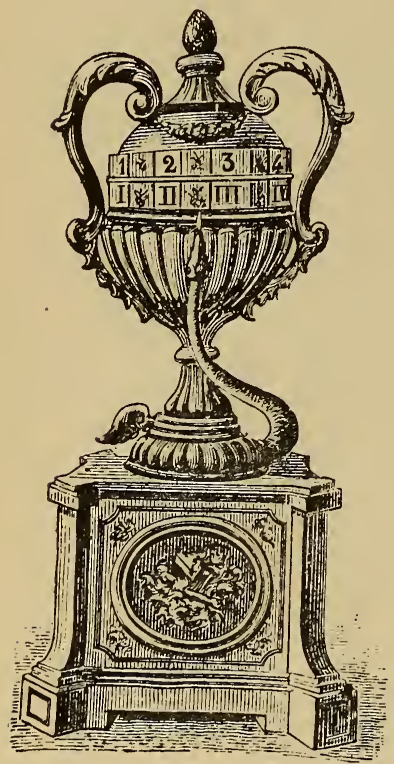

Fig. 613.-Vase Clock of Marie Antoinette. indicate the minute with his scythe.

The Wallace collection also includes more than one fine globe clock with hour and minute revolving bands.

Fig. 613 represents a vase clock, which is said to have belonged to Marie Antoinette. The movement was covered by a handsome carved marble pedestal, the urn being of porcelain with bronze mountings. A serpent coiled round the foot of the vase had its head erect to point to the hour on the double polygonal band.

Fig. 614 shows a larger urn or vase mounted on an elaborately carved square plinth; a somewhat similar clock by "I.e Loutre, horloger du Roy, Paris." realised $£^{903}$ at the Hamilton sale in 1882.

In Fig. 61.5 is reproduced a magnificent design by Falconet, wherein the Three Graces are portrayed, one of whom indicates the hour with her finger. The vase is supported by a column standing on a handsome plinth; the panels of the plinth show very choice carvings of groups of children at play. Etienne Maurice Falconet, whose production of this and some other clockcases stamps him as an artist of the front rank, was born in 1716 and died in 1791, and seems to have been more appreciated after his death than before. The Three Graces clock was sold in the early part of the nineteenth century for 1,500 francs, and in 1855 was purchased for 7,000 francs by Baron Double, whose collection was sold in 1881 
French Clocks and Cases in the French Style 465

when Comte de Camondo secured the Three Graces for 101,000 francs. His son, who is the present owner, has, it is said, refused an offer of over a million francs for the treasure, which, in accordance with the wish of his father, he will bequeath to the French nation.

Negress-Head Clock.--Among the eccentricities of French horology

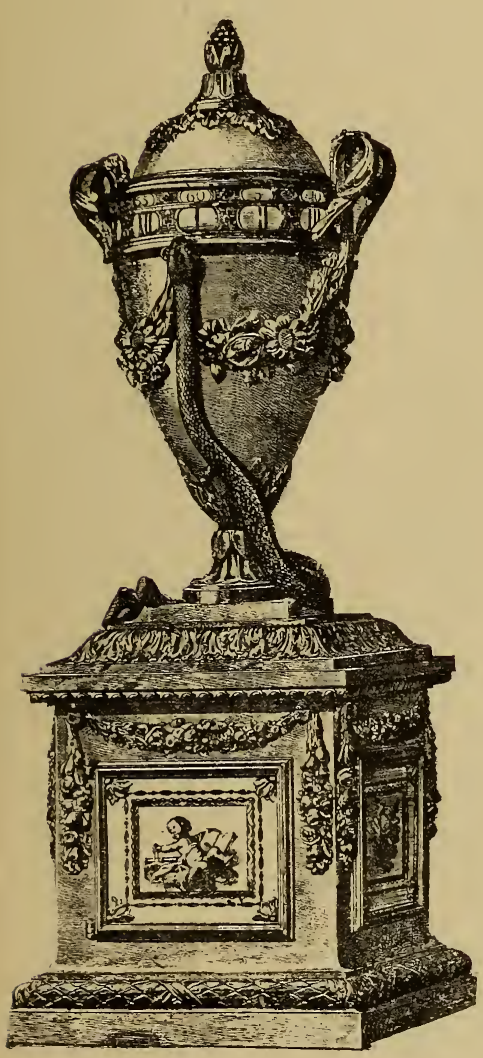

FIG. 614.-Urn or Vase Clock.

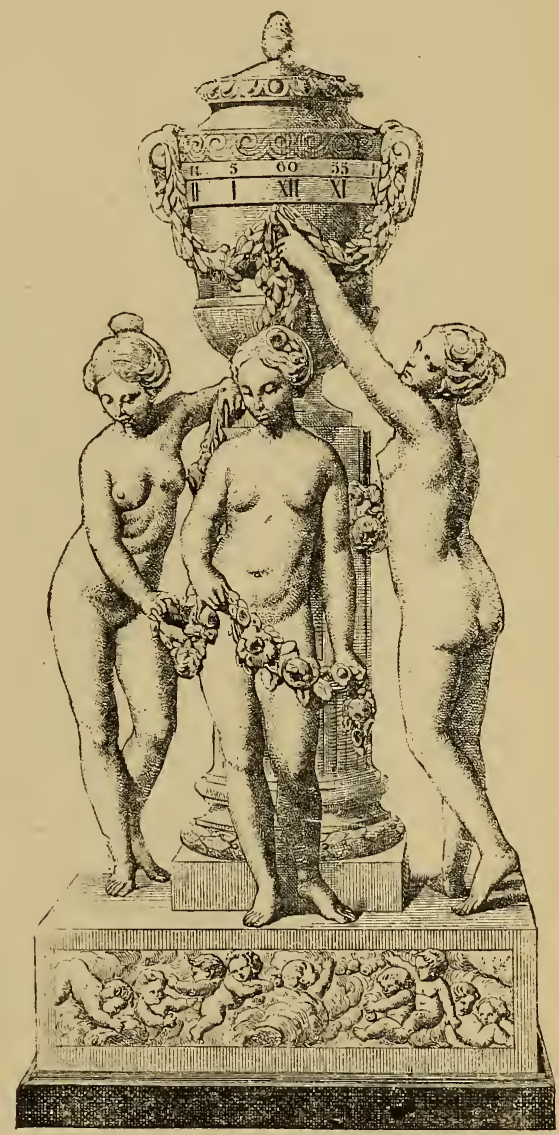

FIG. 615.--Three Graces Clock.

is one at Buckingham Palace in the form of the head of a negress, as shown in Fig. 616. Figures corresponding to the hours appear in proper order in one of the eyes of the negress, the minutes being denoted in the other eye in a similar way. By closing the eyelids the figures may be rendered invisible.

Rolling Clock.-This ingenious device appears to have been 
466 Old Clocks and Watches and their Makers

patented by that universal genius, the Marquess of Worcester, in 1661 (No. 131). It was also made by Grollier de Servière, probably about the same date. Maurice Wheeler published a description of it as his invention in Lowthorp's "Abridgment of the Philosophical

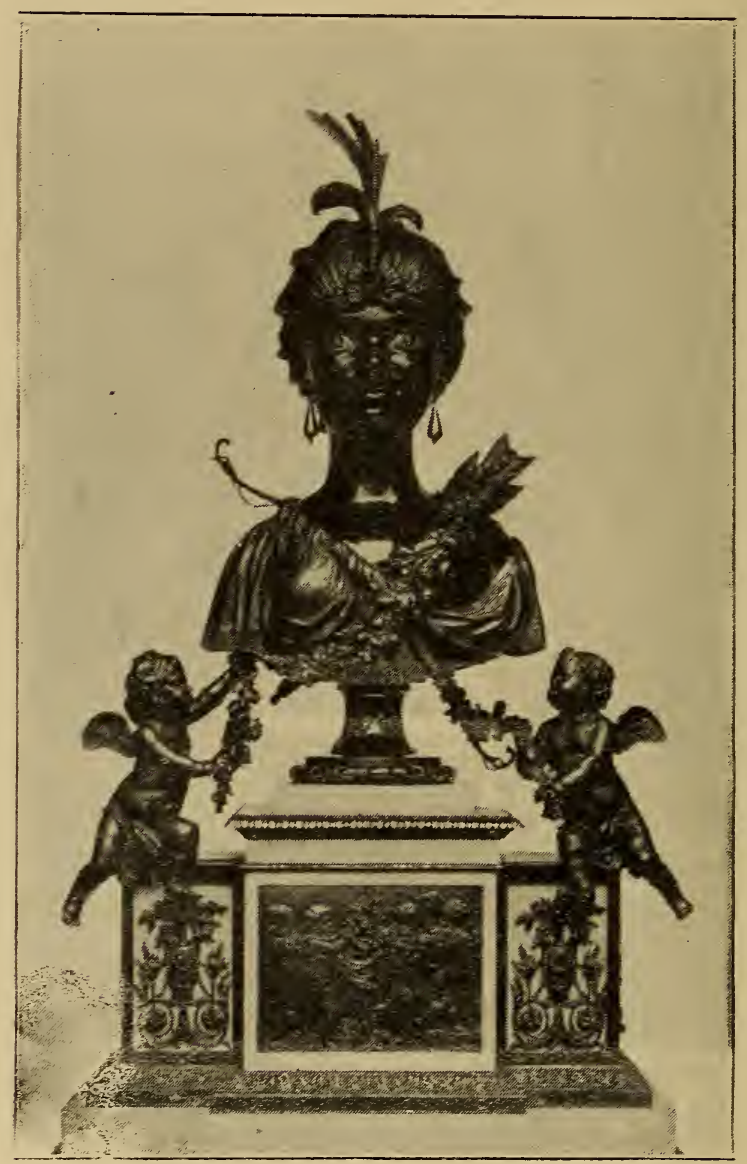

FIG. 616.-Negress-head Clock at Buckingham Palace.

Transactions in 1684." Its construction will be understood from the uncovered view of the front, Fig. 617. There is a train of wheels and an escapement as in a watch. The great wheel $a$ carries the hand and also the weight $b$. The clock never requires winding. It is every morning simply placed at the top of the inclined plane, down which it gradually rolls during the day, the hand pointing to the hour marked 
on the dial, which of course covers the mechanism. The length of the plane had better be more than twice the circumference of the clock case $c$. Its inclination may be regulated by the screw $g$. The hand may be in the form of a figure of Time, as in Fig. 617, a serpent's head, or other grotesque design.

Schmidt's Mysterious Clock.-The weighted lever of the rolling clock, as shown in Fig. 617, has been utilised in another form of mysterious timekeeper, an exterior view of which is given on p. 468 .

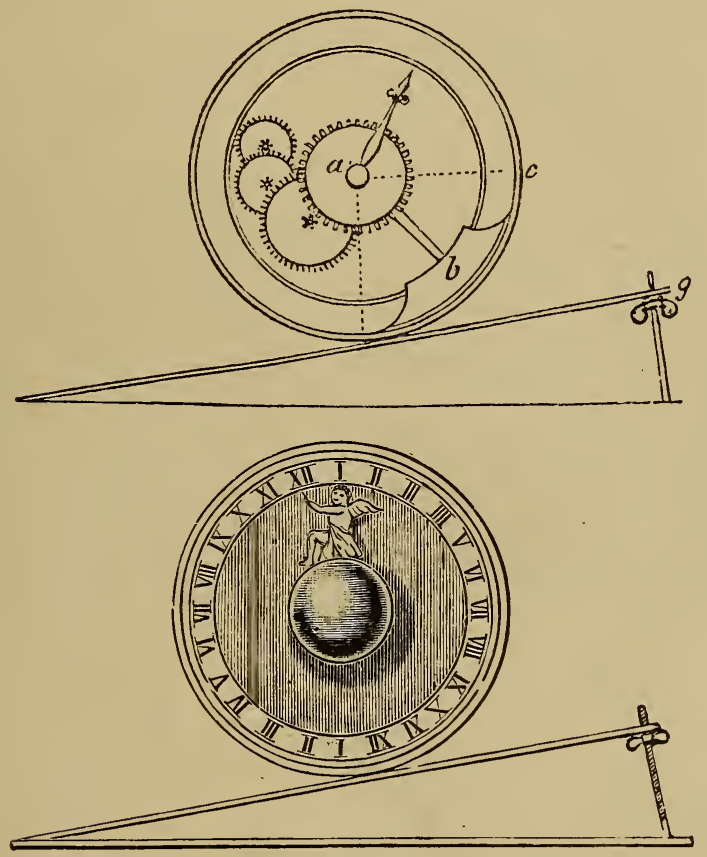

FIG. 617.-Rolling Clock.

In the Upper View the Dial is removed to exhibit the Actuating Mechanism described on page 466 .

It was patented in 1808 (No. 3,185) by John Schmidt, a watchmaker, living in St. Mary Axe. He called it "The Mysterious Circulator, or Chronological Equilibrium." The ring is divided into hour and fiveminute spaces. The watch movement, with the weighted lever, is contained in the box $\mathrm{c}$, but it is now driven by a mainspring in the usual way. The hand is pivoted to the tail of the dolphin. $\mathrm{D}$ is a counterweight. The weighted lever revolves once in twelve hours; it would be nearest to the centre of motion of the hand at twelve 
o'clock, and farthest from it at six o'clock; it is easy, therefore, to see that by this displacement of the centre of gravity the weighted lever would cause the hand to revolve and point to the time. It appears that Schmidt was a Dane, who was taken prisoner at Copenhagen, and brought to England. The clocks were sold by Rundell \& Bridge, whose shop was in Ludgate Hill. Several distinguished persons are stated to have become purchasers. Some years ago I saw one which bore the name of $\mathrm{McNab}$, Perth. It was then in the possession of

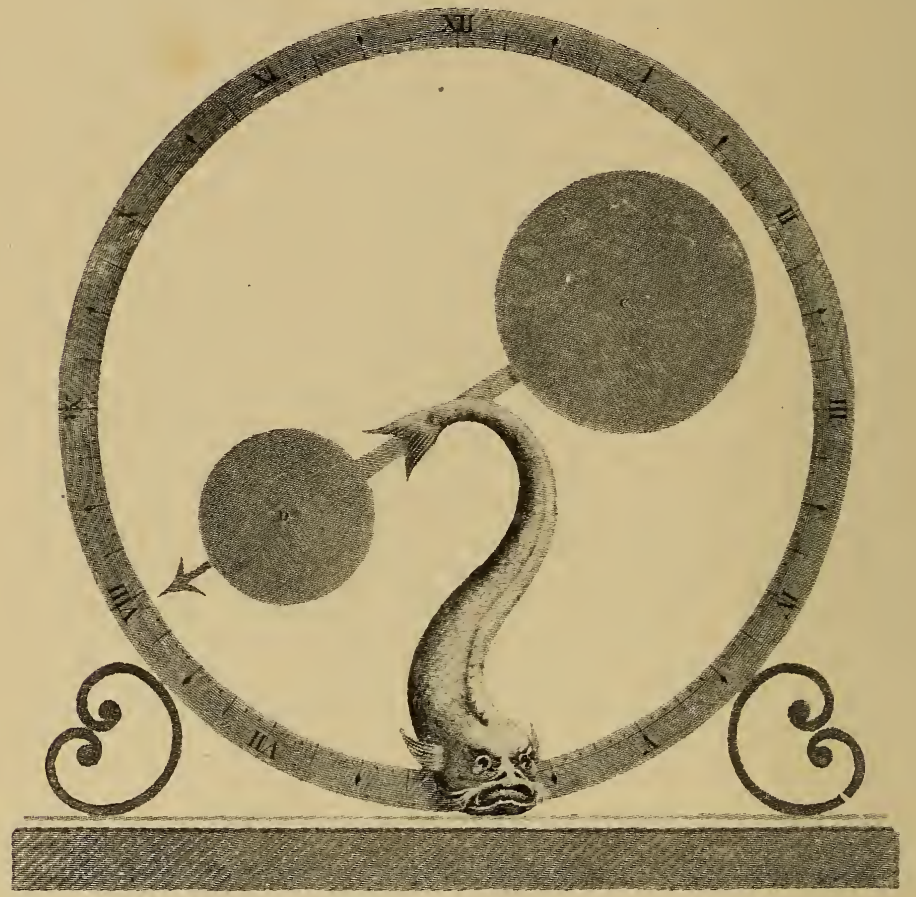

FIG 618 -Mysterious Timekeeper.

Mr. Robert Napier, but afterwards belonged to the late Mr. Henry Levy.

This device has been several times re-invented, but never, I think, in so elegant a form as the original.

Fan-shaped Clocks.- The late M. Planchon owned an engraving of the tutor to Charles, son of Philip II. of Spain, on which is shown a timekeeper, the dial being composed of a double fan of white and black slats which expanded and contracted to suit hours of varying length in day and night throughout the year. This dates from about 1570 . 
Other forms of fan timekeepers have been constructed and should be mentioned as among horological curiosities. The illustration, Fig. 619, was published some time ago in La Nature. The fan, composed of thirteen very light slats, is pivoted to a backing covered with velvet, and at six o'clock in the morning and in the evening would be wide open as shown, and a serpent, fixed by its tail to the velvet, would point to the hour with its tongue. Immediately after siz o'clock the fan suddenly closes, the serpent still pointing to six, but it would then be the figure on the right-hand side of the fan. On a continuation of the joint of the fan is a pinion actuated by a rack in connection with a snail-shaped cam, which causes the fan gradually to open as the hours progress, and then suddenly close.

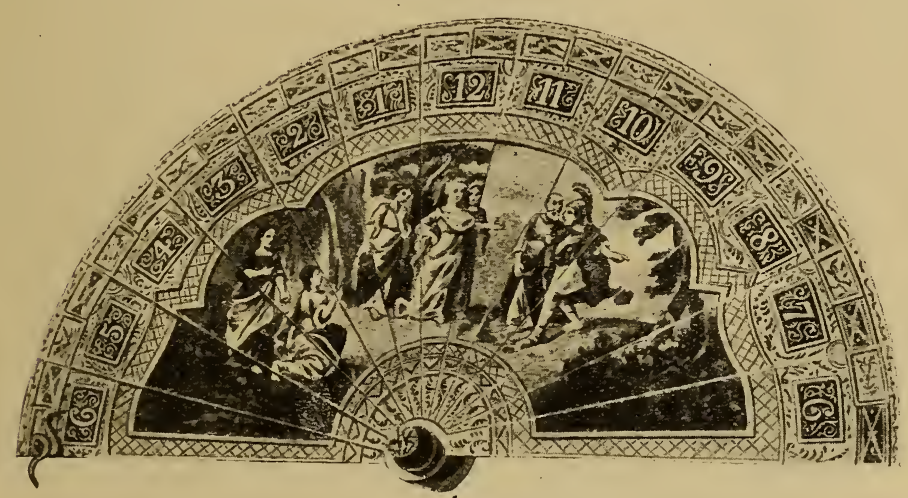

FIG. 619.-Fan-shaped Clock.

Suspended Bird-Cage.-This, from the Schloss collection, is probably a combined French and Swiss production of about 1780 . An enamelled dial with centre seconds hand projects below the bottom of the case, the actuating mechanism being hidden in the plinth, which is adorned with oval enamels of scenery in the Swiss style. In niches at the corners are fine statuettes of Sèvres biscuit. At the completion of each hour the birds move, flutter, and trill a sort of duet, their actions and notes being remarkably natural. By means of rotating pieces of glass, a double-fall fountain appears to be playing in the centre. These motions can be caused to repeat at pleasure by pulling a string. The few somewhat similar clocks known to exist are highly prized by their owners. One not so decorative as the example here shown is in the King of Italy's summer palace at Monza. 
Magnetic Timekeepers.-Grollier de Servière devised a timekeeper resembling a shallow bowl with a wide rim, having marked thereon the twelve hour numerals, as in Fig. 621; the bowl being filled with water, the figure of a tortoisa was placed on it and at once

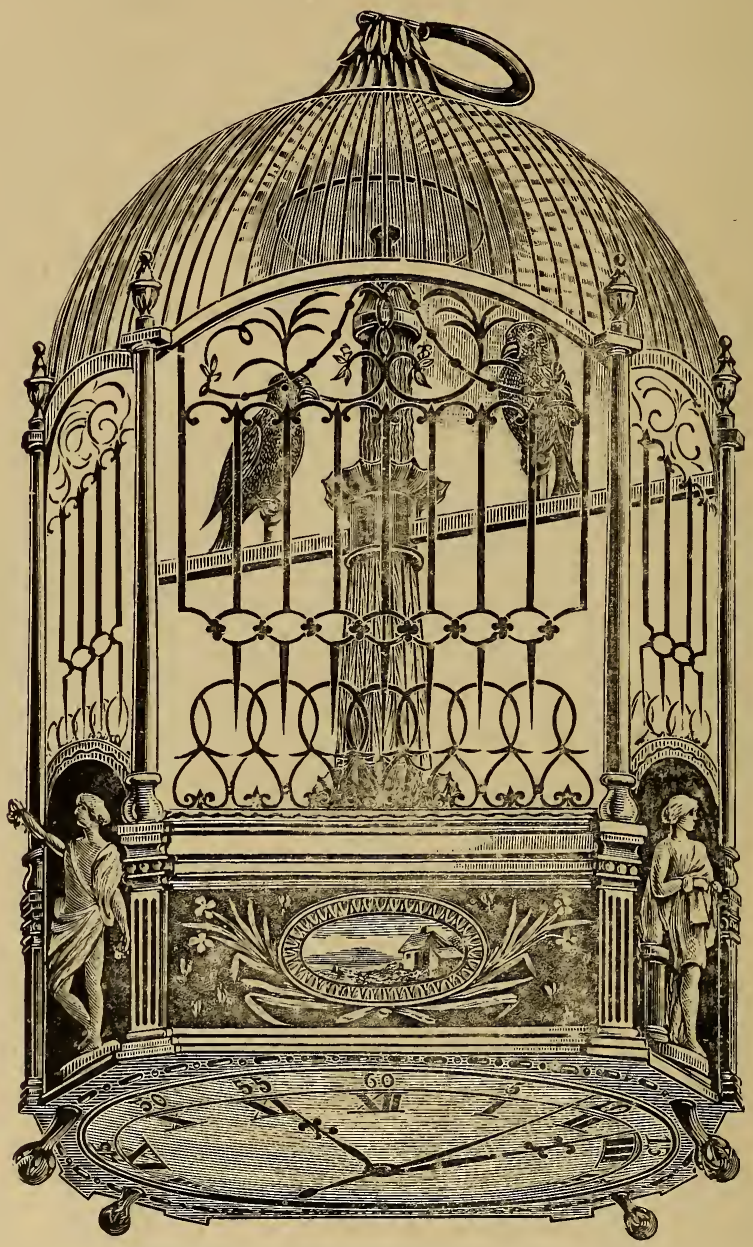

FIG. 620.-Bird-cage Clock about 1780 .

floated round till it pointed to the time, and then gradually crept to the figures in succession as the hours advanced. Underneath the rim of the bowl was a magnet of the horseshoe type, which was caused to revolve once in twelve hours; the tortoise was of cork and carried the "keeper" of the magnet. By the same agency he was 
French Clocks and Cases in the French Style 471 enabled to cause a lizard to ascend a column and a mouse to creep along a cornice with the hours marked on the frieze below.

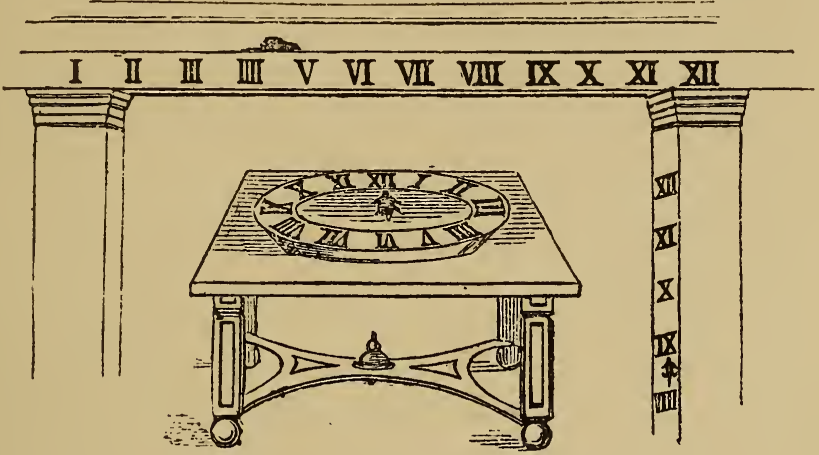

FIG. 621.-Magnetic Timekeeper.

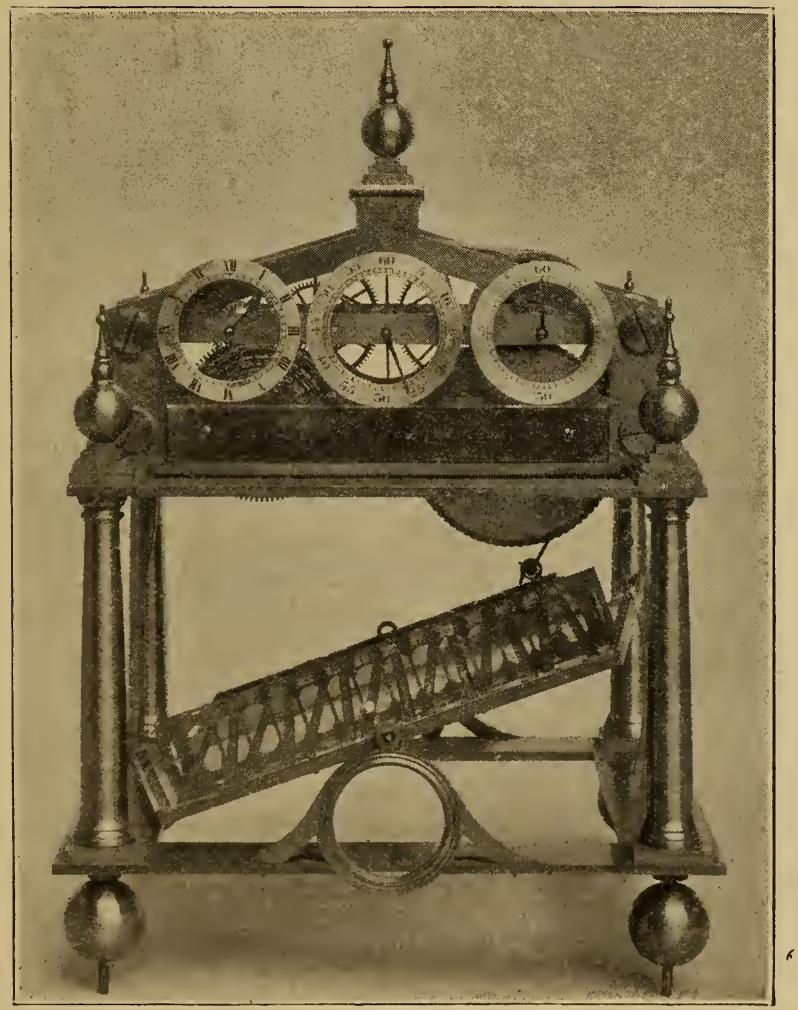

Fig. 622.-Congreve Clock. 


\section{Old Clocks and Watches and their Makers}

Congreve Clock.-William Congreve, best known as an inventor of war rockets, was an ingenious mechanician, an officer in the Royal Artillery, and a'member of Parliament. In succession to his father he became a baronet in 1814 and also Comptroller of the Royal Laboratory at Woolwich. In 1808 he patented a timekeeper in which a small metal ball rolled down grooves in an inclined plane, which was movable on its centre. The grooves were zigzag, forming a succession of V's, so that the ball, once started, traversed the whole surface of the plate by rolling down one groove and entering the next at the point of the V. On arriving at the lowest point of the inclined plane the ball with its acquired impetus unlocked the train, which thereupon reversed the inclination of the plane or table by the intervention of a crank and connecting rod, and the ball started on its journey in the other direction. The ball should be of platinum or other dense material to ensure sufficient impact in unlocking. Congreve clocks, as they are called, go fairly well if made with exactness and kept free from dust, but in spite of their really attractive appearance but few of them appear to have been made. At the Rotunda, Woolwich, is one of these curiosities bearing the following inscription: "This first experiment of a new principle for the measurement of time, invented by William Congreve, Esq., is humbly presented to His Royal Highness the Prince of Wales, 1808." Mr. R. Eden Dickson has one; another belongs to Mr. W. W. Astor ; I saw a fine specimen dating from about 1820, inscribed " John Bentley and James Beck, Royal Exchange." For the example in Fig. 622, which is signed " Henry Bell, Mount St.," I am indebted to Messrs. Jump \& Sons. The three dials indicate respectively hours, minutes, and seconds. This clock is now in the possession of Mr. Hansard Watt.

Fig. 623 is a rack clock in the collection FIg. 623.-Rack Clock. of Mr. Hansard Watt. It is probably 
of foreign construction and of the late 18th century. The board to which the rack is fastened is of ebony and red tortoise-shell. The clock is wound by simply pushing it up to the top of the rack and is its own driving weight. It takes about 30 hours to descend.

Japanese Clocks are peculiar. Formerly the Japs divided the daylight and darkness each into a period of six hours, which therefore, except twice a year, would be of unequal duration. Here $\sqrt{4} 4$ are representations of the six hour numerals which were used twice over and counted backwards. Mr. James Arthur in

7 5 "Time and its Measurement" tells us that animal equivalents were used to distinguish the two sets of hours, 9 at $\frac{1}{\pi} 6$ noon being Horse, and 9 at midnight Rat; the morning 8 , Ox, the afternoon 8 Sheep; the morning 7 , Tiger, the after$t{ }^{7}$ noon 7 , Monkey; the morning 6 (sunrise), Hare, the after78 noon 6 (sunset), Cock; the morning 5, Dragon, the afternoon 丸 5 , Dog; the morning 4 , Snake, the atternoon 4 , Boar. In being indicated by a fixed pointer. The hour numerals for noon and midnight remained stationary, the others were shifted on the dial at intervals as required by the season.

Fig. 624 shows a simple Japanese timepiece. There is no dial, but the progress of time is indicated by the downward motion of the driving weight. A pointer attached to the weight projects through a longitudinal slit running the length of the body of the case, and clasped on to the tront are metal hour marks which may be adjusted to different heights by the thumb and finger. There are thirteen of these marks, the last one being a repetition of the first. To the Rev. D. Holland Stubbs, who has several Japanese clocks, I am indebted for the illustration.

In a form of striking clock presumably used by the more wealthy classes, dials were provided and also two balances of the cross-bar kind, one of which controlled the motion by day and the other by night. At sunset, by means of a pin in the locking-plate of the striking train, one was automatically switched out of connection with the train, and the other substituted. Each arm of the balances had notches throughout its length, and the weights were shifted by hand at fortnightly periods, as in the more primitive timekeepers. Half-hours as well as hours were sounded, the strokes on the bell being given in the following order: $9,1,8,2,7,1,6,2,5,1$, 4,2 . The hours are $9,8,7,6,5,4$, the halves, $1,2,1,2,1,2$. In 
474 Old Clocks and Watches and their Makers
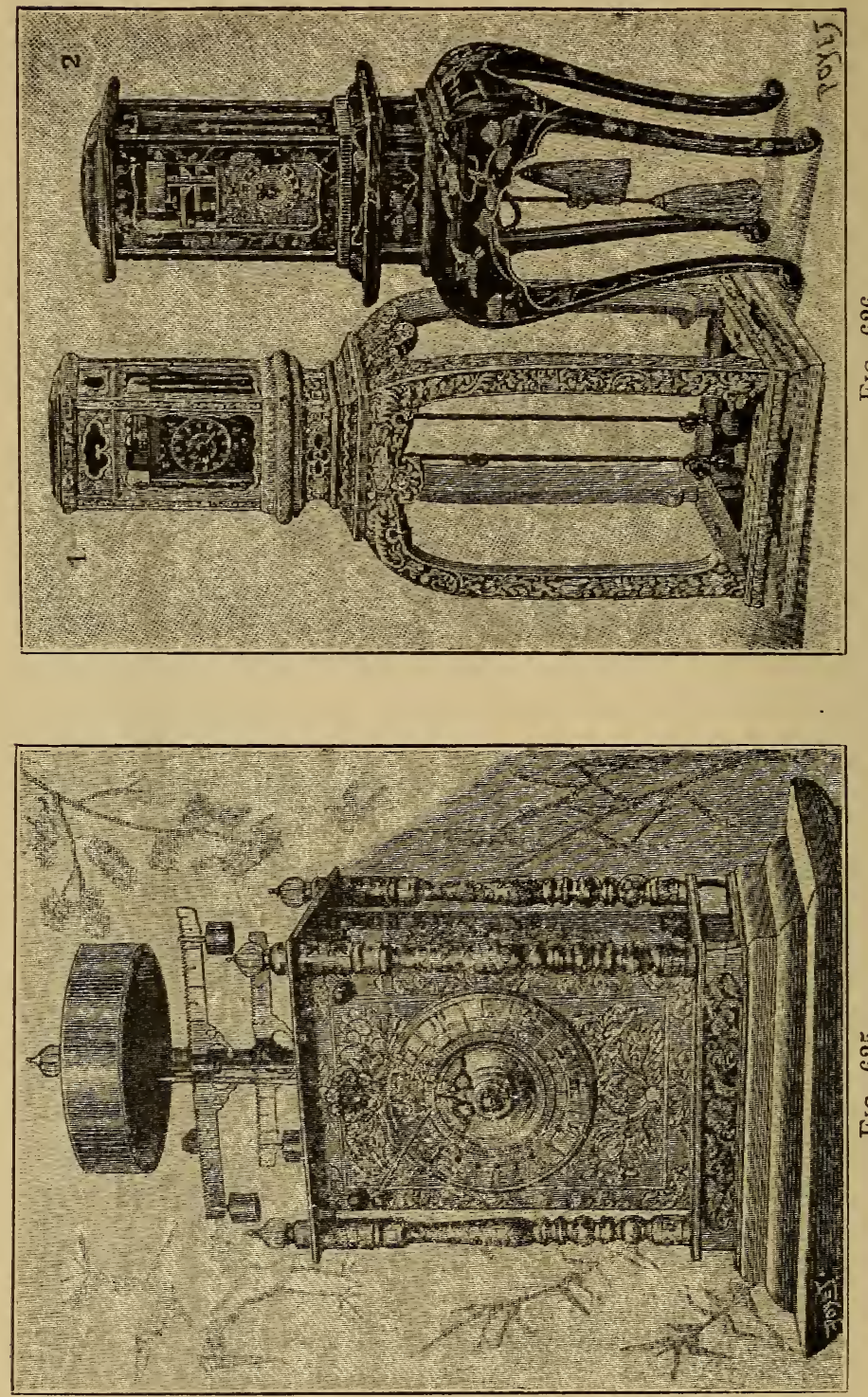

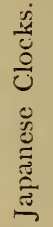

Q 
this way, when the half-hour was struck the hearer knew to which one of any two hours it referred.

There is a cross-bar Japanese clock with dial at the Horological Institute, and one with the automatic alternating arrangement at the South Kensington Museum. Fig. 625 shows this very well. This and Fig. 626 are from L'Horloge, which contains an interesting chapter by Mons. Planchon on Japanese methods of timekeeping. No. 1 of Fig. 626 is of porcelain, and No. 2 is decorated with Japanese lacquer and contains the clock shown in Fig. 625. In the latter the small counterweights are masked with tassels. These clocks and the whole of M. Planchon's Japanese collection are now the property

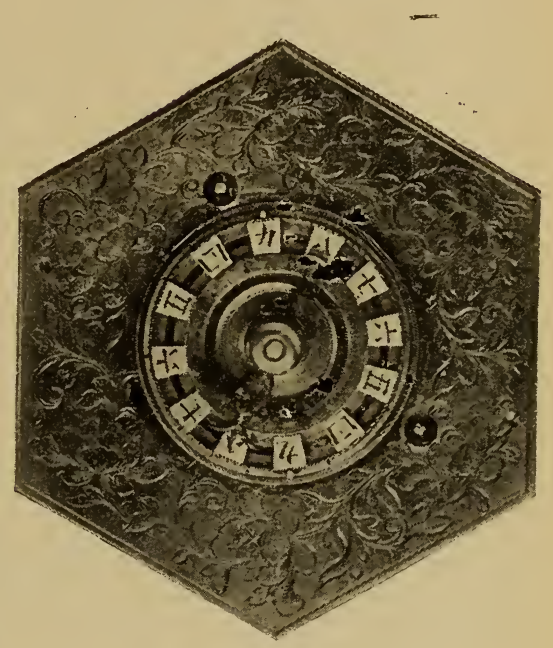

FIG. 627.--Japanese Table Clock. of Mr. J. Drummond Robertson. The death of Monsieur Planchon occurred on November 29th, 1921.

For a view of the exact size of the dial of a table clock I am indebted to Mr. F. Lodder. The hand is stationary and the dial rotates. Attached to the shifting hour pieces are pins which let off the hour striking mechanism at the right moment whatever may be the position of the pieces. 


\section{CHAPTER VII}

\section{THE PROGRESSION OF ENGLISH DOMESTIC CLOCKS}

THE manufacture of chamber clocks for domestic use, as distinguished from the costly and highly decorated timekeepers made for public buildings or to gratify the tastes of the wealthy, seems to have commenced about 1600 . These chamber clocks were of the pattern known as "lantern," " birdcage," or " bedpost." They were either hung against a wall or supported on a bracket, and wound by pulling down the opposite ends of the ropes to those from which the driving weights were hung. In some instances all the hours were struck in regular progression on the bell surmounting the structure, and sometimes the bell was only utilised as an alarm. In all cases the second train, for actuating the hammer, was placed behind the train for the watch, or going part. The framing was composed of four corner posts connecting top and bottom plates, the pivots of the trains being supported in vertical bars. In none of them was the train calculated for going more than thirty hours. At first the escapement with vertical verge and a balance as in De Vick's clock was used as the controlling medium, the verge being usually suspended from a string.

As soon as the pendulum was introduced, it quickly superseded the balance. The escape wheel was then as a rule planted to work in a horizontal plane, the pendulum being attached to the verge, and swinging either between the two trains of wheels or behind, according to the fancy of the maker. The alternate appearance of the pendulum weight at each side of the case led to its being called a " bob " pendulum, and pendulums of this kind are still known as bob pendulums, in contradistinction to the longer variety which at a later period, and with the anchor escapement, vibrated in a much smaller arc.

The movement was enclosed at the back with a brass plate; at the front was the dial plate, also of brass, and superimposed thereon a silvered hour band with engraved numerals ; at the sides were brass doors, and when the pendulum was between the trains, a slit was cut in each door to allow the pendulum to " bob " in and out. 
The Progression of English Domestic Clocks

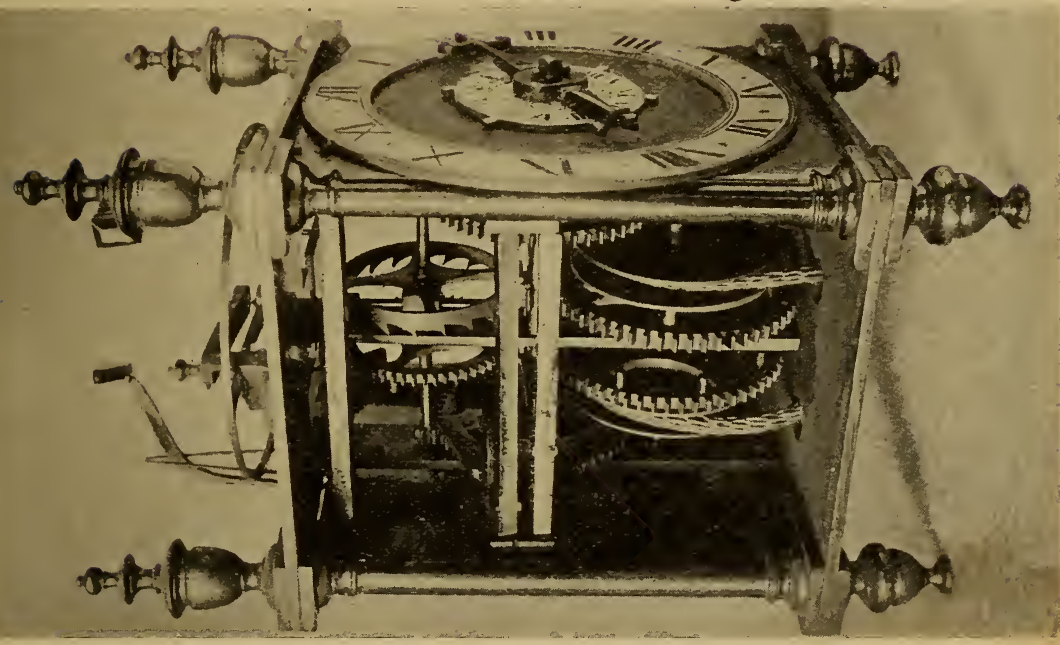

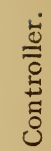

$\pi$

तี

马

త

䓠

尝

ป

픔

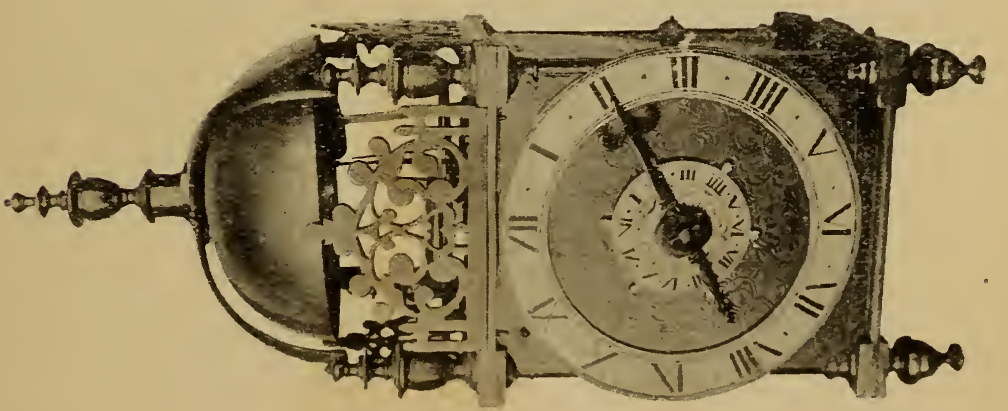

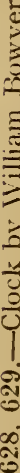


47. Old Clocks and Watches and their Makers

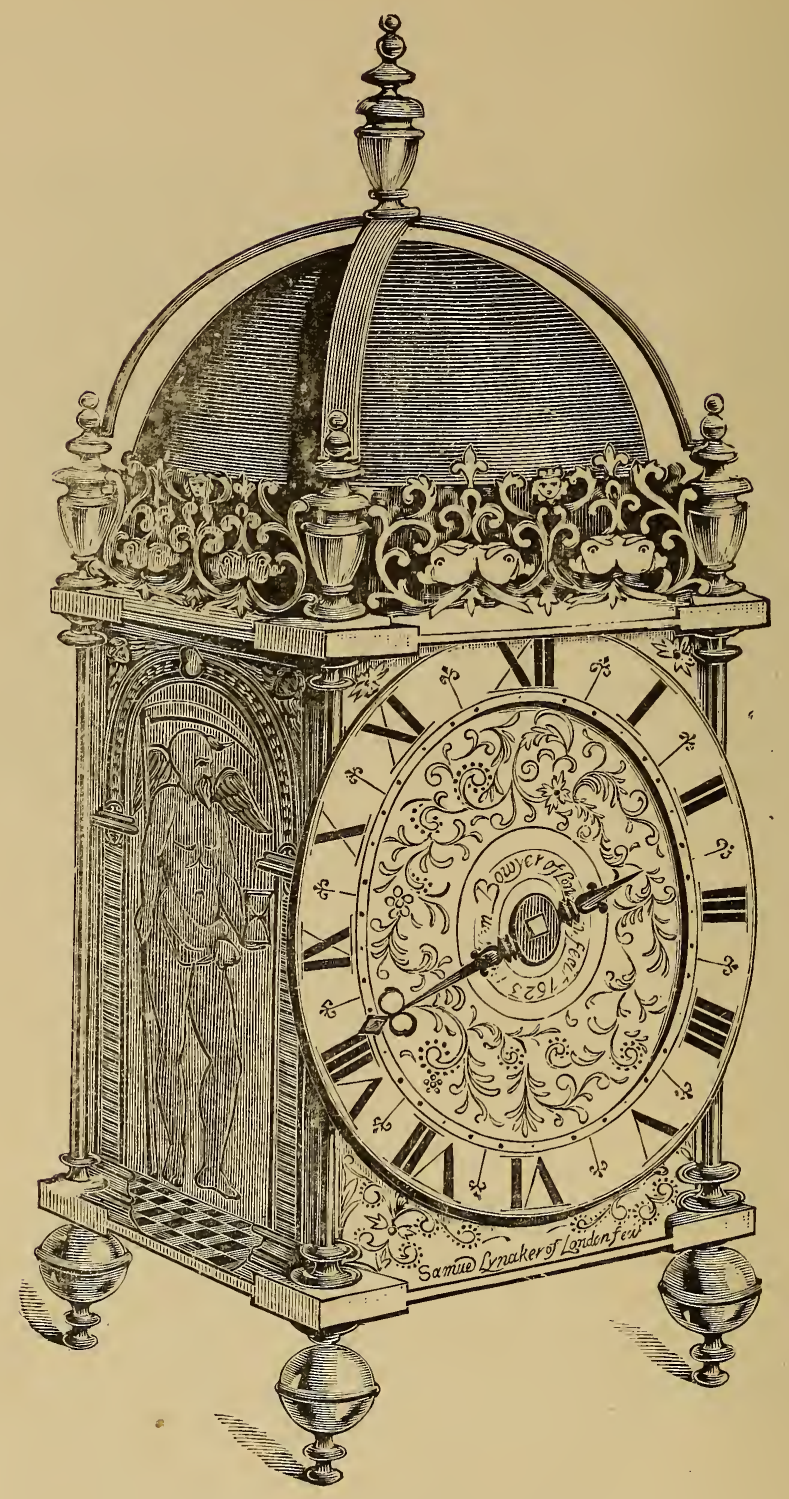

FIG. 630.-“"Great Chamber Clock,” 1623.

In the earliest of these clocks the dials were, as a rule, thickly gilt ; the hour circles narrow and the numerals stumpy, the front one of the frets surrounding the bell at top, in many instances, had a shield for 


\section{The Progression of English Domestic Clocks}

the crest or initials of the owner. The doors were often made of sundial plates, as may be seen from the engraving on the insides of early specimens; doubtless the introduction of clocks played havoc with the demand for the older time recorder, and induced many sun-dial makers to turn their attention to the production of clocks. The maker's name was engraved along the base of the fret; or inscribed at the top or bottom of the centre of the dial, just within the hour ring; or placed out of sight under the alarm plate, the latter practice leading to the assumption that the clock was to be sold by some one other than the maker. It may be assumed that each of the leading craftsmen introduced alterations in style from

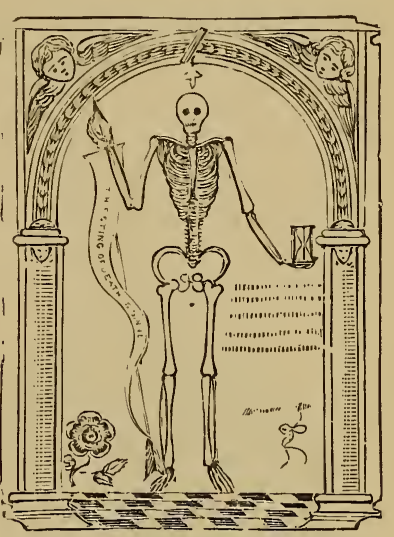

FIG. 631.--Side door of Clock. time to time and designed fretwork and other ornament for his exclusive use ; but it is pretty evident that such variations were speedily copied by the general run of makers, for most clocks of the same period bear a marked resemblance to each other; possibly much of the material was supplied from the same foundry and cast from the same pattern. About 1640 the hour bands were made wider, with longer numerals, and the fret with the crossed dolphins came into use.

Among those who subscribed to the fund for obtaining the Charter of Incorporation of the Clockmakers' Company in 1630 was William Bowyer, who then appears to have been a clockmaker of repute. It is stated in Overall's " History of the Clockmakers' Company," that in 1642 Bowyer presented to the Company a great chamber clock in consideration of his being thereafter exempted from all office and service as well as quarterage and other fees.

Mr. J. Drummond Robertson possesses a lantern clock by Wm. Bowyer, which is shown in Figs. 628 and 629 . It dates probably from about 1620. The hour circle is of a primitive character, there being no division strokes to mark the half-hours and quarters. The trains of wheels run in opposite directions, and the original balance of circular form, $4 \frac{1}{2} \mathrm{in}$. in diameter, is retained. The extreme height of the clock is $16 \frac{1}{2}$ in., and the width of the dial $5 \frac{3}{4}$ in.

Fig. 630 shows another specimen of Bowyer's work. It is a "large Chamber clock," which measures $8 \frac{1}{2} \mathrm{in}$. across the dial, its 
total height being $16 \frac{1}{2}$ in. Around the centre of the dial is inscribed, "William Bowyer of London fecit 1623." This was doubtless formerly covered by an alarm disc. Along the bottom of the dial is engraved, "Samuel Lynaker of London." Now Samuel Linaker was named in the Charter of Incorporation of the Clockmakers' Company to be one

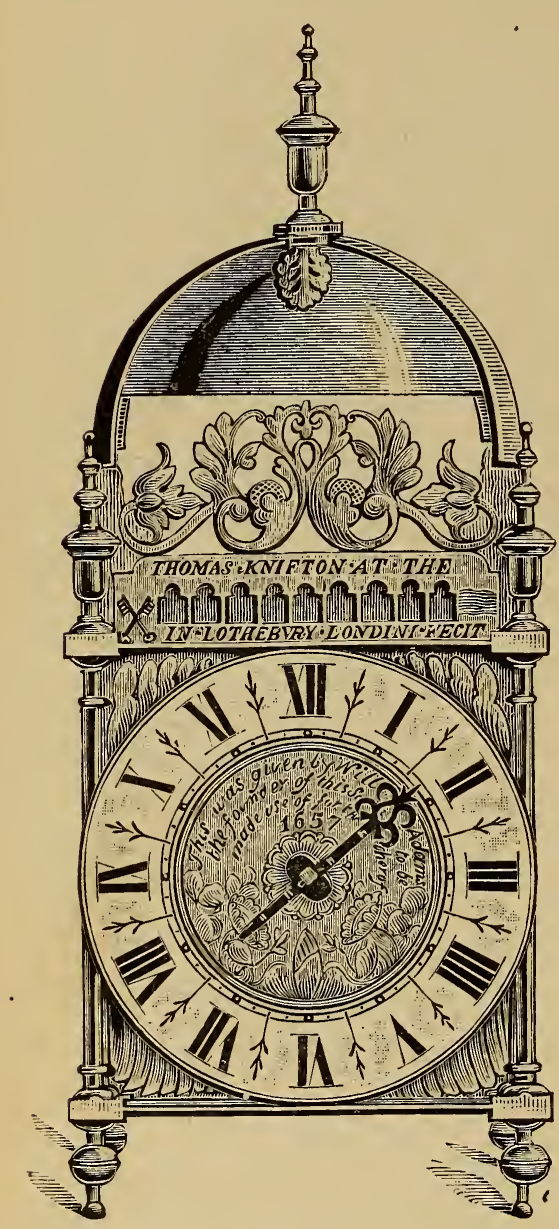

FIG. 632.-Large Lantern Clock, by Thomas Knifton. of the assistants, as the members of the Committee of Management were termed, and it seems to be a fair inference that the clock was made by Bowyer for Linaker.

On the side door of the clock, which is visible in Fig. 630, a figure of Time is engraved; and on the other door a figure of Death, as shown to a reduced scale in the sketch, Fig. 631. In the right hand of the figure appears to be a torch, and depending therefrom is a streamer on which are the words, "The sting of death is sinne." The left hand holds a sand glass, and underneath are the following lines :--

"Man is a glase, Life

Is as water weakly washed about, Sinns brought in death.

Death breakes the glase, So runes this water out."

In larger characters is the admonition, "Memento Mory."

Very possibly the doors of such clocks were engraved to suit the tastes of purchasers. There are no particulars obtainable as to the early history of this example. I remember seeing another large lantern clock by the same maker which was inscribed, "William Boyear, in Ledenhall Streete, fecit." The movement of this clock was arranged in the usual manner, the striking train behind the going, and working 
The Progression of English Domestic Clocks 48I

in three upright bars. It required a great fall of the driving weights to go thirty hours, as each of the main wheels made one rotation per hour. The original vertical escapement, as usual, had been removed; but from parts remaining it could be seen that it was
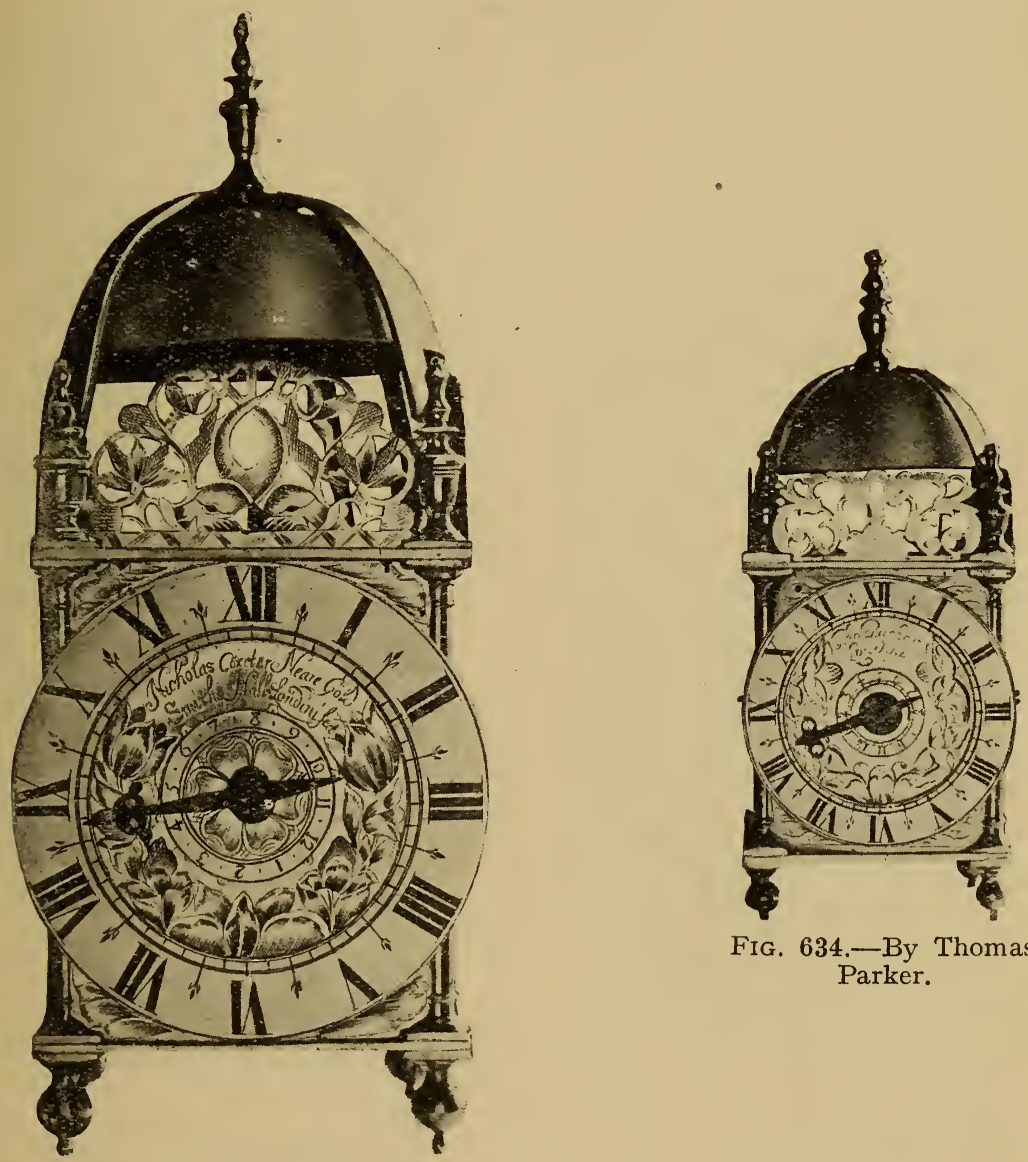

FIG. 634.-By Thomas Parker.

Frg. 633.-By Nicholas Coxeter.

A large and a small Lantern Clock to the same scale, showing contrast in size.

identically the same as the drawings of De Vick's. The wheels and pinions, as one sometimes finds, were very little cut, and though evidently rounded by hand, seemed very nearly correct, and ran 
482 Old Clocks and Watches and their Makers

easily without chattering. The hour wheel was driven by a pinion of four, the end of the main wheel staff being filed up into four pins to serve the purpose.

Mr. Hansard Watt possesses a fine lantern clock which is shown in

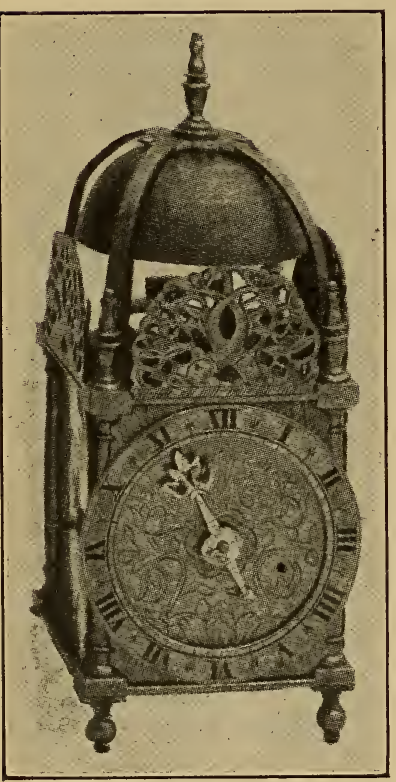

Fig. 635.-Lantern Clock, by Thomas Knifton.

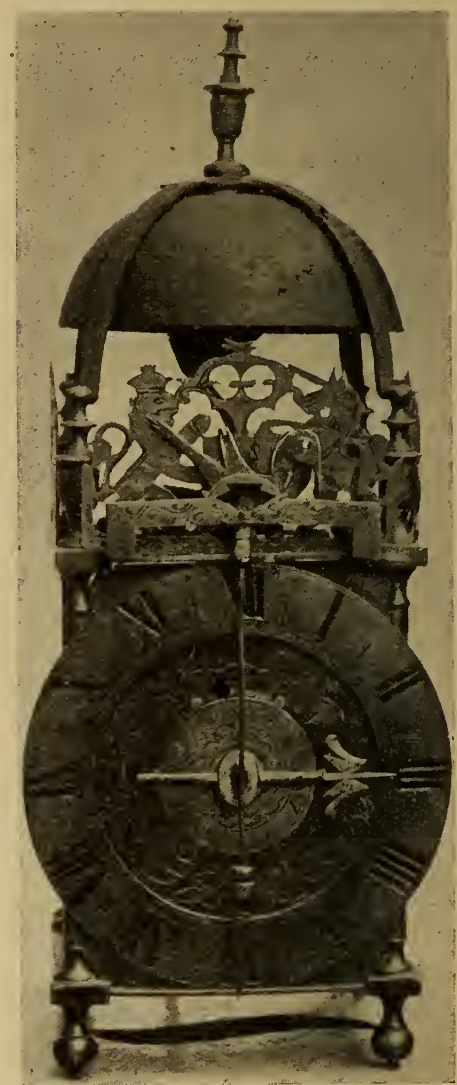

Fig. 636.-Clock with Pendulum in Front of Dial. At the head of the pendulum is the figure of a Snipe which rocks to and fro.

Fig. 635. The example measures $8 \frac{3}{4}$ in. in height, $3 \frac{1}{2}$ in. in width, and $4 \frac{3}{4}$ in. in depth. It has a narrow hour circle of $\frac{7}{16}$ in. and a finely pierced steel single hand. The centre of the dial is engraved with tulips and the maker's name "Thomas Knifton at ye Cross Keys in 
The Progression of English Domestic Clocks 483

Lothbury Londini." The movement is 30 -hour striking, with crown wheel escapement and bob pendulum. It is a fine timekeeper and in perfect state.

Another interesting lantern clock of large size is shown in Fig.

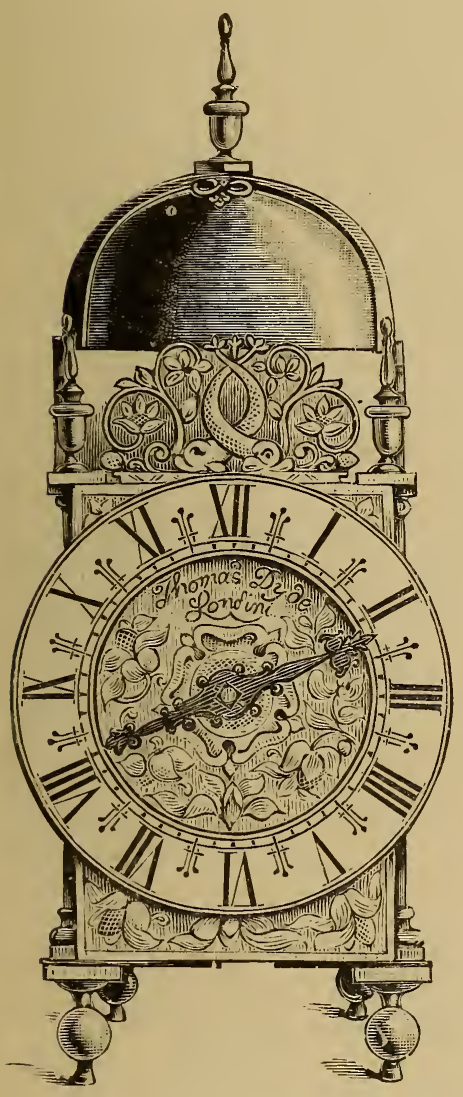

FIG. 637.

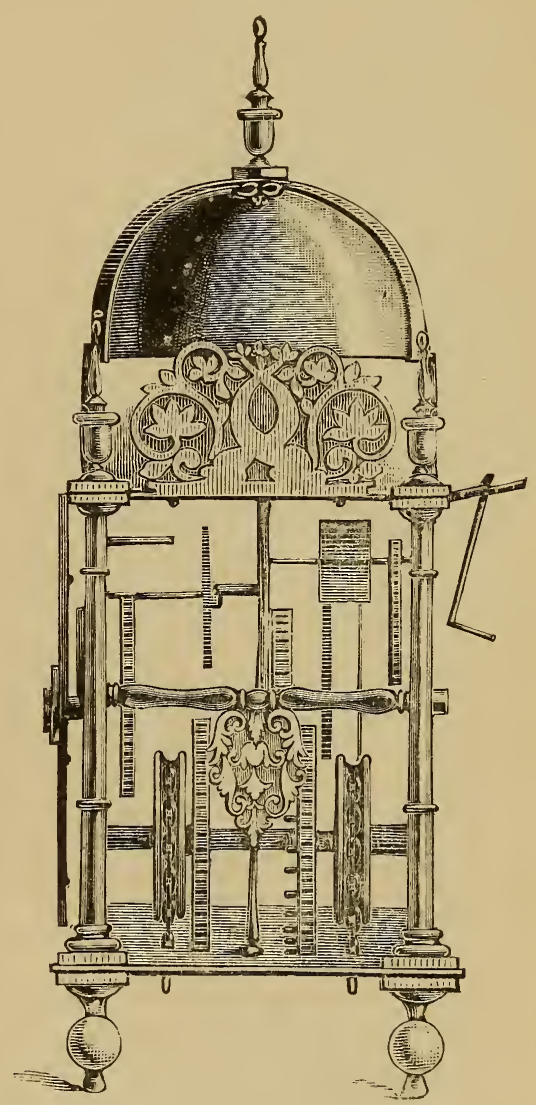

FIG. 638.

Lantern Clock, by Thomas Dyde.

632 , the dial measuring $7 \frac{1}{8} \mathrm{in}$. across. The gallery fret above the dial is particularly well designed, and bears the inscription, "Thomas Knifton at the Cross Keys in Lothebury, Londini, Fecit." Thomas Knifton was well known among the early makers. On the 
upper part of the space within the hour ring is engraved, "This was given by William Adams, the founder of this Schoole, and is to be made use of for the benifit thereof, 1657." The reference is to a school in Newport, Shropshire, founded by William Adams, and by him placed under the superintendence of the Haberdashers' Company, of which he was a member.

Clocks of this size were, I think, exceptional. Most that I have seen of the period varied from about 3 in. by $2 \frac{1}{2}$ in. to 5 in. square. Larger movements were more favoured at the end of the seventeenth century and beginning of the eighteenth century. After about 1660 the dial was, as a rule, increased in size, with relation to the body of the clock so that it projected more on each side of the frame. This departure may be observed on the lantern clock by Tompion, which dates from about 1665 , and is shown on p. 279.

In Figs. 633 and 634 are shown to the same scale a fine specimen dating from about 1650 by Nicholas Coxeter and a smaller piece by Thomas Parker. These are both from the collection of Mr. T. W. Bourne.

For the peculiar arrangement shown in Fig. $636 \mathrm{I}$ am indebted to Mr. W. H. Kendall. The pendulum is in front of the dial, and on the top of it is perched a snipe which moves to and fro as the pendulum swings. The letters "W. S.," presumably the initials of the maker, are engraved on the clock, as is also the date, 1683.

Front and side views of a good specimen by Thomas Dyde, dating from about 1670 , engraved by favour of Mr. Shapland, are given in Figs. 637 and 638 . A particular feature in this clock is the unusually elaborate pierced work attached to the hammer tail detent, which may be seen in Fig. 638.

Fig. 639 represents a little clock fixed to the wall. It is by Thomas Wheeler and belongs to Miss Mary F. Bragg. Fig. 640, taken from a drawing by Mr. William Newton, shows well the usual arrangement on a bracket. The name, William Ruthven, on the door of the clock was probably that of the owner.

Lantern clocks, as a rule, were furnished with an hour indicator only. Fig. 641, from the Wetherfield collection, is an exceptional piece by "Joseph Knibb Oxon " dating from about 1670 . It is $8 \frac{1}{2}$ in. high and $3 \frac{1}{2}$ in. across the dial ; has an alarm and both hour and minute hands. Among the few examples fitted with two hands may be mentioned a much larger clock by Davis Mell, Londini, which dates from about 1675 and belongs to Mr. J. Drummond Robertson. 
It is described in Chapter IX. See also the clock by Edward East, Fig. 417.

Many clocks made during the latter part of the reign of William III. and in the time of Queen Anne had the dials projecting beyond the frames trom 2 to $3 \mathrm{in}$. on each side. These are generally known as sheep'shead clocks. However much the usefulness of the clock may have been increased by the superior legibility of its hour ring, it cannot be contended that the overhanging disc improved its general appearance. A good example by Robert Evens, Halstead, which belongs to Mr. T. W. Bourne, is shown in Fig. 642.

With little variations in the style, these brass clocks seem to have been made from the time of Elizabeth until about the beginning of the reign of George III., the later specimens being principally of provincial manufacture, and with arched-top dials. They are still often to be met with in the country, enclosed in a wooden hood as a protection from dust, with pendulum and weights hanging below. Sometimes they are without any extra case, and, instead of being placed on a bracket, are simply attached to the wall by means of an iron loop and two prongs.

The "fret" at the top of the case may in many instances be somewhat of a guide in estimating the period of a lantern clock. Appended are examples, for several of which I am indebted to Mr. Percy Webster.

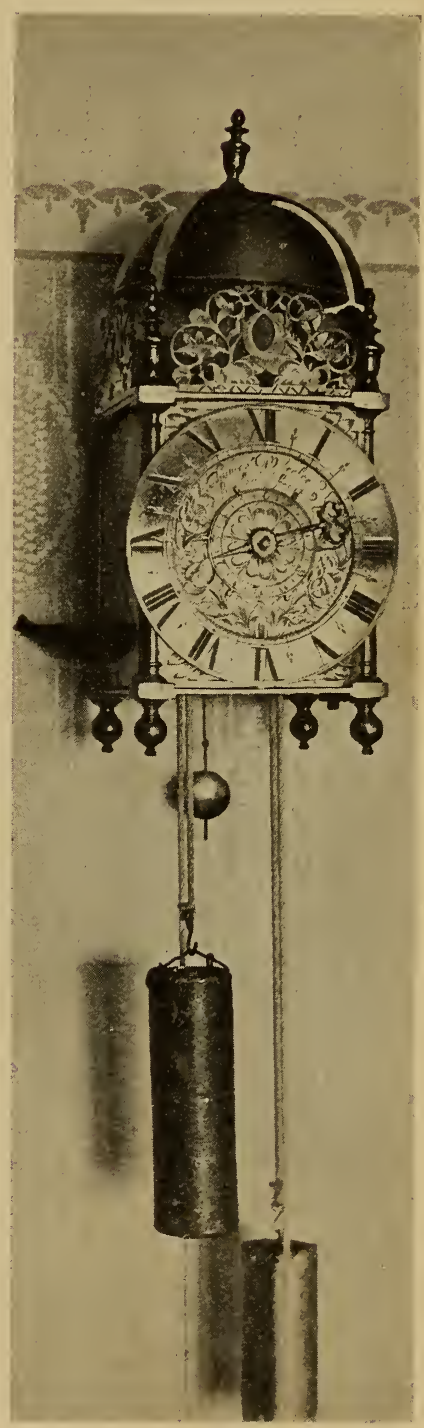

FIG. 639.-Lantern Clock, by Thomas Wheeler, with Alarm as fixed to wall. 
The heraldic fret (Fig. 643) was in use at the earliest period up to 1630 or 1640 . Frets of William Bowyer may be seen on Figs، 628 and 630 . Another fret used by him, and also by Thomas Loomes, is

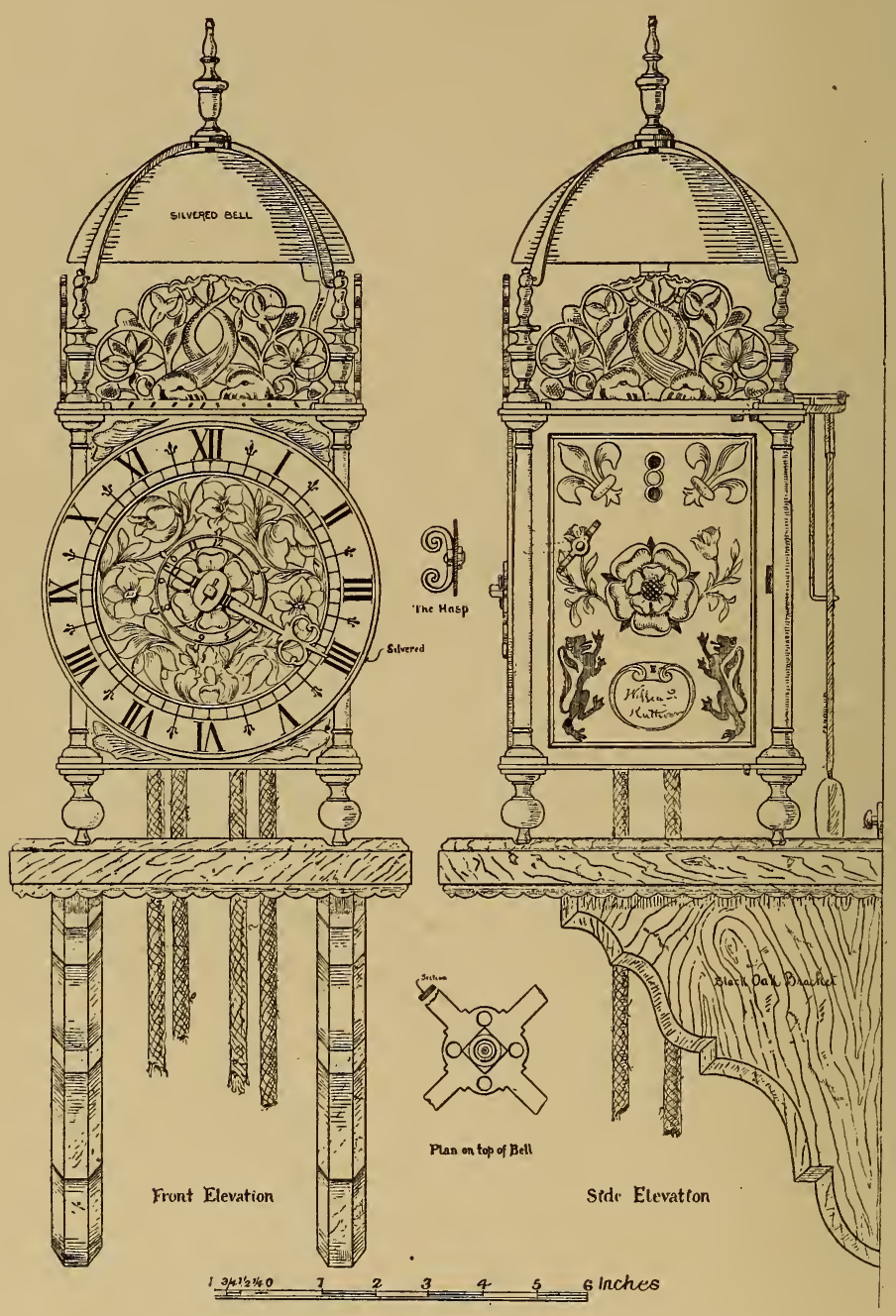

FIG. 640.

shown in Fig. 645. The fret of Bowyer in Fig. 644 was used as well by Peter Closon, another early maker. The Thomas Pace fret (Fig. 646) may be taken to represent the period between 1630 to 1660. 
The crossed dolphins came into use about 1640, and were a favourite pattern from then as long as lantern clocks were made. An uncommon and unusually fine fret may be observed on the clock by Thomas Knifton, shown in Fig. 632. The fret on the clock by Thomas Parker (Fig. 634) will also bear examination. J. Michell of

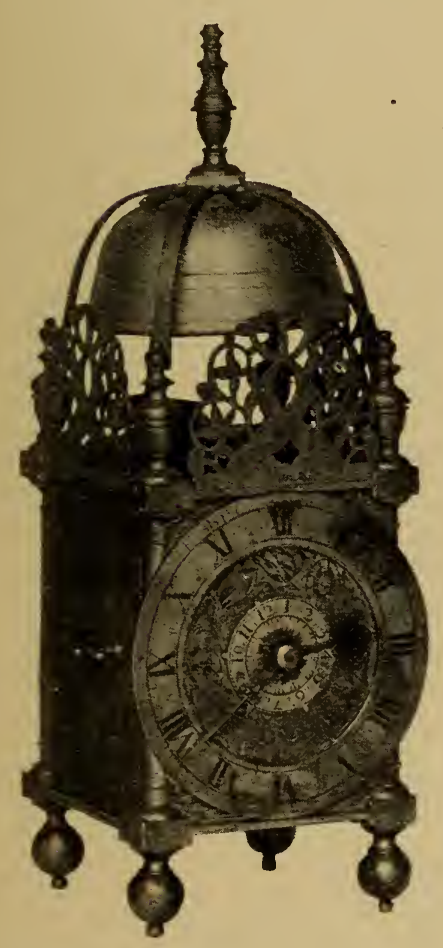

FIG. 641.-Joseph Knibb, London. Alarm, Hour and Minute Hands.

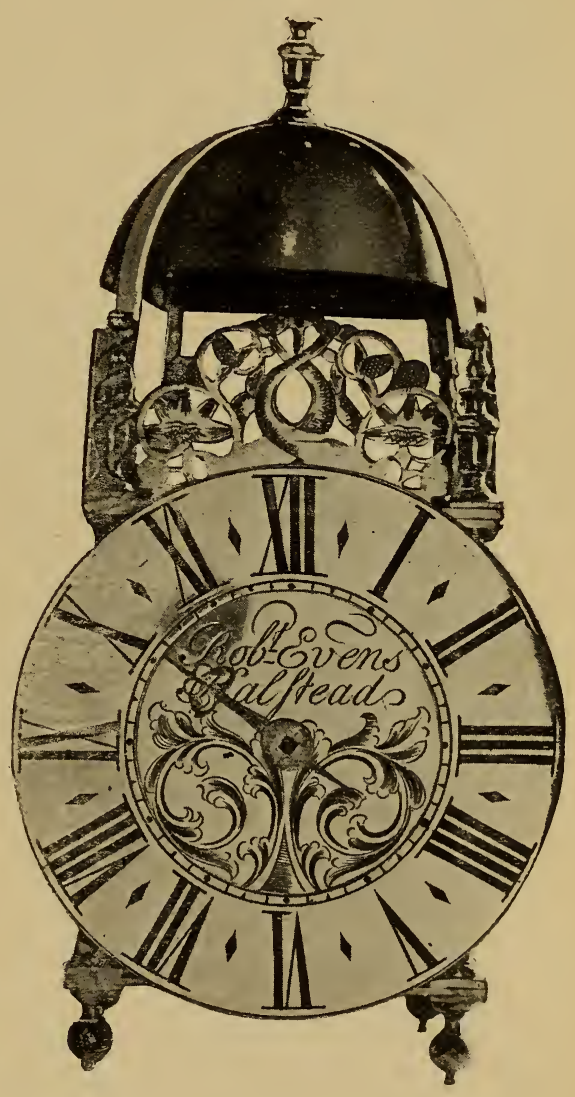

FIG. 642.--Sheep's-head Clock, by Robert Evens, Halstead.

Chardstock, a village in Somersetshire, was an excellent maker of lantern clocks about 1700 , and judging from the number of specimens still existing, he must have had a considerable connection. His frets were good and bore a distinctive character. The one shown in Fig. 648 is from a clock in the possession of Mr. S. Good, Seaton, 

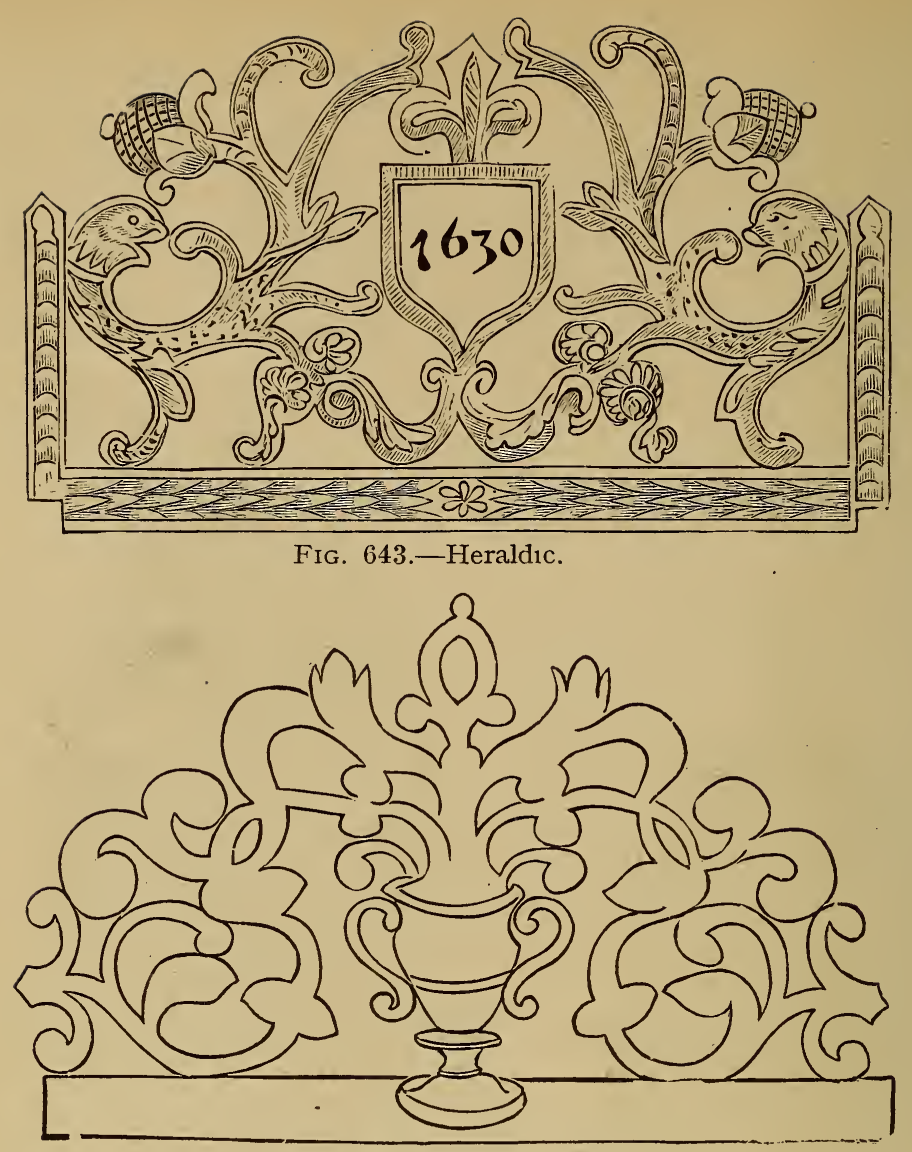

FIG. 644.-William Bowycr.

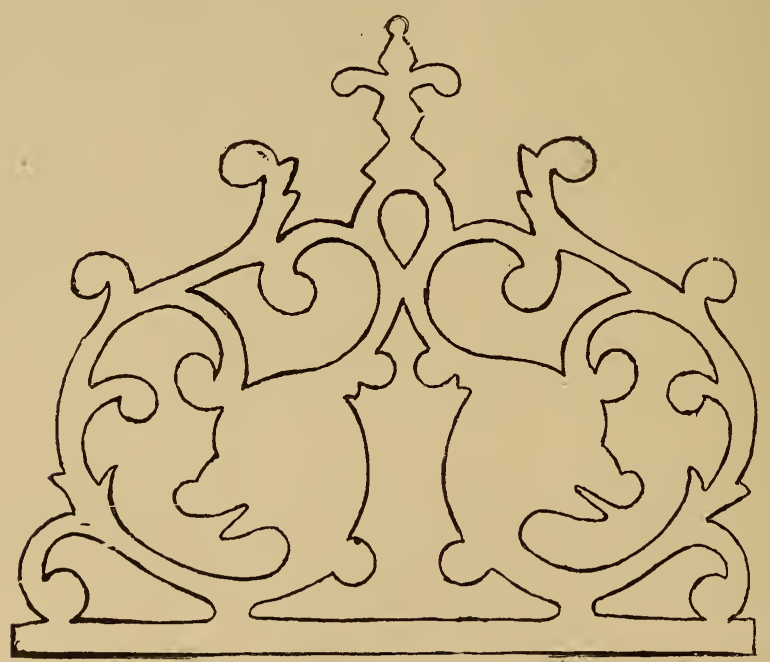

FIG. 645.-William Bowyer; also Thomas Loomes. 


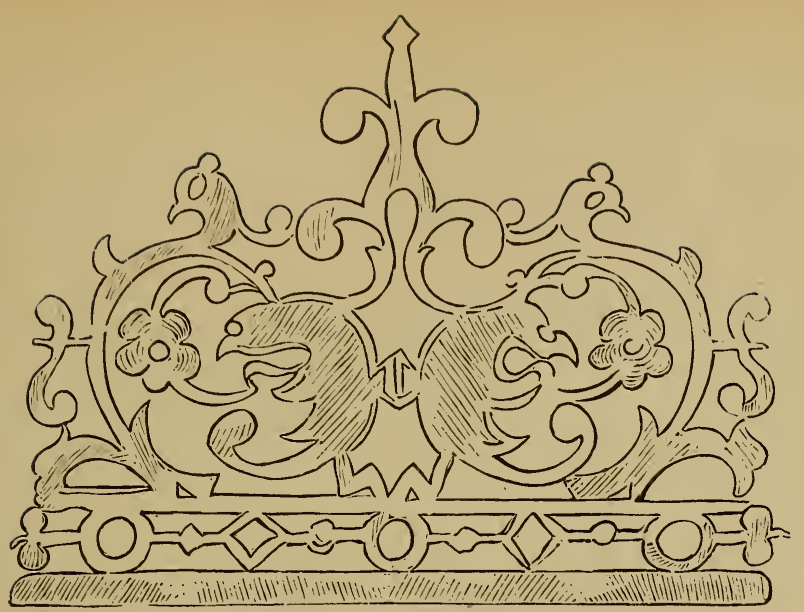

FIG. 646.-Thomas Pace at the Crown.

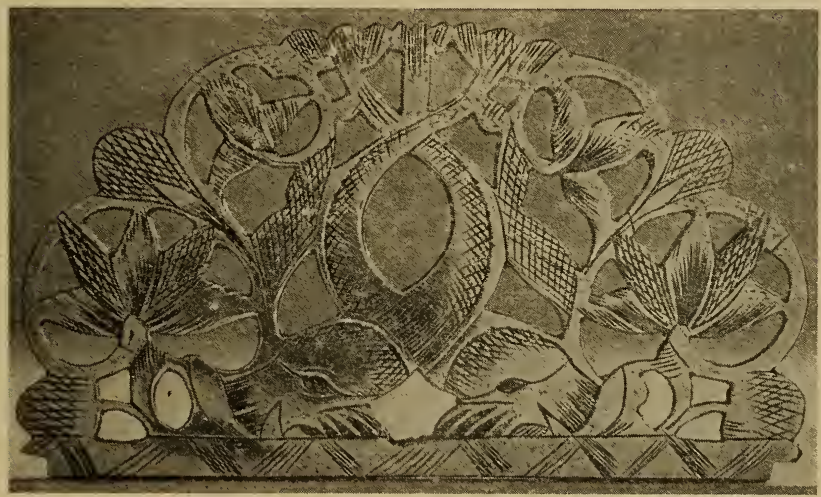

Fíg. 647.-Dolphin fret, from Clock by Nicholas Coxeter.

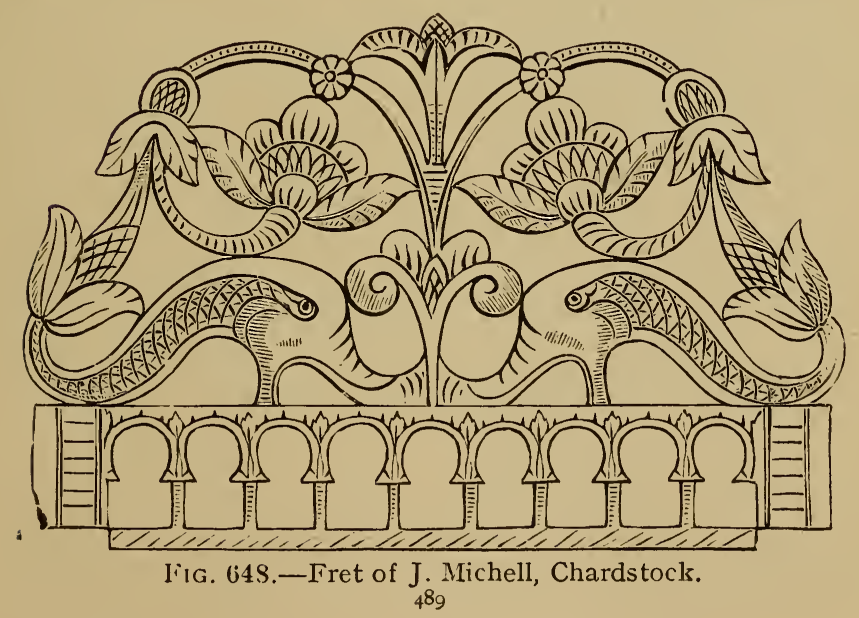


Devonshire. Michell was succeeded by the family of Drayton, of which several generations successively carried on the business till past

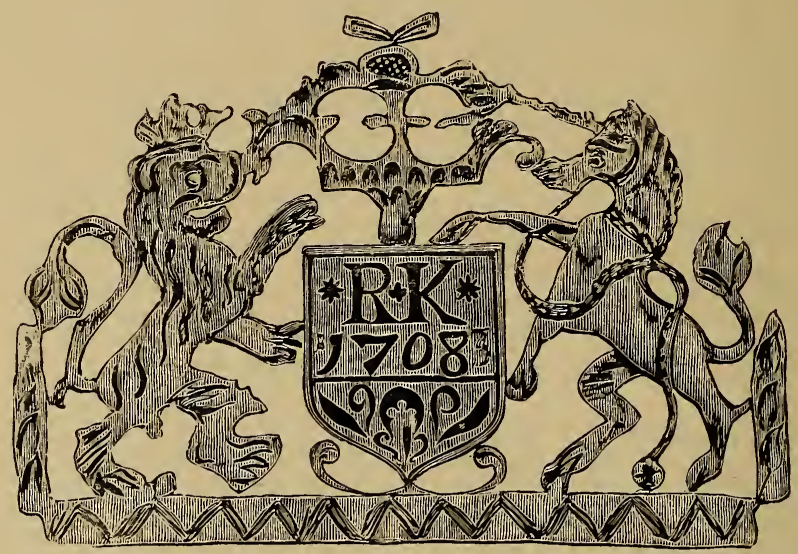

Fig. 649.-Fret similar to the supporters in the Royal Arms.

the middle of the nineteenth century; the last mo mer being Thomas Drayton. A fret as in Fig. 649, embodying something similar to the supporters in the Royal arms, is occasionally to be met with. The

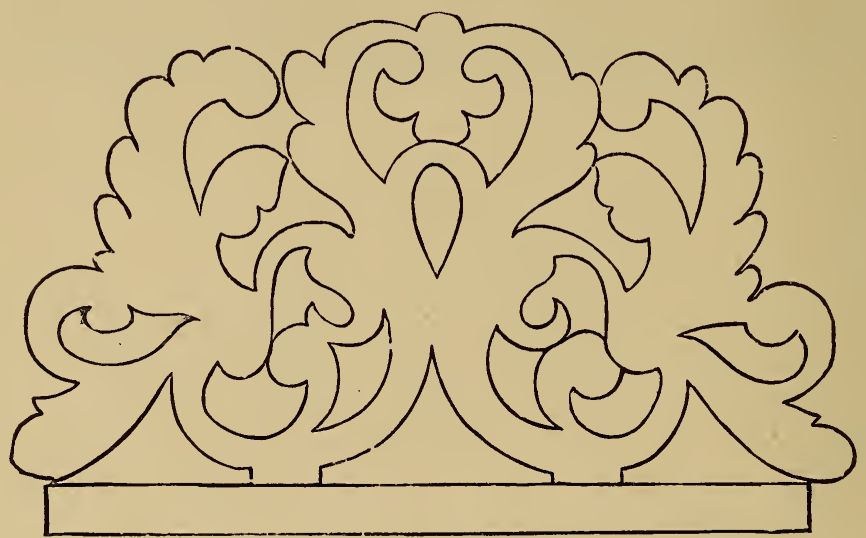

Fig. 650.-Late period Fret used in the Eastern Counties.

initials preceding the date may be those of the owner or the maker. Frets similar to Fig. 650 are found upon later specimens, particularly those made in the Eastern counties. 
The Progression of English Domestic Clocks 491

Hood Clocks.- These have been referred to as a transition between the brass-cased lantern and the wooden long-case. Fig. 651

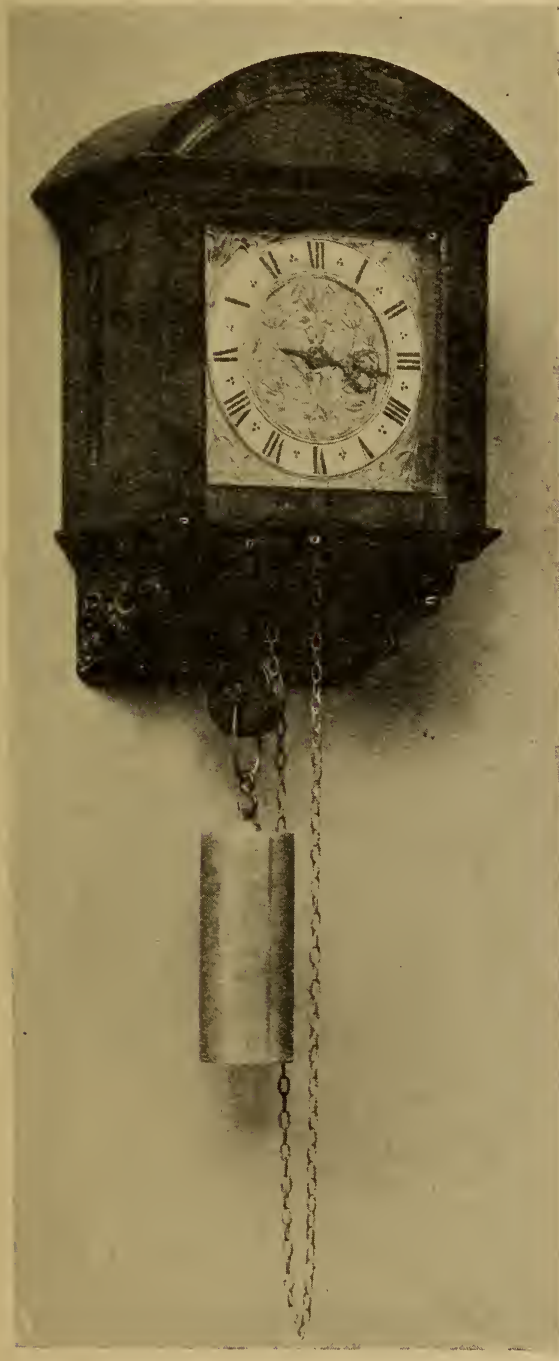

Fig. 651.-Joseph Knibb, London, about 1680 .

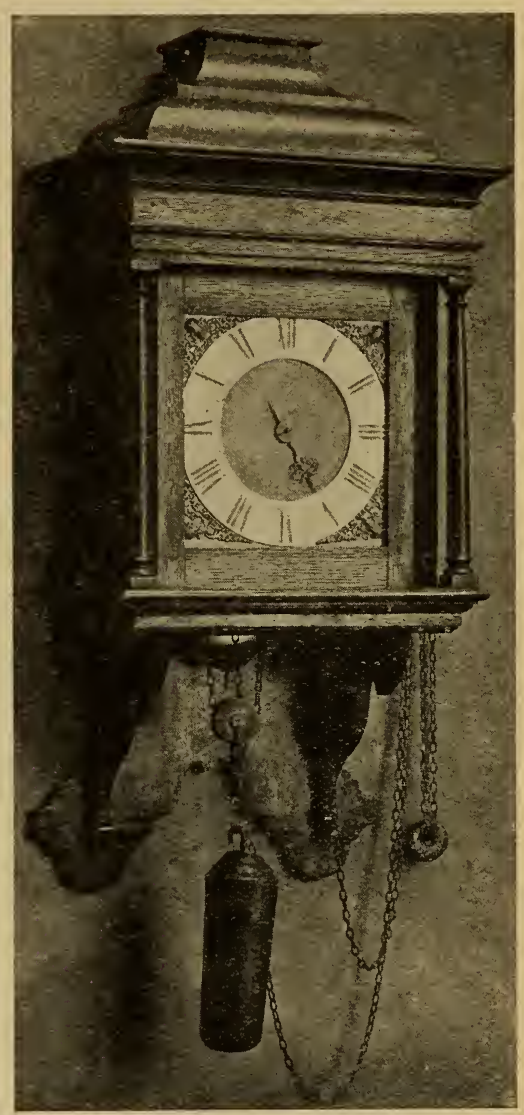

FIG. 652.-Hindley, York, about 1710.

shows a diminutive thirty-hour hanging clock by Joseph Knibb, London, from the Wetherfield collection, and made about 1680 . The carved bracket on which the movement rests and the hood are of walnut. The dial is 5 in. wide. A later and larger example signed "Hindley, York," in an oak case is shown in Fig. 652, by favour of Mr. William Birchall. Captain 


\section{Old Clocks and Watches and their Makers}

Edward Lethbridge owns a clock by Thristle, of Williton, a village in Somerset, with a carved top hood of mahogany. The dial measures about $7 \mathrm{in}$. across, and has an arched top with a figure of Time and the motto "Tempus fugit." A long pendulum swings below the bracket. The date of its production would be about 1730. Mr. W. T. Harkness has one by " Payne, Hadleigh," of the same period, also with a mahogany hood.

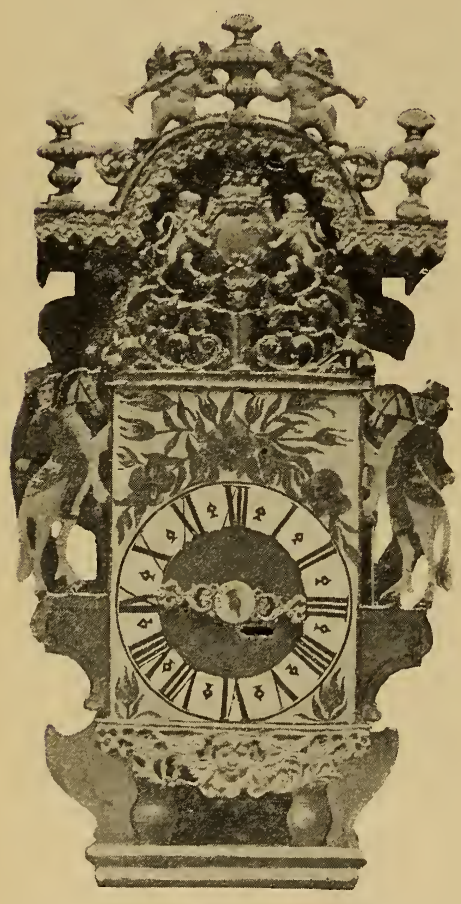

FIG. 653.-Early Friesland Clock.

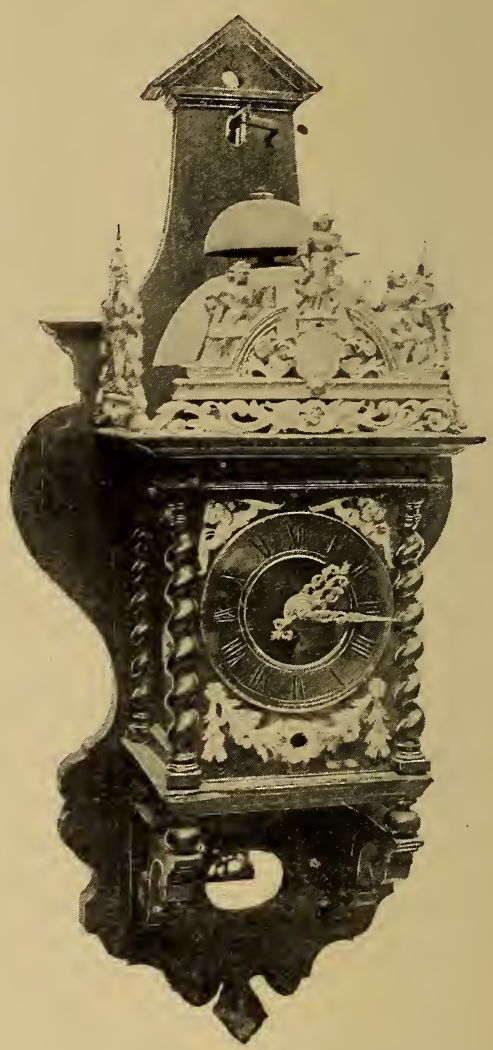

FIG. 654.-Zaaindam Clock.

Hood clocks were popular in Holland for a long priod. The best of these were made in Zaandam, but a larger number in Friesland. The earliest had but one hand, as in Fig. 653, which represents a Friesland clock, presented to the Bankfield Museum by Mr. J. Whiteley Ward. There were usually two bells of different sizes. The completion of each hour was marked by strokes on the large bell, while the same 
number of strokes on the small bell denoted the succeeding half-hour. In the later clocks the intermediate quarters also were sounded, one blow on the small bell being given at the first quarter, and one blow on the large bell at the third quarter. Sometimes the pendulum was in front, and sometimes at the back of the bracket. In the latter case the bob would be of a fancy shape, such as that of a man on horseback, and be visible through an oval hole in the bracket. For Fig. $654 \mathrm{I}$ am indebted to Mr. Webster. Mr. J. Drummond Robertson has a similar Zaandam clock in a case of ebony with the four posts of the movement of rosewood. The dial plate is covered with black velvet forming an effective background for the hour band and outer decorations which are all of brass. The front fret shows Faith, Hope, and Charity.

A much rarer style of Dutch clock, which strikes the quarters, and appears to date from about 1675, is shown in Fig. 655. The movement and case are entirely of iron, the sides and front being adorned with oil paintings, which are very effective. The main dial has an hour hand only and contains no minute marks, but fractions of an hour are indicated on a smaller dial below.

In Dutch movements, made at the beginning of the eigh-

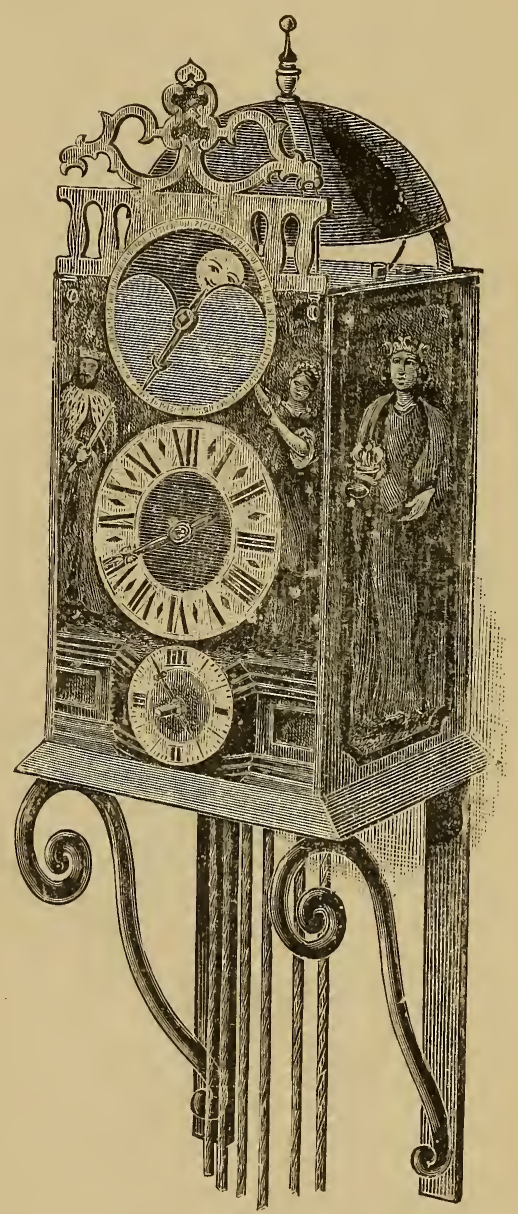

FIG. 655.-Unusual Dutch Clock, with painted case. teenth century, a long while after the adoption of the pendulum, the çrown wheel and verge were retained in a vertical position, and the pendulum was suspended above the movement at the back of the case, quite detached, and connected with the escapement only by means of a light wire crutch, working 


\section{Old Clocks and Watches and their Makers}

horizontally over the frame. Owing to this peculiarity, clocks of such a construction are often supposed to be much older than they really are, especially if, as occasionally happens, the pendulum gets removed or lost ; for, when this occurs, the remaining part of the movement almost identically resembles the drawings of De Vick's clock.

Another instance of the slow appreciation of improvement is the very gradual acknowledgment of the minute hand. Clocks with an hour hand only were produced by country makers till quite the end of the eighteenth century.

Lantern clocks were made long after the long case was introduced. Indeed, one occasionally sees an adaption of the bedpost movement to the needs of the later construction, the two trains being placed side by side to allow of winding with a key from the front, but with six pillars instead of the more simple and convenient back and front plates.

Long-case Clocks.-It would be difficult to say exactly when the brass chamber clock with a wooden hood developed into the long-case variety, now familiarly termed " Grandfather," but it was probably between 1660 and 1670 . In the earliest the escapement was governed by a balance, or by a short pendulum. John Smith, in "Horological Dialogues," published in 1675, says: "If your pendulum clock be of the ordinary sort the trouble and manner of hanging it up is the same with the balance clock, viz., to drive an hook for it to hang on." But he also speaks of "setting up long swing pendulums after you have taken it from the coffin " and adds " the same rule that is given for this serves for all other trunck-cases whatsoever."

In his " Horological Disquisitions," issued in 1694, Smith is much more precise and refers to the anchor escapement and improved pendulum " invented by that eminent and well-known artist, Mr. William Clement." He gives a list of " Crown Wheel Pendulums," from $1 \mathrm{in.}$ to $12 \mathrm{in.} \mathrm{long,} \mathrm{and} \mathrm{then} \mathrm{a} \mathrm{list} \mathrm{of} \mathrm{"royal} \mathrm{"} \mathrm{pendulums,}$ as in his enthusiastic approval he terms those of Clement, from 12 in. to 65 in. in length.

The long or "royal" pendulum, introduced about 1676, was pretty generally adopted by the leading makers for their best work within a few years from that date. The cases of the balance and short pendulum clocks were exceedingly. narrow in the waist, only just sufficient width having originally been allowed for the rise and fall of the weights. In some instances a clock of this kind would be converted to the new style, and then a curious addition, in the form 
of a wing or projection was made on each side of the case to permit the swing of a "royal" pendulum. Sheraton seems to have suggested a revival of these wings in the case shown in Fig. 746.

But for a few exceptions that mark the rule, long-case clocks have the movement contained between two brass plates held together by horizontal pillars. This change came with the rearrangement of the trains side by side, to allow of winding with a key from the front of the dial.

It may be concluded that the earliest long-case clocks would go for but twenty-four or thirty hours between successive windings, and possibly at first they were wound by pulling down the driving cords. There is an early one by Tompion at the Guildhall Museum which has a lantern movement and is so arranged. But there is a very fine thirty-hour clock by the same maker in the Wetherfield collection which winds through holes in the dial. The introduction of the " royal" pendulum and wheelwork for eight days' running seems to have been almost coincident. The evident success of eight-day movements induced clockmakers to calculate trains to go for a month, three months, and even a year, of which there are several examples by Tompion, Quare, and others.

In the striking part of the earliest eight-day clocks the locking plate or count wheel was on the outside of the pillar-plate instead of being attached

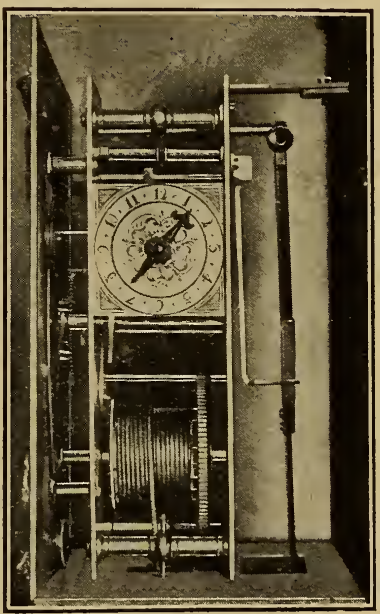

FIG. 656.-Side view of Timepiece Movement, byWilliam Clement, about 1676. to the great wheel. When the rack was introduced it was placed between the plates and lifted by a pin in the arbor; the superior method of an outside rack lifted by a gathering pallet seems to have come into use about 1700 .

Mr. D. A. F. Wetherfield has a month timepiece by William Clement, who is said to have been the first to apply the anchor escapement. It is in all oak veneered-walnut case, the case and dial being very similar to those of the Tompion clock shown in Fig. 710. There is no door to the hood, which has grooves to correspond with the back-board of the case ; the hood thus slides upwards when taken off, or when the clock is to be wound. Preparatory to winding, the 


\section{Old Clocks and Watches and their Makers}

hood is raised until engaged by a spring, which holds it in the requisite position to admit of access to the winding-hole. A side view of the movement is given in Fig. 656. There are six pillars and catches pivoted on one of the plates shut into corresponding slots in the pillars, thus fastening the movement together. The escape wheel is solid, has twenty-four teeth, and is 1 in. in diameter; the pallets are about $\frac{7}{8}$ in. across. The pendulum is $5 \mathrm{ft}$. 6 in. long, each vibration marking a second and a quarter, and the seconds circle has forty-eight divisions only instead of the usual sixty. Between the plates is a small brass dial with figures 1 to 12 engraved on it, and having a hand by turning which forwards or backwards the pendulum is lengthened or shortened. On the spindle to which the hand is attached is a worm which gears into a quadrant carrying an arm, and to this arm the pendulum is hung.

Dials.--In estimating the age of a clock many distinguishing features of the dial may be noted. From the first the hour circles were, with few exceptions, engraved on a separate silvered ring as in lantern clocks; the double circles within the numerals were retained, and in the space enclosed between them were radial strokes, dividing the hour into quarters, the half-hours being denoted by longer strokes terminating in a fleur-de-lis or other ornament. The form of the hour hand differed but little from the indicators on lantern clocks. Fig. 657 shows the dial of a thirty-hour long-case clock by Andrew Prime, London, dating from about 1670, belonging to Mr. C. J. Abbott, of Long Melford. Except for the difference in the name, the engraving on the thirty-hour Tompion clock at the Guildhall Museum is exactly similar. The dial of an early long-case alarm clock by Tompion which belongs to Mr. T. W. Bourne is shown in Fig. 658.

It must not be assumed that of two long-case clocks, one with an hour hand only, and the other with a minute hand as well, the one with the single index is necessarily of the earlier date, for, though the minute hand was applied as early as 1670 , clocks with an hour hand only were quite common throughout the eighteenth century. It is most probable that for some years the minute hand was only applied by the best makers and exclusively to clocks of a superior class; this assumption is justified by the fact that, though many early one-hand clocks roughly made are met with, those with the minute hand are almost invariably well finished. The form of the hands is an excellent guide to the period. Fig. 659 shows the dial and hands of a very fine long-case clock by Tompion, belonging to Mr.Wetherfield, 
The Progression of English Domestic Clocks 497

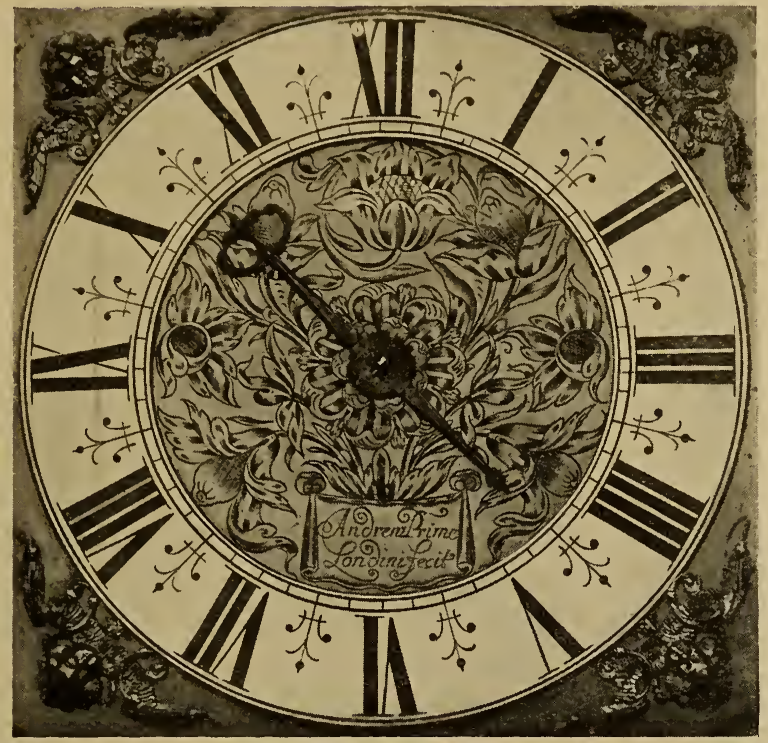

FIG. 657.-Andrew Prime, about 1670.

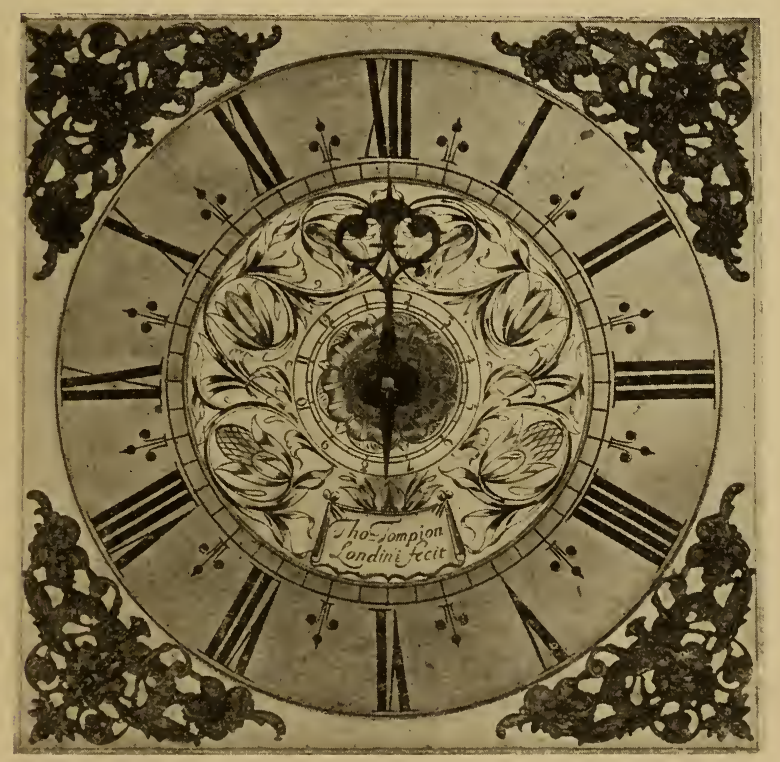

FIG. 658.-Thomas Tompion, Clock with Alarm, about 1670. 
498 Old Clocks and Watches and their Makers

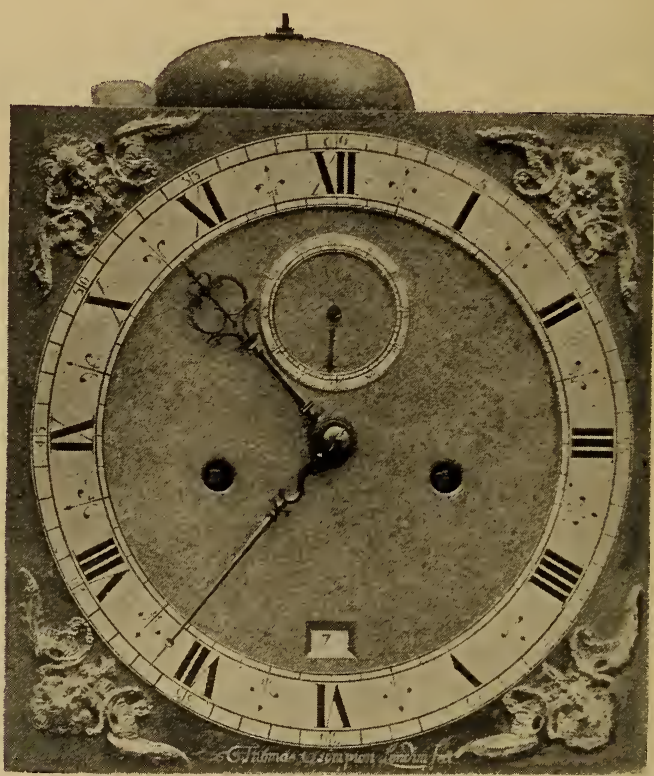

FIG. 659.-Dial of Long-case Clock, by Thos. Tompion, 1676-1680

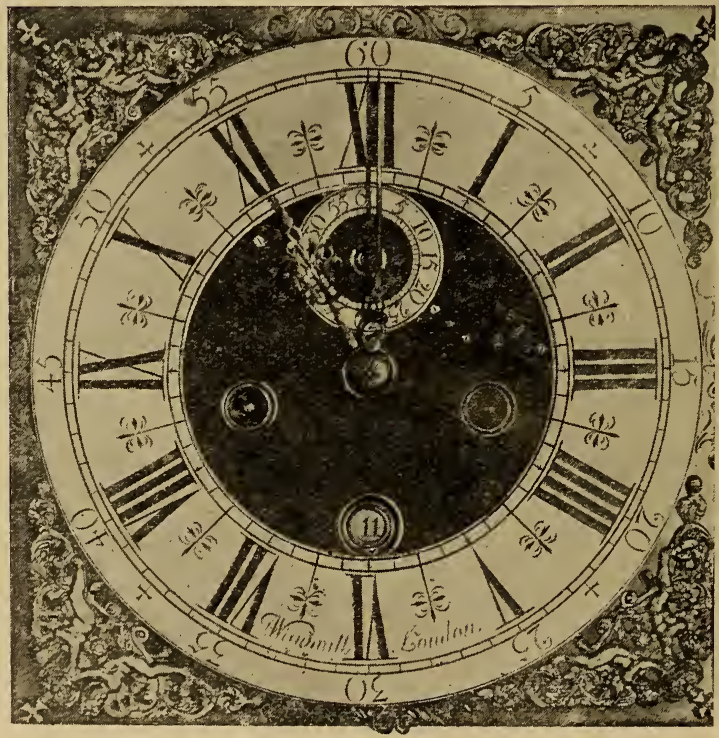

FIG. 660-J. Windmills, with name curved within minute marks. 


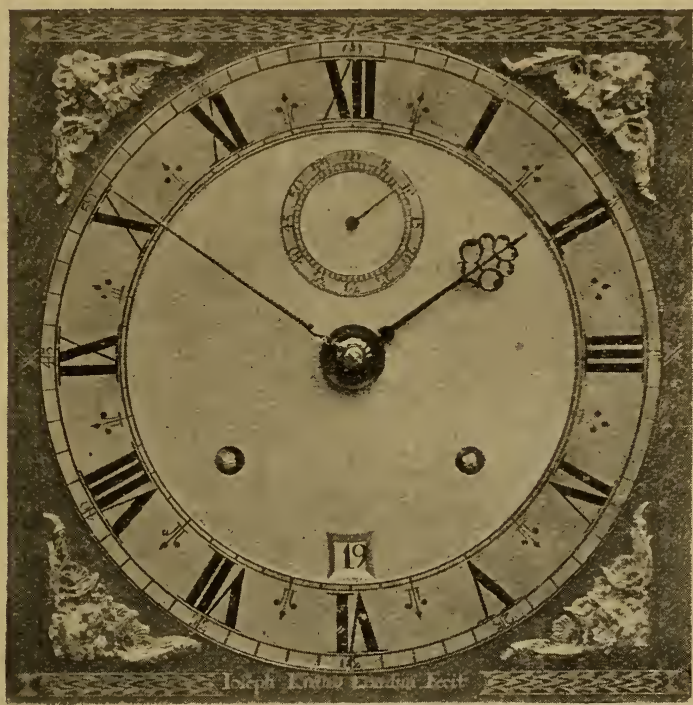

FIG. 661.-Joseph Knibb about 1685 ; 10 in. dial ; month clock, striking on two bells.

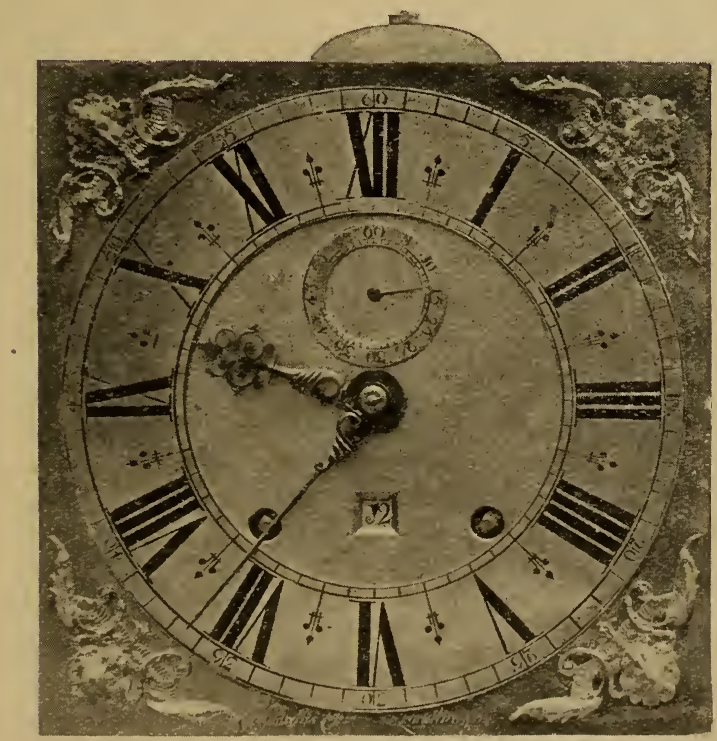

FIG. 662.-Edward East, about 1690; month clock; 10-in, dial, very pretty hands, 
500 Old Clocks and Watches and their Makers.

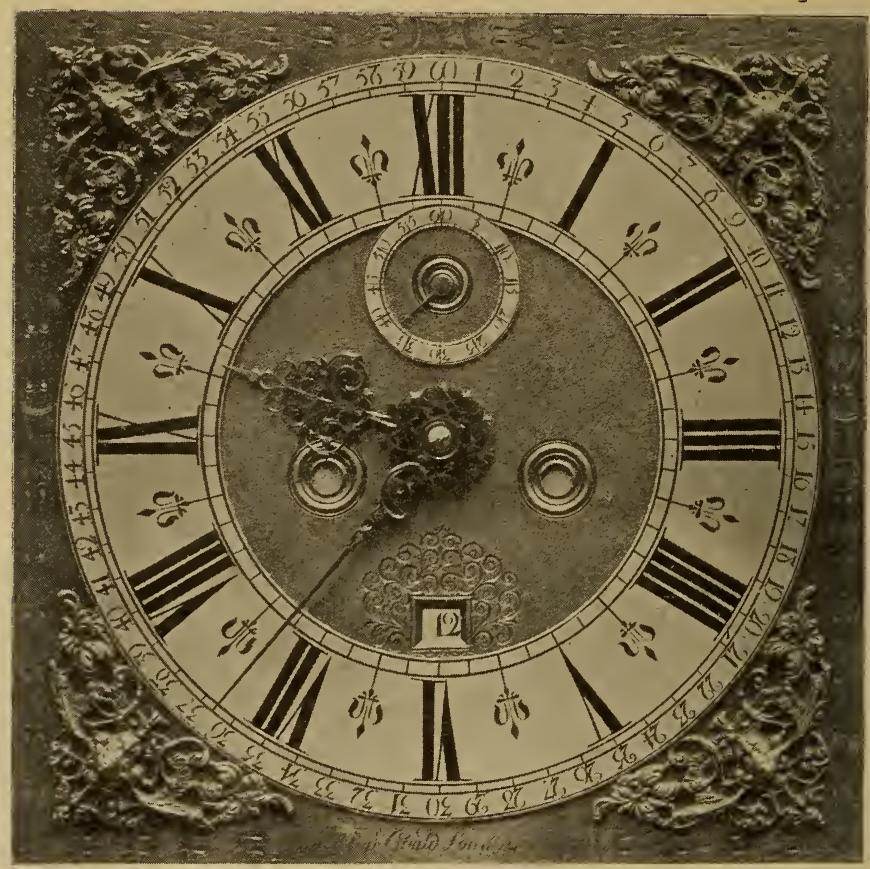

FIr. 663.-Christopher Gould, abcut 1700; 12-in. dial.

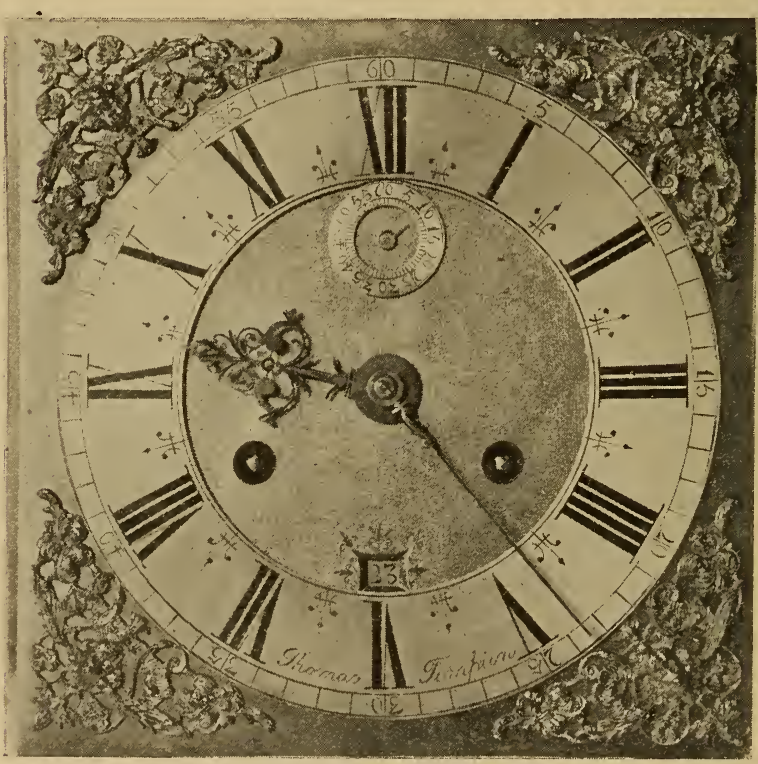

FIG. 664.-Thomas Tompion, about 1705; 10 $\frac{1}{2}$-in. dial. 


\section{The Progression of English Domestic Clocks 501}

and which may be safely placed as dating from between 1676 and 1680. The centre of the dial is matted, and this, though characteristic of the time, was not an invariable custom, for some makers adhered to the engraved centre as seen in lantern clocks of earlier times. The hands are good and well adapted to their office, the seconds indicator being a slender unbalanced finger. It was not till the time of Williamson about 1715 that double-ended seconds hands were applied. On dials of the William III. and Queen Anne periods, even when the centre was matted, there would be usually a " herringbone" or laurel leaf border along the edges, and engraving something in the form of birds and foliage surrounded the aperture showing the day of the month, as in the Quare dial on p. 508. This had a very good effect when burnished bright in contrast to the matting. Further relief was given by turning a number of bright rings around the winding holes. With the exception of those thirty-hour adaptions with lantern movements as in Fig. 657, the maker's name on the earliest of the seventeenth-century clocks was, as a rule, inscribed in a straight line along the bottom of the dial, usually in Latin, thus: " Eduardus East, Londini, Fecit," and visible only when the hood was raised or removed, or the door of it opened. Later it was engraved within the

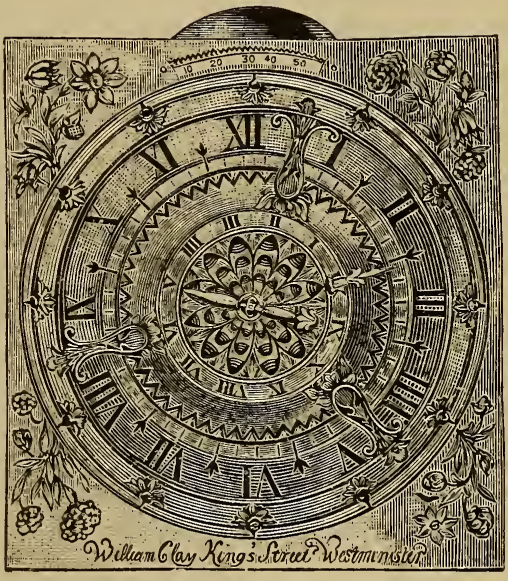

FIG. 665.-Fine Seventeenth-Century Engraved Dial, by William Clay.

minute circles between the numerals VII. and V. and the Latin form of inscription died out so far as the signature is concerned, though it was occasionally indulged in for such popular mottoes as Tempus fugit, Vigilate et Orate, Tempus edax rerum, \&c. Fig. 660 shows the dial of a clock by Joseph Windmills, with the name curving round inside the minute marks. This clock belongs to Mr. Wm. A. Jeffries, of Boston, Mass., U.S.A. A remarkably fine month clock by Tompion in a beautifully figured walnut case, dating from about 1705, which belongs to Mr. J. Drummond Robertson, is shown in Fig. 718. To the top of the pinnacles it is $8 \mathrm{ft}$. 6 in. high. In this the name is inscribed in a straight line along the bottom of the dial, and the signature appears also on a label below the centre of the dial 
as in the Bath and Iscoyd Park clocks by Tompion, of a slightly later date, shown on pp. 287, 290. After about 1710 attached name-plates were occasionally used, but throughout the century most makers showed preference for the curved inscription between the numerals.

Speaking generally, it seems that up to the end of the seventeenthcentury long-case clocks were small in size; all had square dials measuring either $9 \frac{1}{2}$ in., 10 in., $10 \frac{1}{2}$ in., or 11 in. across. Square dials, 12 in. across, were later.

Fig. 665 represents a very early square engraved metal dial which is of particular interest, not only from its handsome appearance but from the fact that it discloses a peculiar plan of denoting the minutes. The short hand in the centre of the dial is the alarm index, which need not be referred to further. The hours and subdivisions representing quarter hours are engraved on the dial plate in the manner usual at the middle of the seventeenth century, and the hours and quarters are indicated by a pointer fixed to a plate of the form shown, and which revolves once in twelve hours. The revolving plate includes an outer ring connected with the centre by three arms, and projecting from the outer edge of this ring are twelve pointers placed equidistantly around the periphery. On the upper part of the fixed dial plate is a narrow band forming $30^{\circ}$ or $\frac{1}{12}$ of the circumference. This band is divided into sixty equal parts, representing the minutes in an hour; and if at the beginning of an hour one of the pointers is just entering this arc, it is obvious it will in its course indicate the minutes which have elapsed since the completion of the previous hour. At the bottom of the dial is inscribed, "William Clay, King's Street, Westminster," and this William Clay was possibly the one recorded as the maker of a watch presented by Cromwell to Colonel Bagwell at the siege of Clonmel. This dial was sketched from a clock in the possession of Mr. Percy Webster.

An arched top to the dial appears to have been first added early in the eighteenth century for the reception of an equation of time register, as shown in Tompion's clock on p. 290. It will be observed that the Hampton Court clock bearing Quare's name, and which was designed to show true solar time, has no arch to the dial, but a subsequent clock on the same plan by Joseph Williamson has an arch containing a calendar for the year, as shown in Fig. 681. On another dial by Williamson, the day of the week is indicated, as seen in Fig. 682. Apart from its utility in this connection, the addition of the arched top was certainly a great improvement to the appearance of 
the dial, and from this time was generally retained for the better class of work even when not required as a field for the exhibition of any of the clock movements. In such cases the space was devoted to decoration, a favoured device being a domed plate on which was inscribed either the owner's or the maker's name, occasionally with a crest or motto, and generally flanked on each side by a dolphin or rococo ornament of the kind apparently introduced by Joseph Williamson, and shown on his dials, Figs. 681 and 682.

Calendar circles in the arch of the dial were very popular. The hands for these were generally worked as shown in Fig. 666 . Gearing with the hour wheel is a wheel having twice its number of teeth, and turning therefore once in twenty-four hours. A threearmed lever is planted just above this wheel ; the lower arm is slotted, and the wheel carries a pin which works in this slot, so that the lever vibrates to and fro once every twenty-four hours. The three upper circles in the drawing represent three star wheels. The one to the right has seven teeth corresponding to the days of the week; the centre one has thirty-one teeth for the days of the month; and the left-hand one has twelve teeth for the months of the year. Every time the upper arms of the lever vibrate to the left, they move forward the day of.the week and day of the month wheels each one tooth. The extremities of the levers are jointed, so as to yield on the return vibration, and are brought into position again by a weak spring, as shown. There is a pin in the day-of-the-month wheel which, by pressing on a lever once every revolution, actuates the month of the year wheel. This last lever is also jointed, and is pressed on by a spring, so as to return to its original position. Each of the star wheels has a click or jumper kept in contact by means of a spring. For months with less than thirty-one days the day of the month hand has to be shifted forward.

The spandrels or corners uutside the circle of the dial form a tolerably reliable sign of the times. In some of the very earliest longcase clocks flowers were engraved there, as in William Clay's dial on p. 501. In Fig. 704 the corners are filled each with a line of verse, but more usually these spaces were occupied by raised gilt ornaments, of which the earliest were the cherubs' or angels' heads, Fig. 667. This pattern will be seen on the clock represented in the coat-of-arms granted to the Clockmaker's Company in 1671, and was largely used until the end of the century. It was succeeded by larger and more elaborate corners like Fig. 668. Then more ambitious designs came into use, notably two cupids or nude boys supporting a crown in the 
504 Old Clocks and Watches and their Makers

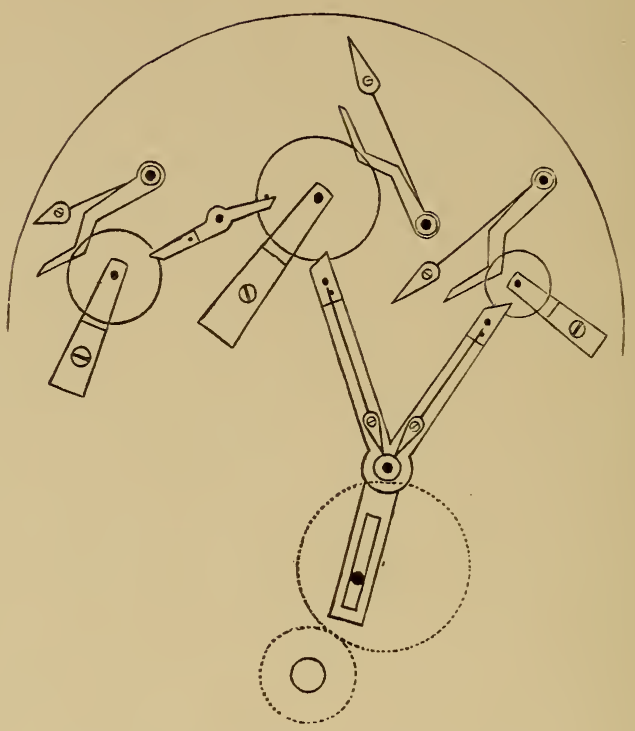

FIG. 666.-Simple Calendar Work.

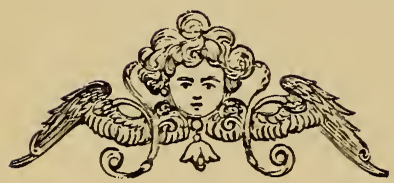

FIG. 667.

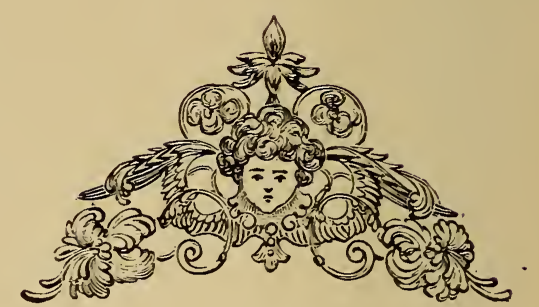

FIG. 668.

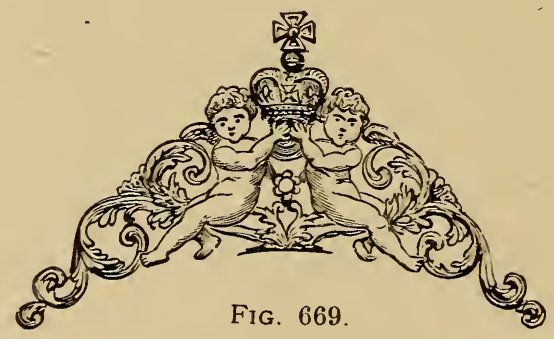

"Corner pieces" of different periods. 
The Progression of English Domestic Clocks 505

midst of ornamental scroll-work (Fig. 669) ; or a crown with crossed sceptres and foliage as in Fig. 670. This is an unusually fine

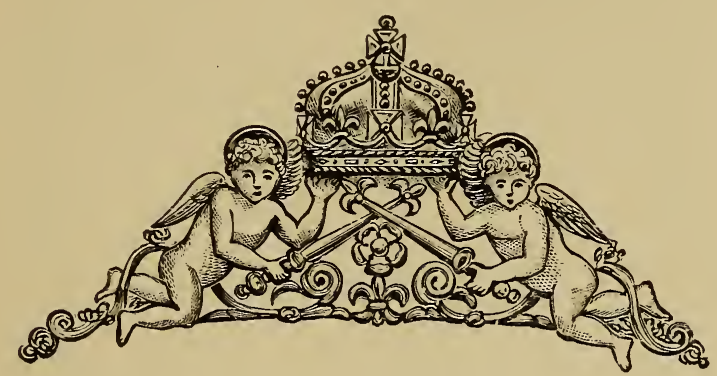

FIG. 670.

specimen taken from a clock of the Queen Anne period by W. Draper, a maker of whom I seem to have no precise particulars, though Mr. William Norman has a metal token issued by W. Draper,

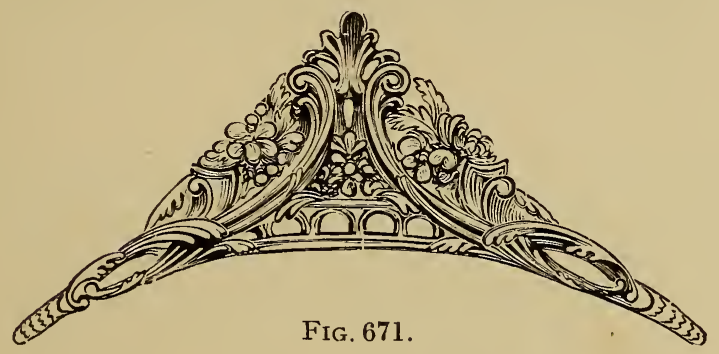

watchmaker, which has on the obverse "Success to the Borough of Maldon" with the arms of the town, and on the reverse the arms of the Clockmakers' Company. Later in the eighteenth century different

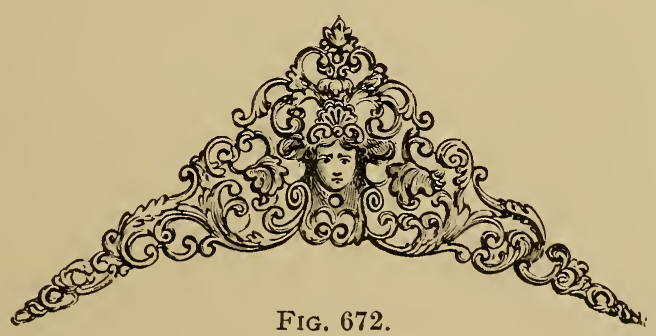

figures representing the four seasons were popular with some of the provincial makers, but they are seldom to be seen on clocks by 
506 Old Clocks and Watches and their Makers

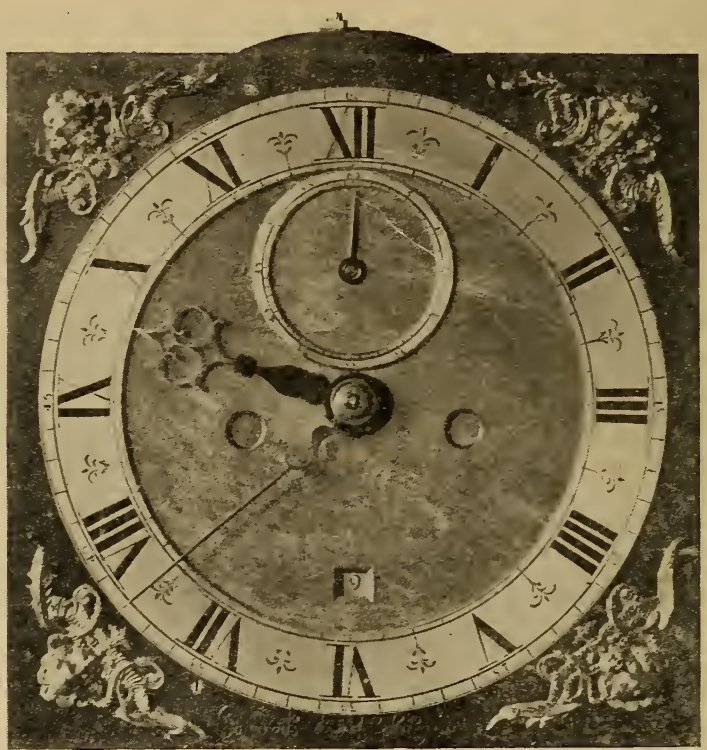

FIG. 673.-Edward East, about 1680. Eight-day clock; 10-in. dial : bolt and shutter maintaining power.

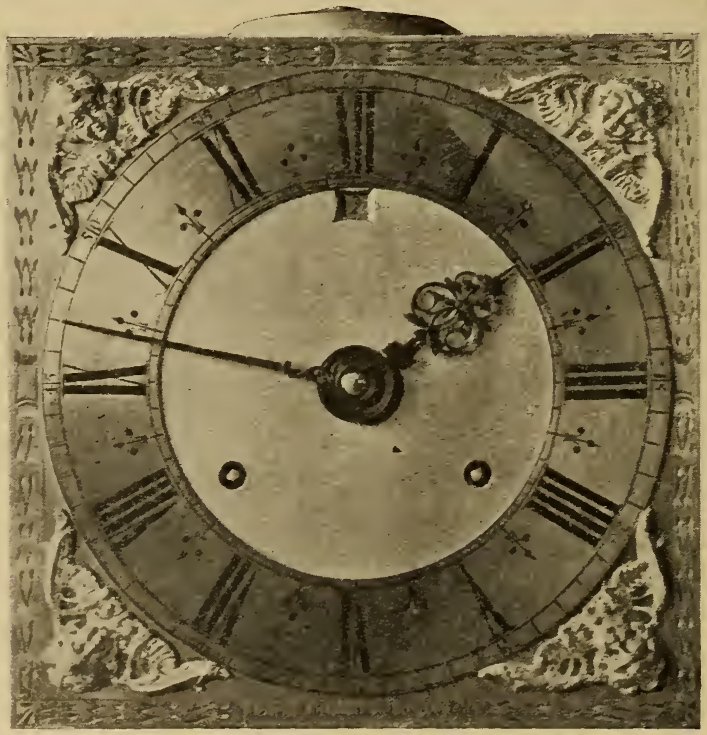

FIG. 674.-Joseph Knibb, about 1690. Month clock: 10-in. diai: unique corner-piece. 
The Progression of English Domestic Clocks 507

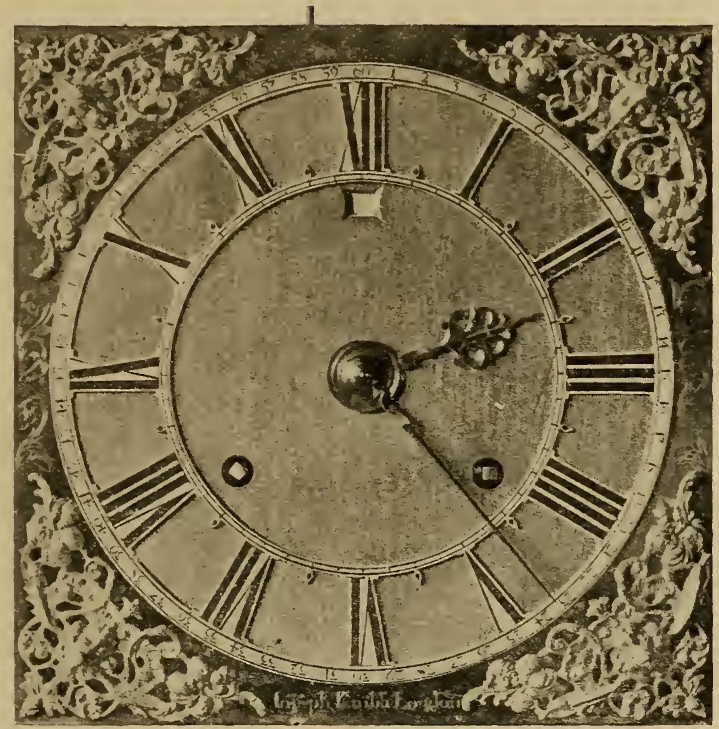

FIG. 675.-Joseph Innibb, about 1695. Month clock; 10-in. dial; Skeleton hour ring; every minute numbered.

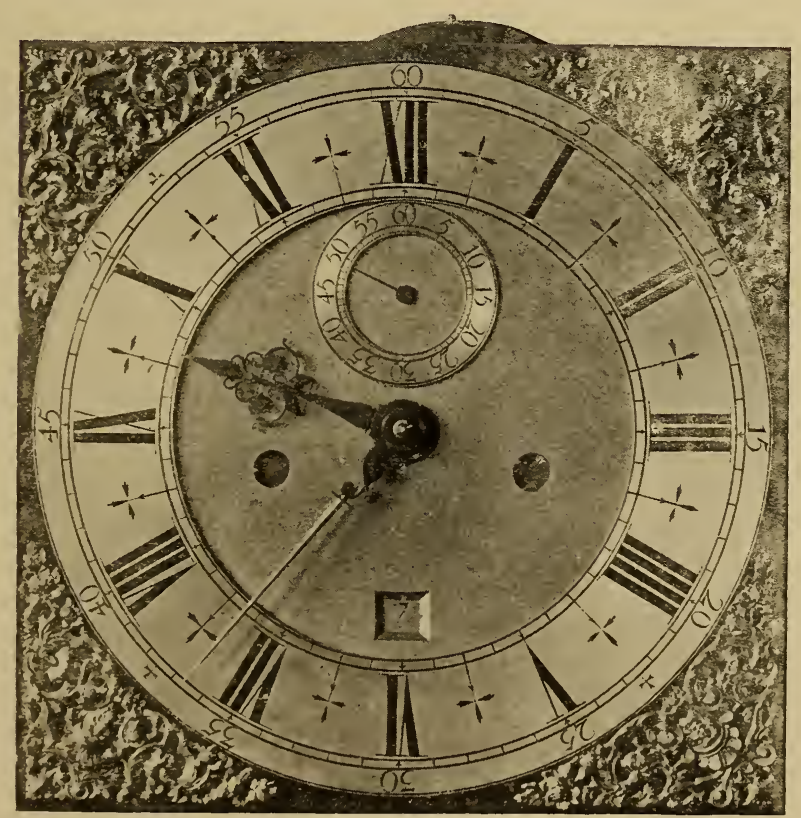

FIG. 676.-Thos. Tompion, about 1700. Month clock; 11-in. dial; bolt and shutter maintaining power. 


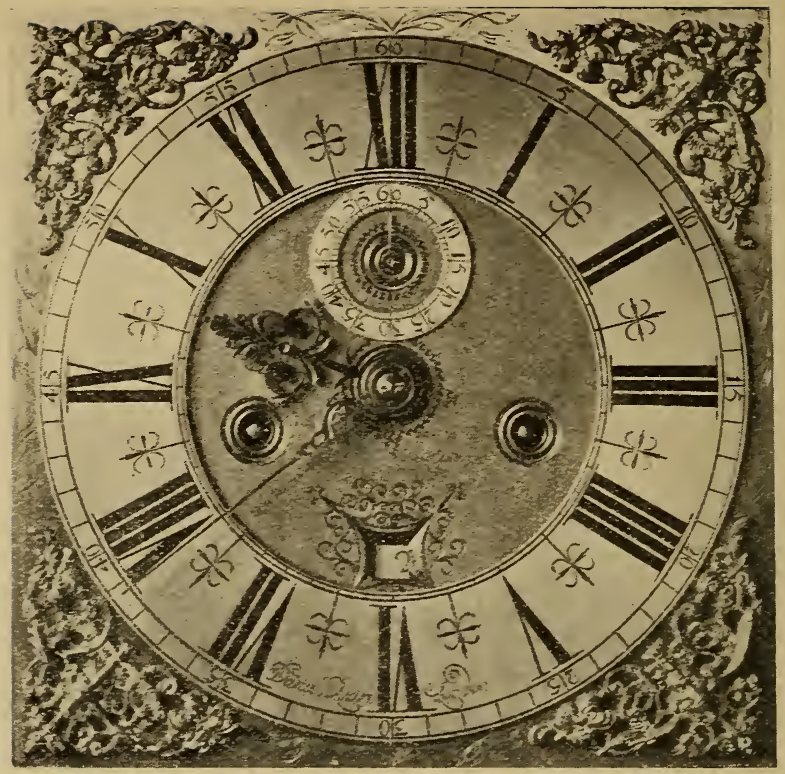

Ifrr. 677.-Daniel Quare, about 1705. Month clock; 11-in. dial.

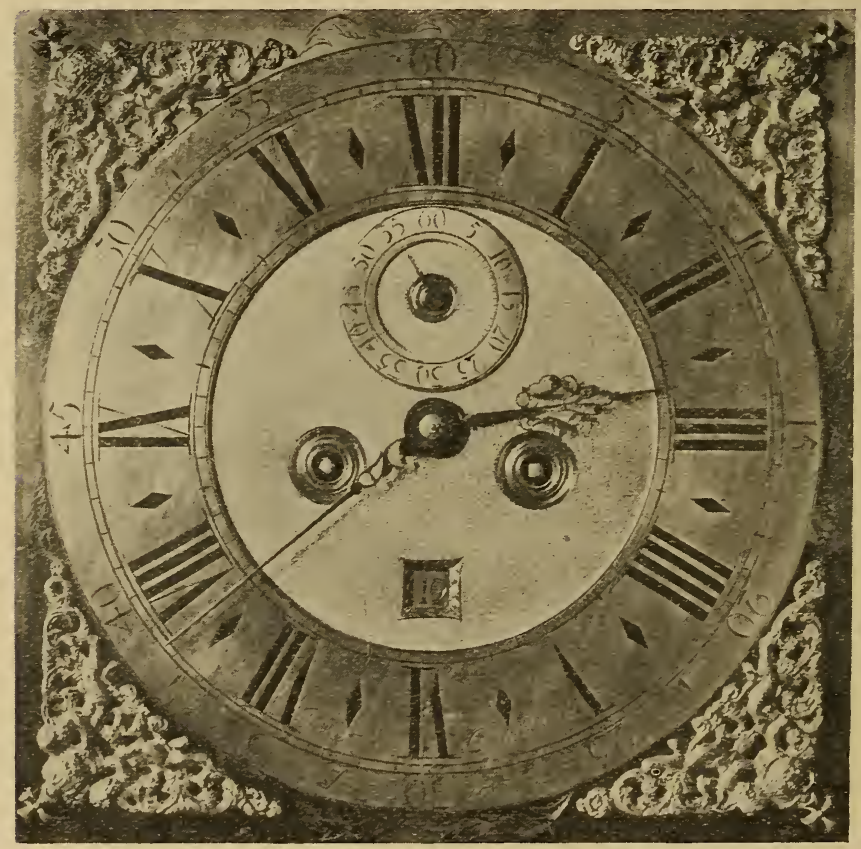

FIG. 678.-Jonathan Lowndes, about 1710. Eight-day clock; 12-in. dial. 508 


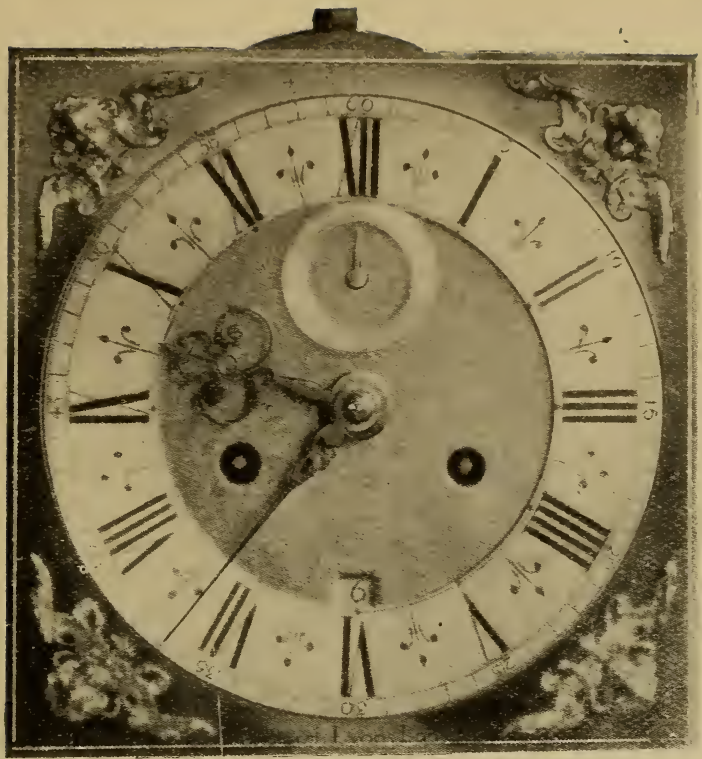

FIG. 679.-Richard Lyons, about 1690. 10-in. dial.

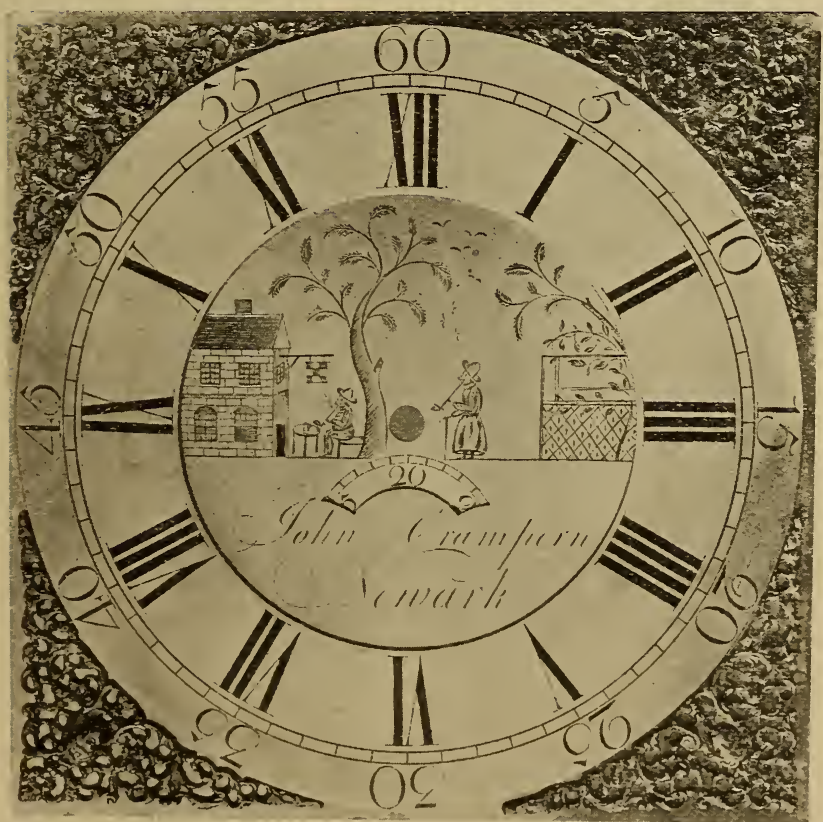

Fig. 680.-John Crampern, Newark, about 1775. Eccentric subject for engraving in centre space. 
London men. The naked boys were followed by various combinations of a rococo character, such as Fig. 671. One of the best and most popular of the designs used during the George III. period is shown in Fig. 672. Some of the corners and arch ornaments of this

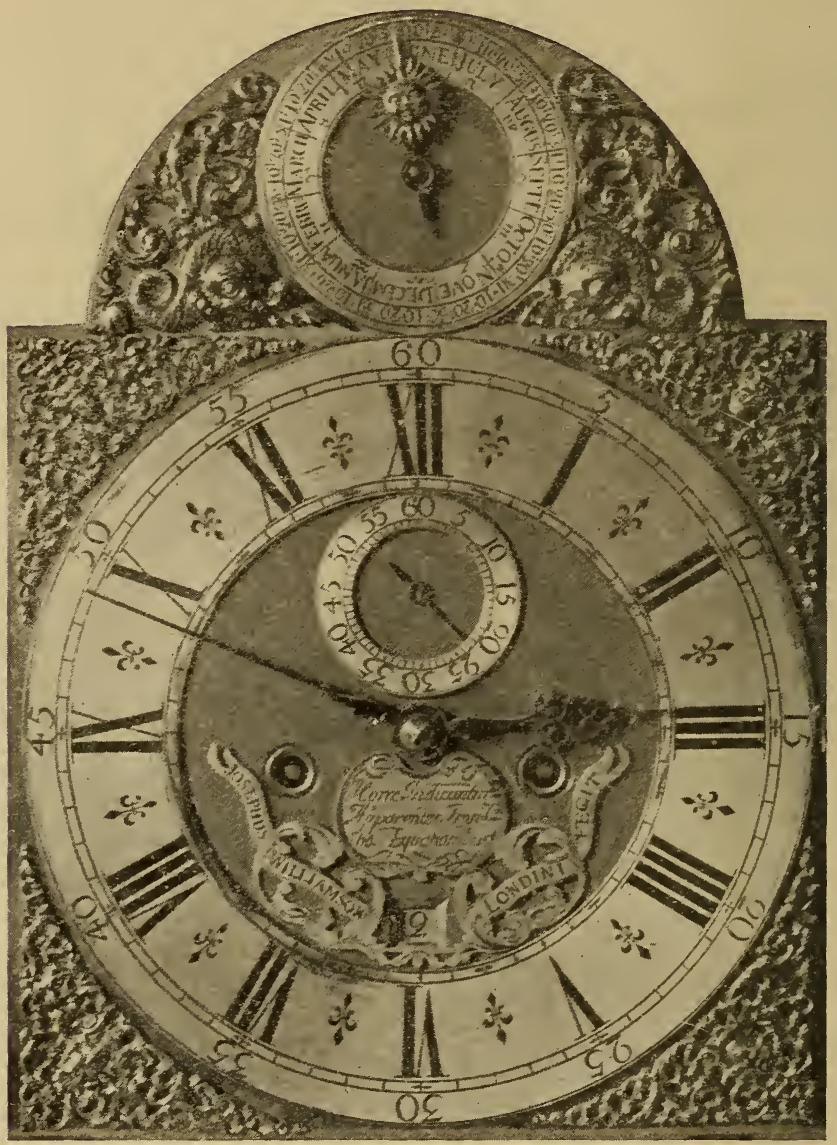

FIG. 681.-Joseph Williamson, about 1715. Month clock; square of dial, 12 in. Inscription, "Hove indicantur apparentes involutis aquationibus." Calendar in the arch.

time were sadly degenerate in form and execution, being merely a mass of unmeaning curves reproduced in rough castings, not touched by the chasing tool or graver, but lacquered just as they left the sand. Many of the dials and corners were water gilt. Occasionally, 
The Progression of English Domestic Clocks 5II

on clocks of a high class, silver corner-pieces pierced and engraved were substituted for the set patterns.

Among other useful purposes to which the arched space was applied, the "strike-silent " hand and the " rise-and-fall " register may

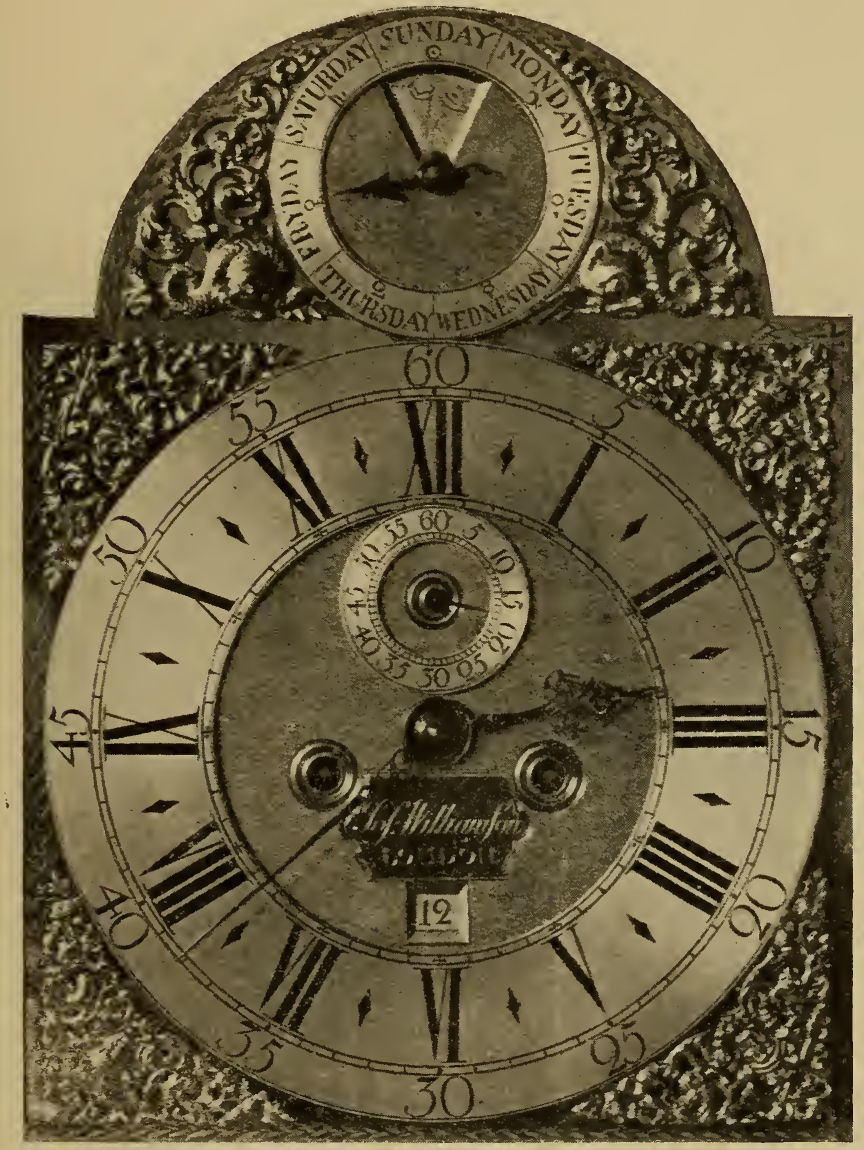

FIG. 682.- Joseph Williamson, about 1720. Eight-day clock; square of dial, 12 in. Lower hour numerals reversed. Day of the week indicated in the arch; an illustration for each day appears through an aperture.

be mentioned as two of the earliest. The titles of these are suggestive of their use. The strike-silent mechanism for stopping the striking of the clock at pleasure is older than the arch, and is to be seen on clocks having square dials. A particular form of strike-siient mechanism 


\section{I2 Old Clocks and Watches and their Makers}

was incorporated in a patent granted to John Rowning, M.A., in 1732 (No. 535). Some dials made just after the accession of George I. contained instead of the words "strike-silent" the letters "S.N."

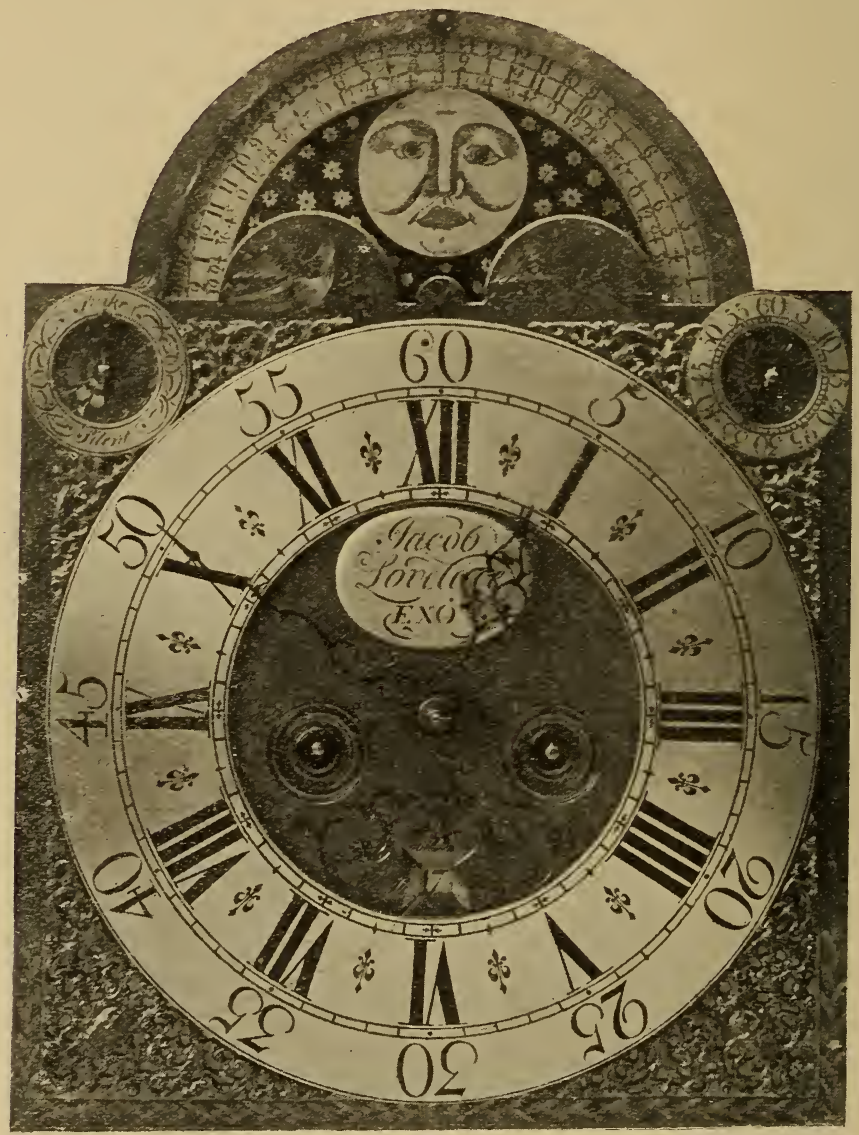

FIg. 683.-Jacob Lovelace, Exeter, about 1735. Day of the month through hole in dial. Figures in the arch show age of the moon and time of high water in hours and minutes. Subsidiary pointers in the upper corners are for respectively "strike-silent" and pendulum regulation.

engraved as a guide to the movement of a lever. The meaning of these letters, which stand respectively for " Schlag," "Nicht," has occasionally perplexed subsequent owners of such a clock, especially if, as was not unusual, the lever had disappeared. 
The Progression of English Domestic Clocks 5 I3

The rise-and-fall hand was connected with the pendulum and served to regulate the time of its vibration by altering its effective length. An early example with this contrivance is the long-case clock

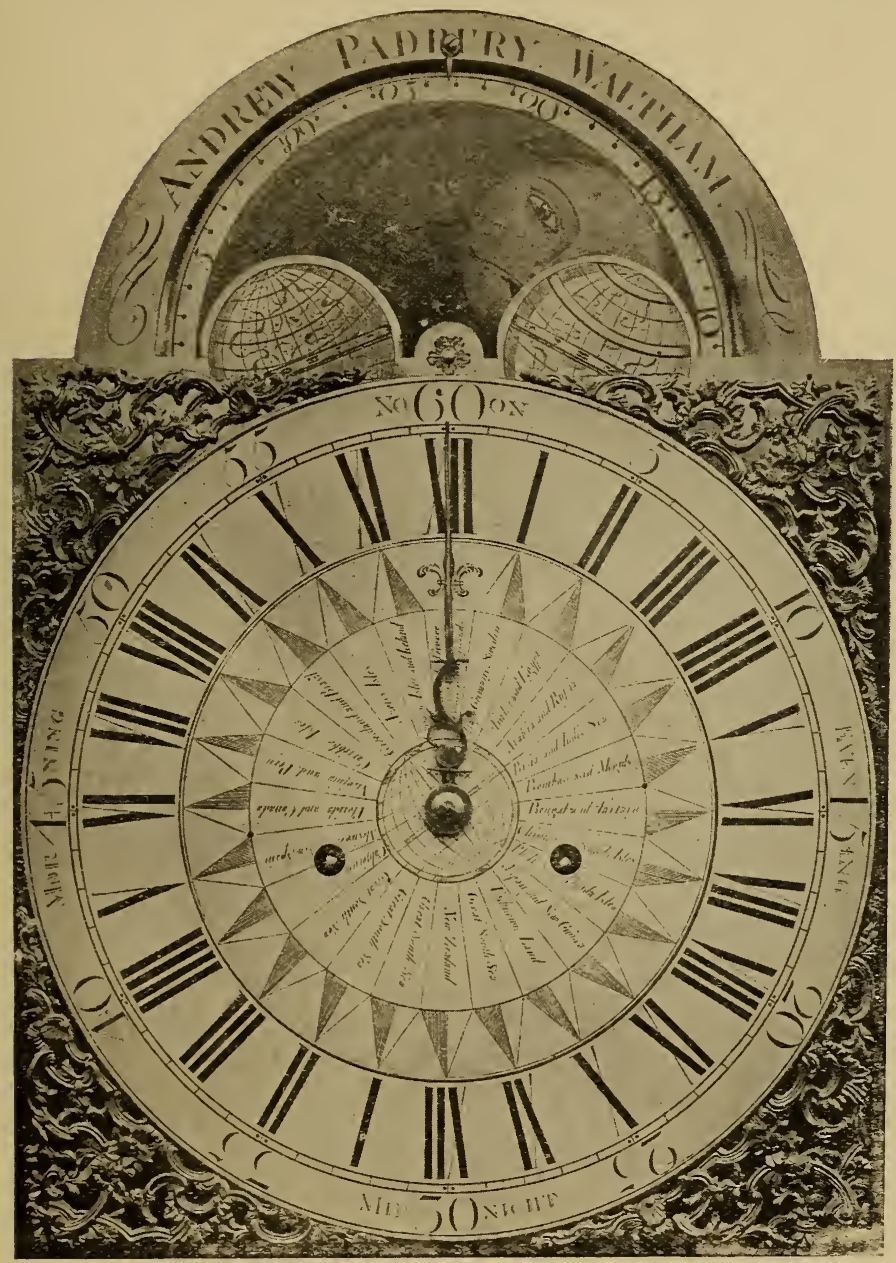

FIG. 684.-Dial of Clock, by Andrew Padbury, with rotating centre to indicate time all over the world.

by Jonathan Puller in the Wetherfield collection which is shown on p. 557.

For many years, but especially during the latter part of the 
eighteenth century, there was a great taste for moving figures placed in this part of the dial, such automata as see-saws, hearing ships, time on the wing, \&c., being especially faroured. The Dutch seem to have

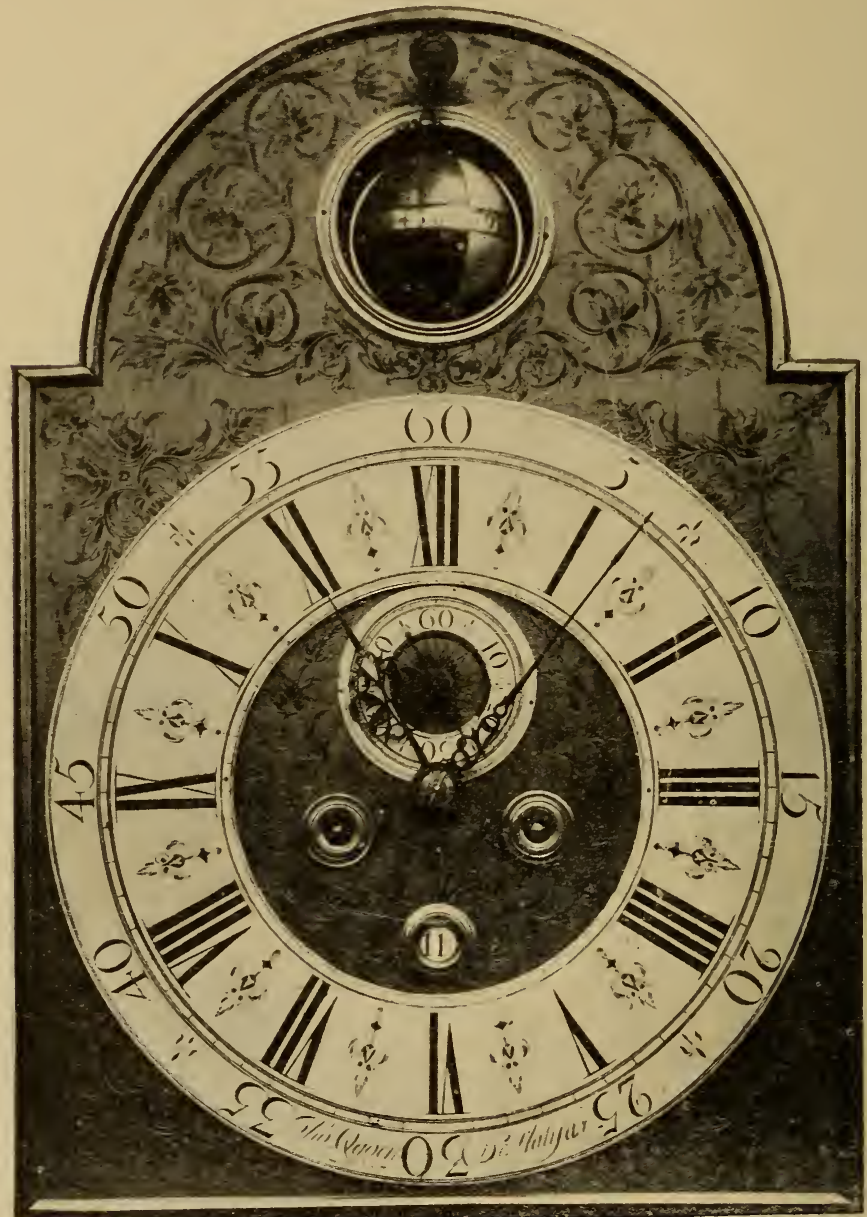

FIG. 685.-Rotating Moon Dial of " Halifax Clock," by Thos. Ogden about 1750 (see p. 520).

greatly excelled at this kind of work. Occasionally an effective but somewhat ghastly attraction was arranged by placing in the arched spare a painting of a human head; behind the head, instead of the 
tossing ship, which was worked to and fro by a wire from the pendulum, would be the eyes continually going to and fro.

Sometimes the seconds indicator was transferred from inside the hour ring to the space above.

The phases of the moon, usually accomplished by a disc turning

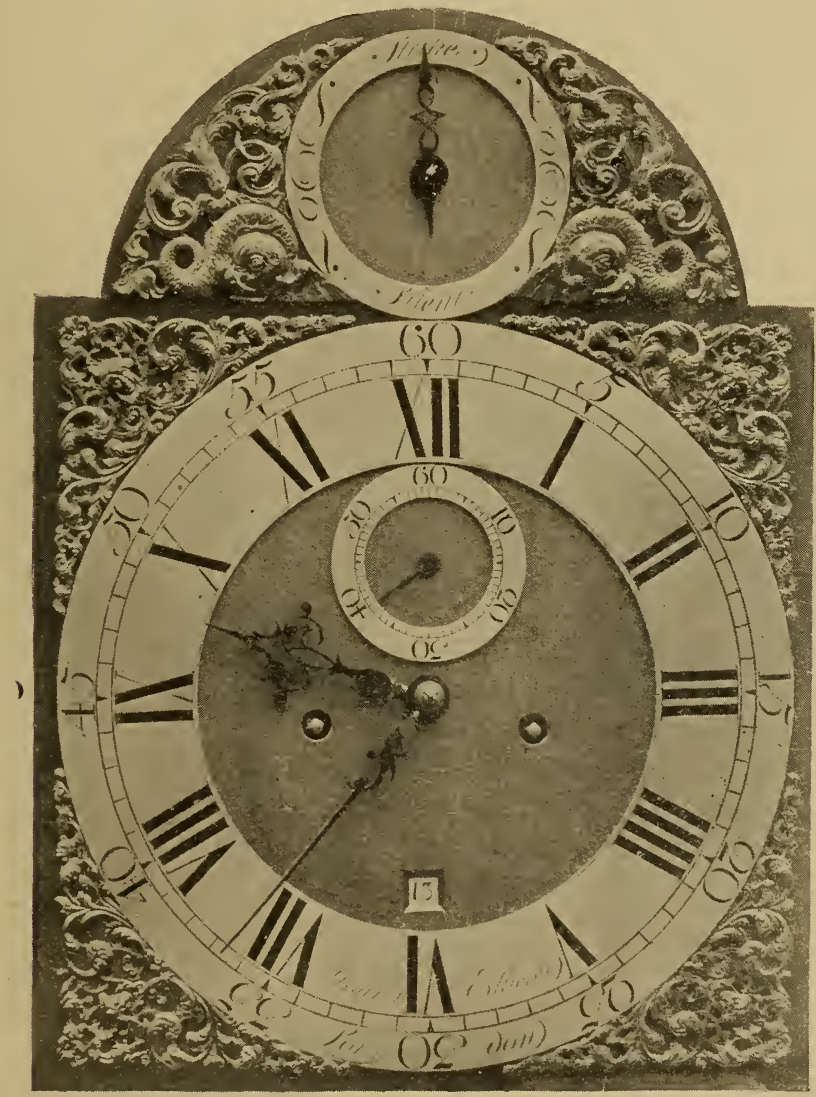

FIG. 686.-John Ellicott, about 1760.

once in two lunations, as shown in Enderlin's clock on p. 394, was also a favourite device for the arch of the dial.

In connection with the lunar record the time of high water at some particular place was popular in certain districts between 1730 and 1780. For people residing near a tidal river, and who desired to 


\section{I6 Old Clocks and Watches and their Makers}

cross a ford, accessible only at low water, an indication of the tides would be especially useful. In many instances the figure of the moon had a slight pointed projection to show the age of the luminary.

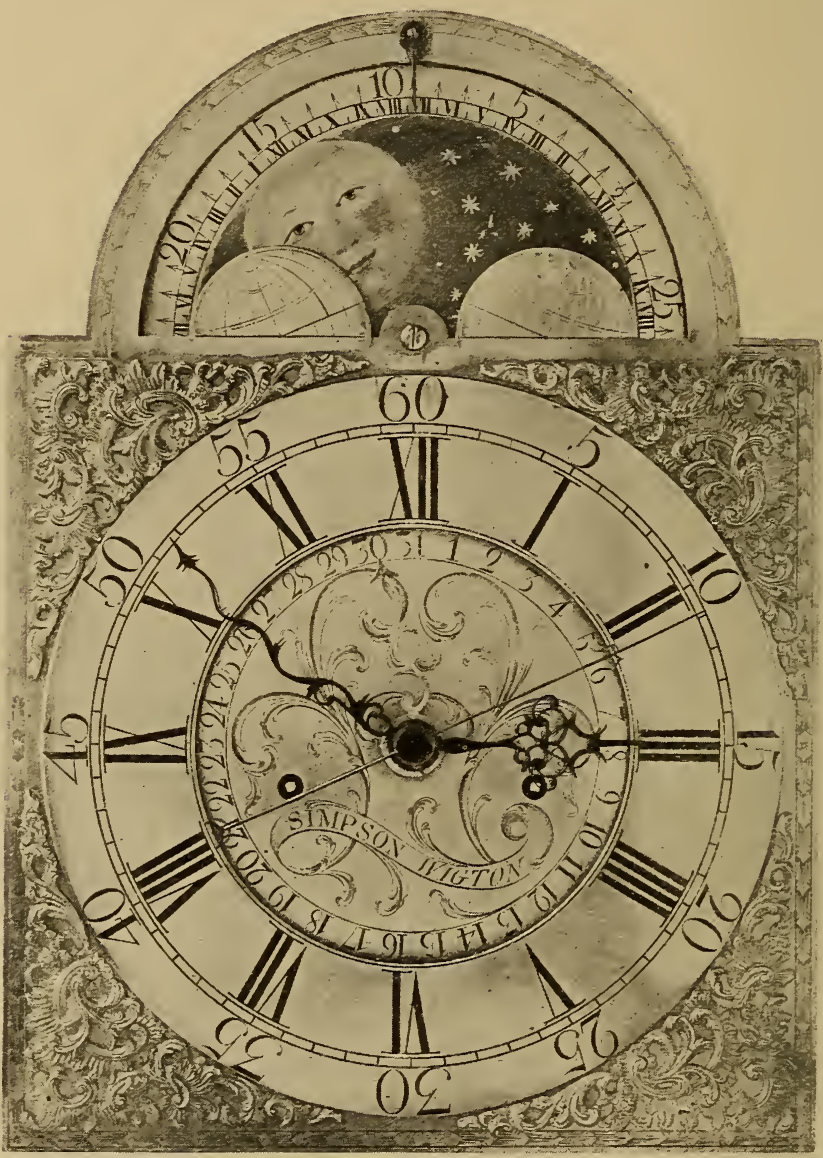

FIG. 687.-Simpson, Wigton, about 1775. Has centre seconds and day-of-themonth hands, and shows in the arch age and phases of the moon and time of high water, probably at Parton, near Whitehaven.

Around the top of the arched space, besides the usual figures for the moon's age would be a row of Roman numerals for the hours of high water, and perhaps a further arc with a register of the number of minutes past. Mr. Charles J. Reynolds has a clock of this kind, 
The Progression of English Domestic Clocks 5I7

with the inscription, " Charles Vaughan,Pontypool,"outside the figures. Or there might be a fixed pointer above the arch; the numbers for the

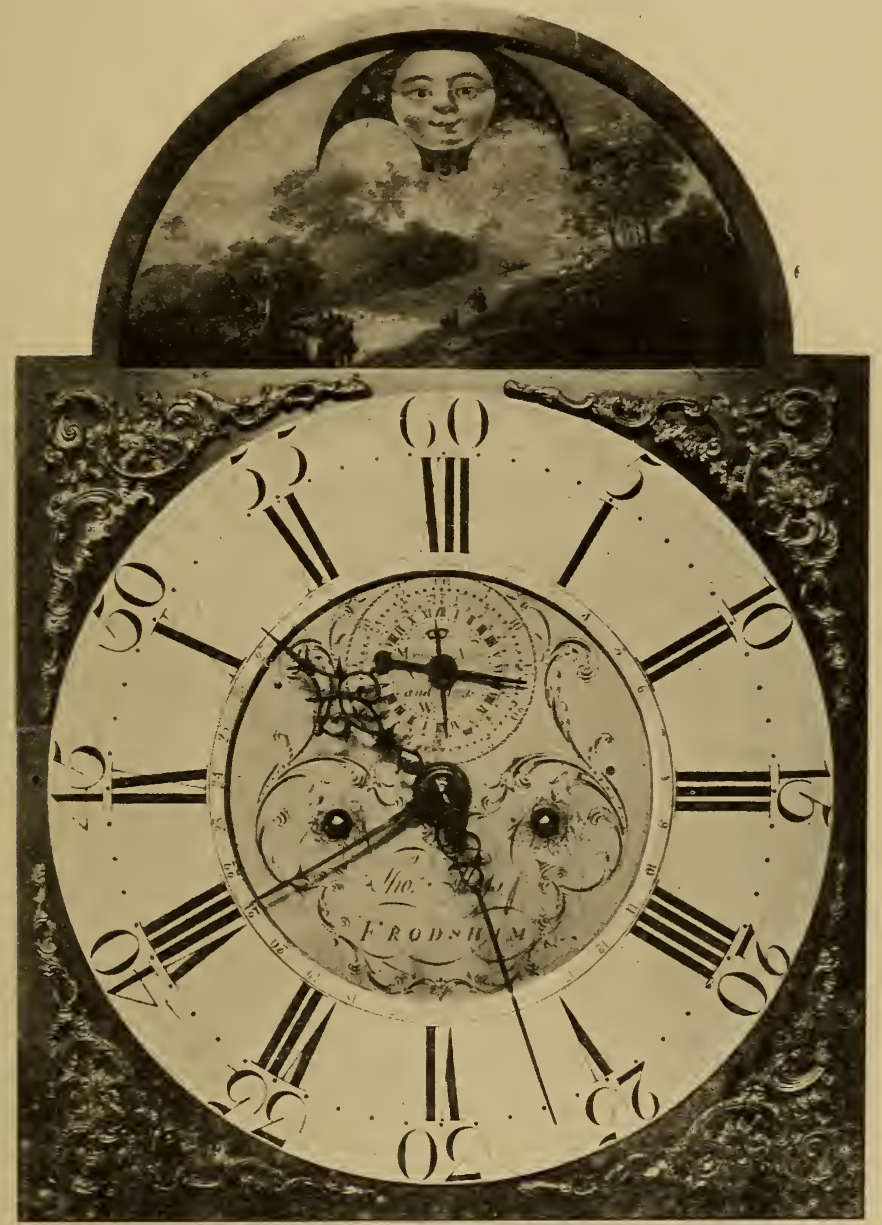

FIG. 688.-Thomas Moss, Frodsham, 1776. Shows days of the month, age and phases of the moon, and time of high water at Frodsham. Water scene and landscape painted in arch.

moon's age and the tides would then occupy the edge of the mocn's disc and travel with it. Mr. George Liddell has a clock, by Jacob Lovelace of Exeter, dating from about 1735 , so arranged. The dial is 
shown in Fig. 683. Miss Mary F. Bragg owns a clock, by Simpson of Wigton, dating from about 1775, with half-hour marks instead of minute figures, as shown in Fig. 687. Another plan was to allow the

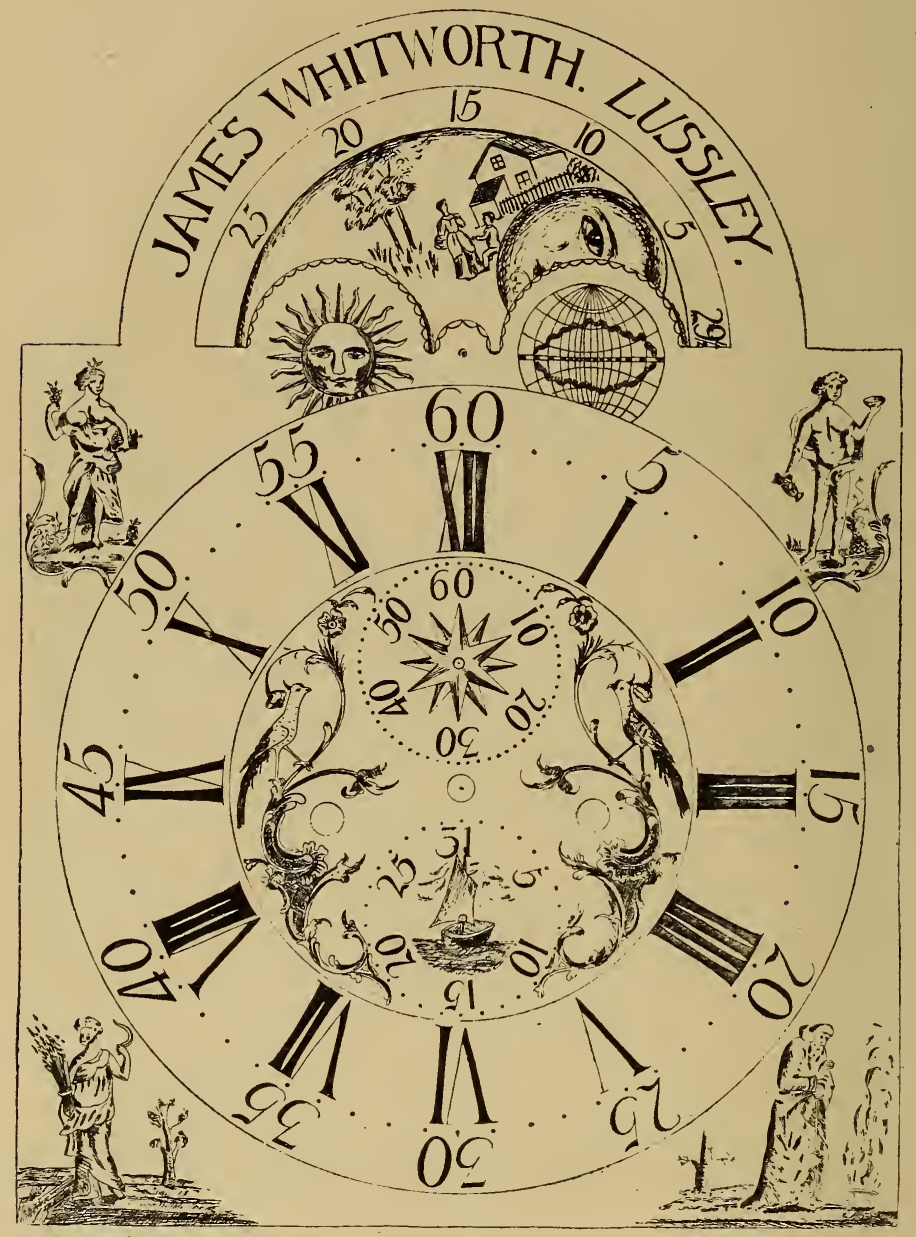

FIG. 689.-Finely engraved Dial, about 1775. Figures at the corners to represent the four seasons.

phases of the moon to be seen through a hole in the arched part of the dial. Three sets of figures would be arranged round a whole circle, and two pointers, resembling an hour-hand and a minute-hand, would indicate the age of the moon and the hours and minutes of 
The Progression of English Domestic Clocks 5I9

high water. A clock like this by Jno. Hunter, Bristol, is in the possession of Mr. H. G. Townsend. Fig. 688 shows the dial of a clock, by Thomas Moss of Frodsham, in which this arrangement

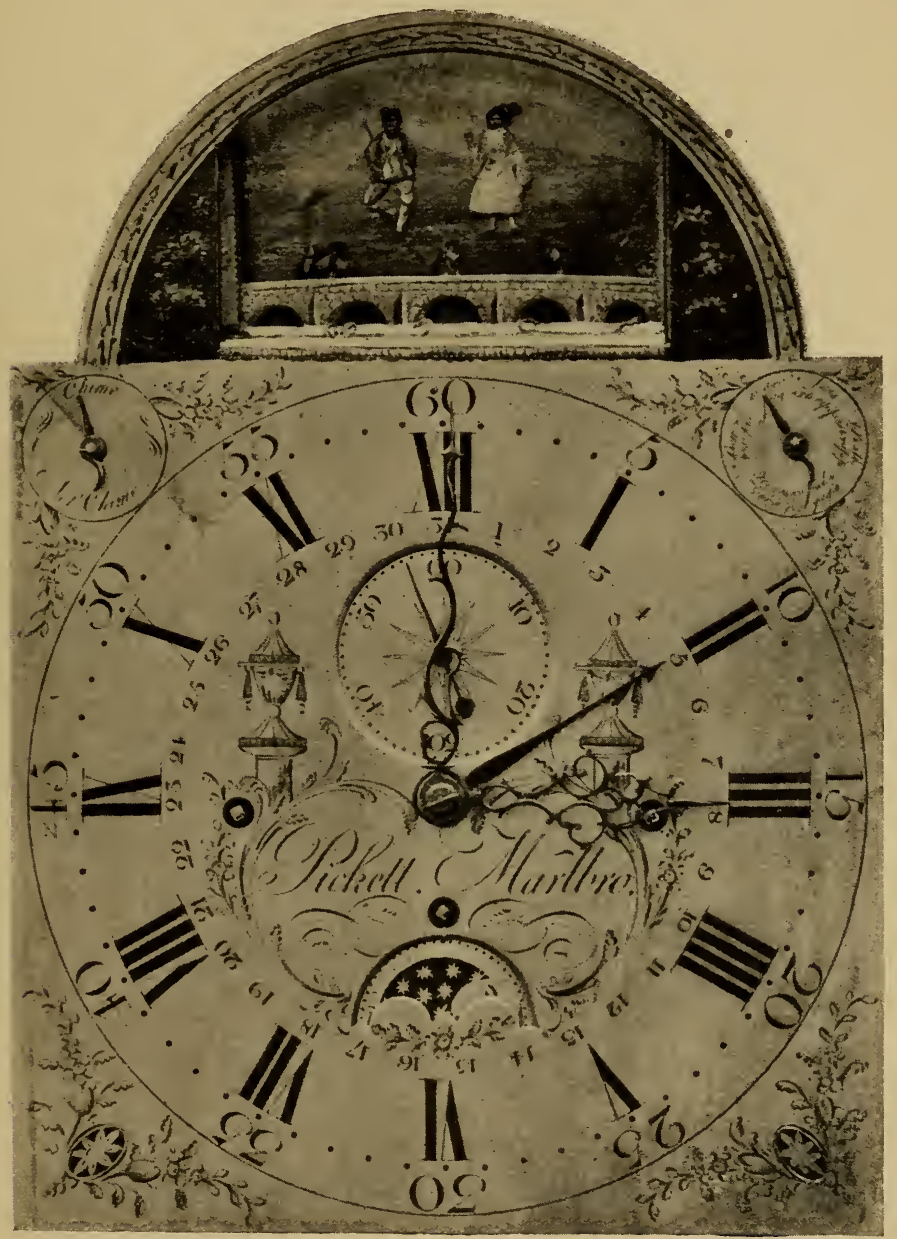

FIG. 690.-Dial with Moving Figures, about 1780 (see p. 564).

occupies a space just above the centre of the dial. This clock belongs to Mr. Wm. R. Moss. On a clock in the Wetherfield collection, by Isaac Nickals, of Wells, illustrated in Fig. 762, a tidal record in the arch may be observed. 
Clocks with a globular rotating moon over the dial, as used by Fromantil, were popular in Yorkshire during the eighteenth century and were known locally as " Halifax clocks." Mr. J. Whiteley Ward had a fine specimen, of which an illustration is given in Fig. 685.

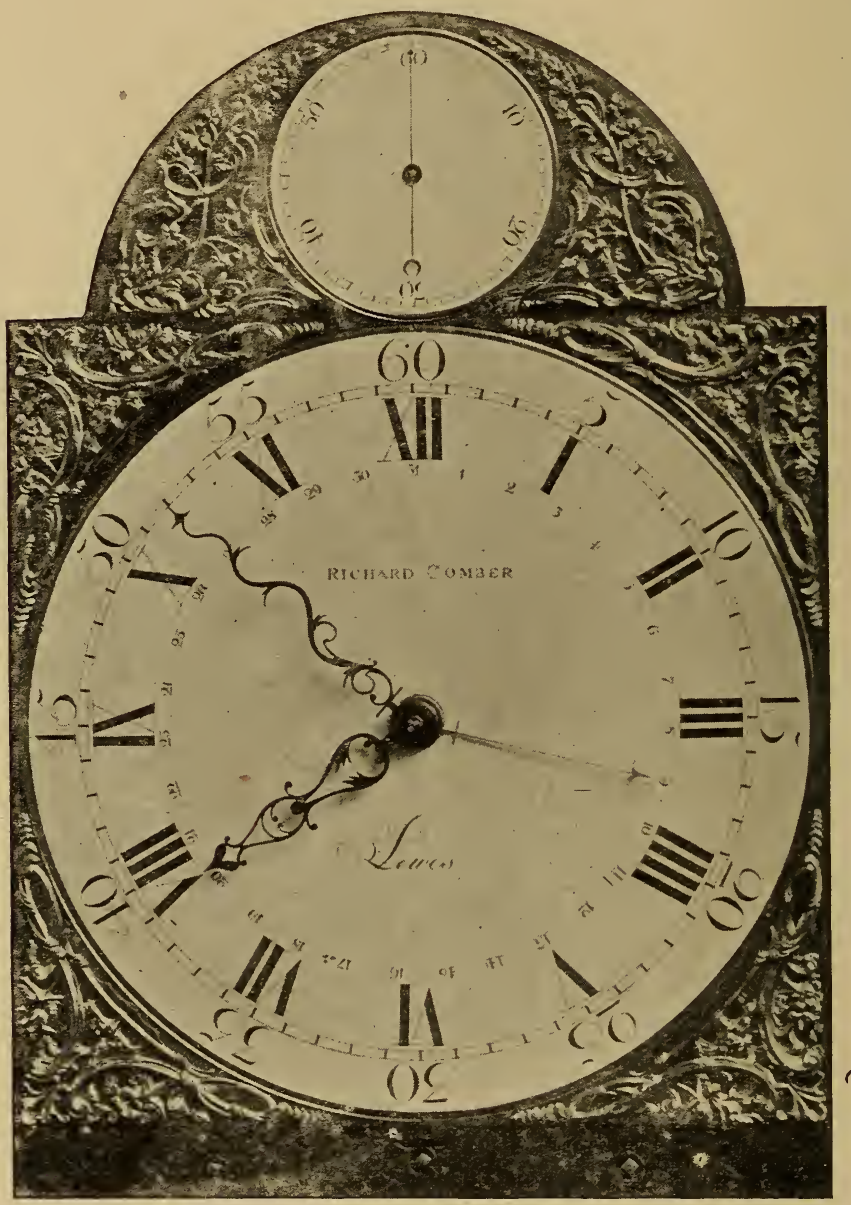

- FIG. 691.-Enamel centre, 1778 (see p. 525).

This clock was made by Thomas Ogden and formerly stood at the top of the stairs of the Old Assembly Room behind the Talbot Inn, Halifax.

The hands on eight-day clocks of the William III. period are 


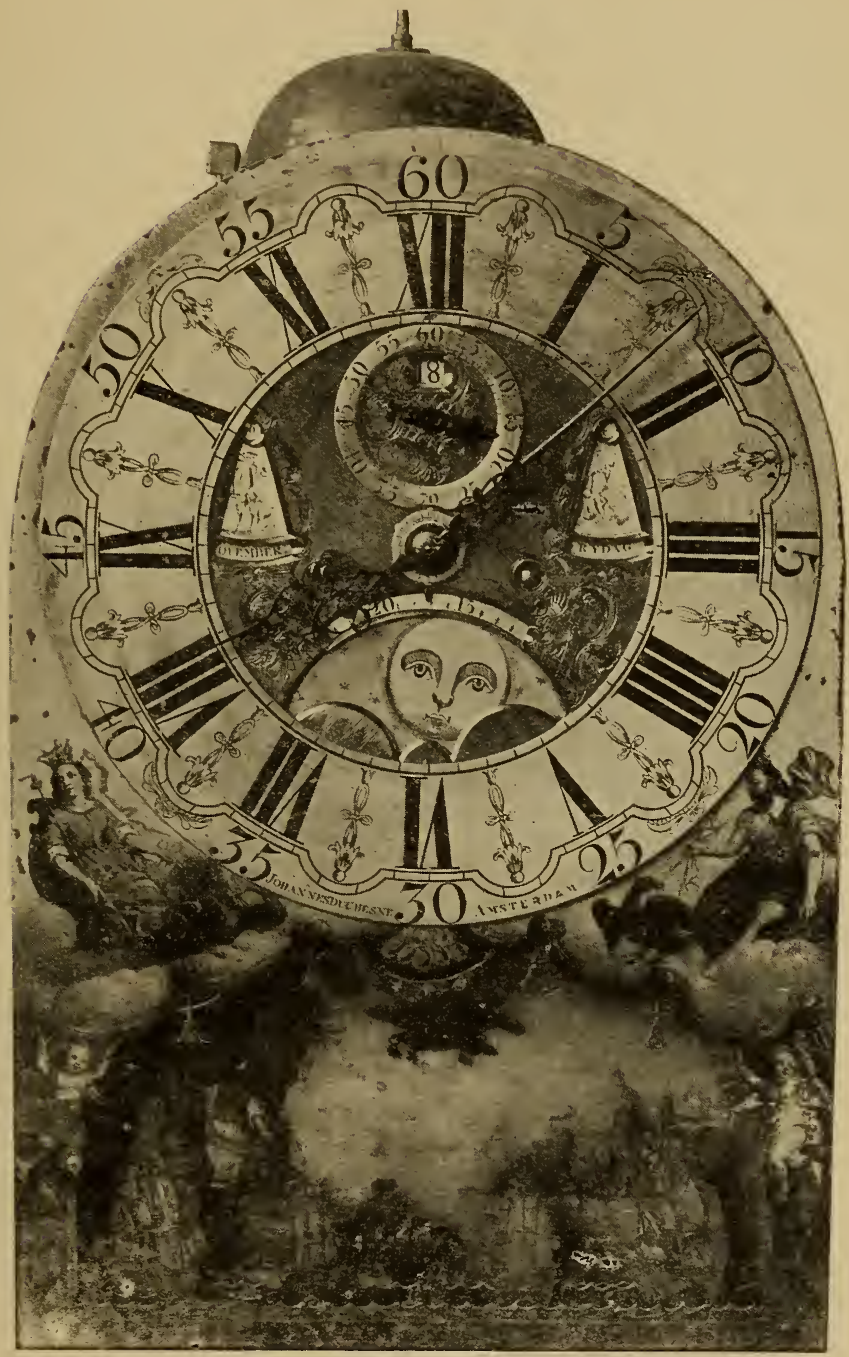

FIG. 692.- “Johannes Duchesne, Amsterdam," about 1750.

Inside the case is the following explanatory account of the remarkably effective painting: "Andromeda, chained to a rock by the order of the Goddess Juno because her friends had said she was as beautiful as Juno. Hydra, the three-headed Sea Monster, was sent to devour her, which, being known to Perseus, the King's Son, he mounted Pegasus, the flying horse, and rescued and married her, and after living very happily together, she was at length placed among the stars." 
most artistic, not only being elaborately pierced, but also carved and shaped on the surface. At my request $\mathrm{Mr}$. Wetherfield has favouredme with a series of dials reproduced in Figs. 659, 61, 62, 63, 73, 4, 5, 6, 7, 8, 8182 , from which may be noted the hands, marks between the hour numerals, and other distinguishing features ranging over about forty years from the Edward East specimen, Fig. 673, which is furnished with bolt and shutter maintaining power as described on p. 317 . The Tompion dial, Fig. 664, is from the collection of Mr. T. W. Bourne, and the Richard Lyons, Fig. 679, is from a clock belonging to

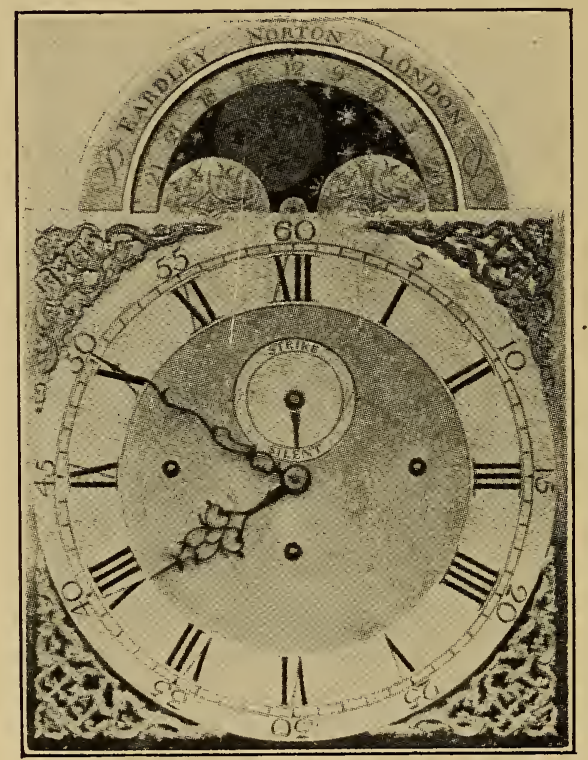

FIG. 693.-Dial of Clock, by Eardley Norton (see Ip. 543.544).

Mr. Bernard Matthews. Later examples, down to the end of the eighteenth century, are shown on succeeding pages. Mr. H. Cook has given me a print of a square dial by John Crampern, of Newark, dating from about 1760 , with quaintly engraved centre. It is shown in Fig. 680.

Dials of brass, silvered all over, without a separate ring for the hour and minute circles, and in which the primitive practice of engraving instead of matting the central space was reverted to, were introduced about 1750 . Many of these dials were characterised by really excellent engraving. Thomas Bewick, the celebrated 
The Progression of English Domestic Clocks 523

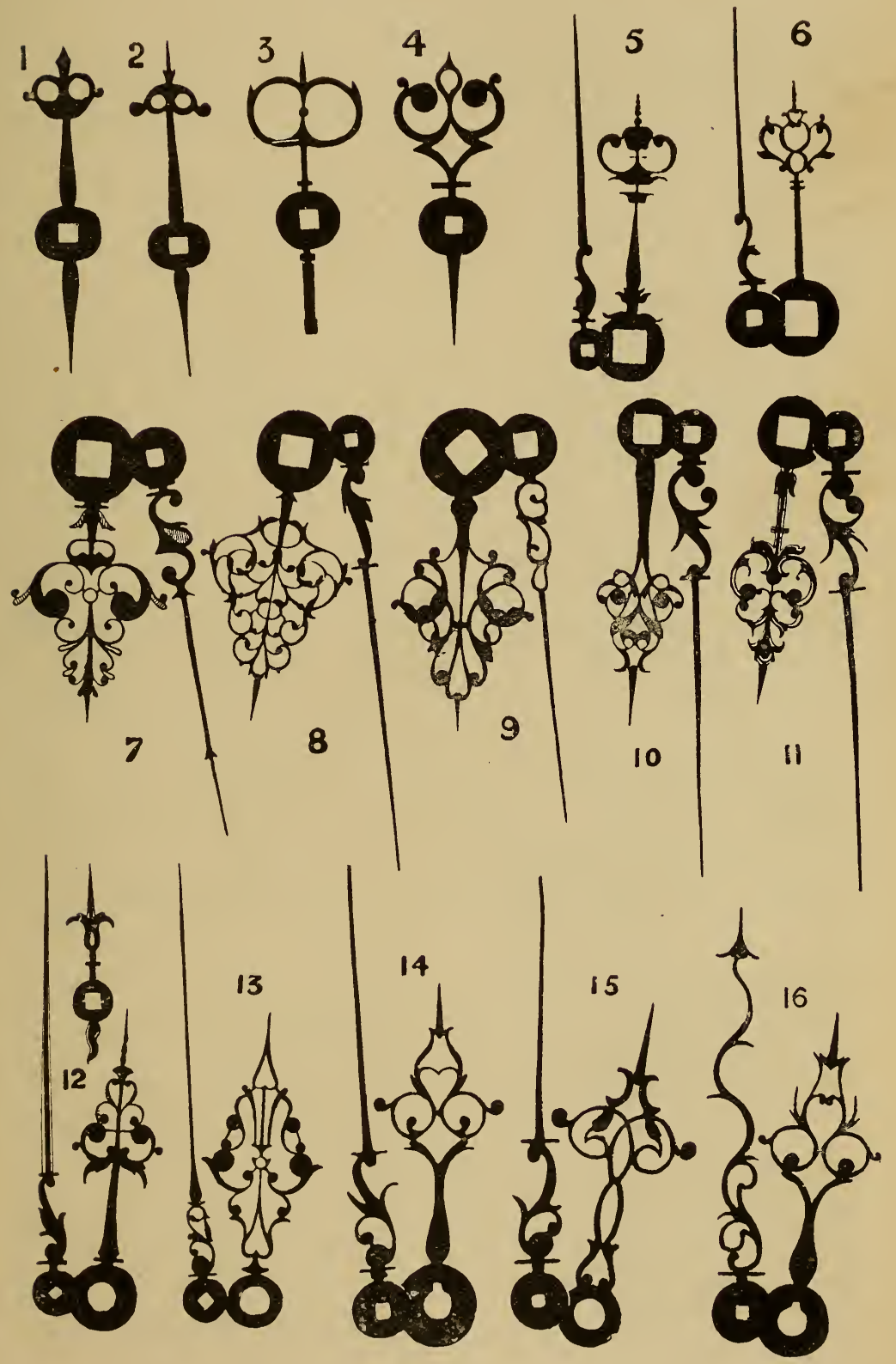

FIG. 694.-Clock Hands (see p. 526). 
524 Old Clocks and Watches and their Makers

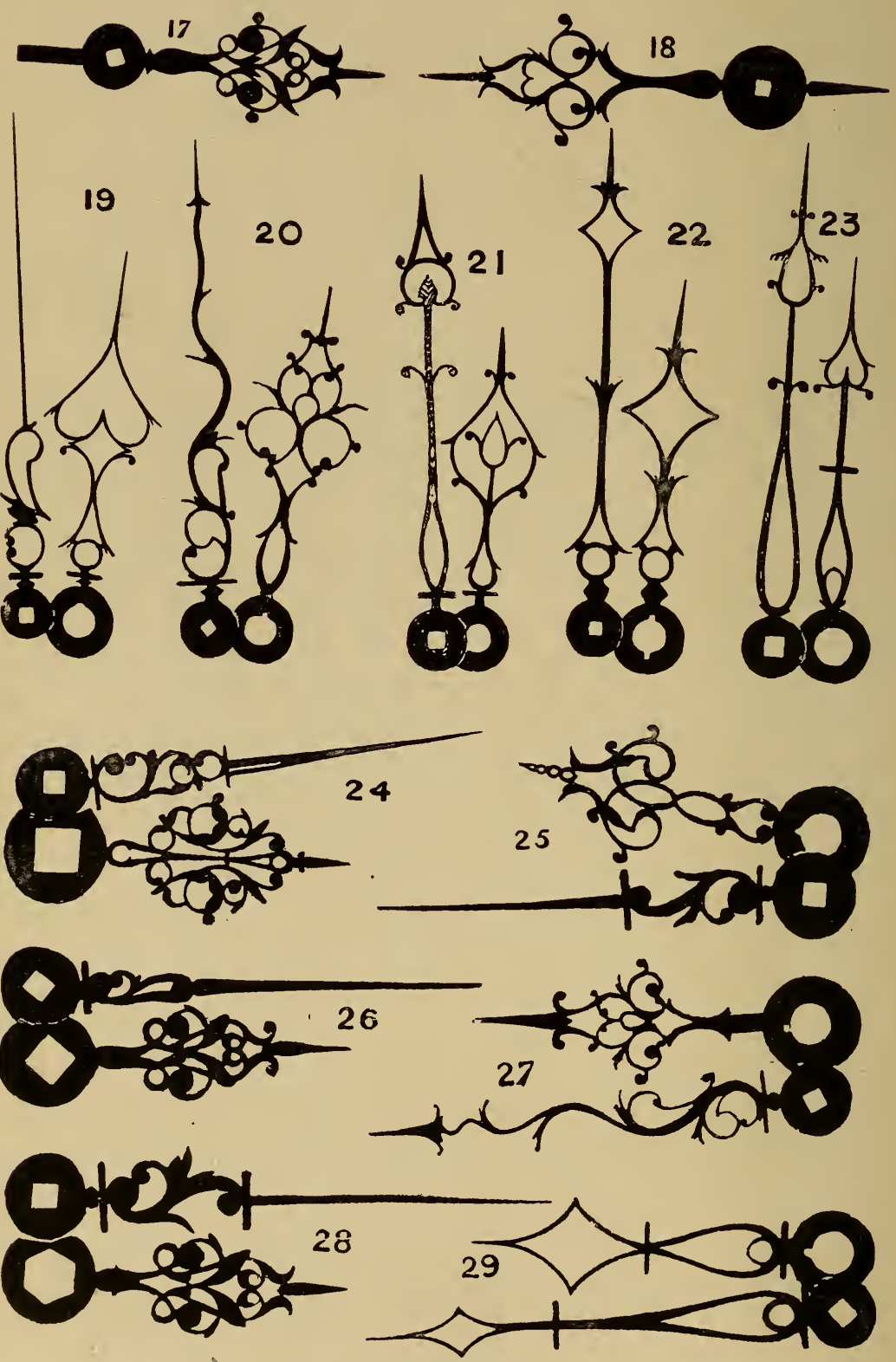

Fig. 695.-Clock Hands (sec p. 526). 
engraver, who died in 1828 at the age of seventy-six, was apprenticed to Beilby, of Newcastle, and during his apprenticeship was frequently engaged in engraving clock dials. By favour of Mr. Thos. Foster, I am able in Fig. 689 to show an excellent specimen, dating from about 1775, by James. Whitworth, of Lussley, a village near Newcastle. The figures at the corners to represent the seasons are engraved on the plate. The disc, which moves in the arch and contains two representations of the moon and rural scenes, is painted, and the moon in its course indicates its age by figures engraved on the fixed part of the arch.

Dials with enamelled centres were occasionally used for superior long-case clocks at the end of the eighteenth and beginning of the nineteenth century, but earlier ones are rare. In Fig. 691 is shown, by favour of Mr. Wetherfield, the dial of a long-case clock dated
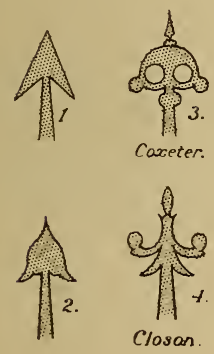
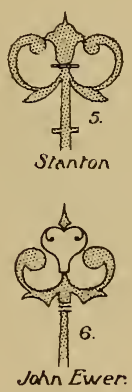
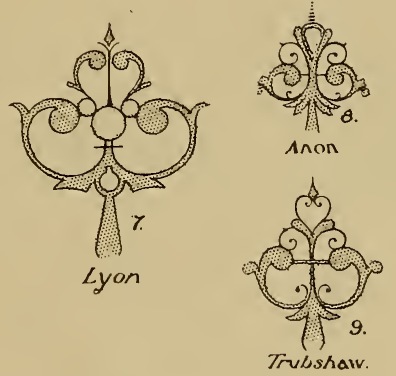

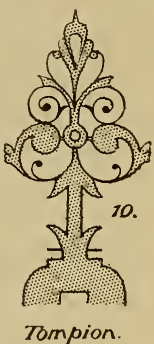

FIG. 696.-Showing gradual development of the Plain Arrow-head Hand.

1778, by Richard Comber, of Lewes, a maker of good repute in Sussex for the excellent character of his work, which this example quite justifies. The hands will bear examination, the corner pieces and arch ornaments are of good design, well chased and water gilt; but the most remarkable feature is the position of the winding squares, which are below the enamelled disc, so that not only is the unsightliness of the holes got rid of, but one of the chief objections to enamel-the danger of chipping rouncl the holes-is a voided. Wheels were added at the back of the movement to bring the winding squares down to the required position.

About 1780 silvered dials shorn of all decorative engraving were sometimes used, and at the same period dials of iron, tin, or wood painted over made their appearance. Speaking generally, the innova- 
tion must be regarded as a degradation, although painted dials ornamented with nicely coloured representations of fruit and flowers after Dutch designs have a pretty effect. Some of the earlier Dutch dials of brass were adorned with pictures of considerable merit of which an example is given on p. 521 .

On pp. 523 and 524 are shown some clock hands, nearly all from examples collected by Mr. G. H. Newton, of Watford. Nos. 1, 2, 3, and 4 belonged to lantern clocks made between 1630 and 1680 ; No. 5 from a clock by Henry Jones, about 1670. Nos. 6 to 23 are from long-case, and 24 to 29 from bracket, clocks. No. 6 by John Tirry, York, about 1680 ; No. 7, J. Windmills, 1690 ; No. 8, John Smith, 1695; No. 9, Simon Lamb, Rochester, 1700 ; No. 10, Saml. Harris, 1710; No. 11, George Hewitt, Marlboro', 1720; No. 12 (hour, minute, and regulation hands ), George Graham, 1730 ; No. 13, Thos. Vernon, Ludlow, 1740; No. 14, Wm. Avenall, Alresford, 1750 ; No. 15, Thos. Andrews, Steyning, 1760 ; No. 16, Wm. Berridge, 1770. Nos. 17 and 18 are typical single hands from early-eighteenthcentury long-case clocks. No. 19, S. Hoole, 1770 ; No. 20, Wm. Skeggs, 1780 ; No. 21, J. Lorimer, 1790 ; No. 22, Hugh Stockell, Newcastle, 1800 ; No. 23, another variety of about the same date ; No. 24, J. Lowndes, 1690 ; No. 25, Asselin, 1720 ; No. 26, Wm. Kipling, 1710 ; No. 27, Joseph Emery, 1780 ; No. 28, Robert Newman 1700 ; No. 29, Thos. Appleby, 1800 . The best of these early hands were not only pierced but shaped or carved on the surface, if the file can be admitted as a carving tool.

For the examples of hour hands in Fig. 696, I am indebted to Mr. T. W. Bourne, who traces progression from the plain arrow-head No. 1. No. 2 is similar, but with curved sides. No. 3, really an ornate form of No. 2, was commonly used by the old makers of lanternclocks. If viewed from a distance, it gives the same effect as the wavy arrow-head. No. 4 marks the first real step in development; above the arrow-head are two new limbs and a pointer. In No. 5 the curved limbs have grown and between the arrow-head and pointer appears a solid enlargement which in No. 6 had been hollowed and rendered more ornamental. This part of the hand has in Nos. 6 and 8 been still further extended, the special features of each being combined in No. 9. No. 10 may be called the final form. The arrowliead has been retained throughout, the superstructure being the special object of extension and enrichment.

Cases.--As material for the cases, oak has been used from first to last, but rarely for high-class work. Walnut cases, both plain and 
inlaid, were largely made during the latter part of the seventeenth and beginning of the eighteenth centuries. The marquetry work rarely extended to the sides of the case, which were plain as a rule, though occasionally panelled; the panels being filled with parquetry, that is, set with angular pieces of thick veneer. Oyster-shell veneer or inlay was another handsomestyle of ornament; the inlay consisted of roundish pieces of veneer cut from cross sections of small branches so as to exhibit the natural formation or ringed structure of the wood.

Ebony, rosewood, and hardwood of reddish colour called, I believe, kingwood, were occasionally used for cases, while laburnum, olive, yew, holly, sycamore, apple and pear as well as tulip wood, Amboyna and other fancy kinds were employed with good effect for inlaying. In some districts chestnut seems to have been utilised to a considerable extent for cases during the eighteenth century. Mahogany was not

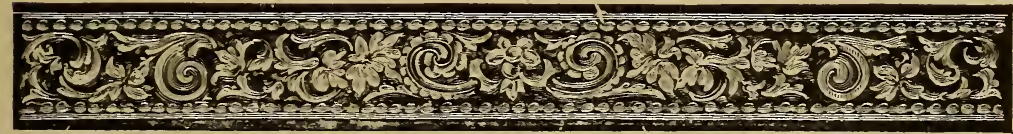

FIG. 697.-Brass Fret from Head of Long-case Clock, about 1700.

used till about 1716. The case of the Tompion one-year timepiece at the Admiralty, which is shown on p. 536, is distinctly later than Tompion's time, and it is related that the movement of a similar piece presented to the Royal Society in $\mathbf{1 7 3 6}$ was discovered among lumber on the premises occupied by the Philosophical Society. At Child's Bank is a long-case clock by Richard Street dating from about 1710 . It is in an oak case veneered with mahogany, but the veneer was, I am satisfied, not applied when the case was made; doubtless the rich appearance of mahogany led to its subsequent application.

The arched head to the long door of the case is not quite so old as the arched dial, but the introduction of curved door heads may be put, I think, at about 1725 .

Numbers of cases covered, with English copies of quaint-looking Japanese or Oriental lacquer-work were made between 1710 and 1750 , and they have many admirers, but marquetry and lacquer-work rapidly declined as mahogany became more known, and it must be 
confessed that some cases of mahogany in the Chippendale and Sheraton styles, inlaid with satinwood, \&c., quite justify the admiration with which they are regarded. An exceptionally early lacquer case in the Wetherfield collection is shown on p. 557 .

In a few of the early long-pendulum clocks a bull's-eye of greenish glass was let into the door of the case opposite the pendulum bob, magnifying and distorting the appearance of the bob as it swung to and fro, and for some years from about 1685 a round or oval hole with a flat glass was quite a usual feature.

The upper part of the case, or hood, which surrounded the dial, was at first made without any door. Most makers fitted the hood with grooves to the back as described on p. 495 . In other instances the hood had to be slid forward and entirely removed to obtain access to the dial. In the early cases the moulding under the hood was convex, as distinguished from the concave moulding almost invariably used afterwards. Corkscrew pillars at the angles of the hood were much favoured during the William III. and Queen Anne periods. The pillars supported an entablature which either terminated with a flat top or was surmounted by a pediment or some kind of ornament.

A domed or canopied structure was common, but there is no particular pattern which can be quoted as absolutely distinguishing the time. Some early hoods terminated in a pediment, simple and appropriate. The styles most in vogue may be gathered from illustrations of examples which I shall be able to give. In nearly all cases a frieze or other band was pierced to emit the sound of the bell ; sometimes the fretwork was of wood and sometimes of brass. The brass fret strips, which were rather pretty, were often removed when the case subsequently underwent repair. One of them taken from a clock dating from 1700 is shown in Fig. 697.

The height of early cases seemed to be adapted in some measure to the places they were to occupy. The flat top of an entablature, as in Fig. 715, was suited for low rooms; where greater height allowed, the dome or double dome would doubtless be selected. For lofty apartments with other furniture of large size there would be gilded figures surmounting a high-topped case, or finials of gilded wood. To increase the height still further, the case occasionally would be stood on a subbase with carved panels. Now and then one may see an old clock in which, to suit the limited extent of low rooms, the top of the case has been shorn of all adornments.

Fig. 708 represents an eight-day Tompion clock dating from $1676-80$, 
the dial of which, $9 \frac{1}{2} \mathrm{in}$. square, is shown separately on p. 498 . The case is of oak veneered with walnut; at the corners of the hood are pillars with helical or "corkscrew" shafts, brass bases, and Corinthian capitals. Well-executed brass festoons of fruit and flowers adorn the hood over the dial and over the side lights. Mr. Wetherfield, who owns this clock, has a timepiece by William Clement which is very similar in appearance.

By favour of Messrs. Horne \& Son, of Leyburn, I am-able to give an engraving of a quaint thirty-hour long-case clock of provincial make which now belongs to Mr. Thomas Bradley, Wensleydale. This case is of oak and panelled. The head is fixed on the trunk, and will not take off. Two slip doors at the sides of the head open to get to the works, and a sash door affords the same convenience for the dial. Both the case door and the sash door open from right to left. The initials E. F. M. with date, 1681, are carved on the case. The clock was made for Edward and Margaret Fawcett; the former was a clergyman, who lived at Hardraw, close to the Hardraw Waterfall. The works are of the lantern type, with a large bell and hammer inside, and small dial as shown in Fig. 704. It was made by John Ogden, Bowbrigg(e). In Ogden's clocks of later date the name of the place was spelled Bowbridge, but the local name is Bowbrigge to-day. In each of the corner spaces outside of the hour circle is engraved one line of the following verse :-

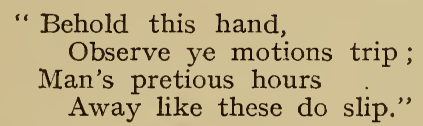

John Ogden was a member of the Society of Friends, and a friend of George Fox, who often visited Wensleydale.

Marquetry (or Marqueterie).-The formation of designs by inlaying wood of different kinds is a very ancient art. The Italians particularly excelled at it in the fifteenth and sixteenth centuries. Early inlaying was done by cutting out from the solid wood which formed the groundwork such parts of a pre-arranged design as it was desired to have of a different colour and then inserting pieces of a suitable and different kind of wood. But in most of the marquetry we see on clock cases the design is cut out of a groundwork of veneer which is filled in with other veneer and attached to the surface of the wood which forms the body of the case. This method is, I think, of French origin and dates from the middle of the seventeenth century, but it was first applied to clock cases about 1685, and remained in 
530 Old Clocks and Watches and their Makers

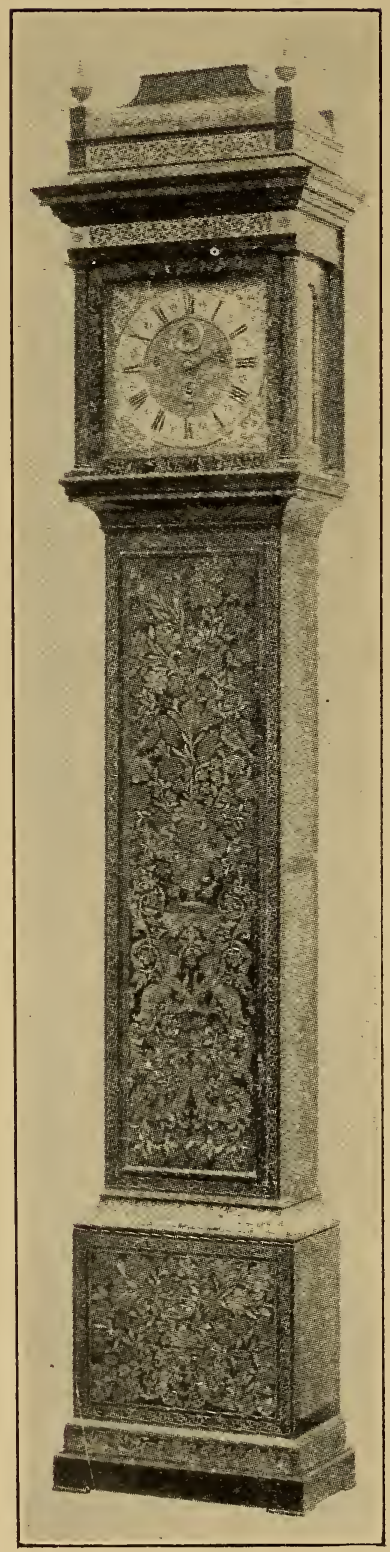

FIG. 698.-Three-train Month Clock, by Christopher Gould ; height $8 \mathrm{ft}$.

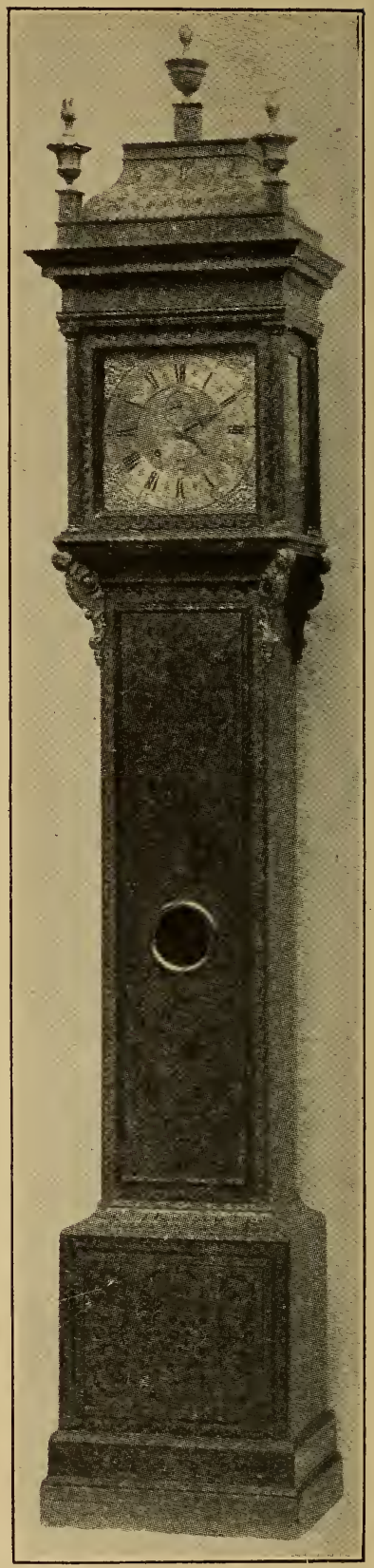

FIg. 699.-Fine Month Clock with perpetual calendar, by Charles Clay; helght $9 \mathrm{ft}$. 
fashion, so far as clock cases are concerned, for about twenty-five years from that date.

Two very fine specimens of long-case clocks in elaborate marquetry cases are shown in Figs. 698 and 699, both from the Wetherfield collection. One is a three-train month clock by Christopher Gould ; it is $8 \mathrm{ft}$. high, with a 12-in. dial, chiming quarters on eight bellsrepeating hours-i.e., "The Grande Sonnerie." The date is about 1705. The month clock by Charles Clay is $9 \mathrm{ft}$. high, and the trusses under the hood, though not a very usual feature, are an appropriate adjunct to the very handsome case. This clock has a 12-in. dial, and is furnished with a perpetual calendar.

Dutch marquetry is effective, of a distinctly bolder or coarser character, and, as a rule, may be distinguished from what may be called English designs, which more favoured the Italian style. Arabesques, fine geometrical patterns, conventional flowers and foliage executed by inlaying wood, which, though of a different colour to the ground, was yet not in violent contrast to it, characterised the English, while Dutch artists, who accentuated more the difference between the groundwork and the inlay, indulged in quaint and fanciful designs in which grotesque masks and figures, as well as vases, birds, leaves, tulips and other flowers were portrayed by means of shading and the use of wood naturally of another colour or stained to the desired tint. It must not be assumed, though, that what is called Dutch marquetry was necessarily executed in the Netherlands ; there is no doubt that when William III. ascended the English throne his followers included Dutch inlayers who settled here and turned the public taste to their particular methods, which were followed by English workers.

Two fine examples of the Dutch type of marquetry case are shown in Figs. 700 and 701. They both date from about 1700. One is a month striking clock by Quare, height about $8 \mathrm{ft} .6$ in. The other is an eight-day striking clock, giving one blow on the bell at the half hour. This clock also is about $7 \mathrm{ft}$. high, with a 12-in. dial, and is signed " Isaac Papavoine, London." Both are from the Wetherfield collection.

At first the marquetry was arranged on the front of the case in panels with semicircular ends, sometimes with a line-border connecting the panels; afterwards the whole of the front surface might be covered with marquetry, the door and base having set designs, enclosed in floral or other borders. In marquetry work of the very highest class, it will be noticed that the whole of the inlay on any one 
532 Old Clocks and Watches and their Makers

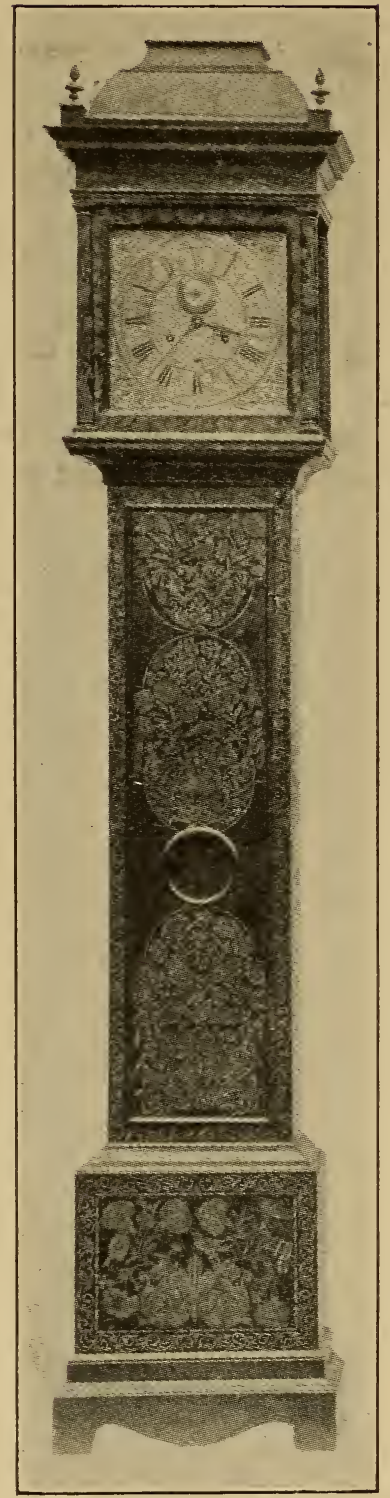

FIG. 70\%),-Long-case Month Striking Clock, by Quare ; height 8 ft. 6 in., date about 1700 .

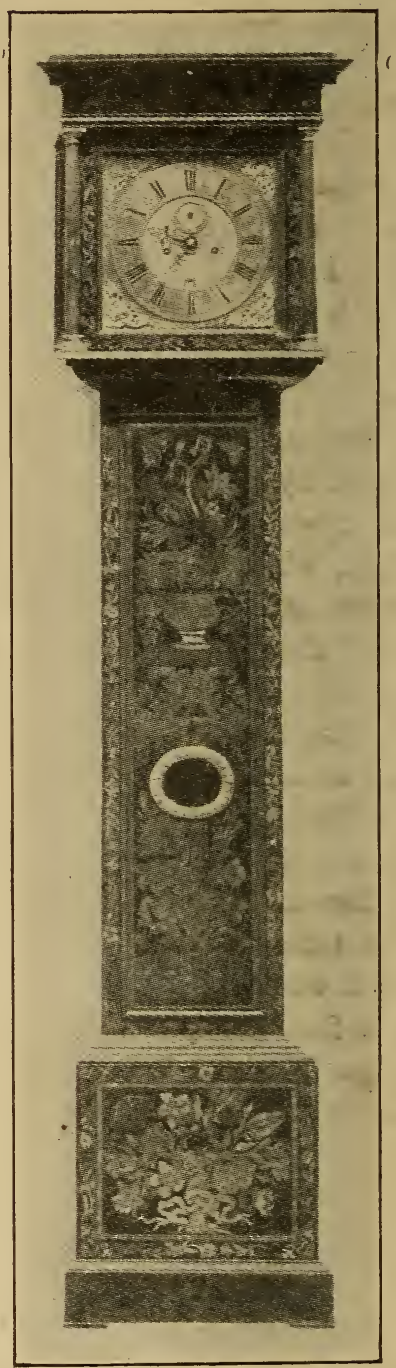

Fig. 701.-Striking Clock, signed "Isaac Papavoine, London"; height $7 \mathrm{ft}$., date about 1700 . 
The Progression of English Domestic Clocks 533

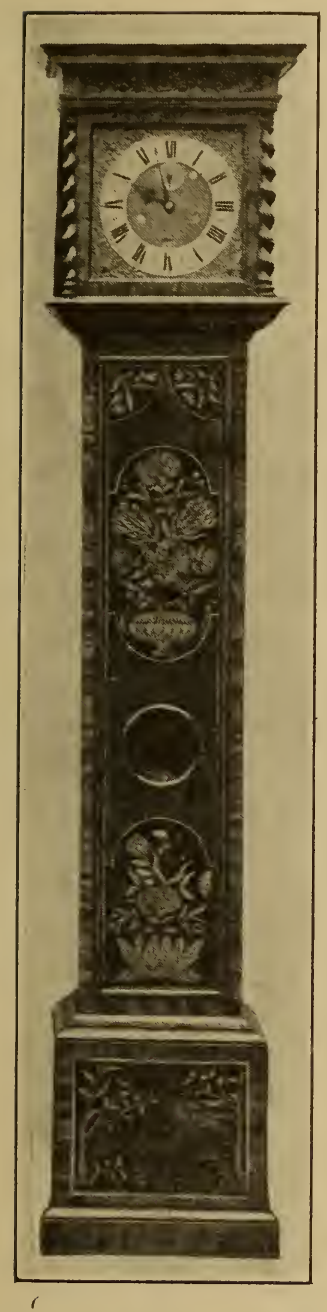

FIG. 702.-Small Squaretopped Long-case Clock, by John Barnett.

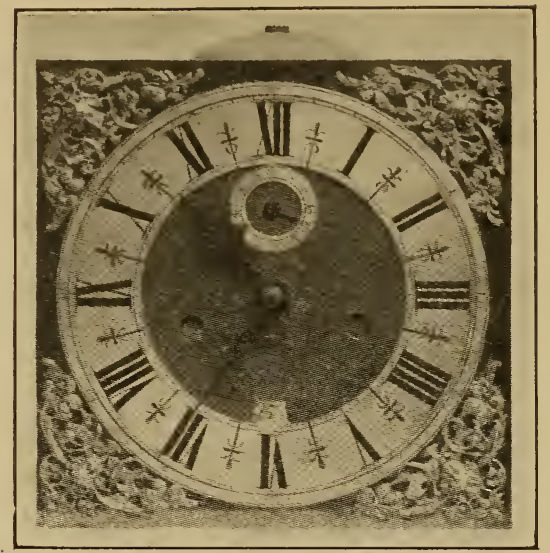

FIG. 703.-Enlarged dial of Fig. 702.

surface forms a complete design ; if birds or figures are introduced they are delineated as a whole and fall gracefully into the conception of the designer. More frequently a symmetrical pattern was taken and two pieces of veneer forming half of the pattern were laid one on the other and pierced together; the halves were then placed side by side and of course matched exactly. But however close the jointing of the halves, the line of junction down the centre may be discerned by close examination. Masks or vases containing leaves and flowers on stalks were commonly selected for such treatment and were displayed very effectively in this way. Sometimes

the halving would extend to a portion of the design only, and advantage would be taken of the outlines of leaves or scrolls to join in the halved pieces very neatly.

Fig. 702, from the collection of Mr. Hansard Watt, illustrates a small square topped long-case clock in burr and oyster-shell walnut. 
The long door inlaid with marquetry of various woods in panels. A rare feature is the hunting scene inlaid in marquetry at the base. Square brass dial 10 in. with matted centre and Tudor rose engraved round centre of hands. Eight-day striking movement; bolt-andshutter maintaining power. Locking plate on main wheel. Recoil escapement. The makers' name "John Barnett, Londini, fecit" engraved at bottom of dial. Height, $6 \mathrm{ft}$. 5 in., width 10 in., depth, $6 \frac{1}{4}$ in.

In the South Kensington Museum are a clock by Mansell Bennett enclosed in a case decorated with marquetry in panel, and an unusually fine example of English scroll marquetry covering the case of a clock by Henry Poisson; on the staircase of the Soane Museum is a clock by William Threlkeld, the case of which is also adorned with marquetry in the English style. The Wetherfield collection contains many choice examples.

Soho seems to have been a favoured district for marquetry workers, though Tonbridge in Kent and St. Ives and other smaller places in Cornwall are spoken of as being famous for marquetry work in the eighteenth century.

After being neglected for fifty years or so marquetry was to some extent revived as a decoration for clock cases. A sparing and tasteful display on a clock by Alexander Cumming dating from about 1790 is shown in Fig. 769. Chaste inlay in the Hepplewhite and Sheraton style, as in Fig. 771, is admirable. Sheraton's designs for clock cases are reproduced on p. 553.

A fine specimen, with English marquetry in panels, which is in the Dean's Vestry, St. Paul's Cathedral, is given in Fig. 705. The date of this can be well authenticated by the following extract which I have been allowed to make from the Cathedral accounts for the period from October 1697 to September 1698, when the clock was paid for:-

"ffor a pendulum Clock for the South East Vestrey that goes 8 dayes in a Wallnut Tree inlade Case $£ 140000 . "$

There is no maker's name on either the dial or movement, but the clock was doubtless the production of Langley Bradley, who was at that time the cathedral clockmaker.

The clock shown in Fig. 706 is the property of Mr. Thomas Boynton, Bridlington Quay, and was made by George Ethrington, London, about 1695. The case is finely decorated with English marquetry. 
A very fine chiming clock, by Tompion, with canopied head, which 1s at Windsor Castle, is shown in Fig. 707. The upper part of the

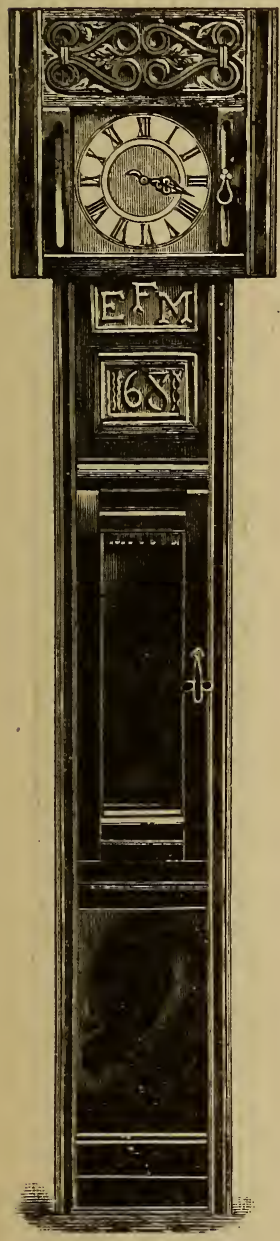

FIG. 704.-Primitive provincial style, 1681 .

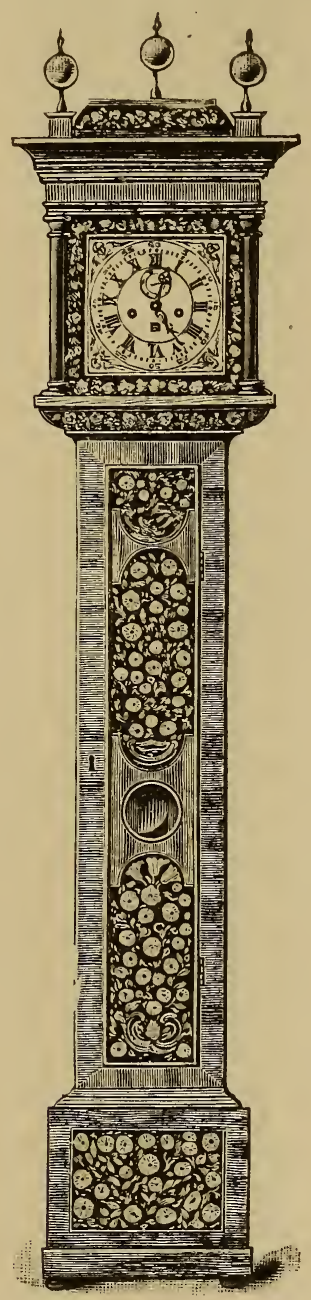

FIG. 705.-Clock at St. Paul's Cathedral, 1698.

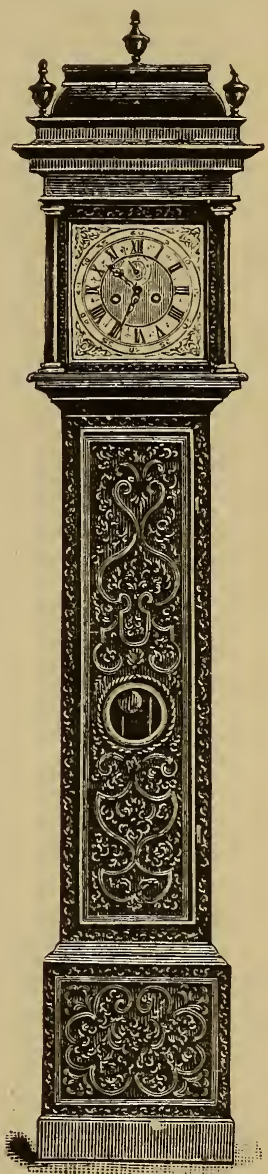

FIG. 706. - “ George

I. Ethrington, London," about 1695

case is particularly good. The trusses supporting the hood, though somewhat unusual features, have an excellent effect.

Fig. 709 represents a Tompion one-year timepiece which is now at the Admiralty. The hours are marked twice from I. to XII. and 
536 Old Clocks and Watches and their Makers

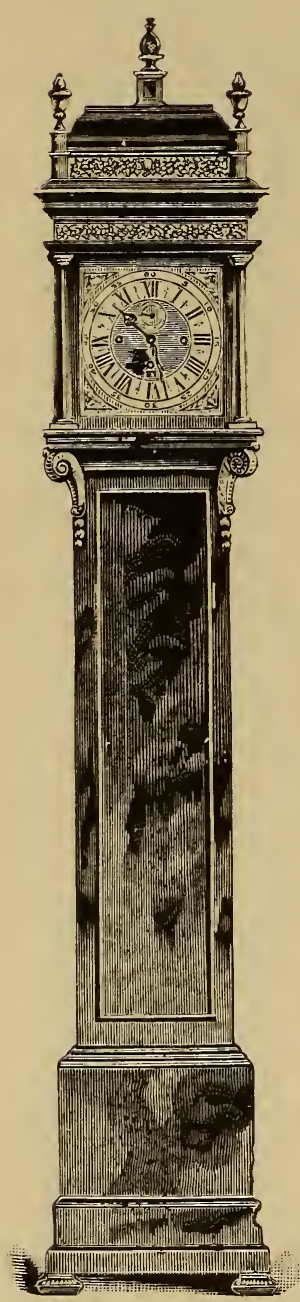

FIG. 707. - Tompion Clock at Windsor Castle.

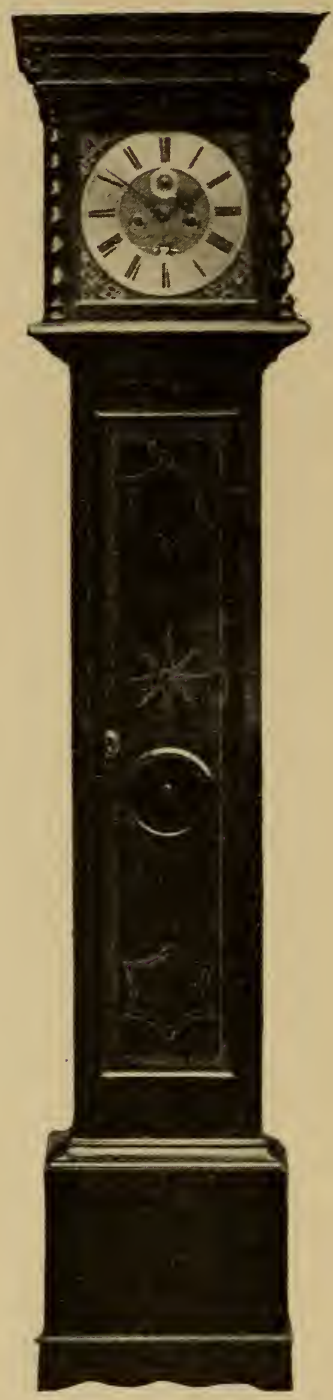

FIg. 708. - Joshua Hutchin, about 1700 .

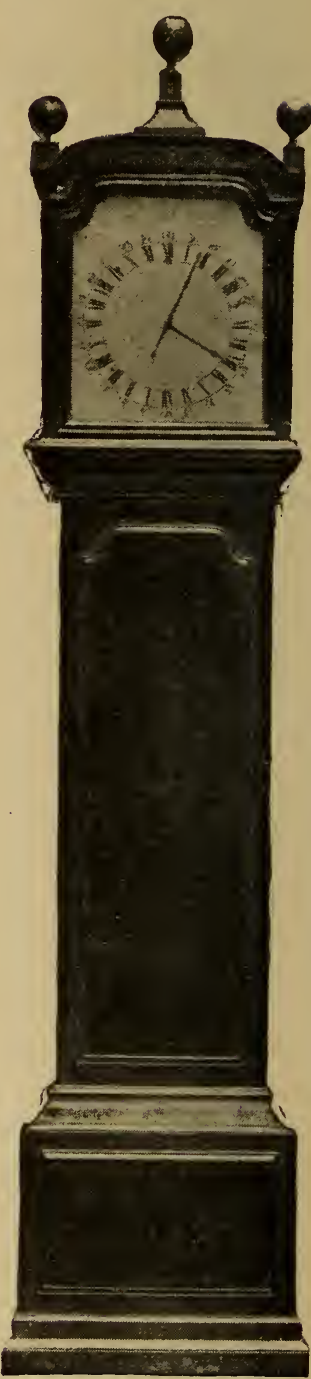

FIG. 709. - Tompion One-year Timepiece at the Admiralty.

at the top of the hood is the inscription, " Presented by Queen Anne." Dividing the hour numerals into two periods of twelve hours each provides a time-teller for the civil, as distinguished from the 
The Progression of English Domestic Clocks 537

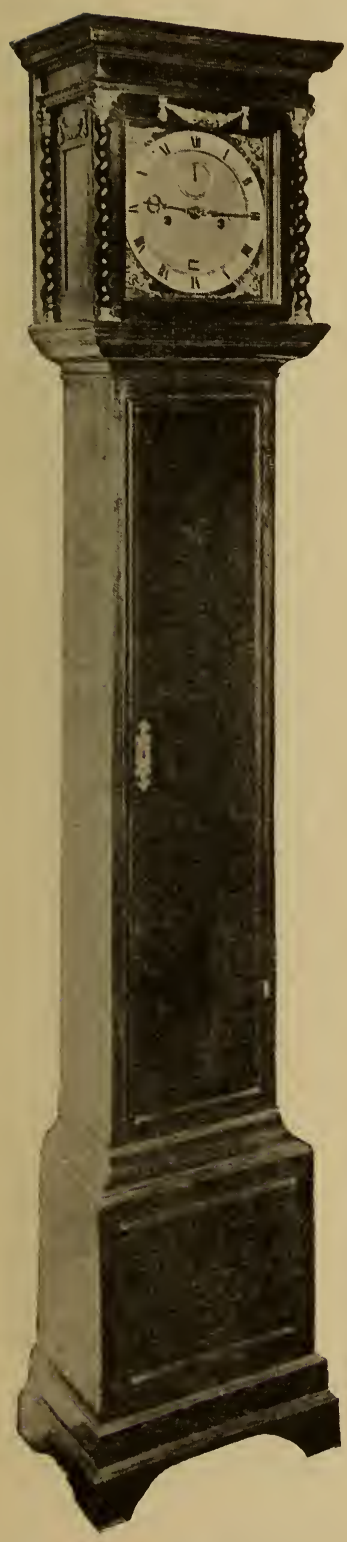

Fig. 710.-Thos. Tompion, 1676-1680 (see p. 528.
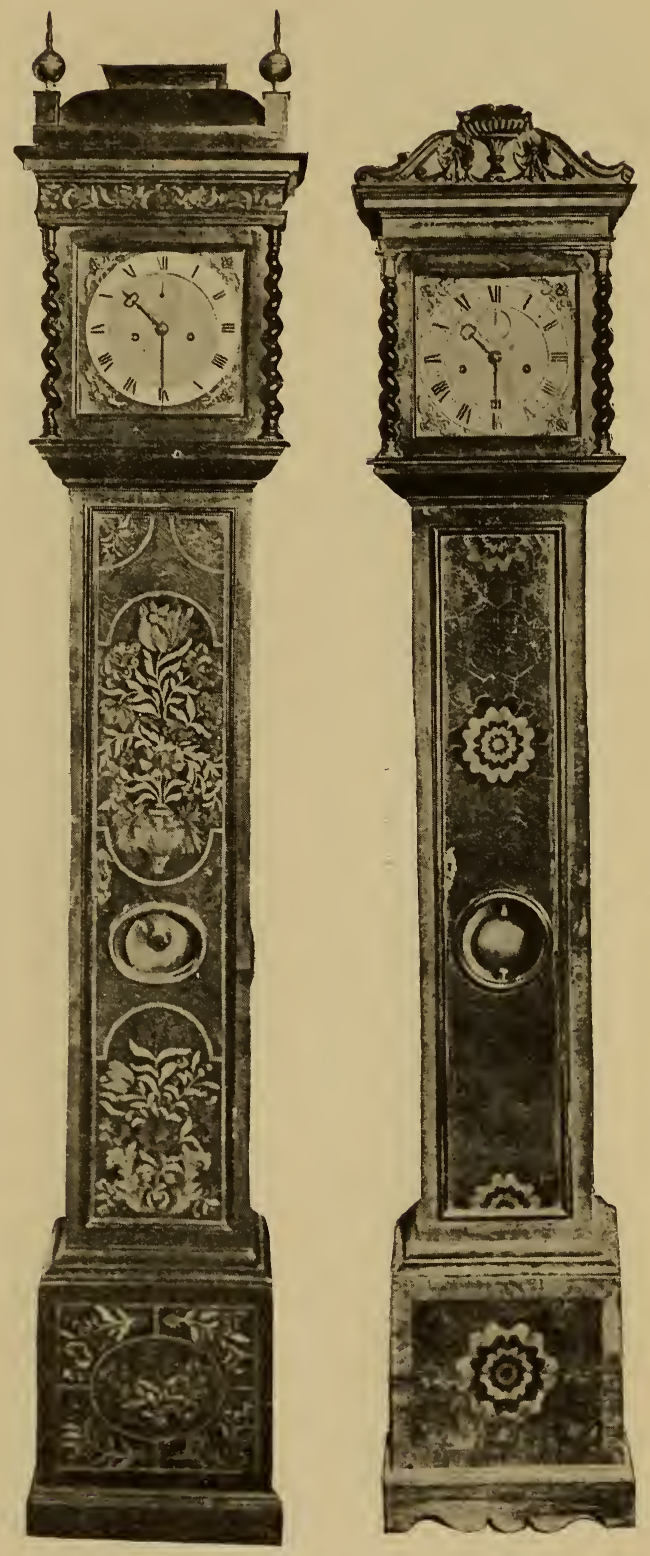

Fig. 711.-Ed. East, Fig. 712.-Jos. Knibb, $1680: 1685$. 
538 Old Clocks and Watches and their Makers

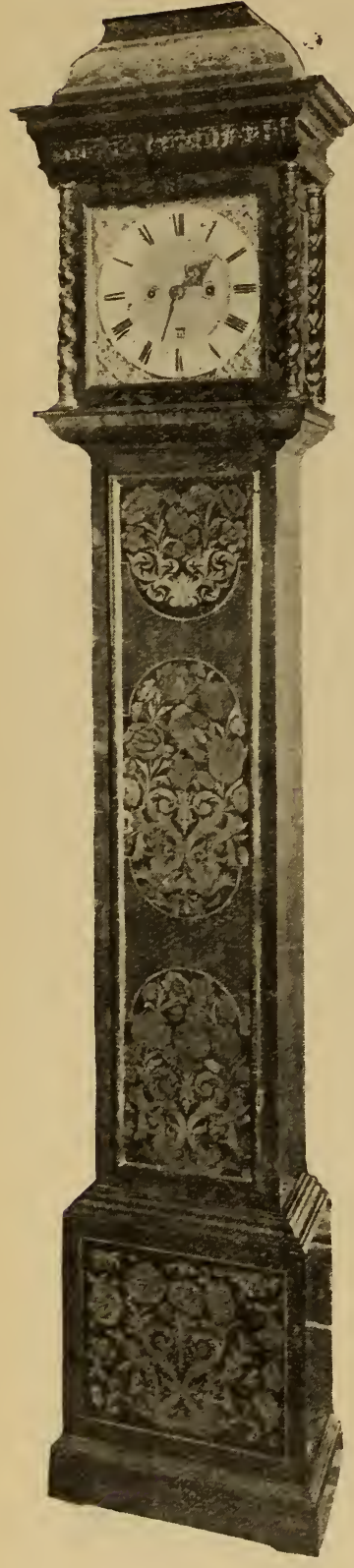

FIG. 713. - Jonathan Lowndes, about 1695.

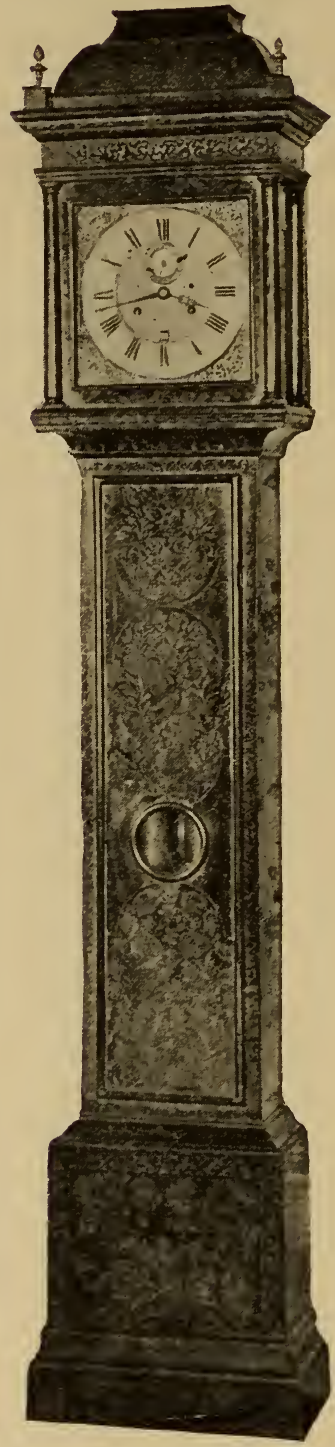

FIG. 714.-Dan. Quare, about 1705 .

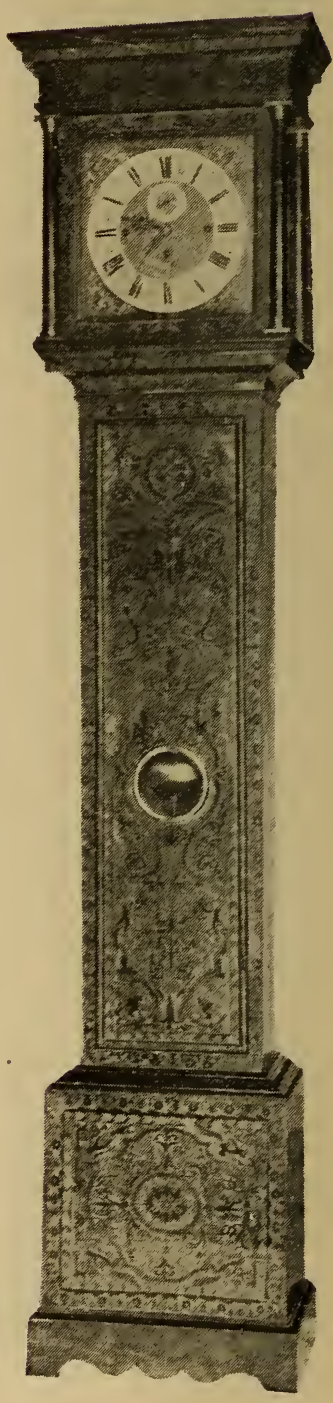

iFrg. 715.-Eight-day Chiming Clock by Peter Garon, about 1705. 
The Progression of English Domestic Clocks 539

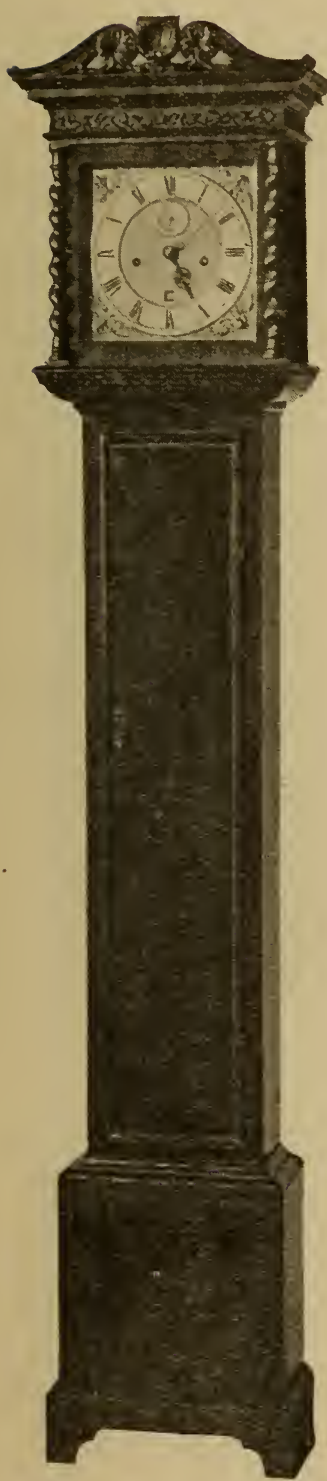

Fig. 716.-Thos. Tompion ; Month Clock, about 1700 .

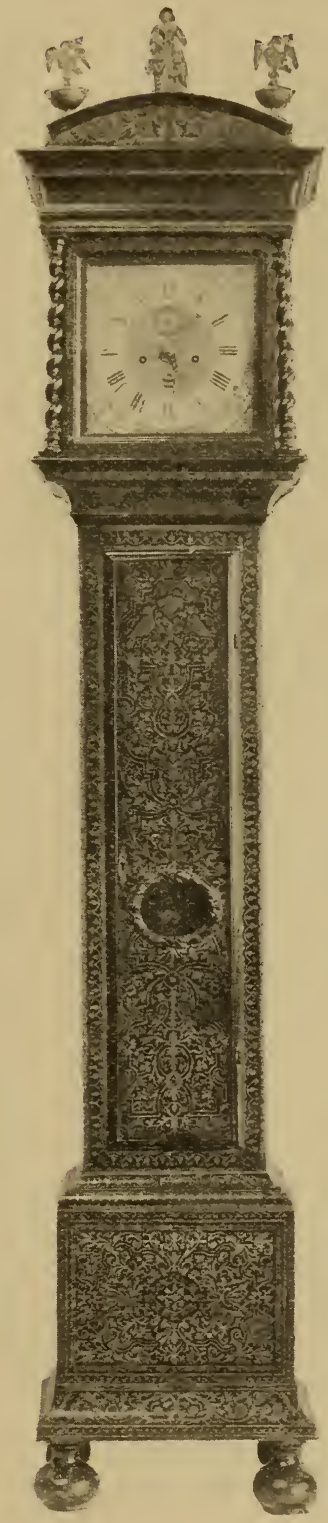

Fig. 717.-Fromanteel \& Clarke, about 1705.

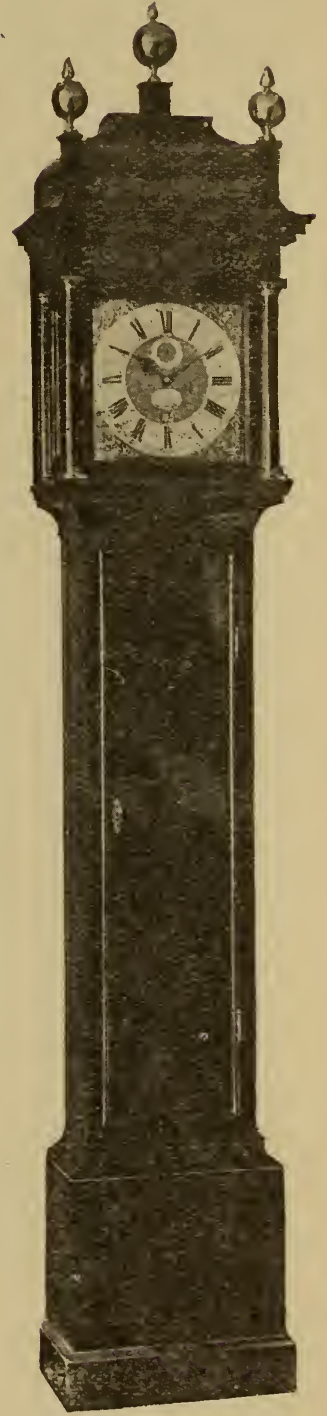

Fig. 718.-Thos Tompion, about 1705 (see p. 501). 
540 Old Clocks and Watches and their Makers

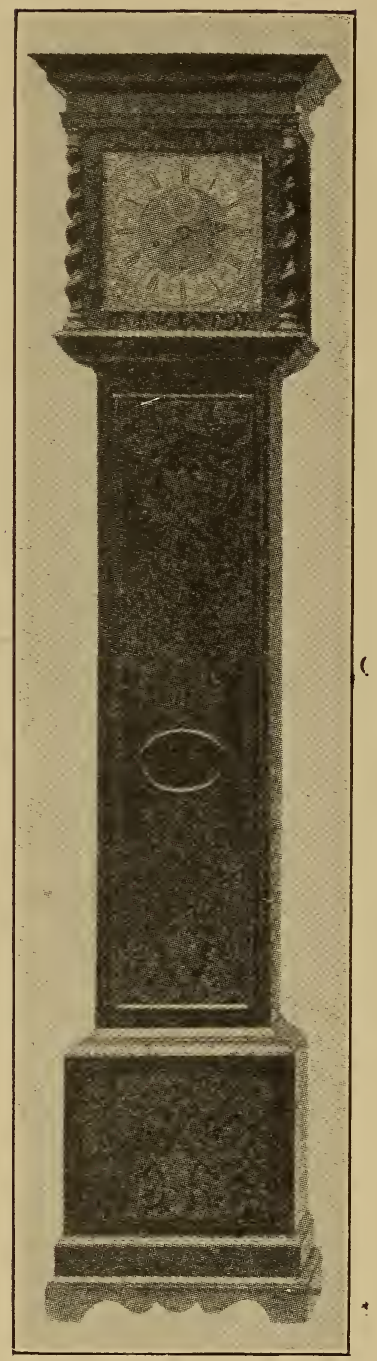

FIG. 719. - Long-case month Striking Clock by Daniel Quare; height $7 \mathrm{ft}$.

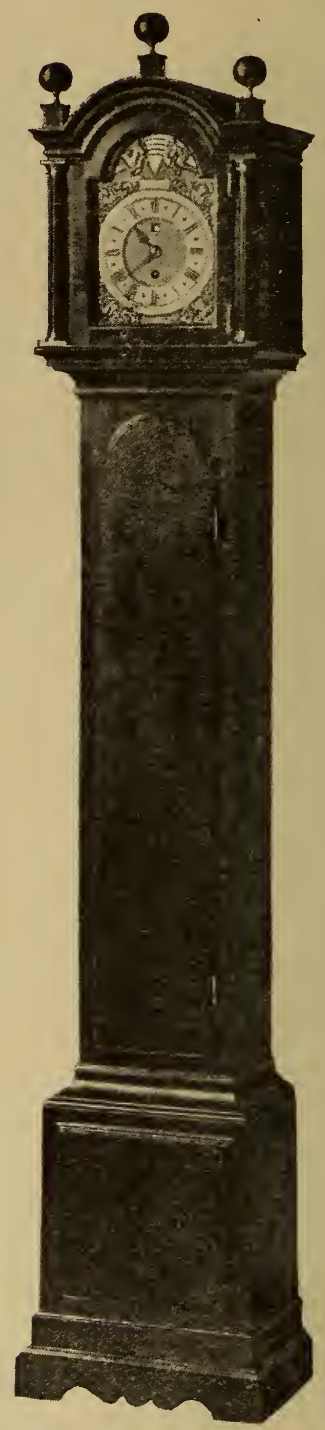

FIG. 720.- Danl. Delander; Year Equation Timepiece about 1720.

astronomical, solar day, but unless desired for some particular purpose such crowding of the hour numerals is objectionable. The case is 


\section{Old Clocks and Watches and their Makers}

certainly later than Queen Anne's time, as I have already said, and the dial looks more like Graham's production than Tompion's. It is quite likely that the timekeeper was ordered of Tompion and intended for Greenwich Observatory and that Graham's well-known desire to make as reliable a regulator as possible caused considerable delay in its construction, or the movement may have been lying by uncased. A very similar twelve-month timepiece bearing Tompion's name, and inscribed "Sir Jonas Moore caused this movement to be made with great care, Anno Domini 1676," was presented to the Royal Society in 1736 .

An example of marquetry arranged in geometrical patterns is shown in Fig. 708, which represents a clock by Joshua Hutchin belonging to Mr. W. K. Bowen. The case, of walnut, is inlaid with stars, curved hexagons, \&c., and a broad herring-bone border which runs around the door, up the sides, and across the top of the body ; a banding inside this border is interspersed with bits of red wood at intervals of 3 in. The stars and hexagons are picked out with holly and set in selected pieces of yew.

The specimen shown in Fig. 711, by Edward East, is from the Wetherfield collection and dates from $1680-1685$. It has a dial $9 \frac{1}{2}$ in. square, goes eight days, and is in a walnut case with marquetry panels showing flowers, birds, and butterflies; somewhat coarse but effective. The hood has a canopied top with brass side ornaments.

From the same collection, and of slightly later date, is the fine eight-day clock with 10 in. square dial, by Joseph Knibb, shown in Fig. 712. The case of oak is covered with burr walnut oyster-shell veneer, the sides are panelled and inlaid down the front with large rosettes of dark and light wood mixed. There are gilt bases and capitals to the corkscrew pillars at the corners of the hood, and over the entablature is a finely carved ornament. There are two bells of Chinese gong shape and on the smaller of these the preceding hour is repeated at the half-hour.

An example of bird and flower marquetry covering a clock by Jonathan Lowndes, shown in Fig. 713, is from the Wetherfield collection, as is also the splendid clock, Fig. 714, which is of later date. It has a dial 12 in. square ; the name "Dan: Quare" being engraved between the hour numerals VII. and VI. and "London" between VI. and V. The case is decorated with marquetry, birds and flowers arranged in panels with scroll borders around the door traming and the base; the pillars at the hood corners are also covered with marquetry. 
An eight-day chiming clock, giving ten changes in the hour, by Peter Garon, in a very fine arabesque marquetry case, the property of Mr. J. Drummond Robertson, is shown in Fig. 715.

The clock b.y Fromanteel \& Clarke in a choice marquetry case which is shown in Fig. 717 belongs to Mr. William R. Moss. It strikes hours and half-hours, has an alarm, shows day of the week and day of the month.

The Tompion clock, Fig. 716, is from the Wetherfield collection, as is also the long-case month striking clock by Daniel Quare shown in Fig. 714.

A one-year equation timepiece by Daniel Delander, shown in Fig. 720, is also the property of Mr. Wetherfield.

Dark oak cases carved in high relief do not seem to have been the fashion of any particular period, but the result rather of occasional efforts by enthusiastic artists in wood, and then in most instances they appear to have been made to enclose existing clocks in substitution for inferior or worn-out coverings. Mr. Harry Clark owns a thirty-hour clock by Thomas Stripling, dating from about 1710. It is in a dark oak case. The bottom panel contains a well-carved scene showing the Lord Chancellor presenting the keys of office to Queen Elizabeth on her coronation. On the door panel is a carved representation of Oliver Cromwell. It is shown in Fig. 721.

Oriental Lacquer.- Cases coated with black, red, or green lacquer, or with a coating of lacquer on black, red, or green ground, the surface being decorated in the Chinese or Japanese style more or less in relief and gilded, were much in favour from about 1710 to 1760 . It is said that at first these cases were sent by ships engaged in the tea trade to China to be decorated, and that a delay of two years or so would occur before they reached England again. Then the Dutch engaged in the art, and afterwards the lacquering or japanning of cases was practised in England. While a few of the specimens now to be met with are worthy of admiration, the greater number attract merely by reason of the grotesque appearance of the ornament. Occasionally may be seen a clock, the door of which is ornamented with Oriental lacquer in relief, while the surface of the rest of the case is merely japanned with poor designs in stencil.

An example of a very fine green lacquer case is shown in Fig. 725, which represents a clock by Eardley Norton, chiming the hours and quarters on eight bells, in the collection of Mr. Hansard Watt. 
544 Old Clocks and Watches and their Makers

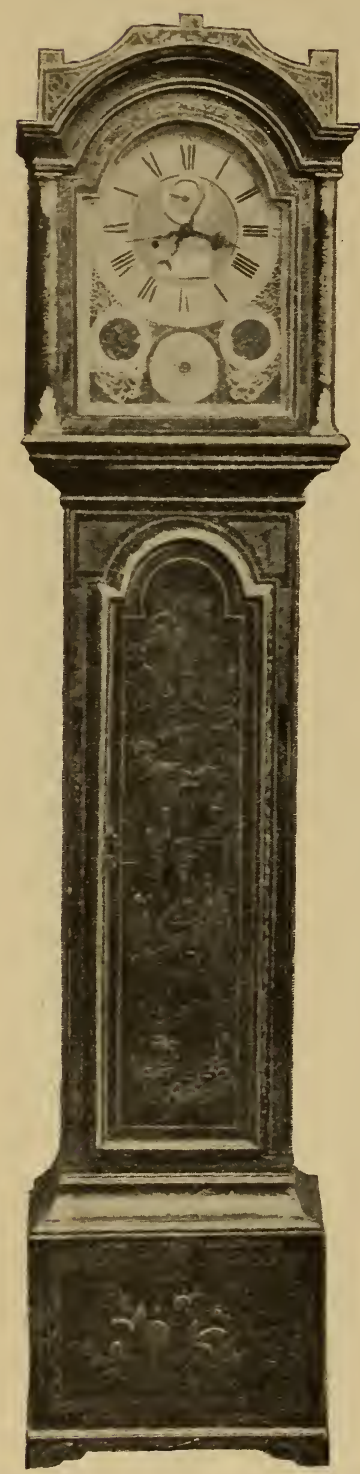

FIG. 724.-Wm. Ball, Bicester; centre seconds, mcon and calendar (see p. 546).

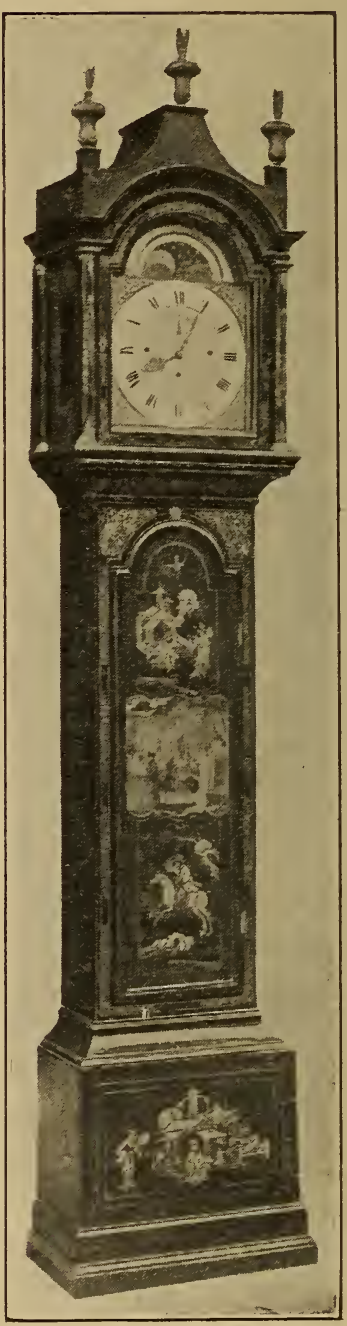

)

FIG. 725. - Clock by Eardley Norton, Green Lacquer Case. 


\section{The Progression of English Domestic Clocks 545}

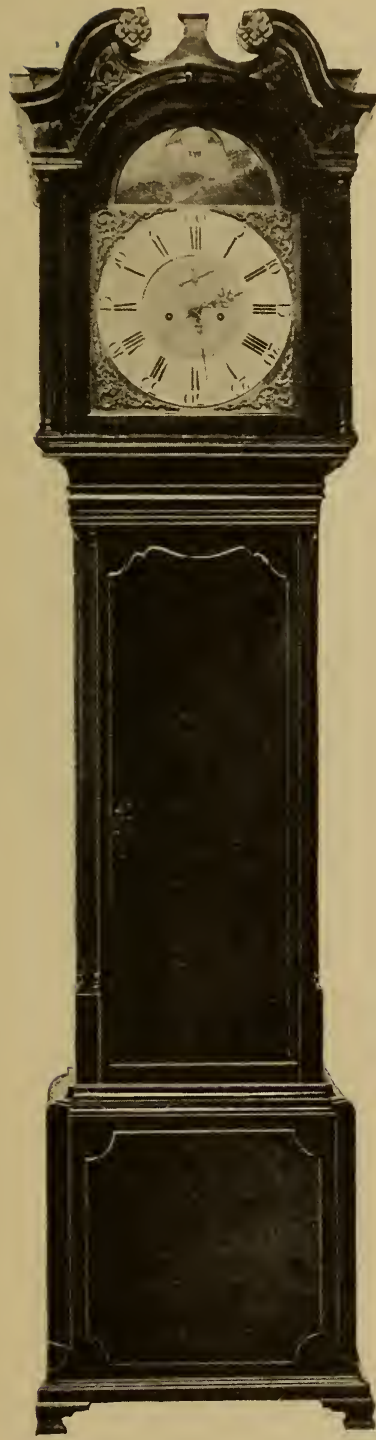

FI G. 726. -Thom as Moss, Frodsham, 1776 ; enlarged view of Dial, on p. 517.

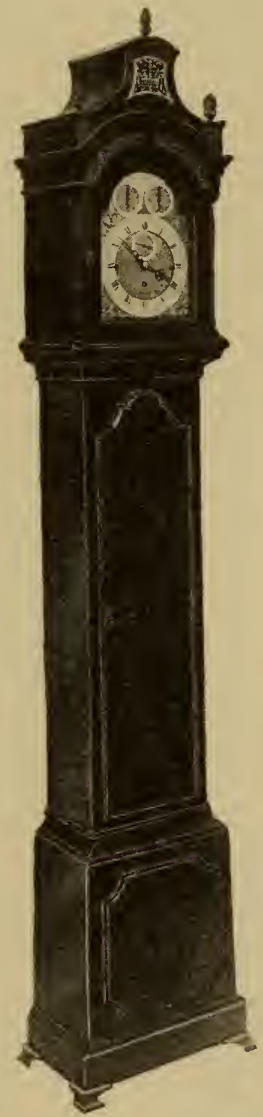

Fig. 727.-Higgs \& Evans; extreme height, $5 \mathrm{ft} .5 \mathrm{in}$. about 1780 .

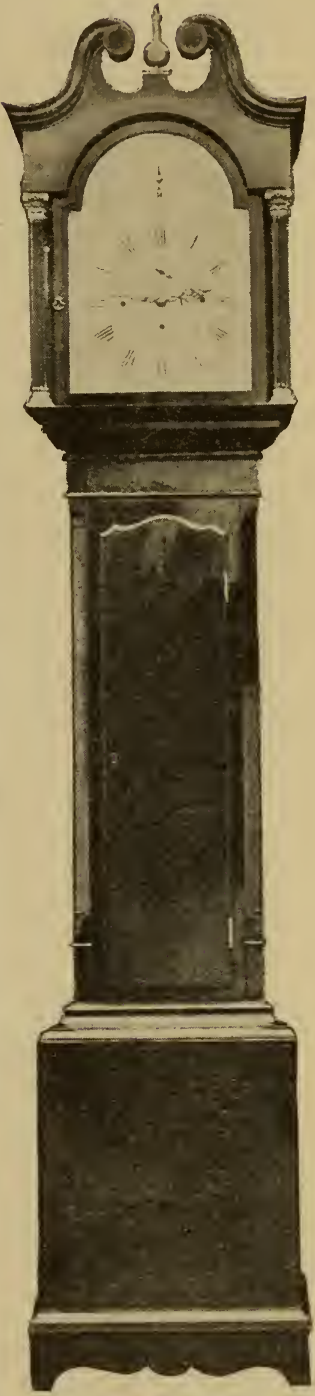

FIG. 728.-Simpson, Southwell, about 1790.

An unusually fine red lacquer case, covering a clock by Philip Abbott in the Wetherfield collection, and dating from about 1750 , is shown 


\section{Old Clocks and Watches and their Makers}

Fig. 723. Another clock with lacquer decoration is shown in Fig. 724. It belongs to Mr. George F. Glenny, and bears the inscription "Wm.

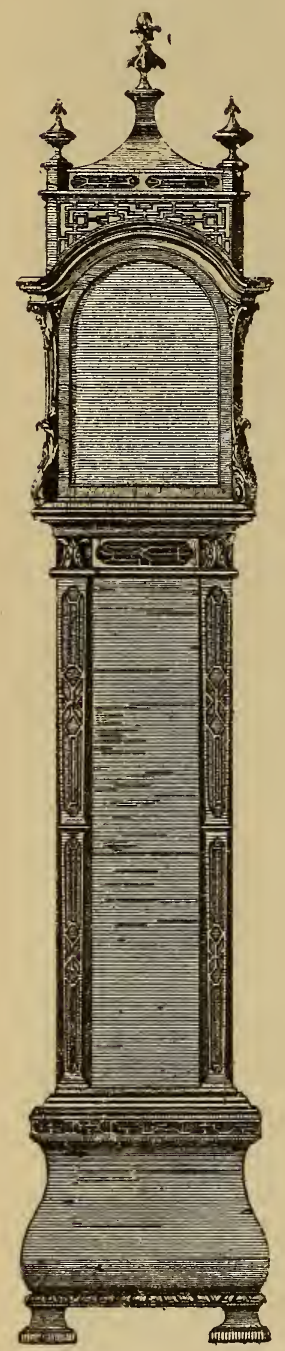

FIG. 729.-Chippendale, with "Fiddle" or " Kettle" Base.

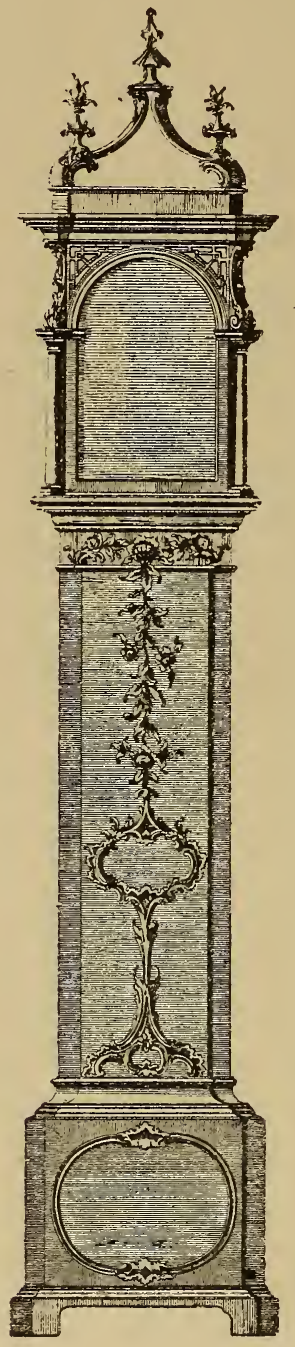

FIG. 730.-Chippendale, with Enriched Front.

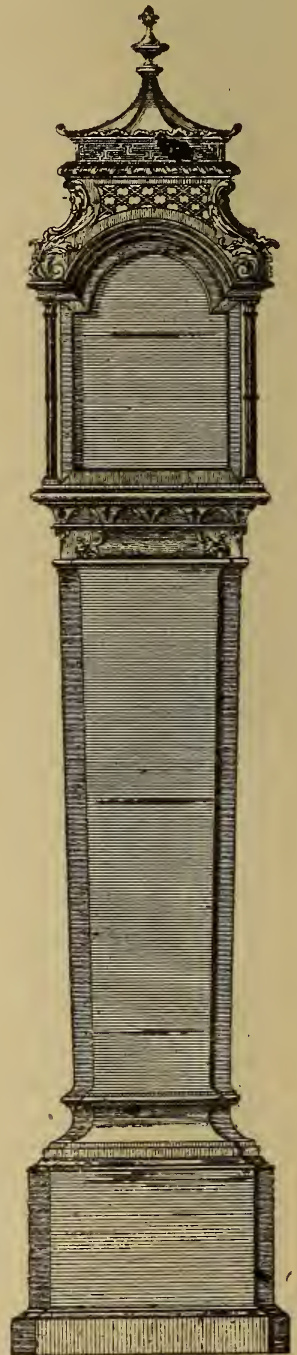

FIG. 731.-Chippendale, with Tapered Trunk.

Ball, Bisceter." It has a centre seconds hand, and just above the centre of the main dial is a subsidiary one showing the age and phases of the moon. The dials below give the day of the month, the title 


\section{The Progression of English Domestic Clocks 547}
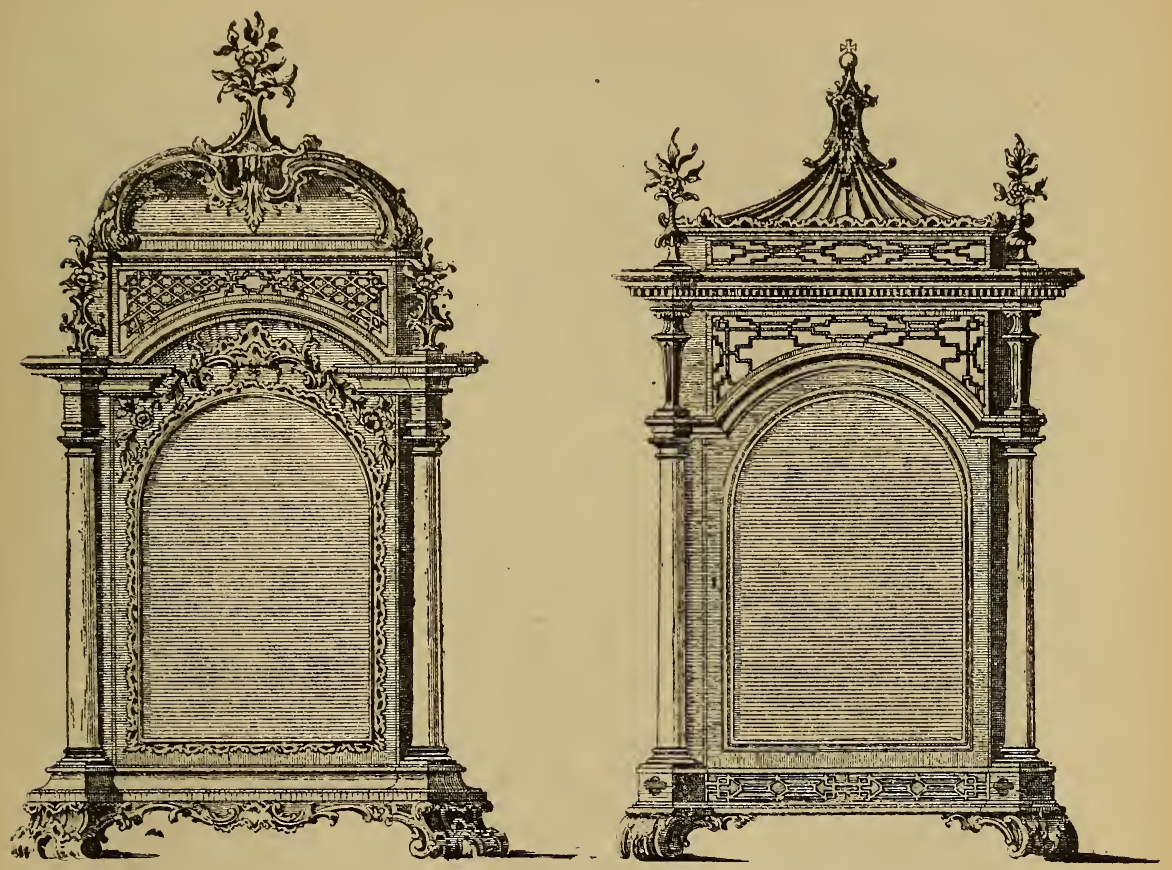

Figs. 732, 733.- Chippendale Bracket Cases.
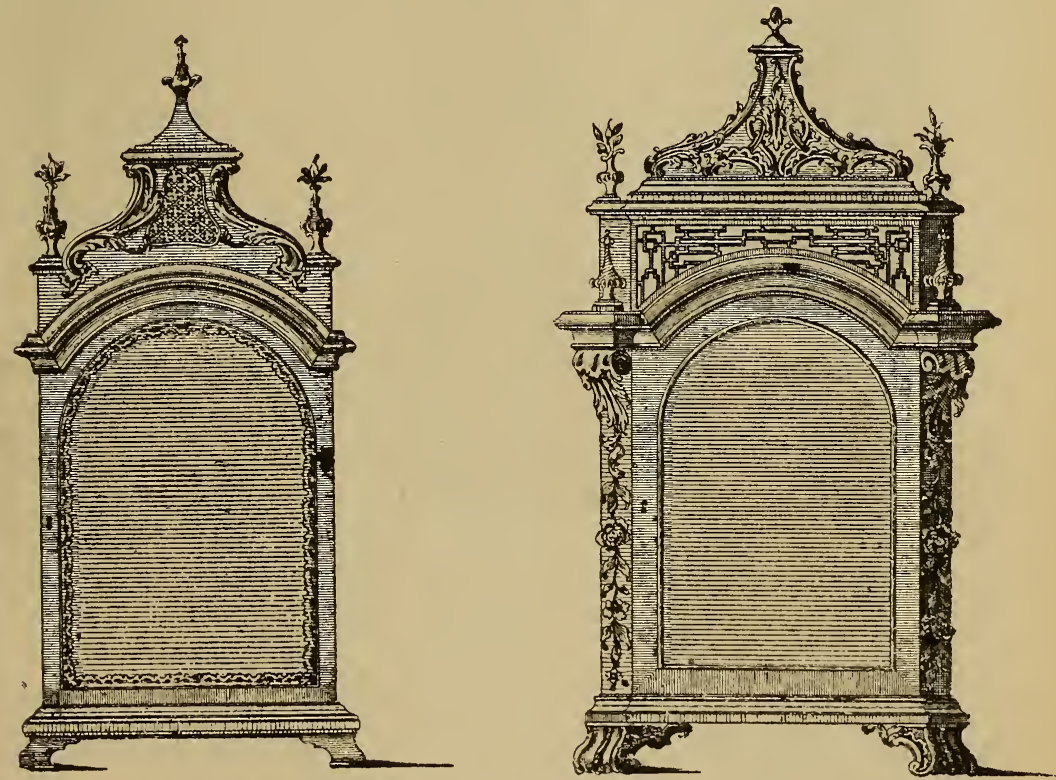

FIGs. 734, 735.-Chippendale Bracket Cases. 


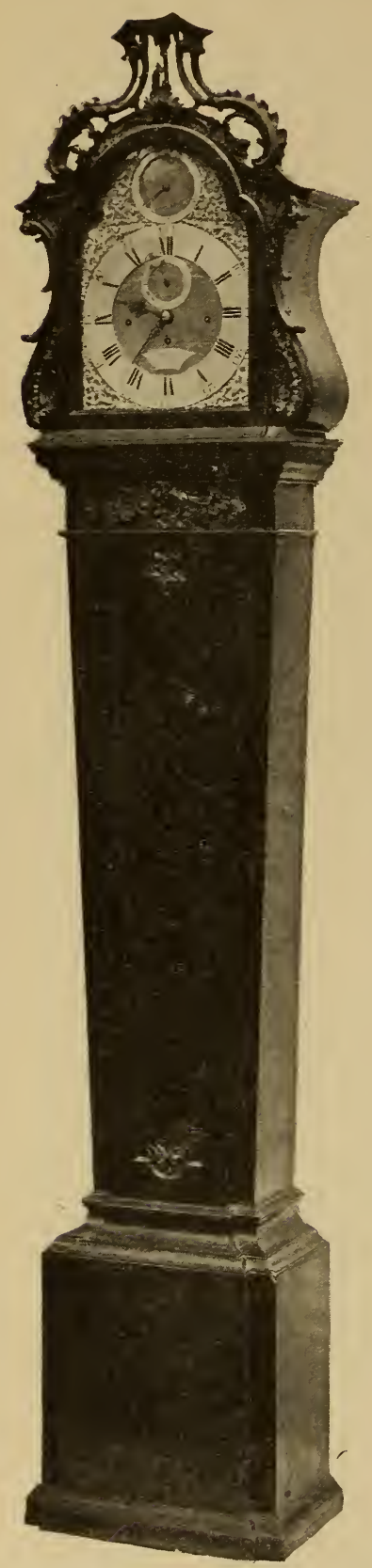

FIG. 736.-Perfect Chippendale _Case Clock by John Holmes. of the day; thus "St. Monday," "St. Tuesday," \&c., and the month of the year. It dates from about 1770 .

Chippendale.-Examples of what is generally accepted as an orthodox Chippendale case are represented on p. 546. It is not easy to define exactly what constitutes a Chippendale case, nor why cases of this pattern should be ascribed to Chippendale. Thomas Chippendale was a noted upholsterer and cabinetmaker in St. Martin's Lane. He published a splendid folio book of designs, of which three editions appeared between 1755 and 1763 . Figs. 729, 730, 731, and 737 are copied from his work by favour of Messrs. B. T. Batsford, Ltd. It must be confessed none of them bears a very close resemblance to the reputed Chippendale patterns. There are also representations of two other long-case clocks, the bracket clock cases shown in Figs. 732, 733, 734, and 735, a cartel case, and two other small wall timepiece cases. The two long cases I have not reproduced are carved very much in the French style, as Figs. 538, 539, Chapter VI.

English clocks in cases following Chippendale's published designs are exceedingly rare. A bracket clock enclosed in a case similar to Fig. 732 bore the name of Jno. Archambo, who carried on business in Princes Street, Leicester Square, between 1720 and 1745. Among the Wetherfield collection is one superb example, which is shown in Fig. 736. It is a clock by John Holmes. The case is of mahogany, and the execution of every part scrupulously good. It dates from about 1770 . 
The characteristics of the cases now usually known as "Chippendale " are the pillars or pilasters rising at the front corners of the case, from the plinth to the entablature under the hood, and the corresponding pillars at the front corners of the hood. Generally the bases and caps are of metal, and the shafts fluted. The case is much higher than the dial, and the top of the pattern shown in Fig. 722, which is considered the more correct, or of the horn-top kind, in which the upper part terminates in two carved scrolls, curving inwards. It will be observed that the head above the dial in Fig. 722 is high, and most after the style of Chippendale's drawings. This clock was made by Richard Vick and is at Windsor Castle, and appears to be earlier than Chippendale's books. The horn-top style, which was very popular with provincial makers, is later. The horn or scroll-top case shown in Fig. 726 encloses a clock by Thomas Moss, of Frodsham, which belongs to Mr. William R. Moss; the dial, to an enlarged scale, is shown in Fig. 688. This clock was made in 1776 or 1778. Fig. 728 represents a clock by Simpson, of Southwell, dating from about 1790 , for which I am indebted to Mr. H. Cook, of Newark. There are no pillars between the base and the hood, but the front corners of the waist are boldly chamfered.

It is a little curious that the handsome curved base of Figs. 729 and 737, though favoured by Dutch and French makers, was very rarely adopted by English. A clock by Joseph Rose, London, owned by Mr. Charles Morson in America, affords an exceptional example of this " fiddle " or " kettle " shaped base, as it is indifferently called, applied to an English production.

A remarkably small and pretty Chippendale case, quarter-chiming clock, which belongs to Mr. R. Lionel Foster, is shown in Fig. 727. Its total height is $5 \mathrm{ft} .5 \mathrm{in}$. The dial rings of enamel are good and clear, and above them is the signature " Higgs y Diego Evans," a form of signature used for the Spanish markets. For the photograph I am indebted to Mr. J. Bolton Smith.

The clock by Andrew Padbury shown in Fig. 738 belongs to Mr. C. J. Bentall. It is remarkable by reason of its dial, which is shown to an enlarged scale on p. 513.

Fig. 740 shows a clock by Nicholas Lambert, London; dating from about 1760 . The case is of walnut with unusual arching at the bottom of the hood. For this and Fig. 742 I am indebted to Messrs. W. Horne \& Son. A clock by Henry Brownbill, Leeds, owned by Mr. Cecil B. Morgan and shown in Fig. 741, has a painted dial. It dates from about 1780 . Fig. 742 represents a clock by John Smith, 
$55^{\circ}$ Old Clocks and Watches and their Makers

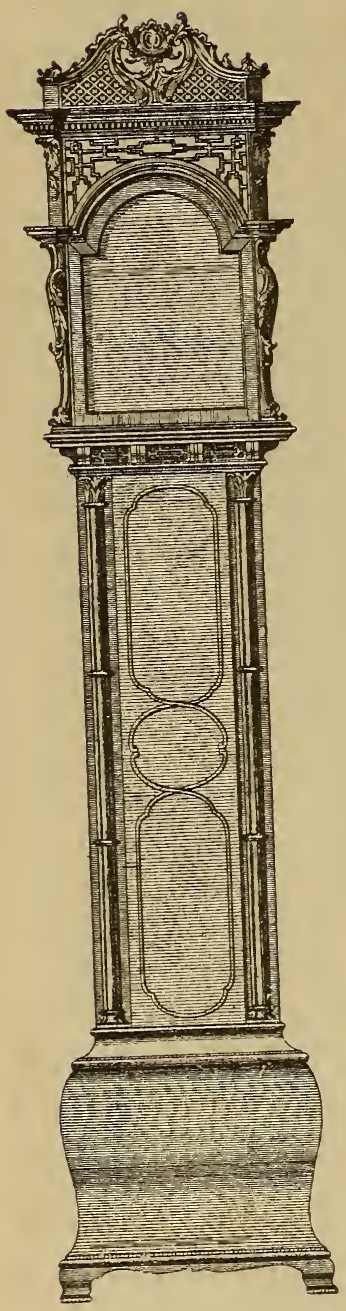

FIG. 737.-Chippendale, with "Fiddle" or "Kettle" Base.

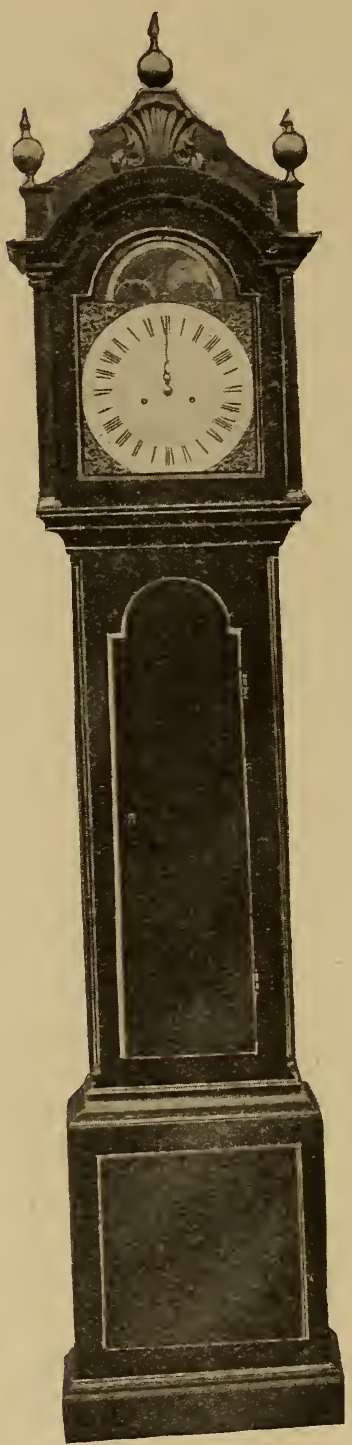

FIG. 738.-Andrew Padbury, about 1760 .

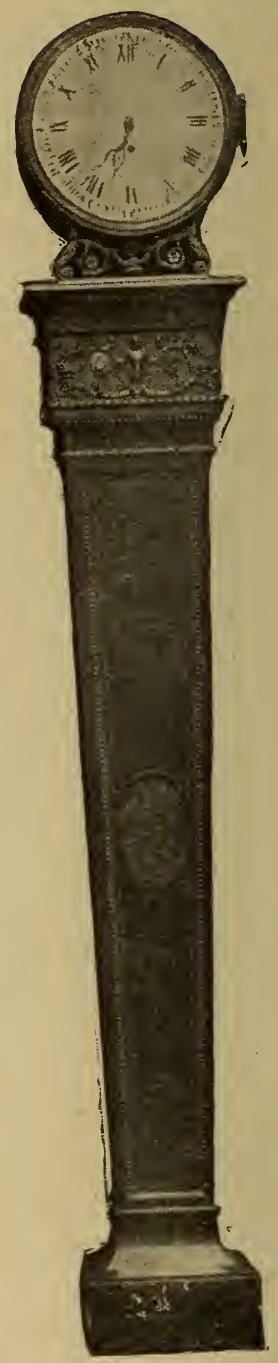

FIG. 739.-Timepiece by Ainsworth Thwaites at the India Office.

Chester; the handsome case is of mahogany with what is called, I believe, a brickwork base. 
The Progression of English Domestic Clocks 55I

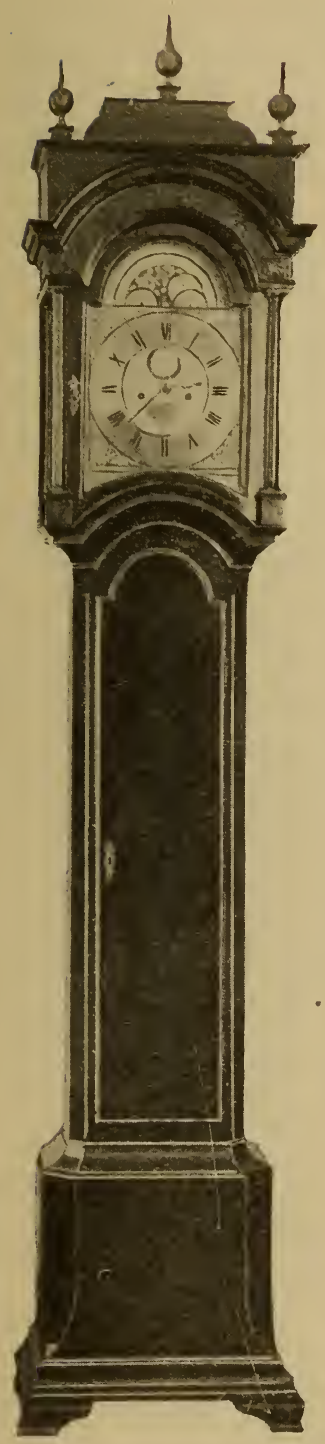

FIg. 740.-Nicholas Lambert, Case arched under dial.

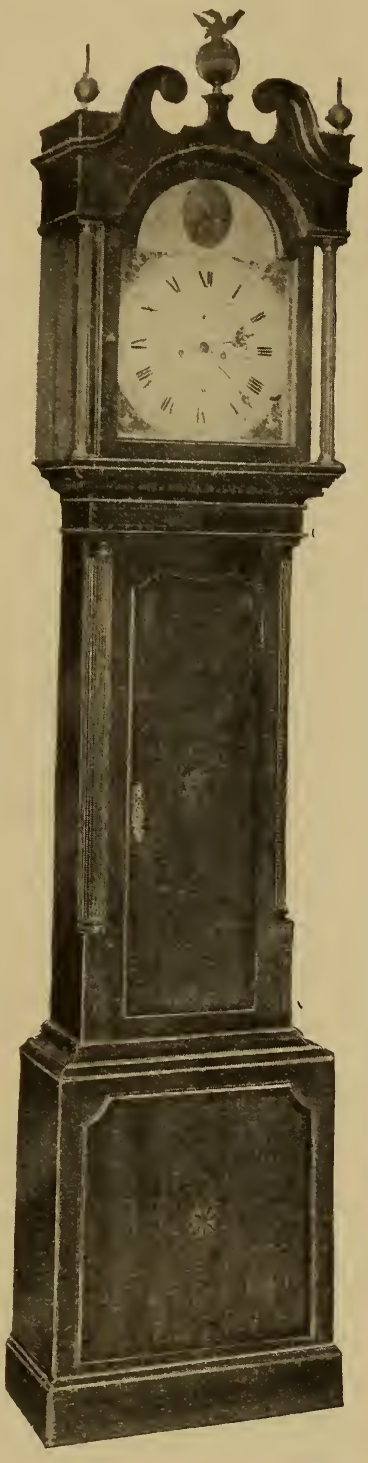

Fig. 741.-Henry Brow1.bill ; finely painted dial, about 1780 .

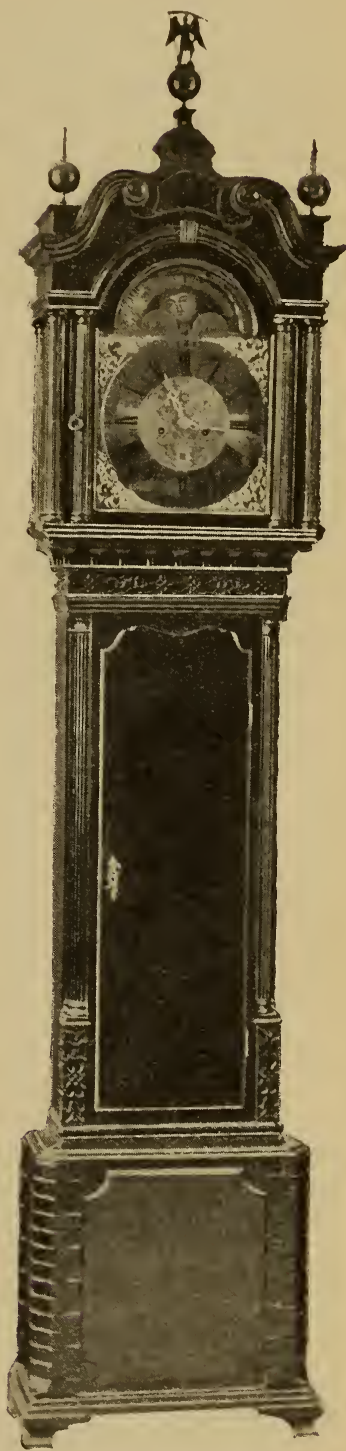

FIG. 742.-John Smitl, Chester, "Brickwork" base.

Examples of the best style of Dutch manufacture are reproduced on p. 552. Sir James M. Moody has a long-case clock by Wm. Gib, 
552 Old Clocks and Watches and their Makers

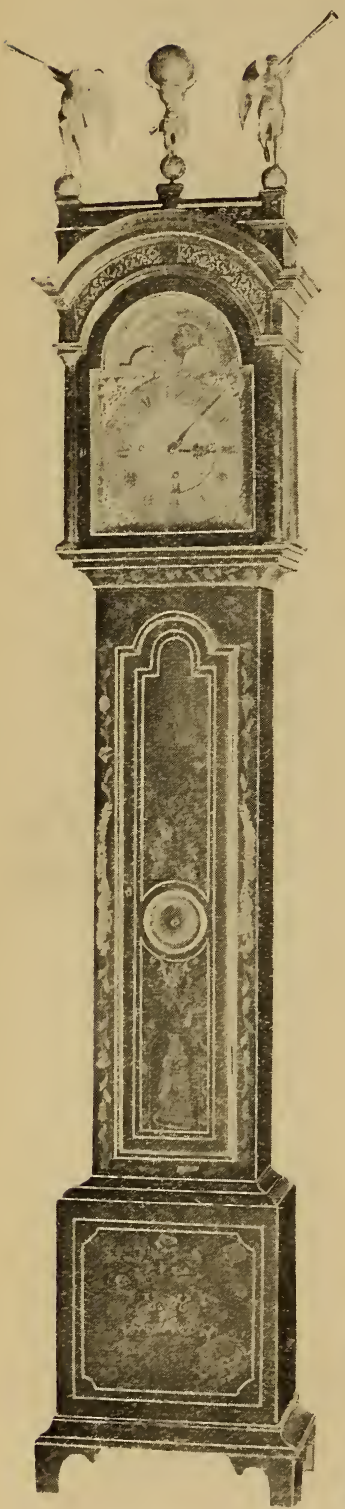

FIG. 743. - William Gib, Rotterdam.

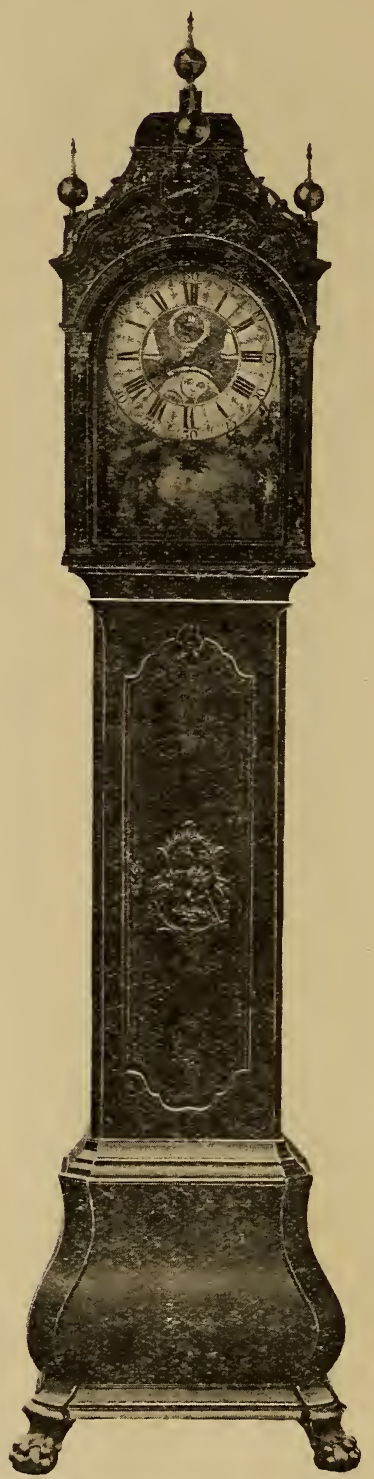

FIG. 744.--Johannes Duchesne, Amsterdam.

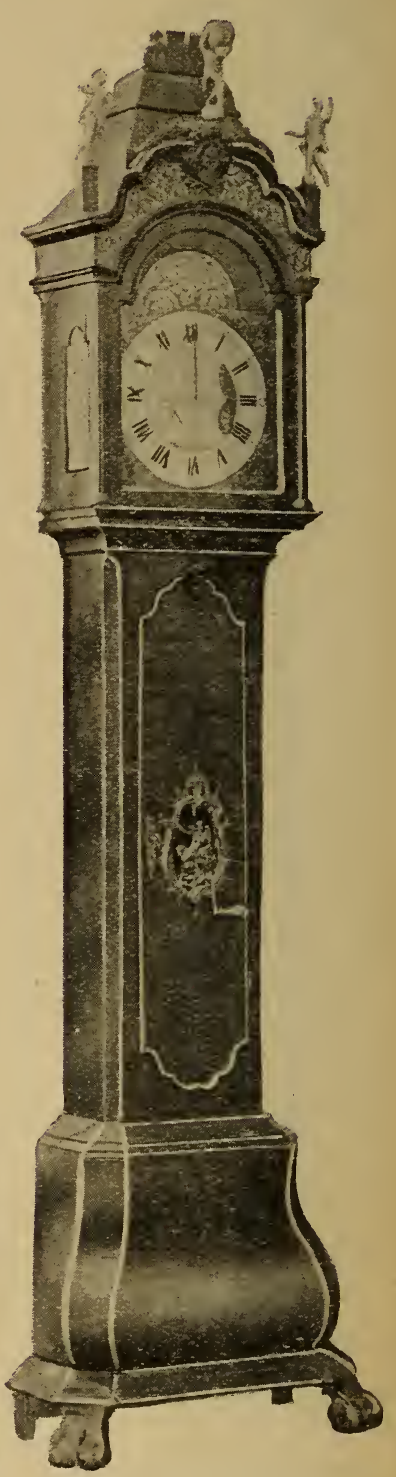

FIG. 745.-Ts. Thomasen, Amsterdam.

Dutch Examples, 1725-1750 (see pp. 552-554). 
The Progression of English Domestic Clocks 553

Rotterdam. It chimes the quarters on eight bells and strikes the previous hour on a small bell at half-past. Representations of the

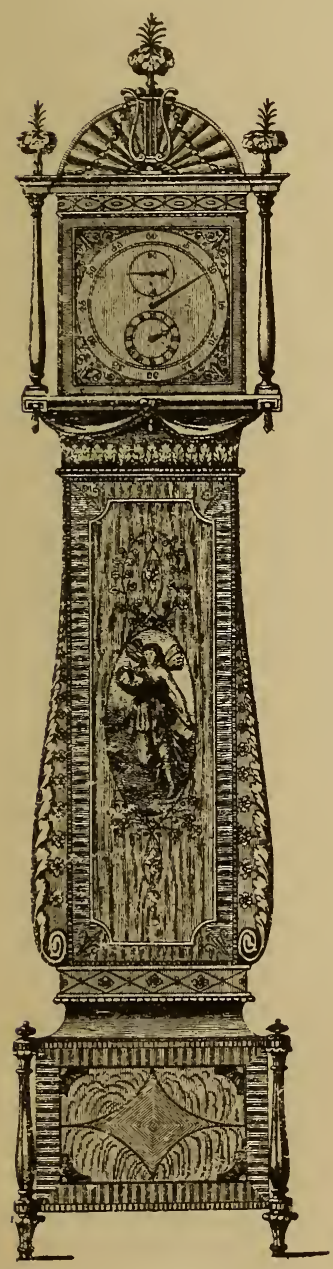

FIG. 746. - Sheraton design, with Side Wings.

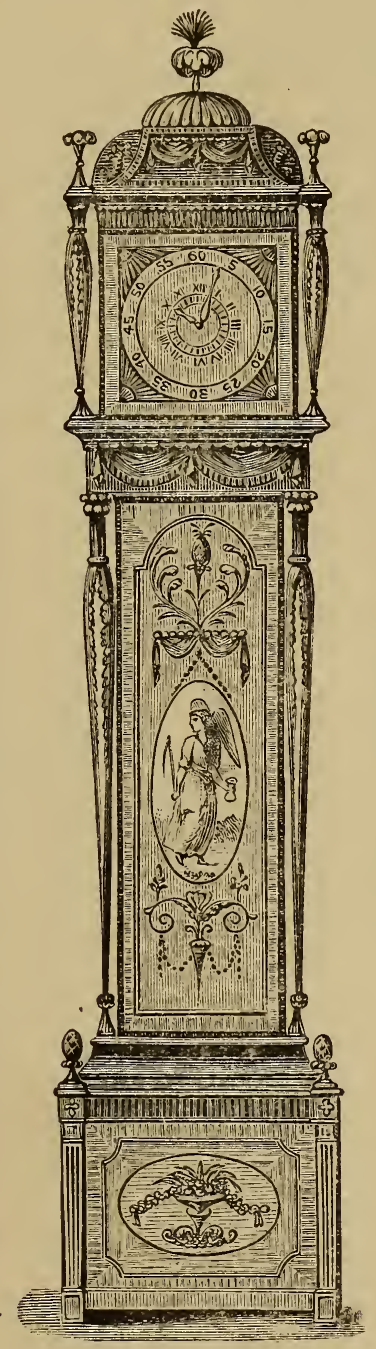

Fig. 747. - Sheraton design suggesting Effective Inlay.

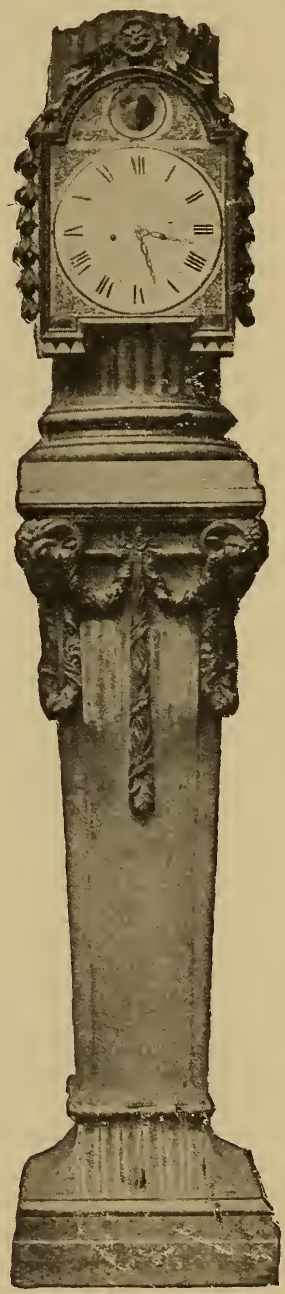

FIG. 748.-Clock by William Dutton, about 1780 .

moon are on cut crystal, gilt at the back. It is shown in Fig. 743 . Fig. 745 shows a clock signed " $\mathrm{T}^{\mathrm{s}}$ Thomasen Amsterdam," which 


\section{Old Clocks and Watches and their Makers}

belongs to Mr. Francis H. Bigelow, of Cambridge, Massachusetts. Fig. 744, in a case of somewhat similar design, is a clock by Johannes Duchesne, Amsterdam, which is the property of Mr. Lawrence Bentall. An especially attractive feature of it is a well-painted picture on the dial plate, which may be viewed with better effect on p. 521, where it appears to an enlarged scale.

Sheraton.-Thomas Sheraton was born at Stockton-on-Tees in 1751 and died in London in 1806. In 1791 was issued "The Cabinet-Makers' and Upholsterers' Drawing Book " by him, and in 1803 " The Cabinet Dictionary," of which another edition appeared in 1808. No mention is made of clock cases in the first edition of this work. From the later edition are copied Figs. 746 and 747. Though rarely made in this form with square dials, the ornate style and beautiful inlaid work associated with Sheraton have been very successfully applied by clock-case makers, and the popularity of Sheraton cases has never declined.

The handsome clock shown in Fig. 739 was made by Ainsworth Thwaites for the East India Company about 1770; the case is of figured wood, doubtless of Indian growth. A companion case, which originally held a dial to record the direction of the wind, seems to have mysteriously disappeared from the offices of the Company and to have been found on the Continent, where it was purchased by an official of the English Government, and the two now appropriately occupy positions in a room at the India Office, being symmetrically placed one on each side of the fireplace.

Fig. 748 represents a long-case clock of novel design by William Dutton, dating from about 1780 , for which I am indebted to Mr. Thomas Wyatt. The case, just upon $10 \mathrm{ft}$. in height, is of pine and mahogany painted light blue and white. The dial is of brass with a convex enamelled centre. The movement has a dead-beat escapement and a gridiron compensated pendulum. The lunar ball in the arch of the dial is rotated from the hour wheel arbor, on which is cut a screw to drive the intermediate lunar train. Below the moon is an oblong slit through which appears the day of the month.

On pp. 555 to 562 are further examples from the Wetherfield collection showing some of the finest productions with variations in style and treatment, trom the end of the seventeenth to the end of the eighteenth century. All will repay examination. Fig. 749, by Joseph Knibb, dates from about 1680 ; the dial is $8 \mathrm{in}$. square, with engraved corner decoration, the case of ebony being but $6 \mathrm{ft}$. 2 in. high, altogether a 
The Progression of English Domestic Clocks 555

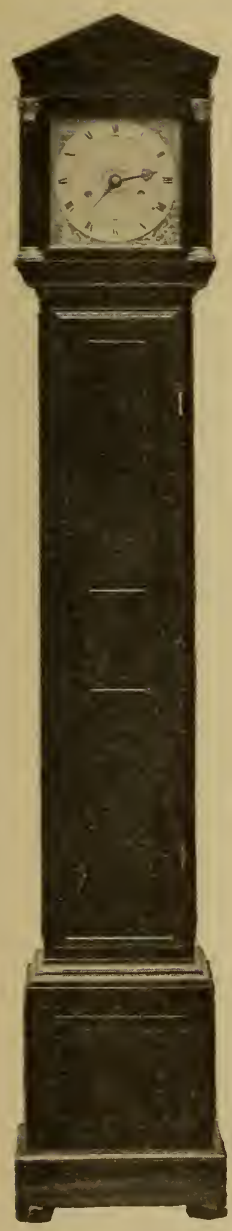

FIG. 749. - Joseph Knibb, Eight-day Quarter Clock, Ebony case, $6 \mathrm{ft} .2$ in. high ; about 1680 .

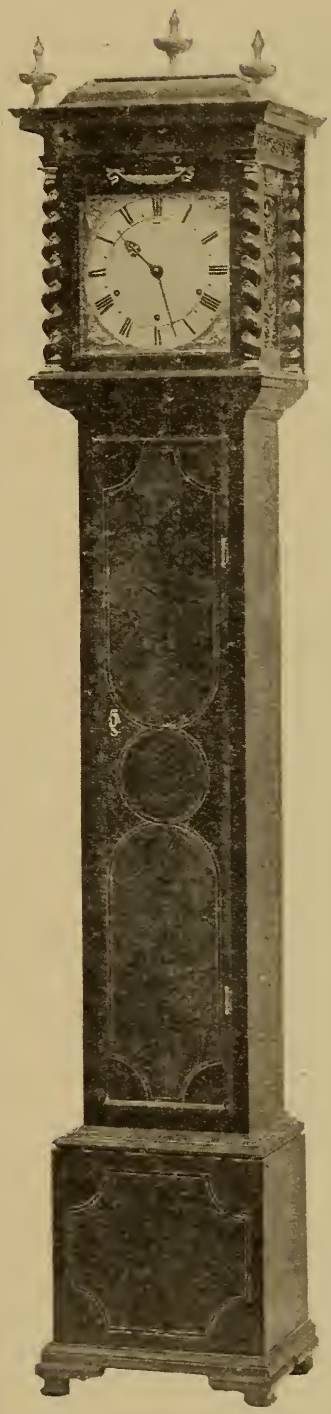

FIG. 750.- Joseph Knibb. Three-train Month Quarter Clock, Clock, walnut case ; about 1685 .

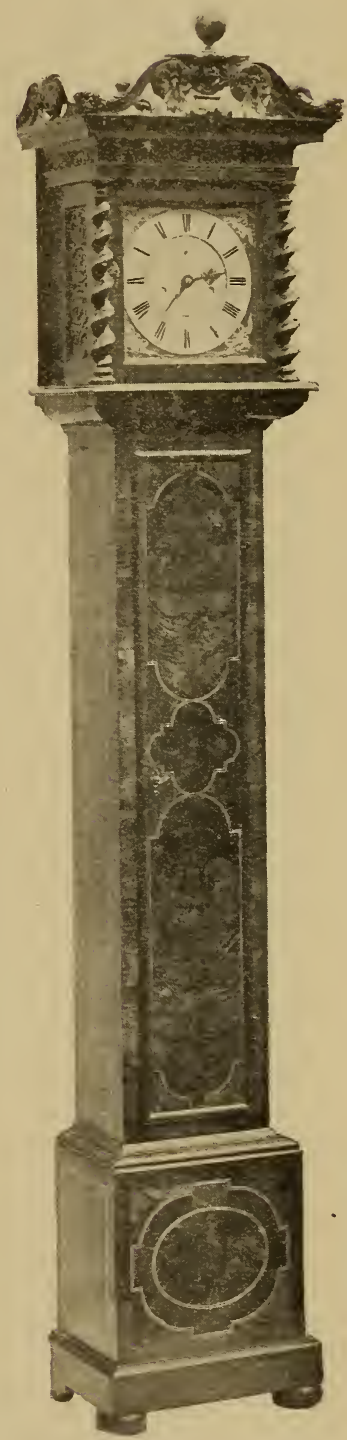

FIG. 751. - Thomas Tompion,Eight-day, walnut case, with carved superstructure ; about 1690 . 


\section{Old Clocks and Watches and their Makers}

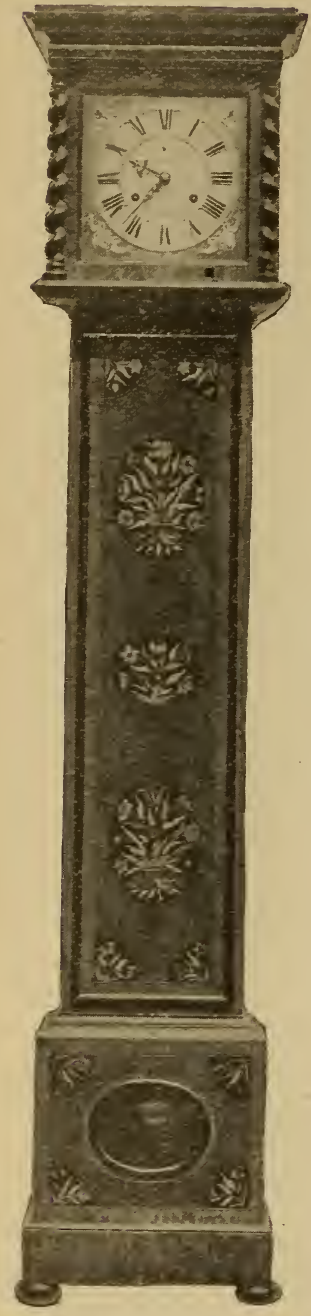

FIG. 752. - Daniel Parker, London ; Month Clock, $1 \frac{1}{4}$ seconds pendulum; door in base and glass therein ; height $6 \mathrm{ft} .8$ in., skeleton dial $10 \frac{1}{2}$ in. square ; about 1690 .

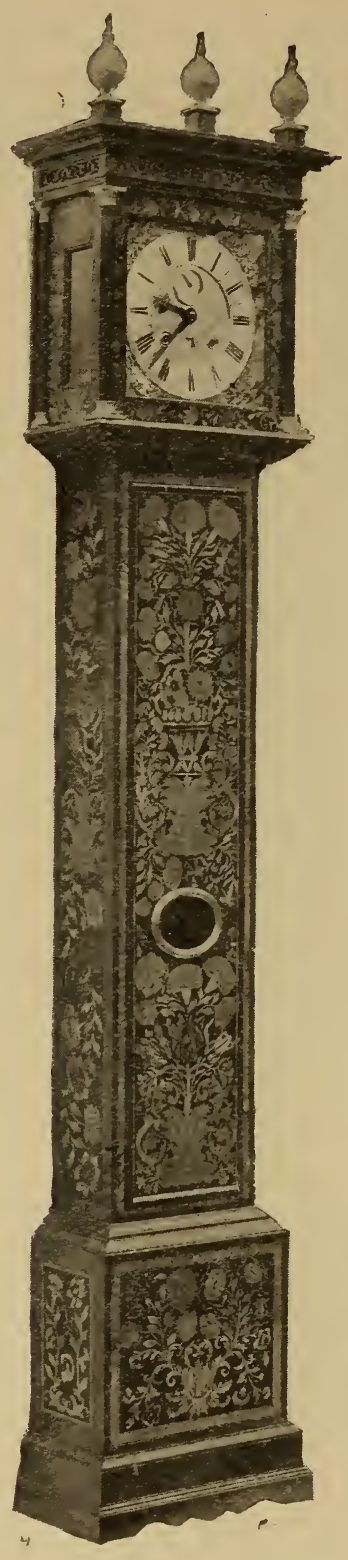

FIG. 753. - James Clowes ; about 1695 ; $7 \mathrm{ft} .2$ in. high, $10 \frac{1}{2}$ in. dial.

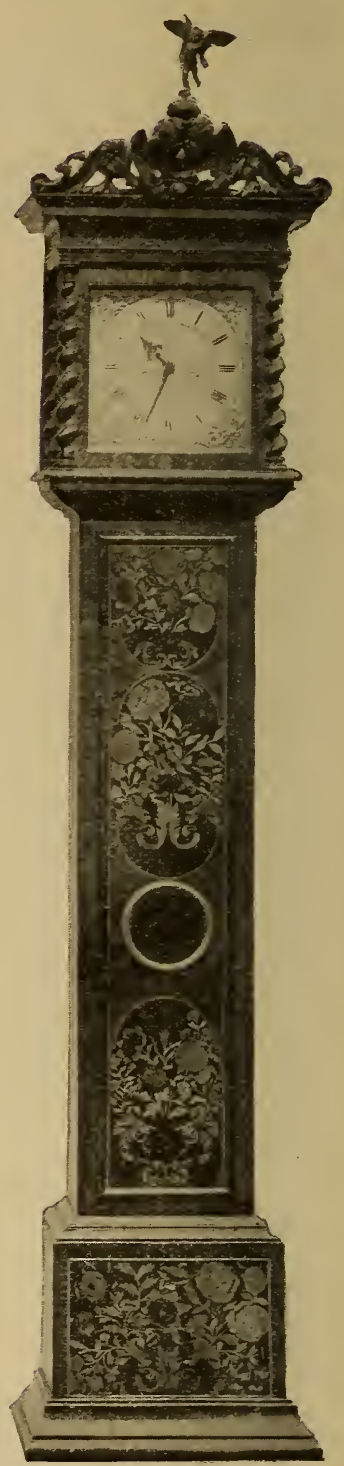

FIG. 754. - Christopher Gould, London ; Eightday, carved pediment surmounted by figure of Cupid, bolt and shutter maintaining $\mathrm{power}$; height $7 \mathrm{ft} .2$ in., dial $10 \frac{1}{2}$ in. square; about 1695. 


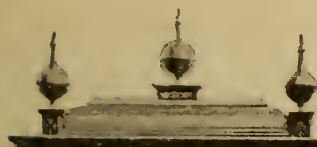

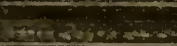
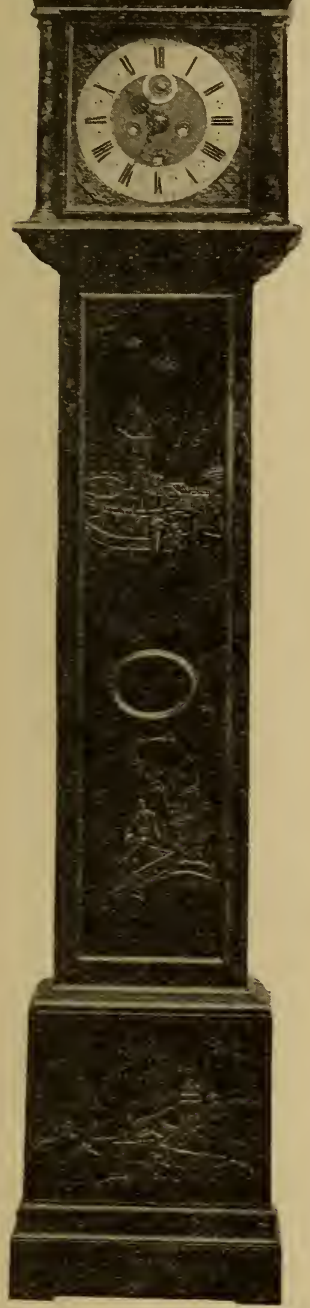

FIG. 755. - Christopher Gould, London ; lacquer decoration, each minute on dial numbered ; height $7 \mathrm{ft} .8$ in., dial 12 in. square; about 1700 .

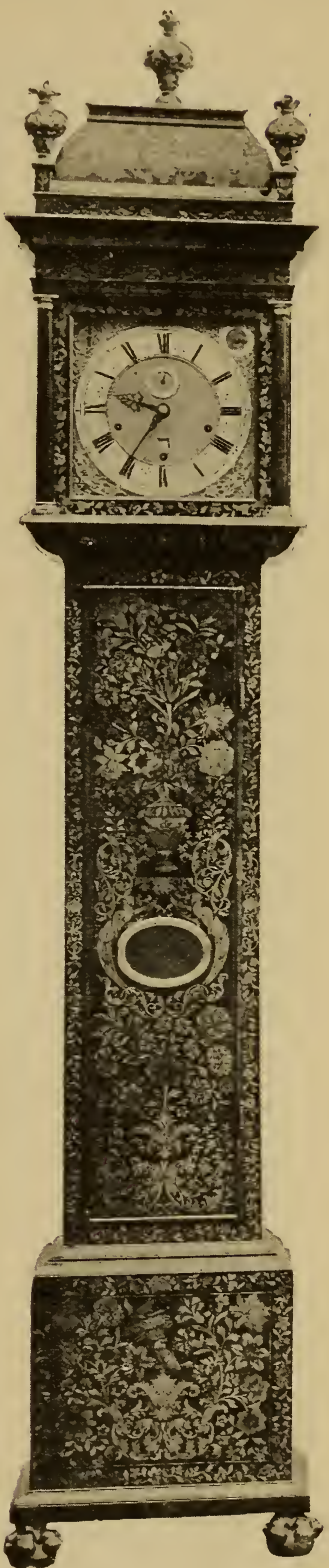

FIG. 757. - Jonathan Puller, Month Clock, chiming on six bells : 12-in. dial, height $8 \mathrm{ft} .1$ in.; about 1700 . 
$55^{8}$ Old Clocks and Watches and their Makers

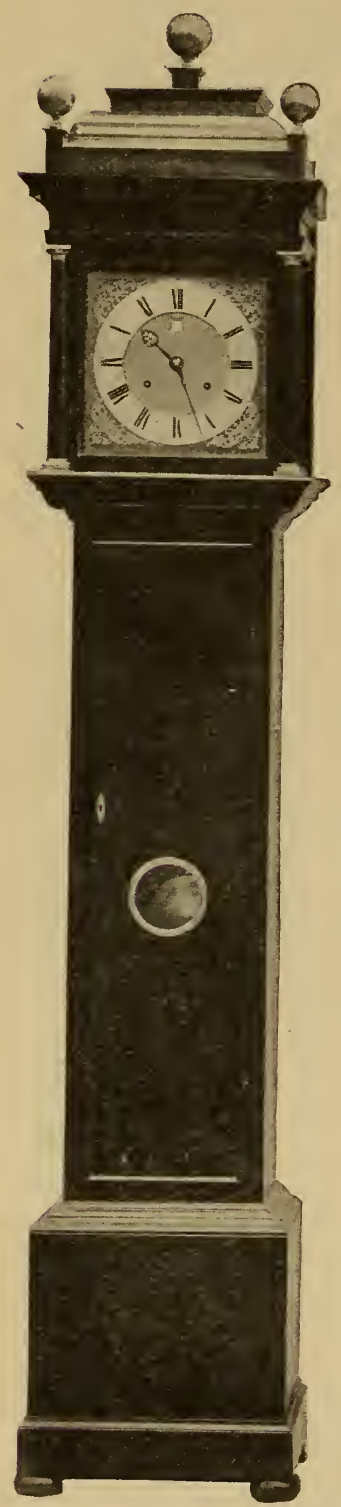

Fig. 758.-Joseph Knibb, " at Hanslop" ; Month Clock, striking on two bells, as explained on p. 328 ; height $8 \mathrm{ft}$.; about 1705 .

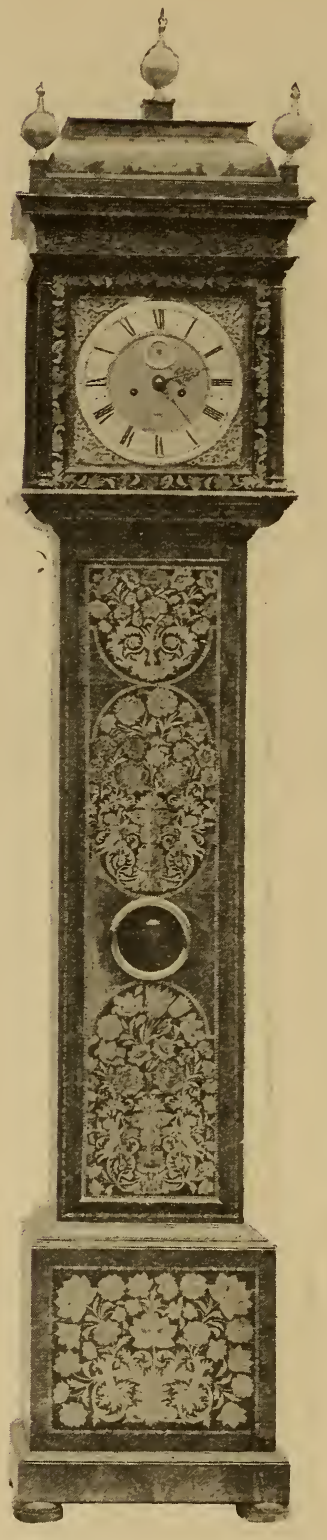

Fig. 759. - Cornelius Herbert, Eight-day marquetry ; 12-in. dial, height $8 \mathrm{ft}$. 4 in. ; about 1700 .

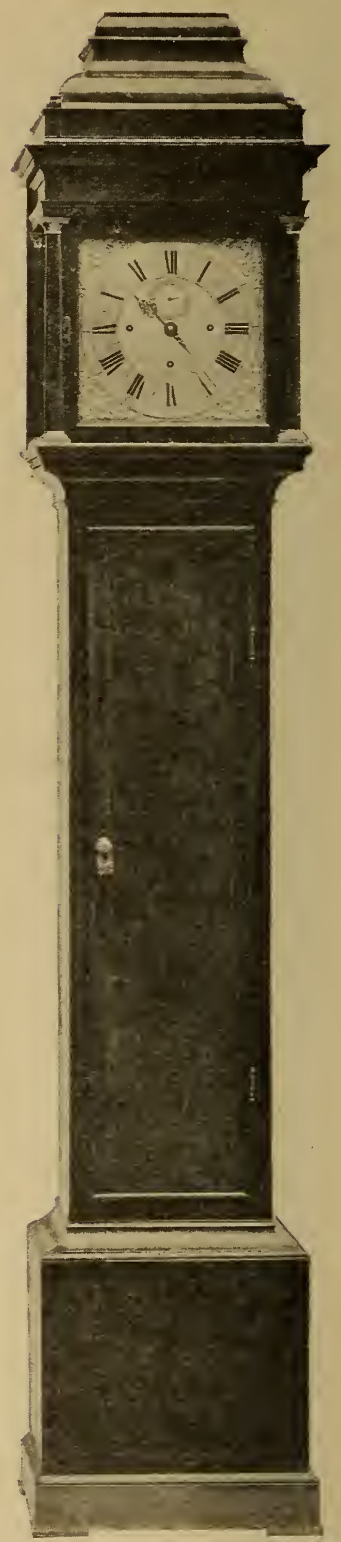

Fig. 760. - Daniel Quare, Three-train Ionth Quarter Clock; burr walnut case; height $8 \mathrm{ft}$. ; about 1705 . 


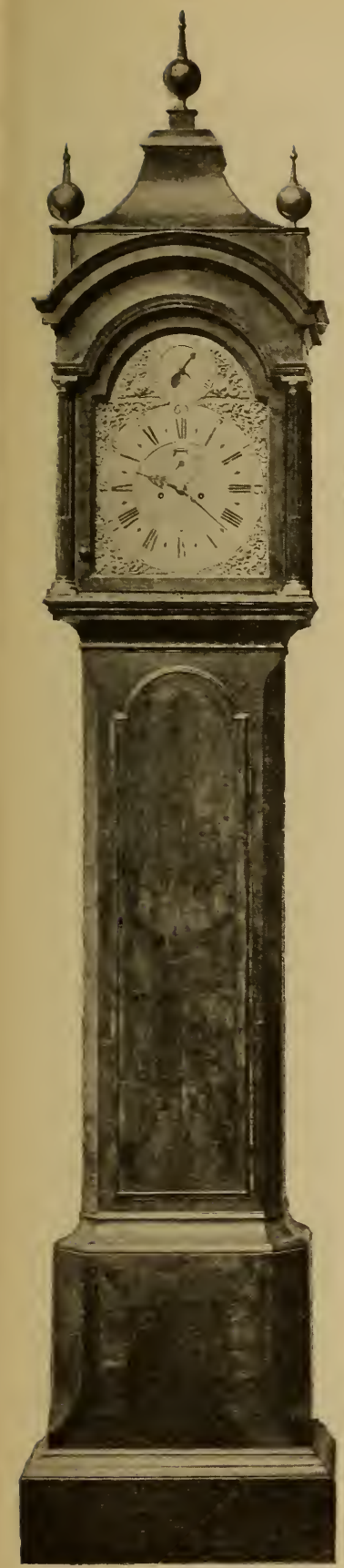

FIG. 761.-Benj. Gray ; $10 \mathrm{ft} .3$ in. high; about 1730 .

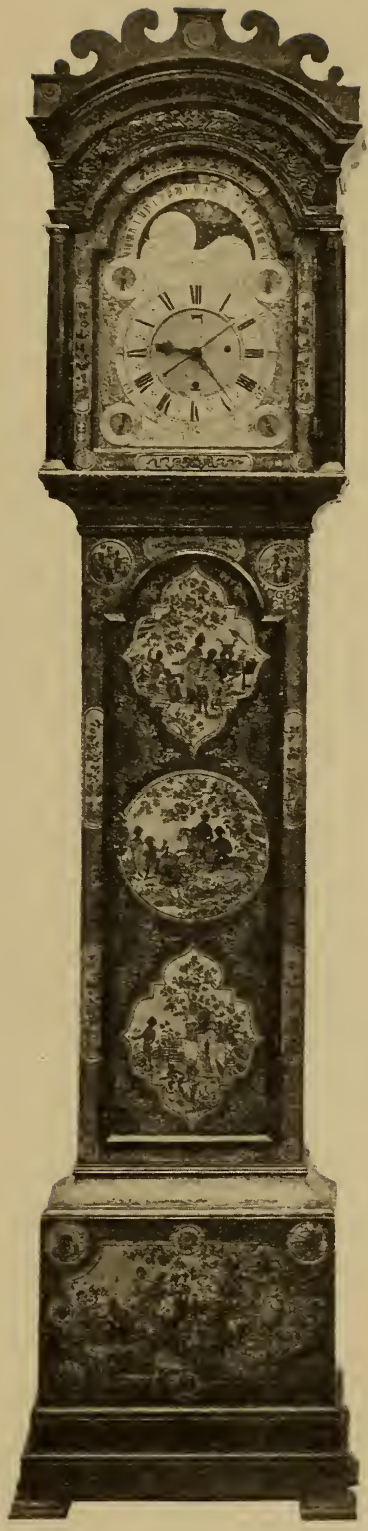

FIG. 762.-Isaac Nickals, Chiming Clock, Tidal Register in arch, lacquer decoration. about 1740.

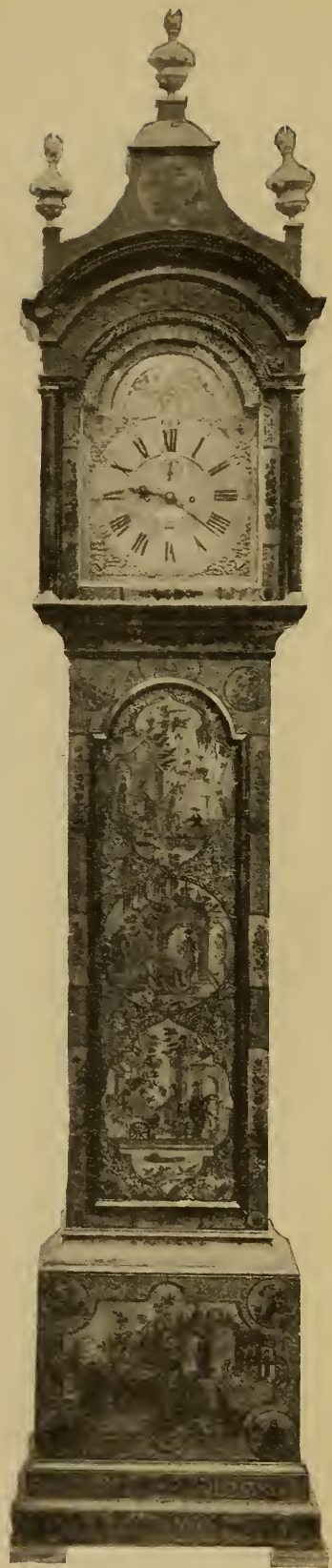

Fig. 763.- Wm. Hawkins, Eight - day, buff-lacquer decoration; 12-in. dial, height $9 \mathrm{ft} .9$ in. ; about 1740 . 


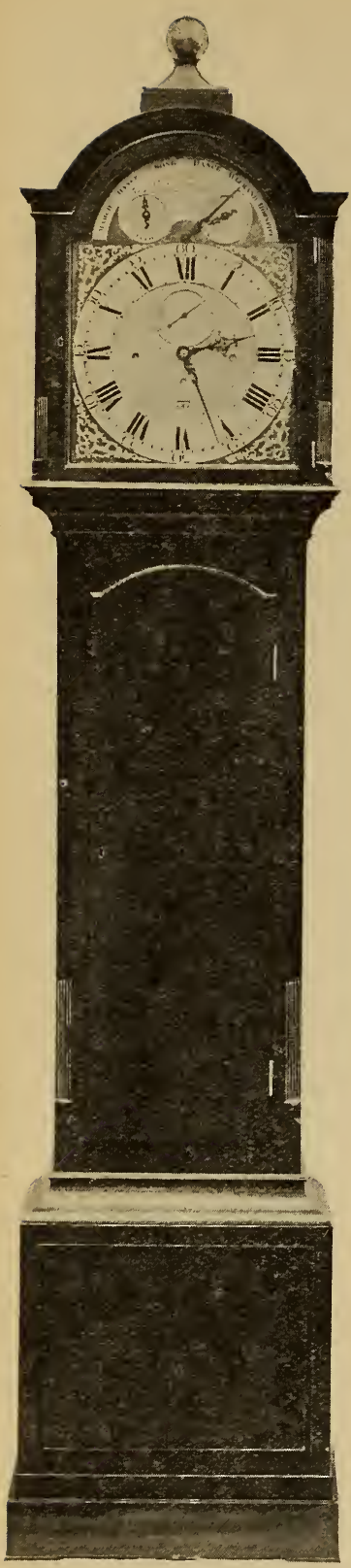

FIg. 764. - George Lindsay, Eight-day Three-train, tune playing ; 14-in. dial, mahogany case ; height $8 \mathrm{ft}$; about 1770.

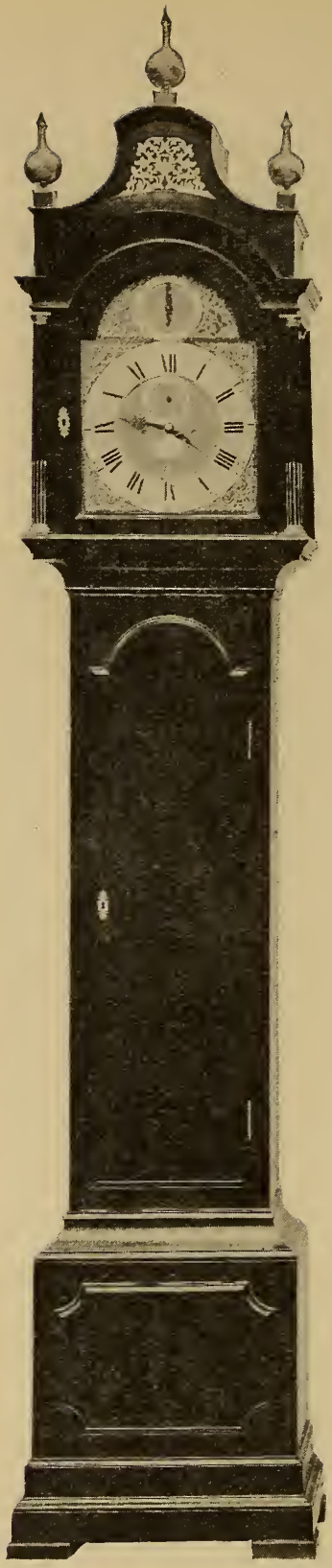

FIG. 765. - Thomas Colley, "Graham's Successor," mahogany case; dial 12 in. wide, height $8 \mathrm{ft} .10 \mathrm{in.}$; about 1770 .

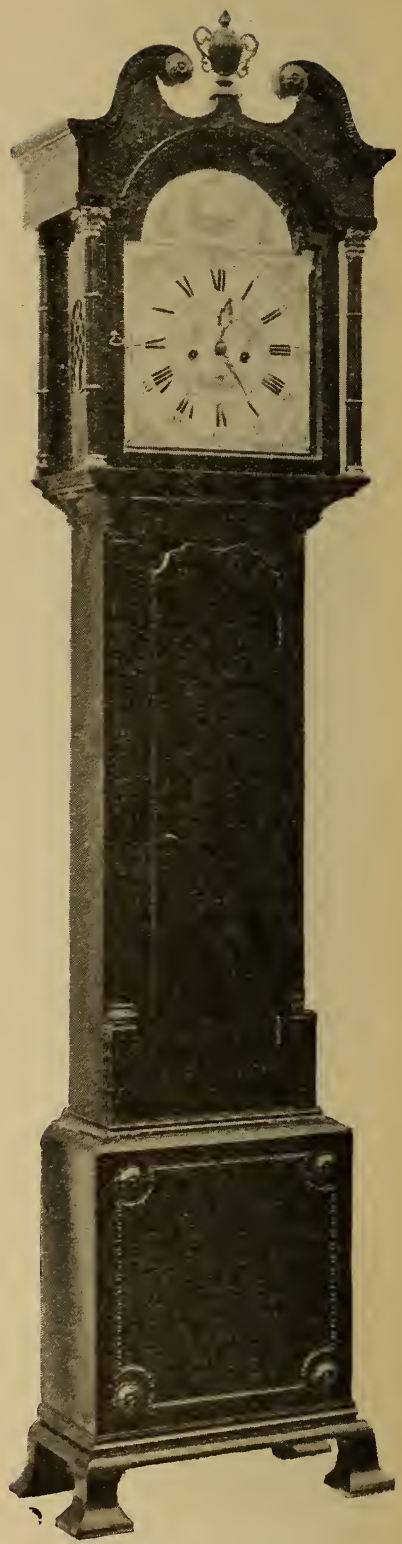

FIG. 766. - Thomas Clare, Warrington; dial of Battersea enamel; 12 in. wide; height $7 \mathrm{ft} . \quad 7$ in. ; about 1775 . 
The Progression of English Domestic Clocks 56I

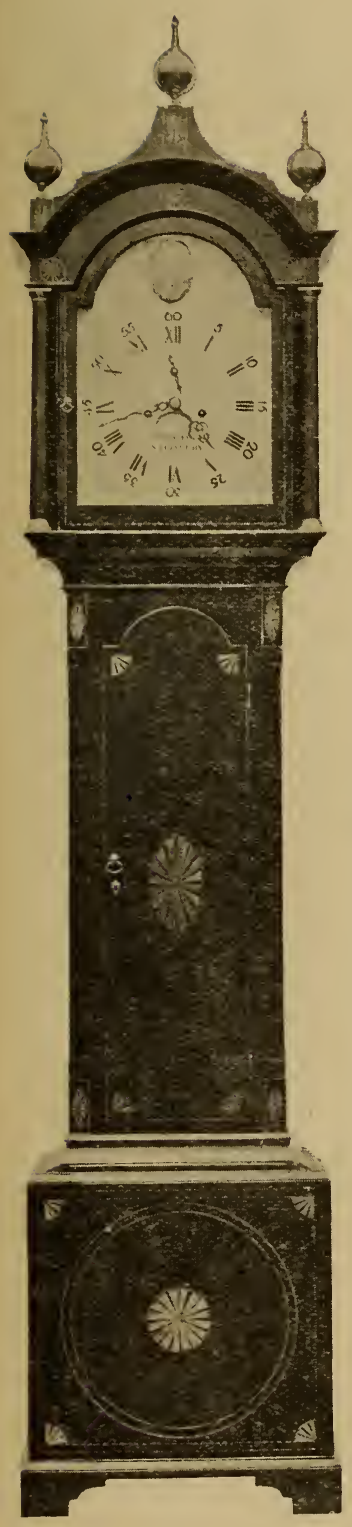

FIg. 767. - Moore, Salisbury. Sheraton style of decoration ; dial 12 in. wide; about 1780 .

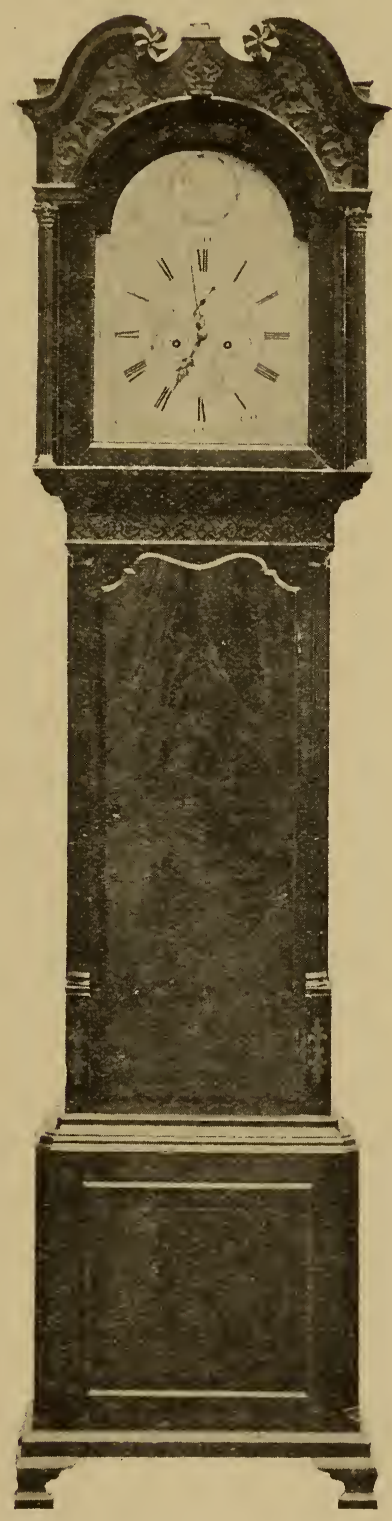

FIG. 768.-James Gray, Edin burgh; silvered dial, height $7 \mathrm{tt} .6$ in. : about 1790 .

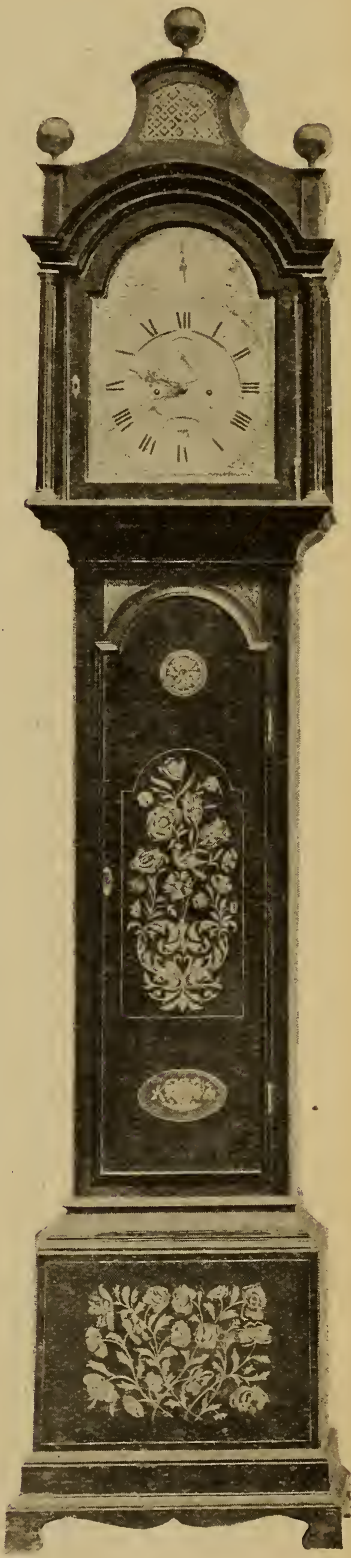

FIG. 769. - Alexander Cumming: height $8 \mathrm{ft}$. ; about 1790 . 
chaste and pleasing design. To the right of it is a larger and more ornate specimen of rather later date by the same maker, in a burr walnut case. It is a month clock, striking the hours on a large bell, and the quarters on a smaller one, in a peculiar way. One stroke is given for the first, and an additional one for each succeeding hour up to the sixth; then seven is given as one, and so on till the twelfth hour which is recorded by six strokes. The third on the page is a clock by Thomas Tompion dating from about 1690 , and furnished with bolt and shutter maintaining power. The dial is 10 in. square, and the case, of burr walnut, is $7 \mathrm{ft}$. $3 \mathrm{in}$. high with a carved superstructure.

Fig. 752, a month clock by Daniel Parker, dating from about 1690, in a prettily arranged marquetry case, has a skeleton dial $10 \frac{1}{2}$ in. square, and good hands. It is $6 \mathrm{ft}$. 8 in. high, with a long pendulum beating once in a second and a quarter; the bob extending below the trunk may be viewed through an oval hole in the regulating door at the base.

A remarkably fine surface of marquetry over the front and sides of the case is the feature of Fig. 753, which represents a month clock by James Clowes. It dates from about 1695, is $7 \mathrm{ft}$. in height with a dial $11 \mathrm{in.square.} \mathrm{On} \mathrm{the} \mathrm{same} \mathrm{page} \mathrm{and} \mathrm{of} \mathrm{even} \mathrm{date} \mathrm{is} \mathrm{an} \mathrm{example}$ by Christopher Gould. The case has a carved head with a finial in the form of Cupid. Altogether it stands $7 \mathrm{ft}$. 2 in. in height ; the dial is $10 \frac{1}{2} \mathrm{in}$. square, and maintaining power during winding is arranged on the bolt and shutter plan.

An unusually early specimen of Oriental lacquer decoration is shown in Fig. 755, another clock by Christopher Gould, dating from about 1700 . It is $7 \mathrm{ft} .8 \mathrm{in}$. high; the dial, $12 \mathrm{in}$. square, has each minute numbered, and the hands are very fine. The other clocks on that and the next page are of about the same date. On the front of the case of Fig. 756 are grotesque pictures in marquetry. This clock is by John Eagle ; the height is $7 \mathrm{ft} .3 \mathrm{in}$., and the dial 11 in. square. Quite a different style of marquetry adorns the case of Fig. 757, a clock by Jonathan Puller, chiming on six bells. The claw feet and finials are worthy of note. It stands $8 \mathrm{ft}$. I in. high, and the dial is 12 in. square, with subsidiary dials in the top corners for chimesilent and regulation.

The dials and hands of three examples on p. 558 are all good, though dissimilar. The first in an ebonised case is a month clock by "Joseph Knibb att Fianslop," and striking on the bells according to the Roman numerals, as explained on p. 328. The centre clock, in a marquetry case is by Cornelius Herbert. It is $8 \mathrm{ft} .4 \mathrm{in}$. high, and has a 12-in. dial. 


\section{The Progression of English Domestic Clocks 563}

Fig. 760 represents a month clock by Daniel Quare in a burr walnut case $8 \mathrm{ft}$. high. It has three trains, striking hours on a large bell, and quarters on a small one. The escutcheon over the keyhole of the door is amusing.

Now we come to the arched dial period, and begin with three examples dating from about 1730. The extra large clock in Fig. 761, which is by Benjamin Gray, stood for 180 years in Sheffield Place, Sussex, being the property successively of the first Earl de la Warr and the three Earls of Sheffield until the death of the last. The bevelled corners of the trunk and base of the walnut case are effective. The dial is $14 \mathrm{in}$. wide, and shows the day of the month, the month of the year, and phases of the moon. It has a dead-beat escapement and maintaining power.

A quarter clock chiming on three bells, with a dial 13 in. wide, exhibiting the day of the week and month, and month of the year, phases of the moon and time of high water, is by Isaac Nickals, of Wells. It is shown in Fig. 762. The case, adorned with buff lacquer decoration is $8 \mathrm{ft} .3 \mathrm{in}$. high.

Fig. 763, a clock by Wm. Hawkins, of Bury St. Edmunds, has a dial 12 in. wide, giving the age and phases of the moon. This case stands $9 \mathrm{ft} .9 \mathrm{in}$. high and is also decorated with buff lacquer.

Fig. 764 shows a clock, by George Lindsay, in a mahogany case of unpretentious design, dating from about 1770 . It stands $8 \mathrm{ft}$. high, and plays six tunes on twelve bells, has a dead-beat escapement with jewelled pallets, and a dial 14 in wide.

Fig. 765 in a mahogany case of the conventional Chippendale style, standing $8 \mathrm{ft}$. $10 \mathrm{in}$. high, encloses an interesting clock signed " Thomas Colley, Graham's successor." It has a dead-beat escapement, and the dial is 12 in. wide.

The well-carved mahogany case shown in Fig. 766 may also be regarded as a typical Chippendale. It encloses a clock by Thomas Clare, of Warrington, having a dial 12 in. wide of Battersea enamel, a material but rarely adopted. It dates from about 1775 , and stands $7 \mathrm{ft} .7$ in. high.

A quarter clock by Moore, of Salisbury, in a mahogany Sheraton style of case, is shown in Fig. 767. It has a painted dial 12 in. wide, and dates from about 1780 . The height is $7 \mathrm{ft} .6$ in.

Another case of mahogany in the Sheraton style is shown in Fig. 768. This clock is by James Gray, of Edinburgh, dating from about 1790. It has a silvered dial $13 \mathrm{in}$, wide, and stands $7 \mathrm{ft} .6$ in high. 
Of about the same date is the clock by Alexander Cumming, the last of the series I have selected for illustration. The case of mahogany is $8 \mathrm{ft}$. high, with tasteful marquetry in panels. The dial is 12 in wide.

In Fig. 771 is shown a remarkably fine musical clock, with moving figures, the property of Mr. E. E. Cook, of Walton-on-Thames. It was made by Pickett, of Marlboro', and dates from about 1780. The silvered dial is engraved with urns, and just inside the usual numeral circle and concentric therewith is a date circle to which an index from the centre points.

At 12, 3,6, and 9 o'clock one of the following tunes is played :-
1. Marlbro' Jigg.
2. Jack's Jigg.
3. Ned's Hornpipe.
4. Batt's Hornpipe.
5. Ben's Delight.
6. Head's Whim.

These tunes are enumerated in the right-hand spandrel ; the lefthand spandrel contains a chime-silent hand. In the arch of the dial is a curtain which rises when the clock chimes, and a male and female figure are discovered dancing. Below them is a river and a bridge; over the bridge people, carts, \&c., pass, including a man carrying his wife to avoid the toll which, tradition says, refers to a local bridge where a heavy toll was exacted. Below the bridge swans, boats, \&c., pass to and fro on the water. In the lower part of the main dial is a moon calendar. On p. 519 the dial is shown to an enlarged scale.

A musical clock of unusually large size, which is the property of Mr. R. Eden Dickson, is shown in Fig. 772. The case of mahogany is $8 \mathrm{ft}$. $5 \mathrm{in}$. high, and the dial measures $18 \frac{1}{2}$ in. by 22 in. The quarters are chimed on eight bells, and at every three hours, after the quarters are chimed and the hours struck, a tune is played. There are sixteen bells and twenty-four hammers; the music barrel is $14 \frac{1}{2} \mathrm{in}$. long and $3 \mathrm{in}$. in diameter. The subsidiary dials are "strike-silent" and " chime-silent," the name " James Lorimer, London," being on the plate between, while in the arch above is the following list of tunes :-
1. La Promenade.
2. Gavot.
3. Minuet.
4. Bagnigge Wells.
5. Duke of Gloucester's March.
6. Neu Alamand.
7. I do as I will with my Swain.
8. Lays of Paties Mill.
9. Flowers of Edinburgh.
10. Cuckoo's Nest.
11. Tweed Side.
12. Portsmouth Psalm.

The pendulum rod is of ebony, and above the bob on a small brass plate is engraved " John Marshall, London." 
The Progression of English Domestic Clocks 565

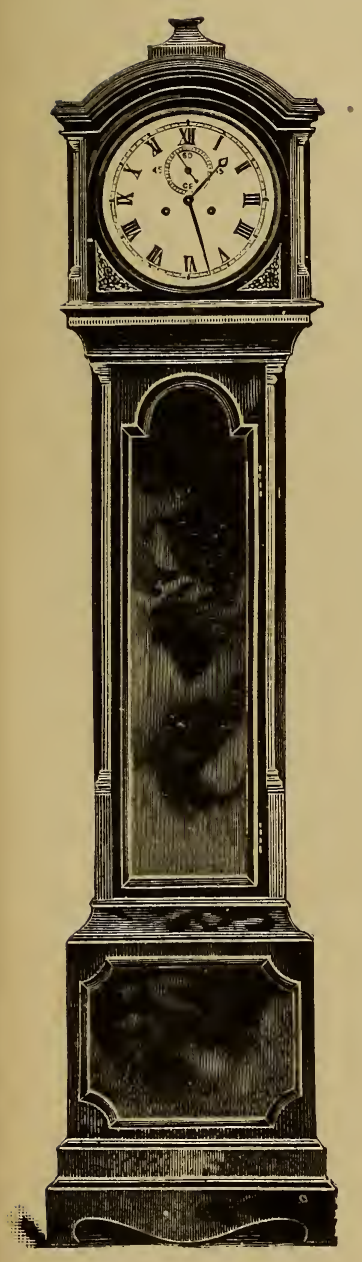

FIG. 770.-At Windsor Castle, by Recordon, about 1800 .

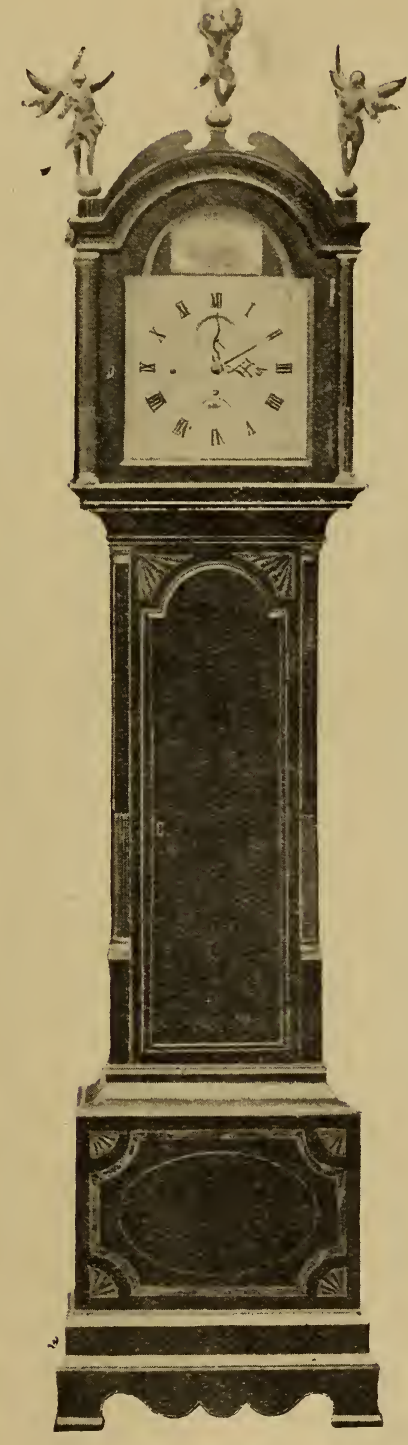

FIG. 771.-clock with Moving Figures, about 1780.

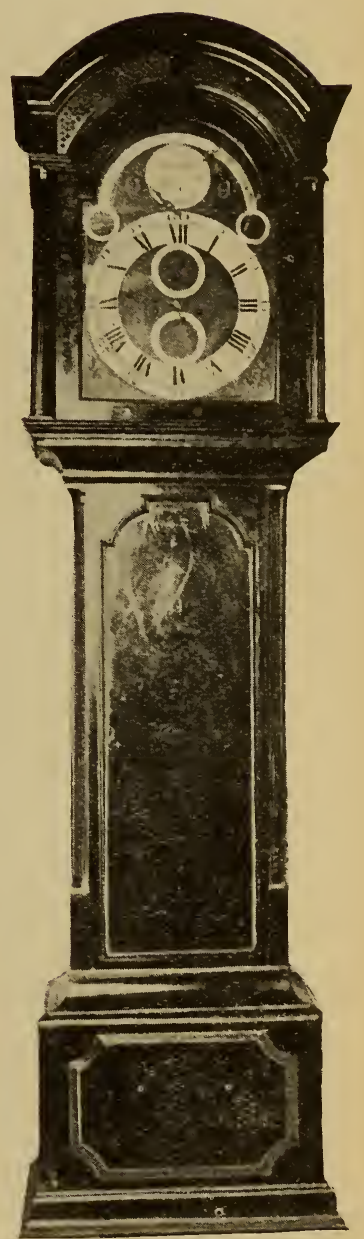

FIG. 772.-Jas. Lorimer, Musical Clock, about 1780 .

As examples of the plain early nineteenth-century clocks of the best class with circular enamelled dials, and usually in cases of 


\section{Old Clocks and Watches and their Makers}

mahogany with finely figured surfaces, may be taken the one by Vulliamy illustrated on p. 374, and one by Recordon shown in Fig. 770. For a really perfect dial on this plan, one has to go to a comparatively obscure provincial maker (see Fig. 691).

Fig. 774 is an eight-day striking clock by Samuel Lee, London, in burr walnut case with black carved mouldings. Its height is

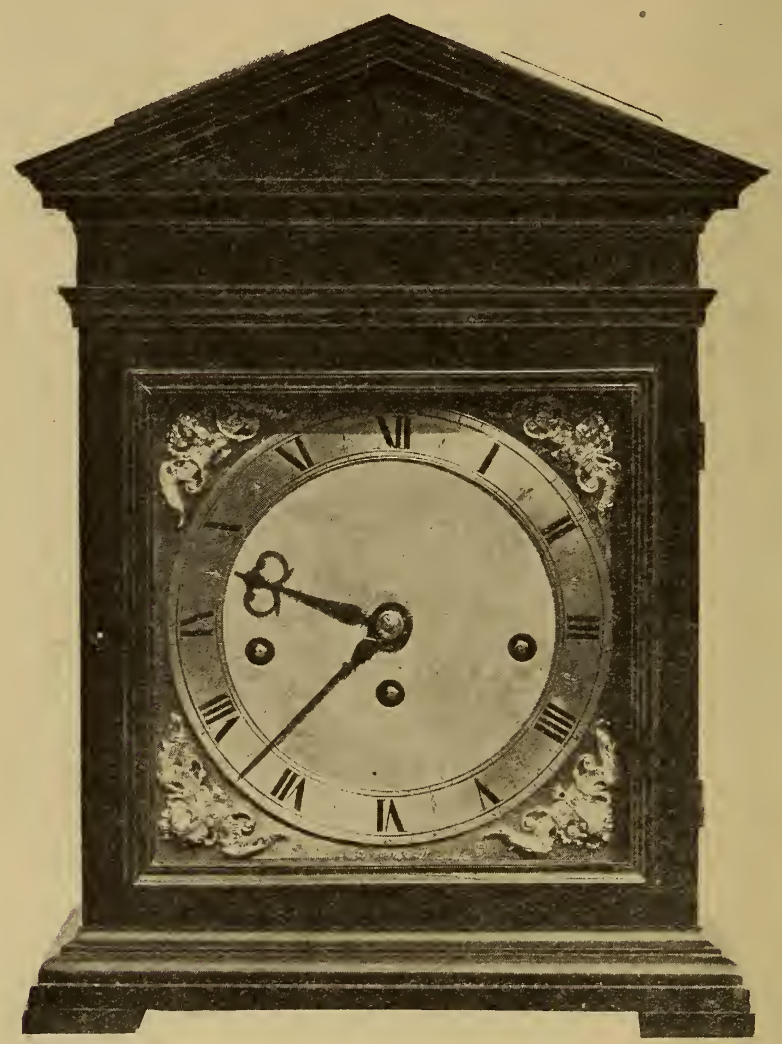

FIG. 773.-Edward Staunton, London, Ebony Eight-day Bracket Quarter Clock; three bells; height 17 in. ; about 1680 .

$7 \mathrm{ft} .8 \mathrm{in}$., the dial is $12 \mathrm{in}$. by $16 \mathrm{in}$., and it dates from about 1720 . Fig. 775 is an unusual specimen, an eight-day striking clock, combining a fine marquetry case with an arched dial, two features rarely found together. It is signed "Andrew Davis, London." Height $7 \mathrm{ft}$. 5 in., dial 12 in. by 16 in., date about 1720 . Both these clocks are in the Wetherfield collection. 


\section{The Progression of English Domestic Clocks 567}

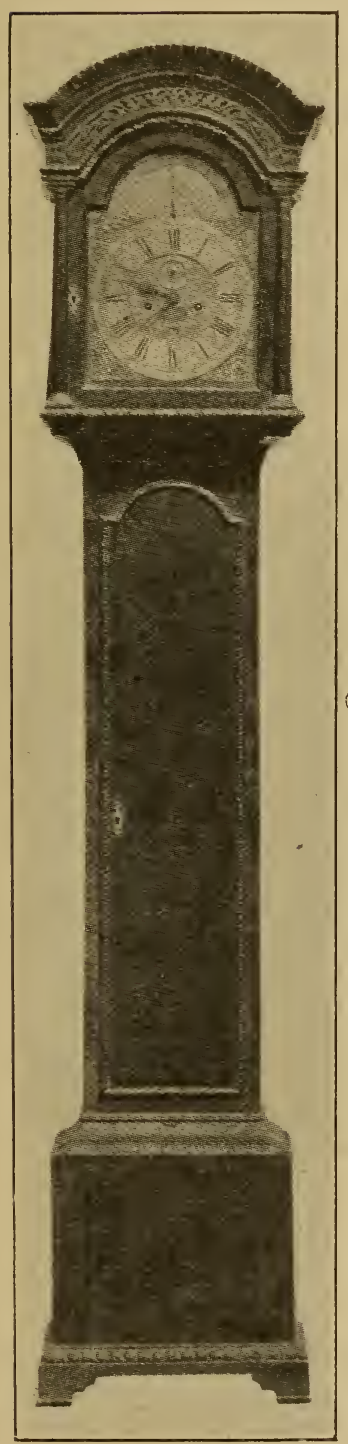

FIG. 774.-- Eight-day Striking Clock in burr walnut case, signed "Samuel Lee, London" ; height $7 \mathrm{ft} .8$ in. ; dial 12 in. $\times 16$ in.; date about 1720.

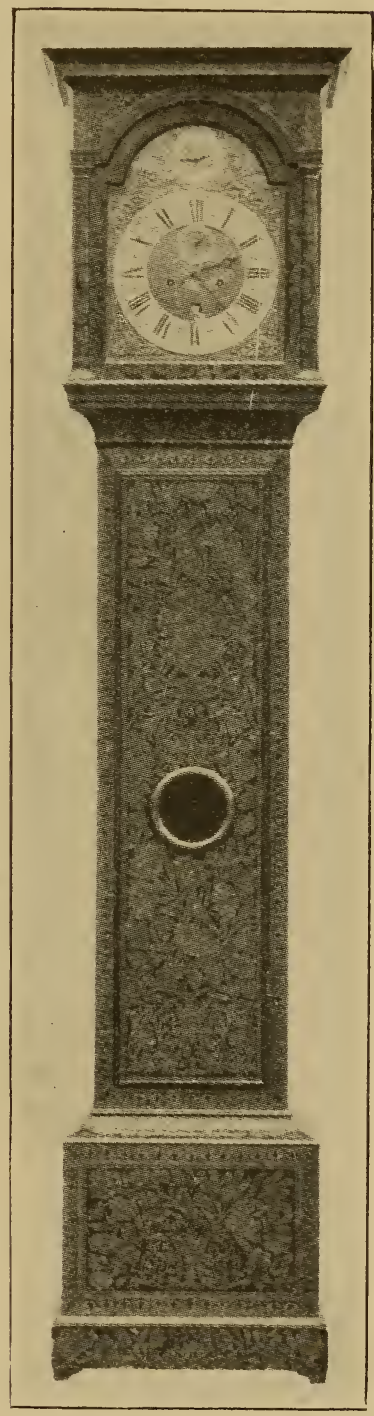

FIG. 775.- Unusual Clock, by Andrew Davis, London, combining a fine marquetry case with an arched dial; height $7 \mathrm{ft}$. 6 in. ; dial 12 in. $\times 16$ in. ; date about 1720 . 


\section{Old Elocks and Watches and their Makers}

The introduction of cheap American clocks was disastrous to the old English ones, and between 1850 and 1860 thousands of good serviceable long-case timekeepers were sacrificed, the cases being chopped up for firewood and the substantial brass movements consigned to the melting-pot.

Bracket or Pedestal Clocks.-Bracket or pedestal clocks, with enriched cases, as distinguished from the plain metal covering of the ordinary chamber clock, were in favour before the advent of the long-case variety.

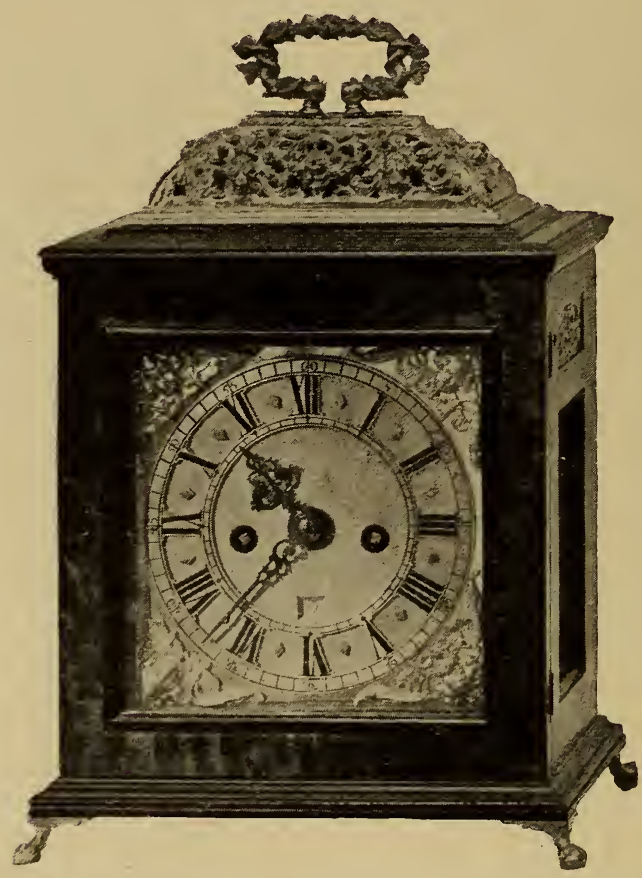

Fig. 776.-Humfrey Adamson, red tortoiseshell case, about 1680 .

Of the early types with metal cases, examples have already been given. Fig. 773 shows a large bracket clock by Edward Staunton which is in the Wetherfield collection, and dates from about $\mathbf{1 6 8 0}$. Here, as in the long-case clock by John Fromanteel on p. 322, and the one by Joseph Knibb on p. 555, the case is surmounted by a pediment. During the latter part of the seventeenth and the beginning of the eighteenth century the square "squat" case of wood with a flat top and plain metal handle for lifting it by, as shown on p. 276 , or with a 


\section{The Progression of English Domestic Clocks 569}

perforated metal dome-shaped addition, chased and gilded, called basket-work, surmounted by an enriched handle, was very popular. The basket top is probably of Dutch origin. Engravings of this variety are given on pp. 568 and 570 . Most of them had a curved slit in the dial through which the motion of a mock pendulum could be seen.

Fig. 776, an early and choice example by Hunifrey Adamson, I.ondon, is from the Wetherfield collection. For Fig. 777, a clock by

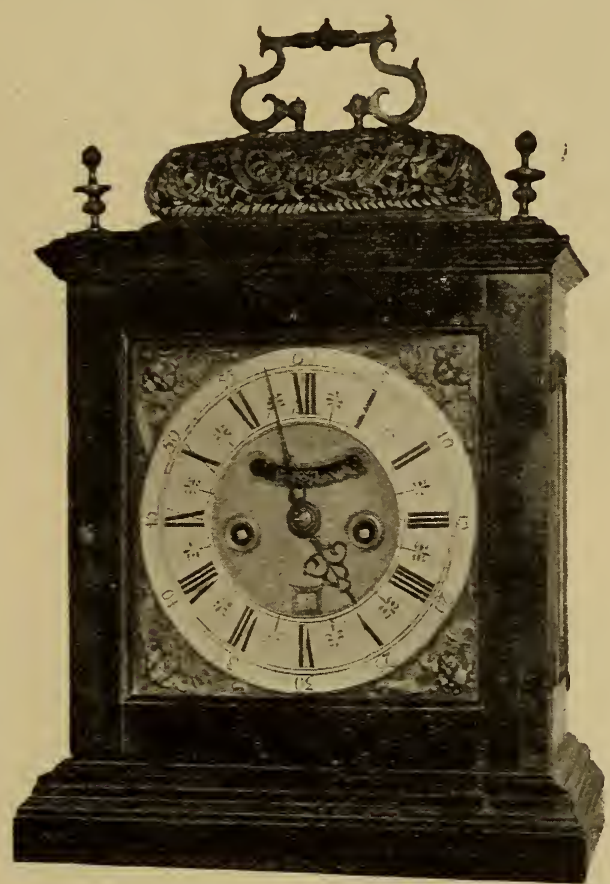

FIG. 777.-Clock, by John Harris, London.

John Harris, London, I am indebted to Mr. William Newton. Mr. J. Drummond Robertson owns the fine double basket top clock by Claudius Du Chesne, London, which appears in Fig. 778.

Sometimes, instead of the open-work metal basket, a basket-shaped curve of wood surmounted the case. The clock by Ben Collier, London, constructed in this way and shown in Fig. 779 belongs to Mr. G. H. . Jocelyn, Writtle, Essex. Five, selected from the Wetherfield collection, are reproduced in Figs. 780 to 784 . One is by Joseph Knibb, London; one in a marquetry case, quite an unusual style of 
570 Old Clocks and Watches and their Makers
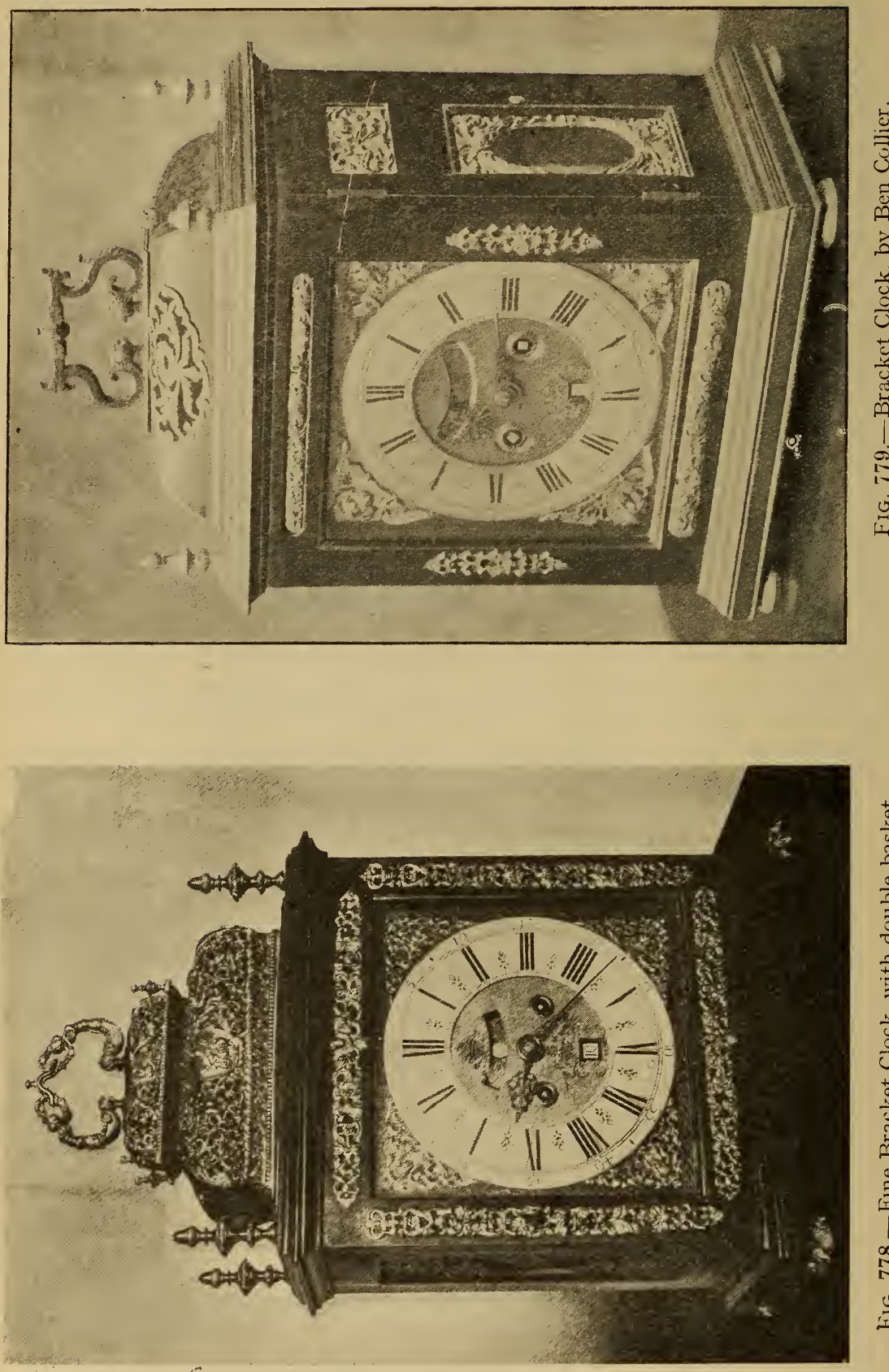

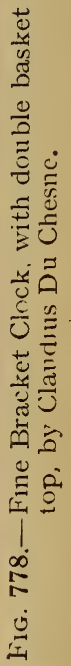


The Progression of English Domestic Clocks
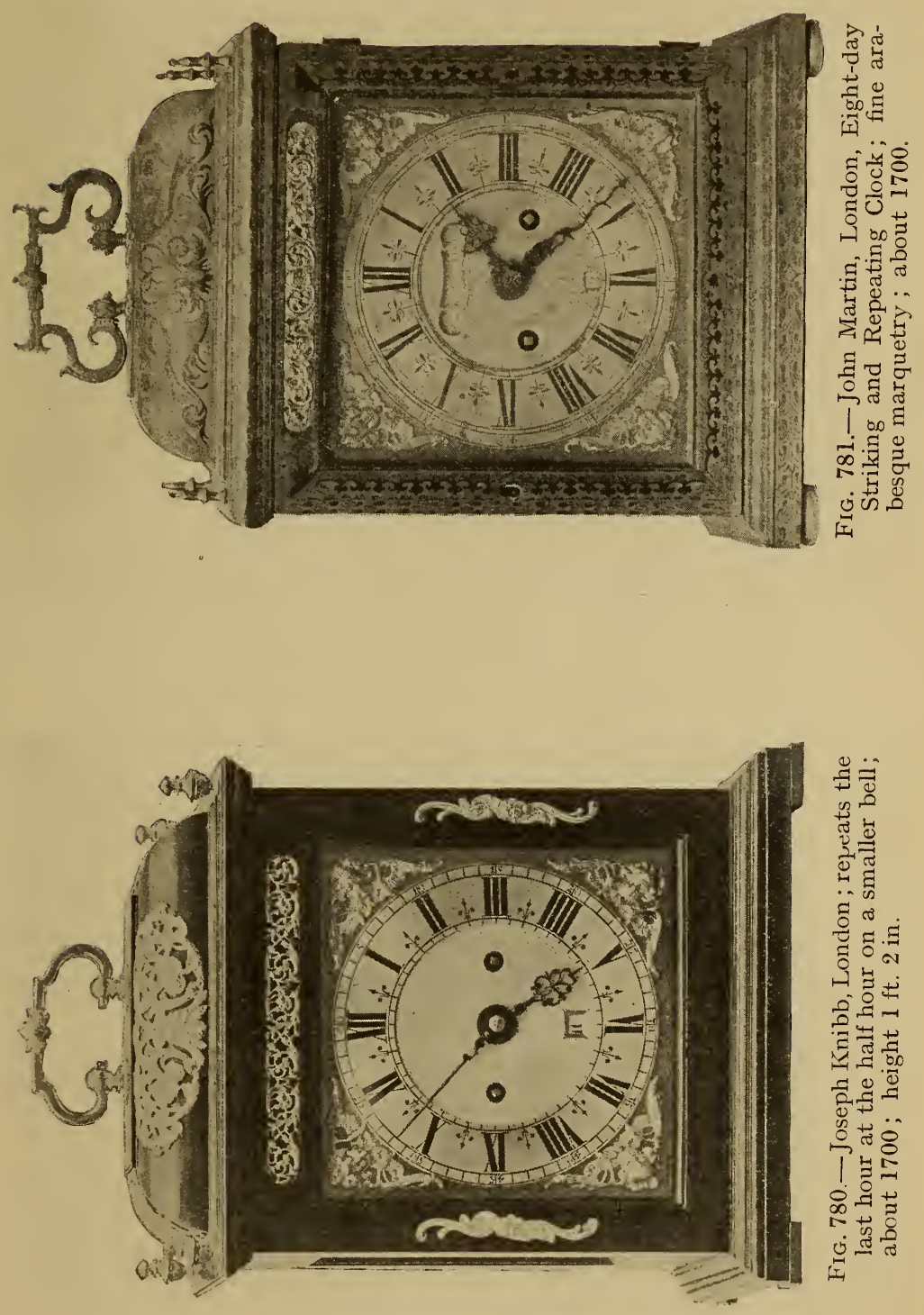
572 Old Clocks and Watches and their Makers
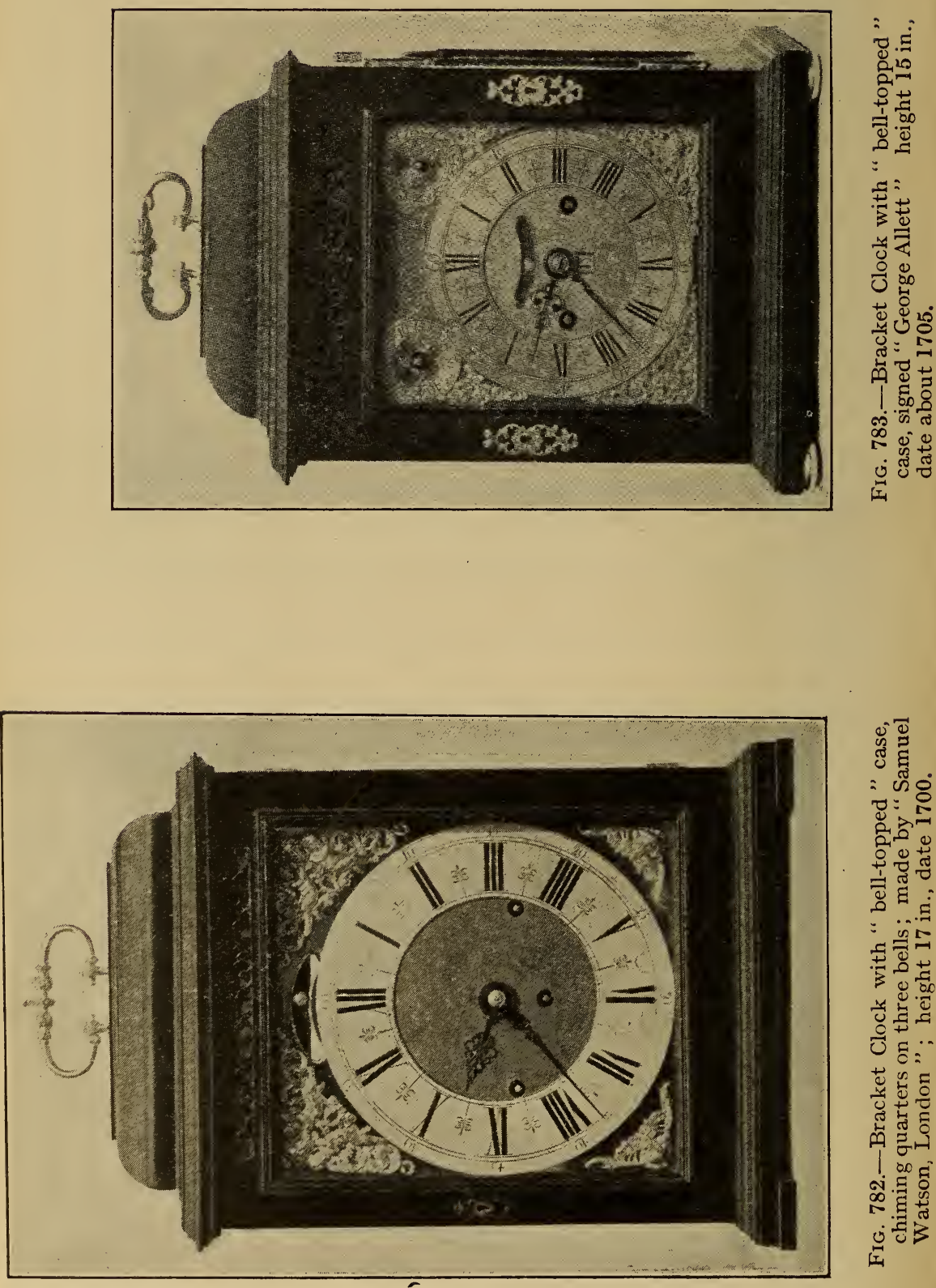

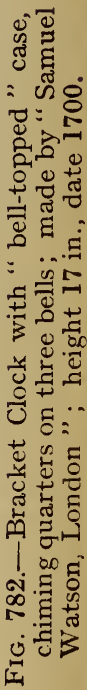




\section{The Progression of English Domestic Clocks 573}

decoration for such a piece, is by John Martin, London ; and one by Thomas Tompion.

After the "basket came the "bell" shaped case, so called from the hollow curved character of the top, as seen in Fig. 785. This is a very early example of that style, in the collection of Mr. J. D. Robertson. It dates from about 1695 , and is inscribed,

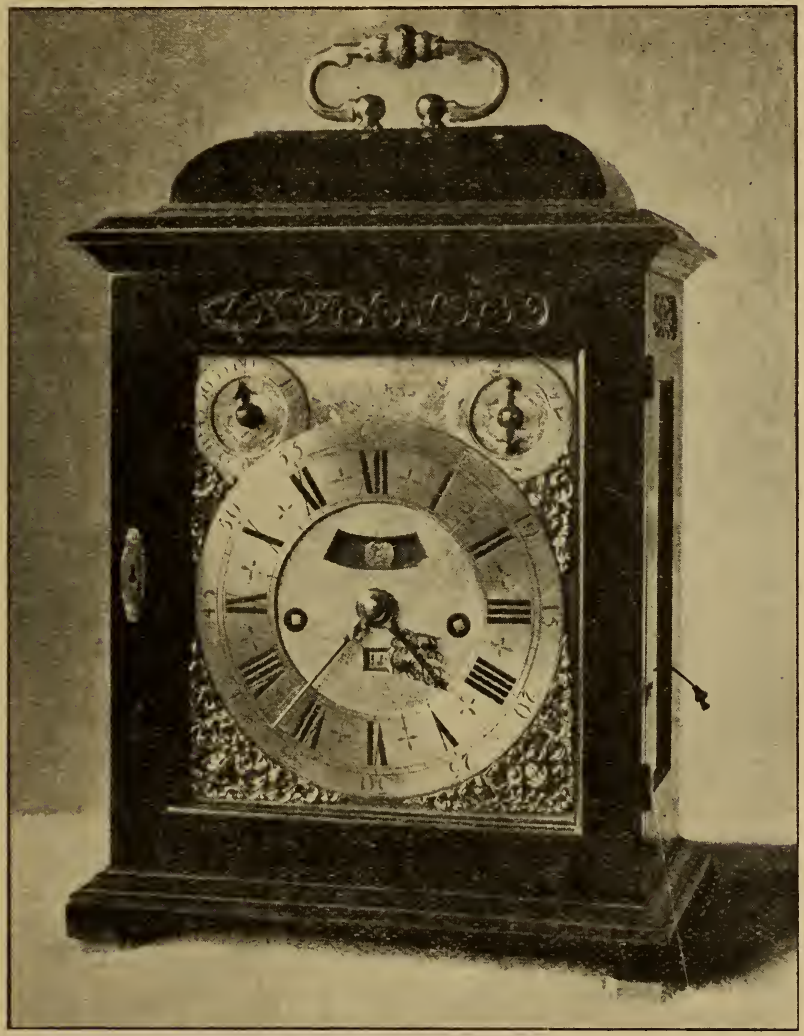

FIG. 784.-Thos. Tompion; repeats quarters by pulling the knob and string on the right; about 1705.

"Stephen Asselin, London." The George Graham in Fig. 786 is from the Wetherfield collection. Mrs. Francis J. Kidson owns a clock very similar to Fig. 786, signed "Tho Tompion \& Edw Banger, London."

The two eight-day striking clocks shown in Figs. 782 and 783, from the Wetherfield collection, may be taken as typical of the "belltopped" style. Both are in ebony, with handsome metal mounts. 


\section{Old Clocks and Watches and their Makers}

The example by Samuel Watson is about $17 \mathrm{in}$. high, and dates from 1700. The other is 15 in. high, is signed "George Allett, London." and dates from about 1705 .

The "bell" top case continued in favour long after the introduction of the arched dial. Two views (Figs. 787 and 788) are appended of an early arch dial bracket clock by Jeremiah Hartley, of Norwich, from the Schloss collection. The case is of ebonised wood

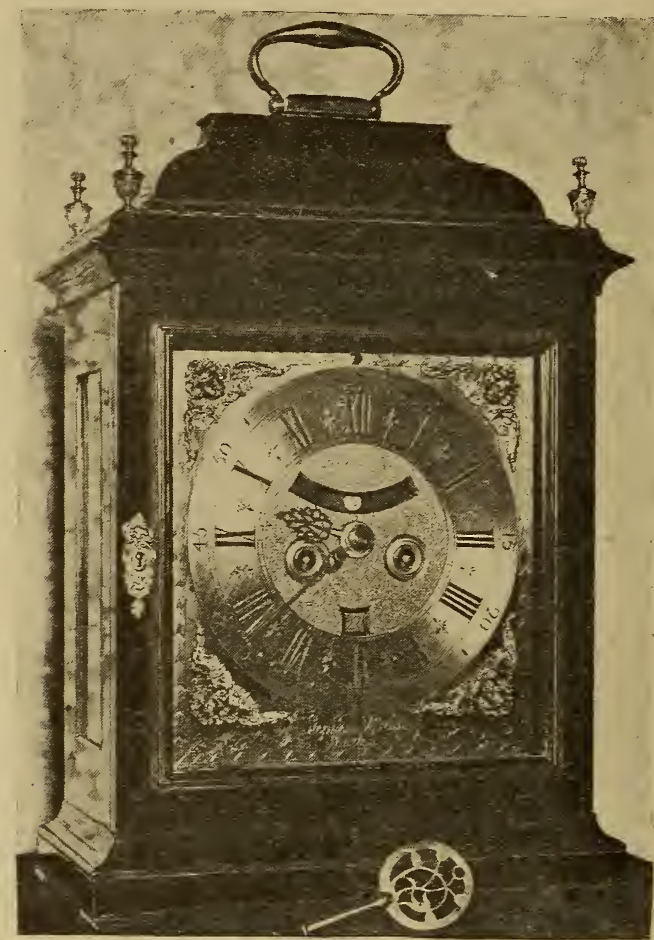

Fig. 785.-Early " Bell " shaped Case Clock, by Stephen Asselin, London.

with brass mounts. In the spandrels of the arch and at the sides is pierced diaper work backed by silk, to permit the sound of the bell to escape and yet prevent the ingress of dust. The clock shows days of the month, strikes the hours and quarters, and the strokes corresponding to the previous striking may be repeated at pleasure by pulling a string terminating in the knob which is seen at the right of the front view. In the arch of the dial is a rise and fall regulator which adjusts the length of the pendulum. 
A later bell-top case with fine claw fect, and surmounted by a plain brass handle instead of the side handles, is shown in Fig. 789.

Of the more ornate styles in vogue during the second quarter of the eighteenth century, the clock by Graham on p. 301 affords a good idea.

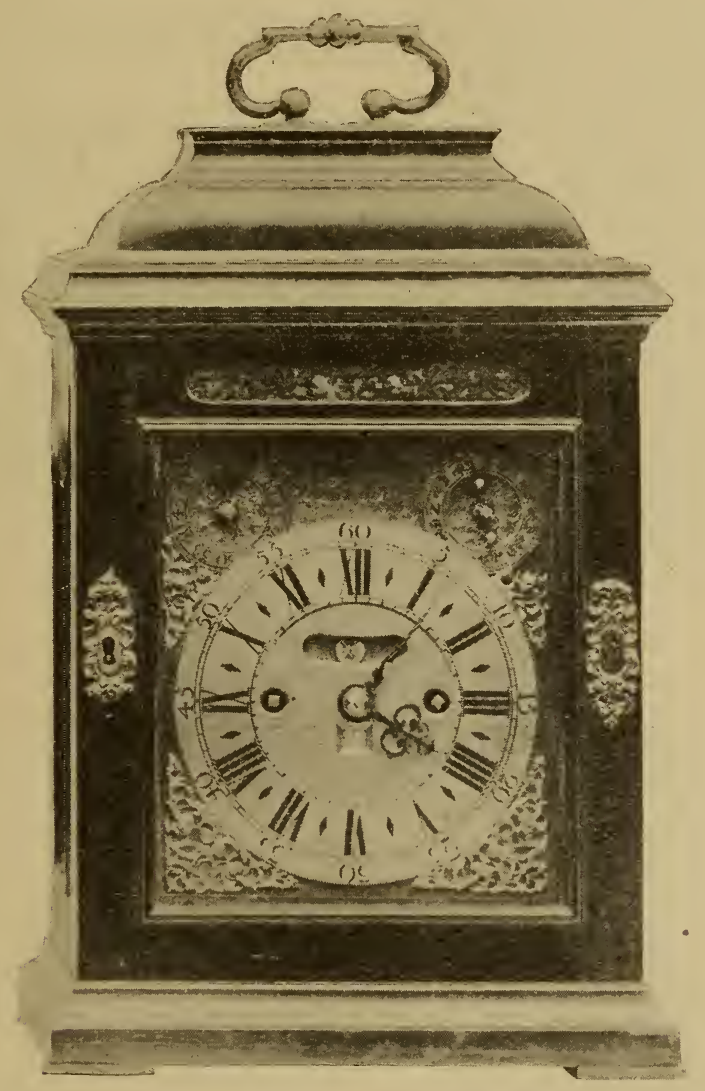

Fıg. 786.-George Graham, ab ut 1715; ebony cas with silver dial ornaments, height 13 in.

What perhaps may be termed a sporadic case of very elegant design is shown in Fig. 790, by favour of Mr. William Horne, Leyburn, Yorkshire. The clock is undoubtedly the work of Edward East, and dates probably from about 1685 , but the case is in many respects characteristic of the Sheraton style. It is of iron with brass mountings, finely chased and gilt, and measures $2 \mathrm{ft} .2 \mathrm{in}$. high and 
576 Old Clocks and Watches and their Makers

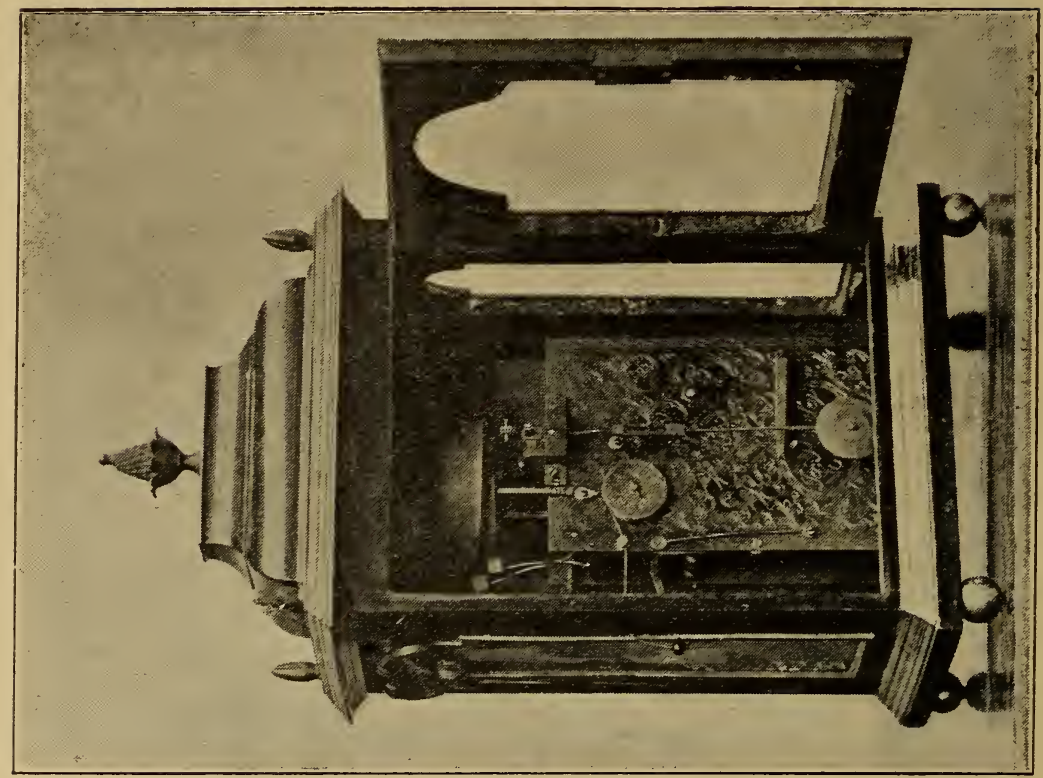

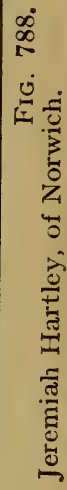

s

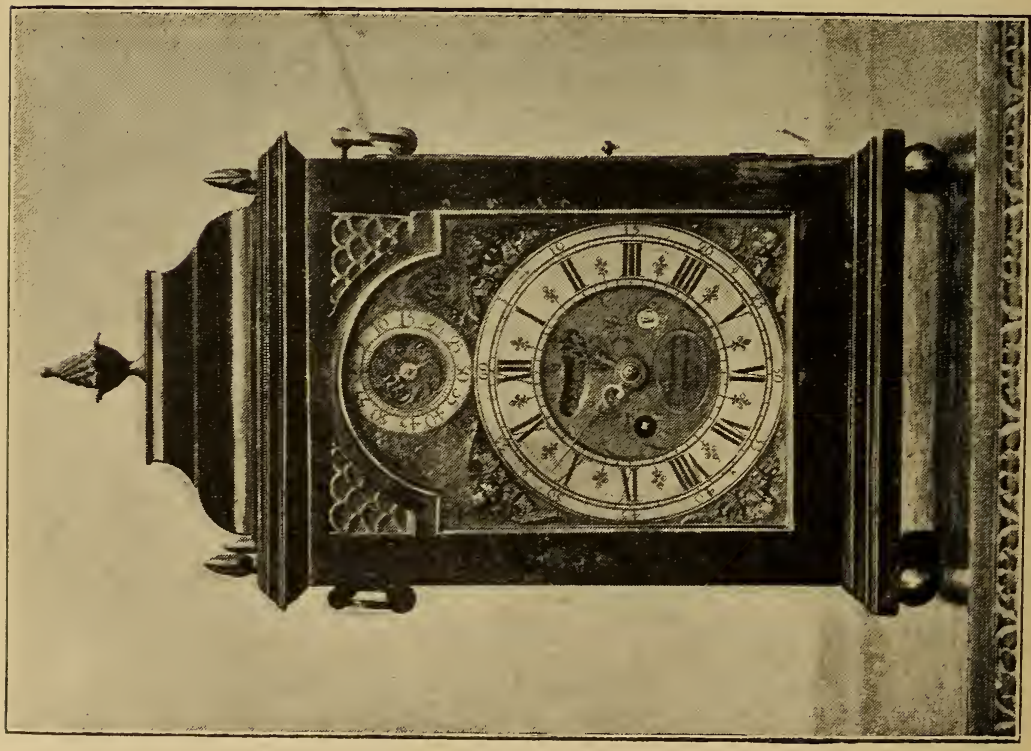


12 in. broad. On the dial of brass is engraved a peacock in full plume. On the back plate of the movement is engraved a basket of flowers, and underneath the inscription, "Eduardus East, London."

The handsome musical clock shown in Fig. 791 belongs to $\mathrm{Mr}$. Herbert A. Evans. The case is of mahogany with heavy brass handles and ornamentation at the corners, sides, and other parts ; the face is a plain white dial, with a smaller dial at each corner, brass ornament filling the intervening spaces. It strikes the hours on a

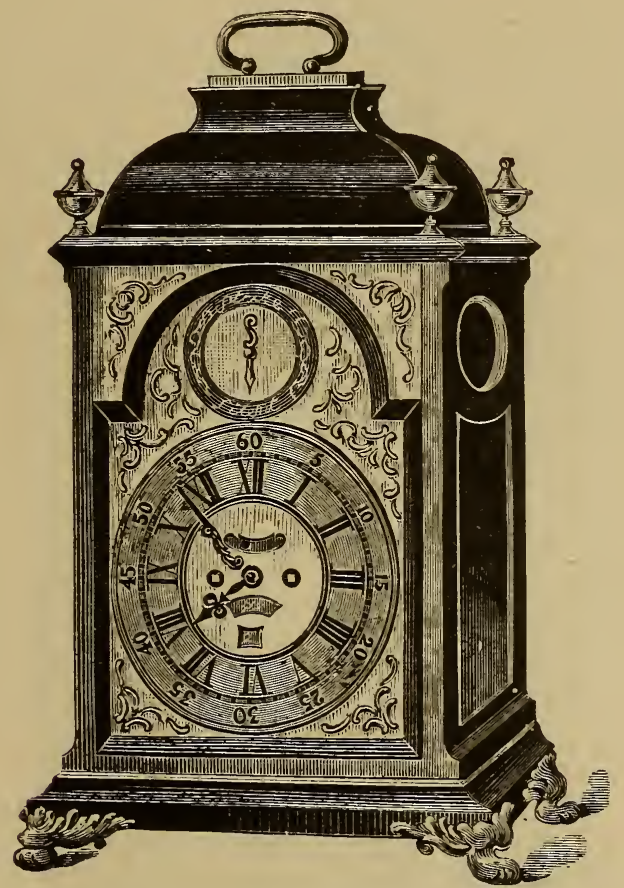

FIG. 789.-A later "Bell" top Case with fine claw feet.

gong which can also be set to ring at any hour as an alarm, and has, besides, a chime of thirteen bells playing four tunes, any of which may be selected by moving a hand on one of the smaller dials. In the arch above the face is painted a landscape scene with three moving figures in the foreground; at each hour these figures respectively beat a drum, play a fiddle, and dance more or less in time to the music. By pulling one of three small knobs at the side of the clock the hour chimes or alarm can be repeated at will. Of the remaining three small dials one has a strike-silent hand, the second 
shows the date of the month, and the third one the age of the moon. The face of the clock is engraved with the maker's name, "Diego Evans, Bolsa Real, Londres," and this is also engraved on the back plate, which is finely chased with arabesques and flowers. James

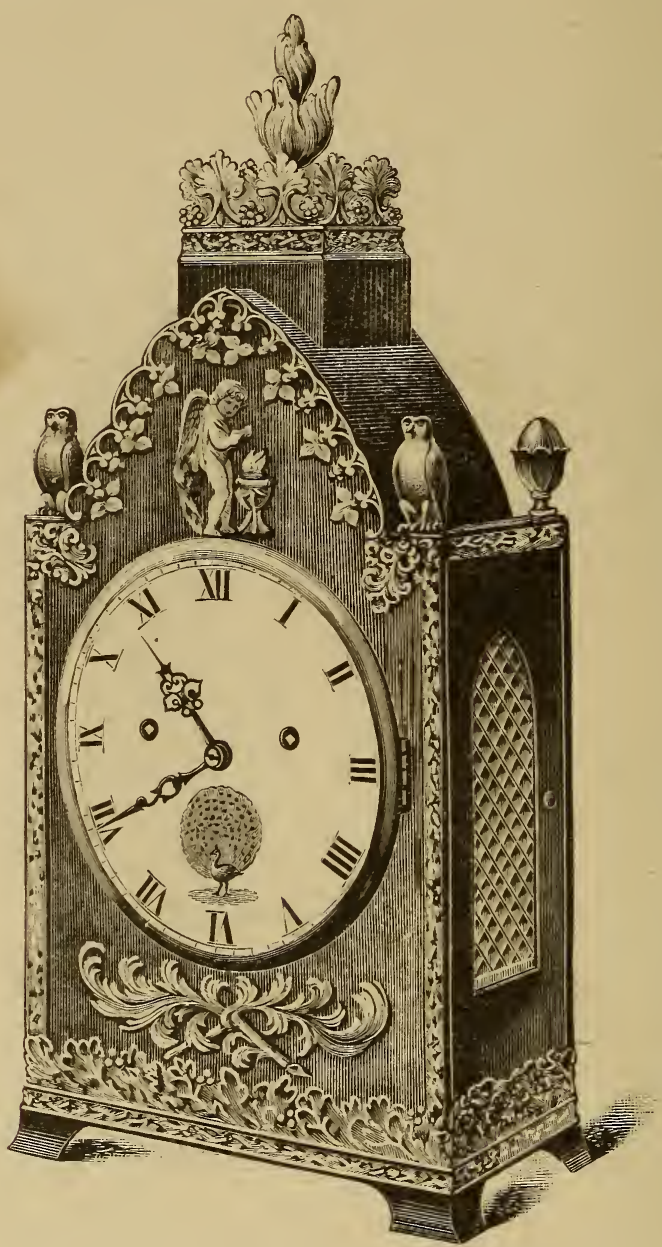

FIG. 790.-Clock, undoubtedly by Edward East, with case of elegant design.

Evans was a well-known maker of good timekeepers for the Spanish markets, by himself and also in conjunction with Higgs. This clock had been many years in the possession of a Bolivian gentleman resident in the city of Potosi. 
The Progression of English Domestic Clocks 579

Clocks for Eastern countries, usually with Turkish numerals, were often in cases of special design in which a domed top was a distinguishing feature. A fine example, dating from about 1730, is given on p. 580. It is a musical clork by "Gecrge Clarke,

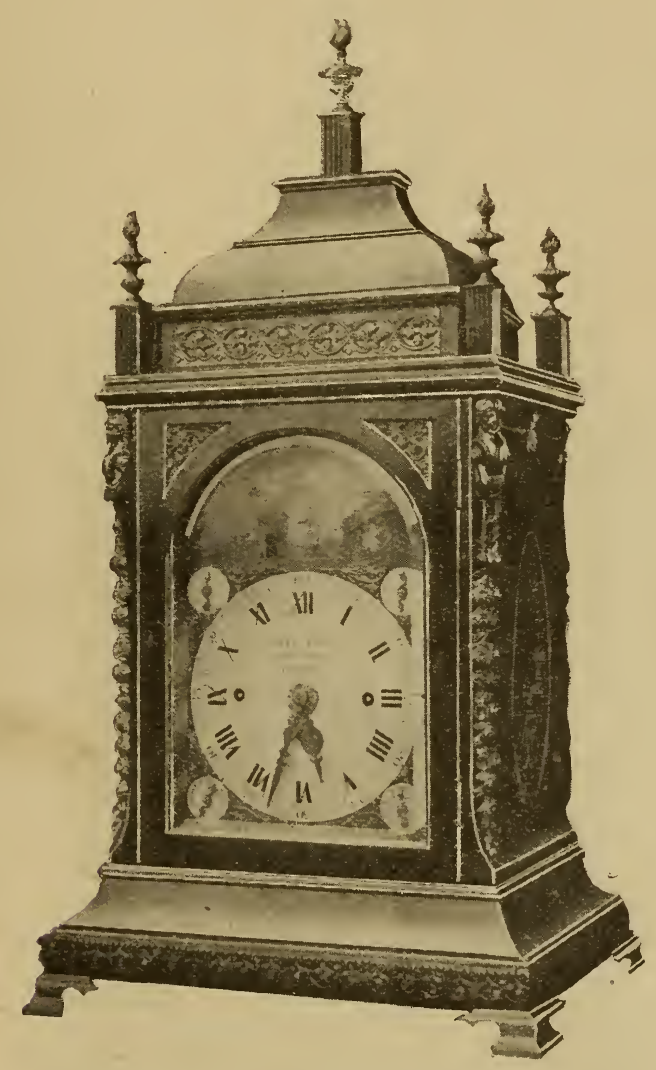

FIG. 791.-Musical Clock signed " Diego Evans, Bolsa Real, Londres." (James Evans, Royal Exchange, London.) See p. 577.

Leaden Hall Street, London," from the Wetherfield collection. The movement is furnished with fourteen bells. In the upper part of the arched dial is engraved the following list of tunes, the playing of any one selected being ensured by moving to it an indicator :- 
Princess Amelia.

A Turkey Tune.

A Gallen of Craden.

A Greeke Song.

A Rigadoon.

A March.
A Rigadoon.

A Minuet.

Greeke Song.

A Minuet.

A March.

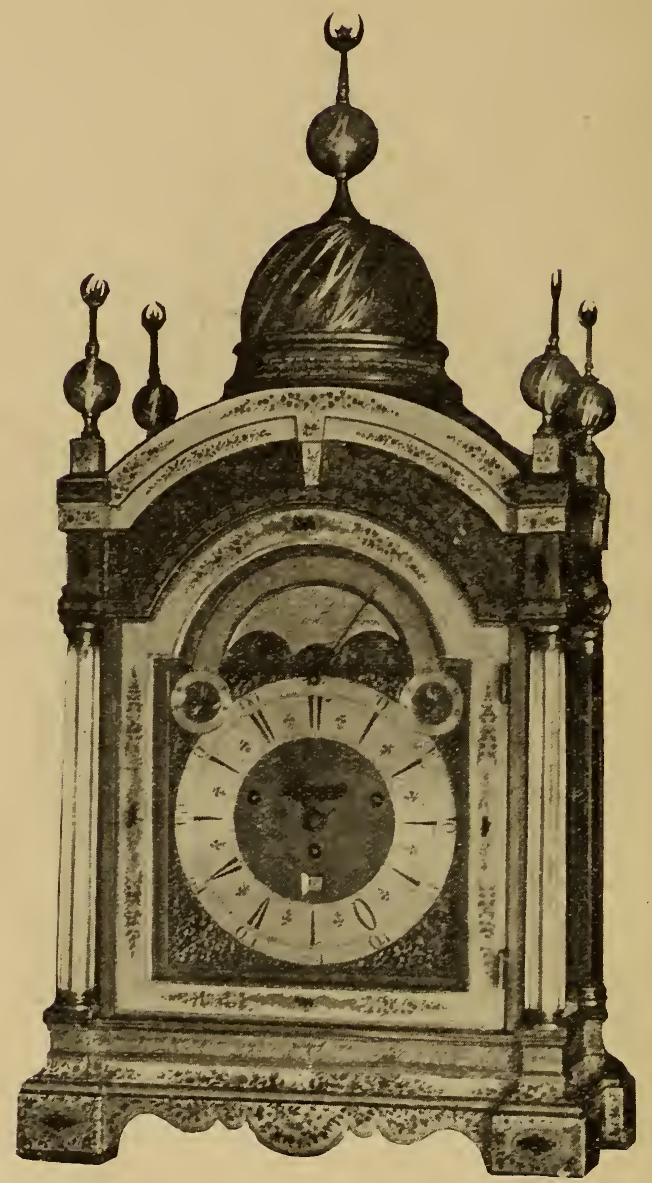

FIG. 792.—Clock, by George Clarke, about 1730 . Turkish hour-numerals.

Subsidiary dials on the left and right are respectively "Strike, Not Strike," and "Chime, Not Chime."

Another handsome domed clock, designed for the Eastern markets, having Turkish hour-numerals, and nearly a century later, is shown 
in Fig. 793. For this illustration I am indebted to Messrs. A. \& H. Rowley. The dials are of enamel, and on the main one is the inscription, " Henry Borrell, Exchange, London." The upper central

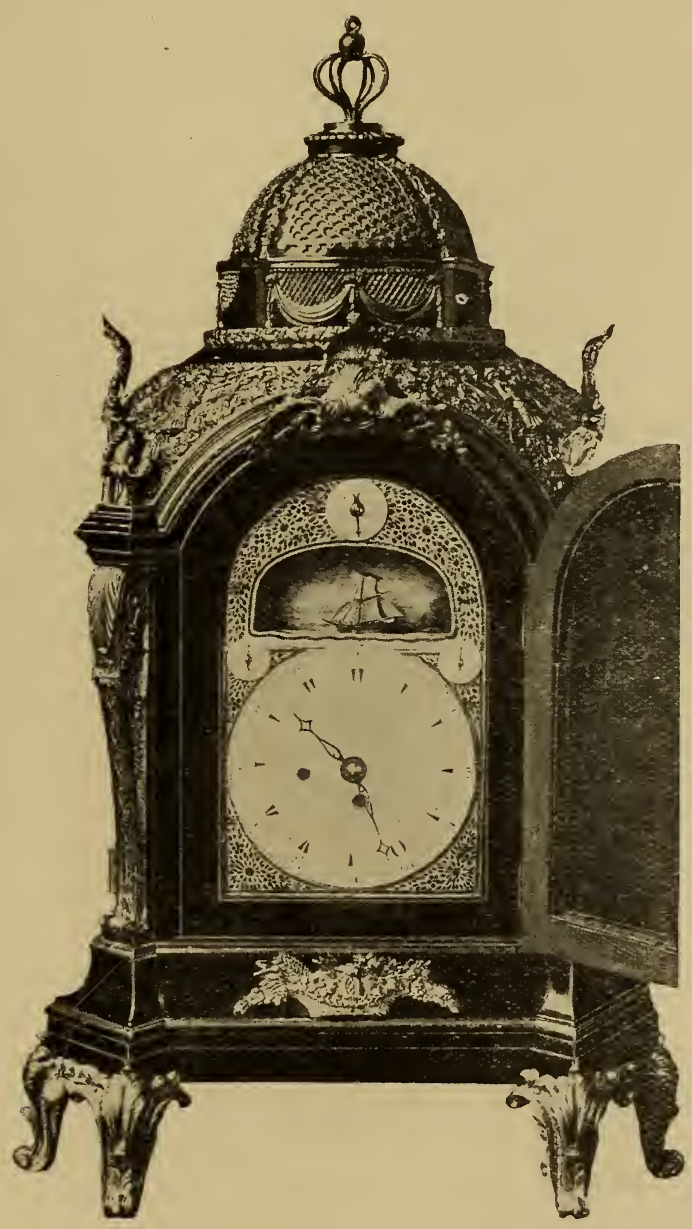

FIG. 793.-Clock, by Henry Borrell, about 1810. Turkish hour-numerals.

disc contains the following list of tunes: "St. James' Minuet, Handel's Gavotte, A Hunting we will Go, Haymakers' Dance." George and John Prior were celebrated for clocks of this character, which are often taken to be older than they really are. 


\section{Old Clocks and Watches and their Makers}

The charming diminutive clock by Josiah Emery, with bracket, shown in Fig. 794, is from the Wetherfield collection.

Towards the end of the eighteenth century the popularity of the " bell-top" case waned, and it was gradually supplanted by three set patterns, the " broken arch," the " balloon," and the "lancet."

The "broken arch" was not, as might be supposed, a circular

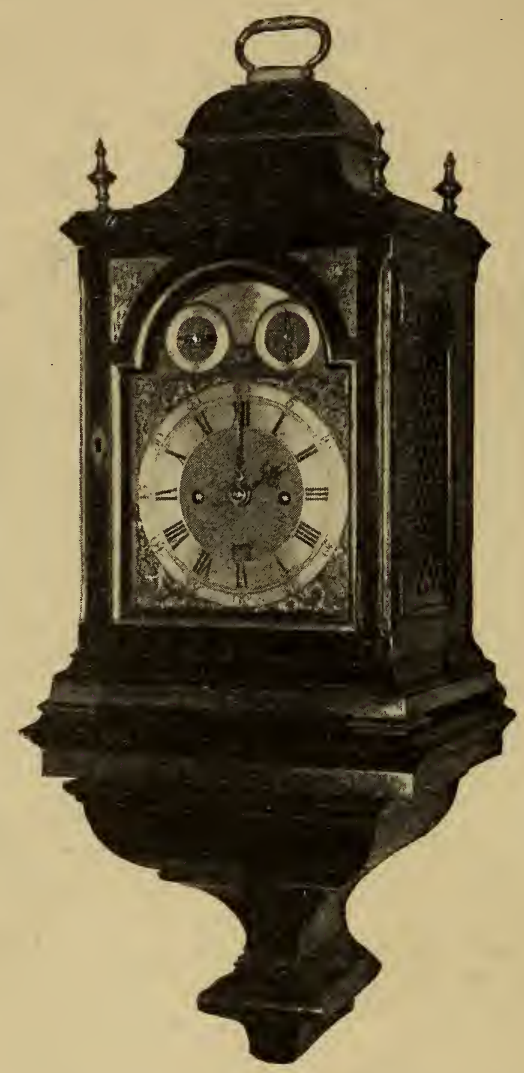

FIG. 794.-Josiah Emery, Eight-day ; pull repeating quarters on six bells.

pediment cut away in the middle, but an arched top not extending to the full width of the dial, the moulding surmounting the arch being continued from its springing along the front of the case in two short straight bands. This seems to have been taken from Chippendale's bracket cases, as in Figs. 732, 733, 734, 735, all of which have circular pediments of this kind, but the ornamental 
The Progression of English Domestic Clocks 583
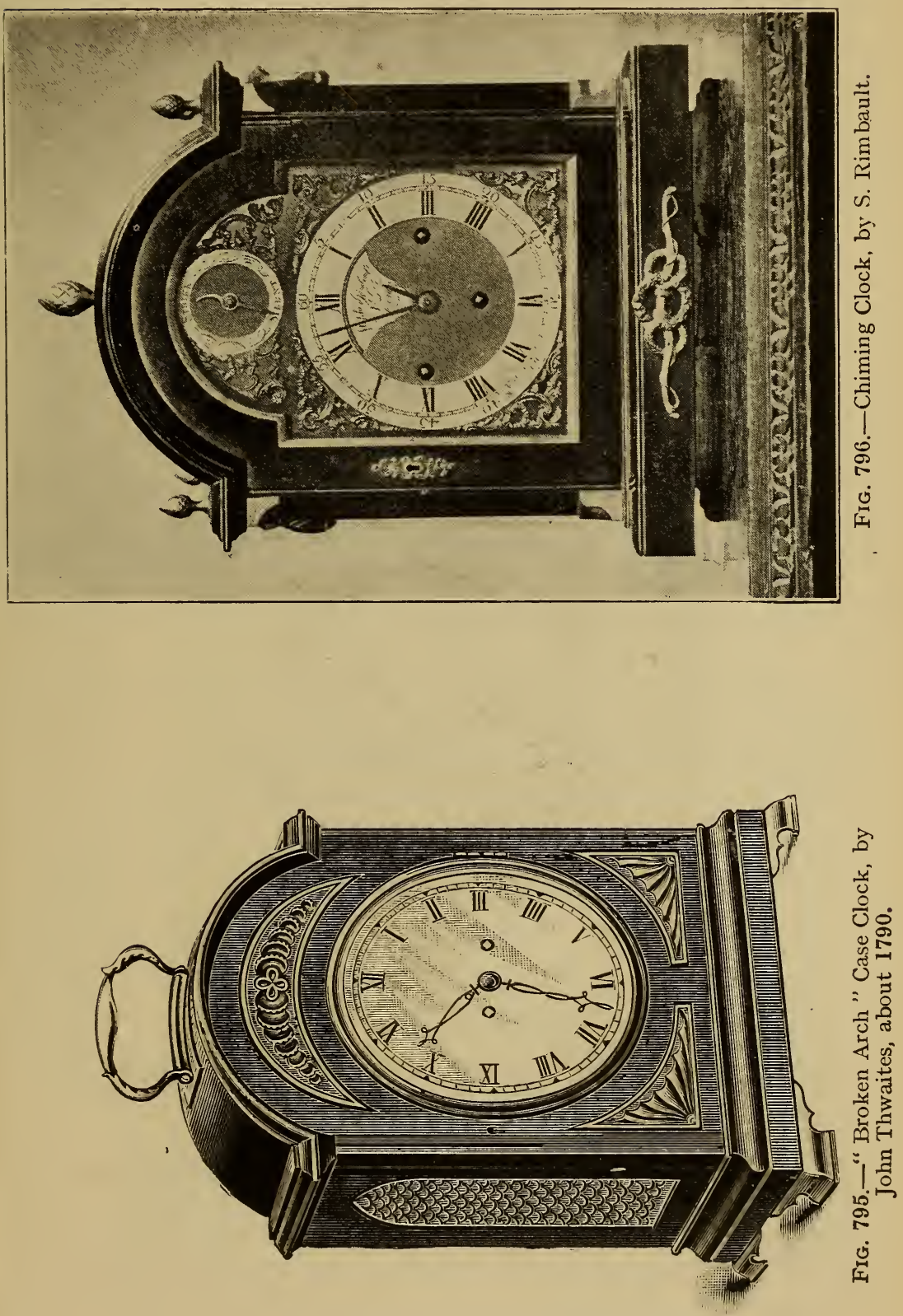
584 Old Clocks and Watches and their Makers

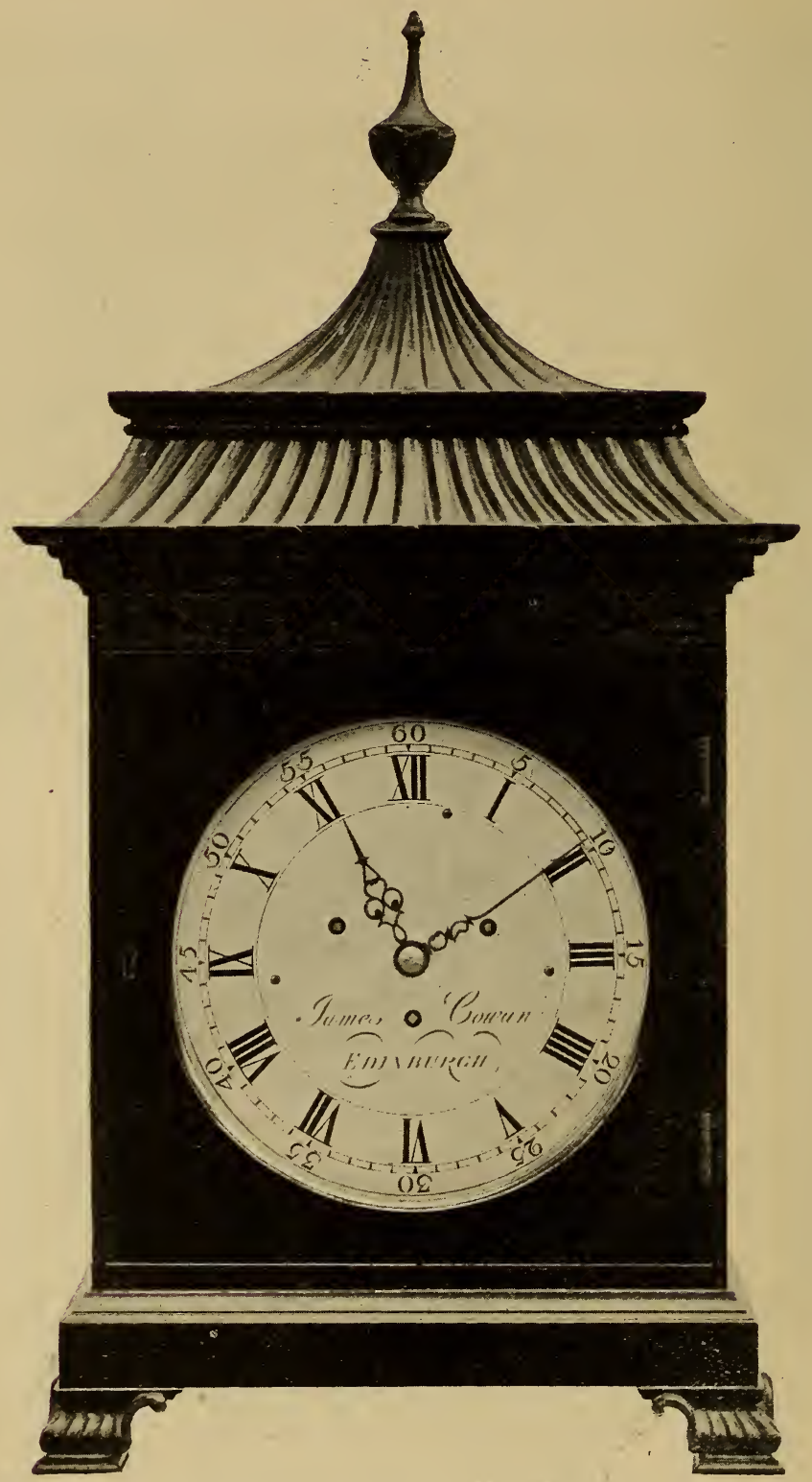

FIG. 797.-James Cowan, Edinburgh, about 1770. Three-Train Bracket Clock, chiming on eight bells; Chippendale Mahogany case, $2 \mathrm{ft} .3$ in. high. 
The Progression of English Domestic Clocks 585

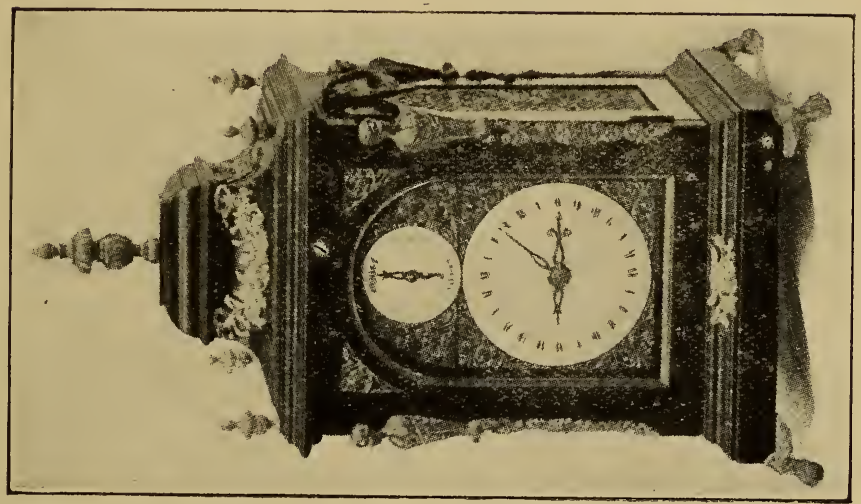

官

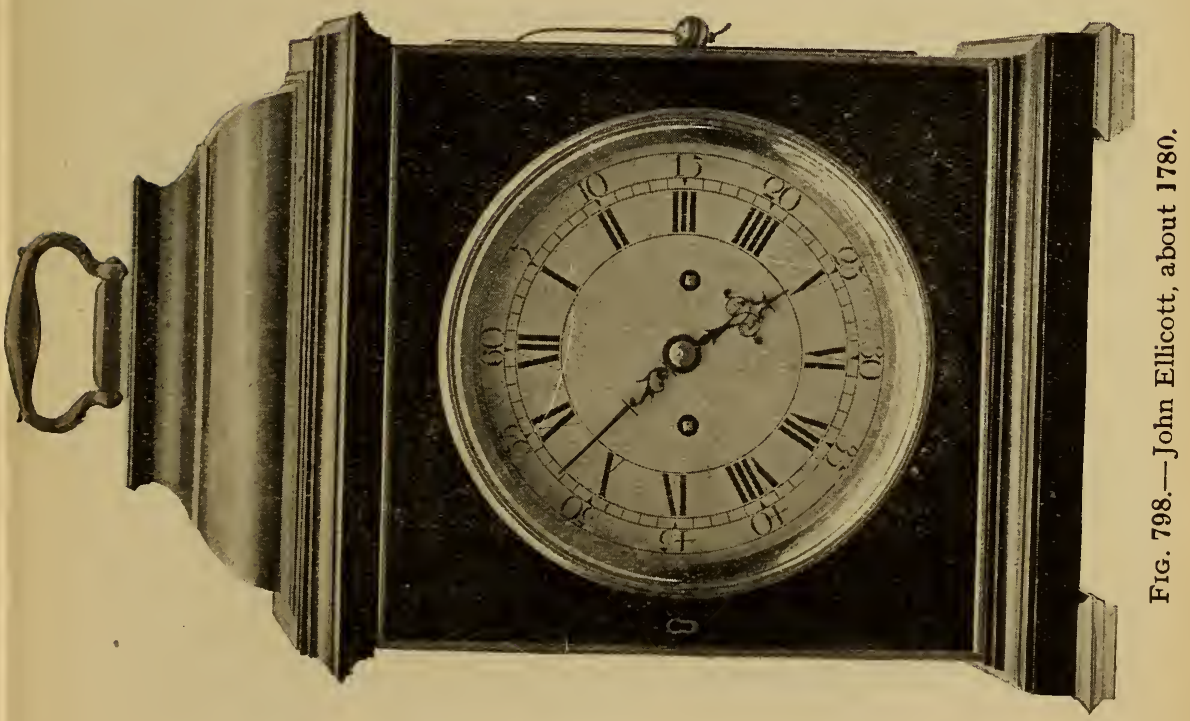


586 Old Clocks and Watches and their Makers
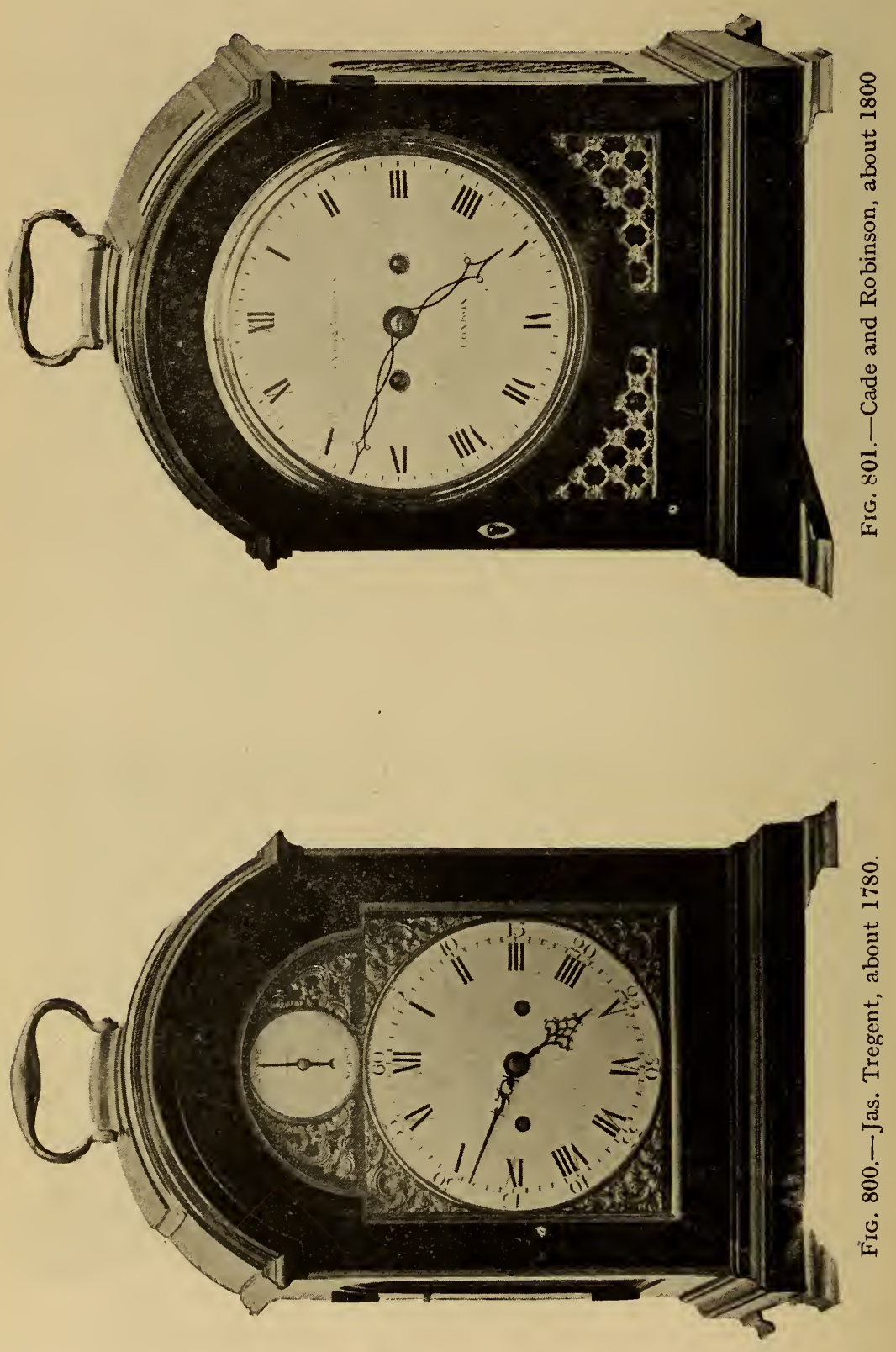
The Progression of English Domestic Clocks 587

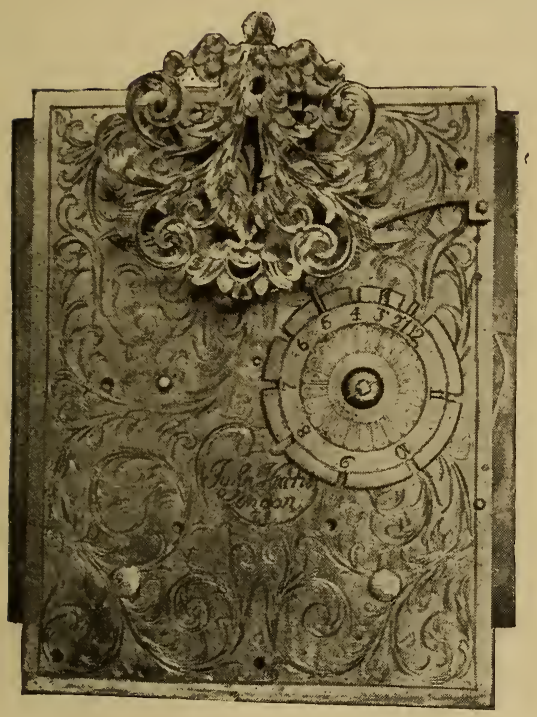

FIG. 802.-John Harris.

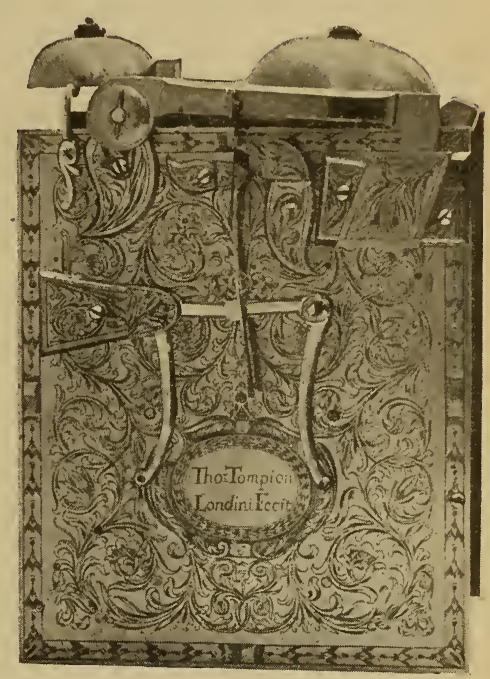

FIG. 803.-Thomas Tompion

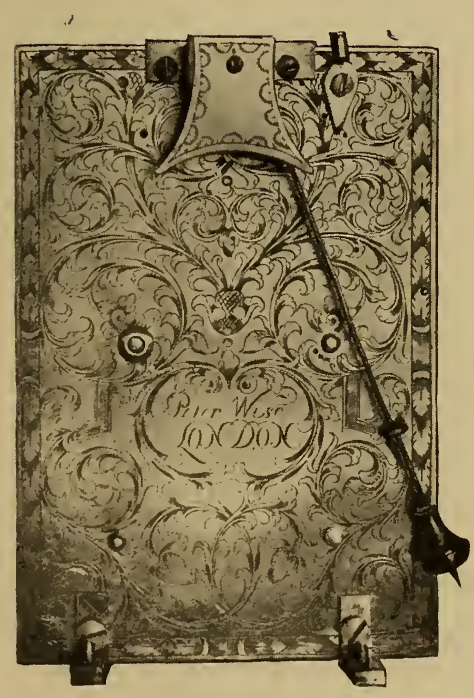

FIG. 804.-Peter Wise.

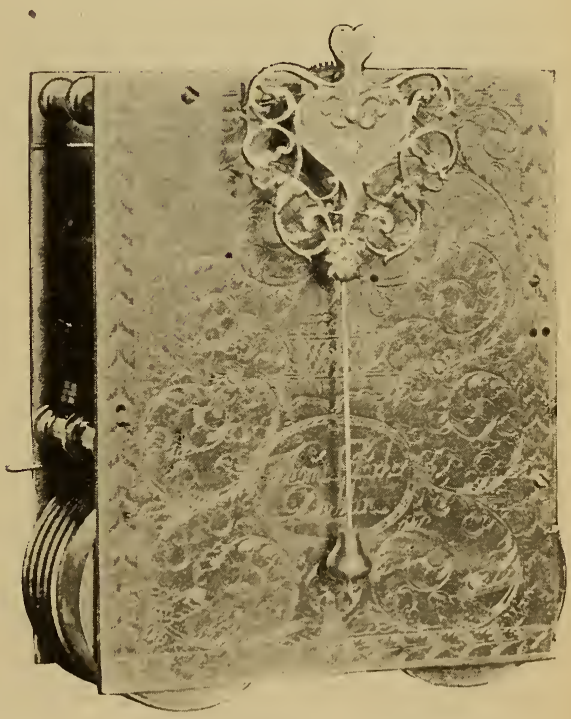

Fig. 805.-Thomas Parker. 
superstructure as suggested by Chippendale was not adopted. What is generally accepted as a "broken arch" case is shown in Fig. 795. It enclosed a clock dating from about 1790 , by John Thwaites, an eminent maker who was several times master of the Clockmakers' Company.

A wide broken-arch mahogany case, containing a musical clock, by Stephen Rimbault, is shown in Fig. 796. The clock plays six tunes on eleven bells. One air is "God Save the King " ; the others are now obsolete and not easily recognised, but no doubt they were most popular about 1780, when the clock was made. A fine musical clock by Rimbault, which was formerly the property of Sir William Drake, is in the Ashmolean Museum, Oxford.

Stephen Rimbault carried on business in Great St. Andrew's Street, St. Giles, and was a maker of repute, particularly excelling in clocks with mechanical figures dancing or working on the dials, and other complicated timekeepers. The artist Zoffany was for some time Rimbault's decorative assistant, and in him his master had a man of great ability and taste, who no doubt helped to make his name. Zoffany painted a portrait of his master which pleased Rimbault so much that he introduced him to Wilson, the portrait painter. Zoffany was then employed by Wilson to fill in draperies, \&c., at a salary of $£ 40$ a year, and while with him his ability was recognised by David Garrick, who put him into the channel of theatrical portraiture, where he made his name, becoming R.A. in 1798.

The following examples are from the Wetherfield collection:-

Fig. 797, by James Cowan, Edinburgh. Fig. 798, a repeating clock by John Ellicott, in a mahogany case $1 \mathrm{ft}$. 5 in. high. Fig. 799, by Marriott, London, is a quarter clock with one bell and two hammers. The dials are of enamel, the hours are marked 1 to 12 twice over, the case, of ebony with brass mounts, is $1 \mathrm{ft}$. 3 in. high. From the Wetherfield collection, Fig. 800, by James Tregent, has enamel dials and an ebony case, 1 ft. 3 in. high. Fig. 801, by Cade \& Robinson, with enamel dial, is in a mahogany case, $1 \mathrm{ft} .4 \mathrm{in}$. high.

Back Plates.-Till towards the end of the eighteenth century bracket clocks had, as a rule, a glazed door at the back through which could be seen the back plate with ornamental engraving thereon. Six examples are given. John Harris, about 1690, from the clock shown in Fig.777 ; Thomas Tompion, 1705, from the clock shown in Fig. 784 ; Peter Wise, 1710, from a clock belonging to Mr. T. W. Bourne ; Thomas Parker, about 1710, from a clock belonging to Mr. J. D. Robertson, having an ornamental pendulum cock similar to that on 


\section{The Progression of English Domestic Clocks 589}

Sir Isaac Newton's clock in the Guildhall Museum; Joseph Knibb, about 1700 ; and John Ellicott, about 1770, which shows on the upper left-hand corner a repeating-barrel. When it was desired that the quarters should be repeated the mainspring in a barrel of this kind would be wound by pulling a cord outside the case ; in unwinding, the force of the spring would be utilised to actuate the hammers. Figs. 803, 806, and 807 are from the Wetherfield collection.

Ornamental engraving is rarely seen on nineteenth-century productions. With the engraved plate disappeared, of course, the glazed door at the back of the case. The utilitarian spirit, which abolished

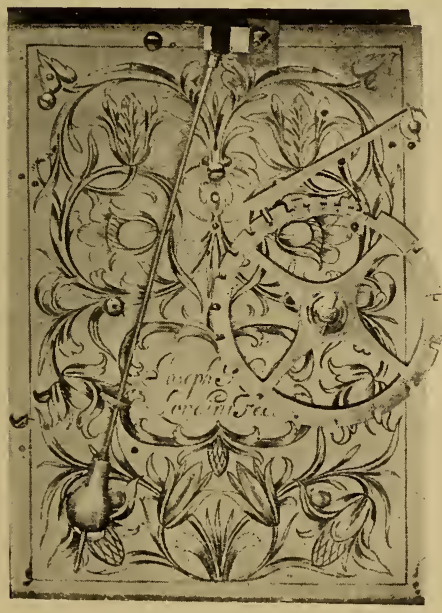

Fig. 806.-Joseph Knibb.

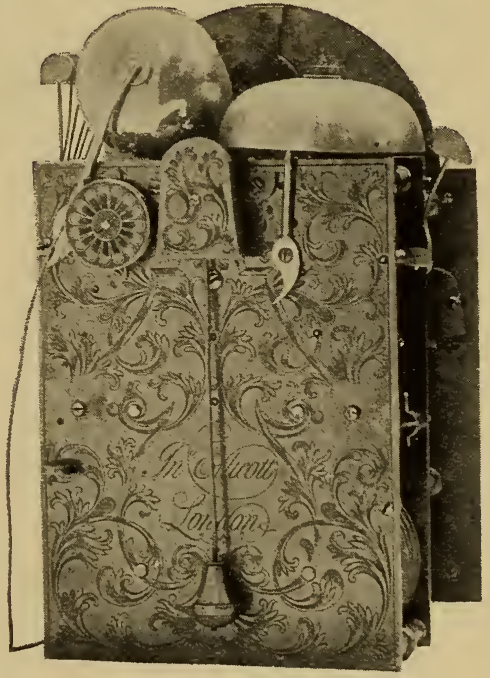

FIG. 807.-John Ellicott.

these features as redundant, has, however, caused fine specimens which survive to be more highly prized. What can look meaner than the bare and often common wood at the back of many pretentious modern clocks if one of them happens to be in front of a mirror?

Fig. 810 represents the lower plate of a long-case clock by J. Jones, of Chalford, Gloucestershire, dating from about 1770 . It was originally part of a monumental brass and is most interesting. The clock is now in the possession of Mr. Hansard Watt, and was formerly in the collection of the late Mr. Norman Shaw. 
590 Old Clocks and Watches and their Makers

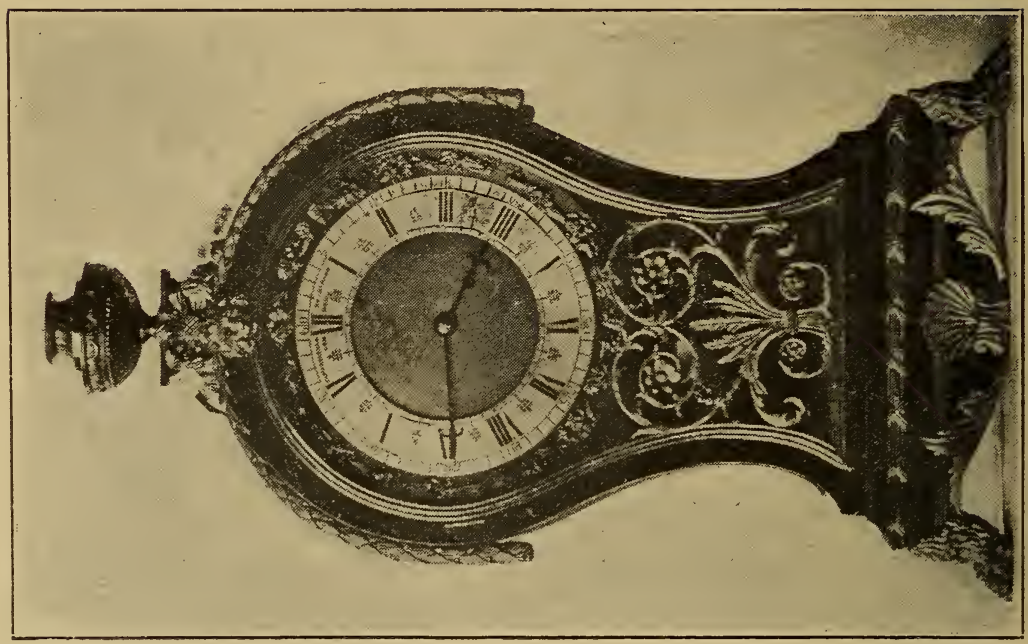

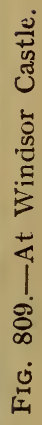

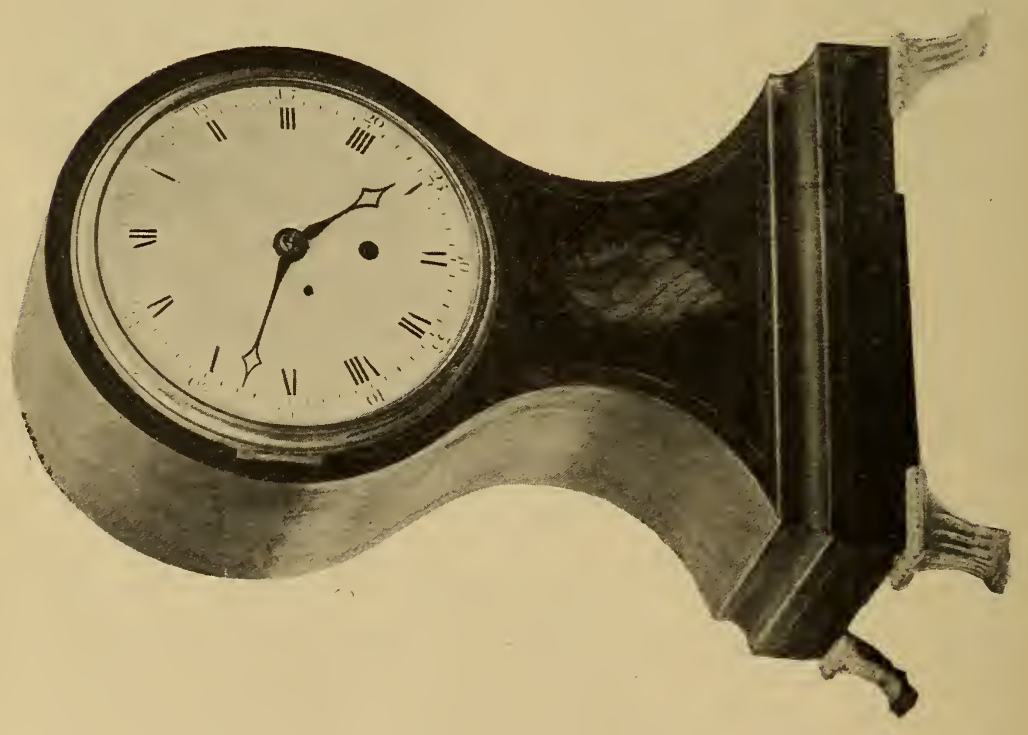

官 


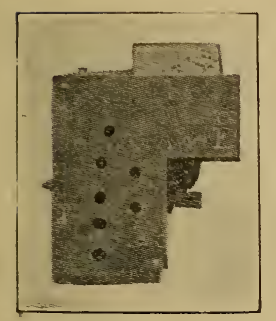

FIG. 810. - Plate of $\mathrm{Clock}$, originally part of a monumental brass.

Balloon. - Fig. 808 gives an excellent representation of a balloon case, inlaid after the Sheraton style, from the Wetherfield collection. The clock is signed "Jos Thompson London," and dates from about 1790. Fig. 809 shows a later and more ornate form of balloon clock at Windsor Castle. For the balloon clock and bracket shown in Fig. $811 \mathrm{I}$ am indebted to Mr. Webster. The graceful harmony of the curves constituting the case and bracket form a complete and pleasing design.

The clock enclosed in this case was made by Robert Wood, of Moorfields. The round knob on top of the case served to regulate the time by shortening or lengthening the effective part of the pendulum. The clock by John Johnson, on a bracket, as in Fig. 812, is from the Wetherfield collection.

Lancet. - T he "lancet" case, in form the counterpart of a pointed Gothic arch, and named from its resemblance to the well - known cutting instrument used by surgeons, is shown in Fig. 813. This clock, dating from about 1820 , was made by George Orpwood.

Of about the same

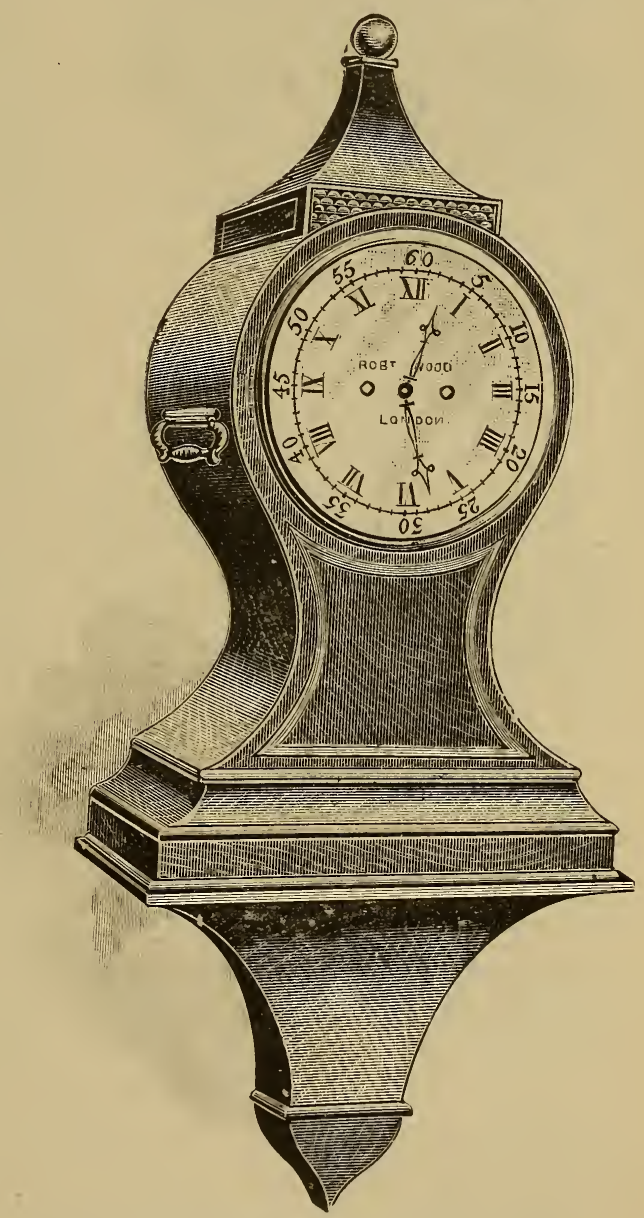

FIG. 811.-Sheraton Style, about 1790. 
date is a pretty little clock at Windsor Castle, which is shown in Fig. 814. It is English, with Boulle work decoration, after the French style.

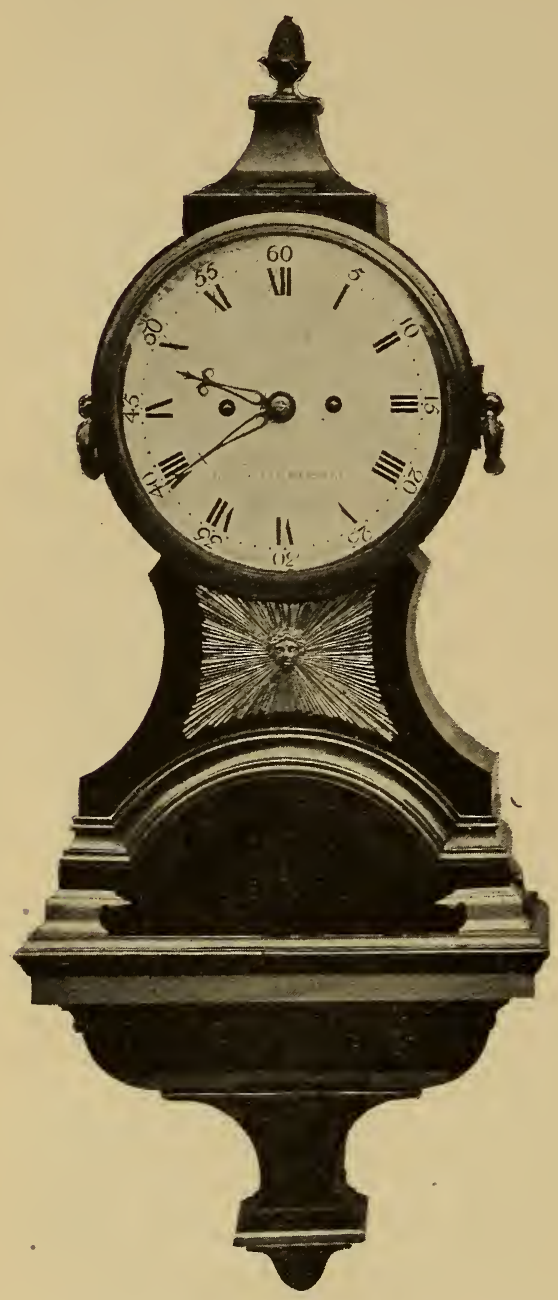

Fig. 812.- John Johnson, Ebony Brassmounted Eight-day Balloon Clock, Pin Wheel Escapement; height, including bracket, 27 in.; about 1800 .
Soon after its introduction, the pendulum was occasionally placed outside of the case in front of the dial, especially in small clocks like Fig. 636, but I saw a very fine bracket clock arranged in this way. It was by John Trubshaw, of London, and dated from about 1700 . To put the pendulum outside is not a good plan, for it is clearly more liable to disturbance than when suspended inside the case. Captain Edward Lethbridge informed me that in the hall of Hinton Ampner House, near Alresford, is a timepiece, probably of German origin, in an oval case of embossed silver, measuring about 20 in. by 12 in., mounted on a velvet block. The pendulum reaches from the top to the bottom of the case, and swings in the front on the outside of the dial. This also would probably be a very earlyeighteenth - century production.

A curious little timepiece, supported by a winged Mercury, shown in Fig. 815, is fitted with a pendulum arranged to swing in front of the dial. Altogether it is 6 in. in height. Around the arch of the dial is engraved, "Cito Perevnt ET IMPVTANTVR" (They pass quickly and are reckoned). On the 
dial are two labels bearing the words "Chasseur, London." The date of its production is uncertain.

On p. 595 are front, side, and back views of an English travelling clock, dating from about 1710 , which is interesting by its rarity, for it is a type, I think, but very seldom seen. From the bottom of the case to the top of the swivelled knob below the carrying ring measures 8 in. The movement is signed "Paulet, London." The gilt metal work of the case is finely pierced and carved, arabesques and faces being executed in a style not usual at this period on clock cases of

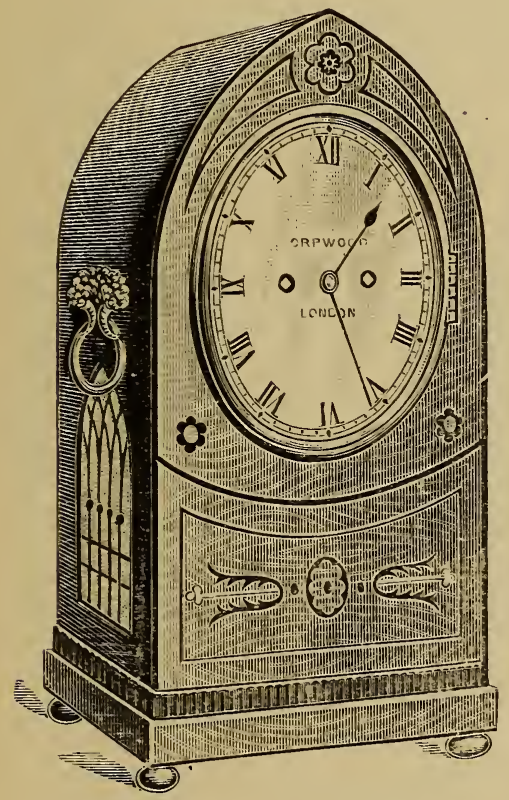

FIG. 813.- "Lancet" Case.

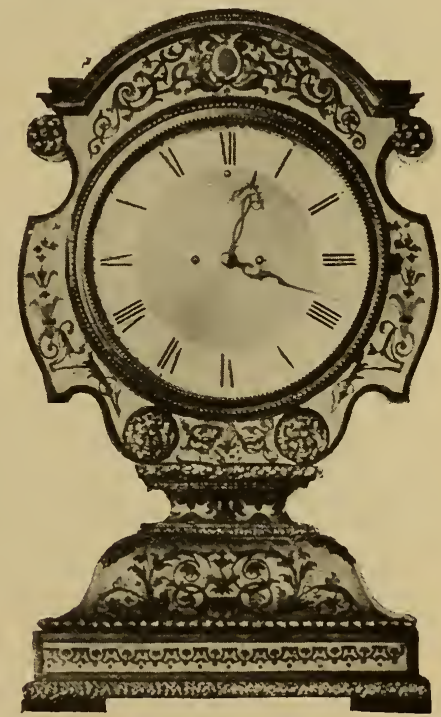

FIG. 814.-Small Clock, at Windsor Castle.

English manufacture. The dial and back plates are covered with open lace work of hammered silver. Besides repeating the hours and quarters, the clock is provided with an alarm, and in a semicircle occupying the arch of the dial the day of the month is indicated. It is from the Schloss collection. A very similar clock by Paulet is to be seen at the South Kensington Museum.

Taxes Relating to Clocks and Watches.-Legislation has on more than one occasion affected the material used for watch cases. In 1719 a duty of sixpence an ounce was imposed on articles of silver, 


\section{Old Clocks and Watches and their Makers}

and this quickly led to an increased use of base metal cases. In $\mathbf{1 7 5 8}$ an annual payment of forty shillings by dealers was substituted for the duty, and in 1759 the amount to be paid for a licence was raised to $£ 5$. But in 1784 the duty of sixpence per ounce was reimposed in addition to the dealer's licence. The effect was remarkable; the

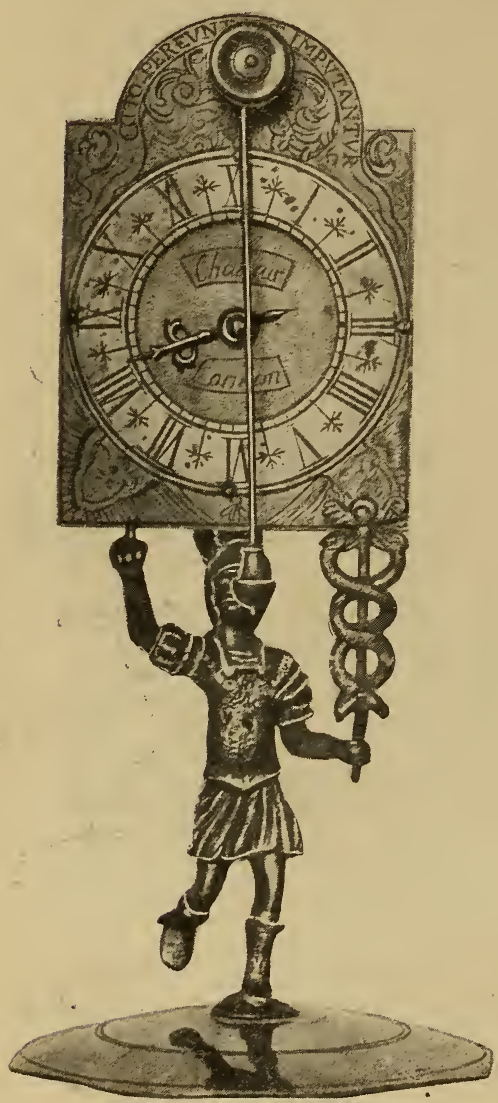

FIG. 815.-Curious little Timepiece, with pendulum in front of dial. use of silver immediately declined, and for the next fourteen years large numbers of base metal cases were made. In 1797 a tax of eight shillings an ounce was levied on gold articles, which doubtless would have led to an increased use of silver-gilt and pinchbeck cases, but that Pitt, not content with taxing the cases, at the same time imposed a tax on all persons in respect of the possession and use of watches as well as clocks. The Act ordained that-

"For and upon every Clock or Timekeeper, by whatever name the same shall be called, which shall be used for the purpose of a clock and placed in or upon any dwelling house, or any office or building thereunto belonging, or any other Building whatever, whether private or publick, belonging to any person or persons, or Company of Persons, or any Body Corporate, or Politick, or Collegiate, or which shall be kept and used, by any Person or Persons in Great Britain, there shall be charged an Annual Duty of Five Shillings. For and upon every Gold Watch, or Watch enamelled on Gold, or Gold Timekeeper used for the Purpose of a Watch by whatever Name the same shall be called, which shall be kept and worn, or used, by any Person or Persons in Great Britain, there shall be charged an Annual Duty of Ten Shillings. And for and upon every 
The Progression of English Domestic Clocks 595

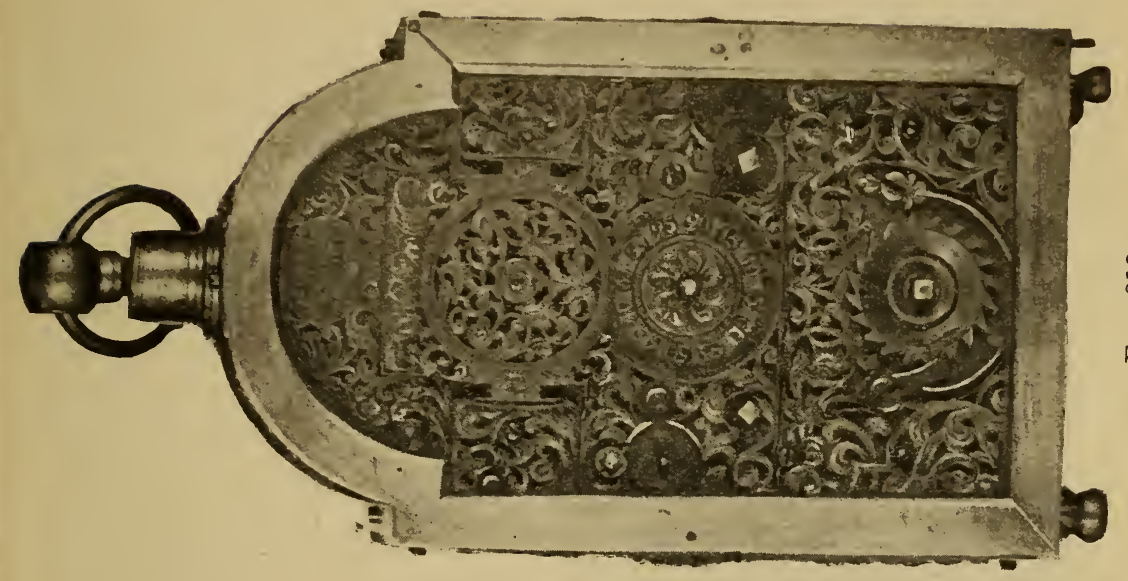

$\underset{\infty}{\infty}$
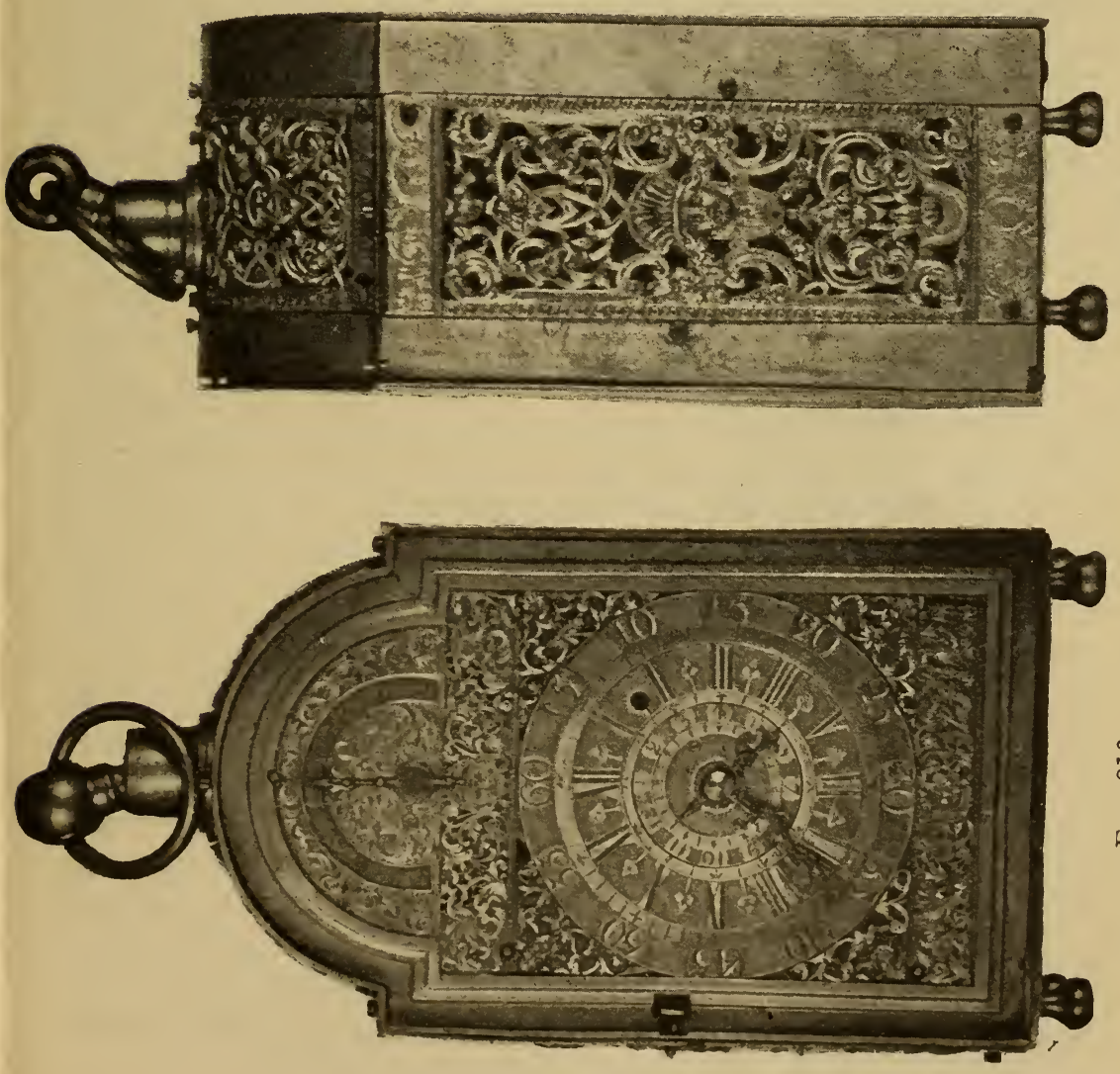


\section{Old Clocks and Watches and their Makers}

Silver or Metal Watch, or Silver or Metal Timekeeper used for the purpose of a Watch, or any other watch, or Timekeeper used for the like purpose not before charged, of whatever materials the same shall be made, and by whatever name the same shall be called, which shall be kept and worn, or used, by any Person, there shall be charged an Annual Duty of Two Shillings and Sixpence."

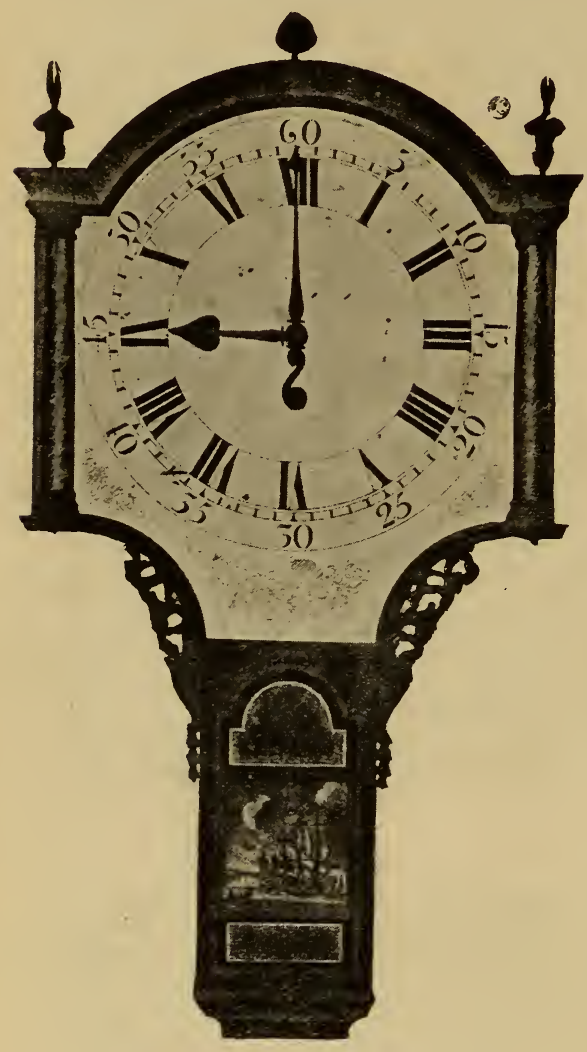

FIG. 819.-Mural Timepiece, India Office.

It requires an effort to realise that such an impost prevailed but little over a century ago. Among other provisions of the Act was one declaring that every watch or clock maker or dealer in the cities of London and Westminster, the parishes of St. Marylebone and St. Pancras, the counties of Middlesex and Surrey shall pay an annual duty of two shillings and sixpence. In any other part of the country such a maker or dealer was let off by paying a shilling duty.

The produce was far from reaching the estimated yield, while the operation of the tax was such as nearly to ruin manufacturers. The demand for clocks and watches decreased to such an extent that in less than a year the general manufacture of these articles in the kingdom, and the various branches of trade connected therewith had diminished by one-half, and thousands of persons were deprived of employment. It is not, therefore, surprising that the Act was repealed in April 1798.

A writer in Notes and Queries mentions that he met with a printed form of receipt for a half-year's taxes, due from a small 
farmer in Essex, in which occurred the item, "for clocks and watches, 5.7 $\frac{1}{2}$." The receipt was dated 10th April 1798, the month in which the Act was repealed.

Although the imposition of this obnoxious tax paralysed the horological trades, it had the effect of creating one new kind of timekeeper; for tavern keepers, anticipating a scarcity of timekeepers among individuals, with one mind seem to have adopted a bold mural timepiece for the benefit of those who visited their public rooms. Mural timepieces with large dials were, of course, in use before 1797, and by favour of Sir George Birdwood I am enabled to represent in Fig. 819 a handsome one, which is now at the India Office. It was formerly at the entrance to the Special Assistants' Room at the House of the East India Company in Leadenhall Street, and dates from about 1725 . Mr. W. W. Hallam has a clock by Jasper Taylor in a similar case with lacquer decoration.

An "Act of Parliament" clock was altogether a plainer affair. It had usually a large dial of wood, painted black, with gilt figures, not covered by a glass, and a trunk long enough to allow of a seconds pendulum. In country inns and other places Act of Parliament clocks may still occasionally be

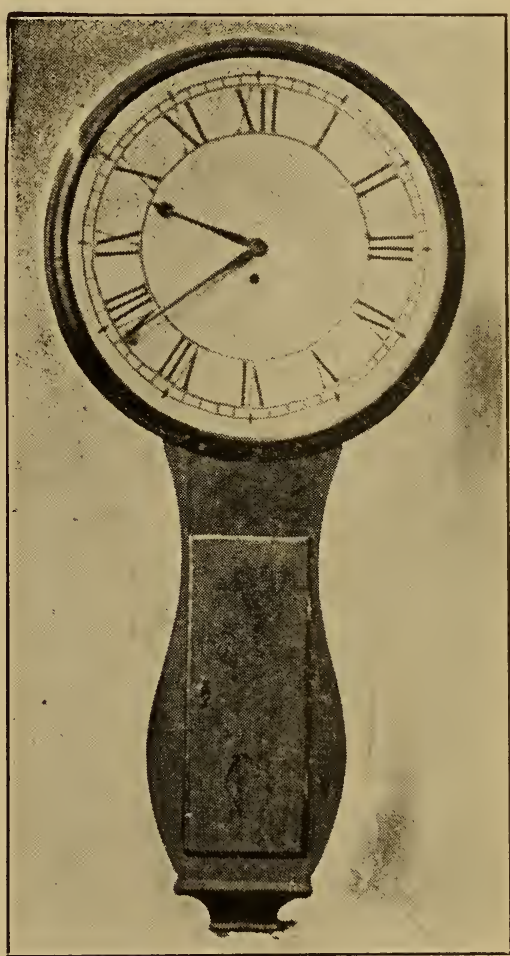

FIG. 820.- " Act of Parliament" Clock.

seen. The appended illustration (Fig. 820) of a specimen at Windsor Castle, with a white dial, is curious, inasmuch as the fourth hour is indicated by "IV." instead of the almost universal "IIII."

Watchmakers obtained from Parliament in 1798 some little recompense for the dire extremity to which they had been reduced, for from that time watch cases have been exempt from the plate duty. But watch manufacturers had nevertheless to continue the annual plate 
licence, [although watch-case-makers were absolved from the necessity of doing so.

In 1803 the licence underwent further alteration; for trading in gold over 2 dwts. and under $2 \mathrm{oz}$., or in silver over $5 \mathrm{dwts}$. and under $30 \mathrm{oz}$., an annual payment of $£^{2}$. $6 \mathrm{~s}$. was then demanded, and for trading in gold or silver articles above those weights an annual payment of $£ 5.15 \mathrm{~s}$.

Hogarth's Dial-I will append as a curiosity a strange dial published by William Hogarth in a paper called The Masquerade Ticket which appears to have been put forth as a satire on the position accorded to Heidegger, "Master of the Revels," whose head is drawn on the upper part of the dial. The date, 1727, is indicated by figures in the corners. The sketch is reproduced from John Ireland's "Hogarth Illustrated."

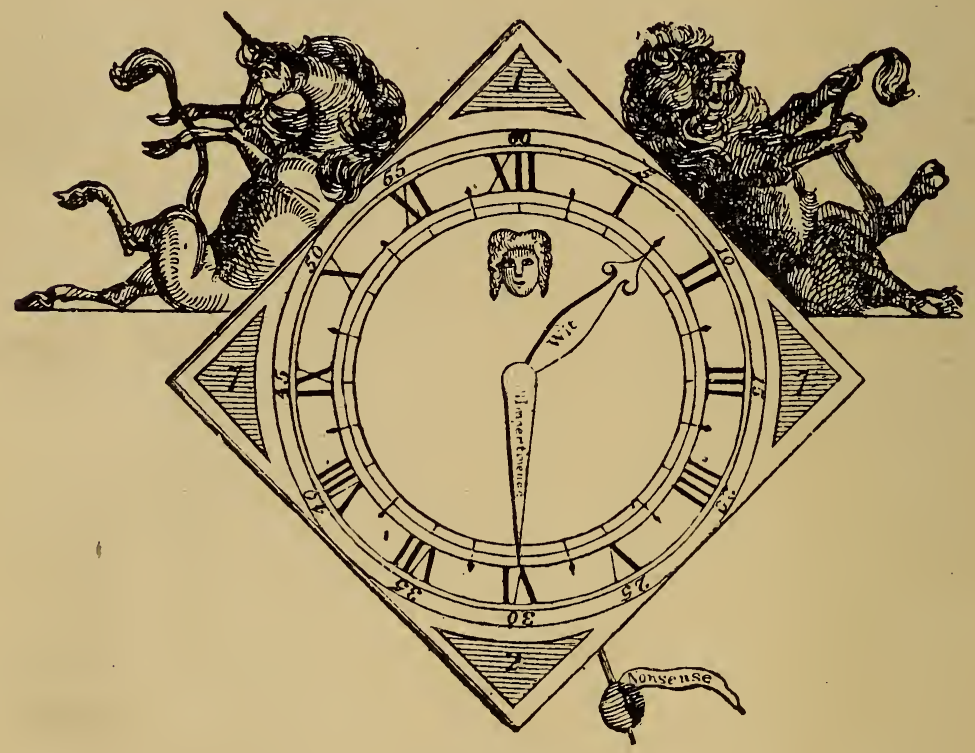

FIG. 821. 


\section{CHAPTER VIII}

\section{MECHANISM OF CI.OCKS AND WATCHES}

THE PENDULUM. - It is not certain who first used the pendulum as a controller for clocks. Galileo, the famous astronomer, in $\mathbf{1 5 8 2}$ remarked the synchronous vibrations of the lamps suspended by long chains from the roof of the cathedral at Pisa, and it is said that when blind he dictated to his son Vincent a method of using the pendulum as a timekeeper, which the latter carried out in 1649. From the drawing of this contrivance it seems to have been merely a train of wheels and a rude escapement to keep a pendulum in motion, in order to determine the time by counting its vibrations. It is shown in Fig. 822, and a working model of it is to be seen at South Kensington Museum.

In the Vienna Treasury is a clock dating from the early part of the seventeenth century, and furnished with a pendulum which it is contended was invented by the maker of the clock, J. Burgi, of Prague, who was appointed as clockmaker to Rudolph II. in 1602.

Then it is stated that Richard Harris constructed a turret clock with a pendulum for the church of St. Paul's, Covent Garden, which has since been burnt down. The authority for this statement rests chiefly on an engraved plate affixed in the vestry-room of the old church, with the following inscription on it:-

"The turret clock and bells of this church were made A.D. 1797, by Thomas Grignon, of Great Russell Street, Covent Garden, the son and successor of Thomas Grignon, who (A.D. 1740) brought to perfection what the celebrated Tompion and Graham never effected, viz., the horizontal principle in watches and the dead beat in clocks, which dead beat is a part of the mechanism of the turret clock. Thomas Grignon, senior, made the timepiece in the pediment at the east end of this parish church, destroyed by fire A.D. 1795. The clock fixed in the turret of the said church was the first long pendulum clock in Europe, invented and made by Richard Harris, of London, A.D. 1641, although the honour of the invention was assumed by Vincenzio Galilei, A.D. 1649, and also by Huygens in 1657. This plate is here affixed by Thomas Grignon, of this parish, 
the son of the above Thomas Grignon, as a true memorial of praise to those two skilful mechanicians, his father and Richard Harris, who, to the honour of England; embodied their ideas in substantial forms that are most useful to mankind."

It would be idle to treat this as conclusive evidence in favour of Harris ; still it is entitled to consideration, for the elder Grignon alluded to was regarded as a man of integrity. He was a con-

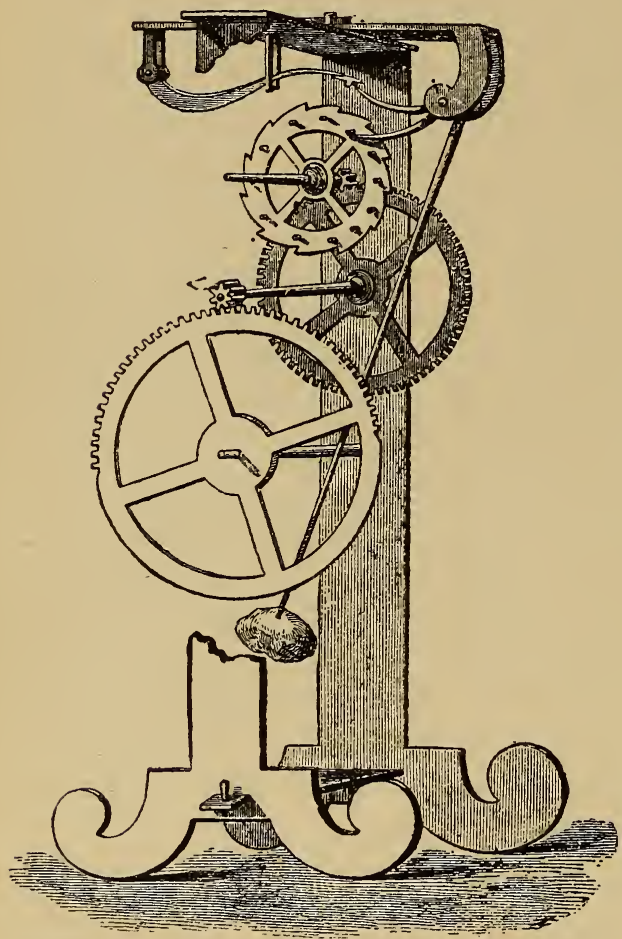

FIG. 822.-Galileo's method of using a pendulum as a timekeeper. temporary and friend of James Ferguson, and one of the first members of the Society of Arts, to which society he in 1759 presented a regulator, which is yet to be seen at the house of the Society in the Adelphi. Besides, that Galileo's observation would be followed by the application of a pendulum to a clock is only just what might have been expected. The weak part of the claim on behalf of Harris is that his application of a superior controller should have remained a solitary instance for twelve years or so, and have evoked no attention from scientists and others interested in the subject.

Huygens, it is certain, studied the action of the pendulum between 1650 and 1655, and demonstrated the fact that the path described as the centre of oscillation should be a cycloid for vibrations of varying extent to be passed through in the same time.

Dr. Hooke also saw the advantage of the pendulum about the same time, and proceeded to apply it.

- Fromanteel and others have also been named with confidence by their respective admirers as being entitled to the honour of introducing the pendulum; but indisputable proof of anyone's claim 
to originality in the matter there is none, and it is therefore useless to pursue this part of the subject further.

Striking Work.-Recording the completion of each hour by strokes on a bell has always been regarded as an important function of public timekeepers. In some of the early clocks, notably the first one at St. Paul's Cathedral, the sound of the striking was the sole indicator of time provided, and in many later edifices, where the exhibition of dials was considered to be incongruous with the general design, timekeepers similarly restricted have been adopted and their convenience appreciated. The Church of St. Vedast, Foster Lane, may be mentioned as an instance of a public building with a tower clock which struck but had no dial. Clocks striking the quarters as well as the hours are common enough, but Westminster Abbey furnishes a solitary instance of striking-work for the quarters only. This is done, not by the turret clock with the well-known exterior dial, but by the timekeeper in the Poet's Corner, which is also peculiar in being probably the largest spring clock ever made, for the barrels and fusees are each over $\mathbf{7}$ in. in diameter.

Some of the early Dutch and German clocks were furnished with two bells, one larger than the other, mounted on the top of the case. The hour was struck on the larger bell; the first quarter noted by one stroke on the smaller bell; at the half-hour strokes corresponding in number to the previous hour were given on the smaller bell, and the third quarter was proclaimed by one stroke on the larger bell. This plan has the advantage of giving fuller information than modern methods. Where one stroke is given at the half-hour, as in most modern French clocks, half-past twelve, one, and half-past one convey the same inexplicit signal.

Clocks by early English makers were occasionally made to indicate the half-hour by repeating on a smaller bell strokes corresponding to the hour last completed. Mr. J. Drummond Robertson has a timekeeper by Joseph Knibb so fitted. On p. 562 is mentioned a clock in the Wetherfield collection by the same maker in which the quarters are sounded on a smaller bell in an ingenious way.

Another and most excellent arrangement for striking on two bells, as carried out by Joseph Knibb, is described on p. 328 .

Unless altered very recently, the clock at the Church of St. Clement Danes, in the Strand, strikes each hour twice. The strokes are given first on a large bell, weighing $24 \mathrm{cwt}$., and then repeated on the Sanctus, a bell in the spire which is said to date back to the fifteenth century, and to have been one of the bells used before 
the Reformation. On account of the roar of traffic along the road, the striking cannot be heard except at night, and when it is heard the effect is curious, for the repetition appears to the uninitiated to be the tardy striking of another clock in some adjacent tower.

Clocks are occasionally to be seen which strike the hours from one to six four times over during the twenty-four hours. In many parts of southern Italy the hours were regularly sounded in this way.

The Japanese had a decidedly ingenious method of sounding the hour and half-hour, which is described on p. 473.

Should the present method of splitting the day in two periods of twelve hours each be abandoned in favour of continuous counting of the hours from one to twenty-four, the striking would possibly be rearranged, and the plans just described give a choice for selection.

The earliest device for causing the hours to be struck automatically appears to be the locking-plate construction, as shown in De Vick's clock. A modification of this principle, to ensure greater exactness by using quicker moving parts to unlock the striking train, is still the most favoured for turret clocks. For house clocks the rack principle invented by Barlow is generally preferred, because in this the striking corresponds with the position of the hands on the dial, whereas with the locking-plate the hours are sounded successively without regard to the hands.

Watch Movements.-Most of the early watches of pocket size were arranged to run for from twelve to sixteen hours between successive windings, the fusee making from ten to twelve turns. The train usually consisted of the great wheel which drove a pinion carrying the second wheel; the second wheel drove a pinion carrying the contrate wheel, and the last named drove the pinion carrying the escape wheel. The great wheel was fixed to its arbor, one end of which fitted loosely into a long hole in the larger end of the fusee; the other end was carried in a hole in that plate of the movement which is nearest the dial, and on the very extremity of this end was a pinion, usually of the lantern kind, gearing with a wheel whose pipe projected through the centre of the dial and carried the hand. Pinions having five leaves were, so far as my observation goes, almost invariably used for the train, and for the wheel teeth the following numbers: great wheel, 55: second, 45; contrate, 40 ; escape wheel, 15. A projection from the verge "banked" against the potence to prevent overrunning. There being a wheel and pinion less in the train than is usual now, the escape wheel ran 
the reverse way; its teeth and the verge therefore appear to be left-handed to the modern watchmaker.

John Fitter, about 1665, made a watch with the extra wheel and pinion, the contrate wheel of which turned once in a minute, but there is no doubt the longer train was not generally viewed with favour till the balance-spring was introduced in 1675 ; very soon after that date it became universal, together with wheel-work arranged for a run of thirty hours.

Among earlier and exceptional departures from the three-wheel train may be mentioned an unnamed watch in the Guildhall Museum which has four low-numbered wheels. The hand work consists of a three-leaved lantern on the great wheel arbor, driving a wheel of twenty-seven attached to the hand; the fusee being cut for

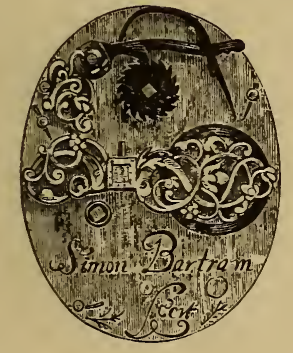

FIG. 823.-English Watch without Screws, about 1600 .

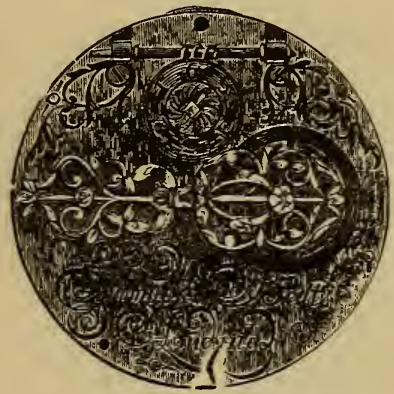

FIG. 824.-English Watch, about 1650 .

twelve turns, the watch would run for fifteen hours only. This specimen dates apparently from about 1650 .

Fig. 823 is a view of a very early-English watch movement, certainly not later, I think, than 1600 . There are no screws used in its construction, and the mainspring is adjusted by means of a ratchet and click. The train is of the numbers already given, the hand is driven by four pegs projecting from the great wheel arbor, acting with a hand-wheel of thirty-six teeth. The fusee makes barely eleven turns. Inscribed on the plate is the maker's name, "Simon Bartram." Either he or possibly his namesake and successor was appointed in the Charter of the Clockmakers' Company to be one of the Assistants," as the members of the Committee of Management were termed.

The first noticeable departure from the primitive arrangement 
was the adoption of a tangent wheel and.screw for the regulation of the mainspring, which was introduced about 1610 , and is shown in Fig. 824. On the barrel arbor above the tangent wheel is a disc of silver with divisions figured as a guide in setting the mainspring up or down; this adjustment being evidently used to regulate in some measure the timekeeping of the watch.

An alternative attempt at regulation before the advent of the balance-spring was to fix on a movable plate two pins to intercept the arms of the balance at longer or shorter arcs, as illustrated in Chapter III., pp. 79, 140 and 145.

A pendulum watch with a slit in the dial was illustrated on p. 232. This proved to be an inconvenient arrangement, but in the early part of the eighteenth century many watches were made

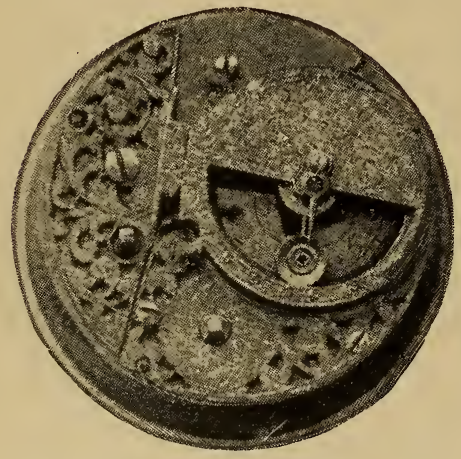

FIG. 825.-Watch with Cap over the Balance.

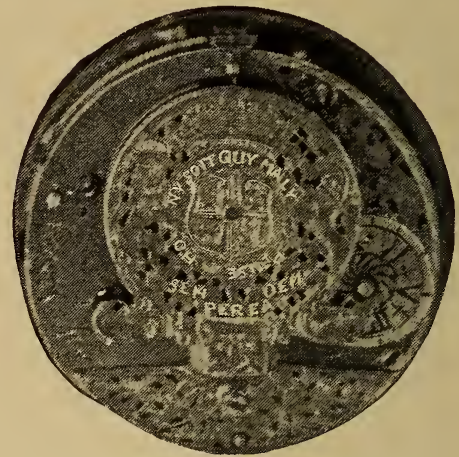

FIG. 826.-Watch with Royal Arms and Motto.

with a cap over the balance, as in Fig. 825. The arms of the balance were weighted, and a semicircular perforation in the cap allowed one weight to be visible, the motion of the weight as it vibrated resembling that of a pendulum. Pendulum watches having caps decorated with painting on enamel were very popular among Dutch makers. The watch illustrated is inscribed, " Flower, London,' and dates from about 1740 .

As a rule, movements of watches were completed without reference to the proximate owner, but an exceptional construction is shown in Fig. 826. The watch dates from about 1700, and is by "Massey, London." Around an heraldic shield bearing the royal arms is the motto, " HONI SOIT QUY MAL Y PENSE," and below, " SEMPER EADEM." It is of Queen Anne period.

The movement of the watch by Mitzell, of which a front view 
appears in Fig. 361, is covered by a silver plate, on which the royal arms with supporters are chased ; underneath is the motto, " Je Main Tiendrai."

The demand for verge watches continued till late in the nineteenth century, and they were made, to my knowledge, in Clerkenwell till 1882 ; the manufacture ceased then only because the verge finishers died out. The last specimens had lever cocks, because there was no one left to make the orthodox patterns.

Balance Springs.--The introduction of the balance-spring, which marks such an important epoch in the manufacture of watches, appears to be due principally to the investigations of Dr. Robert Hooke, about 1660. There is no doubt that Huygens and others also experimented with various materials to find a satisfactory controller for a vibrating balance. Huygens' labours in this direction may, of course, have been spontaneous, but, as recounted on p. 321, Hooke asserted that a communication from him to the Secretary of the Royal Society induced Huygens to turn his attention to the subject.

The engraving (Fig. 827) represents a watch of German origin from the collection of Mr. Willard $\mathrm{H}$. Wheeler. It has a-day-of-the-month ring, and is generally of the construction usual soon after the middle of the

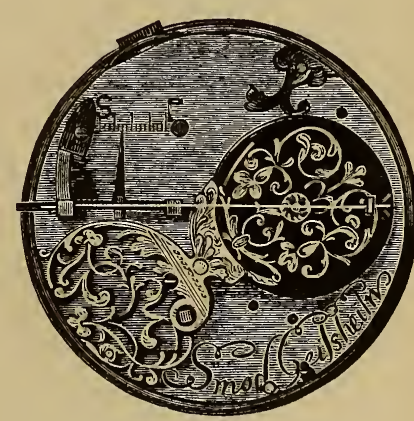

FIG. 827.-Hog's Bristle as a Balance Controller. seventeenth century. But the peculiar feature of the movement lies in the application of a straight hog's bristle to regulate the balance. There is no sign of any other spring having been attached, and the accessories of the bristle are quite in character with the rest of the work. There are two arms which embrace the bristle and practically determine its acting length, and by means of a screw these may be shifted to act over a considerable range.

Steel springs were, however, found to be the most suitable. The primitive straight ones would, of course, allow but a very small vibration of the balance, while the to-and-fro motion between pins where it made contact with the balance involved considerable friction. Of others, curved somewhat to the shape of a pothook, there are still examples, but eventually the more convenient and correct form was found to be a volute which had at first but one or 
two coils. The coils were increased to four or five as the advantage of a longer spring was understood, but the very long springs with which we are now familiar were not applied till the advent of the

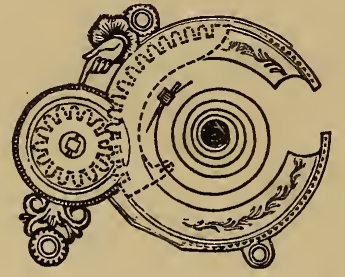

FIG. 828.-Tompion's Regulator.

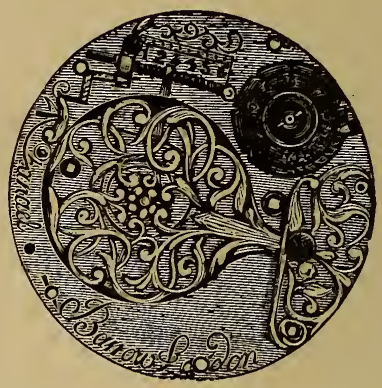

FIG. 829.-Barrow's Regulator.

lever and other detached escapements which allowed the balance to have a larger arc of vibration.

To lengthen or shorten the acting length of the spring, Tompion

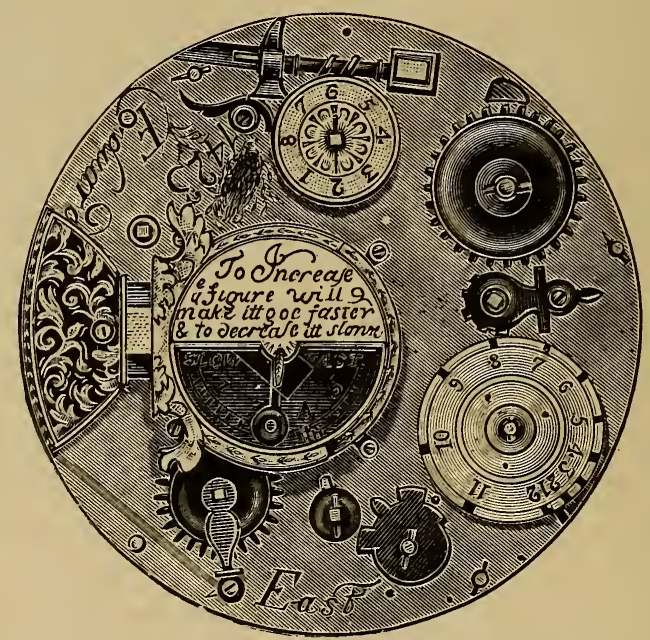

FIG. 830.-An early application of the Balance Spring.

appears to have used the circular slide with an index from the first. This arrangement, which remained in favour for a long period, is shown in Fig. 828. Below, and attached to a silver disc, graduated 
and figured as a guide to regulation, is a pinion which gears with teeth on the outer edge of the circular slide; from the inner edge projects an arm carrying two upright pins which embrace the spring. The projecting end of the pinion is square, so that it could be turned by means of a watch key.

In the Schloss collection was a clock-watch by Nathaniel Barrow, dating from about 1675 , in which the outer end of the spring is continued in a straight line to the stud at the edge ot the plate, and the regulation accomplished very much in the same way as the hog's bristle watch already delineated. Fig. 829 is a plan of this watch movement. The curved stud on the left is continued in a sort of zig-

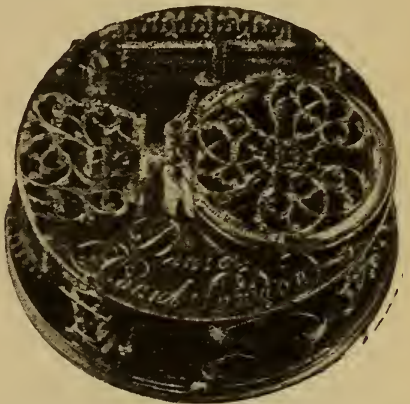

FIG. 831.-Movement with Regulator on Barrow's principle. zag shape to hold one end of the regulating screw. The upper end ot the nut points to an index engraved on the plate, and the lower extremity is notched to receive the spring.

An early application of the balance-spring with quaintly worded instructions for regulating is shown in

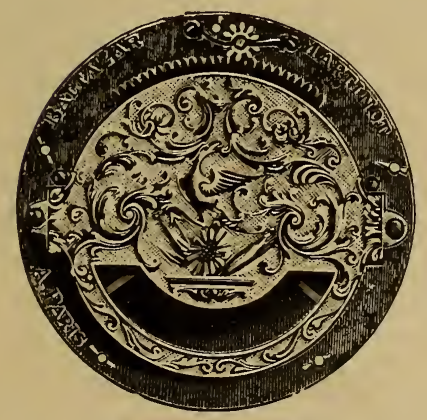

FIG. 832.-Watch, by Baltazar Martinot, showing early French arrangement of Balance-spring Regulator.

Fig. 830, which represents the movement of a large striking and alarm watch by Edward East.

A fine movement by Daniel Le Count, dating from 1680, and having a regulator on Barrow's principle, is shown in Fig. 831.

The chief drawback to Tompion's regulator is that, owing to the backlash or freedom between the teeth of the pinion and slide, a slight reversal of the index has no effect on the curb pins. The simple regulator now generally employed consists of a lever, fitting friction-tight over a boss on the balance cock; the shorter end of the lever carries the curb pins which embrace the balance-spring, while the longer end through which it is moved serves also as an indicator of alterations in the position ot the curb pins. This device was patented by Bosley in 1755 . 
There is one point about the stud used in those of Tompion's watches I have seen which might well be revived. The hole in the stud for the reception of the spring was square. The modern system of pinning, by squeezing the flat side of a spring against the surface of a round hole, is altogether unmechanical and must distort the spring.

Fig. 832 represents the top plate of an alarm watch by the celebrated French maker, Baltazar Martinot. The balance is very large, planted nearly in the centre of the plate and covered by a handsomely engraved bridge. The pinion and teeth of the slide for regulation of the balance-spring are uncovered, and no index appears to have been provided.

A very similar watch by one of the Habrechts of Strassburg has

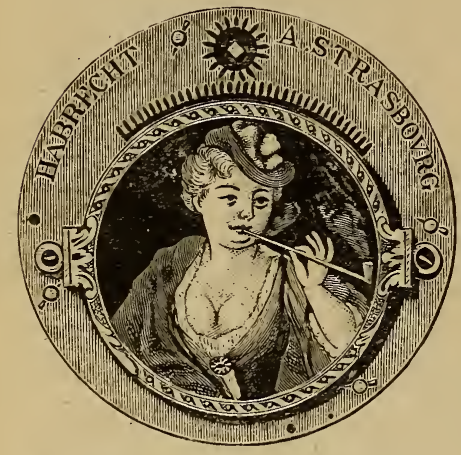

FIG. 833.-Watch, with painted bridge. the bridge covered with the picture of a woman smoking a pipe, as shown in Fig. 833. The painting is finely executed in enamel.

Watch Cocks. - The first of the cocks or brackets used to support one end of the balance-staff were probably quite plain, but so prominent a feature of the movement speedily became an object of enrichment. Of the early pierced and engraved designs examples are given in Figs. 823, 824, 827, 829, 831,429 . These range from the end of the sixteenth century to 1680 , and it will be observed that from its primal office of carrying the balance staff pivot the table of the cock was gradually spread to protect the balance from disturbance. In No. 1 of the subjoined Fig. 834, from a watch by "Jeremie Johnson, Royal Exchange," dating from about 1685, the edge of the table is of a plain circular form and coincident with the outside of the balance rim ; the foot is very wide, but its outer edge is carved, and would not correspond with the outline of the plate, to which it would be screwed.

No. 2 is from a watch by Thomas Windmills, dating from about 1700. Here the outside of the foot followed the curve of the plate. The narrow neck at the junction of the table and the foot seen in this and in the preceding example appears to have been originally provided as a space for pinning the cock to a stud and to have 
survived the introduction of screw fastenings. The floral pierced work in No. 1 and No. 2 is very similar, but the basket or pot in the first is in the latter discarded for a mask, and from this period heads or masks seem to have been incorporated with most of the designs so long as the pierced cocks lasted. Curiously enough, the streamers at the sides of the basket, which look appropriate, are incongruously retained with the head; still, the streamers and masks were associated for thirty or forty years. About 1720 , cocks with solid feet were made, though the pierced variety is met with till about 1770 .

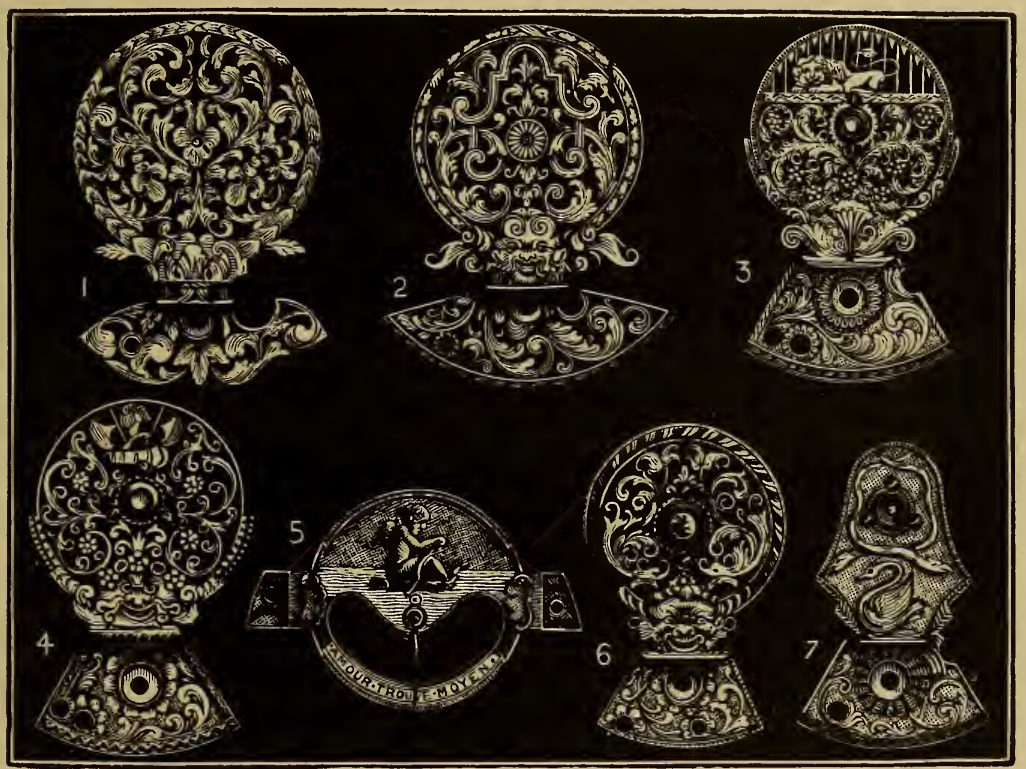

FIG. 834.-Examples of early pierced and engraved Watch Cocks.

No. 3, with a jewelled centre and a representation of a lion in a cage, dates from about 1770 , and No. 4 , with the military emblems, from 1780.

With few exceptions, French and Dutch manufacturers used a bridge instead of a cock. No. 5, a pretty specimen, is from a pendulum watch made about 1740 . Others are shown on pp. 198, 238, and 607 . On pp. 238 and 608 are two finely enamelled.

The beautiful pierced work was unable to withstand the utilitarian spirit of the nineteenth century, though it died hard. No. 6 is from a watch by James Wild, London, with the hall-mark for 1788 . The 
solid lever form of cock (No. 7) was taken from a verge watch with the hall-mark of 1826. A few years ago a taste for watch cock necklaces, brooches, and bracelets arose, and thousands of interesting movements were destroyed in mad haste to supply material for an evanescent fancy.

Watch Pillars.-Though the pillars which connect the two plates of a watch movement are now universally made of a plain cylindrical form, they have been formerly the subjects of considerable enrichment. In most of the early movements of a small size the pillars were round; the larger ones were usually square, and often engraved; but one of the first obvious departures from the utilitarian form in of der to please the eye is shown in No. 1 of the subjoined engraving. This is known as the tulip pillar, and seems to have been introduced in deference to what may be called the tulip mania, which followed the introduction of tulip bulbs into England and led artists to incorporate the flower with almost every kind of decoration. For about twenty-five years from 1676 many of the finest watches

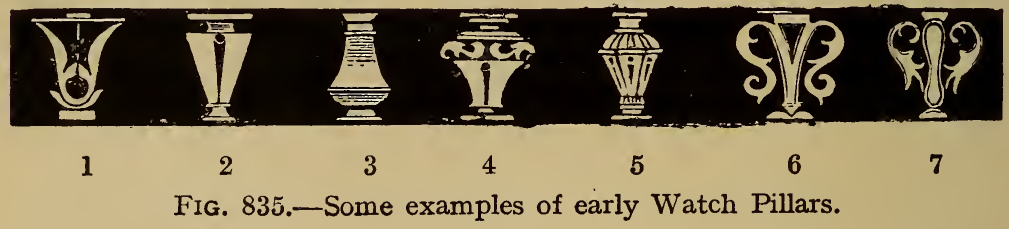

were made with tulip pillars. In some instances the vertical division shown in the engraving was omitted. The square Egyptian pillar, No. 2, was introduced about 1640, and continued in use for many years, the central slit being often wider than the example, with a vertical division and decorations on the face ; silver was the material favoured for the decorations and divisions. Occasionally in an extra wide division a head or bust would be inserted. The plainer square pillar, No. 3, had also a long life, for it is met with in watches nearly two hundred years old, and also in specimens produced in the early part of the nineteenth century. No. 4 is a form favoured by Dutch and some English makers from about 1730 to 1770 , and is occasionally seen applied to much later productions. Pillars like No. 5, dating from the first half of the eighteenth century, are more often seen in French and German watches than in English, and are often of silver. No. 6 is taken from a watch by Ellicott, the case of which has the hall-mark of 1746, and the elegant outline is quite in accord with the popular taste at that time. No. 7 is a little later, and is taken 
from a watch by John Markham, a well-known maker for the Dutch market. During the period devoted to fancy pillars, repeaters and clock-watches where room was an object did not usually conform to the popular taste in this particular, but were furnished with plain round pillars, having small bodies and collars formed at the top and bottom, to afford a more secure bearing on the plates.

Escapements.-The verge, the earliest escapement, was explained on p. 33. About $\mathbf{1 6 6 0}$ the Abbé Hauteville invented the "Virgule," illustrated in Fig. 836. Its action will be understood by those conversant with escapements. Dr. Hooke invented the anchor escapement, which was applied to clocks by William Clement about 1676 . Graham subsequently introduced the improvement known as "deadbeat." Tompion devised a form of watch escapement shown on p. 282 and subsequently were introduced, among others, the cylinder and duplex. In accordance with my promise to avoid technicalities and modern construction, I do not propose to descant on these; they are dealt with fully in the "Watch and Clock Maker's Handbook." The best of all watch escapements, the lever, which Mudge invented and applied to a watch for Queen Charlotte, was analogous in its action to the present form of double roller

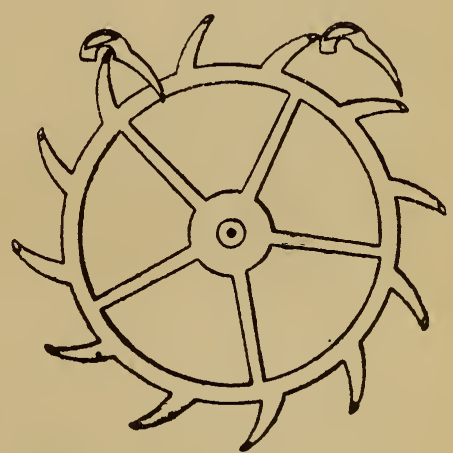

Fig. 836.-Virgule Escapement. escapement, except that the locking faces of the pallets were circular as in the dead-beat clock escapement of Graham. The impulse pin was divided, for the purpose of ensuring the safety action after the finger enters the crescent, and before the impulse pin is fairly in the notch, a result now attained very simply by having horns to the lever. Curiously enough, the advantages of Mudge's invention seem to have remained unrecognised for many years, except by a few of his watchmaking friends. George Margetts and Josiah Emery seem to have been impressed with it, and the latter made for Count Bruhl a watch furnished with a lever escapement on Mudge's plan, which performed so satisfactorily that Emery was induced to continue its use. In 1793 he told a committee of the House of Commons appointed to inquire into Mudge's claim to the Government reward that he had made thirty-two or thirty-three such watches, and that his price for them was $£ 150$ each. 
By favour of Mr. George Burrell, I had the privilege a short time ago of inspecting a very fine watch which Emery made for the Duke of Portland. It had a lever escapement with straight locking faces to the pallets, angled so as to be drawn into the wheel by pressure, and a second roller for the safety action, practically similar to the arrangement in first-class timekeepers of to-day. The impulse pin was of steel and pivoted in jewel holes, so that it rolled in and out of the notch. The watch, Mr. Burrell said, was originally hung in gymbals in a wooden box. Mr. J. J. Hedgethorne has a similar watch by Emery.

In the collection of the Clockmakers' Company at the Guildhall is an interesting watch by John Leroux, of Charing Cross, who was admitted an honorary freeman of the Company in 1781. This watch, by the hall-mark in the case, was made in 1785, and the peculiar

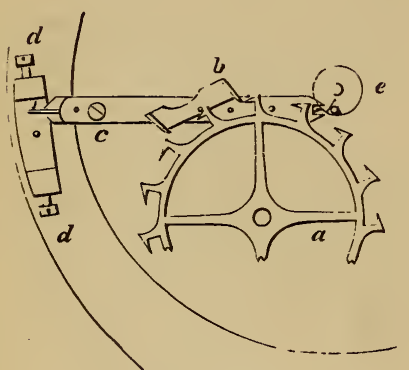

FIG. 837. leier. $d d$. Banking screws. $e$. The detaining roller, below which, on the same axis, is another roller or disc with a ruby pin, 2 s usual, for receiving impulse from the lever fork. a. The wheel. b. The pallets. $c$. The

feature of it is the escapement, which is a lever, but the pallets are of unusual form and act with teeth resembling those of the cylinder escapewheel, as shown in Fig. 837.

Peter Litherland in 1791 patented the rack lever escapement, in which the lever terminates in a segmental rack which gears with a pinion on the balance axis. Although this was an undetached escapement, and therefore wanting in the chief excellence of Mudge's conception, it met with considerable success, a large number being made at Liverpool, in the early
$y$, chiefly for the American market.

part of the nineteenth century, chiefly for the American market.

About 1800, Edward Massey, a Staffordshire watchmaker, invented the crank roller, in which the impulse pin is projected beyond the periphery of the roller, something like the finger in the going barrel stopwork. Contact of the extremities of the lever with the edge of the roller formed the safety action. The final perfecting of the table roller variety is ascribed to George Savage, a Clerkenwell watch finisher, some years afterwards.

Watch Jewelling.-In the early part of the eighteenth century was introduced the practice of using highly polished surfaces of hard stone for the bearings of the smaller quickly moving watch pivots and other rubbing contacts.

In 1704 a patent was granted to Nicholas Facio, Peter Debaufre, 
and Jacob Debaufre, for the application of jewels to the pivot holes of watches and clocks. Facio, the inventor, was a native of Basle, where he was born in 1664, coming to England in the early part of 1687. Here he seems to have busied himself with scientific pursuits, and towards the end of the century he was elected a Fellow of the Royal Society. His co-patentees were watchmakers, living in Church Street, Soho, and an advertisement in the London Gazette of 11th May 1704 announced that jewelled watches were to be seen at their shop, stating also that they made "free watches." A watch bearing the name of "Debauffre" is to be seen at the South Kensington Museum. Before the patent was many months old, the patentees applied to Parliament for a Bill to extend it; but this was opposed by the Clockmakers' Company, and on evidence produced by them a committee of the House of Commons recommended that the Bill be rejected. In reporting the successful result of their opposition, the master of the Clockmakers' Company acquainted the court that in the proofs brought against the Bill, there was an old watch produced, the maker's name Ignatius Huggeford (or Huggerford), that had a stone fixed in the clock and balance work, which was of great use to satisfy the committee.

But the best of the story has yet to be told. In recent years Huggeford's watch was taken down by Mr. E. J. Thompson, a member of the court of the Company, and he reported that "The movement is not in any sense jewelled, the verge holes being of brass. A piece of coloured glass or soft stone, fastened in a disc of silver and burnished into a sink in the steel cock, gives a fictitious appearance of jewelling."

About 1720 Facio settled at Worcester, where he died at the age of ninety, and was buried at St. Nicholas' Church in that city in $\mathbf{1 7 5 3 .}$

Compensation.-Variation in the elasticity of the balance-spring when subjected to changes of temperature proved a fruitful source of trouble to horologists after the application of that most useful adjunct. Harrison's account of his "Thermometer Kirb" is given on p. 345. Mudge strove to avoid the difficulty of regulation experienced by Harrison by using two balance-springs, as stated on p. 356. Breguet invented a compensation curb on Harrison's principle, but shaped like a quadrant in order to get a greater length of laminæ, and therefore more action. One end of the quadrant was fixed to the index and the other carried one of the curb pins, which by the movement of the laminæ in changes of temperature was caused to recede from or approach the fixed curb pin, and thus to give more or less liberty to the spring. Various compensation 


\section{I4 Old Clocks and Watches and their Makers}

balances from the time of Arnold are illustrated in "Watch Springing and Adjusting," and need not be repeated here.

Evolution of Winding Mechanism for Watches.-One of the first references to winding without opening the case of a watch is to be found in an advertisement which appeared in the London Gazette for 10th13th January, 1686 where a watch by R. Bowen, London, is described as having one motion, and the spring being wound up without a key, and it opening contrary to all other watches. Then in Overall's "History of the Clockmaker's Company" it is stated that in 1712 John Hutchinson desired to patent a watch which, among other improvements, " has likewise a contrivance to wind up this or any other movement without an aperture in the case through which anything can pass to foul the movement." The Clockmaker's Company opposed the application, and a committee of the House of Commons examined witnesses, among others George Graham and Charles Goode. Mr. Goode produced a movement made fourteen years before. Mr. Hutchinson confessed Goode's movement was like his, and eventually withdrew his application.

The next in order is Pierre Augustin Caron, a clever watchmaker of Paris, who in 1752 made for Madame de Pompadour a very small watch, which gained for him a prize from the Academy of Sciences. This appears to have been wound either by turning the bezel or with a slide very similar to the winding slide now used for repeaters. A translation of his description is as follows: "It is in a ring, and is only four lignes across and two-thirds of a ligne in height between the plates. To render this ring more commodious, I have contrived, instead of a key, a circle round the dial carrying a little projecting hook. By drawing this hook with the nail two-thirds round the dial, the watch is re-wound and it goes for thirty hours." Caron was an accomplished musician as well as a playwriter, and is better known under the name of Beaumarchais, as the author of "Le Barbier de Séville" and "Le Mariage de Figaro."

In 1764 Frederick Kehlhoff, of London, patented a centre-seconds and going barrel watch with a stackfreed remontoir. A watch on this plan by him was wound by turning the bow, the arbor of which terminated in a contrate wheel gearing with an intermediate wheel which engaged with a wheel on the barrel arbor; but nothing was said in his patent respecting the keyless work.

Lepine, who was associated with Voltaire in the establishment of a watch factory at Ferney, in Switzerland, devised a method of winding in which the button at the pendant was turned partly round 
and then pushed in several times till the winding was completed. This was the first of a series of what is known as "pumping" keyless actions.

In 1792 Peter Litherland, who patented the rack lever, claimed (patent No. 1,889) " winding up watches, \&c., by means of an external lever connected by mechanism by the barrel arbor."

Robert Leslie, in 1793, patented (No. 1,970) another pumping keyless arrangement. His claim says: "On the square on which the key should go is a ratch; the pendant, being alternately moved in and out, turns this ratch by means of two clocks on either end of a fork fastened to the pendant."

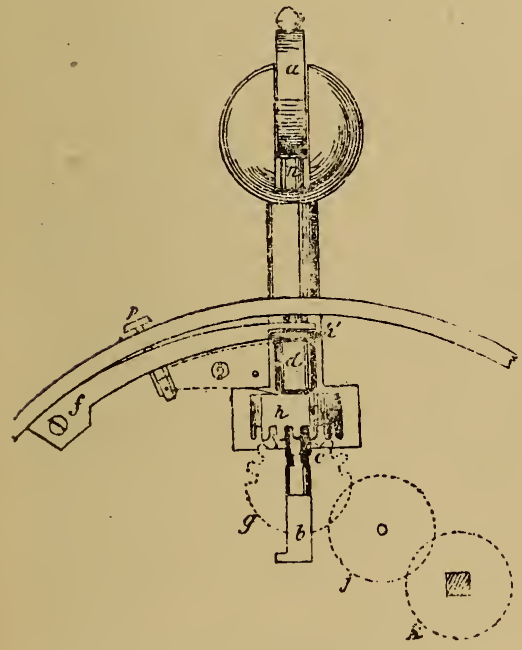

FIG. 838.

A watch, dating from about 1790, signed "Jacquet Droz, London," which is shown in Fig. 320 , is furnished with winding work of this kind.

J. A. Berrollas, in 1827 (No. 5,586), patented a somewhat similar contrivance, but used a chain coiled round the winding wheel. I wore for some years a duplex watch by Ganthony with this keyless work, and it answered well.

Edward Massey in 1814 $(3,854)$, Francis J. Massey in $1841(8,947)$, and Edward Massey again in $1841(9,120)$, patented varieties of pumping keyless work.

Charles Oudin exhibited at Paris in 1806, an arrangement shown in Fig. 838: $k$ is the barrel, $j$ and $g$ intermediate wheels gearing with the contrate pinion $h ; a$ is a disc at one extremity of the rod $n b$. The rod is supported by the cock $d$, and has two grooves, into one of which the spring $f$ presses, according to the position of the rod. One of these grooves is seen at $c$, the other is hidden, owing to the position in which the parts are shown. When out of use the disc $a$ forms part of the ball of the pendant. In order to wind, the $\operatorname{rod} n b$ is pulled up until the nib at the end of $b$ comes in contact with the interior of the pinion $h$, where there is a catch; the spring $f$ then falls into the groove $c$, and then the wis ding is accom- 
plished by turning the ball at $a$. There was no provision for setting hands.

Thomas Prest, foreman to J. R. Arnold, at his Chigwell chronometer factory, patented in 1820 (No. 4,501) a very similar arrangement to the foregoing as far as the winding is concerned, but no provision was made for disconnecting the wheels from the pendant knob.

A. L. Breguet applied winding work to many of his watches, and an arrangement to connect with the motion work for setting hands by pulling out the bow.

Isaac Brown, in $1829(5,851)$, patented a winding-rack attached to the bezel, the bezel being moved round to wind.

Adrien Phillipe, in 1843, invented the shifting sleeve keyless mechanism. Lecoultre and Audemars subsequently made alterations: the present construction of shifting sleeve mechanism is, however, similar in principle to the device of Phillipe.

Adolope Nicole, in 1844 , patented $(10,348)$ a fusee keyless work in which a knob on the pendant was pushed in to make connection with the fusee wheel, and pulled out to connect with the minute wheel.

The rocking bar mechanism for winding and setting hands was patented in $1855(2,144)$ by Gustavus Hughenin.

Self-Winding Watches.-Several methods have been devised for automatic winding, of which two examples are given.

Fig. 839 shows an arrangement by Lebet for winding a watch by the action of closing the hunting cover. There is a short gold arm projecting beyond the joint. This arm is connected by means of a double link to a lever, one end of which is pivoted to the plate. To the free end of this lever is jointed a scythe-shaped rack, which works into a wheel with ratchet-shaped teeth on the barrel arbor. A weak spring fastened to the lever serves to keep the rack in contact with the wheel teeth. Instead of the ordinary fly spring, there is a spring fixed to the plate and attached by means of a short chain to the lever. As this spring pulls the cover open, the teeth of the rack slip over the teeth of the wheel on the barrel arbor. Each time the wearer closes the cover, the watch is partly wound. By closing the case eight or nine times, the winding is completed. The ordinary method of hooking in the mainspring would be clearly unsuitable with this winding work, because after the watch was fully wound the case could not be closed. Inside the barrel is a piece of mainspring a little more than a complete coil with the ends overlapping, and to this piece the mainspring hook is riveted. The adhesion of the loose turn of the mainspring against the side of the barrel is sufficient to drive the watch, but when the hunting cover is closed after the 
watch is wound, the extra strain causes the mainspring to slip round in the barrel.

The method of winding just described can be applied only to-a hunting watch. Fig. 840 represents a watch by Breguet with what is known as a pedometer winding. Louis Recordon, in 1780, patented it (No. 1,249), and it has been several times re-invented. The motion of the wearer's body is utilised for winding. There is a weighted lever, pivoted at one end and kept in its normal position,

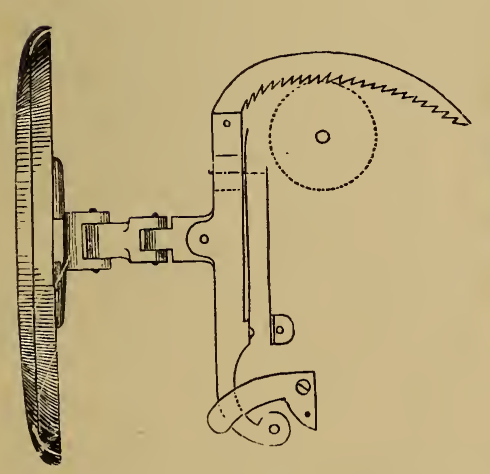

FIG. 839.--Self-winding Watch Mechanism to act on the closing of the Hunting Cover.

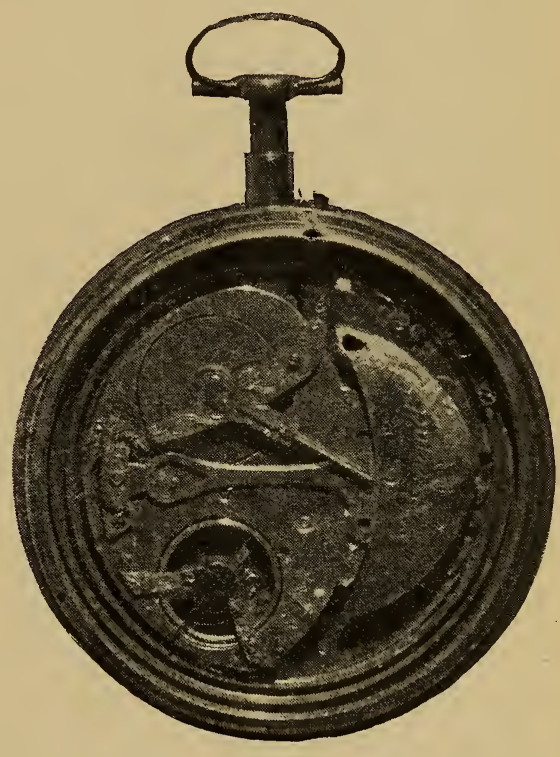

FIG. 840.- Self-winding or " Pedometer" Watch, by Breguet.

against the upper of two banking pins by a long curved spring so weak that the ordinary motion of the wearer's body causes the lever to oscillate continually between the banking pins. Pivoted to the same centre as the weighted lever is a ratchet wheel with very fine teeth, and fixed to the lever is a pawl, which engages with the ratchet wheel. This pawl is made elastic, so as to yield to undue strain by the endeavour of the lever to vibrate after the watch is wound.

Repeating Watches.-While the striking mechanism of clockwatches such as were produced by many of the early makers was founded on that used in De Vick's clock, repeating watches were similar in principle to the rack striking work for house clocks invented 
by either Barlow or Quare. The number of hours or quarte1s struck depends on the position of the snails which revolve with the timekeeping mechanism. The hammers were actuated by a separate mainspring, which was wound every time it was desired that the watch should repeat. This was done by pushing the pendant in. Connected to the inner end of the pendant was a chain coiled round a pulley attached to the mainspring barrel, and also a lever, which, by coming in contact with the snail, stopped the pendant; so that the mainspring was wound much or little according to the number of blows to be struck.

The chain was found to be the most unsatisfactory part of the mechanism, and at the beginning of the eighteenth century Matthew Stogden substituted a rack for it. Other alterations have since been made in the arrangement, one of the chief being the winding of the mainspring by means of a slide projecting from the band of the case. Barlow and Quare used a bell shaped to the inside of the case, such as had been used before their time for clockwatches; wire gongs, introduced by Julien Le Roy, are now used instead.

Graham introduced a " pulse piece," which, upon being pressed, kept the hammers off the bell, but allowed the time to be ascertained by counting the throbs or beats on the pulse piece.

Dumb repeaters, said to have been invented by Julien Le Roy, had neither bells nor gongs, the blows being struck on a solid block fixed in the band of the case.

In 1804 John Moseley Elliott patented (No. 2,759) an ingenious device for dispensing with the repeating train, as well as striking the hours and quarters and other subdivisions with one hammer. By turning a rod running through the pendant to the right, a pallet on the inner end of it moved round a lever till it came in contact with the hour snail, and while this was being done, each of the teeth of a ratchet wheel also mounted on the inner part of the pendant rod, engaged with the hammer stalk and caused it to strike on the bell. The number of blows struck depended, of course, on the position of the hour snail. By turning the pendant to the left, another lever was carried to the quarter snail, and the required number of quarters struck in like manner.

The time might in this arrangement be ascertained without a bell, by first turning the pendant rod as far as the snail allowed, and then reversing it and counting the number of clicks or obstructions caused by engagement with the ratchet. The elder Grant made some dumb repeaters on this plan. 
Musical Watches.-On pp. 232 and 239 are shown musical watches. They must be distinguished from repeaters or other watches which strike notes on gongs. They are provided with pins rising from a metal disc as shown in Fig. 841. The disc rotates and each pin in turn catches the free end of a steel spring of such a length and thickness as to yield the required note. The music may be let off by the striking-work at every hour or at pleasure by a pin which would project through the band of the case, or in both ways. A separate barrel is provided to drive the

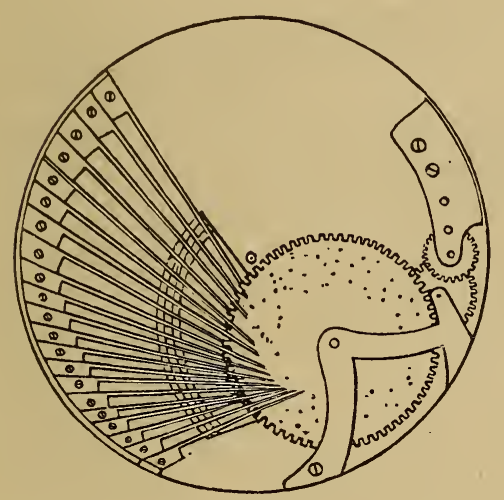

FIG. 841.-

Mechanism of Musical Watch. music disc and moving figures if any. The device is, I believe, of Swiss origin.

Hall - Marks. - These marks are impressed on watch cases, jewellery, and plate after the quality of the metal has been ascertained by assay at certain official Assay Halls. The marking of jewellery is, with few exceptions, optional. The hallmarking of all watch cases of gold or silver made in Great Britain and Ireland is compulsory. The cost is only the actual outlay incurred in assaying and stamping. The hall-mark consists of several impressions in separate shields : there are the standard or quality mark; the mark of the particular office at which the article was assayed; some character by which the date of marking may be traced, and, if duty is chargeable, the head of the reigning sovereign.

The oldest and most important of the Assay Halls is that presided over by the Goldsmiths' Company of London, which is situated in Foster Lane, just at the back of the old General Post Office, St. Martin's le-Grand. The privilege of assaying and marking precious metals was conferred on the Company by statute in 1300 . The Company received a charter of incorporation in 1327, and their powers have been confirmed subsequently by several Acts of Parliament.

Many early watch cases, especially silver ones of London make, are met with which have no hall-mark, the powers of the Company not being so strictly enforced then as now, or the value of the official assay not being so generally recognised. 
Repoussé cases, with other artistic wares of a similar character, are specially exempted from assay.

It was not till 1798 that a lower standard of gold than 22 carat was allowed; 18 carat was then recognised; in 1854 three further standards, 15, 12, and 9 carat were introduced.

The standard mark of the London Hall is a lion passant for sterling silver. A lion passant was also the standard mark on 22-carat gold up to $1845^{\circ}$.

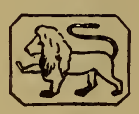

For gold of 22 carats the standard mark is now a crown, and the figures 22. For 18-carat gold the standard mark is a crown and the figures 18.

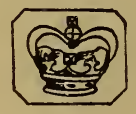

For 15-carat gold 15 and 0.625 Pure gold being 24 carats, these decimals $\left.\begin{array}{llrll}\# 12 & 12 & 12 & 0 \cdot 5 \\ & 9 & 9 & \# & 0 \cdot 375\end{array}\right\}$ represent the proportions of pure gold in the article so marked.

The London Hall-Mark prior to 1823 was a crowned leopard's head; from lst January 1823 it was uncrowned; specimens of both styles are appended.
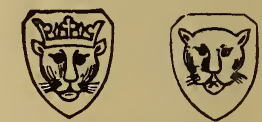

Date-marks of the London Hall, given on pp. 622, 623, are, with one or two exceptions, actual reproductions which I have made from watch cases. Specimens of the earliest marks are not to be obtained.

There was a duty on silver articles of sixpence an ounce from 1719 till 1758, but no special duty-mark; in 1784 a similar duty was imposed, and then the head of the reigning sovereign was impressed to denote the payment of duty. The Act came into operation on 1st December 1784, and at first the head had a curious appearance, being incised, or incuse as it is called, instead of in relief as the other marks were. Cases with the London mark and the letter $\mathrm{K}$, which corresponds to the period from May 1785 to May 1786, have the duty head incuse, after which the head appears in relief with London marks. The wardens of the Birmingham Assay Office have a pair of cases with the head incuse, and the Birmingham mark with the letter $\mathrm{N}$, which would denote the period from July 1786 to July 1787. In 1804 the duty on silver was increased to 1s. $3 \mathrm{~d}$., and on gold to 16s. an ounce. In 1815 a further increase to $1 \mathrm{~s}$. $6 \mathrm{~d}$. and 17s. 6d. respectively was made, and the duty continued at these amounts till 1890, when it was finally abolished. Watch cases were exempted from duty in 1798.

The maker's mark before 1697 was some emblem selected by him ; in that year it was ordered to be the first two letters of his surname; 
since 1739 it has been the initials of the maker's Christian and surnames.

On 25th March 1697 the quality of standard silver was raised from $11 \mathrm{oz} .2$ dwts. to $11 \mathrm{oz} .10 \mathrm{dwts}$. of pure silver in $12 \mathrm{oz}$. of plate ; a lion's head erased was then used as the standard-mark, and a figure of Britannia as the hall-mark; but on 1st June 1720 the old standard of $11 \mathrm{oz} .2 \mathrm{dwts}$., and the old marks of a lion passant and a leopard's head were reverted to, although the higher standard with the figure of Britannia is till occasionally used.
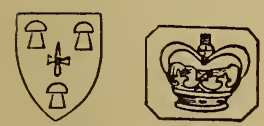

Marks of other Assay Offices. - Chester. - Hall - mark, a sword between three wheatsheaves. Prior to 1779 it was three demi-lions and a wheatsheaf on a sbield. Standard mark for 18-carat gold, a crown and the figures 18. For silver, a lion passant. Before 1839 a leopard's head in addition. Chester date-marks are given on p. 625 .
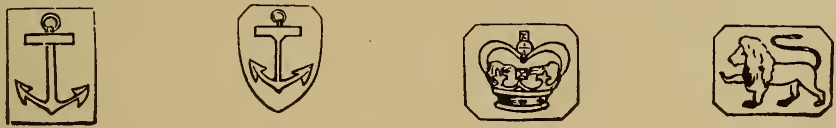

Birmingham.-Hall-mark, an anchor in a square frame for gold, and an anchor in a pointed shield for silver. Standard-mark for 18-carat gold, a crown and the figures 18 ; for silver, a lion passant. Birmingham date-marks are given on p. 624 .

Sheffield.-A York rose and a crown.

Exeter.-A castle with three towers.

York.-Five lions on a cross.

Newcastle - Three castles.
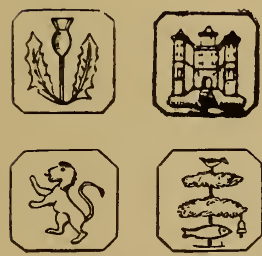

Dublin.-A harp crowned as the standardmark for sterling silver and for 22-carat gold, with the figures 22 added in the latter case ; for 20 -carat gold, a plume of three feathers and 20 ;
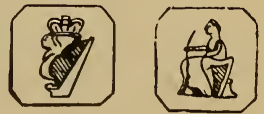

for 18-carat gold, a unicorn head and 18. The lower qualities of 15 , 12 , and 9 are marked with the same standard-mark as is used at the London Hall. The hall-mark for Dublin is a figure of Hibernia. 
622 Old Clocks and Watches and their Makers

DATEMMARK ON GOLD AND SILVER PLATE AND WATCH The shields represented in the subjoined tables are those used for shield is invariably in the shape of a rectangle, with the Note.-The Date-Mark is altered on the 30th of May in the 30 th of May in

\begin{tabular}{|c|c|c|c|c|c|}
\hline 10 & ] $*$ & & & & \\
\hline & 1697 & & & & \\
\hline 10 & 16 & 18 & $\sqrt{1}$ & & \\
\hline 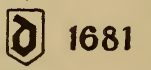 & & & & & \\
\hline 16 & & & 5 & & \\
\hline & & & $\langle\mathbf{I}\}$ & & \\
\hline & (3) & & & & 1 \\
\hline 16 & & & (1) & & \\
\hline 16 & 8 & (I) 1 & [i] 1 & (⿹丁口) & \\
\hline $168 y$ & & (K) 1725 & 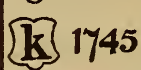 & 囼 & (k) \\
\hline 1688 & 1 & & 15 & (2) & \\
\hline 39 & & & $\geqslant 1$ & 01 & i) 1 \\
\hline 16 & 通 & & n & & \\
\hline 1691 & (1) & (0) 1 & [] & (D) & \\
\hline & 10 & (P) 1 & & & 1 \\
\hline 1693 & . & $\sqrt{9}$ & |ri & (Q) & $\pi$ \\
\hline & & & & & $\lambda^{\prime}$ \\
\hline & & & & & (5) 17 \\
\hline \multirow[t]{2}{*}{1696} & $1 \mathrm{~A}$ & & 754 & $\pi$ & 175 \\
\hline & & & & (i) 1 & $1 / 5$ \\
\hline
\end{tabular}

* This letter appears to have been used only from March to May 1697. Britannia and a lion's head erased was used instead of the $\dagger$ Watch cases marked between December 1784 and May 1798 would 
CASES MARKED AT GOLDSMITHS' HALL, LONDON.

silver and for 22-carat gold. For lower qualities of gold the corners taken off like the one surrounding the $A$ in 1876.

each year, lasting from the date indicated in the Table till the following year.

\begin{tabular}{|c|c|c|c|c|c|c|}
\hline (A) 1796 & (a) 1816 & (a) 1836 & (a) 1856 & (A) 1876 & $\begin{array}{ll}\text { (a) } 1896 \\
\end{array}$ & 10 \\
\hline B) 1797 & (b) 1817 & (iB) 1837 & (b) $185 y$ & (B) $187 y$ & (b) 1897 & h \\
\hline C) 1798 & (C) 1818 & (if) 1838 & (C) 1858 & (C) 1878 & (C) 1898 & \\
\hline (D) 1799 & (d) 1819 & (iid) 1839 & (d) 1859 & (D) 1879 & (d) 1899 & \\
\hline (E) 1800 & e 1820 & (iR 1840 & (D) 1860 & (E) 1880 & (e) 1 & \\
\hline F 1801 & (f) 1821 & (fit) 1841 & (โ) 1861 & (F) 1881 & f & \\
\hline (G) 1802 & (g) 1822 & (10.6) 1842 & (g) 1862 & (G) 1882 & (g) 1902 & \\
\hline (H) 1803 & (h) 1823 & (国) 1843 & (b) 1863 & 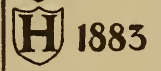 & (h) 1903 & \\
\hline (I) 1804 & (i) 1824 & (3) 1844 & (i) 1864 & (I) 1884 & & \\
\hline (K) 1805 & (k) 1825 & 樞 1845 & (田) 1865 & (K) 1885 & (k) 1905 & \\
\hline (L) 1806 & (1) 1826 & (菏) 1846 & (I) 1866 & (1) 1886 & [1] 1906 & \\
\hline M 1807 & m 1827 & 184y & $\mathfrak{m i n}_{1867}$ & $(\widetilde{M}) 18 \dot{8}$ & m 1907 & \\
\hline (N) 1808 & (n) 1828 & 1848 & (iil 1868 & (N) 1888 & (In] & \\
\hline (0) 1809 & (0) 1829 & (10) 1849 & (1) 1869 & (О) 1889 & [0] 1 & \\
\hline (P) 1810 & (p) 1830 & (1850 & (⿹) $18 \% 0$ & $(\mathbb{P}) 1890$ & (p) 1910 & \\
\hline (Q) 1811 & (9) 1831 & (19) 1851 & (9) $18 \% 1$ & (0) 1891 & (9) 1911 & \\
\hline (R) 1812 & (r) 1832 & (1R) 1852 & $(\mathfrak{1}) 1872$ & (R) 1892 & (I) 1912 & \\
\hline (S) 1813 & (S) 1833 & (\$) 1853 & (G) 1873 & S) 1893 & \begin{tabular}{l|l} 
S) & 1913
\end{tabular} & \\
\hline (T) 18 & (t) 1834 & (e) 1854 & (1) 1874 & T) & t 1914 & \\
\hline (U) 1815 & (u) 1835 & (ain 1855 & (') 1875 & (U) 1895 & $\begin{array}{ll}U & 1915\end{array}$ & \\
\hline
\end{tabular}

From the 25th March 1697 to the 1st june 1720 the figure of crowned leopard's head and a lion passant, see page 620 . bear an extra stamp representing the head of George III.; see page 620. 
624 Old Clocks and Watches and their Makers

BIRMINGHAM ASSAY OFFICE DATE-LETTERS.

NotE.-The Date-Mark is altered on lst July of each year, lasting from the Date indicated in the Table till the June following.

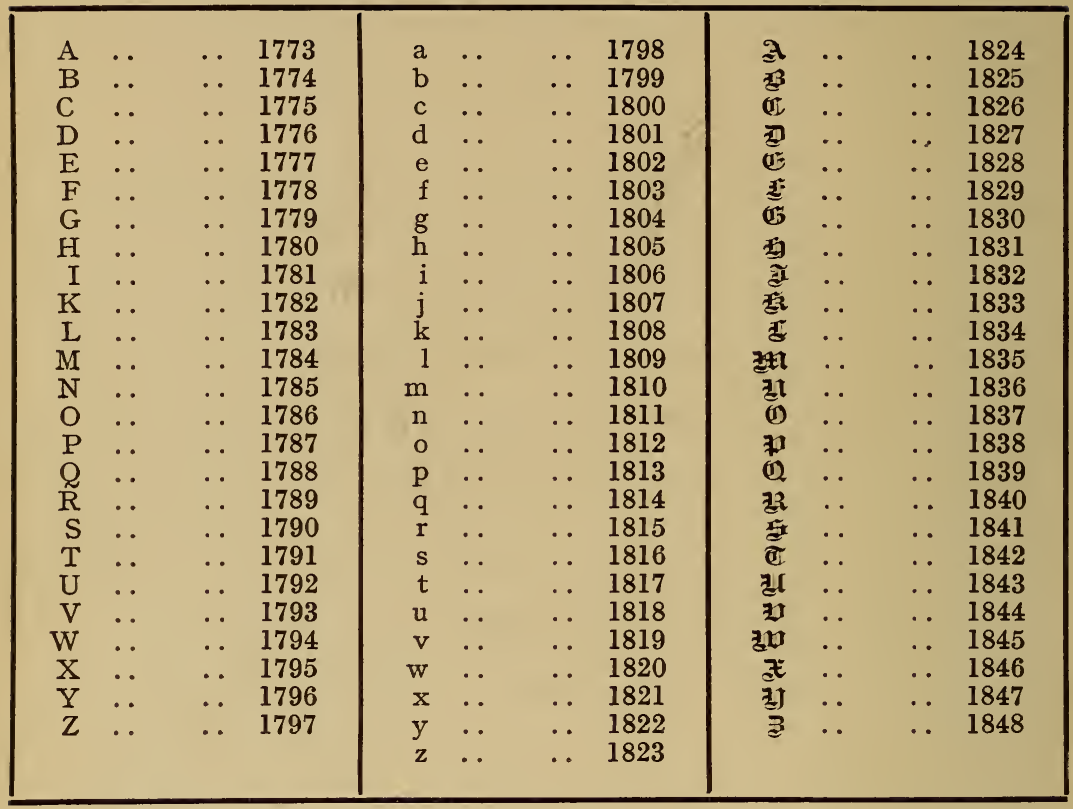

\begin{tabular}{|c|c|c|c|c|c|c|c|c|c|}
\hline A & .. & .. & 1849 & $\mathfrak{\alpha}$ & . & 1875 & a & .. & 1900 \\
\hline B & .. & . & 1850 & b & . & . 1876 & $\mathrm{~b}$ & .. & .. 1901 \\
\hline C & .. & .. & 1851 & $\mathfrak{c}$ & . & .. 1877 & c & . & .. 1902 \\
\hline D & . & .. & 1852 & 2 & . & . 1878 & d & . & . 1903 \\
\hline $\mathrm{E}$ & . & .. & 1853 & e & . & . 1879 & $\mathrm{e}$ & . & .. 1904 \\
\hline $\mathrm{F}$ & .. & .. & 1854 & $f$ & . & .. 1880 & f & $\ldots$ & .. 1905 \\
\hline G & .. & .. & 1855 & $\mathfrak{g}$ & .. & . 1881 & g & . & . 1906 \\
\hline $\mathrm{H}$ & .. & .. & 1856 & i) & .. & . 1882 & $\mathrm{~h}$ & . & . 1907 \\
\hline I & .. & .. & 1857 & $\dot{i}$ & .. & .. 1883 & $\mathrm{i}$ & $\ldots$ & .. 1908 \\
\hline $\mathrm{J}$ & .. & . & 1858 & $k$ & .. & . 1884 & $\mathrm{k}$ & . & . $\quad 1909$ \\
\hline K̆ & .. & . & 1859 & 1 & . & .. 1885 & 1 & . & .. 1910 \\
\hline L & . & .. & 1860 & $\mathfrak{m}$ & .. & . . 1886 & $\mathrm{~m}$ & .. & .. 1911 \\
\hline M & . & .. & 1861 & $2 \pi$ & . & .. 1887 & $\mathrm{n}$ & . & 1912 \\
\hline $\mathrm{N}$ & . & .. & 1862 & a & .. & . $\quad 1888$ & o & $\ldots$ & .. 1913 \\
\hline $\mathrm{O}$ & . & . & 1863 & $\boldsymbol{p}^{p}$ & .. & .. $\quad 1889$ & $\mathrm{p}$ & $\therefore$ & .. 1914 \\
\hline $\mathrm{P}$ & .. & .. & 1864 & $\mathfrak{q}$ & .. & 1890 & $q$ & . & 1915 \\
\hline $\mathrm{Q}$ & .. & .. & 1865 & $x^{2}$ & .. & .. 1891 & $\mathrm{r}$ & . & .. 1916 \\
\hline$\tilde{\mathrm{R}}$ & .. & .. & 1866 & 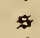 & . & .. 1892 & $\mathrm{~s}$ & $\ldots$ & .. $\quad 1917$ \\
\hline $\mathrm{S}$ & .. & .. & 1867 & $t$ & .. & .. 1893 & $\mathrm{t}$ & .. & .. 1918 \\
\hline $\mathrm{T}$ & .. & .. & 1868 & tr & .. & . $\quad 1894$ & $\mathrm{u}$ & . & .. 1919 \\
\hline $\mathrm{U}$ & .. & .. & 1869 & $\mathfrak{x}$ & . & . 1895 & $\mathbf{v}$ & . & .. 1920 \\
\hline V & .. & .. & 1870 & w & .. & .. 1896 & $\mathrm{w}$ & $\ldots$ & 1921 \\
\hline W & .. & .. & 1871 & 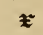 & . & . 1897 & & & \\
\hline $\mathrm{X}$ & $\ldots$ & .. & 1872 & $\boldsymbol{u}$ & .. & . . 1898 & & & \\
\hline $\mathrm{Y}$ & .. & .. & 1873 & 3 & .. & . . 1899 & & & \\
\hline $\mathrm{Z}$ & .. & .. & 1874 & & & & & & \\
\hline
\end{tabular}


CHESTER ASSAY OFFICE DATE-LETTERS.

NotE.-The Date-Mark is altered on the 1st July of each year, lasting from the Date indicated in the Table till the June following.

\begin{tabular}{|cl|cl|rl|rr|rl|}
\hline $\mathrm{A}$ & 1701 & $* A$ & 1726 & $\mathrm{~A}$ & 1752 & $\mathrm{a}$ & 1776 & $* A$ & 1797 \\
$\mathrm{~B}$ & 1702 & $B$ & 1727 & $\mathrm{~B}$ & 1753 & $\mathrm{~b}$ & 1777 & $B$ & 1798 \\
$\mathrm{C}$ & 1703 & $C$ & 1728 & $\mathrm{C}$ & 1754 & $\mathrm{c}$ & 1778 & $C$ & 1799 \\
$\mathrm{D}$ & 1704 & $D$ & 1729 & $\mathrm{D}$ & 1755 & $\mathrm{~d}$ & 1779 & $D$ & 1800 \\
$\mathrm{E}$ & 1705 & $E$ & 1730 & $\mathrm{E}$ & 1756 & $\mathrm{e}$ & 1780 & $E$ & 1801 \\
$\mathrm{~F}$ & 1706 & $F$ & 1731 & $\mathrm{~F}$ & 1757 & $\mathrm{f}$ & 1781 & $F$ & 1802 \\
$\mathrm{G}$ & 1707 & $G$ & 1732 & $\mathrm{G}$ & 1758 & $\mathrm{~g}$ & 1782 & $G$ & 1803 \\
$\mathrm{H}$ & 1708 & $H$ & 1733 & $H$ & 1759 & $\mathrm{~h}$ & 1783 & $H$ & 1804 \\
$\mathrm{I}$ & 1709 & $I$ & 1734 & $\mathrm{I}$ & 1760 & $\mathrm{i}$ & 1784 & $I$ & 1805 \\
$\mathrm{~K}$ & 1710 & $J$ & 1735 & $\mathrm{~J}$ & 1761 & $\mathrm{k}$ & 1785 & $K$ & 1806 \\
$\mathrm{~L}$ & 1711 & $K$ & 1736 & $\mathrm{~K}$ & 1762 & $\mathrm{l}$ & 1786 & $L$ & 1807 \\
$\mathrm{M}$ & 1712 & $\mathrm{~L}$ & 1737 & $\mathrm{I}$ & 1763 & $\mathrm{~m}$ & 1787 & $M$ & 1808 \\
$\mathrm{~N}$ & 1713 & $M$ & 1738 & $\mathrm{M}$ & 1764 & $\mathrm{n}$ & 1788 & $N$ & 1809 \\
$\mathrm{O}$ & 1714 & $N$ & 1739 & $\mathrm{~N}$ & 1765 & $\mathrm{O}$ & 1789 & $O$ & 1810 \\
$\mathrm{P}$ & 1715 & $O$ & 1740 & $\mathrm{O}$ & 1766 & $\mathrm{p}$ & 1790 & $P$ & 1811 \\
$\mathrm{Q}$ & 1716 & $P$ & 1741 & $\mathrm{P}$ & 1767 & $\mathrm{q}$ & 1791 & $Q$ & 1812 \\
$\mathrm{R}$ & 1717 & $Q$ & 1742 & $\mathrm{Q}$ & 1768 & $\mathrm{r}$ & 1792 & $R$ & 1813 \\
$\mathrm{~S}$ & 1718 & $R$ & 1743 & $\mathrm{R}$ & 1769 & $\mathrm{~s}$ & 1793 & $S$ & 1814 \\
$\mathrm{~T}$ & 1719 & $S$ & 1744 & $\mathrm{~S}$ & 1770 & $\mathrm{t}$ & 1794 & $T$ & 1815 \\
$\mathrm{U}$ & 1720 & $T$ & 1745 & $\mathrm{~T}$ & 1771 & $\mathrm{u}$ & 1795 & $U$ & 1816 \\
$\mathrm{~V}$ & 1721 & $U$ & 1746 & $\mathrm{U}$ & 1772 & $\mathrm{v}$ & 1796 & $V$ & 1817 \\
$\mathrm{~W}$ & 1722 & $V$ & 1747 & $\mathrm{~V}$ & 1773 & & & & \\
$\mathrm{X}$ & 1723 & $W$ & 1748 & $\mathrm{~W}$ & 1774 & & & & \\
$\mathrm{Y}$ & 1724 & $X$ & 1749 & $\mathrm{X}$ & 1775 & & & & \\
$\mathrm{Z}$ & 1725 & $Y$ & 1750 & & & & & & \\
& & $\mathrm{Z}$ & 1751 & & & & & & \\
\hline
\end{tabular}

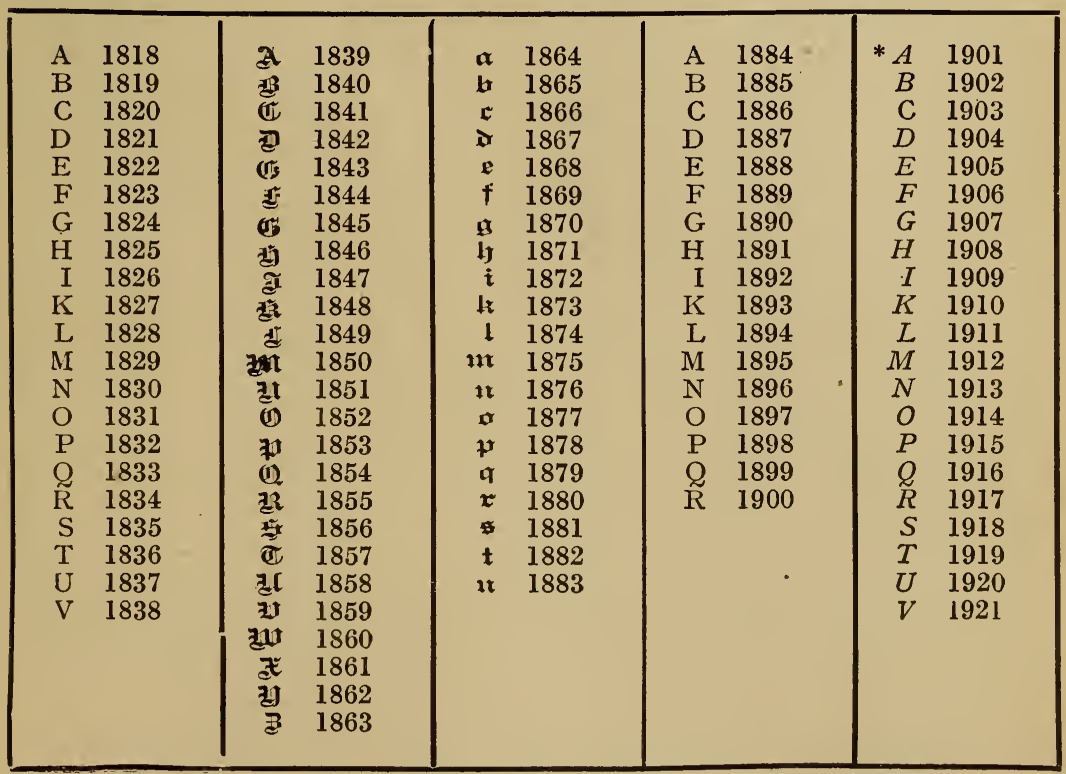

* These are really Script capitals. 


\section{CHAPTER IX}

\section{FORMER CLOCK AND WATCH MAKERS}

$\mathrm{T}^{\mathrm{H}}$

HE dates following the names in this alphabetical list signify the period when the person referred to was connected with the Clockmakers' Company, or known to be in business, or when some example of his work was made. It does not necessarily follow that he then either began or relinquished the trade. The letter $\mathrm{f}$. after a date means that the person then became a freeman. Throughout the list C.C. stands for Clockmakers' Company, G.M. for Guildhall Museum, where the collection of the Clockmakers' Company is located, B.M. for British Museum, S.K.M. for South Kensington Museum, and h.m. for Hall-Mark. Following the names or addresses of some of the makers is a slight description of specimens of their work which have been met with, or of some invention or distinguishing trait. Of the more important men, fuller descriptions are given in the body of the book, and reference is then made to the page where such particulars may be found.

On estimating the age of a timekeeper by a maker the only reference to whom is that he was admitted to the Clockmakers' Company, it may in the majority of cases be assumed that he was at the time of his admission a young man just out of his apprenticeship ; but there are numerous exceptions. Many of those members who constituted the first roll of the Clockmakers' Company were of mature years at the time of their incorporation ; and afterwards men who had made some mark or whom circumstances had brought into notice were then induced to join. The introductory description, "Great Clockmaker," seems to have meant a maker of laige clocks. Hon. freemen, elected after 1780, all had made their reputation before entry.

It is easy to understand that the roll of membership of the Company at no time represented the whole of the clockmakers and watchmakers within its sphere of action. Many who did not care to join would escape observation, and those who were free of other guilds at the incorporation made their apprentice free of the particular company to which they were attached. Horological craftsmen belonging to other 
guilds, if they became associated with the Clockmakers' Company, were designated " brothers."

Although the addresses of the freemen at first are rarely given, it may be taken for granted that they were nearly all within a radius of ten miles, and among the later ones it will be found that very few of them resided at any great distance from the Metropolis.

Tracing the residence or business location of manufacturers is often more difficult than many would imagine. William Clement is referred to in many books as an "eminent London Clockmaker who first applied the Anchor Escapement to clocks," and was doubtless a leading member of his trade. He was master of the Clockmakers' Company and presided when Graham took up the freedom on completion of his indentures, yet his name does not appear in any Directory of the period, and I am quite unable to discover where he resided or practised his craft. To mention another instance of a century later, Earnshaw, after he had enlisted the interest of Dr. Maskelyne, Astronomer-Royal, who tried a watch of his at the Greenwich Observatory, was told by the doctor that he had lost an order for two watches because Maskelyne did not know where he lived!

On some of the early clocks and watches the name inscribed was that of the owner; but in $\mathbf{1 7 7 7}$ an Act of Parliament required the name and place of abode of the maker to be engraved. Still it must not be concluded that in every instance the name engraved on a timekeeper indicates its maker or even that the inscription represents any corporeal existence. In 1682 the C.C. seized from workmen " using the art of clockmaking four unfinished movements two whereof have engraven thereon Ambrose Smith, Stamford and William Burges fecit, and another Jasper Harmer, all of which names are greatly suspected to be invented or fobbed." The practice of using apocryphal names has continued to the present day. Sometimes it was adopted by manufacturers of repute for watches of a lower quality than those of which they cared to own the paternity. Occasionally in such instances the letters composing the name of the manufacturers would be placed backwards. Many watches marked " Rentnow, London," are to be met with, and they doubtless emanated from the Wontners, well-known makers of a century ago. The mark "Yeriaf" on a watch in the Guildhall IIuseum is probably another example of this reversion. Some watches with fictitious names would be the production of workmen who occasionally made a watch for a private customer, and preferred 
thus to conceal their identity rather than brave the displeasure of their employers. The late Mr. Evan Roberts had a watch marked " Notyap, London," which was possibly the production of Payton, a casemaker who in 1790 carried on business in Addle Street. But in most instances such pseudonyms appear to be really the trade-marks of wholesale dealers, who in ordering watches would supply particulars of the name to be engraved. Many hundreds of watches for the Dutch market were marked "Tarts, London," or "Jno. Tarts, London." Yet I do not think anyone has been able to trace a manufacturer named Tarts. Between 1775 and 1825 the custom of having the name of the owner and not of the maker was often re verted to, usually with A.D. preceding the date figures, and occasionally also " aged 21," or " married," or " born." Watches by provincial makers sometimes had "London" engraved as the place of origin.

The more reprehensible act of adopting celebrated names appears also to have been of early origin. In Overall's " History of the Clockmakers' Company," it is stated that in 1704 the master of the C.C. reported " certain persons at Amsterdam were in the habit of putting the names of Tompion, Windmills, Quare, Cabrier, Lamb, and other well-known London makers on their works, and selling them as English." It is to be feared that some English makers were not free from suspicion of similar misdeeds both then and since.

Numbers on watch movements are very little, if any, guide to the extent of a maker's business. Till quite recent years the custom was for a new manufacturer to begin with a high number, the date, or two or three figures of the date, being often selected as a starting point. L.etters following the name are seen on some nineteenth-century watches. They represent a cryptogram whereby the initiated can obtain the date of manufacture.

Watches and clocks with Turkish numerals often bore more than one name. It appears that only the timekeepers of certain favoured manufacturers or dealers whose names were registered were admitted into Turkey, and on watches for the Byzantine markets made by others a registered name would be engraved, followed by the name of the actual producer. This, I presume, was usually done by arrangement with the "maker" who had the right of entry. On watches for Turkey the word "Pessendede," signifying " warranted,' sometimes followed the name or names. Occasionally the first and perhaps the sole, name inscribed would be merely that of a registered agent. Persian and Turkish numerals are the same.

The locality of the residences may not in all cases be readily 
recognised. A place called Swithen's Alley in early eighteenthcentury records, but more generally known as Sweeting's Alley, Cornhill or Royal Exchange, evidently a favourite spot with the craft, was where the statue of Rowland Hill now stands. It was not rebuilt after the destruction of the Exchange by fire, in 1838 . Bethlem, or Bethlehem, was in Moorfields, facing London Wall. In the early part of the eighteenth century the three Moor Fields extended from there over the space now occupied by Finsbury Circus and Finsbury Square to Windmill Hill Row, a continuation of which, called Hogg Lane, led into Norton Folgate. The whole of this thoroughfare is now known as Worship Street. Windmill Hill is now Wilson Street. The portion of the City Road by Bunhill Fields was then Royal Row. Love Lane now forms part of Southwark Street, and Maid Lane of Southwark Bridge Road. Rosemary Lane is now Royal Mint Street, Coppice Row is merged into Farringdon Road. Pickaxe Street was so much of Aldersgate as lies between the Barbican and Fann Street. Butcher Row, now pulled down, occupied the wide part of the Strand between the Church of St. Clement Danes and Temple Bar. Brick Lane, St. Luke's, is now Central Street, and Swan Alley is Great Sutton Street. Swallow Street is now incorporated with Regent Street, and Princes Street, Leicester Square, is merged into Wardour Street. Cateaton Street is now Gresham Street. One side of Wilderness Row remains; the Row was widened and transformed into the thoroughfare which cut through St. John's Square, and is called Clerkenwell Road. Union Street, Bishopsgate, or Spitalfields, is now Brushfield Street; the Bishopsgate Street end, with the larger part of Sun Street, was absorbed in building the terminus of the Great Eastern Railway, and the Post Office on the western side of St. Martin's-le-Grand occupies the site of Bull and Mouth Street. Wellington Street, St. Luke's, is now Lever Street. King Street, Clerkenwell, is now Cyrus Street; King Street, Holborn, is Southampton Row, and Kingsgate Street, which was adjacent and parallel to it, has disappeared altogether. Grubb Street is now Milton Street. The Fleet Street end of what was Water Lane in Tompion's time is now Whitefriars Street. Orange Street, Red Lion Square, is now Purton Street.

It is stated that Prescott Street, Goodman's Fields, was the first London street in which the houses were numbered consecutively, and that this thoroughfare was so treated in 1708. Swinging signs were interdicted in 1762 , though symbols on stiff brackets and mural carvings as signs for particular buildings were preferentially employed for some years after. 
Hick's Hall is mentioned. This was the title given to the Sessions House, which at that time stood in the middle of St. John Street, near Smithfield Market. It was afterwards rebuilt on Clerkenwell Green.

Taking into consideration the difficulty of obtaining precise information respecting the early names, added to the vagaries of seventeenth-century orthography, I hope and believe the list is as nearly as possible correct, and tolerably complete, so far as London makers are concerned. Outside of the Metropolis I have not attempted to do more than record the facts which happened to be within my reach, and I venture to beg the favour of communications respecting corrections and additions.

Octavius Morgan's " List of Freemen of the Clockmakers'Company" published some years ago, has been of assistance, and particulars of some French makers have been obtained from Havard's " Dictionnaire d'Ameublement " and the "Book of Collections" by Alph. MazeSencier. The term "garde-visiteur" attached to members of the Paris Guild appears to indicate a committee-man or inspector. Mr. J. Whiteley Ward kindly placed at my disposal his extensive list of old makers, but he rarely ventured to hazard an approximate date. For several Edinburgh makers I am indebted to Mr. John Smith's papers in the Weekly Scotsman. It will be noticed that in the seventeenth-century records of the Edinburgh "Incorporation of Hammermen," the word "Knok" or "Knock" is used to designate a clock. For many of the American names I am indebted to Mr. John H. Buck, Curator at the Metropolitan Museum of Art, New York, who has compiled a list from various sources.

Some of the old art metal workers of Augsburg and Nuremberg affixed their signatures to clock cases of their production, a custom often followed by French clock case designers of more recent times. It should be remembered that such names, as a rule, have no reference to the movements. During the Reign of Terror in France timekeepers by the leading makers were mostly unsigned. As stated on p.392, Breguet watches are to be met with in which his name is scratched on the enamelled dial in well-formed script letters, but so tiny as not to be distinguished except with the aid of a very strong magnifying glass. The silent period, as it may be termed, extended more or less for nine or ten years from 1789 .

After 1842 the names are given only of those above mediocrity, or concerning whom some peculiarity is known, and who have ceased to carry on business. Many of those who are traced to 1842 probably continued for years afterwards, but the list is not intended as a guide to clock and watch makers of to-day. 
Aaron, Benjamin, 17 Bury St., St. Mary Axe, 1840-42.

Abbis, J., 37 Bishopsgate St. Within, 1807

Abbott. Richard, apprenticed in 1668 to Helkiah Bedford ; C.C. Philip, London ; C.C. 1703 (see p. 545). Peter, C.C. 1719. Wm., long-case clock marked "Wm. Abbott Saroon, fecit," about 1720. Wm., Knaresboro', watch, three cases, about 1760. Wm., Prescot, 1770. John, admitted C.C. 1788 ; charged with making an agreement to go to St. Petersburg to work at clockmaking, and convicted at Hicks' Hall of the offence; known as a maker of long-case clocks, 1787-1800. Thos., 41 Allen St., 1820-22. Francis, Manchester : 3 Smithy Door, 1825; afterwards at 50 Market St. ; watch paper, C.C., about 1840 ; wrote a book on the management of public clocks (n.d.), about 1838 .

Abdy, William, livery Goldsmiths' Company, 5 Oat Lane, Noble St., 1768-1817. Jno., London; watch, 1784.

Abeling, William, 7 Wynyatt St.,Clerkenwell, 1817 ; 36 Spencer St., 1835-42.

Aberley, Joseph, apprenticed in 1664 to Isaac Sutton; C.C.

Abraham. Ebenezer, Olney ; watch, 1773. John, 27 Steward St., Bishopsgate, 1820-23.

Abrahams. H., 21 Bevis Marks, 1800-20. Godfrey, 51 Prescot St., Goodman's Fields, 1835-42. Samuel, 23 Little Alie St., 1840-42. A., 9 Great Prescot St., 1840-42. Elijah, 27 Hanway St., Oxford St., 1840-47.

Absolon, - , London ; long-case clock, strike-silent, sunk seconds, scroll and foliage corners, about 1770.

Acey, Peter, York, f., 1656.

Achard, George, et Fils, Geneva ; watch, about 1780 .

Achard, G., Geneva ; watch, about 1810.

Achurch, Wm., apprenticed in 1691 to Wm. Jacques, C.C.

Ackers, William, St. Andrew's, Holborn ; pair-case watch in S.K.M., early part of eighteenth century ; his bankruptcy noted Lond. Gaz., 28th Oct. 1706.

Acklam. John Philip, 423 Strand, 1816 ; 138 Strand, 1840. T., 14 Birchin Lane, 1825-33.

Acton. Jno., Clerkenwell, C.C. 1677. Abraham, apprenticed in 1691 to Henry Montlow ; C.C. 1700. Chris., bracket clock, about 1725 .

Adam, Melchior (? Melchior Adam), Paris; octagonal crystal-cased watch, Soltykoff collection, about 1585 ; A., watch, Pierpont Morgan collection, signed " Melchoir Adam," balance-cock pinned on, about 1610 .

Adams. Geo., apprenticed to Jos. Dudds, 1745 ; C.C. 1752 ; 60 Fleet St.,
1770 ; table timepiece, Guildhall Museum, about 1795. Jno., Halesowen, 1760 . John, 1 Dove Court, Moorfields, 1770-72. Stephen, 3 St. Anne's Lane, 1774 ; Stephen \& Son, 1788. C. \& J., 10 King St., Cheapside, 1788. John, 31 Maiden Lane, Covent Garden, 1790-94. Hy., Church St., Hackney ; fine long-case clock, about 1800 ; watch, h.m., 1808; on a paper in the outer case the following :-

\begin{abstract}
To-morrow ! yes, to-morrow ! you'll repent
A train of years in vice and folly spent.

To-morrow comes-no penitential sorrow

Appears therein, for still it is to-morrow.

At length to-morrow such a habit gains,

That you'll forget the time that Heaven ordains,

And you'll believe that day too soon will be

When more to-morrows you're denied to see."
\end{abstract}

Adams. John, Dove Court, Moorfields ; surety for clerk of the Cutlers' Co. in 1769. Francis Bryant, succeeded Benj. Webb at 21 St. John's Sq., Clerkenwell ; master C.C. 1848 ; 1810-48. F. B., \& Son, 21 St. John's Sq., 1830-42 (see Moore, Geo.). Thos., partner with Widenham in Lom bard St. ; afterwards at 84 Cannon St. ; died at Catford, 1870. Of U.S.A.; Nathan, Boston, 1796-1825 ; Wm., 1838; John, Coventry, died 1916.

Adamson. Humfry, maker of a clock for Whitehall Chapel, 1682; bracket clock, about 1690; Wetherfield collection, see p. 568. John, admitted C.C. 1686; "A Gold Minute Watch, lately made by Mr. Adamson, over against the Blue Boar in Holborn" (Lond. Gaz., 3rd March 1686). -. Paris ; clockmaker to the Royal Family, 1790.

Addis. William, Cannon St., afterwards at 3 Birchin Lane, son of Robert A., of Bristol ; apprenticed to George Sims, 1738; admitted C.C. 1745, master 1764. George Curson, 3 Birchin Lane, afterwards 47 Lombard St. ; livery C.C. 1787 ; 1780-98. George, 79 Cornhill, 1786-94.

Addison. Edmond, apprenticed in 1678 to Joseph Ashby, C.C. Josh., London; watch, 1770. Jno., York, f., 1789. Josh., Lancaster, 1817 ; f., son of James Addison, London.

Adeane. Henry, apprenticed to Rich. Scrivener in 1663 ; C.C. 1675 . Henry, C.C. 1705 .

Adkins, Thos., Shoe Lane, 1735.

Adney, Richard, Bull and Mouth St. 1770-76.

Agar. -, York. Several generations. Jno., f., 1707. Francis, 1708. Seth, f., 1743. Jno., f., 1760; died 1808; Mr. Thos. Boynton has a fine regulator by him. Charles, f., 1779, settled at Pontefract. John, f., 1782, settled at Malton. Thos. London; watch, 1804. Thos., Bury, 1814. Thos., Chorley, Lancs. 1814. 
Agerou, à Paris ; watch, M. E. Gélis, 1750-80.

Aicken, Geo., Cork; watch, 1780.

Ainsworth, Geo., Warrington, 1818.

Airey, Jno., Hexham, about 1770.

Airy, George Biddell, Astronomer-Royal, $1835-81$; K.C.B., 1874 ; died 1892 , aged 90; devoted much attention to the perfecting of timekeepers.

Aish, Simon, Sherborne; long-case lantern-movement clock, 10-inch dial, about 1690 .

Aitken, John, 55 St. John's St., Clerkenwell; received in 1824 a prize of twenty guineas from the Society of Arts for a c.lock train remontoir; 1800-26.

Aitkins, Robt., London; watch, 1780.

Akced, Jno., London; watch, 1795.

Akers, Jas., Derby ; watch, 1802.

Alais, M., Blois ; watch, about 1680 .

Alasti, - , signature on case of sixteenthcentury watch, Pierpont Morgan collection.

Albert, Isaac, C.C. 1731.

Albrecht, Michael George, gold repeating watch in the S.K.M., bearing the royal arms, outer case repoussé, about 1720 .

Alcock, Thomas, petitioner for incorporation of C.C. 1630; warden 1646, clicl not become master (see p. 256).

Alden \& Eldridge, Bristol, Conn., 1820.

Alder, J., London, bracket clock, crown wheel escapement, about 1700 .

Alderhead, Jno., 114 Bishopsgate Within ; livery Goldsmiths' Company 1775-94; card, Ponsonby collection, " at the Ring and Pearl, Bishopsgate St., near the Southsea House."

Alderman, Edwin, 22 Barbican, 1818-34; I very C.C. 1822 .

Aldred. Leonard, C.C. 1671. Jno., apprenticed in 1686 to Hy. Reeve, C.C. Wm. 64 Wood St., 1793; watch-spring maker.

Aldridge. Daniel, apprenticed in 1806 to Hy. Young, C.C. Edward, striking and f ull quarter repeating bracket clock, about 1710. Chas., Aldersgate, 1714. John, ( C. 1726. James, 11 Northumberland St., Strand, 1816-30.

Aldwin, Thos., London; watch, 1767.

Aldworth, Samuel, brother C.C. 1697. Mr. (j. E. Atkins has a lantern clock, inscribed "Saml. Aldworth, Oxon.," about 1700; ¿ bracket clock had under name-plate "John Knibb, Oxon." ; "Saml. Aldworth, Strand."

Aldy, Edwd., Lincoln, 1760.

Alezander. Robt., Edinburgh, 1709. Isaac, Nottingham; watch, about 1760. Wm., 10 Parliament St., 1828-40. A., \& Co., 25 Bedford St., Bedtord Sq., 1840 ; Gray's Inn Passage, 1847. Richard, Chippenham, 1845.

Alexandre, Jacques, Paris ; a priest who devoted much attention to timekeepers; published in 1734, "Traité Général des Horloges."

Aley, Thomas, 18 Park Side, Knightsbridge, 1840-42.

Alibert, F., Paris ; watch, 1800.

Alker, Jno., Wigan, 1818.

Alkins (? Atkins), London, about 1730. Alsope, see Allsop.

Allam. Andrew, Grubb St., apprenticed in 1656 to Nicholas Coxeter; C.C. 1664; maker of lantern clocks. Michael, London, 1723. Robt., next St. Dunstan's Church, Fleet St., 1736-65. William, Fleet St., 1770-80. \& Stacey, 175 Fleet St., 1783. Wm., New Bond St., 1780-1800.

Allams, Gabriel ; repeating watch, silver cases, inner one pierced, outer one repoussé with Minerva, \&c., about 1760, Pierpont Morgan collection.

Allan. George, 9 New Bond St., hon. freeman C.C. 1781 ; 1760-83; maker of a watch found in a chimney at Newton St., Holborn, in 1895, and said to have belonged to Lord Lovat, who was beheaded in 1747 ; unfortunately for the legend, the hall mark corresponded to 1768 . \& Clements, 119 New Bond St., 1785-94. John, 119 New Bond St., 1798-1800. \& Caithness, 119 New Bond St., 1800-4.

Allaway, John, apprenticed to Bernard Rainsford ; C.C. 1695.

Allcock. Jno., 30 St. Martin's Lane; card, B.M., 1787. William, watchhand maker, 36 Allen St., Clerkenwell, 1820.

Allen. Jas., brother C.C. 1635 . Elias, brother C.C., master 1636 ; died 1654 . Nathaniel, apprenticed in 1650 to $\mathrm{Wm}$. Bowyer, C.C. Thos., apprenticed in 1663 to Robt. Whitwell, C.C. John, C.C. 1720. John, brother C.C. 1753. P., Macclesfield, 1770. John, 42 Poultry, 1772-75. George, Fleet St. ; liveryman C.C. 1776. Thos., Deptford, 1780. John, watch-case maker. Barbican ; convicted in the Mayor's Court for refusing to become a member of the C.C., although he was at the time free of the Goldsmiths' Company, 1785-89; Aldersgate St., 1794. James, 76 New Gravel Lane ; an ingenious watchmaker to whom the Board of Longitude awarded f.105 for engine dividing, 1790-1800, George, 14 Red Lion Passage, Holborn; watch paper, C.C. 1812-42. T., Preston, 1814. Jno., London; watch, 1820 . Of Boston, U.S.A. : Jas., 1684.

Allenbach, Jacob, Philadelphia, 1825-40. Allet, George, apprenticed in 1683 to Solomon Bouquet, but turned over to Thos Tompion ; C C 1691 ; bracket clock, ebony case, Wetherfield collection, about 1705 (see plate facing p. 572)

Allié, M., Geneva; centre seconds 
repeating watch with calendar, about 1790 , Horological School, Geneva.

Alliez, Buchelard \& Térond Fils, Geneva; watch, about 1820 , Dr. H. Goudet. Alling. Richard, admitted C.C. 1722. James, 22 Red Lion St., Whitechapel; "foreman to Mr. Hatton, London Bridge" ; watch paper, C.C. 1838-42.

Allis, Jno. H., Bristol, 1845.

Allison. Wm., Liverpool, about 1765 . Gilbert, Sunderland, 1775. Thos., London; watch, 1790.

Allkins, - Horncastle ; watch, 1785. Allman, W., Prince's St., Storey's Gate, Westminster ; card, B.M., 1798.

Allory, 一, Moorfields, 1774.

Allport, - Birmingham; bracket clock, about 1770 .

Allsop, Joshua, Northamptonshire, brother C.C. 1689; handsome long Oriental lacquer-cased clock belonging to the Blecker family, New York; long-case clock, richly inlaid, inscribed "Josh. Alsope, East Smithfield," about 1710.

Allvey, Hy., 5 Old Sq., about 1795.

Almond. William, Lothbury ; maker of a clock for Hall, Bishop of Exeter; C.C. 1633. Ralph, apprenticed to Oswald Durant in 1637 ; C.C. 1646 , master 1678 . John, C.C. 1671.

Alric Fils, à Toulouse; repeating watch, virgule escapement, about 1810 , Mons. E. Gélis.

Alrich or Alrichs). Jonas, Wilmington, Del., born 1759, died 1802 . Jacob, born 1775.

Alston \& Lewis, 30 Bishopsgate St., 1820; Alston \& Hallam, 1830-42.

Alvey, Samuel, apprenticed to Jas. Wood ; admitted C.C. 1757.

Alyers, Jas., Southwark; watch, 1779.

Alysone, Jas., Dundee, 1663.

Amabric. Abraham, Geneva, 1760-80 ; barrel-shaped gold watch with repoussé ornament enamelled, Pierpont Morgan collection; dial apparently later signed Amabric Frères. Frères, Geneva, 1793.

Amant, "maitre horloger, Paris"; spoken of by Thiout in 1741; he invented the pin wheel escapement about 1749 . Peter, Philadelphia, 1793.

Ambrose. Edward, apprentice of Elias Voland, 1634. David, C.C. 1669.

Ames, Richard, apprenticed in 1648 to Peter Closon; C.C. 1653; died in 1682, after election as master; clock by "him with dolphin frets and bob pendulum working between going and striking, clock marked "Richard Ames Neere St. Andrews Church in Holburne fecit." In 1684 Robert Browne was apprenticed to Katherine Ames. William, apprenticed to Richard in 1675 ; C.C. 1682 .

Amey, Robt., London; watch, 1780.
Amourette, à Marseille ; watch, about: 1650, Mons. E. Gélis.

Ampe, Abraham ; watch, Napier collection, 1607.

Amyot. Peter, Norwich ; lantern clocks, about 1660 . \& Bennet, Brigg's Lane, Norwich; in 1793 they issued a little book by $\mathrm{J}$. Bennett on the management of a watch.

Amyott. Peter, Norwich; watch, Nelthropp collection, about 1720 . Thos., London; watches, h.m., 1751-71; one, Nelthropp collection, about 1770 .

Anderson. Wm., apprenticed in 1646 to Simon Bartram. Robt., apprenticed in 1691 to Thos. Tompion, C.C. Richard, Lancaster, 1767, f. ; also at London and Preston. Alex., London; watch, 1770. Wm., Lancaster, about 1770 . J., London ; watch, 1775. Geo., sued in 1777 by Cabrier for putting his name on five watches. Richard, Preston; watch, 1778. Wm., Lancaster, 1780. Alex., Liverpool; watch, 1786. Hugh, London; watch. 1792. R., London; watch, 1812 , Edward C., Newington Butts ; a successful watchmaker who carried out the not unreasonable rule of making a charge for furnishing a repairing estimate if it involved taking a watch to pieces ; 1835-85. Wm., Bristol, 1845.

Anderton. Jno., Little Wild St.; repeating watch, about 1750 . Wm. London; watch, h.m., $1767 . \quad J n o .$, Huddersfield, 1833.

Andrew, J., 14 Queen St., Ratcliff Cros:, 1820 .

Andrews. Robert, apprenticed in 1661 to Benj. Hill ; C.C. 1709. Isaac, apprenticed in 1674 to Edm. Fowell, C.C. Thos., apprenticed in 1686 to Joshua Hutchin; C.C. 1705 . John, Leadenhall St.; ad. mitted C.C. 1688. Richard, C.C. 1703 ; watch 1730 . James, C.C. 1719 . William, Bishopsgate St.; C.C. $1719 . \quad$ Benj., Bar' tholomew Lane, 1725. Abraham, Bank Coffee House, Threadneedle St., 1759. Thos., Steyning, 1760 (see p. 526), Rich., 124 Leadenhall St., 1775. Eliza, 85 Corn. hill, 1790-1800. Wm., Royston, 1825.

Angel, Richard, repairer of clock at: Wigtoft, Boston, Lincolnshire, 1484.

Angus, Geo., Aberdeen; long-case clock, about 1760 .

Annat, Nicholas, apprenticed in 1673 to Henry Jones, C.C.

Anness, William, 102 Cheapside, 1798. 1820 ; livery, C.C. 1802.

Annin, M., New York, 1786.

Annis, Jno., 13 Sparrow Corner, 1810-18. Annott, Chas., apprenticed in 1673 to Jas. Ellis, C.C.

Ansell (or Anselme), Richard, appren. ticed to Jeffery Baily; C.C. 1680. \& Son, 
watch-spring makers, 22 Whitecross Place, 1798-1802. Hy., 17 Colchester Sq., Savage Gardens, 1830; 74 Lennan St., 1838.

Anspach, -, Geneva; watch with virgule escapement, about 1810 .

Anstey, Jno., apprenticed to George Nau in 1683.

Antes, Jno., London ; apprenticed to Wm. Addis; pocket chronometer, G.M., h.m., 1787.

Anthony. -, clockmaker to Henry VIII., 1529. John, Maidenhead, 1790. William, 55 Red Lion St., St. John's Sq., Clerkenwell. There was in the Dunn Gardner collection a magnificent long oval watch by him, in a gold case, bearing the hall mark for 1796 . It was rather a large size, back enamelled and decorated with diamonds and pearls; but the peculiar feature was that the dial was also oval; the hands were jointed, and automatically lengthened and shortened as they travelled around. This watch fetched $£ 200$ at Christie's in 1902. Another example is an 8-day watch of similar shape, duplex escapement, movement beautifully engraved, fromerly in the Bentinck-Hawkins collection. He is reputed to have been one of the most expert watchmakers of his day, and such specimens of his work as remain quite bear out this belief. He carried on a successful business in Red Lion St., St. John's Square, and most of his watches bore the inscription "Wm. Anthony, St. John's Square." At one time he was in good circumstances, and took an active part in founding the Watch and Clockmakers' Benevolent Institution in 1815, though he lived to be a recipient of its bounty. Apart from his art he did not exhibit particular sagacity. He engaged in litigation with Grimaldi \& Johnson, which ended disastrously, and expended a large amount in the purchase of royal and other wardrobes of the time of Charles I. Of these he formed an exhibition at the Somerset Gallery, next door to Somerset House, and now 151 Strand. This also turned out an expensive failure. He had a considerable sum invested in good leasehold property on the Doughty estate. He died in Jerusalem Passage in 1844, and was then about eighty years of age. After his death the leases of this property were found in his safe. Curiously enough, the term for which he held had just about expired, but he had not troubled to collect any rents for at least twenty years previously, and it was concluded he had forgotten all about his possessions. David, 18 Union St., Bath, 1835.

Antis, Jno., Fulneck, near Leeds; received in $1805 £ 21$ from the Society of Arts tor a clock escapement.
Antoine, -, Rue Galande, Paris, 1770.

Antram, Joseph, London ; apprenticed to Chas. Gretton ; C.C. 1706 ; long walnutcase clock, square dial, cherub corners, circles round winding holes, about 1700 ; watch, about 1720; "watch and clock maker to his Majesty."

Antt, G., 158 Strand, 1769-88.

Apiohn (Upjohn), Henry, apprenticed in 1649 to Robert Whitwell, C.C.

Appleby. Edward, London; watch, abuut 1700 . Joshua, Bread St.; apprentice of Daniel Quare; C.C. 1719, master 1745. Thos., Charing Cross, 1800 (see p. 526). P., London; watch, 1825.

Applegarth, Thomas, apprenticed in 1664 to Hugh Cooper ; C.C. 1674.

Appleton. Jno., Liverpool, 1818. Henry, 50 Myddelton Sq., 1840-42 ; afterwards in partnership with Birchall in Southampton Row.

Appley, Edmund, Charing Cross ; apprenticed to Jeffery Bailey 1670 ; C.C. 1677; small repeating bracket clock, black case basket top about 1680 .

Appleyard, R., London; watch about 1790 .

Archambo, Jno., Prince's St., Leicester Fields; bracket clock in case, similar to Chippendale's design, Fig. 732, p. 547 ; marquetry case clock, arch dial; repoussé case watch, hall mark 1730, and another watch of a later date; 1720-50.

Archer. Henry, subscribed $£ 10$ for incorporation of C.C. and was the first warden; 1630-49. John, apprenticed in 1650 to Jas. Starnill ; admitted C.C. 1660. Edward, C.C. 1711. Walter, long-case clock, about 1715 , at the Van Courtland Mansion, New York. W., Stow, about 1715. Samuel, 15 Leather Lane, 1794; 33 Kirby St., Hatton Garden, 1810 ; a prominent man in the trade. In 1820 he was treasurer to the Watch and Clockmakers' Benevolent Institution. Sam. Wm., Hackney, 1805-12. Thomas, 6 Long Lane, Smithfield, 1814-20. Geo., Rochdale, 1818.

Argand l'Aîné, Geneva, about 1740. J. L., Place Dauphine, Paris, 1770 ; repeating watch "Argand, Paris," about 1770, Pierpont Morgan collection.

Ariel. James, watch-movement maker, 10 Wilderness Row, 1815-20. John, 10 Percival St., 1822-39.

Aris. Samuel, Leicester Fields; watch, 1750, Mr. Evan Roberts ; long-case clock, about 1760 . Jno., \& Co., Old Jewry, 1794.

Arlandi, John, chain-maker for watches, Red Rose St., Covent Garden, 1680 ; C.C. 1682.

Arlaud. Anthoine, cruciform watch, Pierpont Morgan collection, late sixteenth century Henry, fine calendar watch, Schloss collection, about 1630 , silver case. 
back inscribed " Richard Baille, at the Abbay." This watch was probably English work. Another specimen of a rather later date was inscribed "Arlaud, London." Benjamin, maker of a large silver repeating watch in the B.M., about 1680 .

Arlott, Thos., Sunderland, 1770.

Armand, J., Copenhagen; born 1732, died 1809 ; a talented horologist.

Armingand, - Paris; watch, 1790.

Armitage. \& Co., 88 Bishopsgate Within, 1798. Thos., Manchester, 1815.

Armstrong. John, C C 1724 Thos., Manchester, 1818.

Arnold. Thomas, apprenticed in 1687 to Nat. Chamberlaine, jun. ; admitted C.C. 1703. John, Devereux Court, Fleet St., 1760 ; 112 Cornhill, 1780. Hy., 46 Lombard St., 1769-88. Wm., London ; watch, 1790. Edward, London; watch, 1790. \& Son, 112 Cornhill, 1798 . John Roger, Bank Buildings, 102 Cornhill, 1804 ; 26 Cecil St., 1816-30. John R., \& Dent, 84 Strand, 1830-40. John R., 84 Strand, 1842 (see Frodsham, Charles).

Arnolts, - Hamburg, 1635 ; pair-case silver watch signed "Thomas Volffgang Arnolt, Hamburg," about 1680.

Arnott, Richard, 18 Red Cross St., Barbican, 1810-25.

Arnould, - French clock, about 1720, inscribed "Arnould pève."

Arter, - Bristol, 1845.

Arthanel, Aron Louis, table clock, about 1640.

Arthaud, Louis à Lyon; silver alarm watch, nicely pierced case, Schloss collection, about 1650 .

Arthur, William, apprenticed in 1669 to Nich. Coxeter; C.C. 1676; watch, "Arthur à Paris," about 1720, Mrs. George A. Hearn.

Arwen, Wm., Huddersfield, about 1770. Ascough, see Ayscough.

A.sh. - subscribed $£^{2}$ for incorporation of C.C. $1630 . \quad$ Ralph, C.C. 1648. \& Son, 64 St. James's St., 1822. Joseph, 146, Aldersgate St., 1822.

Ashbourne, Leonard, at the Sugar Loaf in Paternoster Row, next Cheapside ; inventor and maker of a clock lamp, 1731.

Ashbrooke. Thos., apprenticed to Cuthbert Lee in 1685 ; C.C. Jno., apprenticed to Zach. Mountford in 1686 ; C.C.

Ashby. Joseph, apprenticed in 1663 to Matthew Crockford; C.C. 1674; Edmond Addison was apprenticed to him in 1678 .

Ashdown, - Green Terrace, 1851.

Ashley. Jas., apprenticed in 1647 to Robert Smith, C.C. Chas., London; watch, 1767. Jno., English watch, 1780. J. P., 99 Baches Row, City Rd., 1800. \& Manser, 34 Rosoman St., Clerkenwell,
1825-35, afterwards at 15 Garnault Place; watch by them, h.m., 1823, cylinder escapement, brass escape wheel ; the teeth, instead of being in one horizontal plane, were on three different levels, touching on different parts of the cylinder, and so spreading the wear over a larger surface; they were succeeded by E. F. Ashley; he retired from business in 1898, and died in 1908. Edward,9 John St., Pentonville, 1842.

Ashman \& Son, 462 Strand, 1822.

Ashton. Miles, apprenticed in 1663 to Benj. Wolverstone, C.C. Jno., apprenticed in 1672 to Jno. Savile, C.C. Thos., apprenticed 1687 to Thos. Bradford, C.C. J. Tideswell, long-case clock, about 1710 , Mr. J. F. Hall Tempe, Arizona, U.S. Thos., Macclesfield, 1760. Saml., Bredbury, 1765. Thos., Leek, 1790 . Jno., Leek, 1830. Francis, Bristol, 1845. -, Philadelphia, 1797.

Ashurst. William, C.C. 1699. James, Chorley; watch, 1777.

Ashwell, Nicholas, apprenticed in 1640 to Robt. Grinkin; C.C. 1649.

Ashwin \& Co. ; long-case clock, about 1760, Mr. H. C. Campion.

Aske, Henry, apprenticed in 1669 to Edward Norris; C.C. 1676; George Graham was apprenticed to him in 1688 ; 1676-96.

Askell, Elizabeth, apprenticed in 1734 to Elinor Mosely.

Askwith, Jno., York, f. 1740.

Aspinall, Hy., Liverpool, about 1770.

Aspinwall. Thomas, small oval watch, about 1605. Samuel, clock-watch in possession of Lord Torphichen, about 1655 ; clock-watch, similar period, Evan Roberts collection. Josiah, brother C.C. 1675. John, Liverpool ; long-case clock, about 1750. Robt., Liverpool, 1818.

Asprey, Wm., 4 Bruton St., 1820.

Asselin, Francis (French), C.C. 1687 ; bracket clock, case covered with tortoiseshell on a red ground, about 1690; another somewhat similar clock, inscribed "Stephen Asselin" (see p. 574). Mr. W. T. Harkness has a 28-day long-case clock by Asselin, London, about 1700 .

Astley, Ed., Liverpool, 1833.

Astwood, Joseph, apprenticed in 1659 to Ben. Bell, C.C.

Atchison, Robert, apprenticed to Robert Harding, 1753 ; C.C. 1760 ; 1760-1819.

Athaud, Louis, à Lyon ; midseventeenth-century Watch, S.K.M., silver case pierced and engraved.

Athern, Jno., Liverpool ; long-case clock, Mr. E. H. Coleman; above dial motto, "Time shows the way of life's decay," about 1780 (?).

Atherton. Thos., Liverpool ; watch, 1776. T., London; watch, 1780. 
\& Hewett (tcols), 49 Red Lion St., Clerkenwell, 1789-94.

Atis, Leonard, London; lantern clock, about 1660 .

Atkin. Robt., Liverpool, 1818. Also Francis, same date.

Atkins. Joseph, apprenticed to Robt. Fowler, 1654 ; C.C. Jonathan, apprenticed in 1659 to Sam. Clay, C.C. Francis, 35 Clement's Lane; born 1730; apprenticed to Joshua Hassel 1746; C.C. 1759, master 1780, clerk 1785; died 1809. Samuel, Palgrave Court, Temple Bar, 1752-65. Samuel, \& Son, Palgrave Court, Temple Bar, 1759-63. George, son of Francis, born 1767; 35 Clement's Lane; warden C.C. 1809, afterwards clerk ; died 1855. Robert, Palgrave Court, Temple Bar 1769. Robert, 20 Salisbury St., Strand, 1770-88; Snow Hill, 1800. Danl., London; watch, h.m., 1776. Wm., Chipping-Norton, 1780. S., watch-case maker, 14 Bridgewater Sq., 1810. W., 7 Upper Ashby St., Clerkenwell, 1820. William, 71 High St., Poplar, 1835-42. W., 3 High St., Hoxton, 1835. Jno., Bristol, 1842. George, \& Son, 6 Cowper's Court, Cornhill, 1840-42. Samuel Elliott, son of George, whom he succeeded in business and as clerk of C.C., which office he resigned in 1878; chosen master in 1882; born 1807; died 1898. Of U.S.A.: Rollin, Bristol, Conn., 1826.

Atkinson. James, C.C. 1667, assistant 1697. Joseph, Gateshead, 1770-90. Lancaster : Thomas., $1767 \mathrm{f}$. Richard, $1785 \mathrm{f}$. Wm., 1817 f. Robert, apprenticed to W. Bell, died 1900 , aged 57, a clever mechanician. Thos., 38 Piccadilly, 1814-17.

Atlee. Henry, apprenticed in 1662 to Charles Rogers; C.C. 1671. Roger, apprenticed in 1664 to Job Betts, C.C.

Attbury, J., watch-movement maker, 15 York St., St. Luke's, 1835.

Attemstetter, David, Augsburg ; a celebrated enameller, 1610 .

Attwell. Thos., London ; clock, about 1750. - - near the Court House, Romford ; watch paper, C.C., about 1790 . Robt., Brown's Lane, Spitalfields, 1810-18. Wm., 11 Pitfield St., 1815-25.

Attwood, Geo., born 1746, died 1807; an eminent mathematician ; studied watch work, and reported to Parliament on Mudge's timekeeper, 1793.

Atwood. - Lewes; watch, 1774. Richard, 41 Poultry, 1800-10. Geo., 17 Leonard St., Shoreditch, 1820.

Auber, Daniel, Whitefriars, 1750.

Aubert. Jean Jacques, Paris ; " horloger du Roy," 1737. Etienne, Rouen, 1775. D. F., Geneva, 1820; afterwards partner in London with C. J. Klaftenberger. \& Klaftenberger, 157 Regent St., 1835-42.
Audebert, D., Amsterdam ; long-case clock, about 1720 .

Audemars, Louis, La Vallée, Switzerland, 1811.

Audley, Jos., apprenticed to Thos. Tompion in 1683.

Aughton, R., London; pull-alarm bracket clock, about 1720 .

Augier, Jehan, Paris; maker of large watches, about 1650 .

Aukland, Wm., London ; watch, 1790.

Auld, see Reid \& Auld.

Ault. Jos., Belper ; clock, about 1800. Thomas, 34 Prince's St., Leicester Sq., 1820-25.

Aussin, -, French cruciform watch, Wallace collection, about 1650.

Austen, John, Shoreditch; C.C. 1711; bracket clock with square dial, pullchime, black bell-top case, 1711-25. Cork; about 1820 he made three-wheel clocks (see p. 381 ).

Austin. Isaac, Philadelphia, 1785-1805. \& Co., 176 Oxford St., 1820. John, 136 Oxford St., 1830-40.

Autray, Paris; watch, 1750.

Aveline, Daniel, " 7 Dials " ; died 1770, when warden C.C. ; 1750-70.

Avenall (or Avenell), a family well known as clockmakers in Hampshire for two centuries. Ralph, Farnham; balance escapement clock, about 1640. Edwd., apprenticed to Joseph Duke; C.C. 1706; bracket chiming clock, "Avenell, London," about 1710. Jno., son of Edwd.; C.C. 1735. Wm. Avenall, Alresford, 1770.

Avery. - , church clock, Kingston by Mere, Wilts., 1740. Amos, Cheapside, 1774. Philip, Red Cross Sq., 1790-94.

Avice, - Reims ; watch, about 1723. Axeborough, - , Otley, 1730.

Aylosse, Elizabeth, apprenticed in 1678 to Joane Wythe (widow); C.C.

Aylward, Jno., Guildford ; lantern clock, about 1695 ; another about 1710 , said to be inscribed " John Aylward, Braintford."

Aymes, see Ames.

Aynsworth, J., Westminster ; maker of lantern clocks, 1645-80.

Ayres. Samuel, apprenticed in 1664 to Edwd. Norris, C.C. Richard, apprenticed in 1670 to Hy. Jones ; C.C. 1680 . Thos., 160 Fenchurch St., 1800-30. \& Bennett, 160 Fenchurch St., 1815-20.

Ayscough, Ralph, livery Goldsmiths' Company; St. Paul's Churchyard, 1758 ; 18 Ludgate St., 1766-76.

Baccuet, - , watch enamelled, painting, " Roman Piety," on back, about 1690.

Bachan, Henry, London; long-case clock, about 1770 .

Bachelder, Ezra, Denvers, U.S.A., 17931840 . 
Bachoffner, Andrew, 112 Shoreditch, 1775.

Backhouse, Jas., Lancaster, 1726 f., died 1747.

Backler, Benj., London ; long-case clock, Mr. R. Eden Dickson, about 1760. Benj., Masham, 1823.

Backquett, Davyd, C.C. 1632.

Baclulet, Mathieu, Paris, about 1640.

Bacon. John, brother C.C. 1639.

" Paid Mr. Bacon, clockmaker, of Tewkesbury, for a clock and case, $y^{e}$ summe of six pounds and five shillings," 1708. (" Diary of Thos. Newnham.") Charles, C.C. 1719. Jno., London; watch, 1810. Charles, escapement maker, 37 Gerrard St., Islington, was in the early days on the Council of the British Horological Institute, and took an active interest in its work; died at Barnet, 1917, aged 79.

Bacott, Peter, London, about 1700.

Baddeley, Phineas, apprenticed to Evan Jones 1652 ; C.C. 1661 ; long-case clock, signed "Baddeley, Tong," about 1720; long-case clock, dead beat escapement, about 1750, signed " Jno. Baddeley, Tong."

Badger. Hy., apprenticed 1672 to Jno. Harris, C.C. John, apprenticed to Brounker Watts, C.C. 1720.

Badiley, Richard, London ; long walnutcase clock, about 1730 .

Badley, Thos., Boston, U.S.A., 1712.

Badollet (several generations at Geneva).

J. J., 1770 . John, 50 Greek St., 1842.

Baffert à Paris; clock, Jones collection, S.K.M., about 1780 .

Baggs, Samuel, 3 South St., Grosvenor Sq., 1820-35.

Bagley, Thomas, apprenticed to Richard Morgan 1650 ; C.C. 1664.

Bagnall. Benj., Boston, Mass., about 1700. Benj., Charleston, U.S.A., 1740-60, (or Bagnell), W. H., 42 Union St., Bishopsgate, 1835-40; 193 Bishopsgate Without, 1842.

Bagnell. William, C.C. 1719. Wm., watch-spring maker, Greenhill's Rents, Smithfield, 1794.

Bagot, Jno., Lancaster, $1823 \mathrm{f}$.

Bagshaw. Edwd., apprenticed in 1681 to Thos. Wheeler; C.C. .1691. William C.C. 1722 . Hy., London; watch, 1820 .

Bagwell, Richard, 3 Queen St., Cheapside, 1790-94.

Bailey, Jeffery, “ at ye Turn Style in Holburn" ; C.C. 1648, master 1674; maker of lantern clocks. Jeremiah, C.C. 1724. Ed., 13 Oxford St., 1730. Jno., London; bracket clock, about 1730. Jno., Hanover, U.S.A., 1770-1815. Catherine, watch-case maker, 22 Clerkenwell Green, 1790-94. \& Upjohn, 12 Red Lion St., Clerkenwell, 1798. Chas., London, about 1805. Jno., London ; watch in case of gilt metal decorated with machine engraving, about 1780, S.K.M. ; another watch, h.m., 1812. W., 19 Radcliff Row, Clerkenwell, 1835. William, 10 Essex St., Strand. In 1885 he took over the well-known business of the late Mr. John Jones of 338 Strand, which business he carried on until the time of his death in 1911 .

Baillon. Albert, Paris; watch, about 1695, Mr. Evan Roberts. Estienne, Paris ; watch. about 1750 , Mons. E. Gélis. Jean Baptiste, Paris ; horloger de la Reine Marie Leczinska, 1751, later on horloger de la Reine Marie Antoinette; he did a large trade and was reputed to be the richest watchmaker in Europe; enamelled watch formerly in the Dunn Gardner Collection, S.K.M., inscribed " J. B. Baillon, horlog. du Roy." Francis, à Choudens, 1780.

Bailly l'Aîné, Paris ; an eminent maker, 1750-75; clock on elephant's back, about 1760. Fils à Paris, about 1780 ; watch, "Bailly, Paris," 1790.

Bain, Alexander, Edinburgh ; inventor of electric clocks, 1838-58.

Bains, Jno., Snaith, 1770.

Baird, John, 190 Strand, 1770-83. W. \& J., 4 Hatton Garden, 1810-30. Geo. Carlisle, 1833.

Baitson, Thos., Beverley, 1822.

Baker. Richard, brother C.C. 1685 ; pull quarter repeating bracket clock, Wetherfield collection, square ebony case, brass basket top. about 1680 ; 8-day clock, ebony marquetry case, square dial, cherub corners, no door to hood; also a similar clock in oak case, fine hands, 16851710. Henry, Maidstone; one hand lantern clock, about 1700 . "A silver Minute Pendulum watch with a silver outcase and a coat-of-arms engraven on it (a Lyon Passant with three Cross Croslets, made by Richard Baker, London), lost in Dunghil Fields nigh Whitechapel Church" (Lond. Gaz., March 3-6, 1689). "A silver watch with a shagreen case, with G. M. on it, and with Baker on the Dyal Plate" (Lond. Gaz., April 15-18, 1685). Richard, C.C. 1726. Francis, Poultry, 1738. Thos., Gosport; watch, about 1740 . - Hull, 1760. Pointer, London; repeating watch, h.m., 1772. John, 5 King St., Covent Garden; hon. freeman C.C. 1781 ; 1768-84. Hy., hon. freeman C.C. 1781, Edward, 33 White Lion St., 1785-1805, afterwards at Angel Terrace, Pentonville ; duplex watch, G.M., h.m., 1787. Thos., Upper Stamford St., 1833. W., 35 Long Acre, 1835-42 ; afterwards at 30 Cranbourne St. Thos., Devizes, 1842.

Bakewell, - , lantern clock, about 1700 , inscribed "Thomas Bakewell, on Tower Hill, fecit."

Balch. Of U.S.A.: Daniel, Newbury- 
port, 1760-90. Thos. H., died 1819. Chas. H., 1787-1808. Benj., Salem, 1837. Jas. (\& Lamson), 1842.

Baldwein, of Marburg. In conjunction with $\mathrm{H}$. Bucher, he made a clock similar to Fig. 40, p. 56, 1563-68.

Baldwin. Chris., apprenticed 1656 to Jno. Freeman, C.C. Thos., apprenticed 1672 to Jno. Benson; C.C. 1685 . Robt., apprenticed 1682 to Thos. Virgoe, C.C. Jno., C.C. 1685 . Jno., apprenticed 1691 to Stephen Rayner, C.C., long-case clock, minute hand curved in the Dutch style, inscribed " J. F. Baldwin, Feversham, Kent," about 1740. J., Andover, 1760. Geo., Sadsburyville, 1808-32. Anthony, Lancaster, U.S.A., 1810-30. T., 69 Curtain Rd., 1830-35. Thomas, 50 Brudenell Pl., New North Rd., 1840-42.

Baldwyn, Thomas, C.C. 1706.

Bale. Thomas, C.C. 1724. Robert Brittel, Poultry; dials bearing his name, 1813. Thos., Bristol, 1842.

Balestree, J., 2 Queen St., Soho, 1811. Baley, Thos., C.C. 1786.

Balfour, Gilbert, London; watch, 1760.

Ball. Victor, 1630-50. John, C.C. 1637 ; fine long lacquer-case calendar clock about 1760 , signed " Wm. Ball, Biceter," Mr.Geo. F. Glenny (see Fig. 724, p. 544). Jno., Newport Pagnell, 1760. Sam., High-Wycombe, 1786. Edwd., 32 Ironmonger Row, 1794. \& Macaire, watch-case makers, 32 Northampton Sq., 1820; 26 Myddelton St., 1835.

Ballantyne, Wm., 6 Cable St., 1815-20 ; 2 White Lion St., Goodman's Fields, 1835 ; $1820-42$.

Ballard, Geo., Frome, 1842.

Ballinger, Chas., 7 Northumberland Pl., Bath, 1845.

Balliston, Thos., 5 Banner St., 1842.

Balmer, Thos., Liverpool, 1833.

Baltazar. Chas., Paris; about 1710. Cadet (the younger), Place Dauphine, Paris, 1769 ; " clockmaker to Mesdames filles de Louis XV." Noel, Paris ; about 1770.

Balteau à Lyon; cruciform watch, Pierpont Morgan collection, about 1610 .

Banbury, John, C.C. 1685.

Bance, Matthew, Kintbury; watch dated 1775, owned by Mr. Thomas Fisher.

Bancroft, Wm., Scarborough, 1822.

Band, Wm., London ; watch, 1805.

Banfield, Jno., 116 Cheapside, 1814-17.

Banger, Edward, apprenticed to Joseph Ashby for Thomas Tompion 1687 ; C.C. 1695 (see p. 295).

Bangiloner, -, London; clock-watch, about 1660 .

Banister. Thos., Norton; long-case clock, about 1765 (see also Hedge \& Banister). Joseph, Colchester ; patented a crutch for clocks in 1836 (No. 7,083).
Henry, succeeded Jno. Grant the younger at 75 Fleet St., 1852, and remained there till 1860 .

Bankes, William, apprenticed 1690 to Ben. Bell ; C.C. 1698 ; on a large lantern clock, "Wm. Bankes in Sheffield," date about 1680 .

Banks. S. \& W., Leicester ; chiming clock, about 1760 . J. C. \& B., London; watch, 1802. J., 68 Long Alley, Finsbury, 1830-35.

Bannerman, Gilbert, Banff, 1760.

Bannister. Anthony. C.C. 1715 ; watch with sun and moon indicator, signed "Anthony Bannister," on dial " Bannister, Liverpool," about 1705. Thomas, London, about 1801. James, 14 Clerkenwell Close, 1820-35 ; 32 Prince's St., Leicester Sq., 1810-42. Thomas \& James, 39 Kirby St., Hatton Garden, 1825.

Banstein, John, Philadelphia, 1791.

Banting, William, C.C. 1646.

Barachin, Stephen (French), C.C. 1687. Barbaull, see Widman, J.

Barber. Jonas, Ratcliffe Cross, brother C.C. 1682 - Lincoln, wall clock on Smeaton-Franklin plan in the collection of Mr. Hansard Watt, about 1770. Jonas, Winster, Windermere; died 1720; the Rev. F. C. Townson has a long-case clock, “'J. Barber, Winster," about 1750 ; watch, " J. Barber, Winster," 1755. Wm., 30 Cornhill, 1785-94. Benjamin, 21 Red Lion St., Clerkenwell, 1788-94. Josh.y 168 Borough, 1795-1817. Hy., Landon; watch, h.m., 1805. Thos., 75 Lamb's Conduit St., 1810-17. Jas., York, f. 1814. \& Whitwell, York, 1818. Cattle \& North, 1830. Abraham, 56 Cheapside, 1835-42. \& North, York, 1838.

Barberet, Jacques, Paris ; octagonal watch, Garnier collection; cruciform watch, about 1620 ; splendidly enamelled watch, formerly in the Hawkins collection, about 1640.

Barbier le Jeune, sur le Pont Marie, Paris, 1770.

Barbot, Paul, Greek St., Seven Dials, 1768-69. et le Maréchal, Paris, much later.

Barcelet, Mathieu, Paris, about 1570. M. Leroux has a square table clock, with dome over, by him.

Barclay. (? Barkley) Samuel, apprenticed to George Graham; C.C. 1722. Hugh, Edinburgh, 1727. C., London; watch, 1815. James, 7. Jamaica Terrace, Commerical Rd., 1820; James Pyott succeeded him in 1873.

Barcole, John, admitted C.C. 1648.

Bareham, Samuel, 9 Chapel St., Pentonville, 1842.

Barford. Thos., apprenticed 1655 to Thos. Daniell, C.C. Henry, London; watch, 1780 . 
Bargeau, Peter, London ; long Oriental lacquer-case clock (Tempus fugit), 1740.

Baridon \& Fils, Geneva; gained a prize in 1823 for a curious gravity regulator, Geneva Horological School.

Baril. Lewis, Tokenhouse Yard, 1754-59. Bercher, 29 Prince's St., near Mansion House, 1763-72.

Barilon, - , Paris; watch, 1770.

Barin, John, livery C.C. 1776.

Barjon, John, C.C. 1685.

Barked, Edward, 2 St. Martin's Churchyard, 1820 .

Barker. William, C.C. 1632. Daye, London ; clock, about 1720, lantern movement, 7-inch dial arched, Mr. G. F. C. Gordon. Thomas, Portsmouth, clock, about 1740 . Wm., Wigan; about 1760 . B., New York, 1786. Benj., 21 Red Lion St., 1788. Thos., London ; watches, 1792 1813. R. (tools), 4 Benjamin St., Clerkenwell. 1820-25. James, 38 Colet Pl., Commercial Road, 1840-42.

Barkham, Geo., 1630-50; C.C.

"Barkley \& Colley, Graham's Successors"; on a long-case clock, with ingenious mechanism for a perpetual diary, about 1760; see Colley.

Barling, - Maidstone, 1835.

Barlow. (Booth) Edward, invented the rack striking work and cylinder escapement; born 1636, died 1716 (see p. 276). -, served as steward C.C. 1677. Thos., C.C. 1692. W. Ashton, 1760. Mat. Brumhill, Wilts., 1770. Jas. Oldham, 1775. Jno. Oldham; long-case clock, 1780. Benj., Ashton, 1780. Benj., Oldham, 1780-85. Geo., Oldham; long-case clock, about 1790 . J., London ; watch, 1798. J. H., \& Co., 7 Vere St., 1812-20.

Barnard. Nich., apprenticed 1662 to Thos. Claxton, C.C. Jno., apprenticed 1675 to Francis Dinnis ; C.C. 1682 . Ralph, apprenticed 1778 to Jno. Cotsworth, C.C. Phil., London ; long japanned case clock, about 1745. Wm., Newark, 1760-80. Wm., London ; watch, h.m., 1762. Chas., Ashton, 1770. Thos., 72 Strand, 17831823. \& Savory, 1786-99. \& Kidder, 72 Strand, 1809-12. Jno., 36 Little Sutton St., 1817. Jas., Peckham ; bracket clock, about 1825. Franz, 57 Leman St., 1840-42.

Barnardiston, Jno., London ; long-case clock, 1760 .

Barnes. Ri., Worcester; oval watch, S.K.M., about 1600 ; another, Schloss collection, about 1610. Geo., apprenticed 1693 to Josh. Allsopp, C.C. Jno., Badger Row, Red Lion St., 1770-94. Timothy, Litchfield, U.S.A.; maker of American clocks, 1790.

Barnett. John," at ye Peacock in Lothebury" ; apprenticed 1675 to Jno. Ebsworth; C.C. 1682 ; long marquetry case clock, ebonised dome top, 10-inch dial, Wetherfield collection. Mr. Hansard Watt has a very fine clock signed " John Barnett, Londini, fecit" (see p. 533). J., "the corner of Shakespeare's walk, near Shadwell Church, Ratcliff Highway," card, Hodgkin collection, about 1780 . G., 10 Staining Lane, Wood St., $1800 . \quad$ J., 48 Shadwell High St., 1810-15. J. W., watch-case maker, 43 Galway St., St. Luke's, 1835. Montague, 16 Swan St., Minories, 1842.

Barnish. Wm., Rochdale, died 1776. Jno., a well-known maker of Toad Lane, Rochdale, who probably succeeded Wm., is traced till 1816 .

Barnitt, Joseph, 23 London-Prentice St., Birmingham, 1768.

Barns. Timothy (Thomas), Lichfield, 1790. \& Co., 53 Duke St., Smithfield, 1800.

Barnsdale. Thos., Bale, Norfolk, 1770. John, City Rd., 1840.

Baron, Edmd., apprenticed 1692 to Thos. Feilder, C.C.

Baroneau, Louys, Paris ; clockmaker to the Queen, 1760; fine enamel watch, about 1680 .

Barr. Thos., Lewes; lantern clock, about $1700 .-$, Bolton; about 1790.

Barraclough, John, Haworth, 1750. Afterwards at Thornton.

Barratt, P., Strand, 1785 ; 71 Swallow St., 1812; 83 New Bond St., 1830.

Barraud. Hy., presented a spoon to C.C 1636 ; see Beraud. Francis \& Paul Jno., Wine Office Court, 1759-94; watch, h.m. 1756. Paul Philip, 86 Cornhill; master C.C. 1810, 1811; 1796-1813. Fredk. Joseph, Committee of C.C. 1813. \& Sons, 85 Cornhill, 1813-36 ; 41 Cornhill, 1838. \& Lund, 41 Cornhill, 1838-42.

Barret, - . In the churchwardens' book at Halifax Parish Church in 1720 is "Paid Wm. Barrett for Clock work $£ 0$ 9s. 0d."

Barrett. Simon, apprenticed 1668 to Joseph Wells; C.C. 1678. Robert, C.C. 1687. Thos., Lewes; known as a maker of lantern clocks; in 1690 he agreed to mend the town clock for twenty shillings. "Also hee to have four pounds yearley for ringing 'Gabriel ' the Curfew Bell at four in the morning and eight at night." Henry, apprenticed to Chas. Gretton ; admitted C.C. 1692. Samuel, C.C. 1701. Thomas, C.C. 1702. Joseph, Cheapside, 1738 ; clock-watch $4 \frac{1}{2}$ in. in diameter, pair of metal gilt cases, the inner one pierced, the outer chased, about 1760 , inscribed " Barrett, London." William, 50 Aldersgate St., 1783. Henry William, 24 Queen St., Bloomsbury, 1815 ; 25 Museum St., 1820 ; 18 Plumtree St., 1835-42. John, 47 New Compton St., 1820. 
Barridge, Jno., apprenticed 1654 to Hugh Cooper, C.C.

Barrington, Vrian, apprenticed 1677 to Nat. Delander ; C.C. 1684.

Barrister, Jas., 33 Fetter Lane, 1815-17.

Barron, - London; watch, 1830.

Barrow. Nathaniel, apprenticed to Job Betts 1653 ; C.C. 1660 , master 1689 ; in the Guildhall Museum are an astronomical watch and a repeater by him (see p. 325); "A large silver chain watch, having two motions, the hour of the day, and the day of the month, with a black case studded with silver, lined with red sattin, and a silver chain to it, made by Nathaniel Barrow, in London" (Lond. Gaz., July $26-30,1677)$. John, apprenticed 1671 to Francis Ireland; C.C. 1681, master 1714. Samuel, apprenticed to Jno. Barrow 1688 ; C.C. 1696 ; " at the Spring Clock in East Smithfield, near Hermitage Bridge" (see Gatewood) ; 8-day long marquetry case clock, "Samuel Barrow at the Hermitage," about 1705 . James, see Brown, Andrew. William, admitted C.C. 1709; Hatton, 1773, highly esteems the work of a watchmaker, named Barrow. Wm, Lancashire ; came to London before 1744 ; left London soon after 1746 (Ludlam).

Barry, Jas., Chippenham, 1845.

Barry, Waller, Still Yard, Tower, 1788-94.

Bartholomew. Jno., C.C. 1675. Josiah 25 Red Lion St., Clerkenwell; watch, B.M. He was a witness before the select committee of the House of Commons to inquire into the causes of the depressed state of the watch trade in $1817 ; 1800-42$.

Barthop, - Isleworth ; long-case clock, about 1780 .

Bartlett. Edward, London; watch, 1818. H. \& G., watch-case makers, 3 King Sq., 1830-35. Patten Sargent, born 1834 , died 1902; entered the employ of the watch company at Waltham, Mass., in 1855, where he designed several watch movements; was connected in 1864 with the inception of the National Watch Company, Chicago, afterwards the Elgin National Watch Company.

Bartley, Anrew (also Mark), Bristol 1842.

Bartlitt. Geo., f., York, 1801 ; Malton, 1810. Robt., Malton, 1823.

Barton. Samuel, brother C.C. 1641. Jas., Prescott, about 1750. Thomas, Cheapside, 1750-78; Earnshaw challenged him to a contest of work in 1776 Jos., Eccleston; long-case clock, about 1760. Jas., Whitehaven; watch, 1751, Rochdale Museum. T. \& J., Market Pl., Manchester; watch, h.m., 1770. John, 64 Red Lion St., Clerkenwell, 1780-83. Wm., London ; large watch with Turkish numerals, Captain H. D. Terry, on dial " Markwick
Markham, Wm. Carpenter," about 1780. Thos., 7 Bermondsey Sq., 1799-1823; Thos. Mudge, jun., refers to Thos. Barton as "eminently skilled." James, 194 Strand, 1819-23.

Bartram. Simon, petitioner for incorporation of C.C. and one of the first assistants, master 1646. William, C.C. ; 1684. \& Austin, 109, 103 Oxford St. ; card, B.M., 1808.

Bartrand, see Bertrand.

Barts, Geo. Fred., Neards Court, near Ssho Sq., 1775.

Barugh, William, C.C. 1715.

Barwell, Wm., Bath ; bracket clock, about 1700; month long-case clocks, about 1720, Mr. F. J. Young.

Barwick. A, Great Alie St., 1788-93. H. \& B., 35 Wapping, 1794-96.

Barwise. Nathanael, London ; clockwatch, 1770. Lett, Cockermouth, 1770. John, 29 St. Martin's Lane, 1790; Weston \& Jno., 1820-42; in 1841 John Barwise was associated with Alex. Bain in a patent for electric clocks, and in 1842-43 chairman of directors of the ill-fated British Watch Company. \& Sons, 24 St. Martin's Lane, 1819-23.

Basil, John, 76 St. Paul's Churchyard, 1768 .

Baskerville. Thos., Bond St. Stables, 1730. Richard, London; clock in the sacristy of Bruges Cathedral, about 1750.

Basnett, Wm., 1 Bond St., Bath, 1798.

Bass, George, admitted C.C. 1722.

Bassereau, Gui., Palais Royale, Paris, 1780 .

Basset. Thos., apprenticed 1668 to Isaac Webb, C.C. Jean, Jacques, Louis, York, f., 1771. Chas., 58 Upper East Smithfield, 1788-93; clock, Wm. Bassett, Mayfield, about 1790 , Mr. E. B. Faithfull. Geo. Francis, Philadelphia, 1797.

Bassold, Edwd., 55 King Sq., 1855 (afterwards Money \& Bassold).

Bateman. - , seventeenth-century oval watch belonging to the Rev. Chas. Beck, mentioned in vol. xxiii., Archreological Journal. Nathaniel Bateman said to have worked for Delander in 1730. Nathaniel, apprenticed to Nathaniel Delander ; C.C. 1747. Hy., 10 Bunhill Row, 1780-85. P. \& A., 10 Bunhill Row, 1798-1818. H., Dublin, 1802-5. Andrew, 5 Great Tower St., 1804-20. Teresa, 5 Great Tower St., 1820-30. Wm., 108 Bunhill Row, 1828-32.

Bates. Thomas, C.C 1684 Joseph, White Alley, Holborn; admitted C.C. 1687. T. P., Liverpool, 1780; issued a token " works, Duke St., Retail, Exchange St." Ed., London ; a good workman mentioned by Earnshaw, 1780-90. John, watch pinion maker, 40 Great Sutton St., 1820. \& Lowe, London; clock, about 1835. 
Bath. Thomas, 4 Cripplegate, 1740. Jas., Cirencester ; clock, about 1775. J. L., Bath, Scmerset, maker of grandfather clocks, musical clocks, and complicated watches. 1870-1920.

Batten. John, brother C. C. 1668. Edwd., apprenticed 1670 to Jno. Mark; C. C. 1677 .

Battersbee, - Manchester, 1770.

Batterson. Robert, C.C. 1693. Henry, C C. 1701. James, New York, f., 1708-9 ; also at Boston, " lately arrived from I.ondon." R., clocik, long-case, lacquer decoration, abcut 1770 .

Battie, Jas., Sheffield, 1770.

Battin, Thomas, apprenticed 1654 to Ed. Ward; C.C. 1661 ; a contrate second wheel of a "dyal" taken trom him, and judged by C.C. to be bad, 1658 .

Batting, - , Camomile St., 1842.

Battinson, Jno., Burnley, 1818.

Batty. Anthony, Wakefield, 1750. Jno., Halifax; long-case clock, 1760. Joseph, Halifax, 1760-70. Jno., Wakefield, 1770. Jno., Moorfields, 1775 Edwd., Lancaster, 1826 , f.

Baudit, Peter, 4 St. Martin's Lane, 1790-94.

Bauer, Carl, Amsterdam; cruciform watch, about 1650 .

Baufay, B., \& Son, 3 Bridgewater Sq., 1790-94.

Baugh, Valentine, Abingdon, U.S.A., 1820-30. 1745 .

Baugham, John, Bridgewater Sq., about Bauldwin, see Baldwin.

Baume \& Lezard, Paris ; clock, about 1830.

Baumgart, Charles, 37 Dean St., Soho, 1840-42, afterwards in Maddox St.

Baute \& Moynier, Geneva; watch, about 1823, dial gold à quatre couleurs, numerals of pearls, case with pearl decoration, Mr. H. K. Heinz.

Bautte, J. F., Geneva, 1820-25 ;.splendid watch by him, deccrated with enamel, belonging to Dr. Pasteur.

Bavis, Geo., C.C. 1687.

Bawdyson, Allaine, clockmaker to Edward VI., 1550.

Baxter. Wm., C.C. about 1640. Charles, C.C. 1681. Matt., St. Neots; watch, 1723. Pointer, London, 1772. Wm., London; watch, 1790. Thos., Conderton; long-case clock, about 1790. John, watch-case maker, St. Luke's, 1835. Thos. (Grimshaw \& Baxter), 35 Goswell Rd.; died 1897, aged 54 .

Bayes. John, brother C.C. 1647, warden 1658; maker of a watch given by Charles I. to Mr. Worsley on his removal to Hirst Castle, November 1647 ; another example, a lantern clock, inscribed "Johannes
Bayes, Londini," date on fret 1643 ; watch, S.K.M. Benjamin, apprenticed to Jno. Bayes 1661; C.C. 1675.

Bayford, George, Upper Shadwell.

Bayle, Thomas, C.C. 1703.

Bayles, Chas., London ; bracket clock, about 1760 .

Bayley. William, apprenticed 1654 to Ralph Ash ; C.C. 1663. Edward, C.C. 1658. "A silver watch with a silver studded case engraven Edwardus Bayley, London " (Lond. Gaz., December 19-22, 1687). Jno., Harrow, $1725 . \quad$ Geo., London; watch, $1750 . \quad$ \& Street, Bridg. water ; long-case clock, Col. J. B. Keene about 1750. S., London; watch, 1765. John, 106 Wood St., 1768-75. Richard, Ashford ; watch, $1780 . \quad$ Thomas, summoned to take up livery C.C. 1786 . \& Upjohn, Red Lion St., Clerkenwell, 1794. Simeon C., Philadelphia, 1794. Barnard \& Son, 3 Bridgewater Sq., 1800-5. Richard, 12 Red Lion St., Clerkenwell, 1807.

Baylie, see Bailey.

Baylis. J., Tewkesbury ; lantern clock, about 1700. Wm., Bristol, 1842.

Bayly. John, C.C. 1700 . Richard, Ashford; watch, 1770 .

Bayne, Wm., Alston, 1833.

Bayse, Thomas, C.C. 1695.

Bazeley, Nathaniel, C.C. 1694.

Bazin, Paris, about 1700.

Beach, Thomas, Maiden Lane, Covent Garden, 1765-70.

Beadle, Wm., apprenticed 1667 to $\mathrm{Wm}$. Raynes, C.C.

Beake, Jonathan, Savage Gardens, 1725.

Beal, Martin, 19 Gerrard St., Soho, 1842.

Beale. Jno., apprenticed 1658 to Nich. Coxeter, C.C. Robert, apprenticed 1677 to Bernard Rainsford, C.C. Chas., London ; watch, 1767. Wm., London ; watch, 1805 . Jas., 38 Regent St.. 1820-25.

Beard. Wm., apprenticed 1667 to Jas. Ellis, C.C. Chris., apprenticed to Jas. Atkinson 1670 ; C.C. Duncan, Appoquinemonk, U.S.A., 1755-97. Wm., Drury Lane, 1812-17.

Beare, John, Pilton, 1780.

Beasley. Thos., C.C. $1683 . \quad$ Nat., apprenticed 1686 to Hy. Hammond, C.C. John, C.C. 1719.

Beaton. Andrew, 22 Cannon Street Rd., St. George's East, 1835. \& Campbell, 110 High St., Whitechapel, 1840.

"Beatson, 32 Cornhill " ; M'Cabe's lowest grade full-plate watches, in silver cases, were so engraved.

Beauchamp, R., 147 Holborn Hill, 1819-23.

Beaufort, Henri, Paris ; watch, revolutionary decimal time, about 1796.

Beaumarchais, see Caron.

Beaumont. -, said to have made a 
clock at Caen in 1314 (see p. 27). Philip, apprenticed 1689 to Wither Cheney, C.C. Joseph, Howden, 1770.

Beauvais. Anthoine, Paris, 1544 (see p. 404). Simon, admitted C.C. 1690 ; a celebrated maker; among his productions is a double-case verge, with a rack and pinion motion work, the hour hand travelling round the dial in twelve hours, but the minute hand travelling only from IX. to III., in one hour, and, when arrived at the III., jumping back to the IX. The hand-setting is between III. and IIII., and the centre of the dial and motion work are hidden by a sn!all painting on ivory. There is in the B.M. a similar watch of a later period by a Germin maker ; 16901730. Paul, London; watch, about 1730.

Beavin, Hugh, 34 Marylebone St., Golden Sq., 1800-30.

Beavis, John, Peartree St ,1789. John, his son, afterwards at Wellington St., died 1860

Beck. Richard, "near ye French Church," C.C. 1653. Nicholas, apprenticed 1660 to Thos. Webb; C.C. 1669. Joseph, C.C. 1701. Christopher, Bell Alley; apprenticed to Francis Perigal ; admitted C.C. 1761, livery 1787. James, 5 Sweeting's Alley, Cornhill, 1815-23, see Bentley. Long-case clock about 1790, inscribed "Thos. Beck, Bishampton."

Becke, John, apprenticed to John White, but served Daniel Quare; C.C. 1681.

Becket, Francis, Chester-le-Street, 1770.

Beckett. M., long-case clock, Mr. T. F. Walker, about 1710. Jno., 23 Greenhill's Rents, Smithfield, 1796-1803. Sir E., see Denison.

Beckitt, Thos., Durham, 1770. Mann, Durham, 1780.

Beckman. Daniel, C.C. 1680 . "A watch with a double case of Silver, with Minutes, Seconds and Hours, the name [Beckman] under the Crystal" (Lond. Gaz., March 27-31, 1701). John, C.C. 1695. Daniel, C.C. 1726.

Beckford, Wm., London ; watch, about 1780.

Beckner, Abraham, Pope's Head Alley ; admitted as a brother C.C. 1652, warden and died 1665; known as a maker of oval watches ; 1650-65.

Beckwith, Wm., Rotherhithe St., 1794.

Beddel, see Biddle.

Bedell, Peter, Hull, 1822.

Bedford, Helkiah, in Fleet St. ; C.C. 1667; maker of lantern clocks; to him in 1668 was apprenticed Richard Abbott. Sam., apprenticed 1691 to Joseph Windmills, C.C. Wm., London; watch, Nelthropp collection, about 1790. Alfred, for thirty years London representative of the Waltham Watch Company; died 1912, aged 79 .
Beefield, - London; watch, 1760.

Beeforth, Jno., York, f., 1680.

Beeg, Christiana, C.C. 1698 .

Beesley. Jno., Dean St., 1725. Jas., Manchester ; long-case clock, about 1760 ; watch, 1787. G. B., London, died 1918, aged 80 .

Begulay, Jno., Swanton, Norfolk; church clock at Ludham, 1676.

Beliard, Francois, watch, about 1780 ; repeating watch," Beliard Hor du Roy," about 1780 .

Belk, William, Philadelphia, 1796.

Bell. Benjamin, apprenticed to Thos. Claxton 1649; C.C. 1660 , master 1682 ; maker of a large verge watch weighing over 8 oz." 1660-83. "Taken way by 4 Highwaymen in Maiden-head Ticket, A plain silver chain watch made by Benjamin Bell, the case lined with Red Satten, on the back of the case a Perpetual Almanack and little spikes placed at every Hour" (Lond. Gaz., July 7-10, 1690).

"Lost on the 2nd inst., a gold watch with one motion, having a gold chain and a steel hook; made by Benjamin Bell. Whoever brings it to Mr. Sweetapple, a Goldsmith in Lombard Street, shall have 2 guineas reward" (Lond. Gaz., May 4-7, 1691).

Lost a silver watch with a black case studded with Silver, made by Benjamin Bell, with an Onyx Stone in a gold Ring tied to the watch in which is engraven the Head of King Charles the First. Whoever brings the said watch and seal to Mr. William Penrice, at the Black-Boy in Gracechurch Street, shall have 2 guineas reward " (Lond. Gaz., December 3-7, 1691).

Bell. Joseph, C.C. 1691. Thos., apprenticed 1691 to Sam. Mather, C.C. John, C.C. 1719; 30-hour long-case clock, "fecit 1751," Mr. C. Atkinson. Jno., New York, 1734. Wm., Sunderland, 1740. Joseph, Shoe Lane, 1759. Jno., Gàrstang, 1760. Peter, Garstang, 1770. Jno., Doncaster, 1780. James, watch, h.m., 1792; 131 Mount St., Berkeley Sq., 1842. Thos., London; long-case clock, about 1800. Wm., 2 Clement's Lane, 1812-18. Jno., Leyburn, 1822. John, musical clockmaker, 8 Elm St., Gray's Inn Lane, 1835-40, Henry, Mount St., 1850. Jno., Bath, 1855; Jas., Edinburgh, 1855. William, Lancaster, apprenticed to his uncle William Hodgson, died 1910, aged 80 .

Bellamy, Adey, 10 Poultry, 1779-85.

Bellard. John, C.C. 1674. François, Paris ; horloger du Roy, 1783.

Belle, T., French clock, about 1780 .

Bellefontaine, A., 59 Brewer St., Summers Town, 1835.

Belliard, Chas., Pall Mall, 1769-94.

Bellin, see Mott \& Bellin. 
Belling, John, Bodmin, 1780. 1840.

Bellinge, Jas., Liverpool, 1770

Bellinger, Richd., apprenticed 1676 to Edwd. East; C.C. 1686 . Ch., apprenticed 1686 to Jno. Pellinger, C.C. John, C.C. 1725.

Bellinghurst, Henry, Aldersgate St. ; liveryman C.C. $1776 ; 1765-77$.

Bellis, Jas., 9 Pall Mall, 1769-88.

Bellman, Daniel, Broughton, Lancs., 1818 .

Bellune, Peter, 1630-50 ; C.C.

Belon, Pierre, Paris ; clockmaker to the dowager Queen, 1649.

Belsey, John, Poland St., 1835.

Belson, Thos., 1630-50 ; C.C.

Benard, F., Paris ; oval watch with sundial inside cover, about 1600 (sun-dial signed "Chauvin ") ; Pierpont Morgan collection.

Benbrick, Jas., apprenticed 1671 to Helkiah Bedford, C.C.

Benbridge, Thos., apprenticed to Robt. Starr 1669 ; C.C. 1683.

Benfey, B., \& Son, 3 Bridgewater Sq., 1794.

Benford, John, 1 Garnault Pl., Clerkenwell, 1832-38.

Benjamin. Joel, 12 Bury St., St. Mary Axe, 1820-35; J. Benjamin \& Co., 1840. M., Bernard St., Commercial Rd., 1820; 77 Leman St., 1840-42. A., Myrtle St., Hoxton, 1835.

Benn. Thos., apprenticed 1660 to Ben. Hill, C.C. Jno., C.C. 1678. Robert, Fleet St. ; C.C. 1716. Anthony, 1750; died when master C.C. 1763.

Benner, Johannes, "Aug " ; table clock, about 1680 .

Bennett. William, C.C. 1607. Thomas, apprenticed 1667 to Henry Harper; movement of his condemned by C.C. 1677 , John, Fleet St. ; C.C. 1678. Mansell, Dial and 3 Crowns, Charing Cross; C.C. 1685-99 ; fine marquetry long-case clock, S.K.M., about 1695; Mr. Robert Meldrum has a very similar specimen. John, Bristol; C.C. 1712. Richard, C.C. 1715. Samuel, C.C. 1716. Thomas, apprenticed to Thos. Windmills; C.C. 1720 ; fine long-case clock in the Wetherfield collection, on the inside of the door directions for winding, and at the foot thereof "Thos. Bennett, at the Dial in Exchange Alley, 1722." William, New St. Hill: C.C. 1729. J., Bugg Lane, Norwich ; watch, 1786. Thos., Norwich ; watch, 1795. R., 159 Fleet St., 1817. Joseph, 60 Red Lion St., Holborn, 1830-38. Wing, \& Co., 60 Red Lion St., Holborn, 1840; " to H.R.H. the Duke of Sussex" ; watch paper, C.C. E., Stockwell St., Greenwich, 1840. John, 45 Seymour Place, 1842. John, Greenwich, 1810; John, his son, did a large business in Cheapside from 1846 ; Sheriff of London in 1872, when by virtue of his office he was knighted in commemoration of a Royal visit to the City; died 1897, aged 81 .

Benniworth, T. \& W., St. Albans, 1780.

Benoit. J. E., watch, apparently English, about 1780. A. H., Versailles; born 1804 , died 1895 ; many fine watches, signed " A. Benoit à Paris."

Bensley, J., maker of a watch for the Duke of Sussex, 1790-1820.

Benson. Jno., apprenticed 1652 to Jas. Starnell ; C.C. 1669; long-case clock dated 1709. Samuel, C.C. 1700 ; watch, 1730. - Whitehaven; long-case clock, about 1760. \& Higgs, London; bracket chiming clock, Sheraton case with lionhead handles, about 1790 . William, watch and clock spring maker, 60 St. John's St., 1818-23. Robt., 16 Wilderness Row, 1818-40 ; auditor Watch and Clockmakers' Pension Society 1820.

Bent, Wm., Chadwell St., 1820-44.

Bentele (?' Bentley), Jacobus, clock, Imperial collection, Vienna, 1735.

Bentley. John, Thirsk, 1770. Sam., Kingsbridge; watch, 1790. \& Beck, 1815. John, 5 Pope's Head Alley, 1820; Sweeting's Alley, 1823 ; " foreman to Jas. McCabe," watch paper C.C.

Benton, Wm., London; -watch, h.m., 1825 .

Benwell, B., London ; watch, 1785.

Berain, J., Paris; designer and chaser of clock cases, 1655-1711.

Berard,--, London ; watch, about 1730.

Beraud. Henri, Sedan, 1565 . - oval watch, about 1600 , signed " $\mathrm{A}$. Beraud à Bloys," Garnier collection. Jas., 1632. Hy., maker of a watch in the form of a shell, silver case enamelled, crystal over dial, about 1650 ; C.C., but date of election uncertain.

Berault, Jno., apprenticed 1691 to Thos. Jones, C.C.

Beresford, Thos., London ; watch, 1828. Berg, F. L., Augsburg ; table clock, Nelthropp collection, 1719.

Bergier, S., Grenoble ; watch, Marfels collection, about 1550 .

Bergstien, Lulam, 113 Great Tichfield St., $1840-42$.

Berguer. John, 44 Great Russell St., Bloomsberry, 1810-20. Frederick, 201 High Holborn, 1810; 135 High Holborn, 1818-20. Franz, 17 Vere St., 1817. Charles, musical clock maker, 13 Richmond Buildings, Soho, 1825.

Berkenhead, John, 31 Gutter Lane, 1783-94.

Berkley, -, London; watch, 1810.

Berlinson, Hy., Ripon, 1833.

Berman. J., \& Co., wooden clockmakers, 40 Norton Folgate, 1830-35. 
\& Co., 30 Park Terrace, Regent's Park Rd., 1830-42.

Bernard. Nicholas, Paris; watch in case of rock crystal, primitive movement, balance-cock pinned on, about 1590, Pierpont Morgan collection; two watches, bearing the same name, S.K.M., one about 1660 and the other about 1690 . E., Southampton ; clock, about 1770.

Berninck, Jan, Amsterdam; watch, B.M., a French enamelled inner case by G. Bouvier, outer repoussé case by $\mathrm{H}$. Manley, about 1750.

Bernstein, H., Glasgow, 1830.

Berquez, Francis, 17 Vere St., 1822 ; 6

Thayer St., Manchester Sq., 1825-35.

Berquin, Urbain, Paris ; clock, 1680.

Berraud, see Barraud, also Beraud.

Berres, T., London ; watch, h.m., 1793.

Berridge. Jno., Boston ; made a clock with compensated pendulum 1738 for $\mathrm{Mr}$. Fotheringham, a Quaker of Holbeach. Wm., 69 Oxiord Rd., 1770-94. Robert, 2 John St., Oxford St., 1790-95. William, 4 Holles St., Cavendish Sq., 1800-20, see Bowra.

Berrington. Uriah, apprenticed to Nathaniel Delander; C.C. 1684. -, Bolton; watch, 1808. Jas., St. Helens, Lancs., 1818.

Berrisford, Edwd., apprenticed 1663 to Ben. Wolverstone, C.C.

Berrollas, Joseph Anthony, Denmark St., St. Giles-in-the-Fields, 1808 ; Coppice Row, Clerkenwell, 1810: afterwards 51 Wellington St., Goswell Rd. ; an ingenious watchmaker. In 1808 he patented a repeater somewhat similar to Elliott's, in 1810 a warning watch, in 1827 an alarm watch, also pumping keyless work (p. 615) ; 1800-30.

Berry. John, St. Clement's Lane ; apprenticed 1674 to Richd. Pepys; C.C. 1688 , master 1723 ; maker of a long-case clock at Merchant Taylors' Hall, arch dial, brass figures holding trumpets on top of case ; 1688-1730. "Lost Nov. 14th, 1705, from a Gentlewoman's side between Honey Lane market and Great Eastcheap, A plain Gold Watch case. Whoever brings it to John Berry, watchmaker at the Dial in Clement's Lane, Dombard St., shall have 20 s. reward for so doing " (The Daily Courant, 15th Nov. 1705). Francis, Hitchin; lantern clocks, about 1700 . Samuel, C.C. 1705. John, St. Clement's Lane; C.C. 1728. Jas., Pontefract; about 1740. Jno., Manchester; 1760. Wm., London; watch, 1815. Frederick, 2 Arcade, Hungerford Market, 1842.

Berthoud. Ferdinand, born in Switzerland 1727; went to Paris when nineteen and settled there ; died 1807 ; an eminent watchmaker, author of " Essai sur 1'Horlo- gerie," "Traité des Horloges Marines," "Histoire de la Mesure du Temps," and other works containing a mass of useful information concerning the history, theory, and practice of the horological art, dealing with Harrison's, Sully's, and le Roy's inventions, and, indeed, everything known in Berthoud's time. There are three clocks by him in the Wallace collection, one a splendid regulator in case of ebony with boldly chased mounts of gilt bronze; around the dial is a serpent with the head and tail meeting-an emblem of eternity. This clock is said to have been taken from the Iuileries in 1793, having been whitewashed to hide its value. It and a commode were sold in Paris some years ago to the Marquis of Hertford for 100,000 francs. Louis, Paris ; nephew of Ferdinand ; died 1813 ; watch, " Berthoud Frères à Paris," about 1800, Evan Roberts collection.

Bertram, William, died in 1732 , when master C.C.

Bertrand. Michand, "hor du Roy" (Francis I.), 1515-47. Josèphe, Paris (garde-visiteur), 1769. Robert, 2 Stewart St., Spitalfields, 1790-94; Mr. A. E. Owen has a long-case clock signed " Robert Bartrand, London," dating from about 1770. L., Paris, 1810.

Berwick, Abner, Berwick, U.S.A., 1820. Besse, Jeremy, 4 Richmond Buildings Soho Sq., 1840-42.

Best. Robert, 5 White Lion Court, Birchin Lane; a watch by him, S.K.M., hall mark 1769 ; 1765-88. Thos., 3 Red Lion St., Clerkenwell ; between 1770 and 1794 he made a large number of watches for the Dutch market ; also known as a maker of musical clocks and watches. T., at the Dial in Lewes ; card, B.M., 1780. Thos., Newcastle ; watch, 1785. Robert (formerly foreman to Brockbank,) 4 White Lion Court, Birchin Lane, 1790; 4 Sweeting's Alley, 1798 ; 1 Windsor Place, St. Paul's 1810-20. He attested the value of Earnshaw's improvements in 1804. Richard, 3 Fountain Court, Strand, 1830-42.

Bestwick. In 1672 Jas. Dearmar was apprenticed to Katherine Bestwick, widow C.C. Henry, C.C. 1686.

Bethell. R., London; watch, 1760. Jno., Stowmarket; clock, about 1800 .

Beton, Jno., London; watch, 1800.

Betson, J., London ; watch, 1797.

Betterton, -, London; watch, about 1780.

Bettinson (or Bettison), Solomon, Newark, 1776-92.

Betts. Samuel, back of Exchange; short train watch by him, about 1645 (see p. 277). He was an early member of the C.C., and in 1656 attested the genuineness of Jas. Lello's masterpiece. In the 
-Wetherfield collection is a 30 -hour bracket clock by him; died before 1675 (see Varquet). "Lost on the 8th Inst. betwixt Enfield and Wormley, on the rode to Warre a gold watch with a case and chain of gold, the Chrystall out, and the case lined with Pink-coloured Sattin, made by MIr. Betts in Lumbard Street. Whoever shall discover and return or cause it to be returned to Mr. Austin, Goldsmith at the Starre in Fenchurch St., shall have 40 s. for his peynes" (The Intelligencer, 13th June 1664). Job, C.C. 1656. "Stolen from Cheyne Rowe, of Walthamstowe, in Essex, Esq., a gold watch with a gold chain made by John Betts, with a silver Drinking Cup and other Plate. Whoever brings the said watch and chain or the watch only to MIr. Johnson, Jeweller, at the 3 Flowerde-Luces in Cheapside, shall have 20s. reward, and charges, or if pawned or sold their money again with content" (Lond. Gaz., August 11-15, 1692). Samuel, apprenticed to Samuel Davis for Job Betts 1675 ; C.C. 1682 ; calendar watch with revolving ring dials, to which a figure of Time points, in Dover Museum. In the G.MI. is another specimen of his work: bracket clock, square dial, walnut case, Wetherfield collection, 1682-1700.

1725 .

Bettwood, Jno., Rywick ; watch

Beverley, Jas., apprenticed 1683 to Robt. Doore ; C.C. ; bracket clock, about 1695; watch pendulum balance, about 1700 , inscribed " Ja. Beverly, London."

Bevington, J., Bolton, Lancs., 1814.

Bewley, George, Whitecross St. ; C.C. 1780 .

Bezant, A. W., Hereford; watch, 1840.

Bezar, Stephen, brother C.C. 1648.

Bibberton, Thos., Silver St., 1774.

Bibley, Jno., Corporation Row, 1790-94. Bickerlo, see Poole.

Bickerstaff, Wm., Liverpool, 1770.

Bickerton, Benjamin, 14 Jewin St.,

1795-1810. T. W., 14 Jewin St., 1816-20.

Bickley, Thomas, 195 Ratcliff Highway, 1790-94.

Bicknell. Francis, apprenticed to Job Betts 1653 ; C.C. 1665 . Joseph \& Co., 119 New Bond St., 1807-13.

Bickton, Geo., London; watch, 1775.

Bidard, - , watch mentioned by Thiout, about 1730 .

Bidault, Paris (see p. 405); a long succession of court clockmakers: Claude, 1628, lodged at the Louvre 1642; Henri Auguiste, succeeded his father at the Louvre 1652 ; Augustin François, 1693.

Biddle, Joseph, C.C. 1684.

Bidlake. Jas., 31 Minories, 1765-94. James, 16 Sun St., 1798-1804 ; livery C.C. $1816 ; 48$ Chiswell St., 1816-20. Thomas,
16 Sun St., Bishopsgate St., 1804-18; livery C.C. 1818 . James, \& Son, 48 Chiswell St., Finsbury, 1820-45.

Bidles, Thomas, London; maker of bracket clocks, about 1760 .

Bidley, Wm., 24 Rahere St., Clerkenwell, 1840-42.

Biefield, Chas., London; watch, 1780.

Bieler à Bienne, calendar watch, about 1790.

Bigaud, Paris, about 1750 .

Bigg, Ben., apprenticed 1678 to Robt. Cooke, C.C.

Biggs, Roger, 5 Crescent, Jewin St., 1800 .

Bilbee, - , London ; long-case 30 -hour clock, one hand, about 1710.

Bilbie. A well-known Somerset family of clockmakers. The Hon. H. Hannen has a lantern clock by Thomas Bilbie dating from about 1660 ; the fret in front shows the royal arms, and the side frets are of the dolphin pattern. Among other specimens are a long-case clock by Edward Bilbie, Chewstoke, about 1700; one of later date by Thos. Bilbie, Chewstoke; an 8-day long-case clock by William Bilbie, of the same place.

The following is from an upright gravestone at Oxbridge :-

$$
\begin{aligned}
& \text { "Bilbie, thy } \\
& \text { Movements kept in play } \\
& \text { For thirty years or more, } \\
& \text { "We say. } \\
& \text { "Thy Balance or thy } \\
& \text { Mainspring's broken, } \\
& \text { And all thy movements } \\
& \text { Cease to work. }
\end{aligned}
$$

"John Bilbie, of this parish, clockmaker, who died Sept. 13, 1767, aged 33 yeirs."

Bilcliff (or Bycliff), York. Jno., i., 1617. Robt., f., 1627. Jno., f., 1639. Robt., f., 1653.

Bilger, Matthias, watch-spring maker, 4 New St., Covent Garden, 1790-94.

Billie, John, C.C. seized watches and movements by him 1687 .

Billing, H. C., Cheapside, 1835.

Billinger, Jno., C.C. 1637.

Billinghurst. Wm., apprenticed to Thos. Fenn 1668; C.C. Anthony, apprenticed to Helkiah Bedford 1673 ; C.C. Wm., apprenticed 1694 to Sam Watson, C.C. Henry, 67 Aldersgate St. ; livery C.C. $1766 ; 1760-71$.

Billings, Jno., Bishopsgate, 1775.

Billington, -, Harborough, 1760.

Bllon \& Co., Philadelphia, 1797.

Billop, William, C.C. 1688.

Bindley, - , apprenticed 1674 to Rich. Pierce, C.C. William, 24 Rahere St., 1842

Bingham. Thos., watch-chain maker 3 Middle Row, Holborn, 1769-81. Wm., 27 Bucklersbury, 1842. \& Bricerly. Philadelphia, 1778-99. 
Bingley, Giles, apprenticed 1692 to Edwd. Eyston, C.C. John Bingley, watchmaker, advertised for in Lond. Gaz. lst June 1696.

Bing, Dan, Ramsgate, 1775.

Bings, Edward, "Whereas there was stolen from the House of Mr. Thos. Dummer in Wellclose on Saturday night, between the hours of 9 and 11 o'clock, a Gold Pendulum Watch with a chain made by Mr. Edward Bings. You are desired to stop them and give notice to Mr. Thos. Beach, Goldsmith, at the Black-a-Moors Head in Cheapside, and you shall have 2 guineas Reward" (Daily Courant, 23rd Sept. 1706).

Binks. Thos., Birmingham, 1740. London; watch, G.M., about 1820.

Binley, J. W., Ironmonger Row, Old St., 1790.

Binns. - Halifax; clock 1720. George, 137 Strand, 1832-38.

Birch. Thomas, apprenticed to Thos. Mills 1649 ; C.C. 1658 ; Mr. John H. Baker has a lantern clock inscribed "Thomas Birch in the longe walke Neere Christ Church Londini fecit." Thos., apprenticed 1675 to Sam Clyatt ; C.C. 1682. Richard, Bread St., Birmingham, 1776-87. William, succeeded Wm. Turner at 173 Fenchurch St., about 1840 ; died 1903, aged 88 .

Birchall. \& Son, Warrington, 1770. M., Derby, 1790. Wm., 5 St. James's Walk, Clerkenwell, 1816 ; 5 Wellington St., 1834-42. Peter, a well-known chronometer maker. In partnership with Appleton, he succeeded Molyneux at Southampton Row ; shortly after Appleton's death he disposed of the business to Wm. Cribb ; lived subsequently at Islington; died 1885 , aged 85 .

Bird. Michael, apprenticed to Ed. Gilpin in 1648; brother C.C. 1682; bracket clock inscribed "Michael Bird, London." On a 30-hour clock, one hand, about 1650 , was inscribed "Michael Bird, Oxon." Wm., apprenticed 1667 to Hy. Crump, C.C. Luke, apprenticed 1675 to Jas. Delander; C.C. 1682. Nat., C.C. 1693. Edwd., London, 1710. Robert, Yeldham, about 1740 . Thos., London ; watch, h.m. 1753 ; 10 Salisbury St., Strand, 1816. Wm., London; watch, 1760 . John, one of the examiners of Harrison's timekeeper 1765. \& Branstor, 30 Cheapside, 1775. Jacob, 7 Cornhill, $1783 . \quad$ Rich., watchchain maker, Bartlett's Buildings, 1794. Edward, Bristol, about 1810. Samuel Joseph, watch-case maker (apprenticed to Jaspar Swindells), Little Compton St. ; C C. 1813. John, \& Son, 19 Bartlett's Bulldings, Holborn, 1822-25. John, 11 St. John's Sq., 1840-42.
Birdwhistell. Francis, C.C. 1687. Isaac, C.C. 1692 ; plain pair-case gold watch, small swivel bow to the inner case, larger bow on the outer one, high movement, very rich gold dial, nicely wrought square pillars, finely engraved and pierced balance cock, excellent work throughout; 1692-1705. Thomas, C.C. $1693 . \quad$ John, C.C. 1718.

Birge. Mallory \& Co., Bristol, Conn., 1830. Peck \& Co., 1830. John, Bristol, 1830-37.

Birkhead, Nicholas, removed from King's Head, Holborn, to White Hart, Knightsbridge (Lond. Gaz., 29th May, 1st June 1693).

Birley, J., Sheffield ; curious watch, one hand, " 1638 " on metal dial in place of name, probably made sixty or seventy years after that date.

Birney, Jno., Templepatrick, 1785.

Birt, Nathaniel, London; long-case clock, square dial, about 1710 .

Bisbee, J., Brunswick, U.S.A., 17981825 .

Bishop. Samuel, Portland St., 1769-94 ; hon. freeman of C.C. 1781. Thos., Wych St., 1774 ; watch, date on movement 1810. James Griffin, 97 Fetter Lane, 1816-24. William, 70 New Bond St., 1830.

Bisot, Jacques, Paris ; clockmaker to the Duchesse d'Orléans, 1681.

Biss, E. H., Bath, 1850.

Bisse, -, English alarm clock in gilt metal case, about 1620, S.K.M., signed "Edward Bisse Fecit." The dial is provided with projecting pins for feeling the time at night, see Bysse.

Bissett, Jas. (late Gibson), 12 Sweeting's Alley, Royal Exchange, 1815-20.

Bittleston, John, 207 High Holborn, 1765-94; hon. freeman C.C. 1781 . Example of his work-a very curious astronomical watch, with two elaborate enamel dials-one at the front, and one at the back-showing the hour and minute both sides, two centre seconds-one the usual long hand, the other having a small rotating enamel dial-day of the month, day of the week, the month, moon's age, the tide, and a regulator, case pinchbeck, with a border each side of fine old paste in imitation of rubies and diamonds.

Bittner, William, 26 Dean St., 1840-42.

Bixler. Christian, Easton, Pennsylvania, U.S.A.; clock, about 1750. Christian, Easton, 1785-1830; a famous 8-day clock manufacturer.

Black, W. C., born in Scotland, a student at the British Horological Institute, settled in Buenos Ayres, 1887; died 1914.

Blackborrow, James, admitted C.C. 1711: died 1746, when warden. 
Blackbourn, Saml., London; watch, about 1780 . 1730 .

Blackbourne, William, Paternoster Row,

Blackburn. William, summoned to take up livery C.C. 1786 . Jno., watch-spring maker, 20 Aldersgate St., 1789-99; watch so named, 1790. Robt., Lancaster, 1817, f.

Blackhall, J., London; watch, 1800.

Blackie. Geo., Musselburgh ; long-case dead-beat clock, about 1820, musical barrel playing on fourteen bells added, Norman-Shaw collection. George, born in Scotland; settled in Clerkenwell as a duplex escapement maker and manufacturer; afterwards took Wilson \& Gandar's shop at 431 Strand; died 1885, aged 74 .

Blackmore, Jno., apprenticed 1689 to Ben. Bell, C.C.

Blacknell, Peter, London ; bracket. clock, about 1705 .

Blacksmith, Robt., London ; watch, 1831.

Blackwell. Thos., C.C. 1654 . J., 43

Plumber St., City Rd., 1820.

Blainville, - Rouen; calendar watch, about 1795, Mrs. Geo. A. Hearn.

Blake. Jonathan, Fulham ; watch, 1784.

Wm., Whitecross St., 1789-90. Chas., 14

Bishopsgate Within, 1813.

Blakeborough. Henry, Burnley, 1818. Richard, Ripon, 1838.

Blanchard. Robt., within Temple Bar, 1675. Abraham, London; watch, 1730. Charles, Bartlett's Buildings, London; long-case clock, about 1750; chiming quarter bracket clock, square black case, strike-silent, bronze, handle on top, about 1760. Wm., Hull, 1822.

Bland, Jas., 33 Norton Folgate, 1816-23.

Blandford, Hy.W., London; watch, 1794.

Blanford, William, born in London 1838 , emigrated to America in 1879 where he died, 1920. Maker of a wonderful astronomical clock now erected in the Public Library Aurora, Illinois.

Blay, William, 6 Princes St., Leicester Sq., 1825 .

Blaylock, Jno., Carlisle, 1830-42.

Bligh, Thomas, watch-case maker, 37 Great Sutton St., 1820.

Blinker, Thos., London, about 1745-70.

Bliss, Ambrose, C.C. 1653 ; sig $_{1}$ ed a petition in 1656 .

Blissett, Isaac, 70 Leadenhall St., 1823.

Block, Francis, apprenticed 1689 to Jno. Bellinger, C.C.

Blog, - 129 Aldersgate St., 1825.

Bloud, Ch., à Dieppe, 1660 .

Blundell. Jno., apprenticed 1678 to Geo. Nau; C.C. Richard, threatened with prosecution by C.C. for exercising the art, not being admitted; he promised to take up his freedom at the next quarter court, 1682. William, C.C. 1715. Jos., Dublin; bracket clock, about 1770. Henry, musical clock maker, 7 Red Lion St., 1830, see also Walker \& Blundell. Thos., Liverpool, 1833.

Blundy, Joseph, 21 St. John St., Clerkenwell, 1781; Brookes Market, 1790.

Blunt, Morris, 1630-50; C.C.

Boad, Thos., apprenticed 1684 to Robt. Nemes; C.C. 1692.

Boak, Samuel, Golden Spread Eagle, Without Aldgate, 1692.

Boardman, T., London ; watch, 1774. Chauncey, Bristol, Conn., 1815-38.

Bobeus, Alphee, à Tolose ; alarm watch about 1620, Mons. E. Gélis.

Bobinet. Abraham, cruciform watch in a case of crystal with a gilt and engraved cross, about 1630 , probably French, Pierpont Morgan collection. Chas. (French) watch in circular crystal case, S.K.M., about 1650, also (Salting collection) a cruciform watch in crystal and silver case; a circular watch by him in an agate case is in the Pierpont Morgan collection.

Bock, Johann, Frankfort ; oval calendar watch, about 1620; Pierpont Morgan collection ; clock, Vienna Treasury, about 1630 ; watch showing days of the month, about 1640 .

Bockel, Mathys, Haarlem ; oval watch, S.K.M., 1610.

Bockels, - Amsterdam ; in the Roskell collection was a handsome oval alarm watch by him, of large size, dating from about 1640 ; the inner case is of silver, and the outer one covered with fish skin; on the dial is inscribed "Oliver Cromwell"; the watch belonged to the late Mr. Evan Roberts.

Bockelts. Jan Janss, watch, Napier collection, 1620. —, watch, B.M., about 1640.

Bockett, Richd., London, 1712.

Bodd, Thos., London, watch, 1715.

Boddell, Josiah, apprenticed to Danie Delander ; admitted C.C. 1741.

Bode, William, Philadelphia, 1797.

Bodenham, Edward, apprenticed to Brounker Watts; C.C. 1719 .

Bodham, Steph., apprenticed 1680 to Ed. Enys; C.C.

Bodily. Elizabeth, C.C. 1692. N., 21

Butchers' Hall Lane, Newgate St., 1823.

Boekett, Jan Janse, Hague ; oval watch, about 1610, stolen from the Horological Institute in 1873.

Bogardus, Everardus, New York, f., 1698.

Bohm, Marcus, Augsburg; pendulum clock, about 1660 .

Boisson. Etienne, London ; watch, 1700. M., London; watch, 1745.

Boislander,-,Nancy ; watch, about 1690.

Boislandon à Metz; watch, about 1590 .

Horological School, Chaux de Fonds. 


\section{Boiteau, S., à L'Arcenal, Paris ; watch,} 1695.

Bold. Jno., Warrington, 1770. Wm., Liverpool, 1833.

Boley, Gustav, Esslingen, Würtemberg ; noted maker of watch and clock makers' tools ; died 1891, aged 56 .

Bollard, Richard, London ; bracket clock, about 1770 .

Bolt, Jno., London; watch, 1820.

Bolton, -, Wigan, about 1760; Mr. James Arthur has a finely made skeleton timepiece inscribed "Bolton, London," dating from about 1800 .

Bompard, -, à Paris ; timepiece, G.M., about 1800 .

Bonbruict à Blois, 1650 .

Boncher, A., musical watchmaker, 23 Frith St., Soho, 1835.

Bond, Tho., apprenticed 1685 to Wither Cheney; C.C. G., London; watch, 1800. -, Boston, U.S.A. It is claimed that in 1812, William Bond, the founder of this business, made the first marine chronometer produced wholly in the United States, and that, in default of a mainspring, he used a weight to drive it. Richard F. Bond in 1850 invented a remontoir, or spring governor, to be applied to a clock for ensuring continuous motion of an equatorial telescope.

Bone, Wm., Fssex, about 1790.

Boney, Caleb, a well-known Cornish clockmaker; died at Padstow 1827.

Bonfanti, Joseph, 305 Broadway, New York; advertised in 1823 "German clocks, some plain with music and some with moving figures, and French clocks, some with music, and will play different tunes." In 1824 he issued the following yerses-

"Large elegant timepieces playing sweet tunes, And cherry stones to that hold ten dozen spoons;

And clocks that chime sweetly on nine little bells,

And bixes so neat ornamented with shells.'

Bonna Frères, Geneva, 1780-1800.

Bonner. Charles, apprenticed to Nich. Clark 1650; C.C. 1658; watch, 1690, Evan Roberts collection; long-case marquetry clock, Wetherfield collection, about 1710. Jasper, C.C. 1704. Thos., Fair St., Southwark, 1790-94.

Bonnet, J. B., Geneva ; "watch, about 1825, Dr. H. Goudet.

Bonnington. Wm., clock-case maker, 6 Red Lion St., Clerkenwell, 1793-99. \& Thorp, clock-case makers, 22 Red Lion St., 1793-1816.

Bonny, -, London ; maker of a repeater centre-seconds watch for the Duke of Sussex ; 1790-1820.

Booker, Nugent, Dublin ; long-case clock about 1750, Mr. J. W. Gunnis.
Boole, Jonathan, apprenticed 1676 to Sarah Payne, C.C. Thos., Reigate ; watch, 1758 .

Boone, Edward, apprenticed to Robert Dent, and came by several appointments to Thos. Tompion; admitted C.C. 1691.

Boot. Jno., long marquetry case clock, inscribed " John Boot, Sutton, Ashfield," dating from about 1710, formerly belonging to Joseph Jefferson, the distinguished actor, now owned by Mrs. Thomas D. Goodell, New Haven, Conn., U.S.A. John \& William, 1725. John and James, 1735 ; clock. Jno., about 1740 .

Booth. Josh. Manchester; 30-hour long-case clock, about 1700 . W., longcase clock, about 1710. Benj., Pontefract; watch, 1738. Jas. Bowker, Manchester, 1765. Jno., Huddersfield, 1770. Jno., Manchester, 1775. Ben., London; watch, silver dial, red tortoiseshell case, piqué, inlaid landscape in silver, about 1780; Pierpont Morgan collection. Jno., London; watch, 1780. R. B., Selby, 1785. Jas., 20 Little Tower Hill, 1788-92. R., Church Hill, Woolwich, 1812-17. Jno., Stalybridge," $1818 . \quad$ Wm., Leeds, 1828.

Bor, J., Paris ; fine clock in a square brass case, minutes shown on a small circle below the hour dial, minute hand driven from fusee; about 1590.

Bordier. Denis, watch, crystal case, about 1630. A., Geneva; watch, Schloss collection, case beautifully enamelled, about 1785 ; watch in octagonal case, " Leonard Bordier," S.K.M., 1800. In the Paul Garnier collection is a watch signed " Bordier, Paris, 1806." It is in a square case of rock-crystal. Frères, Geneva; 1820-30, see also Roux.

Borellas, J., 15 Spencer St., 1840.

Borelli, J., 8 Aldersgate St., 1790-95.

Borgin, Henry, Without Bishopsgate, issued a token bearing a dial and hands about 1677 .

Borrel, A. P., Paris ; pupil and successor of A. Wagner; born 1818, died 1887.

Borrell. Henry, 15 Wilderness Row, 1795-1840; watch in finely enamelled cases, Turkish numerals, on dial "Markwick Markham, Borrell, London," h.m., 1813. Maximilian, J., 19 Wilderness Row, 1830-42.

Borret, P., 5 Staining Lane, Wood St., 1805-16.

Borrett. Geo., Stowmarket; watch, G.M., about 1750. M. M., London, about 1790 .

Borrough, Jno., Brampton, 1770.

Borwick, Jno., Bartholomew Hospital ; watch, 1785 .

Bosch, Ulrich, C.C. 1652.

Bosen, -, Paris ; watch, 1806.

Bosley. Joseph, Leadenhall St. ; C.C. 
1725 ; Clerkenwell Green, 1730 . In 1755 he obtained a patent for using in watches pinions with more teeth than usual. This involved an extra wheel and pinion, and the balance wheel turned the contrary way. Also for (secondly) a slide index for watches, which has no wheel, but turns upon a brass socket and points to an arc of a circle, with the word "faster" at one end, and "slower" at the other. Patent unsuccessfully opposed by C.C. 1725-63. Chas., Ratcliff Cross ; succeeded Wm.. Kipling ; 1750-66 ; livery C.C. Charles, livery C.C. 1766. Thos., London ; bracket clock, about 1780 .

Bostock, Thos., Sandback, 1833.

Bottomley, Jno., Clayton, about 1750.

Bottrill, Ebenezer, Coventry, about 1740.

Botzmayr, Johann Simon, Dantzig; clock-watch, about 1740 .

Boucher, W., 4 Long Acre, 1820.

Boucheret. Jacob, C.C. 1728. Jno., London, 1750.

Bouchet, Jean Louis, Rue Saint Denis,

Paris; clockmaker to the King 1769.

Boudon, - octagonal watch inscribed “ J. Boudon à St. Flour," a bout 1600.

Boudry, Gustavus, 64 Frith St., Soho, 1826-42.

Boufler, see De Boufler.

Bouguet, see Bouquet.

Bouhier. Octagonal watches said to have been introduced by Bouhier à Lyon 1538 .

Bouillard, Paul, " at the Eagle and Pearl in Great Suffolk St., near the Haymarket "; card, Ponsonby collection, about 1775 .

Boulanger, David, apprenticed 1691 to Wm. Bertram, C.C.

Boult. Joseph, C.C. 1709. Michael, Cheapside, 1738. - Bath; watch, 1760.

Boulter. Noel, long-case chiming clock, about 1790. Samuel, 12 Gloucester Place, Chelsea, 1840-42.

Boulton. Job, at the "Bolt and Tun," Lombard St., had a gold and a silver watch, with other jewellery, stolen in 1683 . Robt., Wigan, 1770 . T., watch-case maker, 49 Gray's Inn Lane, 1820. John, in St. Oswald's Churchyard, Durham, is a headstone with the inscription:-

"To the Memory of John Boulton. Clock and Watchmaker, Durham, who died Oct. 27th, 1821, aged 60 years.

“ Ingenious artist ! few thy skill surpast In works of art, but death has beat at last.

Thuugh conquer d, yet thy Deeds will ever shine,

Time can't destroy a genius large as thine."

“Monumental Inscriptions," by C. M. Carlton.

Boulu, " élève de Lepine horloger de l'impératrice, à Paris," about 1805.

Bouquet, David, London ; C.C. 1632 ; died 1665 (the books of the C.C. in 1676 and for some years after refer to Dorcas
Bouquet, who was probably the widow of David) (see Knight, Thos. and Walkden, Thos.) ; maker of a watch in the B.M., fine case enamelled in relief and encrusted with jewels ; another and earlier example, an oval watch with covers back and front; in the Dunn Gardner collection was a watch in a finely enamelled case, the movement clearly signed " D. Bouguet, Londini," 1610-40. "Lost lately a steel watch, finely cut and the work of it made by Bouquet, in a black shagreen case. Whoever hath fould the same, if they bring it to Mr. Michael Scrimpshire, Goldsmith, at the sign of the Golden Lyon in Fleet St., shall have 20s. reward " (Lond. Gaz. Jan. 10, 1680).

"A Pocket Clock made some years since by Mr. Boguett of Black Fryars, Watchmaker, it hath two Silver Cases, the outmost plain, the other wrought; two Brass Keys, one of the usual form, the other forked for turning the hand of the Alarum, tied to a Silver Chain; it hath the day of the Month, Tides, age of the Moon, and some other motions; it strikes every hour " (Lond. Gaz., March 3-7, 1689).

" Lost the 15 instant, between Rosse and Linton in Herefordshire, a watch with an alarum in a Silver Case, with a Silver Chain, the case lined with Crimson Satten, being an old piece ; the name of the maker being exprest thus: Daniel Bouquet, Londres" (Lond. Gaz., June 19-22, 1696). Solomon, C.C. 1650 ; a celebrated maker 1650-70. Solomon, C.C. 1683 ; in the B.M. is a watch of his with highly engraved gold cases, 1680-1700. N., calendar watch, Schloss collection, about 1700 .

Bouquett, David, apprenticed 1662 to Solomon Bouquett, C.C. ; watch made for a member of the family of Sir Hugh Brown, of Newington Butts, is in the Fitzwilliam Museum, Cambridge.

Bourchier, W., 13 Broad St., Long Acre, 1835.

Bourdon, Pierre, master engraver of Paris ; did much to advance the art of engraving as applied to clocks and watches. He published an essay on the subject in 1703.

Bourelier, John Francis, Arundel St., Strand, 1769-83:

Bourghell, J., New York, 1786.

Bourne, Aaron, Maiden Lane, Covent Garden, 1869.

Bourret à Paris ; watch showing revolu. tionary, decimal, and ordinary time, about 1798, Mons. E. Gélis.

Bourrit, Daniel, Geneva ; watch, 1775.

Boursault. Helie, Chatellerault, about 1680 . J., Paris; watch, about 1690.

Boutell, Sam., London ; watch, about 
Boutevile \& Norton, 175 Aldersgate St., 1810-19. Wm. Hy., 1823.

Bouts, David, last representative of Parkinson \& Bouts, Gracechurch St.; died 1883, aged 61 .

Bouvet, Geo., Coleman St., 1730.

Bouvier. G., a well-known French painter of watch cases in enamel, about 1740. Jacques, watch, about 1770 . Frères, watch with performing automata (Swiss), 1780.

Boverick, -, "To be seen at Mr. Boverick's, Watchmaker, at the dial, facing Old Round Court, near the New Exchange, in the Strand, at one shilling each person, the furniture of a dining-room in a cherrystone, a landau with horses complete, so minute as to be drawn along by a flea; 4-wheeled open chaise weighing one grain, so small, driven by flea also; a flea chained 200 links, padlock and key all weighing one-third of a grain; and steel sizzors so minute that six pairs could be wrapped in wing of fly, but cut large horse hair" (handbill 1745).

Bovet, - Fleurier, began making, watches for the Chinese market in 1830 .

Bowden, Jno., London ; long-case clock, about 1740.

Bowdon, J., fine striking watch, about 1590.

Bowen. Richard, apprenticed to Robt. Smith 1650; C.C. 1657. A " Richard Bowen "was maker of a large silver watch with two cases, the outer one chased and engraved with a border of flowers and the figure of the king praying, and the words, "And what I sai to you I sai unto all, WATCH." It was said to have been given by Charles I. while at Carisbrooke to Colonel Hammond, 1647. Francis, apprenticed to John Bowyer ; brought his masterpiece on completion of his indentures, and was admitted C.C. 1654. Anchor escapement lantern clock inscribed "Francis Bowen in Leaden Hall streete Londini," in possession of Mr. J. Drummond Robertson. Richard, apprenticed to Richard Bowen 1670 ; C.C. 1678 . In 1677 Jno. Bowen was apprenticed to Mary Bowen. " Lost, a watch in black shagreen studded case, with a glass in it, having only one Motion and Time pointing to the Hour on the Dial Plate, the spring being wound up without a key, and it opening contrary to all other watches, ' $\mathrm{R}$ Bowen, Londini, fecit,' on the back plate" (Lond. Gaz., Jan. 10-13, 1686). Thos., apprenticed to Hy. Brigden 1684. John, C.C. 1709 ; clock with tidal record, about 1730, signed "Bowen, Bristol." David, Windsor, 1775. Thomas, 6 Charing Cross, 1797-1813; livery C.C. 1811. John, 143 Long Acre, 1807-10; 2 Tichborne St., Haymarket, 1812-42 (Bowen \& Holt
1814-18). D., Alfreton, Derbyshire, died 1877.

Bower. Jno., London; large lantern clock; dolphin frets, about 1690. Peter, Redlynch, 1760-80. Michael, Philadelphia, 1790-1800.

Bowers, Wm., Chesterfield ; watch, 1807. Bowles, Jno., Poole, 1790.

Bowley. Devereux, 54 Lombard St. ; a well-known maker of repeating clocks; born 1696, died 1773 ; apprenticed to $\mathrm{Wm}$. Tomlinson; C.C. 1718, master 1759 ; was a member of the Society of Friends, and bequeathed a large sum to their school in Clerkenwell, as well as $£ 500$ to the C.C. ; a clock belonging to Mr. G. P. Osbaldeston bears the signature 'Devereux Bowly'; the name is similarly spelt on the dial of another clock in the possession of Mr. G. W. Toland, Washington, D.C. Jno., London ; watch, 1760.

Bowman. James, apprenticed to Daniel Delander; admitted C.C. 1743. Jas., London ; watch, 1815. Joseph, Lancaster, U.S.A., 1821-44.

Bowness, Geo., Lancaster, born 1836.

Bowra, John, 4 Holles St., Oxford St., 1820-28; "successor to W. Berridge", watch paper, C.C.

Bowtell. Samuel, C.C. 1681. William, C.C. 1703 .

Bowvier, Chas. F., Geneva, 1780.

Bowyer. Wm., a good maker ; subscribed for incorporation of C.C. ; in 1642 he presented to the C.C. a great chamber clock, in consideration of his being thereafter exempted from all office and service, as well as quarterage and other fees (see p. 477) ; 1623-42. Jno., possibly successor to Wm., see Bowen, F., \& Bower.

Box. John, 17 Ludgate St., 1775-86. William B., Clerkenwell; died 1892, aged 76 .

Boyce. Thos., apprenticed 1687 ; C.C. Jas., C.C. 1692 ; long marquetry case clock, square matted dial, circles round winding holes, silvered ring, angel and crown corners, about 1720 .

Boyer, T., London; lantern clocks, about 1690.

Boyle. Richd., apprenticed 1652 to Jno. Bayes; C.C. 1660. Robert, Clare Market, 1780. William, 11 Arundel St., Strand, 1840-42.

Boynton Jas., Howden, 1770.

Boys, A., \& Duduict, Jacques, makers of a large clock-watch, G.M., about 1700 .

Bracebridge ( \& Pearce, Coppice Row, 1800). Edward, 8 Red Lion St., Clerkenwell, 1805-15. (Bracebridge \& Sons, 1816-18). J. \& E. C., 8 Red Lion St., Clerkenwell, 1820-90; for a short time in 1865 they also had the shop 199 Bond St. James, treasurer to the Watch and Clock- 
makers' Benevolent Institution; died 1892, aged 66 .

Bracewell, Huntley, Scarborough, 1822.

Brackenrig, Robert, Edinburgh ; made

a Duplex escapement $\mathbf{1 7 7 0 .}$

Brackley, George, C.C. 1677.

Bradberry, 一, Leyburn, 1805.

Braddock, -, Hayfield; clock, about 1760.

Bradford. Thomas, C.C. 1680 . Thomas, C.C. 1692 ; watch, about 1700 , Norman Shaw collection. Robert, London; $\mathrm{Mr}$. Eden Dickson has a small watch by him, with fine gold dial, about 1700 . Thomas, Strand; son of Robt. ; watch G.M. ; C.C. 1710-70. J., Liverpool ; watch, 1816. Hy., 89 Bethnal Green Rd., 1820.

Bradin (or Braen), Caspar, Westminster Churchyard; C.C. 1715.

Bradl, Anthony, Augsburg, 1680.

Bradley. Henry, C.C. 1681. Langley, Whitechapel, afterwards in Fenchurch St. ; apprenticed to Joseph Wise 1687; admitted C.C. 1695 , master in 1726 ; maker of the St. Paul's and other turret clocks (see p. 331) ; long-case clock, Wetherfield collection. " Stolen out of Mr. Bradley's Shop, the 'Minute Dyall' in Fanchurch St., on the 8 th Inst., a Gold minute watch in an engraven case," \&c. (Flying Post, 8th Oct. 1698). Benjamin, apprenticed to Langley Bradley; admitted C.C. 1728. L. \& B., made a clock for Bancroft's School, Mile End, the date on the bell being 1734 ; the clock is now in Bancroft's new school at Woodford. Thos., Ilkston, 1760. Wm., London; watch h.m., 1784. John H., 3 Great Russell St., Bloomsbury, 1842.

Bradshaw, Jno., apprenticed 1651 to Lancelot Meredith, C.C. Jno., C.C. 1658. Hy., apprenticed 1687 to Wm. Slough, C.C. ; Thos. Reynolds was apprenticed to him in 1699. Edwd., Puddle Dock Hill; C.C. 1725 . John, C.C. 1731. \& Ryley, Coventry, 1760 . Jno., York, f., 1762; at Manchester 1770. Wm., Liverpool, watch, 1810.

Braemar, Gerrett, P., Amsterdam ; repeating watch, S.K.M., about 1735 .

Braene, Caspar, London, 1729 ; C.C.

Brafield, William, C.C. 1678 ; fined 5 s. by C.C. in 1688 for making a bad watchcase. Thos., London; long-case clock, about 1705 .

\section{Braillard fils, Besançon, 1680.}

Braithwaite, Geo., Lombard St., 1738. \& Jones, Cockspur St. ; the Hon. Gerald Ponsonby has a fine repeater by them, about 1800 .

Bramble. Joseph, 407 Oxford St., 1804-35; clock, enamel dial, Mr. T. D. Chapman, "Joseph Bramble London," about 1805. Wm. \& Edwd., 407 Oxford St., 1840. Eliza,'9 Wells St., Oxford St., 1842.
Brambley, Joseph, 10 Maiden Lane, Wood St. ; in 1797 founder and citizen ; petitioned against being compelled to take up freedom in C.C. 1783-97.

Bramer, Paulus, Amsterdam ; watch, about 1700. Garrit, Amsterdam; clockwatch, about 1750 .

Bramwell, Frederick, Fishergate, Preston; died 1913.

Brand. Basil, apprenticed 1660 to Jno. Matchett, C.C. Alexander, Edinburgh, 1727 ; though not apprenticed in Edinburgh, he was by favour admitted to the Incorporation of Hammermen, and in return presented a clock which is still in Magdalen Chapel, Cowgate, then the meeting-place of the Incorporation. \& Matthey, Philadelphia, 1797. C. (see Brandt), musical watch maker to H.M., 22 Frith St., 1814-19.

Brandon, Benjamin, C.C. 1689.

Brandreth, Joseph, C.C. 1718 ; long-case clock, "Brandreth, Middlewich," about 1750.

Brandt, Chas., musical watch maker, 74 New Compton St., 1815 ; 82 Theobald's Rd., 1820 ; 145 Regent St., 1825 ; 22 Upper Belgrave Place, Pimlico, 1835.

Branston \& Bird, 39 Cornhill, 1775 (Thos. Branston, livery Glovers' Company)

Brant, Richard, apprenticed to Sam Davis 1649 ; C.C. Richd., apprenticed 1692 to Jno. Dickens ; C.C. 1700 . John, Stockholm, 1730. Brown \& Lewis, Philadelphia, 1795.

Brasbridge, Joseph, 98 Fleet St., 1794. \& Son, 198 Fleet St., 1825.

Brasier, Amable, Philadelphia, 1811.

Brass. Jno., Guildford, 1725. Thos., London; long-case clock, about 1750; Mr. B. L. F. Potts has a bracket clock signed "Thomas Brass, London," about 1760. It formerly belonged to Jno. Thorpe, the antiquary. 1770 .

Brasseur, 一, Rue Bourg l'Abbé, Paris,

Bratt, Andre, Augsburg, about 1740.

Bray. Robert, C.C. 1728. Thomas, St. Margaret's Churchyard, 1798-1804; 8 Little Queen St., Westminster, 1807-25. Wm., 171 Tottenham Court Rd., 1840. James, 40 Cheapside, 1846-1918. A clever horologist. Served on the Council of the British Horological Institute for many years.

Brayfield. William, apprenticed to Thos. Williamson 1671 ; C.C. 1678 . " Drop'd the 2 lst December in Little Weld St. or thereabout, a middle siz'd Silver Minute Pendulum watch, going Thirty hours, with a chain, in a silver case, the name 'William Brayfield, London.' Whoever brings it to Redmond Regard, Clockmaker, at the upper end of Russell St., near Drury 
Lane, shall have 40s. reward" (London Gaz., January 25-28, 1691). Thos., apprenticed 1675 to Erasmus Micklewright; C.C. 1682 . John, C.C. 1716.

Brayley. Joseph, 6 Little Guildford St., Bernard St., Russell Sq., card, Hodgkin collection, about 1810 .

Breakspear \& Co., Oxford St., 1807.

Breames, Leonard, C.C. 1633.

Breani à Paris, skeleton clock, about 1825.

Brear, Jas., Philadelphia, 1793-99.

Brearley, -, Spa Fields; C.C. 1782. Jas., Philadelphia, 1797-1811.

Brebant (or Brebent), Peter. Mr. F. T. Proctor, Utica, N.Y., has a regulator by Peter Brebant, London, about 1710; repeating watch, Peter Brebent, London, about 1690

Breese, Jas., 5 North Place, Gray's Inn Rd., 1842.

"Breghtel, J. H. C., Hagae," signature on case of late-seventeenth-century clock, S.K.M., see Van de Bergh.

Breguet, Abraham Louis, born 1747, died 1823 ; a French watchmaker of rare attainments and inventive power; Berthoud, who was Breguet's senior by two years, ends a brief notice of hisbrilliant contemporary thus: "Il n'a rien publié." Breguet lived sixteen years longer than Berthoud, but, unfortunately for us. it must still be recorded " he published nothing" (see p. 385). Louis Antoine, son of the above; retired 1833. Louis, son and successor of L. A. ; born 1804, died 1883, see Brown, Edwd.

Brentwood, Wm., London; watch, 1775.

Brest, Edwd., Prescot, 1770.

Breton, Henry, keeper of the Westminster clock 1413.

Bretonneau, Auguste, Paris, a watch by him belonging to Earl Amhurst described in Archaological Journal, vol. xvii.. enamelled, Holy Family on one side, St. Catherine on the other, about 1680 . In the Pierpont Mcrgan collection is a clock-watch by him of later date, with white enamel dial enclosing a gilt centre, silver case beautifully pierced with flowers and bird, a coat-of-arms on the back.

Brett, Jas., lantern clock, about 1695. Thos., London; bracket clock, about 1730 .

Bretton, Jno., Milsom St., Bath, 1798.

Brewer. Edwd., apprenticed 1665 to Stafford Freeman, C.C. John, C.C. 1677. Richard, Norwich ; long-case clock, about 1720. Mr. Sheldon, Leicester. Richd., Lancaster, 1783, f. Wm., Philadelphia, 1785-91. J., 25 New Surrey St., Blackfriars, 1810-15. Wm., Blackburn, 1814-24. Thos., Preston, 1818. W., 149 Great Surrey St., Blackfriars, 1825.
Brewster \& Ingraham, Bristol, Conn., 1827-39.

Brewton, Robt., apprenticed 1660 to Jno. Archer, C.C.

Breynton, Vaughan, C.C. 1693.

Brice. Wm., Sandwich ; watch, 1784.

Brickell, Edmund, London ; clock, red lacquer case, about 1730 .

Brickenden, Nat., apprenticed 1651 to Robt. Whitwell, C.C.

Bricker, Wm., Hosier Lane, 1730.

Brickle, William, 5 Church St., Mile End, 1842.

Bridgden, Henry, C.C. 1682.

Bridge, Wm., C.C. 1674. Thos., Wigan, 1690-1720. Thos., London ; long-case clock, marquetry in panels, "Thos. Bridge Londini fecit," about 1695; another, arabesque marquetry, about 1700, Wetherfield collection. Richard, London; watch, 1748. Edwd., London; watch, 1802.

Bridgeman, Edwd., apprenticed 1655 to Jno. Matchett, Russell St., Covent Garden ; C.C. 1662.

Bridger, Samuel, admitted C.C. 1703.

Bridges. Henry, Waltham Abbey (see p. 396-8), 1730-41. Thos., London ; longcase clock, bird and flower marquetry in panels, about 1700. Robt., London ; watch, 1784.

Bridgman, Richard, an excellent workman, some years with M'Cabe, then in Mount St., afterwards with Charles Frodsham \& Co., then for a short time in the Haymarket, in partnership with Brindle; died 1904, aged 62 .

Briggs, John, " a cutter of glasses for watches"; brother C.C. 1669 ; several generations of Briggs, clockmakers, in Gargrave and Skipton, Yorkshire.

Bright. Jno., 72 Long Acre, 1780-94. John, Sheffield, I790. Isaac, Sheftield, 1810. \& Sons, Sheffield, 1817-33. Richd., 9 Foster Lane, 1815-26, see Upjohn.

Brille, - Paris; clock, about 1750.

Brimble \& Rouckliffe, Bridgwater, 1770; clock by them belonging to Mr. Edwin Ash ; their names are also on the weathercock of St. Mary's Church, Bridgwater.

Brind, Walter, livery Goldsmiths' Company, 34 Foster Lane, 1773-88.

Brinkman, George, 12 Union St., Bishopsgate, 1815-40. \& Gollin, 1842.

Briscoe, Stafford, at the "Three Kings and Golden Ball," Cheapside, 1738-59. \& Morrison, 1768, see Morrison, Richd. Sam., London ; watch, 1810.

Bristow. Jno., apprenticed 1653 to Richd. Craille, C.C. Tim., apprenticed 1691 to Vrian Berrington, C.C. Wm. G., 6 Hoxton Fields, 1790-1835 ; trunk dial, Guildhall, about 1800 , inscribed " Bristow, London."

British Watch Company, 75 Dean St., Soho, formed in 1843 , to manufacture 
watches with duplicating tools invented by P. F. Ingold. John Barwise was chairman of the directorate, and he with Thos. Earnshaw and Thos. Hewitt formed a committee of managers. John Frodsham \& Son, Gracechurch St., were to be the London " agents." An excellent watch was designed, and several were made, but the "trade" successfully opposed the application to Parliament for an Act of Incorporation, and the enterprise came to a close. Ingold afterwards went to America ; and although he was not successful in forming a company there, it is said that some of the tools made for the British Watch Company formed the nucleus of the American factory system.

Brittaine. Boaz, apprenticed to $\mathrm{Wm}$. Speakman 1670 ; C.C. 1679 . Stephen, C.C. 1692.

Britten, S., watch-glass maker, 11 Charles St., Hatton Garden, 1835.

Britton. Stephen, C.C. 1728. Sandys, 48 Wynyatt St., 1835 .

Broad. Thomas, C.C. 1682. John, Bcdmin, 1790-1820. Wm., 53 Leadenhall St., 1804-30. R., 204 Bermondsey St., 1820.

Broadhead, Benjamin, C.C. 1709.

Broadley, Jas., 24 Wood St., 1772.

Broadwater, Hugh, C.C. 1692.

Broadwood, - London ; watch, 1795.

Brock, James, foreman to Dent, afterwards at 18 George St., Portman Sq., died 1893, aged 67 .

Broadbank. John, apprenticed to Joseph Hardin 1761; C.C. 1769, livery 1777; 7 Queen St., Cheapside, card, Hodgkin collection; afterwards at 5 Cowper's Court, Cornhill. John \& Myles, 6 Cowper's Court; Myles was the son of Edward Brockbank, of Corners, in Cumberland, and was apprenticed to his brother John at 17 Old Jewry, 1769 ; C.C. $1776^{-}$; they were eminent chronometer makers; John died early in the nineteenth century, and Myles retired about 1808 ; they were succeeded by their nephews, John and Myles Brockbank, who for a few years carried on the business as John Brockbank \& Company. \& Grove, 6 Cowper's Court, 1812-14. \& Atkins, 6 Cowper's Court, 1815-35. Atkins, \& Son, 6 Cowper's Court, 1840-42. Brocke, Samuel, oval watch, Whitcombe. Greene collection, 1600-25.

Brockedon, - Totnes, about 1790.

Brockett, Richd., Lcndon; bracket clock, about 1750 .

Brockhurst, Thos., Coventry ; clock, about 1720 .

Brocot, Achille, Paris; a celebrated clockmaker; born 1817, died 1878.

Brcgden. Robert, York, f., 1713. Joseph, York, f., 1774. James, at the Dial in Aldersgate St. ; liveryman C.C. 1765-94.
\& Marriott, 148 Aldersgate St., 1770-1804. James, 6 Bridgewater Sq., 1820-28. \& Garland, 1830.

Bromley, Chas., Halifax, 1830 ; alsc Wm., also Edwd.

Bronson, Jno., London ; long-case and bracket clocks ; 1760-80.

Brook. Edmund, C.C. 1709. Richard, \& Son, Poultry, 1795-1802; Richard Brook 1804-18; C.C. 1810.

Brook. John, C.C. 1632 . George, C.C. 1681. William, 192 Upper Thames St., 1783-94.

Brooker, Richard, C.C. 1694. Nugent, Dublin ; watch, 1770.

Brookes. Jno., apprenticed 1685 to $\mathrm{Wm}$. Clement, C.C. Edward, C.C. 1690. George, London ; watch, 1700. Josh., London; watch, 1810. Samuel, watch-case maker, 5 Ashby St.; Clerkenwell, 1835.

Brookhouse \& Tunnicliff, Derby ; watch, Mr. H. Cook, on plate " Brookhouse's Improved Rolling Lever " ; the impulse pin was a pivoted roller such as Emery made, h.m., 1819.

Brooks. Jno., apprenticed 1693 to Mat. Crockford, jun., C.C. William, Church Row, Aldgate; liveryman C.C. 1776 ; watch, 1790, "Wm. Brooks, Pentonville"'. John, 115 Bunhill Row; liveryman. C.C., 1786-88. Thomas, watch-case maker, 22 Golden Lane, 1790-94. Robert, London ; watch, 1795. John, 4 Bridgewater Sq., 1794-1813. W., 14 Clerkenwell Green, 1825. J. W., watch-spring maker, 5 Berkley Court, Clerkenwell, 1835. Samuel Augustus, watch jeweller, Clerkenwell, took an active part in trade affairs ; died 1901 , aged 79 .

Brooksted, Jno., apprenticed 1671 to Jno. White, C.C.

Broome, Thomas, admitted C.C. 1652.

Broomhall, Chas., 41 Stanhope St., 1794.

Broon, Nich., London ; watch, about 1760, Rochdale Museum.

Bross, John, 106 Britannia St., City Rd., 1820-35.

Brosy, Michael, London : alarm watch, about 1640 .

Brought, Hy., Workington, 1770.

Brounner, -, Lucerne; watch, 1780.

Browmer, - London ; watch, 1830.

Brown. James (Croydon), C.C. 1687. Andrew, Edinburgh: apprenticed to Hum. phey Mylne, made a frefman of the Incorporation of Hammermen in 1675, his essay being, "Ane knock with a watch luminary globe upon the dial " ; died 1712 . James Barrow, aged about twenty, of a low stature, a little pock-marked, speaks the English accent, had on when he went away a short flaxen coll-cut wig, in an ordinary habit, run away from his master 
the nineteenth instant with a plain gold watch without a crystal (glass), with an enambiled dial. The enambling on the figure is broken off. A silver pendulum watch, made by William Young, at Charing Cross, London, with a shagreen case ; the centre and balance wheels pierced. A plain silver watch and an oval brass watch and several other things. Whoever can secure the said youth, and give notice thereof to Captain Andrew Brown, watchmaker in Edinburgh, shall have two guineas reward " (Edinburgh Gazette, 1699). The title of " Captain" refers to Brown's position in the Trained Band which was organised to defend the city. Thomas, C.C. 1703. Jonathan, Lavington, about 1710-15. Jno., Edinburgh, 1720. Henton, Borough, admitted C.C. 1726 ; master, 1753 ; livery, 1766; a maker of fine watches; 58 Lombard St. in 1754 . Nathaniel, Manchester, 1750. Thos., Birmingham, 1760. John Wm., 14 Cheapside, 1760-83. Thos., 36 Bull Ring, Birmingham; watch, silver cock, h.m., 1761. John, 76 St. Paul's Chyd., 1769-83. Geo., Beverley, 1770. Jas., Matlock, 1770. J., King St., Seven Dials; an excellent cutter of clock-wheels on an engine designed by Hindley, 1770-1810. Thos., Chester; member of the Goldsmiths' Company, 1773. John, 118 Fleet St., 1775-83. Nathaniel, Whitefriars, liveryman C.C. 1776 . John, 65 Charing Cross, 1783-1810. Thos., 14 Cheapside, 17881800. John, 30 Grafton St. Soho, 1790-94. Geo., mahogany broken-arch bracket clock signed " George Brown, Holbourn Hill," about 1790. Richard, watch-key and pendent maker, Greenhill's Rents, 1790-94. -, 119 Holborn, card, B.M., 1798. Wm., 40 Piccadilly, 1800-10. -, 65 Charing Cross; watch, 1804. James, 56 George St., Portman Sq., 1810-42. Geo., 8 Great Sutton St., 1820. Isaac, 32 Gloucester St., Clerkenwell, maker of bezel winding watches, patented 1829 , No. 5851; 1820-35. James, 60 Rahere St., 1842. Roger, 25 Shepherd St., Mayfield, 1842. Edwd., an accomplished horologist, head of the house of Breguet, died at Paris, 1895 ; aged 66 . Of U.S.A. : Garven, Boston, 1789. J. C.. Bristol, 1827-37. David, Providence, 1834-50.

Brownbill. Liverpool : Jas., 1760 ; Jno., 1780. Hy., Leeds, 1780; he issued tokens of good design in 1793. \& Son, Leeds, 1810 (see Fig. 741).

Browne. Matthew, C.C. 1633. John, C.C. 1652 ; master 1681 . Thos., apprenticed 1653 to Richd. Beck; C.C. 1676. Richard, C.C. 1675 ; at ye Green Dragon in Cheapside, on lantern clock, gallery frets, bob pendulum. "A watch having two motions, Richard Brown being engraved on it, in a studded case" (Lond. Gaz., June 16-20, 1687). Philip, apprenticed 1680 to Nich. Beck; C.C. 1688. Robt., apprenticed 1684 to Katherine Ames, C.C. Moses, apprenticed 1687 to Robt. Nemes, C.C. Chas., apprenticed 1692 to Thos. Brayfield, C.C. Chas., London ; watch, 1820. Richd., see Paterson.

Browning. Jas., apprenticed to Thos. Platt, 1650 ; C.C. Isaac, Penrith, 1770.

Brownless, George, Staindrop (Darlington); clock, about 1720 ; died 1799 , aged 54 .

Brownlie, Alexander, Edinburgh, 1710-25.

Brownson, Thos., London; watch, 1799.

Bruce. James, C.C. 1721. George, London; long-case clock, about 1740 . Cranbourne St., Leicester Sq. ; watch, 1830 .

Brugercia, C., musical snuff-box and clock maker, 13 Richmond Buildings, Dean St., 1820.

Brugger. John, Lynn, 1815 ; 252 High Holborn, 1830. Beck \& Co., 15 Crown St., Finsbury, 1840-42. L. A., wooden and musical clockmaker, 79 High Holborn, 1840-42.

Brulefur, Jean, London ; clock in fine marquetry case, S.K.M., about 1690.

Brumwell, -, Pall Mall, about 1760.

Brunette, Samuel, 13 Castle St., Bloomsbury, 1814; 34 Gloucester St., Queen's Sq., 1825.

Brunner, Gaspard, made a clock at Berne, 1557.

Brunsley, William, apprenticed to Thos. Carrington, but turned over to Thos. Gray; admitted C.C. 1766 . On reverse of a token "William Brunsley "; at Lilly House, against Strand Bridge, his halfpenny, on obverse a clock dial and hands.

Brunwin, Henry, Whitecross St. 1770-85; watch, about 1780 , stolen from Newington Free Library, engraved on the plate an eagle and a snail as a guide to regulation.

Bruton. Thos., Bow, 1790 . J., dial enameller; died 1863.

Bryan. Robt., apprenticed 1663 to $\mathrm{Wm}$. Seabourne, C.C. Sam., apprenticed 1685 to Jas. Hassenins, C.C. Richard, C.C. 1696. Saml., 104 Golden Lane, 1755-94; japanned long-case clock, about 1760 . Henry, Strand, 1768. Jno., 3 Shadwell Dock, 1790-94.

Bryant. Geo., apprenticed 1657 to $\mathrm{WVm}$. Smith, C.C. \& Son, 47 Threadneedle St., 1781. John, Hertford; maker of good clocks, 1790-1829.

Bryars, Saml., Chester, 1833.

Bryce, Clement, apprenticed 1689 to Vere Martin, C.C.

Bryer, John (apprenticed to E. J. Dent), 20 Northampton Sq., 1838, afterwards at Barbican; died 1894. 
Bryers, Arthur, Chester, 1814-18.

Bryson. Alexander, Edinburgh ; "Her Majesty's clockmaker for Scotland " ; died 1854; succeeded by Robert Bryson, his son, who died 18\$6. Jno., Dalkeith; apprenticed to Thos. Pringle, 1842.

Buchan, Henry, 37 IVindmill St., 1830-42.

Buchanan. Arch., Dublin; long-case clock, about 1760 . Jno., Ashton-underLyne, 1818.

Buck, Edward, exhibited his masterpiece, and was admitted C.C. 1632.

Buckenhill. Jno., apprenticed 1664 to IVm. Thorogood, C.C. 1672. Edward, C.C. 1687 .

Bucket, (? Bouquet), subscribed to Incorporation of C.C. 1630.

Buckhill, Jas., apprenticed 1768 to Robt. Fole, C.C.

Buckingham. Joseph, Black-moor's Head and Dial, Minories, 1690-1725; longcase clock with fine marquetry case, about 1700, inscribed " Joseph Buckingham, London." " Stolen from MIr. Richard Parke, in Pey Alley, Fanchurch St., a gold watch made by Jos. Buckingham " (Lond. Gaz., July 13-16, 1691). Joseph, junr., Minories, 1740-60.

Buckland, Jno., bracket clock, 1795.

Buckley. G., Hartshead ; clock, about 1760. Jno., Ashton-under-Lyne, 1818.

Bucklie, David, Bridgewater Sq., 1780-94; livery C.C. 1787.

Bucknall, Thos., Brrkhampstead ; watch, 1740, Evan Roberts collection.

Bucknell. W., 20 Kirby St., 1810. Wm., 10 Parliament St., 1816-28; succeeded by

Wm. Alexander.

Buckner. Philip, apprenticed 1658 to Nich. Coxeter; C.C. 1667. Richard, C.C. 1710.

Bucksher, J., 37 Three Colts St., Limehouse, 1817.

Bucquet, Dan., 56 Cannon St., Ratcliff, 1812-20.

Budgen, Thos., Croydon, about 1740.

Buffet, Jno., Colchester ; watch, silver cock, 1735 .

Bugden, -, 20 Brydges St., Covent Garden; watch paper, C.C., about 1800.

Buggins, Thomas, (Thwaites \& Reed), 15 Bowling Green Lane, a clever clockmaker, died 1921, aged 87 . 1780 .

Buguon, - Paris; repeating watch,

Bukingham, see Buckingham.

Bulet, D., Geneva, about 1750 .

Bull. Rainulph, keeper of the " great clock in His Majesty's Palace of Westminster" (see p. 252); watch, probably by hirn. B.M., inscribed "Randolph Bull" and dated 1590. Edmd., Fleet St. ; about 1610 (see p. 252). John, subscribed to incorporation of C.C. 1630 ; admitted 1632. Jno.,ap- prenticed 1691 to Ben. Graves, C.C. Wm., Stratford, Essex, about $1770 . \quad$ Jas., 124 Leadenhall St., 1813-18. Thos.,Bristol, 1842. Bullby, John, C.C. 1632.

Bullimore, Hy., apprenticed 1687 to Jno. Fitter, C.C.

Bulline, Ben., London; watch, h.m., 1763 ; long-case clock, about 1770 .

Bullingford, Benjamin, Liverpool ; watch, about $1780, \mathrm{Mr}$. W. Farrow.

Bullman, Thos., Swan Alley; large marquetry case clock, twisted pillars, square dial, about 1690 .

Bullock. Edmund, Ellesmere, about 1740 A well-known family of clockmakers in Somerset and Wiltshire. Wm., Bradford, a bracket clock, about 1740, of Widcombe, Bath. Zephaniah, 1742; Thos., son of Z., 1765-95; Wm., son of Thos., died 1846 ; succeeded by his nephew, Wm. Vokes. Jas., Furnival's Inn Court, 1790-94. Christopher, London; bracket clock, mahogany case, painted dial, about 1800 . Jas., 31 Milson St., Bath, 1845; at the same date, Wm., Bradford-on-Avon ; Thos., Chippenham; Jno., Melksham, Jno., Westbury.

Bulman, Jacob, Nuremberg; clockmaker, master of the Locksmiths' Guild, 1780-98.

Bulstrod, Wm., apprenticed 1671 to Henry Hester, C.C.

Bult. Jas., London; watch, silver case with landscape painted on the back, Schloss collection, about 1780 . James, \& Co., 86 Cheapside, 1815-25.

Bultry, Dan., apprenticed 1655 to Ralph Greatorex; C.C. 1663.

Bumstead, Robert, in Holborn; C.C. 1707 ; fine pair-case repoussé repeater in leather case.

Bunce, Matthew, C.C. 1698.

Bunch, Nich., Bramshot ; 30-hour longcase clock, about 1730 .

Bunnett, Wm., London; watch, 1780.

Bunon, -, Rue Coquillière, Paris, 1770.

Bunting. William, Pope's Head Alley, Cornhill ; admitted C.C. 1646 ; watch in the B.M., on the dial is inscribed, "Ioanni Miltoni, 1631." Joshua, apprenticed to Wm. Bunting, 1648, C.C. Josh., apprenticed in 1651 to Wm. Bunting for Thos. Wolverstone, C.C.

Bunyan, Robert, London, about 1780. Bupert, Michel, Paris ; clockmaker to the Duke of Orleans, 1641.

Burchall, Thos., Nantwich, 1760.

Burchett, John, C.C. 1731.

Burckhardt, J. C., 14 Northumberland St., Strand, 1816.

Burdon, Francis, 3 Hollen St., 1816.

Burgar, John W., 23 Banner St., 1842.

Burge, Caleb, apprenticed 1682 to Simon Barrett. 
Burges. Henry, long-case clock, about 1690 ; Mr. W. J. Clayton, South Australia. Jno., London ; about $1720 . \quad$ Chas., London; watch, about $1740, \mathrm{Mr}$. T. W. Bourne ; another, pendulum-balance under dial, 1750. Thos., Gosport, 1750-60.

Burgess. Edwd., Londini ; long-case clock, about 1690 . Jno., Wigan, 16901740. Elias, London; long marquetry case clock, 11-in. dial, Wetherfield collection, about $1700 . \quad-$, Old Bailey, 1774. _, 20 Cheapside ; card, B.M., 1782; "from T. Wright, watchmaker to the King," watch paper, Ponsonby collection, about 1795. Geo., 10 Bishopsgate St. Without, 1790 ; watch by him, 1768. E., clock-case maker, 23 Percival St., 1835.

Bürgi, Jobst (De Burgi or Burgius), Prague, born 1552, died 1632; a talented mechanician, who in 1602 was appointed clockmaker to Rudolph II. In the Vienna Treasury is a clock with a pendulum attributed to him. There are two oval dials of rock crystal framed with plates of smoky topaz. One dial shows the minutes and hours, and the other the days of the week, as well as the age and phases of the moon. Striking work for the hours is behind one dial, and quarter-hour striking mechanism behind the other. The case, in the form of an obelisk, is of agate, adorned by three circlets of garnets.

Burgis. John, subscribed to incorporation of C.C. 1630 ; 1632 ; oval calendar watch, in Dover Museum, about 1625. Thomas, apprenticed to Thomas Knifton, 1654. Charles Edward, apprenticed to James Clowes, 1678; long-case clock, bird and flower marquetry in panels, "Edwd. Burgis," about 1690: bracket clock, black bell-top case, back plate nicely engraved and inscribed, " Edward Burgis, Londini, fecit" ; about 1720. John, London, 1680. Elias, London. C.C. 1681; long-case clock, about 1700, Wetherfield collection. George, London; maker of a tall oak-case clock, 1720-40. Wm., London ; watch, 1720.

Burke, 一, 1630-50 ; C.C.

Burkeloe, Samuel, Philadelphia, 1797. Burkham, -, London; watch, 1720.

Burkhardt \& Brandt, Chaux de Fonds, 1810 .

Burleigh, Ninyan, C.C. 1692 ; bracket quarter clock, ebony case, finely engraved back plate, inscribed, "Nin Burleigh, Durham," about 1730.

Burlingham, D. C., King's Lynn, a Quaker, died 1901, aged 78 .

Burlinson, Hy., Ripon, 1830-40.

Burnap, Daniel, maker of brass clock movements at East Windsor, Connecticut, U.S.A., $1780-1800$.

Burnet, Thomas, Bow, 1700.
Burnett. Richard, C.C. $1705 . \quad$ Philip, C.C. 1715 . Jno., London; watch, 1755 . Chas., London; watch, 1760. Jno., Rosemary Lane, 1822.

Burns. Richard, Liverpool, 1770. Manchester, 1777; watch, Rochdale Museum. Jas., 76 Lisson Grove, 1804-42. Hugh, Philadelphia, Dty., 1811.

Burpull, John, Tooley St., 1720-50 ; a long-case clock dating from about 1735 , appeared to be inscribed " John Burputh, Tooley St., near London Bridge," and Mr. $j$. Terry has one signed John Burputt.

Burpur, " Lost Oct. 29, about 11 of the clock, at the Queen's Head Ale House, a plain watch with a silver case made by one Burpur. Any person that shall see this watch offer'd to be sold or pawn'd are desired to send word to the Red Lyon behin'd the Royal Exchange, and they shall have a guinea reward " (The Postman, Nov. i, 1705).

Burrill, Boys Err, Great Sutton St., 1805-20.

Burrows. Edwd., Fordham, about 1740. Joseph, apprenticed to Wm. Addis ; C.C. 1777 ; livery 1803 . James, 30 Goodge St., 1820-25. E., 4 America Terrace, King's Rd., Chelsea, 1830-42.

Burton. Abraham, apprenticed in 1650 to Richd. Masterton, C.C. 1657 ; watch, 1700. Jno., apprenticed 1672 to Richd. Warren, C.C. Roger, apprenticed 1678 to Ch. Bonner, C.C. E., one-hand clock inscribed "E. Burton, Kirby Kendall," body of case very narrow with side wings, about 1690 . William, London; repeating watch, about 1740 ; known also as a maker of spring clocks about 1760. Emanuel, Kendall, 1760-90. Jas., Whitehaven, 1750-70. John, Blue Anchor Alley, liveryman C.C. 1776. W., Kendal, 1780. Jas., Lincoln's Inn Gate, Carey St., 1806-20. Hy., London; watch, 1810.

Burwash. Wm., watch-case maker, 3 Red Lion St., Clerkenwell, 1782-1804. Wm., 45 Red Lion St., Clerkenwell, 1790. Thos., 91 Bishopsgate Without, 1825.

Busby, Nich., 1630-50 ; C.C.

Busch, Abraham, Hamburg; watch, about 1710 .

Buschman. Hans, Augsburg ; astronomical clock by him, Vienna Treasury, about 1600. David, Augsburg; watch, Pierpont Morgan collection, about 1610; pretty floral balance-cock pinned on; another watch, Vienna Treasury, about 1620 ; large alarm watch in pierced brass case, Schloss collection, inscribed, "David Buschman Augusta," about 1680 ; table clock, "David Buschman Augsburg," semicircular dial with long light hand that jumps back, and three other dials ; Norman Shaw collection. Hanns, clock, 
1690. John (German), C.C. 1692. John Baptist, C.C. 1725.

Bush, James, C.C. 1729. James, 104 High St., Shoreditch, 1804-42. James, 6 Hackney Rd., 1835.

Bushby, - London; watch, 1780.

Bushell. Timothy ; his son John was in 1681 apprenticed to Wm. Lavell of the Cutlers' Company. Edward, apprenticed 1687 to Wm. Bennett, C.C. Samuel, apprenticed 1690 to Wither Chesney, C.C. Matthew, Arley (Cheshire), 1740; on long-case clock, about 1750, "Matthew Bushell, Ashton."

Bushman. Jno., watch, Nelthropp collection, tulip pillars, revolving hour circle, about 1670. “Jno. Bushmann, London," calendar watch, about 1720 , Mons. E. Gélis. John Baptist, livery C.C. 1786. - Northwich, 1790. Wm., Stratford, Essex, watch paper, C.C., about 1800. Jno., Bolton, 1814.

Bushnells, Thos., at the Dial in East Smithfield, 1692.

Butler, John, C.C. 1724. Jas., Bolton, Lancs. ; long-case clocks, about 1760-80.

Butter, Joshua, 36 New Bond St., 1804 ; 239 Oxford St., 1807.

Butterfield à Paris ; silver pocket sundial, about 1690 . Jno., Todmorden, 17701820. Thos., London; large-sized Parliament type of clock in japanned case, about 1790 .

Butterbay, Jno., Horsham ; lantern clock, about 1700 .

Butterworth. -, long-case clock, " John Butterworth fecit," about 1725. Samuel, Rochdale, 1760.

Button \& Putley, 204 Bnro', 1788 ; card, B.M.

Buz, Johannes, octagonal striking calendar watch, in brass case, German, about 1640 .

Bye, Henry, clockmaker to the City of Paris, 1413.

Byford, William, 23 St. Mary-at-Hill, 1820-35.

Bysse, Edward, curious watch, at the B.M., about 1620 ; prohibited from working by C.C. 1632 , but afterwards joined the Company, see also Bisse.

Byworth, Thos., 28 King St., Snow Hill ; and 12 Bridge St., Lambeth, 1840-42.

Cabot l'Aîné, Rouen, about 1750 .

Cabrier. Charles, Broad St., admitted C.C. 1697 ; clock, long marquetry case ; "Carolus Cabrier, Londini, fecit," about 1690 ; in the B.M. is a very thick rounded repeater watch, period 1690 , in the centre of the outer case an enamel medallion, this is surrounded by a circle of repoussé work, outside of which the case is nicely pierced; another example of his work is a silver verge watch, outside case em bossed, 1690-1726. Charles, 79 Broad St., a celebrated maker ; C.C. 1726 ; master 1757 ; Pig St., Threadneedle St., in 1759. Charles, C.C. by patrimony, 1756 ; in 1777 an action was tried in the King's Bench, Cabrier $v$. Anderson, the defendant having put on five watches the plaintiff's name, without his knowledge or consent; a verdict was given for the plaintiff with $f_{100}$ damages. Specimens of Cabrier's work are in the Guildhall Museum; one of them is a bell repeating verge watch movement, with nicely wrought and pierced pillars having broad bases and caps. The Czar of Russia's collection in the Winter Palace, St. Petersburg, contained a prettily decorated repeating watch by him, h.m., 1752-53. It is suspended from a chatelaine which, like the watch, is ornamented with agate and sprays of diamonds. Charles, Stepney, C.C. 1692. John, son of Chas., C.C. 1730 . \& Leeky, 15 Basinghall St., 1781-1804. Favey, \& Exchequer, 14 Wilderness Row, 1794. Favey \& Son, 1798.

Cachard. - " "successeur de Charles Le Roy à Paris," about 1780. Gasper, 13 Oxendon St., 1820, afterwards at Henrietta St., Covent Garden.

Cade. Simon, admitted C.C. 1688. Geo., Market Weighton, 1820. \& Robinson, 153 Leadenhall St., 1820-25 ; 8-day bracket clock, mahogany case, Wetherfield collectıon, see p. 586.

Cadgell, Thos., aprpenticed 1682 to $\mathrm{Wm}$. Elmes, C.C.

Caesar, Daniel, admitted C.C. 1703.

Caffieri. Philip, born at Rome 1634, died at Paris 1716 ; Jacques, Paris, 16781755; Philip, son of Jacques, 1714-74. Noted designers and makers of clock cases.

Caillate, A., Geneva, about 1725 .

Caille, - , London, about 1770.

Cailliate, Abraham, watch, about 1610, Garnier collection; another about 1630, Pierpont Morgan collection.

Cainden, Wm., London ; long-case clock, about 1760 .

Cairns. John, Providence, U.S.A., 1788. Ralph, Brampton, 1833.

Caithness, - New Bond St.; verge watch, about 1750 , see Allan \& Caithness.

Cake, Thos., Bath, 1835.

Calbeck, Jno., apprenticed 1672 to Jas. Field, C.C.

Calcot, Tobias, admitted C.C. 1664 .

Calderwood, Thomas, C.C. 1724.

Caldwell, -, Appleton ; clock, about 1770.

Callam. Alexander, 74 Lower East Smithfield, C.C. 1790-96. Brothers, Castle St., Long Acre; celebrated makers of repeating mechanism, 1795-1825.

Calledon, - , London; watch, 1795. 
Calliber. John, C.C. 1703. Thomas,

C.C. 1727.

Callin, G. P., Geneva, about 1650.

Callwood, Jno., Liverpool, 1770.

Calvert, Nich., apprenticed 1665 to Robt. Grinkin, C.C.

Cam, William, C.C. 1686 ; lantern clock, inscription," William Cam, Londini, fecit."

Cambridge, Samuel, C.C. 1697.

Camden. William, Plumtree Court, Shoe Lane; C.C. 1708 ; Mr. Alfred Bedford has a splendid long-case clock by him; it is still a really excellent timekeepr, and is in a handsome mahogany inlaid case; repeating watch in pierced cases B.M.; watch reputed to have belonged to Charles XII. of Sweden, silver case, handsomely chased silver dial, silver balance-cock, the movement altogether a very fine one, 1708-35. Geo., London; watch, about 1820

Cameel, C., Strasburg; octagonal watch, S.K.M., about 1610.

Camerer. (Ropp, \& Co., 2 Broad St., Bloomsbury, 1788.) A., \& Co., wooden clockmakers, 2 Broad St., Bloomsbury, 1830-42. M., wooden clockmaker, 13 Brownlow St., Drury Lane, 1840.

Cameron, D., 318 Strand, 1820-25.

Camille, André ; watch, B.M., about 1675.

Camp, Hiram, New Haven, Conn., 1840-53.

Campart, Jno., Bishopsgate, 1774.

Campbell. John, 3 Crowns, Strand, 16911701. Neil, Aylesbury, 1725-60. Wm., Carlisle, U.S.A., 1765 ; Philadelphia, 1799. Charles, Philadelphia, 1797. Chas., Bo'ness, about 1780. Alex., 393 Strand, 1800-05. Colin, Cherry Bank, Nr. Perth; watch, 1810. W. F., 60 Hatton Garden, 1825-35.

Campe, Tho., apprenticed 1672 to Corn. Harbottle, C.C.

Camper, James, 99 Bridge Rd., Lambeth, 1800-40.

Campey, Joseph, York, f., 1758.

Canby, Charles, Wilmington, 1815-50.

Canche, Jacques, London, brother C.C. 1692 ; silver alarm watch, in the B.M., plain silver cases, the outer one perforated.

Cann. John, brother C.C. 1649. Judah, apprenticed to Jno. Cann, 1650.

Cannans, John, London; maker of clocks, about 1790 .

Cannon, Joseph, London ; Long Chippendale case clock, day of week, day of month, age of moon, high tide, dead beat escpt., centre seconds, about 1790 .

Cansard, -, clock, about 1760, signed " Cansard, horloger du Roi, suivant la cour."

Canson, see Cawson.

Capper. Sam., apprenticed 1674 to $\mathrm{Wm}$.

Bridge, C.C. Michael, Philadelphia, 1779.

Capstick, Thos., Knaresboro', 1745-85.

Capt, Henry, 56 Frith St., 1840-42.
Card, Edmund, admitted C.C. 1679.

Cardwell, Thos. C., Liverpool ; died 1905, aged 68 .

Carell, John, Philadelphia, 1791-93.

Carey. George, admitted C.C. 1679. Jasper, "in Gray's Inn " ; watch, about 1700. Thomas, admitted C.C. 1705. James, Brunswick, U.S.A., 1808-50. George, 3 Singleton St., 1842.

Carfoot, Chas., 32 Aldersgate St., 1814-25.

Carleton, Robt., apprenticed 1687 to Joseph Bates, C.C.

Carley, George, 18 Wilderness Row, 1842 ; afterwards at Ely Place; died 1879 .

Carlill, Jas. B., York, f., 1801.

Carlow, P., maker of a watch for the Duke of Sussex, 1780-1800.

Carltasse, Abraham ; watch, about 1650 , Mons. E. Gélis.

Carmichael, Jno., Greenock, 1750.

Carncel, C., Strassburg, maker of octagonal pillar timepiece in S.K.M., about 1600 .

Carolan, James, 69 Red Lion St., Holborn, 1816-25.

Caron, Daniel, Lizy-sur-ourg, France. Andreas Charles, his son, an eminent. watchmaker, Paris; horcloger of Louis XV. 1720-60. Peter Auguste, Paris; son of A. C. ; he and Lepaute claimed the invention of an improved Virgule escapement. and in 1753 the Academy of Sciences decided the point in favour of Caron, who had by then, it is said, made a watch for the king and a very small one for Madame de Pompadour ; a fine enamelled watch ; he was an accomplished musician as well as a playwriter, and is better known, under the name of Beaumarchais, as the author of "Le Barbier de Seville," and "Le Mariage de Figaro," born in the Rue St. Denis, 1732, died 1799.

Carovagius, - Paris, 1550.

Carpenter. Thos., C.C. 1767. Thos. \& Richd., watch-case makers, 5 IslingtonRd., 1776-1823. William, 10 St. Martin's Court; hon. freeman, C.C. 1781 ; 15 Frith St., 1793 ; 5 Haberdashers' Walk, Hoxton, 1817 ; 1770-1817. \& Son, 4 Andrew St., Seven Dials, 1785-90. Thomas, 5 Islington $\mathrm{Rd}$., summoned to take up livery C.C. 1786 (see T. \& R. Carpenter). F., 21 Percival St., 1830. Wm. 4 Percival St., 1842.

Carr, Fred., 18 Bridge St., Westminster, 1822-25.

Carre, Daniel, calendar watch, Nelthropp collection, about 1690 .

Carrington. James, posting office, 1730 ; warden C.C. 1767. Robert, Noble St., 1730,22 Old Bethlem, 1760 ; livery C.C. 1766. Thos., St. Paul's Churchyard, 1730, afterwards Bishopsgate St.; liveryman C.C. 1766 . Richd. London; clock, about 
1760 ; watch, 1765. Geo., livery C.C. 1786 \& Son, 22 Old Bethlem, 1794.

Carruthers, Geo., Blewett's Buildings, Chancery Lane, 1789-94.

Carswell, Joseph, Hastings ; long-case clocks, about 1760 . J., London; watch, 1770. Wm.,58 Bishopsgate Within, 1822-25.

Carte, John, C.C. 1695; a large thick watch by him, inscribed "John Carte, in Garden Court, in the Middle Temple" ; double sets of hour and minute numerals in relief on silver dial; hour hand rotates once in 24 hours, minute hand once in 12 hours. When Peter the Great was in England, he sold him a great geographical clock which told the time at any part of the world. "John Carte, watch maker from Coventry, and lately lived at the Dial and Crown near Essex St. in the Strand, is now removed to the corner of Lombard St." (Flying Post, Oct. 1696).

Carter. Thomas, C.C. 1659. Jno., apprenticed 1669 to Andrew Allum, C.C.; Francis, apprenticed 1670 to Robt. Dingley, C.C. ; Sam., apprenticed 1683 to Wm. Fuller, C.C. ; Thos., apprenticed 1690 to Joanna May; C.C. 1699. Wm., Ampthill ; long-case clock, about 1710. Wm., Cambridge; watch, 1720, Evan Roberts collection. Wm., Cambridge; watch, 1725 . Leon Augustus, C.C. 1726. John, Bartholomew Close, C.C. 1728-72. Wm., Ampthill; curious short " Grandfather " clock, inlaid case, gives age of moon, high water at London Bridge, solar time, \&c., about 1750. William, Bermondsey St., 1760 ; 207 Tooley St., 1794. Jas., Hampstead; fine chiming long-case clock, about 1770 . Hewes, Cambridge, 1790. J., 57 Church St., Mile End, 1804-20. Wm., jun., 1805-26. John, son of Wm. Carter, Tooley St. ; apprenticed to Boys Err Burrill in 1819,207 Tooley St., 1829-42; afterwards 61 Cornhill; Lord Mayor, 1857; master C.C. $1856,1859,1864$; died 1878 . Hy., Ripon, 1833. William, watch-case maker, 22 Galway St., St. Luke's, 1835. Thos., Bristol, 1842.

Cartier, Jacques, maker of a watch said to have belonged to Oliver Cromwell, 1635 ; another watch, " Cartier, London," about 1680 ; watch, "Cartier, Geneva" about 1810 .

Cartwright. Benj., 18 West Smithfield, 1669-72. Thomas, apprenticed to Christopher Gould, 1693. He lived " behind the Exchange" ; watch by him in gold repoussé case, Schloss collection, inscribed "Thos. Cartwright, watchmaker to the Prince," about 1715; another example in the Guildhall Museum is a watch with crystal cock, jewelled, 1700-30. Geo., C.C. 1706-12. Wm., C.C. 1713 ; long walnut case clock, about 1713, signed "Benjam n
Cartwright junior, London," Mr. Geo. F. Glenny. N., Lombard St., watch with pierced silver pillars, in Guildhall Museum, about 1720. Ann, 45 New Bond St., 1783.

Carus à Paris; clock-watch, S.K.M., Paris hall mark for $1733-4$; silver gilt case pierced and chased, outer case of tortoiseshell.

Carver. Isaac, C.C. 1667. Jacob, Philadelphia, 1797.

Case. Erastus, Bristol, Conn., 1830-7. Harvey, 1830-7. Dyer, Wadsworth, \& Co., Augusta, U.S.A., 1835-6.

Cashmore, John, 11 Bevis Marks, 1852, afterwards at Eldon St., Finsbury.

Casinghurst, Christopher, apprenticed 1690 to Robt. Nemes, C.C.

Casper. (Ellis \& Co., 29 Finsbury Place, 1804-42.) Nathaniel, 13 Bury St., St. Mary Axe, 1804-42.

Cass, George, London ; long-case clock, the late Mr. R. B. Prosser, about 1790.

Cassiway, Chas., apprenticed 1656 to Thos. Mills, C.C.

Castan, Stephen, \& Co., Philadelphia, 1819.

Castang, Philip, London ; watch, Nelthropp collection, 1777 .

Caste, J., London; watch, about 1690.

Caster. Wm., apprenticed 1690 to

Joshua Hutchin, C.C. Wm., Ripon, 1765. B., London; watch, silver outer case embossed, about 1770 .

Castlefranc, Peter, 40 Pall Mall, 1769-83.

Caston. Jno., Kirkham, 1765. Wm., Kirkham, 1780.

Catchpool. Thos., 113 Strand, 1823. Wm., Fenchurch St., 1830-35.

Cater. - widow, Moorfields, 1671.

J., London ; about 1780.

Catherall, J., Chester, 1814.

Catherwood. Joseph, 10 Bunhill Row, 1775-1825. Joseph \& William, 2 Newcastle Place, Clerkenwell, 1804-42. G. \& R., 35 Kirby St., Hatton Garden, 1809-30. Robert, 35 Kirby St., Hatton Garden, 1835. Catlanes, -, Stockton; clock, about 1800. Catley, Dan., C.C. 1731.

Catlin (a Quaker family of horologists at King's Lynn. Three Daniels died, 1770, 1812 , and 1918); bird cage clock, 4 in. by 3 in.; bob pendulum, Mr. Albert Hartsshorne; watch, Evan Roberts collection.

Caton, Robt., New St., 1730.

Cattell. William, Fleet St., C.C. 1672 ; lantern clock, inscribed "William Cattell, in Fleete Street, Londini," 1671-90. Thomas, C.C. 1688. "Lost in Chancery Lane, a silver Minute Pendulum Watch, with a green and silver ribbond to the key, the watch made by Cattle, London " (Lond. Gaz., January 19-23, 1692). Thos., apprenticed in 1691 to Thos. Cattell, C.C. Wm., York, 1822. 
Catterall, Jno., Liverpool, 1770.

Cattle, John, fecit 1633, inscription under alarm disc of a lantern clock. Robt., York, f.; 1807, Lord Mayor, 1841, died 1842 (see Barber \& Cattle).

Cattlin, James, 58 Great Marylebone St., 1804-42.

Catton, Richd., Leadenhall St. ; duplex watch, h.m., 1818.

Caul \& Dennis, 19 Plumtree St., 1816.

Causard, clock mounted oil elephant, Mr. James Arthur, signed "Causard Hor. du Roy suivt La Cour," date about 1760.

Cave, see Robinson \& Cave.

Cavell, Nataniel, Ipswich; clock, one hand, long case of oak, about 1700, Mr. H. Hogarth.

Cavendish, Richard, livery C.C. 1810.

Caveton \& Clark, Fetter Lane, 1730 ; clock, about 1760 .

Cawdrey, see Corderoy.

Cawdron, Geo., apprenticed 1675 to Jas. Graves; C.C. by patrimony, 1684.

Cawkutt, Thos., apprenticed 1693 to Nat. Bird, C.C.

Cawley. Robert, Chester; watch, 1719.

Sam., 115 Bermondsey St., 1842-8.

Cawne, Robt., apprenticed 1663 to Lionel Wythe ; C.C. 1675.

Cawson, Liverpool and Lancaster : Jas., 1779 , f. ; at Lancaster, Edwd., 1790, f.; Wm., 1817, f. Ellen, Liverpool, 1833.

Caygill, C., Askrigg, died 1792, aged 90.

Cayne, Andrew, Without Bishopsgate, 1696.

Cazard, H., Paris, about 1750 .

Cellar, Jno.; wooden clockmaker, 4 Westgate St., Bath, 1798.

Cellier, - , Lyons, 1580-90.

Ceson, Londres ; on a watch with chainrepeating work, about 1710 .

Cetti. Joseph, London; watch, 1800.

\& Co., London; watch 1830.

Cext, Catharine, apprenticed to James Hubert and his wife, 1730.

Chaband, Hy., 9 Plumtree St., Bloomsbury, 1816-25.

Chadd \& Ragsdale, New Bond St., 1775.

Chadwell, Nat., London; long-case clock, ting-tang quarters, moon in arch, Mr. W. W. Pope.

Chadwick. John, Liverpool, 1770. Jno., 36 Cornhill, 1783-1813 ; 138 Holborn Hill, 1817. James, 18 Great Bath St., Clerkenwell, 1804-42. Joseph, Boscowen, N.H., U.S.A., 1810-31. Joshua, 138 Holborn Hill, 1820-55. Wm., London; watch, 1825.

Chalfont, Walter, Barnsbury, an inventive watchmaker, 1850-86.

Chalk, James, 36 Bishopsgate St. Within, 1798.

Challoner, William, Skinner St. ; liveryman C.C. 1776.
Chalmers, George, 1 Prince's St., Leicester Sq., 1783-88.

Chamberlain. Thomas, Chelmsford ; in the B.M. is a watch by him, about 1630 ; calendar and striking watch, S.K.M., with pierced case of silver-gilt, movement signed "T. Chamberlain fecit"; oval watch, Cluny Museum, "F. Chamberlin fecit." Dan., apprenticed 1660 to Thos. Chamberlain. Jno., Hertford; long-case clock, about 1780. C., London; watch, 1800 .

Chamberlaine. Nathaniel, apprenticed 1650 to Ben. Hill ; C.C. 1685 ; master 1717. "These are to give notice that Nathaniel Chamberlin, Watchmaker (who hath lived several years at Chelmsford, in Essex), for the better accommodation of his friends and customers, hath, at the request of divers of them, taken a Chamber at Mr.John Rust's, in Angel Court, in Lombard Street, where he doth intend, God willing, to attend the last Fortnight in every Term for the mending his own Work, and accommodating all persons that shall have occasion for New" (Lond. Gaz., January 22-25, 1676-77). Nathaniel, C.C. 1659. Thomas, apprenticed to Samuel Ross, and turned over to Henry Harper ; C.C. 1687. John, Bury ; C.C. 1687 ; watch with day of the month ring, B.M., about 1670; lantern clocks, about 1700. Joseph, Norwich ; "A little Gold Watch made by Joseph Chamberlain, of Norwich, with a plain Dial Plate in a plain black Shagreen Case" (Lond. Gaz., March 15-19, 1687). - Mark Lane, 1717.

Chamberlayne, Webb, Salisbury, 1790.

Chamberlin, G., for nearly 40 years employed at Hampton Court Palace, where his duties included the care of the famous Astronomical Clock in the Clock Court of the Palace, died 1914, aged 75 .

Chambers. Edwd., apprenticed 1670 to Evan Jones, C.C. Jonathan, London ; long black and gold case clock, 10-in. dial, about 1690 , Wetherfield collection. James, 3 Squirrils, St. Dunstan's Church. 1690. - 56 Cornhill, 1823. Wm., watch finisher, City Rd., 1830; afterwards in partnership with Prior, Ed., at 18 Powell St. East, King Sq. 1780 .

Cha mbley, Jno., Wolverhampton,

Champion. Robert, lantern clock, " Robert Champion, of Wells, fecit 1630." John, brother C.C. 1641. John, C.C. 1651-76. Denis, Paris ; clockmaker to the Duke of Orleans, 1669. Guillaume et Isidor, Paris ; watch, in the possession of Mr. Edward Watkins, Manchester, formerly the property of Love-Jones Parry, Carnarvonshire, about 1680 . John, London ; a watch by him in S.K.M., outer case of shagreen, about 1770 ; watch, about the same date, pair cases, the outer one of 
agate, Chinese figures on dial, Pierpont Morgan collection; another, enamelled case, Schloss collection, about 1780. Charles, Paris ; about 1770. Aré, Paris ; alarm watch, about 1820 .

Chance. B., London; maker of a watch in the B.M., about 1720 . W. \& G., London; watch, 1815.

Chancellor. Jno., 81 Bishopsgate Without, 1793. \& Son, Sackville St., Dublin, well-known clockmakers, $1800-40$; in 1811 Jno. Chancellor patented (No. 3,487) a musical clock.

Chancey, Jas., London; watch, Nelthropp collection, 1741.

Chandlee, John, Wilmington, U.S.A., 1795-1810.

Chandler. George, lantern clock, about 1680. B., Nottingham, 1770. \& Son, London; watch, 1775. Timothy, Concord, U.S.A., 1780-1840. Robert, Martin's Court, 1793; 8 Leicester Sq., 1815-25. Abiel, Concord, 1829-58.

Channell, Geo., London; watch, 1795. Chantler, -, London ; about 1750. Hatton speaks with admiration of his watches.

Chapeau, Peter, London, extra large repeating watch belonging to $\mathrm{Mr}$. Chas. Freeman; cylinder escapement, three cases, inner pierced case silver, h.m., 1746, second case repoussé group portraying Æneas and Dido; outer case fish skin.

Chapman. Thos., apprenticed 1648 to Ralph Ash, C.C. Simon, C.C. 1675 . Jno., apprenticed 1679 to Wm. Herbert, C.C. Titus, apprenticed 1683 to Thos. Williamson, C.C. Peter, C.C., St. Anne's Lane, 1730. Thos., Bath ; long case musical clock, about 1760 . B., London; watch, 1765 . Jno., " opposite the Riding House in the Garrison, Sheerness," about 1780. William, 6 New Round Court, Strand, 1790-94. J., clock-case maker, 6 Red Lion St., Clerkenwell, 1835. Wm., Bristol, 1842 .

Chappel. Robert, C.C. 1720; maker of small size sheep's-head arch-dial clocks, " Robert Chappel, London," on disc. Thomas, Little Tower St., 1753-63.

Chappuis, Jubilé, Geneva, 1800.

Charas, Charles Samson, C.C. 1692.

Charle, George, watch with Turkish numerals, h.m., 1794; 19 Wilderness Row, 1804-42.

Charlepose, -, London ; gold repeating watch, silver cap engraved with the arms of Queen Anne, outer case set with lapis lazuli, rubies, and diamonds, about 1705 . Charles, D., Brompton, Kent; watch, 1798. G., Paris ; clock, about 1840.

Charleston, Jno. apprenticed 1676 to Ed. Clough, C.C. ; watch, 1685 ; $\mathrm{Mr}$. Edwd. Sudell has another of a later date.
Charison. P. London ; watch, h.m., 1764. J., London ; watch, about 1790 . W., London; watch, 1800.

Charlstrom, William, Percival St. ; livery C.C. 1810 ; 1800-38.

Chariton. John, one of the first assistants of the C.C. ; master 1640. Matjonah, apprenticed to Geo. Graham; admitted C.C. 1728. Jno., Durham, 1770. Jas., 13 Lisson St. North, 1842.

Charman, Peter, 64 Piccadilly, 1816-26.

Charnock, Jas., apprenticed 1693 to Thos. Wheeler, C.C.

Charrington, S., died while master C.C., 1768.

Chartier. - Blois; excelled as a watch-case enameller, 1650-70. Francis, 1 Angel Court, Throgmorton St., 1765-71.

Charwell, James, London; repeating watch, S.K.M., outer cáse shagreen piqué, about 1740 .

Chase, Timothy, Belfast, U.S.A., 1826-40.

Chassereau, Robt., 4 Beech St., Barbican, 1804-8.

Chasseur. -, London; small timepiece with pendulum swinging in front, about 1700 (see p. 594).

Chatbourne, Jno., apprenticed 1677 to Jno. Bennett, C.C.

Chater. James, C.C. 1727. James, \& Son, 3 Cherry Tree Court, Aldersgate, 1754-59. Eliezer \& James, 3 Cherry Tree Court, $1760-86$; in 1785 Jas. C. patented (No. 1,785) a watch guard. Eliezer, 10 Exchange Alley, Cornhill; master C.C. 1772 ; livery 1776. Richd., 14 Cornhill, 1787-1812. \& Livermore, 2 Exchange Alley, 1790 ; 10 Bartholomew Lane, 1794; 30 Tokenhouse Yard, 1800. W., 134 Goswell St., 1804-42.

Chaters, J., watch motion manufacturer, 17 Gee St., Goswell St., 1835.

Chatfield, - . "Lost on Saturday last, between Frith St., Sohoe, and Lumbard St., a Silver Minute Pendulum Watch in a tortoise shell case with a black ribon, engraved on the Dyal Plate (Chatfield, Londini). Whoever brings it to Mr. Clerkson at the King's Head, near the Pump in Chancery Lane, shall have 20s." (Lond. Gaz., April 4, 1695).

Chatham, Wm., London ; watch, 1782. Chatier, Isaac, 1 Angel Court, Throgmorton St., 1768-88.

Chaudron, S., \& Co., Philadelphia, 1811.

Chaulter. Hatton, writing in 1773, esteems his work.

Chaund, John, London ; long-case clock, about 1760 .

Chaunes, -, Paris ; watch, 1620 ; small watch, "Chaunes le jeune," about 1650.

Chauvell, James D., Old Broad St. ; C.C. 1699 ; clock-watch, 1705 ; also a repeating 
watch in S.K.M., about 1720 ; watch, 1714 signed "James Chauvel, London."

Chauvin, see Bernard.

Chawner, Thos., 34 Ludgate Hill, 1783-88.

Cheasbrough, Aaron, long-case clock, about 1705 ; Rev. W. B. Atherton.

Cheeny, J., clockmaker at East Hartford, Connecticut, U.S.A., 1790.

Cheeseman, Daniel, C.C. 1699.

Cheesman, R., Horsmunden; lantern clock, about 1700 .

Cheetham, -, Leeds; long Sheraton case clock, about 1790 .

Cheltenham, Michael, C.C. 1712.

Cheneviere. Urban, Geneva, 1760.

Deonna, Geneva, about 1880.

Cheney. Withers, apprenticed 1646 to Elias Allen ; admitted C.C. 1657 ; elected master 1695, but excused on making a contribution to the poor box. Benjamin \& Timothy, East Hartford, Conn., 1745-81.

Benjamin, Manchester, U.S.A., 1770-80.

Cheriton, Geo., apprenticed 1685 to Jno. Buckenhill, C.C.

Cherril, Edwd., 6 Newcastle Pl., 1814.

E. \& Son, 1825-30.

Chesneau, J., à Orleans, watch, a bout 1610.

Chesnon, Solomon, Blois ; maker of a very diminutive watch in the B.M., with outer leather case, about 1640; another watch by him described in vol. xi., Archceological Journal, had no hands; the hours indicated by an escutcheon engraved on a circular plate, which revolved within the hour circle. "Lost on Sunday, the eighth of this instant March, about 12 o'clock, between St. Paul's and St. Dunstan's Church, a French gold watch enameld with Flowers in a Case studded with gold studs made by Solomon Chesnon at Blois, tyed with a Pink-coloured Ribbon. Whoever shall bring the same watch to Major Pinkney's shop at the Three Squirrels over against the West End of St. Dunstan's Church in Fleet Street shall have fourty shillings" (Lond. Gaz., March 12, 1673).

Chesson, Thos., Ludgate Hill, 1754-59.

Chester. George, from London, opens a shop at the sign of the Dial, on the New Dock (advt., New York), 1757. Wm., 55 Shoreditch, 1804-40.

Chettle, W., 35 Commercial Road, Lambeth, 1830-38.

Chetwood, John, apprenticed 1692 to Jno. Pilcher, C.C.

Cheuillard, -, Blois ; watch, Marfels collection, about 1620 .

Chevalier. ( \& Co., Geneva ; watch, about 1750). \& Co., Paris ; many watches, 1760-90.

Chevallier aux Tuileries, Paris ; clockmaker to Louis XV.; fine long-case clock, somewhat similar to Fig. 546, about 1760. \& Cochet, Paris, 1790-1805.
Chilcott. Richard, C.C. 1690 ; long-case clock, about 1700, inscribed " Richard Chillcott, London," John, C.C. 1721.

Child. Richard, Fleet St., C.C. 1632 ; warden 1640-43; in 1638 the Blacksmiths' Company sued "Child, the clockmaker," for breach of his oath. Henry, brother, C.C. 1642 ; died, while master 1664 ; Mr. Eden Dickson has a three-train " ting tang " lantern clock by him, inscribed "Henricus Childe, Londini." Ralph, C.C. 1661. Henry, apprenticed 1670 to Nich. Russell, Tower Royal, Budge Row, 1677-93. " Lost the 28 instant at Aldermary Church, or between that and the Tower Royal, a plain Gold Pendulum Watch, in a new Fashion Gold Grav'd case, name, Henry Child. It had a Tulip Hand, long freised hours, in the middle of the dial plate engraven with two Birds and Flowers; it was in a Gold Pinned Case" (Lond. Gaz., May 25-29, 1693). Jno., apprenticed to Thos. Taylor, C.C. 1769.

Chilton, Thos., London; lantern clock, with arch dial added about 1700 .

Chinn, T. W., Huddersfield ; three-train bracket chiming clock, arch dial, walnut case, about 1720 , Wetherfield collection.

Chipp, Robt., apprenticed 1679 to Robt. Seignior, C.C.

Chippendale, Gilbert, Halifax, 1781.

Chismon, Timothy, summoned to take up livery C.C. 1786; master 1803.

Chophard, Saul, Artillery Lane, apprenticed to David Hubert; admitted C.C. 1730.

Choudens, see De Choudens.

Christian, Jno., Aylsham ; clock, about 1750.

Christie. Wm., 22 Chancery Lane, 1804-42. Hy., 3 Duke St., Manchester Sq., 1842.

Christin, -, Paris, 1770.

Christmas, Jas., apprenticed 1682 to Thos. Birch, C.C.

Chubb, Jno., Ringwood, Hants, 1785.

Church. Jno. Thos., 19 Oakley St., 1835. Lorenzo, Hartford, U.S.A., 1846. Duane, H., Mechanical Superintendent and Master Watchmaker at the Waltham Watch Factory, died 1905. " Of superior ability as a practical watchmaker, he possessed to a marked degree the inventive faculty, which in his last years found opportunity for exercise in the designing of automatic machines for the production of the various parts of Waltham watches. In this line of work Mr. Church ventured into original fields in which he evinced the boldness of his convictions, and in which his successes were many and his failures relatively few," is the testimony of Mr. E. A. Marsh who was closely associated with him for some years. 
Churchill, Chas., London ; centreseconds watch, h.m., 1787.

Churchman, Michael, C.C. 1694.

Clagget, Thomas, Newport, U.S.A., 1730-49; also Wm., same date.

Clapham, Geo., Brigg, 1770.

Clarburg, Jno., made a clock for York Minster in 1370.

Clare. S., Hatton (near Warrintgon), 1770. Peter, Manchester, 1780-1818, a Quaker and watchmaker; in an account of the village of Hatton, Chester, where he resided, the following reference to him is made :-

\section{There's the cottage of Peter, That cunning old fox, \\ Who kept the sun right By the time of his clocks.}

$\mathrm{He}$ appears to have been derided for asserting that the sun was wrong and his clocks right, though, of course, if mean time was desired he would have been doubtless correct in his assertion. Peter, son of the foregoing; born in Manchester in 1781 , was a prominent figure there till he died in 1851. Thos., Warrington; long-case clock, Battersea enamel dial, Wetherfield collection, about 1790. Henry T., 15 Meredith St., 1804-42.

Clark. Mary, apprenticed 1674 to $\mathrm{Hy}$. Fevon and Christian his wife, C.C. Elizabeth, apprenticed to the same, 1676. Stanford, London, C.C. 1696; watch, 1710. Thomas, C.C. 1720. Wm., Kendall; clock, 1720. Wm., 26 Abingdon St., 1730; Bishopsgate St., 1754-74; Paternoster Row, 1775. -, Lancaster: Cornelius, 1733, f. ; Thos., 1767, f. Jas., Morpeth, 1750. Cure, watch, 1750 . Wm., York, f., 1758. Anthony, Serjeants' Inn, Fleet St., 1763. Edw., 56 Cornhill, 1768-75. Thos., Ulverstone, 1770. Edwd., 17 Middle Moorfields, 1772 . Robert, clock and watchspring maker, Providence Row, 1775-99; watch, Robert, London, 1780 . David, watch-case maker, 58 Featherstone St., 1789-94. Francis, 10 Jewin St., 1789-94. Jno., 73 Mark Lane, 1794-1823. Wm., 6 King St., Clerkenwell, 1800 . Thos., 9 Goswell St., 1830-40. George, 54 Bartholomew Terrace, St. Luke's, 1842. Of U.S.A. :-Benjamin S., Wilmington, 1737-50. Benjamin, Edward, Ephraim, Philadelphia, Dty., 1797. Benjamin \& Ellis, Philadelphia, 1811. Jesse, W. \& C., Philadelphia, 1811. Daniel, Waterbury, 1815-20. Sylvester, Salem Bridge, 1830.

Clarke. John, Bristol ; watch, B.M., in an outer case of leather piqué, 1630-40. George, Whitechapel ; C.C. 1632 . William, C.C. 1654. Humphrey, Hertford, C.C. 1668 ; lantern clock by him about 1700 . Andrew, apprenticed 1682 to Chris. Gould, C.C. Sam., apprenticed 1687 to Jno.
Martin, C.C. Wm., apprenticed 1688 to Thos. Clifton, C.C. ; on the mantelpiece of the Punch Dining Hall at Bouverie St. is a small bracket clock inscribed " Wm. Clarke Whitechaple," dating from absut 1700. Jno., C.C. 1691 . John, Stanford, C.C. 1696 \& Dunster, London; repeating watch, about 1705 , Mr. E. Wehrle ; repeating watch in silver cases, pierced, engraved, and repoussé, early eighteenth century, S.K.M. Thomas, admitted C.C. 1709 . Richard, Cornhill, C.C. 1720 ; calendar watch by him, dials back and front, 1745 ; Richard Clarke \& Sons, Cheapside, 1815. Geo., Leadenhall St., 1725-40 ; the Earl of Macartney, our first Ambassador to China, mentioned as a prominent object in the palace of the Chinese Emperor at Pekin, a musical clock inscribed "George Clarke, Clock and Watch Maker in Leadenhall Street, London" ; it was in a case ornamented with crystal and coloured stones and played twelve old English tunes, " Black Joke," "Lillibullero," and other airs of the Beggars' Opera. There is a fine table clock by him in the Wetherfield collection. Edward, 9 Holborn, 1768. Jas, Paternoster Row, 1768. William, George: Yard, Whitechapel, 1769-72. John Basul, St. John's Lane, liveryman C.C. 1776. Jas., 52 Rahere St., 1778-1840. Wm., 87 Gt. Sutton St., 1804-20. Robt., York, f., 1807; settled at Hull. Jos., Tuxford ; watch, 1812. -, Richmond, Yorks., 1814. Hy., warden C.C. 1822-26. William \& Sons, 8 Goswell St., 1830-42. Job Guy, 15 King William St., London Bridge, 1851-8; Sir Edward Clarke, K.C., is his son, and when a lad was his assistant. William (Clarke \& Sons, Gos• well Rd.), died 1875, aged 75. Abraham (Clarke \& Sons, Goswell Rd.), died 1890 aged 79. Daniel (Clarke \& Sons, Goswel Rd.), trustee of the Horological Institute master C.C. 1892 , died 1897 , aged 78 .

Clarkson. Jno., apprenticed 1649 to Jno Nicasius ; C.C. 1657. H., Stockport, 1770.

Claxton, Thomas, C.C. 1646; signerl petition against oppression of the Company in 1656 ; master 1670 .

Clay. William, brother C.C. ; maker of a watch Cromwell presented to Col. Bagwell at the siege of Clonmel; also of a clock, inscribed "William Clay, King's Street, Westminster" (see p. 502) ; watch of later date, G.M., 1645-80. Thomas, Chelmsford; lantern clocks, about 1650 , Samuel, apprenticed to Jeremy Gregory, 1680 ; C.C. 1687 . Charles, Stockton, Yorkshire (see pp. 377-8), petitioned Parliament for a patent in respect of a repeating and musical watch or clock, his invention; Mr. Quare produced a watch to answer the same end as Mr. Clay's; the AttorneyGeneral reported in favour of Mr. Clay; 
C.C., however, opposed Mr. Clay, and after a tough fight, extending from Feb. 1716 to the latter part of 1717 , the patent was not granted. He seems to have lived subsequently in the Strand. Charles, Fenchurch S. ; watch in crystal case, S.K.M., 1740 ; another example with chased outer-case, about 1750 . Wm., London; about 1750 . B., London ; watch, h.m., 1770.

Claypot, Dennis, York, f., 1697.

Clayton. Thomas, admitted C.C. 1646 ; assistant, 1671. Jno., Prescot, about 1745. Ralph, Marple, 1750. Jno., Marple, 1765. Jno., Blackburn, 1770. Chas., London ; watches, 1805-20.

Cleare, Wm., apprenticed 1688 to $\mathrm{Hy}$. Jones, C.C.

Cleeke, Henry, C.C. 1655.

Cleeve, William, brother C.C. 1654.

Clegg, - , London; long-case clock, about 1790 .

Cleghorn, Saml., 65 Shoe Lane, 1790.

Clemence, J. A., founder of the firm of Carley \& Clémence Ltd., and Chairman of the Company. He was admitted to the livery of the Clockmakers'. Company in 1891, and was associated with many of the trade charities and institutions. Died in 1915 , aged 72 .

Clement. Edward, C.C. 1671 ; the inscription " Edward Clement, Exon," on a lantern clock may apply to him. William, brother C.C. 1677 ; he applied to clocks the anchor escapement invented by Dr. Hooke, probably about 1676 ; this allowed of the use of a long pendulum with a lesser angle of vibration than was possible with the verge escapement ; instead of hanging the pendulum from a cord or a shackle he used a spring to suspend it from; this proved to be a much better attachment and one which has continued in favour. $\mathrm{He}$ was master of the C.C. in 1694. Mr. Wetherfield has a long-case timepiece by him inscribed " Gulielmus Clement, Londini fecit," the construction of which is very similar to that of the clock by Jno. Fromantil described on p. 315. In 1684 William Clement, presumably his son, was apprenticed to him. \& Son, Tring, 1773 ; watch, " Clement, Tring," 1798. F., Paris, about 1690 .

Clements. Robt., C.C. 1686. Moses, Broadway, New York, 1747. Thos., Liverpool, about 1790. Thos., London; maker of bracket clocks, about 1760 . Jno., London; watch, 1820 ; 214 Oxford St., 1840.

Clementson, - , Dunstable, 1780.

Clemson, Richd., apprenticed 1661 to Thos. Claxton; C.C. 1673.

Clench, - Dublin; watch, 1797.

Clent, Geo., apprenticed 1684 to Jno. Barnett, C.C.
Clerk, Jno., Bristol, 1687.

Clerke. Danl., Amsterdam, about 1720. Jno., Brentwood, about 1780. George, 3 Cherry Tree Court, Aldersgate St.; summoned to take up livery C.C. $1786 ; 1780$ 1820. Geo., Cherry Tree Court, son of the foregoing ; livery C.C. 1810-42. Nathaniel, London ; watch, h.m., 1811. F. W., Cornhill ; died 1885, aged 65 .

Clewes, see Clowes.

Clidesdale, -, Bell Yd., Temple Bar; C.C. 1780 .

Cliff. Wm., apprenticed 1670 to Sam. Davis, C.C. Jno., Royston, about 1725.

Clift, Thos., Hull ; long black lacquer case clock, about 1730 .

Clifton. Thomas, brother C.C. 1651. Thomas, apprenticed to Chas. Gretton C.C. 1687. John, 14 Fazakerley St., Liverpool, 1785-90.

Clinch, George, London ; long japanned case clock, about 1740 .

Clinsworth, G., Warrington ; bracket clock, about 1790 (he was really a bellfounder).

Clinton, James, London ; clock, 1790. Cliverdon, Thomas, Holborn; C.C. 1722 .

Clodion, Michel Claude, born at Nancy 1728 , died at Paris 1814 , celebra ed artist and designer of clock cases.

Clopton, Wm., apprenticed 1655 to Onesiphorus Helden, C.C.

Closon, Peter, at Holborn Bridge ; subscribed to incorporation of C.C. 1630 ; three years senior warden, $1636-38$; lantern clock with balance escapement, inscription on fret, " Peter Closon at London, fecit." On another example is " Peter Closon, at Holborne Bridge." Sir Theodore Fry has a lantern clock inscribed " Peter Closon, neare Holborn Bridge, fecit."

Clothier, Jas., 121 Pall Mall, 1842.

Clough. Edward, Fetter Lane; a watch of his make, with an outer case of leather piqué, in the B.M., is inscribed, "Mayor Johne Miller, his watche," 1630-40. "Stolen a silver watch in a black case, studded about the edges, and one studded flower at the back of it, having a minute motion and the figures of the hours and minutes twice over the plate, made by Edward Clough, near Gray's Inn Gate, in Holborn " (Lond. Gaz., October 6-9, 1690). Samuel, Boston, U.S.A., 1701.

Clowes. Jas., brother C.C. 1670 ; longcase clock, about 1690. John, C.C. 1672; elected a warden, 1713 , but unable to serve through ill-health; small square bracketclcck, bob pendulum, locking plate, cherub corners, inscribed, " J. Clowes, Londini, fecit" ; long-case clock inscribed, "Jon. Clows, Russell St., Convent Garden." Ralph, London, about 1700-5. B., Liver- 
pool ; watch, 1795. O. B., Liverpool ; watch, 1805. Robt., London; watch, 1812.

Cluer. Obadiah, apprenticed 1682 to Hy. Evans ; C.C. 1709; long-case clock signed, "Obed. Cluer," a man-of-war above the dial rocks with the swing of the pendulum; underneath are the words,

"The Royal Ann." John, 22 Skinner St., Clerkenwell, 1835.

Cluter, William, C.C. 1709.

Clutton \& Co., 48 Rupert St., 1825.

Clyatt. Samuel, C.C. 1672, Bell Alley, Coleman St. Abraham. C.C. 1680. John, C.C. 1708. William, C.C. 1709. Samuel, - C.C. 1711.

Clymer, Jno., Bristol, 1842.

Coastfield, Jno., apprenticed 1682 to Robt. Starr, C.C.

Coats. Archibald, Wigan ; about 1780. Thos., London; watch, 1780.

Coates. John, London, Mr. C. G. Kcaly has a bracket clock by this maker, date a pout 1740 . W. \& J., Cirencester; watch, 1786. Jas. \& R., Wigan; watch, 1794.

Cobb. Wm., York, f., 1659. John, apprenticed to Andrew Yeatman; C.C. 1703.

Cobham. Jno., Barbican ; C.C. 1725; pendulum watch, 1750 . Stockley, C.C., Red Lion St., Clerkenwell, 1730.

Cochard, Geo., 10 Henrietta St., Covent Garden, 1822-25.

Cochin. D., a celebrated repoussé chaser of watch cases, 1735-70. D., Paris; watch, 1790.

Cochran. Saml., 291 Wapping, 1760-94. Mr. Edward C. Cockey, New York, has a pair-cased watch by him, h.m., 1768. W., 266 Regent St., 1825.

Cock. Jno., London ; long-case square dial clock, chiming on six bells, about 1700 . Chas., Bow Lane ; apprenticed to Thomas Reynolds; C.C. 1736. Chas., Macclesfield, 1760.

Cockeram, Jno., Downham; Halifax clock, lacquer decoration, about 1750 .

Cockerton, Jonas, 1751-78.

Cockford, Matthew, C.C. 1693.

Cocks, Sam., Worcester, 1800.

Cockshutt, Edmund, Liverpool, 1770.

Cocky, Cockey, Cokey, Cockney. Several generations of Somerset clockmakers; clock, Wm. Cokey, Wincanton, about 1700; astronomical clock, dating from about 1780 , by Edward Cockney, Warminster, formerly belonging to Lord Carrington sold at Stevens' in 1900 for $£ 235$.

Codevelle, - , Rue de Bussy, Paris, 1770. Codling, W., Sutton ; clock, about 1795.

Cogdon, Thomas, Budge Row, chronometer maker, apprenticed to Jno. MacLennan, died 1885, aged 67.
Coggs, John, against St. Clement's Church, 1690-1700.

Cogniat, - Paris; watch, 1720.

Cohen. Sam Jacob, 3 Castle St., Whitechapel, 1815. A. S., 9 Newcastle St. Whitechapel, 1820.

Coignet, - began in 1665, and in 1667 finished the clock of the Pont Neuf, Paris, since known as "l'horloge de la Samaritaine."

Coke, Wm., apprenticed 1673 to Wm. Glazier; C.C. 1681.

Coker, Ebenezer, Clerkenwell Close, 1754-69.

Colambell, Anthony, Aldersgate St. liveryman C.C. 1776.

Colbert, J. G. I., Grafton St., 1825.

Cole. Daniel, apprenticed to Geo. Graham ; C.C. 1726. John, C.C. 1729 ; long-case clocks, 1729-60. Thos., Lombard St., 1754-63. Richard Stinton, Ipswich, watch by him in the Ispwich Museum. 1780 ; Richard, Ipswich, 1830. Wm., Gutter Lane, 1780-1805; pedometer by him, B.M. I. B., 54 Barbican, 1785. James Ferguson, Hans Pl., Chelsea; then Park St., Grosvenor Sq. ; then 9 Motcombe St., Belgrave Sq.; born 1799, died at Tower House, Bexley Heath, 1880; an able watchmaker and expert springer; he devoted much attention to the lever escapement, of which he devised several forms, and was for some time a vicepresident of the Horological Institute. Thomas, 11 Upper King St., Bloomsbury, an excellent maker of spring clocks ; brother of J. F. Cole; died 1864. Geo, Bristol, 1842. Wm., Devizes, 1844. Richard Wright (Usher \& Cole), son of Richard Stinton Cole of Ipwsich. Did much to support trade charities, for over forty years on the Committee of the Clock \& Watchmakers' Asylum, for many years a Vice-President of the British Horological Institute. Died 1919, aged 79.

Colehed, Richd., Liverpool, 1800.

Coleman. - , clock, signed "F. Francis Coleman, Ipswich, fecit, 1665." Fr., Ipswich; watch, 1720. Geo., London ; bracket clock, about 1780 . John, 115 Newgate St.; hon. freeman of C.C. 1781; 1768-83. William, Arthur St., $1790 ; 14$ Strand, 1794-99. Sampson, London ; watch, 1795. Thomas, 6 Westmoreland St., St. Mary-le-bone, maker of bracket clock, Chippendale style of case, 1810-42 ; livery C.C. 1813.

Coles, M. A., 25 Red Lion St., 1790.

Coley, S., London; watch finely enamelled royal blue, Schloss collection, 1795.

Colladon. - Geneva ; watch, silver bridge, about 1765 . \& Sons, watch, painting on dial, about 1785 . 
Collard, Leonard, apprenticed 1675 to Jno. Delander.

Colles, Christopher, long-case clock, about 1700 .

Collett, Thos., Acton ; watch, about 1770. John, Royal Hospital Row, Chelsea ; mahogany long-case clock, about 1780 ; watch, h.m., 1799.

Colley. Joseph, apprenticed to James Harrison; C.C. 1752. Thos., Fleet St., 1765-80; an exceedingly fine long-case clock, Wetherfield collection, inscribed " Graham's successor Thos. Colley London" (see p. 560); see also Barkley \& Colley. \& Creist, " Graham's successors,' Fleet St. ; watch, 1780.

Colliber, Jno., apprenticed 1690 to $\mathrm{Wm}$. Slough, C.C.

Collier. Benjamin, a noted maker ; C.C. 1693 ; Lord Chesham has a gold doublecase repeater made by him; 1693-1730 see Collyer; also p. 569. Robt., C.C., Gutter Lane, 1730. David, Gatley; clock, about 1760. Thos., Chapel-en-le-Frith, 1760. Sam., Eccles; clock, about 1770 . John, Red Lion St., Clerkenwell, 1770-85. Peter, Manchester, 1784. Archibald, 9 New Bond St., 1790-1830. Chas., 159 Sloane St., 1822.

Collingridge. Edmund, 27 Wilderness Row ; livery C.C. 1810 ; 1793-1830. Thos., 136 Aldersgate St., 1838-42.

Collingwood. Samuel James, 8 Long Alley, livery C.C. 1786 ; 1766-94. Robt., Rochdale, 1816. Henry, Rochdale, 1833.

Collins. Robt., apprenticed 1646 to Ahasuerus Fromantil, C.C. Peter, apprenticed 1679 to Jas. Atkinson; C.C. 1687. John, C.C. 1701; at the "White Horse and Black Boy," Great Old Bailey, in 1705, see Shelton, John. Clement, C.C. 1705. John, C.C. 1727 ; repeating watch, silver case pierced, silver dial with raised figures, about 1730. Jno., Wattisfield, born 1750, died 1829. Richard, Margate, 1798. Wm., London; watch, 1810. R., 52 Strand, 1813. Jas., 66 Long Acre, 1822.

Collinson, Jas., London; watch, 1770. Collis. Chas., London; watch, 1720. Richd., Romford, 1802-7.

Collomby. Jacob, London ; watch said to have belonged to Oliver Cromwell, Mr. Ambrose Phelps. Henri, Hüningen (Upper Alsace), 1680-1730; watch in enamelled case, S.K.M., signed "H. Collomby à Huninguen."' Jaques, watch, Pierpont Morgan collection, silver cases, outer one chased, about 1700. Abraham, Geneva; watch, 1745, Mr. Paul Ditisheim; another with calendar, Messrs. Lambert; another specimen suspended from a long and handsomely enamelled chatelaine, outer case enamelled and studded with diamonds about the same date at the S.K.M. is a calendar watch, about 1750, signed "Abr. Collomby, London."

Collum, A., 74 Lower East Smithfield, 1800 .

Collyer, Benj., London; long green lacquer case clock, arch dial, about 1725, Wetherfield collection.

Colman, - Ipswich; watch, one hand, about 1685, Evan Roberts collection.

Colson (? Colston), Richd., apprenticed 1637 to Jas. Vantrollier; C.C. 1646.

Colston. Jno., C.C. 1653. Richard, free of C.C. by patrimony, 1682 ; curious 24day clock at Battle Abbey, Sussex ; other examples of his work are a fine watch, Evan Roberts collection, with pierced con-. trate wheel, and a watch (inscribed " Colston London"), with sun and moon pointers; long burr walnut case clock, 12-inch dial, Wetherfield collection ; watch, about 1720, Pierpont Morgan collection.

Colyer, see Collyer.

Combault à Paris, watch, about 1780 .

Comber, Richard, Lewes, died 1824, aged 82 ; chiming clock, 1778 (see p. 525), dial illustrated in Fig. 520; clock, Victoria Hospital, Lewes, about 1790. Mr. S. Tanner, Lewes, says : "I have never met with a bad or imperfect specimen; his work will endure for many generations."

Combes, Simon, watch, 1780 .

Combret, Pierre, Lyons ; calendar watch 1613 ; watch in shell-shaped case, S.K.M., about the same feriod; cruciform watch, about 1620, Pierpont Morgan collection.

Combs, Joseph, C.C. 1720.

Comfort, William, brother C.C. 1647 ; signed a petition in 1756 .

Comley, Thos., London; watch, G.M., about 1780 .

Commander, Sam., St. James' St., Clerkenwell, 1845 .

Compigné, - , bracket clock, about 1710 , inscribed "Compigne, Winton" ; watch, "Dav. Compigne, Winton," about 1750; good long-case clocks by him are to be met with in Hampshire.

Comport, Ebenezer, Temple Bar ; C.C. 1728.

Compton Walter, Vere St., 1692. Adam, C.C. 1716.

Comtesse, Louis, watch-case maker, succeeded Peterman \& Debois at Soho, 1810; afterwards at East St., Lamb's Conduit St., see Stram.

Conant, Elias, Bridgewater, U.S.A., 1776-1812 ; Lynn, 1812-15.

Condé, E. J., Bristol, 1842.

Conden, Robert, 51 Clerkenwell Close, 1780-85.

Conduitt, Sam., apprenticed 1671 to Robt. Halstead, C.C.

Condy, Thos., apprenticed 1684 to Cornelius Jenkins ; C.C. 1692. 
Congreve, William, Garden Court Temple, and at Woolwich; inventor of curious clocks (see p. 472).

Connell, William, 22 Myddelton St., 1839 ; a clever watchmaker who succeeded Ganthony, at 83 Cheapside, in 1845 ; died 1862 ; his son, Wm. Geo., died 1902.

Connelly, Wm., 93 Piccadilly, 1825.

Connoley, M., Dublin ; watch, 1790.

Conrad \& Reiger, German octagonal timepiece in S.K.M., about 1590.

Constable, W. \& G., Bunhill Row, 1804 ; 27 Finsbury St., 1807. William, Dundee, 1806.

Constantin (or Constatine). Vincent Dieppe; oval watch, about 1620. Philip, London ; bracket clock, a bout 1710 ; longcase clock, about 1730. —- Geneva; heart-shaped watch, S.K.M., about 1740 .

Constantine, Pet., 33 Park St., Grosvenor Sq. ; card, B.M., 1802.

Contandois, see Le Contandois.

Contard \& Co., Paris ; 15-day watch, 1831.

Cony, John, brother C.C. 1641.

Conyers. Richard, C.C. 1689 . Thos. London; watch, about 1715, Major R. H. Raymond Smythies.

Cook. Wm., London; long-case clock, about 1700. Edwd., 210 Borough, 1763-72. John, 22 Cheapside, 1768; 24 Wood St., 1772-75. Joshua, Blue Anchor Alley, 1793. Zenas, Waterbury, 1815-20. J., watchcap-maker, 5 Robert St., Hoxton, 1835.

Cooke. Lewis, f., of York, 1614 ; petitioner for incorporation of C.C. 1630-32, John, apprenticed to Isaac Law, 1641 ; C.C. 1649; hexagonal watch in case of rock crystal set in enamelled gold, Wallace collection, about 1660 . John, apprenticed to Wm. Dobb, 1655 ; C.C. 1662 ; fine longcase clock, marquetry case, about 1680 . Robert, C.C. 1667. William, C.C. 1681. Edwd., apprenticed 1687 to Wm. Kenning. Thomas, C.C. 1699; long-case clock, "Thos. Cook, London," about 1720. William, C.C. 1708. John, C.C. 1712. Joseph, C.C. 1715. \& Gurney, Foster Lane, 1754-59. John, 22 Cheapside ; livery Goldsmiths' Company, 1765-77. Robert, 7 Star Alley, Fenchurch St., 1804-10. G. E., 5 Jewin St., 1822 .

Cooley, Hy., London; long Sheratoncase clock, about 1805 .

Coombes. Wm., apprenticed 1689 to Isaac Lowndes, C.C. Fisher, admitted C.C. 1728. Jas., 10 Mitchell St., St. Luke's, 1815; 3 Clerkenwell Green, 1825.

Cooper. Hugh, C.C. 1653. Stephen, apprenticed 1675 to Thos. Morgan, C.C. Jas., apprenticed 1693 to .Wm. Boad, C.C. Jon., Cardiff ; watch, pendulum balance showing through dial, minute hand only, blued steel rotating hour disc showing through curved slit in the lower half of the dial, silver medallion over top plate, with finely chased female head and military trophies, about 1700. Edwd., London; watch, silver dial, riased figures, about 1730 , conversion to rack lever and very large balance, about 1805 . Geo., London ; mahogany long-case clock, about 1760 . Jos., Whitchurch, 1765. Benj., Brownlow St., 1775. Wm., Derby, 1770 . \& Son, Derby ; watch, 1786. Edward, clock-case maker, 91 Sutton St., 1789-94. Thos., Newport; watch, 1796 . Thomas, 1 King St., Little Tower Hill, 1800 . Wm., 8 Old Bailey, 1804. William, 44 Red Lion St., 1816 ; 12 Gee St., 1820-42. E., Wynyatt St., 1820. Thomas Frederick, Duncan Place, City Road, and afterwards at 6 Calthorpe St.; a well-known watch manufacturer who made chiefly for the American market. His son told me the American reputation was obtained through the good going of a watch by Cooper, which was used as a Greenwich time standard on a ship when the chronometer had accidentally failed, 1820-62.

Coote, Thos., Dublin; bracket clock in pear-wood case, about 1750 .

Cooth, Jno., London; watch, 1720.

Cope. Peter, brother C.C. 1638 . Chas. Jno., 38 Berners St., 1800-30; he was a man of some note, and attested the value of Earnshaw's improvements in 1804.

Copeland, Alexander, 113 Leadenhall St., $1800-15$; livery C.C. 1810.

Copestake, Hy., 8 New Bridge St., 1793.

Coppet, Reg. A., watch ; on plate over balance," Geo. Virtue his watch. From Berne, - 1750."

Copping. Richd., about 1640 ; C.C. Geo., apprenticed to Richard, 1654 .

Coppinge, - , long-case clock, " Richard Coppinge, at St. Edmund's Bury in Suffolke," about 1720 .

Copplestone, Wm., apprenticed 1683 to Wm. Robinson, C.C.

Corbet, Nathaniel, maker of a silver watch with studded case, frosted dial plate (Lond. Gaz., Sept. 21-25, 1693).

Corbett. -, Hadleigh ; watch, G.M., about 1780 . 'J., 42 Clerkenwell Close, 1825. T., 22 Goswell Terrace, 1835.

Corbigny, - French watch, 1700.

Corbitt, Ben., apprenticed 1682 to Thos. Snelling, C.C. -, 10 Short's Bdgs., 1835.

Corderoy. Thos., apprenticed 1663 to Nicholas Coxeter ; C.C. 1670. Phil., apprenticed 1672 to Robt. Seignior; C.C. 1679. Walter, apprenticed 1692 to Thos. Taylor.

Cording. Jno., 232 Strand, 1812-30. Josh., 21 Holborn Hill, 1817-25. Chas., 118 Minories, 1822-25. Thomas, 38 Aldgate, 1822-30. 
Cordingley, Thos., Leeds, 1829.

Cordon, Richard, C.C. 1729.

Cordrey, see Corderoy.

Cordwell, Robt., C.C. 1646.

Corghey, John, Fleet St., 1754-59.

Corker. D., 18 Langley Place, Commercial Rd., 1820-42. Nath., 48 Sth. Moulton St., 1842.

Corless, Richd., Stockport ; about 1750.

Cormier. In 1481 a sum of four livres tournois was paid to Pierre Cormier, locksmith, for making a clock case and doing sundry other work for Louis XI. for his Château at Plessis-du-Parc.

Cornelius, Jacob, London ; small diamond-shaped spring timepiece, catgut line, about 1620 ; C.C., but date of election uncertain.

Cornish. Wm., apprenticed 1659 to Robt. Hanslapp, C.C. Michael, C.C. 1661.

Cornwallis, William, London; watch, silver case, enamelled dial, with Hope and a ship, about 1800 .

Cornwell. Danl., London; small silver watch, Mr. A. E. Clarke, about 1750. Hy., London; watch, 1790; another, 1800. Daniel, Billericay, Essex ; " Act of Parliament" clock, about 1798 .

Corp, Wm., 84 Aldersgate St., 1835.

Corrall, Fra., Lutterworth, 1740.

Corrie, - , Langholme ; long-case clock, about 1770 .

Corson. Joseph, Maryport, Cumberland, 1832. Thos., 119 High St., Wapping, 1835-42.

Cortauld. Samuel, Cornhill, opposite Royal Exchange, 1759-63. P. \& Cowles, 21 Cornhill, 1768-75.

Cosbey, Robert, at ye Diall, Rood Lane, C.C. 1653-79.

Cosens, Nicholas, hour glass maker, York, f., 1638.

Cosman, Philip, Amsterdam ; watch, about 1790 .

Cosse, James, Cornhill; watch, 1720.

Cosson, S., St. George's East, 1835.

Costa. Timepiece of gold, signed, " Inventé et executé par Jh. Costa Amateur d'Horlogerie à Marseille," Turkish numerals, Wallace collection, about 1790 .

Costen. Adam, Kirkham; died 1788, aged 77 ; long-case clock, about 1760 ; on another clock, about 1770, " Adam Costen Kirkham." William, son of above, died 1831, aged 71 .

Coster. Robert, C.C. 1655. William, admitted C.C. 1660.

Costontin, Vincent, Dieppe ; watch, Schloss collection, about 1660 .

Coteau, - Paris ; his signature on many good clock dials, Louis XVI. period.

Cother, William, brother C.C. 1668.

Cotsworth, Jno., C.C. 1669; Edwd. Crouch was apprenticed to him in 1691 ; long-case month clock, about 1730, signed

"John Cotsworth, London."

Cottel, John, lantern clock, inscribed, "John Cottel, fecit 1653."

Cotter, Ebenezer, 13 Goldsmith Ct. Wood St., 1775.

Cotterel. William, C.C. 1694. John,

C.C. 1721 .

1830.

Cotton. John, London C.C. 1695 ; watch, sun and moon hours, about 1710 . John, \& Son, watch, about 1715 . John, admitted C.C. 1718; he worked for Pepys in 1730 . Wm., London ; watch, 1740. Francis, 90 Shoreditch, 1822 . R. \& T., watch-spring makers, 17 President St. East, 1835.

Cottonbelt, John, Wild St., C.C. 1729.

Couche, Charles, C.C. 1727.

Couchon à Paris; fine Boulle clock, Wallace collection, about 1690 .

Couldray, Julian, Paris, 1529. William, clockmaker to Henry II., 1550.

Coulin Frères, Geneva; watch 1780.

Coulon. Charles, Panton St., watch, 1762; Prince's St., Leicester Fields, 1765-68. - Geneva, 1780.

Coulson, Charles, Soho, 1769. Robert, Whiskin St., $1800-38$; livery C.C. 1810 . Saml., 16 North Audley St., 1825.

Coulton. Richd., apprenticed 1641 to Morris Blunt, C.C. Francis, C.C. 1690. Wm., York, f., 1701; long-case clock, about 1740. Jno., York, 1780.

Coupé. Jacques, Paris ; clockmaker to the King, 1680; watch, enamelled case and dial, about 1670 , name-plate engraved " James Coupé, London " ; underneath on the plate of the watch was inscribed "Marc Grangier." Edward, Paris ; clockmaker to the King, 1683. Elizabeth, " Horlogeuse du Roy" on watch, about 1700 .

Courter, Wm., Ruthin, 1780.

Courtois, -, Rue Saint-Jacques, Paris ; clockmaker to Louis XV. 1750-72 (see p. 433).

Courvoisier à Paris; fine ormolu wall clock, belonging to the Hon. Gerald Ponson by, about 1780 ; many watches bear this signature; others signed " Courvoisier Frères" ; see also Robert and Courvoisier. Fredk. Alex., Chaux de Fonds, born 1799, died 1854.

Cousens. Thos., pendant maker, Bunhill Row, 1793. R. W., 6 York St. East, Commercial Rd., 1835.

Cousins, Wm., 13 Finsbury Place, 1814-18, see Cozens. \& Whitside, 20 Davies St., 1842; 14 Pont St., 1850. Herbert, 7 York St., Bath, 1845.

Couta, G., 12 Blenheim St., Oxford St., 1822-25.

Coutois, Jha., London ; watch, Pierpont Morgan collection, about 1780 . 
Covell, Richd., apprenticed 1671 to Chris. Maynard, C.C.

Coventon, Joshua, clock-case maker, 60 Red Lion St., Clerkenwell, 1835.

Coventry. Carr, apprenticed 1649 to Sam. Davis; C.C. 1657. R., 12 Queen St., Clerkenwell, 1830 . J., 8 Paragon Place, New Kent Rd., 1835.

Coverdall, Dan., apprenticed 1683 to Thos. Rudkin, C.C.

Covies, Wakefield, 1780.

Covigny de Paris; watch, about 1700 .

Cowan, James, Edinburgh ; apprenticed to Archibald Straiton 1744 ; on completion of his indentures he went for a short time to Paris, and worked under Julien Le Roy ; watch, Schloss collection, engraved Jas. Cowan, Edinburgh, gold repoussé case, about 1765; bracket clock, about 1770, Wetherfield collection (see p. 584); died 1781, see Reid, Thos.

Coward, William, apprenticed to John Fromanteel ; C.C. 1681. \& Co., Cornhill ; centre seconds watch, 1780 . \& Jefferys, 149 Fleet St., 1783. Wm., Lancaster, 1797-1830.

Cowderoy, R. F., fine watch, Hawkins collection, about 1750 .

Cowdery, Geo., 6 King St., Holborn, 1817. Cowell, John, 97 Royal Exchange, 1763-1800.

Cowen, H., 3 Sidney's Alley, Leicester Sq., 1800 .

Cowie, Jno., 8 Aldermanbury Postern 1:14-18.

Cowles, Geo., \& Co., 30 Cornhill, 1780-90. Cowley, Robt., Chester; member of the Goldsmiths' Company, 1773.

Cowling, Richd., London; watch, 1820.

Edwd., Richmond, Yorks, 1823.

Cowpe. James, C.C. 1654. Edward, brother C.C. 1687.

Cowper, -, London; watch, 1800.

Cowta, Geo., 12 Blenheim St., Oxford S., 1817.

Cox. Thomas, C.C. 1708. Jason, Long Acre, 1745-60. James, 103 Shoe Lane, a clever mechanician, who opened at Spring Gardens a museum of quaint clocks, singing birds, and costly mechanical toys. There were fifty-six pieces in the collection, and the charge for admission was half-a-guinea each person; a regulation providing for the presence of but few visitors at one time was, needless to say, quite unnecessary; in the B.M. is a large centre seconds elaborate watch by him, suited for the Oriental market, 1760-88 (see pp. 401-2, also Merlin). Wm., 70 Cox Court, Little Britain, 1763-72. Samuel, Long Acre, 1770. \& Watson, 23 Aldersgate St., 1780-85. Jas. \& Son, 1789-1800. Robt. N., Pickering, Yorks,. 1822-40.
Rd. W., Bristol, 1842: Nathaniel, 140 Goswell Rd., 1835-42. J. M., Bath, 1850.

Coxall, Samuel, "from London, late apprentice and now successor to Mr. Thos. Kefford, at the Dial in Fore St., Royston," advertisement inside long-case clock, about 1750 .

Coxeter. Nicholas, apprenticed to Jno. Pennock 1638 ; C.C. 1646 ; master 1671 , 1677 ; a celebrated maker ; lantern clock, inscription, "Nicholas Coxeter, neare Gold Smiths' Hall Londini fecit," Mr. T.W. Bourne (see p. 481); clock, Wetherfield collection, small narrow long-case with olive and laburnum veneer with stars inlaid. Wm., apprenticed to Nich. Coxeter 1647 ; C.C. 1654 . John, master C.C. 1661-63. Thos., C.C. 1673 .

Cozens, William, 3 Wilderness Row, 1804-10; 13 Finsbury Place, 1822-25; a prominent man in the trade; trustee to the W. and C. Benevolent Inst. in 1820; died 1842. William \& Son, 10 Bunhill Row, 1822-42. J., 10 Bunhill Row, 1835-42 afterwards Cozens, Matthews \& Thorpe.

Crabb, Jas., Sarum, 1780-95.

Cradock, E., 13 Charlotte Terrace, Lambeth, 1835.

Cragg. Richard, C.C. 1660. Sam., apprenticed 1690 to Jno. Northcott, C.C. Jas., Lancaster, 1779, f. John, 10 President St. East, 1835 ; 8 Northampton Sq., 1840-62.

Craig, Chas., Dublin ; cylinder repeating watch, 1780 .

Craighead \& Webb, Royal Exchange, 1848-54.

Craigingle, John, 90 Park St., Grosvenor Sq., 1839-42.

Cramber, R. P., London; watch, 1810.

Crampern. Wm., Newark, died 1770. John, Newark: long-case clock, about 1775 (see Fig. 680, p. 509).

Crampton, Edwd., Newark, 1780.

Cranage (or Cronage), Thos., Liverpool, 1818 , also Joseph.

Cranbrook, Geo., London; watch, 1770. Crane, Thos., apprenticed 1682 to Thos. Holl s, C.C.

Cranfield, Henry, C.C. 1706.

Cranmer, Chas. London; watch, 1800. Crathorne, Jno., Maidstone, about 1750.

Cratzer, Nicholas, clockmaker to Henry VIII., 1538 (see p. 249).

Craven, Thomas, brother C.C. 1688.

Crawiord. Alex., Scarboro', 1770. Alex., jun., Scarboro', 1822.

Crawley. Thomas, C.C. 1660. William, apprenticed to James Harrison ; admitted C.C. 1756 . J., London; watch, 1785.

Crawshaw. Wm., Washborough (near Barnsley), 30-hour clock, about 1720. Jas., Rotherham, about 1740. Thos., Rother- 
ham, 1770. Thos., Retford, died about 1814. Andrew, Rotherham, 1810-42.

Crayle. Richard, member of the Blacksmiths' Company, petitioner for incorporation of C.C. (see p. 255), 1610-55. William, Fleet St. ; afterwards at the Black Boy in the Strand; watch by him, B.M., about 1660. " Lost a plain gold watch made by William Crealy, in a black shagreen case with gilt pins. If any can give notice to one of the King's Trumpeters next doore to the Kirk House near Charing Cross, they shall upon delivery thereof have five pounds for their peyns " (The Intelligencer, Jan. 11, 1663). "Lost on the 13 inst., a Gold Watch enamelled, the outside case seal-skin studded with gold; in the backside of it was the history of St. Paul's Conversion, with small character Saul, Saul, quid me persequeris? And on the Dial part was the stoning of Stephen, with Lanskip round about; and in the inside of the back, a Damask Rose exactly enamelled, the Key fastened with a black Ribon. Whoever gives notice of it to $\mathrm{Mr}$. William Crayle, a watchmaker at the Black Boy in the Strand, near the Savoy, shall have $3 l$. reward " (Lond. Gaz., July 13-17, 1676). "Lost on Wednesday, the 2nd Inst., at night, in Kings St., near Southampton Fields, a Gold Watch with a Pink coloured Sattin Ribon to it, the case studded with a Heart darted and the watch made by Mr. Crayle in the Strand, and St. George and the Dragon engraven on the Dyal Plate. Whoever brings it to Mr. Norman Nelson, Stationer, at Grays Inn Gate, shall have 40s. reward " (Lond. Gaz., 3rd June 1680). "Lost on the 22 inst., between St. Andrews Church in Holborn and the further end of Grays Inn Road, a gold watch with the outer case studded, with Mr. William Craile's name engraved on the bottom plate of the said watch. Whoever gives notice of the said watch to Mr. John Wheatley, at the 3 Cups in Hatton Street, shall have two guineas reward" (Lond. Gaz., March 20-24, 1690).

Crayton, Wm., London; watch, 1770.

Creak, William, Cornhill and Bunhill Row; watch, G.M., 1740-68.

Creaser, Thos., York, f., 1815-22.

Creed. Thomas, brother C.C. 1668. Thomas, brother C.C. 1674. Robt., apprenticed 1689 to Thos. Tompion; C.C. 1699.

Creede, John, C.C. 1727.

Creeke, Henry ; a suit by C.C. for using clockmakers' trade contrary to the statute, compromised by Creeke promising to present to C.C. a new house clock and alarm, and 20s., 1654.

Crespe, François, Geneva ; "Essai sur les Montres à répétition," 1804 .
Cressener, A. M., Red Lion Sq. ; long inlaid case clock, about 1725 .

Cressent, Charles, Paris ; maker of clock cases (1720-60), two examples, Wallace collection.

Cressner, Robert, London ; maker of lantern bracket clocks, 1690-1730.

Creswell, Joseph, corner of Adelphi, Strand, 1775.

Creuzé. Francis Creuzé, a Huguenot, settled in London, carried on business in the Parish of St. Peter le Poor ; resided at Clapton; died in 1758, aged 64 , and was buried in the old Churchyard at Hackney. His sons, Francis and John, carried on business at Broad St., City. Francis, born 1726, died 1809, and was buried at Leyton, Essex. John, born 1737, died 1823, at Stoke-next-Guildford. For most of these particulars I am indebted to Mr. Herbert H. Sturmer.

Crewe, James, an able horologist, many years in London, where he died in 1908.

Cribb, William, 58 Theobald's Rd., $1816-22$; 17 Southampton Row, 1829 ; a chronometer maker who succeeded Birchall \& Appleton, formerly Molyneux; died 1876.

Cripple, Wm., C.C. 1702.

Cripps. John, St. Thomas Apostle, 1758-63. John \& Francillon, 43 Friday St., 1769 ; 24 Norfolk St., Strard, 1793.

Crisp. Nicholas, Bow Churchyard, 1754-59. John, 22 Old Jewry, 1783. Wm., Wrentham, 1790. William Baker, Clerkenwell ; apprenticed to John Bryer, Northampton Sq., became a chronometer maker of repute, lived for some time at $174 \mathrm{St}$. John's Street Rd.; died at the Clockmakers' Asylum, New Southgate, 1895, aged 70.

Cristoff, - , fine travelling watch, signed " Jo. Cristoff, Kerizer."

Critchley, Wm., Liverpool, 1818.

Croker. James, C.C. 1716. Wm., 34 Great Alie St., 1842.

Crockford, Matthew, C.C. 1659 ; lantern clock, engraved on the fret "At the Royall Exchang."

Croft. John, C.C. 1665. John, watchcase maker, 51 Wynyatt St., Clerkenwell, 1835.

Crofts, Richard, at the Bear in Foster Lane, right against Goldsmiths' Hall. " A gold watch by Goulon à Paris, the inside a landscape, a studded case, lost near St. Martin's, to be taken to him if found "

(Lond. Gaz., March 25-29, 1675).

Crolee. Jam., London ; clock, about 1730. Natt., Londen; watch, 1775.

Crolet à Paris ; late-seventeen th-century watch in engraved brass case, S.K.M.

Crome, Robt., apprenticed 1644 ot Sampson Shelton, C.C. 
Cromey, Wm., Bristol, 1842.

Cronier à Paris, about 1790; watch, G.M. ; clock, Wallace collection ; bracket clock, Mr. Alfred Spencer.

Crooke. Sampson, apprenticed 1661 to Sam. Horne ; C.C. 1668. Isaac, apprenticed 1675 to Nicholas Russell. Peter, C.C. 1724. Benj., Church St., Hackney, 1802-8.

Crosbey, -, long-case clock, about 1690 , inscribed "Robert Crosbey, In King Street near the Sqr."

Crosby, Joseph, Bridlington, 1838-41.

Crosmier (? Cronier), - , Paris, 1790.

Cross. Jas., apprenticed 1687 to Jno. Browne, C.C. Jno., Liverpool, 1770. James, Fetter Lane, liveryman C.C. 1776. Edward, Blewitt's Buildings, Fetter Lane, 1780-94. John, 131 Old St., 1804; 35 Cursitor St., 1823. John Berryhill, Jewin St., and 10 Charterhouse Sq., 1822-45; 23 Moorgate St., 1850-52; livery. C.C. 1834.

Crossley. James, London ; maker of lantern clocks, about 1710. Richd., 14 Giltspur St., 1800-25. Jas., King's Ct., Bunhill Row, 1814-18. Humphrey, also Henry, Manchester, 1818.

Crosthwaite, Jno., Dublin ; a good maker mentioned by Earnshaw, 1760-95.

Crouch. George, C.C. 1668. Edward, apprenticed 1682 to Jno. Cotsworth ; C.C. 1691 ; master 1719 ; in 1697 his address was " Under St. Dunstan's Church in Fleet St.," see Westoby. Robert, C.C. 1722. John, Knightsbridge, 1761.

Croucher, Joseph (associated with J. G. Ulrich), 27 Cornhill, 1825; livery C.C. 1828 ; Swithin's Lane, 1838.

Croudhill, Thomas, 19 Bedford St., Bedford Row, 1790-94.

Crow. Nat., apprenticed 1654 to Wm. Petty; C.C. 1661. George, Wilmington, U.S.A., 1740-70. John, 1770-98. Thos., 1770-1824.

Crowford, G., London ; watch, 1768.

Crowther. Wm., London; watch, 1805. Wm., Halifax, 1830.

Croydon, C. H. E., Tavern Street, Ipswich ; died 1916, aged 69 .

Crucifex. Robert, Sweeting's Alley; brother C.C. 1689; bracket clock, about 1700 , Mr. A. W. H. Hcrnsby-Drake ; longcase clock, about 1725 . John, brother C.C. 1712 ; maker of sheep's-head brass clock, with arch dial, bought in Holland, and of a similar one at Stirling Castle.

Cruickshanks, Robert, 17 Old Jewry, 1772-75.

Crump. Henry, admitted C.C. 1667. Thos., Liverpool, 1770.

Cruttenden, Thomas, apprenticed to John Fromanteel ; C.C. 1677 ; f. of York, 1680 ; died 1698.

Cryton, Wm., see Crayton.
Csacher, C., Prague ; watch, 1750.

Cubley, Thos., 54 Crawford St., 1820; Homer St., New Rd., Marylebone, 1830. Cuendel, Samuel, 52 Red Lion St., Clerkenwell, 1815.

Cuff. James, London ; C.C. 1699 ; Mr. Charles Winter has a fine marquetry longcase clock by him, dating frcm about $1700-$ 05. John, C.C. 1718. Wm., Shepton Mallet; long-case clock, Bishop's Palace, Wells, about 1720; his name is also cn the sun-dial in the palace grounds. Broadhurst, 204 Regent St., 1823. Jno., 138 New Bond St., ard 106 Regent St.,1823. Jas., 70 St. Paul's Churchyard, 1823.

Cufford, Francis, C.C. 1718.

Culliford, J., Bristol, 1680-1700.

Cullum, A., Lower East Smithfield, 1789-94.

Cumming. Alexander, F.R.S., born at Edinburgh, about 1732, died at Pentonville, 1814; a celebrated chronometer and clock-maker, who first suggested curved teeth for the cylinder escape wheel; he published in 1766 "The Element of Clock and Watch Work" ; elected hon. freeman of the C.C. in 1781; he carried on business at the Dial and 3 Crowns in New Bond St., 1777 ; resided at 12 Clifford St. till 1794, then he kept a shop in Fleet St., which after his death was occupied by his nephew, John Grant; among the fine and curious clocks at Buckingham Palace is one by Alexander Cumming, made for George III., which registers the height of the barometer every day throughout the year; he had $£ 2,000$ for the clock, and $£ 200$ a year for looking after it; in the Wetherfield collection are a bracket clock, and a long mahogany-case clock with marquetry decoration (shown on p. 561), by him, dating from about 1790 ; some time ago I saw a watch inscribed Cumming \& Grant, London ; it has no case, but dated from about 1805. W. M., Bond St., 1756-64. Alex., Inverary ; watch, 1775. John, "at the Dial," 202 Oxford St. 1816-42, see Panchaud \& Cumming.

Cummings. T., London; watch, 1802. G., London; watch, 1805 . William, Roxbury, U.S.A. 1820-30. Charles, 148 Leadenhall St., 1842, a maker of chronometers and fine watches; a watch by him contained an ingenious form of fusee stop which seems to have been invented, though, before his time; a little finger projecting from the smaller end of the fusee was pressed by the chain into the way of a stop on the plate.

Cuninghame, James, Haddington, about 1776.

Cunningham. Hugh, Dublin, 1770. London ; silver watch, enamelled dial with Arabic numerals, about 1790. 
Cuper. Watch, about 1590, signed " Pierre Cuper à Blois," Garnier collection. Josias (French), Blacksmiths' Company and C.C. 1627-34. Loys, C.C. 1632. James Boyd, clock, about 1700 .

Current, Jno., London; watch, 1770.

Curryer, Thos., watch-glass maker, 134 Whitecross St., 1835.

Curson, George, livery C.C. 1756.

Curteen, see Monkhouse.

Curtis. John, C.C. 1671. Solomon, Philadelphia, 1793. Jas., London; watch, 1810.

Curtiss, Wm., Exeter ; watch, 1805.

Curzon, Chas., Tottenham; an excellent lever escapement maker; some time teacher at the Horological Institute, died 1903, aged 79 .

Cusin. Charles, born at Autun, in Burgundy, settled in Geneva, where it is said he introduced watch manufacturing, about 1587 ; cruciform watch, about 1600 , signed "J. Cusin," Pierpont Morgan collection. Noel, Autun; Mr. H. Martin Gibbs inherited a watch by him, dated 1627. A., clock-watch, Pierpont Morgan collection; signed "A. Cusin à Corbigny," about 1700.

Custer, J. D., Norristown, Pa. ; watch marked " Feb. 4, 1843, Patented."

Cutbush. Jno., Maidstone; long-case clock at Welbeck Abbey, dating probably from about 1700 ; at the top of the door of the case is an index hand pointing to the following, arranged in short lines to suit the width of the door down which the words are cut in relief: "Master, Behold me Here I stand, To tell ye hour at thy command, What is thy will 'tis my delight, To serve thee well by daye and night, Master be wise and learn from me, To serve thy God as I serve thee." Edwd., Maidstone ; long-case clock, about 1705.

Cuthbert. Amariah, C.C. 1694 . J., 27 Piccadilly, 1790-94.

Cutler, Geo., apprenticed 1692 to W. Jacques, C.C.

Cutlove, John, Harlestone, Norfolk ; long-case clock, moving ship, about' 1760 . Cutmore, Jno., watch, h.m., 1819; 6. St. Ann's Lane, 1846-58.

Cutting, Christopher, C.C. 1694.

Cuzner, Jeremiah, Shepton Mallet, 1844.

Dadswell, John, Burwash, 1700-20 ; maker of lantern clocks; Mr. H. Stanley Cooke has a converted lantern in wooden case about $6 \mathrm{ft}$. high.

Daft, Thomas, New York, 1786.

Daglish, Joseph, Alnwick, 1770.

Daillé, fine ormolu three-part clock, Wallace collection, signed " Daillé horloger de Madame La Dauphine," about 1750.

Daking, Richd., Halested; watch, 1780.
Dalby, John, 105 New Bond St., 17831804.

Delacour, H. W., Bath, 1850.

Dale, Roger, Baynes Row, 1774.

Dalemaige, Jehan, Paris; clockmaker to the Duchess of Orleans, 1401.

Dalgleish, J., Edınburgh; long-case clock, about 1750 .

Dallas, James, maker of a pocket chronometer for the Duke of Sussex, 1800-20.

Dallaway, Hy., 31 Milsom St., Bath, 1835.

Dallington, William, London ; maker of a watch, silver case and dial, day of the month, circle, about 1680 .

Dalton. Jac., London; watch, 1720. James, watch movement maker, Red Lion St., 1790; 12 Bunhill Row, 1810; 27 Percival St., 1815-20. Jno., 27 Percival St., 1816-22. Jno., York, f., 1830.

Damant, Saml., Ipswich; watch, 1800.

Dammant, Barn., Colchester ; long-case clock, about 1700; watch, 1715 ; lantern clock, square dial, about 1725 ; removed to London, 1735.

Damper, W., Tunbridge Wells, 1810.

Dana, Payton \& Nathaniel, Providence U.S.A., 1800.

Dancer, see Tolkien.

Dane. Thos., 133 Oxford St., 1790-1817; Regent St., N., 1823. Robert, 72 Long Acre, 1807.

Danell, Joseph, 214 Oxford St., 1822-30.

Daniel à Paris; watch, about 1650 . Stephen, brother C.C. 1698 . Robert, C.C 1708. Thomas, 20 Foster Lane, 1783.

Daniell. William, C.C. 1632. Hy., apprenticed 1646 to Hy. Kent, C.C. Edward, brother C.C. 1647. Isaac, C.C. 1648; warden 1674 ; did not bəcome master.

Thos., C.C. 1656. Thos., Kirkham, 1770.

Daniels, London ; watch, 1820.

Dannes, Robert, Clerkenwell, liveryman C.C. $1776 ; 1766-80$.

Darby. Jas., London; watch, 1770. John, 51 Gee St., 1820-42.

Darbyshire, -, Wakefield ; ' centre seconds watch, 1785 .

Dare \& Peacock, 103 Minories, 1770-72.

Dargent, James, C.C. 1700-05.

Dariford, -, maker of fine repoussé gold pair-case watch, gold dial, with calendar, about 1735 .

Darle, Thomas, London, about 1769.

Darling. Robert, Fenchurch St. ; Sheriff of London, and knighted in 1766 ; on the court of C.C. 1766. \& Wood, York, 1810. Wm., f. of York, 1829.

Darlow, Thos., apprenticed 1685 to Geo. Deane ; C.C. 1692.

Darno, D., London; watch, about 1750.

Darrell. Francis, apprenticed 1693 to Thos. Speakman, C.C. Joseph, 214 Oxford St., 1812-15.

Darrow, Elijah, Bristol, Conn., 1822-30. 
Darvell (or Darwell), Robert, apprenticed to John Ellicott, C.C. 1708. Edwd., 64 Watling St., 1775-94.

Darvill, Geo., London ; watch, G.M., 1766.

Darwin, E., London; watch, 1770.

Dashper, Frederick, 10 Pierpont Row, Islington, 1820-46. To him was apprenticed Egbert Storer.

Dasypodius, Conrad, born 1531 ; supervised second Strassburg clock, 1571 (see p. 40); died 1601.

Dauthiau, Paris; clockmaker to the King of France, 1735-56.

Davenport. Wm., apprenticed 1669 to Robt. Smith, C.C. Jas., London ; watch, 1780. Sam., 15 Lime St., 1788. Jas., Macclesfield; watch, 1790.

Daverill, Jno., C.C. 1636.

David, Louis, 1550-60.

Davidson. C., London ; watch, h.m., 1802. J., 12 Red Lion St., Clerkenwell, 1814-17. Adam, 21 Norton St., Fitzroy Sq., 1835 ; 44 Goswell St., 1842.

Davie, Joseph, 201 High Holborn, 1830-42.

Davies. William ; Mr. E. J. Nally, of Chicago, has a sun-dial inscribed "William Davies, Clerkenwell, 1670." Jenkin, London, long-case clock, 1770 . Timothy, Clifford St., Broad St., 1783; 15 New Bond St., 1793. Wm., Chester ; watch, 1784. Robert, 85 Gracechurch St., 1788-94. John, 153 Leadenhall St., 1788. Richard, 85 New Bond St., 1790-1800. T. \& H., 39 Brewer St., Golden Sq., 1800. James Callard, College Place, Camden Rd.; in 1840 he patented (No. 8,515) a one-year clock. Joseph, Bristol, 1845.

Davis. Samuel, at $y^{\mathrm{e}}$ Golden Ball in Lothbury, C.C. 1647-82. Tobias, C.C. 1653. John, brother C.C. 1653. Sam., junr., C.C. 1673. Thomas, C.C. 1674 . Benjamin, C.C. 1678 ; fine long marquetry-case clock, Mr. Miller Christy. John, Windsor; walnut long-case clock with pendulum beating $1 \frac{1}{4} \mathrm{sec}$, about 1678 , the front of the base formed a door to get at the pendulum for regulation, and contained a bull's-eye of glass through which the bob could be seen; clock in the Curfew Tower, Windsor Castle, made by him in 1689. Andrew, apprenticed 1679 to Robt. Nemes, C.C. ; fine marquetry long-case clock, Wetherfield collection, about 1720. Wm., Boston, U.S.A., 1683. Jeffry, C.C. 1690. John, apprenticed to Daniel Quare, admitted C.C. 1697. William, C.C. 1699. Jas., Ratcliff Highway, about 1705. George, C.C. 1720 . Thomas, C.C. 1726 ; watch, Newington Free Library, 1740. I., probably the son of John Davis, of Windsor, made the clock at Colnbrook Church, Bucks., 1746. Wm., Lancaster, 1761, f. John, Lamb's Conduit St., 1769. \& Bennett,
London; watch 1795. John, New Holland, 1802-05. Wm., 124 Newgate St., 1810-23. Saml., Pittsburgh, Dty., 1815. David, 28 Bury St., St. Mary Axe, 1830-42. \& Plumley, 9 Red Lion St., Clerkenwell, 1830. A. \& C.. 118 Houndsditch, 1835.

Davison. William, C.C. 1686. Jno., London, 1786. C., London; watch, 1820.

Davy, Robt., Hoveton ; clock, about 1770 ; watch, about the same date, signed "Robt. Davy, Aldeburgh."

Daw, Josh., 39 Cheapside, 1822.

Dawes, Wm., 131 Upper St., Islington, 1835-42.

Dawkes, John, admitted C.C. 1707.

Dawson. Thomas, petitioner for incorporation of C.C. 1630 ; transferred from the Imbroderers' Co. to C.C. 1636 . Wm., apprenticed 1659 to Ben Wolverston, C.C. Robert, of Alford, C.C. 1678. Jno., C.C. 1688; long-case clock, bird and flower marquetry in panels, 11-in. dial, domed hood, about 1700 . John, Holborn Bridge, 1763. Wm., London; watch, 1778; another, 1805 .

Day. Isaac, C.C. 1678. Thomas, C.C. 1691. Edmund, C.C. 1692 ; long marquetry case month clock, Wetherfield collection, about 1700; bracket clock showing day of the month, and in an oak case veneered with tortoise-shell; $1692-$ 1720. Jacob, apprenticed 1693 to Isaac Day, C.C. Jno., Wakefield, 1770. Richd., 14 Drury Lane, 1780-94.

Deacle, Joana, apprenticed 1672 to Eliza, widow of Thos. Webb, C.C.

Deacon. Samuel, Barton-in-the-Beans, Leicestershire; Grandfather clock, 1771. S. (Rev.), maker of Lutterworth clock, 1790. Joseph, 27 Rosoman St., 1814-18. Thos., Pentonville, 1830. F., St. Michael's Alley, 1835 . J. C., 18 Guildford St., Borough, 1835-42.

Dealtry, Thomas, 85 Cornhill, 1783.

Dean. George, engraver, admitted to C.C. 1671 ; in 1677 he presented to the Court. through Mr. Henry Tones, a plate with the coat of arms. Deodadus, 80 Minories, 1793-1804. Thos., Old Jewry, 1810 ; 1 Swithin's Lane, 1820-42.

Deard. J., Corner of Dover St., Piccadilly, 1775 .

Dearmar. Jno., apprenticed 1672 to Katherine Bestwick, widow, C.C. 1680. Abraham, apprenticed 1692 to Thos. East, C.C.

Death, Isaac, Maldon ; watch, 1790.

Deaves, Richard, Whitechurch ; longcase clock, about 1770 .

De Baghyn, Adrian, Amsterdam, 1710-50; watch, silver dial with pierced centre, silver cases, the outer one repousse, said to have belonged to the first Duke of Marlborough. 
De Baufre, - , watch, Garnier collection, signed "De Baufre, Paris," about 1650.

Debaufre. Peter, Church St., Soho; admitted C.C. 1689. The Debaufres were an exceedingly clever French family of horologists, probably driven over here by the revocation of the Edict of Nantes. Peter and Jacob were associated with Facio in the patent he obtained in $\mathbf{1 7 0 4}$ for watch jewelling. Peter Debaufre also invented a dead-beat or " club-footed " verge escapement, in which there were two escape wheels, having between them a truncated cone formed of diamond, and cut away at the side to form an impulse plane acted on by the wheels alternately. Sir Isaac Newton had a watch so made, and spoke favourably of its performance. Sully modified it by using two pallets and one wheel. Under the title of the club-footed verge, each kind was used for watches by Garratt, of Ormskirk, and also by Houghton, of the same place. More recently the two-wheel form has been revived for French carriage clocks ; alarm watch, about 1710 , inscribed " 'Pie,' De Baufre, Inglese, Roma," 1686-1720. James, Church St., Soho, admitted C.C. 1712 ; gold watch, S.K.M., h.m., 1723 ; another example, large silver watch with day of the month circle; 1712-50.

De Beaulieu. M. Eugene Wehrle has a fine striking alarm and calendar watch, signed "C. De Beaulieu a Basl," about 1640.

De Belle, Paris; watch, about 1780 .

Debelle, -, Paris, 1790.

Debenham, -, Melford ; lantern clock, about 1690 .

Debois, see Desbois, also Dubois.

De Bon, Jacque, Paris ; clockmaker to the Duke of Orleans, 1776.

De Boufler, Andrew, London, completed his apprenticeship 1769.

Debry, Theodore, a famous French chaser of watch cases, 1590-1630.

Deburge, Paris ; watch, about $1590, \mathrm{M}$. Ernest Roux.

De Caux, Lucas, Norwich; pendulum watch, 1700 .

Decele, Sam., Norwich ; lantern clock, about 1710, Mr. Hy. Brittain.

De Charmes. David, admitted C.C. 1692; plain silver pair-case repeater, rich cock and pillars, "Des Charmes, London," inscribed on enamel dial, 1692-1740. Simone (French), Warwick St., Charing Cross ; came here through the revocation of the Edict of Nantes ; built Grove Hall, Hammersmith, in 1730; his son David lived there; admitted as a brother C.C. 1691 ; 1688-1730. " Lost between Convent Garden and Leicester fields, on Wednesday, Nov. 14th, a silver Watch with a silver Chain, a steel Chain Diamond Cut, \&c. Whoever brings the said Watch to Mr. S. de Charmes, Watchmaker, at his House the Sign of the Clock, the corner of Warwick St., Charing Cross, shall have 2 guineas Reward" (The Daily Courant, Nov. 16, 1705). J., bracket clock, 1740. A David De Charmes was buried in Fulham churchyard in 1783.

Décheoly à Caen, 1730-40; example at S.K.M.

De Choudens, watchmakers in France and Switzerland from the end of the seventeenth to the end of the eighteenth century.

Decka. John, apprenticed to Wm. Addis; C.C. 1757; maker of an 8-dav long-case clock, mahogany case, inlaid with marquetry ; 1757-90. \& Marsh, Broad St., Ratcliff Highway, 1790-1800.

Declair, Claude, à Lyons; cruciform watch, about 1610 .

De Clareburg, see Clarburg.

Decle, J. H., père, Paris ; (garde-visiteur, 1769).

De Cologny, Geneva ; about 1770.

Decoviguy, - Paris ; watch, 1710.

De Crüe, Geneva ; about 1775.

Dee, William, Blackfriars ; C.C. 1729.

Deeme, Henry, Honiton ; clock, 1760.

De Féalins, Jehan, clock for Rouen, 1389 (see p. 28).

De Fontaine, L., 18 Wilsted St., Somers Town, 1835.

De Fontayne, James, London, about 1735 .

Deforges, - à Dijon ; watch, 1700 .

Defour Fob et Cie., fine gold repeater, probably French, about 1780.

Degan, Mathew; watch, Vienna Treasury, oval brass case, about 1630 .

De Handis, see Handis.

De Heck, Gerhart; engraved a watch said to have belonged to James I.

De Jersey, Westminster ; maker of longcase clocks, about 1810 .

De Kabors à Geneva; clock-watch, about 1725 .

Delabere, London; watch, Mr. George Carr Glyn, about 1730.

De la Chana, Dan., C.C. 1687.

De la Chaussée, fils, Rue Galande, Paris, 1770.

De Lacor, J. N., Geneva ; watch, about 1790.

De la Corbière à Nismes, 1790 .

Delacroix, -, Paris ; died 1862.

De la Fonds, watch-spring maker, 44 Salisbury Court, Fleet St., 1790.

De la Fons. John, Pinner's Court, Old Broad St., 1790-94. James, Royal Exchange, and 66 Threadneedle St., 1790-95. John, 66 Threadneedle St., 1800 ; corner of Bartholomew Lane, 1810; 25 St. 
Swithin's Lane, 1815 ; received 30 guineas from the Society of Arts in 1801 for a remontoir; in 1805 he patented (No. 2,893 ) a marine alarm chronometer.

Delafosse, Samuel (French), brother C.C. 1692 .

De la Garde. Spherical striking watch, signed "Jacques De la Garde, Bloys, I551," Garnier collection. A., Paris, 1630. Gustavus, 17 Lowther Arcade, 1840-42.

Delaine, 一, "South Work"; clock, about 1720.

Delamare. Marc, Paris, about 1720. Louis, Paris, about 1775.

De Lance, Jas., Frome, 1720-35; Mr. F. J. Butts has an early long-case 30 -hour one-hand clock by him; it plays a tune at twelve, four and eight.

Delande, Pierre, à Paris ; octagonal watch, about 1600, Pierpont Morgan collection.

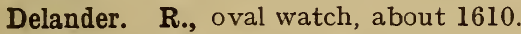
Nathaniel, brother C.C. 1668; assistant 1689. John, case-maker, admitted C.C. 1675 ; Salisbury Court, 1730. " Lost on Monday, August 2, between Fleet Street and the Old Bailey, a gold watch box not finished, in a brass case. Whoever gives notice of it to Mr. John Delander, watchcase maker, over against St. Clement's Church, shall have 10s. reward" (Lond. Gaz., August 5-9, 1675). Daniel, apprenticed 1692 to Chas. Halstead; C.C. 1699. According to the Spectator, D. Delander in 1712 moved from Devereux Court to a house between the two Temple Gates; he had been servant to Mr. Tompion. Mr. Wetherfield has a gilt framed hanging 8-day timepiece and a fine thirteen-month clock with equation work by him (see p. 540); at Child's Bank in Fleet Street is a long trunk mural timepiece in a japanned case by him; other examples of his work are a silver-gilt clock-watch and a watch in silver pair cases, notable as being an early application of a jewel to the centre of the balance-cock, both in the Pierpont Morgan collection. "Lost some time since a large jewel watch, the box and case in one, it winds up on the dial plate and has a steel plate inlaid with gold to make it go faster and slower made by Dan Quare; whoever brings it to Dan Delander, watchmaker within Temple Bar, shall have $10 l$. reward and no question asked, where all sorts of repeating jewel watches and other are made and sold" (Lond. Gaz., October 5-9, 1714). 1699-1721. John, Salisbury Court; apprenticed to Nathaniel; C.C. 1705. Nathaniel, Fleet St., near Temple Bar, son of Daniel Delander, C.C. 1721; master 1747. John, apprenticed to Richard Conyers, C.C. 1744.

De Landre, Peter, brother C.C. 1641.
Delandre, James, brother C.C. 1668.

Delaplaine, Jas. K., f., New York, 1786.

De la Porte, C. H., Delft, 1720.

De la Salle. Thomas, Brookers Row, Moorfields, 1780; 42 St. Catherine's, Tower Hill, 1800-18. Jas. Thos., 18 Cannon St., 1810-42 ; livery C.C. 1826 ; succeeded by his nephew, Wm. Christie.

Delaunay à Paris ; large bracket clock, inlaid with tortoise-shell and brass, about 1760.

Delaunce, James, brother C.C. 1650.

De Laundre, see De Landre.

Delauney, Peter, 68 New Bond St., 1822-25.

Delaversperre, Wm., brother C.C. 1650.

Delaville, Jas., apprenticed 1662 to Evan Jones, C.C.

De Lespinasse, Paris ; very fine pair of obelisks, veneered with lapis lazuli, Wallace collection; on one a clock, over the dial a female figure holding a fan through a diminutive hole in which the light passes and at noon crosses a vertical meridian line, after the style of Fig. 2; on the companion obelisk is mounted a barometer.

Delisle \& Moricand, watch .so signed, about 1760 , Mr. Willard $\mathrm{H}$. Wheeler.

Dell, Isaac. Bristol, 1845 .

Dellesser, Ellis, Liverpool, 1818

Dellung, Paul, apprenticed 1659 to Paul Lovell, C.C.

Delolme. Nicholas, London, 1770-96. Henry, 48 Rathbone Pl. ; a good watchmaker who also imported Swiss watches and materials; died 1890 , aged 87 .

De Lorme, Paris, 1720-40 ; alarm watch, Evan Roberts collection, with inscription,

" From Admiral Lord Nelson to Post Captain Jonas Rose," silver pillars.

Delunésy ; finely decorated clock, Wallace collection, about 1770 . - à Paris; clock presented by the municipality of Lyons to the Duc de Mortemar, governor of that city, gilt case finely chased by Gouthière and dated 1771, now in the Wallace collection.

Del Valle, Vincent, Gibraltar; watch, 1780.

De Manière à Paris ; clock, about 1750 , M. Spitzer. See also Manière.

Demaza, George, 95 Strand, 1825.

Demelais, - , London; watch, Dutch style, 1750.

Demole, -, Geneva; watch, about 1780, M. J. Rambal.

De Moylym, John, keeper of the Dulwich College clock in 1553.

Dempster. Anthony, York, 1822. Mark Anthony, York, f., 1829-34.

Demster, Roger, London, about 1790.

Denham, Geo., London; watch, Haw kins collection, about 1785 . 
Denier, M., Paris ; vase-form clock with revolving band and held up by two boys, Legion of Honour, 1844.

Denison, Edmund Beckett, born 1816 ; elected President of the British Horological Institute, 1868; succeeded his father as a baronet, taking the title of Sir Edmund Beckett in 1874; called to the House of Lords under the title of Baron Grimthorpe, 1886 ; died 1905; designer of the Westmnister clock, see Dent, E. J., \& Dent, F.

Denizave, - London ; watch, 1802.

Denman, Geo., 24 Greek St., Soho, 1820 ; 39 Newgate St., 1823. John F., 13 Cannon Street Rd., Commercial Rd., 1842. E. G., apprenticed in 1857 to Ashdown of Green Ter., London; died 1916, aged 71.

Denn, Basil, Tooley St., 1776.

Denne, John, 28 Lamb's Conduit St., 1820-23.

Dennett, Jas., St. Helens, Lancs., 1818.

Denning, J., 32 Ludgate Hill, 1840.

Dennis. Thos., apprenticed 1672 to Jas. Wightman, C.C. Francis, brother C.C. 1673. Peter, C.C. 1712. D., 54 New Bond St., 1816.

Dennison, Aaron L., born at Brunswick, Maine, 1812, died at Birmingham, 1895 ; a pioneer of American watch-making; in 1853 he started a factory at Roxbury; in 1854 removed to Waltham ; subsequently settled in England and devised machinery for making watch-cases at Birmingham, see Howard, Ed.

Dent. William, C.C. 1674. Robert, London, C.C. 1681; watch, 1710. Canon Greenwell has a long-case clock marked on dial " Dent London, 1746." Edmd., case maker, C.C. 1730. Edward John, born 1790 , died 1853 ; was apprenticed to a tallow chandler, but disliking that business induced Richard Rippon, in whose house he lived, to instruct him in making repeating mechanism; he worked as a finisher of repeating watches till 1830 , when he joined J. R. Arnold in partnership, at 84 Strand ; during the ten years they were together the business was greatly extended, chiefly through the energy and ability of Dent, who, when the partnership expired, established himself at 82 Strand, afterwards removing to No. 61 ; he also took Desgrange's shop at 33 Cockspur St., and another inside the Royal Exchange near the entrance to "Lloyds"; he married the widow of Richard Rippon, whose sons, Frederick and Richard, took the name of Dent; he turned his attention to the compensation of chronometers, and secured the confidence of Professor Airy, the Astronomer-Royal. When the Royal Exchange was rebuilt, Dent, on Airy's recommendation, was selected to provide the large clock; for this work Dent equipped a suitable workshop in the Savoy and made an excellent clock, which was fixed in the tower of the Exchange in 1844. In the same year Vulliamy was commissioned to prepare a plan for the great clock of the Houses of Parliament. Dent asked to be allowed to compete for the making of the clock, but objected to having anything to do with Vulliamy's plans; he said he would be willing to follow instructions of the Astronomer-Royal, as he had done with the Exchange clock. The Commissioners applied to Airy, and on his advice plans and estimates were obtained from Vulliamy, Dent and Whitehurst of Derby. In May 1847 Airy reported and recommended Dent for the work. In 1851 Lord Seymour, Chief Commissioner, asked Edmund Beckett Denison, a barrister who had taken an interest in horology, to act as referee with the Astronomer-Royal, and in February 1852 a contract was signed with Dent to make the clock, he to do everything ordered by the referees who described in a general way what was required. Airy went abroad for a time about March 1852, giving Denison power to act for him. E. J. Dent died in March 1853. The businesses in the Strand and Royal Exchange were taken over by Frederick Dent, and the one in Cockspur St. by Richard. \& Son, watch-glass makers 50 Northampton St., Clerkenwell, 1835. (Rippon), Richard, stepson of E. J. Dent, 33 Cockspur St.; died 1855. (Rippon), Frederick, stepson of E. J. Dent, 61 Strand; died 1860 . The initial proceedings in connection with the Westminster clock have been related under the head of Dent, E. J. Frederick had but little liking for clock work, and as the Astronomer-Royal in November 1853 resigned the office of joint referee, which he had held in conjunction with E. B. Denison, the superintendence of the making of the Westminster clock movement was left entirely to Denison. Dent's contract did not include the dials, and hands, which were designed by the architect, Mr. (afterwards Sir Charles) Barry, nor the provision or fixing of the bells. The clock was set going in May 1859. On the frame of the movement is the inscription, "This clock was made in the year of our Lord 1854 by Frederick Dent of the Strand and Royal Exchange, clockmaker to the Queen, from the design of Edmund Beckett Denison, Q.C. Fixed here 1859." Vulliamy had many influential friends, and what with their opposition at every stage and the incidental difficulties of the work, any less determined man than Denison would have thrown up the matter in disgust. He prepared a specification for the bell founders in February 1855. The 
first hour bell, weighing nearly 16 tons, cast in August 1856, became cracked and useless ; the second bell, weighing 13 tons $11 \mathrm{cwt}$., was tried with the four quarter bells in June 1858, but shortly after the clock was started a fissure was noticed, and in October 1859 the striking was stopped. Then for a short time the hour was struck on the largest of the quarter bells, but afterwards the hour bell was turned round so as to present a different surface to the hammer, and has ever since performed its office satisfactorily. The first set of hands, with their counterpoises, weighed $2 \frac{1}{4}$ tons and proved to be too heavy for the clock to drive. The hour indicators were retained, but the minute hands rejected in favour of lighter ones made of copper and tubular, and so the clock was not really finished till 1860. All's well that ends well, and the splendid time-keeper at Westminster, of which the nation may be proud, remains as an appropriate tribute to the ability and dogged perseverance of E. B. Denison (Lord Grimthorpe). Some particulars of the mechanism are given in the " Watch and Clock Makers' Handbook." The hour bell was named "Big Ben " in honour of Sir Benjamin Hall (Lord Llanover), who, as Commissioner of Works in 1856, gave the order for it to be cast.

Denton. Robert, Oxford; long-case clock, about 1750, Mr. H. Clark. Joseph, Hull; long-case clock, about 1760, Mr. Thos. Boynton. Wm., Oxford; watch, 1764. Sam., High St., Oxford, 1780. Isaac, London, about 1790. Wm., Poultry, 1816-20.

Depree (or Dupree), Elie, C.C. 1634.

De Presles, Jean, Paris, 1544 (see p. 404). Derby. Aron, apprenticed 1687 to Wm. Garfoot, C.C. Charles, Salem, U.S.A., 1846-50.

Derham, William, born 1657, died, and buried in Upminster, in 1735 ; a clergyman and Canon of Windsor, author of "The Artificial Clock-maker," published in 1696 ; second edition in 1700 ; third in 1714; fourth and last in 1734. He appears to have been acquainted with and assisted by Hooke, Tompion, and Langley Bradley.

Dermere, Abraham, C.C. 1703.

Derne, Louis, Nancy; watch, B.M., about 1640 .

Deroche (or Deroches), Fras. Geneva; watch, Wallace collection, about 1720 ; enamelled watch, about 1750; watch signed "Frs de Roches \& Fils," about 1760 ; another "Derocher Geneva," 1775 ; clock, " De Roque à Paris," about 1770, M. Spitzer Derrick. Jas. Bristol, 1844.

De Rouvroy, Jean. In 1446 he acquired the title of clocksmith and horloger of the town of Amiens.
Derwood, W. M., London ; watch, h.m., 1780 ; another, 1805.

De Salle à Caen ; watch, about 1720 .

Desarts, - et Cie., Geneva ; watch, 1780.

Desassars, Abraham, C.C. 1682.

Desbois. Several generations of this family have carried on business in the neighbourhood of Holborn. \& Wheeler, 9 Gray's Inn Passage ; a watch by them is in the Guildhall Museum; 1803-35. Daniel, apprenticed to John Johnson, whom he succeeded at 9 Gray's Inn Passage; died 1848, aged 75. Daniel, 9 Gray's Inn Passage, and afterwards 79 High Holborn ; died 1885, aged 76. Edwin, 79 High Holborn, and afterwards 10 Brownlow St., for many years Hon. Treasurer of the British Horological Institute, took an active interest and was on the Committee of the Clock and Watch Makers' Asylum ; died 1917, aged 76 .

Desborough, Christopher, C.C. 1665.

Desbrow. Elizabeth, apprenticed 1676 to Hy. Jevon and Christian his wife; C.C. Robert, C.C. 1704.

Des Granges, Peter, successor to Recordon, 33 Cockspur St., 1816-42, see Dent.

Deshais, Matthew, London; bracket clocks, 1690-1710.

Desmarais, Peter, St. Martin's Court, 1794.

Desmee à Paris ; watch, enamelled dial, Schloss collection, about 1750 .

Desmore, T., 11 Clerkenwell Green, 1830. Destaches, Jno., C.C. 1660.

De St. Leu, Daniel, a good maker ; was watchmaker to George III. In 1753 his establishment in Cloak Lane was called "The Golden Head"; later it was 17 Cloak Lane. A fine large watch of his make sold in 1895 from the Bentinck-Hawkins collection; in the Hilton Price collection is a clock-watch by him, made for Eastern markets ; it strikes hours and quarters, is in a pinchbeck case, with outer case of imitation tortoise-shell: bracket clock, chiming on eight bells, inscribed "To Her Majesty." He afterwards removed to 38 Cornhill, and was succedeed about 1790 by Rivers \& Son.

Destouche à Middelbourg ; watch, about 1800.

Dethau, Matthew, London; about 1720. Devall, Jno., apprenticed 1670 to Andrew Pryme ; C.C. 1677.

Devere, Frederick, 7 Angel Court. Throgmorton St., 1769-75.

Deverell. Jno., London; watch, 1780. John, Boston, 1789.

De Vick, Henry. About 1364 he made for Charles V. of France the first turret clock of which we have reliable record (see p. 32).

De Villeneuve, -, Rue de l'Arbre Sec, Paris, 1770. 
Devis. William, Fleet St., 1750-65. John, Gloucester St., Bloomsbury, 1764, afterwards 76 Lamb's Conduit St.; hon. freeman C.C. 1764-83.

Dewe, Jno., Gravel Lane, Southwark; C.C. 1730 .

De Welke, Christian, one of the signatories to the petition of incorporation of C.C. In the eighteenth century an oval watch by him was found in a field near Kettering ; 1620-30.

Dewey, William, Dutch clockmaker, 59 Broadwall, Blackfriars, 1835.

Dewin, - , watch-case maker, 17 Red Lion St., Clerkenwell, 1835.

Dexter, M., London ; watch movement, G.M., about 1790 .

Deykin, - , long-case clock, signed "Tho. Deykin,inWorcester, fecit," beautiful inlaid case, birds and flowers, about 1700; 30 -hour long-case square dial clock, inscribed " Henry Deykin, Worcester," about 1710.

Dichous à Paris; clock, about 1785 .

Dickens, John, C.C. 1688.

Dickenson, Richd., London; watch, 1710. F. C., I Upper Ashby St., 1840.

Dicker, Thos., Reading, 1810.

Dickerson, Danl., Yarmouth, about 1750.

Dickie. Andrew, Edinburgh ; repeating watch in S.K.M., h.m., 1735. Andrew, London; long-case clock, 1765.

Dickinson, Rd., Liverpool ; watch, 1715. Robert, York, f., 1810-16. Thos., Lancaster, f., 1817-20. Frederick C., Bristol, 1845.

Dieu, R., à Paris ; oval watch, no screws, about 1590; another, later, Newington Free Library.

Digby, - , London; repeating watch, 1760.

Dighton, Wm., apprenticed 1687 to Sam. Rosse, C.C.

Dike, Nathaniel, C.C. 1663.

Dillington, - , London ; watch, Mr. Geo. Carr Glyn, about 1750.

Dingley. Robert, George Yard, Lombard St. ; apprenticed 1661 to Lionel Wythe; C.C. 1668; Mr. G. Ericsson, of Stockholm, has a beautifully inlaid longcased clock by him, about 1700 ; another specimen of his work is a gold watch, hourhand only, case with appliqué gold flowers, enamelled. Robert, Bishopsgate St., corner of Great St. Helen's, 1728-40.

Dingwall \& Bailliam, 9 St. JamesSt., 1813. Dinizard, -, Paris, 1790.

Dinnis, Francis, engraver ; C.C. 1666.

Dinnott, Robt., London ; watch, 1795.

Dissmore, Richd., York, 1818.

Distin, Jno., Totnes, 1750.

Ditchfield, Richd., C.C. 1677.

Divernois, -, Rue Dauphine, Paris, 1770.

Dixon, Wm., apprenticed 1686 to Dan. Beckman, C.C. Wm., 26 Smith St., Clerkenwell, 1835; 32 King's Sq., 1840-42.
Dobb, William, brother C.C. 1646.

Dobbings, Wm., Leeds, 1830.

Dobell, Ebenezer, Hastings; patented electric clocks in 1853 (No. 2,036). J., Canterbury. Red lacquer bracket striking clock in the collection of Mr. Hansard Watt, about 1780 .

Dobree. Elisha, London; watch, h.m. 1761. John, 3 Charing Cross, 1815; 69 Charlotte St., Oxford St., 1823.

Dobson. William, brother C.C. 1670 ; large lantern clock, about 1680, inscribed "William Dobson, in High Holbourne, Londini, fecit." Arl., London; watch with finely enamelled case in the B.M. ; another example is an oval watch at S.K.M., inscribed "This watch was a present from $y^{e}$ King to the Countess of Monteith, 1675." Thos. Red Lion St., Holborn; C.C. 1730. Arlander London; pull repeating bracket clock, about 1740 ; watch, 1765. Charles, Coldbath Fields; livery C.C. 1776. Frank, Gt. Driffield, 1822. Geo., Leeds, 1829.

Dockwray \& Norman, 16 Princes St., Leicester Sq., 1815-19.

Dod, Richard, London ; long-case clocks, 1695-1720.

Dodd. G., wrote a paper on clockmaking in British manufactures, 1845 . G. P. \& Son, Cornhill ; chime clock, about 1855. Doddington, Jno., apprenticed 1685 to Ben Wright, C.C.

Dodemare, L., Caen, 1770.

Dodson, Jno., apprenticed 1655 to Isaac Law, C.C.

Dodsworth, John, brother C.C. 1648.

Doke, Richard, Prescot; eminent as a chronometer wheel-cutter; died 1906, aged 83.

Dolley, Thos., ,master C.C. 1808.

Donac, - , London ; inscription on a watch, gold cases, outer one repoussé, h.m., 1807.

Donaldson, Geo., 121 Pall Mall, 1842.

Dondi. John, maker of a clock with wheels and balance, 1334. Joseph, son of the foregoing, 1350-60.

Donisthorpe, Geo., 85 High St., Birmingham, 1770, died 1802. Ludlam speaks of him as " the best maker of church clocks I know."

Donne. Anthony, Red Lion St., Holborn; C.C. 1730. Robert, Lamb's Conduit St., 1763-94. Griffith, Denton St., Somers Town; apprenticed to John Moore \& Son, afterwards at Dent's; died 1884, aged 70 . Lewis, 49 Cornhill, 1822, Birchin Lane, 1880-1918, liveryman C.C.; died 1918, aged 78 .

Doolittle, Isaac, New Haven, 1785 . 1810.

Doore, Robt., C.C. 1671.

Dorer, Robt., Paris ; about 1760. 
Dorigny, Robert, clockmaker to the Duke of Orleans, 1397.

Dormer, P., London ; watch, 1800.

Dormes, London ; watch in the Paul M. Chamberlain collection, about 1760 .

Dorrell. Francis, Honeysuckle Court, Grub St.; known as a maker of long-case clocks; C.C. $1702 . \quad$ Francis, C.C. 1755. William, Bridgwater Sq., summoned to the livery C.C. 1786: restored Cripplegate Church clock, and made it to strike the hours on the tenor bell, in 1797.

Dorsett, Wm., London; watch, 1790. Dossett, Gregory, C.C.. 1662.

Doud, James. Mr. T. W. Greene has an oval metal watch by James Doud, dating from about 1600 .

Doughty. Tobias, C.C. $1696 . \quad$ Jno., York, f., 1772. Thos., Charles St., Somers Town; invented a compensation pendulum, 1811. Wm. P., 10 Great Ormond St., 1816-20.

Douglas. J., London ; watch, 1745. Robt., Bolton, 1775. Walter, Dollar ; longcase clock, four season corners to dial, about 1790. Alex., 18 Cross St., Hatton Garden, 1810-18. Jno., 52 Red Lion St., 1816. Sam., Liverpool, 1818 ; also Robt., same date.

Douglass, John, New Haven, 1800-20.

Dove. Arthur, apprenticed to Wm. Clay; C.C. 1659. Henry, C.C. 1667. Arthur, " Gold Watch taken by Highwaymen with a gold Chain and a gold studded case made by Arthur Dove, of St. Martin's," \&c. (Lond. Gaz., Sept. 8, 1681).

Dover, - Westgate St., Bath, 1770.

Dovey, Richard, 6 Craven Buildings, Drury Lane, 1765-70.

Dow. Roger, Vere St., 1780-85. Robert, Clerkenwell Close, 1790; 72 Long Lane, 1810-35. James, watch-case maker, $15 \mathrm{St}$. James's Buildings, Clerkenwell, 1820. William, watch-case maker, 54 Percival St., 1835. Robert, 96 Upper St., Islington, 1842 .

Downes. Chris., C.C. 1632. Jere., apprenticed 1688 to Jas. Jackson, C.C. Jno., Shoe Lane; C.C. 1725. Joe, London; watch, h.m., 1774. Valentine, Louth, 1790. Robt., Clerkenwell Close, $1793 . \quad$ Robt., Long Acre, 1798-1818. Joseph, Coventry, 1817.

Downie, Will., Edinburgh, 1770.

Downing, Jno., Liverpool, 1770. George, watch-chain maker, Covent Garden, 1790.

Downinge, Humfrey, apprenticed to $\mathrm{Mr}$. Grinkin, free of Barber Surgeons ; Blacksmiths' Company in 1637 applied to have him disfranchised.

Downs. Benj., Mansfield, 1790. Anson, Bristol, Conn., 1830; also Ephraim.

Dowse, Gabriel, apprenticed 1649 to Wm. Godbed, C.C.
Dowsett, Jeremiah, C.C. 1708.

Dowson. - Bath; watch, 1760. John, 77 Holborn Bridge, and Field Court, Gray's Inn; watch, skeleton movement, h.m., 1764 ; a later specimen, G.M. \& Peene, Gray's Inn, 1800.

Doyle, James, watch-glass maker, Queen's Sq., Bartholomew Close, 1790.

Drabble, J., London; bracket clocks, 1710-20.

Dracque, J., Nerac; watch, silver case in the form of a fleur-de-lis, about 1620 , Garnier collection.

Drake. John, Fleet St. ; action by Blacksmiths' Company to disfranchise him 1633 ; C.C. fined him $£ 10$ for binding his apprentice to the Blacksmiths' Company 16-; signed a petition to C.C. 1656 ; Lady Fellows had a round silver watch of his make, with plain outer case, silver dial, and steel hand, now in the B.M. ; 1630-59. J., London ; watch, 1760.

Drakeford, Edwd., Congleton, 1818 ; also Jno., same place and date.

Draper. Simon, apprenticed 1688 to Sam. Drosade, C.C. John, C.C. 1703 ; Mr. T. D. Chapman has a long-case clock by Jno. Draper, Maldon, about 1720 . James, C.C. 1712. William, Maldon; lantern clock, about 1760 (see p. 505).

Draycott, Francis, C.C. 1678.

Drayton, -, Chardstock, eighteenth century (see p. 490).

Drescher, Jno., Hull, 1822.

Drew. John, C.C. 1684; long-case clock, about 1695, inscribed "'John Drew, Johnson Court in Fleet St." Edward, C.C. 1692. Jas., Bristol, 1843.

Drills, Jno., London, 1780.

Drosade, Samuel, C.C. 1675 ; watch by him, B.M., about 1680 ; another, with sun and moon hour indicators, about 1690 .

Droshute, John, C.C. 1632.

Drouynot, -, large striking watch signed "Pierre Drouynot à Poitiers," about 1610, M. Artus.

Drown, C. L., Newburyport, U.S.A., 1848 .

Drcz. Pierre Jacquet, born at Chaux de Fonds 1721, died at Bienne 1790; a clever mechanician ; he made a curious clock for the King of Spain; his sons, Henri Louis (born 1752) and Daniel, also good watchmakers in Chaux de Fonds; Humbert Droz settled in Philadelphia in the latter part of the eighteenth century. Henry Louis, son of.Pierre Jacquet; born 1752 died 1791 ; excelled, if possible, his father as an ingenious mechanician; he journeyed to England, France, and Spain ; was condemned to death at Madrid by the Inquisition as a necromancer, and saved by the Bishop of Toledo. \& Leschot, clock, a pout 1795, signed "Pierre Droz \& Leschot." 
Humbert, Philadelphia, 1797. Humbert A. L., Philadelphia, 1811. \& Sons, 1811. Charles A., 1819.

Drozte, Jeune, Rouen ; watch, 1799.

Drummond. Francis, apprenticed 1676 to Sam Davis the elder; C.C. Thos., Liverpool, 1818.

Drury. James, C.C. 1694, master 1728, clerk 1731 ; died 1740 . John, Red Lion St., Clerkenwell ; C.C. 1720. Dru., 32 Strand, 1770-85 ; card, Ponson by collection, " Dru; Drury, Goldsmith to Her Majesty, in the Strand, successor to Nath. Jeffreys." There seems to have been an earlier D. Drury. Mr. J. Hall has a clock, long-case inlaid in front, oyster-shell veneers on sides, spiral pillars to hood, which has no door, dial signed " D. Drury, London," dating from about 1705 . Wm., 32 Strand,

- 1800-25. James, Banbury, Oxon., 17801800. J. F., 19 Clerkenwell Green, 1810.

Dryden, G., 30 Little Guildford St., 1835.

Dryer, Sam., London ; single-case watch by him, about 1674 , belonging to Mr. Geo. Carr Glyn; another specimen, silver dial, about 1690.

Drysdale, Wm., Philadelphia, 1819-51.

Dubant à Grenoble; watch, about 1690 .

Dubbar, Hugh, apprenticed 1648 to Jno. Freeman, C.C.

Dubie, J., Paris ; Court goldsmith who resided in the Louvre, excelled in fine enamelled watch-cases, 1640-50.

Dubois (or Debois). Jacob, apprenticed to David Hubert; C.C. 1730. G., small pillar clock, Wallace collection, signed . Gm. Dubois, in Paris," about 1770. Et Fils, watch, with modification of $\mathrm{De}$ baufre's escapement, bought in Hanover by George IV., G.M.,, about 1770 ; watch,. Wallace collection, about 1785 . Frederic Wm., Neuchâtel; born 1811, died 1869. Pierre, Paris ; wrote " Histoire de l'Horlogerie" 1849, "La Tribune Chronométrique " 1852 , and description of the Soltykoff collection 1858 .

Duboule, Jean Baptiste, lion-shaped watch, about 1600 ; watch in nut-shaped case, Wallace collection, about 1620 .

Dubuisson, - , Paris, his signature on many good clock dials, period Louis XVI.

Duc, -, alarm watch, Garnier collection, signed "Dominique Duc à Loche," about 1570.

Ducastel, Isaac, admitted C.C. 1703.

Duchemin, Dr., horloger, Rouen, 1570.

Duchen. In the B.M. is a watch by him, in a chased case by D. Cochin, 1730 .

Duchêne, Ls. \& Fils, Geneva; watch in gold egg-shaped case, S.K.M., about 1785 .

Duchesne, Claude, in Long Acre (of Paris); C.C. 1693; square full-repeating bracket clock, inscription on back plate, "Claudius du Chesne, in Long Aker"; ong-case clock in lacquer case, Agence de Commerce Etranger Ltd. ; John Wesley's long-case clock by him, arch dial, age of the moon, walnut case, is still preserved in the Wesley Museum, City Rd. In the Green Vaulted Chambers of the Treasury at Dresden is a pair of long-cased clocks in walnut cases signed "Claudius du Chesne, Londini, fecit" ; they stand about $12 \mathrm{ft}$. high ; the dials show the phases of the moon, the months, and days of the month, which are written in French; both clocks chime and play tunes before striking the hour; on the dial of one is a list in Dutch of the tunes played, and the repertory of the other consists of "Air Polonais No. 1," "Air Polonais No. 2," "Air Italien," and "The King enjoys his own." Fine bracket clock (Mr. J. Drummond Robertson), (see pp. 569 and 570) ; 1690-1720. Johannes, Amsterdam ; fine clock, about 1750, Mr. Lawrence Bentall (see pp. 521, 554).

Ducimen, Jacop, Amsterdam; large oval watch, Pierpont Morgan collection, about 1625 .

Duck, H., London, about 1720.

. Ducker, H., 3 South Place, Kennington Lane, 1835-42.

Duckworth, R., Halifax, about 1670.

Ducommun, A. L., Philadelphia, 17971820.

Duddell, Thos., 106 Holborn Hill, 1817-23.

Dudds, Joseph, Coleman St., 1730; Geo. Adams apprenticed to him in 1745 ; livery C.C. 1766 . In the Czar of Russia's collection at the Winter Palace, St. Petersburg, was a watch by him. It has a case of faceted crystal and is suspended from a chatelaine, see Stephens.

Dudley, Benjamin, Newport, U.S.A., 1840.

Dudson, Simon, Tower St. ; C.C. 1654.

Duduict, Jacques, Blois, 1560-90.

Duerre, c. W. R., Kings Rd., Chelsea, 1853-1907. A clever horologist, he possessed considerâble inventive faculties, and his was the original idea of the old kangaroo bicycle which was at one time so popular.

Duet, Pierre, Paris ; fine enamelled watch, Pierpont Morgan collection, about 1740.

Dufalga, Ppe., Geneva ; watch, about 1775.

Duff, James, 24 Castle St., Houndsditch, 1840-42.

Duffett, Jno., Bristol ; long-case tidal clock, "High Water at Bristol Key," about 1780 .

Duffield, Edward, Philadelphia, 1741-80.

Dufour. Abraham, watch, leather case, ornamented with silver, Schloss collection, 
about 1630 . Mr. Willard $\mathrm{H}$. Wheeler has a curious and well-made watch dating from about 1710 signed " Isac Dufour." The collection of the Czar of Russia in the Winter Palace, St. Petersburg, contained a repeating watch signed "Dufour, London "; the outer case is cut out of a solid piece of lapis-lazuli carved with scrolls in the Louis XV. style, and set with a large spray of very fine diamonds; it is suspended from a chatelaine with decoration of the same character; in the Evan Roberts collection is an alarm watch of about 1798 by "Dufour, Geneva." Paris; curious watch by him, B.M., enamelled portrait over the dial, about 1730. \& Ceret, associated with Voltaire at Ferney, 1770, see Lepine. - Geneva; alarm watch, about 1800 .

Dugard, Thos., 34 Red Lion St., Clerkenwell, 1812-19. \& Simpson, 1830.

Dugdale, Richd., 12 Broad St., 1800-5 ; 39 Great Marlborough St., 1817.

Duhamel, Pierre, Blois. In the Hawkins collection was a small watch by him with enamelled dial in plain gold case, black shagreen outer case studded with gold, and with gold plate engraved with the monogram of Mary, Queen of Scots; a cruciform watch by him, about 1590 , Ecole d'Horlogerie, Geneva.

Du Hamel à Paris; mid-seventeenth century watch in enamelled gold case, S.K.M. Isaac, long-case clock, Canon Greenwell, watch, G.M., about 1785 .

Duke. John, Fleet St., watch, B.M., 1650. Nat., apprenticed 1656 to Thos. Wheeler ; C.C. 1663 . Joseph, apprenticed 1666 to Jas. Markwick; C.C. 1682. Joseph, C.C. 1728 . George, 8 St. John's St., Clerkenwell, 1835-42.

Dulin, W. T., 10 Cornhill, 1816-30.

Dumbell. Josh., Prescot, 1816, see Dunbill. Thos., Rochdale, 1818. Joseph, Rochdale, 1833.

Dumont Frères, Besançon ; watch, silver cock, one hand, Schloss collection, 1735 .

Dumvile, Nat., Stockport, 1820-33.

Dunbar. Geo., London; watch, 1770. Butler, Bristol, Conn., 1830.

Dunbill, Josh., Prescot; watch, Evan Roberts collection, h.m., 1820.

Duncan. Geo., London; watch, 1737. Jas., watch, h.m., 1775, Mr. William Ranken ; 98 Chancery Lane, 1800-10; 44 St. James's St., 1815-25; 33 Old Bond St., 1825-30. Robt., London; watch, 1790 ; fine lancet-case clock, "Duncan London," Dr.W. J. Dunwoody, about 1800. Duncarton, Robt., London ; watch, 1765. Duncombe, Richard, master C.C. 1798. Dundas, Jas., Edinburgh ; apprenticed to Andrew Brown in 1710 .

Dunheim, Andrew, New York, 1775.
Dunkerly, Samuel, 1770.

Dunkley, Benj., London ; long-case clock, japanned case with rococo figure subjects painted on door and base ; plays seven tunes; on each side of the usual date a wedge-shaped opening showing month and day of week; moon in arch, about 1760. John, 88 Bethnal Green Rd., $1825 \cdot 35$. Thos., 25 Galway St., St. Luke's, 1840.42.

Dunlop. Andrew, C.C. 1701 ; known as a maker of watches and long-case clocks; turret clock, Hawley House, Blackwater, Hants, dated on movement 1716. Conyers, Spring Gardens, Charing Cross; C.C. 1733, master 1758 .

Dunn. Henry, C.C. 1677. Benj., apprenticed 1691 to Thos. Gibbs, C.C. Anthony, C.C. 1719. Jno., Hull, 1822. William, Islington Green, $1835 . \quad$ Chas., apprenticed to Richard Hislop, carrierl on business in Upper Gloucester St., Clerkenwell, died 1907, aged 88 .

Dunster, Roger. In the Hawkins collection was a repeating watch by him in delicately pierced and chased gold case; hands and thumbpiece set with diamonds gold outer case chased with allegorical figures ; pierced border chased with scrolls, about 1700. M. Ern. Roux has a clockwatch and repeating movement by him; on the plate and the cock is engraved Omnia metitur tempus sed metior ipsum, see Clarke \& Dunster.

Dunston, Paul, apprenticed 1687 to Simon Chapman, C.C.

Duntnell, Danl., 131 Oxford St., 1783.

Du Peron, C., à Lyon ; oval watch, brass case with rock-crystal cover, Pierpont Morgan collection, about 1600.

Dupin, Paul, London; fine repeating watch in gold pair cases, Schloss collection, about 1710; also bracket clock in red shell case, about 1720 ; repeating watch, G.M., three cases, inner case engraved and pierced, enclosed in a richly chased one by Moser, outer case of leather piqué, h.m., 1739 ; in the B.M. is a repeating watch by him inscribed "Dr. Samuel Johnson 1767."

Duplock, Chas., 129 Borough, 1790-1815. \& Wiggins, 1816-30.

Dupons, Edwd., London ; watch, 1785.

Dupont à Castres ; watch, B.M., about 1650. Peter, London ; long-case clock in raised ornament Oriental lacquer case at the Armoury Museum, Government House Malta, about 1725; another clock inscribed "Peter Dupont, St. John's, London." J. P., Rotterdam, about 1750. Paul, 27 Ivy Lane, Newgate St.; watch, G.M. case finely worked in repoussé by Moser, 1759-72 ; clock, "Dupont late Emerys," not later than 1780 Chas., Cockspur St, 1798-1800, 
Duppa. Chas., apprenticed 1646 to Wm. Clay, C.C. James, 15 Aldgate Within, 1765-70.

Dupré à Paris; watch, about 1730 , Mons. E. Gélis.

Dupree, Elias, a Dutchman, who worked for Edwd. East in 1635; he had then been in London about twenty years.

Dupuy. Odran, Philadelphia, 1735. Jno., 1770.

Durade, Abel; watch, bridge over balance with enamelled portrait, Dutch style, about 1770, Pierpont Morgan collection.

Durand, - octagonal watch, Garnier collection, about 1585, signed " P. Durand à Rouen "; watch, P. Durand, London, 1790.

Durant. Oswald, petitioner for incorporation of C.C. ; admitted as brother in 1632 ; warden in 1645 ; did not become master; Ralph Almond apprenticed to him in $1637 ; 1630-45$. J. L., a watch in B.M., finely enamelled case, about 1690 .

Durdent, Andrew, C.C. 1662.

Durfalga, Paris, 1790.

Durley, T., 33 Northampton St., 1835. Durn, -, Paris ; watch, 1690.

Durrant.' Richd., 36 Museum St., 182042. Thomas, near the Broadway, Hammersmith, 1840.

Durtnall, Daniel, 131 Oxford St., 17801805.

Durward, Jno.,; watch paper dated 1816. “ John Durward, 6 Leith Street, New Edinburgh."

Duseigneur, Pierre, Geneva, about 1750.

Dutens. Geo., London; small watch in case of blood-stone, diamond push piece, silver cock over balance, about 1750 . Peter, Leicester Sq., 1759-65.

Dutertre, Jean Baptiste, Paris, 1750-80 ; inventor of an escapement with two balances. Mr. H. W. Wilson has a clock by Jean Baptiste Dutertre very similar to that shown in Fig. 557, but on a bracket more resembling the one in Fig. 556 ; there were others of the family; a vase-shaped clock by Dutertre in Louis XVI. style fetched $£ 441$ at the Hamilton sale in 1882 . Repeating watch, "Dutertre Paris," about 1750, Pierpont Morgan collection.

Du Thuillay, -, Hull; watch in large medallion frame, S.K.M., frame signed 'J. S. Meyer, Zerbst, 1788.'

Dutton. William, apprentice of Graham, and afterwards partner with Mudge, 148 Fleet St. ; C.C. 1746, liveryman 1766 ; 1746-94. Guy quarter clock, Shandon collection, about 1760 . Jno., Liverpool, 1770. Matthew \& Thomas, 148 Fleet St. ; Matthew Dutton, son of and apprenticed to William Dutton; admitted C.C. 1779, assistant 1793, livery 1785 , master 1800 ;
Thomas Dutton, also apprenticed to William, admitted C.C. 1791, livery 1796 ; long mahogany-case clock inscribed "Matthew and Thomas Dutton," about 1795, Wetherfield collection ; \& Sons, 1810-18. Jno., Liverpool, 1818. Matthew, 148 Fleet St., 1819-42; he returned to Church St., Stoke Newington, and died about 1843.

Duval. John, C.C. 1677. Francis \& John, Warnford Court, Throgmorton St., 1755-65. Frederic, Paris, 1780, à Paris ; fine clock, about 1810 .

Duvivier l'Aîné, Paris, about 1740. Et Queoncl, Rouen, about 1775.

Dwerrihouse, Thos., Garston ; watch, h.m., 1774 .

Dwerryhouse. John, 23 Charles St., Berkeley Sq., 1770-1805; hon. freeman C.C. 1781. \& Carter, 30 Charles St., Berkeley Sq., 1809-18; 27 Davies St., 1823 ; bracket clock, Wetherfield collection, about 1810; bracket clock, Dwerryhouse, Carter \& Son, Berkeley Sq., about 1820 ; Mr. T. S. Wheater. Ogston \& Co., 27 Davies St., Berkeley Sq., 1835-42. \& Bell, 131 Mount St., 1840.

Dyde, Thomas, London; lantern clocks and watches, $1640-70$ (see p. 483). He was free of the C.C., but date of election uncertain.

Dyer. Joseph, Addle St., 1735-40. \& Newman, 9 Lombard St., 1768-72.

Dyke, - Exchange Alley, 1685.

Dymond, John, watch-case maker, Windmill Court, Smithfield, 1790.

Dyson. John, admitted C.C. 1694. Humphrey, Manchester, 1818. \& Brookhouse, Sheffield, 1833 . John, founder of the firm of Dyson \& Sons, of Leeds, died 1916, aged 72 .

Eaden, Richd., London ; watch, 1800.

Eady, Wm., 14 West St., Smithfield, 1800-18.

Eagle. John, C.C. 1690; long-case clock, about 1700 , Wetherfield collection. Nath., London; metal-case watch, outer case tortoise-shell, about 1776 .

Eagleton, Christopher, apprenticed to Charles Halstead 1683. In the G.M. is a watch by him, silver case, silver dial, outer case tortoise-shell piqué ; 1690-1710.

Eames. \& Barnard, 9 Ave Maria Lane, 1816. Jacob, also Thos., Bath, 1850.

Earle, Thos., admitted C.C. 1720.

Earles. - (or Eryles), subscribed to incorporation of C.C. 1630 . Jno., London, 1700-15.

Earnshaw. Thomas, Ashton-over-Lyne ; Mr. T. R. Howarth has a 30 -hour one-hand clock by him, about 1730 . Lawrence, a clever watchmaker; born at Mottram, 
near Longendale, Cheshire, 1705, died in 1767 , aged 62 years; a monument was erected to his memory by public subscription in 1868. Edwd., Stockport; an ingenious clock and watch maker, his shop was said to be a " regular Noah's Ark of mechanical nicknacs "; he was a friend of Jas. Ferguson, 1740-70. Thomas, 119 High Holborn, born 1749, died 1829 (see p. 362), Thomas, junr., 87 Fenchurch St., 1825-42.

East. Jeremy, admitted as a brother C.C. 1640 ; maker of a small hexagonal watch, balance-cock pinned on, plate inscribed " Jeremie East, Londini," crystal case, about 1600 ; also a small oval watch, plain silver dial, one hand, about 1610 . Edward, Pall Mall, 1632; Fleet St. later; one of the first assistants of C.C. ; a very eminent maker (see pp. 265-273) ; 1610-73. Mr. Hansard Watt has a very beautiful night clock signed " Eduardus East Londini " (see p. 272. Also a large lantern clock (see p. 271). Jere., apprenticed 1653 to Jas. Seabourne, C.C. Thomas, C.C. 1677. Peter, C.C. 1692. Edward, apprenticed to R. Lyon and turned over to Saml. Clyatt ; admitted C.C. 1696. Edward, junr., apprenticed to Thomas East; admitted C.C. 1710. Jordon, son of Edward East C.C. 1720. Edwd., case-maker, Addle St., C.C. 1730. Edward, apprenticed to Joseph Pomroy; freeman C.C. 1743.

Easterley, John, New Holland, 1825-40.

Eastland, Thomas, London; maker of repeating watches, about 1750 .

Eastley, - 73 High Holborn, card, Hodgkins collection, about 1810 .

Eastman. Of U.S.A.: Robert, Brunswick, 1805-08. \& Cary, Brunswick, 1808. Abel B., Haverhill, 1816-21.

Eastwick, Adrian, 102 Aldersgate St., 1770-85.

Eastwood, Wm., Burnley, 1748-70.

Eaton, J., London ; watch, 1790.

Eave, John, 8 Oxford St., 1790.

Eayre. Thos. Kettering; Ludlam in 1758 wrote, "He was for 40 years the first in his profession, chiefly church clocks and bell foundry; he died greatly regretted, 1757." Josh., St. Neots ; watch, 1770

Ebben,Wm., 37 Islington Green, 1816-42. Ebbs, Jno., Dublin, clock about 1740.

Eberman, John, Lancaster, U.S.A., 1780-1820.

Ebsworth. John, a good clockmaker. (See pp. 273-4). C.C. 1665, master 1697. Christopher, C.C. 1670.

Ecles, Hy., apprenticed 1654 to Tobias Davis, C.C.

Eclipse, Jno., London; watch, 1798.

Eden. William, admitted C.C. 1726.

Ralph, Liverpool, 1770.

Edgecombe, Thos., St. Stephen's, 1780.
Edington. -, $24 \mathrm{~N}$. Audley St., 1815. Jno., 10 Portland St., 1816. \& Son, 1830.

Edkins, James, 2 High St., Kensington, 1830-42.

Edley, Wm., London; watch, 1748.

Edlin. John, apprenticed to Robert Webster ; admitted C.C. 1687. George, 6 Aldgate Within, livery C.C. 1800-13.

Edlyne, Edgar, Nevill Alley, Fetter Lane; C.C. 1710-30 ; verge bracket clock, engraved back.

Edmonds. Eliza, apprenticed 1679 to Hy. Fevon and Christina his wife, C.C. Chas., apprenticed to Thos. Taylor; C.C. 1772. \& West, 14 Strand, 1779-1810. D., Liverpool ; watch, 1810. Jno., 14 Strand, 1820-30. T., Bath, 1850.

Edmondson. Jno., apprenticed 1660 to Hugh Cooper, C.C. Jno., Liverpool, 1770.

Edmunds, Wm., London; watch, painted outer case, Schloss collection, about 1785 .

Edson, Jonah, Bridgewater, U.S.A., 1815-30.

Edwards. Joseph, apprenticed 1655 to Jno. Nicacius, C.C. Thos., apprenticed 1680 to Robt. Player, C.C. Nich., apprenticed 1687 to Robt. Dingley, C.C. Isaac, C.C. 1719. Thos., Epping, 1720. T., London; watch, h.m., 1766. Adam, London; watch, about 1768 . Jno., Norwich, 1770. William, 4 Holborn ; livery Blacksmiths' Company; 1775-83; 109 Cheapside, 1790-94. Wm. Jno., Coleman St., 1783. D., Liverpool, 1790. James, 180 Fleet St., 1790-94. Wm., 26 New Bond St., 1800. Jas., Commercial Rd., 1814-35 ; watch marked " near the West India Docks," 1913, in the possession of Mr. Thomas Fisher. Jas., 93 Wood St., Cheapside, 1820-25. Robt., Great Sutton St., 1820-25. Benj., 17 Shoreditch, 1830-42. W. \& Son, 2 Theberton St., Islington, 1835-42. A., watch-cap maker, 14 Great Sutton St., 1835. \& Hunter, London, 1840-2. Jas., 43 Cornhill, 1841-49.

Effington, John, admitted C.C. 1702.

Egersley, Jas., apprenticed 1660 to Wm. Godbed, C.C.

Egleton, Christopher, apprenticed to Charles Halstead in 1863, admitted C.C. 1695.

Ehrhardt, Wm., a clever horologist; founded a watch factory on advanced principles at Birmingham; born 1831, died 1897

Eiffe, James Sweetman, born 1800, died 1880 ; a clever chronometer maker, who for some time carried on business at 48 Lombard St. ; in the Wetherfield collection is an astronomical regulator by him; he invented a compensation balance very similar to that patented by Molyneux, see Fletcher, Jno.

Eiselé, W. A., Brussels; oval watch Pierpont Morgan collection, about 1760 . 
Eisen, Heinrich, Nuremberg, 1510.

Elchinger, Hans Conrad, Amsterdam ; watch, the dial engraved with representation of a pedlar crossing a brook, 1620 .

Eldridge, John, admitted C.C. 1677 ; long-case clock inscribed " John Eldridge, Alresford," about 1730.

Eley, James, 11 Fenchurch St., 1770-85.

Elfes. Thos., apprenticed 1671 to Geo. Hambleton, C.C. Benjamin, C.C. 1674.

Eliason, Daniel, 18 Leman St., Goodman Fields, 1785-90.

Elisha, Caleb, Duke St., St. James's ; bracket clock, about 1810, Mr. William A. Atkinson ; 3 Marylebone St., Golden Sq., 1820 ; 175 Piccadilly, 1835 ; 8 New Bond St., 1842.

Elkins. Chas., apprenticed 1677 to Dan. Le Count, C.C. William, apprenticed to John Ellicott ; C.C. 1710 ; assistant 1730 ; large bracket clock at the India Office, "Windmills and Elkins," about 1725.

Ellam, Thos., Runcorn, 1833.

Elled, -, London, 1780.

Elleston, Robt., Lancaster, 1721, f.

Ellicott. John, C.C. 1696; apprenticed to John Waters, 1687, All Hallows, London Wall, 1696-1733. John, 17 Sweeting's Alley, Cornhill, an eminent maker (see pp. 335-39) ; born 1706, died 1772 . John \& Sons, 17 Sweeting's Rents, 1769-88. \& Taylor, Sweeting's Alley, Cornhill, 1811-30. \& Smith, 17 Sweeting's Alley, Cornhill, 1830 ; 27 Lom bard St., 1839-42. Edward \& Sons, Edward Ellicott, master C.C. 1834 ; 17 Sweeting's Alley, Cornhill, 1783-1810.

Elliot, Wm., Whitby, 1770.

Elliott. Jno., apprenticed 1681 to Jno. Goode, C.C. Henry, brother C.C. 1688. Thos., Greenwich ; long-case clock, about 1740. Josh., Berkhamsted ; musical clock, about 1750. Jas., Oxford St., 17801800. Wm., London; watch, h.m., 1787. -, Nottingham, 1795. John Moseley, Aylesbury St., Clerkenwell ; patented a repeater in 1804 (No. 2,759) (see p. 618). \& Son, 119 Oxford St., 1805. J. J., clockmaker, Clerkenwell; died 1904, aged 55.

Ellis. Jacob, York, f., 1636. James, C.C. 1667. Richard, Westminster, apprenticed 1673 to Geo. Deane; C.C. 1683; bracket quarter clock, about 1730. Thomas, C.C. 1682. Paul, brother C.C. 1682. John, Little Old Bailey, C.C. 1726. Griffith (successor to Mr. Newton), 29 Little Moorefields, 1780. \& Collins, 52 Strand, 1804. Henry, Exeter, 1810. David, 2 John St., Oxford Rd., 1817. T., London; watch 1838. Michael, 18 Bevis Marks, 1842.

Ellison. Caleb, apprenticed 1691 to Sam. Vernon, C.C. Thos., York, f., 1826. Elliston, Robert, Orange St., 1770 ; 12 Charles St., Covent Garden, 1790-1820. His son, Robt. Wm, Elliston, a celebrated actor, was born at Orange St., 7th April, 1774.

Ellwood. Martin, brother C.C. 1687; a watch by him in the Guildhall Museum, silver dial, curious tortoise-shell case inlaid with silver, 1680-1700. John, C.C. 1702; long marquetry case clock, square dial, 1702-25.

Elly, Jas., 52 Rathbone Place, 1816.

Elmes. William, brother C.C. 1667. Joseph, apprenticed 1673 to Wm. Elmes, C.C. Richard, apprenticed to Edward Banger, admitted C.C. 1708 ; worked for Webster in 1730.

1770.

Elsgood, Wm., Norwich ; clock, about

Elson, David, brother C.C. 1646.

Elsworth, David, Windsor, U.S.A., 17801800 .

Elton. John, C.C. 1675 . Thos., C.C. 1677.

Ely, James, 8 Soho Sq., 1825.

Eman, Jno., apprenticed 1669 to Isaac Daniell, C.C.

Emanuel. Joel, Bevis Marks, 1812-17. Lewis \& Son, 36 Swan St., Minories, 1820-42. Brothers, 1 Bevis Marks, 1830.

Embree, Effingham, New York, Dec. 1785 .

Emerson ; lantern clock, signed " Richd. Emerson, fecit," about 1690.

Emery, Josiah, an eminent Swiss watchmaker, who settled here and carried on business at 33 Cockspur St., Charing Cross. Mr. Hedgethorne has a watch by him made about1780, lever escapement with draw on the locking faces of the pallets ; hon. freeman C.C. 1781 (see p. 612); an 8-day watch by him with extra wheel in the train, about 1780 ; another example is a watch in the Guildhall Museum, ruby cylinder, helical balance-spring, compensation curb; a bracket clock by him in an ebony case, dating from about 1790, is in the Wetherfield collection; 1770-1805 (succeeded by Recordon).

Enderlin, -, Basle ; maker of equation clocks (see p. 393), 1715-60.

Enen, Wm., apprenticed 1687 to Thos. Wise, C.C.

Engall, Abraham, brother C.C. 1648 .

Engaz, -, Paris ; handsome clock, about 1790 (see p. 448).

England. Jno., apprenticed 1692 to Thos. Taylor, C.C. Thos., Bristol, 1844. Wm., Nth. Petherton, 1844.

Englois, Geo., apprenticed 1648 to Ed. Ward, C.C.

Enock, Ezra, London, and later at Sibford, a Quaker, 1827.

Enon, Chas., apprenticed 1666 to Jere. East, C.C.

Entwisle, Laurence, apprenticed 1638 to Thos, Place, C.C. 
Enys. Edward, C.C. 1658. Edmund, C.C. 1684 .

Erb, Albrecht, cross-shaped watch, care enamelled-white, with bevelled cover of rock crystal, date doubtful.

Erbury, Henry, C.C. 1650.

Erhardt, J. C., watch, B.M., about 1700.

Ericke. Robert, Maiden Lane, C.C. 1719. William, C.C. 1730 ; watch by him with extra wheel in the train, the minute hand travelling once round the dial in two hours.

Errington, F., Savile Row, Walworth, 1835.

Ervin, see Irvine.

Eryles, see Earles.

Esplin, -, Wigan, 1790.

Esquivillon. Several watches, ranging from 1710 to 1774 . Esquivillon \& De Choudens ; melon-shaped gold enamelled watch; watch with gold outer case set round with pastes, portrait in enamel of a lady on the back, also set in paste; these two examples are in the Pierpont Morgan collection, and date from about 1765 . Esquivillon Frères \& De Choudens, Paris ; watch, repoussé outer case, about 1774 .

" Esquivillon et Cie.," watch, probably Swiss, enamelled case, about 1770.

Essen, -, Paris, 1790.

Essex. Joseph, Boston, U.S.A., 1712. Robt., 223 Strand, 1823.

Ester (Esther). Henry (French); a watch resembling a pelican, S.K.M. ; another (B.M.) in the shape of a fleur-delis ; another example of his work is a watch in the Vienna Treasury, the case is circular, worked à jour representing foliage and enamelled in different colours, on the dial of enamelled gold are the signs of the zodiac, 1630-60. J., tulip watch, about 1680.

Esterbrook, -, Theobald's Rd., 1830-70

Eston, Edward, C.C. 1708.

Etchinger, Hans, Amsterdam ; watch, B.M., about 1650 .

Etherington. George, Fleet St., C.C. 1684 ; master 1709 ; Mr. F. Hockliffe, has a choice bracket pendulum clock of his make, and Mr. J. Francis Mallet owns a somewhat similar specimen; a long-case clock by him belonging to Mr. Thos. Boynton is illustrated on p. 535. "A Gold Minute Watch with a green Shagreen case, with gold studs, made by George Etherington " (Lond. Gaz., Dec. 25, 1689). " George Etherington, Watchmaker, is Removed from the Dial in Fleet $S^{t}$ to the Dial over against the New Church in the Strand, London, where all sorts of Jewel Watches and others are made and sold "(Lond. Gaz., October 5-9, 1714). Of York: Thos., f., 1684 ; Thos., f. 1727 ; Thos., f, ,1740; Wm., f., 1788.
Ettry, Abram, Vlissingen; bracket clock, about 1740, Mr. J. H. Davidson. Joel, long-case 30-hour clock, about 1790. Etty, Marmaduke, C.C. 1716.

Eustace. Richd., apprenticed 1687 to Withers Cheney, C.C. Edwd., Bristol, 1845

Eva, Richard, Falmouth, 1775 ; curious long-case chiming and tidal clock, about 1780 , planaterium in arch, with comet, signed " Eva Falmouth."

Evans. Thomas, apprenticed to Samuel Davis, C.C. 1673. Henry, apprenticed to Thomas Bagley for Thomas Trippett, C.C. 1682. Geo., apprenticed 1692 to Geo. Rant, C.C. Thomas, apprenticed to Jane Barker, widow of Richard Barker, C.C. 1718. Thomas, apprenticed to George Cartwright, Royal Exchange ; C.C. 1720 ; watch, 1749. Robert, Halstead; 30-hour clock, one hand, about 1740. Thomas, New York, 1766. Thomas, apprenticed to William Haward, and turned over to Josiah Alderson, C.C. 1769. Jno., Shrewsbury, 1770. David, Baltimore, 1770-73. James \& Son, 7 Sweeting's Alley, 17701800 ; Evans, Thomas, of Swithin Alley, son of James Evans, C.C. 1788; James, son of Thomas, was admitted in 1811; many timekeepers of good quality bear the names of some member of this family, which had a considerable connection in Spain and the Spanish markets; clocks dating from the latter part of the eighteenth century, signed "Diego Evans, London," or "Diego Evans, Bolsa Real, Londres " (James Evans, Royal Exchange, London), are to be met with; Higgs \& Evans, both of Swithin, or " Sweeting's" Alley, seem to have been associated in partnership from about 1780 , or 1785 , although the name of Evans appears independently after that date, see Higgs \& Evans (see pp. 577 and 579). William, 23 Aldgate Without, 1775. Pryce, Shrewsbury; watch, 1789. David, see Higgs \& Evans. Dymoke, C.C. 1800 ; James, C.C. 1816 ; Samuel, C.C. 1822 . W., Dublin; watch, 1802. William Fredk., Handsworth, Birmingham, succeeded John Houghton ; died 1899, aged 81 . John, apprenticed to Gartner, carried on business in Mount St., Grosvenor Sq., died 1905, aged 67 ; clock by him with double three-legged gravity escapement, Wetherfield collection.

Eve, John, 19 New North St., Red Lion Sq., 1842.

Evens, Robt., Halstead ; lantern clock, about 1710 .

Everell, John, " by ye new church in $y^{\mathrm{e}}$ Strand "; maker of a verge watch, square pillars, outer case of tortoise-shell, 1730-60.

Everett, Jno., London ; watch, 1770.

Evers, Peter, Chester ; 1814-18, Chas., Coventry, 1818 . 
Evill. Two or three generations of clockmakers in Bath. James Evill, about 1750. William Evill, Union St., about 1800.

Ewbank, Geo., Ellam, 1770.

Ewen, John, Aberdeen, about 1800.

Ewer, Jno., apprenticed 1687 to Luke Bird; maker of long-case and bracket chime clocks, see Eyre.

Ewett, Robt.. C.C. 1636.

Exchagnet, Louis, Wilderness Row, 1790.

Exelby. James, St. John's Lane ; C.C. 1718; a good watchmaker, quoted by Hatton, known also as a maker of longcase clocks; 1718-50. George, watch jeweller, 6 Red Lion St, Clerkenwell, 1790-94.

Eyre. Richd., apprenticed 1637 to Oswald Durant, C.C. John, C.C. 1703.

Eyston, Edward, C.C. 1659.

Ezekiel, -, Exon; watch, h.m., 1794.

Faber, Joseph, apprenticed 1678 to Edwd. Whitfield, C.C.

Faber, G., Paris, 1620.

Facio, Nicholas, born at Basle, 1664. died in Worcester, 1753; introduced watch jewelling (patent No. 371, May 1704) (see p. 612).

Fage, Edward, admitted C.C. 1667.

Fagg, John, Queen St., Margate ; watch, h.m., 1781; lever alarm watch, 1821.

Fairclough, Thos., C.C. 1660. Richard, Liverpool, 1770. Edwd., Liverpool; watch, about 1795, with the pedometer self-winding device patented by Recordon in 1790, Mr. Edwd. H. Bulley. Sam., Halifax, 1830.

Fairer, Joseph, Bishopsgate, 1850; he seems to have been but a short time in business, but his name was on several clocks for public companies.

Fairey. John, 22 Ratcliff Highway, 1810-42. Richard, 150 Tooley St., 1814-42.

Richard, junr., 68 High St., Borough, 1835.

Fairfax, Wm., apprenticed 1685 to Jno. Warner, C.C.

Fairhurst,Wm., 1 Argyle St., Bath, 1845 .

Fales, James, New Bedford, 1810-20.

G. S., 1827.

Falke, - Leipzig; watch, about 1780.

Falkner. Edwd., apprenticed 1692 to Cornelius Herbert, C.C. ; quarter clock, Mr. Eden Dickson, about 1740. Wm. W., shagreen case maker, Shoe Lane, 1793. John, 153 Newman St., Oxford St., 1824-28.

Falks, Robert, C.C. 1720-25.

Fallow. Matthew, Liverpool, 1814. Matthew \& Co., Manchester, 1820 also J. Fallow \& Co., same date.

Fard, Pierre, Blois ; very small watch, about 1670 .

Fardoil, Pierre, Blois; alarm watch, about 1680, M. Gélis ; watch, "Peter Fardoil, London," h.m., 1700.
Fardon, Jno., Dedington, 1800.

Farewell, John, apprenticed to Isaac Nicholls, and turned over to Charles Gretton, C.C. 1697.

Farmer. Leonard, received $£ 37$ in 1617 for a clock and chimes and "twoe dyalls, and for a barrel and pricking thereof," from the churchwardens of St. Margaret's, Westminster. Thomas, C.C. 1647. Thomas, C.C. 1653 ; in the St. Margaret's, Westminster, churchwardens' accounts for 1658 appears "Item to Mr. Farmer for making of the new diall on the westward of the church, as by his bill appeareth, 14l. 10s." ; also, "Item to Mr. Farmer for a new diall at the west end of the church on the churchyard side, 7l." ; 1653-60. Jno., C.C. 1657. Jas., apprenticed 1661 to Ralph Almond, C.C. Richard, C.C. 1683. Thomas, brother C.C., 1689. Thos., Stockton, 1770. William, 20 Hanover St., 1800. G. W., 32 Tavistock St., 1822-30. Farnborough, Richd., apprenticed 1685 to Wm. Newton, C.C.

Farquhar, W., Tower Hill, $1830 ; 6$ Upper East Smithfield, 1835-42.

Farquharson, Geo., 66 Strand, $1775 ; 421$ Strand, 1780 ; 8 Exchange Alley, 1793.

Farr, John C., Philadelphia, 1831.

Furran, Robt., watch-chain maker, 9 Moorfields, 1780-83.

Farrar. Jonathan, long-case clock, about 1720. Joshua, Brighouse, 1750. Charles, Pomfret, 1790.

Farrend, V., 48 Cheapside, 1825.

Farrer. Samuel, York, f., 1625. William, Pontefract ; 1-day long-case clocks, about 1730. Abraham, junr., Pontefract, 1760 ; Benj., also Jno., 1790; and Joshua, 18001834. Thos., London; long-case clock, about 1770.

Farrett, Richard, C.C. 1670.

Fatio, L. U., Geneva, died 1887.

Fatton, Frederick Louis, New Broad St. ; independent centre seconds watch marked "Fatton élève de Breguet patent, London, No. 16 " ; in 1822 he patented an astronomical clock and watch (No. 4,645) ; many fine travelling clocks and good watches in the Breguet style of about the same period signed "Fatton, Paris."

Faulkner. Edward, master C.C. 1734; 1710-35. William, 1770-88; livery C.C. 1787.

Faux, John, Worship St., Moorfields, 1780-85.

Favey. Francis, 12 Wilderness Row, 1785-90. \& Son, 5 Corporation Row, 1804.

Favre. Henrique, Londres; watch, the Hon. Phinney Baxter, Portland, Maine, U.S.A.; bracket clock, about 1730 . Henry, London; watch, the Edward Devotion House, Brookline ; bracket clock, about 1730. -, London; watch, about 1750 . 
John James, Philadelphia, 1797. Henry, 27 Pall Mall, 1800-18.

Fawcett. Wm., apprenticed 1638 to David Bouquett, C.C. William, Liverpool ; long-case clock, about 1730. Jno., apprenticed to J. Bartholomew, Clerkenwell ; settled in Richmond, Yorks.; a good maker; died 1869, aged 88 .

Fayrer, Thos., Lancaster, 1744, f. Jas., clockmaker and wheel cutter, 35 White Lion St., Pentonville, 1810; in 1819 he was at 40 White Lion St., and was awarded by the Society of Arts the silver Isis medal for a sidereal regulator with a three-wheel train. I recently saw a fine regulator by him inscribed "Invt. and fecit" ; he had a son a clockmaker.

Fazakerley, Thos., " at the Dial and Crown in St. John's St., near Hicks' Hall, London" ; card, Hodgkin collection, about 1780 .

Fazy. Jean, gold enamelled watch, S.K.M. (French), about 1750 , see Terrot. John, 7 Red Lion Court, Fleet St., 1780-85. Feale, Wm., Bristol, 1844.

Fealins, see De Fealins.

Fear, Edwin, Bristol, 1844.

Fearn, John Geo., 114 Strand, 1800 ; 73 Strand, 1813 ; 18 Cornhill, 1814; 22 Regent St., 1840 ; among the effects of Charles Kean sold at his decease was a gold duplex watch, gold dial with raised polished numerals, serpent hands, hall mark 1816, movement inscribed " J. G. Fearn, 73 Strand."

Fearnley, Peter, Wigan, 1780-1816.

Fearon, Daniel, Fetter Lane, liveryman C.C. 1776. \& Stacey, Poultry, 1780.

Feau, - , sixteenth-century table clock, Paul Garnier collection, inscribed

"Nicolas Feau à Mercelle."

Febuce, see Le Febuce.

Feymel, Andreas, table clock, about 1680.

Feilder, Thomas, C.C. 1689; master 1715 ; $1689-1716$.

Fell. William, C.C. 1705 . John, C.C. 1727. Abraham, Ulverston, 1740-70; he made a new style for the church sun-dial in $1763 . \quad J a s .$, Lancaster, 1767.

Felmore, E., London ; watch, 1778.

Felter, Thomas, C.C. 1709.

Felton, George, Bridgnorth ; long-case clock, about 1780 , Mr.W. P. W. Phillimore.

Fémérette, Antoine, " horloger de Louis XIII." (1610-43).

Fenn. Thos., apprenticed 1647 to Thos. Claxton; C.C. 1657. Robert, Westminster, C.C. 1687 ; long marquetry case clock, Wetherfield collection, about 1690 . Isaac, Oxford Road, 1770. Daniel \& Samuel, 105 Newgate St.; D. Fenn, master C.C. 1766 ; 1760-1804. Samuel \& Sons, 105 Newgate St. ; S. Fenn, master
C.C. 1793 ; 1806-15. Joseph, 105 Newgate St. ; master C.C. 1842 and 1863 ; 1830 till 1868 , when the shop, which projected by the railings of Christ's Hospital, was pulled down to widen the thoroughfare.

Fennell, Richd., C.C. 1679 ; bracket clock, arch dial, bell-top shape with handle; also a long mahogany case clock inscribed " R. Fennell, Kensington."

Fenney, - Liverpool ; clock, about 1770.

Fenton. John, apprenticed to Thos. Taylor; C.C. 1662. Jas., York, f., 1740. Wm., Newcastle, 1780. Wm., London ; watch, h.m., 1784. Jno., Congleton, 1833. Sam., 4 Gower Place, Euston Sq., 1840.

Feré, Adrien, Paris, about 1680.

Ferguson. James, born 1710, died and buried in Marylebone churchyard, 1776; astronomer and mechanician (see p. 37880). Wm. Alnwick; long-case clock, about 1770 .

Ferment. John, C.C. 1679 ; Wood mentions a square pedestal watch by Ferment, 1670-90. Paul, London; watch, about 1745.

Fernal, Jno., Wrexham, 1770.

Feron. -, Rue Dauphine, Paris, 1770. Jno., Lewes; watch, 1780.

Ferrers, Jno., London ; long-case clock, about 1700 .

Ferrey, Jas., London ; clock, about 1770 , Mr. W. Popkin.

Ferrier. Antoine, Paris ; lodged at the Louvre 1607. William, son of Antoine, whom he succeeded in 1622. Thornton, Hull, 1822.

Ferris. Benjamin, C. \& W., Philadelphia, 1811. Tiba, Wilmington, U.S.A., 1812-50. David, Calne, 1843.

Ferron. John, London; C.C. 1692. Lewis, London; long marquetry case clock, pull chime quarters, angel and crown corners, about 1720. Abraham, St. Anne's Churchyard, C.C. 1730.

Ferron, Lewis, London ; watch, 1750.

Ferry, Bernard, " horloger de Henri III." (1574-89).

Fessler, John, Frederickstown, U.S.A., 1782-1840.

Fétil, Pierre, born at Nantes 1753 , died at Orleans, 1814.

Fetter, Nicholas, C.C. 1632.

Fetters. Henry, East Smithfield ; free Blacksmiths', 1630 ; C.C. 1653 . Richd., C.C. about 1640 .

Fever, Hy., Pall Mall ; watch, about 1750 , see Favre.

Fevon, Hy., C.C. 1674.

Fiacre, Clement, Paris; watch, 1700.

Fidgett, William, C.C. 1789 ; Dockhead, Bermondsey ; and 3 Bell Court, Fenchurch St., 1780-1825.

Fidler, -, made an orrery for Dr. Pearson 1805. 
Fidley, Geo., see Findley.

Fieffé, Jean Jacque, père, Rue de la Vieille Draperie, Paris (garde-visiteur), 1769.

Field. Jas., C.C. 1672. Wm., London; C.C. 1733 ; watch, 1750 . \& Son, Aylesbury, 1770. T. W., Aylesbury; watch, 1790. Thos., 2 Bond St., Bath, 1795-99. Daniel, 21 Red Lion St., Clerkenwell, 1798. Geo., London ; watch, 1800 . James, Hertford long-case clocks, about 1800.

Fielder, Thomas, apprenticed 1678 to Withers Cheney; C.C. 1687.

Fieldhouse, -, Leinster ; clock, about 1740 .

Fierville, -, Caen; watch, 1770.

Filber, John, Lancaster, U.S.A., 1810-25.

Filon, -, Paris, 1790.

Finch. John, C.C. 1675, master 1706

"A gold minute pendulum watch, with a chain and a large gold engraved case, made by John Finch, of London, about $£ 20$ value, was put to be mended to a watchmaker in Bristol who is since gone" (Lond. Gaz., June 16-19, 1706). Thomas, brother C.C. 1676-1706, possibly a cousin of T. Tompion (see p. 295). Jacob, apprenticed 1686 to Isaac Carver, C.C. William, Kingston ; C.C. 1691 ; maker of long-case clocks, 1691-1720. Robert, C.C. 1691. Simon, C.C. 1706. Wm., Halifax; watch, 1759.

Finchett, Arnold, Cheapside; a water clock by him in B.M., 1735 (see p. 14).

Findbow, Chas., London ; long=case clock, about 1780 .

Findley. J., 5 Duke St., 1820. Geo., 43 Ratcliff Highway, 1835-42.

Fine, Oronce, Paris; professor of mathematics and designer of clocks ; born 1494, died 1555 (see p. 55).

Finelly, -, Aix; watch in the form of a pectoral cross, about.1560.

Finer. Jno., apprenticed 1688 to $\mathrm{Hy}$. Merryman, C.C. John, 5 Hatton Garden, 1791-1800. Thomas \& Nowland, 5 Hatton Garden, 1800-5 ; 48 High Holborn, 180823. Horatio, 48 High Holborn, 1840-42.

Finlow, Zach., London, 1780.

Finney, Thos., Liverpool ; curious watch, 1735, Evan Roberts collection. Josh., Liverpool; long-case clock, about 1750, Mr. Duncan D. Dexter, Boston, U.S.A.; clock-watch, about 1760. Picton, in his "Memorials of Liverpool," says, "Mr. Joseph Finney, a clock and watch maker in Thomas St., designed an octagonal chapel about 1763."

Finnie, Henry, admitted C.C. 1728.

Fish. Henry, 4 Sweeting's Alley, Royal Exchange; black bell-top case bracket clock, inscription on arch " Henry Fish, Royall Exchange," probably son of Henry Poisson; 1730-75, William, 1737. John, apprenticed to his mother, Mary, wife of William Fish ; C.C. 1766 . Sam., " at the Golden Lion, St. John St., Smithfield," 1775. C. H., I3 Mill St., Hanover Sq., 1830-35.

Fisher. Chas., apprenticed 1679 to Thos. Player, C.C. Rebeckah, apprenticed to George Taylor and Lucy, his wife, 1715. Ebenezer, C.C. 1725 . Jno., Preston ; longcase clock, about 1750, with the inscription "Dum Spectus Frigis." Dan., Bunhill Row, 1769-72. Joseph, 2 Leicester Sq. ; livery Cutlers' Company 1773-1815. Hy., Preston, 177.5. Daniel \& Son, 9 Worship St., Finsbury, 1790-1804. Isaac, 3 Cockspur St., 1804-23. - 97 Portland Place, Edgeware Rd. ; bracket clock, about 1810. Edwin E., 14 Bond St., Bath, 1835.

Fishwater, John, C.C. 1726.

Fitree, Samuel, Whitecross St., 1790.

Fitter. John, Battersea, C.C. 1685 ; splendid watch by him, 1665; Wood mentions a gold enamelled watch by Fitter, 1660-1700. Thomazon, 37 St. John's Sq., Clerkenwell, 1759-83; watch, h.m., 1759, Mr. Edwin P. Baker.

Fitton. Thos., apprenticed 1638 to Thos. Laud, C.C. Chas., apprenticed 1667 to Sam. Horne ; C.C. 1674. Dan., apprenticed 1675 to Jno. Bartholomew, C.C.

Fitzjames, Thos., apprenticed 1648 to Jno. Walters, C.C.

Fix, Joseph, Reading, U.S.A., 1820-40.

Flack, G., 9 Princess St., Drury Lane, 1820.

Fladgate. ( \& Wilder, Conduit St, Hanover Sq., I765.) John, Conduit St., Hanover Sq., hon. freeman C.C. 1781. In the B.M. is a small clock by him, brass dial with arch cherub corners. Mr. Thos. Boynton has a bracket clock in ebonised case by him; 1760-63, see Simpson, H.

Flaig, Robert \& Co., wooden clockmakers, 39 Kingsland Rd., 1840.

Flameyer, B., London; small watch, silver pair cases, outer one curiously engraved, h.m., 1765.

Flashman, George, 18 Fleet St., 17901815 (succeeded by Jno. Tunnell).

Flaut, -; large watch, B.M., about 1620.

Flavck, Thomas, watch, about 1650 .

Fleetwood. John, Dorrington St., Clerkenwell; · born 1748, died 1812. Robert, Featherstone Buildings, Holborn, 1760; 13 Abchurch Lane, 1776; liveryman Goldsmiths' Company, died 1789; Robt. Fleetwood \& Co. till 1792.

Fleming. Andrew, C.C. 1725. Curtis, opposite Shadwell Church; livery C.C. 1774. David, 36 Shadwell High St., 1817.

Flemming, Wm., 105 Whitechape, 1815-19, 
Fletcher. Daniel, brother C.C. 1646 ; in 1653 Richd. Roberts was apprenticed to Eliza Fletcher. Widdon, Ant. Freeman was apprenticed to him in 1653 ; C.C. Jno., apprenticed 1654 to Jno. Saville, C.C. Thomas, in St. Martin's ; admitted C.C. 1676 ; threatened with prosecution by C.C. for undue taking of apprentices 1682 . Bazil, apprenticed 1692 to Thos. Wise, C.C. Edward, C.C. 1697. Jno., Barnsley, 1750. Jno., Ripponden, 1760. Jno., Holbeck ; clock, about 1760. William, Leeds, 1770. Geo., Dewsbury, 1770. - Cecilia, Rotherham, 1780. Tobias, Barnsley, 1790. Robt., Chester, 1814-34. Jas., Rotherham, 1818. Thos., Leeds, 1829. M., 25 Charlotte St., Fitzroy Sq., 1835. Charles, 29 Marylebone St., Piccadilly, 1840-42. John, a Lancashire pinion maker, who started in London as a chronometer escapement maker, and afterwards manufactured unsprung marine chronometers for the trade at 14 Chapel St., Liverpool Rd. During a period of depression in the chronometer trade Fletcher bought the business of Dwerrihouse in Davies St., Berkeley Sq., which he carried on for a year or two. But as a West End shopkeeper he was quite out of his element, and on looking out for a more congenial sphere of action he learnt that Eiffe, who had made for himself a name as a chronometer maker in Lombard St., was anxious to retire; and Fletcher made arrangements to take over Eiffe's shop. In Lom bard St. Fletcher was most successful. He learnt springing from William Cribb, and settled down as a chronometer maker, springing and adjusting his own work. When the lease of the premises in Lombard St. expired, he bought the business of Cummins at 148 Leadenhall St., and having by this time also established a reputation of his own, he did a very flourishing business there for many years. As age crept on him he gave up the more active superintendence of his business, which declined; and after removing from 148 , which was pulled down, to 99 Leadenhall St., and again to Billiter St., he finally retired about 1880, and died in 1882 , aged 80 .

Fleureau, Esaye, London; in the Wetherfield collection is a long-case clock by him, dating from about 1710 . It embodies a fine specimen of arabesque marquetry, which is continued on the moulding supporting the hood, over the base and round the sides of the case.

Fleutry, -, Paris, 1788.

Flexney, Hy., apprenticed 1657 to Gower Langford, C.C.

Fling, Daniel, Philadelphia, 1811.

Flockhart, Andrew, 5 King St., Covent Garden, 1814-35.
Floden, William, 20 Skinner St., and Coburg St., Clerkenwell, 1835.

Flood, Humphrey, received $£_{220}$ for a clock "covered with gold and set with rubies and diamonds, delivered to his Majesty's use " (James I.), 1607-17.

Flook, J., Strand, London; bracket clocks, about 1750 .

Flournoy. Henry, 1690. P., Paris, about 1740 .

Floward, Wm., London ; watch, 1790.

Flower. Geo., apprenticed 1670 to Jas Atkinson; C.C. 1682 ; watch, about $1700^{\circ}$ Jno., Fenchurch St., C.C. 1725-30. Thomas, C.C. 1730 ; pendulum watch. Schloss collection, fine dial, about 1740 , Henry, Philadelphia, 1753. \& Mainwaring. London; watch, 1818.

Flowers, Edward, Rolls Buildings, Fetter Lane; watch, beautiful outer case, set with pearls, h.m., 1783; 1769-84.

Floyd, Wm., apprenticed 1660 to Richd. Lyons, C.C.

Fly, Joseph, London; calendar watch, Schloss collection, about 1770; another, about 1780 .

Foden, -, Congleton ; clock, about 1770.

Fogg. Hugh, near Exeter Change, Strand, 1765-70. Chas. W., Waltham, Mass.; died 1893, aged 76 . He patented a safety pinion formed with an internal screw for attachment to the centre arbor of a watch, so that it could twist to recoil from a shock induced by the breaking of the mainspring.

Foggo, James, London ; clock, about 1760 .

Foilman, John, watch-glass maker, George St., St. Martin's Lane, 1790.

Foissey, Jules, Boulogne; died 1892, aged 57.

Fol, - Paris, 1770-87; watchmaker to the King of Poland; maker of 8-day watches. His son was clockmaker to Louis XVI.

Fole, Robert, C.C. 1667.

Folkard, Jas., 124 Great Surrey St., 1823.

Follett, Richd., apprenticed 1653 to

Thos. Wolverstone, C.C.

Fontac, -, London; watch, 1796.

Fontane, John \& Moses, London ; halfquarter silver repeating watch, about 1790 .

Foote, William, admitted C.C. 1726.

Forbes. Wm., London; watch, 1805 ; Hide Market, Leadenhall, 1838. John, 122 Leadenhall St., 1835-40.

Ford. Hy., apprenticed 1647 to David Parry, C.C. Robt., apprenticed 1652 to Richd. Record, C.C. Thomas, C.C. 1724. Jno., Arundel, 1750. William, C.C. 1770. -, 31 Gracechurch St., 1820. \& Simmons, 16 King St., Seven Dials, 1842.

Forde, Jno., Oxon., 1750. 
Fordham. Jno., Dunmow ; large lantern clock, about 1680, Mr. G. F. C. Gordon. Thomas, C.C. 1687. Joseph, Bocking, 1700 ; fine long-case clock by Thos. Fordham, Braintree, Essex, about 1730.

Foreman. Francis, St. Paul's Gate; petitioner to Charles I. for incorporation of C.C. and one of the first assistants; lantern clock, about 1620; 1620-49. Michael, livery, C.C. 1810.

Forester, J., Union St., Bishopsgate ; card, Hodgkin collection, about 1810.

Forestier, Joseph, Geneva ; watch, 1810.

Forfaict, N., Paris ; maker of an octagonal watch presented to John Knox by Mary, Queen of Scots, which is now in the B.M. ; oval watch, about 1590 , Pierpont Morgan collection.

Forfard, Augustin, Sedan ; oval watch, about 1650 .

Forfax, Isaac, Sedan; oval watch, Schloss collection, about 1605 .

Forgat, -. "A round brass clock, the Box well gilt and pearced all over, in a leather Case, the name Forgat" (Lond. Gaz., March 29 April 1 1680.)

Formant, Philip, C.C. 1687.

Forrest. Matt., apprenticed 1672 to Jno. Lowe C.C. Joseph, C.C. 1692. John, 12 Hanover St., 1850; afterwards 29 Myddelton St. ; died 1871; most of his customers were chapmen in Scotland, where his watches obtained some repute; several years after his death the use of his trade mark, a tree, led to litigation.

Forster. John, apprenticed 1680 to D. Quare; C.C. 1689. William, brother C.C. 1681. Clement, C.C. 1682. Jacob, apprenticed 1690 to Jno. F. C.C. John, C.C. 1726. John, Carlisle, 1810.

Forsyth, James, Albion Buildings, Bartholomew Close, 1790-1800.

Forte, John, C.C. 1672.

Fortfart, Isaac, Sedan, 1585.

Fortier, see Stollewerck.

Fortin, Auguste, père, Rue de la Harpe, Paris; garde-visiteur 1769. Michel, same date.

Foss (? Fox), Thomas, 131 Strand; maker of 8-bell chime clock, brass dial, with strike-silent, silvered circles at top; 1780-95.

Foster. Joseph, Exchange Alley; C.C. 1691. Thos., apprenticed 1693 to Nat. Smith, C.C. Wm., Marnham; 30-hour clock, about 1740. S., Birchin Lane; watch, bloodstone and gold case, Hawkins collection, about 1780. Isaac, 1 Bartlett Passage, 1788. J. Benj., 22 Cursitor St., 1817. Nathaniel, Newburyport, 1818-28. Thomas, Ashton-under-Lyne ; died 1913, aged 81 .

Fothergaile, Jas., apprenticed 1661 to Ralph Almond, C.C.
Fotter, Wm., C.C. 1660

Fouch, Wm., Goswell St., 1775.

Foucher, B., Blois, 1630 ; the Comte de Lambilly has a watch signed "Blaise Foucher A Blois."

Foulcon, Benj., London; about 1780. Fould, Humphrey, apprenticed 1646 to John Willowe, C.C.

Foulkes, David, apprenticed 1671 to Peter Southworth, C.C.

Fowell. Edmund, C.C. $1670 . \quad$ J. \& N., Boston, U.S.A., 1800-10.

Fowkes, Gabriel, Dartford ; long Oriental lacquer-case clock, with picture in centre of door, arch dial, engraved silver centre, flower and scroll corners, about 1750; bracket clock, about 1780 .

Fowlds, Andrew, 9 St. John's Sq. 1790-94.

Fowle, Thos., East Grinstead, about 1700. Several generations after till 1842 .

Fowler. Robt., C.C. about 1650. D., London ; lantern clock, about 1690. Abraham, Amersham, about 1760. Wm., London; watch, 1780. Thos., London; watch, 1782. F. of York: Robert, 1810, settled at Leeds ; Geo., 1819, afterwards at Doncaster. Robt., Leeds, 1829.

Fowles, Allen, Kilmarnock; said to have made a watch for Robert Burns in 1771.

Fowls, And., London; watch, about 1780 , case decorated with pearls.

Fox, Charles, C.C. 1662 ; lantern clock, belonging to Mr. Meggat, U.S.A., inscribed "Charles Fox, at the Fox, Lothbury, Londini, fecit," about 1670 ; Mr. Meggat has also a stumpy bracket clock by him. There must, I think, have been a second Charles Fox; I saw a long-case clock dating from about 1730 inscribed " Charles Fox, London." Mordecai, C.C. 1689. Isaac, 39 Minories, 1772 ; 7 Great Prescot c., 1782-94. \& Son, 7 Magdalen Buildings, Prescot St., 1788. Thomas, 131 Strand, 1790 , see Foss. Hudson, Beverley 1822.

Foy. At Deene Park is a Louis XIV. chiming clock in Boulle work case which belonged to the Duke of Sussex and was acquired by the late Earl of Cardigan ; it is marked "T. Foy La Roux à Paris." Jas., Taunton about 1770. Henry Jno., London; clock about 1790.

Frail, Thos., 92 Edgware Rd. 1814-18. Fraincomme, - London; watch 1778. Framborough, Edward, admitted C.C. 1689 .

Frame, -, Warrington ; long-case clock about 1770. Geo., Gateshead, 1833.

France, -, Warrington, about 1720.

Francillon, Ernest, Longines, Switzerland, did much to advance the duplicating system of watchmaking; died 1900.

Francis. Balmer, St. Bartholomew's C.C. 1731. Basil \& Alexander, Baltimore, 
1766. William, 15 King St., Clerkenwell livery C.C. 1810 .

Franciycifs, Joh., Dresden ; clockwatch, about 1740 .

Franck, Thos., crystal-cased watch, about 1580 .

Frankcom. - 7 Quiet St., Bath. Chas., 1795-1807. \& Mowat, 1835, afterwards Alex. Mowat.

Franklin. Joseph, apprenticed 1679 to Hy. Harper, C.C. ; tall oak double-dome case clock at Innholders' Hall, signed on convex disc in arch of dial "Josephus, Franklin, London," about 1720. Thos., apprenticed 1692 to Ben. Merriman, C.C. William, C.C. 1712. William, C.C. 1731. William, watch shagreen-case maker, Shoe Lane, 1790; livery C.C. 1810.

Fraser, John, apprenticed 1681 to Edwd. Eyston, C.C.

Frazer, -, Bond St., 1788.

Frearson, John, C.C. 1689.

Free. Jno., Oxon. ; watch, about 1700. A., Blackburn; long-case clock, 1770.

Freebody, Jno., apprenticed 1671 to Jno. Sweetby, C.C.

Freeman. John, C.C. 1646, assistant 1671 ; died 1680. Anthony, apprenticed 1653 to Widdon Fletcher, C.C. Stafford, apprenticed 1656 to Wm. North; C.C. 1663. Thomas, C.C. 1698. James, C.C. 1719. Jas., St. Botolph, Bishopsgate; apprenticed to John Watford, and turned over to Francis Robinson; C.C. 1736; in 1769 he patented a stop watch (No. 946). Nathaniel, 26 Upper King St., Bloomsbury, 1840-42.

Freestone, Thos., Bury, 1765.

Freethy, Jno., apprenticed 1672 to Chas. Rogers, C.C.

French. Thos., Norwich, 1770. John, 21 Tavistock St., 1783-88; Mile End, 1800. James Moore, 15 Sweeting's Alley. 1808-38; 18 Cornhill, 1839-42 ; livery CC. 1810, see also Mitchell \& French. James, 17 Castle St., Holborn, and 21 Tavistock St., 1810. Jas., Bristol, 1844. Wm., 9 Royal Exchange, 1850.

Frencham, James, C.C. 1698.

Freshfield. Jas., watch-case coverer, 19 Smithfield. James, junr., C.C. by redemption 1744; letter as to non-payment of quarterage, 1796; centre seconds watch, about 1800 . James William, son of the foregoing, C.C. 1801.

Frippett, John, C.C. 1665-70.

Frisby, Jno., 5 Duke St., Grosvenor Sq., 1816-25.

Frisquet, Peter, 30 Lothbury, 1768-75.

Frodsham. William, Kingsgate St., Red Lion Sq. ; born 1728; hon. freeman C.C. 1781 ; Earnshaw claimed to have taught him watch jewelling; he attested the value of Earnshaw's improvements in 1804; died 1807. For some years from 1790 the business was carried on in conjunction with his eldest son, William, under the title of William Frodsham \& Son; the younger William predeceased his father, and the elder William bequeathed the business in Kingsgate St. to his grandson, John Frodsham. William James, F.R.S., born 1778; grandson of the first-named William; eldest son of William and Alice Frodsham (Alice being the granddaughter of John Harrison, famous as the inventor of the marine timepiece; he entered into partnership with William Parkinson, and commenced business in 1801 in Change Alley; admitted C.C. 1802, master 1836 and 1837 ; died 1850 , bequeathing $£ 1,000$ to the C.C., to be known as the Parkinson and Frodsham Charity; he had brought up four sons to the trade: Henry, who settled in Liverpool; George, who succeeded him; John ; and Charles. John, born 1785 ; he entered into partnership with one Baker in 1809, and, under the style of Frodsham \& Baker, continued the business at Kingsgate St. till about 1823 , and afterwards at 31 Gracechurch St. ; elected to the livery of the C.C. in 1830; died in 1849; he had two sons associated with him in the business: Henry John, who died 1848, and George Edward, who succeeded him. Charles, son and apprentice of W. J. Frodsham, born 1810, died 1871; a skilful and successful watchmaker, 7 Finsbury Pavement, 1842; afterwards succeeded J. R. Arnold at 84 Strand; he conducted many experiments with a view of elucidating the principles underlying the action of the compensation balance and the balance-spring, and wrote several papers on technical subjects; he was for some time a vice-president of the Horological Institute; admitted C.C. 1845, master 1855-62. George Change Alley, 1850-73. His son, G. W., at Change Alley and other places in the city of London, died 1912.

Froissard, - Geneva, about 1800.

Fromanteel. Ahasuerus, East Smithfield ; Blacksmiths' Company 1630 ; C.C. 1632 (see p. 314); 1630-50. Ahasuerus, Moses Alley, Bankside ; C.C. 1655. Dan., apprenticed 1661 to A. F., Sen., C.C. Ahasuerus, Ye Mermaid at Lothbury and Moses Alley, Bankside; apprenticed to Simon Bartram; C.C. 1663-75; Daniel O'Connell had a clock by A. Fromanteel dating from about 1675, which is now in the possession of Mr. Walter Conan, Dublin ; it has a verge escapement, and is in a long-case of oak veneered with ebony ; the hour band is of silver. Mr. Hansard Watt has a choice bracket clock by this 
maker as shown in Fig. 317. John, Ye Mermaid at Lothbury; apprenticed to Thomas Loomes; $1663-80$ (see p. 314); one of John Fromanteel's long-case clocks at the Dutch Church. Austin Friars, is dated 1679. Ahasuerus, apprenticed 1679 to Jno. F., C.C. Abraham, son and apprentice of Ahasuerus Fromanteel ; C.C. 1680 ; refused to serve as steward 1701. \& Clarke, London; watches, from about 1680 ; long marquetry case month clock, domed hood with gilt figures on top, 12-in. dial, strikes the quarters, about 1710 ; a somewhat similar specimen, in the possession of Mr. Wm. R. Moss, is shown in Fig. 717 ; it strikes hours and half-hours on different bells, has an alarm and shows day of the week and of the month ; Mr. Walter H. Durfee, Rhode Island, U.S.A., has a long-case clock by Fromanteel \& Clarke with the additional signature "A. Fromanteel "along the bottom edge of the dial.

Frost, - Exeter ; put Lovelace's clock in order in 1849 (see p. 400).

Frotheringham, Samuel, Holbeach, a Quaker, died 1745 .

Frowde, Jno., apprenticed 1646 to $\mathrm{Hy}$. Wansey ; C.C. 1658.

Fry, Edward, 13 Park Side, Knightsbridge, 1835 .

Fryer. William f., of York, 1809 ; settled at Pocklington. John, f., of York, 1812 ; then at Pocklington. Moses, York, 1822. William James, 50 Cheapside, 1842.

Fryett, S., 130 Whitecross St., 1823.

Fueter, -, Berne, about 1740.

Fulkener, Edward, C.C. 1702.

Fuller. William, C.C. 1675. Samuel, 64 Red Lion St., Clerkenwell, 1800-40; gave evidence in 1817 before a committee of the House of Commons on the distress among watchmakers in Clerkenwell. Crispin, Monkwell St., 1817.

Fulwell, Hy., apprenticed 1649 to $\mathrm{Hy}$. Child, C.C.

Furet. Clock, Wallace collection, about 1740, signed "Furet l'aîné à Paris."

Furnace, Geo., Dublin; watch, 1781 .

Furness. Joseph, Uppingham, 1784. -, Monkwearmouth, 1802. John, 9 Cross St., Hatton Garden, 1830.

Furnesse. Thomas, near Three Compasses, Gravel Lane, 1701. Joseph, Monkwearmouth, 1770.

Furnifull, Richard, C.C. 1722.

Furnis, Thomas, 25 Crawford St. 1840-42.

Furstensteller, Benedict, Fribourg ; hexagonal alarm table clock, brass case, silver dial plate, Hilton Price collection, about 1650 .
Gabrier, Charles, London ; this name on clocks and watches 1705-20 may possibly be fictitious, see Cabrier.

Gadsby, -, Leicester, 1770 .

Gadsdon, Wm., London ; long-case clock, about 1750 .

Gagnebin, Dan., Chaux de Fonds, about 1750.

Gaill, Mattheis, large German watch; S.K.M., about 1670 .

Gailliard, N., oval watch, about 1590 , Pierpont Morgan collection.

Galbraith, Patrick, Philadelphia, 17971811.

Gale. James, 64 Cannon St., 1783-89. John, 5 Red Lion Court, Spitalfields, 1790 1829; Lamb St., 1800-42.

Galemin, Watch, Pierpont Morgan collection, signed "J. Galemin Autin," about 1620 .

Gallhans, Gabriel, watch, Pierpont Morgan collection, about 1740 .

Gallimore, Joseph, Manchester, 1775.

Gallott, Isaac, apprenticed in 1655 to Thos. Weekes, C.C.

Galloway. Christopher, clock in a gateway of the Kremlin, Moscow, 1626. Jno., apprenticed in 1683 to Wm. Foster, C.C. Walter, Kilbirnie, 1780. The Galloways were well known in Leeds: Jas., J. \& T. S., Matthew ; all about 1830.

Galt, Samuel, Williamsburg, U.S.A., 1751.

Gamble. Thomas, C.C. 1657. Henry, Bramley, 1770.

Gammage, T., musical clockmaker, 6 Bridgwater Sq., 1823 ; 8 Wood St., Goswell Rd., 1835. Mr. B. G. Wattson has a " Universal " clock by him, which was shown at the 1851 Exhibition.

Gammon. Jno., London ; lantern clock inscribed "John Gammon, Londini, fecit," about 1670 ; silver watch, about $1680, \mathrm{Mr}$. J. Drummond Robertson. Jno., Lambeth ; watch, 1725 ; another, 1760.

Gamod, G., Paris ; watch, about 1660 ; another watch signed " G. Gamos, Paris."

Gamp, P. J., wood clockmaker, 28 Hatton Wall, 1835.

Gandy, -, Cockermouth ; long-case clock, inscribed " LIDDL Wm. and Mary, 1768."

Ganeral, Aug., 7 Baker St., Clerkenwell 1835.

Gannery, - , chronometer maker, died 1851.

Ganter, J., 39 Marshall St., London Rd., 1835. Geo., Newark 1840.

Ganthony. Richard, 27 Cannon St., 1803 ; 49 Lombard St., 1807 ; 83 Cheapside, 1825 ; master C.C. 1828-9. Richard Pinfold (son of the above), 83 Cheapside ; died while master C.C. 1845 , see Connell.

Gantlett, Q., Calne, 1843. 
Gany, Thomas, C.C. 1699.

Garbett, Jere., apprenticed to Conyers Dunlop, turned over to Arthur Downes; admitted C.C. 1768.

Garbrand, Jno., apprenticed 1654 to Thos. Loomes, C.C.

Gard, Henry, Exeter : clock, 1770

Garde, Jas., London ; bracket timepiece, square black case, minute circle within hour circle, about 1700 .

Garden. William, C.C. 1712. Philip, St. Paul's Churchyard, 1759.

Gardener. John, C.C. 1682. Joseph, Lancaster, 1767, f. Henry, 36 Norton Folgate, 1794-1804. Edward, Lancaster, 1841. George, Lancaster, 1885.

Gardiner. John, Croydon; C.C. 1687. Henry, Rolls Buildings, Fetter Lane, 1759-60.

Gardner. Thomas, C.C. 1689; Mr. Walter Hosmer, Wethersfield Conn., has a long-case clock by him; another in the Wetherfield collection, a three-train chiming clock, arch dial, burr walnut case, about 1710 . William Obadiah, C.C. 1711. William, Sandwich; walnut long-case clock, about 1760 . T., London; watch, 1762 Joseph, Lancaster, 1767, f. Thos., London; bracket clock, plain mahogany case, about 1790 . Jno., Hull, 1822. W. K., Bridlington, 1822. Edwd., Lancaster, $1841, f$.

Garfoot, William, C.C 1680

Garland, John, Barbican; liveryman C.C. $1776 ; 1766-98$.

Garle, Richd., apprenticed in 1682 to Joseph Windmills, C.C.

Garne, T., London; bracket clock, about 1680 .

Garnegy, Chas., 55 King St., Soho, 1817.

Garner, Thos., London; watch, 1770.

Garnet, W., London ; watch, 1766.

Garnett. Jno. Anthony, apprenticed in 1672 to Chas. Gretton, C.C. ; he settled in France. Wm., London, about 1680.

Garnham, Ảbel, 1 Lincoln's Inn Fields, 1816.

Garnier. Watch, about 1700, “F. Garnier à Paris." Jean Paul, Paris ; born at Epinal, France, 1801 ; settled in Paris, 1820 ; died 1870.

Garon, Peter, London; C.C. 1694; watch, B.M., with day of the month circle ; curious watch with one hand; Mr. J. Drummond Robertson has a long-case chiming clock with ten changes in the hour by him (see pp. 538, 543) ; his bankruptcy noted (Lond. Gaz., Oct. 31, 1706).

Garrandol, - French hexagonal watch crystal case, Wallace collection, signed " Garrandol à Verdun," about 1640.

Garrard. R. S. \& Co., London; watch. case set with rubies, 1780 . Robt., 31 Pan- ton St., Haymarket, 1815-18, see Wickes, Wm. R. J. \& S., 31 Panton St., 1822-42.

Garrat, Hugh, Ormskirk; maker of watches with Debaufre's dead-beat escapement, 1775-1800.

Garraway, C., Queen St., Westminster, 1820.

Garret. Ferdinando, English watch in the form of a Tudor rose, about 1600 . Hugh, see Garrat.

Garrett. Charles, C.C. 1690. Charles, admitted C.C. 1720. William, 188 Wapping, 1804-15. Philip, Philadelphia, 1819.

Garritt, Thos., London; watch, 1790.

Garron, see Garon.

Garrot, Jno., Warrington, 1770.

Garth, John, Aylesbury St., Clerkenwell, 1750-55.

Garthwaite, Jno., Colne, Lancs., 1818.

Gartly, Jno., Aberdeen, 1810.

Gartner, C. M. E., Ashby St., Clerkenwell; in 1856 he, in conjunction with W. S. Mitchell, patented a form of winding for fusee watches and a regulating lever actuated by a screw.

Gascoigne. Wm., Newark ; maker of lantern clocks, born 1659, died 1740 ; Owen Gascoigne, Newark ; long marquetry case clock, about 1705; another, rather later, " Owen " Gascoigne. Richd., apprenticed in 1676 to Sam. Gascoigne, C.C. Samuel, C.C. 1676. " Lost, between Ludgate and Lothbury, on the 8th instant, a pendulum watch in a tortoise-shell Case, with a steel Chain and 2 Swiffles; made by Samuel Gascoigne" (Lond. Gaz., July 14-18, 1692).

Gaskell, Thos., Knutsford, 1760.

Gaskin, Jno., Dublin ; watch, 1780. 23.

Gass, David \& Co., 42 Oxford St., 1810

Gastling, Thos., Diss, about 1845.

Gate. Archer, apprenticed in 1674 to Jas. Ellis, C.C. Thos., Carlisle, 1770.

Gates, Francis, London ; watch, 1795.

Gatewood. "Lost on 26 July 1705 a silver minute Pendulum Watch on the upper plate Gatewood and on the dyal Plate, Gatewood, London. Whoever has taken it up if they will bring it to Sam. Barrow, Clockmaker at the Sign of the Spring Clock in East Smithfield near Hermitage Bridge, shall have 20s. reward" (The Postman, July 31. 1705.)

Gatford, Wm., Uxbridge ; watch, 1759.

Gathercole, John, London ; maker of a bracket clock, silvered arch dial, about 1780 .

Gatty, Thos., Bodmin, 1790-1820.

Gatward, Thos., apprenticed in 1693 to Dan Rose, C.C. Jos. (from London), Sevenoaks, 1780.

Gaudron, P., Paris ; clock and wartch maker of repute, $1690-1730$; spoken of as 
an authority by Thiout and by Lepaute; watch by him, Mr. Henry Carr Glyn ; watch, leather case piqué with gold, wind in centre of dial, about 1720, Evan Roberts collection.

Gaudy, J. A., Geneva, about 1780.

Gaunt. Joseph, apprenticed to James Wood, and turned over to Francis Rooker, and afterwards to Samuel Allvey, admitted C.C. 1761. John, 2 Bridgewater Gardens, 1825-42.

Gauthier, Pierre, Paris ; enamelled watch, Pierpont Morgan collection, about 1710 .

Gautier, J. A., first director of the Geneva Observatory, died 1881.

Gautschy, Jas., London ; watch, apparently Swiss, about 1785 .

Gavelle. James (alien), C.C. 1683 ; clock with square dial, boy and crown corners, " James Gavelle, Londini, fecit," on circle ; 1683-1700. Jno., Moorfields; long-case clock, about 1705. --, Paris ; clock, 1820.

Gay, see Guy.

Gaze, James, Primrose St., Bishopsgate, 1782. Samuel B., son and successor of James, a well-known clockmaker, 26 Princes St., Spitalfields, 1814-59. Peter, Liverpool Rd., son of Samuel B., died 1892, aged 73 ; he and his brother were among the best clockmakers of the period. James, Liverpool Rd., brother of Peter, and last surviving son of Samuel, died 1913, aged 87.

Gazuet, Jérôme, admitted C.C. 1682 ; lantern clock, about $1700, \mathrm{Mr}$. E. Wehrle, Brussels ; long-case clock, at Belem, Lisbon, signed " J. Gazuet, St. John's, London," about 1710.

Geater, Hy., Bristol, 1844.

Gee, see Guy.

Gefael, U., 28 Langley Place, Commercial Rd., 1835-42.

Gegenreiner, F. Z., Augsburg, about 1720.

Geldarte, Jno., York, f., 1674.

Gell, York: Jno., f., 1634 ; Jno., f., 1663.

Gells, Thomas, admitted C.C. 1720.

Gent. Joseph, Walsall, 1818. Ralph, London; made watches for the Turkish market, 1842.

George. Andrew, apprenticed in 1649 to Peter Delaundre, C.C. Richard, C.C. 1681.

Gerard, J. B., Quai des Grands Augustins, Paris (garde-visiteur), 1769.

Gernon, Bernard, apprenticed to Solomon Wagson, of Bristol ; admitted C.C. 1659.

Geronst, Alex., Coventry St., London ; bracket clock, about 1730, seen at the Hague.

Gerrard, John, London ; bracket clock, about 1725 ; verge watch, h.m., 1740 .

Gervas, Thos., Epworth ; clock, about 1770.

Gewoll, Gregory, senr., London, 1730.
Gib. William, Rotterdam ; two pendulum watches, G.M., about 1710; watch, silver cock, Nelthropp collection, about 1725 ; fine long-case chiming clock, Sir James M. Moody (see p. 552). B., Rotterdam ; watch, Nelthropp collection, about 1720 .

Gibbard, Thomas, Quakers' Buildings, 1780-85.

Gibbons. Edward, New St., C.C. 1730. Benjamin, C.C. 1750 ; died 1769 . Joshua, 45 White St., Borough, 1810-18. John, 6 King St., Clerkenwell, 1810-23; 64 Hatton Garden, 1836-42 ; livery C.C. 1811.

Gibbs. Walter, admitted C.C. 1648. Thomas, apprenticed 1672 to Hy. Hester; admitted C.C. 1681 ; master 1711. Joshua, apprenticed in 1689 to Thos. Gibbs, C.C. William, Moorfields, C.C. 1707-30; paircase verge watch, repoussé case, about 1720 . Jas., Whitefriars, C.C. $1725 . \quad$ Stephen, Milford Lane, C.C. 1728 ; watch, 1750. Richd., London, 1760; long-case clock, said to be signed " Pick Gibbs," is probably by him, and signed " Rich. Gibbs." Jno., 11 Castle St., Aldersgate, 1815-19. Thomas, 11 Nichol Sq., Aldersgate St., 1825. Geo., 38 Banner St., 1835-42. Chas., Bath, 1848.

Gibson. Benj., apprenticed 1654 to Richd. Masterton, C.C. James, brother C.C. 1669 . G., Thetford, about 1690. Newcastle, about 1750. Mary, at the Dial and Crown, Newgate St., dealer in all sorts of clock and watch makers' tools and materials, and for nearly twenty years the first in the business; having acquired a good fortune with a fair character, she retired from business in 1757 (Ludlam). Jno., Beith ; curious geographical clock, 1761 . John (? Jas.), Whalebone Court, Loth bury, 1761-1813. Wm., Barnard Castle, 1770. John, Jedburgh; long-case clock, about 1770. Edward, livery C.C. 1787; master 1802 ; $1780-1803$. \& Faust, 5 Charlotte St., Rathbone Place, 1800. Jno., Royal Exchange, C.C. 1800-10 ; succeeded by Jas. Bissett. C., 71 Bishopsgate Within, 1830.

Gideon, Robert, admitted C.C. 1691.

Giffin, Thos., London, 1820.

Gifford, Thomas, apprenticed to Robert Seignior, and turned over to Robert Webster, admitted C.C. 1692.

Gil, Wm., Rotterdam; watches, $1770-90$; wátch, about 1780 , signed " Gil l'aîné," see Gib, also Gill.

Gilbard, Thos., watch-case maker, Clerkenwell Green, 1793.

Gilbert. Thos., apprenticed 1656 to Robt. Coster, C.C. A.ustin, C.C. 1661. Richd., apprenticed in 1664 to Thos. Hancorne, C.C. Joseph, apprenticed in 1682 to Thos. Fenn, C.C. William, C.C. 1695. Charles, C.C. 1700, à Paris; watch, about 1780 . - Chichester; long-case 
clock, about 1800. Philip, 20 Cockspur St., 1807 ; 5 St. James's Sq. 1830 , see Green.

Gilbertson, Jno., Ripon, 1770.

Gildchrist (or Gilchrist). Archibald, C.C. 1729. Sterling, Lombard St. 1755-65.

Gilkes. Richd., apprenticed in 1678 to :Vm. Hancorne ; C.C. 1686. Geo., apprenticed in 1693 to Richd. Watts, C.C. Jno., Shipston, on plate of watch, Mary Gilkes on dial, hall-mirk, 1766. Richard, Devizes, a Quaker, died 1822.

Gill. Wm., Maidstone ; lantern clock, about 1770 Dr. Wm. A. Day. John, C.C. 1707. John, Gracechurch St., 1753-65. Daniel, Rye, 1790. Wm., Rotterdam; Natch, 1794.

Gille, -, Paris, 1769.

Gillepsy, Chas., Iublin ; watch, 1796.

Gillett. Cha. Edw., Manchester; 30hour ore-hand clock, about 1740. Edwd., \& Son, Manchester, 1775. \& Healy, Manchiscer, 1800. Chas. Ed. Manchester, died 1819, aged 74 .

Gillier, C., Berne ; maker of an oval watch, about 1650 .

Gillies, Robt., Beith, 1780.

Gillmore ; lantern clock, inscribed " Jno. Gillmore, Battel," about 1700.

Gilpin, Edmund, petitioner for incorporation of C.C. ; a watch by him mentioned in Archoological Journal, vol. xxii. ; oval watch, about 1620, Wrhitcombe Greene collection.

Gimblet, Jno., junr, \& Vale, 106 Snow Hill, B.rmingham, 1770.

Gingner, Anthony (French), admitted as a brother C.C. 1687.

Ginn, William, freeman C.C. 1699.

Giox, - , Paris ; enamelled watch, 1780.

Girard. Marc, Blois ; oval watch, Soltykoff collection, about 1590; watch signed "M. Girard, Bloy," in case of rock crystal, about 1580, Pierpont Morgan collection. Marc, Paris ; oval chased watch-case of silver-gilt and rock crystal, Shandon collection, about 1600. J., London; watch, 1700 ,

Girardier l'Aîné, Geneva, 1780-1805.

Giraud, Christophe, Geneva, 1814.

Girod. Gasper ; an astronomical watch by him in B.M., about 1610 . James (French); watch, about 1660, signed " Jacques Girod à Copet," admitted C.C. 1692 ; bracket clock, about 1700 , inscribed " James Girod, London." Benj., London ; repeating watch, 1775 .

Giroust, Alexander, Coventry St., 1760 ; clock, Mr. Eden Dickson. à Paris; fine clock, about 1790 .

Giteau, Eve de Breguet, Paris; watch, 1790.

Gitter, Jno., apprenticed in 1683 to Nat. Pyne, C.C.

Gladstone, Thomas, C.C. 1703.
Glaesner à Lyons; clock, about 1775. \& Prud'homme, Lyon; repeating watch, about 1780, M. Th. de Saussure.

Glanville, Richard, Strand, 1775.

Glase, Thos., Bridgnorth; watch, 1790.

Glasgo, Phil. \& Son, Dublin; pull repeating bracket clock, about $1720, \mathrm{Mr}$. D. T. Halsey; watch, 1770.

Glasgow, David, born in Coleraine, Ireland, emigrated to Lordon, worked for J. R. Losada in Regent St., afterwards in business at 20 Myddelton Square; maker of watches for the Spanish markets, a Vice-President of the Horological Institute; died 1911, aged 87.

Glass, Alexander, 306 High Holborn, 1783. Jas., Bristol, 1844.

Glassup, Thos., London, bracket clock, about 1755; another, about 1780 .

Glazebrook, Jno., Mansfield, 1780.

Glazier, William, C.C. 1666 ; to him Simon Lamb was apprenticed in 1669. 1700 .

Gleave, Matthew ; watch by him, G.M.,

Gleeter, -, London ; watch, about 1740 .

Glenc, Joseph, Prag ; watch, about 1710.

Glenny, Jnseph, watch-case maker, 20 Red Lion St., Clerkenwell ; livery C.C. 1810.

Glossop, Robt., London; watch, 1815.

Glover. Samuel, C.C. 1694. Daniel, C.C. 1699. Thos., New St., C.C. 1700 . Richard, C.C. 1703. Boyer, Leadenhall St., C.C. 1740 ; died while serving as senior warden, 1768. Ralph, Hyde Park Corner ; watch, about 1770 . Wm., Worcester, 1770. —, watch-spring maker, 81 Aldersgate St., 1800-5. - , Pimlico, 1810. J., Manchester; watch, about 1820, Dr. H. Goudet. J., 9 May's Buildings, St. Martin's Lane, 1835. Jno., chronometer maker ; apprenticed to J. R. Arnold, 1835-80.

Gluck, Adam ; watch by him in B.M. in a case of blocdstone, 1650-60.

Glyd, Jas., Westminster; watch, h.m., i 771 .

Glynn, Richard, C.C. 1705.

Gobels, Jan, Bloemgracht (Flower Canal), Amsterdam, 1767. Mr. James has a fine long-case clock by him with kettle base and marquetry decoration, shows moon, tides, day of the month, day of the week, and astronomical signs.

Gobert. Peter (French), admitted C.C. 1687. Matt., London; watch, 1760.

Gobrecht, Christian, Baltimore, 1820.

Godbed. William, apprenticed 1638 to Thos. Reeve, admitted C.C. 1646 ; watch, Whitcombe Greene collection, inscribed " Guliemus Godbed, Lombert Street, Londini," octagonal case ; another at the B.M. ; signed a petition to C.C. 1656. Matt., apprenticed in 1657 to $\mathrm{Hy}$. Kent, C.C. 
Godbere, Saml., "late Mr. Stamp, 85 Cheapside," card. Ponsonby collection.

Goddard. Reymond, $1600 . \quad J o h n$, Houndsditch (from Paris), described as a Papist who resided with and worked for Isaac Sunes in Houndsditch, 1615-18. Thos., apprenticed 1638 to Richd. Child, C.C. Isaac, apprenticed 1675 to Thos. Grimes, C.C. 1684; long-case clock, Museum, Brunswick, inscribed "Isaac Goddard. Londini." Thos., apprenticed 1685 to Jno. Stanley, C.C. Ben., apprenticed 1691 to Isaac Goddard; C.C. 1701 ; long-case clock by him in the Mosque of Achmet, Constantinople. Stephen, C.C. 1727; long-case clock, about 1740. Nicholas, Newark; maker of lantern clocks; died 1741. Francis, 49 Oxford St., 1792; 8 Rathbone Place, 1794-1825. T., 28 Pitfield St., 1814 ; 20 New Gloucester St., Hoxton, 1835. Of U.S.A. : Luther, Shrewsbury, Mass.; between 1809 and 1817 he manufactured watches.

Godeau, see Lestourgeon.

Godemar, Frères, Geneva ; virgule watch, about 1910. Mons. E. Gélis; see also Pouzeirt.

Godfrey. Jno., apprenticed in 1682 to Jas. Hatchman, C.C. Henry, C.C. 1685. "A pretty large-sized Pendulum-watch in a Tortoiseshell Case ; it shews the Hours and Minutes with a Sun and Moon Dial Plate, made by Henry Godfrey, London " (Lond. Gaz., Oct. 7-10, 1700). Wm., Winterton, 1773; succeeded by his son Wm., see Tate, Thos. George, 22 Charterhouse St. 1835. \& Storer, 19 Princes St., 1860.

Godlyman, Peter, Hurley ; clock, brass dial $5_{\frac{1}{2}}$ in. square, lantern movement, about 1700 .

Godon, -, clock, about 1750 , signed "A. L. Godon, R. de Camera de S.M.C.," M. Spitzer.

Godon, -, Paris, 1780-90; appointed horloger to the Court of Spain in 1786 ; splendid clock in vase-shaped case of Sèvres porcelain, painted with birds in a medallion, and mounted with handles formed as caryatid figures, dating from about 1785 , which was in Lord Strathallan's collection, fetched 2,000 guineas at Christie's in 1902.

Godwin. John, 161 Strand, see Goodwin. Jas., 304 High Holborn, 1801-42.

Goff, Thos., 8 Rosoman St., 1793.

Golay, Télémaque, Geneva, 1831-1920. C. H., Clerkenwell, 1869-1911, a clever horologist specializing in complicated watches, died in Switzerland 1920, aged 70 .

1843.
Gold. Christopher, London ; watch, B.M., gold repoussé case, about 1760 . Rich., London ; watch, h.m., 1772. John 118 Fleet St., 1806-19.

Golding, J., 55 Cornhill, 1775.

Goldney, Thos., 4 St. James's St., 1815-25.

Goldsborough, Geo., Scarborough, 1775

Goldsmith. John, C.C. 1681. Thos., apprenticed in 1683 to Wm. Brafield; C.C. 1692 . William, C.C. 1719 . John, C.C. 1720 .

Goldsworthy, E., Chelsea, 1820.

Golledge, Richard, Stratford, 1835.

Gom, David, I,yons ; maker of a watch cased in jacinths, about 1650 .

Gomps, - , hexagonal watch, silver case, signed "Gomps à Armstrand, 1586."

Gondoux, Jno., London; watch, 1780.

Gooch. ( \& Harper, 12 Red Lion St. Clerkenwell, 1810-13.) Jno., 25 Banner St., 1814-18. Albert, 13 Red Lion St., Clerkenwell, 1816-25. 'Wm., Bunhill Row, 1825. H., 25 Coppice Row, Clerkenwell, 1830.

Good. John, author of "The Art of Shadows ; or, Universal Dialling," 2nd ed., London, 1711 ; C.C. 1678 . John, 305 High Holborn, 1780-94.

Goodall. Geo., Micklefield ; long-case clock, square dial, about 1720 . Jas., London ; watch, 1779. Chas., 26 Bridges St., Covent Garden, 1793-1818.

Goodchild, John, C.C. 1726.

Goode, Charles, brother C.C. 1686; bracket quarter clock and also very fine long marquetry case clock, about 1690 , Wetherfield collection.

Goodfellow. Wm., 378 Oxford St., 1793. William, Philadelphia, 1797.

Goodfriend, John, London; bracket clock, about 1750 .

Goodhall, Geo., Aberford, 1775.

Goodhugh. R. \& B., 2 Welbeck St., Cavenidsh Sq., 1825-35. William, 126 Regent St., 1825. Richard, 32 Edward St., Portman Sq., from 2 Welbeck St., Cavendish Sq., 1840-42.

Gooding, Henry, Boston, U.S.A., 1810-30. William, associated with Messrs. Rotherham \& Sons of Coventry for forty years, died at Boscombe, 1917, aged 75 .

Goodlad, Richard, admitted as a brother C.C. 1689 .

Goodlin, Peter, admitted C.C. 1637.

Goodman. Timothy, Towcester ; lantern clock, about 1680. Geo., London, 1771 ; fine repeating watch, Pierpont Morgan collection; watch in case of red agate, about 1780. Pierpont Morgan collection; another watch, about 1785 . H. N., London; watch, 1820 . J. \& Son, I New Chappel Place, Kentish Town, 1840-42. 
Goodrich. Wm., apprenticed in 1689 to Amos Winch, C.C. Simon, received a reward from the Society of Arts in 1799 for an improved escapement.

Goodwin. Wm., apprenticed in 1675 to Jno. Harris, C.C.; lantern clock, about 1700 , inscribed " Wm. Goodwin, Stowmarket"; watch, about 1720 , with the following on a paper in the outer case :-

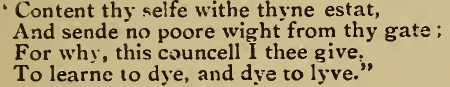

Content thy selfe withe thyne estat,

And sende no poore wight from thy gate;

For why, this councell I thee give.

To learne to dye, and dye to lyve."

Thos., London ; watch, about 1760 . John, 70 Strand, 1770-1800. James, watch and clock enameller, 37 Red Lion St., Clerkenwell, 1810-40. Hy., Newark, 1820-42.

Goodyear. John, Shoe Lane ; C.C. 1722. Joseph, Shoe Lane; C C 1732.

Gordon. John, Black Spread Eagle, Ludgate St. ; C.C. 1698 ; bracket clock, black case, arch dial inscribed " John Gordon, London," on oval silvered plate, 1698-1712. Robert, Edinburgh; an eminent maker; admitted freeman of the Incorporation of Hammermen in 1703 , atterwards " boxmaster" or treasurer; was also captain of the trained band for protecting the city; a chiming clock by him in the Bank of Scotland, another in the possession of Mr. L. W. Auchterlonie, Amhurst Park, Stamford Hill ; 1703-30. Thos., Edinburgh, 1703, f. ; long-case clock, arabesque marquetry, about 1710 Patrick, Edinburgh, 1705-17. Thomas, "from London " ; opposite the Merchants" Coffee House, New York, 1759. Alex., Dublin; watch, about 1750 . Jas., Beith, 1780. William, 15 Cross St., Islington, 1794-1805. \& Fletcher, Dublin ; watch, 1795. Alex., 336 Strand, 1815-19. Jas., London; watch, 1842. Theodore, Great James St., Bedford Row ; born at Barbados; apprenticed in Aberdeen ; horizontal and duplex escapement maker, also assistant of B. L. Vulliamy, sometime editor of the Horological Journal; died 1870 , aged 81 .

Gore, Wm., Dublin ; watch, 1770.

Goret, Jean, Rue Courture Ste. Catherine, Paris ; garde-visiteur, 1769.

Gorham, Janes, High St., Kensington, 1815-42.

Gorsuch. Thos., Salop; watch, 1720. Thos., watch pillar maker, 199 St. John St., 1792.

Gosler, Thos., 51 Fore St., 1815-19.

Gosling. Richard, apprenticed in 1649 to Thomas Claxton, C.C. Richard \& Son, 55 Cornhill, 1765-75. Rokert, 160 Fenchurch St., 1770-85. Joseph, 55 Cornhill, 1775-85. Wm., watch-case maker, 4
Corporation Row, 1793. Thos., watch-case maker, 3 Staining Lane, 1793.

Gosse. Jno., apprenticed in 1662 to Richard Scrivener, C.C. Jeremiah, C.C. 1667.

Gosselin, J. Ph., Rue St. Honoré, Paris ; clock, about 1760; garde-visiteur, 1769.

Gossoin. In 1667 he constructed the clock at Val de Grace, for which he received 3,000 livres.

Gostage, Sam., Birkenhead, 1833.

Goubert, James, admitted C.C. 1890.

Gough. Wm., Devizes ; watch, 1720, in each of the pillars a niche containing a silver statue. Wm., London; watch, 1745, also curious touch watch, G.M., about 1760 ; in this a push piece at the pendant drove a rod against a snail pivoted to the plate, and turned by a pin in the cannon pinion.

Gougy, Pierre Frederick, Tavistock St., Westminster; bracket clock at Windsor Castle, about 1830 ; patented in 1839 (No. 8,308 ) a supplementary second hand, so adjusted by mechanism that it may be stopped while the other second hand is going, and on being set free will recover its original position, and rotate as before along with the other.

Goujon. Jean, Paris ; cruciform watches, about 1590. Stephen, Seven Dials ; C.C. 1725. Peter, London; watch, 1735. Samuel, 42 Newgate St. ; master C.C. $1760 ; 1752-94$.

Gould. Christopher, C.C. 1682 ; in the Wetherfield collection are long-case clocks by him : one with bolt and shutter maintaining power, $10 \frac{1}{2}$-in. dial, in marquetry case with finely carved pediment, about 1685 ; another, exceedingly small, repeats the quarters on five bells, dial $7 \frac{5}{8}$ square, burr walnut case with domed hood, about 1690 ; watch, Pierpont Morgan collection, about 1700 . " Supposed to be drop'd in a Hackney coach on the 4th inst., a gold watch in a black shagreen case, made by C. Gold, the word 'Friendship' graved on the Movement " (Lond. Gaz., March 18-21, 1694). Mr. Jno. T. Trotter had a longcase clock by him of later date. Abel, C.C. 1683 . "Lost on the 28th inst., a gold watch with two movements, having a black filagreen case studded like shells, made by Abel Gould " (Lond. Gaz., March 26-30, 1691). Thos., London; watch, 1780. Chester, Red Lion St., Clerkenwell : he patented in 1803 (No. 2,706) a nautical time glass, 1780-1803.

Goullons. à Paris; watch by him in Guildhall Museum, short train, escape wheel of 17, handsome enamelled case, $1 \frac{1}{8}$ in. in diameter, and $\frac{1}{2} \mathrm{in}$. thick, abcut 1660 , see Crofts à Marseille ; fine enamelled watch, about 1670 . 
Gourdain à Paris; watch about 1720 , Mons. E. Gélis.

Gourlay, Alex., London ; watch, 1785.

Gounouilhou, Geneva. Simon \& Francis, about 1825; very thin watches marked "Tissot Gounouilhou," about 1842.

Gout. Ralph, 6 Norman St., Old St., 1770-1800; 122 Birchin Lane, 1815; he patented in 1799 (No. 2,351) apparatus for recording the paces made by man or horse, also an application of the invention for recording the revolutions made by the wheels of a carriage; Mr. Thos. Boynton has a bracket clock by him, mahogany case, silvered dial, engraved with festoons, \&c., quarters chimed on eight bells, see Recordon. David Ralph, 122 Bunhill Row, 1830-42.

Gouthière, -, Paris ; celebrated chaser and gilder of clock cases; from 1740 (see p. 451 ).

Gow, Wm., London; watch, h.m., 1787.

Gowerth, John, Oxford, 1701.

Gowland. Clement, Sunderland, 1775. Thos., 15 Bishopsgate Without, 1834; 5 Leadenhall St., 1838-42. James, 11 Leathersellers' Buildings, London Wall, 1835 ; London Wall, 1860 ; died 1880 ; in 1837 he patented (No. 7,456$)$ a device for communicating motion to a balance through the balance-spring.

Grace. Wm., Cronton; sun and moon watches, about 1695. Thos., London ; bracket clock, about 1720, Major W. G. Thorold.

Gradelle, -, London ; watch, Schloss collection, about 1740 .

Graet, Philip, Lintz; fine travelling watch, about 1695 .

Grafton. John (alias Solomons) ; in 1831, on the passing of an Act of Common Council permitting the admission of Jews to the freedom, C.C. withdrew opposition to his election. J. \& E., 42 Coleman St., 1834 ; 81 Fleet St., 1838-42 ; afterwards Edward Grafton, who published a small historical review of horology. Henry, 18 Barbican, 1840.

Graham. George, "honest George Graham," a most eminent clock and watch maker (see p. 295-303) ; C.C. 1695, master 1722 ; died 1751 , aged 77 , a Quaker. Mr. Hansard Watt has a longcase clock and small travelling alarm clock by this maker (see pp. 299-300). William, at the Dial in Lombard St. ; a good maker; fine repeating watch, Mrs. H. Sidebottom, S.K.M., 1724; long-case clock, Wm. Graham, London, about 1730. D., London; watch, 1798. James, 85 Piccadilly, 1800-5. Jas., London; watch, 1825. Frank, Newcastle-on-Tyne, died 1855.
Grainger, Richard, apprenticed in 1685 to Francis Munden, C.C. -, Holborn Hill ; watch, 1830.

Gramot, G., Paris ; watch in enamelled case, Pierpont Morgan collection.

Gran, -, Fleet St., watch, h.m., 1776.

Grand, John, 3 Cockspur St., 1780-1800; see Fisher, Isaac.

Grandeau, - oval watch, about 1590 , signed "Grandeau à Paris," Garnier collection.

Grandin, Jno., 2 Macclesfield St., Soho, 1815-19.

Grandjean, David Henry, Locle, died 1845. Henry, Locle, born 1803, died 1879 .

Granger, Richard, C.C. 1695.

Grangier (French), about 1650 .

Grant. Wm., London; watch, 1740. Richard, London; bracket clock, 1760. John, 75 Fleet St. ; apprenticed to Alexander Cumming, whose nephew he was; hon. freeman C.C. 1781, warden 1810, when he died; several specimens of his work are in the Guildhall Museum. John, 75 Fleet St., son of the preceding, and an equally celebrated maker; C.C. 1817, master five times 1838-67; he left Fleet St. in 1852 , and for some years carried on a pawnbroking business in London Wall which had been bequeathed to him; he died 1882 , aged $85 ;$ he was succeeded in Fleet St. by Henry Banister. Chas., London; watch, 1800 . Joseph, Chester, 1814-18. Jesse, 16 Woodstock St., 1830. Henry, 9 Finch Lane, 1835. William, 36 Haymarket, 1835. \& Terry, 35 Prince's St., 1840.

Grantham, J., London, 1750-70.

Grape. Richard, apprenticed in 1685 to Jno. Wheeler, C.C. John, London ; watch, G.M., 1737.

Gratrex, Edward, Birmingham longcase clock, about 1750 .

Graupner, J. G., clock, Green Vaulted Chambers, Dresden, about 1700.

Grave. Joseph, apprenticed in 1687 to Joseph Williamson, C.C. Geo., 271 Whitechapel Rd., 1815-42.

Gravell. (\& Tolkein, successors of Eardley Norton), 49 St. John St., 17901820 ; in 1817 they made a new clock for Winchester Town Hall, the cost of which was borne by the Powlett Family. William \& Son, 49 St. John St., 1820 ; later and till 1850 at 29 Charterhouse Sq. ; W. Gravell, master C.C. 1840 ; well-known watchmakers; in the outer cases of their watches were papers with the equation of time printed round the edge; they were succeeded by Robert Rolfe.

Graves. Jas., C.C. 1675. Benjamin, C.C. 1716 , master 1705 , clerk 1719 ; died 1731 ; Wm. Neighbour apprenticed to 
him, 1678. Wm., York, f., 1730. Hy., 25 Goswell Terrace, 1835.

Gray. Timothy, brother C.C. 1633. Jno., apprenticed in 1680 to Jno. Westoby, C.C. ; long-case clock, "John Gray in Johnson's Court, Londini, fecit," about 1705. William, apprenticed in 1691 to Peter Lodowick, C.C. ; watch, about 1730 , belonging to M. Chas. Sivan, is inscribed "Wm. Gray, Bond St., London." Benjamin, Pall Mall ; clockmaker to George II. (see p. 370) ; in the G.M. is a gold repeating watch by him, which was made for Sir Peter Somes in 1732; extra large longcase clock, with dead-beat escapement, about 1730, Wetherfield collection, 1720-60. \& Vulliamy, Pall Mall (see p. 370), 1746-60. Jas., London; watch, 1756. Jos., Durham, watch, 1777. Jno., 68 Leadenhall St.; apprenticed to Thos. Hardy ; C.C. 1769 ; watch by him, .G.M., 1769-1817. \& Constable, Sackville St.; makers of a thin verge watch decorated with enamel and jewels, G.M., about 1780 . Thomas, 25 Strand, 1780; 42 Sackville St., 1793. James, Edinburgh ; long mahogany case clock, Sheraton style, about 1790, Wetherfield collection. Adam, 17 Berkeley St., Clerkenwell, 1788-1812. Robert \& William, 13 New Bond St., 1793 ; William, 1800-28. T. J. \& G., 25 Strand, 1800-5. G. \& W., 114 Fleet St., 1830.

Graye, -, subscribed $£^{2} 10$ s. for incorporation of C.C. 1630.

Grayham. Timothy, Workington, 1770 Chas., London; watch, 1810.

Grayhurst. B., London; watch, 1778. P. \& M., 65 Strand, 1785-1800. \& Harvey, 65 Strand, 1810-30. Harvey, Denton \& Co., 64 Strand and 128 Regent St., 1835-40.

Grayson,Wm., Henley-on-Thames, 1826. Greatorex. Ralph, C.C. 1653. Henry, C.C. 1711 ; in the Postman, 1710, is an advertisement for a silver pendulum watch, lost in White Conduit Fields, for which Mr. Greatorex at Bushby's Folly offers a guinea reward, 1710-11.

Greaves. Samuel, London ; marquetry long-case clock: square dial, about 1720 . Wm., Newcastle, 1760. Robert, Macclesfield, 1770. S., Mansfield, 1770. Thos., 92 High St., Birmingham, 1770. Wm., York, died 1796.

Grebauval. Jérôme, watch, B.M., about 1600. Robert, Rouen; fine octagonal watch, G.M., about 1620 .

Grebauvel, Hiérosme, Lyons ; oval watch, Soltykoff collection, about 1595 .

Grebay. Phillipe, à Londres; watch, about 1610. Phillipe, Paris ; alarm watch, S.K.M., about 1670 .

Greblin, see Gribelin.
Green. Geo., apprenticed in 1661 to Matt. Crockford, C.C. James, Morefields ; C.C. 1664 ; lantern clock.with handsomely chased dial. Edwd., apprenticed in 1682 to Thos. Davis, C.C. Nat., apprenticed in 1688 to Dan Beckman, C.C. Peter, Liverpool, about 1695. Jno., London ; sheepshead lantern clock, about 1700. Joseph, C.C. 1723 ; long-case clock signed "Jos. Green, North Shields," about 1730. Jno., St. Martin's Court, 1750-70. Joseph, North Shields ; bracket clock, about 1750 , Mr. E. C. Cheston. James, 5 Fenchurch St. ; calendar watch, pinchbeck, set with garnets, Hilton Price collection ; Ludlam, in 1755 , refers to him as a watchmaker and seller of tools; master C.C. $1784 ; 8$ Philpot Lane, 1794. Richd., Richmond, Yorks, 1760. George Smith, " an eccentric watchmaker of Oxford, with a turn for literature." died 1762. Margaret, St. Martin's Court, Leicester Sq., 1765-71. \& Aldridge, 62 St. Martin's-le-Grand, 1765-85; Henry Green, livery Clothworkers' Company. Robt., Lancaster, 1767, f. Joseph, North Shields, 1770. Geo., Leicester, 1775. Samuel, 112 Bunhill Row, 1788-1800. Edwd., 10 King's Stairs, Rotherhithe; watch for the Turkish market, Schloss collection, about 1790. \& Bentley, makers of a very complicated long-case musical and astronomical clock, about 1790. Joseph, tools, 129 Whitecross St., 1793. \& Ward, 1 Ludgate St., 1793. John, Philadelphia, 1794. Robt., London : watch, 1798. Ward \& Green, 1 Ludgate St., 1800 ; 20 Cockspur St., Pall Mall, 1817-38. Abraham, London; watch, 1804. Wm., Grantham; watch, 1830. J. \& Son, 94 Hatton Garden, 1830. Thos., 30 Rahere St., 1835; 9 Lower Ashby St., Northampton Sq., 1842. Henry, 10 Quebec St., 1835-42. Robt., 20 Cockspur St., 1842.

Robert (also S.), Bristol, 1844.

Greenaway. Richard, Whitecross St. ; C.C. 1718. Wm., Cripplegate ; C.C. 1730 Geo., Bath, 1798. John, 54 Bath St., St. Luke's, 1842. John, 4 St. John's Sq., 1842.

Greene. James, apprenticed to Henry Jones ; C.C. 1685. John, C.C. 1711.

Greenhill. Nat., apprenticed in 1674 to Edwd. Clough, C.C. Richard, freeman of the City of Canterbury by redemption, 1676 ; long-case clock, Mr. Alfred Grimes. Samuel, Canterbury, apprenticed to Richard, his father, 1707 . Charles, watchkey maker, 12 Great Sutton St., 1842.

Greening, Chas., Bristol, 1844.

Greenough, N. C., Newburyport, U.S.A., 1848.

Greensill. Joseph, 36 Strand, 1775-1800. Edwd., 34 Strand, 1793.

Greenwood, G. 12 Hanway St., 1817. 
Gregg. Francis, apprenticed to John Clowes, 1691 ; in the Wetherfield collection is a long-case clock with a remarkably fine dial having a revolving equation of time calendar showing through an aperture below the centre; above the centre is the inscription, "Fran. Gregg, Covent Garden." "Francis Gregg, watchmaker, is removed from the Dial in Russell Street, Covent Garden, to the Dial in St. James St. over against the Palace Gates" (Lond. Gaz., October 11-23, 1714). In the G.M. is a repeating watch by him with silver cap, 1698-1715. Rd., London, about 1730. Wm., London ; watch, 1796.

Gregoire, P., à Blois ; striking watch about 1620.

Gregory. Jeremie, at ye Royal Exchange ; early oval watch by him, Stamford Institution; C.C. 1652, master 1665 , 1676 ; died 1685 ; a good maker of lantern clocks and watches ; in Mercurius Publicus, 7 th May, 1663, is advertised a gold watch lost. "Give notice to Mr. Gregory, watch maker, near the Castle Tavern in Cornhill." In the Lond. Gaz., Oct. 13, 1678, he advertises for Nestor Holmes, aged 18, a runaway apprentice. "A silver watch with a String, made by Jeremiah Gregory, showing the days of the month, the Box engraven with the King's Picture in the bottom " (Lond. Gaz., March 29, 1680). Mr. John H. Baker has a lantern clock, inscribed " Jeremie Gregorie at the Royal Exchange." Thomas, C.C. by redemption 1671. Robert, C.C. 1678. Jeremiah, C.C. 1694. Jno., Upton Magna, 1760. Jas., Ormskirk; watch, Debaufre escapement, Guildhall Museum, about 1765.

Gregsby, Edwd., clock, 1685.

Gregson. Philip, apprenticed in 1663 to Ahasuerus Fromanteel, junr., C.C. Pierre, Paris, horloger du Roy; watch, case finely enamelled, medallion with figure painting in centre, surrounded by a border of royal blue, 1780-90; watch, about 1795, signed Gregson à Geneva. John, watchmaker to the Prince of Wales, 36 Bruton St., Hanover Sq., 1794-1800. \& Jefferson, 36 Bruton St., 1800-5. Jno., Lancaster, 1818.

Grendon, Henry, at ye Exchange ; admitted C.C. 1640 ; watch, S.K.M., about 1610 ; another watch inscribed "Henry Grendon at Exchange, Fecit," not later than 1630, Pierpont Morgan collection.

Grennell, Richard, maker of a fine longcase clock, about 1750 .

Gretton. Chas., The Ship, Fleet St. ; apprenticed to Lionel Wythe in 1662 ; C.C. 1672 , master 1701; an eminent maker; to him was apprenticed in 1697 the celebrated Henry Sully; in the Wetherfield collection are a lantern clock, a bracket clock repeat- ing the quarters on six bells, and three long-case clocks by Chas. Gretton. " Lost the 24th Instant, a Gold Pendulum watch in a gold Fillegreen case, with a plain shagreen case over it, the name Charles Gretton, London, with a round Pendulum Spring, a steel chain, and Tulip Pillars, the Dial Plate straight, and a small long Hand to show the Hour. Whoever gives notice of it to Mr. Charles Gretton, Watch Maker in Fleet Street, shall have two guineas reward" (Lond. Gaz., March 2, 1683). " Lost or taken away the 13th Instant at night out of a Gentleman's Pocket, a gold watch, with a gold chain to it, the case studded with gold, of $\mathrm{Mr}$. Gretton's making, watchmaker living in Fleet St. over against Sergeants Inn Gate. Whoever brings the aforesaid watch to Mr. Fowles, goldsmith, at the Black Lyon in Fleet Street, shall have five guineas reward" (Lond. Gaz., Jan. 18, 1685-6). "Taken away the 2nd Instant at night by two Highwaymen, a large silver watch by Charles Gretton, London. If the said watch be offered to be sold, Pawned, \&c., you are desired to stop the watch and Party, and give notice to Mr. Charles Gretton at the Ship in Fleet Street, and you shall have a guinea reward " (Lond. Gaz., Sept. 20, 1697). William, of Black Fryers; maker of a lantern clock, balance escapement, dolphin frets, about 1665 .

Greville, Jno., apprenticed in 1675 to Jere. Gregory, C.C.

Grey. Joseph, Durham, 1765. John, 68 Leadenhall St., 1823-30.

Gribelin. Abraham, Blois ; in the B.M. is a watch by him, dated 1600 ; another, S.K.M., 1614 ; afterwards at Paris ; clockmaker to the King, 1631. Nicholas, Paris ; square watch, about 1600, Pierpont Morgan collection; very small oval watch in crystal case, with enamelled gold mounting, Garnier collection, early seventeenth century. Simon, C.C. $1686 . \quad$ N., Paris; watch by him, B.M., case finely enamelled by Muisard, about 1700 ; lateseventeenth-century French watch, in brass case, signed "Gribelin à Paris," S.K.M.

Grice. Thomas, 1675. Wm., apprenticed in 1687 to Mordecai Fox, C.C. Job, Lancaster, 1797-1830.

Gridin (or Gredin), Paris ; watch, Pierpont Morgan collection, about 1750.

Griell, Sam., apprenticed in 1648 to Peter Bellune, C.C.

Griffin. John, Noble St. ; C.C. 1720. \& Adams, 76 Strand, 1800-23. Francis, 25 Gloucester St., Clerkenwell, 1820-42. G., 30 King St., Clerkenwell, 1835. 1782 . 
Griffith. Jas., C.C. 1667. Robt, London; C.C. 1706 ; watch, 1725 . Wm., Shoe Lane ; C.C. 1720. Richard, London; long-case clock, 1790. R., Denbigh; watch, 1830. J. W., 15 Wentworth Place, Mile End Rd., 1840-42.

Griffiths. Edward, River St., Islington ; livery C.C. 1810. Nehemiah, Chester, 1833. \& Son, 1 Ireland Row, Mile End Rd., 1835.

Grigg, Jno., apprenticed in 1684 to Edwd. Hunt, C.C.

Griggs Richd., C.C. about 1660.

Grignion. Daniel \& Thomas, fine repeating watch with beautifully enamelled case, about 1730 ; another watch in the Dunn Gardner collection bears the hall mark for 1748; a clock in the possession of Mr. Eden Dickson is inscribed "Dan. and Tho. Grignion from the late Mr. Quare." "Thos. and Danl. Grignion, finisher to the late Mr. Danl. Quare, at the King's Arms and Dial in Russel Street, Covent Garden," card, Hodgkin collection. \& Son, Russell St., Covent Garden, 1775 ; spring clock with peculiar dead-beat escapement, G.M. (see p. 599). Thomas, 7 Great Russell St., Covent Garden (see p. 599) ; a watch by him with a repoussé case in S.K.M. ; small travelling clock dated 1780, Major R. H. Raymond Smythies; died 1784, aged 71 . Thos., 7 Great Russell St., Covent Garden, 1800-25.

Griliat, - In 1729 had a project for stamping dial-plates for watches, discouraged by C.C. as being detrimental to engravers.

Grimadell. - , Holbeach, 1760. Peter, Stamford, 1770.

Grimalde. Peter, 431 Strand, a celebrated chronometer maker, 1800-10. \& Johnson, 431 Strand, 1815-25; see Anthony, Wm.

Grimar à Ath ; clock, about 1730 .

Grimes. Edwd., apprenticed 1640 to Elias Allen, C.C. Thomas, C.C. 1671. William, C.C. 1682; long-case clock, Dutch marquetry, about 1700.

Grimley, William, C.C. 1694.

Grimshaw. Jno., Liverpool, 1814. James, 146 Goswell St. ; died 1846, aged 43. William, senr., 130 Goswell St. ; died 1851, aged 80. William, a Quaker, eldest son of W. Grimshaw, senr., Goswell Rd. ; died 1853, aged 54. Frederick, Goswell Rd. (Grimshaw \& Baxter); died 1893, aged 77 .

Grimstead, Thomas, St. Paul's Churchyard, 1753-63.

Grindley, William, 32 Crown St., Moorfield, 1820.

Grindon, W., 7 Tabernacle Walk, 182030 ; watch paper with the following lines :-
“ Canst thou recover thy consumèd flesh

From the well-feasted worms, or put on fresh?

Canst thou redeem thy ashes from the dead,

Or tree thy carcass trom its sheet of lead?

Canst thou awaken thy earth's closed eyes?

Or yet unlock thy monument and rise?

All this thou may'st perform with as much ease

As to repent, ye mortals, when ye please."

Grinkin. Robert, C.C. 1632, master 1648, 1654; died 1660 (p. 253). Edwd., petition C.C. 1656.

Gritting, Jno., London ; long-case clock, about 1750 .

Grizell, John, C.C. 1687.

Gro, Wm., Rotterdam; watch, about 1770.

Grocot, Thos., Liverpool ; a watch by him with Manx crest on cock, 1780.

Grohe, James (succeeded Haley), 7 Wigmore St., 1834-42, see Pennington.

Grollier de Servière, Nicholas, born at Lyons in 1593; maker of many curious clocks and automata; died, aged 93.

Gros, - Paris, 1780.

Grose. Richard, C.C. 1632. Anthony, C.C. 1658 .

Grosrey, Calestin, 74 Newgate St., 1838-42.

Gross, Philip, 12 Panton St., 1817.

Grossmann, Moritz, Glashütte, Saxony ; winner of the prize offered in 1863 by the British Horological Institute for the best essay on the lever escapement. A very capable horologist ; born 1826, died 1885 .

Grosvenor \& Jones, 85 Wardour St., 1815.

Grotz, Isaac, Easton, U.S.A., 1810-35.

Grounds, Jonathan, Lordon ; watch, Nelthropp collection, about 1690.

Grounet, S., Amiens, 1650.

Grout, William, C.C. 1660.

Grove. Thomas, C.C. 1715. George, 95 Wood St., Cheapside; C.C. 1715. Wm., watch, 1781. Richard, 93 Wood St.; livery C.C. 1786 ; 1770-1817. W. R., partner with Myles Brockbank; C.C. 1811-15.

Grover \& Co., 10 Greek St., 1817.

Groves. George, 105 Bishopsgate St., 1790-95. Wm., Leeds, 1829.

Gruber, Hans, Nuremberg; clockmaker and master of the Locksmiths' Guild in 1552; died 1597. Michel, Nuremberg, 1600 .

Gruet, -, a Swiss, inventor of fusee chain, 1664 .

Grundy, J., Whalley, 1760.

Gruse in Wien; watch so signed, about 1840.

Guardsell, -, London ; long-case clock, about 1770 .

Guay, see Le Guay.

Gudgeon, Jno., Bury ; watch, 1794.

Gudin, Jacạues Jérôme, Quai des Orfèvres, Paris, 1769; clock by him at Windsor Castle, about 1770 (p. 430). 
Guepin, Jno., apprenticed 1687 to David Minuel, C.C. ; bracket chiming clock inscribed "Peter Guepin," about 1750, Mr. G. F. C. Gordon.

Gueriman, G., London ; watch, about 1720 , Mr. Horace L. Wheeler, Boston, Mass.

Guerint, Francis, Geneva ; said to have invented engine turning, about 1780.

Guest. Georgius, 30-hour long-case clock, abjut 1690. Geo., Aston, 1760. Jno., 64 Fleet Market, 1816.

Guex, Paris; watch, 1790.

Guibet l'Aîné à Paris; clock, Jones collection, S.K.M., about 1790 .

Guidon \& Co., Paris, 1795.

Guiguer, -, London ; watch, about 1750 ; another about the same date signed "Guiguer, Amsterdam."

Guillaume. E. T. \& George, 16 Myddelton Sq., 1836-45. E. \& C., 16 Myddelton Sq., 1846-65. Louis Alex., 24 Spencer St. ; died 1873, aged 59 .

Guillemot, -, London; about 1810.

Guillin à la Charité ; watch, about 1690 , Mons. E. Gélis.

Gullock, Philip, 31 Minories, 1790-95.

Gunston, John, London ; bracket clock, about 1750 .

Gunter. Hildesley, apprenticed in 1693 to Jno. Eagle, C.C. R., Queen St., May Fair, 1790-95.

Gurden, Benjamin \& Son, 144 Wood St., 1775. Benj., 1794.

Gurney, Ezekiel, apprenticed in 1692 to Edwd. Speakman, C.C.

Gutch, John, C.C. 1673.

Gutheridge, William, C.C. 1728. 1770.

Guthrie, 一, Glasgow ; clock, about

Gutteridge. John, 54 Coppice Row, 1835. Chas., Bath, 1850.

Guy. Samuel, apprenticed in 1692 to Jno. Andrews, C.C. ; fine long-case clock, decorated with Oriental lacquer work, about 1730 ; another clock by him belongs now to Mr. Wm. Craig, Detroit, U.S.A. Henry, C.C. 1702. Charles, C.C. 1714. Jno., Liverpool, 1770. Edwd., 49 Rahere St., 1830 ; 19 Powell St., King's Sq., 1842. E., Devizes, 1844.

Guydamons à Paris ; clock, about 1750 . M. Ch. Mannheim.

Guye, Auguste, a pioneer of machine watchmaking in England; born at St. Olivier, Switzerland, 1835; settled in London 1856, where he died in 1893.

Guyerd, - Paris; watch, 1812.

Gwillim, Eli, brother C.C. 1647.

Gwinnell, J., 34 London Rd., 1812-15.

Gyott. Abraham, C.C. 1648. Abraham, apprenticed in 1648 to Abraham Gyott, C.C.
Haas-Privat, I., Geneva ; died 1881.

Habel, watch, gold case in the form of a mandoline, enamelled white and blue, signed "Joh. Georg. Habel à Güngs," about 1790 ; Pierpont Morgan collection.

Habert. James, C.C. 1682. David, Strand; C.C. 1730.

Habrecht. In 1571 the mechanical construction of the Strassburg clock was entrusted to Isaac Habrecht, a clockmaker of Schaffhausen, Switzerland, and his younger brother Josias (see p. 41); before this work was begun Josias migrated to Cologne, having been summoned by the Elector to make a clock for the castle of Kayserswerth. Of other clocks constructed by Isaac an example is given on p. 55 . He died in 1620, aged 76. Michael Isaac Habrecht restored the Strassburg clock in 1669 , and Jacques $\mathrm{S}$. made a further restoration in 1732 . Skull watch by Daniel Habrecht, about 1630.

Hack, Grace, apprenticed in 1692 to Jas. Jenkins, C.C.

Hackett, Simon, Royal Exchange ; C.C. 1632 ; master 1646-60 ; watch with movement 1 in. in diameter, pierced square pillars; dial of metal with a raised hourband; outside of it an engraved border with the figure of a cherub over the XII. inside the hour-circle a view of Old London Bridge, tolerably well engraved. Case ornamented in high relief, and enclosed in an outer case of shagreen ; movement exceedingly rough, and on the top plate, partly hidden by the balance-cock, an inscription, "Simon Hackett, of the Royall Exchannge, fecit," the form of the letters being as fanciful as the spelling; in the S.K.M. are an alarm watch by him, in a pierced and engraved silver case, and one in an enamelled case ; watch, about 1635, in enamelled case, Pierpont Morgan collection.

Hackings, John, successor to Henry Haines. Ludlam in 1759 wrote, " has worked for me constantly since midsummer, 1753; all my best tools were made by him ; whatever has been done by him may be depended on."

Hackney, Thos., London ; chime clock, 8 bells, about 1740 .

Haddack. Wm., 14 New Bridge St., Bath, 1798-1800. \& Lansdown, Pulteney Bridge, Bath, 1832; afterwards George Lansdown.

Haden, Thos., clock, about 1720.

Hadley, Humfrey ; received in $1708 £ 16$ from the churchwardens of Aston, near Birmingham, for a new clock.

Hadwen, -, Kendal ; clock, about 1710. In each corner of the dial was engraved one line of the following verse, "Winged 
Time, Will not stay, Fleeting hours, Glide away."

Haehnel, C. H., London; repeating watch, decorated with portraits of Joseph II. and his family; Pierpont Morgan collection, about 1780 ; there is no hall mark in the case.

Hager. Johan Georg, Neüs ; clockwatch, about 1725 . \& Wolffenbutel; watch by them, about 1730 , mentioned by Thiout.

Hagger, James, Grove Hall Lane, square bracket clock, Japanese case, cherub corners to dial, pull repeater, style about 1700.

Hague, Jas., London ; watch, 1760.

Hahn, Mathias, Stuttgart ; designer of clocks; born 1739.

Haines. Francis, admitted C.C. 1706. Hy., " an excellent workman " ; worked for Ludlam from 1747 to 1753 , when he was succeeded by John Hackings. Robert, Oxford, 1775. C., Swindon, 1870. Jno., 49 Northampton St., Clerkenwell, 1835.

Hair. George B., 129 High St., Borough, 1835-42. Wm., Birmingham ; clock movement, S.K.M., dated 1809 , in Italian case, dated 1592.

Hairl, Jno., Horselydown, 1817.

Halaicher, Mathias, Augsburg; watch, about 1650 .

Hale \& Broadhurst, 81 Cheapside, 1800-5.

Haley. Sam., apprenticed in 1657 to Jno. Hillersden, C.C. Thos., Norwich, 1750. Thos., London, 1781. Charles, 7 Wigmore St. ; a celebrated maker, hon. freeman C.C. 1781 ; patentee of a remontoir escapement for chronomters 1796 (No. 2,132). He was one of the experts appointed by the select committee of the House of Commons to report on Mudge's chronometers in $1793 ; 1770-1800$. \& Milner, 7 Wigmore St., 1800-15. \& Son, 7 Wigmore St., 1832; see Grohe.

Halford, Robt., 3 Old Orchard St., St. Luke's, 1823.

Halifax. John, London, 1759 ; watch inscribed " G. Washington to Gilbert Mortier de Lafayette, Lord Cornwallis's Capitulation, Yorktown, December 17th, 1781." Sam. Joseph, London ; watch, silver cock and name-plate, $\mathbf{1 7 7 5}$; watch, "Halifax London," Fitzwilliam Museum, Cambridge.

Halked, Thomas, C C. 1702.

Halksworth, William, 58 Fleet St., 1840-42.

Hall. Ralph, C.C. 1638. Christopher, apprenticed in 1646 to Simon Bartram; C.C. 1655. Peter, C.C. 1648. Jno. Baptist, apprenticed in 1669 to Edward Clough, C.C. ; long-case clock, square dial, inscribed " John Hall, London," about 1700. Thos., apprenticed in 1675 to Geo. Hamble- ton, C.C. ; timepiece, "Thos. Hall, London," about 1700 . Wm., apprenticed in 1680 to Cornelius Herbert, C.C. ; long-case clock, about 1720 , inscribed "Wm. Hall, Woodborrow." Joseph, apprenticed in 1684 to Edwd. Norris, C.C. ; Mr. John Albree, junr., Boston, Mass., has a lantern clock, inscribed "Jos. Hall, London," dating from about 1700. Edwd., C.C. 1710. Thos., Runcorn; watch, 1763. Jno., Beverley, 1770. Martin, Yarmouth, 1780. James, from Westminster, settled in Philadelphia about 1768 . John, Philadelphia, 1811. Wm., 39 Gee St., 1814-19. Wm., 93 High St., Marylebone, 1815-19. Charles, 162 Fleet St., 1817 ; 118 Chancery

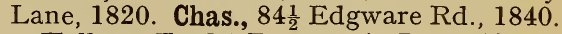

Hallam, E., 15 Bateman's Row, Shoreditch, 1835 .

Hallett,Wm. Geo., Bradford, Wilts., 1843.

Halleway, -, London; clock-watch, about 1685 .

Halley, Wm., apprenticed in 1663 to Thos. Battin, C.C.

Hallier, - , London, about 1800.

Hallifax. John, Fleet St.; maker of chime clocks ; his bankruptcy noted Lond. Gaz., June 14-17, 1740 ; Mr. Eden Dickson has a fine specimen of his work, a musical clock with automatic figures. John, Barnsley ; on his tombstone in St. Mary's Churchyard, Barnsley, is the tollowing: "In memory of Mr. John Halifax of this town, whose abilities and virtue few in these times have attained. His art and industry were such that his numerous inventions will be a lasting monument of his merit. He departed this life Sept. 25, 1750." A fine long-case by him is at Wentworth House, the seat of Earl Fitzwilliam. His second son, Thomas, came to London, and carried on business as a goldsmith, became a partner in the bank of Glyn \& Hallifax (afterwards Glyn, Mills \& Co.), was Lord Mayor of London in 1776 , knighted in 1778 , sat in Parliament as member for Aylesbury in 1784 , and died in 1789 .

Halliwell. Wm., Chorley, $1765 . \quad-$ York, 1814.

Halloway, Wm., Blackburn, 1776.

Hallows, Jonathan, Liverpool, 1818.

Hallsman, Wm., London; watch, 1790.

Hallus, alias Linus Franciscus, author of "Explicatio Horologii in Horto Regis," London, An. 1659 (see p. 8).

Hally, Thos., London ; bracket clock, about 1660; watch, 1675 .

Halsey, Geo., C.C. 1687 . Jno., Norwich, 1725.

Halstead. Richard, C.C. 1669 . Charles, C.C. 1677. John, C.C. 1698; long-case clock, arabesque marquetry. William, C.C. 1715 . 
Halsted, Robert, Fleet St. ; bad watch movement seized by C.C. 1662 ; admitted C.C. 1668 ; master 1699 .

Ham. Jno., apprenticed in 1673 to Geo. Stevens, C.C. John, 47 Skinner St., Snow Hill, 1820 ; 126 Newgate St., 1835-42, livery C.C. 1821.

Hambleton, George, C.C. 1669.

Hamden, Jno., apprenticed in 1638 to Jno. Charlton, C.C

Hames, Jno., 9 Chandos St., 1835.

Hamilton. Geo., apprenticed in 1690 to Nathaniel Delander, C.C. Richard, C.C. 1712. John, Glasgow; bracket clock, about 1780, Mr. Ivory. Jas., London ; watch, 1800 .

Hamlen, George, Augusta, Me., 17951820.

Hamlet, Thos., 1 and 2 Prince's St., Soho; in partnership with Francis Lambert, 1800 ; subsequently carried on business by himself; maker of a gold horizontal watch for the Duke of Sussex; 1795-1832.

Hamley, junr., Newcastle St., Strand; bracket clocks, about 1790. J. 0., 1 Warwick Place, Bedford Row, 1800-10; 24 Red Lion St., Holborn, 1816-40. J. 0., \& Son, 284 Holborn, 1810-16. 0. Jas., 23 Duke St., St. James's Sq., 1815̃-18.

Hamlin, Richard, London; bad watch of his seized by C.C. 1676 .

Hamlyn, Thos., apprenticed in 1638 to J. Bisse, C.C.

Hammers, Jno., London; long-case clock, about 1715 .

Hammersley, Jno., Clerkenwell ; afterwards at Ventnor, at Walham Green, and at St. Albans ; a clever watchmaker ; died 1901 , aged 82 .

Hammon, J., 9 Northampton Sq., Clerkenwell, 1840-60.

Hammond. Hy., C.C. 1680. Anthony, apprenticed in 1681 to Jno. North, C.C. \& Co., 45 St. Martin's-le-Grand, 1768. Thos. C., York, f., 182 .

Hampson. Warrington; lantern clock, about 1700; long-case clock, "Robert Hampson, Warrington." about 1730 . Trexham; long-case clock, about 1720, Mr. Henry Grogan. \& Thelwall, Manchester, 1812-23. Robert, Manchester, 1823-30.

Hampton. Joseph ; long-case clock, about 1700, Mr. J. H. Fleming. Rd., London; watch, 1782. W. \& Sons, 77 Theobald's Rd., 1842.

Hanbury, Jno., apprenticed 1664 to $\mathrm{Hy}$. Jones, C.C.

Hancock. Yeovil; long-case clock, about 1800. Anthony, Otley, 1822. Thomas, 17 Bond St., 1830-35.

Hancorne. Thomas, C.C. 1658 ; elected warden 1683, but excused on paying a fine. Jas., apprenticed in 1675 to Philip Buckner, C.C. William, C.C. 1676.

Handcock. - Yeovil, 1773. Edwd., 23 Queen St., Clerkenwell, 1842.

Hande, Thomas ; in the B.MI. is an oval tulip-shaped watch by Thos. Hande, about 1700.

Handiside, Geo., London ; repeating bracket clock, about 1720 .

Handley. ( \& Moore, apprentices of Jno. Thwaites, 39 Clerkenwell Close, 1798; a specimen of their work B.MI. ; G. Handley died 1824), see Moore, Jno. \& Sons. Jno., Runcorn, 1833.

Hands, Tim., London ; watch, Guildhall Museum, about 1750 ; another, 1765 .

Handscomb, E., Woburn, 1780-90.

Hanet. S., London ; long-case clock, Mr. J. Drummond Robertson, about 1725.

John \& George, Porter St., Leicester Fields, 1768 ; a specimen of their work B.M.

Hanks, Benjamin, Litchfield, Conn., U.S.A., patentee of self-winding clock with air vanes, 1783 .

Hanne, see March.

Hannet, Samuel Stephen, London ; longcase clocks, about 1780 .

Hannington, Wm.,London ; watch, 1800.

Hansard, William, watch-spring maker, 6 King's Head Court, Holborn, 1790.

Hanslapp. William, C.C. 1603. Robert; apprenticed to Edward East; C.C. 1653.

Hanson. Geo., apprenticed in 1688 to Jno. Clowes, C.C. George, Windsor ; watch, 1791. Wm., Windsor, 1820. Charles Huddersfield, 1833. Charles, $160 \mathrm{High}$ Holborn, formerly of Huddersfield; in 1845 he patented a detent escapement (No. 10,876) ; 1839-45.

Hanush, - , maker of a clock for Prague Town Hall, about 1497.

Hanwell. Zachariah, C.C. 1694 ; fine marquetry long-case clock, straight pillars, square dial, cherub corners, " $Z$. Hanwell, Londini," on circle, Mr. J. Drummond Robertson.

Happack, -, London ; repeating watch, about 1760 .

Harben, Thos., Lewes, 1740-70 ; longcase clock, inscribed "In the Cliff, Lewis." One-hand clock of rather earlier date, Mr. Jno. Stringer, Johannesburg.

Harbert, see Herbert.

Harbottle, Cornelius, C.C. 1667.

Harbud, Jeremiah, watch-movement maker, 2 Green Terrace, 1810-38; livery C.C. 1812 .

Harcourte, - , maker or repairer of clocks, near Westminster Abbey, 1469 (see p. 48).

Harden, Chas., 120 Fleet St., 1816-25.

Hardie \& Christie, Manchester, 1818.

Hardin, Jos., St. John's Lane, 1730 , afterwards at Old Jewry; livery C.C. 1766. 
Harding. John, C.C. 1685. Francis, C.C. 1687 ; clock, about 1700 , inscribed "Francis Harding, Portsmouth." John, C.C. 1721. Robert, London, 1753 . Thomas \& Co., 43 Minories, 1760-1800. Wm., London; watch for the Dutch market, finely embossed outer case, 1769 . Jno., Portsmouth, .1780; long-case clock with rotating hour dial as in figure on p. 501. Jno., Abingdon; watch, 1782. Sam., 131 Oxford St., 1816-23. \& Co., 26 Great Winchester St., 1817. Henry, 1 Holles St., Cavendish Sq., 1840.

Hardstaff, Zach., apprenticed in 1655 to Jno. Samon, C.C.

Hardwidge, Wm., 52 Wapping, 1823.

Hardy. John, Smithfield, 1730, afterwards 8 Bridgewater Sq.; livery C.C. 1766. Edwd., Hull, 1770. Jno., Morpeth, 1775. Robt., C.C. 1776 ; watch G.M., h.m., 1803. Thomas, watch-case maker, 14 Rosoman St., Clerkenwell, 1780-1820. Joseph, 26 Clement's Lane, Lombard St., 1800. Richd., Newark, 1805. William, 28 Coppice Row, Coldbath Sq., Clerkenwell ; a chronometer and clock maker of repute; he devised a compensation balance and an escapement for clocks for which he in 1820 received from the Society of Arts the gold medal and fifty guineas, 1800-30. Thos. \& Son, Newark, 1840.

Hare, Alexander, 17 Grenville St., Hatton Garden; hon. freeman C.C. 1781; maker of a finely enamelled watch, h.m., 1782 ; a verge metal watch by him in the Guildhall Museum; 1770-1815.

Harford. Lantern clock inscribed John Harford in Bath, 1658." -, South Parade, Bath, 1770.

Hargraves (or Hargreaves). Wm., Settle, 1710-30. Thomas, Settle, 1770.

Hargroves, Wm., apprenticed 1688 to Isaac Carver, C.C.

Harker, George, matter C.C. 1852.

Harland. Hy., apprenticed in 1647 to IV. Godbed and put to Peter de Laundre; C.C. 1654. T., Norwich, Conn., U.S.A., $1750-90$ ? ; to him was apprenticed Ely Terry in 1786 .

Harley, Wm., Salop; fine clock, 1760. Reid mentions Harley, of London, maker of ruby cylinders, about 1785 , working with Mallet, a watch jeweller there.

Harlock, James, 7 Horseferry Rd., Westminster, 1842 .

Harlow, Samuel, Ashbourne, Derby, in 1789 patented (No. 1,708) the Breguet or tipsy watch-key, in which the upper and lower portions are connected by means of a ratchet clutch kept in gear by a spring, so that the upper part will turn the lower part in the proper direction for winding, but if the upper part is turned in the opposite direction, the ratchet clutch slips without moving or straining the lower part: of the key. In 1813 he published "The Clockmakers' Guide to Practical Clockwork." He there described himself as clockmaker and brassfounder, Summer Hill, Birmingham, but mentions that his book may be obtained at his house in Ashbourne and also of Walker \& Sons, 49 Red Lion St., Clerkenwell.

Harman, Jno., apprenticed in 1681 to Thos. Jenkins, C.C. ; lantern clock, " Jno. Harman, Horsham," Mr. J. H. Mercer. John, "watchmaker and astrologer," of Blooms bury, 1753. George, HighWycombe, maker of the chimes of Cripplegate Church, 1792.

Harmar, Jas., London ; watch, 1690.

Harmer, Jaspar, near Smithfield Bars, cited by C.C. for exercising the art of clockmaker without having served seven years, 1685 .

Harns, Geo., Old Jewry, 1808-10.

Harold, Richard, C.C. 1690.

Harper. Henry, Cornhill, apprenticed 1657 to Humphrey Pierce; C.C. 1664, assistant 1682; watch by him in silver case, Schloss collection, said to have belonged to Cromwell's daughter Bridget; the arms of the Protector incorporated with the royal arms are engraved on the case ; in 1688 at the Mayor's Court some watch or pocket clock chains of steel belonging to him, and seized by C.C., were declared to be insufficient, and broken; he was the maker of a longcase month clock, presented to the Ironmongers' Company by John Woolfe, about 1689 ; a very similar clock at the Balls Hut Inn, Walberton, was sold by auction in 1910; a gold watch by him mentioned in Lond. Gaz., Jan. 11, 1691; in the Guildhall Museum is a watch movement signed "Harper, London" ; it has tulip pillars, and dates from about 1680 . Thomas, son of John Harper, of St. Gilesin-the-Fields; apprenticed to Theophilus Davys, C.C. 1760 ; long-case clock, about 1770. Thomas, apprenticed to Henry Taylor, C.C. 1771. \& Son, Salop; clock, about 1775. Thos., 207 Fleet St., 1800-30. John, 1 Pear Tree St., Goswell St., 1810 ; 16 St. John St., 1815; 78 Goswell Rd., 1825.

Harplett, Cornelius, apprenticed in 1659 to Davis Mell, C.C.

Harrache, Thos., Pall Mall, 1765-75.

Harris. John, one of the first assistants C.C. 1631 ; master 1641. Richard, said to have been the maker of a pendulum clock for St. Paul's Church, Covent Garden, in 1641 (see p. 599). Jacob, apprenticed in 1646 to David Bouquett, C.C. John, Holborn Bridge; C.C. 1659 ; master 1688 (see p. 569). Geo., apprenticed 1668 to 
Thos. Long ; C.C. 1674. John, C.C. 1677. Thomas, in $y^{e}$ Strand; good lantern clock, inscribed " Thomas Harris, in ye Strand," about 1680 . Ebenezer, apprenticed in 1682 to Ben Bell, C.C. Anthony, C.C. 1683 ; lantern clocks by him; also a fine long Oriental lacquer case clock, goes $\operatorname{sev} \in \mathrm{n}$ weeks; formerly at Ruchbrooke Hall, Suffolk. John, C.C. 1690; long-case clock, Wetherfield collection, about 1700 . Richd. apprenticed in 1693 to Thos. Brafield, C.C. Charles, apprenticed to Robert Webster, C.C. 1695. Christopher, Lom bard St., admitted C.C. 1695; 1695-1720. Jeffrey, " ting-tang" pull repeating bracket clock, inscribed " Jeffrey Harris, London," about 1700. Francis Wm., C.C. 1702. Samuel, C.C. 1708 (see p. 525, No. 10). Geo., Fritwell, 1710-30. Henry, Barbican, C.C. 1711; watch, silver dial, 1711-20. Robert, London, about 1745-50. Joseph, at the Dial and Cup, just above ye Upper Court House, Maidstone, about 1770; card, Hodgkin collection. Thos., St. Sepulchre's ; in 1770 he patented (No. 965) a rotating dial. Wm., Chippenham; clock, about 1770. William, Temple Bar, liveryman C.C. 1776. Saml., London, C.C. 1787; long-case clock, about 1790. Richard, 27 Old Jewry, 1790-1810. E., Warrington; watch, 1790 . John, apprenticed to Robert Poole, 27 Old Jewry, C.C. 1795-1808. Matthias, 8 Horse St., Bath, 1798. William, 27 Goswell St., apprenticed to Joseph Robinson, C.C. 1796; master 1830-32. Saml., C.C. 1802. L., Brown Lane, Spitalfields, 1810. Henry, 6 Curtain Rd., 1815-25. Geo. Harris, same address. Jas., 8 Parliament St., 1820. Clement, 76 Cornhill, 1822-42, C.C. 1816 ; livery 1825; chronometer, Guildhall Museum, signed " Harris, late Hatton and Harris." T. R., Clerkenwell, 1835. Wm., watchcase maker, 21 Red Lion St., Clerken well, 1835. John James, 11 Upper East Smithfield, 1840-42. J. D., Bath, 1850.

Harrison. George, apprenticed 1689 to Johana May, widow ; turned over to Thomas Tompion, C.C. 1698. William, C.C. 1699. Anthony, Birchin Lane, apprenticed in 1693 to Joana May, widow ; C.C. 1701 ; in 1721 appeared an advertisement respecting a small gold watch made by Anthony Harrison, and lost between Leadenhall and "Spittelfields" markets; the finder was offered nine guineas reward, and no questions asked, if the watch were restored to Mr. John Chadwell, goldsmith, Castle Alley, Birchin Lane, 1701-20. John, born 1693; died in Red Lion Sq., and buried in Hampstead churchyard in 1776 (see p. 340-349). James, Barrow; brother of the preceding; long-case clock by him in the G.M., 1720-50. John, Newcastle; bracket clock, about 1765 ; Jas., Grub St., C.C. 1730. Thos., Liverpool, 1770; clock, Thos. \& Finnie Harrison, Liverpool, about 1780. Edwd., Warrington, 1776. James, apprenticed to James Freeman, C.C. 1776. Wm., 48 Fetter Lane, 1780-94. James, Waterbury, Conn., U.S.A., founder of the Connecticut wooden clock industry, 17901830. Edwd., Warrington; centre seconds watch, 1795. Thos., 68 Fetter Lane, 17951804. Thos., Regent St.; watch, with hare and snail indicator, 1810. James, Barton-on-Humber and Hull ; a grandson of John Harrison and a clockmaker of some celebrity, made a fine clock for Christ Church, Hull; a clock by him in Filey Church had a detached escapement, an invention for which the Society of Arts awarded him a silver medal and $£ 10,1810$ 30. Francis, 91 Broad St., Ratcliff, 1835-41.

Harrocks. Lancaster: Joshua, 1748, f. ; made a church clock in 1759 ; Jno., $1783, f$.

Harrys (Harris), Thomas, Water Lane; maker of the celebrated clock with figures on the front of Old St. Dunstan's Church, Fleet St. (see p. 314, 315), 1671.

Harshell, D., 12 Bevis Marks, 1830.

Hart. Noe, C.C. 1695 . John, C.C. 1720. Henry, C.C. 1720. Aaron, Westminster, 1790. S. \& M., 52 Prescot St., Goodman's Fields, 1804-18. Jacob, Hull, 1822. \& Harvey, 5 King's St., Finsbury, 1825. Andrew B., London ; watch, 1830. Napthali \& Son, 5 King's St., 1835-42. \& Son, 77 Cornhill, 1839-47 ; two watches supplied to the Sultan of Turkey in 1844, cost $£ 2,000$; they were pair-case repeaters 5 in. in diameter; duplex escapements. Orrin, Bristol, Conn., 1840. Maurice, 6 Haydon Sq., 1842. Sam., Devizes, 1846.

\section{Hartford, Jno.; C.C. 1632.}

Hartley. -, New St., Shoe Lane; cited by the C.C. for trading in watches and clocks without having served seven years in the trade, 1680. Jeremy, Norwich; fine bracket clock, abour 1715 ; Mr. W. H. Helm has a long-case clock by him of rather earlier date; he voted at the Parliamentary election in 1710. Thos., Snaith, 1770 Jno., George Court, Red Lion St., 1790-94.

Hartman, John George; watchmaker to the University of Halle, 1756.

Hartnup, John, superintendent of Liverpool Observatory, Birkenhead, from 1843 to 1885 . He invented a compensation balance with an oblique laminated rim, and tabulated the errors arising from the change of temperature in ordinary chronometers.

Hartung, Chas., 61St.Martin's Lane, 1840.

Hartwell, Francis, apprenticed in 1678 to Dan. Stevens, C.C.

Harvey. Jno., apprenticed in 1691 to Philip Corderoy, C.C. Samuel, C.C. 1696. 
Alexander, C.C. 1726 ; in 1730 he worked for Clark, Leadenhall St. B., Weymouth, 1770. John, 16 Fenchurch St., a Quaker, 1798-1809; 3 Falcon St., 1815 ; 17981818. Thos., York, f., 1808 . -, Richmond, Yorks.; watch, 1814. \& Co., 2 King's St., Finsbury, 1830. George, 110 High St., Whitechapel, $1830 ; 22$ Cannon St. Rd., 1840 ; 142 Ratcliff Highway, $1842 ; 1830-42$.

Harward, Robert, C.C. 1730.

Harwood. Jas., Churchwardens' book, Halifax Parish Church, " 1714 paid James Harwood for clock mending $£ 1$ 12s. 6d." ; again, "1721, paid James Harwood for mending the clock, 10s." Laurence, "Acorn," Belle Sauvage Yard ; died 1716.

Hasius, see Hassenius.

Haskins, William, 79 Quadrant, Regent St., 1830.

Haslam. Watch signed " John Haslam, Cheshire," 1810.

Hasleden, Charles, 20Waterloo St., 1840.

Haslewood, Roger, 53 Salisbury Court, 1772 .

Hasluck, Jacob, St. John St., London ; watch, with sun and moon hour indicator, about 1695, Pierpont Morgan collection.

Hassell, Joshua, Carter Lane, C.C. 1730, see Atkins, F.

Hassenius, James (alien), admitted C.C. 1682. Mr. W. B. Redfern, has a long-case clcck inscribed " J. Hasius, Amsterdam," possibly by him. Jacobus, London, abcut 1710.

\section{Hastings, David, Alnwick, 1770.}

Haswell. Alex., 10 Clifford St., New Bond St., 1780-94. Archibald, 13 Skinner St., Clerkenwell, 1835 ; 8 Woodbridge St., Clerkenwell, 1840-42. Robert, 12 Upper Ash by St., 1842, afterwards at 49 Spencer St., Clerkenwell; died 1874, aged 58.

Hatch, John, admitted C.C. 1693.

Hatchman, James, C.C. 1680.

Hatfield, David, Bosworth ; watch, h.m., 1737.

Hathornthwaite, Lancaster : Peter, 1703; Jno., 1744, f., long-case clock, "Peter Hathornthwaite, Kirby Lonsdale," about 1750 .

Hatton. Jno., C.C. about 1650. Peter, Stafford, 1735. Thomas, Lombard St.; watchmaker, and author of " Introduction to the Mechanical Part of Clock and Watch Work," published 1773; 1760-74; watch, "Thos. Hatton, Preston," 1776. Sam., Rose St., Soho, 1775. Joseph Yorke, 40 Tooley St. ; apprenticed to Newman Peachey, and turned over to John Chancellor; C.C. 1796; livery 1810 ; St. Magnus, London Bridge, 1830 ; many watches inscribed " Yorke Hatton, Thames St." James, 4 St. Michael's Alley; apprenticed to Geo. Margetts ; C.C. 1799 ; livery $1810 ; 1799-1812$. Christopher, apprenticed to George Margetts, and turned over to James Hatton; C.C. 1815. \& Harris, 4 St. Michael's Alley, Cornhill, 1816-20, see Harris, Clement. Geo. C., Lancaster, 1826, f. Wm., Horselydown, London, 1830. J., 15 Store St., 1835.

Hauchar, J. D., Paris, élève de Breguet ; watch, about 1830 .

Hauck, Antoine, Bamberg; repeating watch, Mr. Alfred A. de Pass, about 1690.

Haughton. Wm., C.C. ; in 1703 he worked for Heardman. Geo., London, about 1760; long-case chiming clock, Hôtel de Madrid, Seville.

Hautefeuille, John (The Abbé), Paris ; born 1647, died 1724. He is said to have invented, about 1722 , the rack lever escapement which was patented in England by Peter Litherland in 1791. Huygens, endeavouring to obtain a French patent for the balance-spring, was successfully opposed by the Abbé, who claimed to be the prior inventor of it.

Havelland \& Stephens, 32 Aldgate High St., 1794.

Haven. Thos., C.C. 1652 . Robt., C.C. 1657.

Hawes, John, 31 New Bond St., 1775.

Hawkes, Susan, apprenticed in 1683 to Sam. Davis and Mary, his wife, C.C.

Hawkesbee, Eenjamin, C.C. 1709.

Hawkesworth, John, C.C. 1709.

Hawkins. Pretty lantern clock, about 1650 , inscribed "Ambrese Hawkins Je Wells, ffecit." Marke, Bury St. Edmurds, 1670. Wm., apprenticed in 1676 to Francis Dinnis ; C.C. 1684; fine lacquer long-case clock, about 1740, signed "Wm. Hawkins, St. Edmund's Bury," about 1730, Wetherfield collection. Richd., apprenticed in 1677 to Wm. Fuller, C.C. Geo., apprenticed in 1688 to Ben. Wright, C.C. Mark, Bury St. Edmunds, 1710. James,C.C. 1730 . Wm., Bury St. Edmonds, 1735 . Thomas, C.C. 6 Castle Alley, Cornhill, 1777-1816.

Hawksey, Enoch., Nantwich; watch, 1787.

Hawley. Thomas \& Co., 75 Strand; " watchmaker to His Majesty," 1760-1828. -, 120 Fleet St., card, Hodgkin collection, about 1830. John, 56 Frith St., Soho, 1842. - High Holborn, 1860-62.

Hawthorn, D., Darlington, about 1705. Hawthorne, Ferguson \& Co., London ; watch, 1808.

Hawting, Jno., Holywell, Oxford, 1770-80.

Hawton, Sam., apprenticed in 1690 to Jno. Wise, junr., C.C:

Hawxhurst, Nathaniel, New York, 1786.

Hay. Alexander, Edinburgh ; 1718. Peter, 20 Davis St., Berkeley Sq., 1805-40. Geo., York, f., 1808. Elizabeth, York, 1822. 
Hayden. John, Deptford ; long-case clock, about 1710. William, C.C., Noble St., 1717.

Haydon, William, Croyłon, C.C. 1687.

Hayes. Walter, C.C. 1654 ; master 1680. Jno., apprenticed in 1676 to Jas. Wolverstone, C.C. Edmond, C.C. 1682. Wm., apprenticed in 1686 to Daniel Le Count, C.C. Jas., apprenticed in 1693 to Harris, C.C. Wm., Warrington; watch, 1782.

Hayford, Henry, 2 Star Alley, Fenchurch St., 1842.

Hayle, -, watch, Whitcombe Greene collection, in fritillary shaped case of silver, beautifully engraved dial, movement inscribed "Thomas Hayle (or possibly Hople) in Popeshead Alley," about 1650.

Hayley, William, 30 Great Marylebone St., 1788-93.

Haynes. John, C.C. 1676 . Wm., apprenticed in 1680 to Thos. Williamson, C.C. F., London ; pendulum watch, about 1708 , see Haines, Francis. \& Kentish, 18 Cornhill, 1804-18.

Hays, Michael Solomon, New York, f. 1769.

Hayter, Wm., apprenticed in 1685 to Jno. Parker, C.C.

Hayton, F., London ; watch, 1760.

Hayward. William, Union Ct., Holborn ; C.C. 1720. Robert, Bermondsey, 1815-35. John, 22 Bush Lane, Cannon St., 1820. J., 2 Summers Court, Bishopsgate Without, 1835-42.

Haywood, Peter, Crediton, Devon. In 1766 he patented (No. 836) a calendar ring.

Head, Thomas Cartwright, apprenticed to Christopher Gould in $\mathbf{1 6 9 3 .}$

Headworth, P., 46 St. John's St., 1815-42 Heady, George, apprenticed to Dan. Quare 1675 ; admitted C.C. 1682.

Healey. Jno., Manchester, 1818; also Thos., same date.

Heap, Richard, 5 King St., Covent Garden, 1800-4 ; 39 Maiden Lane, 1815-25.

Heaph, Jno., Stockport, 1770.

Heardman. Jacob, Plum-tree Court ; C.C. 1720. Joseph, Plum-tree Court ; C.C. 1730-35.

Hearn. Joseph, apprenticed in 1690 to Cornelius Jenkins, C.C. Hen., London ; watch, 1775 .

Heath. Ben., apprenticed in 1661 to Chas. Rogers, C.C. J., London ; watch, h.m., 1770 .

Heathcote, Timothy, C.C. 1698.

Hebditch, accounts of Bristol Cathedral, 1630 , by favour of Mr. Edwin P. Morgan. "Item, Paide to Ríchard Hebditch for making ye Horloge at ye lower ende of ye Cathedrall church, with divers and sundry motions in ye sume of $£ 13$ 6s. 8d."

Hebert. Anthony, "Moorefields, nere London," 1670 ; Mr. Benj. G, Wattson has a long-case clock so inscribed which strikes the hour twice ; bracket clock, about 1690 , inscribed, "Anthony Hebert in Porter Street." Anthony Hebert, 7 Dials ; C.C. 1725. J., Brightelmston, about 1716 . Jno., Isleworth, 1770 .

Hebden. Francis, Halifax, 1830 ; also Jas.

Hebrat, Jean, Brussels, 1640.

Hebting, F., wooden clockmaker, 19 Moor St., Soho, 1835.

Heck, see De Heck.

Heckel, Francesco, à Fridberg, 1730 .

Heckle, A., Liverpool, 1818.

Heckstetter, Joseph, C.C. 1694.

Hedge. Nathaniel, Colchester; lantern clocks, about 1740; also a fine long-case clock, about 1780. \& Banister, Colchester, known as makers of long-case and other clocks, about 1800 ; watch by them, 1808 .

Hedger. W., London; watch, 1790. George, 48 Great Sutton St., 1822-35; 10 St. John's Row, St. Luke's, 1842.

Hedges, John, 4 St. James's Walk, Clerkenwell, 1800.

Heeley \& Burt, Deptford; long-case clock, 1780.

Heerman, John (Dutch), C.C. 1691.

Heffer, W., 2 George St., Grosvenor Sq., 1835 .

Heidmark, P., London ; watch, 1780.

Heilig. Jacob, Philadelphia, 1770-1824.

John, Germantown, 1824-30.

Heitzman, F. \& Co., 40 Norton Folgate, 1840 .

Heizman, Matthew, 1 Charles St., Soho Sq., 1840.

Helden. Onesiphorus, C.C. 1632 ; warden, 1648; did not become master. Cornelius, apprenticed in 1686 to Dan. Delander, C.C.

Hele, Peter, Nuremberg, invented the mainspring, 1500; died 1540.

Heliger, J., Zug ; crystal case watch, about 1590 .

Hellam, James, apprenticed to Daniel Steevens, and turned over to Evan Jones, and afterwards to Henry Jones ; C.C.1690.

Hellier, Wm., London; watch, 1740.

Helliwell. - Warrington ; clock, about 1770. Wm., Leeds, 1829.

Helme. -, London, 1700 . Thos., Ormskirk; repaired town clock, 1770.

Helsby, Jas. G., also Jno., Liverpool, 1833.

Helye, F. Baptiste, Paris ; clock, about 1780.

Heming. Ed., Bicester, about 1705 clock, Mr. Samuel E. Groves, inscribed "Ed. Heming, Bisiter." Thomas, Piccadilly, 1763 ; 131 New Bond St., 1769-75. Artis, Shadwell, liveryman C.C. 1776 . \& Crawner, New Bond St., 1780-90. Geo., 151 New Bond St., 1793. 
Hemingway, Jno., Manchester, 1818.

Hemlett, J., London; watch, 1810.

Hemmen, Edward, London; watch, about 1710 ; another, h.m., 1760.

Hemming. Chas., apprenticed in 1678 to Jas. Wolverstone, C.C. Hen., London ; watch, 1780 .

Henche, Uldrich. Payment to him of $£ 100$ for a clock " in manner of a branch," made by him and set up at Whitehall, 1605 .

Henderson. Robert, Scarborough; a Quaker, died 1756, aged 78; long-case clock, about 1715, Sir Theodore Fry. Robt. Edinburgh; watch, S.K.M., about 1750. Thos., Hull, 1770. Robert, St. Martin's Court, 1772 ; 18 Bridgewater Sq., 1800-5 ; Gen. J. Watts de Peyster, New York, has a chiming bracket clock by him; names of tunes engraved in the arch of the dial,

"March from Scipio, Sukey Bids Me, Miss Fox's Minuet." John, 13 Broad St., Exchange, 1775 ; 21 Cornhill, 1783-1800. R. T., St. Martin's Court, 1800 . E., "Treatise on Horology," London, 1836.

Hendrick, Jno. \& Peter, Liverpool, 1818. Hendricks, Aaron, Devonshire St., 1760-68.

Hendrie, Ja., Wigton, 1770.

Heney, Richard, apprenticed in 1646 to Isaac Law, C.C:

Hening (? Heming), Josh., long-case clock, about 1780 .

Henkels. Jean, Amsterdam: watch, 1730. H., Amsterdam; watch, 1780.

Henley. J., London; watch, 1810. Thos., London; watch, 1829.

Hennett \& Son, 16 Foster Lane, 1772.

Hennington, Wm., London; watch, 1765. Hennon, William, C.C. 1674.

Henriot à Geneva; watch in case of tinted gold, S.K.M., about 1785 .

Henry. Autin à Paris; clock-watch, about 1740. Peter, London; watch, 1780 . W. \& S., 44 Taylor's Buildings, Islington, 1804. S., 59 Lower Brook St., 1810. S., 70 Leman St., 1830. Stephen, 3 Berkeley Sq., 1835-40.

Henshaw. Walter, C.C. 1669 ; master 1695. John, C.C. 1696.

Hepton. Thos., Northallerton, 1770. Frederick, Philadelphia, 1785. Jno., 1823-40. Wm., 1840.

Herant Brothers \& Son, Berlin ; enamelled watch, S.K.M., about 1680 .

Herbault, L. Fr., Rue St. Honoré, Paris ; garde-visiteur, 1769.

Herbert. Wm., apprenticed 1663 to Hy. Child; C.C. 1671; watch without a balance-spring, about 1675. Edward, C.C. 1664. Cornelius, London Bridge, 16701720. Jno., apprenticed in 1672 to Nich. Payne; C.C. 1682. Thomas, Whitehall, C.C. 1676 ; red tortoise-shell bracket clock, about 1690, Wetherfield collection.
Morgan, clock-watch, 1690. Cornelius, London Bridge, apprenticed to the above C. H., 1690 ; C.C. 1700 ; master 1727 ; in the vestry of St. Lawrence, Jewry is a long-case clock by him, dated 1721 , and among the church papers is a receipt as follows: "Received from the church for the clock the sum of eight pounds. Cornelius Herbert" ; a fine marquetry long-case clock by him in the Wetherfield collection is shown on p. 558. Evan, C.C. 1691. Edward, Old Bailey, C.C. 1710-30. Henry, C.C. 1713 . Cornelius, apprenticed to his father, Cornelius ; C.C. 1735. Jas., London; repeating watch, 1740.

Herman. Peter, Leeds, 1830. Ignaz, 13 Compton St., Clerkenwell, 1840.

Herne, Edwd., apprenticed in 1680 to Cornelius Jenkins, C.C.

Heron, Isaac, New York, 1769-80, f., 1769 ; watch by him belonging to Philip Livingston, signer of American Declaration of Independence in 1776, now in the museum of the "Sons of the Revolution," New York. Wm., Newtown Ards, 1784.

Herring. Joseph, free C.C. by redemption, 1770. (Herren), Joshua, 38 Cornhill, known as a maker of bracket clocks, 1753-75. Richd., Newark, 1805-20.

Hertford, see Hartford.

Hertham, T. S., London ; watch, 1795.

Hervé, fine clock, Wallace collection, signed "Hervé à Paris," about 1740.

Herwick, Nicholas, Cheapside, 1580.

Heselwood, Jno., York, f., 1835.

Hesk, William, Horseferry Rd., Westminster, 1835.

Hess, L. Zurich, watch, about 1760.

Hessen à Paris ; enamel watch, about 1775 .

Hessichti Dionistus, book-shaped watch, 1627.

Hester. Henry, C.C. 1670. Henry, junr., C.C. 1687. "Lost in Whitehall, on Sunday the 26th past, a Gold Watch with a plain Outside Case, made by - Hester, of Westminster, with a ribbon tied to it of Changeable Purple and Gold, and upon that two Seals, the one an Onyx with a Head cut in it, set with small Diamonds; and the other Seal a Stone set with rubies. Whoever brings the said Watch, \&c., to Mr. Snagg, Goldsmith, in Lombard 'St., shall have 5 guineas reward " (Lond. Gaz., July 30, Aug. 3, 1691.).

Hettich, C., Lynn, 1825.

Heuss, George, Nuremberg, 1509-60. He made a clock with automatic figures.

Heward, Jno., apprenticed in 1686 to Jno. Miller, C.C.

Hewison, Chas., London ; watch, 1800.

Hewitt, Geo., Marlboro', 1720-30 (see p. 525): Benjamin, C.C. 1724. Alexander, London, C.C. 1725 ; watch, 730. Jas., 
Sunderland, 1760. Thomas, 12 Upper Ashby St., and 10 King St., Tower Hill ; a chronometer maker who devised different forms of compensation balances; was a director of the British Watch Company; born 1799, died 1867. Sam., 60 St. Martin's Lane, 1836. Thomas, Lancashire, 1833. Thomas, J.P., London; a clever horologist, served on the Council of the British Horological Institute and was for many years Vice-President, died 1919, aged 85 .

Hewkley, John, C.C. 1732.

Hewlett, Bristol; long-case clocks ; Isaac, about 1750 ; Isaac and Joshua, about 1780; Andrew, a little later.

Hewlitt, G., Foxley, 1780.

Hewson, Jno., apprenticed in 1683 to Jno. Sellars, C.C.

Heydon, Saml., London ; watch, 1757.

Heyer, F. M., Amsterdam ; watch, 1775.

Heywood, William, 12 King St., Covent Garden, 1807-10; 35 Goodge St., 1815-42.

Heyworth, John, 218 Tottenham Court Rd., 1823.

Hibbert, John, 7 Jewry St., Aldgate, 1840.

Hiccox, Jno., apprenticed in 1650 to Nicholas Ashwell ; admitted C.C. 1657 ; repeating watch, inscribed "Jno. Hiccox, London," about 1710.

Hick, Matthew, York, f., 1812; died 1834.

Hickling, John, 122 St. John's St., Clerkenwell, 1835-42.

Hickman. Joseph, 20 Bridgewater Sq., 1779. Wm., 89 Borough, 1816-25. Edwd., High St., Oxford, 1818-20.

Hicks. Thomas, C.C. 1664. "Lost Sept. 21, betwixt Ingerstone and Rumford, a watch with a silver-pinned Case, showing the day of the month, the hour of the day, made by Thomas Hicks, Londini, with a blue taffety ribon fastened to the key thereof. Whoever will give notice thereof to Mr. Christopher Maynard, watchmaker at the Royal Exchange, London, shall have 40s. reward" (Lond. Gaz., Sept. 23-27, 1675). Thomas, C.C. 1666 . John, C.C. 1694. Samuel, London, about 1780 . Jas., 112, Whitechapel, 1804-15. Chas., 112 Whitechapel, 1810-15.

Hickson, Thomas, C.C. 1690.

Higgins. Banger, apprenticed to Edward Banger, and turned over to William Wilde; C.C. 1724. Thos., London ; long-case clock, about 1760.

Higginson. Henry, C.C. 1662. Samuel, C.C. 1697. Hatton speaks of the splendid polish of the work of Higginson Brothers, watch finishers. Geo., East India House, C.C. 1730. Richard, Fazakerley; watch, 1743. John, 27 Strand, 1780 ; 38 Southampton St., Strand, 1798-1815. -, Kirby St., 1782 .
Higgnett, Jno., London ; watch, 1725. Higgs. John, apprenticed to Robert. Robinson, C.C. 1661. Jno., C.C. 1688. Robert, apprenticed to Richard Blundell C.C. 1714; Mr. R. W. Llewellyn has a small bracket clock by him, finely engraved back plate, two bells, coming hour struck on smaller one, pull for repeating hour at pleasure. Thomas, C.C. 1716. Robert \& Peter, 7 Sweeting's Alley, 1740-69; Peter Higgs was apprenticed to Robert, C.C. 1740 , and became master in 1767 . Robert, London; long-case clock, about $1750, \mathrm{Mr}$. W. L. Unkill, Mexico City ; half-quarter repeating watch, 1785 . \& Evans, 7 Sweeting's Alley, 1780-1822; a verge watch movement by them, with curious pillars, in the Guildhall Museum; clocks inscribed, "Higgs y Diego Evans," for Spanish markets (see pp. 579, 577).

Highfield, Josiah, 55 Rosoman St., 1790-94.

Highmore. Lancaster, apprenticed in 1685 to Jno. Fitter, C.C. Edwd., C.C. 1687. Jacob, 52 Aldersgate St., 1790-94.

Higon, Pierre, Place du Palais-Royal, Paris ; garde-visiteur, 1769.

Hildebrandt, J. C., 1730.

Hildeburn. Samuel, Philadelphia, 1811. \& Woodworth, Philadelphia, 1819.

Hill. John, petitioner for incorporation of C.C. 1630. Benjamin, C.C. 1641; master 1657 ; in the B.M. are specimens of his work, one a small circular watch in a blue steel case, with exceedingly handsome covering of filigree gold; another plainer with outer case of shagreen; in the S.K.M. is a watch by him in a case of rock crystal; he died 1670. "Lost a gold watch made by Benjamin Hill in a black case studded with gold, with a double chain, and the key on a single chain with a knob of steel upon it. Whoever gives notice of it to Mr. Ambrose Mead, at the Bird-in-Hand, Fleet St., shall be rewarded" (The Newes, April 27, 1665). Francis, C.C. 1679. Thomas, Fleet St., $1680-90$; his name was engraved, in conjunction with that of Henry Harper, on a long-case clock in possession of the Ironmongers' Company; on the clock is the further inscription, " The gift of John Woolfe, member of the Company." " Thos. Hill, over against Chancery Lane, Fleet St.," card, Ponsonby collection. He was a liveryman of the Ironmongers' Company. Wm., apprenticed in 1682 to Sam Clyatt, C.C. Edward, C.C. 1698. Jno., King St., Covent Garden ; long-case clock, about 1700. John, Seven Dials ; C.C. 1705-30. Wm., Walsingham, long-case clock, about 1713, Mr. Geo. F. Glenny. John, Fleet St., C.C. 1731-70. Geo., Lambourn, about 1770. Abel, Petworth, 1730. Sam., 
Sheffield, maker of good clocks, 1770-1814. Jno., Prescot, 1775. Thomas, Aldersgate St., 1777-86; Thomas Hill was the maker of a gold verge watch, embossed case, said to have belonged to Captain Cook. Matt., Devonshire St., London, about 1790. Chas., 3 Charing Cross, 1793-95. Jas., 5 Ball Alley, Lombard St., 1793-1810. Sampson, C. 9 Ball Alley, Lombard St. : card, Hodgkin collection, about 1815 . Leonard, 61 Fleet St., 1817-23. John, 15 James St., Covent Garden, 1820. D., Reading, 'U.S.A., 1820-40. Sam., 13 Hooper St., Clerkenwell, 1842. Joseph, Bristol, 1844.

Hillcoat, William, 33 Queen St., Cheapside, 1790-94.

Hillersden, Jno., C.C. 1656.

Hillery, Jno., apprenticed in 1681 to Richard Farrett, C.C.

Hilliard, G., 35 Queen St.,Cheapside, 1820

Hillier. William, C.C. 1679 . James, watch-glass maker, 12 Church St., Spitalfields, 1790-1810.

Hillings, Bernard, C.C. 1652.

Hillman, Wm., Plymouth Dock, 1770.

Hillrich, Johann, Pestteine ; regulator, Buda-Pesth Museum, about 1800.

Hills. Fleet St., 1774. Ralph, Sunderland, about 1775; he was apprenticed to David Paterson, who was apprenticed to Jno. Ogden. Amariah, New York, 1845.

Hilson, Thos., apprenticed in 1674 to Jno. Mark, C.C.

Hilton. John, apprenticed to Wm. Moraley but turned over to Thos. Tompion, admitted C.C. 1698. Emanuel, Portsmouth ; long-case clock, about 1790 . Jno., Halifax, 1830. —, London; watch, 1840.

Himele, Jas., New York, 1786.

Hind, Paris, watch jeweller, 26 Spa Rd., 1790-94.

Hinde. Thos., Bolsover, died 1836. Benjamin, musical-clock maker, 20 Banner St., Clerkenwell, 1835-40.

Hindley. - , hanging clock, about 1710 , signed "Hindley, York," oak case, Mr. Wm. Birchall (see p. 491). Henry, York, f., 1731, died 1770 ; a clever clock and watch maker; watch by him in S.K.M., London, h.m., 1766 ; made a clock for York Minster in 1750; also several others with pendulums $56 \mathrm{ft}$. long ; is credited with having invented the screw-cutting lathe about 1740 ; about the same date he devised an improved wheel-cutting engine, see Brown, J. Joseph, York, f., 1754; made a clock for Holy Trinity Church, Hull, in 1772.

Hine. Thos., Fleet St., 1760-74. John, 68 Red Lion St., Clerkenwell, 1790-94.

Hinks. Wm., Southampton; lantern clock, Mr. WV. W. Tamplin, about 1700.

Hinksman, -, Madeley; clock, about 1770 .
Himmers, Robert, Edinburgh ; watch, about 1800 .

Hinton, J., 91 Boro', 1815-20 ; 20 Tabernacle Row, Finsbury, 1835.

Hiorne. John, Bartholomew Close ; C.C. 1707, master 1744. Jas., Snow Hill, C.C. 1730 .

Hirsch,Ad.,for forty-three years Director of the Neuchâtel Observatory, died 1901.

Hirst, Bury St. Edmunds : Isaac, 1740 ; John, 1760. Sam., Leeds, 1770-95. Sam. \& Son, Leeds, 1830.

Hiscocks. T., 9 Princes St., Drury Lane, 1835. Zachariah, 7 Little Russell St., Covent Garden, 1840-42.

Hislop. Richard, Rosoman St., Clerkenwell, 1775-1803. Richard, son of the above, 53 Rosoman St., 1804-42. William, younger son of the first-named Richard, 15 Rosoman St., 1820; 96 St. John St. Rd., 1835-72 ; was some time hon. sec. and an active member of the governing body of the Horological Institute; died in $\mathbf{1 8 7 6 .}$

Hitchen. John, Queen St., C.C. 1720. watch, 1740.

Hitchens, Joseph, Brown's Buildings, St. Mary Axe, 1779-94.

Hitchman, Nicholas, apprenticed in 1677 to Richard Ames, C.C.

Hoadley, Calvin, associated with Eli Terry at Plymouth, Connecticut, in the production of American clocks during the early part of the nineteenth century.

Hobart, Gabriel, York, f., 1750.

Hobbins, -, Freckenham, Worcester, 1820 .

Hobbs. James, Lambeth, 1830. Jas., 142 Great Tower St., 1830.

Hobler. Paul, Porter St., Newport Market; hon. freeman C.C. 1781 ; 1770-90. Fras., Porter St., Newport Market, 1793. Hobson. John, petitioner for incorporation of C.C. 1630. James, 21 James St., Oxford St., 1835.

Hoch, John, London, 1836-1918; a native of Denmark, for many years engaged in business at Brixton as a turret clock and watch maker.

Hochicorn, Isaac, C.C. 1728.

Hochnadel. Small repeating bracket clock, about 1700, inscribed "Pietro Hochnadel, Venezzia," Mr. Louis Prevost Whitaker, Washington.

Hock, C., wooden clockmaker, 40 Charles St., Hatton Garden, 1840.

Hocker. John, Reading ; apprenticed to John Martin, and turned over to Edward Josslin ; C.C. 1729; lantern clock, about 1730. Jos., Basingstoke; 30-hour clock, about 1740 .

Hockson, Jno., London; watch, 1700.

Hoddle. John, Reading; maker of lantern clocks, 1688. Jno., Pye Corner, C.C. $1705-30$. 
Hodge, H. London ; watch, 1795.

Hodges. Nathaniel, " in Wine Office Courte, Fleet Street" ; C.C. 1681 ; bracket clock, small square dial, ebony case with brass basket top, about 1685 , Wetherfield collection; another specimen, about 1700 . William, C.C. 1719. Jono, 227 High Holborn, card, B.M., 1780. Thos., Antigua, 1780. James, London; long mahogany inlaid Sheraton style case clock, Wetherfield collection, about 1800. Fredk., Dublin ; rack lever watch, about 1806 . J., Kingsland Rd., 1835.

Hodgkin. Sarah, C.C. 1699. Robert, 8-day square dial clock, fine movement, inscribed "Rob. Hodgkin, Londini," about 1705 .

Hodgkins, Robt., London ; bracket clock, about 1750 .

Hodgson. York: Marcus, f., 1676 ; watch, inscribed "Mark Hodgson, Eboraci," 1710. Jno., Skipton, 1720. Wm., Philadelphia, 1785. Lancaster : Hy., 1816 , f. ; Wm., 1820, f., long-case clock, about 1840, with name "G. Hodgson," Mr. Taylor Heape.

Hodierne, Jno., apprenticed in 1638 to Platt, C.C.

Hodsoll. William, 31 Primrose St., Bishopsgate, 1800-8. William, 29 Ratcliff Row, City Rd., 1842.

Hodson. Jno., apprenticed in 1666 to Thos. Rotherham, C.C. At Bolton: Geo., 1765 ; Wm., 1780. Wm., Bristol, 1844.

Hoffman, octagonal watch, Marfels collection, signed "Melchior Hoffman, Augspurg," about 1600.

Hoffner, Hy., Philadelphia, 1791.

Hogan. J., watch movement maker, 6 Badgers Yard, St. John St., 1808-20. \& Smith, 15 King St., Clerkenwell, 1835.

Hoguet à Paris. M. Olivier has an eighteenth-century clock so signed.

Höheer, Johan Christoph, clock, green vaulted chambers, Dresden, about 1680 .

Hohwii, Andreas, born in Schleswig 1803, apprenticed to his father, Thomas Hohwii ; for four years to 1839 he worked in Paris for the house of Breguet; settled in Amsterdam, where he died in 1885 ; a celebrated maker of chronometers and astronomical clocks.

Holborn, Robt., Sheffield, 1770.

Holborough, Thos., Ipswich, 1715.

Holbrook, Hy., Liverpool, 1770.

Holdcroft, Hy., apprenticed in 1678 to Chas. Halstead, C.C.

Holder, Henry, London; watch, brass inner, enamelled outer case, 1760.

Holds, Chas., Silver Dials, St. Bartholomew Close, 1793.

Holdway, George, 305 Strand, 1779.

Hole. Henry, 11 Lisle St., Leicester Sq., $1810 ; 12$ Kingsgate St., 1817-23.
F. W., Weymouth Terrace, City Rd., patented a mainspring in 1852 (No. 40).

Holeyard, Samuel, C.C. 1705.

Holgate, -, Wigan, 1770.

Holland. George, petitioner for incorporation of C.C. 1630-55. Thomas, C.C. 1632 ; master 1656 . Henry, probably apprenticed in 1657 to Walter Gibbs, C.C. ; the Hon. H. Hannen has a bracket clock by him-it strikes the hours but has only one barrel; black case. Thomas, C.C. 1658. Lewis, apprenticed in 1691 to Thos. Birch, C.C. Lewis, C.C. $1699 . \quad$ Robert, London; bracket clock, about 1740 . Gabriel, Coventry ; bracket clock, about 1750. John, 5 Bishopsgate Without, livery Goldsmiths' Company, 1765-77. James, Bury (Lancs.), 1770. Reuben, London; bracket clock, about 1780 . Wm., Chester, 1814-18. Thos., 167 Fleet St., 1815-18.

Hollidaie, Edwd., freeman of C.C. and signed petition in its favour, 1656.

Hollier, Jonathan, Skinner St., liveryman C.C. 1776, see Houlliere.

Hollinshead, Jacob, Salem, 1771.

Hollis, Thos., apprenticed in 1649 to Jas. Seabourne ; C.C. 1656.

Hollisone, Alex., Liverpool : watch, 1795 ; another watch, "Alex. Hollisone, London."

Holliwell, Wm., Liverpool ; clock, about 1750 .

Holloway. Robert, C.C. 1632. Edward, C.C. 1650. -, brass clock, signed "William Holloway, at Stroud," 1669. Richard, apprenticed in 1675 to Cornelius Herbert, C.C. William, Cullem St., C.C. 1697. Thos., Winton, 1740.

Hollyar, Sam., apprenticed in 1693 to Jno. Barrow, C.C. ; clock, about 1710.

Holm, Jno., Lancaster, 1783.

Holman, see Kemp and Holman.

Holmden; John, musical clockmaker, 18 St. James' Walk, 1806 ; 50 King St., Goswell Rd., 1840 ; livery C.C. 1807.

Holme. John, Cockermouth, freeman of Lancaster, 1783. Lawrence, Liverpool, about 1820.

Holmes. Nestor, apprenticed in 1674 to Jere. Gregory, C.C. ; he ran away from his apprenticeship (see p. 700). Thos., apprenticed in 1686 to Peter Miller; C.C. John, apprenticed to Peter Miller; C.C. 1697. John, C.C. 1697. Thos., Cheadle, 1735. Saml., Liverpool; watch, 1758. Edward, 9 Foster Lane, Cheapside ; 1773-94. Wm., 12 Clerkenwell Green, 1783. John, 156 Strand, near Somerset House ; he seems to have been one among the leading mechanicians, and when the turret clock at Greenwich Hospital was destroyed by fire in 1779 was given the order for a new one, in connection with the 
design of which he sought the advice of Smeaton and Ludlam; a gold watch by him is in the Fitzwilliam Museum, Cambridge ; it belonged to William Pitt, and bears the Pitt crest, a heron holding an anchor in the right claw; the Wetherfield collection contains two long mahoganycase clocks of his manufacture, one a particularly choice example of Chippendale dating from about 1770 , which is illustrated on p. 548, and another about twenty years later; he was one of the experts appointed by the select committee of the House of Commons in 1791 to report on Mudge's timekeepers. George Yonge succeeded him in 1798 . Wm., 156 Strand, 1810-12. Matthew Steel, 10 Shoemaker's Row, Blackfriars, 1820-42 ; livery C.C. 1825. Richd. Hy., Hull, 1822.

Holoway, Jo., Newberry ; watch, with sun and moon hour indicators, 1680 .

Holroyd. Jno., Wakefield, 1775-1814. T., Huddersfield, 1810-14. Richard, Chester, 1833.

Holt, Lancaster : Thos., 1747, f. ; Wm., 1767, f. Matthew, Wigan, 1775. Richard, Newark, 1804-42. T., Wakefield, 1814. John, Rochdale, 1818; also Valentine, 1818-21. Matthew, Coventry, 1818.

Holtham, Geo., London ; watch, 1720.

Holtzman, Johannis, in Wien ; in the Schloss collection is a watch invented by him about 1775 , in which the dial is raised much above the movement, the hands being driven through a tube.

Hone, Rt., London ; watch, 1750.

Honeybone, Thomas, Old Brentford, $1830-40$.

Honeychurch, Saml., Cheapside ; longcase clock, about 1770 .

Honison, J., Wilderness Row, and 5 Charlton Place, Islington, 1835.

Honton, Richd., Oversley-Green, Warwick, about 1790 .

Hood., Jas., London ; watch, 1805. James, Meredith Street, Clerkenwell ; died 1917.

Hooke. Robert, born 1635, died 1703 ; invented the balance-spring for watches and the anchor escapement for clocks (see pp. 320-323). A., silver-gilt watch, Fellows collection at the B.M., inscribed "A. Hook, 1661." John, C.C. 1698.

Hooker. Thos., London ; long-case clock, about 1780. Jas., 22 Five Fields Row, Chelsea; card, B.M., 1791.

Hoole, S., London, 1770, clock hands (see p. 526).

Hooper. Jno., Winton; clock, about 1760. Henry, 39 Cheapside, 1792. G., Bath, 1850.

Hope. Wm., watch, h.m., 1767. Edward Bridge St., Strand, 1775 ; 97 Oxford St., 1783-85, Peter, Liverpool ; pair-case watch, h.m., 1795, Evan Roberts collection. Chas., London, 1820. Geo., London ; watch, 1825 .

Hopetown, Wm., London ; watch, 1822.

Hopgood, T. B., 202 Bishopsgate Without, 1807-23; afterwards Hopgood \& Salmon.

Hopkins. John, C.C. 1641. Thos., Maiden Lane ; C.C. 1730. John, Fleet St., 1753-56. Edwd., 48 King St., Soho, 1817; Mr. W. H. Naish has a long-case timepiece, corner figures representing seasons, signed "Edwd. Hopkins, Bradford," about 1800. Asa, Northfield, U.S.A., 1820 . A. B., 32 Aldgate, 1823. John, Coventry; died 1915 , aged 74 .

Hople, see Hayle.

Hopper, Jas., Stockport, 1770.

Hopperton. Long-case clock, " Emmanuel Hopperton, Leeds," about 1760. Saml., Leeds, 1770.

Hornblower. William, C.C. 1713 ; longcase clock, Japanese decoration, arch dial, style about 1740 . William H. (possibly a son of William) was beadle of C.C. 1779. Wm., 9 Powell St., King's Sq., 1842.

Hornby. Geo., Liverpool, 1765. Gerard, Liverpool, 1780. Jno., Liverpool, 1790. Richd., Pool Lane, Liverpool, 1810-30. Hy., Liverpool, 1818. 一, London; watch, 1825 .

Horne. Samuel, C.C. 1654 ; master 1672-73. George Henry, C.C. 1718. Henry, London Bridge, master C.C. 1730-68. William, 114 Ratcliff Highway, 1830-42. Hornsby. Robert, apprenticed to William Harris, admitted C.C. 1788. Gerrard, Liverpool, 1817.

Hornsey, Thos. E., York, f., 1826.

Horseman, Stephen, was apprenticed to Daniel Quare 1702, admitted C.C. 1709; Quare, prior to his death, seems to have taken Horseman into partnership, judging from examples with their joint names, including repeating and clock-watches, and a 30-day clock, 1724-40.

Horsfall, Wm., Bradford, Yorks., 1830.

Horsley, Cornelius, York, a Quaker, f., 1656. Ben., apprenticed in 1693 to William Watson, C.C.

Horsnaile, Geo., Warfield ; one-hand clock, about 1730 .

Horstmann, Gustave, inventor of perpetual clock (see p. 402); died at Bath, 1893 , aged 66 .

Hoskins. Danl., clock, about 1630. \& Bird, 11 St. John's Sq., Clerkenwell, 1822-30. Jonah, 6 Hatton Garden, 1840. George, 75 Old Broad St., 1842.

Hotham, Hy., apprenticed in 1665 to Jno. Pennock: C.C. 1673.

Houblin l'Aîné, Rue Montague, St. Geneviève, Paris; garde-visiteur, 1769.

Houdin, Robert, Paris, 1820-30, 
Hough. Jno., Knutsford, 1740. Jno., Warrington; clock, about 1760.

Houghman, Charles, Aldersgate St. ; C.C. $1770-80$.

Houghton. Richard, C.C. 1690. Jas., Macclesfield ; clock, about 1770. Thos., Chorley, 1780-1840. James, 198 Tooley St., 1790-94. James, Ormskirk, assistant of William Garrat, and afterwards maker of watches with Debaufre's dead-beat escapement, with two escape wheels as modified by Sully, known in Lanarkshire as the club-footed verge, 1800-20. John, Handsworth, Birmingham; a well-known clockmaker, died 1863, see Evans, W. F. Wm., Lever St., died 1890, aged 75 .

Houlhere, -, " Jona Houlhere at the sign of the spring clock in Broad St., London," watch paper, Ponsonby collection, about 1760 , see Hollier.

Houllgatt, - , oval watch, S.K.MI, inscribed "W. Houllgatt, att Ipswich," about 1640 .

Houlton, - , Orange Grove, Bath, 1770.

Houriet, Jacques Frédéric, Locle ; born 1743 , died 1830; clever horologist and maker of spherical balance-springs.

House. J., Gray's Inn Lane ; pair-case silver verge, showing day and night by means of a revolving plate, serving as hour hand, minutes shown in the usual way, period 1700 . Matt., Cork Lane; C.C. 1730. Robert, 32 Upper Moorfields, 1790.

Housman, Jacob, Lancaster, 1732, f.

Houson, Jas., York, f., 1832.

Houston, S., Dublin ; watch, 1799.

How. William, C.C. 1667 ; elected assistant but excused, 1697. Thos., apprenticed in 1670 to Isaac Romien, but turned over to Nat. Delander; C.C. 1677. Benjamin, C.C. 1691. \& Masterton, White Hart Court, Gracechurch St., 1750-60.

Howard. John, C.C. 1694 . Richard, apprenticed to Daniel Delander ; C.C. 1718; long-case clock, arch dial, Mr. D. Foale, inscribed " Richard Howard, New Brentford." Wm., repaired the clock at Exeter Cathedral, 1760 (see p. 38). - , at the Ring and Pearl, New Round Court, Strand, 1770. Edwd., 5 Kirby St., Hatton Garden, 17751804. Wm., London; watch, h.m., 1777. Thomas, Philadelphia, 1789-91. John Jarvis, 68 Aldersgate St., 1790-94. H. \& M., London ; watch, steel index disc, 1792. Edward, died 1904, aged 90 ; apprenticed to Aaron Willard, Boston, U.S.A. ; joined in 1847, David P. Davis, who had been a fellow-apprentice; Howard \& Davis made clocks and scales at Roxbury. Met A. L. Dennison in 1849 and became associated with him ; a factory was built at Waltham, and, in 1854, watches produced there marked "Dennison Howard \& Davis ;" Waltham factory disposed of to Royal E.
Robbins in 1857 ; in 1861 Howard returned to Roxbury and started the Howard Clock \& Watch Company; in $\mathbf{1 8 6 3}$ the title was altered to the Howard Watch \& Clock Company; from this he retired in $\mathbf{1 8 8 2 .}$

Howarth, Ja., Blackburn, 1770.

Howden. James, Edinburgh ; long-case clock, about 1800. Francis, Edinburgh, 1842.

Howe. Samuel, C.C. 1712. Ephraim, apprenticed to Graham, C.C. 1729. Jno., Alresford, 1800. Jubal, Boston, U.S.A., 1833. Samuel, 173 High Holborn, 1840.

Howell. Dan., C.C. 1637. Benjamin, C.C. 1699. Joseph, Golden Sq., C.C. 1721 . John, Bull's Head Court, Newgate St., C.C. 1724-30. Stephen, London; watch 1770. Wm., Bristol ; Sir Theodore Fry has a long-case clock by him, dating frcm about 1770, which shows " High Water at Bristol Key." Geo., London; watch, 1785.

Howells. William, Kennington, apprenticed to Thos. Sheafe; C.C. 1780; one of the experts appointed by the select committee of the House of Commons to examine Mudge's timekeepers (see p. 356). William Henry, apprenticed to William Howells; admitted C.C. 1820.

Howes. Jno., C.C. 1672. Thos., London; clock, Mr. W. H. Wilding, about 1680. Wm., Temple Bar, C.C. 1730. Jos., Fleet St., 1760-75. S., Downham ; clock, abont 1770 .

Howlbrook, see Holbrook.

Howlett. Stephen, apprenticed in 1657 to Peter Bellune, C.C. John, London, known as a maker of good watches, about 1750 ; a specimen in a gold repoussé case, Schloss collection, about 1770 . Jno., son of the above, migrated from London to Bath; his son afterwards carried on business at Calne.

Hows, Thos., The Sun, Pope's Head Alley; admitted C.C. 1632 ; known as a maker of watches, 1630-40.

Howse. John, Croyden, C.C. 1687. Joseph, 1698, see Howes. John, admitted C.C. 1706. William, 13 Fleet St., C.C. 1731 ; master 1777 ; 1731-80. Charles, 5 Great Tower St. ; watch, 1768 , master C.C. 1787 ; 1768-94.

Howson, John, admitted C.C. 1699.

Hoyle. Hy., C.C. 1677 . Wm., Boltonle-Moors, 1818.

Huaud (or Huaut) ; this Swiss family, noted as painters in enamel for watch cases, from about 1660-1750.

Hubbard. John, C.C. 1722. Joseph, watch gold hand maker, St. John's Sq., 1790. E., musical-clock maker, 33 Gibson St., Waterloo Rd., 1840.

Hubberd, C., watch-case maker, 9 Peer lessRow, City Rd., 1835. 
Hubert. Timothée, oval watch, signed " Timothée Hubert à Rouen," in crystal case, about 1600 , Pierpont Morgan collection; melon-shaped watch, Ashmolean Museum, silver case, richly chased dial, about 1650 . Noel, Rouen; oval watch, S.K.M., about 1620 . Jean, Rouen ; oval silver watch, about 1650 ; Buhl case bracket clock, about 1670 ; verge escapement, brass dial arched, silvered circle inscribed "Jean Hubert;" below is a figure of Time with scythe, under which is the inscription, "Solem Audet Dicere Falsum ; " in the Pierpont Morgan collection is a watch, signed "Jean Hubert, Rouen, au Grd. Monarque;" it has Turkish numerals, and dates from about 1680 ; watch, Evan Roberts collection, about 1795 , inscribed " $\mathrm{P}$. Hubert l'aîné à Toulouse." Estienne, Rouen ; maker of a watch said to have belonged to Mary, Queen of Scots ; in 1657 John Smith was fined 10s. for putting the name of Estinne Hubert on a watch ; alarm watch in pierced and engraved silver case with inscription,

" Estinne Hubert à Rouen," S.K.M., about 1610 ; watch, Pierpont Morgan collection, of about the same date. "Lost upon Newyear's-day, above stairs in Whitehall, a gold watch with a plain shapen case ; the watch was made at Rouen, maker's name Hubert. Whoever brings it to her Royal Highness the Princess of Denmark's porter at the Cockpit, shall have two guineas reward " (Lond. Gaz., Jan. 2, 1689). Estinne l'aîné, Amsterdam; repeating watch, abcut 1690 . Watch, about 1710 ,

" B. Hubert, à la Rochelle," Mrs. Geo. A. Hearn. David, Strand; admitted C.C. 1714 , master 1743 ; repeating watch, silver case engraved and pierced, enamel dial, Roman hour numerals, Arabic figures outside for minutes, the plate covered with engraving, and inscribed "Dav. Hubert, London;" the late Mr. Evan Roberts had a repeating watch by him which sounds the minutes, and is therefore an early specimen of the kind ; another specimen of his work is a bracket clock repeating the quarters on six bells by pulling a cord, which winds up the quarter repeating train, brass arched dial, strike-silent, day of the month, verge escapement; 1714-48. Oliver, his son; C.C. 1749. James ; Charlotte Hubert was apprenticed to him and Elizabeth his wife in 1725 ; and in 1730 Catherine Cext was also apprenticed to them. Pascal le Jeune, Roten ; enamel watch ; 1749.

Hubner, - Vienna; gold watch, Fitzwilliam Museum, eighteenth century(?).

\section{Huchason, Richard, C.C. 1702.}

Hudleston. Chas., apprenticed in 1673 to Hy. Harper, C.C. Letter from L. Hudleston, to Mr. Keats, surgeon in Parlia- ment St., 40 th Oct. 1773 , relating to a watch made by him for Miss Walter, Bury Hill, near Dorking ; the price of the watch was 80 guineas, including enamelling, gold hands, and shagreen cases:-

\begin{abstract}
"As to the inside I can speak with more confidence, as there is not a single article but what is in part or altogether the work of my own hands and this is one reason why 1 cannot dispatch a watch as expeditiously as others who trust to the work of other men's hands without making use of their own. To alter its going the silver plate in the inside should be moved by the little end of the key, bringing a higher figure towards the index in the cap to make it go faster and vice-versa. Moving the plate from one division to another will alter the watch's going about 2 minutes per day." "MSS. of the Earl of Verulam.")
\end{abstract}

Hudson. Jno., apprenticed in 1684 to Chas. Halstead, C.C. Richard, "from Fleet St. at Grahams Head in Leadenhall St.," 1770. John, St. Martin's Churchyard, 1780-85. Jno., Nottingham ; watch, 1780. T., Cheapside, near the Hen Cross, Nottingham, about 1790. William, Griffin St., Shadwell, 1835.

Hues. Pierry (Peter), C.C. 1632. Thos., apprenticed 1662 to Jno. Pennock, C.C.

Huges, Jno., Maidstone; lantern clock, about 1710 .

Huggeford, Ignatius, brother C.C. 1671 ; a watch by him played a prominent part in respect of the petition of Facio and Debaufre for extension of their watch jewel patent (see p. 613), 1671-1705. Peter, apprenticed to Ignatius Huggeford, 1686, C.C.

Huggins, J., Macclesfield, 1810-15. London, about 1830.

Hughes. Morris, apprenticed in 1691 to Hy. Hammond, C.C. John, C.C. 1703 ; long-case clock, about 1710, signed "John Hughs, London," see Huges. Thomas, Broad St. Buildings ; C.C. 1712-35. Hugh, long-case clock, about 1750. Thomas, 25 Broad St. Buildings, master C.C. 1765 ; first liveryman $1776 ; 1750-83$. S., Gracechurch St., 1774. William, 119 High Holborn, hon. freeman C.C. 1781 ; centre seconds watch by him in the Guildhall Museum ; four of Earnshaw's watches with his name thereon were deposited for trial at Greenwich Observatory in 1791 ; small enamelled watch, Schloss collection, about 1790 ; the late Mr. Henry Levy had a fine travelling watch by him from the Summer Palace, Pekin; it is in pair-cases 7 in. in diameter, chimes on six bells and sets in motion mechanical figures, 1766-94. He was succeeded by Thos. Earnshaw. Thos., junr., London, about 1790 . John, 94 Minories, 1800. H., Caernarvon; watch, 1806. David, 30 Frith St., 1835-42.

Huguenail, Charles T., Philadelphia, 1799 . 
Huguenin. Charles F., Philadelphia, 1795. Aimé, Liverpocl, 1820 . A., 67 Great Russell St., 1830-42.

Hulbert, William, Castle Green, Bristcl, 1708. S., Bath, 1850.

Hulier, Wm., apprenticed in 1669 to Thos. Creed ; C.C. 1679.

Hull. Philip, apprenticed in 1693 to Wm. Young, C.C. Hy., apprenticed to Geo. Graham, C.C. 1738 ; a cylinder escapement maker, who worked for Ellicott and other celebrated manufacturers. Jno., York, 1822.

Hulme, Peter, Preston, 1814. Jas., 11 Bow St., 1817.

Hulst, Jacob, admitted C.C. 1645 .

Hulton, John, admitted C.C. 1724.

Humber, Thos., London; long-case clock, about 1790 .

Hume, Benj., apprenticed in 1691 to Jno. Barnett, C.C. Chas., London; watch, 1830.

Humfrey, Nicholas, apprenticed in 1689 to Thos. Wheeler, C.C.

Humfreys, Wm., apprenticed in 1692 to Nat. Higginson, C.C.

Humfurey, W. H., 17 Great Surrey St., 1830-35.

Humphreys. Samuel, Fore St., C.C. 1728. Wm., watch, about 1760 . T., Barnard Castle, Yorks; watch paper, about 1780. Wm., Barnard Castle, long-case clock, 1829 , referred to by Dickens.

Humphries, J., London ; mantel clock, about 1750 .

Humphrys, William, C.C. 1699.

Hunot, Sam., 28 Rathbone Place, 1842.

Hunsdon, Edwd., Chelmsford, 1750.

Hunt. Robt., apprenticed in 1611 to Lawrence Sindrey, C.C. John, C.C. 1671. Edward, apprenticed to Thos. Williamson ; C.C. 1684; watch movement with tulip pillars, in the Guildhall Museum. " Lost the 17 past, out of Mrs. Man's Lodgings in Sohoe, a gold minute pendulum watch. with a gold-studded case, the inward box marked E.H. and a coronet, made by Edw. Hunt" (Lond. Gaz., Septem ber 15, 1692). -, long-case clock, square dial, cherub corners, inscribed " Rich: Hunt, Bristoll," about 1700. James, C.C. 1708. William, Ludgate St., 1753-56. Jas., 5 King St., Cheapside, 1772. Thos., 151 Tottenham Court Rd., 1835. Wm., Stafford St., Bond St., 1835. Saml., Buttesland St., Hoxton, 1842. Geo., Bristol, 1844. Hiram, Robbinston, Maine, U.S.A.; was said to have been the original "Sam Slick" of Haliburton ; he died at an advanced age in 1886 .

Hunter. Thomas, 43 Lombard St., 1754 ; 156 Fenchurch St., 1763 ; liveryman C.C. $1768 ; 1754-94$. Jno., Bristol, about 1760 (see p. 519). William, 51 Lombard
St., livery Goldsmiths' Company, 1766-94. Jno., Bridlington, 1770. Thos., Liverpool, 1780. Thomas, junr., 156 Fenchurch St., 1781-1800. Thomas, 54 Goswell Road, 1788-94. Wm., 156 Fer church St., 1804. \& Son, 156 Fenchurch St., 1810-17. J., Clapham; watch, 1815. Jno., Bridlingtcn, 1822. \& Edwards, 43 Cornhill, 1840-42.

Huntley. Wm., Bradford, Wilts, 1842. Francis H., Melksham, 1844.

Huon, Jacques, Paric; splendidly enamelled watch, S.K.M., about 1650 .

Hurley, Isaac, Red Lion St., Clerkenwell ; C.C. 1730-80.

Hurst. Isaac, C.C. 1677. Arthur, Ashford; lantern clock, about 1690. Stephen, Liverpool ; watch, 1807. W., (?M.) 9 Lambeth Walk, 1835-42.

Hurt. Noe, apprenticed in 1686 to Joseph Biddle, C.C. Henry, Ludgate Hill ; C.C. $1730-56$.

Hurtin \& Burgi, Bound Brcok, U.S.A., May 1766.

Husband, Thomas, Hull, 1760-80; longcase clock, Mrs. Maria Duane Bleecker Cox, New York.

Hussam, Chas., apprenticed in 1672 to Jas. Wolverton, C.C.

Hussey, Joseph, admitted C.C. 1685.

Hutchin. Joshua, C.C. 1682 ; in the B.II. is a watch by him, handsome silver dial with a semicircular slit above the centre, through which appears blue sky, the sun in the day and the moon at night. pointing to the hour; Mr. IV. K. Bcwen has a long-case clcck by him, case of walnut with fine gecmetrical marquetry (see p. 536) ; 1670-1705. James, C.C. 1697. Joseph, C.C. 1703 . John, C.C. 1703.

Hutchins, Abel (also Levi), Concord, U.S.A., 1785-1818.

Hutchinson. Wm., apprenticed in 1688 to Geo. Ethrington, C.C. Anthony, Leeds; clock, about 1700. Richard, C.C. 1702-36. -, Worksop, clock, 1710-20. John, petitioned Parliament to grant a longer period than usually covered by a patent for his improved watch, which would be wound without an aperture in the case ; successfully opposed by C.C., Mr. Charles Goode producing to the committee of the House of Commons a watch made fourteen years previously, which Mr. Hutchinson confessed was made as his; 1712 . Retford; clock, 1720. Edwd., London; watch, Nelthropp collection, abcut 1750 . Jno., Burnley, 1780-1818. Jno., London ; watch, 1825 .

Hutton. Richd., apprenticed in 1691 to Thos. Brafield, C.C. Jos., London; watch, 1750. Thos., London; mentioned by Earnshaw, 1776. Patrick, 83 Cannon St., 1790. John, chronometer maker, Commercial Rd., E, 1830; Mark Lane, 1830-68. 
Hux. Thos., London; watch, 1825. John, 41 Percival St., 1840-42. R. R., Spencer St., Clerkenwell, a well-known maker; died 1869.

Huxtable, Jno., Frome, 1844; also at Trowbridge.

Huygens, Christian, born 1629, dicd 1695 (see p. 323).

Hyams. Woolf, Portsea; watch, 1815. Joshua, 32 Leman St., Gccdman's Fields, 1840-42.

Hyatt, Jno., Chester, 1818.

Hyde. Jno., apprenticed in 1637 to Simon Hackett, C.C. Thos., apprenticed in 1691 to $\mathrm{Hy}$. Harper, C.C. Thomas, 33 Gutter Lane, 1773-94. James, 38 Gutter Lane, 1783.

Hyett, Nicholas, apprenticed in 1648 to Richd. Morgan, and put to Robt. Rothwood, C.C.

Hyland, Jno., London; watch, 1770.

Hyman. Watch, signed " $\mathrm{S}$. Hyman, Dock," 1811.

Hynam. Robt., horloger de la Cour, St. Petersburg; quarter clock, about 1750 ; he probably went from London, for he was on the livery of the Joiners' Company till 1776, when his address was given as "Russia." In the Czar of Russia's collection, at the Winter Palace, St. Petersburg, was a small watch by him entirely covered with brilliants; it is suspended from a chatelaine of seven chains set with diamonds which also carries a watch key, a small seal of agate, and an enamelled acorn. Robert, 4 Clement's Lane ; Hatton says, "the much improving Mr. Hynam makes his watches withcut collars to his pendants;" liveryman C.C. 1769-90.

Hyon à Paris, on a watch, S.K.M., about 1740 .

Ibel, Thomas, watch-spring maker, Featherstone St., 1790.

Idelot. Fine Boulle work clock and bracket, inscribed "Idelot à Paris," about 1710 .

Ilbury, Wm., Goswell St., 1780 ; afterwards at Duncan Terrace, died 1851; a well-known manufacturer of fine enamelled and other watches for the Chinese market. Mr. Willard H. Wheeler has a watch dating from about 1800, signed "Ilbury, Paris," the case is finely decorated with pearls.

Iles, Thomas, London ; long-case clock, Mr. D. A. F. Wetherfield, about 1790.

Imhof, Nicholas, 24 Curtain Rd., 1848.

Imison. Jno., Manchester ; clock, about 1770. - London; watch, h.m., 1786.

Immisch, Moritz, clever horologist ard electrician; died 1903.

Inches, Robert (Hamilton \& Inches),
Edinburgh ; died 1918 ; Lord Provost of Edinburgh from 1912-16, when he was knighted.

Ingerham, Thos., apprenticed in 1686 to Alex. Warfield, C.C.

Ingersoll, Daniel, G., Boston, U.S.A., 1800-1810.

Inglish. Jas., 36 Watling St., 1790. David, Manchester, 1818. Adam, wocden clockmaker, 39 St. John's Sq., 1840.

Ingold, Pierre Frederick, born at Bienne 1787, a clever mechanician, who devised machinery for duplicating parts of watches. $\mathrm{He}$ visited Paris about 1817, and workcd for Breguet; started business for himself in Paris 1830; came to London 1840. In 1842 and 1843 he took out various patents for protecting the tools to be used by the British Watch Company; visited New York in 1845; afterwards returned to Switzerland and devoted himself to the manufacture of the "Ingcld Fraise," a serrated cylindrical cutter for shaping wheel teeth; he died 1878 .

Ingram. Thomas, C.C. 1695. William, C.C. 1730 . John, Spalding, 1770. William, 40 Goswell St., 1842.

Inkpen, John, Horsham ; long-case clocks, about 1770 .

Inman, Jas., Colne, Lancs., 1818; Stockport, 1833 ; and at Burnley.

Innes, R., London ; watch, 1760.

Innocent, Robt., 16 Gwynn's Place, Hackney Rd., 1835.

Inwood, S., Lcndon; watch, green leather case piqué, about 1700 ; another watch exhibited at the Guelph Exhibiticn by Mr. Geo. Carr Glyn.

Ireland. Henry, Lothbury ; C.C. 1654 ; maker of lantern clocks, 1650-75. Francis, C.C. 1668. Ant., Mile End; long-case clock, about 1770. John, 21 Maiden Lane, 1779.

Irons, Thos., Alcester, about 1790.

Ironside \& Belchier, Lcmbard St., 1737-40.

Irvin, Jean, 32 Kirby St., Hatton Garden, 1825.

Irvine, J., watch movement maker, 23 Rahere St., 1835.

Irving. Alexander, C.C. 1695 ; longcase clock, about 1700 , signed "Alexander Irving, Londini, fecit;" another, inscribed "Alex. Ervin, London." J., Blackburn, 1770 .

Isaac. Sutton, apprenticed in 1655 to Jno. Samon; C.C. 1662. Daniel, assistant C.C. $1670 ; 1660-70$.

Isaacs. Levy, 57 Mansell St., 1769-83. Lewis, 23 Houndsditch, 1830-42.

Israel, John, 180 Whitechapel, 1783.

Israels, Jsh., London, a bout 1775

Ive. Francis, C.C. 1634 . G. H., 10 Finsbury Place, 1825 ; also at 17 Cornhill, 1826-42. 
Ivery, John, repairer of the clock of St. Margaret's, Westminster, 1548.

Ives. Zacharia, C.C. 1682 ; 30-hour clock, hour hand only, inscribed "Zac. Ives, fecit for Thos. Sclater, Gentl." Jno., apprenticed in 1693 to Jno. Benscn, C.C. Francis, C.C. 1709. Joseph, Bristol, Conn., 1811-25. Lawson, 1827-36.

Ivison, Jno., Carlisle, 1810.

Ivory. Jas., Dundee, 1760-90. Thos., son of Jas., 1795-1810.

Izod, William, admitted C.C. 1649.

Jaccard, J., 60 Red Lion St., Clerkenwell, 1820-22. David, 26 Percival St., 1840-42. Ami, son of David, suicide 1909, aged 69 .

Jackman, Joseph, large verge watch movement in the G.M., inscribed "Jos. Jakeman, on London Bridge," about 1690.

Jackson. Richard, C.C. 1632 . Joseph, C.C. 1646 . Sampson, apprenticed in 1656 to Joseph Jackson, C.C. Edward, C.C. 1669. Edward, Newington, Surrey, apprenticed in 1672 to Robert Wilkins; C.C. 1680. John, C.C. 1682. David, apprenticed in 1684 to Luke Bird, C.C. Thomas, C.C. 1688. James, C.C. 1689. Martin, C.C. 1697, master 1721; maker of a bell-top ebony case, pull-repeater clock, brass arch dial, 1697-1721. Matthew, C.C. 1730. William, Old Broad St., afterwards Tower St., $1730-76$; bracket clock by him in walnut case, about 1750, Wetherfield crllection ; known also as a maker of longcase clocks; liveryman C.C. 1776 . John, 37 Basinghall St., 1759-74. Thos., Preston, 1760. John, 2 Bridgewater Sq., livery C.C. 1776, master 1796; 1760-1800. Randal, 8 Chapel Row, Spa Fields, 1780. Henry, 29 St. Martin's Lane, 1790-94. Thomas, 52 Upper East Smithfield, 1790; 53 Red Licn St.: Clerkenwell, 1810. Isaac, Wylam, Northumberland; born 1796, died I 862; a good mechanician: clock by him with three-legged gravity escapement, at Stephenson's factory, Newcastle. Wm., Frodsham, f., of Lancaster, 1801. Joseph H., Philadelphia, 1802-10. Isaac, 145 St. John's St., 1804. Geo., 82 Charlotte St., Rath bone Place, 1815-25. Wm. W., Frodsham, 1817, f., of Lancaster. Edwd., York, 1818. Jno., Lancaster, 1820. Wm., 31 Cowcross St., $1820 . \quad$ John, junr., Bridgewater Sq.; master C.C. 1822; 1800-30. John, watch-case maker, 10 Norman St., St. Luke's, $1835 . \quad$ William, 6 Brunswick Pl., Brompton, 1835-42. Henry \& Son, 66 Red Lion St., Clerkenwell, 1835-42, afterwards W. H. \& S. Jackson; Samuel Jackson for many years identified himself with the work of the Horological Institute, filling in succession the offices of Treasurer and Vice-President; died at Tonbridge 1904, aged 81. William, 29 Exeter St., Sloane St., $1835 . \quad J o h n, 72$ Hackney Rd., 1842.

Jacob. Benjamin, C.C. 1706. Benjamin, C.C. 1718. Dennis, Cockspur St., 17751800. Dan., 57 Margaret St., 1817.

Jacobs. Jean, Harlem; octagonal watch, "dated 1560. Conrad, Leewarden; watch, about 1610 . Judah, Whitecross St., 1769 ; 1 Little Mitre Court, Fenchurch St., 1771; Mr. Thos. Boynton has a bracket clock by him, brass and silvered dial, mahogany case. E., 86 York St, Westminster, 1820; 25 Bevis Marks, 1825-35. A., Bowery, N.Y., 1833-36. Edward 29 Earl St., Westminster, 1835. J., Bristol, 1844.

Jacques, see Jaques.

Jadwin, Robt., apprenticed in 1647 to Wm. North, C.C.

Jaggar, Edward, Fleet St. ; C.C. 1702-30. Jakeman, - , see Jackman.

James. John, apprenticed to Thomas Loomes; C.C. 1661. Francis, C.C. 1662. Joseph, C.C. 1689 ; long-case clock, one hand, about 1700 , signed " Benj : James, Shaston" (Shaftesbury). Monaghan, apprenticed in 1692 to Chas. Goode, C.C. J., London ; long-case clock,, 1770. W. Bath; watch, 1796. Robert, 23 White St., Borough, 1835.

Jameson, George, Portsea, about 1810. Jamison, George, 33 Charing Cross, $1800-5$; in conjunction with Howells \& Barraud he completed chronometers on Mudge's plan; he also attested the value of Earnshaw's improvements in 1804; afterwards he carried on business at High St., Portsmouth. Wm., Dublin; watch, 1809.

Jammett, - , admitted C.C. 1704.

Janaway. Wm., apprenticed in 1675 to Jno. Saville, C.C. Jno., 114 Cheapside, 1815.

Jannings, Arthur, Butter Market, Ipswich, sole partner of Boby \& Jannings ; died 1913 ; aged 63 .

Janvier, Antide, born 1751 at St. Claude in the Jura, settled in Besançon, and became an authority on horological construction ; migrated to Paris and repaired Passemant's clock for the first Consul. His "Essaj sur les Horloges" was published at Paris in 1811; died 1835.

Japy, Frédéric, Beaucourt, France ; born 1749 , died 1812 ; in 1799 he patented a series of machines for producing parts of watches by unskilled labour; this appears to be the first attempt to manufacture watches on the factory system.

Jaques. William, apprenticed in 1679 to Jno. Wright, and turned over to 
Nathaniel Delander; C.C. 1687 ; master 1716; Wm. Achurch apprenticed to him in 1691. William, C.C. 1724 . Aug., 4 President St., 1842; small watch, gold case enamelled, "G. Jaques, L.ondon," h.m., 1843.

Jaquet; watch, inscribed "Jaquet, London," silver dial and cock, brass cases, inner one beautifully engraved and pierced, Pierpont Morgan collection, about 1705 ; another watch of later date, inscribed "Peter Jaquet, London."

Jardin, John, Bartholomew Close, one of the witnesses to the will of Christopher Pinchbeck the younger in 1780 ; admitted hon. freeman C.C. 1781 ; repeating watch in shagreen case, about $1750 ; 1750-81$.

Jordan, Timothy, Snow Hill, 1770.

Jarman. John, C.C. 1728. John B., 25 Strand, 1815-23. \& Co., 33 St. James's St., 1825.

Jarossay, - , Paris, 1788.

Jarratt, Wm., London, about 1760 ; long-case clock, belonged to Mrs. Inchbald.

Jarrett. Richd., C.C. 1632. Richard, C.C. 1670 ; master 1685 ; watch, Schloss collection, about 1665. \& Sons, watch-case engravers, Albemarle St., St. John's Sq., 1780-94. Barnard, City Rd., livery C.C. 1786-1820. John Wm., livery C.C. 17861816.

Jarvis. Simon, apprenticed in 1670 to Richd. Ames, C.C. Joseph, apprenticed in 1670 to Bart. Powell, C.C. Saml., Birmingham, 1710. George, C.C. 1728. John, Aldersgate St., 1775-94.

Jeanin, A., 28 Cranbourne St., 1842.

Jeeves; fine Chippendale long-case clock, Gillespie's School, Edinburgh, inscribed "Anthony Jeeves, musical clock maker from Oxford," about 1770; the name "Daniel Davidson" in arch of dial. Jefferies, John, C.C. 1639.

Jefferson. Samuel, 35 Bruton St., 1805-42. \& Son, 38 Fetter Lane, 1815. Reed \& Walton, 38 Fetter Lane, 1820-25. Jno., Gt. Driffield, 1822. Matthew, 236 High St., Shadwell, 1835-42.

Jeffery. William Knight, C.C. 1712. Thomas \& Jones, Cockspur St., Charing Cross, 1769-94.

Jefferys. Nathaniel, 22 Queen St., Mayfair, 1768-1804. Nathaniel, Strand; 1771, see Drury Dru. Thomas, Cockspur St., 1771 . Sam., Chancery Lane, 1780. Nathaniel, junr., 70 Piccadilly, 1780-94. Geo., Chatham; long-case clock, 1790. Henry, 96 Fleet St., 1793; 49 Salisbury Sq., 1798-1804. G., 86 New Bond St., 1800. \& Gilbert, Cockspur St., 1800. \& Jones, London, about 1800 . \& Ham, 49 Salisbury Sq., Fleet St., 1810-15; 46 Skinner St., 1825. Geo., Bath, 1835.
Jeffreys, John, Holborn, C.C. 1726 ; to him was apprenticed Larcum Kendall in 1735 .

Jeffreys \& Jones; thin watch, Evan Roberts collection, about 1794.

Jeffs. John, apprenticed to Jeffery Bayly, and turned over to John Walter; admitted C.C. 1697. Benjamin, C.C. 1702.

Jelf, William, C.C. 1717.

Jenkins. Thomas, C.C. 1678: Cornelius, C.C. 1678. James, C.C. 1692 ; fine month clock, arch dial, by him, about 1710 . Henry, 68 Aldersgate St., maker of curious astronomical and other clocks, 1756-83 (see p. 382). Henry, Cheapside, 1774 ; long-case clock, mahogany Chippendale case, about 1780. F., 7 Tyler St., Regent St., 1835 .

Jenkinson, J., Sandwith; watch, 1770.

Jennens, J. C., London ; chiming bracket clock, about 1790 , seen at The Hague.

Jennings. Emanuel, apprenticed 1682 to Jno. Colston, C.C. Robert, C.C. 1703. Thomas, C.C. 1721. Charles, C.C. 1725.

Jernegan, Edward, Great Russell St., 1737-40; Featherstone Buildings, 1750-59.

Jerome, Chauncey, pupil of Eli Terry, maker of American clocks, born at Canaan, Litchfield Co., 1793 ; with his brother, Noble Jerome, he began business at Bristol, Conn.; in 1842 he shipped clocks to England, which the Customs authorities seized and paid for, believing they were undervalued. Shortly afterwards he started the Jerome Manufacturing Co., at New Haven, Conn.

Jerrad, Henry, Hinton ; clcck, about 1770.

Jersey, Francis ; bracket clock, abc ut 1760.

Jervis. Francis, apprenticed in 1656 to Ralph Greatcrex, C.C. Jno., Stockport, 1833 .

Jessop, Josias, 38 Southampton St., Covent Garden, 1781-90, see Wilson, W. Jeubi, Josias, Paris ; watch, about 1630. Jevon. Henry, C.C. 1673. May, C.C. 1706.

Jeyes, Sam., apprenticed in 1670 to Philip Smith, C.C.

Job. W., London ; watch, 1795. Robert, 25 Charlton St., Somers Town, 1835; 7 Park Terrace, Camden Town, 1842. Fredk., 25 Sherrard St., Golden Sq., 1835; 17 Tichborne St., Haymarket, 1842.

Jodin, Pierre, born at Geneva 1715, died 1761 ; author of "Les Echappemens à repos à ceux échappemens à recul," published in 1754 .

Johann; clock at Mainz, about 1820 , signed "Nicolas Alexius Johann à Mayance." A., author of "Traité Générale d'Horlogerie," born 1822, died 1882 . 
John, Hans, Königsberg ; maker of a curious watch, B.M., having attached a small wheel-lock pistol, supposed to have been used as an alarm, about 1650 .

Johns, Thos., London; about 1700.

Johnson. Roger, petitioner for incorporation of C.C. 1630 . George, C.C. 1649. Jery, Exchange Alley; apprenticed in 1660 to Abraham Beckner; admitted C.C. 1668 ; in the B.M. is a small watch of his make in an irregrlar octagonal-shaped case with a faceted crystal over the dial, about 1650. Wm., f., of York, 1665-1713. Jeremiah, Exchange Alley, C.C. 1668-90 ; bracket clock, strike-silent, full quarter, about 1700 . John, C.C. 1678 . John, 3 Flower de Luces, Cheapside; C.C. 1680, see Betts, Job. Michael, Barnard Castle ; C.C. 1687 ; watch, about 1720 . Benj., London; long-case clock, about 1690. William, apprenticed to Dan. Quare in 1690 ; C.C. 1702 ; bracket clock, bell-top ebony case, with handle, brass dial, bob pendulum, style 1725 , strike-silent. Cornelius, C.C. 1694. Robert, Edinburgh, apprenticed to Andrew Brown in 1696; watch, signed " R. Johnson, Wooltown," 1720. Thomas, C.C. 1700 ; Mr. R. Eden Dickson has a fine inlaid long-case clock, inscribed "Tho. Johnson Ratcliff Cross," about 1705. John, C.C. 1701. John, Fleet Lane, 1701. Isaac, C.C. 1705 ; watch by him, 1720. James, apprenticed to James Delaunder ; C.C. 1706. Thomas, Richmond ; C.C. 1713 ; watch, S.K.M., about 1745. Isaac, C.C. 1723 . Thomas, 9 Gray's Inn Passage, about 1730. Charles Jacock, apprenticed to Robert Higgs ; C.C. 1750. Roland, Liverpool, 1766. Jno. \& Thos., also James, Prescott, $1770 . \quad$ Richard, Ripon, 1770. Jno., Walton ; clock, about 1770. Wm., Flixon; clock, about 1700. John, 9 Gray's Inn Passage, 1770-99; balloon bracket clock, round enamelled dial, case and bracket of ebony with brass mountings, about 1790, Wetherfield collection (see p. 592). Christopher, Knaresborough, 1775. Peter, Mitcham; watch, 1790. James, New Rd., St. George's East, 1790-94. John, Elm St., Gray's Inn Lane, 1790-1835. Joseph, Liverpool, 1796-1830. J. F., Dublin; watch, 1812. Richd. 18 Francis St., Bedford Sq., 1815-20. C., 7 Sweeting's Alley, 1820-23. J. \& W., 19 Cross St., Hatton Garden, 1825. L eond. 19 Bartlett's Buildings, 1825. William, 50 Strand, 1825-42 ; diminutive bracket clock, about 1825. \& Co., London ; repeating watch, 1830. James, 18 Paddington St., 1835-42. - High Wycombe; long-case clock, about 1840. Edward Daniel, 9 Wilmington Sq. ; a leading watch manufacturer, formerly with James Stod- dart; retired from business 1879 ; died at Highbury, 1889, aged 73. J. M., Huddersfield, 1880-1918.

Johnston \& Brecians, London ; watch, h.m., 1816. G., 7 Queen St., Northampton Sq., 1835. Jno., Glasgow ; patented a pedometer watch in 1840 (No. 8,645). A. A., head of the firm of Gillett \& Johnston, Croydon, died 1916.

Jole. Robt., C.C. 1667 . Thos., apprenticed 1680 to Robt. Fole, C.C.

Jolly. J., watchmaker to the Paris Town Hall in 1550; worked also for Catherine de Medici; a watch by J. Jolly, Paul Garnier collection; skull watch (Soltykoff collection) by Jacques Jolly, about 1580 ; two watches by Joshua Jolly, Vienna Treasury, splendidly enamelled cases and dials, about 1670; at Deene Park is a magnificent Louis XIV. bracket clock, inscribed " I Jolly à Paris ; " it belonged to the Duke of Sussex and was purchased at the sale of his effects by the late Earl of Cardigan. Dan., apprenticed in 1637 to Jno. Droshute, C.C. Joseph, 11 Dean St., Fetter Lane, 1790-94. François, 1790.

Joly, Jacques, London; in the B.M. is a watch by him, 1620-30; watch, signed " Geo. Joly à Mondont; " on dial, "Joly le Cadet," about 1765.

Jon, J., London; lantern clock, arch dial, about 1730 .

Jonas, Saml., Exon ; watch, 1783.

Jones. Evan, C.C. 1648 ; signed petition 1656, assistant 1671. Marmaduke, apprenticed in 1652 to Evan Jones, C.C. Henry, Inner Temple Gate; apprenticed in 1654 to Edward East; C.C. 1663; master 1691 ; an eminent maker (see pp. 274-276). "Lost on 29 th instant in Lincolns Inn fields, one silver striking watch with the day of the month in a steel case studded and garnished with silver made by $\mathrm{Mr}$. Jones in the Inner Temple Lane, watchmaker. Whoever can give notice hereof and bring the said watch to Mr. Humphry Davis at the Duke's Head in Lincolns Inn Fields or to Mr. Jones aforesaid shall have 40s. reward " (Lond. Gaz., 27 Jan. 1675-6). Chas., apprenticed in 1663 to Walter Gibbs, C.C. William, C.C. 1663. Henry apprenticed in 1668 to Chas. Bonner, C.C. Dan., apprenticed in $\mathbf{1 6 7 2}$ to Edwd.Wilson, C.C. Benj., apprenticed in 1676 to Richd. Halstead, C.C. Thomas Wm., C.C. 1679 ; very small watch by him, Schloss collection, gold dial, raised figures, outer case leather piqué; another with splendid pillars, balance-spring stud underneath plate ; watch, "Thos. Jones, London," about 1680 . Wm., apprenticed in 1682 to Henry Jones, C.C. Edwd., apprenticed in 
1686 to $\mathrm{Wm}$. Bartram, C.C. Jas., apprenticed in 1687 to Philip Thacke, C.C. Jonathan, apprenticed to Robert Smith, and turned over to Nathaniel De Launder ; C.C. 1687. David, C.C. 1687 . Sam., apprenticed in 1688 to Edmund Massey, C.C. Henry, apprenticed in 1690 to $\mathrm{Hy}$. Jones, his father; C.C. 1698. Henry, C.C. 1697-8. Richd., London; long-case clock, about 1700. Valentine, C, C. 1704 . John, C.C. 1716. John, master C.C. $1762 ; 1748-63$. Saml., Bath; watch, 1769. J., Chalford, Stroud, maker of Chalford Church clock; clock by him in the collection of Mr. Hansard Watt, about 1770. Jno., London; repeating watch, 1775 . Jenkin, 61 St. James's St., 1775-83. Owen, Little George St., Minories ; livery C.C. 1786 ; 1780-94. William, 27 Barbican; livery C.C. 1786 ; 31 Little Moorfields, 1810 ; 1780-1810. David ; watch-pendant maker, 69 Bunhill Row, 1790-94. James, 65 Banner St., 1795-1810. Robert, 49 Little Bartholomew Close, 1800. Wm., White Cross St., 1810-15. Jno., Chester, 1814-28. \& Grant, 123 New Bond St., 1815-18. Robert, Ruthin; watch, 1819. Sam., 78 Cheapside, 1820-25. John, 338 Strand, 1821 ; succeeded by his son, John Jones, a man of high attainments and a successful manufacturer; vice-president of the British Horological Institute; he retired from business in 1885 ; and died at Send Green, near Woking, 1910, aged 94. \& Forester, Hull, 1822. F., 62 Cornhill, 1825. W., 132 Holborn Hill, 1825. John \& Timothy, 20 Red Lion St., Clerkenwell, 1825-30. Timothy, 18 Ludgate St., 1826-40. Robt., Lancaster, 1889-1919.

Jonnereau, see Gounouilhou.

Jonston, Robt., Cumber ; clock, about 1770.

Jordan. Jas., Chatham, 1710. Jno., Bristol ; watch, silver cock, about 1720 ; long-case clock, about 1730. Timothy, 40 Snow Hill, 1770-80. Thos., Stadhampton, Oxon., 1780. Aaron, London, 1790.

Joselin (or Josslin), Edwd., apprenticed in 1690 to Jas. Wolverston, C.C. ; John Hocker served him as apprentice in 1728. Josephson, - London ; many watches, Dutch style, 1760-90.

Joslyn, James, New Haven, 1798-1820. Jouard, L., Paris; garde-visiteur, 1769. Jourdain. William, apprenticed in 1646 to Robt. Smith, C.C.; timepiece with crown wheel escapement, short pendulum with pear-shaped bob, and 8-in. silvered dial; through a short circular slit in the upper part of the dial is shown a small silvered star, which vibrates with the pendulum, about 1680 ; clock by him, German oak case, dial Dutch style, in the Central Hotel, Kassel ; watch, about 1690. A.,
6 Wheeler St., Spitalfields, 1790-94. R., 29 Marshall St., Golden Sq., 1835.

Jovat, - London; calendar watch, about 1700 .

Joyce, George, C.C. 1692. Jno., Ellesmere, 1698. Stephen, Moor St., Soho, 1769. Samuel, \& Co., 38 Lombard St., 1790-1842. James, Whitchurch, a well-known clockmaker, died 1883, aged 62 .

Joyne. Jno., apprenticed in 1660 to Jno. Smith, C.C. 1687. Jno., St. Germain, Paris; watch, B.M., square case, crystal cover, 1690-1710.

Judson, Thomas; sent a letter to C.C. relative to watches seized, 1790 .

Juhan, A., Dortrecht ; watch, 1776.

Juler, Jno., N. Walsham, 1770.

Julian, Gregory, C.C. 1664.

Jullion. John, Brentford, 1730. \& Son New Brentford, 1771 ; watch, " J. Julien, Brentford," 1792. Francis, London ; longcase clock, about 1780 .

Julliott, Solomon, London ; verge watch by him in the Guildhall Museum, date on mainspring, 1738.

Jump. Richard Thos., inventor of the proportionate gauge called a sector, which is used chiefly for wheels and pinions; joined B. L. Vulliamy in 1812. Joseph, son of R. T., apprenticed in 1827 to B. L. Vulliamy, with whom he remained till Vulliamy died in 1854 ; afterwards at Bond St. and Pall Mall; died 1899.

Jung, Herman, a clever Swiss horologist who settled in Clerkenwell; assassinated 1901 .

Jŭrgensen. Joergen, Copenhagen ; died 1811. Urban, Copenhagen, son of the foregoing; born 1776, died 1830; an eminent maker; author of " The Higher Horclogical Art" and "Principes de la Mesure du Temps" ; Jürgensen was associated with the leading men of his day; he experimented with compensation balances made of brass and platinum, and strongly advocated the use of gold springs for marine chronometers; he made many excellent chronometers for the Danish navy, and very successful metallic thermometers. Louis Urban, Copenhagen, eldest son and successor of Urban ; born 1806, died 1867. Jules Frederik, another son of Urban, was born in 1808 at Locle during a short sojourn of his parents there in 1808 ; on attaining manhood he returned to Locle where he founded a business : his watches were highly esteemed in America; he died in 1877. F. U., son of Jules F., published in 1887 a biography of Ingold.

Just. Leonard, St. John's Sq. ; 17901825; maker of watches for the Chinese market. Leonard, Myddelton Sq., 183042. George, 22 Anderson's Buildings, 
City Rd., 1830-42; he made watches with movements wholly of steel, except the jewels and the bushes for the larger pivot holes, which were of gold; they were chiefly for the Chinese market; the pinion leaves wore into ruts quicker than if working with brass wheels.

Justis \& Comp, Well Yard, St. Bartholomew's Hospital, 1769.

K. Watch ; tambourine case of brass, stackfreed, foliot balance, signed "A.K.," about 1570, Pierpont Morgan collection; octagonal watch, about the same date, marked " M.K."

Kaiser, Kleyser \& Co., wooden clockmakers, 4 Broad St., 1840.

Kaltenback \& Fuller, 77 Blackman St., 1834-42.

Kammerer, Joseph, wooden clockmaker, 51 King St., Borough 1840.

Kangiesser, S., 24 Șouthampton St., Strand, 1816-25.

Kanns, John, C.C. 1712.

Kater, Captain Henry, R. S., conducted experiments for determining the length of the seconds pendulum in the latitude of London, 1817.

Kay. David, Dundee ; made a clock for St. Mary's Church in 1554. Jno., London ; long-case chime clock, about 1750 .

Keal, Wm., London; watch, 1799.

Keandler, Chas., Jermyn St., 1793.

Keat. Joseph (?Kent), 19 Cock Hill, Ratcliff, 1810. Edward, 69 Banner St., St. Luke's, 1830-40. Mrs. Mary Anne,19 Broad St., 1840. Sophia, 60 Banner St., 1842.

Keate, Robt., Wallingford, 1780.

Keates, Wm., 135 Fleet St., 1783-1800.

Keating, A., 114 Strand, .1796-1815.

Keddon(or Kedden),Daniel,LittleBritain, C.C. 1717 ; fine japanned long-case clock, about 1730 ; watch, about 1740 .

Keef, Thomas, 22 Rosoman St., Clerkenwell, 1835.

Keeling, George, musical clock maker, Webber St., Blackfriars Rd., 1840.

Keely, W. ; gilder, Orange Court, Clement's Lane, 1790-94.

Keeys, Jeremiah, London ; watch, 1800.

Kefford, Thomas, Royston; lantern clock, about 1710 ; long Oriental lacquer case clock, about 1730 , see Coxall.

Kehlhoff, Frederick, St. George-theMartyr, Southwark; patented in 1764 (No. 819) a centre-seconds going-barrel watch, with stackfreed and remontoir.

Kelham, Mathias, near Vintners' Hall, C.C. 1730 .

Kell, Jno., C.C., about 1650.

Kellet, Thos., fined by C.C. for defective watch, 1635 .
Kellet, - , Bredbury ; long-case clock, about 1770, Mr. T. R. Howarth; at top of the arch is the motto, "Time feasts on all terrestrial things." 30 .

Kelley, Allan, Sandwich, U.S.A., 1810

Kello, Simon, apprenticed to John Higgs and turned over to Jos. Jackman; C.C. 1723.

Kells, Edwd., Shepley, 1770.

Kelly, Jno., Bristol, 1884.

Kelly, Richard, Devereux Court, Strand ; long Chippendale case clock, about 1790.

Kelme, - London; small timepiece on a horse, in the Massey-Mainwaring collection, 1670.

Kelton, Simon, C.C. 1723

Kember, Jos. Shaw, watch, 1776.

Kemble. William, New York, 1786. J. T., Knightsbridge, 1817.

Kemp. Charles, apprenticed to Prettyman Sergeant, and turned over to Charles Gretton; C.C. 1688; Thos. Tompion, junr., apprenticed to him in 1694. Richard, C.C. 1701 . - Lewes; watch, 1760. \& Holman, Lewes; watch, 1782. William, livery C.C. 1786. Joseph, Curtain Rd., 1790.

Kemps. Anthony, 1650. Matthew, son of Anthony ; C.C. 1670.

Kendal, James Francis(Kendal \& Dent), died 1911, aged 67 .

Kendall. Larcum, born at Chalbury, Oxford, 1721; apprenticed in London to John Jeffreys, 1735 ; 20 Wood St., Cheapside, 1750 ; Furnival's Inn Court, 1765, when he was one of the judges appointed to report on Harrison's timekeeper; in 1766 he agreed to make a duplicate for the Commissioners of Longitude, undertaking to reproduce faithfully the various parts without being held responsible for the performance; the price was to be $£ 450$, and he stipulated that one-half should be paid in advance; the date on this instrument is 1769 ; but it was in January, 1770 that he addressed a letter to the Committee desiring them to inspect it. Kendall afterwards made a much simpler instrument than Harrison's without the remontoir action, and with an ordinary seconds hand; the date on this is 1771; it was presented to the United Service Institution by Rear-Admiral Sir Thomas Herbert, K.C.B., in 1854, when this inscription was engraved on it by Messrs. Lambert: "This Timekeeper belonged to Captain Cook, R.N., and was taken by him to the Pacific, 1776. It was again taken to the Pacific by Captain Bligh in the 'Bounty,' 1787. It was taken by the mutineers to Pitcairn Island, and was sold, 1808, by Adams to a citizen of the United States, who sold it at Chili, 
where it was purchased by Sir Thomas Herbert." There is a fine watch with a remontoir escapement by him in the Guildhall Museum. He died in 1795. 17 St. John's Sq., 1790-94.

Kendrick. John, C.C. 1719. John, C.C. 1726. Wm., 36 Lombard St., 1772.

Keney, Vincent, received $£ 19$ 16s. 8d. from Henry VIII. for " $\mathrm{xj}$ clocks and dialls," 1530.

Kenfield, Richd., Winton ; fine long-case clock, about 1740 .

Kennedy. Thos., Wigan ; watch, 1759. Patrick, Philadelphia, 1797. Jas., London ; fine duplex watch, Mr. Thos. Fisher 1813.

Kenney, William, threatened with prosecution by C.C. for exercising the art, not being admitted, 1682 .

Kenning. Wm., C.C. 1684. Edwin, London; lantern clock, about 1705.

Kennon, Wm., apprenticed in 1656 to Job Betts ; C.C. 1674.

Kent. Henry, Westminster ; C.C. 1646. Wm., apprenticed in 1681 to Sam. Marchant, C.C. Jas., Manchester, 1759. Jno., Manchester, 1770 . - Monmouth ; watch, 1799. Joseph, 19 Cock Hill, Ratcliff, 180617. John., 19 Broad St., Ratcliff, 1817-35.

Kentish. John, Pope's Head Alley, 1758-61. John, \& Haynes, 18 Cornhill, 1769-88; watch,skeleton movement,about 1800 , signed "John Kentish, junr."

Kenton, Joseph, admitted C.C. 1686.

Kerby, Thomas F., London; clocks, about 1760. Fras., St. Helier ; long-case clock, about 1810, Mr. C. Davis.

Kerner \& Paff, 245 Water St., New York, 1796 ; "Musical clocks with figures, and cuckoo clocks" (advt. New York).

Kershaw, George, Tyler's Court, Carnaby Market, 1780-94.

Kersill, William, 21 Aldersgate St., 1775 .

Kessborer, Johan, Ulm (South Germany), watch in engraved silver case, second half of seventeen th cen tury, S.K.M.

Kessels, Heinrich Johannes, Altona; a celebrated maker of astronomical ciocks ; died 1849 .

Kettle, G., London ; watch, 1795.

Kettlewell, Jno., Ripon, 1833.

Kewell, Thos., apprenticed in 1685 to Richd. Colston, C.C.

Key, Jno., Warrington, 1770.

Keyes, Markham, apprenticed in 1653 to Jere. Gregory, C.C.

Keymes, Joseph, apprenticed in 1673 to Dan. Stevens, C.C.

Keys, David, Craven St., Strand, a wellknown manufacturer of watches, died 1887, aged 74 .

Keyte, Rd., Whitney, 1770.
Keyzor, Louis, 16 Tottenham Court Rd., 1835-40.

Kiblich, Matthew, Presburg ; watch by him, Vienna Treasury, oval white enamel case ornamented with flowers, bezel encrusted with brilliants and emeralds, about 1716 .

Kidd, Jno., apprenticed in 1656 to Job Betts, C.C. Gilbert, Malton, 1760-80.

Kidder, John, 6 Strand, 1816-23.

Kidson, Wm., York, f., 1614.

Kilbey, F., Cheltenham, died 1911.

Killingworth, Jno., 200 Brick Lane, Spitalfields, 1815-18.

Kilminster, Henry, C.C. 1677.

Kimbell, Thomas, 214 Tottenham Court Rd., 1842 .

Kinable, -, lyre clock (see p. 436).

King. Thomas, C.C. 1669 ; marquetry long-case square dial clock, 1669-90. Jonathan, C.C. 1689 . Nehimiah, lantern clock, Mr. C. H. Read, dated 1693 . William, in " Birching Lane, watchmaker," admitted a freeman of the Cutlers' Company in 1707. Peter, Long Acre, C.C. 1715 ; Mr. Norman Shaw has a long-case clock by him in a fine marquetry case. William John, Monkwell St., C.C. 1720; in the B.M. is a watch by him with repoussé case, 1730 ; another example, a repeating watch, 1745 . Henry, Lincoln's Inn, C.C. 1720; watch, gold repoussé case, Schloss collection, h.m., 1786. John, C.C. 1729. Isaac, Moorfields, 1730. John, Gough Sq., 1758-61. Thomas, Alnwick, 1773. Wm. Jno., Berkley Court, Clerkenwell, 1780. Thomas \& Benjamin, 82 Upper East Smithfield, 1802-25. W., 34 High Holborn, 1822-30. Thomas, 130 Minories, 1835-42. Alfred, Chippenham, 1843.

Kingman, Jas., 104 Leadenhall St., livery Goldsmiths' Co. 1774-83.

Kingsmill, George, C.C. 1667.

Kingsnorth, Jno., apprenticed in 1688 to Thos. Stubbs, C.C.

Kinnear, Charles, 33 Frith St., 1833.

Kinning, John,C.C.1701 ; watch, encased in glass, B.M., 1700-30.

Kipling, William, Broad St., near Ratcliff Cross; oak long-case clock, square dial, about 1710 ; watch with sun and moon hour indicators, Whitcombe Greene collection, about 1720 ; another watch, h.m., 1730 ; another example, bracket clock, brass arched dial, strike-silent, day of month, elaborately inlaid case of hard wood, prolongation of pendulum seen through arc slot in dial; brought from the Emperor's Summer Palace at Peking, 1860 ; had then crown escapement, and was a "pull repeater" with eight very sweet bells ; engraved back plate, 1705-37. Mr. Edward Campbell has a clock by him with Turkish numerals and corner pieces 
(in the dial in the form of a crescent. "Wm. and John Kipling, London," on clocks about 1750 , see Bosley, Charles.

Kippis, Geo., apprenticed in 1687 to Chris. Gould, C.C.

Kirby, Robert, C.C. 1722. Charles, London; watch, 1795.

Kirk. John,C.C.1677. Joseph, Nottingham; long-case clock, about 1750 . Wm., Stockport, 1760. Wm., Manchester, 1770.

Kirke, Charles, Bristol, Conn., 1840.

Kirnier \& Kleyser, 14 Oxford St. ; card, B.M., 1791.

Kirton. John, apprenticed to Daniel Quare; C.C. 1705. R., enameller, Red Lion St., 1790.

Kissar, Samuel, C.C. 1712.

Kitchen (or Kitching). Jno., Nantwich, 1775. \& Lloyd, Nantwich; long-case clock, about 1790. B., 32 Compton St., 1842.

Kitching, Joshua, 14 D'ver St., Piccadilly, 1816-23.

Klaftenberger, C. J., 157 Regent St., a skilful watchmaker, some time vicepresident of the Horological Institute; died 1874 , aged 79 , see Aubert.

Kley. The late Mr. R. Norman Shaw had a musical clock which plays every hour dating from about 1750 , and inscribed "John Kley, London." It was brought from Amsterdam.

Kleyser. Jno., wooden clockmaker, 191 High Holborn, 1790-94. George, \& Co., wooden clockmakers, 3 Little Tower Hill, 1790-94. \& Kaltenback, wooden casemakers, 196 High St., Borough, 1810-25. T. \& J., 191 High Holborn, 1810-30. \& Fritschler, 405 Oxford St., 1835-42. John; wooden case-maker, 66 Borough High St., 1840 .

Kline, Philadelphia : Jno., 1820； B., 1841 .

Kloch, P., Amsterdam; enamelled watch, about 1700 .

Kneeshaw, Robt., Stokesley, 1822.

Kneller, Johann Michael, watch, B.M., square brass case with silver filigree overlay, $1630-40$.

Knibb. Samuel, C.C. on redemption 1663. Joseph, Oxon., C.C. 1670 (see p. 325). Mr. Hansard Watt has a fine miniature timepiece by this maker (see p. 329). Peter, C.C. 1677. John, Oxon., verge watch movement, with curiously wrought pillars, G.M., style 1690 ; long-case clock, about 1695 ; in the Wetherfield collection is a bracket repeating timepiece by him, see Aldworth. Ed., apprenticed in 1693 to Joseph Knibb, C.C.

Knifton, Thomas, at $\mathrm{Y}^{\mathrm{e}}$ Cross Keys in Lothebury, 1640-57. Fine lantern clock by him (see p. 480). Another specimen is in the possession of Mr. A. Stanley Cooke. Mr. Hansard Watt has a lantern clock by this maker as shown in Fig. 635. He was probably succeeded by John Ebsworth.

Knight, Michael, apprenticed to Lionel Wythe and turned over the Thos. Tompion, C.C. 1681 ; fine long-case clock, bird and flower marquetry, about 1690. Richard, C.C. 1682. Charles, Flower-de-luce, Great Russell St. ; C.C. 1685-97. Thos., apprenticed in 1686 to Dorcas Bouquett. Henry, C.C. 1723. Wm., West Marden, about 1750. - Thaxted, 1760 . John, 6 Carpenters' Buildings, London Wall, 1768. $\rightarrow$, Dunmow, 1780. Benjamin, New St.; Dockhead, 1790. - - West Marden, abjut 1790 . Valentine, gold dial maker and engine turner, Newcastle Place; first president of the British Horological Institute; born 1793, died 1867. Jno., Portsea; watch, 1837. Thos., Bristol, 1844.

Knollys, Francis, apprenticed in 1669 to Jno. Harris, C.C.

Knott, Robt., aprenticed in 1682 to Clement Forster, C.C.

Knottesford, William, apprenticed to Hy. Child; C.C. 1663; master 1693; bracket clock, about 1680, with seconds dial and maintaining power; walnut case with spiral ebony columns as seen on hoods of long-case clocks; circular silver watch, B.M., also a repeater in S.K.M., h.m., 1684, and a large clock-watch, G.M. Jno., apprenticed in 1680 to Wm. Knottesford. C.C. ; month chiming clock in fine marquetry long case, Wetherfield collection, about 1700, inscribed "John Knotsford, London.'

Knowles. Andrew, Epsom, 1730. Joseph, Epsom; watch, 1760. Wm., Dublin, 1780, James, 2 Hospital Row, Chelsea, 1835-40.

Knox. John., Belfast, 1729-83 ; John, nephew of the preceding to whom he was apprenticed, started business in Larne, and on the death of his uncle succeeded him in High St., Belfast; engraved a portrait of Washington for a watch paper ; retired 1816, see Neill, R. Alex.,Berwick, 1770. Wm., Paisley, 1780.

Köberle, Wilhelmus, Eijstet (Eichstadt, South Germany); early clock-watch in case of gilt brass, pierced and engraved, S.K.M.

Koch, Johann, Cöllen ; alarm calendar watch, about 1630 , Miss M. Humphreys.

Kock. Jacob, Stockholm ; watch, 1740. Peter, Harlem; watch, 1780.

Koppaun, Christof, German square table clock, S.K.M., signed and dated 1582 .

Koster. Dirk, Amsterdam ; watch with sun and moon indicators, G.M., about 1695. Wm., Amsterdam, about 1700 .

Kotte, Jacob, antique watch, Shandon collection, about 1630 .

Kover, - Iondon ; handsome watch, gold repoussé case, about 1720 . 
Kratzer, see Cratzer.

Krauth, F. T., Gt. Hampton St., Birmingham, died 1909 , aged 62 .

Kreitt-Mayer,Johann, about 1645 ; watch ascribed to Bruce.

Kreizer, Conrad, watch in the form of a cross, Vienna Treasury, case of crystal, dial of silver, dial of gold, with instruments of the Passion engraved thereon, about 1600 ; octagonal watch, S.K.M., about1600.

Krenckel, Peter, Eüchstet (or Füchstet); alarm table clock belonging to Major W. J. Myers, S.K.M., about 1700.

Kroese, J. P., Amsterdam; watch, fine enamel painting of Cleopatra; about 1770.

Kullberg, Victor, born at Gothland, Sweden, 1824. In 1851 he came to London, where he died in 1890 . One of the most brilliant and successful horologists of the nineteenth century. Inventor of a compensation balance with a flat rim.

Kyezor, Louis, 46A Edgware Rd., 16 Tottenham Court Rd., and 3 Great Turnstile, 1842.

Kyffin, Edward, apprenticed in 1682 to Jno. Brown, C.C.

Kynvyn, Jonas, maker of a clock belonging to the Earl of Essex, 1593.

Laborne, Christopher, Gt. Driffield, died 1831

Labru, - London; hexagonal table clock, about 1680 .

Lacey. Paul, Bristol, 1780. Chas., 12 Ludgate St., 1783.

Lacon, Peter, London ; watch, 1785.

Lacour, Daniel, New St., Covent Garden, 1825.

Ia Croix. - , Rue Denis, Paris ; handome clock, about 1790. —, Geneva; watch, 1814.

Ladd. Sam., C.C. $1709 . \quad$ J., 35 Cornhill, 1823.

Ladoneau, Jean, Paris ; clockmaker to Louis XIV., 1680.

Lafons, see De Lafons.

Lafosse,Wm., 32 Old Broad St., 1738-94.

Lagoe, Jno., apprenticed in 1671 to

Richd. Halstead, C.C.

Laidlaw, Thomas, 16 Salisbury Sq., 177094; hon. freeman C.C. 1781.

Lain'́, -, Paris. Miniature alarm clock in collection of Mr. Hansard Watt, about 1790.

L'Ainge, -, 82 Cheapside, 1842.

Lainy. David, watch in the Guildhall Museum, about 1670. John. C.C. 1720. Laisne, Sibelin, Neuchâtel, about 1750.

Lake. Bryan, C.C. 1674 ; 30-hour clock, bob pendulum, "J. Lake, 1723," Mr. A. A. Carnell. Thos., Taunton, 1770.

Lamb (or Lambe). Several generations beginning with Thomas Lambe, 1630; in
1704 it was reported to the C.C. that among other well-known makers the name of Lamb had been engraved on watches by persons in Amsterdam, which watches were sold as of English make. Abraham, apprenticed in 1651 to Wm. Petit, C.C. Simon, apprenticed 1669 to Wm. Glazier, C.C.; long-case clock, about 1700,inscribed "Simon Lamb, Rochester" (see p. 526). Luke, apprenticed in 1683 to Johnson Weekes, C.C. Jno., Henrietta St., C.C. 1714. Benj., 21 St. John's Sq., 1760-79. \& Webb, 21 St. John's Sq., Clerkenwell, 1780-95. Thos., Union St., Spitalfields, 1790. Jno., 13 Red Lion St.,Clerkenwell, 1822-52. Sarah, 2 Lower Queen's Row, Pentonville, 1842 .

Lambden, Richd., apprenticed in $\mathbf{1 6 8 5}$ to Joseph Hussey, C.C.

Lambe, Thomas, C.C. 1632. Edward, C.C. 1675 ; long-case clock, about 1690 . John, 29 Fetter Lane, 1774-1800.

Lambell, Samuel, Northampton, 1750.

Lambert. Pierre, Abbeville; watch. about 1680 . Jno., London ; Mr. Herbert Southam has a long-case square dial clock by him, the movement dated 1703 . Wm., Cannon St.; C.C.1730. Nicholas, London, 1750-70; long-case clock (see p. 551); chiming clock by him on the mantelpiece of the vestry of Lady Huntingdon's Chapel, Bath, with the inscription, "This clock is the property of the Church at the Vineyards, Bath, given by the Countess of Huntingdon for the use of the minister for the time being." Jas., London ; watch, 1760. John, 2 Tichborne St., 1775-1810. -, Besançon; French enamelled watch, about 1780. Francis, partner with Hamlet in 1800; afterwards started business at 12 Coventry St., and subsequently entered into partnership with Rawlings at the same address. Henry, 93 Piccadilly, 1840. Henry, 119 Cheapside, 1842.

Lamione, A., Philadelphia, 1811.

Lampe, John, Henrietta St., admitted C.C. 1713 ; Chippendale long-case clock, large hood and gallery round the top, inscription on disc, "John Lampe, London;" 1713-65.

Lamplough, Jno., Bridlington, 1822.

Lamport, -, Bow St., Bloomsbury ; watch, h.m., 1810 .

Lamson, Charles, Salem, 1850, see Balch.

Lamude. Peter, apprenticed in 1684 to Nat. Delander, C.C. Jno., Chard, about 1740. Reu., Chard; watch, 1760.

Lancaster, Richard., apprenticed in 1677 to Thos. Hollis, C.C. Nicholas, apprenticed in 1679 to Stafford Freeman, C.C. Richard, apprenticed in 1684 to Hy.Merriman, C.C. Francis, London; a good workman, 1790-1800. 


\section{4.}

Landlen, Thos., 16] Salisbury Court, Landre. Pierre, Blois; skull watch, Pierpont Morgan collection, about 1630 . L., Brussels, about 1650. P., Brussels, 1700.

Lane. Jno., apprenticed in 1679 toSam. Vernon, C.C. W., Calstone; long-case chiming clock, about 1750. Henry, Bristol ; long-case clock, tidal time in arch, and above, "High Water at Bristol Key." about 1780. John, Fetter Lane, about 1785. Geo., 185 High Holborn, 1893.

Langcroft, Richard, C.C. 1718.

L'Ange, A., 5l Cornhill, 1835.

Lange. Adolf Ferdinand, born and apprenticed at Dresden ; afterwards worked for Winnerl, Paris; an excellent and progressive watchmaker; settled at Glashütte, Saxony; died 1875, aged 60. Christian, 99 Strand, $1870-86$.

Langford. Gowen, C.C. 1652. Ellis, apprenticed in 1663 to Gowen Langford; C.C. 1672. Wm., Ludlow, 1770. Thos., hon. freeman, C.C. 1781 ; long-case clock, "Langford, Southampton," about 1780; White Horse Hotel, Romsey ; broken arch bracket clock, enamel dial, about 1795 . Wm., Bristol, 1844.

Langhorne, Thomas, Threadneedle St., liveryman C.C. 1776.

Langley. Thomas, C.C. 1664. Cornelius, C.C. 1706.

Langstaff, Thos., Middlesboro', 1843.

Langton, Jas., Founders' Ct., Lothbury, 1776.

Langwith, Jas., York, f., 1722. Sam., York, 1770 .

Lansdown, Geo., 42 Wilson St., Bath, 1845 , see Haddack.

Lanson, J., Bradford ; long-case clock, about 1750 .

Lants, Niklas, Innsbruck, 1550.

Larrard. Thos., Hull, 1814-40. Jas.,

7 New Bridge St., 1830-42.

Larcay, L., Paris ; an eminent horologist, $1725-35$; he is spoken of by Thiout as Larsé.

Large. Jonathan, London ; long-case clocks, about 1790. Augustus, 51 Cornhill, 1840.

Larmett, Abraham, C.C., about 1650.

Laroch, John, 18 High St., Bloomsbury, 1815-25.

Lasarus, Abraham, Gun Yard, 1760-65. Lashbrook. Jno., apprenticed in 1655 to Wm. Pettitt, C.C. Thos., apprenticed in 1693 to Richd. Conyers, C.C. Henry, C.C. 1715 .

Lasoffe, William, 52 Old Broad St., 1765-70.

Lassel. -, Toxteth Park, Liverpool ; long-case clock, "Lassel, Park," about 1735. William, several long-case clocks, 1740-70. Thurstan, long-case clock, about 1775 .
Lasseter, William, Arundel ; maker of long-case clocks, about 1770 .

Last, W. R., Yarmouth; watch, 1810. Latham. Hy., apprenticed in 1655 to Humfrey Downing, C.C. John, C.C. 1700; watch with gold repoussé case, S.K.M.; 1720 ; in the Church of the Capucino, Cadiz, is a long-case clock by him; Mr. Beck, the Plough Inn, Cadsdean, Princes Risborough, Bucks., has another in a mahogany case, inscribed " John Latham, London." Wm., Macclesfield, 1775. T., London; watch, 1795. Jas., Preston, 1814. Latimer, Jas., Philadelphia, 1819.

Latour, René, admitted C.C. 1730.

Laud, Thos. In 1638 Thos. Fitton was apprenticed to him; C.C.

Launay, David F.,watchmaker, 9 Warren St., New York, 1801, "has a high finished clock which decorated the library of the late King of France, made by Charles Berthand, of the Royal Academy; its original price 5,000 livres; to be sold for 500 dollars."

Laundy, Jno., apprenticed in 1692 to Thos. Walford, C.C.

Lauriere, J., 62 St. James's St., 182230.

Lautier, Bath, see Vigne.

Laver, Benjamin, 4 Bruton St., Berkeley Sq., 1790-1800.

Lavespeare, Wm., C.C., about 1650.

Law. Isaac, forbidden to work by C.C. in 1632, afterwards made free of the Company. Silvester, apprenticed in 1689 to Richard Baker, C.C. Timothy, apprenticed in 1690 to Wm. Cart, C.C. Jere., Rochdale, 1780. Thomas, 27 Thomas St., Southwark, 1790-94. Anthony, 68 Borough High St., 1840-42.

Lawell, Paul, C.C. 1653.

Lawley. Alvis, Bath, 1826. Jno., also F., Bath, 1835. Bernhard, 253 Borough High St., 1840-42.

Lawrence. Hy., apprenticed in 1691 to Richd. Colston, C.C. Lancaster: Jno., 1761, f. ; Wm., 1785, f., Bristol : Henry, 1770 ; Wm., 1780 ; -, Bath, 1763 ; W., Thame, 1765. Thos., London; watch, 1772. James, 13 Bolingbroke Row, Walworth Rd., 1835. G., 74 Paradise St. Rotherhithe, 1835-42. \& Son, 171 Tooley St., 1835.

Lawrie, -, Carlisle ; clock, about 1770.

Lawriere, Jno., 13 St. James's St., Pall Mall, 1815-19.

Lawson. Sam., Keighley, 1740. Jno., Bradford, 1750. Jno., London ; watch, 1763. Thos., Keighley, 1765. Wm., Newton-le-Willows, 1770. Ramsey, Wigan, 1770. Wm., Keighley, 1780; long-case clock bearing the inscription :-

" So glide the hours, So wears the day, These moments measure life away. 
John Edwd., 58 Bishopsgate Within, 1800-25 ; livery C.C. 1812. W., Keighley, 1810-14. Jno., Warrington, 1818.

Lawton, Thos., London ; watch, 1820.

Laxton, Thomas, C.C. 1642. Thomas, C.C. 1653.

Laybourn, Christopher, Driffield, 1770.

Layfield, Robt., Lancaster, 1785, f

Layton. John, C.C. 1653. Francis,

C.C. 1726. Thomas, Dean St., liveryman

C.C. $1776 ; 82$ Wardour St., 1794-1823.

Lazare, - a Serbian ; made a clock for Moscow, 1404.

Lazarus. H., 112 Upper East Smithfield, 1815. J., 15 Carter St., Houndsditch, 1825 ; 39 Minories, 1830. J., 13 Oakley St.. Lambeth, 1835. H. L., 3 Bury St., St. Mary Axe, 1835. E. \& Son, 3 Bury St., St. Mary Axe, 1840-42.

Lazenby. R., Knightsbridge ; on a small clock with sunk seconds and day of the month circles, about 1770 . Wm.,

Paradise Row, Chelsea ; card, B.M., 1784.

Lea. Samuel, London; clock in the Wetherfield collection, about 1720. Thomas, Old Jewry, livery C.C. 1766; master $1782 ; 1760-83$.

Leach. Thos., Lombard St., 175360. Caleb, Plymouth, U.S.A., 1776-90. Benj., Winchester; watch, 1790; longcase clocks by him are much esteemed in Hampshire; in 1803 he submitted an estimate of seven guineas to repair the Winchester Town Hall clock, and substitute a long pendulum for the short one then existing, which would necessitate a new wheel and pinion. Jno., Kirkham, 1816. Chas., 59 King William St., London Bridge, $1820-30$.

Leadbeater. Peter, Congleton, 1818-34. Chas., Wigan, 1820. Thos.,Sandbach, 1833.

Leadbetter, William, Cross Keys Court, Little Britain, 1785-94.

Leah. Samuel Henry, 29 Bath St., City Rd., 1823-42. Sam. Hy.,junr.,Mare St., Hackney, $1835 ; 79$ Shoreditch, 1842.

Leake. Faith, apprenticed to John White, but served Daniel Quare; C.C. 1685. George, apprenticed to John Wright, C.C. 1693 .

Leathwaite, Geo., Ulverstone, 1770.

Leavenworth, Mark, also Wm., Waterbury, Conn., 1810-30.

Leaver. Nat., apprenticed in 1679 to John Wright, senr., C.C.; bracket clock, about 1730, inscribed "Leaver, London." Wm., 45 Great Sutton St., 1822-30.

Le Blond ; watch, signed " Le Blond," in rock crystal case, about 1600 . Robt., Artillery Lane, Stewart St. ; livery Blacksmiths' Company 1770; watch, 1770 ; bracket clock, 1790.

Le Bon, Alex., Paris ; maker of equation clocks, 1727-30 ; clock, Jones collec- tion, S.K.M., about 1770, inscribed "Le Bon a Paris."

Lechaud, John ; one of the first makers of lever escapements in Geneva, died 1882.

Leckie, Andrew, watch, 1780.

Le Clerc, Paris ; bracket clock, about 1630

Le Clerk, Daniel, Paris ; watch, Pierpont Morgan collection, about 1630 .

Lecomte (Lecount). Daniel, brother C.C. 1676. " Taken from Mr. Robert Murrel, on the 5th inst., by Foot Pads, near Newington, a Pendulum Watch made by Daniel Lecount" (Lond. Gaz., Aug. 4-8, 1692). The Hon. H. Hannen has a clock by him with long case, finely inlaid ; clock-watch, Turkish numerals, silver-gilt pierced case, Pierpont Morgan collection. James, C.C. 1687. "Stolen a silver watch, made by Mr. Le Count" (Lond. Gaz., Feb. 15-18, 1691). J. R., 60 Dean St., Soho, 1763-83.

Le Contandois, Nicolas, Paris, 1554 (see p. 404).

Lecoultre. Antoine, La Vallée, Switzerland, 1825. H. A., talented Swiss horologist ; devised an improved form of shiftingsleeve keyless mechanism, died 1881.

Lecount, Peter, livery C.C. $1810 ; 36$ Pitfield St., 1823.

Ledart, Richard, in Strassburg; watch, about 1620 .

Ledeur, - London; hexagonal table clock, about 1600 ; small octagonal watch, rock crystal case, signed "R. Ledeur," Pierpont Morgan collection.

Ledieu, Jas., Soho, 1817.

Ledru, Wm., London, 1795.

Lee. Ezekiel, apprenticed 1668 to Jeffrey Baily, C.C., lantern clock, about 1700. Cuthbert, C.C., 1676; long-case month clock, about 1710, signed "Cuthbert Lee, Jewen St." Underwood, apprenticed in 1688 to Edwd. Staunton, C.C. Christopher, apprenticed in 1691 to Wm. Young, C.C. Samuel, C.C. 1694 ; long-case clock, arch dial, burr walnut case with black carved mouldings, Wetherfield collection, about 1720. Roger, Leicester ; watch by him, about 1700 , Leicester Museum. John, C.C. 1719. Thomas, apprenticed to Francis Robinson, C.C. 1730. George, Lombard St., 1737-40. John, 31 Noble St., Forster Lane, 1800-4. Isaac, 10 Devonshire Buildings, Great Dover St., 1840-42.

Leeds, W. H., 20 Wilderness Row, 1817.

Leekey. Gabriel, 15 Basinghall St., 1755-78. Gabriel, probably son of the foregoing, C.C. 1778-1815. Samson, watch in the Paul M. Chamberlain collection, about 1805 . See also Cabrier.

Leeming. Edwd., livery C.C. 1787. Edward, watch-case maker, 8 Little Britain, 1790-94. 
Lees. Jonathan, Bury, 1770. Thomas, Bury, 1790-1816. Wm., Haslingdon, 1816. Sam., Ashton-under-Lyne, 1818. Jno., Middleton, 1818. Thomas, Drury Lane, 1821-32. Thos., Chorley, 1851. J. Henry, Chorley, 1861.

Leeson, William, Coleshill, Birmingham ; well known as a maker of turret clocks throughout the Midland counties; died 1886, aged 77 .

Le Faucheur, Alexandre, Paris ; horologer to Louis XV. in 1746; his son Jean Ignace succeeded him in 1773. In December 1905 a clock by Alex. le Faucheur fetched 1,150 guineas at Christie's.

Le Febuce, Charles (French), admitted C.C. 1687.

Le Febure, E., Rouen ; watch, about 1660.

Lefebury. Dan., apprenticed in 1686 to

Dan Lecompte, C.C. Chas., C.C. 1687.

Lefebvre, Th., Rue St. Louis, Paris ; garde-visiteur, 1769.

Lefferts (Chas.) \& Hall, Philadelphia, 1819.

Leffin, Thomas, C.C. 1720.

Lefosse, Wm., 52 Old Broad St., 1769-72

Lefroy, George, Wisbech, about 1785.

Leg, Jno., London; a good workman, taught by Earnshaw, 1780 .

Le Gaigneur, Jean, master clockmaker in Paris. Received in 1639 the sum of 1,500 francs for a clock for the Château de Saint-Germain-en-Laye.

Legeips, John, London; in the B.M. a very large repeating watch with silver case decorated in repoussé, 1720-30.

Leger à Paris; watch, about $1780, \mathrm{Mr}$. Geo. A. Hearn.

Legg, John, C.C. 1724 ; watch, signed " John Legg, Blechingly," 1787.

Le Grand. James, C.C. 1641. Francis, C.C. 1647. Simon, Paris; clockmaker to the King, 1657.

Legrand, James, junr., C.C. 1664.

Legrande, -, Rouen, 1552.

Le Gros, P. J., 1 Upper Crown St., Westminster; bracket clock, about 1800 . In 1817 Philip Gross carried on business at 12 Panton St., Haymarket.

Le Guay. Fine Boulle clock with bracket inscribed " Guillaume Le Guay, à Paris, au Louvre," about 1750.

Leguesse, L. J., about 1720 .

Lehr, Sebastian; clockmaker to the city of Nuremberg; died 1556.

Le Huray, Nich., Philadelphia, 1819.

Leicester, Jas., Drury Lane ; pull repeatng clock with visible pendulum, about 1710. Black lacquer long-case clock, inscribed " $Y^{e}$ Strand, London."

Leif, G. T., Sheffield, 1821.

Leigh. Thomas, C.C. 1730. Wm., 71 Oxford St., 1792. \& Phillips, 40 Mansell St., 1840.
Leighton, - Warrington ; clock, about 1770.

Leignes, Charles Peter, Northumberland St., Strand, 1790-94.

Lejeune, -, Paris; enamelled watch, about 1780 .

Lello, James, apprenticed in 1647 to Thos. Alcock; C.C. in 1656, on producing his masterpiece with his name, its genuineness being attested by Samuel Betts.

Le Loutre ; "horloger du Roy, Paris," 1754-80. A large case clock realised $f 903$ at the Hamilton sale in 1882 .

Lemaindre, Nicholas, Blois, large alarm watch in pierced and engraved brass gilt case, S.K.M., 1620-30.

Lemaire à Blois ; hexagonal watch, rock crystal case, Wallace collection, about 1610.

Le Maire, London ; watches, Nelthropp collection, about 1700 .

Lemaitre, Paul, watch tool maker, .28 Grafton St., 1790-1810.

Leman, Thos., London ; watch, 1738.

Lemand, - Blois, about 1580.

Lemann, Johan, Wien ; clock, about 1800.

Le Mazurier, -, Rue de la ComédieFrançaise, Paris ; garde-visiteur, 1769.

Lemmon. Edwd., London; watch, 1790. Hy., 19 Grenville St., Hatton Garden, 1835; 6 Upper North Place, Gray's Inn, 1842.

Le Montjoye, Paris; clock, Wallace collection, about 1770 .

Lemude, Reuben, long-case clock, about 1715.

Lenham, Wm., London; watches, 1815-25.

Lenker, Elias, Nuremberg, celebrated silver clock-case maker, died 1591.

Lenoir à Rennes, watch winding from the centre of the dial, G.M., about 1700 .

Le Noir, Baptiste, Paris ; alarm watch, brass case, pierced and chased, about 1760 . Pierpont Morgan collection. Marie Toussaint, fils cadets, Place du Pont St. Michel, Paris; garde-visiteur in 1769. Eight watch and clock makers of that name at about the same period, Etienne Le Noir being the most celebrated.

Lens, William, C.C. 1711.

Lenwood, Sam., apprenticed in 1655 to Thos. Claxton, C.C.

Leon, George Isaac, 56 Great Prescot St., 1842 .

Lepaute. Jean André, born at Montmedi, 1709, attained considerable eminence as a clockmaker in Paris; was appointed "horloger du Roy." He improved the pin-wheel escapement of Amant by putting pins on both sides of the wheel. Lepaute constructed several fine turret clocks and clocks for the Louvre at Paris, wound by means of an air current and fan, a method re-invented recently. $\mathrm{He}$ made many 
curious timepieces (equation, one-wheel clocks, \&c.), and was the author of an excellent "Traité d'Horlogerie" (Paris, 1760), revised and augmented, says Moinet, by the celebrated Lalande. In the second edition of this work appears Lalande's treatise on " perfect pitching." In the Jones collection at S.K.M. is a fine clock in case of Vincennes porcelain and ormolu with the date letter for 1754 and signed "Lepaute de Belle fontaine à Paris." Twelve-month timepiece by him at Vindsor Castle (see p. 427) ; there are four clocks by him in the Wallace collection. Jean Baptiste, brother and pupil of J. A. ; continued his business and was in turn succeeded by his sons.

Lepine. -, "There is lately arriv'd in this city, Monsieur de l'Epine, Engineer and Machinist of the late King of France, who has brought over with him a piece of ingenuity, which is an Opera by Machines, that had been seen by his Majesty, by their Royal Highnesses the Princesses, likewise by a great number of persons of quality of this kingdom, with their general applause and satisfaction. And being to make but a short stay here, he invites the curious to come and see the said machine, giving no other explication of the same, only that there are symphonies, musick-master, whistler, drawing of the curtain, changes of scenes, thunder and lightings, \&c., and what surprises the more, is, that all is performed without any body's touching it. To be seen from Ten in the morning to Ten at night, at the Mews Chocolate House near Charing Cross, up one pair of stairs, Price Half a Crown " (Daily Post, Feb. 1720). This is of interest, because the Lepine referred to was probably the father of John Antoine, a watchmaker of remarkable attainments who is referred to below. Jean Antoine was born at Gex, in France, in 1720 , and is said to have been apprenticed to one Decrose of Grand Sacconex, Switzerland; at the age of 24 he went to Paris and worked for A. C. Caron; afterwards he established a reputation, and became watchmaker to Louis XV. ; about 1770 he introduced bars for carrying the upper pivots of a watch train instead of a top plate, rearranged the movement, dispensed with the fusee, used the cylinder escapement, and a mainspring barrel arbor supported at one end only. Forty or fifty watchmakers having been exiled from Geneva, Voltaire, it is said, engaged Lepine to establish a watch factory at Ferney, about a league from Geneva. Voltaire for a time ensured its success by persuading political friends to buy the watches, but after a few years the artisans returned to Geneva. Whatever part Lepine may have taken in advising Voltaire, I have the positive assurance of M. Leopold Reverction that Lepine never left Paris, where he died in 1814; watch by him in 1810 marked " horloger de l'impér atrice," at the Geneva Horological School. The business was continued by his grand-nephew. In 1902, a clock by Lepine in an altar-shaped case of ormolu with figures by Falconet, and dating from about 1760 , fetched 450 guineas at Christie's (see p. 442). High St., Canterbury; watch, 1805.

Leplastrier. John, 138 Upper Shadwell, 1790 ; 125 Minories, 1815. Louis, 142 High St., Shadwell, 1804-15. \& Son, 142 High St., Shadwell, 1820-28. Isaac, 17 King William St., Strand, 1828 ; 21 Holles St., Cavendish Sq., 1840-42 ; livery C.C. 1829. \& Son, 20 Ludgate Hill, 1835. \& Young, London ; good bracket clock, oak case, about 1840 ; Mr. Kimpton. Louis, 50 Alfred St., City Rd., 1842.

Leptrope, -, London; long-case clock, about 1740 .

Le Queux, see Pierre.

Lerolles ; fine ormolu-cased clock signed "Lerolles Frères," about 1760, sold for $£ 336$ at Christie's in 1902 ; on another clock in the possession of Mr. Hy. Townsend is a representation of Amphitrite in Neptune's chariot, accompanied by her son blowing his concha to still the ocean.

Leroux. Alexander, C.C. 1706. Jno., London ; watch, 1710 . - , Rue Guenegaud, Paris; maker of repeating watches, 1770-89. Jno., 8 Charing Cross; hon. freeman, C.C. 1781 ; there is a fine watch by him in the Guildhall Museum (see p. 190) ; 1750-1800, see Rigby, Jas.

Le Roy. " Lost a Gold Watch, made in Paris, not so broad as a shilling, in a case of black leather with gold nailes, on the 11 th instant, about 11 at night, betwixt King Street, Westminster and Convent Garding. Whoever gives notice to Mr. Le Roy at the signe of the Pearle of Venice, in St. James Street, Convent Garding, shall have three pounds for his pains" (Mercurius Publicus, 8th Jan. 1662). This is interesting as showing that one of the French family of Le Roy resided here before the time of the distinguished Parisian member, Julien. Julien, Paris ; a scientific watchmaker, born 1686 , died 1759 ; he devised a form of repeating mechanism much used in French watches, and substituted springs for the bell in use before; fine long-case clock at Windsor Castle (see p. 422); two fine watches by him, Wallace collection, and one in the Pierpont Morgan collection. Pierre, eldest son and successor of Julien Le Roy, born 1717 , died 1785, the most eminent of French horologists; among his concep- 
tions was a form of duplex escapement and an escapement on which the present chronometer escapement is founded; in 1766 he exhibited a chronometer having a compensation balance composed of mercurial thermometer tubes, a plan afterwards adopted by Loseby.

Leroy. Chas., Paris ; 1765, succeeded by Cachard; clock, about 1808, signed "Leroy \& Fils" (see p. 452). Théodore Marie, Paris ; chronometer maker, died 1899 , aged 72 .

Lesage, Augustus, Cockspur St., 1775 ; St. James's, Haymarket, 1788.

Le Schegs, Abraham, Amsterdam, 1730 .

Leschot. Jean Frederick, apprenticed in Geneva to P. J. Droz in 1784. Georges Auguste, Geneva; son of Jean F., born 1800 , died 1884 ; in 1840 he designed a series of machines for watchmaking on the factory system ; it is claimed that he was the first to make lever escapements with draw on the pallets, but in this he was certainly anticipated by Emery (see p. 612).

Lescot, Pierre, Paris ; cruciform watches about 1588 .

Leslie. Jas., 6 Maiden Lane, Covent Garden, 1784-88, seconds and calendar watch, Schloss collection, about 1786 ; 5 Parliament St., 1790-94; 35 Oxford St. ; card, B.M., 1799. Robt., Philadelphia, 1788-91.

Robert, Merlin Place, Clerkenwell; patentee of pumping keyless work (No. 1,920); 1793. \& Price, Philadelphia, 1799.

Lesser, T., Paris; enamelled watch, S.K.M., about 1770.

Lessware, -, Dublin ; large trunk-dial timepiece, about 1800 .

Lester. Thomas, C.C. 1697. - , Lom bard St., 1774. Robert, Philadelphia, 1791-98.

Lestourgeon. David, in the Register of the French church, Spitalfields, for 1689 , he is mentioned as a witness respecting David, the son of François Gcdeau, orlogeur ; brother C.C. 1698 ; watch, sun and moon hour indicator, Schloss collection, dated 1696 ; another watch with finely piersed cock and pillars ; curious pendulum watch, Pierpont Morgan collection; on the movement is a medallion portrait of William III. and the date 1702 ; inlaid long-case clock, flat top, about 1715 ; a specimen of his work is also in the G.M. ; 1690-1731. David, C.C. 1721-51. Thomas, 49 High Holborn; maker of long-case clocks, 1760-75.

L'Estrange, David, C.C. 1697.

Letwitch, William, 42 Lombard St., 1769-72.

Leudl, Johan ; maker of a skull watch, about 1630 .

Leumas, J. \& L., London ; watch, 1828.
Leutier, Pierre, Paris ; timekeeper mounted on the back of a finely moulded bull of Dresden china, about 1750.

Levasseur, Firmin, Frith St., Soho, 1825-56.

Levens, John, Shoemakers' Row, Blackfriars, $1790-94$.

Lever, Ben., 3 Bruton St., 1792.

Levin. Moses, 7 Cook's Court, Carey St., 1790-94. Lewin, 63 Prescot St., 1804 ; 51 Mansell St., 1815; 123 Leadenhall St., 1830.

Levitt. Jno., apprenticed in $1681^{-}$to Robert Williamson, C.C. -, sometime partner with Tobias, whose nephew he was.

Levy. Michael, Hull, 1770. Hyam, 121 Whitechapel High St., 1775-85. Joseph, New Round Court, Strand, 178085. Lyon, 121 Whitechapel High St., 1780-85. M. \& C., 19 Maiden Lane, Covent Garden, 1790. Philip, 30 Jewry St., Aldgate, 1798-1803. Jonas, 18 Somerset St., 1800 ; 135 Whitechapel, 1810 ; 38 Minories, 1820. J., Coventry St., Haymarket, 1815. B., High St., Whitechapel, 1820. J. \& Son, 49 Tooley St., 1820. \& Co., 408 Strand, 1825. A., 17 Camomile St., 1825-35. S., 19 Crutched Friars, 1830. Jonas, 13 Bevis Marks, admitted free of the C.C. by redemption, being the first Jew, 1831; 1820-42. A., 183 Ratcliff Highway, 1835. Abraham, 36 Trinity Sq., Tower Hill, 1840-42. \& Moss, 1 Liverpool Buildings, Bishopsgate, 1842. Joseph, Bristol, 1844.

Levyson, Montague, 125 Pall Mall, 1840.

Lewin, William, C.C. 1731.

Lewis. E., London; small watch, about 1590, Mr. F. A. Poynder. John, C.C. 1705. Ambrose, C.C. 1725 . T., London ; watch, 1776. Joseph, 38 Foster Lane, 1783. \& Alston, 30 Bishopsgate Within, 1815-25. Henry, London; watch, 1830. Hy., Bristol, 1844.

Lewton, Richd., Bristol, 1844.

Ley. William, C.C. 1711. Jno. K., London; about 1760 . Hy., Bath, 1835. Leyden, see Stubbs \& Co.

Leyland, Thos., Prescot, 1816.

L'Hospital, J., 13 Oxenden St., Haymarket, 1842.

Liddel, Chas., Stcckton, 1770.

Liddell, Joseph, Old Swinford, Worcester, 1760 .

Liddiard, Thomas, 54 St. Paul's Churchyard, 1775-83.

Liddle. Jno., Morpeth, 1770. Adam, Newry; long-case clock, about 1830, Mr. J. W. Gunnis.

Lief, Geo., Shefield, 1814.

Lietuyt, John, from Delft; 1368 (see p. 27).

Lieutaud, Honoré, Marseille ; watch, about 1750 , 
Light. John, C.C. 1648. Ben., apprenticed in 1687 to Geo. Cawdren, C.C. Jno., Lit. Old Baily, C.C. 1730. Jno., Bristol, 1844.

Lightfoot, Peter, a monk, maker of the Glastonbury and Wimborne clocks (see p. 25), 1335.

Like, George, 29 Butcher's Row, 1785-94. Lillie, Charles, corner of Beaufort Buildings, Strand; " a seller of watches, \&c.," 1710.

Lilly, - Smithfield Bars, 1775.

Limeburner, John, Philadelphia, 1791.

Limmard, - 54 St. Paul's Churchyard, 1796.

Limoniere, Stephen, C.C. 1712.

Limpard, John; a watch by him in the B.M., about 1620 .

Linaker, Samue] ; oval watch, Pierpont Morgan collection, about 1610. Samuel Linnaker was named in the Charter of the Clockmakers' Company to be one of the assistants (see p. 262).

Lincoln, -, London ; bracket clock, about 1790 .

Lind. Nich., 4 Norman St., Old St., 1780-95 ; watch, silver cock. John, Philadelphia, 1791-99. William, apprenticed to William Harris, admitted C.C. 1796.

Lindd, Hy., Farnham; lantern clock, about 1700 .

Lindemann, G. H., director of the Horological School at Glashiitte, died 1885.

Lindesey (or Lindsay), George, watchmaker to George III. ; a verge movement by him in the Guildhall Museum; died 1776. A three-train long-case clock in the Wetherfield collection, signed " Geo. Lindsay sert to the Prince of Wales London" (see p. 560). Fine long-case clock with dead-beat escapement, about 1770. On his watch papers, "G. Lindsay, watch maker to His Majesty and Her Royal Highness the Princess Dowager of Wales, at the Dial in the Strand."

Lindley, -, 10 St. Martin's Court, Old St., 1810.

Lindsey. Wm., London ; watch, G.M.. about 1780. John, 69 Banner St., 1825.

Lindstrom, -, London; bracket clock, strikes the hours with but one barrel, about 1800 .

Linford. Thomas, London ; watch, 1626. Hy., apprenticed in 1691 to Edwd. Orton, C.C. 1798

Lingford, Jno., Nottingham ; watch,

Linley, Thos., Leather Lane, C.C. 1732

Linnet, John, 9 Cursitor St., 1815-25.

Linney, John; watch-case maker and liner, Featherstone St., 1790.

Lipp. Nicholas, Basle; maker of a remarkable clock at Lyons, 1598. Peter,
Pool Terrace, St. Luke's ; a noted finisher of repeating watches; died 1848, aged 79 .

Lippyus, see Lipp.

Lipscomb, Benj., London ; maker of long-case clocks, about 1760.

Lipsy, Dan., 136 Old St., 1817.

Liptrop, Peter; a well-known wheelcutter; born in Prescot, 1793; died in London, 1879.

Liptrot, Wm., London; watch, Mr. H. Hogarth, about 1780 .

Lister. Thos., Luddenden, Yorkshire, born 1718, died 1779. John, Noble St., C.C. 1730. Thos., Halifax, son of the above Thos., born 1745, died 1814 ; a good maker ; in 1774 he contracted to make, for $£ 60$, Halifax Church clock ; in 1801 he made to the order of Dr. Birkbeck, for the Anderson College, Glasgow, an orrery which had been designed by Joseph Priestly, of Bradford; in 1802 he made for Illingworth Church a clock having a pendulum $30 \mathrm{ft}$. long, vibrating twenty times a minute. On a paper pasted inside one of his long-case clocks was the following :-

$$
\begin{aligned}
& \text { "Lo! Here I stand by you, upright, } \\
& \text { To give you warning, day and night; } \\
& \text { For ev'ry tick that I do give, } \\
& \text { Cuts short the Time you have to ive. } \\
& \text { Therefore, a warning take by me. } \\
& \text { To serve thy God as I serve thee; } \\
& \text { Each day and night be on thy guard, } \\
& \text { And thou shalt have a just reward." }
\end{aligned}
$$

William ; long - case clock, about 1750 , inscribed "William Lister, Midgley," bearing the motto," No Time for Sin "; longcase clock of slightly later date, signed "Wm. Lister, Keighley"; another, about 1770, signed "Wm. Lister, Halifax." Sam., Bolton, 1770. —, Lombard St., 1770. Joseph, Halifax; died 1805.

Litherland, Peter, Liverpool ; patentee of the rack lever escapement (No. 1,830), Oct. 1791; and in 1792 (No. 1,889) of (1) a watch to beat once a second and (2), a compensation curb, and (3) mechanism to wind watches by means of an external lever. Under the title of Peter Litherland $\&$ Co. he carried on a successful business for some years. A watch so named belonged to Col. Benjamin Tallmadge, an intimate friend of Washington, and is now in the museum of " Sons of theRevolution," New York. Early in the nineteenth century his patent lever watches were made in large numbers by Litherland, Whiteside \& Co., first at Ranelagh St., and afterwards at Church St. In 1816 the firm became Litherland, Davies \& Co. Of other members of the family were John and then Richard Litherland at Brownlow Hill. Richard in 1817 patented (No. 4,103) a modification of the chronometer escapement and also a compensation curb. 
Little, Joseph, 179 Strand, 1800.

Littlemore, Whitestone, apprenticed to Thos. Gibbs, but turned over to Thos. Tompion; admitted C.C. 1698.

Littleton, Jas., London; repeating watch, 1773.

Littlewort. George, 34 Cannon St.; maker of watches for the use of the guards of the Royal Mail coaches, 1816-32. Geo., Rahere St., 1834.

Livermore, Edward, 30 TokenhouseYard, Lothbury, and 3 Cross St., Islington, 1798-1810.

Livesay. - , Bolton, Lancashire ; lantern clock, about 1700. Jno., Bolton; long-case clock, about 1730 .

Livingstone, J., London ; watch, 1785.

Livy, see Levy.

Lloyd. William, Pye Corner ; C.C.1668. Edwd., C.C. 1670. Joseph, C.C. 1673. Lewis, apprenticed C.C. 1673. Nat., apprenticed C.C. 1673 . David, C.C. 1677. Richard, C.C. 1681. Charles, apprenticed to Thos. Tompion; C.C. 1691. James, C.C. 1700. James, Sheep Pens, Smithfield; C.C. 1722. Philip, Bristol; long-case clock, about 1770 . - 128 Minories, 1785 ; card, B.M. \& Northleigh, London; watch, 1785. - at the "Dial," 21 Aldersgate St.; card, B.M., 1790. John, 21 Aldgate Within, 1790-94. J., Brecon; watch, 1802. Joseph, Wigan, 1816. Wm., 6 Britannia Row, Hoxton, 1842.

Lochard. Robert, apprenticed in 1647 to Jno. Matchell; C.C. 1655 . John, C.C. 1655 ; thick round silver watch, gut to fusee, engraved dial, serrated trident hand, inscribed " John Lochard,fecit," 1655-70.

Lock, Jas., New WestgateBuildings, Bath, 1790-1800, afterwards at 11 Quiet St.; long case clock, about 1795,Mr. C. B. Oliver.

Lockin, Wm., apprenticed in 1687 to Isaac Goddard, C.C.

Lockwood. Robt., apprenticed in 1647 to Edward Taylor, C.C. David, long-case clock, about 1730. Benj., Swaffham, Norfolk; long-case clock, a boutl 740; watch, 1765

Loddington, Isaac, "The Dial," Tavistock St., Covent Garden. Anna Maria Shaw was apprenticed to him and to Elizabeth his wife, $1733 ; 1719-34$.

Lode, - London; pocket chronometer, about 1802 .

Lodge, Thos., London; " Ordered that the Master should give directions to the Clerk to deliver the clock to Mr. Thomas Lodge to be cleaned" (Minutes of the Cutlers' Company, Ist Octo ber 1713); maker also of a long-case clock, about 1730 .

Lodowick, Peter, admitted C.C. 1689.

Loftuss, Thos., Wisbeach ; lantern clock, about 1720 .

Logan, Jno., Waltham, Mass; good maker of balance-springs; died 1893, aged 49 .
Logg, M., Vienna ; about 1725.

Loggen, Johannes, Amsterdam ; fine calendar watch, Schloss collection, sun and moon hour indicators, about 1680 .

Lomas. Jas., Blackburn, 1770. Jno., Sheffield, 1814.

Lomax, Sam., Blackburn, 1780.

Lombart, F., à Paris ; watch, about 1590 , Mons. E. Gélis.

London, Jno., Bristol ; lantern clock, about 1690 .

Long. Thomas, C.C. 1653 . John, C.C. 1677. Jno., Nottingham ; clock-watch, about 1692. John, C.C. 1698. Henry, 200 High Holborn, 1770-80. Thomas, hon. freeman C.C., 1781 ; 1760-81. \& Drew, enamellers, 5 Red Lion St., Clerkenwell, 1794-1810. Theodore, Gateshead, 1833.

Longland. Francis, apprenticed in 1671 to Bert. Powell, C.C. John, brother C.C. 1677 ; Mr. Chas. M. Newcomen has a longcase clock by him, William III. period, inscribed " Johannis Longland, Londini, fecit" ; case, oak, with walnut veneer. Thomas, London ; 30-hour long-case clock, about 1725 .

Loomes,Thomas, at ye Merma: $d$ in Lothebury, apprenticed to Jno. Selwood, brother C.C. 1649 ; a celebrated maker. Example, a small lantern clock (frets, Fig. 645), inscription, "Thomas Loomes, at ye Mermayd in Lothebury, fecit, 1674" ; 1630-74.

Loor, Thos., Amsterdam; watch, 1715.

Lord. Richard, C.C. $1632 . \quad$ Joseph, apprenticed in 1684 to Jonathan Puller, C.C. \& Godard, Rutland, U.S.A., 17971830.

Lorimer. Isaac, London; long-case clock, about 1740. Jas., London; musical long-case clock, about 1780 (see p. 565). David, 17 Shoreditch, 1805-18; afterwards Lorimer \& Edwards. William, 24 Crown St., Finsbury, 1830; 93 Wood St., Cheapside, $1835-40$.

Losada, José R., a Spaniard who in his younger days was attached to the Court at Madrid, came to London and in 1835 set up as a watch and clock maker close to Euston Road ; afterwards at Regent St., near the Polytechnic ; then at 105 Regent St. He did a large business in really firstclass timekeepers, chiefly with Spain and SouthAmerica; after his death his nephew, Riego, continued at 105 Regent St., till about 1890.

Loseby. Edward, Shiffnal ; long-case clock, about 1790. Edward Thomas, apprenticed to Rotherhams, of Coventry, afterwards at Gerrard St., Islington; inventor of a compensation balance, which acted by the expansion and contraction of mercury in a curved glass tube fixed at each end of the laminated rim, which was shorter than usual (Patent 1,011, Dec. 1852); he was 
successful at the Greenwich chronometer trials, but feeling aggrieved at what he considered to be inadequate appreciation on the part of the Admiralty, he retired in dudgeon to Leicester; for the Market Hall, at Coventry, he made a remarkably fine clock, which may be called the standard timekeeper of the place. He died in 1890.

Lossier, -, London ; watch, 1770.

Louarth, Jasper, C.C. 1641.

Loubet, Felix, au St.Esprit; French table clock in gilt brass case, engraved with the four seasons, after Etienne Delaune, second half of the sixteenth century, S.K.M.

Louchet, -, Boulogne ; watch, 1815.

Loudan, Wm., 149 Great Surrey St., $1822 ; 228$ Blackfriars Rd., 1840-42.

Lough. Thos., apprenticed in 1680 to Geo. Tomlinson, C.C. Robert, Penrith, 1770.

Loughton, William, C.C. 1683.

Lounde (Lowndes), Jonathan, in Pall Mall, C.C. 1680 ; steward 1696 ; a celebrated maker. Square black basket-top bracket-clock, Wetherfield collection, about 1685 ; walnut inlaid long-case clock, about 1695 ; bracket-clock belonging to the Long Island Historical Society of New York, about 1700 ; fine long panelled marquetry case, domed hood clock, 11-in. dial, Wetherfield collection, about 1700 ; another 12-in. dial, about 1710 (see Fig. 713).

" Lost in St. James Chappel on Sunday the 17 February a gold pendulum minute watch, going with a chain the maker Lowndes in Pall Mall London : it hath two gold cases, the out case graved with a cypher and an earl coronet over it: Whoever can bring the said watch to Jonathan Lowndes at the Dial in Pall Mall shall have 3 guineas for their trouble" (Lond. Gaz., 18th February 1683-4).

"Lost on the 19 past, from a gentlewoman's side, a gold pendulum watch with 2 gold cases, the outer case engraved; made by J. Lowndes, in Pall Mall,London. Whoever brings it to Mr. Lowndes, at the Dyal, in Pall Mall, shall have three guineas reward ; or, if bought, their money again with content" (Lond. Gaz., Oct., 1-5, 1691).

" Lost on the 10 instant, in a Hackney Coach, between Covent Garden and Jermyn St., a Gold Pendulum Watch, the maker's name Lowndes, the Chrystal crack'd ; with 2 Steel Seals tyed to it, the Coat of Arms, 10 Crosses and a Baron's Coronet, and a small Famble (sic), made up of 2 little Diamonds and 4 or 5 Rubies. Whoever brings them to Sir Francis Child, Goldsmith, within Temple Bar, shall have 2 guineas reward " (Lond. Gaz., Nov. 16-19, 1691).
Loundes. Charles, Pall Mall ; apprenticed in 1674 to Thos. Player; C.C. 1682 ; maker of a long-case clock belonging to the Bishop of Chester; also of a striking and repeating basket-top bracket clock. Isaac, Pall Mall Court, C.C. 1682; long clock, Wetherfield collection, panelled marquetry case with domed hood, 12-in. dial, about 1705 ; long walnut case month clock, about 1710. Jonathan, Pall Mall Court, about 1685-95. Wm., apprenticed in 1690 to Charles Loundes, C.C.

Lovatt, - Newcastle, long-case clock, about 1780 .

Love. Jas., 23 Aldgate, 1770-90; enamelled watch, S.K.M. Christopher, 6 Old Bond St., 1816-25.

Lovelace, Jacob, Exeter ; died 1766, age 60 ; maker of a famous clock (see pp.398$400)$. Mr. Geo. Liddell has a long-case clock by him, dial illustrated in Fig. 512.

Loveland, -, London; watch, 1770.

Loveles, W., 14 Charles St., Hoxton, 1796.

Lovell. Paul, subscribed to incorporation of C.C. in 1630 ; in $1654 \mathrm{Mr}$. Paul Lovell the elder did deliver to the renter warden one silver bowl in full of all demands due to the Company. Paul, apprenticed to Paul Lovell in 1646 ; C.C. 1653. Nathan, apprenticed in 1655 to Jno. Samon, C.C.

Lovett, Jonathan, apprenticed in 1692 to Hy. Pigott, C.C. William, C.C. 1702 ; watch, about 1710 .

Low, Jno., C.C. 1672.

Lowden. Jas., Edinburgh ; watch, about 1760. Thos., London; watch, 1768.

Lowe. Edwd., London; watch, 1793 : Jno., 19 Lower Smith St., Northampton Sq., 1802-18. Thos., Dartford ; watch, hare and snail indicator, 1818. Edwd., Chester, 1833. Geo. \& Son, Chester, 1833 . Jno., Chester, 1840-42. John F., head of the well-known firm of Lowe \& Son, Chester died 1911, aged 74. James F., Assay Master at Chester,died 1911. G. B., of the firm of Lowe \& Sons, Chester, brother of the above John and James, died 1911.

Lowens, David, Philadelphia, 1785.

Lowrie, J. C., London; watch, 1800.

Lowry, Morgan, Holborn, 1700; Leeds, 1760 ; long-case, twelve-month clock, about 1730, Mr. John Walker. Morgan Lowry was sergeant-at-mace for the borough of Leeds till 1755.

Lowther, Thomas, clock-case maker, 58 Red Lion St., Clerkenwell, 1822-30.

Loyd, see Lloyd.

Lozano, Thos., London ; watch, 1700 ; bracket clocks, 1700-15.

Lucas, William, C.C. 1669 ; watch, apparently English, S.K.M., about 1690 , inscribed "Lucas Amsterdam," in a finely enamelled case, signed "Huaud l'aisnẹ 
pinxit a Geneue." Edward, C.C. 1727. Henry, C.C. 1731. Wm., London; fine chiming clock, inlaid mahogany case, about 1800, Mr. Samuel W. Scoble. John, Pear Tree St., 1800-10.

Lucie, John, C.C. 1663.

Ludford, Ralph, apprenticed in 1665 to Wm. Almond, C.C.

Ludlam, William, Professor of Mathematics at Cambridge, regarded as an authority on horology; one of the judges of Harrison's chronometer, 1765 . He corresponded with John Holmes in 1779.

Ludlow. Samuel, C.C. 1706. Benj., Gt. Yarmouth, 1760.

Ludwig, John, Philadelphia, 1791.

Lueb, Michael, apprenticed in 1655 to Isaac Daniel, C.C.

Lugg, Jasper, "of Glocèster, fecit" ; miniature lantern clock, with pendulum shaped like an anchor, Mr. J. D. Robertson, about 1690 .

Luitprand, a monk of Chartres, who at the end of the eighth century resuscitated the art of glass blowing, is said to have also invented the sand glass (see p. 16).

Luke, William, shagreen and morocco case-maker, 147 Aldersgate St., 1810.

Lukins, Isaac, Philadelphia, 1790-1828.

Lullin, Paul, watch without hands, French or Swiss, about 1690.

Lum, Joseph, Spitalfields, 1700.

Lumb. Jos., London, 1760. John, 16 Southampton Buildings, 1790-94.

Lumbley, G., junr., watch, 1760.

Lumley, Geo., Bury ; watch, 1780.

Lumpkin, Thomas, C.C. 1694 ; maker of a walnut marquetry long-case clock, centre engraved; over day of month circle G. R. and three crowns ; 1694-1715.

Lumsden, Jas., Aberdeen, 1770.

Lund. John Richard, Hatton Garden, and afterwards 41 Cornhill; apprenticed to John Pennington, senr., for some time partner in the well-known firm of Barraud \& Lund ; died 1868, aged 63 . John Alexander (Barraud \& Lund), died 1902, aged 66.

Lunod, H., Geneva, 1799.

Luntley, Thos., apprenticed in 1684 to Wm. Dobson, C.C

Lupton. Wm., York, f, 1645; died 1680. Wm., York, f., 1681. Geo., Altrincham, 1780. Jno., Altrincham, 1825. \& Gillam, 23 St. Martin's Lane, 1825. Clifford, some time with Barraud, afterwards at 3 Newman's Court, Cornhill; died 1910, aged 85 .

Lushbrook, 一, admitted C.C. 1701.

Luttman, William, C.C. 1720.

Lutwiche. Wm., Fenchurch St., livery Embroiderers'Company, 1775. Thos. Wm., Forgate St., Worcester, card, B.M., 1794.
Lutz, Jean Celanis, Geneva, born 1800 ; introduced superior balance-springs at a low price, 1847 ; died 1863.

Lyddiatt, Thos., London; watch with sun and moon hour indicator, Mr. Drummond Robertson, about 1695.

Lyddon, Jno., Bristol, 1844.

Lyman, -, London, watch, 1810.

Lynaker, Samuel, one of the first assistants of the C.C. $1630-49$.

Lynam. Philip, apprenticed in 1682 to Jno. Harris, C.C. \& Bull, " at the Golden Salmon, 36 New Bond St.," card Ponsonby collection, about 1785 . \& Warwick, 76 Strand, 1793.

Lynch, Robert, admitted C.C. 1670.

Lyndon,G.,30 Gerrard St., Soho, 1825-30.

Lyne, William, C.C. 1703.

Lyon. Matthew, Lanark, 1770. Thos. Geo., St. Martin's-le-Grand, 1793. Craven, Bridlington, 1822. Lewis, 64 Gray's Inn Lane, 1840. Solomon, Bristol, 1844.

Lyons. Richard, apprenticed in 1649 to Wm. Almond ; C.C. 1656 ; master 1683 ; calendar watch by him, Shandon collection 1670-84. Fine long-case clock, about 1690 belonging to Mr. Bernard Matthews ; case of figured walnut veneered on oak, $6 \mathrm{ft}$. 8 in. high ; hood slides up and had a contrivance to keep it in position above the winding holes; the door of the case as it is shut pushes forward a spoon-shaped piece of iron which keeps tne hood from being raised ; twisted columns at corners of hood, bases and caps carved in Corinthian style with acanthus foliage; dial 10 in. square (see Fig. 679). Jno., Bristol, 1844.

Lysney,Sebastian, clockmaker to Edward VI., 1548.

Mabb, Wm., apprenticed C.C. 1688 .

Maberley, John, Red Lion St:, Clerkenwell ; master C.C. 1738. The springs of Harrison's chronometer were made by Maberley in $\mathbf{1 7 5 5 .}$

Mabille, Chas., Paris; fine repeating watch, about 1785 .

Macaire, F., London, 1732 ; handsome alarm watch by him, belonging to M. G. Mirabaud. Antoine, Paris; watch, silver repoussé case, 1770 ; watch, about 1775 .

McCabe. This house was much esteemed for fine watches and clocks, especially in India. James McCabe was from a watch and clock making family in Belfast. He came to London at the latter part of the eighteenth century, and was at 11 Bell's Buildings, Fleet St., in 1778 ; 34 King St., Cheapside, in 1783 ; 8 King St., Cheapside, in 1788 ; 97 Cornhill Royal Exchange in 1804. He was hon. freeman C.C. 1781 ; livery 1786 ; warden 1811, when he died, and was succeeded by his son James, who 
was apprenticed to Reid \& Auld, and admitted to the C.C. in 1822. The business was carried on as McCabe \& Son, 99 Cornhill, till 1820; McCabe \& Strahan, 1825-26; J. McCabe, 97 Cornhill, till 1838, when the Royal Exchange was destroyed by fire; then J. McCabe, 32 Cornhili. Robert Jeremy McCabe, nephew of James who succeeded his uncle at 32 Cornhill, retired in 1883 , when he closed the shop, declining all offers to purchase the business. He dicd in 1902, aged 67. MIcCabe's best watches were engraved "James McCabe," the second grade " McCabe," and the lowest quality "Beatson." - Lurgan ; clock, about 1770. Wm., Newry; watch, 1798.

McCarthy, Jas., 47 Holborn, 1798.

MacDonald. Joseph, Liverpcol, 1770 ; John, Inverness ; watch, about 1780 ,Mr.J. D. Robertson.

MacDowall. Jas., Philadelphia, 1797. 1825. Chas. \& Joseph, " Helix lever and horological machine manufacturers, "Vicar Lane, Leeds, 1830. Charles, Church St., Kensington, 1836 ; 8 Victoria Rd.,Piml:co, 1839 ; 2 Mall, Kensington, 1840 ; Jermyn St., 1858; a clever horologist, born in Wakefield; patented the single-pin escapement, 1851; made a 30-day skeleton clock, with Hooke's helix gearing; died 1872, aged 82. Joseph Eden, 257 High St., Southwark, patented an escapement in 1838 .

\section{McDuff, Jas., 47 Bury St., 1835.}

Mace. Barthelmy à Blois; enamel watch, about 1660 . Lawrence, Drapers' Court, Aldermanbury, C.C. 1730 ; to him was apprenticed $\mathrm{Wm}$. Plumley, 1749.

Macfarlane. John, Boston, U.S.A., 1800-10. Peter, London; watch, 1801. Macgregor, J., 14 Charterhouse St., 1830.

Macham, Samuel, London ; long-case clock, about 1710 ; repeating bracket clock, about 1720 .

1820 .

Mackarsie, G., 14 Great Queen St., Mackarthy, James, 47 Holborn, 1790.

Mackdonald, Peter, New Compton St., 1790-94.

MacKenny, G., 8 Lower Ashby St., $1840-42$.

Mackie. Janes, Banner St., Bunhill Row, 1810-35. Geo. \& Son, 54 City Rd., 1822-25. James, 4 White Rose Court, Coleman St., 1830-42. James \& George, 31 City Road, 1835-42.

McLachlan. Jno., C.C. 1791. Hugh, son of Jno., 17 Upper East Smithfield, 1810-42; E. J. Thomson was apprenticed to him in 1829.

Maclennan. Kenneth, May's Buildings, St. Martin's Lane, 1778-1825; in 1801 he made a planetarium for the Royal Institution. R. \& W., 9 Great May's Buildings, St. Martin's Lane, 1815-25. John, a watch and chronometer maker of the front rank, who worked for McCabe ; born at Dingwall, died in London, 1886, aged 72 .

McMaster, Wm. Jno., 26 Bartlett's Buildings, 1814-19.

McNab, -, Perth, about 1816 (see p. 468).

McPhail, C., 14 Regent's St., Pall Mall, 1830.

Macpherson, Normand, London ; longcase musical clock, about 1790 .

Macure, Thomas, musical clockmaker, 7 Great New St., Gough Sq., 1788.

Macy, Benjamin, C.C. 1712.

Madden, Thos., apprenticed in 1647 to Wm. Rogers, C.C.

Maddock. Thos., Leek ; long-case clock about 1725. Randle, Leek; long-case clocks, about 1760. L., London; watch, 1787.

Maddox, Edwd., London ; centre-seconds watch, h.m., 1769 .

Madelainy, - Paris ; curious watch, about 1690 , formerly in the Dunn-Gardner collection, sold at Christie's in 1902; the movement, suspended on a gymtal ring and controlled by a short pendulum, was inserted in a spherical case rather less than 2 in. in diameter.

Madell, Charles, I Waterloo Place, Clerkenwell Close, 1835.

Maffid, P., Monmouth; watch, 1798.

Maggs, William, claimed to be successor to D. Quare, 1724-30.

Maginie, Samuel, Duke's Row, Pimlico, and 9 Prince's St., Westminster, 1835.

Magito, - Rue Saint Dominique, Paris, 1770 .

Magniac, Francis, St. John's Sq.,Clerkenwell, manufacturer of complicated clocks and automata. 1770-1814; made for the Emperor of China two musical clocks with figures of soldiers, musicians, birds, and beasts put in to motion by the mechanism ; was Colonel in command of the Clerkenwell Volunteers, who were organised in 1797 and disbanded in 1814 .

Magnin, J. S., London ; watch, 1760.

Magnus, N., 7 James Court, St. Martin's Lane, 1823.

Magson, John. Essex St.; in the Hawkins collection was a repeating watch by him, in pierced and finely engraved gold case, second case chased with classical figures and scrolls, in outer case of shagreen, about 1700; long-case clock, about 1720, signed " John Magston, Essex St., London."

Maillett, Hy., 16 Bartlett's Buildings, 1790-94.

Mainglair à Geneva ; wácun, about 1795. 
Mainwaring. Thos., apprenticed in 1686 to Jeffrey Staines,C.C. -, Terrace Walk, Bath, 1770.

Maire, - Nancy; horloger de la Reine ; watch, about 1730 .

Mairet, Sylvain, born 1805, died 1895 ; a clever Swiss watchmaker; lived in London 1831-34, manufacturing chiefly for B. L. Vulliamy; returned to Switzerland and settled in Locle; inventor of keyless mechanism for watches with two barrels ; his son, Charles, who settled in London, died 1908 .

Maisonneuve, Benjamin, Craven St., Strand, 1769-72.

Major, Nat., apprenticed in 1686 to Thos. Player, C.C.

Makepiece, Robt., 6 Serle St., Lincoln's Inn, 1775-88; afterwards Makepiece \& Walford.

Malden, Samuel, Rainham, Essex, maker of lantern clocks, about $\mathbf{1 7 2 5}$.

Malleson, Thos., 62 Cornhill, 1769-83.

Mallet. Peter, London; long marquetry case clock, about 1695, see Harley. L., Paris, "Horloger duc d'Orleans" ; repeating watch, about 1790 .

Mallett. Stephen, apprenticed in 1689 to John Trubshaw, C.C. - a Devonshire family of clockmakers. John Mallett, Barnstaple, 1842.

Malley. Timothy, Lancaster, 1825. John, Lancaster, 1825.

Mallingley, Robt., 135 Goswell Rd., 1709-93.

Malpas, J., 91 Wood St., 1753-75.

Maltby. Henry, York, f., 1812. H. D., York, 1814-22.

Man, Jonathan, Retford, 1770.

Manasiere, -, Smithfield, 1774-82.

Manby. Edwd., London; watch, 1828. Jno., Skipton, 1833.

Manchester, John, C.C. 1700.

Mangaar, J. A., Maiden Lane, Covent Garden; very fine duplex centre seconds watch, 1834.

Mangeant, -, Rue de Pourtour-SaintGervais, Paris, 1770.

Mangie, Edwd., York, f., 1659.

Manière, -, Paris ; Louis XVI. clock by him sold at Christie's in 1905 for $£ 1,260$.

Maniglier, John, 4 Frith St., Soho, 1840-42. 60 .

Maning, Richard, Ipswich, U.S.A., 1748-

Manley. Dan., apprenticed in 1650 to Ed. Gilpin ; C.C. 1660. -, Norwich ; lantern clock, about 1680 . Daniel, watch by him, Lond. Gaz., Sept. 21-25, 1693. H., repoussé watch cases. 1695-1730 ; fine specimen S.K.M., signed "H. Manly,Fec."

Mann. Joseph, apprenticed in 1687 to Thos. Davis, C.C. Theo., apprenticed in 1693 to Jas. Boyce, C.C. Jno., Kentish
Town ; long-case clock, about 1770. Percival, Lincoln's Inn Fields, 1780; Charlotte St., Oxford St., 1790-94. Josh., London; watch, 1782. \& Muddell, 114 Leadenhall St., 1830.

Manning \& Edmonds, Strand ; watch, 1780 .

Manross, Elisha, Bristol, Conn., 1827-40.

Mansell, William, watch-case maker; 1800, Rosoman St., Clerkenwell ; fined $£ 15$ by C.C. in 1813 for refusing to take up the livery ; 26 Spencer St., 1826.

Manser, Robert, Clerkenwell, 1780, afterwards Ashley \& Manser.

Mansfield, Jno., London; clock, about 1750.

Mansir, R., watch-case maker, Northampton Sq., 1835.

Mantir, G., 71 Snow Hill, 1830.

Mants, -, London; watch, 1760.

Manwaring, Thomas, C.C. 1694.

March. "Lost from a gentleman about the 14th Instant, but he knows not how, a silver minute Pendulum Watch, the name William March, London. Anyone that will bring it to Mr. Hanne, Goldsmith, at the Bunch of Grapes in the Strand, near York Buildings, shall have a guinea reward " (Daily Couvant, Feb. 19, 1705).

Marchand, -, Geneva, about 1725 . Fils à Paris; watch, about 1790 .

Marchant. Richd., apprenticed in $\mathbf{1 6 6 4}$ to Jere. Gregory, C.C. Samuel, C.C. 1689 ; warden, 1704; did not serve as master. -, Prince's St., Leicester Fields, nephew of - Archambo, 1750. Andrew, London; watch, 1760. William, 255 High Holborn, 1775-83. M., 350 Oxford St., 1823. R., 20 Mortimer St., 1823.

Marche, -, Rouen; watch, 1730.

Marchet, Richard, Fulwood Rents, Holborn, 1790-94.

Marder, Henry \& William, 20 Artillery Place, Finsbury, 1842.

Marduit, Isaac, C.C. 1724.

Maré, J. Louis, Geneva ; enamelled watch, Marfels collection, about 1790 .

Margan \& Sherban, 6 Strand, 1793.

Margary, Thos., 4 Walbrook, 1790.

Margetts, George, 21 King St., Cheapside, 1785 ; 3 Cheapside, 1804; a celebrated maker, C.C. 1779, livery 1799 (see p. 383).

Margot. Green, Pall Mall, 1700.

19 Arlington St., Clerkenwell, 1835.

Margotin à Paris ; bracket clock with Boulle decoration, about 1770 .

Marie, David, St. Martin's-in-the-Fields. In 1762 he patented (No. 771) a form of going barrel.

Marilic à Rouen ; watch, B.M., about 1680.

Marinot, see Martinot. 
Mariston, Robt., apprenticed in 1649 to O. Helden, C.C.

Mark, Jno., C.C. 1667.

Markham. Markwick, behind the Royal Exchange. From the number of watches and clocks bearing his name and having Turkish hour numerals, it may be assumed that he did a large business with the Turkish market; there are two watches by him in S.K.M., two in the G.M. In the Pierpont Morgan collection are several examples ; in the Czar of Russia's collection at the Winter Palace, St. Petersburg, was a large repeater watch in a pierced gold case with repoussé decoration; it is attached to a chatelaine. I have seen scores of watches dating from the end of the eighteenth century, and inscribed Markwick Markham together with the name of another maker added, e.g., " Markwick Markham, Perigal ;" "Markwick Markham, Recordon ; " this may possibly have been done by arrangement with Markham's representatives after his death, and seems to show that he left a good reputation, 1720-60. Robert, behind the Exchange, 1736-40. John, London; maker of watches for the Dutch market, 1760-85. Also George.

Marks. Saml., Cowbridge ; clock, about 1770. Lewis, 127 Jermyn St., $1830-35$; 59 Prince's St., Leicester Sq., $1840-42$.

Markwick. James, Royal Exchange ; apprenticed to Edmund Gilpin; C.C. 1666-98; in the Wetherfield collection is a bracket clock signed "Jacobus Markwick London," dating from about 1680 , see Marquet.

"Dropt the 3rd instant between the Cross Keys in Holborn, and the Temple Gate, a Gold Pendulum Minute Watch made by Jacobus Markwick, London. Whoever brings it to Mr. Wilkinson at the Black Boy against St. Dunstan's Church, in Fleet Street, shall have $3 l$ reward" (Lond. Gaz., July 6-9, 1691). James, C.C. 1692 ; master 1720 ; several watches by him in the B.M. ; one, in very large silver cases, is inscribed, "Made for F.B., M.D.," another, a clock-watch of a slightly later period; long marquetry case clock, "Marwick Londini," about 1695, Mr. Robert Meldrum.

Marlack, White C., New York, f., 1769 ; afterwards Wm.

Marquet. Jacob, Augsburg, 1567.

(Markwick ?). "That divers Watches and Pocket Clocks which were Mr. Samuel Betts, deceased, are to be sold at his late shop, now the shop of Mr. Marquet, watchmaker, on the backside of the Royal Exchange" (Lond. Gaz., Feb. 28, March 2, 1675).
Marr. Jas., C.C. ; about 1650. Frères \& Geneva; watch, about 1795.

Marriott. John, C.C. 1715. W., 10 Fetter Lane, about 1760. John, musical clock maker, 10 Fleet Lane, $1780 ; 175$ Fleet St.,1790 ; master C.C.1799; bracket clock, ebony case with brass mountings, enamel dial, about 1780. Wetherfield collection (see Fig. 799). J., 148 Aldersgate St., 1806-10. Wm. \& J., 27 Fenchurch St., 1823-30.

Marris, Chas., Hull, 1822.

Marsden. John, C.C. 1698; master 1731. Josh., Gainsboro' ; long-case clock with motto, "The Moon Do's Best Appear" "When ye Air is most Clear,"about 1760 . Samuel, 4 Leathersellers' Buildings, 1820. Thos.,Hensingham, 1833. Samuel, 23 Great Winchester St.; 1835-42.

Marsh. Jno., apprenticed in 1676 to Thos. Parker, C.C. Jonathan, London; apprenticed in 1691 to Richard Symonds, C.C.; long-case clock, about 1720. Anthony,

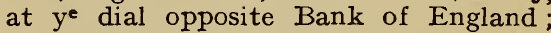
C.C. 1724 . Jacob, 78 Lombard St., 175468. Richd., Ipswich, 1770 . James \& Samuel,79 Broad St., Ratcliffe, 1790-1810. Sam., 79 Broad St., Ratcliffe, 1793-1818. Wm., B. London; handsome long-case clock, about 1800 . Thos., King St., Clerkenwell; in 1811 he patented (No. 3,488 ) an escapement. Jas., watch movement maker, 22 Tysoe St., Clerkenwell, 1855. Jno., watch-case maker, 35 Clerkenwell Green, 1835. Edward \& John, 61 Whiskin St., 1840. H., 20 Down St., Piccadilly, 1840-42. Richard, Diss, 1846.

Marshall. Benjamin, C.C. 1680. Matthew, C.C. 1689. John, Rain bow Coffee House, Cornhill, apprenticed to Sam.Rouk, but turned over to D. Quare ; C.C. 1689 ; long panelled marquetry case clock, hood with spiral pillars, 12-in. dial, about 1705, Wetherfield collection. "Lost out of a gentleman's pocket on the 2nd inst., a silver minute watch in a studded shagreen case. John Marshall, watchmaker, at the Rainbow Coffee House in Cornhill, near Birchin Lane" (Lond. Gaz., March 12, 1693-4). Chris., appointed in 1701 to uphold the clock and chimes of Halifax Church in succession to Sam. Ogden. Samuel, New St.; C.C. 1718. John, Newark; long-case calendar clocks, aboutl730. Geo., New St. C.C. 1734. Richd., 1751. Francis, Durham, 1770. Wm., Newark: died 1770 . Jno., London; probably about 1780. Thos., Lincoln ; watch, 1790. Wm., 3 Corporation Lane, 1816 ; 6 Percival St., 1830-35. Hy., 3 Fore St.,Limehouse, 1817. E., 61 Cannon St., 1825-30.

Marshinville Frères; repeating watch, about 1750, M. E. Chenevière. 
Marster, W. J., 26 Bartlett's Buildings, Holborn, 1825.

Marston. Jno., his movement seized by C.C. 1661 . William, C.C. 1669 . Thos., about 1705 . John, 4 Oxenden St., Haymarket, 1842.

Marten, Hy. \& Wm., 20 Bunhill Row, 1840.

Martin. Edwd., apprenticed in 1662 to Jno. Nicasius C.C.; pair case watch, Dutch style, Fitzwilliam Museum, Cambridge. Zacharie, clockmaker to Louis XIV. 1674. John, White Gate Alley, admitted C.C. 1679 ; threatened in 1682 with prosecution by C.C. for undue taking of apprentices. Abraham, engraver, C.C. 1682. Francis, apprenticed 1683 to Jno. Wells, C.C. Jno., apprenticed C.C. 1684 ; bracket clock repeating quarters on six bells, marquetry case with domed top, Wetherfield collection, about 1700 . Jeremiah, apprenticed to Wm. Dent and turned over to Thos. Tompion; C.C.1687 Thomas, Royal Exchange ; apprenticed in 1692 to Jere. Martin ; C.C. 1699; diminutive bracket clock, about 1705 . Richard, Northampton ; maker of lantern clocks, about 1695. William, Bristol; lantern and bracket clocks, 1700-30. Benjamin, Newton Head, Fleet St., "a friend of Jas. Ferguson" ; maker of a curious table clock; born at Chichester 1704, died 1782. William, C.C. 1709. St., à Paris ; repeating watch, about 1750 , Mons. E. Gélis. William, apprenticed to John Uffington; C.C. 1751. Jonathan, London; watch, repoussé case, hall-mark, 1759. John, 16 Brownlow St., Bedford Row, 1763-69. T. G., Dublin, 1771 . Thomas,son of Thomas Martin, citizen and poulter, being by trade a clockmaker,C.C. 1771 ; a good maker; mentioned by Earnshaw, 27 Cornhill, 1778-81 ; St. Michael's Alley, 1788-94 ; pocket-chronometer, G.M. h.m., 1780. Jno., Spalding, 1773 ; longSheraton case clock, signed " Jos. Martin, Kippen," about 1790. Edmund, London; long-case clock, about 1790. Edmund, 44 Queen St., Cheapside, apprenticed to William Howells, C.C. 1795. John, Eton Bridge, 1809 ; long-case clock, about 1820 , Mr. Gerald Watts. J. F., 26 High St., Marylebone, 1810. William, 75 King St., Westminster, 1810-40. \& Saul, 9 Bow, 1817. G., 13 Church Lane, Whitechapel, 1835. H., Bunhill Row, 1835. James, 26 Hanway St., 1835. M., 18 Aylesbury St., Clerkenwell, 1835. \& Mosse, 8 Charing Cross, 1835.

Martineau. Joseph, St. Martin's Court, 1750-70; bracket clock, engraved " Josh. Martineau, senior;" maker also of gold repoussé watches; repeating watch, Pierpont Morgan collection, about 1760.
Joseph, 65 Red Lion St., Clerkenwell, 1790-94.

Martinique à Paris ; clock in vase-shaped case of white statuary marble with side figures of nymphs of chased ormolu, dating from about 1790 , sold for 350 guineas at Christie's in 1901.

Martinot. Gilbert, Paris ; clockmaker to Henry III., 1572 (see p. 404) first of a long succession of Court clockmakers: Denis succeeded in 1611; Zacharie in 1637; Gille in 1662 ; Jean in 1686; Louis Henry in 1688 ; Henri, nephew of Jean and son of Gille, succeeded his father at the Louvre in 1670 (see p. 419); Jérôme in 1695; Jacques in 1718 ; Jean in 1727 ; Claude in 1729. Barnaby, Farringdon Within, 1618. Alfred Franklin says one of the Paris Martinots, who had become a Protestant, was successful in a London business after the revocation of the Edict of Nantes, but I have never met with any timekeepers by him. Balthazar, Paris; horologer to Louis XIII., 1637. "A four-square Gold Watch, made at Paris by Monsieur Martinot. Whoever can give notice of it to Mr. East, watchmaker, at Charing Cross, or else to the porter of Madam Gwinn's House in Pall Mall, shall have 20s. reward" (Lond. Gaz., June 4-7, 1677). B., Rouen ; specimen at B.M., about 1680. M., Avignon; a watch by him, G.M., about 1700 ; presented an armillary sphere to the King of France in 1701. Baltazar, Paris; watch, 1714 ; Boulle-work clock, Jones collection, S.K.M. about 1725. Jérôme, Paris ; " horologer du Roy;" fine astronomical and calendar clock by him in the Paris Observatory, described by Thiout in 1741; clock, in case of ormolu, supported by a bronze elephant, Jones collection, S.K.M., about 1760 ; the case is inscribed "fecit par Caffieri."

Mascarone, Gio. Batt., padlock-shaped watch, about 1635 .

Masey, Thomas, mended St. Mary's clock, Oxon., 1550.

Mason. Richard, C.C. 1632. Robt., apprenticed in 1658 to Peter Bellune,C.C. Jno., Bristol ; made a clock for the church of Alderly to the order of Sir Matthew Hale, 1673. William, C.C. 1688 . Several generations of Mason in Yorkshire:Timothy, Gainsborough, 1695 ; then John,Doncaster; long lacquer case clock by him, about 1740 ; then John at Bawtry ; Thomas at Bawtry ; Timothy at Chesterfield, watch, h.m., 1795; then John, apprenticed to Timothy at Chesterfield, began business at Rotherham in 1801. Samuel, C.C. 1712 . John, C.C. 1712 ; lantern clock, square dial, cherub corners, bob pendulum, 1712-20. Henry, C.C. 1715 . John, C.C. 1718; long-case 
clocks, 1718-30. William, near East Lane, Rotherhithe Wall, 1760-69; Dockhead, Southwark, 1781-83. - Bedford; watch 1763. Wm., Bexley; watch, 1768. \& Hudson, Strand, 1772. J. Ladson, London ; watch, 1780. Robert, 11 Strand; in 1790 he sent a letter to the Clockmakers' Co. respecting watches seized on his premises. J. \& E., Worcester, about 1790 . John, 3 Helmet Row, 1816-20; 1 Jubilee St., Mile End, 1840. John, High St., Rotherham, died 1914, aged 83 .

Masquerier. \& Perigal, Coventry St., 1775. Lewis, 12 Coventry St., 1780-85. Wm., Gerrard St., Soho, 1790-94.

Masse, James, Broad St., 1753-60.

Masset, Peter, long marquetry case clock, about 1700 (? Mallet, Peter).

Massey. Edmund, C.C. 1682. Paul, Coventry St.; long-case clock, revolving months, date dial, about 1760 , see also Massey, Paul. Mr. A. W. H. HornsbyDrake has a long-case clock, dated 1725, inscribed “ Jon Massey, Dundalke." Benj., 116 Leadenhall St., 1810-26. John, 89 Strand, and 40 Bridge Rd., Lambeth, 1810-35. C., 40 Bridge Rd., Lambeth, 1823-35. F. \& E., King William St., City ; peculiar watch to show tenths of a second, h.m., 1835. Thomas, 4 Birchin Lane, and 32 Wilmington Sq., 1835-42. Edmund, 89 Strand, probably the son of John, of the same address, 1835-42 ; a watch by him, Evan Roberts collection, centre seconds, beating full seconds, the balance nearly as large as the plate, makes 3,600 vibrations an hour; it has a lever escapement, the pallets anchor-shaped as in a clock. Edward John. 78 Cornhill, and 3 Tysoe St., Spa Fields, 1835-42; in 1838, when he patented a chronometer escapement (No. 7,678 ), he is described as of Liverpool. Francis Joseph, 17 Chadwell St., 1840-42. Edward, 28 King St., Clerkenwell; a Staffordshire watchmaker, who migrated from Burslem to Coventry, from thence to Prescot, and afterwards settled in London ; inventor of a form of lever escapement called the crank roller, and forms of keyless winding for watches (see p. 615); he died in 1852 , aged 82 , and was buried at St. John's, Duncan Terrace, Islington.

Massingham, J., Fakenham; bracket repeating clock, about 1770 , Mr. H. Langley.

Masson. R. Aimé, London; watch, Evan Roberts collection, about 1700 . Denis, Paris; clock, Jones collection, S.K.M., about 1760.

Massy. Nicholas, a French refugee, brother C.C. 1682 ; in the Pierpont Morgan collection is a small watch, signed "Nicholas Massy à Blois," balance-cock pinned on, gold case with outer case of leather piqué with gold, about 1660 ; in the same collection is a silver alarm watch, signed "Massy, London;" this dates from about 1690 ; no minute hand, pair cases, pierced, the outer one of particularly fine design and workmanship, has on the back a cypher, C.B., reversed. "Lost the 17 instant, between the Haymarket and Temple Bar, a new Silver Pendulum Watch made by Nich. Massy, with a tortoise-shell studded case, the studs wrought, and the case lined with red sattin ; and 2 seals" (Lond. Gaz., Nov. 24-28, 1692) ; 1690-1712. Henry, son of Nicholas ; C.C. 1692 ; Charles St., near St. James's Sq., 1707; thick round silver watch, silver dial, showing day of the month, elaborately pierced movement. Nicholas, son of the foregoing Nicholas, Cranbourne St., near Leicester Fields ; C.C. 1693 ; striking watch, Schloss collection, royal arms and motto Semper Eadem on the movement; a watch movement by him, with an index on top of the cock, is in the Guildhall Museum. Jacob, Leicester Fields; C.C. 1715; maker of a black arch bracket clock, 1715-25. Paul, Coventry St. ; long Oriental lacquer case musical clock, tunes as engraved on the dial, " Grannadears' March," "The Happy Clown;" shows also days of the week and month, and signs of the zodiac, about 1740. \& Windham, 4 Birchin Lane, 1830-35.

Master, W. J., 26 Bartlett's Buildings, 1823.

Masterman, J., White Hart Court, Gracechurch St., 1769-73; Masterman \& Springhall, 1793.

Masters. Richard, transferred from Clothiers to C.C. 1636. William, C.C. 1701. Jno., London; watch, single case, about 1735. - Wade's Passage, Bath, 1770. Jno., Bristol, about 1780. James, 52 Strand; card, B.M., 1803 ; livery C.C. 1810; after much negotiation he was in 1812 transferred to the Goldsmiths' Company on payment of $£ 30$ to C.C.

Masterson. Richard; early watch signed " Ri Masterson at the dyall at Mooregate," balance-cock pinned on about 1610, Pierpont Morgan collection; afterwards at the Royal Exchange; subscribed to the incorporation of C.C. in 1630 ; C.C. 1633 ; master 1642 ; died 1653 ; in the G.M. is an oval watch by him, cockle-shell case, plain silver dial, hourhand only, catgut; a somewhat similar watch by him, Whitcombe Greene collection. Jno., apprenticed in 1648 to Richd. Masterson, C.C.

Maston. Richd., apprenticed in 1649 to Wm. North, C.C. Thos., Bawtry, 1775. D., London; watches, 1795-1820.

Matchett. John, Covent Garden, C.C. 1648; signed a petition against the Com- 
pany's oppression, 1656 ; assistant, 1670 ; suspended, as well known to be a Popish recusant, 1678. " Lost on the 11th inst. about Lincoln's-Inn-Fields or Covent Garden, a silver watch ingraven with several Figures, made by John Machett, a studded case with silver Pins " (Lond. Gaz., June 12-15, 1676). " Lost on Thursday, the 3 rd instant, between eight and nine in the evening, in the Pall Mall, a gold watch with a silver-gilt chain, and a little cabinet key linked to it, made by John Matchet in Convent Garden. Whoever brings it to Mr. Mawson, Goldsmith, at the Golden Hind in Fleet Street, over against St. Dunstan's Church, shall have five pounds reward" (Lond. Gaz., June 1680). Geo., apprenticed in 1651 to Wm. Petty, C.C.

Matham, Robt., 66 Newgate St., 1783.

Mather. Samuel, C.C. 1691. D., watch with skeleton movement, about 1820 .

Mathew, Francis, C.C. 1656.

Mathews. William, 27 Fleet St., apprenticed to Charles Tolley, and turned over to John Smith; C.C. 1731; assistant and livery, 1766; one of the examiners of Harrison's timekeeper in 1765; watch, 1800 , signed "Matthews, Leighton, Buzzard." W. \& C. S., 128 Minories, 1817. \& Thorpe, 10 Artillery Place, 1840-42.

Mathey, Lewis, Philadelphia, 1797.

Mathieu. C., Paris, 1780. - Paris ; Horloger du Roy, 1830-42.

Mathison, -, London, 1750.

Matlack, W. C., f., of New York, 1769.

Matthew, John, C.C. 1731 ; long oakcase clock, with day of the month circle, about 1740 .

Matthews. Thos., London ; clock with figure of Time working backward and forward ; motto, "Tempus Fugit," dated 1702. Wm., 1765 ; watch paper " opposite St. Dunstan's Church, Fleet St., late apprentice to Mr. Graham." J., Leighton ; long-case clock, about 1810, Mr. Wm. Norman. John, 36 Goswell Rd., 1840. Jacob, Bristol, 1844.

Mattison, Thos., 62 Cornhill, 1793.

Mattocks, John, St. Bride's Lane ; livery C.C. 1786 .

Maubert, Peter, apprenticed in 1679 to David Meggret, C.C.

Maude. Benjamin, 53 St. Martin's-leGrand, 1770-94. Edward, 14 St. Paul's Churchyard, 1793-98.

Mauds, B. E., Daventry, 1780.

Maudsley, G., Wakefield, 1770.

Maughan, Jos. H., Gateshead, 1833.

Maurer, Johann, in Fiessna. In the B.M. is a small skull-watch by him, 1650-60.

Mauris, signature on chased watch case, about 1760 .
Mavor, Jno., apprenticed in 1637 to Jas. Allen, C.C.

Maweis (possibly Mauris), -, chased watch case, about 1770-80, see Potter, Harry, and Smidt.

Mawkes. T., Belper ; long-case clock, about 1710. J., Derby; watch, 1794.

Mawley. Robt., London: Mr. Donald Armour has an all-brass bracket timepiece with alarm by this maker, dating from about 1695, case plain except the sides, which are decorated with a Cupid's head with radiating bars ; bracket clock, about 1725. H., watch, 1705 .

Mawman, Geo., Beverley, 1822.

Mawson, see Matchett.

May. William, C.C. 1679. Edwd., Henley; long-case clock, lantern movement about 1680. John (Dutch), C.C., 1692; watch, about 1710; Pierpont Morgan collection. John, Witney; long-case clock, about 1700 Edwd., Witney; longcase clock, about 1725, no minute divisions on outer circle. Geo., C.C. 1754. "A large quantity of gold and silver watches, with a time piece, and some other curious things of value, were found in the gully hole at Holborn bridge, by the workmen, in cleaning it. These things had been taken some days before from the house of $\mathrm{Mr}$. May, watchm'ker, in Bridgewater square; and were returned on the payment of 10 guineas, promis'd by advzt. for the recovy. of them" (Gent.'s Mag., Aug. 24, 1765). David, Prescot, 1770. \& Son, Dublin, 1798. Samuel, 51 Myddelton St., Clerkenwell; an expert watch and chronometer springer; died 1871, aged 58 .

Maybon, E., St. Germain ; watch, B.M., about 1670 .

Mayers, Jno., Richmond, 1770.

Mayes, John, 8 Lower Charles St., Goswell Rd., 1842 .

Mayhew. Hen., Parham; lantern clock, say, 1690. Wm., Woodbridge ; a wellknown Suffolk maker of "Act of Parliament" and long-case clocks. A notice of his death with a eulogium of his virtues appeared in the Ipswich Journal of Jan. 29, 1791. Mr. R. Eden Dickscn has some fine tall clocks in lacquer cases by this maker.

Mayland, Thomas, C.C. 1698.

Maynard. -, Long Melford; he made the church clock there about 1650 ; lantern clock, Mr. W. B. Redfern. Christopher, Royal Exchange, apprenticed to Hackett, C.C. 1667, see Hicks. Geo., apprenticed in 1692 to Chris. Maynard, C.C.; f. of New York, 1702. Geo., Metford; watch, 1767. Chas., St. Martin's-le-Grand, 1774.

Mayne, -, 111 Union St., Stonehouse ; watch paper, about 1790 .

Mayo. Wm., apprenticed in 1676 to Robt. Cawne, C.C. Thomas, Hereford, 
1760. Joseph, Craven St., Strand, 1769-72. -, Coventry, about 1780-90.

Mayr. At Buckingham Palace is an astrological clock dating from 1680 , signed " Jacob Mayr Junger, Augsburg," square case covered with turtle-shell, adorned with silver scrolls and bands; four dials.

Mayrium, Johann Georg, Munich ; spherical clock about 1690 .

Maysmore, Wm., Wrexham, about 1720 .

Mayson. John, C.C. 1704. M'Cabe \& Strachan, London 1822.

Mazurier, Antoine, Paris ; watch, case enamelled by $\mathrm{H}$. Toutin, about 1670 .

Mazzel, Cor., Bolney; watch, 1740.

Mead. R., Lancaster, 1760. Benjamin, Casline, Me., 1800-10. Wm., I Corporation Lane, 1835. Abraham, London, 1840-1919.

Meade, Garrett, C.C. 1703.

Meader, J. W., London, died 1915.

Meades, Thomas, C.C. 1687.

Meadows, Wm., London; watch, 1760.

Meak, John, musical clock and watch maker, 7 Worship St., 1825.

Meanley, - London; pair-case verge watch, with an engraving on the back representing the Queen of Sheba before Solomon; ; about 1770.

Mears. Isaac, apprenticed in 1661 to Robt. Whitwell, C.C. Josias, Dublin ; long-case clock, about 1760, Sir Theodore Fry. Jno., watch engraver, 48 Cloth Fair, 1790-94. Jno., York, 1822.

Measure, A., 420 Strand, 1815-20.

Mebert, Isaac, C.C., about 1660.

Medcalf, Wm., Liverpool, 1770.

Medhurst, Richard, Croydon, C.C. 1687.

Meeberry, Elizabeth, apprenticed in 1680 to Edwd. Norris and his wife, C.C.

Meek, Jno., musical clock and watch maker, 7 Worship St., 1812-18.

Meeks, Edward, junr., 114 Maiden Lane, New York, 1796; " has eight-day clocks and chiming time pieces" (advt.).

Mehrer, Johann Ferdinand, Augsburg ; table clock, about 1670, Mons. E. Gélis.

Meigh, Moses, C.C. 1712.

Melchior, see Adam.

Mell, Davis, C.C. 1655. Cornelius Harplett was apprenticed to him through the C.C. in 1659; Mr. J. Drummond Robertson has a fine lantern clock, inscribed "Davis Mell in Crutched Fryers, Londini," about 1675 ; it has a minute hand, and the first fourteen minutes of each quarter hour are marked on the minute band in Arabic figures, the quarters being distinguished by Roman numerals, IIII. at the hour, I. at 15 minutes, II. at 30 , and III. at 45 minutes past the hour; beneath the hour bell are three smaller ones; it repeats the hour on a small bell at the halfhour, and chimes ting-tang quarters; in John Aubrey's "Miscellanies" is men48 tioned "Mr. Davys Mell (the famous Violinist and Clock-maker)." $\mathrm{He}$ was Bandmaster to Charles II.

Mellin, Gui, Blackfriars, maker of an oval watch in the B.M., glass over the dial, 1600-20.

Mellinsh, Jas., Bath Easton, 1835, afterwards 3 Balnstrand, Bath.

Melly Frères, Paris ; watch, 1780.

Melrose, James, 34 Nicolson St., Edinburgh; watch paper endorsed "July 9. 1827, Captain Smith."

Melville. John, hon. freeman C.C. 1781. \& Stoddart, 61 Red Lion St., Clerkenwell, 1804-10. Jas., watch-case maker, 13 Spencer St., 1816. Robert, 40 King St., Clerkenwell, 1835.

Memeis, Robt., Margaret St., Wilmington Sq. ; clock, about 1820.

Mendham, - received a silver medal from the Society of Arts in 1807 for a remontoir.

Mends, James, Philadelphia, 1795, afterwards Benj.

Menessie, Elisha, Aldersgate St., 1790-95.

Meniall, James (French), threatened with persecution by C.C. for exercising the art, not being admitted, paid costs, and was admitted forthwith, 1682.

Menzies. J.,Philadelphia, 1811-16. John, 4 Charles St., Northampton Sq., 1840-42.

Mercator. Evelyn's "Diary," 28th Aug. 1666 : "To the Royal Society where one Mercator, an excellent mathematician, produced his rare clock and new motions to perform the equations, and Mr. Rooke" (evidently should be Hooke) " his new pendulum " (see p. 320).

Mercer. Edwd., apprenticed in 1690 to Cuthbert Lee, C.C. John, Hythe, maker of long-case clocks, 1720. Brothers, Coventry, about 1770-90. John, Manchester, about 1800 . Jno., Liverpool, 1818. Thos., born at St. Helens, Lancashire, 1822, died 1900; a leading chronometer maker; he learnt springing from Jno. Fletcher, carried on business for some time in Clerkenwell and afterwards at St. Albans ; was for many years treasurer of the British Horological Institute.

Merchant, Samuel, admitted C.C. 1677 ; assistant 1698 .

Mercier. Louis, Geneva, about 1690. - London; watch, 1725. - Paris ; watch, 1750, Sd Geneva; watch, 1845.

Meredith. Lancelot, C.C. 1637 ; signed a petition against the tyranny of the Company, 1656. John, C.C. 1664. Jno., Carlisle, about 1740. Jno., London; watch, gold box, h.m., 1758, outer case repoussé. Wm., Chepstow; fine long-case clock, about 1775, Mr. W. W. Trotman.

Merigeot, John, livery C.C. 1766. 
Merison, Jas., Anderston; clock, inscribed "Dial made for Robt. Liddal."

Meriton, Samuel, livery 'Turners' Company, 18 Foster Lane, Cheapside, 17631800.

Merlin, Joseph, mechanical genius ; born 1735 at Huys, near Liège. Arrived in England in 1760 . Soon after this became principal mechanic at Cox's Museum, which he left in 1773 ; was an expert designer of engines, mathematical instruments, and a watch and clock maker. He constructed a curious dial or regulator which was wound by the room door opening; died 1803.

Mermillon Frères et Cie., Swiss watch, 1780.

Merny, Charles, Spitalfields, liveryman C.C. 1776 .

Merrell, Jno., London; watch, enamelled case, 1790.

Merrick, Joseph, 28 Paul St., Finsbury, 1835-42.

Merrill. Charles, livery C.C. 1810. H., Hill St., Richmond, 1840.

Merriman. \& Dunbar, Bristol, Conn., 1810. Titus, 1830 .

Merrin, Henry, 100 High St., Shadwell, 1840-42.

Merry. Charles, London; long-case clock, about 1740; livery C.C. 1766 ; master 1768. F., Philadelphia, 1799.

Merryman. Henry, C.C. 1674. Benjamin, C.C. 1682 ; clock-watch mounted as a sedan chair timekeeper, Captain R. Feilden; watch, tulip pillars, about 1695 , inscribed "Benj. Merriman, London." Thos., apprenticed in 1692 to Ben. Merryman, C.C.

Merton \& Co., Liverpool ; watch, 1792.

Merttins, George, Cornhill ; goldsmith and watchmaker, succeeded to the business of his father; C.C. 1688; master, 1713; knighted, 1713 ; Lord Mayor, 1724 ; died 1727.

Mesniel, James (French), C.C. 1682.

Mesnier, Claude, Paris ; clockmaker to the Duke d'Anjou, 1655.

Mestager, Henry, C.C. 1712.

Mesure, Anthony, 8 Craven Buildings, Drury Lane, 1810; 420 Strand, 1814-23. Metcalf. Edwd., apprenticed in 1684 to Richd. Blundell, C.C. George Marmaduke, Round Court, St. Martin's-le-Grand, admitted C.C. 1781; livery 1786; 122 Newgate St., 1794-1825. Josh., 146 Oxford St., 1816-42.

Metcalfe. Mark, Askrigg; died 1776, aged 89. \& Nicholl, Halifax, 1780.

Methem, Robt., 66 Newgate St., 1775.

Meuron. -, Paris; watches, 1770-90. \& Co., Paris, about 1798; watch signed "Meuron, Silliman \& Co., Chaux de Fonds," about 1770.

Meybom, F., Paris, 1650.
Meye, Diet, Basle ; watch, about 1750 .

Meyer. Jacques, Basle ; about 1760 . Paris; watch, 1780. L. J., Bristol, 1844.

Meyers, John, Frederickstown, Md., U.S.A., 1793-1825.

Meylan, F. \& A., Geneva ; watch, 1820.

Meyrick, Wm. Thos. Meyrick, son of Wm. Meyrick, watchmaker, deceased, late of St. Andrews, Holborn, apprenticed to Jno. Williams, citizen and author, minutes of Cutlers' Company, 1803.

Micabius, John, C.C. ordered him to be sued for failing to pay a promised contribution towards incorporation, 1632.

Michael, D. \& Sons, Swansea; watch, 1801.

Michand, P., Paris ; about 1755.

Michant, Daniel, 28 Greek St., 1794.

Michaud. Repeating watch, signed

"Vve. Michaud, Paris," about 1750, Pierpont Morgan collection.

Michel, Jacques, Paris ; lantern clock, about $1650, \mathrm{Mr}$. John H. Baker.

Michelez, Eve, de Breguet; equation clock, about 1828 .

Michelin, Saml., à Langres ; splendid travelling watch, about 1680 .

Michell. Jo., Chardstock; lantern clocks, about 1700 (see p. 487). Jam., London ; long-case clock, marquetry flowers in vase, about 1710. Geo., Bristol, Conn., 1827-37.

Michells, - 63 St. Mary Axe, 1830.

Micklewright. Erasmus, C.C. 1673. -, C.C. 1708 .

Middlecoats, Wm., Newington, Surrey ; bracket clock, about 1730 .

Middleditch, John, 156 High St., Shadwell, 1835-42.

Middlemiss, Robt., Hull, 1822.

Middleton. Timothy, apprenticed in 1680 to Robt. Dingley; C.C. 1687. William T., 10 Grenada Terrace, Commercial Rd.; 1835-42.

Midgley, Richd., Halifax, 1720-40 ; many long-case clocks.

Midnall, John, in Fleet St., one of the first assistants C.C. ; maker of a small oval watch said to have belonged to Oliver Cromwell, B.M. ; small oval watch, Pierpont Morgan collection; pretty balancecock pinned on, about 1620; another watch by him of rather later date, in silver cases, outer case engraved with flowers.

Midwinter, Jno., London ; watch, h.m., 1763.

Miege à Genève ; watch, G.M., about 1750.

Milborne, John, admitted C.C. 1698.

Miles. - Stroud ; clock, lantern movement, square brass dial, about $1700, \mathrm{Mr}$. W. Birchall. -, Lowley; chiming clock incorporated with mahogany bureau, about 
1750 , Mr. G. A. W. Tuckley. \& Morgan, 32 Ludgate St., 1790-94. Septimus, 32 Ludgate St., 1794 ; livery C.C. $1810 ; 8$ Little Carter Lane, Doctors' Commons, 1825-42. G., Guildford St., Boro', 1830.

Milfield, D., London ; watch, 1790.

Mill, David, see Mell.

Millard, D., à Paris ; alarm watch with enamelled dial, pierced and engraved silver case, late seventeenth century, S.K.M.

Millenet, Daniel ; clock-watch with alarm, about 1630 .

Miller. John, C.C. 1674 ; lantern clock, dolphin frets, inscribed " John Miller, Showe Lane," belonging to Mr. Edward Sudell ; Fromanteel in 1665 speaks of one Miller as taking many apprentices. Peter, C.C. 1681. Ralph, C.C. 1697. Joseph, C.C. 1728 ; Jas. Wood apprenticed to him in 1738. Aaron, Elizabethtown, New Jersey, U.S.A., 1747. Wm. Jas., Ludgate St., 1760. - , Lurgan, Ireland ; maker of a curious clock in which the hour was uttered by a human figure, as appears from the journal of the Rev. John Wesley, in a clear articulate voice, 1762. Thos., London ; maker of a pair-case watch, outer case tortoise-shell, painted dial, h.m., 1764; another, Dutch style, 1780 . Geo., Gateshead, 1770. Fred., 38 Greek St.; card, B.M., 1797. Abraham, Easton, U.S.A., 1810-30. Chas., Aldgate Within, 1816-25. Robt., Tottenham, 1820; 2 George St., Commercial Rd., 1835; 4 Upton Place, 1842. F. \& Co., 10 Broad St., Bloomsbury, 1835-40. Jas., 262 High St., Poplar, 1842.

Milleret, - . Extra small watch, gold case, enamelled with a rose.

Millet, William, C.C. 1714.

Millett, Edward, C.C. 1680.

Millig, Michael, Southwark, 1734.

Millington. Thomas, 31 Gutter Lane, Cheapside, 1760-69; watch, brass cases, outer one repoussé and gilt. \& Lancashire, London; watch, 1768 ; watch, signed "Millington Salop," 1780. Thomas, 33 Wapping, 1790.

Mllion, William, Blackfriars, C.C. 1671. Millot. "Horloger du Roy, rue du Bac, Paris," 1764-72 ; fine urn timekeeper, about 1680; the movement was by Dwerryhouse, London.

Mills. Thomas, in Shoe Lane, C.C. $1652 ;$ maker of lantern clock with dolphin frets; another example, inscribed " Tho. Mills, Soe Lane, Londini," 1648-60. Jere, apprenticed in 1676 to Jno. Miller, C.C. Richard, Edinburgh; apprenticed to Humphrey Mylne; made a freeman of the Incorporation, 1678; his essay being, "Ane clock watch and luminary, with the further addition of a lock and key;" declined the office of "box-master" "or treasurer in 1703; died 1705; lantern clock, signed " Humphrey Mills, Edin- burgh, 1685," Mr. Robert Meldrum. "Stolen out of a house near the West Port on the 19th, a gold watch with a steel chain and a shagreen case. Whoever can bring the said watch to Richard Mills, watchmaker in Edinburgh, shall have two guineas reward " (Edinburgh Gazette, 1695). Ralph, apprenticed to Charles Gretton, and turned over to Cuthbert Lee; C.C. 1697. George, long-case clock, "George Mills, de Sunderland, fecit," about 1710. Thomas, London; watch, h.m., 1762. -, Gloucester ; long-case clock, about 1780 Robert, 141 Ratcliff Highway, 1790-94. Wm., same address, 1809-18. Thomas \& Son, 26 Red Lion St., Clerkenwell, 1812-18; 91 Bishopsgate Without, 1823. George, 141 Goswell St., 1825. Hy., 171 Oxford St., 1845.

Milner. Thomas, London ; long-case clocks, some inscribed "Thomas Millner," 1740-70. Henry, 7 Vere St., Oxford St., 1815.

Milnes, Geo., Huddersfield, 1833.

Milton, -, 29 Marylebone St., Golden Sq. ; card, B.M., 1802.

Milward, Geo., 2 Little Brook St., 1806-15.

Mimess, R., Woolwich, 1816.

Minchener, Saml., London; long-case clock, about I 8 Io.

Minchin, J., Moreton-in-Marsh, 17991821, afterwards at Stow-on-the-Wold.

Minchinale, William, C.C. 1701.

Minshull, Wm., apprenticed in 1666 to Nicholas Reeves, C.C.

Minten, Jno., London ; watch, 1760.

Minuel, David, admitted C.C. 1683.

Miroir. A large pull-repeating travelling clock-watch in silver case, outer case of leather with silver mountings, dating from about 1740, signed "Miroir, London;" a very similar watch of apparently rather earlier date, inscribed "J. Miroir, Augspurg," was formerly in the Shandon collection ; another travelling watch dating from about 1760, inscribed " J. Miroir, London."

Miroli, Denis, Geneva ; watch, about 1720 , M. C. Sivan.

Mison, Jere, apprenticed C.C. 1688.

Misplace, R., Searle St., Lincoln's Inn Fields, 1775-88.

Mitchell. Myles, C.C. 1640 . Joseph, apprenticed in 1674 to Nat Delander, C.C. John, St. James's St., apprenticed to Jno. Earles, C.C. 1712. Samuel, St. James's St.; repeating watch, about 1745 ; another, h.m., 1776. Robert, livery C.C. 1766. \& Viet, 6 Cornhill, 1768. Hy., f. of New York, 1787. William, Richmond ; watch, 1804. Jno., 6 Cornhill, 1817. T. \& W., Glasgow ; watch, 1820 . Chas., 84 Tower Hill; watch, 1822. \& French, 5 Clerkenwell Close, 1825. Alexander, Glasgow, 1820. \& Son, Glasgow, 1830. 
Mitchelson. Jas., Throgmorton St., 1753-56. Alexander, 45 Michael's Alley, Cornhill, 1769-72. Walter, 3 Helmet Row, 1780-1880.

Mitford, John, apprenticed to Sir George Mertins, of Cornhill, whose daughter he married in 1714, when he was nineteen years old. $£ 200$ stock of the Exchange Assurance Association standing in his name, which, with interest, had accumulated to $f 6,600$ in 1883 , was then ordered by Mr. Justice Williams to be paid to his nearest relatives.

Mitten, Francis, Chichester ; 30-hour long-case clock, about 1750 .

Mitzell, - London; pendulum watch, Schloss collection, about 1700.

Moginie, Samuel, 1 Prince Row, Pimlico, 1820-42 (succeeded Glover).

Moilliet. Dan., Geneva; watch, 1780. A. \& Co., Geneva; watch, 1790.

Moinau, Auguste, Philpott Terrace, Edgware Rd.; patented in 1840 (No. 8,501) a system of detached weights for clocks.

Moinet, Louis, born at Bourges 1768 ; died 1853. Author of " Nouveau Traité Général Astronomique et Civil d'Horlogerie Théorique et Pratique"; Paris, 1843.

Mole, James, Birmingham; long-case clock, about 1760 , Sir James M. Moody.

Molee, P., 44 Great Sutton St., 1835.

Molens, Charles, C.C. 1709.

Molineux. Thos., Rochdale, 1770. Wm., Rochdale, 1818.

Molleson, Thos., 62 Cornhill, 1788-1810.

Molyneux. R. \& Sons (Robt. \& Henry), 30 Southampton Row, Russell Sq., 183542 ; they were succeeded by Birchall \& Appleton ; Robert Molyneux, junr., went to America and settled there. Robert, a chronometer maker who carried on business at 44 Devonshire St., Queen's Sq. and afterwards in King St., Holborn; inventor of a compensation balance with auxiliary (Patent No. 8,418), March 1840. $\&$ Cope, London ; entered chronometer for Greenwich trial, 1822 ; clock, about 1840.

Moncas. Jno., Liverpool, 1818. John, 75 Myddelton St., Spa-fields, 1835.

Moncrief, Jno., apprenticed in 1688 to Jno. Bellard, C.C.

Monday, Joseph, C.C. 1654.

Money, Henry, 49 King Sq., 1855 (afterwards Money \& Bassold).

Monk. Small sheep's-head clock, signed "William Monk Barwick St. John," about 1730. Edwd., 171 Fleet. St., 1793, see Monks.

Monkes, Geo., Prescot, 1770.

Monkhouse. Thomas, Duke St., fecit, anno 1759 ; inscription on the barrel of a fine 8-day long-case clock with high numbered train, end pieces, and all the repeating work pivoted with cocks; on the dial the name Curteen, 1759. Jas., Carlisle, 1768. John, London; on dial of clock by Vullin, B.M., about 1770. \& Son, Carlisle, 1785-1810.

Monks, Chas., Prescot, 1812 ; also Geo., same date.

Monnée, -, Vienna; tulip-shaped watch, Pierpont Morgan collection, about 1770 .

Monnier, John, 38 Southampton St., Strand, 1812-28, see Wilson, W.

Monro. George, Edinburgh ; watch, Evan Roberts collection, about 1730. Benjamin, 13 Moor St., Soho Sq., 1830-42. Montagu. Jno., apprenticed in 1641 to Jno. Midnall, C.C. T., London, about 1760 ; a watch by him, pinchbeck inner and shagreen outer case, exhibited at the Guelph Exhib.tion by Mr. Geo. Carr Glyn.

Montgomery, Robt., New York, 1786.

Montlow. Henry, apprenticed in 1678 to Richard Browne, C.C. 1685; Abraham Acton apprenticed to him in 1691; fine long-case clock, about 1695, inscribed "Henricus Montlow, Londini-fecit"; another long-case clock, named "Mowtlow." Conon, apprenticed 1691 to Richd. Harold, C.C. Henry, apprenticed to John Delander ; C.C. 1715.

Moody. David, C.C. 1649 ; gave a silver dish in 1651. Charles, 45 Rupert St., Piccadilly, 1815-25.

Moolinger, Henry, Philadelphia, 1794.

Moon. Thos., London; a “" $\frac{3}{4}$ wall clock" by him offered in the Collectors' Circular. \& Co., 4 Holborn Bars, 1790. Christopher, 4 Lower Holborn, 1810; watch, Schloss collection. William, 4 Lower Holborn, 1815-42; livery C.C. 1820.

Mooran, Andrew, London; maker of clocks, about 1760 , see Moran.

Moore. Robt., apprenticed in 1662 to Sam. Davis, C.C. Edwd., London ; lantern clock, 1680. Joseph, C.C. 1690. Wm., apprenticed in 1693 to Ben Johnson, C.C. ; C.C. 1701 ; fine long-case clock with large seconds cricle in the arch of the dial, about 1715. Daniel, C.C. 1697. Thos., Ipswich ; the Wetherfield collection contains a striking and repeating bracket clock by him in an ebonised case, dating from about 1720 ; there are six bells on which the pullrepeating quarters are sounded; Mrr. W. W. Pope has a particularly attractive long-case musical and calendar clock by him; it chimes the quarters on four bells and plays one of seven tunes every hour, in the arch of the dial is an orchestra of eight moving figures; Mr. R. Allen, Bridlington Quay, has a long-case clock by him; at Long Melford Church is a fine long trunk dial by him, the case with lacquer decoration. "Whereas Thos. Moore, clock and watchmaker in Ipswich, 
have for many years observ'd the misfortunes which very frequently happen to
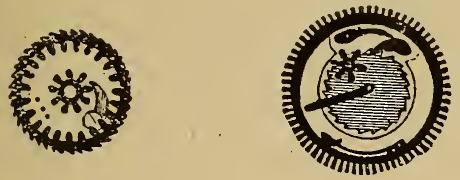

pocket-watches of all sorts-viz., by sometimes coming in to unskilful hands, \&c., and often in to the hands of servants (in absence of the owners thereof) they, endeavouriug to wind up the watch, have turned the wrong way, and by so doing, they have broke the work (and the like often happens when Juice of Grape Predominate). Therefore this to give notice. That the above Thos. Moore have now made up several curious Silver and Gold Watches (and will continue to do so) so curiously contriv'd, that let the watch be wound up which way they please, either to right of left, they cannot fail of winding up the watch, with more safety than if wound but one and the common way, and are to be sold at very reasonable price. Any person or persons may have the freedom to seeing any of the said watches at his house in Ipswich aforesaid " (Ipswich Newspaper, 1729). At the Horological Institute is a fusee of one of Moore's watches, which was sent from Syracuse, New York, by Mr. Geo. R. Wilkins; the great wheel and larger end of fusee are shown in the accompanying cut, and the action will be understood by those conversant with watch work; the device was described by Thiout in 1741, some years after Moore's advertisement appeared. Mr. R. Eden Dickson has a clock by "Moore Melford" which he bought at the sale of the effects of Edward Fitzgerald, to whom it was given by his friend W. M. Thackeray. T., London ; watch, 1763. John, 118 Fleet St., 1769-75. Robt., Stoney St. ; long-case clock, about 1770. F., 37 Gracechurch St. ; 1770-75. Francis, Ferry Bridge; long-case clock, about 1775. Wm., 55 Paternoster Row, 1775-88; 5 Ludgate St., 1793; watch, about 1790 , silver case with crystal back showing the movement, Pierpont Morgan collection.--, Salisbury; long-case clock, Wetherfield collection, about 1780. Peter, 15 Sweeting's Alley, 1780-1806; verge watch by him, square pillars in the Guildhall Museum. \& Gearing, 55 Paternoster Row, 1783. \& Edwards, 4 Holborn, 1793. Patrick, 15 Sweeting's Alley, 1806-10. Jno., Warminster, 1780 ; long-case clock, about 1800 , Mr. C. B. Oliver. \& Starkey, 89 St. Martin's Lane,
1823. E. T., 37 Clement's Lane, $1823 ; 8$ Prospect Pl., Kingsland, 1835 . Jno., formerly partner with Handley, Clerkenwell Close, then Jno. Moore \& Sons ; 182442. Chas., 3 Abbey Churchyard, Bath, 1835. George, third son of Jno. Moore (Handley \& Moore), 23 Percival St., 1838 ; afterwards succeeded F. B. Adams \& Sons at 21 St. John's Sq. ; died 1894, aged 80. G. J., 49 St. John's Sq., son of Geogre ; died 1916, aged 78 .

Moorhouse, -, Knaresborough, about I825.

Moraley. Wm., apprenticed in 1680 to Hy. Child ; turned over to Philip Corderoy, and afterwards to Thos. Tompion; C.C. 1688. Wm., London, 1828.

Moran, Andrew, Earl St., St. Giles. This name appears on the disc at the top of an arch-dial 8-day case clock at the Crown, Harlesden, where it is stated to have been since 1740 .

Morcombe, Jno., made the town clock for Hartland, Devonshire, in 1622-23; " new made " it 1657-58; the latter entry from the accounts refers, it is suggested, to a conversion from balance to pendulum.

More. B., London; watch, 1760 . Jean Louis, Geneva ; watch, about 1810, M. Bastard. Charles, 19 Holywell Row, Shoreditch, 1840-42.

Morecand \& Co., Paris, 1800.

Morehouse, W., London; watch, 1807.

Morel, P., Geneva ; watch, 1780.

Moreland. Thos., Chester; watch, 1726. John, apprenticed to John Pike, C.C. 1738. Thos., Chester, 1810-42.

Morell, Jas., apprenticed in 1676 to Michael Rose, C.C.

Moret, Nicholas, Paris, 1544 (see p. 404). Morey, S., London; lantern clock, 1700.

Morgan. Richard, petitioner to Charles I. for incorporation of C.C. and one of the first assistants, 1629-49. Robert, C.C. 1637. Jude, C.C. 1654. Thomas, C.C. 1658. Hy., C.C. 1677. William, Southwark, 1696. John, C.C. 1703 ; long-case clock, inscribed "John Morgan, Chancery Lane, London." A Minute of the Court of the Cutlers' Company of the 30th October 1710 runs as follows :- " A peticōn was read of Anthy Russell praying to have liberty to prosecute one John Morgan (a watchmaker for fitting up joyneing and selling Swords altho' he served noe apprenticeship to that trade) in the name of this Corporacōn." Thos., Baltimore, Md., 1774. Thos., Philadelphia, 1779-93. \& Miles, 32 Ludgate St., 1790. Wm., London; watch, 1810. Theodore, Salem, 1837-42 ; then Luther. Thos., Minehead, 1844.

Moricand \& Co., Geneva ; watch, 1780. 
Morice. Geo., apprenticed in 1653 to Thos. Eyston, C.C. David \& Son, 15 Fenchurch St., 1804-23; 86 Cornhill, 1826-36 ; Mr.J. Drummond Robertson has a gold watch, h.m., 1816, "D. \& W. Morice, Fenchurch St.; " another watch, 1823, "Fenchurch St. and Cornhill."

Moriffet, R. \& C., 22 Denmark St., Soho, 1783.

Morizot à Paris; watch, about 1824 .

Morland. Jno., Smithfield, C.C. 1734

Wm., Red Cross St., 1780-85. —, 17

Red Cross St., 1790-94.

Morley. Wm., apprenticed in 1691 to Jno. Willoughby, C.C. Robt., York,f., 1732. Robert, Hursley church clock, 1808.

Morliere, -, born at Orleans; excelled as a watch-case enameller at Blois, about 1650.

Mornand, I. Paris ; thick alarm watch, hour numerals on enamel plaques, single case covered with leather piqué, about 1690.

Morpeth, Thos., Hexham, 1770.

Morrel, Benj., Boscowen, U.S.A. 1816-45.

Morrell, Jno., Whitby, 1822-33.

Morreton, -, London ; watch, about 1775.

Morris. Edwd., C.C. 1672 ; assistant 1677. Henry, 82 Fleet St., 1733-75. Wm., King's Head Court, Fetter Lane, 1780. T., 68 Bell Dock, Wapping, 1794. John, C.C. 1799.

Morriset \& Lukin, 22 Denmark St., St. Giles, 1793.

Morrison. Richd., 15 Cheapside, 1769-83. "Richard Morrison at his old shop [No. 15] the Three Kings and Golden Ball opposite Foster Lane, in Cheapside, successor to Mr. Stafford Briscoe," card, Ponsonby collection. William N., 33 Ludgate Hill, 1840. John, 27 Packington St.; a well-known clockmaker; died 1893, aged 77 .

Morritt \& Lee, 93 High Holborn, 1816.

Morse, Richard, 8 Charing Cross, 1835-42 (succeeded Rigby).

Morson. ( \& Stephenson, 98 Fleet St., 1760-72.) Richard, 12 Ludgate St., 1775 .

Mort, Richd., apprenticed C.C. 1693.

Mortimer, -, Dartmouth ; watch, 1825.

Mortimor, Chas., London ; watch, 1824.

Morton. Samuel, 210 Borough, 1775. \& Milroy, 1800.

Mosbrucker à Saverne, about 1750 .

Mose, Jas., Litchfield ; long-case clock, about 1760 .

Mosely. William, C.C. 1680. Lewis, Liverpool, 1770. Charles S., born at Westfield, Mass., 1838; a clever mechanician, devised the early machines of the American
Watch Company of which he was master mechanic in 1859 ; in 1864 he joined the Elgin Watch Company of which he became superintendent.

Moser, George Michael, born at Schaffhausen in 1707; came to England, and in 1768 was appointed keeper of the Royal Academy ; died 1783 ; fine repoussé work by him on watch-cases; he was also of repute as an enameller.

Moses. Selegman, London; long-case clock, about 1775. Ephraim, 135 Whitechapel, 1790.

Mosley. Elinor ; Elizabeth Askell was bound apprentice to her in 1734 ; C.C. 1726-34. Jno., Penistone, 1790. Martin, 28 Goulston Sq., 1804; 6 Bevis Marks, 1815-35. Robert \& Son, 113 Fetter Lane, 1822-42. Moses, 26 Bury St., 1830-42. Ephraim, 48 Leadenhall St., 1838-42. Robert E., Newburyport, U.S.A., 1848.

Moss. Thos., Frodsham ; long-case clock, about 1740 ; Mr. Wm. R. Moss has a belltop bracket clock by him in mahogany case which strikes on three bells and repeats the quarters ; also a long-case clock made in 1776 or 1778 showing days of the month, age and phases of the moon, and time of high water (see p. 519). Thomas, 24 Ludgate St., 1775 ; livery C.C. 1786 ; died 1827. John, 106 Holborn Hill, 1825. B., Tabernacle Walk, 1835.

Mossman, Jas., Edinburgh, died 1912.

Motley, Richard, Wapping ; C.C. 1682 ; long Oriental lacquer case clock, strikesilent, about 1720 ; long-case clock, ship worked by pendulum, mahogany case ; on trade bill inside the case "Richard Motley at the Hand \& Buckle near King Edward Stairs, Wapping."

Mott. (or Moth), Thos., apprenticed in 1648 to Jere. Gregory ; C.C. 1656. Hy., apprenticed in 1655 to Jno. Palfrey, C.C.; watch, about 1665 , inscribed " Henricus Mott in Drury Lane." \& Bellin,91 Bishopsgate Without, 1815. William, 91 Bishopsgate Without, 1830; 55 Cheapside, 1835.

Motteux, Samuel, C.C. 1697.

Mottram, John, Warden Court, Clerkenwell Close, 1780-94; large musical clock by him in splendid case designed apparently for some Eastern potentate.

Mottu Brothers, 11 Richmond Buildings, Soho Sq., 1840-42.

Moulding, S., London ; watch, h.m., 1818.

Moule. Jno., apprenticed in 1679 to Richd. Jarrett, C.C. Jas., London ; longcase clock, about 1785 .

Mouline, A. \& Co., 29 Percy St., Tottenham Court Rd., 1842.

Moulinie \& Co., Geneva ; watch, 1820.

Moulton. Henry, C.C. 1685 . Saml., 210 Borough, 1788-1800. 
Mount, William, C.C. 1692.

Mountford. Zachariah, St. Albans ; admitted C.C. 1684; "Mountford for mending my master's watch 020 " (MSS., Earl of Verulam, 1696) ; long-case clock, about 1700. John, London; long-case arabesque marquetry clock, about 1705 .

Thos., St. Albans, 1715.

Mountlow, see Montlow.

Mousley, Arthur, apprenticed 1671 to Jere. Johnson, C.C.

Mowat, Alex., 7 Quiet St., Bath, 1845, see Frankccm.

Mowbray, Wm., Doncaster, 1770.

Mowlton. Conan, C.C. 1700. Henry, C.C. 1715 .

Mowtlow, see Montlow.

Moxon. Josh., Bradford; watch, 1780. J., skeleton clock at Buckingham Palace, about 1820, inscribed "Invented by William Congreve Esq., J. Moxon fecit."

Moy, Matt., apprenticed in 1661 to Ben Hill, C.C.

Moynier, Geneva ; watch, 1790. Et Fils, Geneva; watch, 1830.

Moysant, -, Blois ; watch, case finely painted in enamel.

Moyse, -, Blois ; maker of a skull watch, 1587.

Moyser, Thos., apprenticed in 1653 to

Wm. Godbed, C.C.

Moysset à Toulouse ; watch, about 1760 . Mons. E. Gélis.

Moze, Henry, Shadd Thames; clock, about 1740 ; watch, 1760.

Muckarsie, George James, 47 High Holborn, 1794 ; livery C.C. 1824.

Muddle, Thos., Rotherfield; lantern clocks, $1700-10$.

Mudge. Thomas, Fleet St. ; a celebrated maker; born 1715, died 1794 (see p. 354). \& Dutton, 148 Fleet St., 1759-90; Reid mentions an equation clock they made for General Clerk, and which, together with a spring clock having the striking work described on p. 328, was entailed on the house of Pennycuick; in the Wetherfield collection is a striking and repeating bracket clock by them dating from about 1780 ; the Rev. A. F. Sutton has a watch inscribed "Mudge \& Dutton," and bearing the hall-mark for 1759; I am uncertain when the partnership was dissolved, but T. Mudge, junr., refers to Dutton in 1790 as Mudge's late partner, see Dutton. Jno., London; long-case clock, about 1800, Wetherfield collection; regulator, about 1830. Geo., 430 Edgware Rd., 1855.

Mugnier, horloger du Roy, Paris ; artistic watches, Breguet style, about 1820.

Mulford. Wm., apprenticed in 1682 to Jno. Norcott, C.C. John, Cursitor's Alley ; died while warden C.C. 1748.
Mulgrave, Geo., London ; watch, 1800.

Muller. Andreas; clock, Soltykoff collection, about 1570. Christoph, Augsburg ; clock, about 1660. Johan Conrad : clock, about 1705. \& Thum, 40 King St., Soho, 1842.

Mulliken, Samuel, Newburyport, U.S.A., 1740-56; then Jonathan, then Saml., at Salem.

Mullineux, Thos., apprenticed in 1693 to Edwd. Boone, C.C.

Muncaster. Lancaster: Thos., 17971830 ; Wm., 1806, f. ; Jno., 1806, f. Jno., Ulverstone, 1818. Jno., Whitehaven, 1833.

Munday. Thos., apprenticed in 1688 to Jno. Benson ; C.C. 1692. Wm., C.C., in 1734 he worked for Marshall.

Munden, Francis, C.C. 1653.

Munkerson, David, Edinburgh, apprenticed to Paul Romieu the younger and admitted a free "knockmaker" in 1712, his essay being a watch movement.

Munroe. Wm., Edinburgh ; long-case clock with dead-beat escapement, about 1800. \& Whitney, Concord, Mass., 1805-25.

Murphy. John, Northampton, 1775. P., Dublin ; watch, 1797.

Murray. Wm., Edinburgh, 1712. T., London; watch, Schloss collection, about 1780. James, a celebrated chronometer and watch maker who carried on busines at Cornhill from about 1814; livery C.C. 1817 ; one Strahan seems to have been in partnership with him at 19 Sweeting's Alley, from about 1816 till about 1825 . James Weddell, in his "Voyage towards the South Pole in 1822-4," stated: "Of chronometers I had one of eight days, No. 820 , made by Jas. Murry; one of two days by Murry and Strachan, No. 403 ; one of twenty-four hours, also made by Murry ; and they all performed sufficiently well to recommend the makers for their very improved mechanism in this important art." After the Royal Exchange was destroyed by fire in 1838 James Murray carried on a successful business at 30 Cornhill; he was succeeded by his two sons, James and John. James afterwards went to India and established a successful business in Calcutta; he died in 1892; John Murray, at 30 Cornhill, was joined in partnership by one Mitchell, and continued there with him for some years.

Musgrave. G., Taunton, 1770. Jno., Keswick, 1833.

Musket, Jno., Prescot, 1770.

Mussard, Daniel (Genevese), C.C. 1686 ; watch in the Hamilton collection, bought by Lord Moray at the auction sale in 1882 . for $£ 154$ 10s.; portraits of the Stuart family were enamelled thereon; 1670-90.

Musson, -, Paris, 1782-95. 
Muston. \& Gath, Bristol, 1796-1844. Geo., Red Lion St., Clerkenwell, 1835-42.

Mut, Gerard, Frankfort ; watch, Vienna Treasury, with train wheels quadrangular and pentagonal, about 1670 .

Myddleton, see Middleton.

Myers. John, f. of York, 1778 ; in London at 255 Borough till 1804; long-case clock by him, S.K.M. John, 255 High Holborn, 1790. Hy., 164 Ratcliff Highway, 1804. Moses, 152 Regent St., 1830. Abraham, 79 Leman St., 1840-42.

Mylne, Humphrey, Edin burgh, admitted as a locksmith and knockmaker 1647; made a clock for Magdalen Chapel, Cowgate, the meeting-place of the Incorporation of Hammermen, in 1666, died about 1690 . G. E., foreman for Yonge ; afterwards at 9 Upper Chadwell St., maker of high-class watches, sometime hon. secretary to the Horological Institute; died 1868, aged 53 .

Mynuel, -, Paris ; clock, S.K.M., 1700 ; another, Wallace collection.

Myrmecides, - Paris, about 1530 ; thought by Dubois to be the inventor of cruciform watches.

Myson, Jeremiah, C.C. 1698.

Nadauld. Wm., 129 Houndsditch, 1804-20. W. R., White Hart Court, Lombard St., 1819-33.

Nagel, Adrien, Wien ; watch, about 1600.

Naish, Jas., London ; clock, about 1770.

Naizon, Francis, 42 Poultry, 1780-85.

Nanta, J., Leuswarden, about 1680.

Napton, Wm., apprenticed in 1686 to Edwd. Engs, senr., C.C.

Nardin, Ulysse, Neuchâtel ; born 1823, died 1876 .

Nash. Wm., oval watch, metal case, Mr. Edwd. Parr, about 1605 . Wm., apprenticed in 1663 to Thos. Birch, C.C. Jno., C.C. 1667. Thomas, C.C. 1717 ; clock, "Tho. Nash, Salop," about 1770. Samuel, 11 Broadway, Blackfriars, 1790-94.

Nathan. Henry, Ratcliff Highway; C.C. 1673 ; maker of long-case clocks, 16731700. Phineas, 9 Magdalen Row, 1840-42.

Nau. Richard, C.C. 1661. George, C.C. 1675 .

Naudey, Francis, 59 Dean St., Soho, 1842.

Naylor. J., Mr. J. B. Cooksen, Meldon Park, Morpeth, has a remarkably interesting astronomical clock by "Ion Naylor, near Namptwich, Cheshire," about 1725; another astronomical clock by him is at the Cluny Museum, Paris. Charles, Liverpool, about 1770 .

Neale. Thos., apprenticed in 1655 to Joseph Quash, C.C. John, Leadenhall St., 1743-59; in 1744 he obtained a patent for a "Quadrantal planetarian."
Neat, J., 40 Duke St., Manchester Sq., 1817.

Neate, Wm., 3 Sweeting's Alley, 1817.

Needham. Jno., apprenticed in 1691 to Richd. Parsons, C.C. Benjamin, C.C. 1709. Jas., Fleet Lane, C.C. 1734. Robt., 56 Piccadilly, 1793. Charles, 55 Piccadilly, 1825.

Negus, Willy, C.C. ; to him was apprenticed in 1815 Samuel Evans. The Neguses who established a leading position in New York during the nineteenth century, possibly sprang from the Willy Negus here mentioned, whose business in London I am unable to trace.

Neighbour, William, C.C. 1685, apprenticed to Ahasuerus Fromanteel, junr., and turned over to Benjamin Graves.

Neild. James, 4 St. James St., 1755-94. J., 4 Upper Thames St., 1788.

Neill, Robert, High St., Belfast ; succeeded John Knox in 1816.

Neiser, Augustine, Philadelphia, 1739-80.

Nelmes, Robert, 21 Whiskun St., 1827 ; 38 Upper King St., Bloomsbury, 1842.

Nelson. James, apprenticed to Oswald Durant, 1638 ; admitted C.C. 1645 ; maker of an astronomical watch in Guildhall Museum. John, apprenticed to Daniel Stevens and turned over to Daniel Quare ; C.C. 1697. Robert, C.C. 1697. Wm., Liverpool, 1775. H., London; watch, 1799. John, 15 Hayfield Place, Mile End, 1842. Thomas, London; chronometer maker, died 1882 .

Nelthropp, The Rev. Henry Leonard, an authority on antique timeke€pers, who gave his collection to the Clockmakers' Company, of which he was master in 1893 and 1894 ; died 1901 , aged 81.

Nemes. Robt., apprenticed to Bart. Powell 1669; C.C. 1667. John, Queen St., C.C. 1724.

Nerry, Jno., London; a watch by him, Guildhall Museum, about 1730.

Netherwood, Job, apprenticed in 1686 to Clem Forster, C.C.

Netter, Robt., apprenticed in 1681 to Jno. Winn, C.C.

Neué, Hen., Strand, about 1740.

Neuens, Peter, 32 Bread St., 1840-42.

Neuren, D. (also spelt Neveren and Neweren), London; maker of verge watches, 1760-90.

Neuwers, Michael, made a clock for the Earl of Shrewsbury (see p. 51), 1599, see Nouwen.

Neve. John, " in ye Strand;" basket top bracket clock, about 1680 . Henry, Strand, about 1700-5.

Nevill, Geo., apprenticed in 1653 to Wm. Comfort, C.C.

Neville, J., London; watch, about 1704.

Newad, W., London; watch, 1760. 
Newbald, James, f., York, 1830.

Newbrough, Jeremiah, Grays Inn, maker of long-case clocks, 1700-10.

Newby. Wm., Kendal, 1770. Jas.,

Kendal, 1785. John, 3 Judd St., 1825.

Newcomb, Joseph, livery C.C. 1810.

Newell, Jno., apprenticed in 1681 to Robt. Doore, C.C. Thomas, Sheffield, U.S.A., 1809-20. William, livery C.C. 1810. 25.

Newland, Ab., London ; watches, 1813-

Newlove, Jno., York, f., 1823-30.

Newman. Nat., apprenticed in 1694 to Hy. Merryman, C:C. ; Broad St. in 1734. Robert, London ; clock, 1700, hands illustrated in Fig. 695, No. 28. Richd., Lynn; watch, shagreen case, Mr. A. E. Clarke, about 1750. John, 49 Lombard St., 1775-83. Joseph, 30 Great Alie St., 1790. John, 17 Piccadilly, 1804-25; livery C.C. 1810. Edward, London, about 1820. Wm., 109 Golden Sq., 1840-42.

Newnham, Nathaniel, C.C. 1703.

Newsam. Jno., York, f., 1568-98. Bartholomew, Strand ; appointed in 1572, clockmaker to Queen Elizabeth, in succession to Nicholas Urseau (see p. 250).

Newsham. Wm., Clerkenwell Close, 1765-93. Richard, Liverpool; calendar watch, 1791.

Newsom, Thos., London; watch, 1828.

Newson, Jno., Basinghall ; C.C. 1734.

Newstead, Chris., York, f., 1797.

Newton. Herbert, apprenticed in 1663 to Thos. Wheeler, C.C. George, London, about 1680. William, East Smithfield, C.C. 1685. Thomas, Fenchurch St., 1753-56. John, 76 Lamb's Conduit St., 1788-1810. Jno., 10 Great Ormond St., 1788-1815. Alexander, Levi \& Co., 4 Bury St., St. Mary Axe, 1839-42.

Nicasius, John, C.C. 1632 ; several times fined for abuse and disrespect, and in 1679 was suspended from being assistant; master 1653-55. Octagonal watch, G.M., inscribed "Nicasius, London."

Nichol, Isaac, C.C. 1681.

Nicholas. -, lantern clock, inscribed David Nicholas, fecit," about 1680. Benj., apprenticed in 1682 to Thos. Taylor (Holborn), C.C. C., London, about 1700-5. John, Daventry ; timepiece with carriagespring for driving, about 1820 . W., 158 Tooley St., 1825. Samuel \& Son, 158 Tooley St., 1835-40.

Nicholls. Roger, C.C. 1667. Thomas, C.C. 1707. George, New York, f., 1728-50. John, clock-case maker, 6 Red Lion St., Clerkenwell, 1804-10. \& Harris, Canterbury, 1815.

Nichols, Thomas, apprenticed to Edward East; C.C. 1720. Peter, Newport, 1. of W., 1783.
Nicholson. Richd., C.C. ; worked for Dudds in 1734. Jno., Durham, 1770. J., Whitehaven, 1775. John, 53 Cornhill, 1816-30.

Nickals, Isaac, Wells ; splendid long-case chiming clock, with lacquer decoration, phases of the moon and time of high water in arch, about 1740, Wetherfield collection.

Nickisson, S., Lower Ash by St., 1815-40 ; 33 Northampton Sq., 1842.

Nicol, Jas., Edinburgh ; long-case clock, about 1740 .

Nicole. John, keeper of the great clock within the Palace of Westminster in 1371, his wages being sixpence a day. Adolphe, Dean St., Soho; a remarkably clever horologist; in $\mathbf{1 8 4 4}$ he patented keyless work (No. 10,348) (see p. 616); the patent included a chronograph with heart-shaped cam; in 1862 he patented an improved chronograph with castle ratchet (No. 1,461$)$

Nicolet. Jacob Louis, settled in St. Imier 1770; made nearly all the parts of his watches, and when he had completed three, rode on horseback to Chaux de Fonds to sell them. Joseph Marce, Philadelphia, 1797.

Nicoll. Wm., 117 Great Portland St., 1790-1835. Wm., junr., London, about 1825. John, 117 Great Portland St., 1814-42.

Nielsen, Emil, Soho Sq., died 1899.

Nightingale. Jno., apprenticed C.C. 1655. Wm., Red Lion St.; liveryman C.C. $1776-94$.

Niloe, Hans (Dutch) ; maker of a musical clock for James I. In August 1609 Sir Julius Cæsar writes to the Clerks of the Signet to the effect that Niloe is pressing for the $£ 300$ due to him for the clock.

Ninnes, Jas., 12 Bath St., Bath, 1835.

Nixon, Thos., oval watch, G.M., about 1605.

Noades, J., Strang, 1775.

Noakes. Jas., watch movement maker, 34 Charterhouse St., 1776-94; livery C.C. 1776. (\& Nydler, 129 Houndsditch, 1790-94). Jas., 126 Houndsditch, 1800 ; 24 Bishopsgate St. Within, 1810-18.

Noble. John, London ; 30-hour longcase clock, about 1690. Phineas, apprenticed in 1693 to Edwd. Whitfield, C.C. Jas., Lancaster, 1733, f. Wm., London Bridge ; long-case clocks, about 1760. Wm., 2 Cow Cross St., 1804. \& Harrison, 35 Fetter Lane, 1816-25. C., 211 Strand, 1830. Thos., Bath, 1850.

Nobson, John, apprenticed to Daniel Quare; C.C. 1697.

Nodes. John, Strand, 1770-75. William, $126 \mathrm{New}$ Bond St. ; in 1790 he wrote tu C.C. respecting watches seized on his premises ; 1783-94. 
Noel. Aymé, maker of a watch, B.M., crystal case, dial and outer case of silver about 1620. Saml., London; watch, Schloss collection, about 1800 .

Noir, -, Paris; watch, about 1770.

Noisy, - Paris, clockmaker to Louis $\mathrm{XV}$., 1750 .

Nokes, see Noakes.

Nolda, J. A., London; watch, about 1740, Mr. E. Wehrle.

Nollorth, Chas., Yarmouth, 1775.

Nolson, Jno., apprenticed in 1689 to Jno. Pilcher, C.C.

Noon. Jno., apprenticed in 1655 to Francis Munden, C.C. -, seller of lamp clocks at the White Hart, in the Poultry, 1731. W., Ashby-de-la-Zouch; good long-case clocks, from about $1800 ; \mathrm{Mr}$. W. B. Hextall has one bought in 1828 , high mahogany case, painted dial.

Norcell, Jno., London; clock-watch, 1681.

Norcott, John, C.C. 1681. " Lost on my Lord Mayor's Day, a middle-size Gold Pendulum and Minute Watch, with an engraven Out-case, having a scarlet French Ribon flower'd with Gold and black, the Inner-Case scraped on the backside with a Touch-stone; the name John Norcott. Whoever brings it to Shuttleworth's Coffee House at Charing Cross, shall have 5 Guineas Reward "(1691).

Norgate, John, C.C. 1712.

Norman. Ralph, Dorsetshire, a Quaker, died 1730. Mr. Norman Penney inherited a long-case clock by him. James, Poole, a Quaker, died 1789 , aged 74 . Chas., London; watch, 1820. Samuel, 50 and 51 Prince's St., Leicester Sq., 1825.

Norris. Edward, at the Cross Keys in Bethlem; apprenticed in 1650 to Wm. Selwood ; C.C. 1658 ; master 1686 ; fullsize lantern clock, balance escapement, dolphin frets, inscribed "Edward Norris, at the Cross Keys in Bethlem, Londini." Joseph, C.C. $1670 . \quad$ Charles, C.C. 1687. Joseph, Amsterdam ; watch, about 1690. Dav., London; long-case clock, about 1750. Chas., 18 Gracechurch St., 1763-94. Patrick, Liverpool, 1765. Wm., Birmingham, 1770. Wm., Liverpool, 1785. Chas., junr., 22 Cheapside, 1795. Alrich, Bristol, 1843.

Norry, N., Gisors ; small clock-watch, about 1620 .

North. - f. of York, 1623. William, admitted C.C. 1639; maker of an oval watch ; silver case, B.M., 1620-64. John, C.C. 1650 . John, Silver St., C.C. 1720 . Richard, Driffield, 1770. Richd., 44 Lombard St., 1772-1800. Wm., White Hart Yard, Drury Lane, 1790. Wm., York, f., 1816. Fredk., 2 Old Compton St., 1816. Thos., same address, 1820.
Northam. J., 46 Greek St., 1817. G., musical clockmaker, Tabernacle Sq., Finsbury, 1825. \& Son, 49 Greek St., Soho, 1825.

Northcote. Jno., C.C. 1681. Samuel, son of a Plymouth watchmaker, and elder brother of James Northcote, the artist, was sent to London to Mudge to be instructed in watchmaking in $1766 ;$ a watch by him inscribed "Samuel Northcote, Plymouth," about 1780.

Northen, Richd., Hull, 1780-1822.

Northey. J., Bethlem Court; watch, 1784. John, 181 Brick Lane, Spitalfields, 1790-94. J., Spitalfields; watch, 1794.

Northgraves, Denton, Hull, 1822.

Norton. Thomas, C,C, 1720. Samuel, Fish St. Hill; liveryman C.C. 1776; 1770-80. Eardley, 49 St. John St., Clerkenwell, a well-known maker of musical and astronomical clocks and watches, 1760-94; in 1771 he patented (No. 987) " a clock which strikes the hours and parts upon a principle entirely new ; and a watch which repeats the hours and parts, so concisely contrived and disposed as to admit of being conveniently contained not only in a watch but also in its appendage, such as a key, seal, or trinket." In Buckingham Palace is an astronomical clock with four dials he made for George III. ; a splendid fourtrain, repeating, and musical clock which is in the possession of Mr. J. E. Whiting, Andover, Mass., U.S.A., was formerly the property of Mr. Edward Savage, Mr. Whiting's grandfather; it is 28 in. high, chimes the quarters on eight bells, and plays on sixteen bells one of eleven tunes every three hours; Mr. W. L. Unkill. Mexico City, has a fine clock by him ; Mr. Hansard Watt has a long-case clock by this maker in a green lacquer case. It chimes the hours and quarters on eight bells (see pp. 543-544), and other Eardley Norton clocks have been seen recently in Russia. A particularly fine musical clcck was specially made for the Empress Catherine. Dr. Tad. Estreicher has a repeating watch by him in gold cases-it formerly belonged to Ambrose Grabowski, a distinguished Polish archæologist; watch, about 1785, inscribed " Eardley \& D. Norton;" they were succeeded by Gravell \& Tolkein. -_, Market Row, Yarmouth, 1788. Graham, clock, about 1790. Thomas, Philadelphia, 1811. W. D., London; watch, about 1820 . B., watchcase maker, 59 Banner St., 1835.

Norton, Yeldaye, London ; bracket clock about 1780 , so named, seen at the Hague; the name is a curicus jumble of " Eardley Norton," a well-known maker of the period.

Notyap, see Payton. 
Nourisson, Guillaume, reconstructed the Lyons clock in 1660 (see p. 57).

Nourse, Thomas, 22 Beach Lane; apprenticed to Edward Avenell ; C.C. 1740 ; livery 1766.

Noury, Pierre, Paris; clockmaker to Louis XIV., 1650.

Nouwen, Michael, London ; 1590-1613 (see p. 253).

Noyes, Leonard W., Nashua, U.S.A., $1830-40$.

Nuer, Jean, "A. Saintes;" oval watch, about 1600 ; Mr. Max. Rosenheim.

Nurse, John, C.C. 1718.

Nutsford, Wm., Whitehaven, 1833.

Oakes. Richard, shagreen case maker, 86 Snow Hill, 1775. John, 4 Grub St., 1775-80. Jno., Oldham, 1818-32. Wm., Oldham, 1833.

Oakey, Jno., apprenticed in 1685 to $\mathrm{Wm}$. Dent, C.C.

Oakley, Wm., 39 High St., St. Giles, 1804-20.

Oatway, John, Torrington, 1797.

Ofard, - , enamelled watch, " Ofard a Gex," about 1675 .

Ogden. Thomas, C.C. 1659. Jno., Bow Brigg, Yorkshire; long-case clock, 1681 (see p. 529). Mr. J. Whiteley Ward had a lantern clock, crown wheel escapement, bob pendulum, by Sam. Ogden, a son of Isaac Ogden, of Sowerby; he was born in 1669 and baptized at Halifax Parish Church; there are numerous entries in the accounts of Halifax Parish Church between 1693 and 1700 of payments to him in respect of the clock; he probably died in 1701, for in that year Chris. Marshall was appointed to succeed him in upholding the clock and chime for 20 s. per annum. There was a James Ogden at Water Green in Soyland, who died in 1715. Two brothers, Samuel and Thomas Ogden, each carried on business at Ripponden; they were nephews of John Ogden and Quakers; experiencing trouble with the Church party at Ripponden they shifted, Samuel to Newcastle and Thomas to Halifax, where he carried on business in Crown St. ; Mr. J. Whiteley Ward had also a longcase clock by Thos. Ogden, Halifax, dial illustrated in Fig. 685 ; in the Churchwardens' accounts at the Parish Church, Halifax, is the following: " 1725 Tho. Ogden for mending the chimes, 3s.; " he died in 1769, and by his will he left his engines, tools, implements of his trade as watchmaker, and stock to John Knight, " he paying for the gold cases prepared for an eight days watch of his own making." John Ogden, son of John Ogden, of Bowbridge Hall, was born 1704 and lived at
Sunderland; Mr. Kobt. Brown has a clock by Jane Ogden, widow of John Ogden, of Sunderland. Ben., Darlington, about 1740. Ogston \& Bell, Davies St.; patented a watch with two barrels in 1826 (No. $5,314)$, see also Dwerryhouse.

O'Hara, Charles, Philadelphia, 1799.

Okeham, Edward, admitted C.C. 1632.

Okes, Thos., Oldham, 1818.

Okeshot, Robt., apprenticed in 1664 to Ralph Greatorex, C.C.

Oldham. Thos. and Saml., Coventry, 1765-75. Joseph, Liverpool, 1818.

Olds, Chas., 22 New Bond St., Bath, 1836.

Oliver. Sam., London ; watch, 1725. -, Cambridge, 1780-95. Thomas, 17 Fleet St., 1780 ; 2 Brook St., Hanover Sq., 17901800. Griffith, Philadelphia, 1785-93. Jas., watch-case maker; died 1892, aged 76 .

Olley \& Clark, Poplar, 1817.

Ollivant. \& Morton, Manchester, 1818. T. \& J., Market St., Manchester, 1832 ..

Oltramare, Estinne, large watch in enamelled case, about 1610. Pierpont Morgan collection.

Oosterwyk, Abram, Middleburgh ; month long clock, Wetherfield collection, repeating on small bell at the half-hour the time struck at the previous hour, 12-in. dial, fine marquetry case, with domed hood, about 1710.

Oram. Morris, apprenticed in 1684 to Richard George, C.C. Thos., Castle Carey, 1840. Geo., 13 Whiskin St., 1842. Geo. Wilmington Sq., died 1904.

Orange,-, Versailles; watch, about 1780.

Ordson, William. In the Guildhall Museum is a verge watch by him, square pillars, enamel dial, the hours represented by letters forming the name "James Newman*," about 1720.

Orel, Thos., London; watch, 1770.

Orford, Robt., 71 Oxford St., 1795-1810.

Orme. Jno., Lancaster, 1712, f. Thos., Oldham, 1818.

Ormond, David, Westminster ; long-case clock, square dial, about 1710 .

Orpwood. Wm., Ipswich; clock, about 1790, Mr. J. O. Payne. Richard, 7 Worship St., Finsbury, about 1800 . Geo., 58 Bishopsgate Within, 1810-42 (see pp. 591, 593).

Orr. Thomas, Philadelphia, 1811. Peter, 17 Myddleton Sq., 1840; he afterwards established a business at Madras.

Orrell, Jno., Preston, 1818.

Ortelli, A., Oxford; watch, about 1790.

Orton. Edward, C.C. 1687. Jno., Manchester, 1818. William F., 5 York Rd., 1835. Preston \& Co., Farmington, U.S.A., 1836.

Osborn, William, C.C. 1700.

Osborne, Birmingham; on clocks, $1800-42$. 
Osmond. Hy., apprenticed in 1681 to Sam. Gascoigne, C.C. Jas., apprenticed in 1681 to. Jas. Clowes, C.C.

Osmont, Jean B., 41 Strand, 1840; 6 Victoria Rd., Pimlico, 1842.

Otley. Thomas, 55 Piccadilly, 1823. Jonathan, Keswick, 1833.

Oudin, Charles, Rue Vivienne, Paris, pupil of Breguet; maker of fine watches, and inventor of a form of keyless work (see p. 615).

Oughtred. Benjamin, C.C. 1639. William, author of several books on mathematics, including "Clavis Mathematicæ," Oxford, 1677; Derham speaks of him with admiration.

Ourry, Louis, Paris, about 1740.

Outhwaite, Thos. \& Co., Liverpool, 1818.

Overall, Henry, Daventry, 1780.

Overbury. Hy., apprenticed in 1687 to Thos. Overbury, C.C. ; pendulum watch, Nelthropp collection, signed " Henry Overbury, Rotterdam," about 1705 ; repeating watch, 1718, signed "Henry Overbury, Overschie." Thomas, brother C.C. 1688.

Overton, P., London; watch, 1835.

Overzee. Gerrard, Isleworth (naturalised), brother C.C. 1678 ; maker of lantern and other clocks, 1670-90. Timothy, apprenticed in 1693 to Thos. Whitehead, C.C.

Ovingham, -, watch, Mr. R. T. Mole, London, h.m., 1819.

Owen. Ben., London, completed his apprenticeship 1694; maker of long-case clocks, 1694-1740. William, Cheapside, 1737-40. Watkin, Llanrwst, 1770. John, Llanrwst; clock, about 1780. Joseph, 10 Helmet Row, 1800 ; 243 St. Margaret's Hill, 1810. Griffith, Philadelphia, 1811; then Jno. Richd., London ; watch, 1830.

Owston, Michael, Scarboro', 1822

Oxley, Joseph, a Quaker, died 1775.

Oyens, Peter, London ; long-case clock, about 1730. Mr. William Norman has a token issued by Oyens, No. 60 Fore St., Dock.

Oyster, Daniel, Reading, U.S.A., 1820-40.

Pace. Thomas, at the Crown in Fleet St. ; maker of several small-sized lantern clocks, originally with balances (frets, Fig. 646), 1630-60. Thomas, 128 Whitechapel; a well-known maker of bracket and longcase clocks, 1788-1840; watch by him, 1800. Jno., 19 Cock Hill, Ratcliffe, 179094. John, Bury St. Edmunds, a Quaker ; patented in 1833 (No. 6,506) a night timepiece. Edmund, 21 Thavies Inn, 1840-42. Chas., 128 Whitechapel High St., 1842. Henry, 11 Green Terrace, Clerkenwell, 1842 ; 35 King St., Cheapside, 1848-58.
Pacificus, Archdeacon, Verona ; one of those to whom the invention of wheel and weight clocks is ascribed. Claim disputed by Dithmar ; 850 .

Pack, Richard, C.C. 1712.

Packer. Jno., Tingewick, 1780. Wm., Buckingham; watch, 1795 . Wm., 376 Oxford Str., 1840.

Padbury. Dorset and Hampshire ; Andrew, 1730-75 ; Thos., 1800; Jno., 1825; Jas., Bishops Waltham; died 1898, aged 82. Mr. C. J. Bentall has an early long mahogany case clock by Andrew Padbury; the centre of the dial rotates with the hour hand showing time at different places throughout the world (see pp. 513, 550).

Pagars, Dan, 44 St. Martin's Lane, 1793.

Page. Joseph, apprenticed to Jeffery Bailey; C.C. 1683. Luke, apprenticed in 1683 to Ben. Marshall, C.C. Henry, Jewin St., C.C. 1713. Thos., Norwich; watch, about 1750. Jno., Ipswich; long-case month timepiece, about 1750 ; bracket clock, crown wheel escapement, having the acting parts of catgut, about 1770 . John, 129 Strand, 1775-90 ; 8 Hind Court, Fleet St., 1794. Wm., 17 Liquorpond St., 1815-18.

Paget, Ambrose, C.C. 1728.

Pagnes, William, Butcher's Row, East Smithfield ; lantern clocks, about 1690.

Paillard. Baptiste, watch, 1760. C. A., Geneva ; inventor of palladium alloy nonmagnetic balances and springs ; died 1896 .

Pain. Benj., apprenticed 1672 to $\mathrm{Wm}$. Watmore, C.C. William, C.C. 1729 ; 8-day clock, brass dial, "William Pain, Darlington." David, London ; watch, gold-chased case, about 1735 ; bracket chime clock, about 1740. Thomas, long-case clocks, about 1760 . Wm., Trowbridge ; long-case clock, about 1790 .

Paine. Edmond, London; watch, 1711. Wm., Trowbridge, about 1785 . John P., 39 High St., St. Giles's ; received in $\mathbf{1 8 2 6}$ a silver medal from the Society of Arts for a method of illuminating dials, 1826-40. \& Balleston, 5 Banner St., 1840.

Pairas, Charles, Blois ; two octagonal watches by him, S.K.M., about 1605 ; on one in the Salting collection the name was spelt Perras.

Palethorp, Wm., Liverpool, 1833.

Palfrey, John, C.C. 1654.

Palin, Wm., Nantwich, 1833.

Pallier, - , locksmith, of Valence; in 1451 contracted with the town of Montelimart for a public clock.

Palliser, Jno., Thirsk, 1822.

Pallisone, Jro., London ; watch, 1792.

Palmer. Jno., apprenticéd in 1647 to Hy. Ireland, C.C. Jno., apprenticed 1692 to Alex. Warfield, C.C. Hy., apprenticed 1693 to Josiah Ridley, C.C. Thos., Shef- 
field, 1740. Robert, liveryman C.C. 1776. Thomas, Fetter Lane, liveryman C.C. 1776. William, Shoe Lane, liveryman C.C. 1776. Thomas, 132 Lower Holborn, 1783-1810. Samuel Richd., gold watch-case maker, 2 Red Lion St., 1790-1810. John, Philadelphia, 1795. Thos., Sheffield, 1800. Joseph, 112 Whitechapel, 1814-18. John, 59 Great Marylebone St., 1825-35. B., 21 K ng St., Covent Garden, 1830. Robert, 24 White Hart Place, Kennington, 183242. Hy., 25 Buttesland St., 1842. W. . B., Bristol, 1843. H. P., a clever horologist, formerly of Leominster, but latterly at Worcester; died 1915, aged 81 .

Pamer, Edward, London; watch, 1802 ; another, 1826.

Pamphillon, William, C.C. 1725.

Panchard, Abel, Oxford St., 1765-80.

Panchaud, David, 202 Oxford St., 17901825 ; livery C.C. 1802 . \& Cumming, 202 Oxford St.: 1806-10.

Panck, Ralph, apprenticed C.C. 1677.

Panier, Jossué, Paris ; clock, S.K.M., 1725 ; also a watch of earlier date, signed Iosve Panier à Paris."

Pannell. Robt., apprenticed in 1653 to Paul Lowell, senr., C.C. Joshua, Northallerton, 1770 .

Panther, B., London; watch, 1785.

Pantin. Jean, Paris, 1544 (see p. 404). Nich., apprenticed in 1651 to Downing, C.C. Robt., apprenticed in 1674 to $\mathrm{Wm}$. Rob nson, C.C. Lewis, 45 Fleet St., $1770-75$; 62 St. Martin's-le-Grand, 1800.

Papavoine, Isaac (French), Duke's Court; admitted C.C. 1687; maker of long-case clocks, 1680-1710. Mr. R. W. Llewellyn has a fine bracket clock by him, basket top, claw feet; long-case clock, Wetherfield collection.

Papon, Leonard, watch, B.M., about 1620.

Papworth, John, C.C. 1688.

Paradise. John, C.C. 1716 . John, 13 Newcastle St., Strand, 1823.

Parbury. This name is on a very fine repoussé gold watch case in the Mainwaring collection; in the Dunn-Gardner collection was a watch by Jno. Latham, h.m., 1719 , enclosed in a choice repoussé case signed Parbury.

Pare, Thos., London; clock, long marquetry case, the late Mir. Norman Shaw, about 1700 .

Paria, S., clock, about 1780 .

Paris. M., Rennes ; watch, B.M., about 1620. John, watch engraver, 7 Dean St., Fetter Lane, 1790-94.

Parish, Simon, C.C. 1723.

Park. Nicholas, C.C. 1641. Jno., apprenticed in 1659 to Jno. Bayes, C.C. Seth, Park Town, Pa., 1790. James, Preston, 1818.
Parke, Solomon, Philadelphia, 1791-1811

Parker. Thomas, " in St. Ann's Lane, neere Aldersgate, fecit," inscribed on a lantern clock; apprenticed to Wm. Almond in 1658 ; C.C. 1669 . Cuthbert, apprenticed in 1659 to $\mathrm{Wm}$. Petty, C.C. John, C.C. 1674 ; John Pinson was his apprentice in 1677. John, Cateaton St. ; C.C. 1678. Daniel, " in Fleete St., London;" marquetry long-case month clock, $1 \frac{1}{1}$ seconds pendulum, about 1690 , Wetherfield collection. Robert, apprenticed to J. Markwick; admitted C.C. 1698. John, apprenticed to James Delander, C.C. $\mathbf{1 7 0 6 .}$ Thos., Dublin; watch, 1709; Mr. J. D. Robertson has a fine bracket clock by him, about 1710. Edward, about 1710. \& Wakelin, Panton St., 1760-75. John, 55 St. Paul's Churchyard, 1769-75 ; Parker \& Sэn, 1794. Jas., Cambridge ; watch, 1770. Thos., Warrington; watch, 1786 . Thos., 37 Berners St. ; watch, h.m., 1786 ; 17861817. Thos., 15 Wilderness Row, 1788. Harry Parker, of Well St., in the City of London, watchmaker, is mentioned in the number of the Cutlers' Company for 1788. John, High St., Marylebone, 1793; 2 Rathbone Pl., 1804. Thomas, Philadelphia, 1797-1811. \& Birketts, 16 Prince's St., 1804. Geo., Ulverstone, 1818. James, 17 King St., Clerkenwell, 1835.

Parkes. ( \& King, watch, about 1750). Jno., Old Change, 1800.

Parkhouse, Roger, Richmond, Yorks., 1730 .

Parkhurst, Michael, apprenticed in 1683 to Jno. Bellard, C.C.

Parkinson. Robt., C.C. 1637. At Lancaster: Wm., 1708, f. ; Robt., 1732 , f. ; Wm., 1789, f. Clock, " Parkinson, Richmond," about 1730. At Settle : Edwd., 1775. Francis, London; watch, 1788. Wm. \& Frodsham, 4 Change Alley, 1801-42; Wm. Parkinson and W. J. Frodsham, both admitted C.C. 1802. At Bury: Thos., 1814. James, 4 Cross St., Goswell Rd., 1820. Henry, 50 Great Sutton St., 1835; 65 Red Lion St., Clerkenwell, 1842. James, 70 Red Lion St., Clerkenwell, 1842. \& Bouts, Gracechurch St., 1857, see Bouts. Parkwick, Jas., assistant C.C. 1698.

Parmier, John Peter, Philadelphia, 1793. Parnell, Thomas, High St., Bow, 1815-42.

Parquot, P., London ; watch, 1706.

Parr. Jno., apprenticed in 1692 to Jno. Herbert, C.C. Thos., 27 Cheapside, 1735-75. William, 20 Strand; watches by him from 1790-1808; in 1804 he published a "Treatise on Pocket Watches." Edward, apprenticed to Jas. Plumbly, 16 New Cavendish St., 1824. Edward Thos., his son who succeeded him, retired in 1906 and died in 1912, aged 78 . 
Parrat. Hy., apprenticed 1678 to Jno. Finch, C.C. Jno., apprenticed 1691 to Chas. Knight, C.C. Sam., Bridge Row, C.C. 1730 .

Parrault, Thos., apprenticed in 1667 to Ed. Whitfield, C.C.

Parry. David, at Fleet Bridge; very small silver watch, Ashmolean Museum, about 1630 ; brother C.C. 1646 ; Hy. Ford was apprenticed to him through the C.C. in 1647. Francis, apprenticed in 1646 to Thos. Laud, C.C. Jonathan, apprenticed in 1659 to Richd. Lyons, C.C. John, Philadelphia, 1797-1811.

Parsons. Richard, apprenticed in 1682. to Isaac Day; admitted C.C. 1690 ; known as a maker of bracket and other clocks at 54 Goswell St., 1690-1730. John, admitted C.C. 1696. John, 8 St. Martin's Court, 1775. Geo., Goswell St.; watch, h.m., 1778. \& Horne, Castle St., Holborn, 1825. \& Williams, Bristol, 1843.

Parten, William, C.C. 1720.

Parter. William, C.C. 1692. Francis, C.C. 1730 .

Partington. J., High St., Marylebone, 1790. William, 53 Paddington St., 1815-42. C. F., author of " Clock and Watchmakers' Complete Guide," 1826.

Partridge. Wm., C.C. 1640 (see p. 260). Walter, London ; long-case clock, Hampton Court, about 1700. Joseph, Bartholomew Close, 1760-63. C., 13 Wentworth Pl., Mile End Rd., 1840-42.

Pascal, Claude, à la Haye, on a splendidly decorated watch, about 1650 .

Pascall, Jas., 18 Wilderness Row, 1820 ; treasurer W. and C. Pension Socy., 1857; died 1863.

Pashler. Jno., London, 1755 ; long-case clock, about 1760 . Edwd., Bishopsgate St., 1774; large ebonised case, bracket clock, tunes at the hour; Psalm 104; March in Rinaldo; air, Duke of Cumberland's Minuet; March in Scipio ; "Britons Strike Home." In addition to the tunes plays " runs" at the 1st, 2nd and 3rd quarter; dial figures in Turkish characters; " strike and silent," " chime and silent," engraved back plate, brass arched dial, ten bells and striking-bell; had formerly crown escapement; bought at the Bazaar at Constantinople in 1881.

Pasquier, -, horloger du Roy. In 1773 made a hunting watch for 1,200 livres for the Comte d'Artois as a wedding present. This Prince, brother of Louis XVI., became Charles X.; see also Pierre.

Passanine, Hy., apprenticed C.C. 1646.

Passement, Admiral, designer of equation and astronomical clocks, 1720-50.

Passevant, Wm., 10 Red Lion Passage, 1793.

Pasteur, Jacques, Geneva, about 1780.
Patching, Elisha, C.C. 1728.

Paterson, David, Sunderland, 1825-40 ; he was apprenticed to John Ogden ; Canon Greenwell has a bracket clock with "D Patirson Sunderland" on dial, and "Richard Browne London" on back.

Patmore, Peter, Ludgate Hill, C.C. 1813.

Patrick. Edwd., London; long-case clocks, 1690-1710. John, C.C. 1712. Thos., Market Weighton, 1775. Miles, Greenwich; cylinder watch, 1790 .

Patron, J., Geneva, 1760-80 ; watch, globular gold enamelled case, Pierpont Morgan collection.

Patry, Alex., Geneva ; watch, 1790.

Pattee, Thomas, Mile End Rd., livery C.C. 1810 .

Pattison. Robert, apprenticed in 1676 to Thos. Tompion; C.C. 1688. George, 16 King St., Seven Dials, 1835.

Patton, Abraham, Philadelphia, 1799 ; also David, then Patton \& Jones.

Pattru, -, watch, B.M., about 1620.

Paty, Wm., London; watch movement G.M., about 1760 .

Paul. Nowell, alien, threatened with prosecution for working as clockmaker within the liberties of C.C. 1668. Thomas, apprenticed to John Fromanteel ; C.C. 1670

Paule. Philip, 15 Cleveland St., Fitzroy Sq., 1810-23. George, 15 Cleveland St., 1830-35.

Paulet, Jno., C.C. ; watch, S.K.M., 1703; another of about the same date, marked "I. Paulet Without Temple Bar;" long arabesque marquetry case clock, Wetherfield collection, about 1705 ; travelling clock, . about 1710 ; repeating watch, 1728; in 1730 he worked for Ellicott.

Paulin, Lewis, 45 Fleet St., 1772.

Paulus, Pieter, Amsterdam; enamelled watch, " Roman Piety," by Huaud, about 1710.

Paxton, Jno., St. Neots ; long-case musical clock, ten tunes; movement said to be by Mudge, about 1770 ; watch, " Jno. Puxton, St Neots," h.m., 1790, probably by him.

Pay. C., London; repeating watch, 1730. Jas., London; watch, 1750.

Payn, John, Southwold, a smith, received $6 \mathrm{~s}$. $8 \mathrm{~d}$. for a new clock from the churchwardens of Walberswick, Suffolk, 1451.

Payne. Wm., East Smithfield, about 1618. Nicholas, apprenticed in 1641 to Wm. Daniel ; C.C. 1648 ; was assistant C.C. in 1671 ; in 1676 Jonathan Boole was apprenticed to Sarah Payne. Geo., apprenticed 1687 to Jere Johnson, C.C. Hadleigh, about 1720. \& Sons, 21 Old Bond St., Bath, 1830. Richd., Carthusian St., C.C. 1730 ; watch, 1765 . Lawrence 
New York, 1732-55, f., 1732 . H. \& John, 44 Cheapside, 1753-75. Southern, Bridgewater Sq., livery C.C. 1766, master 1778. J., 17 Foster Lane, 1794; 18 St. Ann's Lane, Aldersgate, 1800-25. Robt., Waltham, 1813. Wm., 62 South Moulton St., 1816 ; 39 High St., Bloomsbury, 1825 ; 163 New Bond St., $1830-50$; in 1849 he patented (No. 12,516) musical clocks.

Payton, Wm., watch-case maker, 3 Addle St., Wood St., 1790-94; a watch inscribed " Notyap, London," probably by him.

Peachey. William, New St. ; C.C. 1727. Joesph, 1759. Newman, 12 Dean St., livery C.C. $1766 ; 1760-78$.

Peacock. George, 65 Threadneedle St., 1769-75. Geo., " at the Dial behind the Royal Exchange," 1765; 4 Sweeting's Alley, 1778-81. Wm., York, f., 17891832. Samuel, 30 Old Exchange, 1793. —, Richmond, 1814.

Peake, Thos., Soho, died 1905, aged 83.

Pearce. Adam, C.C. 1664 . Jno., Newgate St., 1753-60; Pearce \& Newton, 1760-63. William, livery C.C. 1787, master 1804. J., Stratford-on-Avon; watch, h.m., 1825. John, 101 Great Peter St., Westminster, 1835-40. Thomas, Bourne, Lincs., died 1919, aged 99.

Pearkes, F., 15 St. Martin's Court, 1823.

Pearne, Wm., 11 Leicester Sq., 1793.

Pearsall \& Embree, New York, 1781-86.

Pearse, John, Newgate St., 1753-60.

Pearson. Thos., Berwick, 1765. Mary, 31 Fleet St., 1772-75. Wm., Blackburn, 1775. Sam., Halifax, 1790 . James, London; watch, about 1790. The Rev. W., LL.D., F.R.S., East Sheen, 1811 ; South Kilworth, Leicestershire, 1821; author of the splendid treatise on horology which appeared in Rees' "Cyclopædia," published in 1791 and revised in 1819; died 1847, aged 80 . \& Price, 11 Great Sutton St., 1830.

Peatling, Thomas, C.C. 1682.

Peck. George, C.C. 1725 . Wm., Keysoe; long-case clock, fine Oriental lacquer decoration, about 1750. Edson C., Derby, U.S.A., 1827.

Peckett, John, C.C. 1691.

Peckham, Henry, Bermondsey ; patented in 1798 (No. 2,280) the application of a compass to a watch.

Peckover, Richard, Change Alley, Cornhill ; maker of long-case clocks and repeating watches. He probably succeeded Quare \& Horseman, 1737-56; watch, with Turkish numerals, Pierpont Morgan collection, movement signed " $\mathrm{R}$. Peckover, London," " Markwick Markham Perigal London," on dial, about 1750.

Peers. Jno., apprenticed 1676 to Rob Cosby, C.C. Chester: a noted family of clockmakers from about 1745-1840. Benj., long-case clock, about 1790 .

Peffinhaus. Oval watch, signed "Wilhel Peffinhauss," Pierpont Morgan collection, about 1620 .

Peiras. Oval watch, 1590, Garnier collection, signed "Pasquier Peiras, Blois;" another also in the Garnier collection, about the same date, signed " Charles Peiras, Bloys."

Peirson. Wm., Kirby Moorside, 1770. Worthy, 92 Whitechapel High St., 1840.

Pelleter, Solomon, 14 Broad St., 1775.

Pelletier, -, Paris ; clock, about 1810. Pemberton (Samuel), Son \& Mitchell, Birmingham, 1818.

Penard, Isaac, skull watch, about 1630 .

Pendleton, - , worked for Mulge, junr., 1795.

Penfold. Joshua, C.C. 1695. Miles, 115 Newgate St., 1769-75.

Penkethman, Thomas, C.C. 1692.

Penlington, Thos., Sheffield, 1770-1814.

Penn, Richd., London; watch, 1780.

Pennington. Christopher, Kendal ; watch, 1780. Robert, chronometer maker, Camberwell ; invented an improved form of sector, 1780-1816. John, also Joseph, Liverpool, 1818. Robert \& Son, 11 Portland Row, Camberwell, 1832-42; John Pennington, the son referred to, afterwards succeeded Grohe, at Wigmore St.

Pennock, John, Lothbury, C.C. 1638, master 1660 ; gave a fine house clock of his own make to the Company in 1652 ; on a lantern clock by him, dating from about 1640 , is the address "Within Bishopsgate; " another lantern clock by him with dial, engraved " at Petty France Gate in ye Moorfields."

Penny, Richard, London; watches, 1695-1715. "Deliver'd to a carter in Whitechapel to be carried to Mr. Pearson's, at the Warren by Sir Henry Hicks, an old bob clock with John Webster's name on it, which clock was not brought thither. If any persons give notice of this clock to $R$. Penny of Whitechappel clock maker so as it may be had again shall receive 5s. as a reward" (The Post Man, Aug. 28, 1705).

Penton, Charles, Upper Moorfields, 1760-75.

Penty, Wm., York, f., 1831.

Pepin, - Rue de la Coutellerie, Paris, 1770.

Pepper. Sam., apprenticed in 1655 to Thos. Mills, C.C. Jno., apprenticed 1684 to Geo. Ethrington, C.C. Jas., Biggleswade 1770. Thomas, 5 George St., St. Martin's, livery C.C. 1787 ; 1776-94.

Peppin, Sam., 22 Greville St., Hatton Garden, 1517.

Pepys. John, apprenticed in 1672 to Jno. Harris; C.C. 1680 , master 1707 ; watch 
by him, B.M. ; long-case month clock, 11-in. dial, burr elm case, Wetherfield collection, about $170 \tilde{5}$; other examples are occasionally met with, 1680-1708. Richard C.C. 1674. Peter, apprenticed 1680 to Richard Pepys, C.C. John, junr., Fleet St., C.C. 1715, master 1739. " Lost on Saturday night last a gold repeating watch in chased case with an enamel dial plate, the maker's name John Pepys, London, No. 3,470. Whoever brings the same to Mr; John Pepys, at the 'Crown and Sceptre,' in Fleet St., shall have twenty guineas reward and no questions " (Public Advertiser, April 10, 1744). William, C.C. 1723.

Perchard. Matthew, Cannon St., 175359. Peter, 15 Abshurch Lane, 1760-62.

Percival. Jno., Woolwich ; clock, 1790. N., 36 Old Bond St., 1798-1800. Thos., 36 Old Bond St., 1804. M., Woolwich, 1817.

Perdra, Wm., London ; watch, 1805.

Peres, Mark, C.C. 1680 ; large lantern clock with two bells, about 1700 , inscribed "Marcos Pères," London.

Perier, H., London ; watch, about 1730 , see Perrier.

Perigal. Francis, 9 Threadneedle St., Royal Exchange, the first of a family of able horologists; excellent watches and clocks of their make are to be met with; C.C. 1741, master 1756. Francis, C.C. 1756, master 1775. Francis, junr., Royal Exchange ; apprenticed to his father 1778 ; C.C. 1786 ; livery 1787 , see Francis Perigal \& Son, below. Francis, watchmaker to the King, 37 New Bond St.; hon. f. C.C. 1781 ; watch, S.K.M., signed "Francis Perigal, Bond St., watchmaker to His Majesty," h.m., 1786 ; 1770-94. John, 12 Coventry St., Haymarket; hon. f. C.C. 1781 ; 1770-1800. Francis \& Son, 9 Royal Exchange (Francis S. Perigal, junr., master C.C. 1806), 1790-1808. \& Browne, 11 Coventry St., Piccadilly, 1794-1800. Jno., 55 Prince's Street, Soho, 1810. \& Duterrau "Watchmakers to His Iajesty," 62 New Bond St., 1810-40. Thos., London; watch, 1812.

Perin, Chas. Henry, George Yard, Lombard St. ; patented winding work in 1842 (No. 9,438 ).

Perinot, Abraham, known as a maker of long-case clocks, abjut 1780.

Perins, John, 193 Strand, 1750-94.

Perkin, R., 55 Tooley St., 1790.

Perkins. Jno., apprenticed in 1661 to Sam. Horne, C.C. Eylum, of "Rederiffe, the end of Love Lane;" apprenticed in 1670 to Jas. Atkinson; in 1682 he was threatened with prosecution by C.C. for exercising the art, not being admitted; he promised to take up his freedom at the next quarterly court. James, C.C. 1730. \& Spencer, 44 Snow Hill, 1765-75. Thomas, Philadelphia, 1778-99. Vineyard, 53 Dorset St., Salisbury Sq., 1793. Thomas, Pittsburg, U.S.A., 1815.

Pernell, $\rightarrow$, London; 30 hour long-case clock, about 1730 .

Perra, see Du Peron.

Perrache, - "Fournisseur du Roy," Paris. In 1752 made a clock with a balance-spring going a fortnight.

Perras, see Pairas.

Perrault, - , contrived a clock driven by water and controlled by a pendulum, 1699.

Perregaux. Edouard, Neuchâtel, born 1819, died 1878. Girard, Chaux de Fonds ; pocket chronometer with spherical balance-spring, about 1825 .

Perrelet. Abram Louis, Neuchâtel, born 1729, died 1826. Louis Frédéric, grandson of Abram Louis, born at Locle in 1781, migrated to Paris and worked for Breguet; died 1854.

Perrenoud, F., 192 Brick Lane, Whitechapel, 1810.

Perret, Theodore, " Gentil Horologer de sa Majesté le Roy de Prusse, au Locle;" balloon clock, about 1750 .

Perrier. Peter, apprenticed to Jas. Lello in 1660 , C.C. ; silver watch, the back plate covered with representation of Crucifixion, about 1680. H., 2 Giltspur St., 1830-42.

Perrin, C., Paris, 1780.

Perring, H., 179 Great Surrey St., 1830. Perringham, Francis, back of Exchange, 1790.

Perron. Richd., 7 Worship St., 1790-94. -, Geneva; in 1798 he introduced a lever escapement with round pins as pallets.

Perry. Richd., apprenticed in 1656 to Sam Davis, C.C. Henry, C.C. 1691. Thos., Dock St., New York, 1749. " Thomas Perry, watchmaker from London, makes and cleans all sorts of clocks and watches. He will import, if bespoke good warranted clocks at $£ 14$ they paying freight and insurance, and clocks without cases for f10" (Advt., New York, 1756). New York: Thomas, f. 1750 ; Marvin, f. 1769. Mervin, advertisement, New York paper, 1776, "Mervin Perry repeating and plain watchmaker from London where he has improved himself under the most eminent and capital artists in those branches, has opened shop in Hanover Square at the sign of the Dial. He mends and repairs musical, repeating, quarterly, chime, silent pull and common weight clocks." Thos., London; watch, about 1790 . John, 40 Oxford St., 1835-42.

Persigny, Pierre, Paris ; circular boxshaped watch of white metal, separate dials for hours and minutes, about 1680 , Pierpont Morgan collection. 
Petch, Jno., T., Huddersfield, 1833.

Peterkin, John, 25 Cleveland St., $1810-40$.

Peterman \& Debois, watch-case makers, Bateman's Buildings, Soho Sq., 1800-10, see Comtesse.

Peters, Edwd., Sheffield, 1770-1814.

Petit. Guillaume, petitioner for incorporation of C.C. 1630; Abraham Lamb was apprenticed to him in 1651; gave a silver bowl to the Company in 1656 . Jacob, clock in china case, dated 1827.

Peto, - , prohibited from working by C.C. 1632. -, London; spoken of by Earnshaw as a capital workman, 17801800.

Petri, J. H., Heydelbergh; watch, about 1700.

Petter, Christopher, C.C. 1730.

Pettit. - 54 Bethnal Green Rd., 1835. Isaac, 22 Fieldgate St., Whitechapel, 1835. William, 7 New Rutland St., 1840. Eliza, 22 Fielding St., Whitechapel, 1840-42.

Petty. William, C.C. 1646. -, Richmond, Yorks, 1812.

Pewtress, Thomas, Gracechurch St., $1753-56$.

Peyton, Richard, Gloucester; in the composing room of the Gloucester Journal is a long-case clock by him, which belonged to Robert Raikes, who founded the journal in 1722 and died in 1757.

Pfaff, Jeremas, Augsburg; fine table clock by him, which is provided with an alarm, and repeats the hours and quarters. There are, besides the barrel and fusee for the going part, four barrels, four hammers, and three bells, the largest bell serving for the hour and for the alarm. The cocks and hammers are beautifully engraved, and the work throughout is excellent. The dial ring is about $5 \mathrm{in}$. in diameter, having within it the alarm disc. The case is square, measuring 7 in. across and 3 in. in height, besides the feet. In each of the four sides of the case is a glass panel. It dates probably from the end of the seventeenth century; clock inscribed "Jereme Pfaff, Augsburg," about 1680, the late Mr. R. Norman Shaw.

Pheilps, Francis, London ; watch, about 1750.

Phelippson, J., London ; watch, h.m., 1735.

Phelisot, - Dijon ; crystal case watch, about 1560 .

Phelps, Richard, founder of the great bell for Bradley's St. Paul's clock (see p. 335), 1716.

Philcox, George, 24 Great Dover St., Borough, 1835; 22 Southwark Sq., 1842. He spent his life in endeavouring to improve timekeepers by various inventions in connection with escapements and com- pensation ; died in Watchmakers' Asylum, New Southgate, 1878.

Philibert, -, French clock, about $\mathbf{1 7 8 5 .}$ Philip. -, Brighton, about 1760. Robert, musical clockmaker, 6 New Court, St. John St., 1779-88 (Robert Philip on some watches).

Phillesson, Isaac, London; quarter chime bracket clock, about 1740, see Rimbault.

Phillipe, Adrien, a leading Swiss horologist, partner in the firm of Patek, Phillipe \& Co., Geneva ; inventor of shifting sleeve keyless work; died 1894, aged 79 .

Phillips. Sam., apprenticed 1671 to Nat. Chamberlain, C.C. Joseph, f. of New York, 1713-35. -, Birkenhead; longcase clock, about 1770. Sam., Oswestry, 1780. W., Ludlow; watch, 1782. Philip, 10 St. John's Sq., C.C. 1790-1800. John, Coldbath Fields, 1817 ; 91 Goswell St., 1835. Joel, 35 Norton Folgate, 1820. P., 19 Crown St., Finsbury, 1830; 3 Steward St., Spitalfields, 1840-42. Abraham, 33 City Rd., 1835. Joseph, 55 Belvedere Place, Boro' Rd., 1835. James \& Charles, 25 Coppice Row, Clerkenwell, 1835-40. Brothers, 31 Cockspur St., 1839-42. P., 15 Bury St., 1840-42. \& Phillips, 12 Queen Sq., 1855.

Phillipson, Thos., London ; watch, 1815.

Phipps, James, 40 Gutter Lane, 1783. Phithian \& Garnet, Lancashire; toolmakers, about 1720, quoted by Hatton.

Phylander, Sylvanus, pair-case silver calendar watch, h.m., 1772.

Pichon, -, Cherbourg; watch, 1790.

Pickering, Jno., apprenticed 1686 to Richd. Knight, C.C.

Pickett. William, 32 Ludgate Hill, 176872; succeeded Thead \& Pickett. \& Rundell, 32 Ludgate Hill, 1775-83 ; afterwards Rundell \& Bridge. -, Marlboro'; fine clock, long Sheraton style of case, plays a dance tune every three hours, when a curtain rises in the arch of the dial, a couple appear dancing, while other figures pass in procession, about $1780, \mathrm{Mr}$. E. E. Cook (see p. 564, and Figs. 690 and 771).

Pickford, Jno., Liverpool, 1833.

Pickman, Wm., 57 Dean St., Soho, 181625 ; 6 Albany St., 1835.

Pide, David ; watch, 1740.

Pidgeon, Thos., apprenticed in 1660 to Jno. Bayes, C.C.

Pierce. Humphrey, apprenticed in 1646 to Robt. Smith ; C.C. 1653. Richd., apprenticed in 1646 to Thos. Reeve; C.C. 1657. In 1678 Jno. Papworth was apprenticed to Sarah Pierce. Adam, apprenticed to Edward East; C.C. 1664 . 
In Berkeley churchyard is the following quaint epitaph :-

Here lyeth Thomas Pierce, whom no man taught, Yet, he in iron. brasse, and silver wrought; He jacks and clocks and watches (with art) made, And mended too, when others work did fade. Of Rerkeley five times Maior this artist was, And yet this Maior, this artist. was but grasse ! When his own watch was down on the last day, He that made watches had not made a key To winde it up; but useless it must lie Until he rise again, no more to die.

Thomas Pierce, five times Mayor of this Towne, died Feb. 25, 1665, aged 77.

Jno., apprenticed in 1680 to Geo. Tipping, C.C.

Pierre, Le Queux; clockmaker to the Duke of Orleans, 1396, Pasquier, C.C. 1648.

Pierret. Mathew, Philadelphia, 1795. Victor A., Paris; noted maker of complicated watches; born 1806, died 1893.

Piers, Charles, chronometer maker, Liverpool, 2 Berry St., 1843 ; 34 Strand St., 1847-54 ; 49 South Castle St., 185567 ; 7 King St., 1862-72.

Pigg, Robt., apprenticed in 1674 to Jno. White, C.C.

Pigott, Henry, C.C. 1687.

Piguet, see Piquet.

Pike \& Green, 48 Bunhill Row, 1806 ; Bartholomew Sq., 1820-30.

Pilkington. R. J., London; bracket clock, about 1760 . J., Woolwich, 1815.

Pilling, Jno., Boothfield, 1800.

Pillon, - Paris; watch, about 1720.

Pilon, Germain, Paris ; cruciform watches, about 1590 .

Pilson, Abraham, Plymouth; watch, about 1700 .

Pinard, Paul, 2 New St., Covent Garden, 1775.

Pinchbeck. Christopher, Clerkenwell and Fleet St. ; a clever maker of musical clocks and of watches; inventor of pinchbeck alloy (see p. 349); Mr. Hansard Watt has a very fine clock by this maker as shown in Fig. 489; 1670-1732. Edward, Fleet St. ; son and successor of the above (see p. 352); 1732-66. Christopher, son of the above-named Christopher, Cockspur St.; died 1783, aged 73 (see p. 352.)

Pinckney, W. "There was a watch found some time past near the Temple Gates, which was made in London by a Frenchman. If any person lay claim unto it, so as to describe the same, they may have it at Mr. W. Pinckney's, a goldsmith, near the Inner Temple." (Lond Gaz., March 2-6, 1675).

Pindar, Joseph, apprenticed in 1692 to Geo. Halsey, C.C.

Pine, Philip, 20 Aldgate, 1779-82 ; card, B.M.
Pinfold, Thomas, Banbury, 1760, see Penfold.

Pingo, Jno., apprenticed to Rob Thompson, C.C. 1684.

Pinhorne, -, Portsea; quarter clock, about 1800 .

Pink, J., London ; watch, h.m., 1767.

Pinkart, Jno., apprenticed in 1663 to Joseph Quash, C.C.

Pinkerton, Jas., 20 Percival St., 1836, afterwards Pinkerton \& Miller.

Pinon, - Horologer du Roy and des Princes, 1765-70. Here is a curious memorandum from an account for work done for the Comte d'Artois (subsequently Charles X.): "For repairing a movement of a clock in the Prince's apartment, renew, in fine bronze, the female figure on the clock case which the Prince amused himself in scratching with a knife from one end to the other with the object of cleaning it, renewing the cock and other accessories ; total, livres, 2,068."

Pinson, Jno., apprentice of Jno. Parker, London, 1677.

Piolaine \& Co., 67 Great Russell St., 1815-25.

Pipes, John, London ; maker of longcase clocks, about 1750 .

Pipps, Jno., London; watch, about 1790.

Piquet à Rennes; watch, B.M., 1700. \& Meylan, Geneva, about 1810.

Pistor. Edward, 116 Leadenhall St. and 105 Strand, 1764-90 ; Mr. Beaven, Enfield, had a clock of an earlier date engraved "Edwd. Pistor, Prescott St., Goodman's Fields." Edwd. \& Jno., 116 Leadenhall St.; watch, musical clock, and organ makers, 1793-98.

Pitcher. Job, apprenticed in 1662 to Thos. Claxton, C.C. John, C.C. 1689.

Pitkin, Henry, Hartford, Connecticut, U.S.A. Watches by him and his brother James F., engraved with the American flag, were made in 1838 .

Pitman, John, admitted C.C. 1714; watch, "J. Pitman Dublin," about 1750.

Piton, James, Shad Hill, C.C. 1710.

Pitson, Chas., London; watch, 1700.

Pitt. 'David, Hampstead ; watch, 1780 ; watch, "D. Pitt \& Sons, London," Mr. H. Hogarth. Thyar, 24 Great Bush Lane, livery C.C. 1787; musical clock playing every three hours; 1770-94. William, livery C.C. 1787. Caleb, 292 Oxford St., 1790 ; 43 Duke St., $1800-30$. John, 37 Crown St., Finsbury, 1830-42. Chas., 152 Sloane St., 1835-40. W. G., 25 Thyar St., Manchester Sq., 1840-42. J., Kingsland Rd., 1842.

Pittit, Jno., Bethnal Green Rd., 1817. Pittney, Thos., Featherstone St., 1769-72. Pitts, Sam., apprenticed in 1689 to Robt. Fenn, C.C. 
Plairas, Solomon, Blois, 1620-40.

Plaire, see Player.

Planck, Anthony, Fleet St., 1760-72.

Plankh, Nicholas, Augsburg; clock by him, Vienna Treasury, about 1580.

Planner. Thomas, apprenticed 1694 to Ben Collier, C.C. 1701; 1730. Thomas, C.C. 1730 ; the Planners were known as makers of long-case clocks ; 1730-45.

Plant, Edward, admitted C.C. 1664.

Plantart. French circular table clock, late sixteenth century, stamped $\mathrm{ABB}$ and N. Plantart on a scroll; a similar piece at S.K.M. M. Leroux has, by the same maker, a clock with removable alarm.

Plaskett. Reuben, Raven St., Whitechapel ; died 1845, aged 80 . Jas., West India Dock Rd.; died 1860.

Plate, Richard, 58 Carey St., Lincoln's Inn, 1835 .

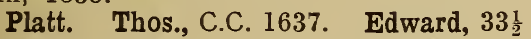
Wilderness Row, Clerkenwell, 1835.

Plattes, Robt., York, f., 1590.

Player. Simon, apprenticed in 1671 to IVm. Speakman, C.C. Thomas, C.C. 1672. "A silver watch in the form of 5 crowns, a Flower-de-Lis under each crown, with a Knot, in the middle the name Thomas Plaire, Londini; the hours engraven in a six-square, with a chain and 5 wheels" (Lond. Gaz., March 29, April 1, 1680). Lionel, apprenticed in 1680 to Sam. Drosade, C.C. Robert, C.C. 1700 ; walnut long-case clock, arch dial, 1700-40. H. J., 2 North Place, Gray's Inn Lane, 1820-40.

Pleuvier (or Plovier), Isaac, a Dutch clockmaker who settled in London in 1641 ; C.C. 1652 ; died 1665 ; a dispute respecting his goods referred to in the Calendar of State Papers, Domestic Series, 1670.

Pley, Geo., apprenticed 1691 to Chas. Loomes, C.C.

Pleydell, Jno., London ; apprenticed in 1666 to Thos. Bagley, C.C. ; long marquetry case clock, square dial, about 1720 .

Plowman, Thos., Lancaster, 1814.

Pluett, Anthony, C.C. 1697.

Plumbly, Jas., 16 New Cavendish St., 1820; Plumbly \& Tupman, 1824; Plumbly \& Parr, 1840-42.

Plumley. Edwd., apprenticed in 1682 to Ed. Millett, C.C. Jno., apprenticed in 1686 to Thos. Taylor, C.C. William, Newgate St. ; apprenticed to Lawrence Mace ; C.C. 1756 ; master 1779 . Wm., 43 Ludgate Hill, son of the preceding; C.C. 1780 ; livery 1797; master 1831; 1780-1825; retired to Shepton Mallet. Chas., 231 Strand, 1835-42.

Plummer. Joseph, apprenticed in 1669 to Chris. Maynard, C.C. G., London ; watch, 1780. Wm., 43 Gutter Lane, 1793.

Plumper, Thos., "Londun ; watch, 1760.
Plunkeld, Richard, 8 Fieldgate St. Whitechapel, 1820.

Pocock, Jno., clock chiming on eight bells, long mahogany case, 12-in. dial, hours marked 1 to 12 twice over; rotating centre with moon indicating time of high water, days of week in corner of dial, phases and age of moon in arch, about 1750 .

Poestdorffer, Johann, Dresden; fine octagonal watch in crystal case, foliat balance, about 1550, Green Vaults,

Dresden.

Pohlmann, Peter, Leadenhall St. ; maker of long-case clocks, 1760-75.

Poidevin, F., 16 Brewer St., 1830.

Poisson, Henry, London; long-case marquetry scroll-work clock, S.K.M., period Queen Anne ; also silver watch of a slightly later date ; 1695-1720, see Fish.

Poite, Jaques, Blois; watch case enamelled by him, Vienna Treasury, about 1720 .

Polack, Benj., Sheffield, 1814.

Pollard, - Crediton, about 1760.

Polliscott, Thos., apprenticed in 1684 to Jno. Brown, C.C.

Pomeroy, Joseph, Whitehorse Alley, Moorfields, C.C. 1728 ; horn-covered paircase verge watch, about 1738 .

Poncy. Abraham, Wells St., Oxford St., 1839-42. J. P. I., Wells St. ; patented in 1840 (No. 8,602) a clock with two springs.

Pons, H. ; clock, about 1844 .

Ponson, Richd., London; watch, 1810. Pontem, Jas., London, 1780.

Pool, J. C., St. Anne's Lane; 1654.

Poole. Geo., C.C. 1654 ; made a clock for the Mayor of Kendal as a gift to that town. On the dial was the motto, " Time runneth. Your work is before you." Jno., near Norfolk St., Strand, C.C. ; arch top bracket clock, about 1712. Robert, Aldersgate St. ; livery C.C. 1766; master 1781; 1760-81. \& Bickerlo, 88 Bartholomew Close, 1769-75. George, 88 Bartholomew Close, 1783-85. John, 36 Charles St., City Rd., 1822; 7 Brunswick Terrace, Commercial Rd., 1835-40. John, born 1818, died $1867 ; 7$ Brunswick Terrace, Com mercial Rd., in 1842, afterwards in Fen. church St.; a clever chronometer makes, and inven tor of an auxiliary compensation. James, Clerkenwell, born 1816, died 1900. Thos., Bath, 1832. Geo., 36 Milsom Street, Bath, 1845. J. U. (James Poole \& Co.), 33 Spencer St. ; died 1918, aged 79.

Pools, Edmonde, admitted C.C. 1722.

Pope. Nich., apprenticed 1678 to Gerard Overzee, C.C. Thos., Wharton's Court, Holborn, 1793.

Poppe, Jno. Hy., Göttingen, 1797

Popplewell, Jno., Bridlington, 1770

Portal. \& Coyle, Ludgate Hill, 1760-63 Abraham \& Gearing, 34 Ludgate Hill, $-1769-75$. 
Porter. Sebastian, apprenticed in 1680 to Jef. Bailey, C.C. Matt., apprenticed 1682 to Thos. Taylor, Strand; C.C. Robt., apprenticed in 1687 to Jno. Cotsworth, C.C. Mark, Oakingham; clock. about 1750 . Chas., 227 Brrmondsey St., 1835-40.

Porteous, Robt., Manchester, 1818.

Porthouse. Wm., Penrith; clock in carved long case, on dial a tablet inscribed "Thos. and Ann Harrison, 1749." Wm., Barnard Castle, 1760. Geo., Penrith, 1790-1810 ; Mr. Francis B. Fairley has a long mahogany case clock with dial inscribed "Matt. \& Catherine Fairless 1771." "Wm. Porthouse, Penrith." The Matt. Fairless referred to was a colliery proprietor; he was murdered for the money with which he was going to pay the men at the pit. Thomas, High St., Poplar, $1815-30$; 10 Northampton Sq., Clerkenwell, 1840 ; treasurer, W. and C. Bene. Inst., died 1860 ; the business was carried on for a short time at 16 Northampton Sq., under the title of Porthouse \& Son.

Portsmouth, Jno., apprenticed in 1660 to Isaac Puzzy, C.C.

Post, William, 42 Fish St. Hill ; watch, 1760 ; long-case clock, "William Post, London Bridge ; " liveryman C.C. 1776.

Potheust à Paris; watch, about 1750 , Mons. E. Gélis.

Potier, Michel, Paris, 1544 (see p. 404).

Potter. George, watchmaker, and Mayor of Coventry, 1727. Christopher, Shoe Lane, C.C. 1730. Harry, 5 Well St., Aldersgate, 1775 ; master C.C. 1795 , and again in 1812 , when he died before the expiration of his year of office; a watch by him, exhibited at the Guelph Exhibition by Mr. Geo. Carr Glyn, had an outer case embossed by Maweis. Ephraim, Concord, U.S.A., 1775-90. Thos., Gainsboro', 1795. James, livery C.C. 1810 .

Pottinger, Jno., 6 Bell's Buildings, Salisbury St., 1793.

Potts. Jno., Partrington, 1775. Joshua, York, f., 1810-33, maker of musical clocks. Jno., Redcar, 1823. Wm., Leeds, 1840.

Pouchet de Claremont; oval watch, about 1650 , B.M.

Pouchoulin, J. L., Geneva, 1750.

Pouilly, - Rue Dauphine, Paris, 1690 (see p. 419, 422).

Poulson, Thos., London ; watch, 1815. Poulton, R., 2 Mayfield Place, High St., Kennington, 1840-42.

Pound, Jno., apprenticed 1673 to Joseph Wincoek, C.C.

Pouzait, Moise, Geneva ; a clever watchmaker; made centre seconds watches; did much to popularise the lever escapement and executed a large model of it in 1786 ; watch, virgule escapement, signed “Pouzait \& Godemar Frères," about 1780.
Pow, see Poy.

Powell. Jno., apprenticed in 1665 to Isaac Daniel, C.C. Bartholomew, C.C. 1668. Robert, Chelsea, C.C. 1710. H., 56 St. Paul's Churchyard, 1793. James, 7 Prince's St., Leicester Sq., 1828-35. Thos., 9 Dover Terrace, Bath, 1835.

Power, Thos., lantern clock inscribed "Tho Power de Wellingborou Hoc Fabricavit," about 1700 ; also a basket-top bracket clock, inscribed "Thos. Power, Wellingbrow.'

Powers, Thos., St. Albans, 1798.

Powis, Robt., 36 Rosoman St., 1806-23.

Powley, - Asby, Westmorland, 1730. Robt., Appleby, 1770.

Pownall, Nat., apprenticed in 1649 to Wm. Izod, C.C.

Poy. Godfrie, a choice, small pullrepeating and alarm clock by him, said to have been made for George II. when Prince of Wales. Gilt case, with military emblems over the arched top surmounted by a handle; silvered dial, in the arch strike-silent plate marked "Schlaat, Nit schla;" engraved back plate ; bell at the bottom of the movement. Also maker of a very fine quarter repeater, inner case pierced and repoussé, h.m., 1729, outer case shagreen; another of his productions is a black, pull-chime bracket clock; in the collection of the Czar of Russia at theWinter Palace, St. Petersburg, was a repeating watch by him, the outer case set with emeralds and diamonds; it is attached to a chatelaine which is also decorated with precious stones; 1718-50. Godfrey, 78 Mortimer St., 1775-95.

Pozzi, A., Wooton Bassett; watch, 1840 .

Praefelt, John, Philadelphia, 1797.

Pratt. Of Askrigg, 1790. He was apprenticed to C. Caygill, and had two sons, Jas. and Wm., who were in partnership till 1830. Wm. continued till 1841. Smith \& Hardy, 82 Cheapside, 1793. Chas., 30 Camden St., Islington, 1830-35.

Preddy, Wm., Taunton; in 1849 he patented (No. 12,656) a sliding plug for watch-keys.

Preist, Wm., corner of Lad Lane, Wood St., 1763.

Prentis. Daniel, 25 Charterhouse Lane, 1788-96. \& Son, 25 Charterhouse Lane, 1804-7. John, same address, 1817.

Presbury, Wm., Coventry, 1780. \& Son, 9 New St., Covent Garden, 1804.

Prest, -, Fleet St., see Priest. Thomas, Chigwell, Essex; patentee of keyless action for watches (No. 4,501), 1820; he was foreman to J. R. Arnold (see p. 616); died 1855.

Prestbury, Chas., 9 New St., Covent Garden, 1793. 
Presticott, Peter, New Rents, St. Martin's-le-Grand, 1790-94.

Prestige, Bartholomew, C.C. 1703.

Preston. Tobias, apprenticed in 1640 to Christopher Vernon, C.C. Edward, C.C. 1721. Wm., Lancaster, 1818.

Prestwood, Joseph, C.C. 1703 ; maker of long-case clocks, 1703-20.

Preudhomme, L. B., Paris, 1780, see Glaesner.

Prevost. Ni., London; year clock, about 1710 ; watch, 1730 . L. N., London; watch, 1750. Adolphe, 20 King St., Soho, $1840-42$.

Price. Jno., apprenticed in 1678 to R. Nemes, C.C. Chas., apprenticed 1680 to Geo. Stevens, C.C. George, St. Martin's Churchyard, 1788 ; 89 Oxford St., 17931806. J., Deptford ; watch, 1796. Isaac, Philadelphia, 1797. W., 17 Maiden Lane, Wood St., 1825. R., Hoxton, 1842. G. F., Hereford, 1851. G. F., son of the above; died 1911, aged 60 .

Prickett, G. J. B., a noted maker of gold and silver dials, 5 Corporation Row ; died 1898 , aged 71 .

Priddith, John, C.C. 1639.

Prideaux, Edmund, 31 Hatton Garden, 1780-94.

Pridgrin, Wm., York, f., 1778. W., Hull ; watch, 1797.

Pridham. Lewis, Sandford; long-case clock, about 1710, Major C. Simmons. William, Great Alie St., Goodman's Fields, 1760-63.

Priest. Thos., St. John's Lane ; C.C. 1729. Jno., Aldersgate, C.C. 1730. John, apprenticed to George Graham, C.C. 1746. -, Fleet St., 1765-75. W. \& James, 30 White Cross St., 1768-72. - Bugg Lane, Norwich; watch, 1796. Jno., Liverpool, 1833. Jas., Newark, 1840.

Priestman. Joseph, apprenticed to Henry Jones, C.C. 1703. M., 19 Prince's St., Leicester Sq., 1817.

Prigg. Matt., London; watch, 1750. John, Bethlehem; livery C.C. 1776 . \& Ansell, clock and watch spring maker, Middle Moore Fields, 1781-94.

Priggin. Jno., apprenticed in 1646 to Elias Allen, C.C. Wm., Hull. Mr. Thos. Boynton has a mahogany long-case clock by him about 1770 , brass and silvered dial, 13-in. in diameter, shows the phases of the moon, time of high water, and days of the month.

Primavesi, Joseph, Warminster, 1843.

Prime. Andrew, C.C. 1647, long-case clock, S.K.M. (see p. 497). Abraham, apprenticed in 1665 to Andrew Prime, C.C. 1672.

Prince. Thos., apprenticed in 1674 to Jno. Bellard, C.C. Richard, C.C. 1680. -, Hammersmith; watch, 1835.
Pringle. Adam, Edinburgh, 1800. Thos., Dalkeith, 1810-43.

Print, Richard, C.C. 1698.

Prior. John, Nessfield, near Skipton-inCraven, Yorkshire, born 1747; received the following rewards from the Society of Arts: 1798, 30 guineas for detached escapement; 1803,30 guineas for improved striking work; 1805 , silver medal and 20 guineas for an alarm; 1811, silver medal and 10 guineas for striking work; 1817 , silver lsis medal and 2 guineas for striking work; 1820, large silver medal and 20 guineas for striking work. George, 31 Prescot St., Goodman's Fields, 1765-88; Rosomond's Row, 1794; 5 George Yard, Lombard St., 1798-1810. Wm., 82 Minories, 1793. George, son of John, of Otley and Leeds; in 1809 he received from the Society of Arts a silver medal and 25 guineas for a clock escapement, and in 1811, 20 guineas for a remontoir escapement; in 1818 he patented (No. 4,214) a remontoir; in the Yorkshire Directory for 1822 he is described as of Woodhouse Lane, Leeds, but he afterwards removed to City Rd., London, and became reputed as a maker of watches for the Turkish market. Edward, also a maker for the Turkish market contemporaneously with the lastnamed George, carricd on business in Clerkenwell at first alone, and afterwards in partnership with $\mathrm{Wm}$. Chambers; a long-case clock by Edward Prior is in the Mosque of Achmet, Constantinople ; watch, " Edward Prior, London," Turkish numerals, about 1800, Hilton Price collection. Leeds: Hy., 1818; Geo., 1840. I. W., Newington Causeway, 1830. Pritchard. Phil., junr., C.C. about 1650. Geo., Madelywood; watch, 1802.

Pritchford, Zachariah, apprenticed 1674 to Ed. Eyston, C.C.

Procter, Wm., apprenticed to John Brockbank; admitted C.C. 1797 ; livery 1810.

Proctor. William, New York, f., 1737-60; then Cardan.

Prosser. Edwd., apprenticed in 1655 to Robert Lochard, C.C. William, Strand, 1769-72. John, 61 Piccadilly, 1822-30.

Pryme, see Prime.

Pryor, Robert, 254 Tottenham Court Rd., 1835-40.

Puckridge. J., 73 Snow Hill, 1716-40. Charles, Goldsmiths' St., Shoe Lane, 1788-94. John, 72 Snow Hill, 1790-1818; livery C.C. 1814. Alfred, 7 Orange St., Bloomsbury, 1840-42.

Pugh. Ellis, Cockspur St., 1775-94. Benj., watch gilder, 34 Jewin St., 1790-94. Puiguer, - London ; watch, about 1780. Pullan, Ben., Bradford, 1710-35. 
Pullen. Jas., apprenticed C.C. 1669. David, Coleman St., C.C. 1730.

Puller, Jonathan, apprenticed 1676 to Nich. Coxeter ; C.C. 1683, assistant 1705 ; long clock, 11-in. dial, marquetry case with domed hood, about 1700 , Wetherfield collection.

"Whereas an old Silver Watch in a black studded case made by one Puller, was taken away from a gentleman on Bagshot Heath, on Monday, April 29. This is to desire them by any hand to send it to Thomas Newman at the Naked Boy in West Smithfield, and no questions shall be asked, but a Reward of 2 guineas shall be given to the Person that brings it" (Postman, 11th May 1706).

"A large House-Clock supposed to be stolen 16 or 18 months since is now in the hands of Jonathan Puller Clockmaker in Red Lion Court in Fleet St." (Lond. Gaz., July 24-28, 1690.)

Punchard, Wm., apprenticed 1676 to $\mathrm{R}$. Seignior, C.C.

Purden, John, London, about 1795.

Purnell, J., 106 Up. Seymour St., 1842.

Purrier, Richard, C.C. 1705.

Purse. William, 336 Strand, 1804. George, 487 Strand, 1804-25. \& Catchpole, 120 Regent St., 1835.

Purton, Francis, 2 Carey St., 1793.

Purvis. Wm., Edinburgh, made a " Knock" for St. Mary's Church, Dundee, in 1540. Alexander, 4 North Audley St., 1825-42.

Putland, G. \& J., 287 High Holborn, 1793.

Putley, Francis, 40 Newington Causeway, 1806-42; livery C.C. 1812.

Puxton, see Paxton.

Puzy, Isaac, London; apprenticed in 1651 to Jno. Freeman; C.C. 1658 ; 12 hour lantern clock, about 1665 , inscribed "Isaac Puzzy."

Pybus. William, 66 Threadneedle St., 1789-94. E. G., watch, 1822 .

Pye, Chas., High St., Birmingham, 1780.

Pyke. John, watch motion maker, Bedford Row, C.C. 1720. Stephen, London; long-case clock, about 1750 . George, son of Jno., C.C. 1753. Jno., Newgate St. ; " clock and watch maker to the Prince of Wales," 1755; centre seconds watch, about 1770. Jno., High St., Eltham, 1820-42; an excellent maker, formerly Arnold's foreman.

Pyne, Nathaniel, C.C. 1677 ; the late Mr. Norman Shaw had a long marquetry case month clock by him.

Pyott, see Barclay, Jas.

Quaife, Thos., Battle, Sussex. In 1853 he patented (No. 1,140) forming watch cases by pressure.
Quare. Daniel, St. Martin's-le-Grand ; afterwards at the King's Arms, Exchange Alley ; a Quaker, born 1648 ; brother C.C. 1671 ; master 1708; died 1724 ; a celebrated maker, inventor of the repeating watch (see pp. 303-314). \& Horseman, at the King's Arms, Exchange Alley; in the Czar of Russia's collection was a gold repeating watch by them ; the outer case is enriched with one large square and four pear-shaped topazes, interspersed with several scrolls of diamonds and twelve large single diamonds. It is suspended from a chatelaine ornamented in the same style: 1700-30, see Peckover.

Quarman. Joseph, Temple Cloud, about 1760-80. Saml., Temple Cloud; longcase clocks, also watch with day of the month hand, silver cases, the outer one repoussé, h.m., 1768 ; he died 1772 ; longcase clock showing " High water at Bristol Key," about 1775. signed " Geo. Quarman, Temple Cloud."

Quarrel, Richd., apprenticed 1691 to Phil. Corderoy, C.C.

Quari (or Quarie), London. Table clock in engraved brass case, about 1700 , S.K.M., inscribed "De Jean Quari, London."

Quartermaine, Joseph, Aylesbury, 17551802 ; watch, tortoise-shell case, Mr. A. E. Clarke, about 1757.

Quartier, Olivier, Locle, Switzerland ; watch in the Paul M. Chamberlain collection about 1850.

Quash, Joseph, apprenticed 1637 to Geo. Smith, C.C. 1646 ; watch, about 1650 , signed " Josephus Quash Londini," silver engraved case, S.K.M.

Quelch. John, C.C. 1646; maker of lantern clocks. Richard, Oxford ; octagonal watch, Whitcombe Greene collection, about 1650 . Jerem., London ; long-case clock, 1735 ; watch, 1754.

Quenonault, Chas.,London ; watch, 1760. Quentin, Gilles, Paris ; clockmaker to Louis XIV., 1657.

Quested, Thos., Wye ; long-case clock, about 1800 .

Quick. Thos., London; watch, 1780. Francis, Bristol, 1843.

Quillan, - Airvalt; French lantern clock, about 1650 .

Quillet, Paris; made the Bastille clock, for which, including three bells with flat tops, he received $£ 3,767$ in 1762 ; he had charge of the clock till his death; his widow in 1776 attended to some repairs.

Quilliam, Liverpool, see Townley.

Quimby. William, Belfast, Me., 1821-50. Phineas Parkhurst, Belfast, Me., 1830-50.

Quin, T. D., 18A Great Titchfield St., 1840. 
Quinton, Stephen, London; maker of long-case clocks, about 1750 .

Quy, -, Bath, 1798.

R. ; cruciform watch, stackfreed movement, signed "A. R.," Pierpont Morgan collection. Watch marked "N. R.," about 1620, Pierpont Morgan collection.

Racine, Chas. Fredk., Chaux de Fonds ; celebrated enameller and dial painter, died 1832 ; watch, Pierpont Morgan collection, modern movement, signed "Racine. Berlin ; " watch, about 1750, marked "Racine, London."

Radcliffe, Charles, Liverpool, 1680.

Radford. Henry, C.C. 1721. Thos., Leeds, 1770. Jas., 75 Gray's Inn Lane, 1793.

Rafe, Thos. ; lantern clock, Mr. Albert Hartshorne, 1661.

Rafford, F., London; watch, 1780.

Ragsdale, George, 25 New Bond St., 1769-83.

Raiment, Thomas, C.C. 1719.

Rainaldi. Giovannia P. ; maker of the first clock in the square of St. Mark, Venice, 1495. Carl, son of the foregoing; assisted by his father.

Rainbow, Wm., London; long-case clock, about 1770 .

Raines (Raynes), William, Butcher Row, East Smithfield; C.C. 1660; maker of lantern clocks.

Raingo, M., Paris ; orrery clock, Windsor Castle, 1823; a similar one in the Soane Museum (see p. 454).

Rainier, John, livery C.C. 1787.

Rainsford. Bernard, apprenticed 1657 to Ed. Clough; C C. 1677. Francis, Charing Cross; apprenticed to Robt. Gregory, 1680; C.C. 1689. Francis, apprenticed to Brounker Watts; C.C. 1708. Jno., New St. Sq., C.C. ; Mr. Thos. Boynton has a clock by him, brass and silvered dial, engraved laurel border, chimes quarters on six bells, shows days of the month, about 1725; another fine longcase clock by him at the Duke of York Tavern, Potters Bar, about 1750 ; in the Wetherfield collection is a regulator by him.

Raitt, Alexander, London; maker of long-case clocks, with striking racks between the plates; 1685-1710.

Raker, P., 95 Bishopsgate St., 1775.

Rallart, - Paris; watch, 1630.

Ram, Hewett, apprenticed 1691 to Thos. Hickmann, C.C.

Rambley, Wm., 407 Oxford St., 1775-94.

Rambrant, Jas., London; watch, 1805.

Ramsay. Of Dundee: Patrick, 1604, then John, then Silvester. David, near Temple Bar, watchmaker to James I. ; first master of the C.C. (see pp. 256-260) ; 1600-50. John, oval watch, Pierpont Morgan collection, signed " John Ramsay, Londres," about 1620 ; tangent wheel and screw adjustment, balance-cock pinned on.

Ramsbottom, Jno., Hall Green; clock, about 1770.

Ramsden. Thomas, C.C. 1648. Jno., apprenticed 1654 to Thos. Loomes, C.C. J., Hall Green ; clock, about 1785.

Ramsey. Jno., C.C. 1637. - Islington, 1800-8.

Rand, Wm., London ; repeating watch, 1760 .

Randall. Hy., apprenticed 1660 to $\mathrm{Wm}$. Dobb. Richd., apprenticed 1665 to Francis Bicknell, C.C. IMorris, apprenticed 1680 to Jno. Dearmar, C.C. Timothy, apprenticed 1683 to Francis Hill, C.C. John, Wine Office Court, Fleet St., 1790-94.

Raneage, Isaac, C.C. 1635.

Ranna, -, Vienna; small watch in lyre-shaped enamelled case, about 1790.

Ransom. T., London; watch, about 1790. M., London; watch, 1802. George, 18 King St., Soho, 1825.

Rant. Geo., C.C. 1687 . Jonathan, C.C. 1687 ; bracket quarter repeating timepiece, arched dial, with calendar, ebony case, Wetherfield collection, about 1710 .

Ranzonet, The Sieur, Nancy; said to have made a musical watch in 1770 .

Raphard, -, London ; watch, gold case, Schloss collection, 1760 .

Rapier, Jno., " in Wisbech, fecit," clock, about 1700 .

Rapson, Thos., 4 Montague St., Portman Sq., 1814-18.

Ratcliffe, J., 45 Clerkenwell Close, 1835.

Ratherain, C., 25 Cursitor St., 1825.

Rattray, James, Dundee, 1842.

Raulet, Samuel, Monmouth, U.S.A., 1800 .

Raven. Crispin, London; long solid walnut-case clock, about 1780 . Samuel, London, about 1795. Wm., Sheffield, 1832.

Rawford, James, 75 Gray's Inn Lane, 1770-90; livery C.C. 1787.

Rawlings. George, 88 Whitechapel, 1790. Charles, Brook St., Holborn; C.C. 1818, livery 1826 ; died 1864 .

Rawlins. Henry, C.C. 1706. James, livery C.C. 1787. Geo., 88 Whitechapel, 1793.

Rawson, Jno., Penrith, 1770.

Raxhall, Chris., apprenticed 1657 to Jas. Seabourne, C.C.

Ray. Daniel, Sudbury ; long-case clock, about 1730. \& Montague, 22 Denmark St., Soho, 1804-19. Samuel, 35 Great Castle St., Oxford St., 1820-30. Henry, 3 Com. mercial Pl., City Rd., 1835; 22 Great Russell St., 1840.

Rayley, Jno., London ; watch, 1830. 
Rayment. Richd., St. Edmunds Bury; a good maker of lantern clocks, about 1700 . Sir Ernest Clarke had one by him, and Dr. L. Brunton another; a later specimen, with arched dial, signed " Richd. Rayment, Bury ;" long-case clock, about 1705, Mr. A. G. Cockburn. Thos., apprenticed to Thos. Taylor; C.C. 1719; watch, repoussé gold case, Schloss collection, about 1768; another, painted tortoiseshell case, Mr. R. T. Mole, about 1765 . Wm., Stowmarket, 1750. Thos., Stamford, 1760 ; clock, long-case with Oriental lacquer, Mr. Thomas Sandall.

Raymond, Jno., Leadenhall St., 1774.

Raymonde. Water clock, dated 1581, and marked " Raymonde, Chester."

Rayner. Step. Jno. Baldwin was apprenticed to him in 1691; watch, S.K.M., about 1730 . John, London; C.C. 1697 ; watch, h.m., 1727.

Raynesford, see Rainsford.

Read. Thos., Manchester, 1770. Geo., 10 Rotherhithe St., 1815-25. George, Old Sq., Lincoln's Inn, 1820. Wm., Newcastle Pl., Clerkenwell, 1820. William, 84 Jermyn St., Piccadilly, 1825. Daniel, Westgate St., Ipswich, 1844.

Reader. Wm., Hull ; long-case clock, about 1760, Mr. W. Metcalfe. J., London, 1825.

Recordon, Louis, Greek St., Soho, 1780 ; afterwards succeeded Emery at 33 Cockspur St., Charing Cross. In 1780 he patented (No. 1,249) a pedometer winding for watches (see p. 617); 1778-1810, see Desgranges.

Red, Cr., London ; watch, 1783.

Redier, Antoine, Paris ; born 1717, died 1792.

Redrupp, Eli, Chesham, 1780.

Redstall, Francis, Overtons; long-case clock, Mr. James Carter, about 1700.

Reead, Thos., C.C. 1632.

Reed. Alezander, admitted C.C. 1706 ; clock-watch, Schloss collection, about 1710 . Wm., Chelmsford, 1770.

Reeve. Thomas, in Pope's Head Alley, C.C. 1632 ; assistant 1655. Robert, York, f., 1660. Thos., Harlestone, 1660. Henry, C.C. 1682. Joseph, Yarmouth, 1700. John, C.C. 1712. Gowar, The Fleet, C.C. 1730. Jarvis, C.C. 1731. Sam., Stonham, 1770. Wm., 24 Ludgate St., 1830 ; 13 Vigo St., Regent St., 1835.

Reeves. Richard, 208 High St., Shoreditch, 1820-42. Wm., 37 Newington Causeway, 1825-42.

Regard, Reymond, clockmaker at the upper end of Russell St., near Drury Lane ; admitted C.C. 1677 ; mentioned in Lond. Gaz., Jan 25-28, 1691.

Regnauld (or Regnault). -, Chalons, France; devised a compensated pendulum
1733; Thiout mentions a repeating clock by him. Pierre, père, Rue Vielle-duTemple, Paris; garde visiteur in 1769; clocks and bells of the Bastille placed in his custody, 1789.

Regnier, "Maître," Paris 1605 ; octagonal watch, Garnier collection, late sixteenth century, case of crystal, movement signed " J. Regnier, Paris."

Regynolds, Geo., York, f., 1641 ; died 1680

Rehle, -, Freiburg; table clock, 1690.

Reicardledert in Strassburg"; oval alarm watch, about 1595 .

Reicheneder, Leopold, Burckhausen ; brass box-shaped circular watch, two dials, numerals up to twenty-four, engraved with views of a town; on back is engraved the Wisdom of Solomon, about 1550 ; Pierpont Morgan collection.

Reid. Thomas, born 1746, died 1831 ; a celebrated Edinburgh clockmaker, apprenticed to Jas. Cowan, whom he succeeded in 1781 ; watch, "Thos. Reid \& Co., Edinburgh, 1800"; from 1806 he was in partnership with Wm. Auld till 1823, when he retired from business; Thos. Reid was author of "Treatise on Clock and Watchmaking," published in 1826, the major part of which was taken from an article by him in Brewster's " Edinburgh Cyclopaedia," published in 1819; hon. f., C.C. 1825. Adam, Clerkenwell and Woolwich ; inventor of an adjustment for Graham's pendulum, 1779-1835. Henderson, in his "Life of Ferguson," speaks of Andrew Reid, a clever watchmaker, who died at Brixton, in 1835 , aged 85 . F., \& Sons, Glasgow, 1786 ; Reid \& Todd, 1825-42. Wm., 32 Rosoman St., Clerkenwell, 1790-1820; fine pocket chronometer, Arnold estapement, h.m., 1795. J., Ball Alley, Lombard St., 1800-16. \& Auld, Edinburgh, 1806-23; E. J. Thompson gave to the Horological Institute a fine regulator, inscribed " Reid \& Auld, 1818." Jno., Edinburgh; long-case clock, about 1820.

Reidl, Joseph, Vienna ; watch, 1770.

Reilly. John, Dublin, 1778. John, Philadelphia, 1785-97. J. C., 12 Middle Row, Holborn, 1815-25.

Reinheld, large octagonal watch, rock crystal case, Pierpont Morgan collection, signed "Johan Georg Reinhold," about 1600 ; see Roll.

Reith, James, repeating watch, about 1700 , in pierced and engraved gold case, signed " James Reith Versailles," S.K.M. ; admitted C.C. 1705 ; long-case clock, about 1715 , Mr. J. Terry.

Relph, E., 183 Tooley St., 1835.

Remmerdell, Thos., Wigan ; watch, 1776.

Renching, Edmd., apprenticed 1659 to Robt. Robinson, C.C. 
Renier, Michael E., Kronstadt; table clock, about 1590.

Rennie, Jas., Carlisle, 1833.

Renshaw, Thomas, Ship Alley, Wellclose Sq., 1825.

Rentnow, see Wontner.

Renton, Jas., York, 1838.

Rentzsch, Sigismund, 2 St. George St., St. James's Sq. ; a clever mechanician and excellent workman; he devised and made a peculiar chronometer escapement; his regulator had original features, among them a pendulum, with the mercury divided in several small tubes; he patented in 1813 an automatic timekeeper somewhat similar to Horstmann's (see p. 402); 1813-42.

Restell, Thos., Tooting. In 1848 he patented (No. 12,154) escapement ; Strand in 1852, when he patented another escapement (No. 324).

Rettord, Jno., London ; watch, 1798.

Revel, -, Palais-Royal, Paris, 1770.

Revell. Sam., apprenticed 1664 to Thos. Loomes, C.C. Jno., Eye, 1775.

Rewalling, Thomas, C.C. 1715 ; watch, about 1720, signed " Thos. Rewalling, London.'

Rex, Thomas, 96 Broad St., Ratcliff, 1842.

Rey, - enamelled watch, about 1785 , signed " Jn. Ant. Rey \& Fils."

Reymond, S., Geneva; very thin watch, about 1840 .

Reyner. Stephen, at ye Dial, Bishopsgate Within, admitted C.C. 1691. Thos., Oxon.; bracket clock, about 1740 .

Reynolds. Alban, apprenticed 1670 to Jno. Wise, C.C. Joseph, C.C. 1691. Thomas, apprenticed to H. Bradshaw ; C.C. 1706; small bracket chiming clock, two trains only, arch dial, with strike-silent hand, inscribed "Thomas Reynolds, St. Martin's-le-Grand," about 1740. Thos., son and late apprentice of the preceding T. R., 2 St. Martin's-le-Grand, admitted C.C. 1736 ; watch, G.M., about 1770 . Thos., Warwick; watch, silver cock, silver name-plate, steel index disc, about 1730 . Jno., blacksmith, Hagbourn, Berks. ; made a clock and chimes for Brampton Church, for which he was paid $£ 34 ; 1732$. Jacob, Shaston; long-case clock, about 1750. Jas., Holborn Hill ; livery C.C. 1760. Thos., Holywell, Oxon., 1770-85. Francis, Kensington, 1776. Thos. \& Son, 1 Sparrow Corner, Minories, 1783-94. G., 10 Gough Sq., 1830. T., 25 Coppice Row, Clerkenwell, 1835.

Rhetorick, Walter, apprenticed 1651 to David Moody, C.C.

Riach, -, London, about 1790.

Ribart. -, Blois; watch, about 1590 , Garnier collection. T., Paris ; oval watch, about 1630 .
Rice, Stephen, 20 Pall Mall, 1793.

Rich. Jno., London; watch on chatelaine, Pierpont Morgan collection, about 1750 ; repeating watch; 1775 . John, Bristol, Conn., 1820.

Richard. Daniel John, born at La Sagne 1665, died at Locle, 1741; is said to have introduced watchmaking into Neuchâtel in 1781 ; his five sons devoted themselves to the new industry. Peter, C.C. 1679. François, Hambourg, watch, S.K.M., about 1780. Louis Jean, Neuchâtel, born 1812, died 1875. -, silver watch, signed "Auguste Richard sur la Port à Rouen," has "John Mattin" round the dial instead of figures, about 1820 ; Pierpont Morgan collection.

Richards. Luke, C.C. 1648. Richd., free of C.C. by redemption, 1652. Jno., apprenticed in 1654 to Wm. Pettitt, C.C. Hugh, Broad St. ; apprenticed 1691 to $\mathrm{Hy}$. Bradley, master C.C. 1735. Henry, London, C.C. 1699 ; watch, 1725 . Thomas, 114 Strand, 1770-72. Jno., London; C.C. 1770 ; several watches, 1780-96. William, Albemarle St., Clerkenwell; liveryman C.C. 1776 . B., London; watch, 1790.

William, 43 Brick Lane, Old St., 1794. Thomas, 17 Bridgewater Sq., Barbican, 1804; 96 Shoreditch, 1830. " \& Morrell, 240 Pearl St., New York, 1809. S. \& J., 1817. Theophilus \& Co., centre seconds watch, about 1820 . W., 49 Oxford St., 1830. Geo., 16 Milsom St., Bath, 1844. Wm. H., Bristol, 1844. T. H., North Main St., Wexford ; died 1917.

Richardson. Wm., apprenticed 1647 to Jas. Starnell, C.C. Richard, C.C. 1675 ; "a good wheel cutter" (Hatton). Henry, London, about 1700. Francis, Philadelphia, 1736. James, Bradford ; clock, " Jas. Richardson. - Bradforth," about 1760. Richard, Liverpool, 1776. Richard, Hexham, 1780. James, Lutton, 1780 ; Pentonville, 1800; master C.C. 1788. Thos., Weaverham ; long-case clock, about 1780 , with the following inscription round arch of dial, "That man is yet unborn who duly weighs an hour." John, Racquet, Court, 1798-1811 ; liveryman C.C. 1810.

Richmond. Joseph, York, f., 1810. Robt., Lancaster, 1817, f.

Rickett, Thos., High Wycombe, 1780.

Rickman, W., 35 Great Pulteney St., 1820.

Ricord. Richard, C.C. 1649 . Jno., C.C. 1657.

Riddlesdon. Samuel, C.C. $1766 . \quad$ Jno., watch-spring maker, Red Cross Sq., 1790-94.

Rider. Thos., apprenticed 1691 to John Johnson, C.C. Job, Belfast; advertise ment 1791 : " Job Rider, from London and Dublin, and last from Hillsborough has 
commenced business at 'The Reflecting Telescope' Shambles Street, where he makes clocks and watches of all kinds to the common manner, with Harrison's and other modern improvements. His turret and steeple clocks are in an entirely new construction;" made a self-winding barometric clock somewhat on the plan of Cox described on p. 401 ; he removed to High St., Belfast, and retired from the clock and watch business in 1807 ; a clock by him is in the possession of $\operatorname{Sir} W$. Q. Ewart. John, Camberwell Green, 1835. -. Poole ; at the Dean sale of Chippendale furniture at Christie's, 15th June 1909, a long-case clock about $9 \mathrm{ft}$. high by him fetched 460 guineas.

Ridereau, -, established at Place Maubert, Paris, in 1769; presented the Academy of Science with a clock striking hours, quarters, and repeating all with the same striking train.

Ridgdale, N. ; oval watch, S.K.M. about 1610 .

Ridge, W. L., Clerkenwell ; died 1914, aged 85 .

Ridley. Josiah, C.C. 1685 ; the late Mr. Frederick Morris had a fine long marquetry case chiming clock by him, dating from about 1700. Joseph, received a reward of 20 guineas from the Society of Arts, for a sector and depthing tool, 1788. In 1793 Joseph, son of Joseph Ridley, watchmaker of St. Margarets, Westminster, was apprentice to Francis Fether, citizen and cutler. Thos., 14 Waterloo Rd., and Enfield, 1830-42.

Riefler, Siegmund, Munich, inventor of the Riefler compensated pendulum and escapement; died 1912, aged 65.

Riego, Miguel, 284 Regent St., 1868.

Riesle, E. ; wooden and musical clockmaker, 2 Garden Row, London Rd., 1840.

Rigaud, - , London; watch by him, about 1740, belonging to Mr. Geo. Carr Glyn.

Rigby. Joshua, 5 Berkeley St., Clerkenwell, hon. freeman C.C. 1781; spoken of by Hatton and by Earnshaw ; maker of a repeater watch for the Duke of Sussex; 1765-1800. E. \& Son, 6 Berkeley St., Clerkenwell, 1795-1800. James, 35 Rosoman St., Clerkenwell, 1804 . James, 8 Charing Cross, 1806-30 (succeeded Leroux, see Morse, Richd.). Thos., 29 Alfred Pl., Goswell Rd., 1816-18. Joshua, 8 King St., Goswell Rd., $1820 . \quad J a s .$, Liverpool, 1830.

Rigmaiden, - Dublin, about 1760.

Riley. John, Gillingham, Halifax, 1804. G., Halifax, 1809, see Ryley.

Rimbault. This family of clockmakers flourished from about 1700 till nearly the end of the century. A clock signed
"Stephen Rimbault, London," belonging to Señor Espéz of Galicia and attributed to the seventeenth century, was mentioned in Notes and Queries for lst October 1910 ; I saw a bracket clock not later than 1730 signed " Rimbault junr.; " on the movement of a clock by " Phillesson" was scratched " Rimbault fecit, 1744." Stephen, 7 Great St. Andrew St., $1760-81$ (see p. 588). Paul, 9 Denmark St., St. Giles's, 1779-85.

Rimer, Wm., Liverpool ; watch, 1769. Ring, Joseph, C.C. 1693.

Ripley, Jno., York, f., 1471.

Rippin, William, Holbeach, Lincolnshire; worked at his trade as watch and clock repairer for thirty years after he lost his sight; vouched for by his daughter and many other persons; he died in 1857.

Rippon, Richard, 46 King St., Seven Dials, 1816 ; afterwards of Cooks' Court, Long Acre ; a well-known maker of English repeating work for watches. E. J. Dent married his widow; fine watch movement by him, G.M.

Risbridger (or Ribridger). William, Dorking ; lantern and 30-hour long-case clocks, about 1700. John, Brentford ; long-case clock, square dial, one hand, with date " 1740 " scratched on back of dial and also " 1777 cleaned." John, New Brentford, 1800-20.

Risdon, Francis, London ; watch, about 1780.

Rishton, James, Rochdale, 1821.

Ritchie. George, Philadelphia, 1785-93. Jas., Leith St., Edinburgh, 1809-42. David, Clerkenwell ; devised a compensation pendulum in 1812. Fredk. Jas., born 1825, died 1906; succeeded his father at Leith St., Edinburgh; he was a capable horologist who perfected a system of electrically-driven clocks described in detail in the " Watch and Clock Makers' Handbook."

Rithe, Jno., apprenticed in 1654 to $\mathrm{R}$. Scrivener, C.C.

Ritherdon. Geo., Aldgate, 1753-83. Robert, 3 Aldgate Within, 1758-1800.

Rittenhouse. David, Philadelphia, 1751-97. Dan., Philadelphia; astronomical clock, 1767. Reid says " an eminent Swiss residing in America."

Rivaz, Pierre de, Paris; a celebrated horologist. In 1748 he made a marine timepiece which had a temperature-compensating device attached to the balance. He converted clocks going a fortnight only into twelve months without winding, and claimed that by adding another wheel his clocks could be made to show the true time, exactly following the sun, even in his equalities. 
Rivers. David, 3 Bridgewater Sq., 1753-75. David, 3 Sweeting's Alley, livery C.C. 1766 ; master 1773 ; 1760-83; watch, David Rivers \& Son, h.m., 1782. Jno., 1 Holborn Bars, 1783. \& Son (successors to D. St. Leu), 38 Cornhill, 1790-1812; Wm. Rivers, master C.C. 1794. William, 33 Cornhill, 1818-20.

Riviere, Samuel Newton, 63 New Bond St., 1790-1804.

Rix, - London; watch, 1750 ; clock, about 1760 , inscribed " I. Rix, London."

Robarts, B., London; watch, 1783.

Robb, Wm., Montrose, 1780.

Robbin, Fabian, London ; walnut marquetry long-case month clock, square dial, bull's-eye in front of pendulum bob, 1690-1700, see Robins, Fabian.

Robbins. J., 24 Percival St., 1842. Royal Elisha, purchased in 1857 the Boston Watch Company of Waltham, Mass., which he steered to prosperity and greatness as the American Watch Company; died 1902, aged 78 .

Roberson, Jas., London, 1760.

Robert. -, Chaux de Fonds; quarter repeating work described by Thiout in 1741. \& Courvoisier, Geneva, 1790-1800. Henri, Paris, chroncmeter maker, 1830-65.

Roberts. Richard, apprenticed 1653 to Eliza Fletcher, C.C. Hugh, apprenticed 1657 to David Bouquett; C.C. 1664 ; in the B.M. is a large astronomical watch by him. Wm., apprenticed 1692 to Mordecai Fox, C.C. Timothy, Otley, 1770. Samuel, C.C. 1776 ; watch, G.M., h.m., 1778. Gideon, Bristol, Conn., 1780-1804; then Jno.; then Jacob. Jno., St. James's Market, 1790. Josiah, 88 Bishopsgate St., 1793. J. B., London; watch, 1795. J., Dudley; watch, about 1800 , around bezel, " Keep me clean and use me well, then I to you the time will tell." Wm., St. James's Market, 1806 ; 5 St. Alban's Place, Pall Mall, 1820-30. C., London ; watch, 1820. George, 27 Marchmont St., Brunswick Sq., 1820. Wm., Bath, 1825. Jno., Bath, 1835. Jas., 87 Union St., Boro', 1842. Edward, Bedford. His articles in the Jeweller \& Metalworker, under the nom de plume of "British Horologist," were well known; died 1912, aged 59. Evan, born Havoty Bach, Gwyddelwarn, 1836, business in Manchester 1861; died in London 1919; owned a large collection of old watches.

Robertson, Benj., 14 Jewin St., 1783.

Robin, Robert, Paris ; born 1742; died 1799 ; clockmaker to Louis XV.; two excellent examples of his work are in the Jones collection at S.K.M., and one in the Wallace collection; a calendar clock by him in case of chased ormolu with figures of boys allegorical of Sculpture and Architecture surmounted by a vase fetched $£ 661$ at the Hamilton sale in 1882 .

Robins. Fabian, London; walnut marquetry long-case month clock, square dial, glass in front of pendulum bob, about 1695, Mr. James Arthur. John, 67 Aldersgate St., 1783-94. Wm., 13 Fleet St. 1783 ; master C.C. 1813. John, 13 Clerkenwell Green, 1800-4; 65 Charing Cross, 1817. John, 13 Frith St., 1823-30.

Robinson. Geo., apprenticed 1631 to Simon Hackett, C.C. Robert, C.C. 1652 ; lantern clock, inscribed " Robert Robinson in Red Cross $S^{t}$ of London," about 1655 , dial 3 in. in diameter of silver, days of the month engraved outside the hour band with indicator on rotating ring; another lantern clock, marked " Robert Robinson at the Style in Lothbury, London," about 1670. William, C.C. 1667. Dan., apprenticed 1681 to Wm. Arthur, C.C. Jno., apprenticed 1681 to Wm. Robinson. Thomas, C.C. 1703. Francis, " in the Temple;" apprenticed to Henry Jones, C.C. 1707 ; master 1725 ; repeating watch with silver case in the G.M., inscribed "Servant to His Royal Highness;" another example, a small square-case clock, square dial with cherub corners, 1707-26. Ruhamer, Gracechurch St., 1713. William, apprenticed to Daniel Delander; C.C. 1720 . James, at the Dial in Grace's Alley, Well Close Sq. ; maker of long-case clocks and watches, 1730-70, afterwards Samuel Robinson. Philip, Fleet St., 1737-40. \& Cave, "232 Strand, near Temple Barr," card, Ponsonby collection, about 1770 . M., repeating watch, gold repoussé case, Schloss collection, 1780. Owen, an escapement maker who worked for Arnold, mentioned by Reid as the maker of a double chronometer escapement, 1710-1810. Thos., London ; watch, 1780. Jno., Lancaster, 1783, f. Anthony, 232 Strand, 1783. Richard, watch-chain maker, 4 Goldsmith Row, 1790. Matthew, watch movement maker, 8 Charterhouse St., 1790-94. Geo., London, 1806 ; clock so inscribed in the lighthouse at St. Agnes, Scilly Islands. Thos., London ; apprenticed to Paul Barraud; C.C. 1812 ; watch, 1825. Wm., Ley, burn, 1822-40. John, Winterton; an ingenious clockmaker; he succeeded to the business of Thomas Tate, and in 1834 made a clock for Winterton Church; the dead-beat escapement had round pins as pallets hinged to allow movement equal to half the diameter of a pin. Richard, watch-movement maker, 27 Ray St., Clerkenwell, 1835.

Robotham. F., Leicester, about 1740. Fras., High St., Hampstead, 1836-40. 
Robson. Wm., Curtain Rd., 1780-94. William, musical-clock maker, 48 Red Cross St., $1797-1810$; master C.C. 1809.

Roby, James, 2 Prince's St., Leicester Sq. 1793-1800.

Rochat. Frères, Geneva; watch, about 1810. Jules, 82 Frith St., Soho, 1840-42. Rochford. M. F., 212 Piccadilly, 1804-25. F., 49 Jermyn St., 1830.

Rodanet, J. H., Paris ; chronometer maker; died 1884, aged 78 .

Rodet, - London; quarter repeating watch in gold case beautifully pierced with birds and scrolls; outer case pierced and ornamented in repoussé with medallions, escallop shells, and flowers, about 1740, Pierpont Morgan collection; another watch of Dutch character similarly inscribed about 1750 ; watch, "Isa Rodet, London," about 1770, Mr. E. Wehrle.

Rodgers. Benj., London, 1720. J., 39 St. Paul's Churchyard ; rack-lever watch, 1818.

Roe, Joshua, apprenticed 1687 to Edmd. Appley, C.C.

Roger, - repaired the clock at Exeter Cathedral, 1424 (see p. 37).

Rogers. William, C.C. 1641 ; Nicasius Russell was apprenticed to him in 1653. Chas., apprenticed 1649 to Wm. Almond ; C.C. 1657. Wm., apprenticed 1682 to Thos. Taylor, Holborn. - Leominster, about 1730. John, C.C. 1731. B., London ; watch, 1735. Isaac, White Hart Court, Gracechurch St., a maker of good watches ; a specimen in gold repoussé outer case is in the B.M. ; did a good trade in foreign markets ; bracket clock with painted case, Persian flower pattern, brass arched dial, Turkish figures; engraved back plate and formerly crown escapement; tunes at the hour; had dancing figures, a ship or other mechanism, showing through dial; the pulleys for this alone remain ; bought in the bazaar, Constantinople, 1881; 1750-94; large travelling watch, dated 1759, Pierpont Morgan collection. S., Fenchurch St., 1774-82. William, Broad St. Buildings, liveryman C.C. 1776 . Isaac, 4 White Hart Court, Gracechurch St.; C.C. 1776; master 1824; succeeded to his father's business 1776 ; removed to 24 Little Bell Alley, Coleman St., in 1802 ; died 1839. Jno., Hackney; watch, 1780. Samuel, Plymouth, U.S.A., 1790-1804. Thomas, 63 Charing Cross, liveryman C.C. 1810. Wm., same address, 1817 . John, 22 Wilmington Sq.; made watches for the American market; born 1817; died 1868 . C., 59 Charlton St., Somers Town, 1820.

Rogerson, Henry, London, about 1780.

Roget, - , London; watch, about 1740 ; another, 1755 .

Rohr, John A., Philadelphia, 1811.
Roizin, -, Rue de Charonne, Paris, 1770.

Rolf, Joseph \& Son, 17 Foster Lane, 1769-88.

Rolfe, Robert, 29 St. John's Sq., Clerkenwell, 1835; succeeded Gravell \& Son in 1850. Robert, his son, died 1901, aged 65.

Roll, George, Augsburg. In 1588 he made a clockwork globe, which Rudolph II. bought for 1,000 florins; at the S.K.M. is a striking clock in a celestial sphere of gilt brass on four feet; the sphere is inscribed "Elaborabat Georgivs Roll et Johannes "Reinhold in Avgvsta Anno Domini 1584."

Rollison, Dolly, Halton; died 1752, aged 36 ; long-case clock, inscribed " Dollif Rolisson, Halton," Dr. Wm. A. Day ; longcase clock, signed "Dolf Rollinson, Halton, Essex," Sir James M. Moody.

Roman, Bordier \& Co., watch, about 1825, see Roux.

Rombach, J., 103 Regent St., 1835-42.

Rome, Wm., 6 Shepperton Pl., North Rd., 1842.

Romer. Flack, C.C. 1661. Thos., 20 George St., Adelphi, 1817.

Romeux, Lewis de, C.C. 1706.

Romieu. L., Rouen ; watch in silver case, outer case of leather piqué with silver, centre of dial enamelled green, hours on white ring of enamel, about 1630, Pierpont Morgan collection. - à Rouen ; enamelled watch, about 1660. Paul, Edinburgh ; long-case clock, about 1700 .

Romilly. John, born in Geneva 1714. A clever watchmaker who migrated to Paris and set up business in the Place Dauphine, where he was very successful ; he advocated 8-day watches and made several, also watches with cylinder escapements and very large balances to vibrate seconds, as well as equation watches; is said to have produced a self-winding watch, possibly on the plan patented in England by Recordon in 1780, and of which Breguet made several (see p. 617); a fine watch by him with enamelled case forms part of the Pierpont Morgan collection; at South Kensington Museum is a watch signed "I. Romilly à Paris," dating from about 1760 ; the case is inlaid with tinted gold; died 1796, aged 82. Peter, 17 Frith St., Soho, 1769-94.; long-case chiming clock, inscribed "Romilly, London," about 1770 .

Romley. Chris., apprenticed to Wm. Addis; C.C. 1755. Ludlam quotes both Chris. and Rob. Romley. Robert, in Horse Shoe Alley, Middle Moor Fields, 1765-75. Romney, Joseph, admitted C.C. 1664. Rondin, Guy, à Nantes, about 1680 . 
Ront, Wm., Endfield; watch, 1765.

Roof, Daniel, C.C. 1676.

Rooke, John, 26 Berkeley Sq., 1765-94; hon. f. C.C. 1781 .

Rooker. Richd., apprenticed 1685 to Jno. Clowes; C.C. 1694. Richard, Chelsea, C.C. 1728 ; large silver watch, silver chased dial, having an aperture behind which an imitation pendulum swings, about 1740 .

Rookes, Barlow, admitted C.C. 1667.

Rooksby. John, York, f., 1647. A small timepiece with repeating work, dial brass gilt, beautifully engraved, inscribed " J. Rooksby in Yorke," about 1690.

"Stolen on the 23rd instant, out of Mr. Jeffreys' House in Yorke, a gold pendulum watch with minutes and seconds, made by Mr. Rooksby, of Hull, with a gold studdied case. Notice to be given to Mr. Hill, Goldsmith, in the Strand " (Lond. Gaz., Nov. 26-30, 1691).

1770 .

Roque, -, Passage du Saumon, Paris,

Rosany, L., Paris, about 1775 .

Rose. Michael, C.C. 1676 ; 8-day chiming clock in long case, with scroll marquetry decoration, signed " Rose \& Son," about 1720. John, Bishopsgate, C.C. 1730. William, London; watch in painted tortoise-shell case, Mr. A. E. Clarke, about 1750. Joseph, London, about 1750 ; Mr. Charles Morson (U.S.A.) has a musical clock by him in a long case, the base of which is kettle-shape. Joseph \& Son, 19 Foster Lane, 1765-68. - junr., St. Ann's Lane, 1774. Joseph, Son \& Payne, 17 Foster Lane, 1771-94. T., St. Clements, Oxon., 1780. Daniel, Reading, U.S.A., 1820-40. John, 96 Fleet Market, 1830.

Roselet, - Geneva; watch, 1809.

Rosier, John, Geneva; watch, 1815.

Roskell, Robert, the elder, Liverpool, many rack lever and cylinder watches by him; he was also a collector of curious horological specimens, 1800-30.

Ross. Thos., Hull, 1770. Jno., Tain, 1775. Wm., Cork; watch, handsome repoussé case, h.m., 1793. \& Peckham, 41 Bedford St., Covent Garden, 1810.

Rosse, Samuel, C.C. 1672.

Rossi, W., 5 Blackman St., 1830.

Rothchild, Joseph, Bristol, 1844.

Rotherham. Thomas, apprenticed to Simon Hackett 1654 ; C.C. 1662 . R. H., Coventry; died 1864, aged 74 . John, Coventry; died 1905 , aged 67 , see also Vale.

Rotherodd, Benjamin, silver rose-shaped watch in the Bernal collection, seventeenth-century work.

Rothwood. Robert, C.C. 1632. Robert, C.C. 1648 .

Roubell, Jno., 4 Orange Grove, Bath, 1798, see_Wadham.
Rouckleiffe, Jno., Bridgwater ; maker of brass clocks, 1770 , see Brimble.

Roumieu. Paul, Edinburgh, probably from Rouen; submitted his essay, made in his own chamber and vouched for by George Mill and Andrew Brown, and was admitted to the incorporation of Hammermen 1677 ; died 1693 ; watch, about 1680 , formerly in the Hawkins collection, now in Nelthropp collection, G.M. Paul, Edinburgh, son of the foregoing, admitted 1682 , his essay masters being Richard Mill and Jno. Sympson; died 1710. "Stolen this day in the Parliament House, out of a gentleman's pocket, a silver pendulum watch with a minute hand and a green shagreen case, some of the studs broken off. Whoever can give notice of the said watch to Mr. Romieu, watchmaker, shall be thankfully rewarded " (Edinburgh Gaz., 1699). Adam, C.C. 1695. John, C.C. 1720. Adam, C.C. 1726. P., Rouen; watch, about 1740 .

Roumyeu, James, C.C. 1692.

Rountree, Robt., York, f., 1828.

Rousby, Jno., York, f., 1683.

Rouse, Robert, apprenticed 1682 to Chas. Baxter, C.C.

Rousseau. David, sixteenth-century cruciform watch, Garnier collection. Jean, a clever watchmaker; a crystal cased watch in the form of a cross by him in the Fellows collection, about 1590 . Jean, son of the above, born 1609 , died 1684 ; silver watch, S.K.M., engraved with figures of the seasons and with flowers. - the father of Jean Jacques Rousseau was a watchmaker of Geneva in the early part of the eighteenth century.

Roussel, - Master Horologer of Paris, mentioned by Thiout in 1741 .

Routh, Saml., C.C. ; to him Jno. Marshall was apprenticed in 1682 ; clock by him about 1720 .

Routledge, Geo., Lydford, Devon, died 1801 ; curious epitaph in Lydford churchyard as follows :-

Here lies in a horizontal position the outside George Routleige, Watchmaker.

Integrity was the mainspring and prudence the regulator of all the actions of his life;
humane, generous and liberal,

His hand never stopped till he had relieved So nicely regulated were his movements that he never went wrong. except when set going by people who did not know his key:

Even then he was easily set right again.

$\mathrm{He}$ had the art of disposing of his time so well, that his hours glided away, his pulse stopped beating.

He ran down November 14.1801 , aged 57 , In hopes of being taken in hand by his Maker, Throughly cleared, repaired, wound up, and set going in the world to come, when time shall be no more. 
Routley, Edwin, 6 Broad St., Bath, 1850. Roux, Bordier \& Roman, Geneva, about 1810.

Rowden, John, London ; apprenticed to Dinnis 1683 ; C.C. 1691 ; watch, silver dial, with raised figures, square pillars, about 1700 .

Rowe. Thomas, C.C. 1699 . Benjamin, C.C. 1708. John, St. Paul's Churchyard, liveryman C.C. 1770-82.

Rowland. Jno., Manchester, 1765. \& Co., 8 Coventry St., 1825.

Rowlands. Walter, Berwick, 1775. Christopher, 132 Long Acre, 1815; 9 Coventry St., 1835; 33 Leadenhall St., 1840. William, Smith St., Clerkenwell, watch-case maker, apprenticed to T. \& R. Carpenter : treasurer and a liberal sup-porter of the Clock and Watchmakers' Asylum ; livery C.C. 1820 ; master 1860 ; died 1868, aged 77. William \& Son, 92 Quadrant, 1823. R., watch-case maker, 35 Meredith St., Clerkenwell, 1835. Christopher, watch-case maker, Smith St., Clerkenwell, son of William, was Treasurer for some years of the Clock and Watchmakers' Asylum; died 1916, aged 86.

Rowley. Eliza, apprenticed 1694 to Andrew Yeatman and Mary his wife, C.C. -, associated with Graham in constructing an orrery, 1716. Francis, removed from Birmingham 1792 to Turnmill St., Clerkenwell ; died 1824, aged 70 . His son Francis, Faulkner's Alley, died 1837, aged 49, the business being carried on by his widow Elizabeth; she died in 1870 , aged 88 . Arthur \& Henry, Red Lion St., Clerkenwell, afterwards at Gray's Inn Rd., and then Theobald's Rd. ; Arthur died 1900, aged 85 ; Henry died 1902, aged 75. Hy., Liverpool, 1833.

Rowning, "Once a bad clockmaker in Cambridge" (Ludlam, 1758) ; John Rowning, M.A., in 1732 patented a clock (see p. 512), and reference is made in the "Dictionary of National Biography" to a brother a watchmaker. In East Anglian Notes and Quevies are mentioned, as early clockmakers, J. Rowning, Newmarket; Stephen Rowning, Thetford ; and Rowning of Brandon; these all probably lived about the middle of the eighteenth century.

Roy. David, C.C. 1682 . Samuel \& Fils, Chaux de Fonds; one-wheel regulator, about 1780, M. Couheru-Meuri. William, 30 Bell Yard, Lincoln's Inn, 1804.

Roycroft, Thomas, admitted C.C. 1699.

Royd, Stephen Joseph, C.C. ; to him was apprenticed Dymoke Evans in 1800.

Royer, William, 40 Gee St.; Goswell Rd., 1820.

Roylands, William, watch movement maker, 29 Chiswell St., 1790-94.

Royle, Jos., Chorley, 1780.
Rozè, A. C., a French horologist, died 1862 , aged 50 .

Rubins, Richard, Grantham, 1780.

Rubottom, Wm., Liverpool, 1770.

Rudkin, Thomas, C.C. 1683.

Rudrupp, Jno., Amersham: maker of lantern clocks, about 1710.

Ruegger, E. M., Geneva, 1800-10.

Ruel, Samuel, Rotterdam ; calendar watch, Schloss collection; nicely pierced work on movement, "The Triumph of Venus," h.m., 1788.

Rugend, -, Auch ; tulip watch, Soltykoff collection, about 1570 .

Rugendas, Nicholas, Augsburg, 1605-30.

Rugg \& Thaine, 15 Cheapside ; enamelled watch by them, Dunn Gardner collection ; this, with a chatelaine partly of gold, fetched $£ 100$ in 1902 at Christie's ; 1769-94.

Rugless. Sam., 37 Ratcliff Highway, 1815-25. T., 3 Cannon St., St. George's East, 1842.

Rule. Jas., Portsmouth; watch, 1779. Jas., York, f., 1797.

Rumault, - Abbeville; oval striking watch, about 1570 .

Rumford, Jno., Bishop Auckland, 1776.

Rundell. Edwd., Norton St. Phillip's ; fine musical clock, about 1710. Philip, Ludgate Hill, livery Drapers' Company, 1770. \& Bridge, 32 Ludgate Hill, 17881824 ; watch, marked " Rundell, Bridge, \& Rundell, 1830 ; " Rundell \& Bridge succeeded Picket \& Rundell ; they were silversmiths to the Crown, and their shop one of the attractions of London; the business was purchased by Francis Lambert, and transferred to Coventry St.

Rush. Samuel, 16 Ludgate Hill, and Porter St., Leicester Fields, 1759-90. \& Shipman, Hull, 1822.

Russel. Thomas, watch-case maker, 18 Barbican, 1775. Charles, 18 Barbican, 1790.

Russell. Nicholas, apprenticed to William Rogers in 1653 ; C.C. 1663 ; master 1692 ; died 1700. "A plain hourwatch goes but 24 hours, the name on it is Nicolus Russell, Londini, fecit" (Lond. Gaz., Dec. 22-27, 1697). Jno., C.C. about 1660. Cornelius, apprenticed 1686 to $\mathrm{Ab}$. Clyatt, C.C. Thomas, at the Clock Case in Barbican; liveryman C.C. 1776. Charles \& Thomas, 18 Barbican, 1787-1815. Thos., Lancaster, 1797, f., 1832. A. C., London; watch, Schloss collection, about 1800 . Benj., Thirsk, 1822. T., 50 Great Sutton St., 1842.

Rust. Wm., Lincoln, 1775. Wm., Hull, 1780. \& Shipman, 1822.

Rutherford, Michael, Hawick, 1803.

Rutland. Jonathan, 110 Oxford St., 1793-1804. James, 83 Oxford St., 1822-30. Rutter, Jno., St. James's Walk, 1793. 
Rycroft, Thos.; a watch by him is mentioned in the Lond. Gaz., Sept. 21-25, 1693.

Ryder. Thomas, C.C. 1698 . Thomas, C.C. 1712. Josh., London; watch, h.m., 1761. Ryland, Jno., London; watch, 1780.

Ryler, William, C.C. 1712.

Ryley. Laurence, apprenticed C.C. 1662. Geo., apprenticed C.C. 1683. Thomas, C.C. 1704. Erasmus, Wood's Close, C.C. 1730. Jno., Coventry, 1812-18.

Rymer, Hy., 6 George St., Adelphi, 1817

Rypplay, Jno., York, f., 1471.

S. ; sixteenth-century tambourine case watch marked "V."S.," Paul Garnier collection.

S., H., see Schnier.

Saber, Edwd., Cannon St., 1783.

Saberty, J., London ; watch, 1765.

Sacheverell, Benassir, apprenticed 1680 to W Thoroughgood; turned over to Tompion; admitted C C 1687.

Sadd, Thomas, East Windsor, U.S.A., 1750.

Sadleir, Samuel, Hackney, warden C.C. 1723.

Sadler. Sam., apprenticed 1687 to Sam. Vernon, C.C. ; long marquetry-case clock, about 1700. Robert, London; long-case clock, about 1740. Thos., Norwich ; longcase clock, about 1770. Stephen, 134 Bishopsgate Without, 1830.

Saer, Joseph, admitted C.C. 1687 ; maker of a square-dial brass 8-day clock, two hands, inscription, " Joseph Saer, in Penpool Lane, London," 1686-1700.

Saffory, John, 13 Tokenhouse Yard, $1760-75$.

Sagar. Edmund, Middleham, 1750. Robt., Blackburn, 1818. 1760 .

Sage, Matthew, Oxon.; watch about,

Sainsbury. Robert, Chippenham, 1775. Richard, Bridgwater; long-case clock, about 1780 . J. (tools), 2 Cowcross St. 1806-23. Hy., 15 Corridor, Bath, 1835. Richard, 9 Wingrove Place, Clerkenwell, 1840-42.

St. Andrew, G., London; watch, 1790.

St. George, Jno., apprenticed 1674 to Barlow Rookes, C.C.

St. Leu, see De St. Leu.

Salisbury, Wm., London ; watch, 1730.

Salmon. Jno., Bristol ; bracket clock, repeating on eight bells, ebony case, Mr. J. Drummond Robertson, about 1700 . Henry, Coventry St., Piccadilly, 1769-82. Robert, 49 Strand, 1790-94. C. E., 151 Bishopsgate Without, 1823.

Saltby, Thos., Grantham, 1770.

Salter. Edward, 20 Cannon St., 1788-94. John, 35 Strand, 1804 ; 73 Strand, 1825-30.
Saltmarsh, Samuel, 74 Middleton St., Clerkenwell, 1840.

Sambrook, John, C.C. 1680.

Samley, -, Gutter Lane, 1775.

Samon, John, C.C. 1654.

Sampson. Umfrevil, apprenticed to Chas. Cabrier, C.C. 1735. Robert, Westminster ; invented a two-part chime clock, described in Transactions of the Society of Arts, vol. iv., 1786 ; card, B.M., "Robert Sampson, 2 Petty France, Westminster, 1788." Wm., London, about 1800.

Samson, London, on many watches, Dutch style, 1760-96. Samuel, Westminster ; watch, B.M., about 1780 ; also a silver repoussé pair-case watch apparently for the Dutch market, h.m., 1800; other examples are a long-case musical clock, inscribed "Samson, maker to His Majesty ; " and a musical and mechanical bracket clock; 1778-1805. J., 11 Denmark St., Soho ; watch with engraving of the Crucifixion in white metal fastened above the balance on a semicircular metal ground, decorated with rubies, emeralds, and topazes, 1800-5. \& Grandin, Denmark St., Soho, 1810.

Samuel. Humphrey, Panton St., Haymarket, 1790. \& Hill, 3 Charing Cross, 1793. Moses, Louis \& Co., Solomon, all of Liverpool, about 1818. David, York, f., 1820. Abraham, 11 Little Alie St., Goodman's Fields, 1820-25. J., 142 High St., Shadwell, 1835. Abraham \& Son, 11 Little Alie St., Goodman's Fields, 1840-42.

Samwell, Jno. ; lantern clock, 1665.

Sande, Thos. ; watch, B.M., 1620.

Sanders. Daniel, C.C. 1632. Alex., apprenticed 1665 to Hugh Roberts, C.C. Chas., apprenticed 1672 to Isaac Carver, C.C. Nath., Manchester, 1770. George, 57 Sion Gardens, Aldermanbury, 1790-94. Jas., 46 St. John St., 1790-94. John, 3 Holborn Hill, 1810-15. George, 8 Gee St., Goswell Rd., 1820.

Sanderson. Jno., Wigton; Mr. Charles Hunt has a long-case clock by him, dating from about 1690 , with these lines in the centre of the dial :-

\footnotetext{
"Days, hours and years goes ower a pace,

So happy are they that mind God's grace,

That when their days are ower and glass is run,

They may receive the sentence of Well Done."
}

On the dial of another clock, dating from about 1715, was engraved the following couplet:-

$$
\begin{aligned}
& \text { "Remember Man that die thou must, } \\
& \text { And after that the judgment just." }
\end{aligned}
$$

He removed to Carlisle about 1730. Jno., Newcastle, eldest son of the foregoing, 1750. Robert, Strand, C.C. 1703 ; afterwards Sanderson \& Son; Hatton in 1773 
speaks of the late Mr. Sanderson as an improver of calendar work, and the son as clever; 1703-50; silver alarm watch, " Robert Sanderson, London," h.m., 1769, Pierpont Morgan collection. George, Exeter, patentee of tools for duplicating parts of watches (1761, No. 763); also a lunar and calendar watch-key (1762, No. 777). Hy., at the Dial and Sun, Strand, 1770-81. Thos., 105 Bishopsgate Within, 1815. Samuel, 63 Mark Lane, 1840-42.

Sandford, William, 15 Conduit St., 1800-25.

Sandiford, Jas., Manchester, 1780.

Sandles, Jno., Feckenham, about 1790.

Sandoz. Jacques, Geneva; fine travelling repeating watch, about 1750 . J. G., Paris; born 1836, died 1891.

Sands. Jno., apprenticed 1668 to Isaac Puzzy, C.C. Stephen, New York, 1786. Jno., St. Dunstan's Alley, 1790.

Sandys. Wm., apprenticed 1662 to Robert Grinkin, C.C. Jas., 137 St. John's St., 1800.

Sanford, Eaton, Plymouth, U.S.A., 1760-76.

Saplin. P., 42 Whitcomb St., Haymarket, 1835-42. T., 17 East Rd., Hoxton, 1842. Sarbitt, John, 11 St. Martin's Court, 1804.

Sargeant. Jacob, Hartford, U.S.A., 1828. B., 43 Garden Row, London Rd., 1835. H., 10 Wells St., Oxford St., 1835.

Sargent. Robert, C.C. 1720. Benjamin, 133 Fleet St., 1769-88. Josh., 106 Jermyn St., $1794-1818$.

Sarl, John, 18 Cornhill, 1842 (afterwards Jno. Sarl \& Sons).

Sarrabel, T., Tours, 1670.

Sarton, Hebert, Liège ; watch, about 1800.

Satchabell, Thomas, 9 Bridgewater Sq., 1804.

Sather, Thos., London ; bracket clock, 1730 .

Sattell, C., watch-case makèr, 36 Clerkenwell Green, 1795-1800.

Saude, Pierre, Paris; clockmaker to the King, 1658.

Saunders. Robt., apprenticed 1675 to Robt. Halstead, C.C. John, C.C. 1721. John, C.C. 1730. Joshua, Cripplegate Buildings, 1765-70. In 1787, Isaac, son of Isaac Saunders, watch-motion maker, of Golden Lane, Cripplegate, deceased, was apprenticed to Thos. Allen, citizen and cutler. D., Parkside, Knightsbridge, 1800-40. Thos., 258 Whitechapel, 1817.

Saunier, Claudius, born at Macon, France, 1816. When a young man, he worked for Patek, Phillipe \& Co., Geneva; author of "Traité d'Horlogerie Moderne, Paris, 1870;" founded in 1859 Revue Chronométrique, which he edited till his death in 1896.

\section{Sanrin, - 1720.}

Sauvage, Paris, on French clock, about 1790 .

Savage. Abraham, apprenticed 1648 to Hy. Child, C.C. Thos., apprenticed 1659 to Joseph Quash, C.C. Thomas, London ; 1677. "Stolen out of the house of John Shorren, Esq., Norfolk Street, a gold watch made by Thomas Savage, of London" (Lond. Gaz., Sept. 10-14, 1691). de Salop, fecit '98, signature on 30 -hour square dial long-case clock. T., Clifton, Cumberland; long-case clock, about 1740, Mr. Jno. J. De Lacy. G., Huddersfield, 1775. \& Vincent, 60 Red Lion St., 1802-15. Thos., livery C.C. 1804 . George, a watchmaker who, in the early part of last century, did much to perfect the lever escapement, besides inventing the two-pin variety; he lived at Huddersfield, where in 1808 he patented a remontoir; afterwards at $5 \mathrm{St}$. James's St., Clerkenwell; in 1822 he received the large Silver Medal from the Society of Arts for a detached escapement for watches, which was a combination of the lever and the chronometer; he in his old age emigrated to Canada, and founded a flourishing retail business in Montreal, where he died. Thos., 3 Red Lion St., 1816-40. W., 8 Chapel St., Bedford Row, 1820-25. Samuel, 8 Red Lion St., Clerkenwell, 1825. D., 7 Queen St., Northampton Sq., 1835. Thos., 21 Sidney St., Goswell Rd., 1842.

Saville. John C.C. 1656; assistant 1675 ; died 1679 ; maker of a watch reputed to have belonged to William of Orange, dated 1656, silver box, outer case of tortoise-shell decorated with silver, 1656-79. John, C.C. 1678 ; there was a brass lantern clock of his production at Blackburn in 1887. Wm., apprenticed 1686 to Jas. Wolverstone, C.C. ; Mr. J. W. Gunnis has a long-case clock marked "Wm. Saville, Dublin," an eighteenth-century production.

Savory. Andrew, apprenticed 1668 to Thos. Parker; C.C. 1676; maker of lantern and bracket clocks. Joseph, 48 Cheapside, 1788. Farrand \& Co., 48 Cheapside, 17931800. Joseph \& Co., 1820. A., 54 Cheapside, 1825. Thos. Cox, 47 Cornhill, 1834-64. Adey B. \& Son, 11 and 12 Cornhill, 1865; afterwards "Goldsmiths" Alliance;" Joseph and $H$. R. Savory, managing directors; closed in 1893.

Sawen \& Dyer, Boston, Mass., 1800-20.

Sawtell, E., Bristol, 1843.

Sawyer. Paul, C.C. 1718. Jno., Leeds, 1770. John, 1 Poultry, 1804.

Saxbey, Christopher, apprenticed to Charles Cabrier, C.C. 1749.

Saxon, Jas., Liverpool ; long-case clock. about 1795 .

Saxton \& Lukens, Philadelphia, 1828-40. 
Say, Nehemiah, C.C. 1654 . Richard, apprenticed 1688 to Jno. Johnson.

Sayer, Matt., Oxon.; watch, 1757.

Sayller, Jno., oval watch by him, Vienna Treasury, about 1650.

Sayre. John, New York, 1800. \& Richards, New York, 1805.

Scafe. William, " at ye sign of the clock in King Street, near Guild Hall ; " C.C. by redemption, 1721 ; master in 1749 . The Hon. B. Fairfax, writing to his nephew in 1727, said, " One William Scaife, a watchmaker, born at Bushey, near Denton (co. York) served his time to his father, a blacksmith, but now the most celebrated workman, perhaps, in London and Europe."

Scale. Henry; of him was bought Huggerford's watch with false jewelling used as evidence against Facio (see p. 613) : 1705. G., musical clockmaker, 15 Wellington St., Groswell St., 1840.

Scales, Edwd., 33 Strand, 1775-80.

Scantlebury, W., 17 Golden Lane, 1780-92.

Scardevile, Jno., apprenticed 1663 to Gregory Dossett, C.C.

Schalck, Johann, Engel, Prague ; cruciform watch, Soltykoff collection, about 1580.

Schardees, Tho., London ; watch, about 1715, Nelthropp collection.

Schegs, Abraham, Nürnberg ; enamelled watch, about 1730, Cluny Museum.

Scheirer, Johan, hexagonal clock, about 1620 , Schloss collection.

Schelhorn, Andreas, Schneeberg, Saxony; clock, Green Vaulted Chambers, Dresden, 1570.

Scherer, George F., 227 Regent St., 1835-40.

Scherwerer, - York, about 1835.

Scheurlin. Jacob, Dresden, 1614 ; " Electoral Saxonian Court Clockmaker." Abraham, Augsburg, born 1616 died 1694 ; apprenticed to Martin Zoller; table clock, about 1650.

Schilsky, Joseph, 90 Houndsditch, $1840-42$.

Schlesinger, C. W., Liverpool, 1833.

Schlotheim, Hans, Augsburg; celebrated "Tower o' Babel " clock by him in the Green Vaulted Chamber, Dresden, 1602.

Schlott, Hanns. In the B.M. is a clock in the form of a ship by him, said to have been made for the Emperor Rudolph II. ; 1578-81.

Schmid ; pendulum watch, about 1700 , handsome bridge with bust of William and Mary, by "Iohan-Jacob Schmid in Basel."

Schmidt. Carl, oval clock-watch, strikes 1 to 6 , brass case, Pierpont Morgan collection, about 1600 . Ulrich, watch. about
1610 ; finely enamelled case, Pierpont Morgan collection; another watch, signed " Jo. Ul. Sch.," about the same date. Nicolaus, clock with automata, signed "Nicolaus Schmidt der junger;" ebony case with the Augsburg work mark, about 1620. Johannes, Amsterdam; clock, about 1700. J., Hamburg; table clock, about 1710. John, St. Mary Axe; patentee of mysterious clock (1808, No. 3,185$)$.

Schmith, Thomas, a clever horologist, born in Gjoelballe, Denmark, in 1849; he eventually settled in London, studied at the British Horological Institute and gained many awards; died in 1912.

Schneider, octagonal pedestal gilt-metal clock, signed "Johannes Schneider Augustæ," about 1620.

Schnier, Hans, sixteenth-century bookshaped watch, Pierpont Morgan collection, signed "H. S." (Mr. F. Hilton Price, to whom it formerly belonged, concluded it was by Hans Schnier, of Speyer, 1583).

Schofield. Major, Rochdale, born 1707, died 1783. Edmund, son of Major; born 1730, died 1792. William, Barnish, 1776. John, Barnish; in 1789 a new clock, with chimes for the parish church, ordered of him, to cost $£ 193$; he was living in 1821 . Jno., 29 Bell Yard, London, 1793. Wm., 35 Cheyne Walk, Chelsea; long-case clocks, 1815-25. William, 2 Clerkenwell Close, 1830-32.

Scholer, Johann, Bavaria; table clock, about 1570 , Mr. H. K. Heinz.

Scholfield. John, long-case clock, lantern movement, about 1690 , Mr. F Johnson ; Mr Richard Heape, Rochdale, has a longcase " Halifax" clock, signed " Johannes Scholfield," dating from about 1720 . James, London ; long-case clock, about 1770 Major, Manchester, 1775.

Schouffelberger, H. A., director of the Horological School at Chaux-de-Fonds, and author of technical works; died 1879 .

Schretger, Johann, Augsburg, 1660-90. Schriner, Martin, Lancaster, U.S.A., 1790-1830.

Schröter, Davidt, 1680-90 (see p. 459).

Schulen, Charles, Jacket St., Ipswich, 1844. Afterwards at Cornhill as Schulen \& Boby.

Schuler, M. \& J., 16 Commercial Pl., London Rd., 1835-42.

Schultz, -, Augsburg; Latin cross watch, Schloss collection, about 1570.

Schuster, Paul, Nuremberg, 1591.

Schute, Jasper, C.C. 1648.

Schwer, Flois (also Cosmon), Bristol, 1843.

Schwilgue, Jean B., born 1776, died 1856; restored Strassburg clock, 1838 (see p. 44).

Science, John, C.C. 1724. 
Scolding, John, 7 Great Prescot St., 1794-1810.

Scotchford, Thomas Charles, London ; a good maker of lever pallets, 1830-76.

Scott. Simon, apprenticed 1647 to Wm. Comfort, C.C. Edwd., apprenticed 1650 to Wm. Rogers, C.C. Joseph, apprenticed 1674 to Cornelius Herbert, C.C. Daniel, C.C. 1697. Joshua; the Minutes of the Cutlers' Company for 1705 record that " Joshua Scott of the parish of St. Botolph without Aldgate, watchmaker, his son Caleb bound to Ephraim How, cutler," \&c. Goe., "Cannon Gate;" long-case clock, about 1740. James, apprenticed to John Jackson, 1752 ; C.C. 1766 ; in 1809 James Scott, watchmaker, of Grafton St., Dublin, communicated to Nicholson's Journal a paper on platinum for balance-springs; in 1820 he took out patents for obtaining motive power. -, Gracechurch St., 1770-82. John, 40 Gloucester St., Red Lion Sq.; bracket clock, Wetherfield collection, about 1775 ; honorary freeman, C.C. 1781 ; 1770-94. Wm., Beith, 1780 . Thos., Gainsboro', 1790. Wm., 39 Dartmouth St., 1790-94. \& Thorpe, Strand; watch, 1796. Thos., 65 Charing Cross, 1810-20. Robert, 20 Bell Yard, Temple Bar, 1815-40. A. \& Co., 64 West Smithfield, 1828-32. Wm., 40 Skinner St., Clerkenwell, 1830-42. Jesse, 45 King Sq., 1835-42. Wing $\&$ Co., 59 and 60 Red Lion St., Holborn, 1840-42.

Scrimgeour, James, Glasgow, invented a remontoir about 1810 .

Scrivener, Richd., C.C. 1639; Henry Adeane was apprenticed to him in 1668 ; long-case clock, about 1710, signed "Richard Scrivener, London."

Scurr, Richd., Thirsk, 1822 ; died 1887 ; long-case clock, Mr. Hy. Limbear.

Sea, Frederick, 18 Bartholomew Close, 1820-30.

Seabourne. James, apprenticed to Richd. Seabourne, 1642 ; C.C. 1649 . Wm., apprenticed 1651 to Sam. Horne; C.C.1659.

Seager, Jno., Liverpool, 1817.

Seagrave. Matthew, C.C. 1730. Robert, 35 Gutter Lane, 1790.

Sealey, Wm., Egremont, 1833.

Seaman, -, London, watch ; Dutch style, about 1765 .

Seamer. (or Seymour), York ; Wm., f., 1627 ; Peter, f., 1636; Abel, f., 1649; also Joseph, same date.

Seamore, W., Minories ; watch, about 1750, Mr. Geo. Carr Glyn.

Searle, George, 15 Wellington St., 1830-40.

Seatoun, G., 29 Gutter Lane, Cheapside, card, Ponsonby collection, about 1795 .

Seddon. James, in St. James's, C.C. 1662. Nathaniel, in St. James's, C.C. 1691 ; watch, Schloss collection. Humphrey, Southwark, about 1730 . John, a Quaker, died 1740. John, Frodsham, 1780. D., Frodsham, 1785.

Sedgwick, Sam., apprenticed 1692 to Thos. Beasley, C.C.

Sedley, Thos., London ; watch, 1710.

Sedwell, Edward, apprenticed to Thomas Loomes; C.C. 1664.

Sefton, Edward, Tadcaster; long-case clock, 1775 .

Segner, Geo., C.C. 1689.

Seheult, J., à Paris ; watch, about 1650

Seigneuret, clock, S.K.M., about 1750 in hanging case of gilt and blued bronze; signed on face "Seigneuret H'ger de M'gneur le Com t D'Artois."

Seignior, Robert, C.C. 1667 ; an eminent maker; received, in $1682, £^{20}$ for a clock set up in the Treasury Chambers; month long clock, 10-in. dial, locking-plate striking; laburnum and olive wood case, domed hood with metal fret and spiral pillars, Wetherfield collection, about 1685 ; bracket clock in case of red tortoise-shell and ebony, same collection, about 1690 .

" Lost at Somer Hill a gold chain watch in a new fashioned case round hours, the chrystal and Pendant Ring broken off, made by Robert Signior, on the outside of the shagreen shell a cipher of 2 L.L.'s. There was tyed to the watch 2 seals, one a small gold seal with a Coat of Arms, the other enameled set with Cornelian, and thereon engraved the Figure of Plenty. Whoever can give notice thereof so that it be recovered by the owner, or to Mr. Hoare, Goldsmith at the Golden Bottle in Cheapside, or to Mr. Robert Signior in Exchange Alley, shall have five pounds reward, and if bought the money that shall be paid with content" (Lond. Gaz:, 9 Dec. 1678).

A silver Pendulum watch, with a Tortoise-shell case inlaid with silver, made by Mr. Seignior, Exchange Alley " (Lond. Gaz., Dec. 16-19, 1695), see also Senior.

Selby. Thos., C.C. ; he worked for Chater in 1730. Peter, Wareham; long-case clock, about 1760. Thos., Knaresboro', 1765.

Sellars. John, C.C. 1667 ; warden, 1692 ; excused from serving as master in 1696 , on account of ill-health. William, apprenticed 1681 to Jno. Clowes; C.C. 1691 ; Long Acre, $1700-40$.

Selwood. William, ye Mermaid, in Lothbury ; C.C. 1633; maker of lantern clocks, 1620-36. John, C.C. 1641.

Sené, -, watch, "Jean Sené à Myes," about 1825 .

Senebier, - , cruciform watch, S.K.M., about 1595 ; watch, G.M., signed "A. Senebier à Geneve," about 1630 . 
Seney, G., " orloger du Roy, à Rouen," crystal case watch in the form of a fleur-delis, S.K.M., about 1640.

Senior (Seignior?), a watch by him mentioned Lont. Gaz., Aug. 1690.

Sens, William, admitted C.C. 1711.

Sergeant. Prettyman, apprenticed 1664 to Hy. Child ; C.C. 1671. Robt., Foster Lane, C.C. 1730. Benjamin, 133 Fleet St., 1754-68. Nathaniel, London ; watch, h.m., 1762; Nathaniel Sergeant, who was admitted to the C.C. in 1763 and who served as master in 1783 , was possibly his son, but he does not appear to have practised the craft.

Sermand, - tulip watch, Nelthropp collection, about 1680 , signed "F. Sermand;" a similar specimen of about the same date, signed " J. Sermand," Pierpont Morgan collection; watch, Marfels collection, outer case piqué with gold pins, about 1675 , signed "J. Sermand, Geneva."

Sermon, Joseph, apprenticed C.C. 1675.

Serré, - London ; repeating watch in finely enamelled case, about 1750, Czar of Russia's collection.

Servant, H., 68 Salisbury Court, 1775.

Servier, see Grollier.

Seugnet, E., London; long-case clock, about 1750 .

Seur, Chas., London, 1700.

Severberg, Christian, New York, 1755-75.

Sewell. Geo., 47 Blackman St., 1790-94. G., Bury, Lancs., 1814.

Sexty, R., 71 Carlisle St., Lambeth, 1830-40.

Seydell, Ferd., London; repeating watch, 1775 .

Seyffert, Frederick W., St. John St., Clerkenwell, patented in 1818 (No. 8,317) a repeating motion.

Seyler, Johann Tomas, a clockmaker, 1620 .

Seymore. John, Cherry Tree Court, C.C. 1711. Jno., Wantage; long-case clock, 1712. John, son of. John Seymore; C.C. 1744 ; watch, G.M., about 1760 . William, Minories; mahogany case bracket clock, handle on top, brass dial, style 1750; watch, h.m., 1780 .

Shakeshaft. Joseph, Preston; also Laurence and William, all 1800-24.

Shalcross, Josiah, maker of cylinder escapements with ruby cylinders, and of duplex escapements; for many years in the employ of McCabes; born 1800, died 1866.

Shaller, Nicholas, apprenticed 1672 to Jas. Grimes, C.C.

Sharp. Jno., apprenticed 1647 to $\mathrm{Hy}$. Child, C.C. Thos., apprenticed 1667 to Robt. Whitwell, C.C. Thos., Stratford-onAvon; the sexton's clock by him spoken of by Washington Irving in his " Sketch
Book" is at the Red Horse, Stratford-onAvon. Died 1799. Thos., Leighton, 1780. \& Williams, 6 Strand, 1790. J., 20 Little Tower St., 1794-1808. John, 30 Fish St Hill, 1806-25. T., 9 Postern Row, Tower Hill, 1816. George, 1822-25. \& Son, 30 Fish St. Hill (John Sharp, master C.C 1833 and 1835 ; 1826-40; watch, h.m. 1823, " Sharp \& Son, London Bridge; ; bracket clock, "Sharpe \& Son, London Bridge," about 1830, Mr.Edmonds Massey.

Sharpe. William, C.C. 1681 . Wm., 75 Holborn Bridge, 1793.

Sharples, Jas., Liverpool, 1817.

Sharpnell, see Shrapnell.

Shaw. John, "near the Bars in Holborn;" apprenticed to Thos. Taylor of Holborn in 1672 ; C.C. 1682 ; master in 1712 ; splendid marquetry case clock as above; another fine specimen bore the signature "John Shaw at the Dyall in Holborne ; "1682-1714. Edward, apprenticed 1689 to Clem. Forster, C.C. Lancaster: Thos., 1726, f. ; Robt., 1789, f. Anna Maria, apprenticed to Isaac Loddington and his wife, 1733. William, 22 Wood St., Cheapside, 1760-72. Jas., Kember ; watch, h m., 1777. Jno., Liverpool ; watch, h.m., 1786. Wm. J., Sheffield ; died 1909, aged 56 .

Shayler. Richard, Ball Alley, Lombard St., 1753-56. William, 44 Lombard St., $1755-75$.

Sheave. William, 16 Bell Alley, Coleman St., 1770-94; watch with "E. Mason, Greenwich," on dial. Thos. ; to him was apprenticed Wm. Howells, 1773.

Shearer, James, 23 Devonshire St., Queen Sq. The Duke of Sussex had a skeleton-movement astronomical clock by him ; 1825-42.

Shearman, Robert, Wilmington, Del., 1760-70; Philadelphia, Pa., 1799.

Shearwood, Jas., London; watch, 1767.

Shedel, Jas., London; small bracket clock, about 1750 .

Sheily, Samuel, 61 St. Paul's Churchyard, 1775.

Sheldrick, Edward, 48 Cheapside, 17981803.

Shelley, Jno., London; lantern clock, 1636.

Shelly. Joseph, C.C. 1717. \& King, 149 Shoreditch, 1772-75.

Shelton. Samson, member of the Blacksmiths' Company ; active in obtaining the charter of the C.C., of which he was one of the first wardens in 1631 ; died 1649, leaving $£ 50$ to the C.C. ; fine clock-watch by him, B.M. ; 1623-49. Jno., apprenticed 1662 to Thos. Mills, C.C. "Whereas ther 3 was a Silver Minute Pendulum Waten dropt on my Lord Mayor's day between the hours of 9 and 10 at night, the name 
John Shelt $n$, London. If the person who took it up will bring it or send it to John Collins, Watchmaker, 'The White Horse and Black Boy,' in the Great Old Bailey he shall receive full satisfaction even to the whole value if desired" (The Post Man, Nov. 1, 1705). John, Shoe Lane, C.C. 1720 ; livery 1766 ; in a letter to the Royal Society from Jas. Short in 1752 , Jno. Shelton is referred to as "the principal person employed by Mr, Graham in making astronomical clocks;" he published a description of the dead-beat escapement in the Gentleman's Magazine for September 1754. Nevil Maskelyne in 1761 tested a clock of his make.

Shephard, Jno., Whitehaven, 1770.

Shepheard, Thos., London ; C.C. 1632 ; maker of an oval watch, about 1620 .

Shepherd. Jno., apprenticed 1674 to Robt. Storr, C.C. Thos., apprenticed 1689 to Jno. Barnard, C.C. Henry, 4 Pope's Head Alley, Cornhill, 1760-75. Thos., Liverpool, 1770. Thos., Wootton-underEdge, 1792. Wm., 199 Strand, 1815-25. Swithin, Bath, 1835. Charles, 53 Leadenhall St. ; in 1849 he patented (No. 12,567) an application of electricity for impelling clocks, and afterwards supplied an electric clock for driving the large dial just outside the gateway of the Greenwich Observatory.

Shepley. John, Stockport; died 1749; long oak case clock, Mr. Benj. Heape; long oak case chiming clock, Mr. R. T. G. Heape ; on another long-case clock, " John Shepley, Glossop and Stockport;" clock, about 1760. William, 1780. Edwd., Manchester, 1780.

Sheppard, Samuel, 1 Hanover St., Hanover Sq., 1830.

Shepperd. Thomas, see Shepheard. Sarah, 199 Strand, 1830. Charles, 7 Chadwell St., 1840-42.

Sherbird, J., Turk's St., Bethnal Green, 1820.

Sherborne. Thos., 6 Strand, 1793-1800. Jas., Shepton Mallet, 1843.

Shere, Henry \& Arnold, 46 Lombard St., 1753-68.

Sherwin,-, London; watch, about 1705.

Sherwood. William, apprenticed to James Delander, 1686, C.C. 1695. Jno., apprenticed 1690 to Hy. Jones, C.C. William, C.C. 1720 ; master in 1740 . John, apprenticed to John Jeffs, and turned over to George Graham, C.C. 1721. James, Yarm, 1816. Thos., Yarm, 1823. Thos., Leeds, 1830.

Shick, William, 43 Brick Lane, Old St., 1820.

Shiel, Alex., London ; bracket clock, about 1710 .

Shield, Thos., apprenticed 1691 to Jno. Harris, C.C.
Shields, John, 19 Bridge St., Lambeth, 1835.

Shindler, Thomas, Canterbury ; maker of long-case clocks, about 1720.

Shipley, John, Hyde, Cheshire; very fine marquetry long-case clock, about 1705.

Shirley. Jas., apprenticed 1679 to Jas. Delander, C.C. John, C.C. 1720 ; in 1724 paid $£ 20$ to be transferred to the Vintners' Company.

Shirt, Wm., 25 Coleman St., Bunhill Row, and 10 City Rd., 1815-35; a capable man; he published a "train card" for watchmakers.

Shole, Sim., Deptford, 1825.

Shorrock, Thurston, Preston, 1770.

Short. Joshua, C.C. 1665. James, Surrey St., Strand, $1740-70$; a maker of repute who sent to the Royal Society in 1752 an interesting letter on compensated pendulums; Harrison's son, before starting on his voyage to Barbados, in 1764, set his chronometer by Short's regulator.

Shorter. In 1798 Edward Shorter, clockmaker, Giltspur St., was associated with Wm. Anthony, of Clerkenwell, in a patent for carriages, \&c. E., 4 Bridge Rd., Southwark, 1830. Harry, escapement maker, died 1917, aged 90 .

Showell. Hy., apprenticed 1660 to Lionel Wythe, C.C. Jas., apprenticed 1691 to David Minuel, C.C.

Shrapnell, James, 36 Ludgate St., 1761-70 ; 60 Charing Cross, 1775 ; afterwards Jas. Shrapnell \& Son.

Shrivell, Robert, Brighton, 1861.

Shrubb, Thos., apprenticed 1689 to Phil. Browne.

Shuckburg, Charles, C.C. 1719.

Shurwood, Thos., Yarm, 1775.

Shute, Geo., London ; bird and flower marquetry long-case clock, about 1705 .

Shuttleworth. Henry, C.C. 1669. Fras., Sarum, 1760. Francis, 23 Duke St., Piccadilly, 1806-10.

Shwerer. Joseph, Hull, 1822. Matthew, also at Hull, 1822 .

Sibbald, William, 4 Cannon St. Rd., 1815-35.

Sibelin l'aîné, Neuchâtel, about 1680 .

Sidey, Benjamin, Cow Lane, Moorfields, C.C. $1730 ;$ master 1761 and 1789 ; known as a good watchmaker, and active in matters affecting the interests of the trade. -, junr., London ; watch, 1798.

Sidley. John, C.C. 1701. Benjamin, Watling St. ; C.C. 1710.

Sidwell, see Sedwell.

Silk (or Silke), Jno., Elmstead ; lantern clock, Mr. F. A. Field, about 1670, longcase clock, about 1710 .

Sillito, Chas., Uttoxeter, 1760. 
Sills. J., Manchester; watch, 1809. J., Manchester ; watch, 1811. William, a marine chronometer finisher of surpassing merit; born 1812; died 1884; he worked for Robert \& Henry Molyneux and other eminent makers.

Silver. Jon., London; watch, 1645. Joseph, 28 Hatton Garden, 1793. Fredk., livery C.C. $1810 . \quad$ J. \& J., 28 Hatton Garden, 1825-30.

Silvester, John, apprenticed to Thomas Bates, and turned over to Henry Jones; C.C. 1693 .

Simcock, Thos., Warrington, 1818.

Simcox. Josiah, apprenticed 1675 to Hy. Adeane, C.C. William, C.C. 1682. Samuel, C.C. 1708.

Simistere, Richard, Birmingham ; longcase clock, about 1765, Mr. Francis $\mathrm{H}$. Bigelow.

Simkin, Ben., 16 High St., 'Boro', 1788-93.

Simkins, Jno., apprenticed 1694 to Thos. Taylor. Sim

Simmons. John, Fleet St., 1753-56. Ebenezer, 1 Pavement, Moorfields, 1816; 26 Coleman St., 1825-76. Geo., 49 King's Sq., 1840-42. Morrice, 40 Great Prescot St., 1842.

Simms, Isaac ; watch, B.M., about 1600.

Simonds. Thomas, Fleet St., C.C. 1661 ; lantern clock, balance escapement; 1661-70. J. L., 19 Holborn Hill, 1820-30.

Simons. John, watch-case coverer, Sutton St., 1790-93. G., 49 King's Sq., 1840-42.

Simpkin, Benj., 6 Tooley St., 1800.

Simpkins. Thomas, C.C. 1710. Benjamin, 35 Frith St., 1800.

Simpkinson, Roger, 41 Fleet St., 1758-75.

Simpson. William, C.C. 1700 . John, C.C. 1723. \& Ward, Fleet St., 1737-40. Stephen, Greta Bridge; long-case clock, with "Peter \& Mary Winder" in the centre of the dial, about 1770. Benj., Halifax, 1776. William Ellison, hon. f. C.C. 1781 ; Miss Mary F. Bragg has a fine longcase repeating clock signed "Simpson Wigton," dating from about 1775 ; hands from the centre of the dial indicate seconds, minutes, hours, and day of the month; in the arch above are shown the age and phases of the moon and time of high water, probably at Parton, nearWhitehaven (see p. 516). Robt., Halifax, 1785. Hector ; card, B.M., "H. Simpson, 9 Old Bond St., foreman to the late Mr. Fladgate," 1785; 127 Pall Mall, 1788-94. Archibald, 10 Prince's St., Leicester Sq., 1790-94. Richd., watch-case maker, 19
Albion Bdgs., Clerkenwell Close, 1790-95. R., 481 Strand, 1805-15. Daniel, Workington, 1810. Anthonj, Cockermouth, 1810. John, 6 Middle Row, Holborn, 1815-40. Robert, 55 Park St., Dorset Sq., 1835-40 ; 15 New St., 1842. Thos., Oxford St., 1835-42. Robert, junr., 11 Great Castle St. Regent St., 1840.

Sims. Wm., apprenticed 1693 to Thos. Bradford. Geo., 1738, see Addis, W. Geo., Canterbury, 1745-91. Henry, Canterbury, maker of long-case clocks, 1758-80. Geo., Rochester, 1760. Geo., Prescot, 1770. John, 64 Lombard St., 1773-78. \& Son, London; watch, 1830.

Simson, -, Hartford, 1780.

Sinclair, Chas., 69 Old St., 1835-42.

Sinclare, -, Dublin; watch, 1782.

Sinderby, Francis H., 14 Devereux Court, Strand, 1790; livery C.C. 1810 ;

18 Bull and Mouth St., 1816-42.

Sindrey, Lawrence, C.C. 1661.

Singer, Jas., Frome, 1842.

Singleton, John, Lancaster, 1806, f.

Skeggs. Wm., London ; long-case clock, about 1780 (see p. 526). L., 355 Rotherhithe St., 1788-1810. Wm., 355 Rotherhithe St., 1816-40.

Skelton, C., Malton, 1823, see Shelton. Skepper, Thos., apprenticed 1675 to Thos. Taylor, Strand.

Skerry, W., Dartmouth St., Westminster, 1835-42.

Skilkelthorpe, Wm. ; clock at St. Cross Hospital, Winchester, 1737.

Skinner. Matthew, apprenticed to Francis Hill ; C.C. 1713; master 1746; watch, G.M., about 1750. Benj., Islington ; bracket clock, Mr. R. S. Weir, about 1770 . Chas., 23 Pool Terrace, City Rd., 1840.

Skipworth, Francis, apprenticed 1670 to Robt. Lynch, C.C.

Skirrow. Jas., Wigan, $1780 . \quad$ Jas.,

Lancaster, 1783, f. - 1818.

Skittlethorpe, Richard, Southwark Rd. lantern clock, about 1690.

Slack. Joseph, C.C. 1723. 一, Ipstones; long-case clock, about 1790.

Slade, J. L., London; watch, 1790.

Slater, W., 13 Ship Alley, Wellclose Sq., 1835.

Slipper, Jere., Maiden Lane ; C.C. 1726. Slough, William, C.C. 1687.

Sly, Robert, C.C. 1720.

Small, Wm., apprenticed 1684 to Richd. Farmer, C.C.; pendulum watch, Nelthropp collection, about 1705 .

Smalle, Lewis, received payments for " keeping the clocke" of Lambeth parish church, 1585-1605.

Smalley. Thomas, C.C. 1687 ; maker of a clock at Battle Abbey, Sussex; 16871700. John, Lancaster, 1721, f. 
Smallpage. Jas., Sandback, 1790. Josh., Leeds, 1829. Jno., Malton, 1840.

Smallwood. Jno., Litchfield ; long-case clock, about 1730. Ed., Dublin, 1780.

Smart. John, C.C. 1682. Orpheus, 1750. Benjamin, 35 Frith St., 1800-18. Thomas, 4 Little Ryder St., St. James's, 1816-30. Saml., 198 South Audley St., 1835. Alex., 70 South Audley St., 1835-40.

Smeaton. John, York, f., 1646 ; in the B.M. is a rather large silver watch by him, silver dial, outer case of leather piqué, about 1650 . Tobias, apprenticed 1664 to Hy. Harland, C.C. Jno. ; at Trinity House is a clock bearing the name of Jno. Smeaton, the celebrated engineer, the initials " J. S." being on the hour socket. There is also preserved at Trinity House a longcase clock, on a brass plate affixed to the door of which is inscribed, " This timepiece was placed in the old Eddystone Lighthouse by John Smeaton, C.E., F.R.S., on the 8th October 1759;" in Smeaton's book on the building of the Eddystone Lighthouse the following reference is made to it: "This timepiece by a simple contrivance being made to strike a blow every half-hour, would thereby warn the keepers to snuff the candles." Mr. T. P. Cooper says Smeaton and Hindley of York were lifelong friends (see pp. 380 and 711); he corresponded with John Holmes in 1779, and with Thos. Reid in 1786 .

Smeed, George, 17 Chapel St., Edgware Rd., 1835-42.

Smint, calendar watch, inscribed " Smint London," silver dial with gilt rosettes between the figures; outer case embossed by "Mavris," about 1775, Pierpont Morgan collection.

Smison, Thos., Hartford ; watch, 1796.

Smith. John, petitioner for incorporation of C.C., and one of the first assistants, 1630-49. Robert, watch, Pierpont Morgan collection, about 1630, inscribed " Robert Smith at Popeshead Alley;" C.C. 1648; warden in 1650 , and died during his year of office. George, C.C. 1632. Walter, C.C. 1641. Nat., apprenticed 1647 to Wm. Bunting, C.C. Wm., C.C. 1654. John, C.C. 1656 ; in 1657 Jno. Smith was fined 10 s. by C.C. for putting the name Estine Hubert on a watch. David, C.C. 1662. Ruth, apprenticed 1674 to Thes. Birch and Jane his wife, C.C. John, C.C. 1674, clockmaker and author of "Horological Dialogues, by J. S., clockmaker, in three parts, showing the nature, use and right managing of clocks and watches; with an appendix containing Mr. Oughtred's method for calculating of numbers;" 120 pp. $12 \mathrm{mo}$, London ; published at " The Three Roses," in Ludgate St., 1675 ; this was probably the first book in English on watch and clock making. J. S. quite appreciated the pendulum as a controller; he remarks, "As to their regularity I shall say only thus much, that those clocks who have their motion regulated by a pendulum are more excellent than those regulated by a balance, and those that are regulated by a long pendulum are far more excellent than those that are regulated by a short one." Rules are given for calculating the length of a pendulum, and a three-second pendulum is mentioned which "will be $28 \mathrm{ft} .8 \mathrm{in}$. from the term of suspension to the centre of the bob." In 1694 he published "Horological Disquisitions" (see p. 494), of which a second edition was issued in 1708; his observations covered a wide field; he discoursed on the Baroscope or quicksilver weather glass, on painting, and on the plentiful use of cold water as a preservative of health. He was a Unitarian and plunged into theological discussion ; the Rev. Francis Gregory answered him and advised him to go back to the noise of his hammers and the use of his pincers. St. Augustine, in the city of London, is given as his residence; but Hatton says he was originally a Lancashire tool maker, and his " engines" the best in use ; he died prior to 1730 , at which date it was advertised that his books could be obtained of Mary Smith, at the Fan and Flower de Luce, over against Somerset House in the Strand, and nowhere else. Robert, C.C. 1695 ; on the disc of a long walnut case clock appeared the inscription, " Robert Smith, Dunstable ;" 1680-1700. Gabriel, long-case clock, signed "Gabriel Smith, Bartholmey," about 1695, Mr. Robert Meldrum. Joseph, C.C. 1700. Thomas, Gray's Inn ; admitted C.C. 1700 ; in the Wetherfield collection is a long-case clock by him dating from about 1710 , with very fine scroll marquetry over the whole surface of the case. Morris (or Maurice), C.C. 1702. Henry, C.C. 1703 ; probably successor to Thomas; Mr. W. C. Woollard has a pull repeating clock in mahogany case, about 1720 , inscribed "Henry Smith, Gray's Inn." John, C.C. 1703; maker of the turret clock at Westminster Abbey, 1730; the movement of this clock was replaced by a modern one in 1860. Maurice, Royal Exchange, 1705-32. Tudor, C.C. 1717. Thomas, C.C. 1718 Obadiah, C.C. 1725 . Dan., Dorking ; sheep's-head clock, dial $11 \frac{1}{2}$ in. square, long pendulum, about 1730 , the late Mr. R. Norman Shaw. Geo., Artillery Ground, C.C. 1730. Edward, Bury, lantern clock, about 1730. Joseph, Bristol; long-case clock, about 1730 . Richard, Newport, I. of W., 1730. Joseph, Chester; bracket clock, about 1740 . James, Stow-on-the-Wold; clock, about 
1740. Joseph, apprenticed to Daniel Delander; C.C. 1742. James, Gosport, 1746. Susanna, apprenticed to Hannah, wife of Jas. Wilson, 1747. Jno., York, f., 1750 ; in 1754 he made a new clock for St. Martin's Church, projecting into Coney St., being paid $£ 30$ for this work. Jas., Chiswell St., 1758-60. William, Cheapside, livery Blacksmiths' Company, 1759; 32 Cornhill, 1769-80. James, 115 Fleet St., 1760-80. Wm., Lancaster, 1767, f. John, son of Benjamin Smith, C.C. 1768. Jas. \& Son, 118 Bunhill Row, 1769-88. John James, London, 1781-90. Edward, at the Parrot and Pearl in Foster Lane, 1770.Wm., (from London), " at the Dial, in upper end of High St., Bristol," 1775. Edwd., Richmond, 1780. Geo., 110 Wood St., 1770-76. Abraham, wooden clock-maker, Manchester, 1770. Gabriel, Chester, 1773. Edwd., Newark, 1780. John, Pittenweem ; 8-day musical clock, described by the namesake of the maker; the case of mahogany is $7 \mathrm{ft}$. high, with fluted columns on each side of the body; the upper part of the head is ornamented with carving, fretwork, birds' eyes, and a golden bird with expanded wings, standing in the middle of the head; there are three dial-plates and a chime of sixteen bells; the work is divided into five parts, each of which has its own weight; the first is the going part; the second drives a small musical barrel, which plays a chime at the first, second, and third quarters, and plays once over a tune before striking the hour; the third part strikes the hours, and the fourth drives a large musical barrel containing eight Scotch tunes, one of which is played every three hours; the last part changes the tune; the clock plays all the eight in the twenty-four hours; the front dial plate measures about $15 \mathrm{in}$., and has an arch which shows the hour, minute, and seconds, with the day of the month, and day of the week; when Sunday comes these words cast up, "Remember Sunday;" at twelve o'clock on Saturday night the clock stops playing till twelve strikes on Sunday night; when the clock begins to play there is a procession of moving figures representing the City Guard of Edinburgh ; the maker of this clock exhibited it at a coffee-house in Edinburgh in 1774 , and tried to dispose of it by lottery. Lord Provost M'Grady, of Dundee, has another musical clock by the same maker ; it plays any one of the following tunes: "Flowers of the Forest," "Willie was a Wanton Wag," " Maggie Lauder," " Logan Water," "East Neuk of Fife," " The Lass of Pattie's Mill;" the titles of the tunes are marked on the dial, and there is an indicator which may be turned to the tune desired. Jno., Thirsk, 1775. Danl., Aldermanbury, 1775. Philip, C.C. 1776. Jas., White Horse Court, Bishopsgate, 1776-90; all sorts of clocks and watches made, mended, and sold by James Smith in White Horse Court, Whitecross St., watch paper, Ponsonby collection, about 1770 ; Bishopsgate, 1776-90. James (clockmaker to George III.), Jermyn St., 1776-94; hon. f. C.C. 1781. John, 143 Houndsditch ; livery C.C. 1776-90. J., 40 Duke St., Manchester Sq., 1780. \& Sharp, 14 Bartholomew Close, 1780-85. Richd., Cloak Lane, 1780-85. Joseph, 49 Lombard St., 1783-90. Geo, 4 Huggin Lane, 1783-90. Jno., Chester, 1785. Sam., Walford watch, 1787. \& Wareham, Davies St., Berkeley Sq., 1790. Jabez, 16 Fenchurch St., 1790. Chas., 118 Bunhill Row, 1790-1823. Jas., 98 Oxford St., 1790-1815. Walter, 98 Bishopsgate St., 1795. Wm., 170 Wapping, 1800-4. Wm., 3 Bridgewater Sq., 1803-10. Jno., Wrexham; watch, 1807. H. D., London; watch, with hare and snail on plate as a guide to regulation, 1808 . Samuel, Coventry; patented (1812, No. 3,620 ) a vertical escape wheel with five teeth; several watches were made on this plan ; 7 Clerkenwell Close, 1819-22. \& Asprey, 4 Bruton St., 1817. George, Charlotte Terrace, New Cut, 1820. T. W., 27 Fenchurch St., 1820-30. Thomas, 17 John St., Oxford St., 1820-35. Horatio, York, f., 1822-32. William, 35 Poultry, 1823. G., 11 St. Martin's Churchyard, 1823-30. John, 27 Cornhill, 1825. H., watch movement maker, 12 Berkeley St., Clerkenwell, 1825-35. \& Co., Piccadilly, 1825. J., 256 Borough, 1825-30. B., 12 Duke St., Lincoln's Inn Fields, 1830. J. \& Son, St. John's Sq., Clerkenwell, 1835-42. John, 70 Charlotte St., Fitzroy Sq., 1842. Joseph, 18 Bride Lane, 1842.

Smithfield, W., Romford, about 1760 .

Smithyes. Wm., Holborn; long-case clock, about 1740 . Jno., London ; bracket clock, about 1750 .

Smitton, Peter, 12 Crown St., Russell Sq., 1820-35. $605)$

Smod, -, Geisheim; watch (see p.

Smorthwaite, -, Colchester; lantern clock, about 1680, Mr. J. H. Davidson.

Smoult. Thos., Lancaster, 1708, f., Mayor of Lancaster in 1739. Jas., 1739, f., died 1768 .

Smyth. Joshua, " Steyning in Sussex ;" maker of lantern clocks, 1690 . Wm., Woodbridge ; long-case clock, about 1800 , Mr. J. Hall.

Smythies. Jas., apprenticed 1679 to Geo. Hamilton, C.C. Jno., London; bracket clock, about 1750 .

Snatt, Jno., Ashford. Mr. Hy. Fitz- 
walters, Salem, Mass., has a brass clock by him dating from about 1700 .

Sneeberger, Michael, Prague; pupil of Burgi, 1605-20.

Snell. George, C.C. 1688-1700; maker of long-case clocks. Albion, Holborn; clock, about 1850 .

Snelling. Thomas, C.C. 1680. James, Poultry, C.C. 1712; master in 1736; watch, B.M. ; another, Dunn Gardner collection, fetched $£ 75$ at Christie's in 1902 , S.K.M. Henry, Ball Alley, Lombard St., 1769-75.

Snidal, Jas., Sheffield, 1770-1814; his second quality watches were signed "Dalsni."

Snoswell, William, 24 Farringdon St., 1835-42.

Snow. Jno., London; in the coffeeroom of Simpson's " Old Choppe House " in the Poultry is a lantern clock inscribed "Jno. Snow Ao dmi 1630." Daniel, lantern clock, 1664. John, Sarum. "A watch the hours in the form of Diamonds, the Outcase holes with bizels for the sound of the Bell " (Lond Gaz., April 1, 1680). Jno., Frome about 1760 . Wm., about 1780 . Thos., Otley, 1780. Z., Bury, 1814. Richd., Pateley Bridge, 1837. 'Thos., Knaresboro', 1837.

Soar, Jas., 5 Paradise St., Finsbury, 1842.

Socteryk, Daniel, Dortrecht ; the Comte de Lambilly has a watch by him with outer case shased by Cochin.

Soffleur, Thos., London, 1680.

Sogden, T., Chichester ; long-case clock, about 1800 .

Solians, -, Paris ; clock, Windsor Castle, about 1790.

Sollinger, Jacob, Vienna, 1760 ; afterwards at Paris; complicated clock with dancing figures, \&c.

Solomon. Hy., Coventry St., 1775. S. C., 13 St. Mary Axe, 1794-1804. Edwd., Margate ; watch, 1799. Moses, King St., 1810 ; Bevis Marks, 1820 ; Great Alie St., 1830. Henry, 46 Duke St., Aldgate, 1835. Henry, \& Co., 31 Houndsditch, 1840-42. P., 26 Mansell St., 1840-42. J., 24 Great Prescot St., 1842. Simon, Bristol, 1843.

Somersall. Mandeville, Fore St. ; C.C., lantern clock, about 1685. John, Cripplegate Church, C.C. 1708. George, Leadenhall St., 1750 ; Finsbury, Moorfields, 1779. Richard, Finsbury Pl., Moorfields, 17761804 ; livery C.C. 1786.

Somillier, Jno., apprenticed 1649 to Luke Richards, C.C.

Sommerson, G., Minories ; lantern clock with Turkish numerals about 1710.

Somner, Jno., apprenticed 1663 to Wm. Raines, C.C.

Sones, Thos., watch-case maker, 6 Lillypot Alley, 1790-94.
Sonley, J., Dunlop, 1770.

Sonnereau à Rochelle ; French octagonal watch, about 1640, S.K.M. ; another is in the Garnier collection.

Soret. Pierre, watch in enamelled case, about 1620. Abraham, Dublin; about 1750. Isaac et Fils, Geneva ; watch, 1765. Jean Robert, Geneva; watch with representations of hammermen striking on bells, G.M., about 1780 .

Soubeyran à Geneva; watch, 1760 .

Sourden, -, Paris, 1699.

South. Joseph, C.C. 1709. Henry, Rotherham, 1710.

Southan. Saml., 28 Red Lion St., 179094. Geo., London; rack lever watch, about 1810 .

Southcote, Josiah, apprenticed C.C. 1681.

Southern, Jno., apprenticed C.C. 1681.

Southwarth, John, C.C. 1689.

Southwood, Sam., apprenticed 1662 to Chas. Fox, C.C.

Southwark, Thos., apprenticed 1677 to Barlow Brookes, C.C.

Southworth, Peter, C.C. 1664.

Souza, Samuel, Philadelphia, 1819.

Sowerby. Jas., London ; long-case clock, lacquer decoration, about $1760, \mathrm{Mr}$. Wm. Bolton. Jno., 100 Brick Lane 1817; 79 Chiswell St., 1830. Thos., 124 Long Acre, 1830.

Sowter, John, admitted C.C. 1683.

Spaldin, Wm., Liverpool ; watch, 1784.

Sparck, Peter, Philadelphia, 1797.

Sparkes, Nicholas, presented C.C. with a piece of plate in lieu of serving as steward, 1659.

Sparks. Thos., London ; apprenticed 1689 to Jno. Drew ; watch, 1732. Angel, Plymouth, about 1760 .

Sparrow. Thos., 113 Leadenhall St., 1790-94. Jno., 15 Leicester St., Leicester Sq., 1815-18.

Spaulding, Edward, Providence, U.S.A., 1788.

Speakman. William, apprenticed 1654 ; C.C. 1661 ; master 1701. Thomas, C.C. 1685 ; Mr. J. Hall has a long-case clock by him dating from about 1710. Edward, C.C. 1691. Jno., apprenticed 1692 to Wm. Speakman. Richd., apprenticed 1692 to E. Micklewright. John, junr., C.C. 1706.

Spear, Jacob, musical clockmaker, 39 Myddelton St., 1835.

Speedwell, London ; bracket clock, red lacquer case, about 1760.

Speight, James, Tong, 1785.

Spence. John, London ; in the B.M. is a silver watch by him, silver dial, matted ground with Roman hour numerals engraved on polished lozenge-shaped plaques, day of the month shown on outer circle, glass over dial ; 1650-70. —, Dublin : watch, 1750 . 
Spencer. Thomas, Strand, threatened with prosecution by C.C. for undue taking of apprentices, 1682 ; C.C. 1685 ; longcase clock, with fine Dutch marquetry, 10 -in. dial, inscription at bottom, "Thos. Spencer, Londini, fecit," about 1695, Mr. E. E. Cook. Richard, Dublin, watch, 1725 . Evan Roberts collection. Arthur, C.C. 1732. Jno., Colne, 1770. \& Perkins, 44 Snow Hill, 1775-94. W., London ; watch, 1785. Eli., Bolton-le-Moors, 1818. J., 20 Red Lion St., Clerkenwell, 1820-30. Thos., Manchester, 1820. Wooster \& Co., Salem Bridge, U.S.A., 1828-37.

Spendlove, Jno., Thetford, 1775-90.

Spiegalhalter, G., musical clockmaker, 6 Mount Place, Whitechapel, 1835-42.

Spilsbury, Jas., London ; watch, 1758. Spink, Marshall, 1 and 2 Gracechurch St., 1772 ; afterwards Spink \& Son, 17721842.

Spittal, Jas., Whitehaven, 1833.

Spittle, Richard, admitted C.C. 1699 ; tall walnut long-case clock, brass dial with arch riveted on, containing Father Time on wing, with the words, " Tempus fugit," 1699-1720.

Spitz, Gaspar, Schwartz ; clock, square case, filigree covers over the dials, Vienna

Treasury, about 1590.

Spratnell, Sam., Cockspur St., 1793.

Sprigg, Hy., apprenticed 1637 to Simon Bartram, C.C.

Springer, Sam., clock, about 1810.

Springfield, T. 0., Norwich ; long marquetry case clock, about 1770 .

Springhall, see Masterman.

Sprogell, John, Philadelphia, 1791.

Spur, Geo., Aylesbury ; lantern clock, about 1710.

Spurgin, Jere., Colchester, 1770.

Spurrier, John, admitted C.C. 1684.

Spyer, J., \& Solomon, 26 Prescot St., 1793-1804; 20 Leman St., 1825.

Stacey. John, C.C. 1683. William, Fleet St.; bell-top mahogany case bracket clock, about 1750; livery C.C. 1766 . Thos., Farnsfield, Notts., 1759, afterwards at Southwell.

Stach, Heinrich, Hanover; watch, 1800.

Stafford. John, C.C. 1708, master 1741. T., Chelsea, 1810-20.

Stainsburgh, Robert, Chippenham. " A silver watch with a black Fish-Skin case, studded with silver, Robert Stainsburg, Chippenham, engraven on the Dial Plate" (Lond. Gaz., Aug. 29, Sept. 1, 1698).

Stainton, Matthew, 1 Aldermanbury, 1772.

Stallard, Philip, 3 New Sq., Shoe Lane, 1793.

Stamford, Richd., apprenticed 1652 to Peter Willerme, C.C.
Stamp, Jas., 86 Cheapside ; livery Goldsmiths' Company, 1775, see Sutton \& Son, also Godbehere.

Stamper, Francis, at " ye Golden Ball in Lumbarde Streete," a good maker; C.C. 1682 ; in 1687 ordered by the C.C. to be prosecuted for refusing to admit to his workroom master and wardens when they were upon a search, but he submitted himself to the court, and was fined 20 s. ; maker of a clock with square dial on a lantern movement ; watch by him, S.K.M., 1682-1700. John, 148 Fleet St., 1772.

Stanbury. Henry, C.C. 1709; 30-hour long-case clock, 1709-20. Thos., Hereford, 1780. Wm., Bath, 1835.

Stancliffe, Jno., Askrigg, 1775-90. $\mathrm{He}$ was apprenticed to C. Caygill. Long-case clock by him with the inscription, "Time stayeth not."

Standish, William, apprenticed to Jeffery Baily; C.C. 1688.

Standring. Jas., Rochdale, 1770-92. Jere., Bolton, 1790.

Stanes, Jeffery, C.C. 1686.

Stanford, Wm., South Walsham, 1780 .

Stanger, Hugh, 46 Old St. Rd., 1835-40.

Stanley, John, C.C. 1732 . Mr. A. H. Turnbull has a long-case clock signed " J. Stanly, N ${ }^{\text {th }}$ Shields."

Stanton. (or Staunton) Edward, Leadenhall St.; apprenticed 1655 to Francis Bowen ; C.C. 1662 ; master 1696 ; bracket clock, three trains, ebony case, Wetherfield collection (see p. 566); Mr. T. W. Bourne owns a long-case clock by him. "A new Gold Clock-Watch graved with a cypher, on the back Edward Staunton, maker" (Lond. Gaz., Nov. 16-19, 1696). Sam., apprenticed 1692 to Thos. Fletcher, C.C. John, C.C. 1692 . Joseph, C.C. 1703 . Samuel, London ; maker of lan tern clocks ; C.C. 1714 . Job., New York, 1810.

Staples. Richd., apprenticed 1684 to Henry Jones, C.C. Jas., Oldham ; watch, 1780. Jas., 7 Rosoman St., Clerkenwell, 1788-94.

Stapleton. Thomas, C.C. 1694 ; watch, about 1700 . W., London; watch, silver dial, about 1730. Stephen, Sutton ; watch, 1750 ; another, rather, earlier, "Stephen Staplets, Sutton."

Staptoe, William, Charing Cross, admitted C.C. 1703; 1703-1710, see Stepto.

Starey, John, 4 Sweeting's Alley, Cornhill ; 1770-94; C.C. 1785 ; livery 1787 ; long-case clock, Mr. W. C. Woollard.

Starkey, Joseph, C.C. 1706.

Starnill, Jas., C.C. about 1660.

Starr, Robt., C.C. 1667.

Startridge, Roger, Gravesend ; clock, about 1750 . 
Statter, Richd. D., wrote a pamphlet on the advantage of a decimal division of the hour; watch on this plan, G.M., is inscribed "Richd. Dover Statter and Thos. Statter, Liverpool, No. 1," h.m., 1862.

Stauffer. Robert, Son \& Co., 43 Skinner St., Snow Hill, 1830-42. Julius, 43 Skinner St., $1830-42$.

Staunton, see Stanton.

Stayne, Thomas, ¿.C. 1654 .

Stead. Thos., apprenticed 1668 to Jno. Webb; C.C. 1678. Jno., Fetter Lane, C.C. 1730 . Jno., apprenticed to David Hubert; C.C. 1747.

Steadman \& Varden, London ; balloon clock, about 1780 .

Steath, Thos., apprenticed 1683 to Jno. Wheeler, C.C.

Steber, J. N., Dover; watch, 1789.

Stedman, Richd., Godalming, 1780. J., Red Lion St., 1790.

Steele. Wm., Milecross; watch, 1819. F., 71 Oxford St., 1825-33.

Steers, Jno., 9 Pall Mall, 1793.

Stegar, John, C.C. 1699.

Steibel (or Stebbell), Christopher, Augsburg; striking clock with minute hand, also square clock with cupola by him, Vienna Treasury, 1635-60. 1752.

Steil, Jno., Edinburgh; watch, h.m.,

Stein, Abraham, Philadelphia, 1797.

Steinmann, Daniel, 29 North Audley St., 1840-42.

Stem, Richard, London ; watch, 1760.

Stennett, Robt., 7 Bartlett St., Bath, 1790-1800.

Stephens. Francis, C.C. 1632. Edwd., apprenticed 1693 to Jonathan Jones. Thos., apprenticed 1693 to Jno. Marshall. Joseph, Whitechapel, C.C. 1721; master 1752. Philip, Minories, C.C. 1730. Joseph, 32 Aldgate; master C.C. 1776. John, "nephew and successor to the late Mr. Dudds, 6 Coleman St.," 1780. Thomas, 93 Strand, 1823.

Stephenson. Benjamin, 5 Ludgate Hill, 1774-77. William, 27 Lombard St., 1793, see Stevenson \& Farrow. Geo., London; watch, 1797. Thos. Sam., Hoxton ; livery C.C. 1810 . D. W., 27 Lombard St., 1820 30. Jno., Leeds, 1830.

Stepto, Wm., St. Giles' ; arabesque marquetry long-case clock, about 1705 .

Sterck, William, Portugal St., Lincoln's Inn, $1760-68 ; 16$ Poland St., 1793.

Sterk, William, Cockspur St., 1772-90.

Sterland, Jno., Nottingham, 1770.

Sterling, Josh., London ; watch, 1791.

Stern, Francis, Charleston, U.S.A. 1840 .

Steuart, James, 8 Green St., Leicester Sq., 1790 ,
Stevens. Daniel, C.C. 1661. Giles, apprenticed 1671 to Robt. Wilkins, C.C. George, C.C. 1673 . Samuel, Grub St., C.C. 1680 ; threatened in 1682 with prosecution by C.C. for undue taking of apprentices. John, apprenticed 1684 to Jno. Wynne; C.C. 1691 ; lantern clock, about 1710 , signed " John Stevens, Colchester." Ralph, apprenticed 1687 to Richd. Warren. Thomas, C.C. 1700 . Nathaniel, C.C. 1702. Samuel, C.C. 1706 ; square-dial lantern clock, cherub corners inscribed "Sam Stevens, Londini, fecit," on circle ; 170618. Richard, C.C. 1715 . Joseph, 32 Aldgate Without ; master C.C. 1752 and 1756 ; 1745-94. Samuel, " 20 Princes St., nere Spittlefields Church," card, Ponsonby collection, about 1780 ; 26 Whitechapel, 1790-93. W., Cirencester, 1795. W., 31 Ironmonger Lane, Old St., 1835. Ezek., 49 King Terrace, New North Rd., 1840-42. William, junr., 11 Ironmonger St., 1840 42. William, 14 Bartholomew Sq., St. Luke's, 1840-42. D., Gloster St., Hoxton, 1842. Edwd., 24 King Sq., 1860-85.

Stevenson. -, Penrith, 1730. Dublin ; centre seconds clock-watch, about 1760. John, Stafford, 1770 . Adam, livery C.C. 1786. \& Farrow, 27 Lombard St., 1810-24. J., Bethnal Green Rd., 1835.

Stever \& Bryant, Whigville, U.S.A., 1830. Steward. Jno., 99 Wood St., 1793. Henry, York, f., 1816, died 1870.

Stewart. James, London ; eight-day striking bracket clock with mechanical figures in arch of dial, about 1760. Joesph, 61 Red Lion St., 1842.

Stiebel, B., 5 Chandos St., 1823.

Stiff, Wm., apprenticed 1676 to Simon Chapman, C.C.

Stileman, Jno., C.C. 1640.

Stiles. John, C.C. 1704. Nathaniel, Wood St., C.C. 1725, master 1751 ; 172570. Richard, probably son of the above ; master C.C. 1790 ; 1770-90. William, 28 Tottenham Court Rd., 1835.

Still, Francis, C.C. 1699.

Stillard, George, London; watch, 1815. Stillas, John, Philadelphia, 1785-93.

Stilletto, Sam., apprenticed to Jno. Spurrier, 1686, C.C.

Stillman, William, Burlington, U.S.A., 1789-95.

Stimner, Richd., Roe Buck Court, Chiswell St., 1780.

Stimson. -, London ; bracket clock, engraved plate, knife suspension, about 1710. H., Sleaford, Lincolnshire, 1780.

Stirling, John, 38 Abchurch Lane, 1788.

Stirrup, Thomas, published " Horometer; or, Complete Dialist," 1652.

Stock, Jabez, Whitechapel ; long black narrow-case clock, with Japanese decoration down the front, and a small circular 
glass in the door, about 1700 ; in the panel the following:-

$$
\begin{aligned}
& \text { "I labour here with all my might, } \\
& \text { To tell the time by day and night; } \\
& \text { In thy devotion copy me, } \\
& \text { And serve thy God as I serve thee." }
\end{aligned}
$$

Stockall. J. J. (Stockall Marples \& Co.), Clerkenwell Rd., died 1918, aged 82.

Stockar, Henry, London ; marquetry long-case clock, about 1700, Mr. Alfred Marks ; Mr. Geo. E. H. Abbot, Groton, Mass., U.S.A., has a long-case clock by him, dating from about 1725 . It formerly belonged to Edward Holyoke, President of Havard College, who died in 1769.

Stockell, Hugh, Newcastle; watch, 1765, signed " Hugh Stokell, Newcastle," 1765-1800 (see p. 526).

Stockler, T., Bolney ; bracket clock, about 1730 .

Stockton, Francis, Yarm, 1820-27.

Stockwell, Hy., Bell's Buildings, 1793.

Stoddart. Robert, 61 Red Lion St., Clerkenwell, 1815-42. James, 13 Red Lion St., 1825-42 ; died at Hastings, 1886, aged 80 . J., 7 Charles St., Northampton Sq., $1835-40$.

Stogden (Stockten), Matthew, worked for Graham; invented improved repeating motion about 1712 (see p. 618); admitted C.C. 1717 ; died in abject poverty, at an advanced age, in 1770 .

Stokel, John, New York, 1820-43.

Stokes, Henry, Turnmill St., Clerkenwell ; bequeathed his best clock to Robert Stokes, 1586. Sam., London; long-case clock, about 1695. Jno., Bewdley, 1760.

Stollewerck à Paris; clock in ormolu case, Jones collection, S.K.M., about 1740 ; two clocks, Wallace collection; a handsome regulator, signed " Alexandre Fortier invenit, Stollewerck fecit à Paris," finely chased gilt mounts, about 1740 ; also a cartel clock, signed " Stollewerck à Paris," about 1770; a clock by Stollewerck in ormolu case chased with masks and festoons and surmoun ted by a vase, fetched $£ 69$ at the Hamilton sale in 1882 .

Stone. Andrew, C.C. 1699. William, C.C. 1700 . Roger, C.C. 1710. Richd., Thame; watch, h.m., 1771. Francis, Bristol, 1790. Chas., Liverpool ; watch, 1798. Samuel, 8 London Rd., 1820. David, Hull, 1822. John, " at the Dial in Aylesbury," 1760-75. J., Aylesbury, 1822-30.

Stonehouse. Richard, Whitby, 1715-65 ; 30-hour long-case clock, Dr. Wm. A. Day. Robt. \& Jno., Leeds, 1829.

Stones. Simon, Sheffield ; made a clock for Marston Church in 1654. Thomas, Lothbury, C.C. 1692, master 1730; small striking and alarm long-case clock, dial 6 in. square, about 1695 , Mr. Hubert Bates; watch, 1735.
Stookes, J., London ; watch, Dutch style, Schloss collection, about 1765 ; another, about 1780 .

Stopforth, Edwd., apprenticed 1691 to $\mathrm{Hy}$. Merriman.

Stoppes, Aylmer, London ; long-case clock, about 1740 ; on another clock, oak long case, the inscription, "Elias Ayl ${ }^{\mathrm{r}}$ Stopes, London."

Store, Jno., Chester, clock, about 1790.

Storer. Robert, born 1721; started business at 11 Berkeley Court, Clerkenwell, about 1743. Robert and James Storer, his sons, at the same address, 1768 ; James retired ; Robt. Storer \& Son, 1788 ; Robert Storer, the elder partner, who was grandson of the first-named Robert, retired to Olney, Bucks, in 1820, and died in 1832, aged 86 ; Robert \& Walter Storer, 1822 . Walter, who was great-grandson of the first-named Robert, retired about 1840 , closing a business carried on at the same address for nearly a century, and died at Olney in 1865, aged 65. Egbert, cousin of Walter Storer, an excellent watchmaker, was apprenticed to Henry Dashper, and resided for some time at 46 Myddelton Sq. ; he went to Switzerland in 1871, returned to London in 1892 ; died 1897 , aged 86 .

Storey. James, C.C. 1703, see Story. Jas. Charles, Sidney Alley, Leicester Fields, 1758-60 ; 1 Poultry, 1743. J., 176 Regent St., 1830.

Storie, W., 8 Warwick St., Charing Cross; card, Hodgkin collection, about 1810.

Storr. ( $\&$ Gibbs, London ; watch, 1745). Marmaduke, 20 Lombard St., 1760-74. Jonathan, York, 1765-80. William, Jermyn St., 1765 ; 44 St. James's St., 1779-94; hon. f. C.C. 1781. \& Mortimer, 13 New Bond St., 1830-42.

Storrs, Joshua, Cheapside, 1835-42.

Story. Jas., London ; long-case clock, scroll marquetry case, about 1710 . Samuel; clock, long red lacquer case. similar to Fig. 723. Rev. J. W. R. Brocklebank. William, Red Lion St., Clerkenwell, 1760-72. Hy., 7 Charterhouse Lane, 1820. Wm. Thos., Dewsbury (also at Halifax and Barrow-in-Furness), died 1912 , aged 74 . In 1889 he patented (No. 13,793 ) a method of showing, on a clock with regulating. square through the dial, the amount of movement required for a certain change of rate.

Stothard, Benj., Sou th Cave, Yorks., 1822.

Stowell, John, Medford, Mass., 1815-25 ; Boston, 1825-36.

Stracey, John, 34 Prince's St., Lothbury, 1790.

Strachan. Andrew, a Scotsman; to avoid prosecution for practising his art 
in the city of London he bound himself apprentice to Thomas Warden; the Chamberlain ordered the indenture to be cancelled, as Strachan was between thirty and forty years old, 1691 ; long-case clock, A. Strachan, Newcastle about 1730 . Archibald, Newcastle ; watch, about 1775 ; clock, Arch. Strachan, Tanfield, about 1790. A. \& J., 125 Long Acre, 1830. See M'Cabe, and also Murray.

Strahan, Jno., London ; long-case clock, about 1780 .

Straiton. Archibald (or Straton), Edinburgh, about 1780. Alexander, a clever watchmaker ; apprenticed to Reid \& Auld, St. Martin's Lane, 1820 ; 146 Leadenhall St., 1825 ; 15 Little Knightrider St., 1842 ; died 1873, aged 83 .

Stram, Alfred, Ashby St., Clerkenwell : born in Switzerland; died 1893, aged 80. An excellent watch-case maker, who succeeded Comtesse.

Strange, Thos., Kingston ; watch, 1799. Stratford. George, C.C. 1704. Jas., London; enamelled watch, about 1790 .

Stratton. Richard, C.C. 1720. Joseph, Church St., Hackney, 1810-35. Jno., 133 Bunhill Row, 1816-25. Of U.S.A. : N. P., born 1836, apprenticed to J. F. Pitkin, associated with $\mathrm{Hy}$. Pitkin at East Hartford; afterwards joined the American Watch Company, and presided over its first London office in 1874; died 1888.

Strebell, Christopher ; watch, Vienna Treasury, oval case, of brass gilt, about 1625.

Strech, Peter, Philadelphia, 1750-80.

Street. Long-case month clock by " John Street Londres," which he presented about 1685 to his friend Abraham Martin, an engraver; Martin was made free of the C.C. in 1682. Geo., apprenticed to Roger Nicholls 1687, C.C. Richard, Shoe Lane; C.C. 1687, warden 1715; maker of a clock costing $£ 50$, which was presented by Sir Isaac Newton to Dr. Bentley, Master of Trinity College, Cambridge, in 1708; long clock, 12-in. dial, walnut case, Wetherfield collection, about 1710 ; Mr. John Lowe had a clock by him in which the hour band was shaped like a heart, the tip of the hand being caused to move in a corresponding path; watch, 1784, signed, "Richard Street, Kepples, Surrey."

Streeter, Gilbert L., Salem, 1846.

Streller, Jacob, Nuremberg; clock, Green Vaulted Chambers, Dresden, about 1700.

Strelly, Francis, C.C. 1665.

Stretch. Sam., Birmingham ; watch, h.m., 1712. Jas., Birmingham; watch, S.K.M., about 1740. Benj., Bristol ; quarter repeating watch, about 1750 . Samuel, High St., Birmingham, 1770.
Stretche, Samuel, Leke (Leek) ; lantern clock, about 1670 .

Stretton, Sarah, C.C. 1710.

Stribling, Benjamin, Stowmarket ; lantern clocks, about 1700 .

Strigel. William F., St. James's St., 1760-75. George Philip, Stafford Row near Buckingham Gate $1760-88$; hon. f. C.C. 1781. Jno. C., 1790.

Strigell, Johan, Christopher Kreilsheim ; handless watch, silver pair cases, Schloss collection, about 1700 .

Strigner, - . In the B.M. is a watch by him in an outer case of carnelian. It was made for James II., and by him given to his daughter Catherine, Countess of Anglesey and Duchess of Buckingham, about 1687.

Stringer, Josiah, Stockport, 1742-50.

Stringfellow, Jno., London ; C.C. 1691; lantern clock, about 1698.

Stripling. Thos., Barwell, about 1700 ; Mr. Harry Clark has a long-case clock by him (see p. 543). Thos., Litchfield; watch, 1816.

Strixner, -, London ; watch, Evan Roberts collection, about 1745.

Strong, T., London ; watch, 1823.

Strongfellow, see Stringfellow.

Stroud. Robt., London; watch, 1822. Elizabeth, 5 Henry St., Pentonville, 183540.

Struggle, Christopher, apprenticed 1671 to Isaac Puzzy, C.C.

Strutt, J. D., London ; watch, 1790.

Stuart, Bernard (Scotsman) ; born 1706, died 1755; clock, Imperial collection, Vienna, 1735.

Stubb, Thos., London ; long-case clock, about 1690 .

Stubbs. Gabriel, C.C. 1675 ; “ a small clockmaker" (watchmaker) and a celebrated member of the Company ; 1675-77. Thos., C.C. 1685. Nathaniel, son of Jno.; " clock-maker, of St. Andrew, Holborne," bound to Job Worail, citizen and cutler, 1719. \& Co., London; on watch movement, about 1760; on dial, Leyden, London. Joseph, 241 Holborn, 1793. J., Prince's St., Leicester Sq., 1830 ; 28 Panton St., Haymarket, 1830; gold chronometer half-quarter repeater, gold dial, raised numerals, 1819.

Studley, David, Hanover, U.S.A., 1806-35.

Stuk, William, Cockspur St., 1781.

Stumbels, B., London ; watch, about 1760 ;

Style. Nathaniel, Wood St. ; C.C. 1725 ; master 1751 ; livery 1766 ; long-case clock, about 1750, signed "Nathaniel Styles, London." Richard, 3 Carey Lane, Foster Lane; livery C.C. 1766; master 1790; 1764-96. H. F., Bath, died 1912.

Sudbury, John, C.C. 1686. 
Sudell, Jno., apprenticed 1683 to Ben. Bell, C.C.

Sudlow, Benj., Yarmouth ; watch, about 1780 ; monogram, " J.D.C.," on balancecock.

Suggate, Geo., Halesworth ; lantern and 30 -hour long-case clocks, about 1700 ; watch, same name and address, 1781.

Sully. Henry, born in 1680, apprenticed to Charles Gretton, C.C. 1704 ; an eminent man who settled in France ; died 1728 (see p. 339). Wm., Langport, 1843.

Sulman, see Hopgood.

Sumer, Jno., C.C. 1634.

Summer. William, C.C. 1662. Francis, 26 Greek St., Soho, 1790-94.

Summerhayes, Robert, Ilminster, afterwards at Taunton; died 1857.

Summers, Chas., London; watch, Schloss collection, case beautifully enamelled, about 1785 .

Supple, John, Vigo Lane, Picadilly, 1783.

Sutherland. D., Leith ; clock, belonging to Mr. Wm. Collie, Manitoba, with moving figures representing Adam and Eve in the Garden of Eden, apparently abcut 1775. Thos., 2 Vigo Lane, 1793.

Sutor, Wm., Edinburgh, 1712.

Sutton. Jno., apprenticed 1661 to Ed. Norris, C.C. Isaac, C.C. 1662 ; to him in 1664 was apprenticed Joseph Aberley. Thos., Maidstone, 1760. Wm., Liverpool, 1770. Wm., \& Co., 85 Cheapside, 1790-93; card, Ponsonby collection, " successors to Mr. Stamp." Robert, Whitehaven, 1840.

Swain, -, London; watch, 1832.

Swale, Jaques (alien), threatened with prosecution for working as clockmaker in liberties of C.C. 1668.

Swan. Edwd., apprenticed 1650 to Ralph Ash, C.C. Wm., apprenticed 1692 to Thos. Tompion ; C.C. 1703. Robt., Bridlington, 1770. Benjamin, Haverhill, Mass, . 1810-40.

Swannell \& Co., Staples Inn, Holborn, 1790-94.

Swannick, G., 38 Banner St., 1820.

Swanson, Robert, C.C. 1730.

Swearer \& Sons, wooden clockmakers, 7 Upper East Smithfield, 1820. J., 30 Park Terrace, Regent's Park, 1840-42.

Sweeby, John, C.C. 1671; fine long inlaid-case clock, about 1700 .

Sweman. - , London ; watch, probably Dutch, about 1730 . William, 5 Banner St., 1790.

Swetman, Thos., London ; 1735-65 ; Mr. Edwin Bradnam has a watch marked "Swettman, London," h.m., 1738; another engraved "Swetman, London," repoussé case with enamelled centre, Schloss collection, about 1760 .

Swift. M., 68 Red Lion St., Clerkenwell, 1793. Thomas, Essex St., Islington, lever pallet maker, 1825-67.
Swinburn, Jno., Bishop Auckland, 1775;

Sunderland, 1785.

Swindells. Jno., Macclesfield, 1792-1825. Jasper, watch-case maker, Salmon and Ball Court, Bunhill Row, 1800-13.

Swinden, Francis Charles, born in Brentford, settled in Birmingham; at Bath St., 1824 ; 91 New St., 1825; afterwards at Temple St.

Swingler, Jas., Holbeach ; watch, 1802.

Swinton, George, water clock, 1661.

Sword \& Sons, Cornhill, 1838.

Sydenham. H. \& J., 126 New Bond St., 1800-4. J., 126 Bond St., 1816-23.

Syderman, Philip, Philadelphia, 1785. Sykes. W., Holbeck, 1790. Geo., Malton, 1823.

Sylvester, John, C.C. 1693.

Symes, Robt., London; long-case clock, about 1800 .

Symms, Isaac, Aldgate, about 1600 ; watch, Pierpont Morgan collection, signed

"Isaac Symmes at Aldgette," about 1620.

Symonds. Richd., apprenticed 1668 to Fras. Strelly; C C 1691 Thomas, 57 Cheapside, 1770-75; 20 Fleet St., 1755-88.

Joseph \& Co., Liverpool, 1780.

Symons, Moses, Hull, 1822.

Taber, Thos., 29 Compton St., Clerkenwell, 1825.

Tackley, C., London ; watch, 1826.

Taf, John James, Philadelphia, 1794.

Tailour, Edward, clockmaker, admitted to Blacksmith's Company, 1629.

Talbot, Thomas, lantern clock, about 1675, Mr. Arthur R. Hinks.

Tallans, Gabriel, about 1720.

Tallibart, Louis, 48 Rathbone Pl., 1842.

Tallis, Aaron, C.C. 1722.

Tallon, -, Paris; watch, 1720.

Tanner. Joseph, C.C. $1682 . \quad$ - clock engraver and varnisher, Fleet Market, 1790-94.

Tanqueray, James, London, 1770-80. Tansley, Thos., Birmingham, 1818.

Tantum. Bracket clock, about 1700 , inscribed " Dan. Tantum, in Derby, fecit."

Tapp. Geo., apprenticed 1691 to Sam. Bowtell, C.C. Francis, 85 Strand, 1775-85.

Tappy, Abraham, watch, 1778, "Abe Tappy, Totveeren;" bracket timepiece, small movement in large mahogany case, about 1790.

Taquet, -, watch, 1790.

Tarbuck. 'Robt., apprenticed 1686 to Thos. Stubbs, C.C. John, St. Mary's Gate, Manchester, died 1739.

Tarles, Jno., C.C. 1690.

Tarleton. Jere., apprenticed 1690 to Walter Henshaw, C.C. Richd., Liverpool, 1760. Wm., Liverpool, 1770-95; he made good watches and did much to advance the 
reputation of Liverpool as a manufacturing centre.

Tarman, J. B., 34 Regent St., Piccadilly, 1825.

Tartover, Stephen, Bristol, 1844.

Tarts, J., London ; watches for the Dutch market, 1755-90.

Tasker, -, Folkingham; long-case clock, about 1780 .

Tate. Ruth, East Sheen ; oak long-case clock, about 1790 . Thos., Winterton ; succeeded Wm. Godfrey; died 1821.

Tatum, Jno., 53 Dorset St., Salisbury Sq., 1817.

Tavan, Antoine, born at Aost, France, 1742, died at Geneva, 1836. An excellent watchmaker who wrote an analysis of various escapements.

Tavernier. Jean Pierre, Paris ; died 1793 Louis, eldest son of J. P.; born 1754, died 1840. Etienne, second son of J. P. ; an eminent watchmaker, born 1756, died 1839; in 1772 he, from the Rue de Bussy, advertised watches in rings, bracelets, tops of canes, and other small articles; his keys were particularly admired ; he constructed one to show the days of the week, the days of the month, the age and phases of the moon; adjusting the key to wind the watch actuated the mechanism concealed in the middle part of the key; this was a device for which a patent had been obtained in England by George Sanderson in 1762 .

Tawny, Pepe, watch, about 1700.

Tayler, Thos., lantern clock, see Taylor. Taylor. A well-known name among London watchmakers from 1640 till past the middle of the nineteenth century ; the two Thomas Taylors, who were active members of the C.C. during the seven teenth century, are distinguished as " of Holborn" and "of the Strand;" in 1676 Thomas Taylor, of Essex House Gate, is mentioned Edwd., apprenticed 1637 to Wm. Almond, C.C. Thomas, Strand ; apprenticed 1638 to Simon Hackett ; C.C. 1646, master 1668 ; watch, Pierpont Morgan collection, signed " Thos. Taylor, Londini," balance-cock pinned on, not later than 1650 . Geo., apprenticed 1648 to Ben. Hill, C.C. Richard, C.C. 1655 . Thos., Holborn; C.C. about 1660. Abraham, C.C. 1668. Thomas, Holborn, at the end of Fetter Lane, apprenticed 1678 to Thos. Taylor, Holborn; C.C. 1685 , master 1710 ; fine pair-case repouseé repeating watch, gold dial. " Lost between Pickadilly and St. James Street, a gold watch made fast in a gold studded case, with high pins at each hour; made by $\mathrm{Mr}$. Taylor, at the Upper End of Fetter Lane, in Holborn. Whoever brings it to Mr. Harrison, Goldsmith, etc., the Three Flower-de-Luces, in the Strand, shall have a guinea reward" (Lond. Gaz., 9-12, 1692). William, apprenticed to John Wright and turned over to Isaac Webb; C.C. 1682. Jasper, in Gray's Inn, apprenticed 1685 to Thos. Taylor; C.C. 1694; pair-case copper verge watch, outside case of leather, with many small rivets, lockspring projecting through the dial, inscription, "Jasper Taylor, in Holbourn." John. C.C. 1687; two clocks by him seen at Moscow ; one in large mahogany case, silvered dial, verge escapement, chimed on eight bells and played a tune. Jon., Ormskirk; long-case clock, about 1690. Rob., apprenticed 1693 to Jas. Hatchman, C.C. John, C.C. 1702 . George, C.C. 1703 ; to him and his wife Lucy, Rebecca Fisher was apprenticed in 1715. Geo., Liverpool, about 1720. Charles, C.C. 1723. Richard, C.C. 1724. Jasper, of Barnard's Inn, admitted C.C. 1729; took an active part in the affairs of the Company; was master in 1754 , and clerk from 1760 to 1770 when he died, leaving $£ 10$ to C.C. for the poor. John, Bath, 1770. James, Ashtonunder-Lyne ; in $\mathbf{1 7 5 4}$ he took out a patent for spinning; in 1769 one for raising weights; died 1813 , aged 89 . Henry, London; watch, 1760. Jno., Petworth; watch, 1762. Jno., Lancaster, 1772, f. Samuel, Maiden Lane, Wood St., 1774; livery Goldsmiths' Company; afterwards at 10 Ball Alley, Lombard St. ; master C.C. 1807 ; 1774-1810. Wm., Whitehaven, 1775. Benj., Ball Alley, Cornhill, 1793 ; 45 Lombard St., 1798-1800. \& Son, Bristol; watch, 1797. Samuel, Philadelphia, 1799. Samuel, London; watch, about 1800 . John S., 8 Wilderness Row, 1809-40. Edward, livery C.C. 1810 ; in the B.M. is a curious watch of his, with symbolical figures and texts of Scripture in the enamel on the dial and case, 1800-30. Wm., Dumfries, 1817. J. \& S., Liverpool, 1818. Edward, 25 Leadenhall St., 182225. Kennard \& Co., 3 Crescent, Jewin St., 1822-30. Joseph, 2 Bouverie St., 1825. Jas., 3 Corporation Lane, 1835. Robert, 47 William St., Regent St., 1835. Charles, 62 John St., Fitzroy Sq., 1840. \& Son, Bristol, 1843. David, 27 Northampton Sq., 1842; between 1850 and 1864 he did a large trade with the American market. Andrew, a watchmaker of exceptional ability, born in Clerkenwell; patented a tourbillon carriage for watch escapements in 1902 ; died 1910 aged 51 .

Teams, John, 25 Red Cross Sq., 1790-94.

Tearson, Stephen, Ipswich; watch, about 1700 .

Tebbatt, Benoni (or Benomi), Little Old Bailey ; apprenticed to Robt. Doore 1676 ; C.C. 1683 . C.C. in 1688 seized at his shop a gold watch-case, both for that it was of 
coarse and unwarrantable gold, and also so extremely thin that it was insufficient in strength. William Brafield who made the case, admitted his fault, and was fined 5 s., the case being broken up.

Telforth, Isaac, London ; watch, 1765.

Tempest, Hy., apprenticed 1638 to Robt. Grinkin, C.C.

Temple, Thomas, C.C. 1720. J., London ; watch, 1780 ; another, 1800.

Templer, Charles, C.C. 1673.

Tenant, Leonard, paid $£ 37$ for a new clock and chimes for St. Margaret's Church,

IVestminster, 1617.

Tennant, Thomas, C.C. 1668 .

Terold, Henry, Ipswich; round silver watch-case with interlacing bands, silver dial, Fellows collection, about 1640.

Terrey, Jas., London ; long-case clock, about 1770 .

Terrier. James, C.C. 1694. Thomas, C.C. 1694 - - Paris ; clock-watch, Pierpont Morgan collection; numerals on porcelain enamel plaques; single brass case covered with leather piqué, 1700. Mary, C.C. 1713.

Terrot. Philippe, Geneva; 1740-50 ; watch in silver case, shaped like a cockle shell, G.M. \& Thuillier, Geneva, 1760-76. Ph., \& Fazy, Geneva ; watch, 1770 ; watch, "Ph. Terrot, Geneva," 1780.

Terroux l'aîné, Geneva, 1770-85.

Terry. Hy., apprenticed 1688 to Richd. Farmer, C.C. John, York, f., 1713 died 1783 ; in 1716 he made a turret clock for York Castle. - Thoralby, 1730. Jno., York, f., 1759 ; watch, 1770. Wm., Bedale; long-case clock, about 1770. Garnet, 54 Paternoster Row, 1785-93; clock-watch, silver embossed case, Schloss collection, probably by him, though apparently of rather an earlier date. Eli, Plymouth, Litchfield County, Connecticut, U.S.A. ; said to be the Sam Slick of Haliburton; patented an equation clock in 1797, and in 1816 patented the well-known type of cheap American shelf or mantel clock which became popular all over the world ; he died in 1853. - Richmond, Yorks., 1820-50. Leonard, York, f., 1822. Wm., Hull, 1822. Wm., Richmond, Yorks, 1822. Isaac, 15 King St., Clerkenwell, 1835; 35 Prince's St., Leicester Sq., 1842.

Terweer, Hy. ; watch, Dutch style, about 1750. 40.

Tesseyman, Geo., Northallerton, 1822-

Teulings, C., 15 Charing Cross, 1793.

Tew, Thos., apprentice; C.C. 1674.

Thacke. Robt., apprenticed 1681 to Jno. Benson, C.C. Philip, C.C. 1685 ; marquetry long-case clock, square dial, about 1770.

Thackray, Robert, York, f., 1832.
Thatcher, Geo., Cranbrook; watch, about 1760 .

Thead \& Pickett, Ludgate Hill, 1758-65, see Pickett \& Rundell.

Theodricke, Hy., apprenticed to Jno. Curtis 1679 , C.C.

Therasby (or Thoresby), Peter, York, f., 1666.

Theurer, Robert et Fils, Chaux-de-Fonds ; watch in the Paul M. Chamberlain collection, about 1860 .

Thierry, -, Caen ; watch, 1690.

Thillier, I. P., London ; watch, 1745.

Thiouist, Nicolas ; calendar clock, about 1730 .

Thiout. Antoine l'aîné ; born 1692, died 1767; Quai Lepelletier, Paris; inventor of many ingenious forms of repeating work, curious clocks, \&c., described in his " Traité d'Horlogerie," Paris, 1741; clockmaker to the Duke of Orleans, 1752 ; garde-visiteur in 1769 . le Jeune, Paris ; bracket clock, about 1780 .

Thitchener. W., 36 High St., Shadwell, 1835-40. J., 14 Maiden Lane, Covent Garden, 1835. Thomas, 18 High Row, Knightsbridge, 1840-42.

Thoermer. Adolf, London; a clever family of watchmakers, died 1892, aged 54. Fritz, died 1898, aged 24 . A. E., London, afterwards at C $\lrcorner$ ventry, died 1918, aged 42. Sons of Adolf.

Thomaque, Abraham, C.C. 1675. Isaac, silver repeating watch, about 1729 .

Thomas. Dan., apprenticed to Jno. Browne 1675 ; C.C. 1682 . Hugh, apprenticed 1686 to Richd. Ellis; C.C. Francis, Dublin ; watch, 1750 . M. \& Sons, Carnarvon; long-case clock, about 1780 Samuel, Keynsham, 1785. Sam., Nantwich, 1790. Thomas John, 55 St. James's St. ; verge watch movement, G.M.; another example, watch with cylinder escapement, 1790-1804. \& Evans, Staining Lane, 1793. Richard, 98 Strand, 1793-1804; 17 Bridgewater Sq., 1817. Jno., 153 New Bond St., 1810. Seth, Plymouth, Conn.; he learnt clockmaking of Eli Terry, whose business he (in conjunction with Silas Hoadley, another of Terry's workmen) acquired in 1810 ; died 1859. F. L. \& J. W., 153 New Bond St., 1821-30. Thomas, 314 Borough, 1825. \& Son, 3 Strand, 1825-30; Wm. Thomas, of 3 Strand, retired to Brompton, and died 1869, bequeathing $£ 200$ to the Watch and Clockmakers' Benevolent Institution. John, New Rd., St. George's East, 1835.

Thomasen, Ts., Amsterdam ; fine longcase clock, about 1760, Mr. Francis H. Bigelow.

Thomegay, Mark, Moorfields, 1760-8. Thomlinson, Geo., apprenticed 1669 to Thos. Bayley; C.C. 1678; lantern clock, 
about 1680 , inscribed " Geo. Thomlinson, in George Yard, in Lumbard Street, fecit."

Thompson. John, C.C. 1662. Rowland, apprenticed 1674 to Kath. Bestwick, widow. Geo., apprenticed 1676 to L. Sindrey, C.C. Robert, C.C. 1681. Jno., York, f., 1692. Isaac, C.C. 1699. William, apprenticed to Thos. Tompion; C.C. 1703; watch, 1725 ; in the Nelthropp collection is a watch, "William Thompson, Chester," date mark, 1703. John, C.C. 1720; large silver watch, 1759, inscribed " J. Thompson, London," in an outer case of fine English chasing, Pierpont Morgan collection. Hy., Bartholomew Close, C.C. 1730. Troughton, C.C. 1731. Thos., Lancaster, 1747, f. C., London, about 1760 ; pair-cased watch by him, outer case enamelled blue ; exhibited at the Guelph Exhibition by Mr. Geo. Carr Glyn. John, 10 Red Lion St., Clerkenwell, 1765-94. Ann \& Son, Red Lion St., Clerkenwell, 1790-94. James, Bride Lane, Fleet St., 1790-94. Jos., London; pretty balloon timepiece, Sheraton style, about 1790 (see p. 590). W., Skinner St., Clerkenwell, 1790. Joseph, Atherstone; clock, about 1800. Edward John, born 1815; apprenticed to Hugh McLachlan 1829, Wellington St., St. Luke's 1842; 5 Percival St., 1848 ; Goswell Rd., 1871 ; Aldersgate St., 1878 ; died 1896 ; he was a trustee of the Horological Institute, and twice master of the Clockmakers' Company. Thomas, \& Storrs, 16 Staining Lane, 1817. Ebenezer, 32 Exeter St., Sloane St., 1830-40; afterwards at 181 Sloane St.; died 1866. John, 19 Red Lion St., Clerkenwell, 1835; died 1847. Hy., London; watch, 1838 . William, 5 Great Tower St., 1844-02.

Thomson. Philip \& Son, 11 Exeter Court, Strand, 1769. James, Pittsburg, U.S.A., 1815. Adam, 25 New Bond St. : a very able man; published "Time and Timekeepers " in 1843; 1830-60; afterwards Thomson \& Profaze.

Thorelet, Jonas, London ; watch in plain silver case, dial with gold centre and large figures on white enamel ring, about 1720 . Pierpont Morgan collection; long-case clock, about 1746 .

Thorn, Thomas, 23 Wood St., Cheapside, 1758-75.

Thorndike, Sam., Ipswich, 1760-94.

Thorne. Sim., Tiverton, 1740. Simon, London; fine bracket clock, pull repeater on eight bells, about 1750. Robert, 12 Wood St., Cheapside, $1760-68$; repeating watch in gold repouseé case, with outer case of shagreen piqué, Pierpont Morgan collection. John, 56 Whitechapel, 17901818 ; John, \& Son, 56 Whitechapel, 1820. Wm., London ; clock, about 1800. James,
Limekiln Hill, Limehouse, 1835-42. John, 49 Rahere St., 1842.

Thornham, Geo., Hull, 1822.

Thornhill, Bryan, apprenticed 1683 to Thos. Bradford.

Thornton. Henry, C.C. 1699 ; long-case clock, playing six tunes, seen in Moscow; Mr. E. Alfred Jones mentions two large chiming clocks bearing his name, one in the Winter Palace at St. Petersburg, and the other in the Troitsa Monastery near Moscow. The collection of the Czar of Russia contained two watches by him; one, a repeater, has cases of gold, the inner bears the hall-mark for 1729-30, and the outer repouseé decoration representing St. Christophorus carrying the infant Jesus; it is suspended from a chatelaine. The other watch, also in gold cases and furnished with a chatelaine, is of about the same period. John, C.C. 1731. William, York, f., 1747. Jas., London ; watch, B.M., h.m., 1771. Thos., London ; watch, 1796. Andrew, Philadelphia, 1811.

Thorogood. John, C.C. 1660 . Wm., C.C. 1660. James, apprenticed to Jno. 1660. Edwd., C.C. 1668. Etinne, 9 Burrows Buildings, Blackfriars. Bridge. Stefano, same address; card, B.M., about 1770 ; watch, "Thoroughgood, S., London," about 1772. Richard, 175 Fenchurch St., 1783-90.

Thorowgood, Luke, apprenticed to Thos. Hunter; C.C. 1768, London; long-case clock, about 1770 .

Thorpe, Jno., C.C. 1657. Edw., Bath, 1835.

Threlkeld. William, " in ye Strand," 1700. "A silver watch with an engraved Case and a Cipher, G. K., in the middle, the Dial Plate having Flower-de-luces at the half-hours, the Maker's name, W. Threlkeld, London " (Lond. Gaz:, May 12$15,1701)$. In the Soane Museum is a clock by him in a long case decorated with fine English marquetry in panel, about 1710. Ralph, London ; bracket clock, about 1740 ; seen at the Hague. D., Newcastle-on-Tyne, 1810.

Threlkell. -, C.C. about 1632. R., London ; watch, 1730.

Thristle. -, Williton; Hood clock, about 1730 (see p. 492). Jno., NetherStowey, 1842.

Thullier, see Terrot.

Thuret. Isaac, Paris; lodged at the Louvre, 1686 . Jacques, son of Isaac, obtained the reversion of his father's privileges in 1694; Boulle clock, S.K M., about 1700 ; another with reclining figure of Time below the dial, Wallace collection.

Thwaites. Ainsworth, Rosoman St., Clerkenwell; made the Horse Guards clock, $1756 ; 1740-80$. Jas., Ratcliff High- 
way ; 1768-90. John., 4 Rosoman St., Clerkenwell; master C.C. three times, $1815,1819,1820$; presented to the C.C. Sully's timekeeper; 1780-1816. \& Reed, 4 Rosoman St., Clerkenwell, 1817-42.

Thylet, London, 1705 ; watch and chatelaine which had belonged to Queen Anne fetched $£ 150$ at Christie's in 1904 .

Tickle. Jno., junr., Crediton ; 30-hour clock, lantern movement about 1730 . Wm., Newcastle, 1765-85.

Tidbury \& Son, 206 Oxford St., 1822-25. Tiese, J., London ; oval watch, 1620. Tillbrooke, Jno., Bury; watch, 1785. Tills, Richd., London, 1760.

Tilly, Joseph, C.C. 1703 ; walnut longcase clock, square dial, 1703-20.

Timner, Richd., London ; watch, 1805.

Tingley, Thos., apprenticed 1686 to Wm. Glazier, C.C.

Tinelly à Aix; cruciform watch, B.M., about 1580 .

Tinham; long-case clock, bird and flower marquetry in panels, about 1690 , inscribed " Samuel Tinham, Sarum, fecit;" another, about 1725 , with the inscription, "Saml. Tinham in New Sarum."

Tinson, Thos., 1 Charing Cross, 1793.

Tipping, George, C.C. 1674.

Tirry, Jno., York, about 1680.

Tissot, see Gounouilhou.

Titherton, Jno., London; long-case rlock, about 1700 .

Tobias. Morris, 68 Bell Dock Yard, Wapping, 1798-1800. Morris \& Co., 68 Bell Dock Yard, Wapping. 1804; in 1812 Morris Tob as patented (No. 3,584) a binnacle timepiece, to show the time by " bells" as watches are kept on board ship ; rack lever watches, "Tobias \& Co., Liverpool and London," 1808-25. \& Levitt, 31 Minories, 1816-42.

Todd. Robt., apprenticed 1654 to Dan. Quare, C.C. Jno., York, f., 1665. Samuel, York, f., 1686. Ben., Aldersgate St., C.C. 1730. Jas., Bradford ; clock, about 1760.

Tolby, Charles, C.C. 1720.

Tolkien. \& Dancer, 145 St. John St., 1807. George, same address, 1810.

Toller Bros., London; watch, 1760.

Tolley, Charles, C.C. 1683.

Tollison, John, C.C. 1714.

Tolson, Ralph, apprenticed 1693 to Cuth. Lee, C.C. ; watch, about 1700, signed "Ralph Tolson, London."

Tomes, Jas., apprenticed to Jno. Saville 1676, C.C.

Tomkins, William, 11 Winchester St., 1768-72.

Tomlin, Edwd., 69 Threadneedle St., 1770-98; bracket clock, mahogany case, round enamelled dial, marked "Tomlin, Royal Exchange."
Tomlins, Nich., apprenticed 1639 to Ed. Stevens; C.C. 1646.

Tomlinson, Thomas, C.C. 1647. William, brother C.C. 1699 ; master in 1733 ; died 1750, a Quaker ; chiming bracket clock in ebony case, about 1710, Wetherfield collection; watch by him in S.K.M., h.m. 1719 ; inside a fine 8-day Oriental lacquer clockcase by him were directions to set up and keep a pendulum clock, and underneath, " The said clocks with all other sorts and all sorts of watches are made by William Tomlinson at the Dial and Three Crowns in Birchin Lane, near the Royal Exchange, London, now in White Hart Court, Gracechurch St." ; he retired to Stoke Newington ; Mr. Geo. E. H. Abbot, Groton, Mass., U.S.A., has a watch by him which belonged to Edwd. Holyoke, president of Harvard College; the outer silver case was made into a drinking cup for Mr. Abbot's father.

Tomlyns, Nicholas, C.C. 1647.

Tompion. Thomas, "father of English watchmaking," Fleet St., born 1638, died 1713, a Quaker (see p. 277). Thomas, junr., apprenticed to Charles Kemp 1694; admitted C.C. 1702 (see p. 295). \&Graham, watch movement, G.M., about 1705 . T., \& Banger, E., on clocks and watches (see p. 295) ; Mrs. Francis J. Kidson has a fine bracket clock. signed "Tho. Tompion \& Edw. Banger London," dating from about 1715 (see p. 573).

Tompkinson, Humphery, Maiden Lane, Covent Garden, 1768-75.

Tompson, J., 9 Hooper Court, Clerkenwell, 1842.

Toms, T. ., 7 Swan St., Minories, 1820.

Tomson, Sn., London; pair-case watch, Mr. F. Geyer, about 1770.

Tooke, -, Lynn ; watch, 1790.

Tootele, Wm., Chorley, 1770.

Topham, J., 9 Basing Lane, 1788-1800.

Topping, Jno., London ; apprenticed 1691 to Wm. Grimes, C.C.

Torado, Francis, Gray's Inn ; brother C.C. 1633 ; oval watch in G.M. His widow became a pensioner of C.C. in 1690 .

Torin. James Lewis, 30 Throgmorton St., 1738-80. Daniel, Hoxton Sq., 1766.

Torkler, Peter, 9 Red Lion St., Clerkenwell, 1782-90.

Tornique, J., London; silver alarm watch by him, about 1670, exhibited at the Guelph Exhibition by Mr. Geo. Carr Glyn.

Tortorre, Jas., London, 1770.

Tory, Sarah, apprenticed 1660 to Richd. Bowen and Mary his wife, C.C.

Tothaker, William, C.C. 1703.

Touch, Chas., St. Albans ; watch, 1744.

Toulmin. Samuel, London; watch, about 1745 ; Wm. Curteen apprenticed to him in 1759. Samuel, 27 Strand, 1765-83; 
centre-seconds watch beating full seconds, cylinder escapement, in the G.M.

Toutin. Jean, Château Surr ; celebrated enamel painter. Henry, Blois (brother of Jean).

Tovey. Wm., apprenticed 1655 to Simon Dudson, C.C. Wm., watch and clock spring maker, 64 Red Lion St., Clerkenwell, 1798; 53 Upper Moorfields,. 1804.

Towell, Nich., apprenticed 1668 to Sam. Davis, C.C. 20.

Tower, Reuben, Plymouth, U.S.A., 1813-

Towers, William, Wincanton, 1830.

Towne, Joseph, Horncastle ; watch, silver dial, about 1700 .

Townley. Lantern clock, signed "William Townley Bourton," with heraldic fret engraved " B.R.F. 1724." Thos. \& Son, Liverpool, 1818. Jno., Liverpool, 1833; also Thos. ; also Townley \& Quilliam.

Townsend. Jno., forbidden to work by C.C. 1632. Samuel, C.C. 1702 (Townson (?). Joseph, Helmdon, 1710. Elizabeth \& John, 61 St. Paul's Churchyard, 1760-69. Rt., Greenock, 1770-90; he was paid $£^{2}$ for keeping the town clock in 1785 ; long-case clock, Mr. E. R. De Long, Boston, Mass. William, 74 Fleet St., 1773 ; 99 Guildford Place, Spafield, 1842. Elizabeth, 119 Fetter Lane, 1804. Charles, Philadelphia, 1811. R., London; watch, 1815.

Towson, Jno. Thos., Devonport; received Vulcan medal and $£ 10$ from Society of Arts for chronometer banking, 1826.

Trabet, - London ; watch, apparently Dutch, about 1750.

Tracy, Richd., apprenticed 1660 to Nich. Coxeter, C.C. Steven, Rotterdam, 1683. Step., London; striking watch, Marfels collection, about 1700 .

Trafford, Thos., London, about 1665.

Trail. Edwin, 68 Old Broad St., 1835-40. Edwin, Edgware Rd., 1835-42.

Tramieri, J., à Turin ; watch in case of rock crystal formed as an escalop shell, about 1600, Pierpont Morgan collection.

Trap, Richard, London; watch, 1762.

Trattle, Joseph, Newport ; clock, about 1780.

Traver, Jno.; watch, h.m., 1748.

Travers. Adam, Liverpool, 1775 ; 9 Red Lion St., Clerkenwell, 1783-94. Wm., Red Lion St., Clerkenwell, 1788-1810. Mathew, watch-case maker, 12 Great Sutton St., 1810.

Travis. Geo., Rotherham, 1770. J., Thorne, 1780. Wm., Leek, born 1781, apprenticed to Joseph Wild, Macclesfield ; died 1875.

Tregent, James, 35 Strand, 1775; 29 Cranbourne St., Leicester Sq., 1780 ; hon. f. C.C. 1781 ; watchmaker to the Prince of Wales; was intimate with Garrick, Sheridan, and other notabilities of the theatre. Kelly refers to him as "Mr. Tregent the celebrated French watchmaker," and relates how Sheridan, by attributing his proverbial unpunctuality to the lack of a timekeeper, obtained from Harris, proprietor of Covent Garden Theatre, a watch of Tregent's make. The Duke of Sussex paid him $£ 400$ for a repeater and alarm travelling watch. A bracket clock in the Wetherfield collection is shown on p. 586. Mr. Thos. Boynton has a long-case clock by him, about 1770 , silvered dial engraved with festoons, \&c., day of the month, strike-silent; bracket clock with Battersea enamel face, Schreiber collection, S.K.M., signed on face " James Tregent, Leicester Square, London," 17701804.

Trelegon. James, Strand, 1775. \& Ockley 54 New Bond St., 1793.

Trembley. J. L., Geneva, about 1710. David, Geneva, about 1750.

Tremlett, Alf., Bath, 1835.

Trenholme, Wm., C.C. 1728 ; in 1735 he worked for Bayley.

Trent., Wm, London ; watch, 1770.

"Trevan, Marseille"; watch, 1780.

Trevor, Thos., apprenticed 1654 to Peter Delandre, C.C.

Trewin, -, Hereford, about 1770.

Trewinnard. Joshua \& James, 16 Rotherhithe Wall, 1790-1842. Joshua, 40 Strand, 1807-10. Edward, Grange Rd., Bermondsey, 1825. James, 32 London Rd., 1835. Joseph, 23 Grange Rd., 1835. George, Kingsland Place, 1835.

Tribe. John, Petworth, died 1728; hanging clock by him repeats hours and quarters, Sir James M. Moody. Daniel, Petersfield, 1730. John Carr, a clever clockmaker, born 1835, apprenticed to James Breese, Grays Inn Road, 125 Old Street, 1860, Percival Street, 1864, Spencer St., 1868 where he carried on business until his death in 1915.

Trigg, Thomas, C.C. 1701.

Triggs, Thomas, C.C. 1708.

Trim, John, London; maker of house clocks, 1790-1800.

Tringham. J., London ; watch, 1790. Geo., 15 Golden Lane, 1828-42.

Tripp, Job, Bridge St., 1772.

Trippett. Thos., apprenticed 1654 to Geo. Poole, C.C. Jno., Kingston, C.C. 1668. Robert, C.C. 1700; long-case clock, about 1705, Rev. W. B. Atherton. William, C.C. 1706.

Triquet, Jas., 35 Strand, 1768-72.

Tritschler \& Co., wooden and musical clockmakers, 191 High Holborn, 1835-40. 
Troth, James, Pittsburg, U.S.A., 1815. Trott, Andrew C., Boston, U.S.A., 180010.

Troughton. Bryan, 35 Fenchurch St. livery Clothworkers' Company, 1760-75. Nathaniel, 25 Rood Lane, 1768. Joseph, London, f. of Lancaster, 1779. Edward, Fleet St. ; invented a wheel-cutting engine in 1780 , and a compensated pendulum in 1790 ; died 1835 , aged 81 .

Troup. W., London ; bracket clock, about 1760 . Jas., 233 Tooley St., 1822. Jno., 120 Cheapside, 1835, afterwards at Hatton Garden ; died 1901, aged 92.

Trout, Thomas, Bond St., long-case clock, about 1710; watch in silver-gilt case, inscribed "Trout, Westminster," about 1790, Hilton Price collection.

Trowe, Jno., apprenticed 1685 to $\mathrm{Wm}$. Speakman, C.C. Gilbert, C.C. 1722 .

Trubshaw, John, apprenticed to Robt. Halsted 1679; admitted C.C. 1686 ; bracket clock chiming on six bells, about 1700 ; a gilt metal-cased repeating watch by him, S.K.M., about 1710 .

Tuck, J. \& L., 8 Haymarket, 1800-30.

Tucker, John, Portsmouth, clock, about 1715.

Tuckey, Thos., C.C. 1646. Edwd., apprenticed 1681 to Robt. Ayres, C.C. Giles, London; repeating watch, 1776. Tudman, James, The Crown, Lombard St., 1697-1710; long marquetry case clock, about 1700, Sir James M. Moody.

Tuite, William, 4l Great Queen St., $176 \mathrm{I}-75$. 65.

Tulloch, Harry, Dundee, died 1912, aged

Tunnell, Jno., successor to Geo. Flashman, 18 Fleet St., 1816-30; livery C.C. 1826 ; watch duplex escapement compensation balance, h.m., 1821, Mr. H. Cook.

Tunstal, Stephen, Skipton; long-case clock, about 1725, Dr. Wm. A. Day.

Tupling, B., 191 Strand, 1820.

Tupman, Geo., Vigo St., 1790 ; 6 Charles St., Grosvenor Sq., 1806-30 ; 6A Old Bond St., 1842 ; there a succeeding generation of the Tupmans, George and James, carried on business for many years; they were noted for good work, and contrary to the usual practice, attended to the winding of customers' clocks and other outdoor requirements themselves, leaving the shop to the care of assistants. George Clifton Tupman, the last of the two brothers, a handsome man of very engaging manners, retired to Ashford, Middlesex, where, having entered his ninetieth year, he died in 1903 .

Turges. Jas., apprenticed 1660 to Ahasuerus Fromanteel. Josiah, 23 Smithfield, 1768-72.
Turlis, Jas., Windsor ; silver watch by him, shagreen outer case, exhibited at the Guelph Exhibition by Mr. Geo. Carr Glyn.

Turmeau \& Kettlewell, 23 Villiers St.. 1793.

Turnbull. Francis, apprentictd 1692 to Sam Marchant, C.C. ; $1740 . \quad$ Thos.. Whitby, 1818. Wm., Whitby, 1823.

Turner. Hy., apprenticed 1694 to Richd. Westwood, C.C. Joseph, C.C. 1717. Thos., London; fine long-case clocks, about, 1745. William, Church St., Spitalfields 1760-72. Wm., 18 Cornhill, 1775; Fenchurch St., 1825-40; see Birch. John. 10 London Wall, 1788-94. J. \& Charles, 58 and 59 New Bond St., 1830.

Turnham, Rd., London; watch, 1785.

Turpin, Benj., 62 Banner St., 1835-40: his widow Susanah afterwards carried on the business for some years and then his two sons, John and Henry, trading as "Turpin Brothers," manufactured ful! plate watches; some marked "Railway Timekeeper" were exported to America. The business lapsed abnut 1885 .

Turton. \& Walbancke, 8 Fore St., 1793. Nath., Manchester, 1818.

Turvee, Jarrett, C.C. 1688.

Tussingham, Jno., apprenticed 1682 to Richd. Prince, C.C.

Tutet, Edward, 10 Fenchurch St. ; liverv C.C. 1766 ; master 1786 ; bracket clock. enamel dial, case very similar to Eliicott's bracket clock shown on p. 585, Wetherfield collection ; 1760-94.

Tuttell, Thomas, C.C. 1695 ; pocket sundial and "Perpetuall Almanacke," aboit? 1700.

Tutton, C., Bath, 1826.

Twell, Geo., apprenticed 16S5 tc Wm. Hawkins, C.C.

Twells, Wm., High St., Birmingharr, 1770 .

Twhing, James, C.C. 1688.

Twycross. Stephen, Gough Sq.. 1793. Stephen \& Son, 8 Haymarket, 1800-4; 13 Newcastle St., 1817.

Twyford. Josiah, Manchester, 1765. Robert, 40 Strand; hon.f. C.C. 1781; 177C82. Wm., Manchester, 1775. John, Bank Top, Manchester, died 1789. Robert \& Co.

9 Finch Lane, Cornhill, 1790 ; 10 Salisbury St., Strand, 1800-10. Josiah, 35 Deansgate. Manchester, 1794. William, 88 Bank Top. Manchester, 1794. R., 20 Salisbury St. Strand, 1815-19. Josiah, Manchester, 1818

Tyas. W. T., Thavis Inn, Holborn, 1820-35. J. A., watch-case maker, 7? Rahere St., 1835 .

Tyler. Jno., apprenticed 1667 to Jno. Matchett, C.C. George. Pope's Head Allev: apprenticed to Robt. Dingley, 1691, C.C. bracket clock in Japanese tortoise-sheil 
case, about 1715 ; bracket clock in walnut case, pull repeating quarters on six bells, about 1720, Wetherfield collection; clock watch, 1735. Richd., Wallingford, about 1740. Jas. Hy., Northampton St., 1835. C., 15 Holywell St., Strand ; watch paper, Ponsonby collection, with portrait of the Queen, and around it "Victoria the First, Queen of England," about 1840.

Tymms. Jno., apprenticed 1666 to Nich. Tomlins, C.C. A., 6 Kennington Lane, 1820. M., 5 Kennington Lane, 1820.

Tyrer. Thomas, Red Lion St, Clerkenwell, patented in 1782 (No 1,311) the duplex escapement. His specification says, "Horizontal scapement for a watch to act with two wheels." Jas. Hy., 32 Northampton St., Clerkenwell, 1806-30. Jas., 65 Red Lion St., 1842.

Tyson, Hy., Egremont, 1833.

Udall. Thos., 8 Flower-du-luce Court, 1793. J., 5 Great New St., Shoe Lane, 1819-22.

Uffington, Jno., 53 Bunhill Row, 1793.

Ullmeyer, Christoph., Augsburg ; clock, Green Vaulted Chambers, Dresden, about 1570.

Ulph, Thos., Stalham, 1840.

Ulrich, John Gottlieb, of many addresses; 26 Nicholas Lane, in 1835; he devised and patented several methods of compensating chronometers, 1830-74.

Underhill, Cave, admitted C.C. 1655.

Underwood. Wm., London ; clock, about 1720. John, 36 Noble St., Cheapside, 175475. John \& Sons, Foster Lane, 1758-63. Robt., 3 Falcon St., 1769-1810. Cæsar, 3 Panton St., 1798-1800 ; 'Ranelagh St., Pimlico, 1820.

Uneman, John \& William, Dutch clockmakers in England (see p. 27), 1368.

Unwin. Wm., Newark, 1776-1804, afterwards Unwin \& Holt. Edward, 30 Upper Lisson St., Paddington, 1820.

Upjohn. Richd., Exon. ; long-case clock, about 1730 . Wm., Exon.; watch, silver dial, raised figures, h.m., 1741. Thos., Exeter, about 1760. James, Threadneedle St., 1760-63 ; Lombard St., 1779 ; watch in gold and enamelled cases, S.K.M., h.m., 1778. James \& Wirgman, 18 Red Lion St., Clerkenwell, 1769-81 ; Jas. \& Co., 1794. Peter, Bideford; watch, 1780. Peter, 11 Red Lion St., 1783-1835. Francis, 1 Bridgewater Sq., livery C.C. 1786 ; suggested distinctive marks on foreign watches 1780-87. T. J., London, about 1805-10. -, Brentford; watch, 1810. W. J., 11 St. John's Sq, 1815-20. J. \& T., 5 Chandos St., Covent Garden, 1835. \& Bright, 5
King William St., Strand, well-known makers for some years from 1840 .

Upton. Nat., apprenticed 1674 to Jno. Nash, C.C. Rich., London; watch, about 1755.

Urick, Valentine, Reading, U.S.A., 1760.

Urseau. Nicholas, entry of a payment to him as a clockmaker in 1553, and on New Year's Day, 1556, he presented a clock to Queen Elizabeth. Nicholas, probably a son of the preceding, clockmaker to Queen Elizabeth, 1572-90.

Usher, Joseph (Usher \& Cole), a clever horologist; died 1903, aged 71 .

Usherwood, William, 19 Strand, 1830.

Utting, Thos., Yarmouth, 1730.

Uytemveer, C., Rotterdam; watch, about 1705 .

Vaart, H. G., Strassburg ; spherical watch, about 1560 .

Va:lliant à Paris; clock, at Nether Swell Manor, about 1780 .

Vale. Samuel, Coventry, 1747. Howlett, \& Carr, Coventry, 1754-90 ; watch, " Vale \& Howlett, London," 1782. Wm., 6 Colmore Row, Birmingham, 1770; see also Gimblet. Wm., 12 Bunhill Row; a good maker, mentioned by Earnshaw, 1776-94.

\& Kenyon, about 1780 . \& Rotherham, Coventry (R. K. Rotherham apprenticed to Vale, Howlett, \& Carr), 1790-1840. William, musical clockmaker, 32 Paul St., Finsbury, 1816-40.

Valentine. William, "At the Dial and Sun, Royston," 1770. Bart., London ; watch, 1800. Chas. D. F., livery C.C. 1810 .

Valeran, -, hexagonal table clock, Wallace collection, stamped on the bottom "E. Valeran, Paris," with the Royal Crown of France and fleur-de-lis, about 1600 .

"Valére, Paris"; watch, 1789.

Valiant. Samuel, Harleston, died 1890, aged 85. John, Harleston, 1860-1902.

Vallance, Thos., 5 Wilderness Row, 1820.

Valleran, Fleurent, Paris, 1544 (see p. 404).

Vallete, Sd. \& Fils, Geneva ; watch, about 1785 .

Vallier, Jean, Lyons; in the Pierpont Morgan collection is a triangular watch, on one side portrait of Charles V. and on another the arms of Besançon, with the date 1564; cruciform watch, about 1590 , Garnier collection; small ornamental watch, B.M.; fine astronomical watch, uncased, by him, B.M., about 1610; watch, Vienna Treasury, case in the form of a star, mounted in brass and silver, covered on both sides with rock crystal, about 1605 .

Vallin, - In the Pierpont Morgan collection is a very small oval watch, 
signed "I. Vallin," which seems to be late sixteenth-century work. On the back is a representation of St. George and the Dragon in raised enamel work, and around the band of the case the inscription " Honi soit qui mal y pense;" this gem was formerly in the Spitzer collection, and at the dispersal by auction fetched $£ 860$. Brass clock, B.M., signed "N. Vallin, 1600 ; " with arms of Viscount Montagu, who died 1629 ; probably from Courdray House, Sussex; modern enamel dial, named "John Monkhouse, London."

Van Aleurs, H., Amsterdam; watch, about 1775 .

Van Blade, Laurens, Hague; watch, about 1780 .

Vanbroff, Jas., watch, Soltykoff collection, about 1605 .

Van Ceule, J. le jeune, Hague ; repeating watch, Pierpont Morgan collection, about 1750 .

Van Ceulen. John, Hague; clock on Huygens' plan (see p. 325), about 1660 ; clock-watch, Schloss collection, about 1700; a watch with large balance and primitive arrangement of spring, in the Pierpont Morgan collection, dating from about 1680 ; bears the signature, "Jo. Gannes Van Ceulen fecit Hagæ." Phillipus, Hague ; watch, B.M., the case enamelled by J. L. Durant, about 1690.

Vanden Bergh, A., large late-seven teen thcentury Dutch clock, in silver filigree case, S.K.M. ; movement signed "Adriaen Vanden Bergh fecit, Hague; " case signed J. H. C. Breghtel."

Vandenburg, J., 8 Owen's Row, 1830.

Vanderwood, -, long-case clock, about 1780 , inscribed " $\mathrm{Wm}$. Vanderwood, London."

Vanenhove, _-, Amsterdam; enamel watch, about 1730 . 40.

Vanham, Leonard, Addle St., 1737-

Vanlone, Matt., brother C.C. 1692.

Van Meiors, Otto, Amsterdam, 1780.

Vans. Pat., apprenticed 1672 to Joseph Knibb, C.C. Chas., apprenticed 1682 to Edwd. Norris, C.C.

Vanscolina. Jere., apprenticed to $\mathrm{Wm}$. Ericke; turned over to Francis Atkins; C.C. 1776. Richard, 70 Charlotte Ter., New Cut, 1842.

Vantrollier, James, one of the first assistants C.C. 1630; watch of an earlier date, Nelthropp collection.

Van Voost; watch, about 1730 , inscribed

Hendrick Van Voost in de Rye."

Vardon, Samuel \& Thomas, 29 Firth St., Soho, 1783-94.

Varley, Wm., 1763.

Varnish, Jno., Rochdale, 1770.

Vaslet, Andrew, C.C. 1717.
Vaucanson, -, born at Grenoble, 1709 ; constructor of automatic movements.

Vaucher. Frères, Swiss watch, 1780; another watch, inscribed " Presented by Napoleon I. to Thalma," now at the museum of the "Sons of the Revolution," New York. Fritz, 27 Gerrard St., Soho, 1842.

Vauchez, -, Paris, 1790.

Vaughan. Robt., apprenticed 1655 to Jno. Broome, C.C. Geo., Pontypool ; clock about 1760 (see p. 517). Geo., Greville St., Hatton Garden, 1816-28. Edwin, Bristol, 1843.

Vauguion, Daniel, " to their Royal Highnesses the Duke of Gloucester and Prince Henry, at the Duke of Gloucester's Arms at the New Opening, Spring Gardens, Charing Cross," 1760-93.

Vauquer, Robt., Blois; a celebrated painter in enamel of watch cases: died 1670.

Vautier, -, calendar watch. Garmier collection, about 1600, signed "Loys Vautier, Blois."

Vautrollier, see Vantrollier.

Vautyer, -, Blois ; handsome octagonal watch, B.M., case decorated with filigree work and jewels, 1620 .

Veale, Chas., Bristol, 1843.

Vecue, Thomas, C.C. 1632.

Veigneur. -, Geneva ; watch, 1775.

Frères, watch, about 1810, Mons. E. Gélis.

Venault, - , Paris; watch, 1790.

Verback, Wm., apprenticed C.C. 1681. Vere, John Henry, 48 Lombard St., 1769 .

Vergo, - : Thiout credits him with the invention of a fusee to wind both ways, see Moore, Thos.

Verité, -, Paris, 1820-30.

Vermeule, Nicholas, Rotterdam ; pendulum watch, about 1714 ; another watch, about 1732, signed "Nicholas Vermeule Amsterdam."

Vermeulen, A., Amsterdam, about 1750. Verneuil. Jne., Paris ; clock, about 1780. —, Dijon, about 1800 .

Vernon. Christopher, in "ye Great Turnstyle, Holborne; "C.C. 1638; lantern clocks, about 1650. Samuel, C.C. 1649 , master 1679. -, C.C. 1685. Thos., watch, repoussé case, about 1710 ; bracket clock, about 1740 (see p. 526); bracket clock, inscribed " Vernon, London," about 1725, plays four tunes on twelve bells; curious motive force consisting of heavy straight springs outside of back plate. Thos., Ludlow, 1780. \& Eden, Liverpool; watch, 1789.

Verow, Jno., Hinckley; watch, with curiously shaped fluted pillars, about 1795.

Vesey, Chris., apprenticed 1692 to Jno. Sowter, C.C. 
Vesper. J., Fore St., Limehouse, 1820. T. \& W., 4 Grosvenor Pl., Commercial Rd., 1835-42.

Vevers, Richard, 2 Cateaton St., 1825-30.

Veyrin, - , Paris, 1775-92.

Vial, Charles, 1685. " Silver pendulum watch made by Charles Vial, with a tortoise-shell case inlaid " (Lond. Gaz., Jan. 17-20, 1697).

Vibrandi, W., Leuwarden ; watch, about 1610.

Vicary, Geo., apprenticed 1682 to Thos. Brafield, C.C.

Vick. Richard, in the Strand ; C.C. 1702 , master 1729 ; repeating watch, inscribed - Richard Vick, watchmaker to his late Majesty;" another, about 1740 or 1750 .

Thos., London; about 1780.

Vicker, Isaac, Lancaster, 1850. Joseph, Lancaster, 1850.

Vickerman, Thos., "Maiden Lane, opposite Goldsmiths' Hall, Cheapside," card, Ponsonby collection, about 1760.

Vidal, A., St. Giroud; fine repeating watch, about 1800 , Lt.-Col. L. D. Mackinnon.

Viel. Richd., apprenticed 1651 to Dan. Fletcher, C.C. Chas., apprenticed 1678 to Richd. Jarrett; C.C. 1686. George, 29 King St., Soho, 1842.

Viet. Mr. Alfred Wood has an early seventeetnh-century striking and alarm watch, inscribed "Jean Viet, Aorlcan;" there are two sets of figures, and between the $\mathrm{X}$ and the II of the outer set are the words " Solem audet dicere falsum," Paul, Blois; fine watch by him, B.M., about 1635 , case beautifully painted in enamel by Henry Toutin. Claude, C.C. 1698; his daughter Marianne was bound apprentice to him in 1715 ; gold watch, inscribed " $C$. Viet, London, watchmaker to Her Majesty," h.m., 1729, outer case engraved, see also Mitchell \& Viet.

Vievar, Geo., apprenticed 1693 to Dan Lecount, C.C.

Vieyres, Anthony, 40 Pall Mall, 1840-43 ; he was one of the directors of the ill-starred British Watch Company.

Viger, -, musical clock, Wallace collection, signed "Viger à Paris," about 1740.

Vigne. James, 2 Strand, 1770-94; hon. f. C.C. 1781. Peter, 15 Green St., Bath, 1798-1800. \& Lautier, 19 Union St., 1809. Benj. Lautier, 2, and then 6, Bridge St., 1819-50; his widow carried on the business for a short time at 4 Orange Grove till 1852, when it was taken over by GeorgeWadham. Mr. J. Stopford Taylor tells me of a pocket chronometer by Vigne \& Lautier, bought in Bombay, where he also purchased a fine clock in lancet case by B. Lautier.

Vigniaux, P., Toulouse, 1788.
Vilbar, -, Paris; horloger de la Reine 1787.

Villiscun, Stephen, Church Alley, Basinghall St., 1780-85.

Vincent. Wm., Portsmouth, 1730. Wm.s York, 1770. Chas., London; watch, 1820. Abe, Bath, 1835. John, 157 Drury Lane. 1840-42.

Vinco, Dan, apprenticed 1691 to Richd. Baker, C.C.

Vine. Jas., 2 Charing Cross, 1790-94. James, 5 Staining Lane, 1825. T. W., (Vine \& Thompson), died 1903, aged 69 .

Viner. Charles Edward, 151 New Bond St. and Royal Exchange, 1776-1820 ; card B.M. ; 19 Sackville St., 1840-42 ; livery C.C. 1819. Charles Edward, \& Hopkins, 8 Sweeting's Alley, 1829; also 235 Regent St., 1829-42 ; Mr. Thos. Boynton has a fine regulator by "'Viner, 235 Regent St., London," which winds at the side without opening the door, about 1835.

Vines. James, C.C. 1708. Joseph, Newbury, Berks. ; curious astronomical clock, 1836.

Viollier, Jacques; crystal cased oval watch, about 1570 .

Vipont, Jno., apprenticed 1682 to $\mathrm{Hy}$. Morgan, C.C.

Virgoe, Thomas, C.C. 1682.

Viridet \& Cie, Paris ; watch, about 1780 ; Geneva repeating watch, about 1810 , M.A., Decruc.

Visbach, -, spring clock, G.M., inscribed " Pieter Visbach, fecit Hague met privilege," about 1700.

Visconti, G., clock at Pavia, about 1410. Vise, see Vyse.

Vitrolle, -, fine bracket clock, signed “ Vitrolle à Paris," about 1650.

Vizier, Barnaby, Dublin, 1790.

Voght. ( \& Co., 35 Wigmore St., 1830). Chas. \& Fredk., 35 Wigmore St:, 1836-42. Vo,ght (or Vogt), Auty, 26 Upper Cleveland St., 1830-35.

Voight. Henry, Philadelphia, 1775-93; then Sebastian ; then Thos.

Voisin, A., l'aîné, Rue Hyacinthe, Paris ; garde-visiteur in 1769. Le jeune, Rue Dauphine, Paris, 1769.

Voisin, Henry, clock, about 1770.

Vokes, William, Widcombe, Bath, died 1870 , aged 59 (see Bullock).

Vokins, Jno., Newton ; long-case clock, centre seconds, dead beat, about 1800 .

Voland, Elias, C.C. 1632; Edward Ambrose apprenticed to him in 1634 .

Volk, P., 38 Goodge St., 1835-40.

Vossière, Thomas, C.C. 1698.

Votter, Peter, Vienna; watch, 1764, Mr. H. K. Heinz.

Voughan. Edward, C.C. 1715. Daniel, Charing Cross, 1775. George, 11 Gran ville St., Hatton Garden, 1820 (see Vauguion). 
Voyce. Gamaliel, apprenticed 1687 to Sarah Payne; C.C. 1694 ; arch-top ebony bracket clock, pull quarters, original rise and fall, about 1710. Richd., apprenticed 1693 to Geo. Ethrington, C.C.

Vrythoff, Jas., Berns, Hague ; enamel watch, about 1740 .

Vrytroft, L., Hague ; clock, about 1790.

Vuicar, J. B., Zug ; small round watch, silver dial, about 1610 .

Vuille. Alexander, Baltimore, 1766. Brothers, 2 Easton St., Spitalfields, 184042.

Vulliamy. Justin, carried on business at Pall Mall, in partnership with Benjamin Gray, whose daughter he married ; 173075. Benjamin, Pall Mall, son of Justin, and father of Benjamin Lewis; hon. f. C.C. 1781 ; 1775-1820. Benjamin Lewis, 68 Pall Mall, an eminent maker (see p. 376), 1810-54. Mr. Hansard Watt has an uncommon and interesting regulator signed "Vulliamy Pall Mall, London" (see p. 376). \& Son, 76 Pall Mall, 1793-1820. Vuolf, J. C., ; skull watch in the B.M., 1600.

Vyse. Wisbech ; Wm., 1730 ; Jno.,1760.

Wade. Henry, apprenticed to William Webster, and turned over to John Rainsford ; C.C. 1728. Jos., Clerkenwell Close, 1793.

Wadham, George, 14 Stall St., Bath, $1850 ; 4$ Orange Grove, 1852 ; then at 6 Bridge St., afterwards at 9 Milsom St. ; a sound horologist; died 1878 (see Vigne).

Wady. Jno., London; bracket clock in japanned case, about 1740. James, Newport, U.S.A., 1750-55.

Waddington, Robert, Coventry, among the original directors of the Coventry Watch Movement Company, died 1917, aged 74 .

Waddy, Jno., London, 1730.

Wagdon, Stephen, C.C. 1724.

Waggitt. Michael, Richmond, Yorks., 1753. Charles, York, f., 1818. Michael, York, 1822.

Wagner. Johan Heinrich, à Pirna; square table clock, about 1650 . E. M., Berne; the Hon. Gerald Ponsonby has a watch by him, pendulum vibrating under dial, very fine painting on enamel over balance-cock, about 1760 . J., born 1800 , settled in Paris 1821; died 1875.

Wagstaff. Edwd., apprenticed 1650 to Edward East, C.C. Thomas, 33 Gracechurch St., 1766-94 ; long plain mahogany case clock in the Kasan Cathedral, St. Petersburg; bracket clock playing four tunes at the hour, black wood case; in the Pierpont Morgan collection is a repeating watch in silver pierced cases, the thumb piece or opener of the outer case being a diamond; there are a number of long-case clocks by him in America, generally in the possession of Quakers and their descendants; I learn from Dr. Walter Mendelson, of New York, that Wagstaff was a Quaker, and members of the Society of Friends, when visiting London, were accustomed to lodge at Wagstaff's house, and on their return frequently took one of his clocks with them; watch, h.m., 1770, Evan Roberts collection, with cap and two train wheels of silver. James, 10 Brown's Lane, Spitalfields, 1835-42. Waight, Wm., Birmingham; watch, 1792.

Wain, Wm., Burslem, 1803.

Waine, -, Queen St., 1774.

Wainwright. John, C.C. 1679. Jno., Manchester, 1765. Humphry, Bunny, Nottingham; musical clock, about 1790.

Wait, Jno., \& Son, Gun Dock, Wapping, 1765-72.

Waithman, Anthony, Leeds, 1830.

Wakefield. Wm., Lancaster, 1782, f. ; Timothy, 1811, f. Robt., Tanfield, Durham, 1820. John, 3 South St., Berkeley St., 1835-42. T., 5 Smith St., Northampton Sq., 1835.

Wakelin \& Taylor, Panton St., 1788-94. \& Garrard, Panton St., 1800-5.

Waker (Walker ?), Peter, C.C. 1663.

Waklin, - , lantern clock, about 1700.

Waldegrave, Thos., apprenticed 1654 to Thos. Belson, C.C.

Waldoe, John, C.C. 1677.

Waldron, John, 38 Cornhill, 1790-82 ; watch, gold case, repoussé, about 1770 .

Waldvogel, Anthony, 82 Ratcliff Highway, $1835-40$.

Wale, Andrew, apprenticed 1664 to Rich. Ricord, C.C.

Walford. Thos., C.C. 1690. John, C.C. 1717. J. G., Banbury, 1830.

Walkden, Thomas, apprenticed 1682 to Dorcas Bouquet, C.C. 1694.

Walker. Jas., C.C. 1632 ; lantern clock, inscribed "James Walker in Lowthbery, fecit." Peter, apprenticed 1681 to Andrew Savory, C.C. ; lacquered long-case clock, about 1730 . George, C.C. 1683 . Jonadab, C.C. 1687. John, Fleet St., and afterwards at the White Horse and Bell, near Cheapside Conduit; C.C. 1717 ; inventor of a lamp clock, 1710-30. Jonah, apprenticed to Langley Bradley; C.C. 1734. Jno., Newcastle-on-Tyne, 1770. In the Czar of Russia's collection at the Winter Palace, St. Petersburg, were two watches signed "Sam Walker London " in cases of greyishbrown agate with plain gold mounts; they both appear to date from about 1760 and are suspended from chatelaines. Ezekiel, Lynn, 1770-1804; wrote an article in 
Nicholson's Journal on longitude and the use of chronometers. Jno., watch-case maker, York, f., 1772. Allen, London ; watch, Schloss collection, handsome repoussé à jour outer case, 1738. T., Louth, 1790. Joseph, 1 Warwick Court, Holborn, 1790-94. Wm., 38 Fettes Lane, 1790-94 John, Newcastle-on-Tyne, 1795. Robert. Montrose; watch, 1795. R., London; watch, 1800. Jos., Nantwich, 1800. Wm., Loughborough; watch, 1804. D. \& Son, 49 Red Lion St., Clerkenwell, 1806-16; 46 Clerkenwell Close, 1820 (see Harlow). Chas., Coventry, 1815. Thomas, 17 Castle St., Oxford St., 1815 ; Thos. \& Son, same address, 1820-30. John, 29 Gloucester St. Queen's Sq., 1816. J., musical watchmaker 7 Nassau St., Soho, 1820. Robert, York, 1820. Geo., Hull, 1822. E., watch-case maker, 46 Whiskin St., 1835. \& Blundell, 4 Red Lion St., Clerkenwell, 1835-42. Edwd., 55 Red Lion St., 1839-42. Jno., 48 Princes St., Leicester Sq., 1840 ; afterwards at 68 Cornhill ; died 1880. William, Standish St., Liverpool, patented 1841, (No. 8,997) a wheel for lever escapement, in which the spaces between the teeth were portions of circles, so as to dispense with the necessity of banking pins.

Wall. Jno., apprenticed 1676 to Thos. Davis, C.C. B., Richmond, 1800. \& Westlake, Chatham; watch, 1805. Jno., \& Co., Coventry, 1810. Wm., Wandsworth; patented an escapement in 1817 (No. 4,097). \& Alney, New Bedford, Mass., 1820-23.

Wallace. Blackett, Brampton, 1760. Michael, Chester-le-Street, 1770. Hy., Royal Exchange, 1775. Thos., Brampton, 1780-1810.

Wallen, Wm., Henley; watch, 1725.

Waller. Richard, watch, the time shown on a semicircular dial by the sun at day and the moon at night, said to have belonged to William of Orange; another, showing regulator on dial, about 1740 . J., 17 Shoreditch, 1790.

Walley, Sam., Manchester, 1770.

Wallington, Sam., apprenticed 1689 to Jno. Shaw, C.C. Wm., Devizes, 1843.

Wallis. William, C.C. 1715. Peter, Fleet St., 1737-40. Henry, Red Lion St., 1765-68. Jacob, London; clock, about 1780. Jno., 14 Skinner St., Bishopsgate, 1825-40.

Wallitt, Richard, C.C. 1693.

Walloon, H., London; watch, 1812.

Walmsley, Alex., London, f. of Lancaster, 1779.

Walsh, Arthur Paul, a celebrated watch and chronometer maker and springer; apprenticed to T. F. Cooper; carried on business as a tool dealer, at Frith St., Soho, in partnership with Robert Oliphant, and afterwards settled in George St., Euston Rd. ; born 1815, died 1893.

Walter, Nicholas, oval watch in the B.M., about 1620; subscribed to incorporation of C.C. 1630 .

Walters. Jno., apprenticed 1638 to Thos. Howse ; C.C. 1645. John, London; bracket clock, about 1750 , strikes one at the hour, plays a tune every three hours, Mr. J. Major.

Walthall, Jno., apprenticed 1684 to Wm. Coward, C.C.

Walton, J., London ; watch, 1807. Christopher, 24 Ludgate St., 1823-35. Joseph, watch-case maker, 7 Upper Charles St., Clerkenwell ; died 1911, aged 77.

Wanfield, Edmd., apprenticed 1655 to Nich. Coxeter, C.C.

Wanford, Jno., apprenticed 1686 to Ed. Whitfield, C.C.

Wansey, Hy., apprenticed 1662 to Jno. Hiccock, C.C.

Warburton. William, C.C. 1693. Jno., Liverpool, 1818.

Ward. Thos., C.C. 1632. Edwd., C.C. 1638. Anthony, Truro; long-case clock, about 1700. Anthony, New York, f., 1724-50 ; then John. John, New St., C.C. 1731. Joseph, f. of New York, 1735. Robert, 19 Abchurch Lane, Cannon St., 1762-85. W. John, Barbican; livery C.C. 1766 ; a tiny pair-case gold watch, diameter of a sixpence, nearly a ball, inscribed "W. J. Ward, London," about 1780. Richard, Winchester; long-case clock, about 1770. Benjamin, London Rd., Southwark; fine bracket clock, about 1770. Henry, Blandford, a well-known clockmaker, from about 1775 to 1820 ; in 1814 the Society of Arts awarded him a silver medal and five guineas for equation work for clocks. Benjamin, London Rd., Southwark, 1780 ; 45 Upper Moorfields, 1790 1808. Richard, Liverpool, 1780. Richard, New Broad St., 1780 ; 18 Tower St., 1790 94. John, 39 Greek St., 1790-94. Robert, Abchurch Lane, 1770. Robert, musical clockmaker, 20 Plumtree St., Bloomsbury, 1790. Jas., Birmingham; watch, 1790. John, 9 Fore St., master C.C. 1797. Nathan, Freybury (Maine ?), 1801. Isaac, Philadelphia, 1811 ; then Jehu. Rich., 27 Banner St., 1826-42. Henry, York, f., 1830. Richard, Salem Bridge, 1832-40. Edwd., Grimsby; on his tomb in Grimsby Parish Churchyard is the following :-

Sacred to the meniory of Edward Ward, who died 12 th Decenber, 1817 , aged 54 years.

"Here lies one who strove to equal time,

A task too hard, power too sublime;

Time stop $t$ his motion, o'er threw his balancewheel,

Wore off his pirots, though made of hardened steel; 
Broke all his springs, the verge of life decayed, And now he is as though he'd ne'er been made: Not for the want of oiling, that he tried,

If that had done, he' $d$ ne'er had died."

Warden. Wm., apprenticed 1666 to Thos. Loomes, C.C. Thomas, 1691 (see Strachan). Robt., London; watch, 1790.

Wardlow, Hy., Liverpool, 1833.

Ware, Robert, C.C. 1701.

Wareham, John, 18 Davies St., Berkeley Sq., 1816-23.

Wareing, Jas., Liverpool, 1818.

Warfield, Alexander, C.C. 1692.

Warmingham, Andrew, Manchester, 1775 .

Warne. Nich., apprenticed 1680 to $\mathrm{Hy}$. Adeane, C.C. Robt., apprenticed 1693 to Sam Stevens, C.C. James, 7 Queen St., Cheapside, 1760-85; repeating watch, Pierpont Morgan collection.

Warner. Wm., C.C. about 1675 . John, Golden Anchor, near Temple Bar, C.C. 1682-92. John, Temple Bar ; apprenticed to Wm. Warner 1689 ; C.C. 1696 . Jno., Draycott; made the church clock at Chipping Campden, Gloucestershire, for $£^{8}, 1695$. Thos., Chipping Campden ; descendant of the foregoing, substituted a dead-beat escapement, about 1820. John, 8 Trinity Row, Islington, 1835.

Warnes, Robert, 2 Leicester Sq., 1822-25.

Warre, W. H., Skinner St., Snow Hill ; free of C.C. by redemption 1857 ; assistant 1863 ; died 1866, leaving $£ 100$ to the Company.

Warren. Thos., apprenticed 1667 to Ben Bell, C.C. Richard, C.C. 1668. Jno., apprenticed 1693 to Richd. Medhurst, C.C. Canterbury, 1820-40.

Warrington, John, Philadelphia, 1811.

Warwick, Jas., apprenticed 1656 to Ed. Gilpin, C.C. Wm., 88 London Wall, 1793. Jas., Newcastle Place; watch, h.m., 1829.

Warry, John \& M. B., Bristol, 1843.

Washborn, John, 30-hour clock, about 1710, Mr. W. P. W. Phillimore. Several generations of Washborns were clockmakers of Gloucester; long-case clock by Nat. Washbourne, Gloucester, about 1750.

Wasbrough, Hale \& Co., Bristol, 1843.

Washbourn. Thomas, Queen Sq., Bartholomew Close, 1750-60. Geo., Gloucester; watch, 1770.

Washington, Mark, apprenticed 1687 to Rich. Brown, C.C.

Wasse, Thos., apprenticed C.C. 1682. Wassell, J., 9 Picket St., Strand, 1830.

Wastnesse, Francis, apprenticed 1671 to Jno. Trippett, C.C.

Waterfall, W. \& J., Coventry, 1814.

Waterman, Wm., apprenticed 1682 to Amos Wirich, C.C.

Waters. John, C.C. 1646; to him in 1687 was apprenticed the elder Jno.
Ellicott. John, C.C. 1683 . Jonathan, apprenticed 1686 to Ed. Hine, C.C. Thomas, C.C. 1731. John, 4 Cornhill, 1775.

Watford, Jno., C.C. In 1729 Jas. Freeman was apprenticed to him.

Watkin, Owen, Llanrwst; watch, 1791.

Watkins. Joseph, 21 Great Warner St., Coldbath Fields, 1800-19; he attested the value of Earnshaw's Improvements in 1804. John, 9 Giltspur St., Smithfield; received $£ 33$ from Society of Arts for improvement in the spring detent escapement, 1804; livery C.C. 1820; Great Sutton St., 1838. -, 126 Drury Lane, 1820.

Watson. Thos., apprenticed 1662 to Jno. Hillersden. Robt., apprenticed 1689 to Jno. Warner, C.C. William, C.C. 1691 ; long-case clock, chiming quarter and half hours, about 1720 ; name-plate inscribed "William Watson, Angel Alley in Leadenhall Street." Samuel, Coventry, admitted C.C. 1692 ; inventor and maker of a curious piece of clockwork; in $\mathbf{1 6 8 2}$ is mentioned a payment of $£ 215$ for a clock he sold to his late Majesty, Charles I. ; the clock "showes the rising and setting of the sun and many other motions" (Lond. Gaz., Sept. 4-8, 1690). Very small bracket clock in black case, about 1710 , inscribed " Samuel Watson, London." "Lost the 15th Instant on Cheshunt Common, a gold watch in a black Shagreen case with Gold Studs, tyed wtih a black Taffaty Ribon to a Steel Hooke, Engraven on the Inside Samuel Watson. Whoever gives notice of the same to Mr. Hcwell at the Penny Post Office in St. Martin's Lane, Westminster, shall have a Guinea Reward " (Lond. Gaz., Oct. 18, 1687). Under the head of Celestial Motions, Derham speaks of an elaborate and curious piece by Mr. Watson; in the Wetherfield collection is an 8-day bracket quarter clock, chiming on three bells, by Samuel Watson, London, dating from about 1700. Walter, C.C. 1720; Hatton, in 1773 , mentions the astronomical or complicated work of $\mathrm{Mr}$. Watson as being rare. John, Michael's Alley, Cornhill, apprenticed to John Hacker; C.C. 174485. Henry, Blackburn, 1760. Thos., Blackburn, 1770. Jno., Kirby Moorside, 1770. Jno., Pocklington, 1770. Wm., Blackburn, 1780. Wm., Glasgow, 1785. Thomas, 23 Aldersgate St., 1785-94. James, 24 Arundel St., Strand, 1788-1805. Wm., 190 Strand, 1793-1805. Wm., York, f., 1815. W., 67 Red Lion St., Clerkenwell, 1820. Edward, 6 King St., Cheapside, 1820-42 ; livery C.C. 1820 . Christopher, York, f., 1822. Francis, Beverley, 1822. \& Bell, York, 1833. Wm., 25 North Audley St., 1842.

Wattes, John, C.C. 1664. 
Watts. Richard, C.C. 1680. "Lost the 22nd Inst. out of a Gentleman's Pocket, a Silver Pendulum Watch, with the name Rich. Watts. Whoever brings it to Charles Ferrers at the Chirurgeons Arms in Queen Street, London, shall have 20s. Reward " (Lond. Gaz., Aug. 30, 1688). Thos., apprenticed 1681 to Ed. Stanton, C.C. Brounker, apprenticed to Joseph Knibb, 1684 ; C.C. 1693 ; a repeating watch by him in the Guildhall Museum, engraved cap, gold dial, well engraved and pierced inner case ; Mr. Eden Dickson has a month clock by him; Mr. Thos. Boynton has an 8-day long-case clock of his make ; watch, h.m., 1720, Mr. William Ranken ; the Rev. A. F. Sutton has a long-case clock, signed "Brounker Watts \& Co.," about 1720. "Lost on the 2lst instant, in Gutter Lane, Cheapside, a Silver Watch with Tortoiseshell Out-case, with a Lion Rampant and 3 oaken leaves for the coat, engraven on the Backside, made by Bro. Watts; the movements are the hours, minutes, and seconds. Whoever brings it to the sign of the Goldsmiths' Hall in Gutter Lane, or to Bro. Watts in Fleet Street, shall have a Guinea reward " (Lond. Gaz., April 27-30, 1696). Walter, apprenticed 1688 to Chas. Halstead, C.C. John, C.C. 1712. James, C.C. 1720. Thos., Lavenham; long-case clock, about 1730. Thos., St. Edmunds Bury, 1760. Robert, Stamford, 1760. Chas., Frome, 1770. William, 8 Cripplegate Buildings, 1770 ; 8 Fore St., 1775. Wm., Wotton-under-Edge ; watch, 1779.

Waugh, Wm., Liverpool, 1818.

Wawen, Gervas, apprenticed 1689 to Richd. Conyers, C.C.

Way. Jno., apprenticed 1659 to Thos. Taylor, C.C. Jas., apprenticed 1681 to Dan Lecount, C.C.

Wayland, Henry, Stratford, Essex; apprenticed to Wm. Bushman, 1820.

Waylett. Jas., 7 Mark Lane, 1793. John, 9 Ball Alley, Lombard St., 17951810.

Waynd, Richard, York, f., 1667.

Weadon, William, C.C. 1695.

Weakman, William, C.C. 1661.

Weare, Robt., Argyle St., Birkenhead. In 1846 he patented (No. 11,776) electric timekeepers.

Wearne, Richard, Camborne, about 1750. Weatherhead, Leonard, Kirby Lonsdale ; died 1774.

Weatherhilt, S., Liverpool ; watch, about 1760 .

Weatherley, Thos., Berwick, 1775. \& Roberts, 9 Poultry, 1800-5. \& Son, 9 Poultry, 1810-23.

Weatherley, David, Philadelphia, 1811.

Wetherston, Jno., Newcastle-on-Tyne, 1770.
Weaver. Cuthbert, C.C. 1682. Simon, apprenticed 1684 to Jas. Wightman, C.C. Geo., Fetter Lane ; C.C. 1730.

Webb. Isaac, apprenticed 1650 to Richard Masterton; C.C. 1660. Thos. ; in 1672 Joana Deacle was apprenticed to Eliza, widow of Thos. Webb, C.C. Edward, Chewstoke; lantern clock, dated 1681; Mr. G. M. Bick has a long-case clock, " Edward Webb Chewstoke 1688," lantern movement, plays three tunes on eight bells ; surmounting them is one larger bell. Matt., Chewstoke; lantern clock, 1688. Dan., apprenticed 1692 to Peter Southworth,C.C. Francis, Watlington, Oxon. ; hood clock, about 1710, Mr. W. Walden ; long-case clock, about 1730. Charles, Cheapside, 1737-40. Peter, 28 Throgmorton St., 175368. Benjamin, " maker to His Majesty:" 21 St. John's Sq., 1778-90 ; hon. f., C.C. 1787; 3 Red Lion St., 1806-10; watch, with compass in dial, inscribed "By the King's Patent; " this appears to have been patented by Hy. Peckham in 1798. Wm. London; watch, about 1780. Arthur, 86 Portland St., 1780-94. Robert, 14 Berkeley St., St. John Sq., 1815-19. Edward, 245 Tottenham Court Rd., 1816-20. Wm. \& Co., 19 Wilderness Row, 1816-20. J., Seward St., 1820. William, 2 Northampton Ter., City Rd., 1840 ; afterwards at Pullen's Row, Islington; a noted watch and chronometer maker; died 1887, aged 78.

Webber, W., Woolwich, 1817.

Webster. Many generations of this family have carried on business in the city of London from 1675. Robert, brother C.C. 1675 ; watch, G.M. ; in 1688 Sarah Webster was apprenticed to Robt. Webster, her father, C.C. John, apprenticed 1676 to Thos. Tompion ; C.C. 1695 (see Penny, R.). Thos., Dundee ; " cnocksmith," 1689. George, C.C. 1703. Henry, C.C. 1709. Thomas, C.C. 1709. William; from the books of the C.C. he appears to have been apprenticed to Jno. Barnett and to have been free in 1710 , though the following extract from the Lond. Gaz., from Nov. 24-28, 1713, seems to refer to him ; "On the 20th instant, Mr. Tompion, noted for making of all Sorts of the best Clock and Watches, departed this Life: This is to certify all Persons of whatever Quality or Distinction that William Webster, at the Dial and Three Crowns in Exchange Alley, London, served his apprenticeship, and served as a Journeyman a considerable Time with the said Mr. Tompion, and by his Industry and Care is fally acquainted with his secrets in the said Art." William Webster was warden C.C. 1734, and died in office 1735. Robt., C.C. 1721. William, 26 Change Alley ; C.C. 1734 ; master 1755 ; 
livery 1766. William, son of and apprenticed to William Webster, C.C. 1763 ; in the Pierpont Morgan collection are two watches by William Webster, one a clockwatch and the other, of later date, a repeater; they are both in finely pierced gold cases. Samuel, livery C.C. 1766. Robt., Whitby, Yorks ; in 1772 he patented (No. 1,021) a repeater. Richard, son of Wiliiam Webster; C.C. 1779 ; livery 1787. \& Son, 11 Change Alley, 1781-1800. Richard, 26 Change Alley, 1784-1840; livery C.C. 1810. Jno., Whitby, 1822 . Charles, 19 Broad St., Long Acre, 1835 ; 24 Red Lion St., Holborn, 1842. Richard, Birchin Lane, 1842 ; 43 Cornhill, 1850, and afterwards at No. 5 Queen Victoria St., which he built in 1872, when the thoroughfare was formed; died in 1882, aged 62; an accomplished horologist. Ambrose, Waltham, Mass., U.S.A., a clever mechanician, engaged in producing machines for watch construction; died 1894, aged 65.

Weedon, Wm., apprenticed 1686 to Nat. Barrow ; C.C. 1695.

Weekes, Thomas, C.C. 1654 ; fined by C.C. in 1657 for abuse to Warden Coxeter.

Weeks. Johnson, C.C. 1683. Charles, C.C. 1713. -, Coventry St., London ; English clock movement, dead beat escapement, in French Empire case, about 1810. John, clock-case maker, Great Sutton St., 1810-23.

Wehrle, -, Cambridge ; watch, 1835. Weight, Henry, Gloucester, 1810-42.

Welborne, William, Leather Lane, Holborn; in 1813 fined $£ 15$ by C.C. for refusing to take up the livery, 1800-13.

Welch, E. N., founder of E. N. Welch Clock Co., Forestville, New England, U.S.A. ; died 1887, aged 78 .

Welcome, John, C.C. 1705.

Welder. Richard, St. Anne's, Westminster, livery Turners' Company 1774. Thos., 40 Foster Lane, 1780-85.

Weldon. Saml., London; watch, Nelthropp collection, date letter, 1774.

Welke, see De Welke.

Welldon. W., silver repoussé and tortoiseshell watch, 1744 ; Hilton Price collection. W., Pierpont Morgan collection, bridge over balance, Dutch style, about 1790 .

Welle, Robt., 30 Red Lion Sq., 1825.

Weiler. (\& Magson, long narrow marquetry case clock, about 1705.) John, C.C. 1713 ; the Prince of Wales exhibited at the Guelph Exhibition a clock-watch by him; on the back three plumes, "Ich Dien " and also "Pro Principe Semper."

Wellington. John, C.C. 1726. Jas., London; watch, 1778.
Wells. Joseph, C.C. 1667. Isaac C.C. 1668. John, C.C. 1682 ; long-case clock. arabesque marquetry, about 1700 . Wm., C.C. 1689. Jonathan, 1700. Neddy, Shipley; fine long-case clock, Mr. J. Whiteley Ward, about 1700. Matthew, Russell Court, Covent Garden, 1755-60. John, 4 Cheapside, 1758-68.

Welsh, Robt., Dalkeith, about 1790.

Wenday, Anne, apprenticed in 1685 to Hy. Jevon and Christian his wife, C.C.

Wenham. John, Dereham ; watch, 1763. David, Dereham; long-case clock, about 1780; watch, Rochdale Museum, h.m., 1819 .

Wentle, Jas., 147 Aldersgate St., 1793.

Wentwon, J., London ; watch, Blackburn Museum, 1780.

Wentworth. Wombwell, apprenticed 1656 to Hy. Harland. Wm., Sarum ; longcase clock, about 1740 .

West. Thomas, London ; completed his apprenticeship in 1694 ; long-case clock, Wetherfield collection, about 1700 ; large metal pair-case watch, elaborate dial and movement, inscribed " Thomas West, London," about 1710; long-case clock, about the same date, with the signature, "Thos. Westt, London; " long marquetry case clock, about 1700, Sir James M. Moody. William, C.C. 1697. Samuel, Royal Exchange, livery C.C. 1766 ; 8-day bracket clock, verge escapement, in black wood case, with brass mounts and brass dial silvered, has a landscape painted at the top, with two men in the foreground playing tennis, the ball being represented by a small brass button, attached by a wire to the staff of the verge, and working backwards and forwards in a slot cut in the dial ; 1750-67. Thos., Reading; watch, 1780. Thos., 3 Ludgate St, 1820-42.

Westaway, John, 1 Gower St., 1840.

Westbrook, William, London ; long-case clocks, about 1700 and 1730 .

Westcott. John, C.C. 1703. Jno., London ; long-case clock, about 1750.

Westerman, Richd., Leeds, 1828; he retired in 1850 .

Westfield, Robt., St. James's St., Clerkenwell; patented in 1813 (No. 3,732) a cylinder wheel with teeth of unequal height.

Westlake, John, 33 High St., Boro., 1820 ; 41 Castle St., Boro., 1835-42.

Westmore, Robt., Lancaster, 1761. Thos., 1779 , f. Robt., 1785, f.

Westoby, John, C.C. 1677. " Lost out of a Gentleman's Pocket on the 12th Inst., between the Rose Tavern without Temple Bar and West Smithfield, a silver Minute Pendulum Watch in tortoise-shell case, inlaid with this figure in the bottom, viz. : A man driving a Hog into a House, the 
name of the watch, Westobe, London. It had a narrow Ribband flowered with silver and gold to hand the key by. when lost. Whoever brings it to Edw. Crouch, Watchmaker, under St. Dunstan's Church, in Fleet Street, shall have a guinea Reward " (Post Boy, 13th April 1697).

Weston. Abram, Lewes; long-case clock, Mr. J. Terry, about 1690 . Sam., Stratford; clock, in lacquer case, about 1730, Mrs. E. Herz. \& Willis, enamellers, 23 Greenhill's Rents, Smithfield, 1810. Wm., Newark, 1810 ; afterwards James ; then James and John. Hy., Bristol, 1843.

Westwood. Richard, C.C. 1691; maker of lantern clocks. Robert, Prince's St., Leicester Sq. ; in 1829 he patented (No. $5,850)$ an 8 -day watch with large barrel extending over the train.

Wethered, Geo., apprenticed 1677 to Hy. Wynne, C.C.

Wetherell. Thos., apprenticed 1664 to Jno. Clarkson, C.C. \& Janaway, 114 Cheapside, 1785-94. Nathan, Philadelphia, $1830-40$.

Weylett, Jos., 7 Mark Lane, 1790-94.

Whaley. Barnaby, apprenticed 1675 to Jno. Fitter, C.C. J., 14 Mount St., Lambeth, 1840-42.

Whalley, Sam., Manchester, 1770-86.

Wham, -, 13 Knightsbridge, 1820.

Whaplett, Thos.; prior to 1686 he presented a tankard to C.C. ; Wharton Rd., London; watch, 1785.

Wharton, Jno., apprenticed 1687 to Thos. Speakman, C.C.

Wheatley. John, apprenticed to Jeffery Bailey, C.C. 1668. William, C.C. 1698 ; long-case clock, about 1700, signed "Georgius Wheatley," Mr. G. Oscar Blacker. John, 18 Bull and Mouth St., 1820-25.

Wheaton, Caleb, Providence, U.S.A., 1785-1822.

Wheatstone, Sir Charles, an eminent electrician, inventor of a system of synchronous clocks driven by magnetoelectric currents; died 1875, aged 73 .

Wheeler. Thomas, apprenticed to Nich. Coxeter, 1647 ; C.C. 1655 ; master 1684 ; lantern clock, dolphin frets, altered balance escapement, inscribed "Thomas Wheeler, near the French Church in Londini ;" another lantern clock by him is owned by Miss Mary F. Bragg (see Fig. 639 ); died 1694 . John, C.C. 1680 . Vincent, apprenticed 1683 to Ed. Holliday, C.C. Thos., London; in the Wetherfield collection is a marquetry long-case clock by him with peculiar high dome, surmounted by carved gilt ornaments, dating from about 1700; 114 Oxford St., 1793.

Wheels, Sam., London ; calendar watch, 1790 .
Whellan, Thos., " in Bishops Gate Street, Londini; " lantern clock, about 1680.

Wheller. Maurice, invented a rolling clock, 1684. John, 17 Shoreditch, 1787-94. Wheynard, Edwd., London; watch, 1784.

Whichcote. Samuel, Crane Court, Fleet St. ; C.C. 1724; master in 1748. Samuel, 175 Fleet St. ; master C.C. 1764 ; livery 1766.

Whinfield, Philip, apprenticed 1651 to Sam Davis, C.C

Whipham. Thos., 61 Fleet St., 1775. \& North, 1793.

Whipp, Thos., Rochdale ; long-case clocks, 1820-42.

Whipple, G. M., superintendent of the Kew Observatory, Richmond ; initiated a system of watch rating in 1884; died 1893 , aged 50.

Whitaker. S., 12 Lang Lane, 1830. Wm., 8 High St., Camberwell, 1835-42.

Whitby, Robt., Chester, 1814-18.

Whitchurch, Samuel, Kingswood, Bristol, 1760-80 ; long-case chiming clock, phases of moon and high water at Bristol in arch, inscribed "Samuel Whitchurch, Kingswood," presented to King Haakon of Norway by the Corporation of London in 1906.

White. Edward, apprenticed 1647 to Jno. White, C.C. John, brother C.C. 1647. John, apprenticed to Thomas Loomes and turned over to Thomas Bagley, C.C. 1670 . Thomas, C.C. 1683 ; watch, gold repoussé case, outer case of shagreen, Schloss collection, 1743. Cæsar, C.C. 1692. Joseph, C.C. 1713. Amos, Fetter Lane ; C.C. 1730. Peregrine, Woodstock; long-case chimney clock, at top of dial list of tunes, "Marquis of Granby" and others, about 1760, at Massachusetts. Sebastian, Philadelphia, 1795. John ; watch, 1829 ; 3 Northampton Ter., City Rd., 1838-42. Wm., 306 Oxford St., 1830 .

Whitear \& Raves, 30 Fleet St., 1790-94.

Whiteaves, Richard, 30 Fleet St. 1804-40; livery C.C. 1812 .

Whitebread, William, High Holborn, C.C. 1728 .

Whitehead, Richard, C.C. 1671 Simon, apprenticed 1677 to Richard Whitehead, C.C. Chas., apprenticed 1693 to Whitehead, C.C. Robt., 3 St. James's St., Clerkenwell, 1810-15.

Whitehear, Richard, C.C. 1648 ; seems to have settled at Reading; lantern clock, dolphin frets, inscribed "'Richard Whitheare, Reading, fecit."

Whitehurst. John, Derby, and afterwards of Bolt Court, Fleet St., F.R.S. ; a well-known maker of turret and other clocks, inventor of tell-tale clocks; born 
at Congleton 1713, died in London 1788 ; his descendants continued the business at Derby ; clock in " The Chauntry," Newark, inscribed "Made 1807, and fixed here 1808, by $\mathrm{Mr}$ John Whitehurst, senior, of Derby " \& Son, Derby ; rack-lever watch, about 1805; Whitehurst of Derby was one of three clockmakers invited to tender for the Westminster clock in 1846 .

Whiteley, Thos., Ripponden, 1833.

Whiterow, Jno., 20 Bridge St., Covent Garden, 1840.

Whiteside, Jas., Ormskirk, 1800.

Whitewick \& Moss, 24 Ludgate Hill, 1790-94.

Whitfield. Edw., C.C. 1663. J., London, about 1749 ; watch by him belonging to Mr. Geo. Carr Glyn, Guelph Exhibition.

Whitford. Thomas, 1 Smithfield Bars, 1790-1800; Whitford \& Son, 1810-23. George, 1 Smithfield Bars, 1830-42.

Whitham, Jonathan, Sheffield, 1770.

Whiting, Riley, Winchester and Winsted, U.S.A., 1798-1820.

Whitlach, Jno., admitted C.C. 1637 ; presented a cup to the Company prior to 1652.

Whitman, Ezra, Bridgewater, U.S.A., 1790-1840. 1811

Whitmore, Wm., Northampton ; watch,

Whittaker. James, long-case clock, abjut 1700 . Edward, C.C. 1711. William, f. of New York, 1731-55.

Whittey, John, 42 Wynyatt St., 1842.

Whittingham, William, cited by C.C., he not having served ten years, 1688. Edw., " at the Dial in Oxford Road near Brrwick St.,"' 1770.

Whittle, Thomas, apprenticed to Henry Harper, C.C. 1683. "Lost in Lincoln's Inn Fields, on the 15th Instant, betwixt 5 and 6 o'clock, a Pendulum Watch in a black seal skin case, studded with silver, a cipher on the back and lined with Red Sattin, made by Angil Whitle. Whoever brings it to Mr Wilson's, at the Fleece Tavern, in Fleet Street, shall have a guinea Reward " (Lond Gaz., Oct. 22, 1688).

Whitton, Chas., apprenticed 1690 to Jno. Higgs, C.C. 1698.

Whitway, Saml., Cheapside, 1735-40.

Whitwell. Robert, apprenticed to Robt. Grinkin, 1641 ; C.C. 1648 ; in 1651 he presented one cup and three spoons to the Company; early minute-hand watch by him, Mr. Charles Shapland. Wm., apprenticed 1649 to Robt. Whitwell, C.C. In 1678, at Cutlers' Hall, Hugh, Whitwell, son of Robert, late citizen and clockmaker, was bound apprentice to Edmond Whitwell, member of the Cutlers' Company.

Whood, Isaac, apprenticed 1680 to Thos. Fenn, C.C.
Wibrandt, Jacob, Leuwarden ; small watch, about 1630 .

Wich, Gabriel, Nantwich, 1780.

Wichell, Samuel, St. James's St. ; marquetry long-case clock, about 1710 ; another long-case clock bears the address, "Pickadilly."

Wichote (see Whichote.)

Wickes. Wm., Threadneedle St., 1680 ; Geo. Wickes, his son, removed to Leadenhall St., and from thence, in 1720 , to the King's Arms, Panton St. ; for continuation of this business see Wickes \& Netherton, Parker \& Wakelin, Wakelin \& Taylor, Wakelin \& Garrard, and Garrard, Robt. John, 27 Cannon St., livery C.C. 1786; 8 Clement's Lane, 1804. John Haughton, 8 Clement's Lane, 1806 ; livery C.C. 1810 ; J. H. Haughton \& Son, same address, 1810-35. W. G., 114 Leadenhall St, 1823. W., 8 Skinner St, Clerkenwēll, 1835.

Wicks. ( \& Netherton, Panton St. 1753-60.) William, London; long-case clocks, about 1800. \& Bishop, 170 New Bond St., 1820-25. Wm., watch-case maker, 34 Percival St., 1820. Thos., 34 Union St., Kingsland Rd., 1835. W. G., 128 Long Lane, 1836. Alfred, 8 Clement's Lane, 1842.

Wicksteed, Edward, 9 Fore St., 1768 ; I 4 Bunhill Row, I 795 .

Widdowson, Joseph, 100 Fleet St., 1830.

Widenham. Richard, 6 East St., Clerkenwell, 1830 ; 13 Lombard St., 1835 . \& Adams, 13 Lombard St., 1840-42.

Widman, Jacob, Augsburg, 1680 ; the late Mr. Norman Shaw had a clock inscribed " Jacob Widman, Augustanus," an English dial engraved " William Barbaull, London," has been added.

Wiedeman. In the Horological Museum, Copenhagen, is a curious watch signed " Theodor Wiedeman, Wienna." It has three balances geared together, and dates probably from about 1700 .

Wieland. Fredk., Walworth, 1835-42. Chas., 12 Workworth Pl., Commercial Rd., 1835-42. R. \& W., 7 Lower Rd., Islington, 1835-42.

Wiggin, Robt., CoIne, Lancs., 1818.

Wiggins, Thos., 129 High St., Borough, 1835 .

Wigginton. Jno., apprenticed 1663 to Bernard Gernon. Wm., 11 St. James's Walk, 1806-20.

Wight, Jas., 12 Union St., Southwark, 1860-20.

Wightman. Jas., apprenticed in 1663 to Ed. Eyston ; C C. 1670. Jno., apprenticed 1688 to Jno. Jones, C.C. Thos., apprenticed 1692 to Hy. Hester, junr.; watch, about 1700 ; gold watch, h.m., 1745, Mrs. G. F. Thompson, Ottawa. William, C.C. 1696 ; the Rev. Lewis Gilbertson has a long-case 
clock by him, very similar to Fig. 705, and dating from about 1700 . Thomas, George Yard, London, about 1800. Thomas, 95 St. Martin's Lane, 1798-1818.

Wightwick \& Moss, 24 Ludgate St., 1775-1804 (John Wightwick, hon. freeman C.C. 1781).

Wigley, Alfred, Edgbaston, Birmingham, senior partner of the late firm of Dennison, Wigley \& Co.. connected with the trade for over fifty years; died 1910.

Wignall (or Wignell), Jno., also F., Ormskirk; long-case clocks, 1760-85.

Wigram, Thos., 67 St. James's St., 1804.

Wilbur, Job., Newport, U.S.A., 1815-40.

Wilcocks, T., 2 Red Lion St., Clerkenwell, 1817.

Wild. Mrs., " in the New Market, near the Borough Market, Southwark," 1780. Jas., Frith St., Soho, 1790. Joseph, Macclesfield ; William Travis was apprenticed to him about 1794. E. (tools), 2 St. John's Sq., 1798-1810.

Wilde. Wm., C.C. 1717-24. Michael, Wakefield, 1775. Josh., Macclesfield, 1782. Saml., Islington ; maker of lever escapements, a remarkably good workman and sound horologist, $1800-42$; his son afterwards with A. P. Walsh. J., Preston, 1814.

Wilder. Richard, Richmond Buildings, Soho ; C.C. 1776 ; watch, h.m., 1785. Jno., C.C. 1790. Ezra, Hingham, U.S.A., 1800 .

Wilders, -, London ; many watches, Dutch style, 1760-80.

Wildman. Watkinson, Cheapside, 1753-63. Samuel, 63 Cheapside, 1760-88. Chas., 6 Great Newport St., 1800.

Wilkes, Jno., London ; watch, 1740.

Wilks, Wm., Wolverton, near Stratfordon-Avon. In 1779 he was paid $£^{20}$ for "erecting and setting up a church clock" for the parish of Clarendon.

Wilkins. Robt., C.C. 1670 . Jno., apprenticed 1693 to Jno. Howse, C.C. Wm., Devizes, about 1730. Robt., London; watch, 1750. John, Bath, 1770. John, Marlborough, 1770. Ralph, Stamford, 1775. \& Son, Long Acre, 1805 . George, 36 Frith St., Soho, 1.810-25; card, B.M. Samuel, 4 Norman St., St. Luke's, 1835.

Wilkinson. Edward, apprenticed C.C. 1655. Jno., Leeds; long-case clock, about 1695. William, C.C. 1718. Willm., Leeds ; long-case clock in the possession of Mr. Alfred Sykes, Huddersfield ; dial, $16 \frac{1}{2}$ in. broad; centre seconds hand; in the arch on a convex disc, "Time stayeth not." On the dial :

" Hark how the fleeting moments pass, How swift they haste away.

$O$, reader, here as in a glass, Behold thy life decay."

-, Wigton, about 1740. Thos., London ; fine musical long-case clock, about 1760 plays at the hour either Lady Coventry's Minuet, or the 101st Psalm. J., London ; watch, 1765. Thos., York, f., died 1776. Wm., Congleton, 1780. T., 32 Piccadilly; 8 Cornhill, 1793; 1825-30. James, 18 Castle St., 1830 ; 19 Farringdon St., 1835.

Willard, -, Boston, U.S.A. Several generations beginning with Benjamin about 1770. In the Boston Gazette for 22 nd Feb. 1773, was announced, "Benjamin Willard, at his shop in Roxbury Street, pursues different branches of clock and watch work, has for sale musical clocks playing different tunes, a new tune every day of the week and on Sunday a Psalm tune. These tunes perform every hour without any obstruction to the motion or going of the clock, and new invention for pricking barrels to perform the music, and his clocks are made much cheaper than any yet known. All the branches of the business likewise carried on at his shop in Grafton." He was followed early in the nineteenth century by Aaron, who had a shop in Boston, and by Simon. "Willard " or "Banjo" clocks, well known in the neighbourhood of Boston, are of the hanging variety, and have below the dial a long trunk, narrow for the greater part of its length, and a square panelled enlargement near the bottom, which is in some instances painted with figures or a landscape, in others having inserted a circular glass through which the motion of the pendulum bob could be seen. Many of these bore the name, "Willard, Jr."

Willcocks, Richard, 46 Red Lion St., Clerkenwell, 1785-1800.

Willen, Johan, London ; watch, 1720.

Willerton, Skull \& Green, 21 New Bond St., 1783-94.

Willett, Jas., London; watch, silver cock, 1727; long Oriental lacquer case clock, about 1730 .

Williami, Justin, London ; clock-watch, the late Mr. Norman Shaw, about 1670.

Williams. Joseph (Ireland), C.C. 1685. Thos., apprenticed 1689 to Isaac Day, C.C. Jno., Leeds ; long-case clock, about 1700. Jno., 11 Old Bond St., 1769. Jno. (" from Mr. Graham's "), Clements, Lancs., 1770. P., Lom bard St., 1770. David," Endfield," 1774. Thos., Haverfordwest; watch, 1780. Jas., 35 Goodge St., 1794 . Thos., Haverfordwest, 1790 . Jas., 14 Market Place, Bath, 1798. John, 168 Shoreditch, 1800-4. R., Liverpool ; watch, 1810. David, Newport, U.S.A., 1810 . Geo., 7 Bridgwater Sq., 1817. John, watch-case maker, 56 Great Sutton St., 1820. John, 4 Amen Corner, 1821; 70 St. Paul's Churchyard, 1831. E., I Albany, Saville Row, 1825. S., 16 St. John's Row, St. Luke's, 1840 ; Baldwin St., 1842. Chas., 223 Oxford St. 
1842. J. G., Denbigh ; watch, 1842. Jas., Bristol, 1843.

Williamson. Robert, St. Bartholomew Lane; apprenticed 1658 to Jas. Letts ; C.C. 1666 , master 1698 ; watch with a shagreen case in the B.M. ; another in case of white agate, about 1740, Pierpont Morgan collection. William, C.C. 1664. Thomas, C.C. 1668. "Lost on the 19th day of August, from Mr. Will. Clinch's house at Epsom, a silver Minute Pendulum Watch with a scollop-shell case studded with silver, made by Thomas Williamson, London, with a silk string and a silver seal with a Coat of Arms. Whoever brings it to Mr. Robert Dingly, watchmaker in George Yard, Lombard Street, shall have 2 guineas Reward" (Lond. Gaz., Sept. 5-8, 1692). John, C.C. 1682 ; late-seventeenthcentury alarm watch, signed "John Williamson in Leeds," S.K.M., silver case pierced and engraved. Edward, apprenticed to Jonathan Puller for seven years ending 1694 ; long marquetry case clock, about 1710; Mr. W. L. Unkill, Mexico City, has a long-case clock, about 1700 , by Dave Williamson. Joseph, a first-rate horologist, inventor and maker of equation clocks; outside of the craft his reputation here was not commensurate with his merits ; he held the appointment of watchmaker of the cabinet of Charles II. of Spain, for whom he made a 400-day longcase equation clock; Mr. Edward Hawes has a long-case clock by him with dial verv similar to the one in the Wetherfield collection which is illustrated by Fig. 681 ; master of C.C. 1724, and died in office, 1725 (see p. 307). Timothy, 196 Fleet St., 1769-75; 90 Great Russell St., 1788; large watch, silver-gilt case, taken from Peking, Mr. H. J. Heinz.(see p. 234). J., London; watch, 1790.

Williamston. Ralph, C.C. 1706 ; watch, " R. Williamston, London," S.K.M., h.m., 1749. Christopher, 24 Cornhill, 1840-42.

Williarme, Pierre, admitted C.C. 1648. A correspondent of Notes and Quevies has an MS. return of strangers dwelling within Aldersgate Ward, October 1635, which states that Peter Williarme, watchmaker, resided in the parish of St. Botolph, and had then been in England twelve years, being a native of Geneva.

Willin, Wm., Percival St., 1800-11; livery C.C. 1810.

Willing, - London ; calendar watch, one hand, nicely engraved dial, Schloss collection, about 1720 .

Willis. Ambrose, apprenticed 1687 to Thos.. Baldwin, C.C. Richard, Truro, about 1770-85. Mary, 81 Bishopsgate St. Without, 1822-5. Jno., enameller, 23 Greenhill's Rents, 1823 ; afterwards Perci- val St. Thos. J., son of Jno., an excellent dial enameller; died 1893, aged 57.

Willmot. Thomas, C.C. 1715. John, 86 St. Margaret's Hill, 1762-75.

Willoughby. Benjamin, High Cross, apprenticed 1676 to Robt. Dingley, C.C. John, C.C. 1686. Benj., Bristol; watch, about 1730; another, about 1765 .

Willowe, John, Fleet St. One of the first wardens C.C., master 1635 ; watch. B.M., in a fancy case of escallop shape, 1620-40.

Wills. Jne, apprenticed 1682 to Wm. Hillier, C.C. Joseph, long-case clock, about 1740, Mr. G. W. Price, Salem, New Jersey, U.S.A.

Willshire. James, Glasshouse Yard, Goswell St., 1769-80 ; Mr. J. L. Raymond, New York, has a long-case clock by him. James, 19 High Holborn, 1781.

Willson. Thomas, C.C. 1659, assistant 1685. George, C.C. 1692. William, C.C. 1693. John, King's Head Court, Holborn ; C.C. 1714. Jas., London; watch, 1768. G. V., 5 St. Alban's Place, St. James's, $1835-40$.

Wilmer, Thos., London, about 1760.

Wilmot. Thos., apprenticed 1653 to Thos. Loomes, C.C. Isaac, apprenticed 1662 to Jno. Bayes, C.C. Stephen, London. apprenticed 1667 to Ed. Staunton; C.C. 1674 ; 30-hour long-case clock, square dial, about 1720 . George, apprenticed to Jeffery Baily and turned over to John White ; C.C. 1670. Jno., apprenticed 1676 to G. Stubbs, C.C., Upper Rosoman Street, about 1810. Richard, 1 Wilmington Sq., 1842, see also Willmot.

Wilmshurst. T., Deal ; watch, Schloss collection, 1746. \& Son, Brighthelmstone (now Brighton); watch, 1765. Stephen, Basingstoke, 1770.

Wilson. Richard, York, f., 1586. William, his son, f., 1607. Thos., apprenticed 1651 to Simon Hackett, C.C. Nat., apprenticed 1658 to Edward East, C.C. Edwd., apprenticed 1663 to Richard Nau ; C.C. 1670. (or Willson) Joshua, London ; apprenticed 1688 to Wm. Fuller, C.C. ; lantern clock, finely engraved dial, about 1700 ; long clock, 11-in. dial, fine marquetry case, about 1705 , Wetherfield collection ; watch, h.m., 1707. Jno., Edinburgh, apprenticed to Andrew Brown in 1711 . James, against St. Lawrence Church ; C.C. 1723 ; Susannah Smith was apprenticed to his wife Hannah Wilson in 1747. George, C.C. 1730. Jno. ; clock in America, dating from about 1740, marked "John Wilson from London." James, Hawick, born 1748, died 1821. John, Corn Market, Belfast, 1750 , afterwards at Linen Hall St., Belfast. Nich., Kendal, 1765. James, 4 King St., Westminster, 1770-94; hon. f., 
1781. Jno., London; watch, 1772. Jn. Ulverstone, 1775 . Titus, Lancaster, 1779, f. Alexander, 132 Drury Lane, hon. f., C.C. 1781; maker of a verge watch, pair of brass cases, with outside case of tortoiseshell, on which are representations of ferns, 1770-94. Jas., Askrigg; died 1786. Will., Kendal, 1790. Thos., London; watch, 1791. Thos., Spalding ; clock, about 1800. Jno., Dublin ; watch, 1804 James, 27 Threadneedle St., 1804 ; Sweetings Alley, Royal Exchange, and afterwards at 53 Lombard St. ; died 1810. G., 17 Craven Buildings, Drury Lane, 1820. W., 38 Southampton St., Strand, 1829-42 ; afterwards Wilson \& Gander, see Jessop. Jno., Peterborough; in 1835 he put a new escapement to the Minster clock. \& Gandar, 431 Strand, 1855-65. see Blackie.

Wilter, John ; watch, G.M., silver dial, silver repoussé case, signed Cochin ; another example, a silver repoussé paircase watch, Dutch style; another, a calendar watch in the Schloss collection, has a painting of the Queen of the Poppies on the back of the case; watch, Evan Roberts collection, $1769 ; 1760-84$.

Wilton. Clay, C.C. 1697 ; watch by him, with embossed case by Cochin, exhibited at the Guelph Exhibition by Mr. Geo. Carr Glyn. John, London ; watch, silver inner case, outer one green shagreen with piqué ornament, about 1767, Hilton Price collection.

Wiltshire \& Sons, 136 Cornhill, 1822-30.

Wimble, Nemih, Maidstone, about 1760 .

Wimper, David, Hammersmith ; longcase clock, about 1740 .

Winch, Amos, C.C. 1677.

Winckles, Jno., London; watch, 1782.

Winder, of Lancaster: Thos., 1795, f. ; Stephen, 1823, f. ; Thos., 1825, f. ; Wm., 1830 , f.

Windess, Lancaster: Thos., 1795 ; Stephen, 1823 ; Thos., 1825 ; Wm., 1830. Windham, Jas., 22 Birchin Lane, 1840. Windmills. Joseph, St. Martin's-leGrand, afterwards in Mark Lane; well known as a good maker of clocks and watches; C.C. 1671, master 1702 ; Mr. Albert Hartshorne has a fine lantern clock of his make; the late Mr. Norman Shaw had a clock by him with very good engraved brass dial, on the upper part of which is inscribed "Thomas Pardey. 1697 ; " another production is a bracket clock, inscribed "Joseph Windmills, at Mark Lane End, next Tower Streete, Londini, Fecit;" among the Wetherfield collection is a long-case clock, 10-in. dial, bolt and shutter main taining power, inlaid laburnum and olive wood case, sliding hood, with spiral pillars, about 1690; another with an 11-in. dial marquetry case, about 1700 ; in the B.M. is a handsome watch by him, silver dial, in which is a semicircular opening above the centre ; through it appears a representation of blue sky, with the sun pointing to the hour by day, and the moon by night; tortoise-shell case ; there is a similar watch by Joshua Hutchin. " Gold watch lost, made by $\mathrm{Mr}$. Windmills, in Mark Lane. Give notice as above, or to Mr. Rudge, over against the Swan Tavern, in King's Street, Westminster" (Lond. Gaz., April 25th, 1687). Thomas, apprenticed to Joseph Windmills. 1686 ; C.C. 1695 , master 1719 ; a repeating watch by him in the G.M. J. \& T., Great Tower St. (Thomas Windmills, master C.C. 1718) ; many excellent long-case clocks by them are to be met with; 1710-40. \& Wightman, London; long-case clock, about 1720. \& Bennett, long-case clock, about 1725. \& Elkins, London; bracket clock, about 1725 .

Windon, Daniel, C.C. 1718.

Windsor, James, 99 Paul St., Finsbury, 1835-42.

Winerow, William, C.C. 1718

Wing, Mark, 27 Goswell St., 1816-42.

Wingate. Paine, Boston, U.S.A., 1789 ; Newburyport, 1803. Frederick, Augusta, U.S.A., 1800.

Wingrove, Jno., St. John's Sq., C.C. 1730 ; watch, about 1745 , inscribed "Sarah Wingrove, London."

Winkley, Jno., Canterbury, about 1760. Winne, Hy., see Wynne.

Winnerl, Joseph Thaddeus, born in Styria, 1799; settled in Paris 1829 ; a celebrated chronometer maker; died 1886.

Winnock. Joshua, apprenticed to Ahasuerus Fromanteel the Elder; C.C. 1672. Daniel, C.C. 1707.

Winrowe, Wm., London; watch, 1760.

Winsmore, John, C.C. 1712.

Winson, Thos., London ; watch, 1782.

Winstanley. Jere., apprenticed 1687 to Jno. Wheeler, C.C. ; long-case clock, about 1750, inscribed "Winstanley, Holy Well, North Wales." Edward, Liverpool, 1770. Peter, Huyton ; watch, silver balance-cock, about 1775, Mr. E. A. Laurence. E., London; watch, with minute circle inside hour circle, about 1780. Alex., Wigan, about 1780. Robt., Ormskirk, 1818. Edwd., Wigan, 1820

Winstendley, Thos., Modely; watch, h.m., 1774 .

Winston, Wm., "Opposite the Cross," Hereford, 1770.

Wint. Dan., apprenticed 1693 to J. Clowes, C.C. Danl., "At the Dial and Crown," West Smithfield, 1774.

Winter. Sam., apprenticed 1683 to Ed. Stanton, C.C. Wm., apprenticed 1686 to 
Robt. Dingley, C.C. Robt., 59 Cannon St., Ratcliffe, 1817.

Winterhalder, -, London; watch, 1810.

Winterhalter, J., 47 St. Andrew St., 1840.

Wintle. David, London ; clock, about 1680. Thos., 9 Poultry, 1760-68.

Wintworth, Thos., Sarum; lantern clocks, 1700-40.

Wirgman, Peter, 79 St. James's St., 1775-94. C. \& G., 31 Castle St., Holborn, 1804. Thomas, 68 St. James's St., 1823. G., Hewitt's Court, Strand, 1825. C., 5 George St., 1830.

Wirrall, Copley, C.C. 1648.

Wise (or Wyse); several generations among the early makers. Jno., apprenticed 1638 to Peter Closon; C.C. 1646. John, C.C. 1669 ; clock, inscribed " John Wise Londini, fecit," given to Zion College in 1672. Richard, C.C. 1679. John, C.C. 1683 ; on lst Nov. 1693, “ John Wise dwelling neere the popes head in Moorefields citizen and clockmaker of London," became a joint surety for Richard Wise, Renter to the Cutlers' Company for 1693-4. Luke, Reading, 1686; watch, about 1720 , stolen from Newington Free Library. Thomas, Fenchurch St. ; C.C. 1686 ; longcase clock in the Vestry of Westminster Abbey, square dial, rings round winding holes; another, signed "Thos. Wise, Fenchurch St.," from the Dunn collection, fetched fifty-eight guineas at Christie's in 1912. Joseph, C.C. 1687 ; in the same year was apprenticed to him the celebrated Langley Bradley. Peter, son of John, admitted C.C. 1693 , master 1725 ; Mr. T. W. Bourne owns a bracket clock by him (Fig. 804) ; 1693-1726. Luke, C.C. 1694. Robert, C.C. 1694 . John, C.C. 1710 . Mark, C.C. 1719. Matthew, London; watch, 1740 ; Daventry, 1780. Featherstone, Hull, 1822.

Wiseman, John, C.C. 1647.

Wiss. Frères, Geneva, about 1775. \& Menu, Geneva, 1790.

Wiswall. Thos., 20 Ely Pl., 1800. \& Co., 52 Red Lion St., 1810.

With, Thos., London ; fine bracket clock, date of the month hand, Sheraton case, about 1790 .

Wither. Jas., apprenticed 1637 to $R$. Child, C.C. Richd., apprenticed 1681 to Andrew Prime, C.C. John, C.C. 1699 ; maker of long-case clocks.

Withers. Wm., London; long-case clock at the Church of the Cappucins, Cadiz, about 1760. Wm., Bristol, 1820-43; lever watch in French case, about 1825.

Witherspoon, Alex., Tranent, Scotland ; invented a clock escapement, 1835.

Witness, Francis, apprenticed 1650 to Job Betts, C.C.

Witson, H., London ; watch, 1825.

Witte, Samuel, C.C. 1660.

52
Wittingham, Wm., London; watch, about 1700 . Chas., London; watch, 1820.

Wittit, James, London; watch, G.M., about 1750 .

Woerd, Charles V., born 1821, died 1888 ; a clever mechanician who did much to advance the art of machine watchmaking by designing automatic tools for the Waltham Watch Co., of which he was mechanical superintendent from 1875 to 1882.

Wogdon, Stephen, Greenwich; small arch-dial, about 1730 .

Wolf, J., Wienne; maker of a bookshaped watch, 1627.

Wolfe. Jno., Noble St., C.C. 1730. Joseph, Mitre Court, near Aldgate, 1762-72.

Wolfgang, Johann, Pollinger, Friatberg; repeating watch, S.K.M., about 1730 .

Wolkstein, David, Augsburg ; associated with Dasypodius in the superintendence of the second Strassburg clock in 1570 . He is said to have invented the Carillon.

Woller, Matt., Coventry, 1816.

Wolverstone. Benjamin, apprenticed to Richd. Richardson in 1647 ; C.C. 1656 ; alarm watch, silver dial, one hand, in the G.M. Thomas, C.C. 1650 . Jas., C.C. 1670.

Womersley; long-case clock, square dial, rings round winding holes, signed " Geo. Womersley," about 1720.

Wontner, John, Minories ; a well-known maker, 1770-1812; livery C.C. 1810. John, \& Son, 125 Minories, 1804-12, see also Rentnow.

Wooborn, Geo., London; watch, 1798.

Wood. Richd., apprenticed 1651 to Jno. Coòke, C.C. G., Exon. ; lantern clock, about 1660 . Jas., apprenticed 1668 to Ed. Gilpin, C.C. Robert, C.C. 1670. Thomas, C.C. 1691. John, C.C. 1701. Henry, C.C. 1720. Thomas, Barbican, C.C. 1727. Dan., London; watch, 1745. James, apprenticed to Joseph Miller, C.C. 1745; Samuel Alvey apprenticed to him in 1750 ; watch, G.M., about 1780 . Peter, long-case clock, about 1750 . Joseph, Scarboro'; long-case clock, about 1760, Mr. Logan. David, Newburyport, U.S.A., 1765-90. John, Philadelphia, 1770-93. " Clocks, watches, gold \& silver work made, mended, and sold at the sign of the Dial, the corner of Front \& Chestnut Streets." F., Scarboro', 1770-90. John, 32 Minories, 1775. Jno., Grantham, 1780. Robert, Horse Shoe Alley, Moorfields, 1785-1810 ; fine bracket clock, about 1790 . Josiah, New Bedford, 1797-1810. Geo., 19 Orange Grove, Bath, 1798. Benj., London; watch, 1800. Robert, 4 Harley Pl., Kent Rd., 1820-35. Thomas Jas., 86 Charlotte St., Rathbone Pl., 1822-30. Hy. Sam., Canterbury, 1835. Thos. Jas., Long Lane; died 1890. Joseph 
J., Richmond ; died 1909, aged 80. Jno., Devizes, 1843.

Woodall. Thos., apprenticed to G. C. Addis ; C.C. 1796. T. J., 3 Birchin Lane, 1804-10. F., 1817.

Woodfine, Rt., Liverpool ; watch, 1809.

Woodford, Jonathan, apprenticed 1684 to Jno. Ebsworth, C.C. ; watch, 1736.

Woodhill, Jabez, 63 St. Paul's Churchyard, 1830.

Woodington, Wm., apprenticed 1638 to Ed. Gilpin, C.C.

Woodman. Jno., London, about 1780. Mary, 29 Paradise Row, Chelsea, 1835. Phillip \& John; succeeded Rowlands as watch-case makers in Smith St., Clerkenwell, did much to support trade charities ; Phillip was for some years treasurer of the Clock and Watchmakers' Asylum ; John died in 1903, and Phillip.in 1908.

Woodruff \& Son, 43 Kirby St., Hatton Garden, 1822-30.

Woods. Thomas, C.C. $1713 . \quad J n o .$, Liverpool, 1770. C. R., 21 White Lion St., 1842.

Woodward. Jno., apprenticed 1656 to Ben. Hill, C.C. Thos., apprenticed 1671 to Jno. Frowde, C.C. J., 8 New Inn Yard, 1835. Thos., 24 Curtain Rd., 1835.

Woolard, John, 14 Bridge Rd., Lambeth, 1810-18.

Wooley, Thos., 41 Hutton St., 1793.

Woolhead, Maj., London; watch, 1780 .

Woolley, -, Tenterden ; Act of Parliament clock, about 1797.

Woolridge, Stephen, apprenticed 1652 to Jere. Gregory, C.C.

Woolverton. Jas., C.C. 1677. James, C.C. 1690 .

Wopshot, Thos., London; watch, 1773.

Worboys. Arthur, 4 Wine Office Court, Fleet St., 1769-85. Jno., 30 Ludgate Hill, 1780-94.

Worke, Jno., London ; many watches, Dutch style, 1760-85.

Workman, Ben., portable sun-dial, B.M., about 1700 .

Worlidge, Nat., apprenticed 1661 to Ed. Norris, C.C.

Wormesley, -, Macclesfield, 1814.

Worrall, John, 71 Goswell Rd., 1836-42.

Worrell, Jno., London ; long-case clock, about 1760 .

Worsfold. Jno., Dorking; long-case clock, about 1720. Jno., Hampton Wick ; watch, 1733.

Worsley. Thos., 22 Cheapside, 17831805. Thos., Liverpool; watch by him said to have been presented to Robert Burns by his brother ploughmen of Ayr in 1785. John, London; watch, 1802.

Worswick, Thos., Lancaster, 1753, f.
Worthington. Edwd., apprenticed 1655 to Jas. Cowpe, C.C. John, C.C. 1721 ; watch, 1740.

Wortley, Humphrey, apprenticed 1653 to $\mathrm{Ab}$. Gyott, C.C.

Wotton, Thomas, Fleet St., maker of lantern clocks, 1690-94.

Wragg, Houblon, C.C. 1724, known as a maker of long-case clocks.

Wranch (?Wrench), Jno., Chester ; lantern clock, about 1700 .

Wrapson, I., Chichester ; long-case clock, about 1800 .

Wren, John, 96 Bishopsgate Without, 1780-85.

Wrench. Edwd., watch, about 1690. John, Chester; died 1716; Mr. Edward Sudell has a lantern clock engraved " John Wrench in Chester," dating from about 1680. John, Chester; died 1751; long inlaid case clock by him, about 1730 . W., Chester; long-case clock, about 1760 . Charles, " near the Turnpike, Shoreditch," card, Ponsonby collection, about 1780 ; 57 Bishopsgate St. Within, 1790; 25 Camomile St., 1798 ; 29 Paternoster Row, 1810-15.

Wright. John, oval watch, B.M., inscribed "Wm. Heade, the owner," representation of the Crucifixion engraved inside, about 1620 ; part of a circular watch movement, dating from about 1640 , and engraved "Johannes Wright in Covent Garden," is in the Guildhall Museum. Robt., C.C. 1634. John, C.C. 1661. Joseph, C.C. 1671. Benjamin, Bell Alley, Coleman St., apprenticed to Abraham Prime, 1678 ; C.C. 1685 . Edmd., apprenticed 1682 to Joseph Knibb, C.C. Wm., London; apprenticed 1684 to Hy. Brigden, C.C. ; long clock, 11-in. dial, panelled marquetry case, with spiral pillars to hood, about 1695 , Wetherfield collection ; at Goldsmiths' Hall is a long-case clock by him. Richd., C.C. 1696. John, C.C. 1700. John, New York, 1712-35; f. 1713 . John, C.C. 1715. Thomas, Duke St., St. Martin's Lane, 1765-75. \& Sellon, watch, 1769. Thomas, 6 Poultry; admitted C.C. 1770; "maker to the King " on a bracket clock; he was a Quaker and a leading watchmaker; in 1783 he patented (No. 1,354 ) a form of detent escapement and compensation balance; died whilst on a visit to Birmingham, 1792; 1770-92, afterwards Wright \& Thorp. Edwd., London ; watch, 1775. Chas., 9 Avemary Lane, 1780; 76 Strand, 1788; 94 Watling St., 1790. Jno., hon.f., C.C. 1781. Jno., Chesterfield, 1785. Josh., Warwick, about 1790 . T., watch-glass maker, Red Lion St., Clerkenwell, 1798; 127 Bunhill Row, 1805-20. Thomas, Dorking, about 1800 . Charles Cushing, New York; after 1812 settled in 
Utıca. S., 141 Ratcliff Highway, 1820. Jas., 181 Union St., Borough, 1820-35. Elizabeth, 141 Ratcliff Highway, 1825. Thos., 22 Lisle St., Leicester Sq., 1835-42. Jno., 16 Wilsom St., Bath, 1835. William, 212 Tooley St., 1840-42. John, Pentonville, 1842 .

Wrightman,Thomas, admitted C.C. 1701.

Wrightson, Thomas, master C.C. 1737 ; 1724-38.

Wrightwick, Jno., long-case clock, about 1770 (? Wightwick).

Writs, W., Amsterdam; watch 1767. Wroley, Geo., Bristol, 1843.

Wutky, - , clock-watch, signed " Johann Wutky in Breslau," about 1660, Pierpont Morgan collection.

Wyatt. Anthony, 367 Oxford St., 1800-18. Hy.,46 South Audley St., 1840-42.

Wych. Jno., apprenticed 1677 to Jno. Fitter, C.C. David, next door to the Cross Keys Tavern, Strand; C.C. 1694.

Wycherley, John, born in 1817, at Prescot, Lancashire, where he founded the machine-made watch movement industry ; died at Southport, 1891.

Wyeth. John, brother C.C. 1655. Lionel, see Wythe.

Wyke. Arthur, apprenticed 1691 to Thos. Wood, C.C. Jno., Liverpool ; longcase clock, about 1760. Jno., Prescot, 1780 ; good maker of tools for watch and clock makers; afterwards at Liverpool, with Green. \& Green, Wyke's Court, Dale St., Liverpool; makers of watches and clocks and parts thereof and watchmakers' tools; published a quarto illustrated catalogue of tools, about 1810 . R., 2 Evelyn's Buildings, Oxford St., 1825. 1720 .

Wyld, John, Nottingham ; clock, about

Wylde, Jno., London; watch, 1810.

Wylder \& Hall, 16 Sun St., Bishopsgate St., 1794.

Wymark, Mark, 5 Percival St., 1816-42.

Wynn. W. M., 135 Fleet St., 1804. William, at Farnham in 1817, when he was awarded the Isis gold medal and twenty guineas by the Society of Arts for a timekeeper and compensation pendulum ; in 1822 he was at 19 Dean St., Soho, and received a prize of twenty guineas from the Society for an improved method of lifting the hammers in striking clocks; maker of an exceedingly fine clock for Boston (Lincolnshire) Church, no dials, hours and quarters on bells; is said to have died in Clerkenwell workhouse; 1810-35.

Wynne. Robt., apprenticed 1641 to Jas. Vantrollier, C.C. Henry, apprenticed to Ralph Greatorex, 1654 ; C.C. 1662, master in 1690. Jno., apprenticed 1670 to Wm. Watmore, C.C
Wyse, see Wise.

Wythe. Lionel, C.C. 1646 ; a good maker; to him was apprenticed Charles Gretton, in 1662. Richd., apprenticed 1682 to Jno. Johnson, C.C.

Yarde, Thomas ; watch, B.M., about 1580.

Yardley, James, Bishop's Stortford: long-case clock, arch dial, date on back of day of month circle, 1763.

Yate, Wm. ; oval watch, about 1605.

Yates. Samuel, C.C. 1648. Wm., C.C. about 1660 . Michael, apprenticed 1664 to Isaac Plovier, C.C. Samuel, C.C. 1685. George, Malden ; watch, G.M., h.m., 1746. Richd., London; clock, 1760. Henry, Liverpool, 1770. Jno., opposite the church, Wandsworth, 1800 . \& Hess, Liverpool, 1833. Thomas, Preston; in 1846 he patented (No. 11,443) having fewer teeth in the escape wheel, so that a watch balance would vibrate only twice a second.

Yeadon, Wm., Stourbridge, 1830.

Yeates, Thos., Penrith, 1832.

Yeatman, Andrew, apprenticed in 1684 to Jas. Woolverton; C.C. 1692 ; silver watch, in the G.M., about 1700 .

Yelah, Jno., Wrexham, 1780.

Yelverton, Wm., 115 Portland St., 1780-94.

Yeomans. Ralph, C.C. 1722. Joseph, Cockermouth; died 1905, aged 65.

Yeriaf, see Fairey.

Yewdall, Jno., Bradford; watch, 1803.

Yoakley, Thos., London ; watch, 1760 ; long-case clock, signed " Thomas Yoakley, Ratcliff Cross, Mr. Edes, Cambridge, Mass.'

Yonge. Robert, Bennet St., Westminster; C.C. 1730. George, 131 Strand, 1798; Yonge succeeded the celebrated Holmes (the shop was pulled down to make the entrance to Waterloo Bridge in 1824). George \& Son, 156 Strand, 1823. Geo. \& Walter, same address, 1830-42. Walter, 171 Strand, 1850-54.

Yorke. Thomas, Turnagain Lane; C.C. 1716. Joseph W., Turnagain Lane; C.C. 1735. John, 8 Nelson St., City Rd., 1840.

Youell, Robt., apprenticed 1689 to Michael Knight, C.C.

Young. William, Charing Cross; C.C. 1661, assistant 1695 ; maker of a long oak case clock, square dial, day of month circle, see Brown, Andrew. Richd., apprenticed 1669 to Ed. Fage, C.C. Henry, near the Wine House in the Strand ; C.C. 1672. " A Gold Watch made by Mr. H. Young, that went with a chain, the Hour of the day and day of the Month. Having a studded Shagrine case, and the square in the inner case where the ring is riveted " (Lond. Gaz., April 26-29, 1680). Henry, 89 Fleet 
St., 1679-1700. Francis, apprenticed 1680 to Hy. Young, C.C. William, Charing Cross, C.C. 1682 ; small walnut and ebony long-case clock, solid hood, spiral pillars, square dial, cherub corners, about 1700 . Thomas, C.C. $1699 . \quad$ Richd., London ; watch, 1775. John, 44 Great Russell St. Bloomsbury, 1778-1807 ; livery C.C. 1781 ; very small bracket clock by him, round enamelled dial fitted in square brass plate. Saml., Perth; watch, 1781. James, 32 Aldersgate St., 1783 ; livery C.C. 1786. Hy., 18 Ludgate St., 1783-88. Wm., Bath ; watch, 1790. Henry, Swaffham, 1790-1800. W., London, about 1800 . Chas., London ; centre seconds, duplex watch, free balancespring, stud screwed to plate, about 1805 ; marine chronometer, G.M., about 1815 ; pocket chronometer, about 1817 . J., 40 Old Gravel Lane, 1820. Wm., 15 Butcherhall Lane, 1825. William, Harrogate, 1827 ; long-case clock with the old sulphur well painted on the dial, Miss Violet Young; in 1838 he made a clock for Low Harrogate Church at a cost of $£ 120$; he died in 1876. Jas., 34 Rosoman St., 1835.

Yver, F., à Saintes ; watch, about 1675 , Mons. E. Gélis.

Zacharie le jeune, clever horologer in Lyons, 1769.

Zachary, John, apprenticed to William Simcox, and turned over to Daniel Quare ; admitted C.C. 1694.

Zahm, G. M., Lancaster, Pa., 1843.

Zech, Jacob, Prague; invented the fusee in 1525; died 1540 .

Zinzanth, Hy., apprenticed 1657 to Jno. Coulson, C.C.

Zoller (or Zollner), Martin, Augsburg ; clock by him, Vienna Treasury, about 1590 ; Abraham Scheurlin apprenticed to him, 1633.

Zucker, Jno., Tiverton, 1710. 


\section{N D EX}

\section{Note.-If particulars of a maker are required, refer first to the Alphabetical List, whrch begins on page $63 \mathrm{c}$}

Abbot, G. E. H., 783, 789

- J. W., 312

Abbott, C. J., 496

Abu Hammon Palace, 26

Achilles and Styx enamelled watch, 190

Acorn watch, 148

Act of Parliament clock, 597

Adams, W., 484

Admiralty, 527, 535

Æ̇neas and Dido repoussé watch, 202-3

Agar-Baugh, J. H., 410

Alarm Clock, circular, 70

— watch, sixteenth century, 135

- striking oval watch, 73

Alarum watch, earliest kind, 70

Albree, J., 703

Alcock, 256

Alderly Church, 738

Alexander and Roxana repousse watch, 202-3

Alfred, King, 15

Allen, R., 744

All Saints', Leicester, 22

Alternating movement Japanese clocks, 475

American clocixs, Cheap, 568

Amhurst, Earl, 652

Anchor escapement, 322

Annunciation and Nativity watch, 256

Apollo and Diana enamelied watch, 185

Apparent time, 2

Apprentices, women sanctioned, 264

Arabesque work, 76

Arched dial clocks, 514, 519, 549, 563, 574

Aries, difference between sign and constellation, 3

Arkwright, J. H., 308

Armagh, Archbishop, 365, 384

Armour, D., 740

Arms of the Clockmakers' Company, 263

Arnold, J., 358, 362, 363

Arrow-head hands, clock, 525

Arthur, D., New York, 45, 47
Arthur, J., Collection, 455, 635, 648, 660

Ash, E., 652

Ashmolean Museum, Oxford, 112, 253, 269, $398,588,715,754$

Assay Office, Birmingham, date-letters 624

- Chester, date letters, 625

- Marks for various towns, 620

Astor, W. W., 472

Astronomer Royal, 345

Astronomical clocks, 86, 109, 110, 315, $354,382,420,432,441,461$

- watches, 93, 143, 236, 237, 238

Astronomico-musical clocks, 350

Atherton, Rev. W. B., 662

Atkinson, W. A., 684

Atlas clock, 462

Auchterlonie, L. W., 697

Augsburg, 68, 70

Augustus the Strong, 88

Aurora Public Library, Illinois, 647

Auxerre clock, 28

Bacchus clock, 114

Back plate engraved, 587 clocks, 588

Bailly, 17

Baker, E. P., 688

- J. H., 700, 742

Balance, 33, 79, 360, 362, 605

- springs, $105,107,280,605,607$

Baldwein, 56

Ball clock, 89

Balloon case clocks, 582, 591 enamelled watch, 192

Balls Hut Inn, Walberton, 705

Bancroft's School, Woodford, 651

Bankfield Museum, 492

Barbaret, enamelled watches, 181

Baret, J., 40

Barges Abbé, 26

Barleys on watch-cases, 214

Barlow, E., 276 
Barnard Castle, 716

Barometer by Quare, 275-311

Barrel mainspring, 78

Barrington, D., 60

Barrow, N., 325

Basket of Flowers watch, 154, 156

- work bracket clocks, 569

Bastard of Orleans, 404

Bastille, 762

Bates, Mr. H., 783

Bath, 725

-_., Pump Room, 287

Batsford, B. T., 548

Battersea enamel, 194

Battle Abbey, 666, 777

Baxter, Hon. P., 686

Beauvais Cathedral, 28

Beaven, E., 338

Beck, 726

-.., Rev. C., 640

Bedpost clocks, 476, 494

Bedroom or portable clocks, 452

Beetle hands, watch, 219

Belem, Lisbon, 694

Bell, C. F., 310, 313

Bell-shaped case clock, 573

top case clocks, 573,575

Bells, Tom of Westminster, 24

Bentall, C. J., 549, 752

- L, L., 554, 680

Bentham, J., 336

Bentinck-Hawkins Collection, 634, 677

Bernal Collection, 102-3, 145. 147, 769

Berne, 28

—_ trade-mark, 68

Bethnal Green Museum, 133

Betts, 277

- - S., 737

Bibliothèque de l'Arsenal, Paris, 416 des Jagellons, Cracow, 461

Bick, G. M., 798

Bigelow, F. H., 554, 777, 787

Bird-cage clocks, 270, 469, 476

Birdwood, Sir G., 597

Birkbeck, Dr., 731

Bishop of Chester, 733

Bishop's Palace, Wells, 671

Birchall, W., 491, 742

Blackburn Museum, 799

Bligh, Capt., 722

Blois, 74

Blue, royal, enamelling, 194

$\mathrm{B} \supset \mathrm{b}$ pendulum, 476

Bodleian Library, Oxford, 25

Bohm, M., 111

Boleyn, A., 50

Bologna, 27

Bolt and shutter maintaining power; 317 , 506,507

Bonbonnière watch, 151

Book-watch, 145, 146

Booth, 276

Boston (Lincs.) Church, 807

Bosulle or Buhl work, 406
Bourne, T. W., 290, 329, 484, 485, 522, $526,588,669,781,805$

Bowen, W. K., 542, 716

Bowyer, 479

Boynton, T., 534, 685, 688, 698, 718, 761, 763, 790, 794, 798

Bracket-clocks, 275, 276, 285, 289, 299, $301,304,306,309,381,402,410,411$, $412,413,415,416,418,566,568,582$

Bradley, L., 53, 331

- T., 529

Bradnam, E., 785

Bragg, M. F., 484, 518, 777, 800

Branch clock, 254

Brass-edge of dials, 216

Breguet, A. L., 385, 392

Brickwork base long-case, 550

Bridge clock, 396

Bridges, H., 396

Bristol Cathedral, 708

British Museum Ccllection, 14, 69, 76, 84, $94,100,104,113,120,131,133,139,145$, $148,149,151,152,153,156,160,161$, $164,165,167,168,169,170,179,182$, $189,200,205,250,252,253,254,256$, $268,270,280,305,332,336,384,451$, $459,635,640,642,644,647,649,654$, $655,656,657,658,660,661,662,663$, $664,665,667,669,670,678,679,680$, $681,682,685,688,690,695,699,700$, $704,710,713,716,720,721,723,724$, $728,730,731,732,736,737,738,739$, $740,741,742,743,744,750,753,756$, $758,760,767,768,771,773,777,778$, $780,784,786,788,789,792,793,794$, $796,803,804,806,807$

Brittain, H., 674

Brocklebank, Rev. J. M. R., 783

Broken-arch clocks, 582

Brown, Sir H., 649

Brown, R., 751

Bruce, R., 60. 62

Bruhl, Count, 355, 621

Bruges Cathedral, 640

Brunner, G., 28

Brunton, Dr. L., 764

Brussels, 28

Bucher, H., 57

Buck, J. H., 630

Buckingham, Duchess, 205, 7.84 Palace, 289, 354, 465, 671, 750

Buda Pesth Museum, 711

Buhl or Boulle work, 406

Bull, 252

Bulley, E. H., 686

Bull's-eye watch-glasses, 170

- watches, 211

Burdett Coutts, Baroness, 427

Burgundy, Duke, 48

Burns, R., 690, 806

Burrel!, (F., 612

Burt. I., 400

Bury St. Edmunds clock, 40)

Buschmair, H., 123 
Bushell, M., 657

Butterfield, 9

Butterfly enamelled watch, 155,157

Butts, F. J., 675

Caen clock, 26, 27

Cæsar, Julius, 13

Caffieri style clock, 433

Calais, 28

Calendar circles in arch of dial, 503

- clocks, 45, 354, 407, 420,427, 448,

$455,461,504,512,530,531,544,546$

- - how rectified, 2

- remembrancer in watch-case, 225

- - watches, $256,332,383$

Cambridge, Duke of, 291

Campbell, E., 723

Camondo, Comte de, 465

Canterbury Cathedral, 25

Cappucirs Church, 805

Cardigan, Earl of, 690, 720

Carnell, A. A., 725

Caroline, Queen, watch-paper, 212

Carrington, Lord, 665

Cartel or hanging clocks, 428,457

Carter, J., 764

Catherine, Empress, 750

Catherine of Braganza, 269, 270

Cavendish, Lord, 303

Ceulen, J. van, 149

Chains, 81

Chalford Church, 721

Chamber clocks, $49 \quad 279,476,479$

Chamberlain, P. M., 679, 727, 762, 787

Champ levé enamelling, 175

- engraving, 204

Changing hour figures, 228

Chapman, T. D., 679

Chapters, dials, 222

Charles I, 267, 641, 650, 797

Charles II., 8, 200, 274, 280, 328

Charles V., France, 677

Charles VI., 48

Charles X., 754, 758

Charles XII., Sweden, 658

Charles Stuart watch-paper, 212

Charlotte, Queen, 355. 611

Chased watches, 76. 199, 200, 204

Chastelux, Abbot P. de, 25

Chateau, 61

Château de Saint Germain en Laye, 728

Chatelaine, 171, 172

Chenevière, E., 737

Cherries with stalks watch, 148

Cherub clock, 351

Cheston, E. C., 699

Child's Bank, 527

Chinese Emperor, Pekin, 663

- scene enamelled watch, 190

- case clock, 37

Chippendale, cases, 548, 549

Chipping Campden, 797

Christchurch Hall, 706
Christchurch, Oxford, 371

Christ, Life of, painted on watch, 182

Christie's Sales, 634, 728, 729, 735, 736, $738,766,770,789,805$

Christy, M., 673

Chronometers, $344,356,368,384,389$

Circular watches, $67,70,150,165,166$, 256,565

Clarendon, 802

Clark, H., 543, 784

Clarke, A. E., 668, 749, 762, 769

$\longrightarrow$, E., 485

- Sir E., 764

Clay, C., 377

Clinch, W., 803

Clockmakers' Company, 261, 479, 748

-..., List of former, 626

Cloisonné enamelling, 175

Clepsammia, 16

Clepsydrae, 9,14

Cluny Monastery, 25

- Museum, Paris, 748, 773

Coblentz, 28

Coccleus, J., 63

Cockburn, A. G., 764

Cockle-shell watch, 148

Cog-wheel cutting machine, 322

Collie, W., 785

Colnbrook Church. Bucks, 673

Compensation, 335, 341, 345, 353, 613

Conan, W., 691

Concentric minute hand, 312

Congreve clock, 472

Conservatoire National des Arts, Paris, 427,456

Constantinople, 754, 761, 768

Conversion of Saul repoussé watch, 202, 203

Corner-piece, spandrel, 504, 506

Cook, Capt., 711, 722

—-, E. E., 564, 757, 781

- - H., .522, 549, 791

Cooke, A. S., 724

$\longrightarrow$, H. S., 672

Cooksen, J. B., 748

Copenhagen, 56

Cork, Earl of, 310

Couheru-Meuri, 770

Counter or metal outline, 410

Courtenay, Bishop, 37-38

Coventry Market Hall, 733

Cox, Mrs. M. D. B., 716

Cracow, 459

Craig, W., 702

Crank roller watch escapement, 612

Cratzer, 249

Crayle, 255

Cripplegate Church, 332, 679

Cromwell, Oliver, 169, 170, 659, 663, 666, 705

Cross-bar balance, 79

- Japanese clock, 475

Cross-shaped watches, 148, 260

Crown wheel penduluins, 494 
Crucifix clock, 121

Cruciform watches, 150

Crystal cases, 133, 149, 151, 170

Cumberland, Duke, watch-paper, 212

Cupid and dog enamelled watch, 194

- in a landscape enamelled watch, 187

Curb, compensation, watch, 353

Cusin, C., 77

Cycle of the Sun, 2

Cylinder escapement, 277, 282

Cylindrical brass-case watch, 70

Cymon and Iphigenia enamelled watch, 192

Czar of Russia, 336, 762, 775, 788, 795

Dasypodius, C., 40

Date-letters, Birmingham Assay Officc, 624

\section{- Chester Assay Office, 625}

Date-marks, gold and silver plate and watch, 622

David, L., 86

Davidson, J. H., 685, 779

Day, Dr. W. A., 695, 783, 791

Dead-beat escapement, 299

Deaf piece, 297

Death's-head watch, 131, 132

Decruc, M. A., 794

Deene Park, 690, 720

De Long, E. R., 790

Demolyn, J., 124

Dennison, F., 216

Derrick, S., 677

Desbois, 328

Desoutter, L., 390

Detent escapement, 360

De Vick, 27, 31, 36

Dexter, D. D., 688

Diamond-studded merlallion watch, 192

Diana and Nymph enamelled on watch, 190

Dickson, R. E., 472, 564, 651, 662, 686, $695,701,720,740,745,798$

Diminutive watch, 154,156

Ditisheim, P., 666

Dog watch, 148

Dolphin "fret" of lantern clocks, 489

Domed-top clocks, 569, 579, 580

Domestic English clocks, 476

Dondi horologium, 27

- J., 27

Donibristle, 291

D'Origny, R., 48

Double, Baron, 464

— basket-top clock, 569

Dover Castle, 36

- Museum, 645, 656

Downes, 45

Drapers' Hall, 305

Drake, Sir W., 588

Dresden, 56, 87, 90

- Green Vaults, 759, 773, 784

Drinking clocks, 328
Drum-shaped watches, 65,136

Dubois, P., 71, 7

Duduict, J., 74

Duke of York Tavern, 763

Dulwich College, 675

Dumb repeaters, watches, 618

Dunn Gardner Collection, 132, 136, 154,

$160,182,291,293,634,637,649,701,735$, $753,770,780,805$

Dunstable, 40

Dunwoody, Dr. W. J., 681

Duration of a year, 3

Durfee, W. H., 692

Dutch Church, Austin Friars, 320, 692 clocks, 493, 551, 554

Dutton, long cases, 554

Eagle watch, 148

Earliest clock, 25

Earnshaw, 362, 364

East, Ed., 265

East India Company, 554

Easter day-how determined, 4

Eastern countries, Clocks for, 579

Ebsworth, John, 273

Eddystone Lighthouse, 778

Edes, 807

Edward VI., 123

Eight-day clocks, 283, 304

Elector of Saxony, 92

Elephant clocks, French, 450

Elizabeth; Queen, 123-4, 125

Ellacombe, Rev. H. T., 38

Ellicott, 335, 337

Ellis, G., 401

Elmer, 327

Fly, Bishop of, 133

Embroidered pads in watch-case, 211

Emperor of China, 735

Enamel, Battersea, 194

- Translucent, 185, 194

Enamelled watches, $74,173,174,175,176$

$179,180,185,187,189,190,195,197$. 198

Enfield, B., 758

Engine-turned cases, 214

English domestic clocks, 476

Engraved and chased watch-cases, 75, 204

Epact, 4

Equation clocks, etc., 307, 338, 393, 394

Equinoctial year, 3

Ericson, G., 678

Escallop watch, 149, 151

Escapements, 18, 33, 277, 282, 299, 341, $347,355,360,362,369,606,611,612$

Espez of Galicia, 766

Essex, Earl, 725

Estreicher, Dr. T., 461, 750

Evans, Dr. H. N., 382

- , H. A., 577

Evelyn, 61

Ewart, Sir W. Q., 766

Exeter, 37, 398, 633, 714, 768 
Fairley, F. B., 760

Falling-ball timepieces, 458

Fan clocks, 403, 468

Farnham, 327

Farrow, W., 655

Father of English watchmaking, 277

Fawcett, E. and M., 529

Féalins, J. de, 28

Fehmel, A., 123

Feilden, Capt. R., 742

Fellows Collection, 169, 713, 769, 787

- L Lady, 679

Female washing her feet, enamelled on watch, 185

Fencing soldiers watch, 230

Ferguson, J., 82, 378

Fiddle or kettle-shaped base of long case, 549

Field, F. A., 776

Fifteenth-century clock, Italian, 28, 49

Filey Church, 706

Finchett, A., 14

Fine, O., 55

Finger-ring watch, 154, 156

First Empire style French clock, 452

Fish-skin watch-case, 160

Fitzgerald, E., 745

$\longrightarrow$, Lady O., 148

Fitzwalters, H., 780

Fitzwilliam Museum, Cambridge, 253, 649, $703,713,715,738$

Flagellation of Jesus Christ clock, 119, 121

Flattened oval-shape watches, 211

Fleming, J. H., 704

Fleur-de-lis watches, 152

Flood, 254

Floral design watches, 152, 153, 188, 189, 198

Flower-bud watch, 153

Fluted-case watch, 268

Foale, D., 714

Fob-chain and chatelaines, 169, 172

Foliot balance, 33

- (le), 73

Forest, R. W. de, 121

Foster, R. L., 549

-, T., 525

Fotheringham, 644

Foucher, 177

Francis I., France, 404

Francisco, J., 204

Franklin, 380 Dennison Collection, 243

Frederick II., Germany, 19

Freeman, Chas., 661

Freizer, C., 114

French clocks, 404

Fret brasses, 485, 527

Frictional brake, 80

Friesland Hood clock, 492

Fritillary flower watches, 156

Frodsham, H. M., 346

Froissart, 34
Fromanteel, 314

Fry, Sir T., 664, 709, 714

Fusee, barrel, mainspring, $78,80,81,616$

Gabb, G. H., 463

Garnier Collection, 136, 152, 161, 247, 638, $643,648,657,672,674,675,679,680$, $682,687,698,700,720,755,764,765$, $769,771,780,792,793$

Garret, 253

Gaston of Orleans, 105

Gaver, G., 54

Gaydon of Kingston, 306

Gebert, 18

Gélis, E., 633, 647, 649, 657, 682, 686, 696, $698,702,732,738,741,747,760,793$, 808

Geneva, 639, 681

- Horological School, 729

Genoa, 27

Geoghagen, R. S., 47

George II., 760

750 III., $63,353,358,390,510,671$, $-1750$

Geyer, F., 789

Gibbs, M., 672

Gilbertson, Rev. L., 801

Gillespie's School, Edinburgh, 719

Glass-cases, watch, 140, 142, 170, 312, 455

Glastonbury Abbey, 22, 25, 29

Glenny, G. F., 546, 710

Globe (revolving hollow) clock, 116

Globes, Urns and vases, 461

Glyn, G. C., 674, 678, 680, 694, 717, 744, $760,766,774,788,789,791,801,804$

Godsal, P. T., 288

Golden Number, 4

Goodell, Mrs. T., 648

Gordon, G. F. C., 690, 702

Goudet, Dr H., 633, 695

Gould, Lieut. R. T., 369

Government clock factories, Paris, 452

G.P.O., 37]

Grabowski, A., 750

Graham, G., 277, 295

Grandfather clocks, 494

Grandison, J. de, 39

Grasshopper escapement, 341

Graupner, 89

Great Peter bell, Exeter, 38

- Tom, 334

Green Dragon, Cheapside, 654

Greene, T. W., Collection, 123, 679

Green's Lichfield clock, 395, 396

Greenwell, Canon, 676, 681, 754

Greenwich Hospital, 712

- see Royal Observatory

Gregorian year, 3

Gridiron compensation marine clock, 343

- pendulum, 341

Grimes, A., 6991

Grinkin, 253 
Grogan, H., 704

Gruber, H., 69

Gruet, 81

Guelph Exhibition, 717, 744, 760, 788, 789, 791, 799, 801, 804

Guild, Paris, 404

Guildhail, London, Collection, 132, 152, $182,201,252,269,275,289,317,325$, $332,340,342,345,371,384,495,589$, $603,612,627,631,634,640,645,648$, $651,657,659,663,666,667,670,671$, $677,678,679,680,681,682,685,694$, $695,697,698,699,700,701,704,705$, $706,710,715,716,721,723,724,725$, $728,729,730,731,737,738,739,742$, $745,748,749,751,754,765,766,767$, $769,774,775,777,780,782,787,789$, $790,794,798,804,805,806,808$

Gunnis, J. W., 648, 730, 772

Haakon, King, 800

Habrecht, 40, 55, 56, 63, 132, 608

Hague, 694, 719

Halifax Church, 731

- clocks, 520

Hall, J., 104, 779, 780 J. J., 37,39

Hall-marks, 619, 623

Hallam, W. W., 597

Halsey, D. T., 695

Hamilton Collection, 747 783

Hammersmith Mall, 351

Hammond Collection, 650

Hampton Court, 53, 54, 293, 306, 307, 393 , 660

- - near L.eominster, 308

Hands, clock and watch, 207, 218, 219, $220,222,224,225,226,312,316,457$, 526

Hanging or cartel clocks, 428

Hannen, Hon. H., 712, 727

Hars of Jena clock, 28, 47

Hardraw, 529

Harkness, W. T. 492

Harlequin and bird clock, 456

Harrison, 340, 342

Harrys, 330

Hartshorne, A., 659, 804

Hawes, E., 803

Hawkins Collection, 205, 370, 638, 669, $675,681,690,769$

Hawley House, Blackwater, 681

Heape, B., 776

-

-—, R. T. G., 776

- - T., 712

Hearne, Mrs. G. A., 635, 647, 715, 723

Heart-shaped watch, 239

Hedgethorne, J. J., 612, 684

Heinz., H. J., 9, 194, 199, 233, 385, 641, $773,794,803$
Hele, 67, 103

-

Helein, Dr., 28

Helical spring, 360

Helm, W. H., 706

Henche, 254

Henlein, P., 63

Henrietta Maria, 179

Henry III., France, 127, 404

- - VIII., 50, 123

Herbert, Sir T., 723

Hertford, Marquis of, 331, 432, 644

Herz, Mrs. E., 800

Hexagonal clocks, 92, 94, 96, 99

Hextall, W. B., 750

Hill, A. F., 247

Hilton Price Collection, 67, 692, 699, $773,791,799,804$

Hindley, J., 40

Hinks, A. R., 785

Hinton Ampner House, 592

Hockliffe, F., 685

Hodgkin, J. E., 351, 639, 652, 653, 683, $687,690,701,706,707,711,783$

Hogarth, H., 660, 731

- dial, 598

Hog's-bristle balance, 605

Holbein, 167

Hole, S. H., 454

Holmes, J. Sancroft, 257

Holy Family enamelled on watch, 177 Trinity, Bristol, 22

Holyoke, E., 789

Hood clocks, 491, 492

Hooke, Dr., 320

Horary numerals on revolving crown clock, 117

Horizontal-dial timepiece, 111

—_ sundial, 7-8

Horloge, 17

Horlogiorum Artificio exercendo, de, 27

Horn watch, 155, 157

Horne, W., 575

- and Son, Leyburn, 529, 549

Hornsby-Drake, A. W. H., 671, 739

Horological Institute, $10,76,358,475$, 647

- Museum, Copenhagen, 801

- School, Chaux de Fonds, 647

Horologium Oscillatorium, 323

Horstmann self-winding clock, 402

Hosmer, W., 693

House, A., 452

Howard, W., 38

Howarth, T. R., 682, 722

Huaud le Puisne, 182

Huggerford, 773

Humphreys, Miss M., 724

Hunt, C., 771

Hunting clock, 89

Huntingdon, Lady, 725

Hursley Church, 746

Hussey, Lord, 255

Huygens, C., 323 
Illingworth Church, 731

India Office, 554

Indicators, sun and moon, 227

Inn yard and pitcher engraved njello work, 204

Innholders' Hall, 691

Insect watches, 156

Intercalary month, 4

Iron clock damascened, 85

Ironmongers' Company, 710

Iscoyd Park, 502

Isochronous spring theory, 369

Italian cartel timepieces, $\mathbf{4 5 7}$

" Jack the Smiter," Southwold Church, 20,22

Jacks, mechanical figures, 19, 21

Jacquemarts at Dijon, 20, 21

Jagellons timepiece, 461

James, 695

- I., 257, 674, 689, 749

Japanese clocks, 473

Jefferson, J., 648

Jeffreys, 769

Jeffries, W. A., Boston, U.S.A., 501

Jehan de Féalins clock, 28

Jenkins, H., 382

Jewelling, watches, 612

Jocelyn, G. H., 569

Johnson, F., 773

-, W., 402

Joicey, J. C., 139

Joly, J., 128

Jones Collection, 446, 450, 451, 637, 727. $738,739,767,783$

Jones, H., 274

Jourance, J., 36

Judgment of Paris repoussé watch, 202, 203

Julian period, 4

Jump \& Sons, 448, 452, 472

Kasan Cathedral, 795

Kassel Central Hotel, 721

Kayserswerth Castle, 702

Kealy, C. G., 665

Kean, C., 687

Kendall, W. H., 484

Kensington Palace, 282

Kettle or fiddle-shaped case, $\mathbf{5 4 9}$

Keys, watch, 225, 247

Kidson, F. T., 573

一, Mrs. F. J., 789

Kimpton, 729

King John and Magna Charta repoussé watch, 202

-_. of France, 726

of Italy, 469

- - Street, 671

Knaresboro', 631

Kneeling bronze figure clock, Breguet, 39]

Knibb, Joseph, 279, 325
Knox, J., 690

Köhler, J. C., 89

Kreizer, C., 118

— clock with revolving crown, $\$ 17$

Laborde, M. de, 48

Lacquer long-case clocks, 543, 545, 5ĩ7, 562

Lambert, 158, 666

Lambilly, Comte de, 93, 435, 690, 780

Lamp timekeepers, 14,15

Lancet clocks, 582,591

Landgraf, William N., of Hesse-Cassel, 57

Langley, H., 739

Lantern clocks, 270, 476, 479, 482, 483, 484,485

Laurence, E. A., 804

Lecky, R. J., 381, 382

Legion of Honour, 676

Legislation on Clocks and Watches, 594, 598

Lehr, S., 68

Leicester, Earl, 124

Lenker, E., 91

Leroux, 638, 759

Les deux frères Huaut, 182

Lethbridge, E., 492, 592

Lever escapement, 355,612

Levy, IH., 226, 230, 468, 715

Lichfield, 395, 396

Lichtenberg, Bishop, 26, 40

Liddell, G., 517, 733

Lightfoot, 25, 31, 37

Limbear, H., 774

Lion (crowned) clock, 112, 146

Lippius, 58

Liverpool Museum, 400

Liverymen of Clockmakers' Company, 264

Livingston, P., 709

Llewellyn, R: W., 710, 753

Lodbury, A. de, 25

Lodder, F., 475

Lowe, J., 784

London, 56

—- Hospital, 338

- Institution, 336

Long Island Historical Society, N.Y., 733

- Melford, 496, 744

Longitude at sea, ascertaining, 365

Louis XIV, 375, 407, 419

XIV, XV and XVI, 435

- XV style clock, 430

XVI, 440,446, 448, 457

- XVIII, 390

Louvre, Paris, 403, 446

Love-Jones Parry, 661

Lovelace, 398,399

Lover and maid enamelled watch, 193

Lovers and landscape enamelled watch, 185 conversing enamelled on watch, 19]

Low Harrogate Church, 808

Lübeck. 28,45

Luitprand, 16 
Linar method, 368

Lund, Sweden, 28

Lunettes for watches, 170

Lutterworth, 673

Lyons, 28, 57, 58

-, R., 522

Lyre clock, Windsor Castle, 446

M'Grady, Lord Provost, 779

Macclesfield, Earl of, 303

Mackinnon, Lt.-Col. L. D., 794

Magdeburg, Cathedral, 18

Magdalen Chapel, Cowgate, 651, 748

Magnetic clocks, 470

Mainspring barrel, 78

Mainwaring Collection, 148, 172, 753

Major, J., 796

Makers' name, where put, 501

Mallet, J. F., 685

Mallock, A., 358

Malta, 681

Maltese-cross watch, 148, 150

Mannheim, Ch., 702

Mantel clocks, 429, 431, 434, 435, 440, 442

Marat's watch, 197

Marble clocks, 371, 372, 431

Marfels Collection, 228, 230, 239, 643, 662, $712,736,775,790$

Margaret, Countess of Derby, 124

Margetts, Geo., sketch of career, 383

Marie Antoinette, 446, 451, 464

Marine Chronometers, 365 clocks and watches, 322, 339, 343, 344,367

Marionettes on clocks, $\mathbf{2 5}$

Marks, A., 783

, Assay Hall, 619, 620, 622

Marlborough, Duke of, 673

Marot, D., 409, 417

- pedestal clocks, 409

Marquetry decorated cases, 529, 531, 533, $542,543,562$

Marquart, J., 93

Mars and Venus enamelled on watch, 185 185

Marston House, 310

Martyn, J., 22

Mary, Queen of Scots, 130, 132, 715

Mary Seaton, 130

Massey-Mainwaring Collection, 133, 401, 722

Matthew the miller and his two sons, 39

Matthews, B., 522, 734

Mayence trade-mark, 68

Mean time, 1, 2

Mechanism of clocks and watches, general, $599,601,614$

Medallion clock, 102, 192

Megestein, J., 18

Meggat, $\ 690$

Meldrum, R., 303, 643, 737, 778

Melon-shaped watch, 269
Memento Mori, Latin cross watches, 133, 148

Menganah clock, 26

Merchant Tailors' Hall, 644

Mercurial pendulum, 298

Meridian dial, 6

Metcalfe, W., 764

Meton's cycle, 4

Metropolitan Museum, New York, 47

Metzger, J. (Metzker), 70

Miniature of lady studded diamonds, enamelled on watch, 193

—_ studded pearls, etc., enamelled on watch, 193

Minute-hand, Early clock with, 100

Mirabaud, M. G., 734

Mirford, W. T., 267

Mole, R. T., 752, 764

Mongolfier watch, 192

Montargis, 26

Monteith, Countess of, 678

Montelimart, 752

Montres d'abbesse, 148

Moody, Sir J. M., 248, 551, 694, 744, 768, 791, 799

Moon and sun indicators, 227

- rotating over dial clocks, 520

Moray, Earl of, 291

Morgan, C. B., 549

- E. P., 708

- O., Collection, 56, 139

- - Pierpont Collection, 126, 132, 143, $160,164,187,193,197,219,245,251$, $254,256,259,268,281,312,336,631$, $632,633,634,638,643,646,647,648$, $652,656,657,661,666,668,672,675$, $680,681,682,683,684,690,692,694$, $695,696,697,698,700,702,703,707$, $715,719,722,726,727,728,729,730$, $731,737,738,739,740,742,744,745$, $751,754,755,756,763,764,765,768$, $772,773,774,775,778,785,786,787$, $788,790,792,793,795,797,799,803$, 807

Morris, F., 766

Morson, C., 549, 769

Mortemao, Duc de, 675

Morton, Lord, 303

Moscow, 28, 692

Moss, W. R., 519, 543, 549, 692, 746

Mostyn, Lord, 282

Monza, 469

Movements of clocks and watches, 172, $173,281,303,307,389,394,494,495$, $504,602,603,604,608$

Moving figures-curious clock, 89

Moyse, Blois, 130

Mudge, Thos., 354-5

Muller, A., 102

Munich, 28, 102

Mural clocks, 432, 597

Murat, Prince, 389, 390.

Myers, Major W. J., 725

Mysterious clock, 467 
Naish, W. H., 713

Naked man and woman enamelled on watch, 193

Name of maker, where put, 501

plates attached, 502

Naomi and Ruth enamelled on watch, 185

Napier Collection, $387,468,633,647$

Napoleon miniature enamelled on watch, 197

- style of clocks, 452

National Museum, Cracow, 459

Nativity, The, enamelled watch, 190

Nautical chronometer, complicated dial, 384

" Nef " or ship clock, 100

Negress head clock, 465

Nelson's watch with chatelaine, 199

Nelthropp Collection, 132, 152, 633, 612, $643,657.658,659,661,694,701,716$. $728,752,769,773,775,777,788,793$, 799

Nether Swell Manor, 463, 792

Neuwers, M., 51

Newcomen, C. M., 732

Newington Free Library, 654, 673, 678, 805

Newsam, B., 126, 250

Newton, G. H., 526

-

—, W., 484, 569

Nicholson, T., 342

Niello-Italian work, 204

Night clock, 270, 272, 315

Niloe, H., 52

Niort, Poitou, 28

Norman, W., 351, 505, 740, 752

North, 254

Norton (Pinchbeck-Norton), 3593

Norwich Cathedral, 22

Notre Dame, Dijon, 21

Nourisson, G., 58

Nouwen, M., 52, 253

Number of direction, 4

Nuremberg, 28, 67 trade-mark, 68

Nut-shaped watch, 148

Octagonal clocks and watches, 94, 99, 136, $156,158,159,160,253,268$

Oliver, C. B., 712, 732, 745

One-year clocks, 282, 306, 310

Orestes and Hermione enamelled on watch, 185

Oriental calendar clocks, 45, 47

Ormolu clocks, 429, 430

Orlogiario, B., 19

Orlogium-Norwich Cathedral, 25

Orrery clock, French, 454

Oval watches, $72,73,140,141,142,143$, $162,163,164,165,253,254,255,259$, 270
Padlock watch, 146

Pair-cases for watches, 199, 201211

Palace Yard, Westminster, 23

Palais de Justice, Paris, 35, 36

- du Louvre, Paris, 416

Palmer, 308

Papers, watch, 211, 212, 213

Parachute, 385

Pavia, 28

Paris Guild, 404

- Observatory, 738

Parr, E., 126, 164

Partridge, Wm., 260

Paschal moon, 4

Pass, A. A. de, 707

Passemants clock, 718

Pasteur, Dr., 641

Paston, Sir J., 48

Patek, Phillipe \& Co., 141

Paul's Jacks, 18

Payn, J., 40

Peake, T., 326

Pearson, Dr., 687

Pearl and ruby musical watch, Margetts, 385

- ornament on watches, 238

Peckitt, H., 81

- Col. R. W., 402

Pectoral cross watches, 148

Pedestal clocks and watches, 138, 408, 409,568

Pedometer wind watch, 617

Peking, 723, 803

Pelican watch, 148

Pendules d'appartement, 406

Pendulum clocks and watches, 91, 111, $231,237,298,314,322,323,324,335$, $337, \cdot 341,379,484,494,592,594,599$, 600,604

Pen-shaped watch, 150-1

Perdue, T., 38

Perforations, watch case, 73

Perpetual motion clock, 401

— watch, Berguet, 388

Perrault, 14

Peterborough, 37

Petitot, 179

Peyster, Gen. J. W. de, 709

Pfaff, J., 120

Pfungst, H. J., 112

Phelps, A., 666

Philadelphia Library, 320

Phillimore, W. P. W., 687

Phillıps, L. F., 392

Pichon, Baron, 84

Pierced chasing, 76, 77, 201, 219

Pierrot and Pierrette clocks, French, 433

Pillars, watches, 610

Pinchbeck, 349, 350

Pinks, W. J., 351

Piqué surface, 207, 209

Pitt, W., 713

Plairas, Watch by, enamelled, 176

Planché, J. R., 30 
Planchor, Mons., 15, 247, 468

Planetarium clocks, 25, 55

Plaque enamelled in terior of watch, 198

Plough Inn, Princes Risborough, 726

Pocket watches, 168

Poets' Corner, 60

Polygonal, double-band clock, 464

Polytechnic, Regents Steeet, 402

Pompadour, Mme. de, 614, 658

Ponsonby Collection, 189, 212, 213, 435 $649,651,656,668,680,696,710,714$ $734,746,767,774,779,782,785,792$, $794,795,806$

Pope, W. W., 660, 744

Pupkin, IV., 687

Poppy-bud watch, 153

Purcelain clock cases, 450

Portable clocks, 22, 62, 101, 125, 452

Portland, Duke of, 612

Post chaise watches, 246

Potosi, Bulivia, 578

Potts, B. L. F., 651

Prague, 28

Praslin, Duc de, 387

Prevost. celebrated enameller, 185

Price, G. W., 803

Prince of Wales, 472, 799

\section{watch, 211}

plumes, gold and colours,

Prosser, R. B., 659

Pulse piece, watches, 618

Pump Room Bath. 286

Pumping keyless-wound watch, 207, 615

Quare, Daniel, 279, 303

Quarter-hour striking clock, 90, 93

Quatre-couleurs decoration watches, 315

Queen Anne, 789

Elizabeth, 792

Queen's House, 354

Rack movement, 276, 472, 495, 612

Raikes, R., 757

Rainaldi, 61

Rambal, J., 5

- M. M., 675

Ramsay, 256, 259, 260

Ram's-eye watches, 211

Ranken, W., 798

Rape of the Sabines, painted on watch, 182

Raymond, J. L., 80

- Smythies, Major R. H., 667

Read, C. H., 723

Rebecca at the Well repoussé watch, 202, 203

Record clock by Tompion, 291

Redfern, W. B., 707, 740

Regulators, watch and clock, 376, 415, 427,606

Religious scenes on clocks, 25

Remontoir escapement, 347, 357
Repeating watches and clocks, 199, 233,

$235,244,276,297,303,387,588,617,618$

Repoussé chasing, 200, 201, 203, 620

Revolving bands and dials, 49, 115, 120 , 462,464

- fly-controller invented, 18

Reynolds, C. J., 516

Ridley, Viscount, 329

Riley, A., 275

Rimbault, 588

Rise and fall register clocks, 511

Roberts, Evan, Collection, 139, 141, 163 $257,275,342,628,634,635,644,647$, $648,659,666,675,681,688,694,713$, $715,719,739,744,781,784,795,804$ Rəbərtıon, J. D., 325, 327, 479, 493, 501, $543,569,573,588,601,650,680,692$ $693,704,734,735,741,746,753,771$

R xaille cartel clock, Caffieri style, 406, 433

- - decoration, 406

Rochdale MIuseum, 653, 656, 799

Rock-crystal case for clock, 102

Rocking-bar wind, watches, 616

Rococo decorated spandrels, 510

Rolfe, R., 443

Rolling clock, 465

Roman Indiction, 4

- - piety enamelled on watch, 182

Romieu, Enamelled watch by, 182

Rosenheim, M., 164, 751

Roskell Collection, 225, 647

Rotating dial, clock, Japanese, 475

Rouen, 28

Roux, E., 674, 681

Rowley, Messrs. A. and H., 581

Royal Arms on watch movement, 604

-. pendulum, 494

- Astronomical Society, 34

- Exchange, 472

- Institution, 735

- Observatory, Greenwich, 14, 346,

$348,349,356,365,542,715$

- Society, $359,527,542$

Rubens long-case clock, 408

Ruchbrooke Hall, 706

Rudolph II, 773

Rue Denis, Paris, 448

Rundell and Bridge, 468

Russell, Earl, 124

Russia, 750

Rutherford, A. E., 354, 387

- J., J., 29

Rye Parish Church, 22

Sablier, 16

St. Clement's Dane, 332, 601

\section{6}

Dunstan's, Fleet Street, 22, 330,660,

____ Lodge, 331

___ Geneviève, Paris, 56

- J James's Palace, 54

_- Margaret's, IVestminster, 334, 718 
St. Mark's, Venice, 28

Martin's-le-Grand, 371

Martin's, Oxford, 22

Mary Ottery, 39

Mary's, Oxford, 39

Mary Steps, Exeter, 22, 38

- Paul's Cathedral, 19, 285, 332, 534, 601 , Covent Garden, 599, 705

- Petersburg Collection, see Winter Palace

— Peter's Cathedral. Geneva, 5

Petrock, 39

Sulpice, Paris, 340

- Vedast, Foster Lane, 601

Salt-cellar clocks, 167

Salting Collection, 150, 256, 647, 752

Sand glasses, 16

Sandall, T., 764

Sardinia, King of, steel-cased watch, 205

Saussure, Th. de, 695

Savage, E., 750

Scalloped-cased watch, English, 198

Scheirer, J., 104

Schloss Collection, 15, 63, 72, 76, 84, 93, $111,113,115,121,132,141,156,162$, $172,179,182,185,197,223,235,253$, $268,440,469,574,593,607,634,635$, $639,648,649,655,656,659,661,665$, $668,669,677,680,681,683,689,690$, $698,705,713,714,715,719,720,723$, $730,732,739,744,747,750,763,764$, $767,770,773,774,783,784,785,787$, $796,800,803,804$

Schlotheim, H., 89

Schlott, H., 100

Schmidt, N., 121

Schmidt's mysterious clock, 467

Schreiber Collection, 790

Schrebbys. N., 40

Schuster, P., 92

Schweder, P. E., 297

Schwerzer, I., 91

Schwilgue, J. B., 44

Scoble, S. W., 734

Scott, Rev. W., 305

Screws for timekeepers introduced, 81

Seaton, S. G., 487

Sedan chair watches, 245

Self-winding clocks and watches, 388, 390, $401,402,616$

Seventeenth-century clocks, 108, 114, 115, 121

Severn, A. R., 298

Seville Cathedral, 28

-, Hôtel de Madrid, 707

Sèvres porcelain clocks, 448, 451

Shagreen-cover of watch, 209

Shakespeare's Walk, Shadwell, 639

Shandon Collećtion, 94, 174, 225, 484, $682,695,724,734,801$

Shaw, Norman, Collection, 224, 280, 589, $647,651,656,723,753,762,801,802$, 804
Shaw, R. N., 757, 778

Sheep's-head clocks, 485

Sheerness, Riding house, 661

Sheffield, Earl of, 563

- Place, Sussex, 563

Sheraton, long cases, 553, 554

Sheridan, 790

Shifting-sleeve keyless-wind watches, 616

Ship or " Nef " clocks, 98, 100

Shorren, J., 772

Shrewsbury, Earl, 51

Sidebottom, Mrs. H., 698

Sidereal time, 2

Sigismund I., 82

Silliman \& Co., 742

Simmons, Major C., 761

Sivan, C., 699

—-, M. C., 743

Sixteenth-century clocks and watches, 67 , $68,69,71,75,81,90$

Skeleton hour-ring dial, 507

Skins of shark and other fishes used for shagreen, 209

Skull watches, 127, 129, 130, 131, 132

Small clocks and watches, 48, 154, 156

Smeaton-Franklin, plan of regulator, 376

- - J., 380, 778

Smith, Capt., 741

- J., 630

—. J. B., 454, 549

Smyth, Capt. W. H., 82

Smythies, Major R. H. R., 701

"S. N." on spandrels, 512

Soane Museum, 358, 454, 534, 763, 788

Society of Antiquaries, 81, 459

Solar time, 1

- year, 3

Soldered on figures in repoussé work, 201

Soltykoff Collection, 70, 71, 74, 77, 85, 94 $99,100,102,105,127,150,151,152,157$, $631,680,695,699,720,747,770,773$, 793

Somes, Sir P., 699

Sons of the Revolution Museum, 709, 731, 793

Sourdine repeaters, 189, 297

Southam, H., 725

South Kensington Museum, 30, 36, 49, $65,70,84,93,100,102.103,136,144$, $148,150,153,154,165,169,172,175$, $179,182,200,236,252,255,256,270$, $312,326,342,358,446,450,451,462$, $475,534,593,599,613,635,637,643$, $644,646,647,648,651,652,654,658$, $659,660,661,662,663,664,666,667$, $670,674,678,680,681,682,685,692$, $698,699,700,701,702,703,709,710$, $711,714,715,716,717,720,723,724$, $725,727,728,729,730,733,737,738$, $739,743,748,752,753,754,756,759$, $761,762,764,765,766,767,768,769$ $774,775,780,781,783,784,788,789$, $790,791,792,793,803,805$ 
Southwold Church clock, 21, 40

Souvenir watch, 239

Spandrels of dial, 503, 511

Spencer, A., 671

Spherical watch, very rare, 133

Spires, Bavaria, 28

Spitzer Collection, 675, 696, 793

Sporadic case clock, 575

Spring-balance, 280

- detent invented, 363

- - helical, 360

- balance, watches, 605

_... laws governing, Hooke, 321 -watch, 63

Square-case watch, 161 table clock, 67, 84

- topped long-case clock, 273

Squat wooden bracket clocks, 568

Stackfreed, 73, 78, 79

Stafford, E., 124

Stamford Institution, 700

Stamp, 785

Standard clock, Windsor Castle, 374

Stanton. J., 304

Star-shaped watch, 154, 157, 257

States of Holland, 323

Steel watch-cases, 161

Stephenson's factory, Newcastle, 718

Steven's sale, 665

Stimmer, T., 40, 56

Stirling Castle, 671

Stockham, Lieut. J., 370

Strassburg clock, 26, 28, 40, 44, 673, 702 773,805

Strathallan, Lord, 451, 696

Streller, J., 89

Strike-silent hand, 511

Striking watches and clocks, 22, 70, $73,77,97,106,157,209,250,428$, 601

Stringer, J., 704

Stubbs, D. H., 47

Sturmer, see Stimmer

—, H. H., 670

Subscription watch, Breguet, 391

Sudell, E., 661, 806

Suffolk, Manor House, 377

Sulley, Henry, 339

Summer Palace, Pekin, 71

Sun and moon indicators, 227

— dial, pocket, with compass, 280

- - how to use, 5

Susanna and the Elders enamelled on watch, 185

Suspended bird-cage clock, 469

Sussex, Duke of, Collection, 326, 328, $643,658,672,690,704,720,766,775$, 790

Sutton, Rev. A. F., 747, 798

Swanwick, E., 326

Sykes, A., 802

Sylvan scene, enamelled on watch, 185

Synchronizer, 385

Synchronons balance watch, 389
Table clocks and watches, $67,68,76,81$, $82,83,90,94,96,99,103,104,105$, $122,127,251,418,454,475$

Talbot Inn, Halifax, 520

Tambourine watches, 65,136

Tamplin, W. W., 711

Tancred and Clorinda painted on watch, 182

Tassaert, P. L., 349

Taylor, J. S., 794

Taxes relating to clocks and watches, 593

Terrestrial globe clock, 463

Terry, Capt., H. D., 640

- J., 764

Thackeray, W. M., 745

Theobalds, 259

Thermometer, Kirb, 345

Three Fates clock, 408

Thompson, Mrs. G. F., 801

Thomson, A., 144

Thorold, Major W. G., 698

Thorpe, J., 651

Three Graces clock sold, 464

- - vase clcck by Falconet, 464 month clock. 291

Thwaites and Reed, 105

- J., 54

Tidal record clock, 517

Tides of sea clock, 379

Time table, watch paper, 213

"Tom of Westminster" bell, 24

Tombstone of Tompion and Graham, 302

Tompion, Thos., 277

Tontin discovered opaque enamelling, 180

Torphichen, Lord, 163, 635

Torrance, Rev., 133

Torricellian tube, 275

Tortoise-shell watches and clocks, 270, $280,311,568$

Tower clock, striking, 91

- of Babel clock, 89

Townsend, H. G., 519

Toy watches, 144

Trade-marks or letters, 68

Travelling or carriage clocks and watche.; $239,241,245,286,300,451,593,595$

Trınity House, 380,778

Troitsa Monastery, Moscow, 788

Tropical year, 3

Trotman, W. W., 741

Trumpet watch, 155,157

Tuckley, G. A. W., 743

Tulip pillar watch, 610

- watch, 152

Turkish numerals, 580

Turquoises bordered round painted watch, 179

Turret clock, 325

Twelve months clocks, 308,427

United Service Institution, 312, 722

Unkill, U. L., 750, 803

Uphill Castle, 295 
Urn clock of Marie Antoinettc, 464

Urns, globes and vases, 461

Ursean, N., 124

Usher, J. W., 206, 232

Val de Grace, 697

Vase clocks, 451,464

Vases, urns and globes, 461

Vatican, 56

Venctian clocks, 59, 61, 86, 219

Venice, 61

Venus and Adonis enamelled on watch, 185 -, Toilet of, enamelled on watch, 182

Verge escapement, $33,7 \mathrm{~s}$

Versailles, 441

Victoria Hospital, Lewes, 66

-, Qucen, 50, 372, 391

$\longrightarrow$ - - watch paper, 212

Vienna Treasury; $70,100,141,187,599$, $643,647,656,685.720,723,725,748$,

$759,773,781,782,784,792,808$

Virgule escapement watches, 611

Visconti, J., 27

Vulcan, Venus and Cupid enamelled cn watch, 185

Vulliamy, 54, 370, 376

Waag, 73

Waddesdon Manor, 416

Walberswick, Suffolk, 40, 754

Walker, J., 733

- S. F., 642

IVallace Collection, $148,412,464,667,668$, $670,671,672,675,677,680,692,693$, $709,728,729,748,767,783,788,792$, 794

Wallingford, Abbot R., 25

Walpole, H., 50, 249 sold, 50

Walter, Miss, 715

Ward, J. W., 492, 520, 751

Warr, Earl de la, 563

Wastell, W. I. F., 22

Watch and chain owned by Cromwell, 169

- clock (1580), 126

Water clocks, 9, 10

Watkins, E., 660

Watt Hansard, Collection, 16, 270, 271, $273,276,285,299,306,310,329,351$, $376,472,482,533,543,589,638,639$, $678,683,691,698,721,724,725,750$, 758,795

Watts, G., 738

Wattson, B. G., 892, 708

Webb Collection, 100

Webster, P., 485, 493, 502, 591

Wehrle, E., Collection, 121, 694, 750, 768 Weight clocks, 17

Weir, R. S., 777

Welbeck Abbey, 104, 672
Welfe, L., 351

Wells Cathedral, 2

Wentworth Hòse, 703

Wesley Museum, 680

Westminster Abbey, 601, 778, 805

Hall, 2

Wetherfield Collection, 270, 284, 285, 288 $289,291,295,299,305,310,320,325$, $328,329,330,332,336,371,375,484$, $491,495,496,513,519,522,525,528$, $529,531,534,542,543,545,548,554$, $566,-568,569,573,579,582,588,589$, $591,601,631,632,639,643,645,648$ $651,652,656,657,660,662,663,664$, $666,669,671,673,675,682,683,684$, $685,687,689,693,696,697,699,700$, $706,707,709,712,713,717,718,720$, $724,727,731,733,737,738,744,745$, $747,749,751,753,754,756,762,763$, $774,778,781,784,789,790,791,792$, $797,799,800,803,804,806$

Wheater, T. S., 682

Wheeler, H. L., 702

- N. N., Collection, 238, 281, 605, 675 . 681,717

Whitaker, L. P., 711

Whitcombe Green Collection, 653, 695, $708,723,739,762$

Whitehall dials, 8

- L London, 254709

White Horse Hotel, Romsey, 726

Whiting Abbot 160

- J. E., 750

Wick timekeepers, 14

Wieck, H., 26

Wigtoft, Lincs., 40

Wilding, W. H, 714

Wilkins, Dr., 321

— , G. R., 745

William of Orange, 772,796

- III. clocks, $282,305,306,522$

$\longrightarrow$, IV., 54

Wilson, H. W., 682

Wimborne, Dorset, 31

Winchester Town Hall, 727

Winding mechanisms, 221, 614, 615, 616, 617

Windmill clocks, 403

Windser Castle Collection, 50, 288, 305, $325,372,373,375,410,411,418,422$, $427,435,446,448,452,454,456,464$, $535,549,591,592,597,673,697,701$, $729,763,780$

- - Viscount, 187, 190

Winter, C., 671

- Palace, St. Petersburg, Collection, $172,336,657,680,681,717,737,760$, $762,788,795$

Winterton Church, 767

Wire-gongs, watches, 618

Wolf, J., 103

Wolkstein, D., 40

Woman and lamb, enamelled English watch, 195 
Woman, child and pet bird enamelled on watch, 194

- suckling child enamelled watch, 190

IVood, A., 794

Wooden hood for lantern clocks, 485

Woollard, W. C., 778, 781

Woolwich, Rotunda, 472

Worsley, 641

Wyatt, T., 316, 554

Wren, Sir Christopher, 332
York Cathedral, 22, 40

Minster, 663, 711

Young, F. J., 640

-, Miss V., 808

Zaandam clocks, 492,493

Zech, J., 80, 81

Zschille Collection, 76 





\section{AFTER 7th DAY, FINE IS TEN CENTS A DAY DATE DUE}

A fine of THREE CENTS each day will be charged for keeping this book beyond date stamped.

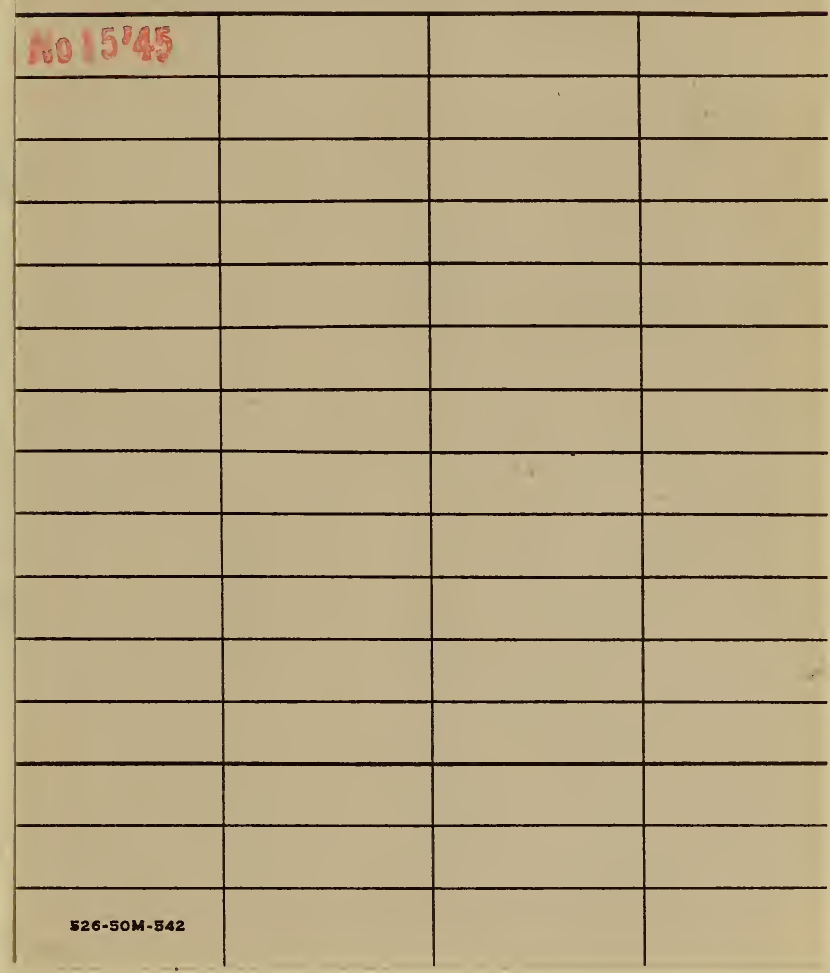


SMITHSONIAN INSTITUTION LIBRARIES

|| || ||||||||||||||||||||||| ||||||||||||||||||||||||||||||||||||

||||||||||||||.|||||||||||||||||||||||||||||||||||||||||||||

$3908800797 \quad 1542$ 